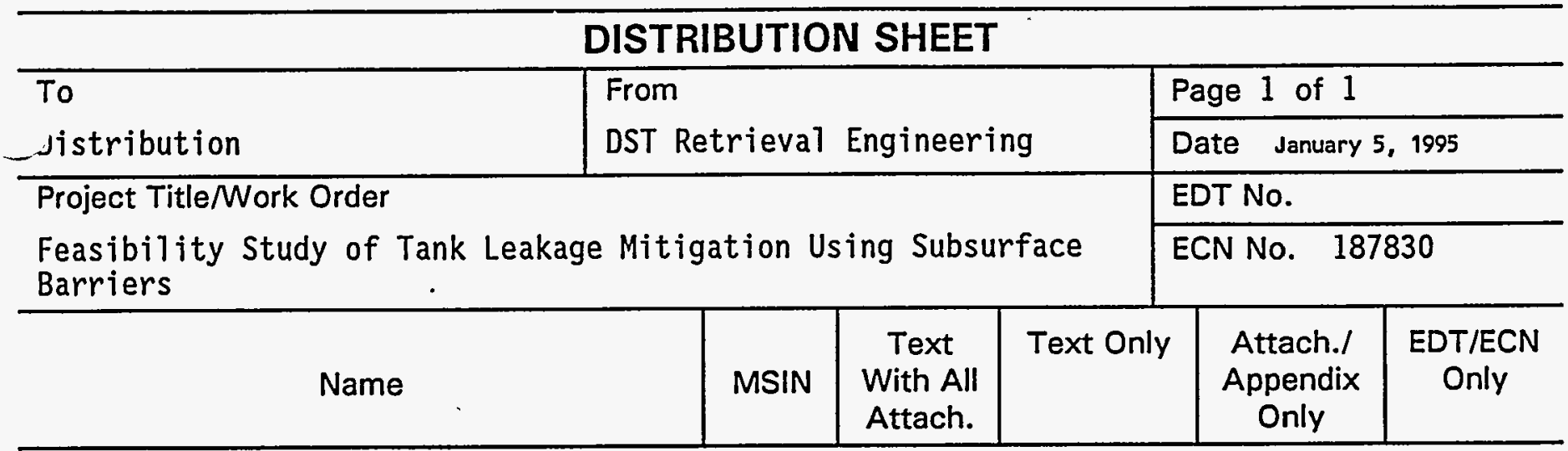

Westinghouse Hanford Company
P. A. Baynes
G. D. Bazinet
J. H. Cruse
L. A. Fort
C. E. Grenard
M. L. Grygiel
D. F. I watate
G. A. Meyer
W. C. Miller
J. P. Mullally
E. J. Shen
Central files
OSTI (2)
PIMS

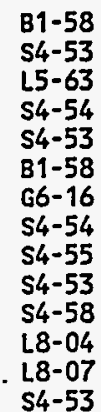

1
1
3
1
1
1
1
1
1
1
2

Pacific Northwest Laboratories

A. J. Brothers

R. E. Lewis

" E. Peterson

D. Vick

K8-10

K6-84

K2-47

K7-94

\title{
RECEIVED
}

JAN 231995

U.S. Department of Energy, Richland Field office

R. G. Holt
B. L. Nicoll
J. E. Rasmussen
W. R. Wrzesinski

R3-74

Ensearch Environmental, Inc.

B. 8. Peters

R. L. Treat

Bovay Northwest, Inc.

J. K. Rouse

Advanced Systems Technology, Inc.

T. J. McLaughlin

\# Advance copies provided to W. R. Wrzesinski - 1/09/95.

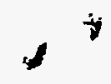




\section{Feasibility Study of Tank Leakage Mitigation Using Subsurface Barriers}

Prepared for the U.S. Department of Energy Office of Environmental Restoration and Waste Management

\section{(2) Westinghouse \\ (2) Hanford Company Richland, Washington}

Hanford Operations and Engineering Contractor for the

U.S. Department of Energy under Contract DE-AC06-87RL10930 


\section{LEGAL DISCLAIMER}

This report was prepared as an account of work sponsored by an agency of the United States Government. Neither the United States Government nor any agency thereof, nor any of their employees, nor any of their contractors, subcontractors or their employees, makes any warranty, express or implied. or assumes any legal liability or responsibility for the

accuracy, completeness, or any third parly's use or the results of such use of any information, apparatus, product, or process disclosed, or represents that its use would not inlringe privalely owned rights. Reference herein to any specific commercial product, process, or service by trade name, trademark, manufacturer, or otherwise, does not necessarily constitute or imply its endorsement, recommendation, or lavoring by the United States Government or any agency thereof or its contractors or subcontractors. The views and opinions of authors expressed herein do not necessarily state or reflect those of the United States Government or any agency thereot.

This report has been raproduced from the best available copy.

Prinled in the United Stales of America

DisCLM-2.CHP (1-91) 


\section{RELEASE AUTHORIZATION}

Document Number: WHC-SD-WM-ES-300, Rev. 1

Document Title: $\quad$ Feasibility Study of Tank Leakage Mitigation Using Subsurface Barriers

Release Date: $\quad 1 / 9 / 95$

This document was reviewed following the procedures described in WHC-CM-3-4 and is: APPROVED FOR PUBLIC RELEASE

WHC Information Release Administration Specialist:

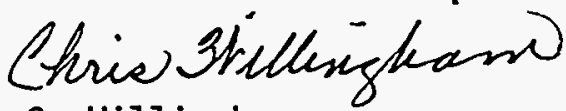

C. Willingham

$1 / 9 / 95$

TRADEMARK DISCLAIMER. Reference herein to any specific commercial product, process, or service by trade name, trademark, manufacturer, or otherwise, does not necessarily constitute or imply its endorsement, recommendation, or favoring by the United States Goverment or any agency thereof or its contractors or subcontractors.

This report has been reproduced from the best available copy. Available in paper copy and microfiche. Printed in the United States of America. Available to the U.S. Department of Energy and its contractors from:

U.S. Department of Energy

Office of Scientific and Technical Information (OSTI)

P.0. Box 62

Oak Ridge, TH 37831

Telephone: (615) 576-8401

Available to the public from:

U.S. Department of Commerce

National Technical Information Service (NTIS)

5285 Port Royal Road

Springfield, VA 22161

Telephone: (703) 487-4650 


\section{DISCLAIMER}

Portions of this document may be illegible in electronic image products. Images are produced from the best available original document. 


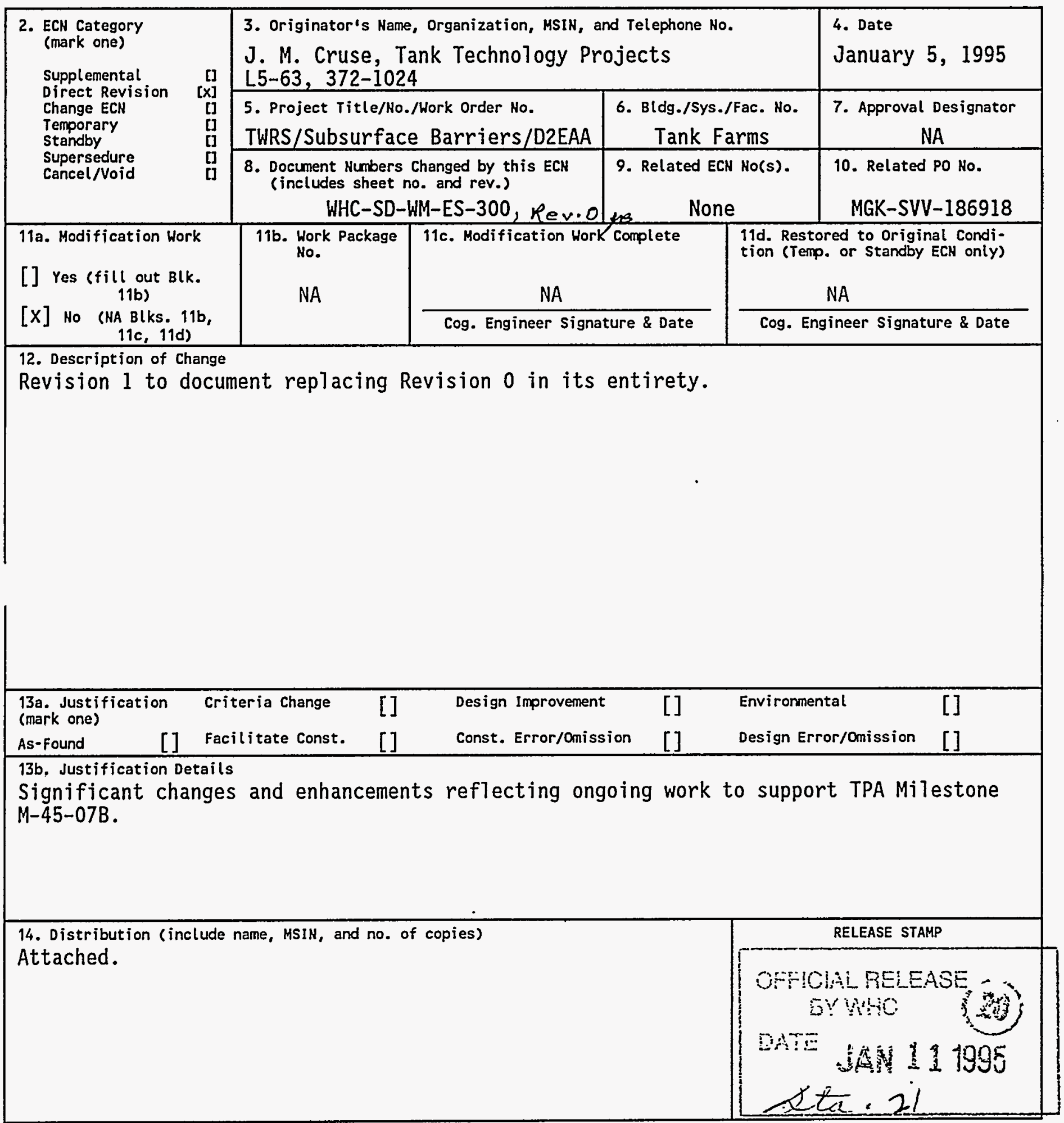




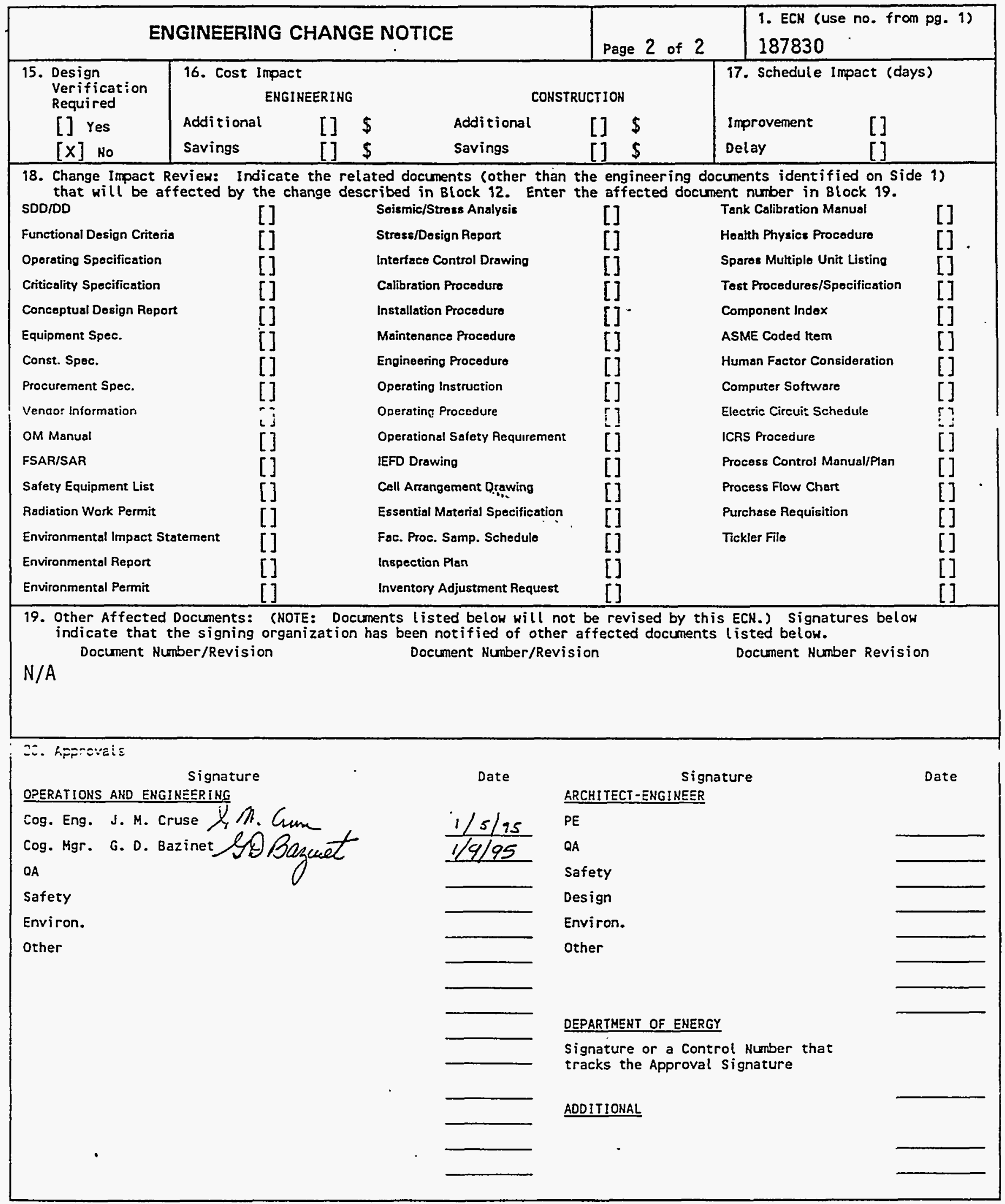


2. Title

Feasibility Study of Tank Leakage Mitigation Using Subsurface Barriers

5. Key Hords

Injected materials, frozen soil and desiccant barriers, functions and requirements, performance criteria.

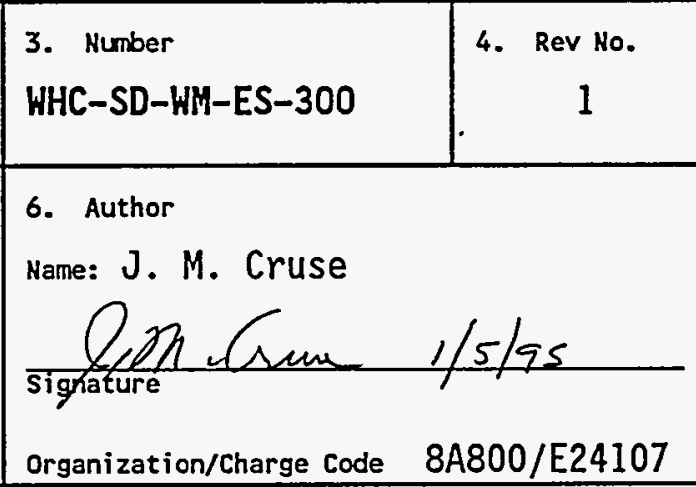

\section{Abstract}

This document reflects the evaluations and analyses performed in response to Tri-Party Agreement Milestone M-45-07A "Complete Evaluation of Subsurface Barrier Feasibility" (September 1994). In addition, this feasibility stuch was revised reflecting ongoing work supporting a pending decision by the DOE Richland Operations Office, the Hashington State Department of Ecology, and the U.S. Environmental Protection Agency regarding further development of subsurface barrier options for SSTs and whether to proceed with demonstration plans at the Hanford Site (Tri-Party Agreement Milestone $M-45-07 B$ ).

Analyses of 14 integrated SST tank farm remediation alternatives were conducted in response to the three stated objectives of Tri-Party Agreenent Milestone M-45-07A. The alternatives include eight with subsurface barriers and six without. Technologies used in the alternatives include three types of tank waste retrieval, seven types of subsurface barriers, a method of stabilizing the void space of emptied tanks, two types of in situ soil flushing, one type of surface barrier, and a clean-closure method. A no-action alternative and a surface-barrier-only alternative were included as nonviable alternatives for comparison. All other alternatives were designed to result in closure of SST tank farms as landfills or in clean-closure. Revision 1 incorporates additional analyses of worker safety, large leak scenarios, and sensitivity to the leach rates of risk controlling constituents. The additional analyses were conducted to support TPA Milestone $M-45-07 B$.

8. PURPOSE AND USE OF DOCUMENT - This document was prepared for use withiv the U.S. Department Af Energy and its contractors it is to be used only to perfirm, direct, or integrate work under U.S. Department of En contracts. This dociment is not approved for public relense an th irexjewed.

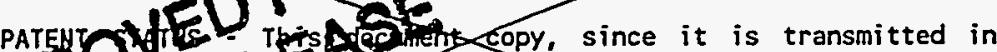

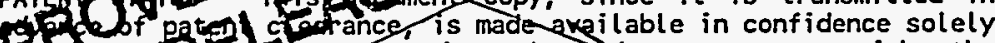

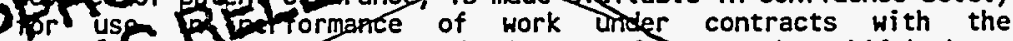
M Us, Df antntent of Energy. This document is net to be published nor 1 taitents otherwise disseminated or used for pucposes other than 1Ufecified above before patent approval for such relesce or use has been secured, upon request, from the Patent Counsel, U.S. Pepartment or Energy Field office, Richland, WA.

DLSCLAIMER - This report was prepared as an 3etount of work sponsered by an agency of the United States Goverment. Neither the United States Government nor any agency thepeof, nor any of their employees, nor any of their contractors subcontractors or their employees, makes anx warranty, expreso or implied, or assumes any legal liability or responsibility for the accuracy, completeness, or any third party's use or the cesults of such use of any information, apparatus, product, or process"disclosed, or represents that its use would not infringe privatety owned rights. Reference herein to any specific commercial product, process, of service by trade name, trademark, manufactúrer, or otherwise, does not necessarily constitute or imply its endorsement, recormendation, or favoring by the United states Government or any agency thereaf or its contractors or subcontractors. The views and opinions of authors expressed herein do not necessarily state or reflect those of the United States Goverment or any agency thereof.

10. RELEASE STAMP

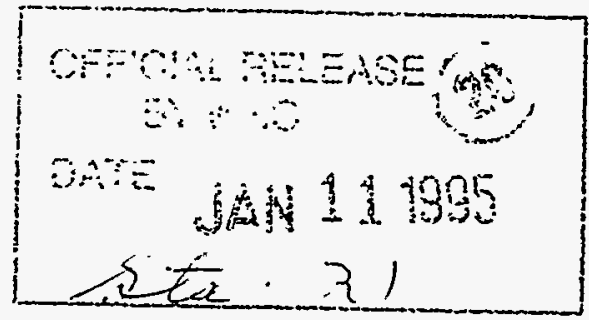

9. Impact Level NA 
(2) Title

Feasibility Study of Tank Leakage Mitigation Using Subsurface Barriers

CHANGE CONTROL RECORD

(3) Revision o 1 RS
(4) Description of Change - Replace, Add, and Delete Pages EDT- $160548,9 / 21 / 94$

(7) Complete revision - Rev. 1 replacing Rev. 0.
Authorized for Release

(5) Cog. Engr. (6) Cog. Mgr. Date

J. M. Cruse G. D. Bazinet

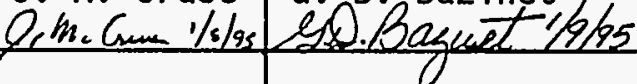




\section{EXECUTIVE SUMMARY}

The U.S. Department of Energy (DOE) has established the Tank Waste Remediation System (TWRS) to safely manage and dispose of the wastes currently stored in single-shell (SSTs) and double-shell tanks at the Hanford Site.

The TWRS program includes a work scope to develop subsurface low-permeability barriers beneath SSTs. The barriers could serve as a means to contain leakage that may result from waste retrieval operations and could also support site closure activities by facilitating cleanup. A number of studies and working meetings have taken place in an effort to identify potentially applicable subsurface barrier system(s) for SST waste retrieval applications and to determine the best approach to develop them. As a result of these activities, three types of subsurface barrier systems have emerged for further consideration: (1) chemical grout, (2) freeze wall, and (3) desiccant, represented in the feasibility study as a circulating air barrier. These barrier concepts may be installed in either close-coupled (against the tank structure) or standoff (with a soil layer between the tank and barrier) configurations.

The TWRS program has begun planning for a demonstration project to further evaluate these concepts. The plan includes an assessment of the feasibility of subsurface barrier systems to satisfy Milestones M-45-07A (September 1994) and M-45-07B (January 1995) of the Hanford Federal Facility Agreement and Consent Order otherwise known as the Tri-Party Agreement. 
Milestone Requirements

The Tri-Party Agreement Milestone M-45-07A requires completion of a feasibility study to accomplish the following:

- Estimate the potential environmental impacts of waste storage and retrieval activities without the application of subsurface barriers

- Establish functional requirements of subsurface barriers to minimize the impacts associated with waste storage and retrieval activities

- Evaluate the application of existing subsurface barrier technologies to meet functional requirements of barriers and the potential reduction in environmental impacts from the application of barriers to SST waste storage and retrieval activities.

The feasibility study will support a decision by the DOE Richland Operations Office, the Washington State Department of Ecology, and the U.S. Environmental Protection Agency regarding further development of subsurface barrier options for SSTs and whether to proceed with demonstration plans at the Hanford Site (Tri-Party Agreement Milestone M-45-07B).

Analyses of 14 alternatives were conducted in response to the three stated objectives of Tri-Party Agreement Milestone M-45-07A. The evaluated alternatives included eight with subsurface barriers and six without. Technologies used in the alternatives included three 
types of tank waste retrieval, seven types of subsurface barriers, a method of stabilizing the void space of emptied tanks, two types of in situ soil flushing, one type of surface barrier, and a clean-closure method. A no-action alternative and a surface-barrier-only alternative were included as nonviable alternatives for comparison. All other alternatives were designed to result in either closure of the SST tank farms as landfills or in clean-closure. Technologies used in each of the 14 evaluated alternatives are shown in Table ES-1.

\section{$\underline{\text { Risks }}$}

First approximations of carcinogenic risk and noncarcinogenic hazards to the maximally exposed individual for 30,000 years were estimated using the Multimedia Environmental Pollutant Assessment System (MEPAS) computer code. This code is capable of projecting radiological and chemical risks and hazards through the groundwater and other pathways. Only the groundwater pathway was analyzed because the purpose of subsurface barriers is to prevent or limit future contamination of the groundwater. If subsurface barriers are determined feasible, then a more comprehensive analysis of environmental risks should be pursued.

Risks estimated using MEPAS were related to an incremental cancer risk range of $10^{-4}$ to $10^{-6}$. This range spans the breadth of potential cleanup objectives usually considered acceptable for cleanup of waste sites. 
Table ES-1. Summary of Alternatives.

$\leqslant$

\begin{tabular}{|c|c|c|c|c|c|c|c|}
\hline Alternative & $\begin{array}{l}\text { Waste Retrieval } \\
\text { Type }\end{array}$ & $\begin{array}{c}\text { Assumed Tank } \\
\text { Waste Retrieval } \\
\text { Effectiveness }\end{array}$ & $\begin{array}{l}\text { Subsurface Barrier } \\
\text { Type }\end{array}$ & $\begin{array}{l}\text { Old Leaks } \\
\text { Flushed? }\end{array}$ & $\begin{array}{l}\text { New Leaks } \\
\text { Flushed? }\end{array}$ & $\begin{array}{c}\text { Tanks } \\
\text { Stabilized? }\end{array}$ & $\begin{array}{l}\text { Surface } \\
\text { Barrier } \\
\text { Used? }\end{array}$ \\
\hline 1. No Action & None & $0 \%$ & None & No & No & No & No \\
\hline 2. Surface Barrier Only & None & $0 \%$ & None & No & No & No & Yes \\
\hline $\begin{array}{l}\text { 3. Traditional Sluicing } \\
\text { (Baseline) }\end{array}$ & Traditional sluicing & $99 \%$ & None & No & No & Yes & Yes \\
\hline 4. Robotic Sluicing & Robotic sluicing & 99.9\% & None & No & No & Yes & Yes \\
\hline 5. Mechanical Retrieval & $\begin{array}{l}\text { Mechanical } \\
\text { retrieval }\end{array}$ & $95 \%$ & None & No & No & Yes & Yes \\
\hline $\begin{array}{l}\text { 6. Close-Coupled Chemical Barrier } \\
\text { with Flushing }\end{array}$ & Traditional sluicing & $99 \%$ & Close-coupled & Yes & $\begin{array}{c}\text { Not } \\
\text { applicable }\end{array}$ & Yes & Yes \\
\hline $\begin{array}{l}\text { 7. Close-Coupled Chemical Barrier } \\
\text { w/o Flushing }\end{array}$ & Traditional sluicing & $99 \%$ & $\begin{array}{c}40 \% \text { None } \\
60 \% \text { Close-coupled }\end{array}$ & No & No & Yes & Yes \\
\hline $\begin{array}{l}\text { 8. Modified Close-Coupled Chemical } \\
\text { Barrier w/o Flushing }\end{array}$ & Traditional sluicing & $99 \%$ & $\begin{array}{l}\text { Vertical } \\
\text { close-coupled }\end{array}$ & No & No & Yes & Yes \\
\hline 9. Box-Shaped Chemical Barrier & Traditional sluicing & $99 \%$ & Box-shaped chemical & Yes & Ycs & Yes & Yes \\
\hline 10. V-Shaped Chemical Barrier & Traditional sluicing & $99 \%$ & V-thaped chemical & Yes & Yes & Yes & Yes \\
\hline 11. V-Shaped Freeze Wall Barrier & Traditional sluicing & $99 \%$ & V-shaped freeze wall & Yes & Yes & Yes & Yes \\
\hline 12. Circulating Air Barrier & Traditional sluicing & $99 \%$ & Circulating air & Yes & Yes & Yes & Yes \\
\hline $\begin{array}{l}\text { 13. Clean-Closure w/o } \\
\text { Subsurface Barrier }\end{array}$ & $\begin{array}{l}\text { Traditional sluicing } \\
\text { \& mining }\end{array}$ & $100 \%$ & None & No & No & $\begin{array}{c}\text { Not } \\
\text { applicable }\end{array}$ & No \\
\hline $\begin{array}{l}\text { 14. Clean-Closure with } \\
\text { Close-Coupled Chemical Barrier }\end{array}$ & $\begin{array}{l}\text { Traditional sluicing } \\
\text { \& mining }\end{array}$ & $100 \%$ & $\begin{array}{l}40 \% \text { None } \\
60 \% \text { Close-coupled }\end{array}$ & No & No & $\begin{array}{c}\text { Not } \\
\text { applicable }\end{array}$ & No \\
\hline
\end{tabular}


Costs

Costs were estimated based on a comparative case of $99 \%$ removal of waste stored inside 12 one-million gallon tanks in a hypothetical tank farm with subsequent closure. The same hypothetical tank farm served as the basis for the risk and hazard analyses. Many assumptions were necessary to conduct these analyses; the guiding philosophy employed was each assumption should represent best judgement. Thus, the overall analyses were intended to be representative of expected performance as opposed to overly conservative or liberal projections of performance.

\section{$\underline{\text { Conclusions }}$}

These analyses served as the basis for the following conclusions regarding the three objectives of Tri-Party Agreement Milestone M-45-07A.

- Taking no action would result in risks approximately three orders of magnitude higher than the assumed upper limit $\left(10^{-4}\right)$ of the target risk range.

- Taking no action other than capping the tank farm with a surface barrier capable of limiting recharge to $0.05 \mathrm{~cm} / \mathrm{yr}(0.02 \mathrm{in} / \mathrm{yr})$ may result in acceptable risks for some tanks, but only if collapse of the tank domes could be prevented.

- The use of either traditional sluicing (assumed capable of achieving $99 \% \operatorname{tank}$ waste retrieval), robotic sluicing (99.9\% retrieval), or mechanical retrieval 
(95\% retrieval), in combination with stabilizing the structure of emptied tanks and using a surface barrier, appears potentially capable of attaining the target risk range for most tanks.

- The retrieval of all tank waste, including tank structures and contaminated soil to effect clean-closure, would likely result in bettering the risk range. The landfill created to contain washed, retrieved soil and debris from the tank farm would represent a new, but relatively small source of risk.

- The clean-closure alternatives would be about as cost-effective as other tank waste retrieval alternatives assuming that all recovered contaminants of environmental concern would be destroyed or treated and disposed offsite in a Federal repository, and assuming that benefit can be represented as a ratio of initial risk to achieved risk. If benefit is represented by the difference in these risks, the cost-benefit is two to 15 times lower than for the other retrieval alternatives.

- Sensitivity analyses show that the effects of uncertainties in various parameters associated with implementing non-subsurface barrier alternatives would have low-to-moderate impacts upon relative risk. These parameters include source inventories of constituents of concern, tank waste inventory, the field capacity of the geology beneath the tanks, solubility-controlled releases, and increased hydraulic head from the tank leakage plume. Because the impacts of these 
parameters on risk are typically within one order of magnitude, the estimated relative risk for most alternatives would remain below the assumed upper limit $\left(10^{-4}\right)$ of the target risk range.

- Other sensitivity analyses involving assumptions of gross deterioration of the tanks leading to very high leakage, low effectiveness of soil flushing, and deterioration of the surface barrier over time show estimated risks above the assumed upper limit. These analyses show the need for reliance on the ability of the tanks to be reasonably effective in containing water during sluicing, and the ability of the surface barrier to limit water recharge to design levels over long periods of time.

- Functional requirements have been established in a companion document, Functions and Requirements for Single-Shell Tank Leakage Mitigation. All functional requirements potentially can be satisfied using any of the subsurface barrier options evaluated.

- The use of any of the subsurface barrier concepts (chemical, freeze wall, and circulating air in close-coupled and standoff configurations) in general applications to tank farms would result in a relatively small incremental reduction in the risk level achievable using baseline technologies. (Baseline technologies include traditional sluicing, emptied-tank stabilization, and surface barriers.) 
- The use of a close-coupled barrier to support clean-closure activities may be cost-effective in comparison to a clean-closure alternative without a barrier because they would reduce the cost and limit the volume of contaminated soil requiring excavation and treatment while reducing risk.

- Except for the clean-closure application, the cost-effectiveness of subsurface barrier technologies are essentially equal and relatively low. The costeffectiveness of the subsurface barriers, calculated by the method most favorable to subsurface barriers, is about 0.0001 times that of surface barriers, and 0.01 times that of the set of baseline technologies.

- Uncertainty in the performance of subsurface barriers is high, but because the impact of subsurface barriers on risk and cost-effectiveness is very low, even best-case assumptions of subsurface barrier performance have a relatively small effect on overall risk and cost-effectiveness of SST disposal options.

- More conservative assumptions could easily lead to order of magnitude or higher projections of risk, potentially rendering some alternatives without subsurface barriers incapable of achieving the target risk range. In the event a conservative analysis is required by the decision makers as a basis for establishing cleanup requirements, the use of subsurface barriers may be necessary to reduce risks sufficiently to satisfy all conditions of a closure permit. 
- Potential risks to workers involved in implementing subsurface barrier alternatives increase by factors of up to 15 times, relative to the baseline technologies. The implementation of subsurface barrier alternatives excluding the clean-closure alternatives would entail worker risks two to five times higher than in the case of the baseline technologies. The implementation of either clean-closure alternative would result in the highest worker risks.

These conclusions were based on the ability of subsurface barriers and other technologies to reduce risk and improve cost-effectiveness in general-use applications to tank farms. Many simplifying assumptions were made and a one-dimensional contaminant transport model was used in developing these conclusions. If a decision is made to demonstrate subsurface barrier technologies for TWRS applications, the data resulting from the demonstrations should serve to reduce the number of assumptions made in future analyses. If the results of the demonstrations appear promising, rigorous modeling of contaminant transport should be considered before proceeding to implementation of subsurface barriers. 
WHC-SD-WM-ES-300 REV. 1

This page intentionally left blank.

xii 


\section{TABLE OF CONTENTS}

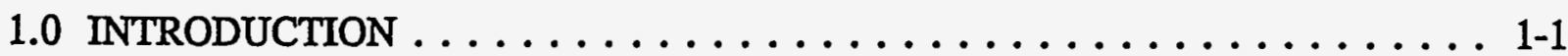

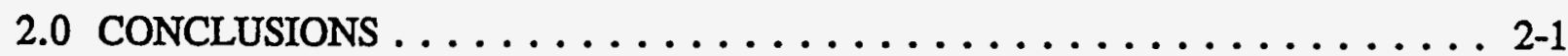

3.0 INTEGRATED SUBSURFACE BARRIER OPTIONS $\ldots \ldots \ldots \ldots \ldots$ 3-1

3.1 CHEMICAL JET GROUT ENCAPSULATION . . . . . . . . . . 3-4

3.1.1 Current Applications .................. 3-4

3.1.2 Test and Demonstration Status $\ldots \ldots \ldots \ldots \ldots \ldots \ldots . . .4$

3.1.3 Advantages and Disadvantages $\ldots \ldots \ldots \ldots \ldots \ldots \ldots$ 3-6

3.1 .4 Other Information . . . . . . . . . . . . . . 3-6

3.2 FREEZE WALLS $\ldots \ldots \ldots \ldots \ldots \ldots \ldots \ldots \ldots \ldots \ldots \ldots \ldots$

3.2.1 Current Applications . . . . . . . . . . . . . . 3-9

3.2.2 Test and Demonstration Status $\ldots \ldots \ldots \ldots \ldots \ldots$. . . . . . . .

3.2.3 Advantages and Disadvantages . . . . . . . . . 3-10

3.2 .4 Other Information . . . . . . . . . . . . . . . . 3-10

3.3 JET GROUT CURTAINS $\ldots \ldots \ldots \ldots \ldots \ldots \ldots \ldots \ldots \ldots \ldots .12$

3.3.1 Current Applications . . . . . . . . . . . . . 3-12

3.3.2 Test and Demonstration Status . . . . . . . . . 3-12

3.3.3 Advantages and Disadvantages $\ldots \ldots \ldots \ldots \ldots \ldots \ldots .14$

3.3.4 Other Information . . . . . . . . . . . . . . . . . 3-14

3.4 PERMEATION CHEMICAL GROUTING $\ldots \ldots \ldots \ldots \ldots \ldots \ldots$. $\ldots \ldots$

3.4.1 Current Applications . . . . . . . . . . . . . . 3-15

3.4.2 Test and Demonstration Status $\ldots \ldots \ldots \ldots \ldots \ldots .3-15$

3.4.3 Advantages and Disadvantages . . . . . . . . . . 3-15

3.4.4 Other Information . . . . . . . . . . . . . . . . . 3-17

3.5 WAX EMULSION PERMEATION GROUTING . . . . . . . . . 3-17

3.5.1 Current Applications . . . . . . . . . . . . . . . 3-18

3.5.2 Test and Demonstration Status $\ldots \ldots \ldots \ldots \ldots \ldots \ldots .18$

3.5.3 Advantages and Disadvantages $\ldots \ldots \ldots \ldots \ldots \ldots \ldots$ 3-18

3.5.4 Other Information . . . . . . . . . . . . . . . . 3-20

3.6 SILICA, SILICATE PERMEATION GROUTING $\ldots \ldots \ldots \ldots \ldots . . \ldots 3-20$

3.6.1 Current Applications . . . . . . . . . . . . . . . 3-21

3.6.2 Test and Demonstration Status . . . . . . . . . . 3-21

3.6.3 Advantages and Disadvantages . . . . . . . . . . 3-23

3.7 POLYMER PERMEATION GROUTING $\ldots \ldots \ldots \ldots \ldots \ldots \ldots$. . . . . . . .

3.7.1 Current Applications . . . . . . . . . . . . . . 3-23

3.7.2 Test and Demonstration Status . . . . . . . . 3-25

3.7.3 Advantages and Disadvantages . . . . . . . . . . 3-25

3.7.4 Other Information . . . . . . . . . . . . . . . . . . 3-26

3.8 FORMED-IN-PLACE HORIZONTAL GROUT BARRIERS $\ldots \ldots \ldots$. . . 3-26

3.8.1 Current Applications . . . . . . . . . . . . . . . 3-27

3.8.2 Test and Demonstration Status $\ldots \ldots \ldots \ldots \ldots \ldots \ldots .27$ 
TABLE OF CONTENTS (cont)

3.8.3 Advantages and Disadvantages . . . . . . . . . . . . 3-29

3.8.4 Other Information . . . . . . . . . . . . . . . . . . . . . . 3-29

3.9 CIRCULATING AIR BARRIERS . . . . . . . . . . . . . 3-30

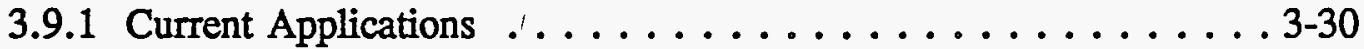

3.9.2 Test and Demonstration Status . . . . . . . . . . 3-30

3.9.3 Advantages and Disadvantages . . . . . . . . . . . 3-30

3.9.4 Other Information . . . . . . . . . . . . . . . 3-33

3.10 RADIOFREQUENCY DESICCATING SUBSURFACE BARRIERS . . . 3-34

3.10.1 Current Applications . . . . . . . . . . . . . 3-36

3.10.2 Test/Demonstration Status . . . . . . . . . . . 3-36

3.10.3 Advantages and Disadvantages . . . . . . . . . 3-36

3.10 .4 Other Information . . . . . . . . . . . . . . . . 3-37

3.11 SHEET METAL PILING SUBSURFACE BARRIERS . . . . . . . . 3-37

3.11 .1 Current Applications . . . . . . . . . . . . . 3-38

3.11.2 Test and Demonstration Status . . . . . . . . . . 3-40

3.11.3 Advantages and Disadvantages $\ldots \ldots \ldots \ldots \ldots \ldots$. . . . . . . .

3.11 .4 Other Information . . . . . . . . . . . . . . . . . 3-41

3.12 CLOSE-COUPLED INJECTED CHEMICAL BARRIERS . . . . . . . 3-41

3.12.1 Current Applications . . . . . . . . . . . . . . . 3-41

3.12.2 Test and Demonstration Status $\ldots \ldots \ldots \ldots \ldots \ldots .43$

3.12.3 Advantages and Disadvantages . . . . . . . . . . 3-43

3.13 INDUCED LIQUEFACTION BARRIERS . . . . . . . . . . . . 3-43

3.13.1 Current Applications . . . . . . . . . . . . . . 3-45

3.13.2 Test and Demonstration Status $\ldots \ldots \ldots \ldots \ldots \ldots$ 3-45

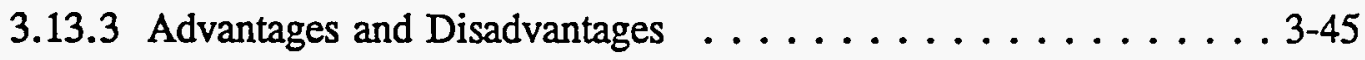

3.14 SLURRY WALLS $\ldots \ldots \ldots \ldots \ldots \ldots \ldots \ldots \ldots \ldots \ldots$. . . . . . . . . . . . .

3.15 DEEP SOIL MIXING . . . . . . . . . . . . . . . . . 3-46

3.16 SOIL FRACTURING $\ldots \ldots \ldots \ldots \ldots \ldots \ldots \ldots \ldots \ldots \ldots$. . . . . . . . . . . .

3.17 LONGWALL MINING $\ldots \ldots \ldots \ldots \ldots \ldots \ldots \ldots \ldots \ldots$. . . . . . . . . . . .

3.18 MODIFIED SULFUR CEMENT $\ldots \ldots \ldots \ldots \ldots \ldots \ldots \ldots \ldots$. $\ldots \ldots 7$

3.19 SEQUESTERING AGENTS $\ldots \ldots \ldots \ldots \ldots \ldots \ldots \ldots \ldots \ldots$. . . . . . . . .

3.20 REACTIVE BARRIERS . . . . . . . . . . . . . . . . . . . . 3-48

3.22 IMPERMEABLE COATINGS $\ldots \ldots \ldots \ldots \ldots \ldots \ldots \ldots \ldots \ldots$. . . . . . . .

3.23 MICROTUNNELING . . . . . . . . . . . . . . . . . . 3-49

3.24 IN SITU VITRIFICATION . . . . . . . . . . . . . . . . . . . . 3-49

3.25 SOIL SAW . . . . . . . . . . . . . . . . . 3-50

4.0 DESCRIPTION OF TECHNOLOGIES SUPPORTING SST WASTE

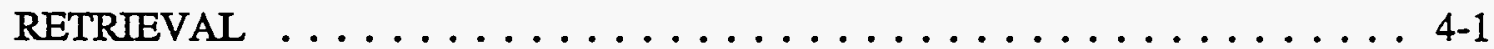

4.1 TECHNICAL SETTING . . . . . . . . . . . . . 4-1

4.2 TANK WASTE RETRIEVAL $\ldots \ldots \ldots \ldots \ldots \ldots \ldots \ldots . \ldots \ldots$ 4-2 


\section{TABLE OF CONTENTS (cont)}

4.2.1 Traditional Sluicing . . . . . . . . . . . . 4-2

4.2.2 Robotic Sluicing . . . . . . . . . . . . 4-4

4.2.3 Mechanical Retrieval .................. 4-6

4.3 LOW-PERMEABILITY SUBSURFACE BARRIERS . . . . . . . . . 4-8

4.3.1 Close-Coupled Chemical Barrier . . . . . . . . . . 4-8

4.3.2 Box-Shaped Chemical Barrier . . . . . . . . . . . . . 4-10

4.3.3 V-Shaped Chemical Barrier . . . . . . . . . . . . 4-13

4.3.4 V-Shaped Freeze Wall Barrier . . . . . . . . . 4-15

4.3.5 Circulating Air Barrier . . . . . . . . . . . 4-16

4.4 SOIL FLUSHING $\ldots \ldots \ldots \ldots \ldots \ldots \ldots \ldots \ldots \ldots \ldots \ldots$. . . . . . . . . . . . .

4.4.1 Traditional Soil Flushing . . . . . . . . . . . . . 4-19

4.4.2 Vacuum Soil Flushing $\ldots \ldots \ldots \ldots \ldots \ldots \ldots$. . . . . . . . . . . .

4.4.3 Flush Water Treatment . . . . . . . . . . . . . . . 4-19

4.5 TANK CLOSURE . . . . . . . . . . . . . . . 4-21

4.5.1 Grout Stabilization . . . . . . . . . . . . . 4-22

4.5.2 Permanent Isolation Surface Barrier . . . . . . . . . . . 4-24

4.5.3 Confined Demolition/Mining System . . . . . . . . 4-26

5.0 OVERALL SYSTEM ALTERNATIVES $\ldots \ldots \ldots \ldots \ldots \ldots \ldots$ 5-1

5.1 DESCRIPTION OF ALTERNATIVES . . . . . . . . . 5-1

$5.2 \mathrm{KEY}$ ASSUMPTIONS $\ldots \ldots \ldots \ldots \ldots \ldots \ldots \ldots \ldots \ldots$

6.0 COMPARATIVE RISK ASSESSMENT . . . . . . . . . . . 6-1

6.1 SOURCE TERMS, BASES, AND ASSUMPTIONS $\ldots \ldots \ldots \ldots . \ldots 6-2$

6.1 .1 General Assumptions . . . . . . . . . . . . . 6-3

6.1.2 Residue In Tank Following Waste Retrieval ......... 6-6

6.1.3 Residue Between Tank Steel and Concrete Foundation . . . . 6-11

6.1.4 Residue Within Tank Concrete . . . . . . . . . . . 6-14

6.1.5 Residue in Soil Due to Old and New Leaks . . . . . . . . . . 6-20

6.1.6 Residue Following Soil Flushing of Old and New Leaks . . . . 6-25

6.1.7 Residue Within Close-Coupled Barrier . . . . . . . . . 6-28

6.1.8 Residue Following Use of Stand-off Barriers . . . . . . . 6 6-33

6.2 CONTAMINANT TRANSPORT AND HUMAN HEALTH RISK . . . . . 6-39

6.2.1 Contaminant Transport and Groundwater Concentrations . . . . 6 6-40

6.2.2 Human Exposure and Health Risk . . . . . . . . . . . . 6-43

6.3 SUMMARY OF RISK RESULTS . . . . . . . . . . . . . . 6-43

6.3.1 Groundwater Concentrations . . . . . . . . . . . 6-44

6.3.2 Health Risk . . . . . . . . . . . . . . . . 6-47 


\section{TABLE OF CONTENTS (cont)}

7.0 COST ANALYSIS $\ldots \ldots \ldots \ldots \ldots \ldots \ldots \ldots \ldots \ldots \ldots \ldots \ldots$. $\ldots \ldots \ldots$

7.1 METHODOLOGY AND GENERAL ASSUMPTIONS $\ldots \ldots \ldots \ldots \ldots 7-1$

7.1.1 Definition of Costing Terms . . . . . . . . . . 7-1

7.1.2 Simplifying Assumptions .............. 7-2

7.2 COSTS OF RETRIEVAL OPTIONS . . . . . . . . . . 7-4

7.3 COSTS OF SUBSURFACE BARRIER OPTIONS $\ldots \ldots \ldots \ldots \ldots \ldots 7-4$

7.4 COSTS OF SOIL FLUSHING OPTIONS $\ldots \ldots \ldots \ldots \ldots \ldots \ldots$. $\ldots \ldots$

7.5 TANK STABILIZATION AND SURFACE BARRIER $\ldots \ldots \ldots \ldots \ldots 7-6$

7.6 CLEAN CLOSURE . . . . . . . . . . . . . . . . 7-7

7.7 SUMMARY OF ALTERNATIVES COSTS $\ldots \ldots \ldots \ldots \ldots \ldots$ 7-7

8.0 COST-BENEFIT AND SENSITIVITY ANALYSIS $\ldots \ldots \ldots \ldots \ldots \ldots$. . . . .

8.1 COST-BENEFIT ANALYSIS $\ldots \ldots \ldots \ldots \ldots \ldots \ldots \ldots \ldots$ 8-1

8.2 SENSITIVITY ANALYSIS . . . . . . . . . . . . . . 8 8-7

8.2.1 Phase I - Uncertainty in Source Inventories and Release Rates . . 8-7

8.2.2 Phase II - Uncertainty in Tank Waste Inventory and Geology . . 8-11

8.2.3 Phase III - Solubility-Limited Release . . . . . . . . . . . 8-19

8.2.4 Phase IV - Very-High Leakage With Variability In Recharge Rate and Flushing Effectiveness ........... 8-27

8.2.5 Phase V - Effect of Large Leak Volume on Travel Time Through the Unsaturated Zone . . . . . . . . . . . . . 8-40

9.0 ASSESSMENT OF RISKS TO WORKERS $\ldots \ldots \ldots \ldots \ldots \ldots \ldots$. . . . . .

9.1 METHODS, DATA, AND ASSUMPTIONS . . . . . . . . 9 9-1

9.1.1 Risks and Risk Factors . . . . . . . . . . . . . 9 9-1

9.1.2 Characterization of Technology Options . . . . . . . . 9-7

9.1.3 Risk Characterization . . . . . . . . . . . . . . 9-9

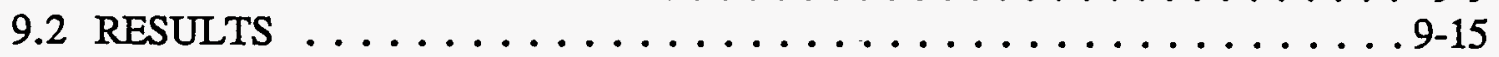

10.0 COMPLIANCE WITH FUNCTIONS AND REQUIREMENTS $\ldots \ldots \ldots$. . . .

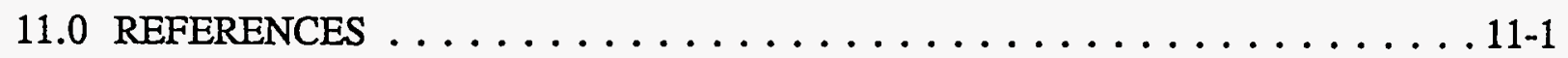

\section{APPENDIXES}

A MEPAS CODE INPUT AND OUTPUT . ............... A-1

B GROUNDWATER CONCENTRATION AND HUMAN HEALTH RISK

RESULTS $\ldots \ldots \ldots \ldots \ldots \ldots \ldots \ldots \ldots \ldots \ldots \ldots \ldots$ B-1

C COST ESTIMATION ................... C-1

D WORKER RISK ANALYSIS $\ldots \ldots \ldots \ldots \ldots \ldots \ldots \ldots \ldots$ D-1

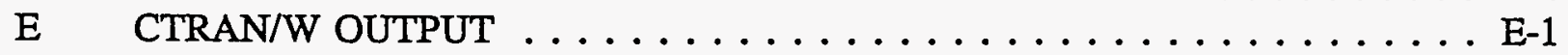




\section{LIST OF FIGURES}

3-1 Chemical Jet Grout Encapsulation . . . . . . . . . . . . . 3-5

3-2 Freeze Walls . . . . . . . . . . . . . . . . . 3-8

3-3 Jet Grout Curtains . . . . . . . . . . . . . . . . . . . 3-13

3-4 Permeation Chemical Grouting . . . . . . . . . . . . . . 3-16

3-5 Wax Emulsion Permeation Grouting . . . . . . . . . . . . . 3-19

3-6 Silica, Silicate Permeation Grouting $\ldots \ldots \ldots \ldots \ldots \ldots \ldots \ldots . \ldots \ldots$ 3-22

3-7 Polymer Permeation Grouting . . . . . . . . . . . . . . . . 3-24

3-8 Formed In-Place Horizontal Grout Barrier . . . . . . . . . . . . . . . 3-28

3-9 Horizontal Circulating Air Barrier . . . . . . . . . . . . . 3-31

3-10 Vertical Circulating Air Barrier . . . . . . . . . . . . . . 3-32

3-11 Radiofrequency Desiccating Subsurface Barrier $\ldots \ldots \ldots \ldots \ldots$. . . . . . .

3-12 Sheet Metal Piling Subsurface Barrier . . . . . . . . . . . . . 3-39

3-13 Close-Coupled Injected Chemical Barrier . . . . . . . . . . . . . . 3-42

3-14 Induced Liquefaction Barrier . . . . . . . . . . . . . . . . . 3-44

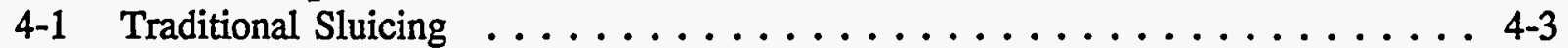

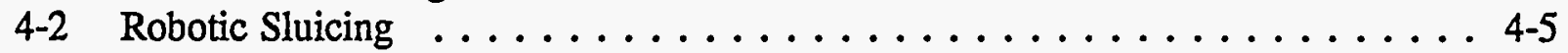

4-3 Mechanical Retrieval . . . . . . . . . . . . . . . . . . 4-7

4-4 Close-Coupled Chemical Barrier . . . . . . . . . . . . . . . . . . . . 4-9

4-5 Chemical Injection Piping for Close-Coupled Barrier . . . . . . . . . . 4-11

4-6 Box-Shaped Chemical Barrier . . . . . . . . . . . . . . . . 4-12

4-7 V-Shaped Barrier . . . . . . . . . . . . . . . . . . . 4-14

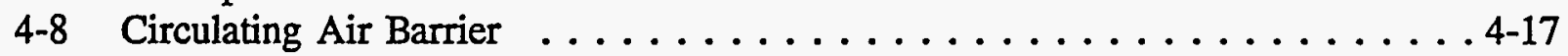

4-9 Traditional and Vacuum Soil Flushing $\ldots \ldots \ldots \ldots \ldots \ldots \ldots . \ldots \ldots$ 4-20

4-10 Tank Stabilized with Grout Following Waste Retrieval . . . . . . . . . . 4-23

4-11 Hanford Permanent Isolation Surface Barrier . . . . . . . . . . . . . . 4-25

4-12 Confined Tank Demolition and Mining System . . . . . . . . . . . 4-27

6-1 Residual Waste in Tanks Following Retrieval . . . . . . . . . . . . . . . 6 6-8

6-2 Residual Waste Trapped Between Tank Steel and Concrete Foundation . . . . 6-12

6-3 Diffusion and Advection of Waste into Concrete Foundation . . . . . . 6-15

6-4 Old and New Leaks to the Soil . . . . . . . . . . . . . . . . 6-21

6-5 Residual Soil Contamination Following Flushing . . . . . . . . . . . . . 6-27

6-6 Diffusion and Advection into Close-Coupled Barrier . . . . . . . . . . . 6-29

6-7 Assumed Lines of Potential Leakage from Single-Shell Tanks . . . . . . . . . 6-30

6-8 Residual Waste Following Use of Stand-off Barriers . . . . . . . . . . . 6 6-34

6-9 Cross-Sectional View of In Situ Flushing Zones for V-Shaped and

Box-Shaped Barriers . . . . . . . . . . . . . . . . . . . . . 6-36

6-10 Summary of Carcinogenic Risks for All Alternatives . . . . . . . . . . 6-48

6-11 Summary of Carcinogenic Risks for All Retrieval Alternatives . . . . . . . 6 6-50

6-12 Summary of Noncarcinogenic Hazard Index for All Alternatives . . . . . . . 6 6-52

6-13 Summary of Noncarcinogen Hazard Index for Selected Retrieval Alternatives . 6-53

8-1 Risk and Hazard Index Versus Total Nitrate in All Sources . . . . . . . . . 8-8

8-2 Carcinogenic Risk for Sensitivity Cases and Selected Alternatives . . . . . 8 8-17

8-3 Hazard Index for Sensitivity Cases and Selected Alternatives . . . . . . . 8 8-18 


\section{LIST OF FIGURES (cont)}

8-4 Relative Carcinogenic Risk for Baseline Alternative: Congruent Release Versus

Solubility-limited Releases . . . . . . . . . . . . . . . . . 8-21

8-5 Relative Hazard Index for Baseline Alternative: Congruent Release Versus

Solubility-limited Release . . . . . . . . . . . . . . . . . . . . . . 8-22

8-6 Summary of Carcinogenic Risk Based on Solubility-limited Releases . . . . 8 8-24

8-7 Summary of Hazard Indexes Based on Solubility-limited Releases . . . . . . 8 8-25

8-8 Summary of Carcinogenic Risks for Very-High Leakage Cases at $0.05 \mathrm{~cm} / \mathrm{yr}$ Recharge . . . . . . . . . . . . . . . . . . . . . . 8-33

8-9 Summary of Carcinogenic Risks for Very-High Leakage Cases at $0.5 \mathrm{~cm} / \mathrm{yr}$ Recharge . . . . . . . . . . . . . . . . . . . . . . 8-34

8-10 Summary of Noncarcenogenic Hazard Indexes for Very-High Leakage Cases at $0.05 \mathrm{~cm} / \mathrm{yr}$ Recharge . . . . . . . . . . . . . . . . . . . . . . . . 8-35

8-11 Summary of Noncarcenogenic Hazard Indexes for Very-High Leakage Cases at $0.5 \mathrm{~cm} / \mathrm{yr} /$ Recharge . . . . . . . . . . . . . . . . . . . . . 8-36

8-12 Comparison of Sources of Cancer Risk for Very-High Leakage Case at $0.5 \mathrm{~cm} / \mathrm{yr}$ Recharge (Baseline Alternative) . . . . . . . . . . . . . . 8-39

8-13 Finite Element Modeling Grid Indicating Contaminant Plume Within the

Soil Profile . . . . . . . . . . . . . . . . . . . . . . 8-43

8-14 Characteristic Curves for Hydraulic Conductivity . . . . . . . . . . 8-45

8-15 Characteristic Curves for Volumetric Water Content . . . . . . . . . . . . 8 8-46

8-16 Comparison of Contaminant Plume Breakthrough Curves Under National Recharge and Large Leak Conditions . . . . . . . . . . . . . . . 8-48

\section{LIST OF TABLES}

1-1 Elements of Feasibility Study $\ldots \ldots \ldots \ldots \ldots \ldots \ldots \ldots \ldots \ldots . \ldots \ldots$ 1-2

3-1 Integrated Subsurface Barrier Options Considered . . . . . . . . . 3-2

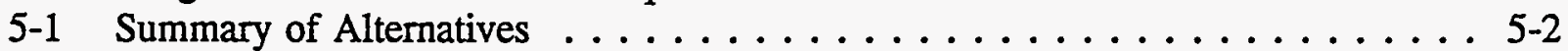

6-1 Comparison of Constituent Rankings ................. 6-5

6-2 Constituents of Concern Evaluated in the Risk Model . . . . . . . . . . . 6-6

6-3 Assumed Contaminant Data for Hypothetical Tank Farm . . . . . . . . . . 6-7

6-4 Tank Residual Nitrate Data . . . . . . . . . . . . . . . . . . . . 6-10

6-5 Nitrate Release Data for Old and New Leaks . . . . . . . . . . . . . . . . 6-24

6-6 Summary of Pre-Flushing Leakage Into Soil . . . . . . . . . . . . . 6-26

6-7 Tank Remedial Alternatives and Applicable Sources . . . . . . . . . . . . 6-42

6-8 Peak Groundwater Contaminant Concentrations ${ }^{2}$ - All Sources . . . . . . . . 6-45

6-9 Peak Relative Cancer Risks and Hazard Index - Each Alternative, All Sources . 6-49

6-10 Relative Cancer Risks and Hazard Index for Constituents of Concern . . . . . . 6-54

6-11 Relative Source Contribution to Carcinogenic Risk . . . . . . . . . . 6-55

6-12 Relative Source Contribution to Hazard Index Risk . . . . . . . . . . . 6-57 


\section{LIST OF TABLES (cont)}

7-1 Estimated Total Costs of Retrieval Options (in millions of dollars) . . . . . 7-4

7-2 Estimated Costs of Subsurface Barrier Options (in millions of dollars) $\ldots \ldots$ 7-5

7-3 Estimated Costs of Soil Flushing Options (in millions of dollars) . . . . . . 7-6

7-4 Estimated Costs of Tank Stabilization and Surface Barrier

(in millions of dollars) . . . . . . . . . . . . . . . 7-7

7-5 Estimated Costs of Clean Closure (in millions of dollars) $\ldots \ldots \ldots \ldots . .7-8$

7-6 Estimated EUAC Costs of Alternatives (in millions of dollars) $\ldots \ldots \ldots \ldots$ 7-9

7-7 Estimated TNPW Costs of Alternatives (in millions of dollars) $\ldots \ldots \ldots \ldots$ 7-10

7-8 Estimated TLCC Costs of Alternatives (in millions of dollars) $\ldots \ldots \ldots \ldots$ 7-11

8-1 Benefit of Alternatives Using Risk-Difference Method . . . . . . . . . 8 8-2

8-2 Cost-Benefit of Alternatives Relative to No-Action Alternative . . . . . . . . 8-4

8-3 Incremental Cost-Effectiveness of Selected Actions . . . . . . . . . . . 8-5

8-4 Summary of Nitrate Levels in Subsurface Barrier Alternative Sources

(thousand $\mathrm{kg}$ of nitrate) $\ldots \ldots \ldots \ldots \ldots \ldots \ldots \ldots \ldots$. . . . . . . . . . . . .

8-5 Projected Impacts of Uncertainty in the Effectiveness of Subsurface

Barrier Alternatives . . . . . . . . . . . . . . . . . . 8-12

8-6 Inventory of Selected Constituents of Concern by Tank Farm Grouping . . . . 8-13

8-7 Average Tank Farm Inventory of Selected Constituents

of Concern by Tank Farm Grouping . . . . . . . . . . . . . . 8 8-13

8-8 High and Low Constituent of Concern Inventory Cases for Sensitivity Analysis 8-14

8-9 Variability in Single-Shell Tank Farm Waste Inventories . . . . . . . . . . 8-15

8-10 Variability in Single-Shell Tank Farm Geologies . . . . . . . . . . . . . . . 8-16

8-11 Summary of Relative Risks and Hazard Index for Sensitivity and

Baseline Cases . . . . . . . . . . . . . . . . . . . 8-16

8-12 Comparison of Contribution to Cancer Risk to Hazard Index by

Constituents of Concern . . . . . . . . . . . . . . . . . . 8-23

8-13 Comparison of Peak Cancer Risk for Congruent Release and

Solubility-limited Release Cases . . . . . . . . . . . . . . . . . 8 8-26

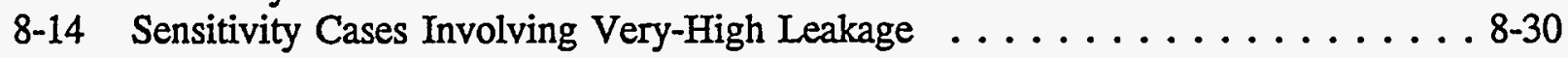

8-15 Peak Cancer Risks and Hazard Indexes for Very-High Leakage Cases . . . . 8 8-37

8-16 Parameters for Water Content and Hydraulic Conductivity Characteristic Curves 8-44

9-1 Remedial Technology Options. . . . . . . . . . . . . . . 9-2

9-2 Alternative Descriptions . . . . . . . . . . . . . . . 9-3

9-3 Unit-Risk Factors for Vehicular Transportation . . . . . . . . . . . 9-5

9-4 Physical Hazard Risk Factors . . . . . . . . . . . . . . . . . 9-7

9-5 Life-Cycle Work Force Requirements for Technology Options (person-years) . . 9-10

9-6 Worker Category Requirements for Technology Options (person-years) . . . . . 9 9-11

9-7 Worker Category Requirements for Alternatives (person-years) . . . . . . . . 9-12

9-8 Risk Calculation Approach $\ldots \ldots \ldots \ldots \ldots \ldots \ldots \ldots \ldots . \ldots \ldots$ 9.13 


\section{LIST OF TABLES (cont)}

9-9 Total Worker Risks Associated with Technology Options (1) . . . . . . . . 9-14

9-10 Fatality Risks Associated with Alternatives (number of fatalities) (1) . . . . . 9-17

9-11 Injury Risks Associated with Alternatives (number of reportable injuries) (1) . 9-18

9-12 Collective Cancer Risks Associated with Alternatives . . . . . . . . . . . 9-19

9-13 Worker Risks Relative to Baseline Alternative Risks . . . . . . . . . . 9-20

10-1 Potential Ability of Subsurface Barriers to Prevent New Leakage . . . . . . . . . 10-2

10-2 Potential Ability of Subsurface Barriers to Confine Past Leaks . . . . . . . . 10 10-3

10-3 Potential Ability of Subsurface Barriers to Support Removal of Soil Contamination . . . . . . . . . . . . . . . . . . . . . . . 10-4

10-4 Potential Ability to Monitor Performance and Verify Compliance of

Subsurface Barriers . . . . . . . . . . . . . . . . 10-5 


\section{LIST OF TERMS}

$\begin{array}{ll}\text { CAB } & \text { circulating air barrier } \\ \text { COC } & \text { constituent of concern } \\ \text { D\&D } & \text { decontamination and decommissioning } \\ \text { DBI } & \text { DBI Gas-und Umwelttechnik Gmblt } \\ \text { DOE } & \text { U.S. Department of Energy } \\ \text { Ecology } & \text { Washington State Department of Ecology } \\ \text { EDTA } & \text { ethylenediaminetetraacetic acid } \\ \text { EPA } & \text { U.S. Environmental Protection Agency } \\ \text { EUAC } & \text { equivalent uniform annualized cost } \\ \text { HDW-EIS } & \text { Hanford Defense Waste Environmental Impact Statement } \\ \text { HI } & \text { hazard index } \\ \text { HLW } & \text { high level waste } \\ \text { HVAC } & \text { heating, ventilating, and air conditioning } \\ \text { INEL } & \text { Idaho National Engineering Laboratory } \\ \text { IITRI } & \text { IIT Research Institute } \\ \text { MEPAS } & \text { Multimedia Environmental Pollutant Assessment System } \\ \text { MIBRAG } & \text { Vereinigte Mitteldeutsche Braunkohlenwenke AG } \\ \text { NSC } & \text { National Safety Council } \\ \text { O\&M } & \text { operating and maintenance } \\ \text { RCRA } & \text { Resource Conservation and Recovery Act of 1976 } \\ \text { RF } & \text { radiofrequency } \\ \text { SEG } & \text { Scientific Ecology Group, Inc. } \\ \text { SLAEMS } & \text { Single Layer Analytical Element Method-Stratified } \\ \text { SST } & \text { single-shell tank } \\ \text { TBP } & \text { tributyl phosphate } \\ \text { TLCC } & \text { total life cycle cost } \\ \text { TNPW } & \text { total net present worth } \\ \text { Tri-Party } & \\ \text { Agreement } & \text { Hanford Federal Facility Agreement and Consent Order } \\ \text { TWRS } & \text { Tank Waste Remediation System }\end{array}$


WHC-SD-WM-ES-300 REV. 1

This page intentionally left blank. 


\subsection{INTRODUCTION}

In 1943, the U.S. Army Corps of Engineers selected the Hanford Site near Richland, Washington to build plutonium production reactors and processing facilities. For more than 40 years, these and other Hanford Site facilities provided nuclear weapons materials for the nation's defense. The processing of spent nuclear fuel to obtain weapons materials resulted in the accumulation of large quantities of high-level radioactive and chemical wastes in underground storage tanks. A total of 149 single-shell tanks (SSTs) and 28 double-shell tanks contain these wastes. The wastes include sludges, saltcake, and slurries that will require retrieval, treatment, and disposal.

The U.S. Department of Energy (DOE) has established the Tank Waste Remediation System (TWRS) to safely manage and dispose of the wastes currently stored in the underground storage tanks. The scope of TWRS includes: tank safety and operations; waste characterization, retrieval, and pretreatment; high-level waste immobilization; low-level waste immobilization; and associated transfer, interim and long-term storage, and disposal of wastes.

The retrieval element of TWRS includes a work scope to develop subsurface impermeable barriers beneath SSTs. The barriers could serve as a means to contain leakage that may result from waste retrieval operations and could also support site closure activities by facilitating cleanup. A number of studies and working meetings have taken place in an effort to identify potentially applicable subsurface barrier system(s) for SST waste retrieval applications and to determine the best approach to develop them (Bovay Northwest 1992; LATA 1992). As a result of these activities, three types of subsurface barrier systems have emerged for further consideration: (1) chemical grout, (2) freeze wall, and (3) desiccant, represented in this feasibility study as a circulating air barrier. These barrier concepts may be installed in either close-coupled (against the tank structure) or standoff (with a soil layer between the tank and barrier) configurations.

The TWRS program has begun planning for a demonstration project to further evaluate these concepts. The plan includes an assessment of the feasibility of subsurface barrier systems to satisfy Milestones M-45-07A (September 1994) and M-45-07B (January 1995) of the Hanford Federal Facility Agreement and Consent Order (Ecology et al. 1990), otherwise known as the Tri-Party Agreement.

The Tri-Party Agreement Milestone M-45-07A requires completion of a feasibility study to accomplish the following:

- Estimate the potential environmental impacts of waste storage and retrieval activities without the application of subsurface barriers

- Establish functional requirements of subsurface barriers to minimize the impacts associated with waste storage and retrieval activities 
- Evaluate the application of existing subsurface barrier technologies to meet functional requirements of barriers and the potential reduction in environmental impacts from the application of barriers to SST waste storage and retrieval activities.

The feasibility study will support a decision by the DOE Richland Operations Office, the Washington Department of Ecology (Ecology), and the U.S. Environmental Protection Agency (EPA) regarding further development of subsurface barrier options for SSTs and whether to proceed with demonstration plans at the Hanford Site (Tri-Party Agreement Milestone M-45-07B).

The feasibility study includes eight elements. These elements and their sources are identified in Table 1-1.

Table 1-1. Elements of Feasibility Study.

\begin{tabular}{|c|c|c|}
\hline \multicolumn{2}{|r|}{ Element } & Source \\
\hline 1. & $\begin{array}{l}\text { Analysis of the mission of subsurface } \\
\text { barriers supporting waste retrieval and } \\
\text { tank closure operations }\end{array}$ & $\begin{array}{l}\text { Mission Analysis for Single-Shell Tank Leak } \\
\text { Mitigation, WHC-SD-WM-MAR-001, Rev. } 0 \\
\text { (Cruse 1994a) }\end{array}$ \\
\hline 2. & $\begin{array}{l}\text { Regulatory assessment of the Hanford } \\
\text { Site tank application of subsurface } \\
\text { barriers }\end{array}$ & $\begin{array}{l}\text { Regulatory Assessment for the Use of } \\
\text { Underground Barriers at the Hanford Site Tank } \\
\text { Farms, WHC-SD-EN-RD-010, Rev. } 0 \\
\text { (Smith 1994) }\end{array}$ \\
\hline 3. & $\begin{array}{l}\text { Functional requirements for the } \\
\text { Hanford Site tank application of } \\
\text { subsurface barriers }\end{array}$ & $\begin{array}{l}\text { Functions and Requirements for Single-Shell } \\
\text { Tank Leakage Mitigation, } \\
\text { WHC-SD-WM-FRD-019, Rev. } 0 \text { (Cruse 1994b) }\end{array}$ \\
\hline 4. & $\begin{array}{l}\text { Qualitative risk assessment of } \\
\text { subsurface barriers vs. no-barriers }\end{array}$ & $\begin{array}{l}\text { Qualitative Risk Assessment of Subsurface } \\
\text { Barriers in Applications Supporting Retrieval of } \\
\text { SST Waste, WHC-SD-WM-RA-010, Rev. } 0 \\
\text { (Hampsten 1994) }\end{array}$ \\
\hline 5. & $\begin{array}{l}\text { Overall conclusions regarding merits of } \\
\text { subsurface barriers for the Hanford Site } \\
\text { tank application }\end{array}$ & This report (Section 2) \\
\hline 6. & $\begin{array}{l}\text { Definition of subsurface barrier } \\
\text { concepts }\end{array}$ & This report (Section 3) \\
\hline 7. & $\begin{array}{l}\text { Comparative subsurface barrier and no } \\
\text { barrier system performance and risk } \\
\text { analysis }\end{array}$ & This report (Sections 4 through 9) \\
\hline 8. & $\begin{array}{l}\text { Evaluation of ability of subsurface } \\
\text { barriers to satisfy functional } \\
\text { requirements }\end{array}$ & This report (Section 10) \\
\hline
\end{tabular}


This report contains analyses of the costs and relative risks associated with combinations of retrieval technologies and barrier technologies that form 14 alternatives. Eight of the alternatives include the use of subsurface barriers; the remaining six nonbarrier alternatives are included in order to compare the costs, relative risks, and other factors involving retrieval without subsurface barriers. Each alternative includes various combinations of technologies that can impact the risks associated with future contamination of the groundwater beneath the Hanford Site to varying degrees. Each alternative also entails different worker risks related to the complexity and the personnel needs of the technologies employed. A more comprehensive quantitative risk analysis is appropriate after considerations of the analyses in this report are made, after the number of alternatives under consideration are reduced, and when actual test data are available to reduce the number of assumptions.

The contents of the remainder of this report are summarized below:

- $\quad$ Section 2 summarizes preliminary conclusions

- Section 3 defines the range of subsurface barrier options considered

- Section 4 describes the unit technologies that make up the 14 alternatives

- Section 5 describes the 14 alternatives

- Section 6 describes the approach and results of the comparative risk assessment

- Section 7 describes the approach and results of the cost assessment

- Section 8 includes cost-benefit and sensitivity analyses, including discussion of uncertainties and the advantages and disadvantages of individual barrier options

- Section 9 includes an evaluation of potential safety risks to workers in implementation of the 14 alternatives

- Section 10 includes an evaluation of the ability of the eight alternatives that include subsurface barriers to satisfy draft functions and requirements

- Section 11 contains references cited in the report

- Appendix A describes the comparative risk assessment model

- Appendix B provides plots of comparative risk as a function of time for each alternative evaluated

- $\quad$ Appendix $\mathrm{C}$ provides details supporting the cost assessment in Section 7 
- $\quad$ Appendix D provides tables of calculated worker risks supporting the risk assessment presented in Section 9

- Appendix E provides initial head values and calculated contaminant fluxes for the sensitivity analysis using the CTRAN/W computer code described in Section 8. 


\subsection{CONCLUSIONS}

This section presents conclusions based on analyses of the costs, risks, and performance of 14 alternatives for the retrieval of waste from Hanford Site SSTs. The analyses were conducted in response to the three stated objectives of Tri-Party Agreement

Milestone M-45-07A. The evaluated alternatives included eight with subsurface barriers and six without. Technologies used in the alternatives included three types of tank waste retrieval, seven types of subsurface barriers, a method for filling the void space of emptied tanks, two types of in situ soil flushing, one type of surface barrier, and a clean-closure method. A no-action alternative and a surface barrier only alternative were included as nonviable alternatives for comparison.

First approximations of carcinogenic risk and noncarcinogenic hazards were estimated using the Multimedia Environmental Pollutant Assessment System (MEPAS) computer code. This code includes a one-dimensional model capable of projecting radiological and chemical risks and hazards through the groundwater and other pathways. Only the groundwater pathway was analyzed because the purpose of subsurface barriers is to prevent or limit future contamination of the groundwater. The MEPAS code has been used for risk analyses in several environmental impact statements in the United States and is the standard risk assessment tool for the Canadian Health and Welfare Department. Although the MEPAS is less rigorous than three-dimensional risk assessment models that have been accepted for detailed baseline risk assessments at the Hanford Site, it is well-suited to the comparative analyses conducted in this feasibility study.

First approximations of risk were estimated using MEPAS and related to an incremental cancer risk range of $10^{-4}$ to $10^{-6}$. This range spans the breadth of potential cleanup objectives usually considered acceptable for cleanup of waste sites. A hazard index (HI) was also estimated and related to a threshold value of one. Potential carcinogenic risk objectives were determined to be somewhat more difficult to meet than potential noncarcinogenic hazard objectives; therefore, most conclusions reported in this section deal with carcinogenic risk.

Costs were estimated based on a comparative case of $99 \%$ removal of waste stored inside 12 one-million gallon tanks in a hypothetical tank farm. The same hypothetical tank farm served as the basis for the risk and hazard analyses. Many assumptions were necessary to conduct these analyses; the guiding philosophy employed was each assumption should represent best judgement. Thus, the overall analyses were intended to be representative of expected performance as opposed to overly conservative or liberal projections of performance.

These analyses served as the basis for following conclusions drawn regarding the three objectives of Tri-Party Agreement Milestone M-45-07A. 
Objective 1 - Estimate the potential environmental impacts of waste storage and retrieval activities without the application of subsurface barriers.

Primary conclusions include the following:

- Taking no action would result in first-approximation risks approximately three orders of magnitude higher than the assumed upper limit $\left(10^{-4}\right)$ of the target risk range.

- Taking no action other than capping the tank farm with a surface barrier capable of limiting recharge to $0.05 \mathrm{~cm} / \mathrm{yr}(0.02 \mathrm{in} / \mathrm{yr})$ may result in acceptable risks for a few tanks, but only if collapse of the tank domes could be prevented. Eventual collapse of the tanks, which would compromise barrier effectiveness and expose the surface environment to high levels of . radioactivity, appears to be credible due to the deliquescent nature of the waste. This property would result in long-term drainage of contaminated salt brine from the tank and creation of voids, which eventually would lead to subsidence. The rate of creation of salt brine was not evaluated, but if it is higher than the projected rate due to recharge through the tank, it could render this option infeasible for all tanks containing deliquescent wastes, regardless if tank collapse can be prevented.

- The use of either traditional sluicing (assumed capable of achieving $99 \%$ tank waste retrieval), robotic sluicing (99.9\% retrieval), or mechanical retrieval ( $95 \%$ retrieval), in combination with stabilizing the structure of emptied tanks and using a surface barrier, appears potentially capable of attaining the target risk range for most tanks. This conclusion was drawn despite a factor of 20 difference in projected risk between mechanical retrieval (the highest-risk option) and robotic sluicing (the lowest-risk option).

- The retrieval of all tank waste, including tank structures and contaminated soil to effect clean-closure, would likely result in bettering the risk range. The landfill created to contain washed, retrieved soil and debris from the tank farm would represent a new, but relatively small source of risk.

- The clean-closure alternative appears to be about as cost-effective as other tank waste retrieval alternatives. This conclusion is based on the assumption that benefit is reflected in the proportional reduction in risk. The calculated costbenefit of the clean-closure alternatives is also predicated on the assumption that all recovered contaminants of environmental concern, except for residual amounts that remain after washing exhumed waste, would be destroyed or treated and disposed offsite in a Federal repository. If disposed on the Hanford Site, treated contaminants would represent a new source of risk. If benefit is represented by the difference in risk, as opposed to the proportional 
reduction in risk, the cost-benefit of clean-closure alternatives is two to 15 times lower than for other retrieval alternatives.

- A five-phase sensitivity analysis, which evaluated the effects of uncertainties in various parameters, determined that the following parameters would have lowto-moderate effects upon the relative risks associated with alternatives not implementing subsurface barriers: source inventories of constituents of concern, overall tank waste inventories, the field capacity of the geology underlying the tanks, solubility-controlled releases, and increased hydraulic head from the tank leakage plume. Large effects on risk would result if it is assumed that gross deterioration of the tanks had occurred, leading to very high leakage, and that the effectiveness of soil flushing is low, or that the performance of the surface barrier deteriorated over time. This analysis shows the need for reliance on the tanks to be reasonably effective in containing water during sluicing and on the ability of the surface barrier to limit recharge water over long periods of time.

- An evaluation of the potential risk to workers involved in implementing the technologies required by each of the alternatives that do not apply subsurface barriers was categorized into three sources of risk: transportation (vehicular travel), operations (exposure to physical hazards), and external radiation (exposure to ionizing radiation). Compared to the baseline technologies (traditional sluicing with tank void grouting and surface barrier), the relative number of fatalities and injuries for alternatives that do not apply subsurface barriers would range from about five times higher for robotic sluicing and mechanical retrieval for both fatalities and injuries, to 13 times more fatalities and 10 times more injuries for the clean-closure non-barrier alternative. About 12 times fewer fatalities and injuries would result if only the surface barrier is applied.

- Cancer risks to workers from radiation exposure would be seven times higher for robotic sluicing and mechanical retrieval alternatives, 15 times higher for the clean-closure non-barrier option, and 50 times less for the surface barrier only alternative.

Objective 2 - Establish functional requirements of subsurface barriers to minimize the impacts associated with waste storage and retrieval activities.

Functional requirements have been established in a companion draft document, Functions and Requirements for Single-Shell Tank Leakage Mitigation (Cruse 1994b). Other supporting documents, including Mission Analysis for Tank Leakage Mitigation (Cruse 1994a), Regulatory Assessment for the Use of Underground Barriers at the Hanford Site Tank Farms (Smith 1994), and Qualitative Risk Assessment of Subsurface Barriers in Applications Supporting Retrieval of SST Waste (Hampsten 1994), provide bases and background for the functional requirements. 
Objective 3 - Evaluate the application of existing subsurface barrier technologies to meet functional requirements of barriers and the potential reduction in environmental impacts from the application of barriers to SST waste storage and retrieval activities.

Primary conclusions include the following:

- All functional requirements potentially can be satisfied using any of the subsurface barrier options evaluated. This conclusion is tempered with the observations that (1) little hard data on the performance of subsurface barriers exist and (2) the draft functional requirements are largely and appropriately qualitative at this early state of development of this application of subsurface barriers.

- The use of any of the subsurface barrier concepts (chemical, freeze wall, and circulating air in close-coupled and standoff configurations) in general applications to tank farms would result in a relatively small incremental reduction in the risk level achievable using baseline technologies. (Baseline technologies include traditional sluicing, emptied-tank stabilization, and surface barriers.)

- The use of close-coupled barriers to support clean-closure activities may be cost-effective because they would reduce the cost and limit the volume of contaminated soil requiring excavation and treatment while reducing risk. Except for the clean-closure application, the cost-effectiveness of subsurface barrier technologies are essentially equal and relatively low.

- The cost-effectiveness of the subsurface barriers, calculated by the method most favorable to subsurface barriers, is about 0.0001 times that of surface barriers, and 0.01 times that of the set of baseline technologies. Uncertainty in the performance of subsurface barriers is high, but because the impact of subsurface barriers on risk and cost-effectiveness is low, even best-case assumptions of subsurface barrier performance have a relatively small effect on overall risk and cost-effectiveness of SST disposal options.

- Assumptions used in the feasibility study have not been widely reviewed by decision makers at this stage of analysis of feasibility. More conservative assumptions could easily lead to order of magnitude or higher projections of risk, thereby potentially rendering some alternatives incapable of achieving the target risk range. In the event a conservative analysis is required by the decision makers as a basis for establishing cleanup requirements, the use of subsurface barriers may reduce risks sufficiently to satisfy all conditions of a closure permit.

- A five-phase sensitivity analysis, which evaluated the effects of uncertainties in various parameters, determined that the following parameters would have low- 
to-moderate effects upon the relative risks associated with alternatives implementing subsurface barriers: source inventories of constituents of concern, overall tank waste inventories, the field capacity of the geology underlying the tanks, solubility-controlled releases, and increased hydraulic head from the tank leakage plume. Large effects on risk would result if it is assumed that gross deterioration of the tanks had occurred, leading the very high leakage, and that the effectiveness of soil flushing is low, or that the performance of the surface barrier deteriorated over time. This analysis shows the need for reliance on the tanks to be reasonably effective in containing water during sluicing and on the ability of the surface barrier to limit recharge water over long periods of time.

- An evaluation of the potential risks to workers involved in implementing the technologies required by each of the subsurface barrier alternatives was categorized into three sources of risk: transportation (vehicular travel), operations (exposure to physical hazards), and external radiation (exposure to ionizing radiation). Compared to the baseline technologies, the relative number of fatalities and injuries for subsurface barrier implementation range from about two to five times higher. The relative number of fatalities and injuries for implementation of clean closure with a barrier is roughly twice that of other subsurface barrier alternatives. Approximately one-half of the potential fatalities are expected to result from vehicular travel and one-third from design and construction activities. Cancer risks from radiation exposure range from about two to five times higher except for the clean-closure alternative which results in a risk of about 15 times higher.

The conclusions presented above were based on the ability of subsurface barriers and other technologies to reduce risk and improve cost-effectiveness in general-use applications to tank farms. Many simplifying assumptions were made and a one-dimensional contaminant transport model (MEPAS) was used in developing these conclusions. If a decision is made to demonstrate subsurface barriers for TWRS applications, the data resulting from the demonstrations should replace assumptions made in this analysis. If the results of demonstrations appear promising, rigorous modeling of contaminant transport should be considered before proceeding to implementation of subsurface barriers. 
WHC-SD-WM-ES-300 REV. 1

This page intentionally left blank. 


\subsection{INTEGRATED SUBSURFACE BARRIER OPTIONS}

This section identifies 13 viable integrated subsurface barrier options being considered for potential application to SSTs at the Hanford Site. The section is divided into subsections by overall method of confinement: 11 standoff concepts (i.e., options intended to be installed some distance from several tanks or around a tank farm) and two close-coupled concepts (i.e., options installed in contact with individual tanks). The viable barrier options are presented in Sections 3.1 through 3.13.

Each viable subsurface barrier technology concept discussion includes a description, a graphical depiction, its current applications (if any), test and demonstration status, potential advantages and disadvantages, and other information (e.g., vendor contacts, costs, regulatory issues, material options, etc.) if available. It should be noted that much of this information is subjective (especially in the advantage/disadvantage sections) and would need to be proved or disproved during a demonstration process if subsurface barriers are to be deemed feasible for application at the Hanford Site.

Subsections of 11 other less viable subsurface barrier concepts are also included to demonstrate that other options were investigated but were determined not to be as viable for SST applications at this time. The rationale related to the viability issue is provided for each concept in this category. In general, these less viable concepts would generate large amounts of spoils and/or were deemed impractical for use around Hanford Site tanks or tank farms. These less viable options are presented in Sections 3.14 through 3.24.

It should be noted that a matrix of the wide variety of deployment methods against the wide variety of materials that could be used for barriers would be too complex to present. For ease of understanding, deployment methods and materials have been combined into "integrated" options. This list of options does not include all possible combinations of deployment and material options but should provide the reader a representative listing of subsurface barrier concepts.

Candidate deployment technologies for these integrated options are traditional vertical drilling, directional or slant drilling, and/or horizontal drilling. Other deployment technologies include vertically oriented $5-\mathrm{m}(15-\mathrm{ft})$ diameter caissons installed in open areas between tanks or outside tank farms, coffered trenches constructed at the boundary of a tank farm, in situ mechanical mixing, slurry trenching, longwall mining, and other tunneling techniques. Additional information regarding subsurface barrier deployment techniques can be found in other Hanford Site documents (e.g., Jensen et al. 1992). Most of these deployment methods are unproven in Hanford Site applications.

Table 3-1 identifies the subsurface barrier materials, deployment methodologies, and their referenced subsections of the feasibility study. The following sections describe the subsurface barrier concepts in detail. 
Table 3-1. Integrated Subsurface Barrier Options Considered. (sheet 1 of 2)

\begin{tabular}{|l|l|l|l|}
\hline \multicolumn{1}{|c|}{ Deployment Method } & \multicolumn{1}{c|}{ Material Applications } & \multicolumn{1}{c|}{ Title } & Sect. \\
\hline \multirow{4}{*}{$\begin{array}{l}\text { Directional Drilling (cone- } \\
\text { or trough-shaped) }\end{array}$} & Cementitious Grouts & Chemical Jet Grout Encapsulation & 3.1 \\
\cline { 2 - 4 } & Ice Encapsulation & Freeze Walls & 3.2 \\
\hline $\begin{array}{l}\text { Vertical \& Horizontal } \\
\text { Drilling (box-shaped) }\end{array}$ & Cementitious Grout & Jet Grout Curtains & 3.3 \\
\cline { 2 - 4 } & Cementitious Grouts & Permeation Chemical Grouting & 3.4 \\
\cline { 2 - 5 } & Grouts with Thermoviscous Fluids & Wax Emulsion Permeation Grouting & 3.5 \\
\cline { 2 - 5 } & Colloidal Silica Sodium Silicates & Silica, Silicate Permeation Grouting & 3.6 \\
\cline { 2 - 5 } & $\begin{array}{l}\text { Grouts with Polymer Grouts, } \\
\text { Polyacrilates }\end{array}$ & Polymer Permeation Grouting & 3.7 \\
\cline { 2 - 5 } & Rubberized Cements, Clays, Grouts & Formed-In-Place Horizontal Grout Barriers & 3.8 \\
\cline { 2 - 5 } & Heated Air & Circulating Air Barriers & 3.9 \\
\hline \multirow{5}{*}{\begin{tabular}{l|l|l|l|l|} 
Directional Drilling \\
Piling + Horizontal
\end{tabular}} & Electrodes & $\begin{array}{l}\text { Radiofrequency Desiccating Subsurface } \\
\text { Barriers }\end{array}$ & 3.10 \\
\hline \multirow{2}{*}{$\begin{array}{l}\text { Directional Drilling } \\
\text { Piling \& Caisson }\end{array}$} & Sheet Metal w/Grout & Sheet Metal Piling Subsurface Barriers & 3.11 \\
\hline
\end{tabular}


Table 3-1. Integrated Subsurface Barrier Options Considered. (sheet 2 of 2)

\begin{tabular}{|c|c|c|c|}
\hline Deployment Method & Material Applications & Title & Sect. \\
\hline \multicolumn{4}{|c|}{ Other Less-Viable Concepts } \\
\hline Slurry Cutoff Walls & Various & Slurry Walls & 3.14 \\
\hline Soil Auguring & Various & Deep Soil Mixing & 3.15 \\
\hline Soil Fracturing & Cementitious Grouts & Soil Fracturing & 3.16 \\
\hline Long Wall Mining & Various & Longwall Mining & 3.17 \\
\hline Pug Mill Injection & Sulfur Cements & Modified Sulfur Cement & 3.18 \\
\hline \multirow{3}{*}{$\begin{array}{l}\text { Vertical \& Horizontal } \\
\text { Drilling }\end{array}$} & Sequestering Agents & Sequestering Agents & 3.19 \\
\hline & Reactive Agents & Reactive Barriers & 3.20 \\
\hline & Surface Coatings & Impermeable Coatings & 3.21 \\
\hline Microtunneling & Various & Microtunneling & 3.22 \\
\hline Electrodes & Glass & In Situ Vitrification & 3.23 \\
\hline Hydraulic Erosion & Grouts & Soil Saw & 3.24 \\
\hline
\end{tabular}




\subsection{CHEMICAL JET GROUT ENCAPSULATION}

Chemical jet grout encapsulation would isolate waste systems by using primarily highpressure jet grouting to form columns of grouted soil via directionally-drilled wells. Standard grouts such as portland cements or bentonite clays would be used. Other, more exotic grouts, could be used for enhanced control over set times and better compatibility with Hanford Site soils. These grouts would need to be compatible with the high pressures encountered with jet grouting. Columns would be allowed to harden before adjacent columns are drilled, partially cutting into the hardened column(s). When completed, the plan view of one configuration could be similar to the spokes of a bicycle wheel in a conical shape (Figure 3-1). Alternatively, lateral barriers could be installed along two sides using vertical wells and permeation or jet grouting; slant jet grouting would then be used to connect the lateral barriers (Naudts 1989). Slant well depths of approximately $66 \mathrm{~m}(200 \mathrm{ft})$ below the bottom of the tank(s) would be required for grout encapsulation.

Slant wells and jet grouting could also be directionally drilled and grouted to form a conical barrier beneath individual tanks; however, this scenario is not as likely for SST applications since only $7.6 \mathrm{~m}(25 \mathrm{ft})$ separate many of the tanks.

\subsubsection{Current Applications}

Current applications of jet grouts are numerous and include foundation repairs, cofferdam barriers, groundwater control, and other specialized uses. The technology has been used in Europe for waste containment systems but has not yet been used in the United States for that purpose (Naudts 1989).

The lengths and angles of the wells required for grout encapsulation are within the capabilities of existing equipment. Since jet grouting has been used extensively for other applications, the use of this technology should be feasible in soils free of large cobbles (up to $51 \mathrm{~cm}[20 \mathrm{in}]$.$) and boulders.$

\subsubsection{Test and Demonstration Status}

Jet grout encapsulation of Hanford Site underground storage tanks has only been conceptually designed. No laboratory or field tests have been performed. The base technologies of jet grouting and directional drilling are proven technologies and should require little modification for this application. 
WHC-SD-WM-ES-300 REV. 1

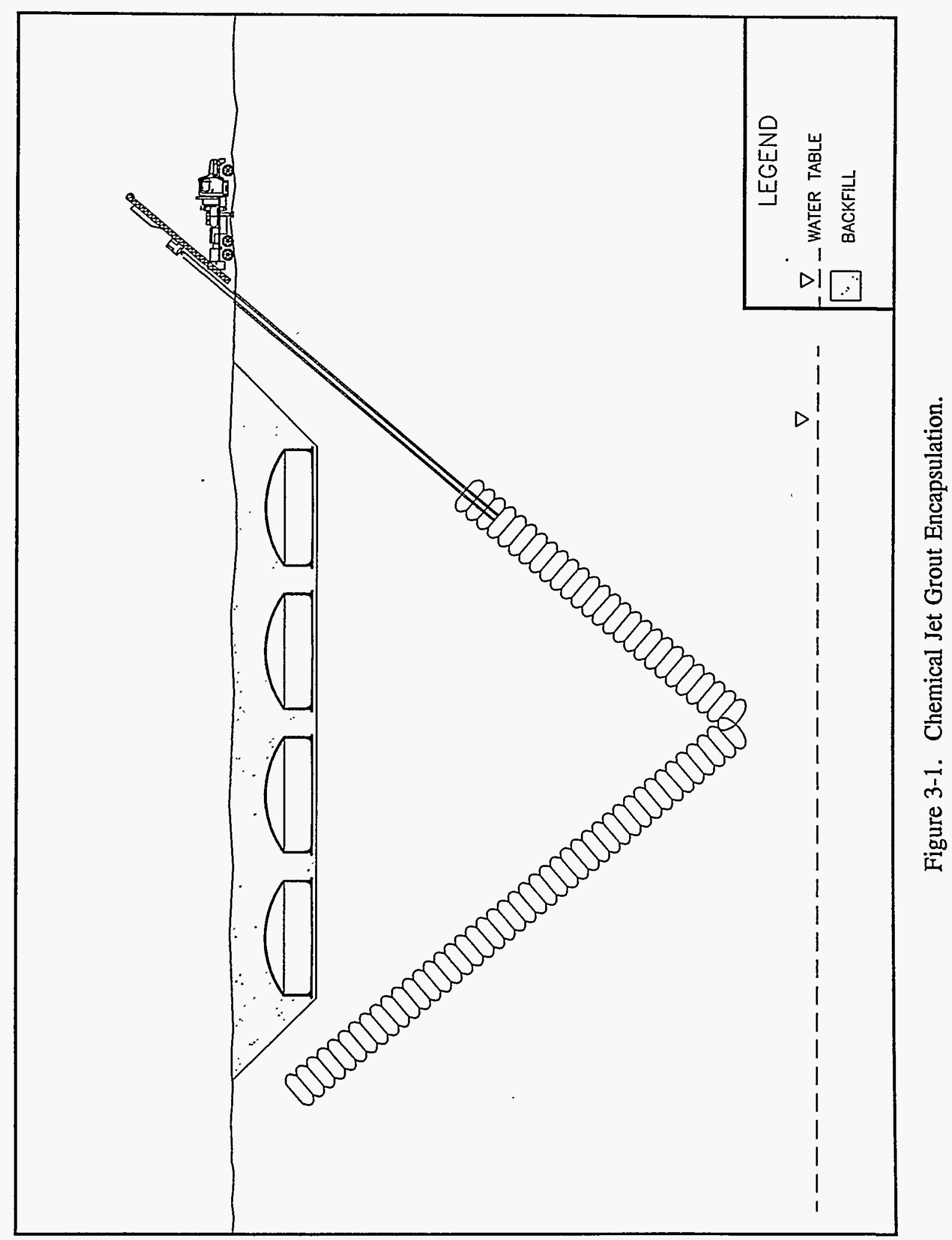




\subsubsection{Advantages and Disadvantages}

\section{Potential Advantages}

- Jet grout encapsulation uses proven drilling equipment and materials.

- Implementation of standoff grout encapsulation should result in little if any stress or heat to individual tanks.

- The passive nature of the barrier would require little or no maintenance or operational expense once installed.

- This method could be considered for application under emergency response conditions.

- Spoils brought to the surface by jet grouting would be encapsulated in the grouting material and could be easily contained.

\section{Potential Disadvantages}

- Drilling through contaminated soils may result in producing contaminated spoils. However, it is envisioned that only small quantities of spoils would be generated.

- Workers would be required to work in protective clothing when handling contaminated material. Contaminated materials brought to the surface would require appropriate management as a mixed waste.

- It could be difficult to construct a complete and uniform barrier without extensive overlapping of barrier sections.

\subsubsection{Other Information}

The integrity of the barriers may be verified by deploying additional slant wells above and below the underlying barrier to provide monitoring wells and a sensor array for enhanced leak detection. Other physical techniques may be feasible for locating leaks and barrier holes.

A variety of grouts with varying viscosities and set-up times are available. The grout formulation can be selected to meet rather broad design requirements, including hydraulic conductivity, strength, and capability for plastic deformation or resistance to chemical attack. 


\subsection{FREEZE WALLS}

Underground freeze walls have been used in the United States and Europe for many decades, particularly in shaft sinking operations, tunneling, and environmental emergency response. During ground freezing, the temperature of the water within the soil is lowered below its freezing point. The formation of ice between soil particles increases soil strength and decreases soil permeability. Figure 3-2 depicts the freeze wall concept.

Two freezing methods have been used: (1) slow-rate freezing or closed-loop systems and (2) fast-freezing or open-loop systems (e.g., liquid nitrogen). For both methods directional drill holes with steel casings are placed along the desired freezing line. Standard black pipe is then inserted in the casing. In the slow-rate freezing system, a header or manifold system provides coolant, such as calcium chloride brine, ethylene glycol, or ammonia, which is circulated and returned to the refrigeration system via the inner pipe. A self-contained refrigeration system pumps coolant around the coolant loop. The fast-freezing method uses an open-loop system with an expendable coolant, such as liquid nitrogen, to achieve a much lower temperature in a shorter period.

Freeze walls created by circulating refrigerated brine are commonly accomplished by use of a calcium chloride solution. Closely spaced wells, typically 0.8 to $1.2 \mathrm{~m} \mathrm{(2.5} \mathrm{to} 4 \mathrm{ft})$ apart, are cased and plugged at the bottom. The refrigerated brine is pumped down tubing to the bottom of the well and back to the surface through the annulus where it absorbs heat from the formation, forming a closed-loop system. Normally, the system would operate at a temperature of about $-37^{\circ} \mathrm{C}\left(-35^{\circ} \mathrm{F}\right)$. As the soil around the pipes is cooled, a zone of frozen earth and water would advance outward from each coolant pipe. Eventually the frozen soil would overlap and form a closed barrier. After the barrier walls are established, a reduced flow of refrigerant would be used to maintain the temperature of the system.

Freeze walls created by the injection of liquid nitrogen into the ground through perforated well casings are open systems. The liquid nitrogen vaporizes and cools the ground, then diffuses through the soil and escapes to the atmosphere. An open system could be used to quickly freeze the soil and then could be coupled with a closed-loop system to maintain the freeze wall barrier.

The freezing process may be completed in as little as two months or may take up to two years depending on the method used, the type of coolant, and the application. The initial freezedown period to establish a barrier is typically about eight months. If the frozen barrier, which would be installed outside the contaminated area, is frozen slowly, it would allow the freezing process to take advantage of its purifying characteristics. Slow crystal growth excludes contaminants from the water molecules within the freeze zone (SEG 1992).

Various technologies are available to follow the progress of barrier formation during the initial freezedown, and to monitor its integrity after it is established. Monitoring could be accomplished using strategically located temperature and chemical sensors, the refrigeration system itself, and the injection tubes. The temperature sensors warn of barrier invasion; 
WHC-SD-WM-ES-300 REV. 1

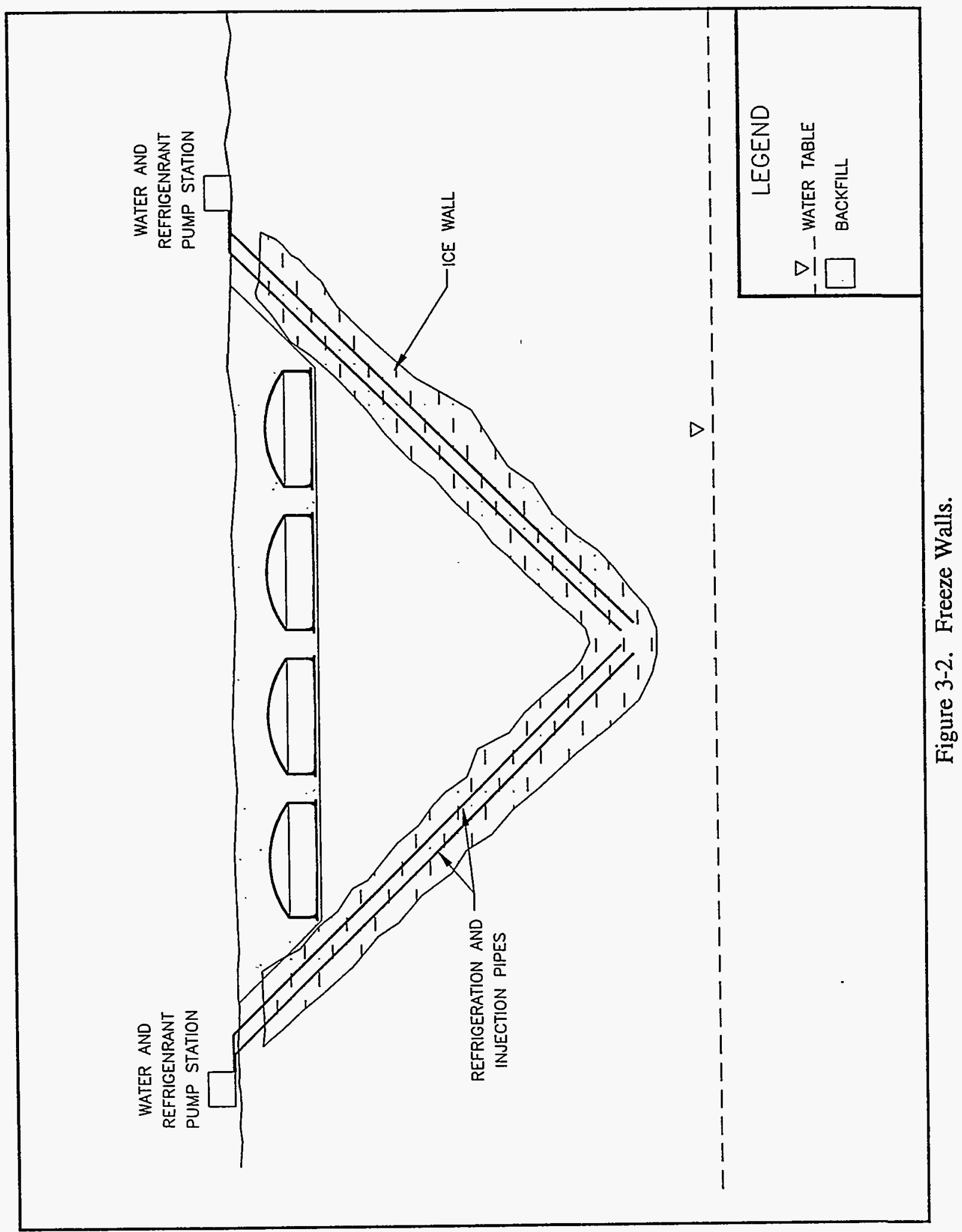


corrective action takes the form of preferentially increasing the amount of coolant to the affected freeze pipes. Chemical and radioactivity sensors can provide continuous monitoring against possible leakage. The refrigeration system itself could be a part of the monitoring system, since changes in cooling load would be reflected in the temperature of the return flow of refrigerant. Leakage tests can be made by pressurizing injection tubes with a nonreactive gas such as nitrogen and measuring the gas escape rate. A detected lack of integrity could be corrected by injecting hot water into the local injection pipe. The hot water would fill the breach in the barrier and freeze to seal it.

Construction costs are determined by several factors, primarily soil conditions, size of the waste site, hazardous nature of working conditions, and the requirements of regulatory agencies. Soil conditions and geography will determine whether the piping can be installed by pile driving, jacking, or drilling. Drilling may be more expensive and would also require special precautions in contaminated ground. The size and shape of the potential freeze wall site are important factors because the cost of containment increases with the peripheral area rather than with the contained volume.

\subsubsection{Current Applications}

Refrigeration in large-scale engineering projects is a well-developed technology. Artificial freezing of ground has been used for bonding wet soils to give load-bearing strength during construction; to seal tunnels, mine shafts and well holes against flooding from groundwater; and to stabilize soils during excavation. Recent applications include several large subway and highway tunnel projects and in-ground liquified natural gas storage reservoirs.

Other uses of artificial freezing include effluent concentration, sludge dewatering, salt water desalination, and temporary immobilization of contaminants. Ground freezing also has potential applications for decontamination of soil, sediments, and sludges.

\subsubsection{Test and Demonstration Status}

Scientific Ecology Group, Inc. (SEG) and RKK Ltd. are currently demonstrating the ice barrier design in wet soils at a private site near Oak Ridge, Tennessee. They have proposed a similar demonstration at or near the Hanford Site using the native dry (semi-arid) soils. Ground freezing has been demonstrated at Idaho National Engineering Laboratory (INEL) to freeze a block of soil containing simulated wastes for subsequent one-piece removal. 


\subsubsection{Advantages and Disadvantages}

\section{Potential Advantages}

- Ground freezing is a well-developed technology with many applications in private industry groundwater containment and mining.

- The integrity of freeze wall barriers can be monitored through refrigeration load and temperature monitors.

- Freeze walls are highly resistant to seismic activity and can be healed in the event a large earthquake causes a breach.

\section{Potential Disadvantages}

- Success would depend on uncontrollable or partially controllable factors (e.g., soil composition and water content). It is unclear if the technology would perform as planned if it were necessary to inject supplemental water into the highly transmissive soils of the Hanford Site.

- Slow migration of water could occur, leading to nonuniform deposits of ice.

- Installation could create some stresses on the SSTs due to the expansion of the soil during the freezing process.

- Freeze walls are an active subsurface barrier concept and would require a refrigeration plant to maintain the barrier indefinitely.

\subsubsection{Other Information}

The joint venture of RKK and SEG has proposed a proprietary freeze wall design called "CRYOCELL" for potential use in SST applications. In the RKK/SEG CRYOCELL barrier design, freeze pipes would be installed around and under the circumference of the waste site. These freeze pipes are typically steel casing, with a second casing installed inside the first. Coolant would be pumped down the annulus and returned through the inner pipe.

The two layers of freeze pipes would be installed at a slant, such that the bottoms come close together and provide closure when ice is formed under the area to be contained. Vertical pipes would be installed to enclose the two ends of the system.

Either brine, polyglycol, ammonia, or liquid nitrogen would be used as the refrigerant. The ice walls form as the interstitial water in the soil freezes. If necessary, additional water can be added to the soil through the injection system. 
If the outer pipes are constructed of carbon steel casing, they are reasonably economic and strong enough to permit installation by pile driving or jacking into most soils. The use of driven or jacked carbon steel casing would reduce both the costs and possible contamination associated with well boring. A second, similar set of pipes would be installed approximately $10 \mathrm{~m}$ (33 ft) inside of the first set. This double set of pipes would allow the entire intervening space to be frozen, producing a solid barrier of intermixed soil and ice 13 to $15 \mathrm{~m} \mathrm{(40} \mathrm{to} 50 \mathrm{ft}$ ) thick. Perforated pipes would be installed between the double row of freeze pipes to facilitate moisture addition. The double array design would afford greater management of the barrier, since the thickness and the temperature of the barrier are independently controlled. The double barrier design also would permit independent control of the refrigerant streams in the inner and outer arrays, so that their temperatures could be regulated separately. This would allow a degree of flexibility that could be advantageous in certain applications. For example, it could be desirable to severely limit the migration of contaminants at a site with a high hazardous/radioactive waste inventory by forming an extra thick barrier for long-term confinement. In this case the ground could be chilled by flowing liquid nitrogen in the inner array (made of special alloy steel), while refrigerating the outer set with a recirculated refrigerant at a much higher temperature.

During freezedown, the outer freeze pipes would be activated first in order to form a frozen barrier totally enclosing the waste site. Then moisture would be added (if necessary) by means of the perforated moisture addition pipes, whereupon the inner freeze pipes would be activated. By freezing the outer pipes first to form an outer frozen barrier, the possibility of enhanced contaminant migration due to moisture addition would be minimized.

According to the CRYOCELL process developers, the considerable thickness of the barrier walls would make them virtually impermeable to most contaminants. Leakage via diffusion is purported to be negligible (i.e., nondetectable after 10,000 years). The ice walls would be highly resistant to chemical degradation and they would remain frozen for up to two years without refrigeration. In the event that the barrier wall is damaged in an earthquake, the developers claim that the overburden pressure would cause the ice to fuse in a short period of time, thereby reestablishing containment (SEG 1992).

A proprietary computer model would be used to predict the thermal characteristics of the frozen barrier. This three-dimensional finite element model requires characteristics such as the number and thickness of soil layers, soil types, soil thermal conductivity, moisture content, and length and spacing of refrigerant pipes, to determine the transient and steadystate response of the earth during ground freezing.

Design and construction of the freeze wall should be oriented toward minimizing maintenance costs, and the piping geometry should be designed to allow the total barrier to be formed slowly (in 4 to 12 months). This would permit use of greater spacing between the

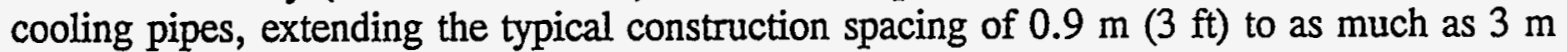
$(10 \mathrm{ft})$. 
The developer estimates that a typical CRYOCELL installation for a site with a surface area of 2 ha (5 acres) would cost $\$ 6$ to $\$ 12$ million (SEG 1992). For site areas in excess of 41 ha (100 acres), with soil conditions permitting installation by pile driving or jacking, the installation cost should range between $\$ 1.50$ to $\$ 3.00$ per cubic meter $(\$ 2$ to $\$ 4$ per cubic yard). After the barrier walls are frozen, the estimated cost to maintain a CRYOCELL system, based on a 2-ha (5-acre) site, would be less than $\$ 100,000$ per year. The 30-year total cost for the same 2-ha (5-acre) site is estimated to be $\$ 3.00$ to $\$ 3.80$ per cubic meter (\$4 to $\$ 5$ per cubic yard).

\subsection{JET GROUT CURTAINS}

The technology for emplacing jet-grouted curtains is similar to grout encapsulation (Section 3.1) except that both vertical or horizontal wells, rather than directionally drilled wells, would be used for injection. A high-pressure jet-grouting head would be lowered to the desired depth and air and cement would be blown through the jet at approximately $4.1 \times 10^{7} \mathrm{~Pa}\left(6,000 \mathrm{lb} / \mathrm{in}^{2}\right)$. Air and cement would be thoroughly mixed with the soil in a column approximately 1 to $2 \mathrm{~m}(3$ to $6 \mathrm{ft}$ ) in diameter. A seal would be made by overlapping the cylinders in the soil/grout columns. Approximately 80 to $85 \%$ of the soil impacted by the jet would be combined with the grout to form the barrier; the remaining 15 to $20 \%$ of the soil volume would be pumped to the surface as the barrier was formed (Naudts 1989; Bovay Northwest 1992).

The horizontal barrier would be completed first. The vertical jet grout curtain would then be added and joined with the horizontal barrier.

The jet grout curtain technology as potentially applied to SSTs is depicted in Figure 3-3.

\subsubsection{Current Applications}

Current applications of jet grouting are numerous and include foundation repairs, cofferdam barriers, groundwater control, and other specialized uses. The technology has been used in Europe for waste containment systems but has not yet been used in the United States for that purpose (Naudts 1989).

\subsubsection{Test and Demonstration Status}

The use of jet-grouting for subsurface barriers for DOE and/or Hanford Site applications has only been conceptually designed. No laboratory or field tests have been performed. The technology of jet grouting is proven and should require little modification for application to SSTs. 
WHC-SD-WM-ES-300 REV. 1

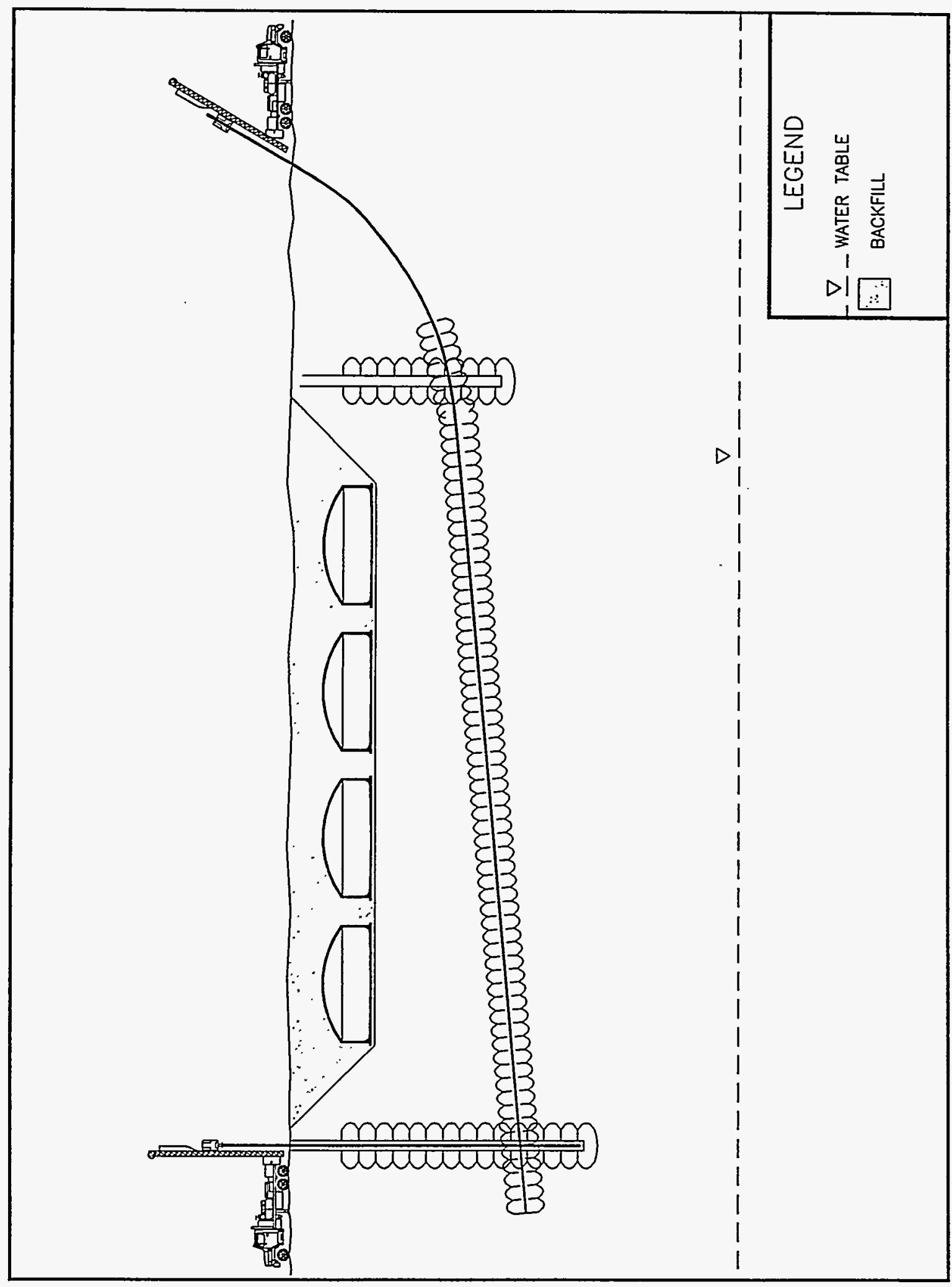




\subsubsection{Advantages and Disadvantages}

Potential Advantages

- Jet grout curtains are stable, flexible, and earthquake resistant.

- Jet grout curtains are resistant to chemical attack.

\section{Potential Disadvantages}

- The potential exists for exposure of personnel to contaminated soils and chemical additives used in the grouting.

- Verification of barrier integrity would be difficult.

\subsubsection{Other Information}

The integrity of the barriers may be verified by deploying additional horizontal wells above and beneath the underlying barrier to enable leak detection. Other physical techniques may be feasible for locating leaks and barrier holes.

A variety of grouts with varying viscosities and set-up times are available. The grout formulation can be selected to meet rather broad design requirements, including hydraulic conductivity, strength, and capability for plastic deformation or resistance to chemical attack.

\subsection{PERMEATION CHEMICAL GROUTING}

Permeation chemical grouts would be injected at lower pressures than would jet grouts (Section 3.1 and 3.3) and could be used to form both vertical and horizontal barriers. Injection pressures would depend upon depth, the length of the injection run, and the porosity of the soil. Other materials could be used with the permeation technique and are discussed in Sections 3.5, 3.6, and 3.7.

The application of horizontal drilling would enable placement of a horizontal permeated grout barrier beneath a tank farm. The drill holes would not have to be exactly parallel. Minor deviations within tolerances of existing equipment may provide sufficient accuracy to permit utilization of the wells for emplacement of a grout barrier. The accuracy of horizontal drilling in Hanford Site soils containing large cobbles and boulders is unknown and may not be acceptable. If the horizontal wells were installed approximately $3 \mathrm{~m}(10 \mathrm{ft})$ apart, the underlying barrier is projected to have a minimum thickness of about $2 \mathrm{~m}(6 \mathrm{ft})$, assuming installation occurs in coarse-grained, homogeneous soils. Vertical permeation barriers would be constructed by conventional techniques and have a thickness similar to that of the horizontal barrier (Naudts 1989; Bovay Northwest 1992). 
The applicability of permeation grouting is highly dependent upon the properties of the grouting materials used and the properties of the soil. The barrier would be constructed by first drilling, washing, or driving a grout pipe and then pumping viscous grouting fluid into the formation as the pipe is slowly withdrawn. The grout would fill the voids in the soil and, as it sets up, would form a low-permeability barrier. Emplacement of a uniform barrier would be difficult to achieve because differences in the soil hydraulic conductivity can cause the grout thickness to be uneven.

The permeation grout technology as potentially applied to SSTs is depicted in Figure 3-4.

\subsubsection{Current Applications}

Permeation grouting is a proven technology commonly used in private industry for cutoff walls, sea walls, and building foundations. It has been used in Europe for both waste management and non-waste management purposes. It has been extensively used by the United States oil and gas industry.

\subsubsection{Test and Demonstration Status}

Permeation grouting for subsurface barriers for Hanford Site underground storage tanks has been only conceptually designed. No laboratory or field tests have been performed. The base technologies of vertical permeation grouting and horizontal drilling are proven at locations outside the Hanford Site and may require little modification for this application.

\subsubsection{Advantages and Disadvantages}

\section{Potential Advantages}

- The quantity of contaminated soil that may be brought to the surface in drill cutting is relatively small.

- Permeation grouting is a well-established technology used throughout the world in construction applications.

- Emplacement of the grout is not likely to cause unacceptable stress to the SSTs.

- There are minimal health and safety issues envisioned.

\section{Potential Disadvantages}

- Earthquake resistance could be relatively low; joints between successively grouted zones could part under tension. 
WHC-SD-WM-ES-300 REV. 1

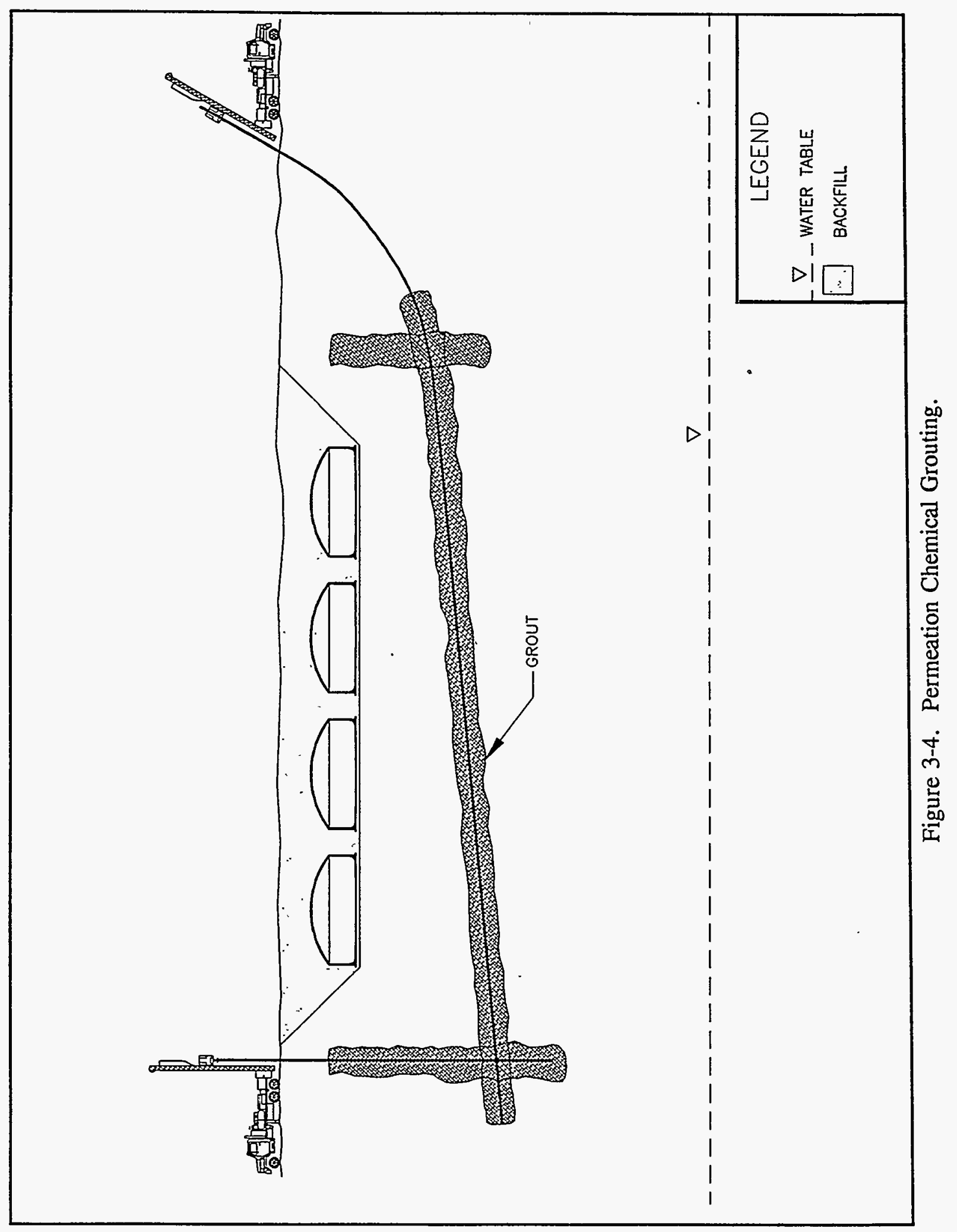


- It could be difficult to verify the integrity of joints because narrow gaps or cracks may not be visible using imaging techniques and other methods used in the construction industry.

- Silt lenses, clastic dikes, and other soil heterogeneities common to Hanford Site soil will prevent uniform permeation of chemicals in the ground which may result in ungrouted areas.

\subsubsection{Other Information}

The integrity of the barriers may be verified by deploying additional horizontal wells above and beneath the underlying barrier to enable leak detection. Other physical techniques may be feasible for locating leaks and barrier holes.

A variety of grouts with varying viscosities and set-up times are available. The grout formulation can be selected to meet rather broad design requirements. Soils with relatively low hydraulic conductivities (i.e., $<10^{-5} \mathrm{~cm} / \mathrm{s}$ ) may not be amenable to permeation grouting due to inability of the grout-forming chemicals to permeate into the fine pores of the soil within the period defined by the set-up or gel time.

\subsection{WAX EMULSION PERMEATION GROUTING}

A mineral wax-bentonite emulsion called "Montan" wax has been developed for grouting applications by a German company described in Section 3.5.1. Montan wax is present in a lignite coal field in Amsdorf, Germany and has been the world's supply of the wax since the 1900s. Montan wax has properties similar to those of natural plant waxes such as those found in carnauba palms. The material features a high-melting point and is composed of C-24 to C-32 esters of long-chained acids and alcohols and includes waxes, resins, and asphaltene-like materials. Montan wax has been used in carbon inks, emulsions, polishes, and lubricants for decades (Golder 1994a).

Montan wax grout consists of a stable emulsion of Montan wax, water, and a surfactant. The emulsion is formed by injecting a stream of melted wax into water near boiling temperatures to solidify the wax into small particles. The size of the particles can be somewhat controlled by varying the temperature or using mechanical shearing. The surfactant is used to maintain the emulsion, ensuring that the wax particles are kept in suspension during the injection process. This allows the wax particles to move through the soil pores with the fluid. Once inside the soil matrix, the wax particles begin to aggregate (therefore increase in size) and move through void spaces in the soil until they bridge an opening and become fixed. Bridging these openings between pores reduces the permeability of the soil (Golder 1994a). 
Figure 3-5 depicts wax emulsion permeation grouting as it might be used in SST applications.

\subsubsection{Current Applications}

Montan wax grout is not currently used in the United States for waste management or environmental restoration purposes; it is, however, being contemplated for containment of contaminated sites in the Halle-Leipzig-Bitterfeld area in Germany. Vereinigte Mitteldeutsche Braunkohlenwenke AG (MIBRAG), a large industrial company, has tested the feasibility of creating containment barriers with Montan wax grout emulsions in several field demonstrations containing unconsolidated soils with high permeabilities. After permeating the soils with a mixture of Montan wax, water, and bentonite, the conductivity of the soil was reduced by as much as five orders of magnitude (Golder 1994b).

\subsubsection{Test and Demonstration Status}

Three field-scale pilot tests have been completed to date by Golder Associates, Inc. (Golder). In addition, on a lab-scale, Golder has recently injected wax emulsion grout into soils from several DOE sites, including the Hanford Site, INEL, and Sandia. Results of these tests show that the hydraulic conductivity of unconsolidated coarse-grained Hanford Site soils can be decreased by 2 to 3 orders of magnitude to $10^{-4}$ to $10^{-5} \mathrm{~cm} / \mathrm{s}$ [2 $\times 10^{-4}$ to $2 \times 10^{-5} \mathrm{ft} / \mathrm{min}$ ]) (Golder 1994b).

Additional field demonstrations by Golder are planned this summer at the city of Richland Sanitary Landfill.

\subsubsection{Advantages and Disadvantages}

\section{Potential Advantages}

- Montan wax has been tested in the laboratory and field, thus reducing development costs and improving understanding of the limits of the technology.

- Materials used in the Montan wax formulation are nontoxic.

- The minimum hydraulic conductivity limit for permeation grouting using Montan wax grout is low enough to permit its use in some Hanford Site soils. 
WHC-SD-WM-ES-300 REV. 1

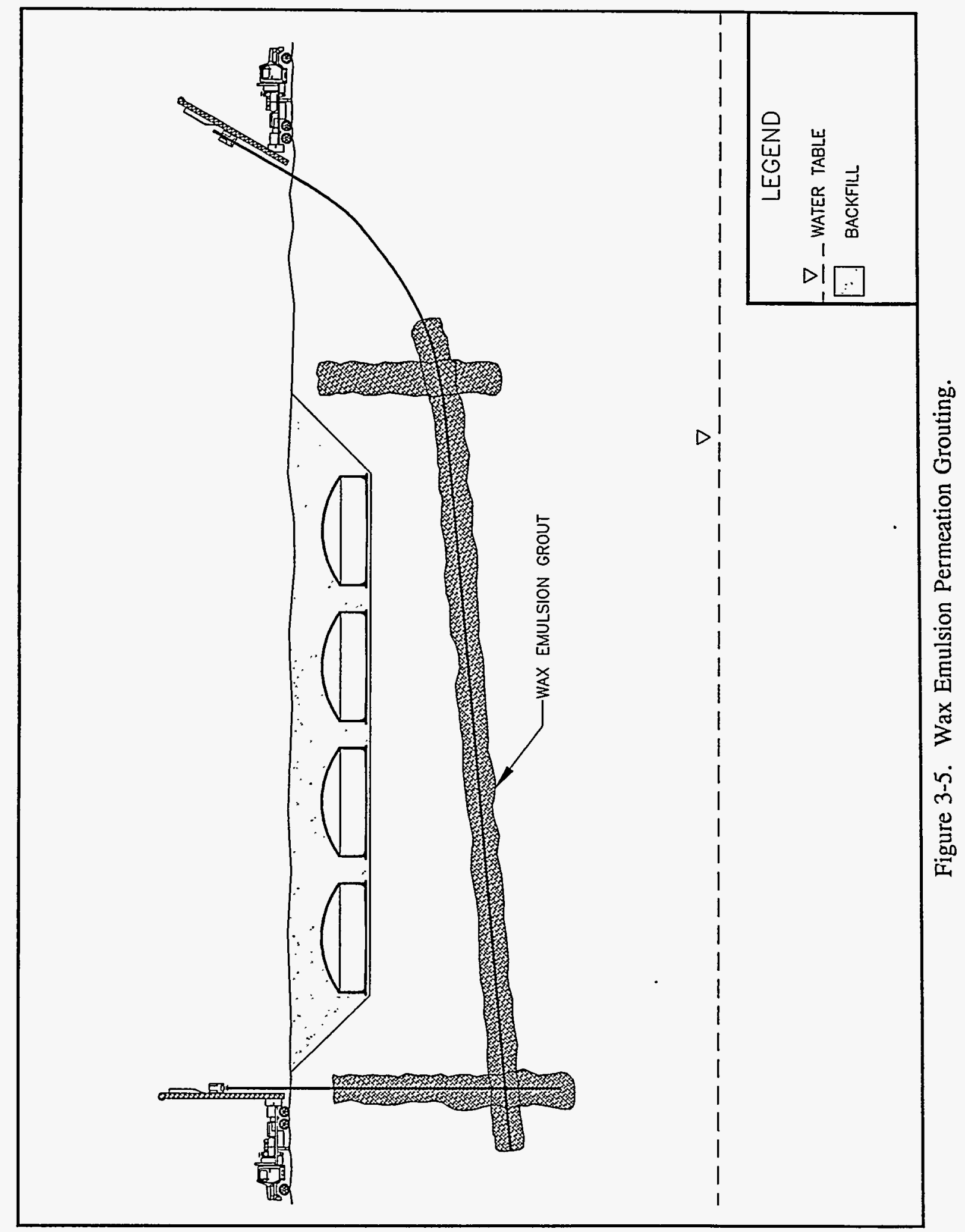




\section{Potential Disadvantages}

- Montan wax grout slowly softens at the surface in the presence of sodium hydroxide; the wax therefore may destabilize in the presence of SST leachates with a high $\mathrm{pH}(>12.0)$.

- Verification of barrier integrity would be difficult.

- Montan wax, like any other petroleum products, may be susceptible to bacterial degradation over time.

\subsubsection{Other Information}

This technology was developed by MIBRAG and DBI Gas-und, Umwelttechnik GmbH (DBI). MIBRAG and DBI have invested more than $\$ 9$ million in the development and testing of materials. The technology was identified by Golder Associates, Inc. when they were involved in a DOE Office of Technology Development funded program entitled International Technical Exchange Project in 1992 (Golder 1994b).

\subsection{SILICA, SILICATE PERMEATION GROUTING}

Permeation grouting using a sodium silicate-based technology was developed by the French chemical company, Societe Fancaise Hoechst, and is sold under the trade name of Klebogel. The material used is a silica-based chemical grout and has favorable characteristics that can be controlled by altering the formulation of the grout.

Sodium silicate grout consists of four components: water, an acidic liquid consisting of glyoxal and additives, an alkaline liquid consisting of silicon dioxide and sodium oxide, and an aqueous suspension of non-agglomerated silica particles in an alkaline medium. The grout is prepared by successively adding the materials together. Set time and grout viscosity can be controlled by altering the proportion of the four components (Golder 1994a).

Another siliceous material being explored for use in forming subsurface barriers at the Hanford Site is colloidal silica, a colloidal suspension with gelling properties. Colloidal silica is widely available and is used in a variety of industries, including paper, textile, and metal casting. If the $\mathrm{pH}$ decreases to less than 10 and the ionic strength increases by brine addition, the colloid would polymerize or gel. The gel would form as the colloidal particles aggregate to form a crosslinked network. Colloidal silica was first used as a barrier material by the petroleum industry for blocking flow in porous media. 
Researchers at Lawrence Berkeley Laboratory have devised methods to overcome the loss of gelling control (i.e., uncontrolled rapid gelling) in situ. These methods include displacement of divalent cations in the soil by preflushing with brine, displacement by using dilute colloidal silica suspensions that gel, and precipitation and complexation of divalent ions by sodium fluoride (Persoff et al. 1994).

Polysiloxanes are silicon-based polymers consisting of a mixture of two fluids and are chemically and biologically inert. They have been used historically for medical implants and as carriers for a variety of medicines injected into humans (Moridis et al. 1993).

Figure 3-6 depicts silica, silicate permeation grouting as it might be applied to SSTs.

\subsubsection{Current Applications}

Silica and silicate-based products have been used extensively in industrial applications in the United States. They also have been used in tunneling applications and as strengtheners in unconsolidated soils in Europe and the United States. The products have seen limited use in barrier applications similar to the ones postulated for use around SSTs.

\subsubsection{Test and Demonstration Status}

Sodium silicates have been extensively tested in the laboratory at the Hoechst facilities in Paris and the Technical University of Clausthal. Golder Associates Inc. injected sodium silicate grouts into soils from several DOE sites, including the Hanford Site, INEL, and Sandia in 1993. Results of these laboratory tests show that the hydraulic conductivity of coarse-grained unconsolidated Hanford Site soils can be decreased by 3 to 4 orders of magnitude to $10^{-5}$ to $10^{-6} \mathrm{~cm} / \mathrm{s}\left[2 \times 10^{-5}\right.$ to $\left.2 \times 10^{-5} \mathrm{ft} / \mathrm{min}\right]$ (Golder 1994b).

Field tests using sodium silicate grouts are being conducted in single-borehole injection and multiple-borehole injection experiments. The single-borehole tests. were performed in conjunction with cement-grout injection studies conducted at Sandia. The multiple-borehole tests to be performed at Sandia are aimed at constructing a large-scale horizontal barrier by connecting grout injected from an array of boreholes (Golder 1994a). Additional field demonstrations are planned for the summer of 1994 at the city of Richland Sanitary Landfill, near the Hanford Site.

Laboratory studies have been successfully conducted on colloidal silica and polysiloxane by Lawrence Berkeley Laboratory researchers using Hanford Site soils (Moridis et al. 1993; Persoff et al. 1994). 


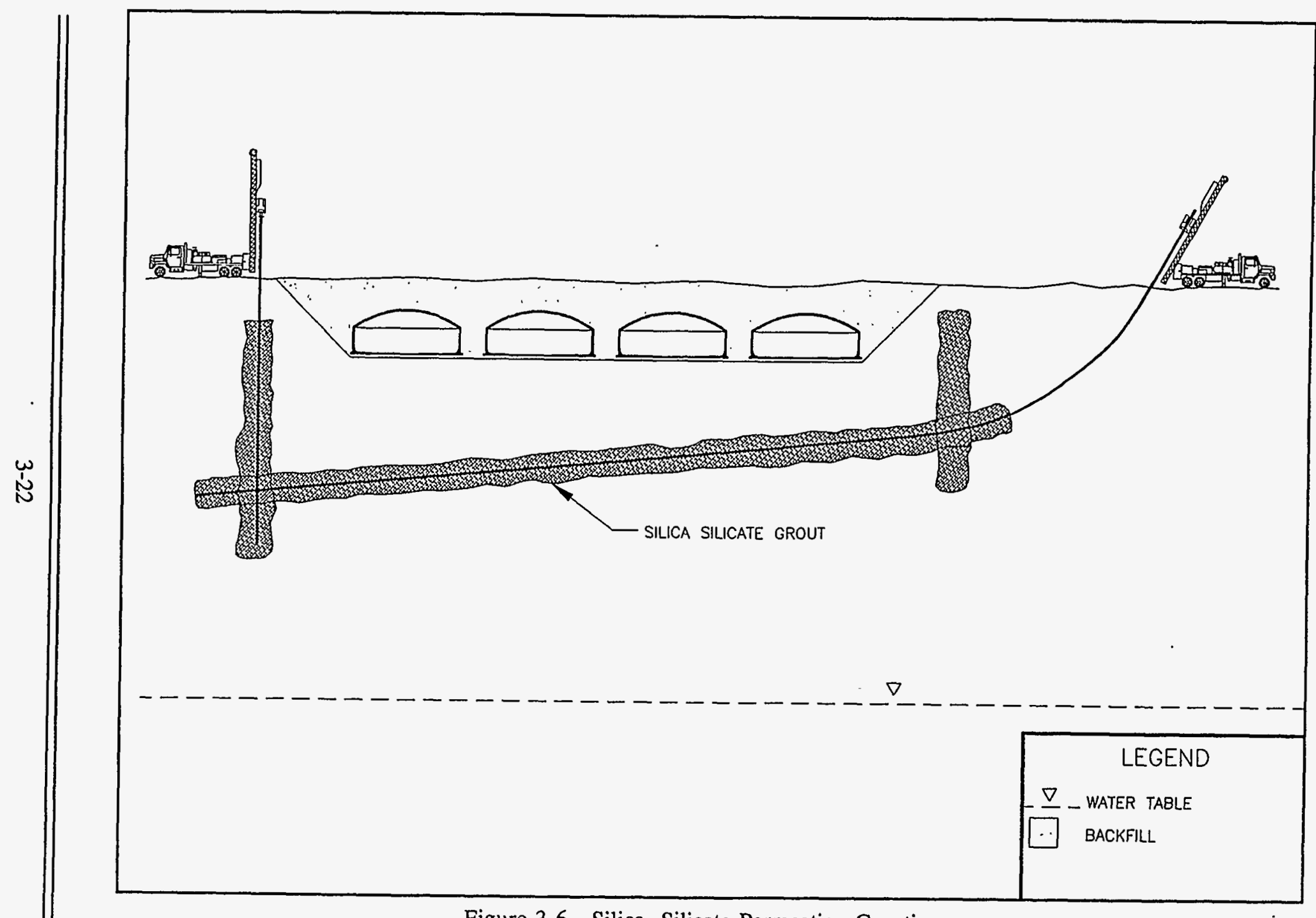

Figure 3-6. Silica, Silicate Permeation Grouting. 


\subsubsection{Advantages and Disadvantages}

\section{Potential Advantages}

- Siliceous materials capable of forming barriers have been tested in the laboratory and field, thus reducing development costs and defining the limits of the technology.

- Siliceous materials considered for use in barriers are nontoxic.

- Pressures required for injection are lower than for Montan wax grout due to the lower viscosity of sodium silicate grouts.

\section{Potential Disadvantages}

- In the presence of sodium hydroxide, silicate grouts degrade rapidly.

- Predicting the movement of injected grout is difficult due to the anisotropy and heterogeneity of most Hanford Site soils.

\subsection{POLYMER PERMEATION GROUTING}

Polymer permeation grouting employs an injected liquid monomer or resin that is converted to a polymer (in place) to form a concrete-like monolithic barrier. A monomer is a molecular species capable of combining chemically to form a high-molecular-weight polymer through a process called polymerization (Fowler 1990; Bovay Northwest 1992). A discussion of the various types of monomers, resins, catalysts, promoters, and additives can be found in Section 3.7.4.

Polymer grouts are compatible with free-standing water and some soil aggregates. Water can be used in some cases for cleaning the mixing and injection equipment. The mixing equipment use for polymer permeation is similar to that used for portland cement concretes. Polymer-forming chemicals could be injected into the ground using the same methods for emplacing cement slurry walls (i.e., sleeve pipes and columns or hydrofraise) (Fowler 1990; Bovay Northwest 1992).

The polymer permeation technology as potentially applied to SSTs is depicted in Figure 3-7.

\subsubsection{Current Applications}

Typical uses of polymer grouts include bridge overlays, pavement repairs, dam repairs, canal locks, tunnels, rapid runway repairs, belowground utility vaults, steam distribution systems, 
WHC-SD-WM-ES-300 REV. 1

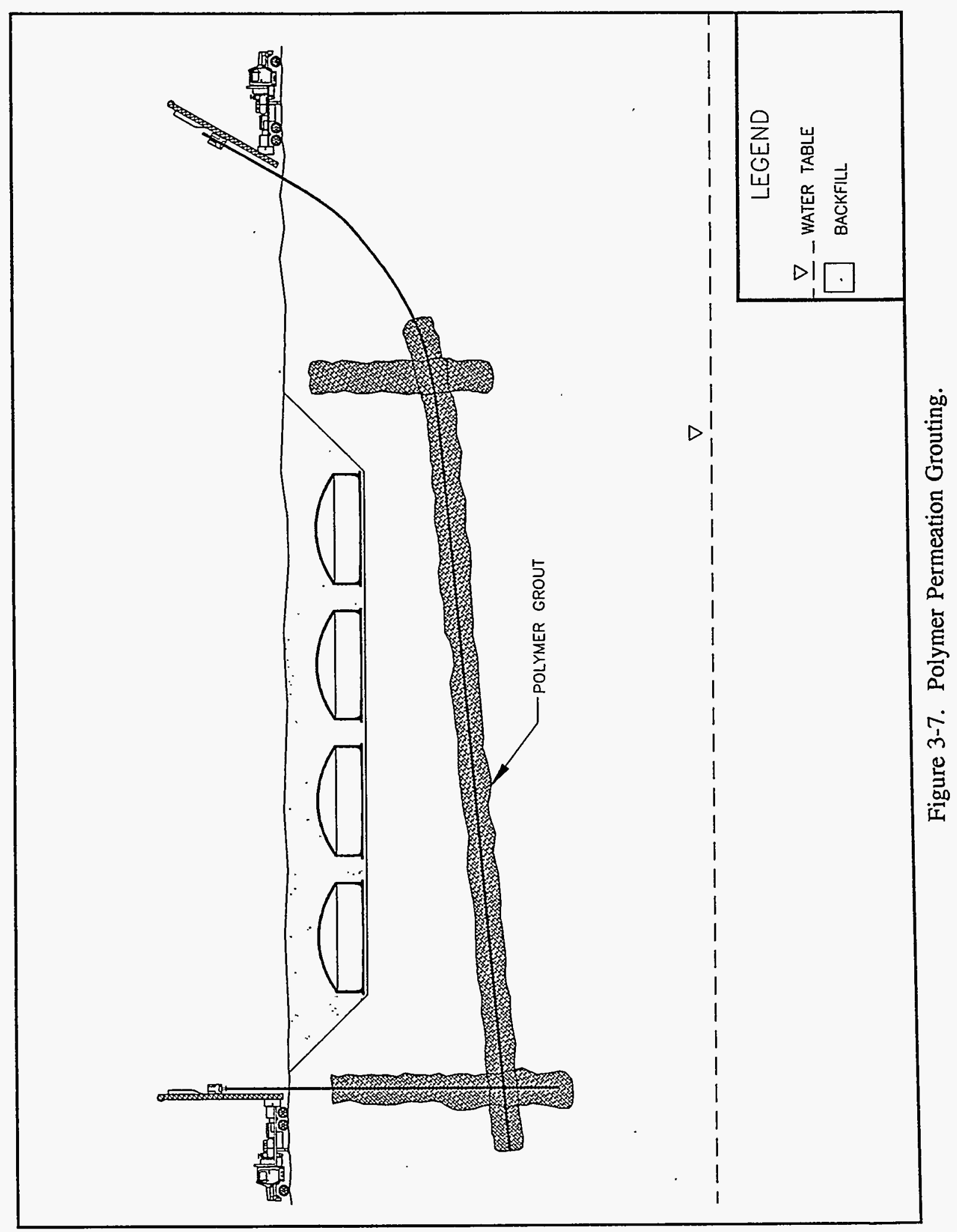


insulation material for liquified natural gas storage tanks, and corrosion-resistant liners for high-temperature piping. Polymer grouts have seen limited use in the United States for waste confinement purposes.

\subsubsection{Test and Demonstration Status}

Polymer grouts are proven technologies in a variety of construction applications. Benchscale testing of polymer grouts with soils from different DOE sites is being conducted at Brookhaven National Laboratory.

\subsubsection{Advantages and Disadvantages}

\section{Potential Advantages}

- Polymer grout is extremely durable.

- Polymer grout has a much lower permeability than standard grout or cement.

- Polymer grout is more chemically, radiologically, and thermally resistant than standard grout.

\section{Potential Disadvantages}

- Polymer grout is expensive compared to standard grouts.

- Except for alcohol-based monomers, polymer grouts are insoluble in water and must be mixed with dry aggregate and/or soil.

- Some polymer grouts (e.g., furfuryl alcohol) are chemically incompatible with Hanford Site soils.

- There may be occupational hazards (fire and health) associated with the use of polymers. 


\subsubsection{Other Information}

Monomers are mixed with different types of catalysts (initiators) and promoters to control set times and set temperatures (up to $300^{\circ} \mathrm{C}\left[572{ }^{\circ} \mathrm{F}\right]$ ). A wide variety of combinations can be used in polymer grouts for various purposes (Fowler 1990; Bovay Northwest 1992). Some of these combinations are listed below:

$\begin{array}{ll}\text { Monomers: } & \begin{array}{l}\text { Styrene + divinyl benzene } \\ \text { Styrene }+ \text { acrylonitrile } \\ \text { Vinylester-styrene } \\ \text { Polyester-styrene } \\ \text { Methyl methacrylate }\end{array} \\ & \text { Furfuryl alcohol } \\ \text { Catalysts: } \quad & \begin{array}{l}\text { Methyl ethyl ketone peroxide } \\ \text { Benzoyl peroxide } \\ \text { Di-tert butyl peroxide }\end{array} \\ \text { Promoters: } \quad \begin{array}{l}\text { Cobalt naphthenate } \\ \text { Dimethyl aniline } \\ \text { Dimethyl toluidine } \\ \text { Zinc chloride }\end{array} \\ \text { Additives: } \quad \text { Latex } \\ \text { Polymers/acrylamides/polyurethane } \\ \text { Silica fume } \\ \text { Fly ash }\end{array}$

For more information on the use of polymer grouts for subsurface barrier applications, refer to the Laboratory Evaluation of Performance and Durability of Polymer Grouts for Subsurface Hydraulic/Diffusion Barriers prepared by Brookhaven National Laboratory (Heiser 1994).

\subsection{FORMED-IN-PLACE HORIZONTAL GROUT BARRIERS}

Formed-in-place horizontal grout barriers could be constructed in situ in a basin configuration without excavation. The method involves the use of a proprietary technology to generate a barrier slab of uniform thickness $(0.3 \mathrm{~m}[1 \mathrm{ft}])$ between guide wires placed by horizontal drilling methods. The technology uses high pressure jets mounted on a reciprocating machine tool. The grout slurry sprayed through the jets disrupts and mixes soils to a mortar-like consistency between the guide pipes. The machine tool passes through this semi-liquid material as the hardware is pulled along the guide wires, forming a uniform 
barrier behind it. Adjacent panels would be emplaced at the edge of the previous panel (before it hardens totally), overlapping the previous panel to some extent to form an extended slab.

Emplacement of multiple horizontal panels could start at ground level and curve down before leveling out at the desired depth (approximately 33 to $66 \mathrm{~m}$ [100 to $200 \mathrm{ft}]$ ) and then curving back up to the surface on the other side of a waste site. The guidance wires on the edges of the site would also bring the sides of the barrier near to the surface, forming a gently sloping oval bowl. A completely horizontal grout barrier installed with this equipment could be coupled with a suitable vertical barrier such as sheet pilings with grouted joints.

Production rates for pilot-scale equipment tested to date vary considerably with soil types but are approximately $100 \mathrm{~m}^{2}\left(1,100 \mathrm{ft}^{2}\right)$ of barrier per hour. Sandy and unconsolidated soils with high void ratios would permit higher installation rates and fewer spoils. The process generates an excess of waste soil cement equal to about $30 \%$ of the barrier volume installed in sandy soils. This excess is displaced at the ground surface. Rocks and other debris larger than the thickness of the barrier would cause the tools to stop. Soft rock would be cut up by the jets. During emplacement in soft rock and other nonideal soils, the machine would produce more than $30 \%$ excess cement grout. Voids and nonuniform soils have posed no difficulty to date for this technology. Oily soils and low permeability soils are compatible with the technology because the soils are intimately mixed with the barrier material by action of the powerful jets.

Figure 3-8 depicts a formed-in-place barrier as it might be used in a SST application.

\subsubsection{Current Applications}

No full-scale application of this technology related specifically to waste management or environmental restoration purposes is known at this time. Applications to date have been limited to clay- and cement-based products for cold demonstrations.

\subsubsection{Test and Demonstration Status}

A test at Halliburton facilities in Oklahoma was conducted in late 1992 with six 3- to 3.6-m (9- to $11-\mathrm{ft})$ wide panels approximately $33 \mathrm{~m}(100 \mathrm{ft})$ long. The tests demonstrated the feasibility of constructing continuous grout barriers of high uniformity, including the joining of the panels. Guide wires in the test were spaced 3 to $3.6 \mathrm{~m}$ ( 9 to $11 \mathrm{ft})$ apart. The demonstration produced one panel in clean soil at DOE's Fernald Site. Results of in situ and ex situ tests and the final demonstration report are not yet available. A second test forming a 13 by $66 \mathrm{~m}$ ( 40 by $200 \mathrm{ft}$ ) panel is planned at DOE's Fernald Site near Cincinnati, Ohio in the summer of 1994. 
WHC-SD-WM-ES-300 REV. 1

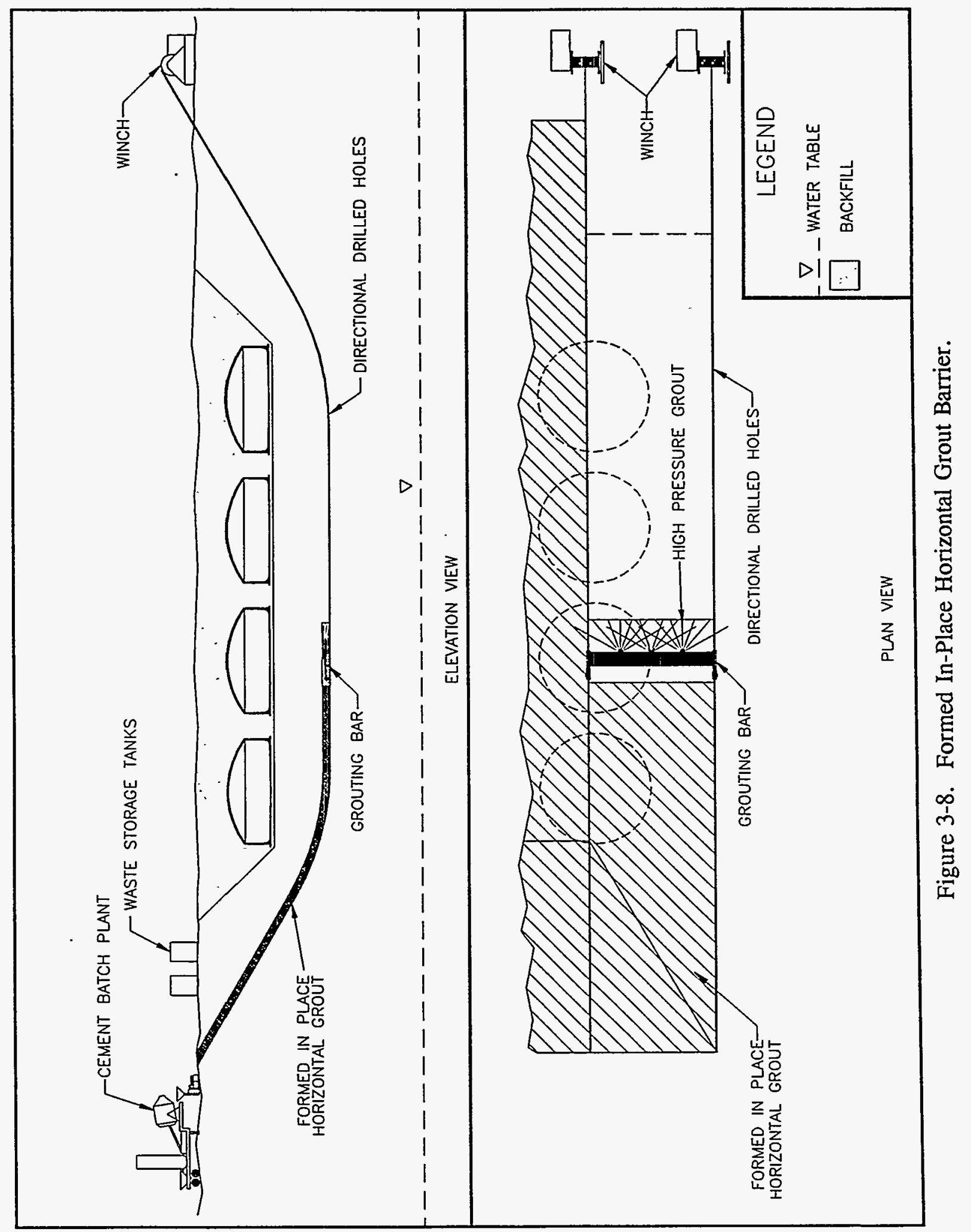




\subsubsection{Advantages and Disadvantages}

\section{Potential Advantages}

- Formed-in-place horizontal grout barriers have a uniform thickness with few, if any, irregularities due to the vigorous mixing action.

- According to the vendor, spacing between the guide pipes could be increased to $33 \mathrm{~m}(100 \mathrm{ft})$ or more and tolerate a spacing error of $10 \%$ by designing a $10 \%$ overlap of individual grout panels.

- The vendor refers to the technology a "self-proving" method of placement; the tool would not pass through soil horizons until they had been liquified and grouted.

- The spoils would be in a relatively easy form to handle (i.e., wet, nondispersable grout) and could readily be disposed as solidified mixed waste.

\section{Potential Disadvantages}

- Formed-in-place horizontal grout barriers have not been proven in soils similar to those that exist at the Hanford Site.

- Unless a full-width panel (approximately $91.5 \mathrm{~m}$ [300 ft]) can be generated, verification that the technology prevents leakage at panel seams will be required.

- Surfacing of chemically or radiologically contaminated spoils will occur if the barrier equipment penetrates a contaminated zone.

- Relatively high volumes of spoils would be produced.

- Breakdowns may lead to hardening of panels and formation of cold joints that may be prone to leakage.

\subsubsection{Other Information}

This technology has been developed and tested by Halliburton NUS, a Halliburton Company subsidiary (also known as Brown \& Root Environmental). Equipment required to support the grout jetting tool is standard oil field equipment and is available on short notice from Halliburton Services. 
The method is capable of being used with any liquid grout material. There are plans to conduct future demonstrations with special materials including a polyacrilate being developed by Brookhaven National Laboratory and a rubberized cement developed by Halliburton Company.

\subsection{CIRCULATING AIR BARRIERS}

The circulating air barrier $(\mathrm{CAB})$ technology would create a dry zone under the area of confinement through which no liquids could penetrate until a critical liquid saturation was exceeded. The critical saturation would be dependent upon the physical characteristics of the porous medium; however, for most sediments at the Hanford Site, the critical saturation is on the order of 5 to $25 \%$. The water currently under the tanks is essentially immobile and, if kept at or below the critical saturation value, would remain immobile (KEHa 1993).

The CAB technology injects dry air from an array of either vertical or horizontal wells. The air would be forced though porous soils to extraction wells, vaporizing water in the process. It has been calculated that with readily achievable injection flow rates, half of the entrained water in the soil would be removed in one to two years (KEHa 1993).

Figures 3-9 and 3-10 depict CAB technologies as they may be applied to SSTs for horizontal applications and vertical applications, respectively.

\subsubsection{Current Applications}

The CAB system is based on standard oil industry practices used to extract liquids from porous media. It has not been used in the field as a subsurface barrier for waste containment.

\subsubsection{Test and Demonstration Status}

Although no large-scale field tests have been performed using CABs, the technology has undergone significant laboratory testing by $\mathrm{BDM} / \mathrm{K} \& \mathrm{M}$ Engineering International. In addition, the injection/extraction technique has been used to recover volatile organic contaminants from groundwater and vadose zone soils.

\subsubsection{Advantages and Disadvantages}

\section{$\underline{\text { Advantages }}$}

- The CAB utilizes several well-established technologies; thus construction and operation would be straightforward. 


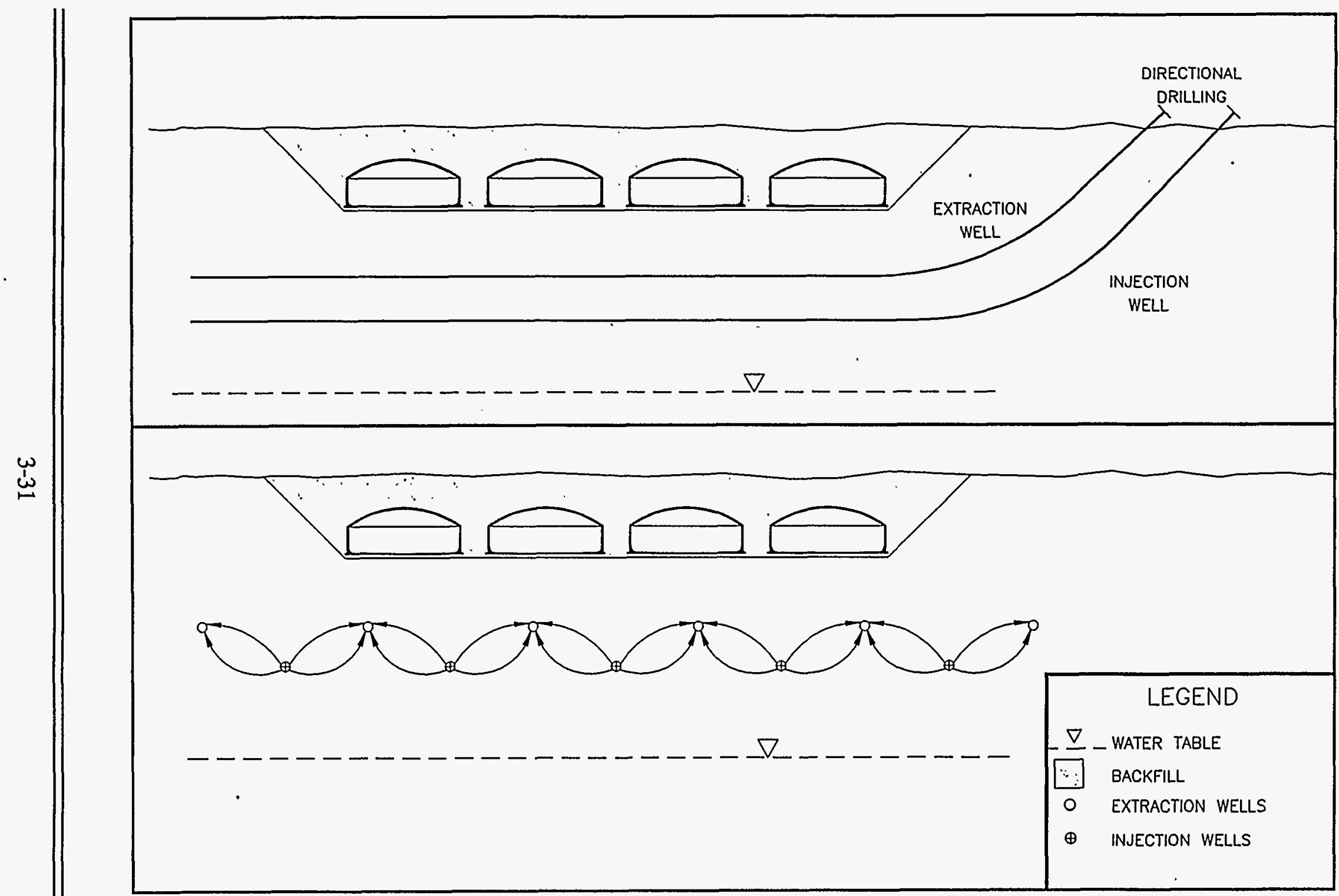

Figure 3-9. Horizontal Circulating Air Barrier. 
WHC-SD-WM-ES-300 REV. 1

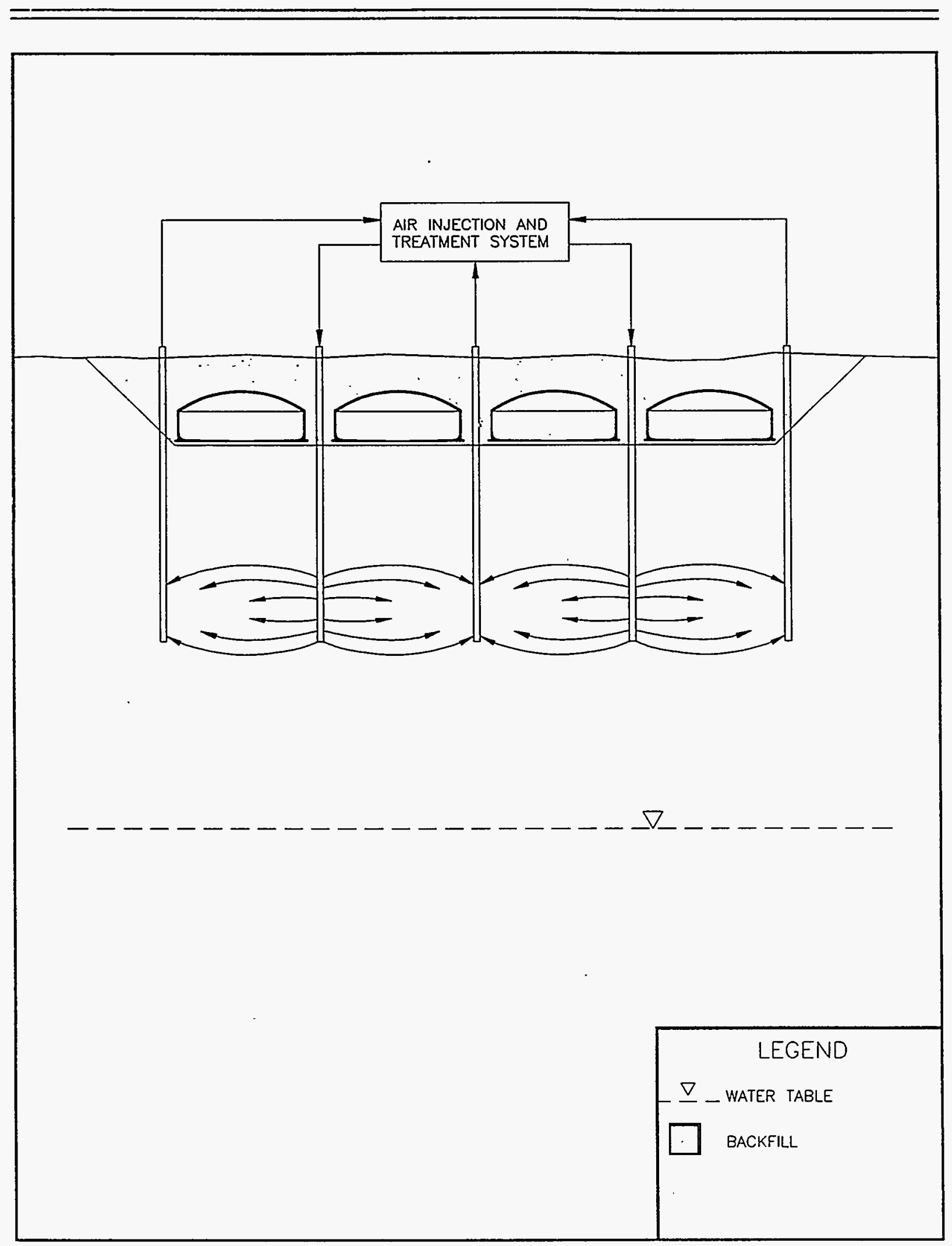

Figure 3-10. Vertical Circulating Air Barrier. 
- Construction and installation of equipment would generate little, if any, contaminated spoils.

- Installation would not induce stresses around the tanks.

- The CABs would tolerate chemical environments.

- The $\mathrm{CAB}$ is one of the least costly of the subsurface barrier options available.

- Prolonged periods of noninjection of dry air could be tolerated without significant migration of leaks.

\section{Disadvantages}

- Containing the air in the zone of interest and in the extraction wells could present technical challenges.

- The air may flow through preferential pathways that may result in uneven drying of the soil.

- The presence of relatively impermeable zones may increase drying time considerably.

- The absence of a physical barrier would complicate recovery of leaked waste using soil flushing.

\subsubsection{Other Information}

According to the BDM/K\&M, an example target for drying soil is below the $\mathrm{C}$ Tank Farm, which encompasses an area of approximately $23,300 \mathrm{~m}^{2}\left(250,000 \mathrm{ft}^{2}\right)$ and is $15 \mathrm{~m}(50 \mathrm{ft})$ thick. Air would be injected just under any pre-existing contaminant plume, about $45 \mathrm{~m}$ $(150 \mathrm{ft})$ below the surface, and down to about $60 \mathrm{~m}(200 \mathrm{ft})$, which is about $15 \mathrm{~m}(50 \mathrm{ft})$ above the water table.

Existing vertical wells could be used as air injection or extraction wells and/or new wells could be drilled using cable tool, sonic, or air rotary drilling methods. Wells would be drilled or deepened to a depth of $60 \mathrm{~m}(200 \mathrm{ft})$. Each well would be equipped with port collars that can be mechanically opened or closed to either inject or extract air. The injection and/or extraction rates could be varied by the depth as needed to optimize drying (KEHa 1993).

Horizontal wells are more efficient for injection or extraction than are vertical wells. Thus, fewer horizontal wells would be required than for vertical operations. Each horizontal well would be equipped with mechanical port collars to provide a large number of injection and 
extraction points and thereby improve extraction from the $15-\mathrm{m}(50-\mathrm{ft})$ interval target for the conceptual design. Positioning of the horizontal wells would not be as accurate as that of the vertical wells; however, extreme accuracy would not be required since the air would flow in a wide-sweeping pattern (KEHa 1993).

The integrity of the barrier could be verified through monitoring the extracted air. Ineffective wells can be detected from pressures, air flow rates, and geophysical well logs. The productivity and injectivity of these wells could be improved by stimulation or plugging using common oil industry technology. Humidity levels of the produced air would be monitored to indicate how well the zone around an injection well had dried (KEHa 1993).

\subsection{RADIOFREQUENCY DESICCATING SUBSURFACE BARRIERS}

A radiofrequency (RF) heating process can be used for the formation of an active desiccating barrier underneath underground storage tanks. Electrodes would be installed in the soil between the source of the contamination and groundwater using horizontal drilling techniques. The RF energy applied to the electrodes would heat a 2 to $3 \mathrm{~m}(7$ to $10 \mathrm{ft}$ ) thick layer of soil to temperatures above $100^{\circ} \mathrm{C}\left(212^{\circ} \mathrm{F}\right)$ to evaporate the moisture. Electrodes would be perforated and maintained under vacuum to remove the steam and volatile organics for aboveground treatment and disposal. As heat is lost from the barrier to surrounding soil, $\mathrm{RF}$ energy would be applied either continuously or intermittently to overcome losses (Sresty 1993).

Figure 3-11 illustrates an active desiccating subsurface barrier as applied to an SST. As shown, a horizontal row of parallel electrodes spaced about 1 to $2 \mathrm{~m} \mathrm{(3.3} \mathrm{to} 6.6 \mathrm{ft})$ apart would be installed by guided horizontal drilling. After installation, pairs of electrodes would be attached to a lower shortwave band RF source. The source would excite the electrodes and cause energy to be absorbed into the soil immediately surrounding the electrodes. This in turn would heat the soil to a temperature of about $150^{\circ} \mathrm{C}\left(302{ }^{\circ} \mathrm{F}\right)$, thereby vaporizing the water present within the soil. Waterborne contaminants would be stopped at the heated zone slab by the vaporization of the liquid carrier. Scale-model tests have demonstrated that a thin slab of earth could be heated to temperatures between 120 and $160{ }^{\circ} \mathrm{C}\left(248\right.$ and $\left.320^{\circ} \mathrm{F}\right)$. The energy required to maintain the heated slab at temperatures above $100^{\circ} \mathrm{C}\left(212{ }^{\circ} \mathrm{F}\right)$ has been estimated to be between 10 and $40 \mathrm{~W} / \mathrm{m}^{2}$, depending on soil properties (Sresty 1993).

The RF heating process would generate high-powered RF signals by converting alternating current power to RF in a modified radio transmitter. The output of the transmitter would be applied to the soil to be heated. The power would be conveyed by coaxial cables through a matching network to the target slab. For in-place applications, an array of electrodes inserted in boreholes drilled through the target slab would be energized with RF power. Frequencies used for the heating of soil formations would be between $10 \mathrm{kHz}$ and $60 \mathrm{MHz}$. The precise frequency of operation would be determined by the electrical parameters of the soil and the size of the slab to be heated (Sresty 1993). 
WHC-SD-WM-ES-300 REV. 1

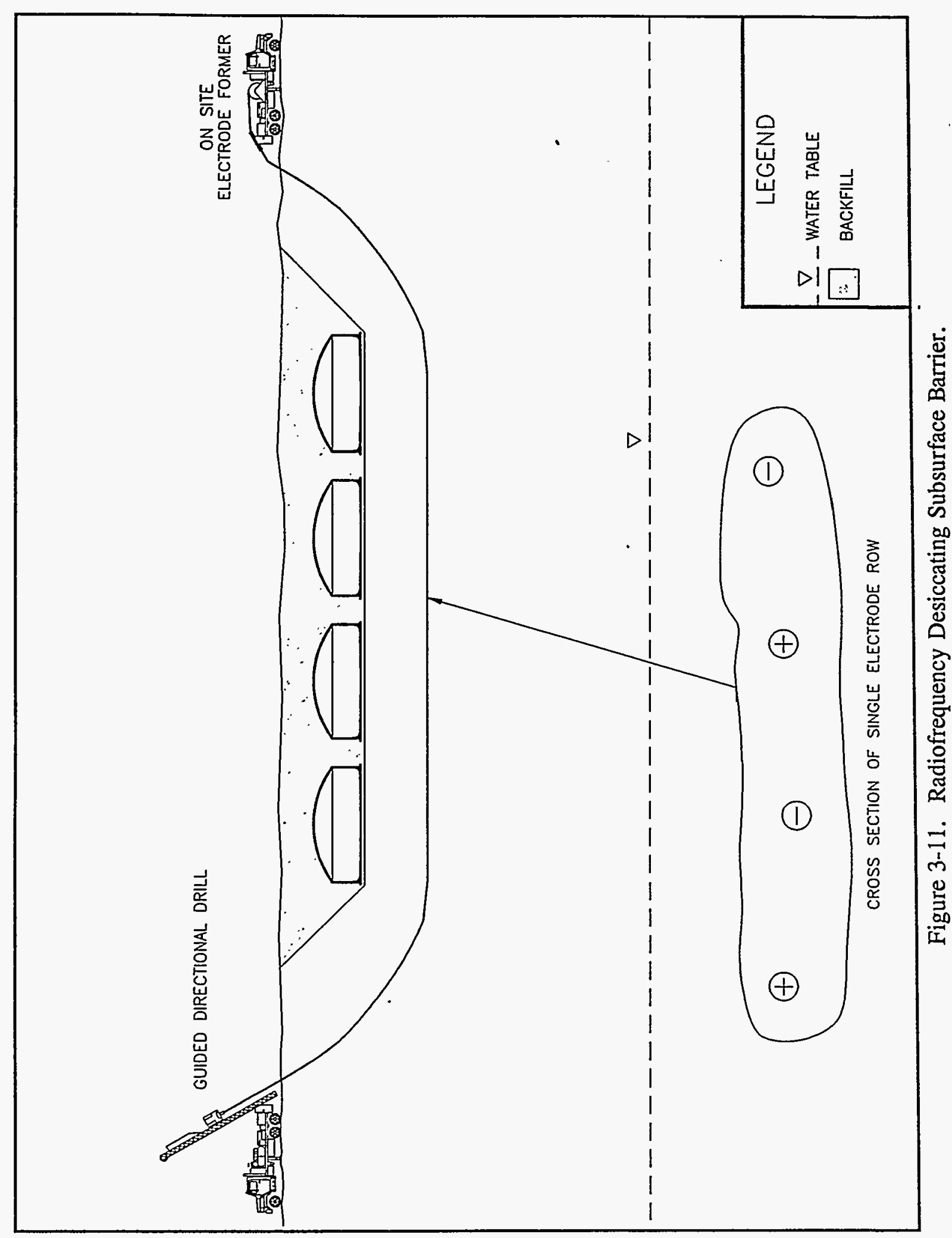


As a general rule, the higher the operating frequency, the more readily soil will absorb the energy; However, too rapid an absorption can cause most of the energy to be absorbed within the surface layers nearest the borehole at the expense of heating the soil deeper in the slab. Lowering the operating frequency improves the depth of penetration since less power is absorbed in the surface layers (Sresty 1993).

\subsubsection{Current Applications}

In the late 1970 s and early 1980 s, the RF heating concept was applied to a fuel extraction process to uniformly heat warehouse-sized blocks of oil shale and tar sand. This technique has since been modified to heat large volumes of earth to decontaminate hazardous waste spills (Sresty 1993).

\subsubsection{Test/Demonstration Status}

IIT Research Institute (IITRI) is currently working with the EPA, U.S. Air Force, Electric Power Research Institute, and other industries to develop, demonstrate, and commercialize this technology for various waste treatment applications. One of IITRI's licensees is currently using the technology for disinfection of hospital waste. A bench-scale test of radioactive resin treatment has been conducted for the Empire State Electric Energy Research Corporation (Sresty 1993).

IITRI has recently completed a project and is currently conducting a second with the Electric Power Research Institute in which a novel method for introducing in situ passive barriers was demonstrated in the laboratory. This technique allows for installation of horizontal desiccant barriers which, in combination with slurry walls, can contain the waste and prevent groundwater contamination. IITRI is currently developing plans for field demonstration of the concept in combination with horizontal drilling techniques in collaboration with Sandia National Laboratories (Sresty 1993).

\subsubsection{Advantages and Disadvantages}

\section{Potential Advantages}

- The velocity of vapor flow into electrodes should be low enough that few contaminated particulates are entrained in the air withdrawn from the extraction wells.

- The installation of the RF heating system would not induce new stresses around the tanks. 
- Once a significant amount of drying has taken place, prolonged periods of nonheating can be tolerated without impairing the function of the barrier.

\section{Potential Disadvantages}

- The use of soil flushing or excavation may be required to recover leaked contamination under a tank farm. The absence of a physical barrier would complicate recovery of flush solution.

- Horizontal holes must be drilled to relatively low tolerances to achieve the required $1-$ to $2-\mathrm{m}(3.3-$ to $6.6-\mathrm{ft})$ spacing.

\subsubsection{Other Information}

The moisture content of the soil dominates the electrical behavior during heating because of the polar nature of water molecules and because water behaves as an electrolyte. It is assumed that the conductivity of the soil will drop significantly as the water is evaporated. Since the heating rate of a material is directly proportional to the conductivity, the drying of soil causes it to absorb less energy. The drying of one zone of soil therefore causes progressive heating into other zones still containing water (Sresty 1993).

The integrity of the active barrier formed by the in situ heating of soil using the RF technology depends on the ability to maintain (continuously or intermittently) a temperature of $100^{\circ} \mathrm{C}\left(212^{\circ} \mathrm{F}\right)$ or more in the entire layer of soil. The dielectric properties of soil favor heating of moist regions and facilitate the formation of such a barrier. Experiments indicate that the conductivity of wet soil is 1 to 2 orders of magnitude higher than that of dried soil. Energy deposition and temperature increase calculations based on measured conductivity data show that the applied RF energy is preferentially absorbed in moist regions of soil to a distance approximately equal to the spacing of the electrodes ( 1 to $2 \mathrm{~m} \mathrm{[3.3} \mathrm{to} 6.6 \mathrm{ft}$ )). Dry soil continues to absorb energy, but at a lower rate. A layer of soil with an approximate thickness equal to the spacing between electrodes can thus be maintained at a temperature of $100^{\circ} \mathrm{C}\left(212^{\circ} \mathrm{F}\right)$ or more (Sresty 1993).

\subsection{SHEET METAL PILING SUBSURFACE BARRIERS}

Sheet metal piling subsurface barriers could be formed by emplacing interlocking metal sheet piling in a vertical configuration. This barrier would need to be coupled with a horizontal barrier to form a complete barrier envelope. Sheets would be sealed by injecting grout where the sheets are joined. The piling could be installed using a jetting shoe, vibratory hammer, or static emplacement methods. A continuous sheet piling wall could potentially be driven to depths of $90 \mathrm{~m}$ (300 ft) in unconsolidated deposits lacking boulders. 
If joints are used, a wedge or plug at the bottom of each joint cavity would displace soil laterally as the sheets are driven into the ground, leaving the joints largely soil-free. Soil that does enter the joints would be relatively loose and easily removed by jetting with water. A watertight sealant would then be injected into the sealable cavities between sheet piles to create a low permeability barrier.

Leakage of water through unsealed sheet piles is acceptable for most civil engineering applications, but generally not for environmental applications. Conventional unsealed sheet piling has a bulk hydraulic conductivity in the range of $10^{-4}$ to $10^{-5} \mathrm{~cm} / \mathrm{s}\left(2 \times 10^{-4}\right.$ to $\left.2 \times 10^{-5} \mathrm{ft} / \mathrm{min}\right)$. In comparison, bulk hydraulic conductivities of $10^{-8}$ to $10^{-10} \mathrm{~cm} / \mathrm{s}\left(2 \times 10^{-8}\right.$ to $2 \times 10^{-10} \mathrm{ft} / \mathrm{min}$ ) are typically achieved in test cells constructed of joint-sealed sheet pile. A hydraulic conductivity at or below $10^{-7} \mathrm{~cm} / \mathrm{s}\left(2 \times 10^{-7} \mathrm{ft} / \mathrm{min}\right)$ would normally be required by regulatory agencies for vertical barriers around waste sites (Waterloo 1994).

A variety of sealant materials could be used including bentonitic grouts, vermiculitic grouts, cementitious grouts, and organic polymers. Sealants would be selected according to site conditions and project requirements.

Potential leakage paths through the barrier would be limited to the sealed joints and therefore the joints would be the focus of quality control procedures. Joints could be inspected between cleaning and sealing operations to confirm that the sheets have not separated and that the complete length of the joint would be open and could be sealed. Each joint would be sealed from bottom to top using sealant injection lines, facilitating the emplacement of sealant into the entire length of the joint. Repair procedures could be initiated if a joint separation or blockage is suspected (Waterloo 1994).

Figure 3-12 depicts sheet metal piling with grouting as applied to SSTs.

\subsubsection{Current Applications}

In civil engineering applications, sheet piling can be used during excavation of compressible soils in urban areas to prevent settlement due to groundwater seepage. The barrier can also be used to limit the amount of dewatering required during construction below the water table. Its use in cofferdams can be cost-effective on longer-term projects by virtually eliminating the necessity for continual pumping in order to dewater the enclosure.

At new industrial sites, sheet pile barriers can be installed to enclose the site as a preventive or security measure to control chemical releases that could occur in the future. Enclosures around new landfills can be coupled with caps or infiltration systems to manage the rate of waste degradation and leachate production (Waterloo 1994). 


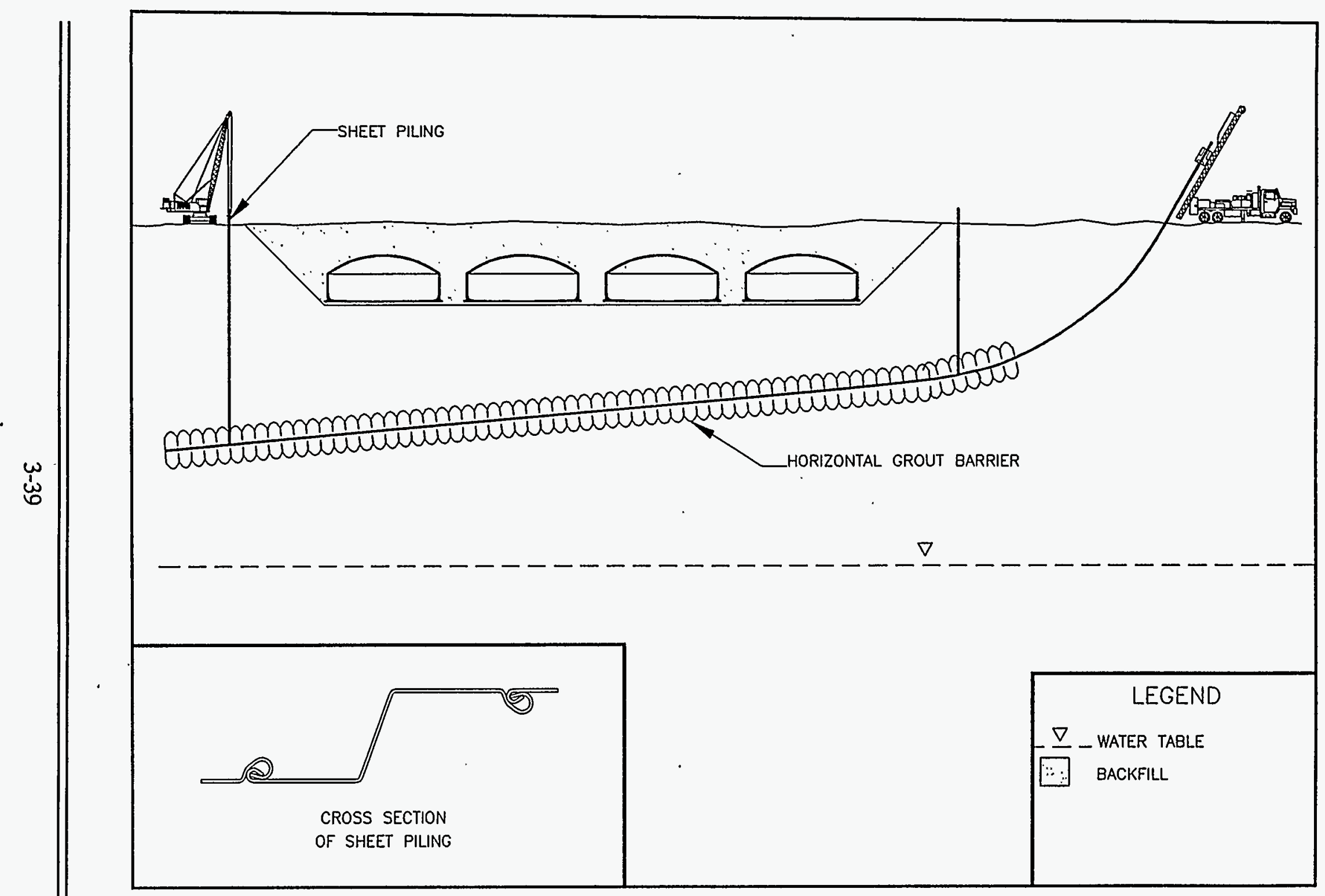

Figure 3-12. Sheet Metal Piling Subsurface Barrier. 


\subsubsection{Test and Demonstration Status}

Sheet metal piling is a proven technology. However, field demonstration of environmental applications of sheet piling for barriers is ongoing, in particular at the University of Waterloo, Canada.

\subsubsection{Advantages and Disadvantages}

Potential Advantages

- Excavation of subsurface materials is not required; damage, disruption, and high costs are avoided.

- Sheet metal piling is relatively easy to install and construct given applicable soil conditions (e.g., no boulders or large cobbles).

- Topography and depth to water table have little effect on installation techniques.

- Sheet metal piling is useful for containment by itself or in combination with other in situ remediation techniques.

- Required sealant volume is small.

- Pump-and-treat costs could be reduced due to a significantly smaller volume of contaminated groundwater being processed.

- Low-strength sealants could allow the barriers to be removed.

\section{Potential Disadvantages}

- The technology is limited to vertical barrier applications only.

- The technology may not be applicable to soils containing boulders or large cobbles.

- Sheet metal pilings may be subject to corrosion unless cathodic protection is provided.

- The installation of sheet piling may induce unacceptable stresses on the tanks. 


\subsubsection{Other Information}

A new type of containment wall composed of sealable steel sheet piling (Waterloo Barrier) has been developed at the University of Waterloo's Institute for Groundwater Research. The interlocking joints between individual sheet piles incorporate a cavity that is filled with sealant after emplacement to prevent leakage through the joints. The Waterloo barrier design is being used commercially by RCI Environmental Inc. of Kent, Washington.

At sites where a very high degree of water tightness is desired, the Waterloo Barrier could be constructed with both an internal and external cavity at each joint. Two sealable cavities would provide exceptional assurance that the joints would be fully sealed, and also provide an opportunity for using more than one sealant at each joint to accommodate different in situ conditions inside and outside the enclosure.

\subsection{CLOSE-COUPLED INJECTED CHEMICAL BARRIERS}

One close-coupled subsurface barrier option adapts the concepts of jet and permeation grouting in angled boreholes using directional drilling methods. Chemicals suitable for injection include portland cement, polymer formers, aggregating emulsions, and others discussed previously in this section. Unlike the concept of jet grouting to create standoff barriers discussed in Section 3.1, the chemical grout would be formed against the sides and bottom of an individual SST. In one concept, a standoff barrier would be installed around an individual tank in a conical configuration. Once the conical grout barrier hardens, vertical or shallow-slanted wells would be drilled between the tank wall and the conical grout barrier to the bottom of the cone. The area at the bottom of the cone would then be filled with costeffective grouting materials within a few meters of the bottom of the SST. The casing would then be blocked and more effective chemical grouts would be injected from the bottom of drilled casings under pressure, allowing the material to percolate upward to encapsulate the SST. Alternately, the close-coupled barrier walls could be installed directly against the tank walls using vertical boreholes. The horizontal members of the barrier could be installed in two layers using horizontal boreholes. This latter option is the basis for evaluation of closecoupled chemical grout barriers in this feasibility study.

Figure 3-13 depicts a close-coupled chemical barrier concept as applied to a Hanford Site SST.

\subsubsection{Current Applications}

No full-scale application of this technology for waste management or environmental restoration purposes is known at this time. 
WHC-SD-WM-ES-300 REV. 1

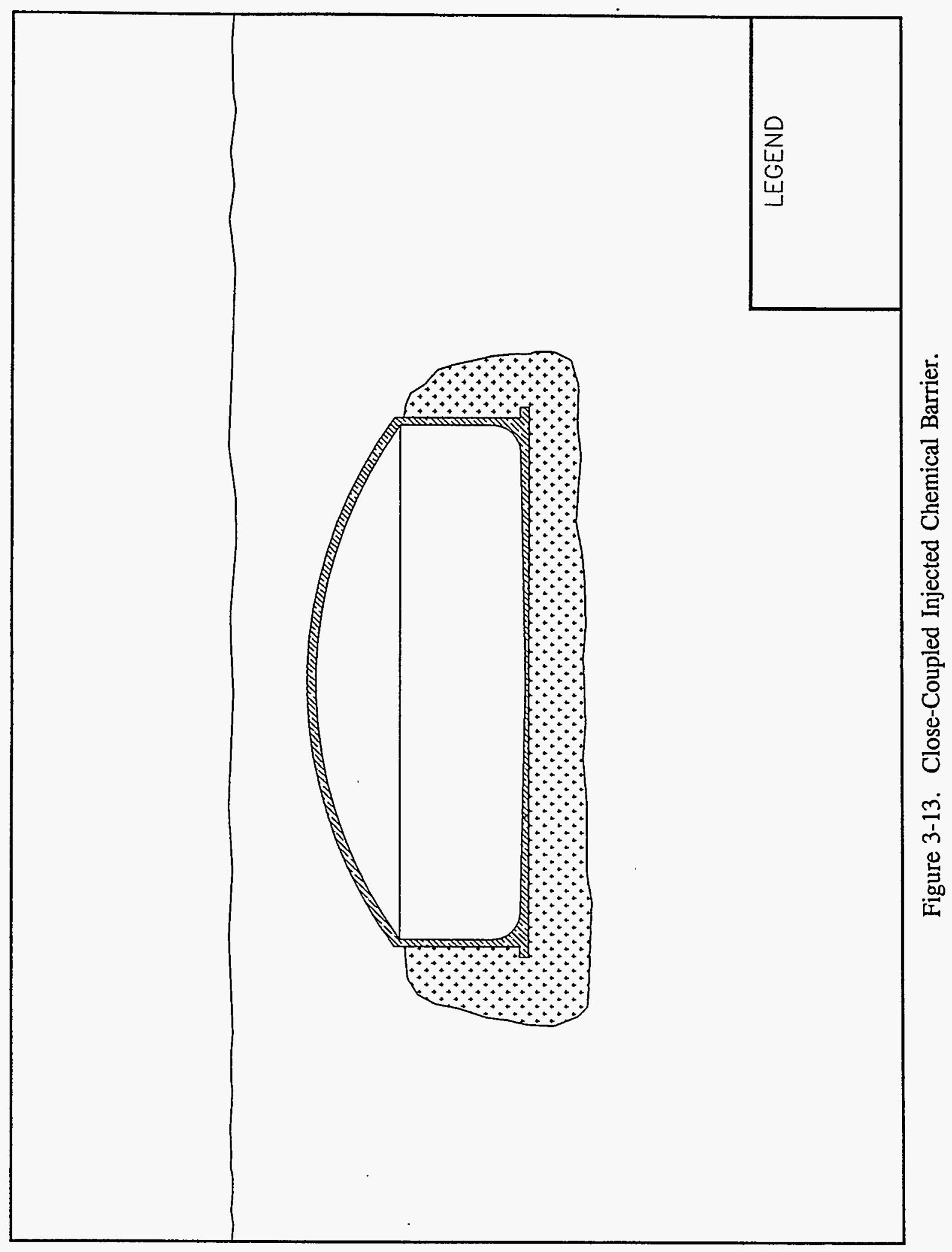




\subsubsection{Test and Demonstration Status}

The materials for this concept have been tested in the laboratory but have not been demonstrated in the field for this type of application.

\subsubsection{Advantages and Disadvantages}

\section{Advantages}

- Little or no spoils would be brought to the surface.

- Close-coupled injected chemical barriers would prevent the creation of contaminated soil by new leaks.

Disadvantages

- Close-coupled barriers may induce stresses on the tank, depending on the emplacement method used.

- Close-coupled injected chemical barriers are relatively unproven and have undergone little testing.

- It may not be possible to emplace the conical jet grout shell given the confining limitations between the Hanford Site SSTs.

\subsection{INDUCED LIQUEFACTION BARRIERS}

Induced liquefaction is a close-coupled subsurface barrier option that combines the concepts of sheet metal piling to create a vertical barrier with caisson-drilled horizontal jet grouting. One to three caissons would first be excavated using a 5- to 7-m (15- to 20-ft) diameter clamshell. Coffered trenches may also be used for installation of the horizontal barrier. An overlapping jet grout curtain would be installed via horizontal wells jacked in through the caisson(s) or coffered trenches to form a horizontal barrier. Sheet metal piles would then be driven or vibrated down to the horizon depth to $\sim 30 \mathrm{~m}(\sim 100 \mathrm{ft})$, depending upon the local strata. Joints between sheets would be grouted to ensure barrier integrity. Finally, vertical injection wells would be installed between the SST and sheet metal piling/jet grout curtain to inject grout, polymers, or other barrier-forming material from the bottom of drilled casings under pressure, allowing the material to percolate upward to encapsulate the SST.

Figure 3-14 depicts an induced liquefaction barrier as applied to Hanford Site SSTs. 
WHC-SD-WM-ES-300 REV. 1

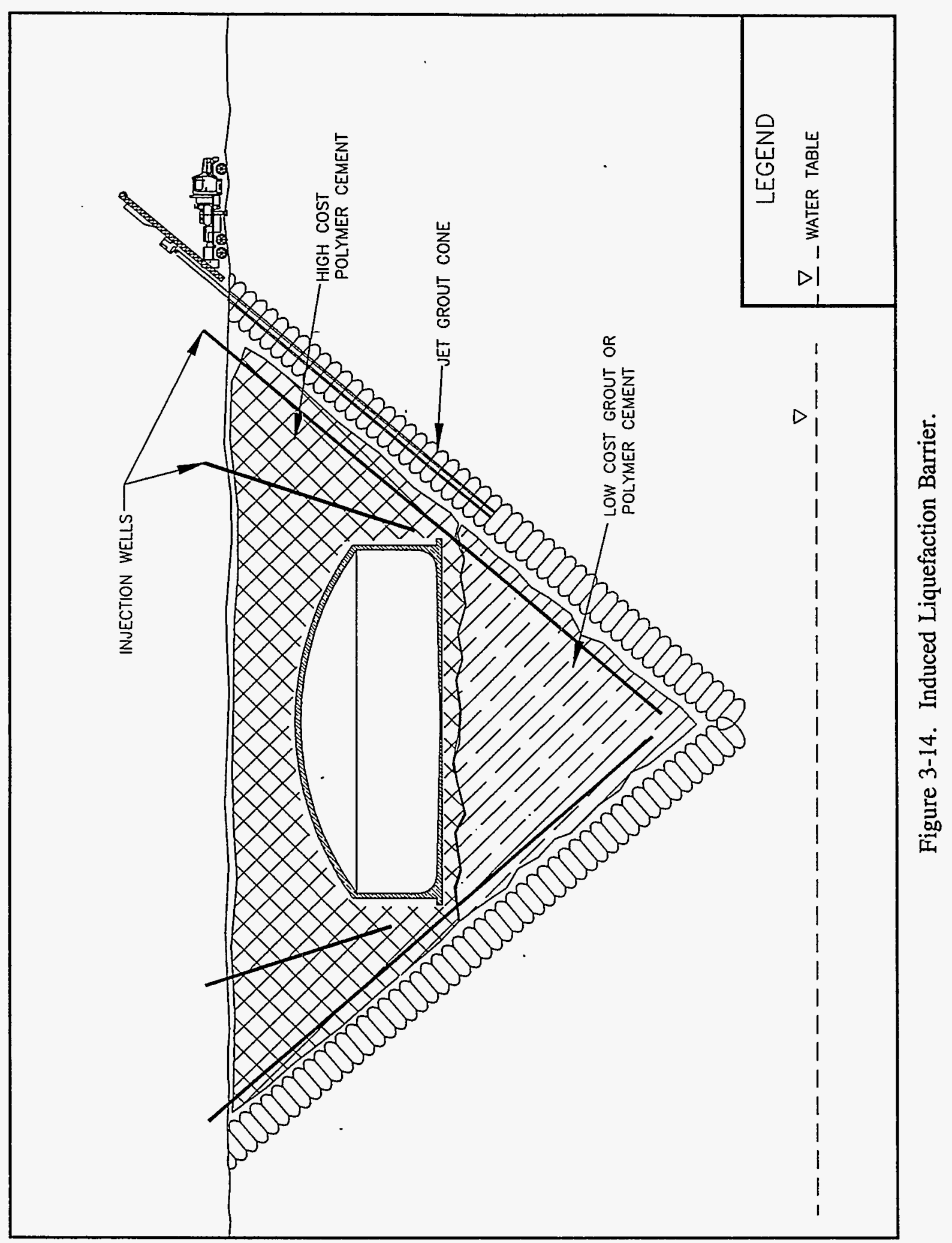




\subsubsection{Current Applications}

No full-scale application of this technology for waste management or environmental restoration purposes is known at this time.

\subsubsection{Test and Demonstration Status}

Sheet metal piling has been demonstrated in several instances in the field at the Hanford Site.

\subsubsection{Advantages and Disadvantages}

\section{$\underline{\text { Potential Advantages }}$}

- No spoils are brought to the surface when installing sheet piling.

- Some of the technologies included in this option, such as sheet piling, caissons, and pipe jacking, have already been demonstrated in Hanford Site soils.

\section{Potential Disadvantages}

- Sheet metal pilings may be subject to corrosion unless cathodic protection is provided.

- Boulders and large cobbles may cause the sheet metal edges to deflect, causing potential gaps.

- The horizontal component of the barrier is based on a conceptual technology with little hard evidence to support its feasibility.

- Large amounts of potentially contaminated spoils could be produced during the excavation of the caissons or trenches.

The remainder of this section includes discussion of other subsurface barrier concepts considered to be infeasible for SST applications.

\subsection{SLURRY WALLS}

Slurry walls (also known as curtain walls, cut-off walls, or diaphragm walls) would be dug either by traditional cut-and-fill methods or by specialized hydrophraising equipment that produces vertical panels. In all cases, the trenches would be kept open by backfilling with a bentonite slurry. Slurry would permeate into the local strata to form a filter cake, which would form a barrier. The slurry could largely be displaced, from the bottom up, with a 
suitable dense barrier material (cementitious grouts, polymers, plastic concrete, etc.). Displaced slurry would be pumped to a conditioning system for reuse (KEHa 1993).

Hydrophraising would involve forming engineered panels in the vadose zone by specialized surface equipment that would dig a deep trench while backfilling with slurry. Once individual panels harden, overlapping of panels would be ensured by cutting new panels into adjacent panels (Bruce 1990).

When applied to SSTs, this technology may not be suitable for the following reasons: (1) the effective working depth may be too shallow for SST applications due to presence of large cobbles and boulders and (2) significant quantities of spoils must be excavated and brought to the surface, thereby creating potential safety and contamination control concerns.

\subsection{DEEP SOIL MOXING}

Deep soil mixing would utilize large $1-$ to $2-\mathrm{m}(3.3-$ to $6.6-\mathrm{ft})$ diameter augers to bore into the soil. As the augers are pulled out of the hole, the cavity would be injected with grout or other suitable barrier formers. It is a relatively simple concept that would be applicable in relatively shallow (25- to $33-\mathrm{m}$ [75- to $100-\mathrm{ft}]$ ) environments where large quantities of spoils would not be a concern.

This technology may not be feasible for SST applications at the Hanford Site for the following reasons: (1) very large quantities of soil would be brought to the surface (thereby creating a waste management concems if contamination is encountered) and (2) the maximum working depth may not be sufficient for the depth of the tanks and existing soil contamination.

\subsection{SOIL FRACTURING}

Soil fracturing is used by the oil and gas industry to open cavities for the purposes of enhancing oil and gas recovery. High pressure muds are injected into normally deep formations to fracture and open soils (Bovay Northwest 1992).

Fracturing, coupled with permeation grouting, would be used in a process to create sheet-like partial barriers. It could also be used to dispose and immobilize wastes. Intermediate level liquid radioactive wastes were disposed at the Oak Ridge Site by hydrofracturing. For SST applications, vertical fracture wells would be drilled between tanks down to the required depth horizon. Grout would be used as the fracturing fluid to achieve a barrier thickness of up to $0.05 \mathrm{~m}(0.2 \mathrm{ft})$. A fracture radius of up to $50 \mathrm{~m}(150 \mathrm{ft})$ may be achievable in some geologies, but probably not at the Hanford Site. Enough fracturing wells would be drilled to provide complete overlap of individual barrier circles. 
This concept may not be viable for application to SSTs for the following reasons: (1) the uncertainty associated with the direction and extent of the fractures both horizontally and vertically, (2) the difficulty in verifying it as a continuous barrier, and (3) the stress or uplift it would induce on the tanks.

\subsection{LONGWALL MINING}

Longwall mining would require installation of vertical shafts or coffered trenches to enable installation of horizontally mined and back-filled barriers. From the bottom of the shafts or trenches, mining machines would cut and remove soils in mass along a horizontal "long wall." As excavation occurs, the resultant cavity would be filled with a supporting barrierforming material, such as grout. The technology has been used extensively in the mineral mining industry. It is unknown if this technology could be accomplished remotely in a potentially contaminated underground environment.

Although this technology would be one of the best for verifying the continuity of the subsurface barrier, it has a number of drawbacks. These include large amounts of spoils, potential for subsidence, and high personnel safety risks.

\subsection{MODIFIED SULFUR CEMENT}

Modified sulfur cement was developed by the U.S. Bureau of Mines to utilize the readily available supply of byproduct sulfur in the United States. Modified sulfur cement is * commercially available under license as "CHEMENT 2000." Modified sulfur cement is a thermoplastic material with a melting point slightly above the boiling point of water. The process for using modified sulfur cement for forming barriers would involve heating aggregate onsite in a rotary drier followed by combination with sulfur cement in a pugmill to form sulfur concrete. A production rate of about 9 metric tons per hour (10 tons $/ \mathrm{hr}$ ) is achievable. Modified sulfur cement has been used in the United States for in-container solidification of radioactive wastes, incinerator ash, ion-exchange resins, sludges, and sodium nitrate. It can be used in the construction of caissons for waste storage and for sealing drill holes and shafts.

Through cut-and-fill deployment technologies, modified sulfur cement could form a continuous free-standing monolithic barrier with no residual water.

This technology may not be viable since the barrier may be prone to cracking and would be difficult to install at the required elevated temperature. It is most viable if installed in the vertical orientation. 


\subsection{SEQUESTERING AGENTS}

The barrier materials used in this concept would be specifically selected to physically or chemically adsorb, precipitate, contain, and isolate contaminants once injected as a slurry into soils. The barrier would be porous, allowing water to pass through. The technology has been used in groundwater applications. Barrier-forming materials would be emplaced using hollow-stem augers, jets, or permeation techniques.

Zeolites (clinoptilolite and chabazite), tethered organic chelates, hydrotalcites, granulated rubber tires, and metallic iron have been studied in the laboratory to determine their applicability as porous barriers to stem the migration of strontium, chromates, carbon tetrachloride, and uranium in Hanford Site groundwater (Cantrell 1993, 1994).

The use of sequestering agents alone may not be viable for SST applications since multiple contaminants would be present, including nitrates and nitrites for which no known sequestering agent exists. In addition, in those cases where "fingers" of contamination may move rapidly through the vadose zone, the agents could become saturated and lose their effectiveness in a short period of time.

\subsection{REACTIVE BARRIERS}

The concept of reactive barriers in the vadose zone is new; however, it has been used previously for groundwater cleanup. The vadose zone technology would involve pumping a reactive chemical through injection wells below an existing or potential contaminated plume. The injected chemicals would be designed to chemically react via biodegradation, chemical degradation, and/or hydrolysis with contaminants as the plume moves through the reactive barrier. The reactive barrier material would be specifically tailored for the contaminants in the plume. Examples of reactive barrier materials that could be used or have been investigated for subsurface barriers include acids, bases, limestone, fly ash, ferrous salts, blast furnace slag, and phosphate salts (Riggsbee et al. 1994). Like sequestering agents discussed in the previous section, reactive barriers would allow water to pass through.

This technology is probably not viable for Hanford Site SSTs because (1) it would require significant research to identify effective reactants for all constituents of concern, and (2) suitable reactants for immobilizing nitrate and nitrite at expected leak concentrations are unlikely to be identified.

\subsection{IMPERMEABLE COATINGS}

This technology would apply impermeable coatings directly to the surface of buried objects following an excavation. Once the excavation has occurred, vacuum and pressure equipment would be used to coat or impregnate the exposed objects in the excavated space (Naudts 1989). 
This technology is viable for precast applications only. Since it would require excavation adjacent to and beneath SSTs, it is unlikely that adequate personnel safety could be assured. In addition, a dry, clean surface is required which may not be possible for SSTs.

\subsection{MUCROTUNNELING}

Microtunneling is a barrier deployment technology that would use vertically-oriented caissons or coffered trenches to install horizontal connecting tunnels. Laser-guided tunneling machines up to $0.7 \mathrm{~m}(2 \mathrm{ft})$ in diameter would be used to form a series of horizontal tunnels as long as $333 \mathrm{~m}(1,000 \mathrm{ft})$ using a slurry spoil removal system. An auger system could also be used, but the working length would be reduced to $83 \mathrm{~m}$ [ [250 ft] due to insufficient torque at the machine face. Once the horizontal tunnels are complete, they would be used for injecting permeation grouts or other suitable materials to form a horizontal continuous barrier.

Microtunneling was developed to install boreholes and casing in shallow soils where utilities are to be installed without disrupting the surface. It is a relatively efficient system for tunneling unconsolidated, fine-grain soils (KEHa 1993).

Microtunneling is not considered a viable option for subsurface barriers for Hanford Site SSTs for the following reasons: (1) a large quantity of spoils would be generated, (2) the tunneling machine is not designed for large cobbles since it cannot be backed up a sufficient length to move around large cobbles, and (3) personnel may be required to maintain the machine at the depth horizon; this may be unacceptable from personnel safety and radiation protection perspectives.

\subsection{IN SITU VITRIFICATION}

In situ vitrification barriers would employ joule heating (i.e., the application of electric current to heat the soil above its melting point) to convert soils to an obsidian-like rock. Conceptually, in situ vitrification would be performed in a progressive series of horizontal and vertical locations. Melt locations would partially overlap to ensure formation of a continuous barrier. The technology has undergone several dozen bench-to-field-scale tests and remediation of at least one hazardous waste site in North America. Although this barrier concept has been modeled thermally, it has not been tested (Garnich 1990).

The in situ vitrification technology has not been tested for barrier applications and, if installed too close to SSTs, may compromise the integrity of the tanks. Vitrification also densifies the medium it is melting, thereby causing the potential for subsidence if used beneath SSTs. 


\subsection{SOL SAW}

The soil saw is a relatively new method of forming deep (54-m [180-ft]) subsurface cutoff walls of relatively uniform quality. It can only be used in vertical applications. The technology employs reciprocating, high-pressure jets of cement grout or bentonite slurry to cut a continuous vertical path through the soil. Jet grouting nozzles are mounted along a rigid beam that reciprocates, thereby producing a sawing action. The combination of sawing and jet slurry grouting, results in the construction of a continuous soil/cement slurry wall.

This technology may not be viable for Hanford Site SSTs since it can only be used in the vertical plane. It has not been sufficiently tested in the field under soil conditions similar to those that exist at the Hanford Site. Once proven, it could be coupled with horizontal barrier technologies to create an integrated barrier for isolation of SSTs. 


\subsection{DESCRIPTION OF TECHNOLOGIES SUPPORTING SST WASTE RETRIEVAL}

This section describes individual tank waste remedial technologies that, when combined into overall remedial alternatives, could result in closure of SST waste sites as landfills or in clean-closure in accordance to the requirements of the Resource Conservation and Recovery Act of 1976 (RCRA) and the Dangerous Waste Regulations of the State of Washington (WAC 173-303 1993).

Section 3 described a wide range of subsurface barrier technologies. This section identifies and further describes five types of subsurface barrier technologies deemed most applicable to SSTs. It also describes SST waste retrieval technologies, contaminated soil cleanup technologies, and closure technologies that, when linked with subsurface barrier technologies, would form complete remedial alternatives for SSTs. The following description of the technical setting for remediating the SSTs is provided to facilitate understanding of the range of technologies required to achieve closure of the SSTs.

\subsection{TECHNICAL SETTING}

Two major tank waste retrieval campaigns have been undertaken at the Hanford Site. From 1952 to 1957, retrieval operations were conducted in seven tank farms involving 43 SSTs as part of a process to recover uranium from tank waste. A second campaign, from 1962 to 1978 , involved the retrieval of strontium-bearing sludges from 10 SSTs. The history of both campaigns is documented in Hanford Tank Sluicing History (Rodenhizer 1987).

These campaigns used sluicing and slurry pumping for tank waste retrieval. Freeing up tank space for storage of newly created waste was an important goal of these historic campaigns. The equipment and technologies used were based on mining industry practices and adapted for use in a radioactive environment. Equipment failures occurred and process limitations were experienced, but overall, the campaigns were generally successful. In most tanks, sluicing was terminated when it was no longer cost-effective to continue operations to gain a few additional inches of storage space. Leaks that occurred during sluicing in two SSTs led to the termination of waste retrieval activities in those tanks.

The use of traditional sluicing technology alone may not be effective in meeting present-day cleanup objectives. Most of the SSTs are at least 40 years old and 67 of the 149 SSTs have been declared as having leaked waste (Hanlon 1993). The use of traditional sluicing in those and other deteriorated tanks may result in higher levels of leakage than have been experienced to date $\left(2.28 \times 10^{6}\right.$ to $3.42 \times 10^{6} \mathrm{~L}[600,000$ to 900,000 gal]) (Hanlon 1993). Moreover, traditional sluicing was found to be ineffective in slurrying rock-like masses of agglomerated sludge in some tanks (Boomer et al. 1993). Thus, large quantities of waste cannot be recovered with traditional technology unless augmented with other technologies. 
The cleanup objectives for tanks and the associated soil have not yet been established. Schmittroth et al. (1993) concluded that more than $99 \%$ volumetric retrieval may be necessary in some tank farms to meet a $10^{-4}$ lifetime risk objective to an individual who uses groundwater beneath the tanks. Retrieval of greater than $99 \%$ of the waste using traditional sluicing may not be achievable (Boomer et al. 1993).

Lowe (1993) concluded that sluicing of Tank 241-C-106, an SST that is currently considered sound, may result in a leak of $152,000 \mathrm{~L}(40,000 \mathrm{gal})$ by the most likely leak mechanism. This mechanism includes a leak through the steel sidewall with penetration of leakage to the soil through the construction joint between vertical and horizontal members of the tank's concrete structure. Lowe (1993) also concluded that a leak of this magnitude would result in exceeding regulatory-based limits in the groundwater unless an impermeable cover over the tank is provided. A cover constructed of plastic sheets or other impermeable material would largely prevent the recharge of precipitation, thereby limiting the spread of contamination until soil cleanup operations are completed.

Several technical options are being considered as potentially more effective than traditional sluicing or capable of improving the effectiveness of traditional sluicing when used in combination (Boomer et al. 1993). These options include the use of improved tank waste retrieval techniques, low-permeability subsurface barriers, soil flushing, and tank closure technologies.

Specific tank waste remediation technologies within the range of options considered by Boomer et al. (1993) were selected for evaluation in this study. The selection was based primarily on analyses of cost and effectiveness reported in Boomer et al. (1993) and other analyses contained in reports cited in Section 11.0, References. The remainder of this section describes the selected technologies that would serve as components of 14 tank waste remediation alternatives evaluated and compared in this study.

\subsection{TANK WASTE RETRIEVAL}

Three separate technologies for retrieving waste from SSTs are described in this section. They include: (1) traditional sluicing, (2) robotic sluicing, and (3) mechanical retrieval.

\subsubsection{Traditional Sluicing}

Traditional sluicing is the method historically used to retrieve wastes from SSTs (Figure 4-1). It would use a large-volume stream of liquid to disperse, dilute, and mobilize sludge. The slurry would then be pumped out of the SST to a waste processing system where the supernatant would be separated from the sludge. The supernatant would be recycled as sluicing liquid. The equipment and staff required for traditional sluicing would be minimal in comparison to arm-based retrieval methods described in Sections 4.2.2 and 4.2.3. 
WHC-SD-WIV-ES-300 REV. 1

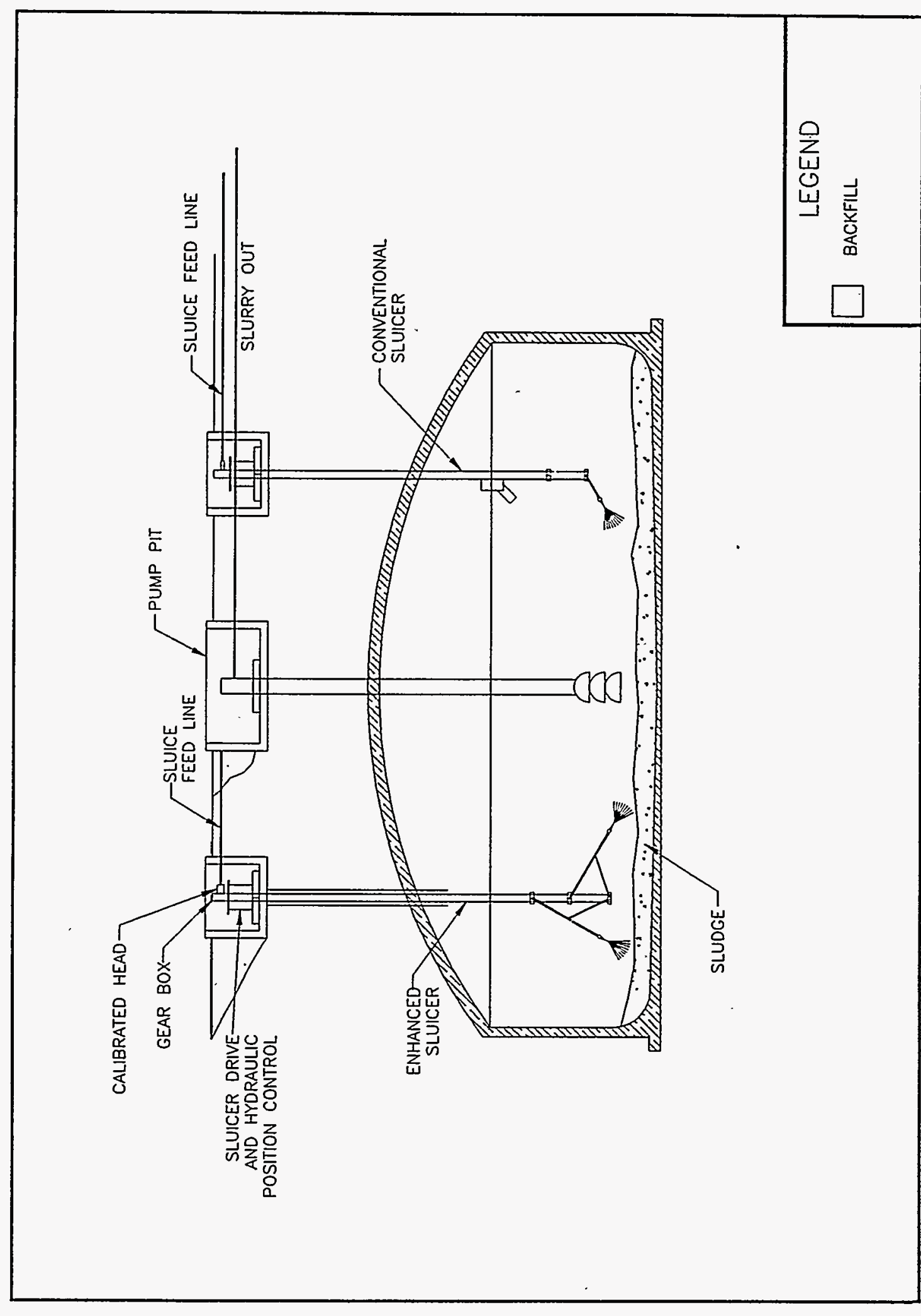

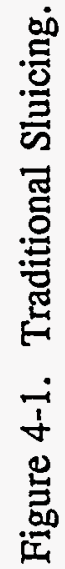


Traditional sluicing would require two $1,140-\mathrm{L} / \mathrm{min}(300-\mathrm{gal} / \mathrm{min})$ capacity sluicers: one in a sluice pit and the other on the opposite side of the tank in an existing slurry pump pit. Each sluicer would access the tank from the pits through existing 30.5-cm (12-in.) risers. The sluicers would be equipped with sluicing nozzles adjusted to spray in the horizontal and vertical planes. The nozzles would be used to disperse and dilute the sludge to a pumpable slurry, typically containing about $30 \%$ solids by weight (Boomer et al. 1993).

Once the desired slurry consistency is achieved, sluicing would be stopped and the slurry would be pumped from a pump heel pit located at the center of the SST via a 2,280-L/min $(600$-gal/min) low-head submersible pump. The pump would transfer the slurry to accumulation tanks via two, $10.2-\mathrm{cm}$ (4-in.) diameter pipelines, jumpers, and a valve pit.

Each of the accumulation tanks would be equipped with a perforated distributor riser and a sluice pump. The distribution riser would distribute the slurry in the accumulation tank. The solids that settle would be pumped to a waste processing system for further treatment. The variable speed sluice pump would return the supernatant, at a minimum rate of $2,280 \mathrm{~L} / \mathrm{min}(600 \mathrm{gal} / \mathrm{min})$, to the sluicer nozzles at a pressure of $1,241 \mathrm{kPa}$ (180 lb/in ${ }^{2}$ [gauge]).

A heating, ventilating, and air conditioning (HVAC) system would be connected to the SST to prevent the spread of hazardous gasses and radioactive particulates to the atmosphere during sluicing operations. The HVAC system would draw approximately $98 \mathrm{~m}^{3} / \mathrm{min}$ $\left(3,500 \mathrm{ft}^{3} / \mathrm{min}\right)$ from the SST to remove corrosive gasses, water droplets, suspended particulates, and organic vapors using wet scrubbing, filtration, and activated carbon filtration.

\subsubsection{Robotic Sluicing}

Robotic sluicing (Figure 4-2) is a variation of a type of robotic armed-based retrieval systems that were first investigated at the Hanford Site in the mid-1970s. The technology is under development, but has not been tested in an actual Hanford Site SST. The system described in this report is based on the system described in Wallace (1993) and is best-suited for retrieval of hardened sludge from SSTs.

An attachment to the end of the robotic arm called an end effector would use high-pressure water jets for dislodging the waste. After the sludge is dislodged, the slurried mixture would be immediately vacuumed through a hose to an air separation system. Following separation the waste would proceed to a processing system.

The robotic arm would be suspended from a bridge-mounted confinement structure. The bridge-mounted confinement structure would be fabricated from I-beams bolted together, and

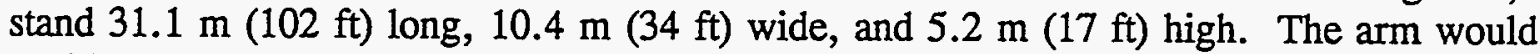
position the high-pressure jets that dislodge the waste with a reach of $18.3 \mathrm{~m}(60 \mathrm{ft})$ deep 
WHC-SD-WM-ES-300 REV. 1

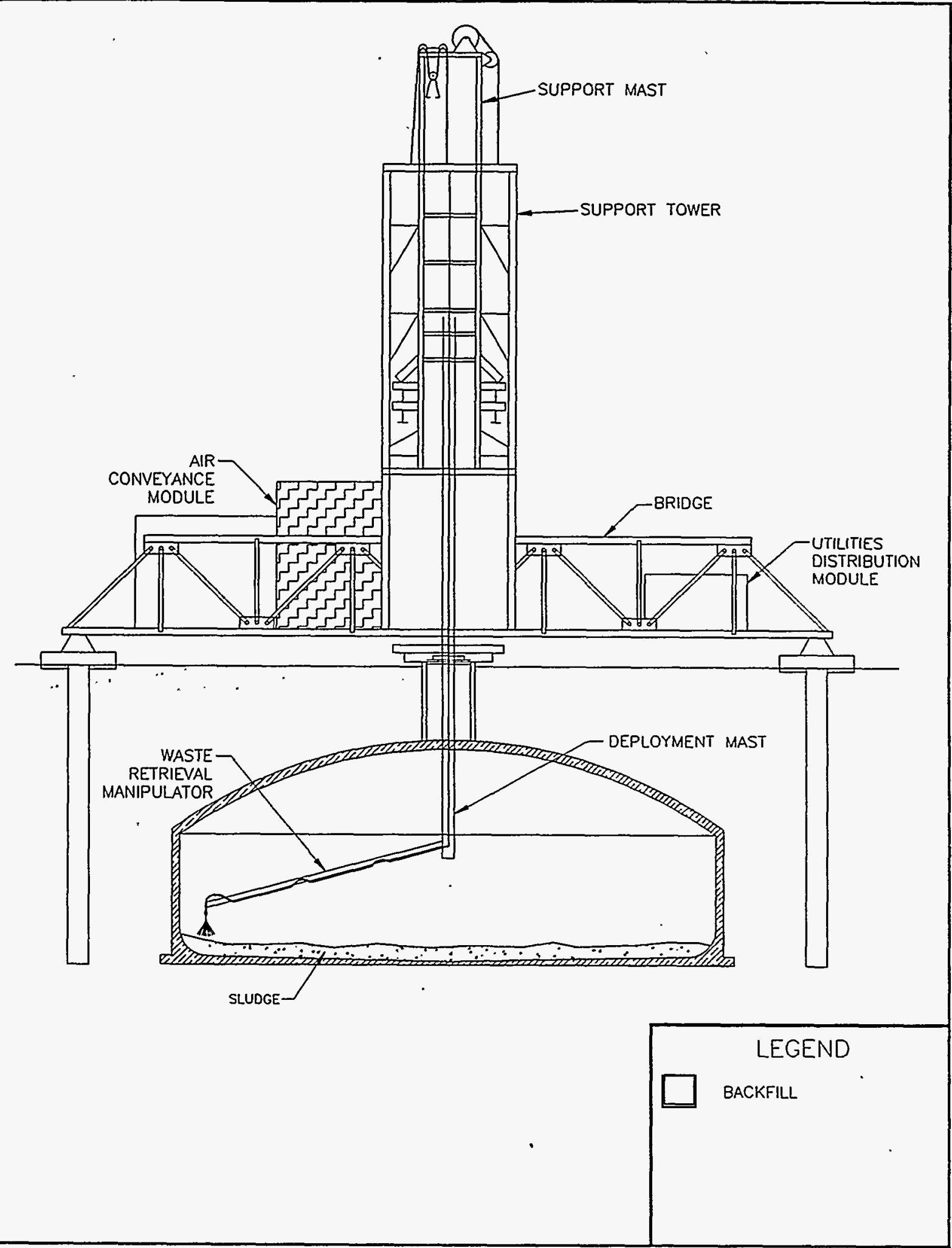

Figure 4-2. Robotic Sluicing. 


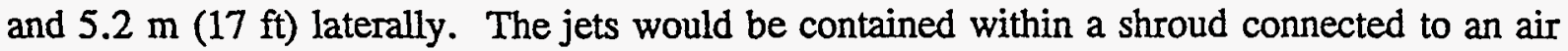
conveyance hose. The air- and water-entrained solids vacuumed through the air conveyance hose would be sent to an air.conveyance module.

The air conveyance module would be housed within a composite concrete and steel building located on a bridge-mounted confinement structure. It would be connected to the SST via the air conveyance hose. Air, waste fluid, solid waste, and debris (of acceptable size) would flow through the hose to the air conveyance module. The air stream would pass through a cyclone where the heavier waste particles would be separated and routed to an accumulation tank. The remaining air stream would be stripped of remaining moisture, heated, and then largely recycled through the air conveyance system. The robotic sluicing system would include other systems to support the primary retrieval components, including maintenance and decontamination capability, air filtration, and circulation.

The high pressure sluicing system should be effective in cutting through hardened sludge, but may also cut through corroded tank walls, which may cause new leaks.

\subsubsection{Mechanical Retrieval}

Mechanical retrieval, which is designed for removal of solid waste and debris as opposed to liquids and slurries, is one of the arm-based retrieval methods currently under consideration for use in the SSTs. It is another of several methods of retrieving waste from SSTs that have been investigated at the Hanford Site since the mid-1970s.

Mechanical retrieval would use a scoop-like end effector affixed to the end of the robotic arm for waste retrieval (Figure 4-3). The end effector would be capable of mechanically excavating the solid waste in the tank. A jack-hammer end effector may be necessary for breaking up the rock-like layer of sludge known to exist in some tanks. The excavated waste would be placed by the robotic arm into an in-tank mechanical waste conveyance system and removed from the SST for further processing.

The robotic arm would be suspended from a bridge-mounted confinement structure above the SST. It would be similar to the robotic arm used in robotic sluicing. The structure would include a deployment mast for mounting and aligning the robotic arm in the SST. The

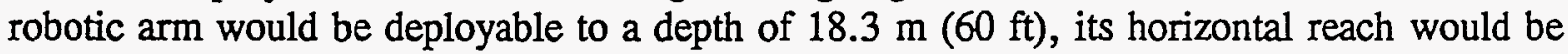

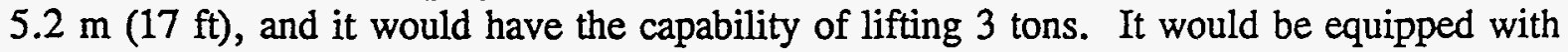
six split buckets, with two shovels each to collect the waste. The arm would deliver the waste to an in-tank transfer system that would consist of a bucket on a separate trolley that could be maneuvered independently of the robotic arm. 


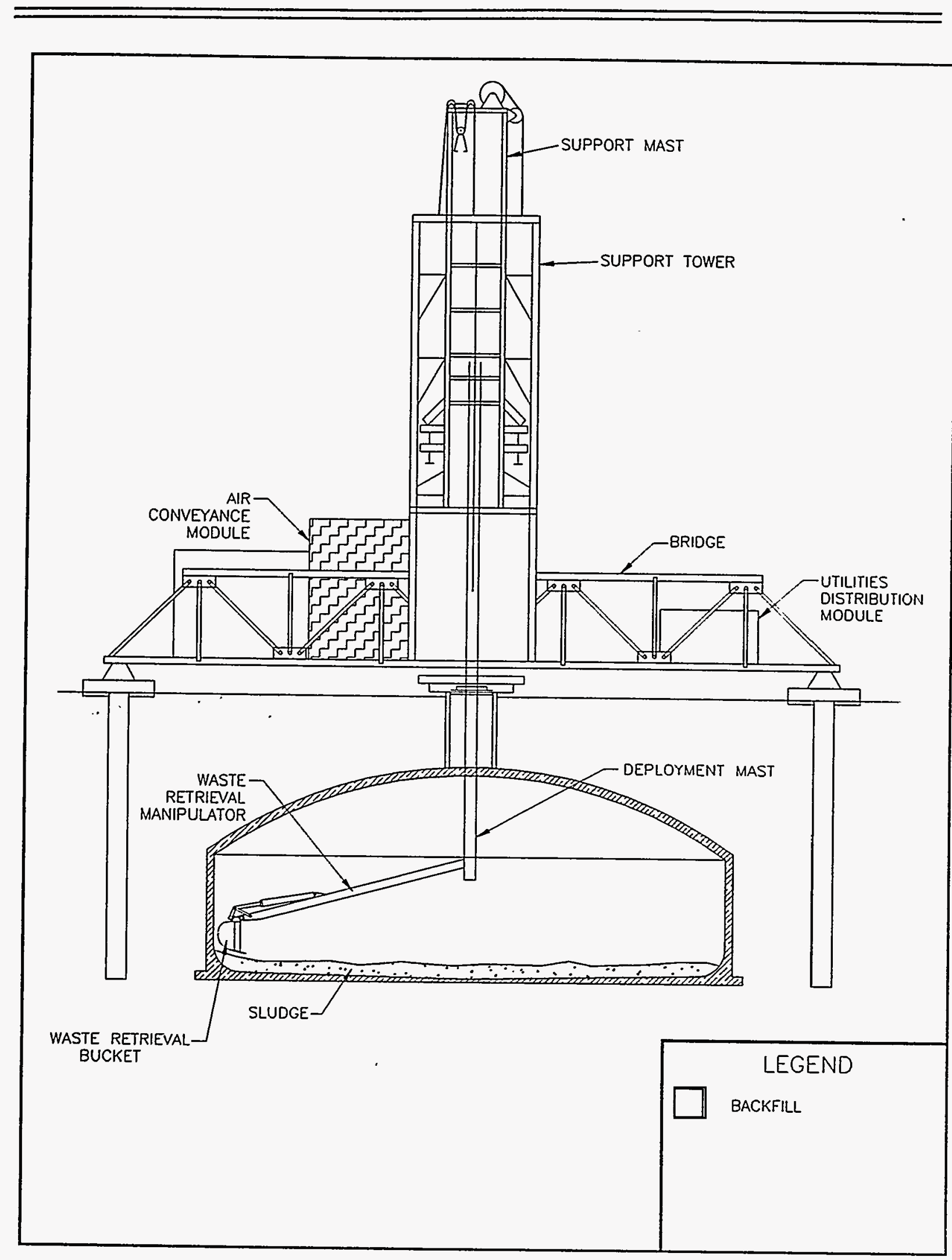

Figure 4-3. Mechanical Retrieval. 


\subsection{LOW-PERMEABILITY SUBSURFACE BARRIERS}

A range of subsurface barrier options potentially applicable to SSTs were described in Section 3. Those deemed to be sufficiently well-developed and potentially feasible for the intended application can be categorized as low-permeability chemical barriers, freeze wall barriers, and circulating air barriers.

The permeation grouting option described in Section 3.4 is considered representative of chemical barriers. A wide variety of chemicals can be employed to create a lowpermeability barrier as described in Section 3. A representative chemical for producing lowpermeability barriers is not specified, although cost estimates were based on the assumption that portland cement would be used to create the barrier.

Five barrier technologies are described in this section:

- Close-coupled chemical

- Box-shaped chemical

- V-shaped chemical

- V-shaped freeze wall

- Circulating air.

The first barrier type described is a close-coupled barrier, the following three are standoff barriers, and the last creates a barrier-like effect by evaporating water in any leak that forms. A close-coupled freeze wall barrier was not described because the high dissolved salt content of the liquid waste may suppress the freezing point of water to a level that prevents freezing. Forces created by frost heaving also may compromise the structural integrity of the tanks.

\subsubsection{Close-Coupled Chemical Barrier}

Chemicals used to create the close-coupled barrier would be injected through vertical and horizontal pipes jacked or drilled into the soil (Figure 4-4). Mudless drilling methods would be required to prevent plugging of soil pores, a condition that would interfere with subsequent chemical injections. It is assumed that the horizontal pipes would be installed from inside vertical $4.6-\mathrm{m}(15-\mathrm{ft})$ diameter caissons, which would be installed in the open areas between tanks. The horizontal pipes could also be installed using coffered trenches. The caissons, if used, would be constructed from sections of culvert pipe that would be lowered in $3.1-\mathrm{m}(10-\mathrm{ft})$ sections into a progressively deeper hole formed by a bucket excavator. Similar caissons have been installed in the A and SX Tank Farms (Raymond 1966). The annular space between the culvert pipe and soil would require grouting to provide structural stability for horizontal pipe jacking. The horizontal pipes could be used to convey flushing solution to the soil. (One conceptual method of removing contaminants from the soil prior to emplacement of the barrier is vacuum flushing of the soil, as described in Section 4.4.2). 
WHC-SD-WM-ES-300 REV. 1

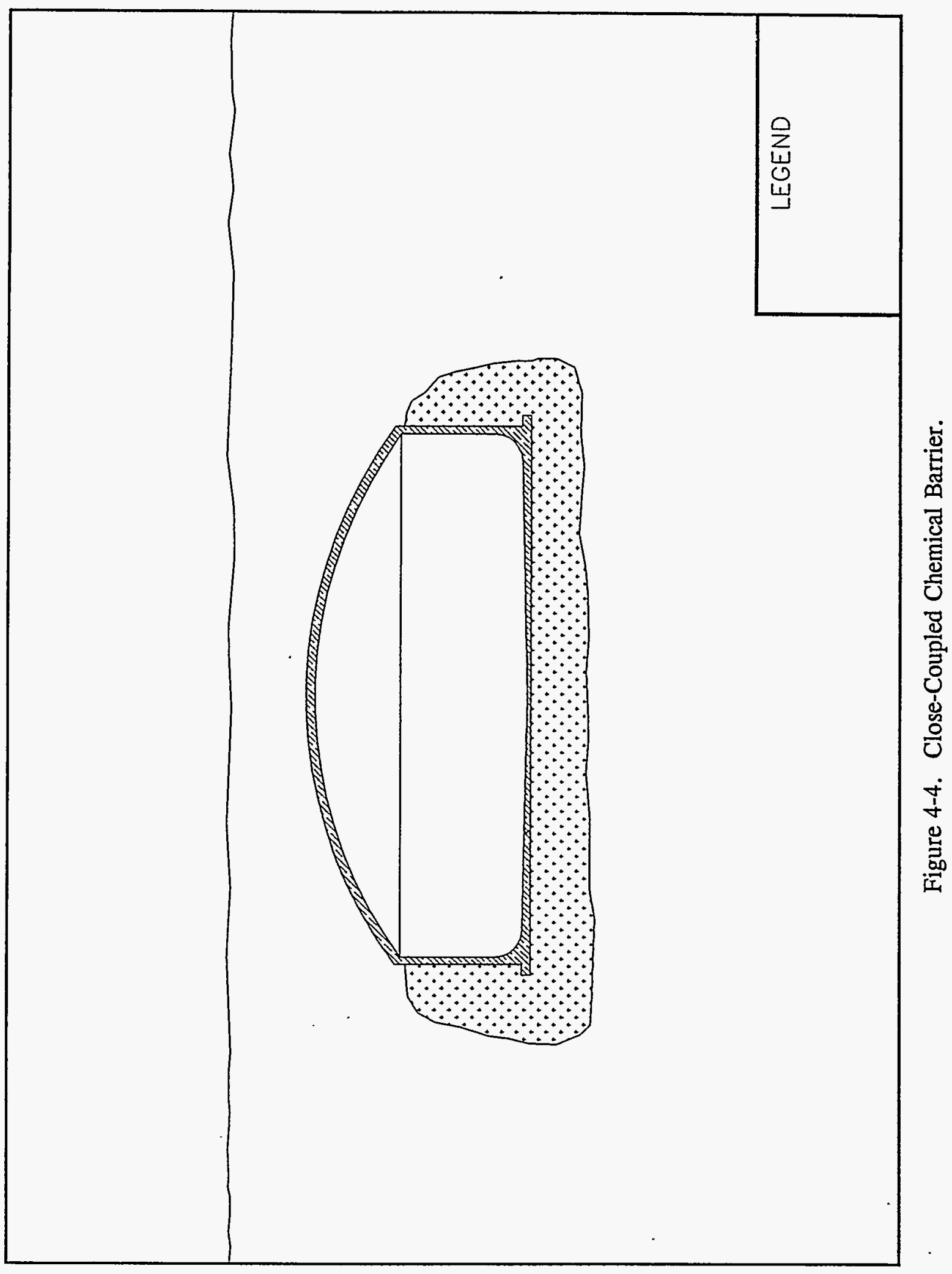


The horizontal injection pipes would be installed in two separate planes beneath the tanks (Figure 4-5). The horizontal pipes would be perforated to allow the barrier-forming chemical to be injected into the soil. Chemicals would be injected through the lower array of pipes first. The injected chemicals would be designed to penetrate a radial distance of about 0.75 to $1.5 \mathrm{~m}$ ( 2.5 to $5.0 \mathrm{ft})$ and begin to gel in about 2 hours. The resulting barrier columns would be designed to overlap, thereby forming a barrier plane. Injection through the upper array of pipes would occur several days later, when the lower barrier plane had fully gelled. Chemicals would be injected through the upper array of pipes under slightly higher pressures than through the lower array to promote full penetration of soil in contact with the tank's structural concrete.

A similar approach would be used at the tank walls. Injection pipes would be jacked or drilled vertically from the surface to the base of the tank footings. Chemicals would be injected through the end of the pipe at this level to tie into the barrier emplaced beneath the tank. Injections would then progressively be made by working upward from the base of the tank wall until a sealed, close-coupled barrier about $3 \mathrm{~m} \mathrm{(10} \mathrm{ft)} \mathrm{thick} \mathrm{is} \mathrm{created} \mathrm{around} \mathrm{the}$ tank.

The primary advantages of the close-coupled chemical barrier are: (1) the amount of injection piping and volume of injected chemical would be minimized because the injected chemical is designed to seal to the tank structural concrete rather than be located some distance away where the areal extent of the barrier is greater and (2) the volume of soil contaminated by new sluicing operations would be minimized because an effective closecoupled barrier would contain additional leakage from the tank, thereby preventing additional contamination of the soil. The primary disadvantages are: (1) soil contaminated from previous leaks may require flushing to remove contamination that would otherwise be incorporated into the injected barrier and (2) forces created by emplacing piping for chemical injection adjacent to the tanks may compromise their integrities.

The durability and quality of the chemical barriers are assumed to be inadequate for effective long-term containment of highly mobile contaminants such as nitrates and ${ }^{99} \mathrm{Tc}$. As discussed in Section 8, diffusion appears to be a significant mechanism in controlling transport of contaminants in the vadose zone when an effective surface barrier is used to minimize recharge. The effective diffusivity of the barrier is expected to be similar to that of soil. Thus, the barrier would have little impact in limiting the diffusive transport of mobile contaminants over the long term.

\subsubsection{Box-Shaped Chemical Barrier}

The function of the box-shaped chemical barrier would be to create a low-permeability basin beneath the level of existing soil contamination (Figure 4-6). The base of this standoff barrier would slope slightly to promote runoff to a low point for collection. Without the slope, liquid waste would collect in subsurface depressions on the surface of the barrier. The resulting ponds of waste could not readily be detected. The potentially high number of ponds 
WHC-SD-WM-ES-300 REV. 1

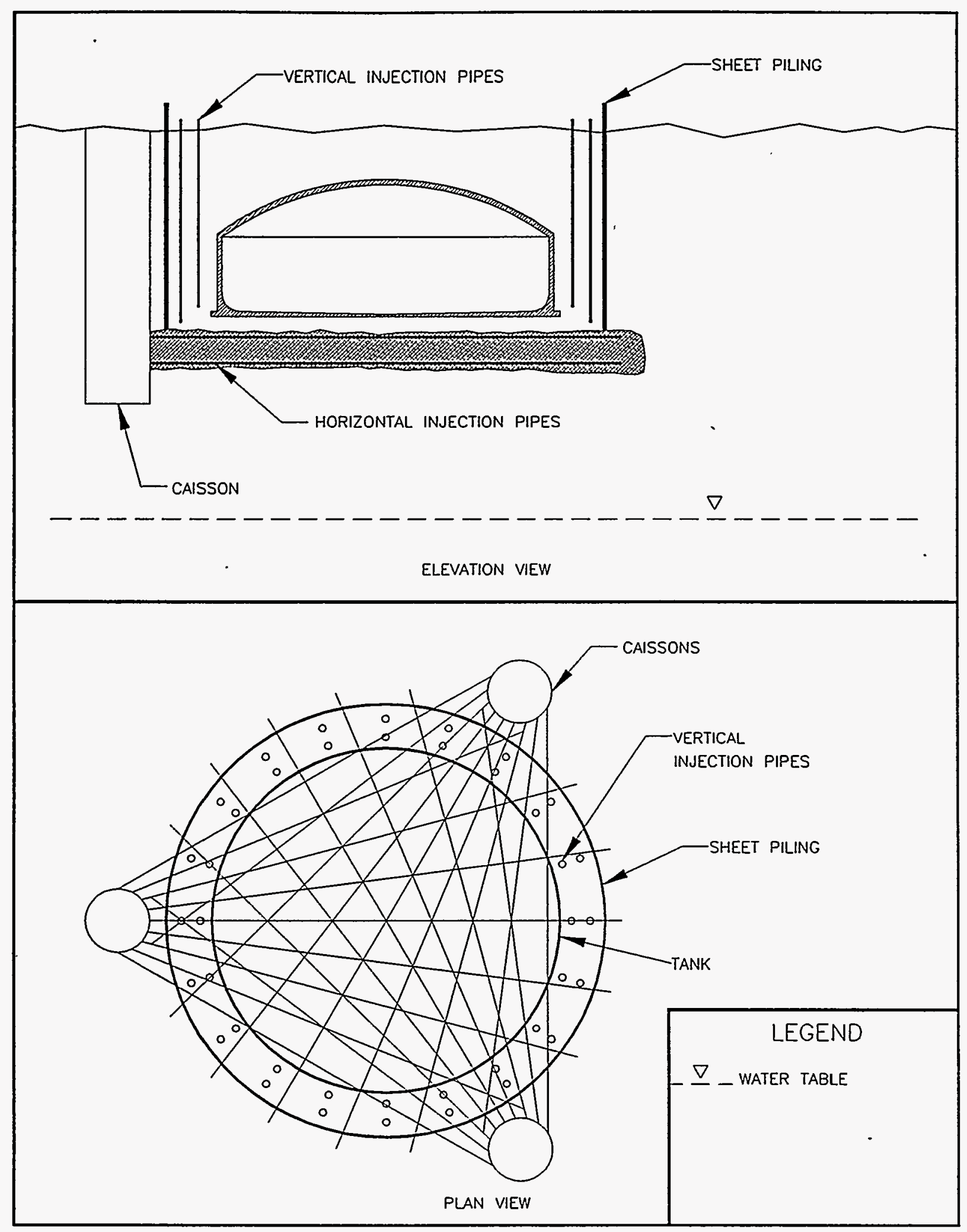

Figure 4-5. Chemical Injection Piping for Close-Coupled Barrier. 
WHC-SD-WM-ES-300 REV. 1

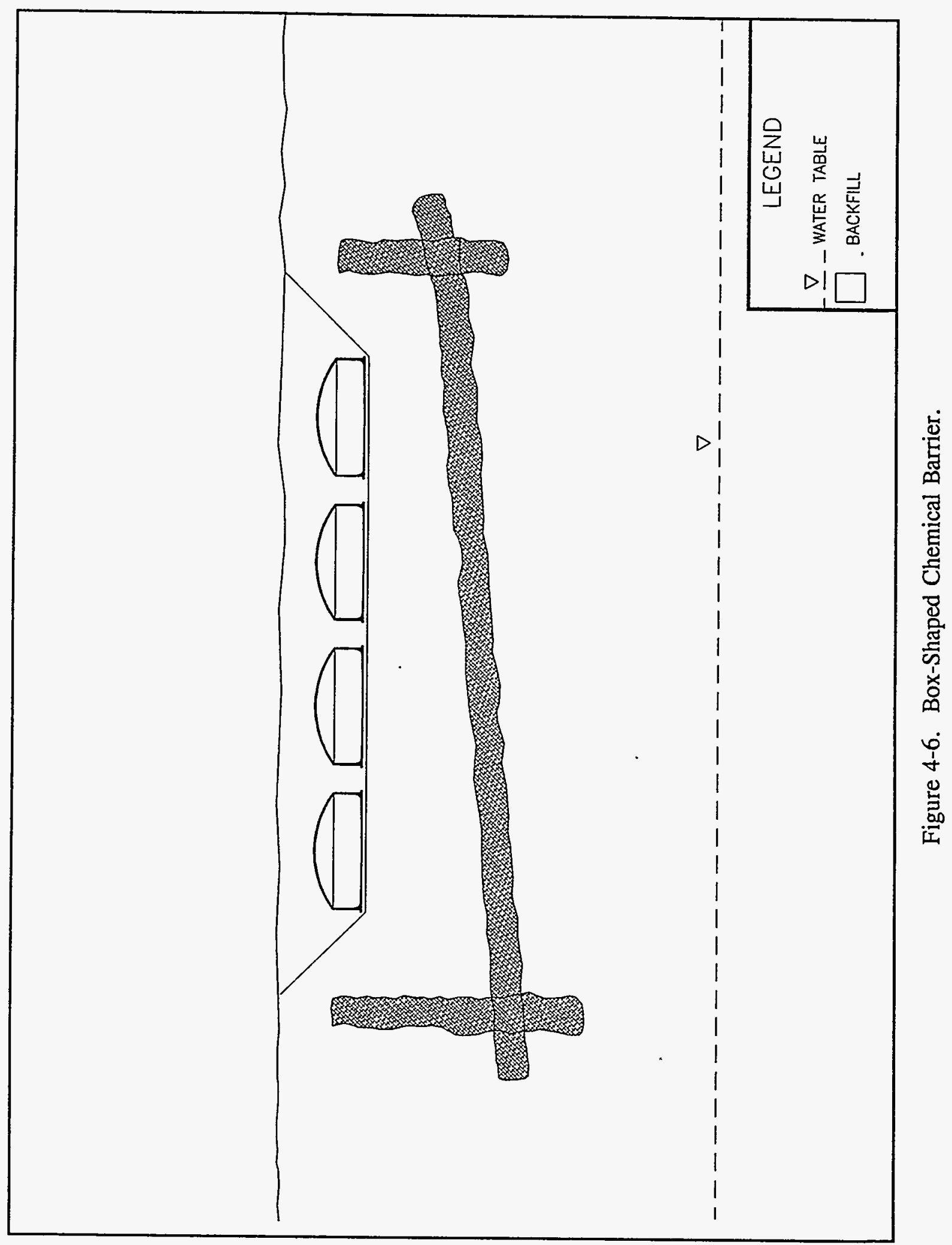


would complicate removal of collected liquid waste.

The box-shaped chemical barrier would be created using both vertical and directional drilling techniques. The use of directional drilling avoids the need to excavate soil to a depth of $30.5 \mathrm{~m}(100 \mathrm{ft})$ or more in order to provide access for horizontal drilling beneath existing leak plumes. Directional drilling must be perfected for Hanford Site conditions if parallel horizontal boreholes are to be constructed beneath the Hanford Site tank farms (KEH 1993a). This type of drilling would begin outside the boundary of the tank farm, with the initial drill angle at $45^{\circ}$ to $70^{\circ}$ from vertical. As drilling progresses, the borehole would be gradually curved until the desired slope of the barrier floor is achieved. Mudless drilling methods must be used to prevent plugging of the soil pores with fine particulates. Soil pores that are plugged would prevent flow of barrier-forming chemicals into the soil.

Each borehole would be cased with an open-ended pipe. The barrier-forming chemicals would be injected through the end of the pipe as it is withdrawn from the hole.

Alternatively, the chemicals could be delivered through sleeve-port piping. A cylindrical barrier section, centered around each borehole, would be created by each of these methods, assuming the barrier-forming chemicals flowed evenly into the ground. The presence of lenses, clastic dikes, and other soil heterogeneities would cause uneven flow. The boreholes would be sufficiently close to ensure that the cylinders would overlap and form a continuous barrier floor. The boreholes were assumed to be spaced $3.1 \mathrm{~m}(10 \mathrm{ft})$ apart, a distance that

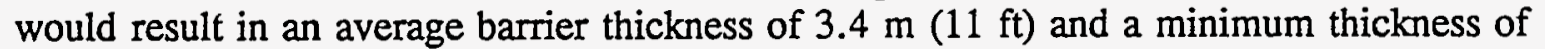

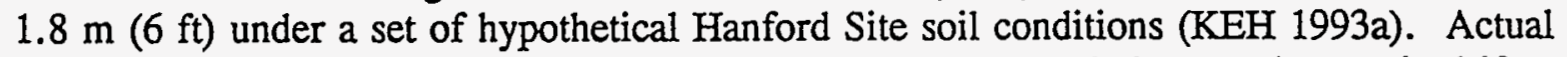
Hanford Site soils are heterogeneous and closer spacing of boreholes may be required if zones of soils with low permeabilities are present as expected in some tank farms. Low permeability would limit the penetration distance of chemicals in the soil.

After the horizontal member of the barrier is formed, vertical boreholes would be drilled and cased to intersect the horizontal member. The vertical casings would be withdrawn as injection of the chemical proceeds. The resultant vertical members of the barriers are assumed to adequately seal to the horizontal member, thus creating a catchment basin for tank leaks and/or for flush water if soil flushing is used.

The primary advantages of the box-shaped chemical barrier are: (1) only one barrier system would be needed for each tank farm rather than one for each tank or leaking tank, (2) drilling to emplace the barrier-forming chemicals would not occur in contaminated soils, and (3) existing leaks would be contained and prevented from migrating to the groundwater. The primary disadvantages are: (1) long directional drill lengths would be required with little tolerance for directional deviation, and (2) the standoff barrier would not prevent or minimize new leaks.

\subsubsection{V-Shaped Chemical Barrier}

The V-shaped chemical barrier would be installed in a standoff configuration as shown in Figure 4-7. The relatively steep slope of the barrier would promote subsurface runoff of 
WHC-SD-WM-ES-300 REV. 1

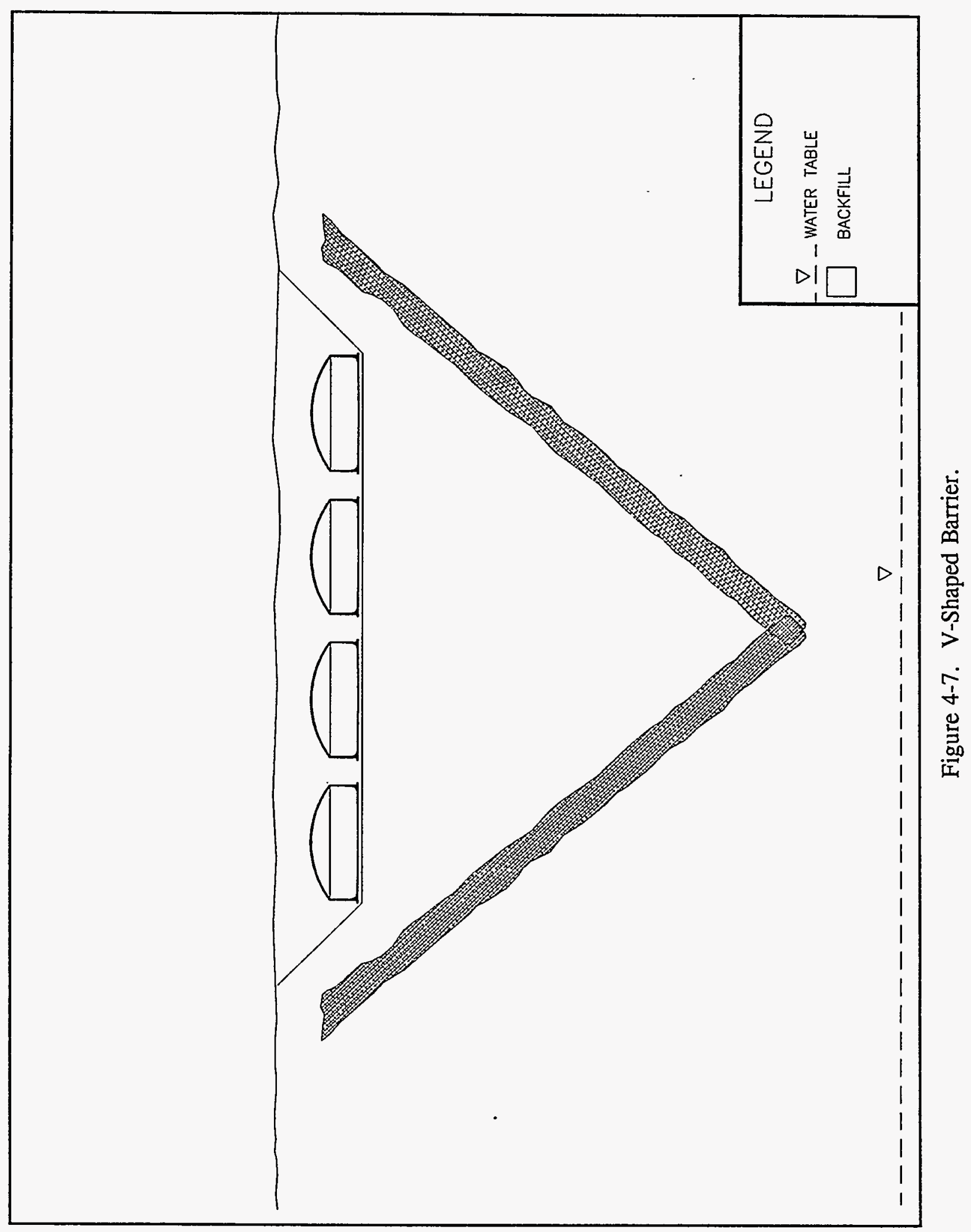


leaked liquid waste or flush water to the base of the barrier where it could be removed by pumping. The angled boreholes required to form the " $\mathrm{V}$ " would be created by slant drilling, a technology that has been demonstrated at the Hanford Site. The ends of the barrier not shown in Figure 4-7 would be vertical. Vertical drilling techniques that do not require drilling muds, such as sonic drilling, are required to form the vertical boreholes for injecting the barrier-forming chemical. The barrier would be formed by injecting chemicals in each borehole at the base of the casing while the casing is being withdrawn.

The primary advantages of the V-shaped chemical barrier are: (1) only one barrier system would be needed for each tank farm rather than one for each tank or leaking tank, (2) drilling to emplace the barrier-forming chemicals would not occur in contaminated soils, and (3) leaks would be contained and prevented from migrating to the groundwater. The straight drilling techniques employed in this technology would be more likely to achieve the hole-alignment objectives needed to ensure a continuously formed barrier than would the directional drilling techniques that would be used to emplace a box-shaped chemical barrier. The primary disadvantages are: (1) long directional drill lengths would be required with little tolerance for directional deviation, and (2) the standoff barrier would not prevent or minimize new leaks.

\subsubsection{V-Shaped Freeze Wall Barrier}

The V-shaped freeze wall barrier would be formed from ice instead of chemicals. The barrier would be constructed to the same drilled dimensions and with the same drilling technology used to create the V-shaped chemical barrier. If needed, drilling muds would be used to help fill the voids in highly permeable soil formations. The nondraining water contained in the drilling muds would help ensure that ice fills the soil pores.

In the freeze wall barrier design, freeze pipes would be installed in a V-shaped configuration around and beneath the tanks. Each freeze pipe would include an internal pipe. Coolant would be pumped down the inside pipe and returned through the annulus. The coolant is assumed to be a salt brine cooled to -15 to $-25{ }^{\circ} \mathrm{C}$ using a refrigeration system at the surface (KEH 1993a). The addition of water to the soil may be required during freezing if the natural water content of the soil is insufficient to form an effective barrier.

The primary advantage of this type of barrier is the potential ability to detect and repair leaks and other flaws in the barrier. Flaws may be detectable by monitoring temperature and pressure within the space occupied by the barrier. Additional piping would be required to enable detection and repair of flaws. The primary disadvantages are the active nature of the barrier system and its high maintenance requirements. The chemical barriers, in contrast, are passive and require little or no maintenance. Another disadvantage of the freeze wall technology is the need for additional development of methods for adding water to highly conductive Hanford Site soils. 


\subsubsection{Circulating Air Barrier}

A circulating air barrier would rely on evaporation of water from the soil, thereby limiting the ability of a leak to migrate through the vadose zone. The circulating air barrier would use circulation of warm dry air through the soil to remove the moisture from the soil (Figure 4-8). Leaked liquids will not readily flow through dried soil until the moisture level of the soil reaches its critical liquid saturation point (KEH 1993a). The critical saturation point depends on the physical properties of the soil. This point may exceed $30 \%$ by volume water for fine-grained soils and may be less than $2 \%$ by volume water for gravels. The critical saturation point for Hanford Site soils ranges from about $5 \%$ to $25 \%$ due to the heterogenous nature of the soils. Thus, the dried soil will vary in capacity to absorb leaked waste.

The flow of dry air through the soil while a leak is occurring would also dehydrate the leaked waste by evaporation of water. As evaporation proceeds, the solubility limits of dissolved constituents would eventually be exceeded and precipitates would form in the soil pores. The precipitates may be effective in blocking additional flow.

The circulating air barrier would be created by injecting warm dry air through an array of vertical boreholes drilled between tanks. The lower end of the pipe casing in each hole would be perforated or screened. Air would flow through the perforations, into the soil, and then into perforated extraction pipes. The extracted air would be treated to remove water, volatile organics, and entrained particulates and would then be reinjected.

The integrity of the circulating air barrier would be inferred by measuring the humidity of the extracted air. A sufficiently low humidity would indicate that the soil is dry enough to absorb a design-basis leak. Well pressures and injected air flow rates would provide other indications of the integrity of the barrier. Dry wells may also be installed under tanks using slant drilling as a means of obtaining pressure, temperature, and humidity data at points between the injection and extraction wells. The loss of injected air through highly permeable soil to the surface of the ground could be minimized by capping the tank farm area with an impermeable plastic membrane or layer of clay.

The primary advantages of the circulating air barrier are: (1) the technology is relatively simple and (2) it would limit the spread of leakage and possibly the volume of contaminated soil. The disadvantages are: (1) contaminated water may be recovered in the extracted air dehydration system, (2) contaminated water would require treatment and disposal, and (3) the circulating air barrier, like the three standoff barriers previously discussed, would not prevent new leakage.

\subsection{SOL FLUSHING}

Soil flushing is an in situ remedial technology that may be effective for cleaning contaminated soil that has resulted from SST leaks. It also may support tank waste retrieval when a close-coupled barrier is used, by removing soil contamination prior to emplacement 
WHC-SD-WM-ES-300 REV. 1

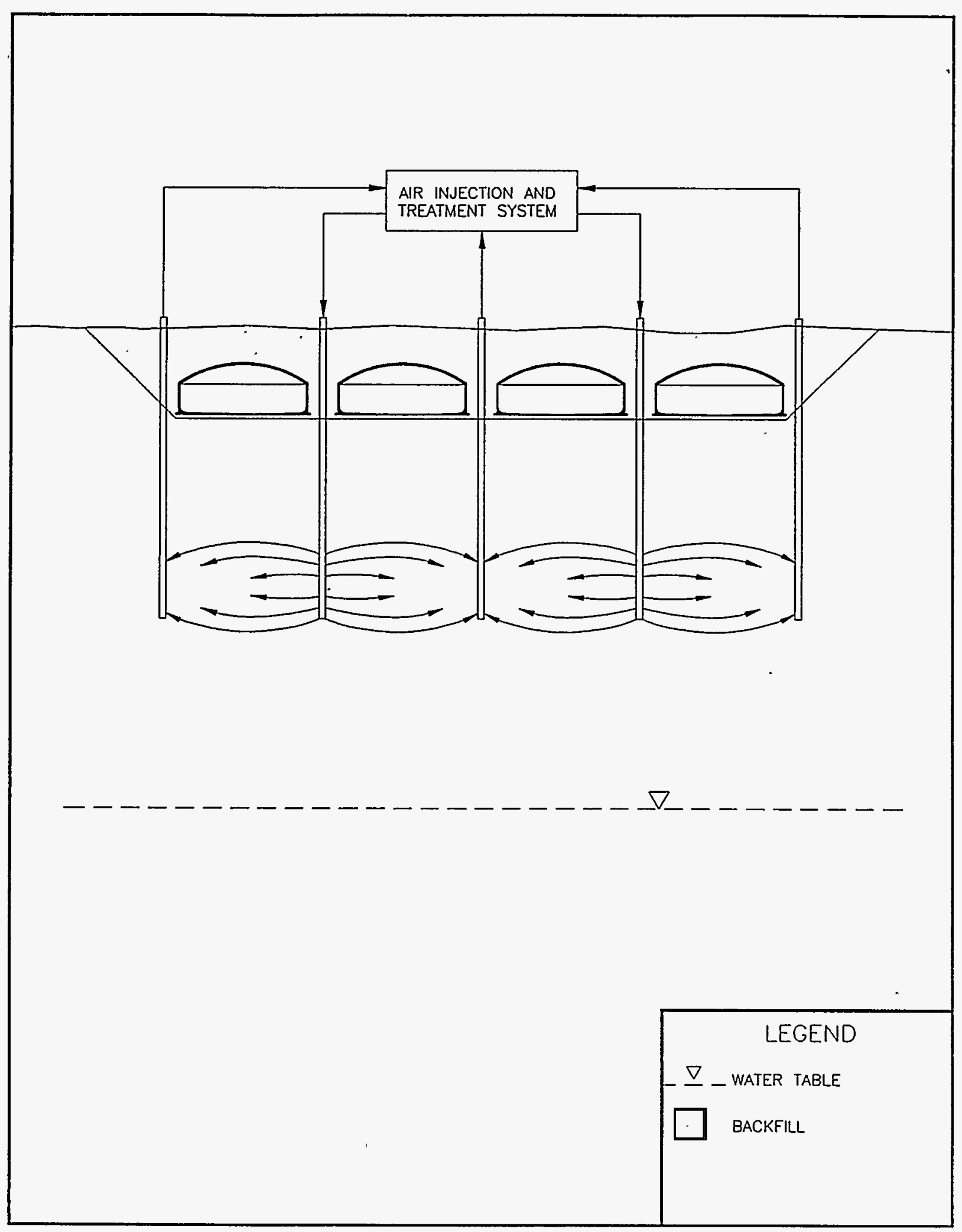

Figure 4-8. Circulating Air Barrier. 
of the barrier. Soil flushing may be used to extract contaminants from soil using water or other flush solutions that solubilize and mobilize the contaminants. A related technology, soil washing, treats contaminated soil that has been excavated from a site. The primary attractiveness of soil flushing is that it eliminates the need for excavation.

Soil flushing consists of injecting a flushing solution into the soil-waste matrix and then collecting the leachate after it has passed through the matrix. The resulting leachate must be treated to remove the chemicals that have been extracted. A variety of methods that can be used for delivery and recovery of the flush solution exist. Selection of the most appropriate method is based primarily on the hydraulic conductivity of the soil.

The relatively permeable nature of the Hanford formation is conducive to soil flushing at the Hanford Site. This permeability, coupled with the high cation exchange capacity of Hanford Site soils and moderate water storage capacity of the vadose zone, led to the historic use of the soil column for disposal of large volumes of slightly contaminated wastewater to the ground via ponds, cribs, and trenches.

An important factor that determines how easily a chemical can be removed from the soil by flushing is the distribution coefficient $\left(\mathrm{K}_{d}\right)$. The $\mathrm{K}_{d}$ is a measure of the ratio of the concentration of a contaminant in the liquid phase of a liquid-solid system to the solid phase concentration at equilibrium. Contaminated soils exhibiting a high $\mathrm{K}_{\mathrm{d}}$ are difficult to clean because very large volumes of flush solution are required to displace contaminants from the soil.

Each of the constituents of concern (COCs) in this study was assumed to feature a $\mathrm{K}_{\mathrm{d}}=0$. These constituents include ${ }^{99} \mathrm{Tc},{ }^{14} \mathrm{C},{ }^{129} \mathrm{I},{ }^{238} \mathrm{U}$, nitrate, nitrite, tributyl phosphate (TBP), and ethylenediaminetetraacetic acid (EDTA). The assumption, $\mathrm{K}_{\mathrm{d}}=0$ for each of these constituents, may be somewhat nonconservative. Some species, such as uranium, may form less soluble and less mobile mineral species over time, for example. The mobility of ${ }^{14} \mathrm{C}$ may also be reduced by isotopic substitution with native carbonate salts in the soil. At $\mathrm{K}_{\mathrm{d}}=0$, these constituents will be associated with the aqueous phase. Cleaning the Hanford Site soil by soil flushing would theoretically be a matter of displacing the residual moisture held in the soil capillaries. The theoretical amount of water required to displace the nonsorbing residual contaminated moisture is one soil pore volume under saturated conditions.

Channeling of flushing water will occur in heterogenous soils, such as those that exist at the Hanford Site, due to the presence of zones of varying hydraulic conductivities. Channeling will reduce the effectiveness of soil flushing. Moreover, some contaminants will have diffused into the pores of larger soil particles and rocks over time. This pore solution would not be displaced by advecting flushing water; affected contaminants must enter the advecting stream by the slow process of diffusion. These conditions render soil flushing less effective than predicted by theory. Thus, a minimum of several pore volume flushes are usually necessary to meet cleanup goals, even when the contaminants are not sorbed to the soil. 
Two different methods of applying soil flushing were considered in this study: (1) traditional soil flushing and (2) soil flushing with vacuum recovery. A method of treating the recovered flush water is also described.

\subsubsection{Traditional Soil Flushing}

Traditional soil flushing employs established pump and treat technology. Flush water would be distributed to the soil via pipes inserted into the ground near the base of tanks (Figure 49). Flush water could also be added to tanks to aid in flushing the leak pathways. Flushing the leak pathways may not be effective if a small crack size or plug limits flow of flush solution from the tank to the soil or if the flush solution follows different pathways to the soil than did the original leak. Contaminants would be flushed to subsurface collection basins created by the installation of standoff subsurface barriers. The collected flush solution would be pumped to the ground surface for removal of contaminants and recycled.

\subsubsection{Vacuum Soil Flushing}

Vacuum soil flushing would involve the injection of flush water into the soil at the periphery and under the base of the tanks where leaks are likely to have occurred (Figure 4-9). Flush water could also be added to the tanks to flush the original leak pathways. The flush water would be removed by vacuuming it from the soil as it migrates through the contaminated zone created by the leak. Injection and vacuum removal of flush water would be accomplished through the use of perforated and porous pipes. The action of removing water from saturated and nearly saturated soil near the porous vacuum pipes would induce the flow of water into the dewatered area by wicking. The porous pipes would be segmented to avoid the preferential extraction of excess air. Each pipe segment could be isolated from the vacuum when low flush water recovery rates are indicated. Recovered flush solution would be collected in a vessel and subsequently pumped to the ground surface for treatment and recycling.

This technology would be most applicable to alternatives that employ close-coupled and circulating air barriers. Otherwise, the used flush water must be recovered by pumping after it collects in the aquifer. The concept would not be effective in highly conductive soils because of their low ability to wick water.

\subsubsection{Flush Water Treatment}

Flush water recovered from the application of soil flushing would require treatment to enable its reuse for flushing. It was assumed that $99 \%$ of the contaminants in the recovered flush water must be removed. This level of removal is necessary for the recycle water to be effective for meeting an assumed objective of flushing $94 \%$ of the contaminants from the soil, as discussed in Section 6. This flushing removal efficiency is based on the assumption 
WHC-SD-WM-ES-300 REV. 1

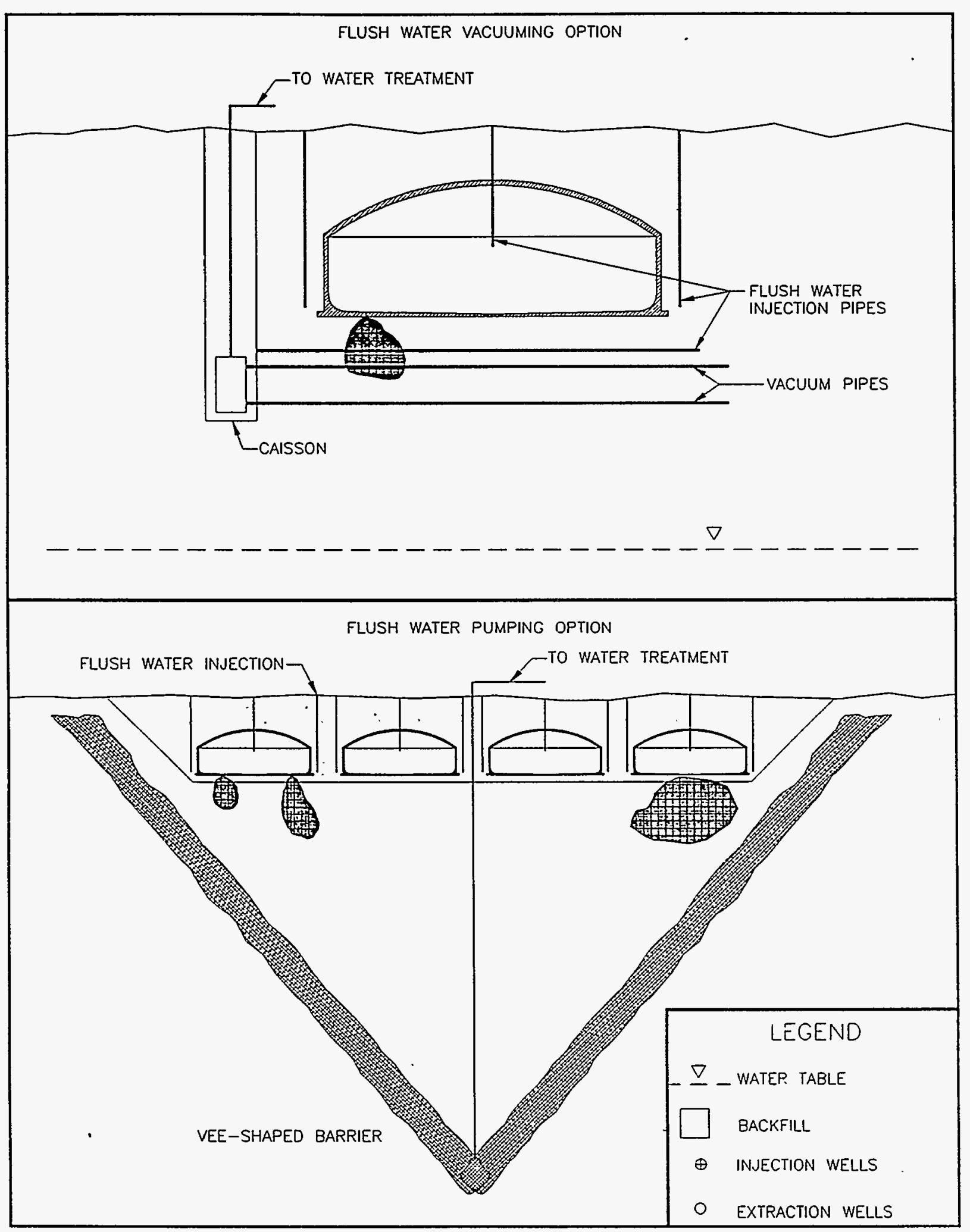

Figure 4-9. Traditional and Vacuum Soil Flushing. 
that each of four pore volume flushes removes $50 \%$ of the contamination in the soil remaining after the preceding flush. Ellis and Payne (1984) reported a laboratory test in which $98 \%$ of a nonsorbing species was removed using three pore volume flushes.

The recovered contaminants would exist as organic, anionic, and particulate species. A limited quantity of cationic contaminants would be recovered due to their low mobilities in Hanford Site soils. The treatment system would be designed for removal and destruction of organic species and for solidification of the concentrated wastes for disposal.

The selection of an optimized wastewater treatment system requires evaluation of many potentially effective technologies in different process configurations. Consideration of regulatory requirements regarding the injection of treated water containing residual contaminants to the soil column is also required. A detailed evaluation of wastewater treatment options for this waste stream is beyond the scope of this study's focus on the feasibility of subsurface barriers. Thus, a low-radioactive liquid effluent treatment facility evaluated by Boomer et al. (1993) is assumed to be appropriate for treating the flush water. A more rigorous analysis of the treatment needs may indicate that a less-complex and expensive treatment facility would suffice.

The conceptual treatment facility evaluated by Boomer et al. (1993) is known as the Liquid Effluent Purification for Recycle or Discharge Facility. The conceptual treatment facility would include four primary unit operations: (1) evaporation of liquid effluent, (2) organic destruction, (3) microfiltration, and (4) reverse osmosis.

Evaporation of the liquid effluent is the first step in this process. The condensed overheads would contain only $0.1 \%$ of the anions and particulate matter of concern, but most of the organics (Boomer et al. 1993). The organics in this stream would be destroyed in the second step using supercritical water oxidation. This technology would employ high pressure and temperature to ensure destruction of $>99 \%$ of the organic fraction. Step three, microfiltration, would use a pneumatic hydropulse filter to remove suspended particulates. Reverse osmosis would be used as a final water cleanup step. Final retentate from this unit operation would be recycled to the evaporator.

\subsection{TANK CLOSURE}

It is assumed that the SSTs would be closed as landfills or clean-closed under RCRA and the Dangerous Waste Regulations of the State of Washington (WAC 173-303) following completion of all waste retrieval activities. Closure as a landfill would include adding grout to the empty tanks to physically stabilize them and then constructing a surface barrier over the stabilized tanks. The goal of this closure approach is.intended to provide long-term, lowmaintenance protection of residual waste from the dispersive effects of environmental processes. 
Clean-closure would include removal of all residual wastes, tank structures, appurtenances, and contaminated soils to meet cleanup objectives. These objectives are assumed to conform to the cleanup regulations of the Washington State Model Toxics Control Act. Removal of tank-related wastes would be accomplished using an enclosed mining operation.

\subsubsection{Grout Stabilization}

The void space in SSTs following waste retrieval would be stabilized with grout. The groutfilled SSTs would serve as load-bearing structures for closure barriers installed over the tanks. Empty tanks would be subject to deterioration and eventual collapse. The collapse of the SSTs and barriers would cause residual waste in the tanks to be exposed to the environment. Structural stabilization of the SSTs by filling them with grout would ensure against their collapse, but it would not ensure that residual contaminants left in the tank would be immobilized (Figure 4-10).

The grout-fill technology that would be used for stabilizing the SSTs is based on established commercial techniques employed in the construction and mining industries. Grout-fill operations would displace vapor and radioactive dust from the empty tanks; a portable ventilation system would be installed to control air emissions.

Grout stabilization would begin with SST preparation and the installation of grout distributors on tank risers. If risers are not available or are unsuitable, new risers would be installed. With the distributors installed, the dedicated piping would be assembled and a connection made to a grout slurry plant centrally located within a tank farm.

The grout slurry plant would receive dry materials mixed at a batch plant located conveniently to serve all of the SST farms. The batch plant would receive the dry components of the grout and mix them in correct proportions. The dry mixture would be transported to the grout slurry plant via haulers on existing roadways.

The grout slurry would be mixed and then pumped through the dedicated piping to the distributors located on tank risers. The grout would be poured in layers if needed to optimize the grout curing process. Self-leveling grout would likely be used in the SSTs.

A typical tank would be filled with grout in approximately two weeks of continuous pumping. The fill monitoring system would include the capability to visualize interior tank operations. Density and compressive strength measurements would be made as indicators of the integrity of hardened grout.

At the conclusion of the fill operations, the distributors and feed hardware would be relocated or disposed, and the tank openings would be sealed with concrete. Tank contents would be monitored as needed and the tank site would be secured pending installation of the surface barrier. 


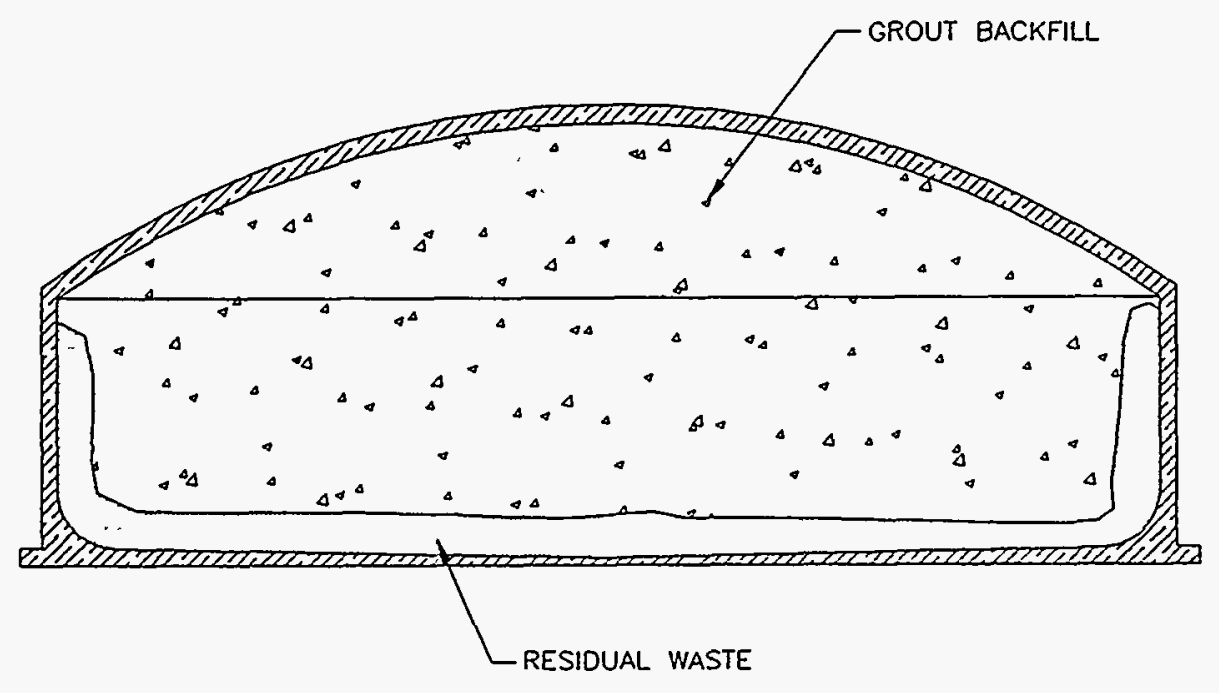

LEGEND

Figure 4-10. .Tank Stabilized with Grout Following Waste Retrieval. 


\subsubsection{Permanent Isolation Surface Barrier}

It is assumed that a Permanent Isolation Surface Barrier would be installed over an entire SST farm following waste retrieval and tank stabilization activities. The Operations and Engineering Contractor for the DOE's Hanford Site, Westinghouse Hanford Company, and DOE's Research and Development Contractor for the Hanford Site, Pacific Northwest Laboratory, are jointly developing and testing the Permanent Isolation Surface Barrier for Hanford Site applications. This barrier would serve to minimize water infiltration, plant and animal intrusion, wind and water erosion, human interference, and gaseous releases. A more rigorous study of risks, level of compliance with regulatory requirements, and cost-benefit associated with other surface barrier options may show that others also have merit in this application.

Existing short-term barrier designs currently are available (EPA 1982, 1990). In general, the design life of these barriers is for relatively short periods such as the 30-year post-closure period specified by RCRA. The performance of barriers during this relatively short period can be monitored, and maintenance activities can be performed to correct any problems that might be encountered. However, it may be desirable to isolate residual SST wastes for much longer than the 30-year post-closure period, perhaps for a millennium or longer.

Preliminary performance objectives that have been established for the Permanent Isolation Surface Barrier include:

- Function in a semiarid-to-subhumid climate

- Limit the recharge of water through the waste to the water table to $\leq 0.05 \mathrm{~cm} / \mathrm{yr}$ $(0.02 \mathrm{in} / \mathrm{yr})$

- Be maintenance-free

- Minimize the likelihood of plant, animal, and human intrusion

- Isolate contaminants for a minimum of 1,000 years

- Minimize erosion-related problems

- Meet or exceed RCRA cover performance requirements

- Limit the exhalation of noxious gases

- Meet regulatory requirements and be publicly acceptable.

The protective surface barrier design (Figure 4-11) would consist of a fine-soil layer overlying other layers of coarser materials such as sands, gravels, and basalt riprap (Wing 1993). Each of these layers would serve a distinct purpose. The fine-soil layer would act as 


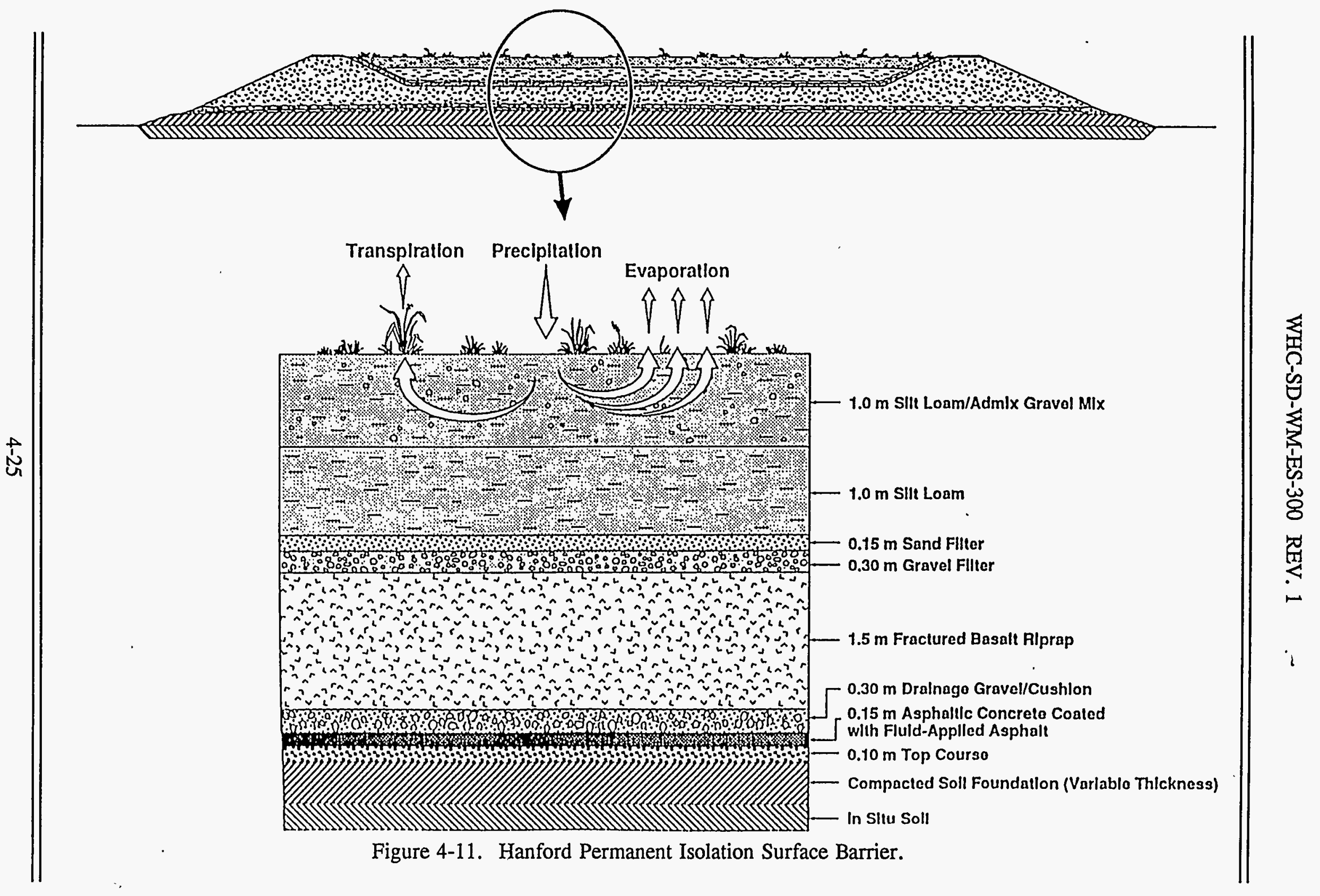


a medium in which moisture is stored until the processes of evaporation and transpiration recycle it back to the atmosphere. The fine-soil layer would also provide the medium for establishing plants that are necessary for transpiration to take place.

The coarser materials placed directly below the fine-soil layer would create a capillary break that inhibits the downward infiltration of water through the barrier. The placement of the silt loam over the coarser materials would also create an environment that encourages plants and animals to limit their natural biological activities to the upper, fine-soil portion of the barrier, thereby reducing biointrusion into the lower layers. The coarser materials also would help to deter inadvertent human intruders from digging deeper into the barrier profile.

Low-permeability layers, placed in the barrier profile below the capillary break, would also be used in the protective barriers. The purposes of the low-permeability layers are (1) to divert away from the waste zone any infiltrating water that passes through the capillary break and (2) to limit the upward movement of noxious gases from the waste zone. The coarse materials located above the low-permeability layers would also serve as drainage media to channel any infiltrating water to the edges of the barrier.

\subsubsection{Confined Demolition/Mining System}

Clean-closure of the hypothetical tank farm would include removal of contaminated tank structures and soils following retrieval of wastes from the tanks. Facilities required to support this removal action would subsequently be decontaminated, decommissioned, and removed, and the site backfilled with clean soil. Few restrictions would be placed on the use of land formerly occupied by the tank farm.

Contaminated residual tank waste, waste resulting from the demolition of tanks, and contaminated soil would be washed in acid and water to remove a high fraction of the COCs. The recovered constituents would be concentrated and processed in the primary tank waste pretreatment system. The washed concrete, steel, and soil would be disposed onsite in a permitted landfill. Most of this waste would be disposed in burial boxes. Some of the boxes would require handling by remote techniques. Facilities used to provide containment of the various tank waste removal actions would be demolished and disposed in a bulk radioactive waste landfill.

Tank waste removal actions would be conducted within the confines of a truss-supported facility that would cover an entire tank farm (Figure 4-12). A movable bridge that spans the width of a tank farm would be the largest structure within the confinement facility. The bridge would support a high-capacity bridge crane with capability to access the entire area

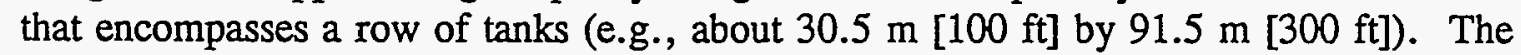
bridge crane would be equipped to use various demolition and retrieval tools, including drills, expanders, shears, cutting torches, and clam-shell buckets. Some of this equipment would be supported by the crane; others would be initially positioned by the crane and independently powered. 
WHC-SD-WM-ES-300 REV. 1

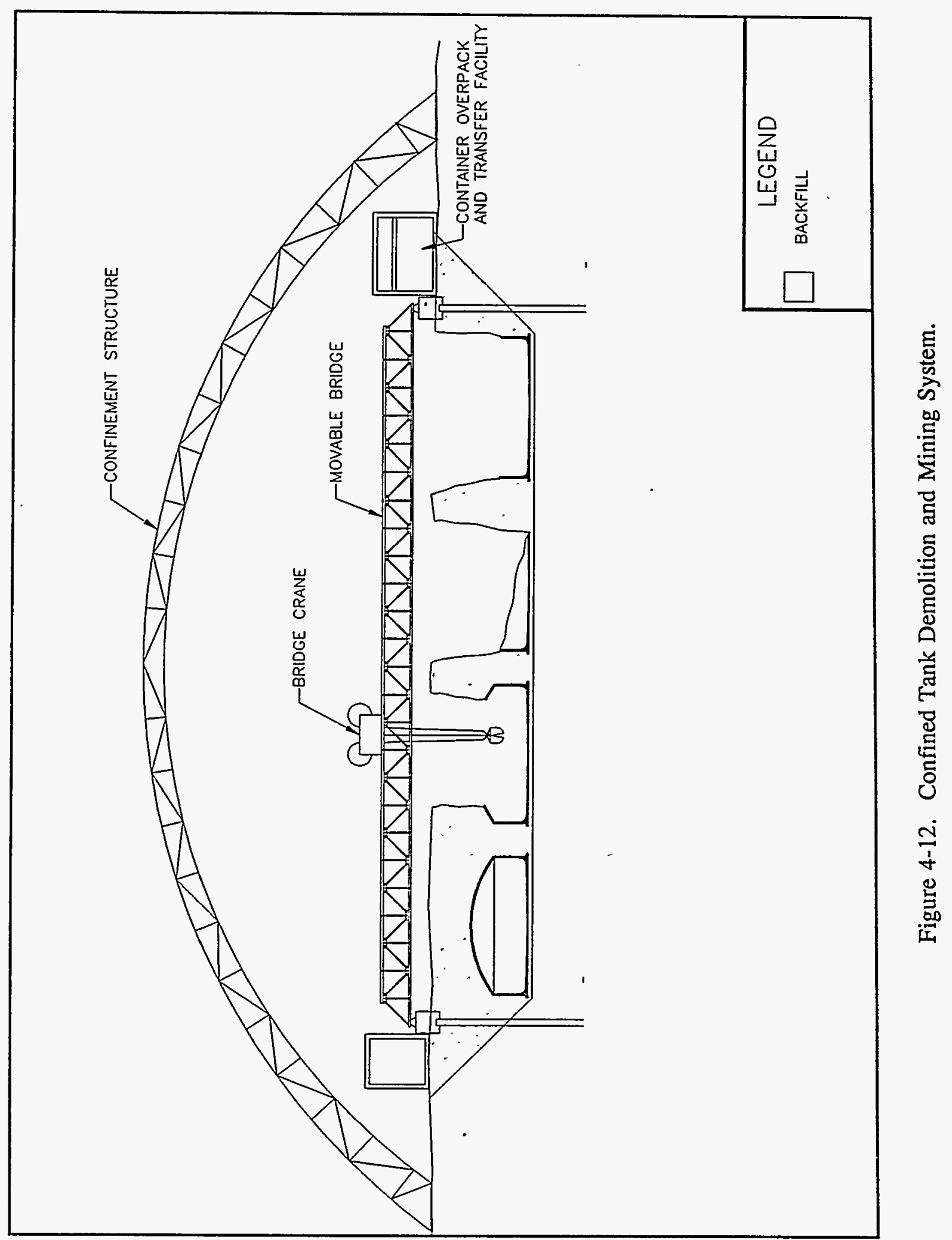


The retrieved waste, debris, and failed equipment would be placed in $38-\mathrm{m}^{3}\left(50-y \mathrm{~d}^{3}\right)$ capacity boxes, overpacked, and hauled in shielded transporters to a decontamination and wash facility. The boxes, overpacks, and repaired equipment would be returned to the tank farm confinement facility for reuse. The confinement facility would also house a shielded facility where boxed waste would be overpacked and loaded out to the transporters. The shielded facility would also receive returned boxes and overpacks, and be capable of decontaminating overpacks. This would necessitate the use of a small, thin-film evaporator for recycling water used for decontamination.

Other important supporting equipment would include shielded crane maintenance facilities, one at each end of the bridge, and an air filtration facility including roughing filters, high efficiency particulate air filters, blowers, and a stack. 


\subsection{OVERALL SYSTEM ALTERNATIVES}

This section describes alternatives that serve as bases for cost and risk analyses in subsequent sections. Unit technologies and concepts described in the previous sections were combined selectively into 14 alternatives. The alternatives were chosen to enable evaluation of a representative range of different retrieval methods, types of subsurface barriers, soil flushing methods, and use of tank stabilization and surface barriers as parts of an overall tank cleanout and closure strategy. The evaluation does not address treatment and disposal of the retrieved tank waste, except where the quantity of overall waste recovered is more or less than assumed for a baseline alternative. Cost adjustments are made in those cases.

The 14 alternatives are distinguished principally according to the absence or presence of the five types of subsurface barriers presented in the previous section. Alternatives 1 and 2 are no-action and minimal-action options presented solely as bases for comparison. Alternatives 3 through 5 include different retrieval technologies, but no subsurface barrier. Alternatives 6 through 8 include close-coupled chemical barriers. Alternatives 9 through 11 involve standoff barriers and Alternative 12 includes a circulating air barrier. Alternatives 13 and 14 are clean-closure alternatives; the latter includes a close-coupled barrier.

This section contains brief descriptions of the 14 alternatives. It also contains a summary of the key assumptions and other bases used for assessment of risk and cost. The primary features of each alternative are summarized in Table 5-1.

\subsection{DESCRIPTION OF ALTERNATIVES}

(1) No-Action Alternative. This alternative involves no action, as the name implies. It is included as a basis for comparing the benefits of other alternatives in reducing risk. The relative risks of the No-Action Alternative and other alternatives analyzed in this study include only those that would result through the groundwater pathway. Severe environmental risks would result from this alternative when tank roofs deteriorate and collapse, exposing the environment to high levels of radiation.

(2) Surface Barrier Only Alternative. This alternative is the same as the NoAction Alternative, but includes a Hanford Permanent Isolation Surface Barrier installed over the tanks. The surface barrier would slow and reduce the contaminant flux from the tanks, thereby increasing the time the contaminant plume from the tanks would reach the groundwater and reducing the peak concentration of contaminants in the groundwater. All alternatives except for the No-Action Alternative and the two clean-closure alternatives employ this surface barrier over the tanks. 
Table 5-1. Summary of Alternatives.

\begin{tabular}{|c|c|c|c|c|c|c|c|}
\hline Alternative & $\begin{array}{l}\text { Waste Retrieval } \\
\text { Type }\end{array}$ & $\begin{array}{c}\text { Assumed Tank } \\
\text { Waste Retrieval } \\
\text { Effectiveness }\end{array}$ & $\begin{array}{l}\text { Subsurface Bartier } \\
\text { Type }\end{array}$ & $\begin{array}{l}\text { Old Leaks } \\
\text { Flushed? }\end{array}$ & $\begin{array}{l}\text { New Leaks } \\
\text { Flushed? }\end{array}$ & $\begin{array}{c}\text { Tanks } \\
\text { Stabilized? }\end{array}$ & $\begin{array}{l}\text { Surface } \\
\text { Barrier } \\
\text { Used? }\end{array}$ \\
\hline 1. No Action & None & $0 \%$ & None & No & No & No & No \\
\hline 2. Surface Barrier Only & None & $0 \%$ & None & No & No & No & Yes \\
\hline $\begin{array}{l}\text { 3. Traditional Sluicing } \\
\text { (Baseline) }\end{array}$ & Traditional sluicing & $99 \%$ & None & No & No & Yes & Yes \\
\hline 4. Robotic Sluicing & Robotic sluicing & $99.9 \%$ & None & No & No & Yes & Yes \\
\hline 5. Mechanical Retrieval & $\begin{array}{l}\text { Mechanical } \\
\text { retrieval }\end{array}$ & $95 \%$ & None & No & No & Yes & Yes \\
\hline $\begin{array}{l}\text { 6. Close-Coupled Chemical Barrier } \\
\text { with Flushing }\end{array}$ & Traditional sluicing & $99 \%$ & Close-coupled & Yes & $\begin{array}{c}\text { Not } \\
\text { applicable }\end{array}$ & Yes & Yes \\
\hline $\begin{array}{l}\text { 7. Close-Coupled Chemical Barrier } \\
\text { w/o Flushing }\end{array}$ & Traditional sluicing & $99 \%$ & $\begin{array}{c}40 \% \text { None } \\
60 \% \text { close-coupled }\end{array}$ & No & No & Yes & Yes \\
\hline $\begin{array}{l}\text { 8. Modified Close-Coupled Chemical } \\
\text { Barrier w/o Flushing }\end{array}$ & Traditional sluicing & $99 \%$ & $\begin{array}{l}\text { Verical } \\
\text { close-coupled }\end{array}$ & No & No & Yes & Yes \\
\hline 9. Box-Shaped Chemical Barrier & Traditional sluicing & $99 \%$ & Box-shaped chemical & Yes & Yes & Yes & Yes \\
\hline 10. V-Shaped Chemical Barrier & Traditional sluicing & $99 \%$ & V-shaped chemical & Yes & Yes & Yes & Yes \\
\hline 11. V-Shaped Freeze Wall Barrier & Traditional sluicing & $99 \%$ & V-shaped freeze wall & Yes & Yes & Yes & Yes \\
\hline 12. Circulating Air Barrier & Traditional sluicing & $99 \%$ & Circulating air & Yes & Xes & Yes & Yes \\
\hline $\begin{array}{l}\text { 13. Clean-Closure w/o } \\
\text { Subsurface Barrier }\end{array}$ & Traditional sluicing & $100 \%$ & None & No & No & $\begin{array}{c}\text { Not } \\
\text { applicable }\end{array}$ & No \\
\hline $\begin{array}{l}\text { 14. Clean-Closure with } \\
\text { Close-Coupled Chemical Barrier }\end{array}$ & Traditional sluicing & $100 \%$ & $\begin{array}{l}40 \% \text { None } \\
60 \% \text { close-coupled }\end{array}$ & No & No & $\begin{array}{c}\text { Not } \\
\text { applicable }\end{array}$ & No \\
\hline
\end{tabular}


Like the No-Aiction Alternative, this alternative is included as a basis for comparison with the other alternatives. The Surface Barrier Only Alternative is not considered viable because deliquescence of the saltcake in the SSTs may create voids. This would eventually lead to collapse of the roofs of the tanks, destroying the effectiveness of the surface barrier and potentially exposing the environment to high levels of radiation. Filling of existing void space in the tanks with grout is not included to avoid the appearance that the Surface Barrier Only is a complete and viable alternative.

(3) Traditional Sluicing (Baseline) Alternative. This alternative would employ the use of traditional sluicing to remove an assumed $99 \%$ of the waste from the tanks (Boomer et al. 1993). Stabilization of the essentially empty tanks with grout and installation of a surface barrier over the tanks would also be included. This alternative would not include actions taken to prevent leakage from tanks nor to clean contaminated soil that resulted from old leaks and that would result from new leaks.

(4) Robotic Sluicing Altemative. This alternative would employ a robotic arm capable of positioning a low volumetric rate, high-pressure sluicing device at any location in the tank. The low volumetric flow rate would result in minimizing the liquid head in the tanks, thus reducing the level of leakage from the tanks. The high pressure water jets would be expected to be more effective than traditional sluicers in cutting through hardened sludge. Thus, retrieval of $99.9 \%$ of the waste in the tanks is assumed (Boomer et al. 1993). The tanks would be structurally stabilized and a surface barrier would be installed following retrieval operations.

(5) Mechanical Retrieval Alternative. This alternative would employ a robotic arm capable of positioning an excavating device within the tank. The wastes would be retrieved without the addition of water. The elimination of water for retrieval is assumed to eliminate the potential for new leaks. Mechanical retrieval is believed to be less effective than other retrieval options. This method is assumed to be capable of recovering $95 \%$ of the tank wastes (Boomer et al. 1993). The tanks would be stabilized and a surface barrier would be installed following retrieval operations.

(6) Close-Coupled Chemical Barrier with Flushing Alternative. This alternative would include soil flushing with vacuuming to remove contamination in the soil caused by old leaks. Water recovered from soil flushing operations would be treated and recycled. After flushing contaminated soil, a close-coupled chemical subsurface barrier would be installed in close contact with each tank's structural concrete. The close-coupled barrier would minimize new leakage while conducting traditional sluicing to retrieve tank wastes. The tanks would be stabilized and a surface barrier would be installed following retrieval operations. 
(7) Close-Coupled Chemical Barrier Without Flushing Alternative. This alternative would initially employ the close-coupled barrier around only those tanks declared to have leaked waste in the past. Traditional sluicing would be used to remove wastes from all SSTs. Thirty percent of the tanks without barriers are assumed to develop leaks during new sluicing operations. Sluicing operations would cease on detection of a leak and the liquid contents of the affected tanks would be pumped to other tanks without delay. Close-coupled barriers would subsequently be emplaced around the newly leaking tanks and traditional sluicing operations would be resumed. Soil flushing would not be used in this alternative. Grout stabilization and surface barriers would be used following waste retrieval.

(8) Modified Close-Coupled Barrier Without Flushing Alternative. This alternative would employ only the vertical component of the close-coupled barrier around all tanks. The intent of this alternative is to seal the construction joint between the vertical and horizontal concrete members of the tank structure where more than half of the leaks are assumed to occur. It is assumed that this strategy would result in preventing $60 \%$ of the leaks that would have occurred without the use of the barriers. Soil flushing would not be employed. Traditional sluicing, grout stabilization, and surface barriers would be used in this alternative.

(9) Box-Shaped Chemical Barrier Alternative. This alternative would include a box-shaped subsurface chemical barrier beneath the level of old leakage from the tanks. Traditional sluicing would be employed to retrieve tank wastes. Soil contamination resulting from old and new leaks would be flushed to a low point in the subsurface barrier. The collected flush water would be pumped to the surface for treatment and then recycled. The tanks would be closed by stabilizing them with grout and installing surface barriers over them.

(10) V-Shaped Chemical Barrier Alternative. This alternative is similar to the BoxShaped Chemical Barrier Alternative. The two alternatives differ in the barrier installation method and shape. The box-shaped barrier would be installed using directional drilling. The V-shaped barrier would employ angled drilling to create boreholes in the soil through which the barrier-forming chemicals would be injected. The shape of the V-barrier would result in the collection of contamination from leaks at a deeper level than in the case of the box-shaped barrier.

(11) V-Shaped Freeze Wall Barrier Alternative. This alternative would include a barrier of size and shape similar to that of the V-Shaped Chemical Barrier Alternative; however, ice would be the barrier-forming material in this alternative. An attractive feature of this alternative is the ability to melt the barrier from the upper side downward. This would enable flushing of 
contaminated soils occluded in the barrier with water while maintaining the integrity of the barrier. Traditional sluicing, grout stabilization, and surface barriers would also be used in this alternative.

(12) Circulating Air Barrier Alternative. This alternative would include a method of drying soil beneath the SSTs using warm dry air. The dry soil and flowing air would serve to evaporate water from leaks expected to occur during sluicing. This would result in minimizing the spread of leakage from the tanks.

Traditional sluicing, vacuum soil flushing, grout stabilization, and surface barriers would also be used in this alternative.

(13) Clean-Closure Without Subsurface Barrier Alternative. This alternative would employ traditional sluicing to recover $99 \%$ of the tank waste. All residual contamination in the tank, tank structures, and soil would then be retrieved using mechanical methods. Most of the COCs would be removed from the retrieved materials and either destroyed or disposed at a Federal high-level waste repository. The excavated site would be backfilled with clean soil after verifying that cleanup limits were achieved. Clean-closure would eliminate the need for grout stabilization and surface barriẹ at the tank waste site.

(14) Clean-Closure With Close-Coupled Chemical Barrier Alternative. This alternative is identical to Alternative 13 except that a close-coupled chemical barrier would be installed initially around only those tanks declared to have leaked in the past. Thirty percent of the tanks without barriers are assumed to develop leaks during new sluicing operations. Sluicing operations would cease on detection of a leak and the liquid contents would be pumped to other tanks without delay. Close-coupled chemical barriers subsequently would be installed around the newly leaking tanks and traditional sluicing operations would be resumed.

\subsection{KEY ASSUMOPTIONS}

The key bases and assumptions used for the comparative risk and cost analyses in Section 6 are summarized in this section. Rationale for these data are also presented in Section 6.

(1) The relative risk and cost analyses are based on a hypothetical tank farm containing twelve, $3.8 \times 10^{6}-\mathrm{L}$ (1-Mgal) SSTs (all alternatives).

(2) The eight constituents of primary concern in this study $\left({ }^{14} \mathrm{C},{ }^{99} \mathrm{Tc},{ }^{129} \mathrm{I},{ }^{238} \mathrm{U}\right.$, $\mathrm{NO}_{3}, \mathrm{NO}_{2}, \mathrm{TBP}$, and EDTA) are soluble with nitrate (i.e., they leach congruently with nitrate) and all feature $\mathrm{K}_{d}=0$ (all alternatives).

(3) The solubility of nitrate in tank waste is $360 \mathrm{~g} / \mathrm{L}(3 \mathrm{lb} / \mathrm{gal}$ ) (all alternatives). 
(4) Each hypothetical tank contains masses of COCs equal to the average of their masses in all 149 SSTs (all alternatives).

(5) Recharge of meteoric water is $5 \mathrm{~cm} / \mathrm{yr}(2 \mathrm{in} / \mathrm{yr})$ without a surface barrier (Alternative 1) and $0.05 \mathrm{~cm} / \mathrm{yr}(0.02 \mathrm{in} / \mathrm{yr})$ with the presence of the Hanford Permanent Isolation Barrier (Alternatives 2 through 12). Vadose zone water travel times of 190 and 19,000 years are estimated for these recharge rates.

(6) It is assumed that recharge water is not deflected by the tank dome to the sides of the tank because deterioration and cracking of the tank dome will allow the water to flow through the cracks and enter the space enclosed by the tank. Sufficient cracking will occur over the long time periods analyzed (30,000 years) to allow water to vertically penetrate into the tank space (Alternatives 1 through 12).

(7) Robotic sluicing (Alternative 4), traditional sluicing (Alternatives 3 and 6 through 14), and mechanical retrieval (Alternative 5) remove $99.9 \%, 99 \%$, and $95 \%$ of the tank wastes, respectively.

(8) The time required to achieve cleanout of a tank by traditional sluicing is 123 days (Alternatives 3 and 6 through 14).

(9) A small void space (averaging $1 \mathrm{~mm}$ [0.04 in.] thick) exists between the tank bottom and its concrete base (all alternatives).

(10) Five of the 12 tanks in the hypothetical tank farm have leaked waste in the past. Waste at interstitial liquid concentrations fills the void space described above in these cases and the same waste has also advected into the concrete (all alternatives).

(11) Waste that has advected into the concrete has done so over the 23-m (75-ft) diametric area of the tank base at an average head of $0.46 \mathrm{~m}(1.5 \mathrm{ft})$ for 15 years (all alternatives).

(12) The hydraulic conductivity and porosity of the concrete are $3.75 \times 10^{-10} \mathrm{~cm} / \mathrm{s}$ $\left(7.38 \times 10^{-10} \mathrm{ft} / \mathrm{min}\right.$ ) and 0.22 , respectively (all alternatives).

(13) The effective diffusivity of the concrete is $5 \times 10^{-8} \mathrm{~cm}^{2} / \mathrm{s}\left(8 \times 10^{-9} \mathrm{in}^{2} / \mathrm{s}\right)$; the moisture fraction is 0.15 (all alternatives).

(14) Advection dominates diffusion as the mechanism that drives contaminants into the concrete and into any chemical barrier (all alternatives). 
(15) Recharge water first dissolves residual tank waste, then quantitatively displaces waste between the tank and concrete base, and then leaches waste in the concrete. The concentration of concrete leachate is one-half the concentration in the waste in the void between the tank and concrete (Alternatives 1 through 12).

(16) Five of the 12 tanks have leaked an average of $41,600 \mathrm{~L}(11,000 \mathrm{gal})$ each to the soil (all alternatives). Leaked waste contains contaminants at one-half their concentrations in interstitial liquid (all alternatives). A total of five of 12 tanks will release new leaks to the soil during new sluicing operations (Alternatives 3, 4 , and 9 through 13). These five tanks include three previously leaking tanks and two newly leaking tanks. Two previously leaking tanks are assumed to be leak-tight during new sluicing operations due to the presence of leak holes above liquid levels required for sluicing or due to pluggage of holes by waste fines.

In the case of the Close-Coupled Barrier Without Flushing Alternative (Alternative 7) and the Clean-Closure With Close-Coupled Chemical Barrier Alternative (Alternatives 7 and 14), the two newly leaking tanks will each release $41,600 \mathrm{~L}(11,000 \mathrm{gal})$ before barriers are installed. In the case of alternatives that employ traditional sluicing but no close-coupled barrier (Alternatives 3 and 9 through 13), it is assumed that the five leaking tanks release $152,000 \mathrm{~L}(40,000$ gal) each. In the case of the Robotic Sluicing Alternative (Alternative 4), it is assumed that $15,200 \mathrm{~L}(4,000 \mathrm{gal})$ are released from each tank. In the case of the Modified Close-Coupled Chemical Barrier Without Flushing Alternative (Alternative 8), it is assumed that $152,000 \mathrm{~L}(40,000$ gal) are released to the soil from two newly leaking tanks.

(17) The average head during traditional sluicing at the leak location is $4.6 \mathrm{~m} \mathrm{(15} \mathrm{ft})$ (Alternatives 3 and 6 through 14); the average head during robotic sluicing is $0.46 \mathrm{~m}(1.5 \mathrm{ft})$ (Alternative 4). These heads will cause further advection of tank waste into the tanks' concrete. The average height of liquid in the tanks during

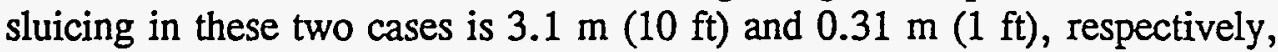
because the specific gravity of the liquid is assumed to be 1.5 .

(18) Leaks of 41,600 L (11,000 gal) per tank (all alternatives) and 194,000 L (51,000 gal) per tank (Alternatives 3 and 9 through 13) are estimated to have resulted in plume thicknesses of 8.5 and $15 \mathrm{~m} \mathrm{(28}$ and $49 \mathrm{ft}$ ), respectively.

(19) Standoff barriers are installed below the level of existing leakage plumes (Alternatives 9 through 11).

(20) Advection of waste into the close-coupled barrier occurs along the construction joint between the concrete base and concrete wall, and/or along a crack in the base. The length of the cracks through which waste can be forced into the barrier material is $10 \mathrm{~m}$ (33 ft) (Alternatives 6, 7, and 14). 
(21) The effective hydraulic conductivity of an injected chemical barrier is $10^{-6} \mathrm{~cm} / \mathrm{s}$ $\left(2 \times 10^{-6} \mathrm{ft} / \mathrm{min}\right)$ (Alternatives 6 through 10 and 14).

(22) The effective porosity of the Hanford Site soil regarding injected chemicalbarrier-forming materials is 0.2 (Alternatives 6 through 10 and 14).

(23) Due to the slow migration rate of leaked waste through the soil to a standoff barrier, traditional soil flushing is necessary to effect cleanup of the leaks (Alternatives 9 through 11).

(24) Soil flushing is $94 \%$ effective in removing COCs after four pore volume flushes; soil porosity is 0.4 (Alternatives 6 and 9 through 12).

(25) The hydraulic conductivity of Hanford Site soil is $1.55 \times 10^{-3} \mathrm{~cm} / \mathrm{s}(4.4 \mathrm{ft} /$ day). Soil heterogeneity and anisotropy are ignored (Alternatives 6 and 9 through 12).

(26) The time to flush four pore volumes to the standoff barrier ranges from 120 to 180 days, depending on design (Alternatives 9 through 11).

(27) The head of flush water on the standoff barrier is limited to $1.5 \mathrm{~m}(5 \mathrm{ft})$ by wellpoint pumping to prevent advection through the barrier (Alternatives 9 through 11).

(28) The volume of water required to effect vacuum flushing of soil in the tank farm is $14 \mathrm{Mgal}$ (Alternative 6) and $20 \mathrm{Mgal}$ (Alternative 12); the volume required to effect traditional flushing using standoff barriers as catchments ranges from 245 to $278 \mathrm{Mgal}\left(9.3 \times 10^{8}\right.$ to $\left.10.6 \times 10^{9} \mathrm{~L}\right)$ (Alternatives 9 through 11 ).

(29) Relative risk is evaluated using the MEPAS, a Hanford Site-developed code with one-dimensional vadose zone modeling capability (all alternatives).

(30) Injected chemical barriers, after they have served their intended purpose to support tank cleanout and closure operations, will not significantly impact the migration of contaminants in the vadose zone (Alternatives 6 through 10).

(31) The entire vadose zone plume entering the groundwater is assumed to be captured by an operating well used to meet the domestic and irrigation needs of a 2-ha (5-acre) farm (i.e., an average water pumping rate of $45 \mathrm{~m}^{3} /$ day [1,589 $\mathrm{ft}^{3} /$ day]) (all alternatives).

(32) Contaminated soils and demolition wastes retrieved during clean-closure operations are treated by washing to remove $99 \%$ of the constituents of concern (Alternatives 13 and 14). The washed soil and debris are disposed in a landfill that, when filled, is covered with a Hanford Permanent Isolation Barrier. 
(33) The COCs recovered during soil flushing and during washing of excavated soil and debris are concentrated and treated along with waste retrieval from SSTs. It is assumed that the COCs are destroyed or disposed offsite at a federal repository such that they do not contribute to risk at the Hanford Site. 
WHC-SD-WM-ES-300 REV. 1

This page intentionally left blank. 


\subsection{COMPARATIVE RISK ASSESSMENT}

This section describes the bases for a comparative risk assessment of alternatives presented in Section 5. It also contains a description of the methodology used to evaluate risk and a summary of risk results.

The primary objective of the comparative risk assessment is to provide a consistent evaluation of alternatives that use, and alternatives that do not use, subsurface barrier technologies to reduce relative health risks to the public from contaminant releases into the Hanford Site aquifer. This assessment was conducted to satisfy Part 1 of Tri-Party Agreement Milestone M-45-07A, "Estimate the potential environmental impacts of waste storage and retrieval activities without the application of subsurface barriers" and the latter half of Part 3, "Evaluate... the potential reduction in environmental impacts from the application of barriers to SST waste storage and retrieval activities." Other important risks, including worker safety, health risks due to atmospheric releases during installation and operation, and ecological risks, were not considered in this risk analysis. They will be considered in separate and more comprehensive analyses if the feasibility of subsurface barriers evaluated in this analysis is deemed sufficient by decision makers to warrant further study.

The purpose of subsurface barriers, used in conjunction with tank retrieval operations, is to reduce the magnitude of contamination belowground and to contain leaks until they can be flushed or excavated. This can be accomplished by the following:

- Reducing the amounts of contaminants that leak from the tanks during retrieval operations using close-coupled barriers

- Reducing the volume of newly contaminated soil underlying the tanks by intercepting liquids that leak from the tanks during retrieval operations. Extraction of those liquids would be accomplished using standoff barriers as catchments.

Subsurface chemical barriers would be in place during waste retrieval operations, which includes the period for extraction of liquids intercepted by standoff barriers and during soil flushing operations. However, it was assumed that the barriers would not remain leak-tight for an indefinite period. If they were designed for long-term leak-tightness, leachate from the residual waste would collect as in a bathtub. A major rupture of the barrier could lead to significant contamination of the groundwater and high risks to users of well water.

For the comparative risk assessment, it was assumed that a chemical barrier would not impede the release and migration of contaminants from the tank and other sources of residual contamination after site closure. This assumption is reasonable because the likely range of hydraulic conductivities of chemical barriers would allow a hydraulic flux through the barrier equivalent to the recharge flux within a short period of time. See Section 6.1.7 for analysis 
of advection into chemical barriers. The relatively high ionic diffusivity expected for barriers would also facilitate migration through the barrier, especially under the low recharge rates assumed in this analysis.

It was also assumed that freeze walls and circulating air barriers would not offer permanent protection of the groundwater. Although the effectiveness of either barrier has not yet been proven for long-term containment (the freeze wall barrier appears likely to be successful with use of sufficient freeze piping and other engineered features), it seems inappropriate to assume that either of these barriers could be actively maintained for thousands of years. As discussed later in this section, the passive surface barrier alone appears capable of preventing contamination from reaching the aquifer for several thousand years, making the need for actively maintaining subsurface barriers questionable.

A first approximation of relative human health risks from exposure to contaminated groundwater was performed in a two-step analysis. The first step was definition of potential residual sources of groundwater contamination following completion of tank waste retrieval operations. This included identifying residual contaminant sources and their potential inventories of contaminants, and estimating the rates and durations of contaminant releases from these sources into the vadose zone. The assumptions and analytical methods used in defining residual contaminant source terms are presented and discussed in Section 6.1.

The second step in the assessment of relative risks involved modeling the transport of contaminants through the vadose zone and aquifer, and estimating potential human exposure and health risk. This was accomplished using the MEPAS Version $3.0 \mathrm{~g}$ computer code (Droppo et al. 1989). The MEPAS is designed to evaluate relative human health risk from radiological and chemical contaminants released into the environment. The assumptions and analytical methods used in modeling contaminant transport and relative human health risk are presented and discussed in Section 6.2.

\subsection{SOURCE TERMS, BASES, AND ASSUMPTIONS}

This section defines the theoretical and parametric bases for potential sources of groundwater contamination that may result from the application of the 14 alternatives. These bases served as input to the MEPAS code to enable prediction of relative risk through the groundwater pathway.

The potential sources of groundwater contamination that were analyzed include the following:

- Residue in tank following waste retrieval

- Residue between tank steel and concrete foundation

- Residue within tank concrete

- Residue in soil due to old and new leaks

- Residue following soil flushing of old and new leaks 
- Residue within close-coupled barrier

- Residue following use of standoff barrier.

General assumptions for the relative risk analysis are described in Section 6.1.1. The potential sources of groundwater contamination and bases for a separate sensitivity analysis are described in Sections 6.1.2 through 6.1.8. The sensitivity analysis was used to assess the potential impact of changes in the performance of the technologies considered. It was also used to assess the importance of parameters that impact the source term.

\subsubsection{General Assumptions}

A hypothetical SST farm comprising twelve, $3.8 \times 10^{6} \mathrm{~L}$ (1-Mgal) tanks was selected for modeling relative risk through the groundwater pathway. The tank farm was assumed to exist in a three by four array with each of the $22.9 \mathrm{~m}(75-\mathrm{ft})$ diameter tanks on $30.5-\mathrm{m}$ $(100-\mathrm{ft})$ centers. The base of each tank was assumed to be $15.3 \mathrm{~m}(50 \mathrm{ft})$ belowgrade. The plan dimensions of the tank farm were 83.9 by $114 \mathrm{~m}$ ( 275 by $375 \mathrm{ft}$ ), which yielded a surface area of $9,580 \mathrm{~m}^{2}\left(103,000 \mathrm{ft}^{2}\right)$. This area defined the assumed capture zone for precipitation, part of which was assumed to recharge through the tank-related contaminated media. The contaminants mobilized by the recharge water were assumed to be transported to the groundwater where they subsequently were drawn into a well used for drinking water, irrigation, and other uses.

One-million gallon tanks are the largest tanks used at the Hanford Site. They were selected for this analysis because they feature the largest cross-sectional area for capturing recharge water. A greater amount of recharge water corresponds to faster leaching of residual contaminated media from the tanks following sluicing. This results in a somewhat conservative analysis.

6.1.1.1 Recharge. Two recharge conditions were assumed: (1) a recharge rate of $5 \mathrm{~cm} / \mathrm{yr}$ ( $2 \mathrm{in} / \mathrm{yr}$ ), which corresponds to the approximate recharge through Hanford Site soils with minimal surface vegetation or a wetter climate (DOE 1987) and (2) a recharge rate of $0.05 \mathrm{~cm} / \mathrm{yr}(0.02 \mathrm{in} / \mathrm{yr})$, which corresponds to the expected maximum recharge through the Hanford Permanent Isolation Surface Barrier described in Section 4 (Gee et al. 1993). Wastes within the confines of the tanks were assumed to be mobilized by recharge through the area defined by the combined area of the 12 tanks. This area is $4,900 \mathrm{~m}^{2}\left(53,000 \mathrm{ft}^{2}\right)$. All wastes outside the tanks are assumed to be mobilized by recharge that occurs over the entire area of the tank farm.

6.1.1.2 Selection of Constituents of Concern. The full spectrum of constituents known or expected to be contained within the underground storage tanks includes more than 150 chemicals and radionuclides. To simplify the evaluation, a shorter list of COCs was developed. These include the constituents that contribute most of the risk to human health. 
For the purposes of developing the list of COCs, the Single-Shell Tank Constituent Rankings for Use in Preparing Waste Characterization Plans report (Droppo et al. 1991) was reviewed. That report provided an analysis and ranking of tank waste constituents, based on risk to human health. Droppo et al. (1991) evaluated risks, based on leakage and transport to groundwater and human health exposure through ingestion and use of groundwater for irrigation. Table 6-1 lists the constituents that were determined in that study to result in a carcinogenic risk greater than $1 \times 10^{-6}$ or a noncarcinogenic $\mathrm{HI}$ greater than 1 at recharge rates of $10 \mathrm{~cm} / \mathrm{yr}(4 \mathrm{in} / \mathrm{yr}$ ). A separate evaluation of these constituents was also performed as part of this study using the MEPAS code. The results of this second evaluation are also presented in Table 6-1. The list of COCs derived in the second evaluation is shorter, but generally consistent with the results obtained by Droppo et al. (1991).

Neither evaluation addressed organic constituents that are known or suspected to be present within the tank wastes, except for EDTA. The organic constituents in the tanks have been estimated in the Hanford Defense Waste Environmental Impact Statement (HDW-EIS) (DOE 1987). Included in the HDW-EIS evaluation are approximately 40 organic chemicals in neutralized cladding removal wastes, double-shell slurry wastes, and organic complexant wastes. The types of organic chemicals identified include solvents, volatiles, chelating/ complexing agents, and acids. However, inspection of the list of chemicals revealed that many of these constituents may no longer be present in the identified form as a result of chemical interactions with each other or with the inorganic materials within the tanks. Furthermore, from the list of organic constituents above the detection limit identified in tank wastes, only EDTA and TBP have known toxicity values. Therefore, only these two organic constituents were included in the list of COCs.

From the evaluations described above, the final list of COCs to be evaluated in this study was developed and is presented in Table 6-2. The COCs selected are those that ranked in the top $90 \%$ of the cumulative risk contributors from the MEPAS evaluations. Although they did not rank in the top 90\%, EDTA and TBP were also included because they are common organic contaminants in the tank wastes.

6.1.1.3 Contaminant Inventory. The original inventory of waste within the 149 SSTs was assumed to be $223,000,000 \mathrm{~kg}(491,000,000 \mathrm{lb})$ as reported by Boomer et al. (1993). This mass includes $97,000,000 \mathrm{~kg}(213,000,000 \mathrm{lb})$ of nitrate. It was assumed that the 12 tanks in the hypothetical tank farm include an average amount of nitrate, i.e., $650,000 \mathrm{~kg}$ $(1,430,000 \mathrm{lb})$ each. Thus, the 12 tanks contain a total of $7,800,000 \mathrm{~kg}(17,200,000 \mathrm{lb})$ of nitrate. Table 6-3 shows the assumed total inventory of the eight COCs considered in this study. These inventories, which were derived from Boomer et al. (1993), reflect total masses in the hypothetical tank farm. Table 6-3 also shows the assumed concentrations of the contaminants after dissolving in recharge water and the assumed concentrations present in interstitial liquid (the aqueous phase that drains from and through the saltcake and sludge). Interstitial liquid probably exists in chemical equilibrium with the salt cake and sludge. It collects in the bottom of SSTs and is periodically removed by pumping. 
WHC-SD-WM-ES-300 REV. 1

Table 6-1. Comparison of Constituent Rankings.

\begin{tabular}{|c|c|c|c|}
\hline \multicolumn{4}{|c|}{ Constituent Rankings } \\
\hline \multicolumn{2}{|c|}{ Droppo et al. (1991) } & \multicolumn{2}{|c|}{ This Study ${ }^{2}$} \\
\hline Carcinogens ${ }^{b}$ & Noncarcinogens ${ }^{c}$ & Carcinogens & Noncarcinogens \\
\hline As & $\mathrm{Sb}$ & ${ }^{14} \mathrm{C}$ & $\mathrm{Sb}$ \\
\hline${ }^{238} \mathrm{U}$ & EDTA $^{d}$ & ${ }^{99} \mathrm{Tc}$ & $\mathrm{NO}_{3}$ \\
\hline${ }^{99} \mathrm{Tc}$ & $\mathrm{Hg}$ & ${ }^{238} \mathrm{U}$ & $\mathrm{V}$ \\
\hline${ }^{14} \mathrm{C}$ & $\mathrm{NO}_{2}$ & ${ }^{129} \mathrm{I}$ & $\mathrm{NO}_{2}$ \\
\hline${ }^{129} \mathrm{I}$ & $\mathrm{V}$ & ${ }^{241} \mathrm{Am}$ & $\mathrm{Cr}$ \\
\hline${ }^{235} \mathrm{U}$ & $\mathrm{Cr}$ & & $\mathrm{F}$ \\
\hline${ }^{242 m} \mathrm{Am}$ & $\mathrm{Be}$ & & \\
\hline${ }^{240} \mathrm{Pu}$ & $\mathrm{NO}_{3}$ & & \\
\hline${ }^{239} \mathrm{Pu}$ & $\mathrm{Na}$ & & \\
\hline${ }^{238} \mathrm{Pu}$ & $\mathrm{F}$ & & \\
\hline${ }^{234} \mathrm{U}$ & $\mathrm{SO}_{4}$ & & \\
\hline${ }^{241} \mathrm{Am}$ & $\mathrm{CN}$ & & \\
\hline${ }^{242} \mathrm{Cm}$ & $\mathrm{Cu}$ & & \\
\hline${ }^{237} \mathrm{~Np}$ & & & \\
\hline${ }^{233} \mathrm{U}$ & & & \\
\hline${ }^{241} \mathrm{Pu}$ & & & \\
\hline${ }^{93 \mathrm{~m}} \mathrm{Nb}$ & & & \\
\hline
\end{tabular}

${ }^{a}$ Derived using MEPAS - Multimedia Environmental Pollution Assessment System.

bonly constituents that were determined to have a risk greater than $1 \times 10^{-6}$ are included on this list.

'Only constituents with a hazard index of greater than 1 are included on this list.

${ }^{d}$ EDTA - ethylenediaminetetraacetic acid. 
Table 6-2: Constituents of Concern Evaluated in the Risk Model.

\begin{tabular}{|c|c|}
\hline Radionuclides & Chemicals \\
\hline${ }^{14} \mathrm{C}$ & $\mathrm{NO}_{3}$ \\
\hline${ }^{99} \mathrm{Tc}$ & $\mathrm{NO}_{2}$ \\
\hline${ }^{129} \mathrm{I}$ & $\mathrm{TBP}^{\mathrm{a}}$ \\
\hline${ }^{238} \mathrm{U}$ & $\mathrm{EDTA}^{\mathrm{b}}$ \\
\hline
\end{tabular}

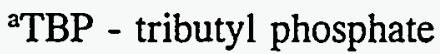

${ }^{b}$ EDTA - ethylenediaminetetraacetic acid

The concentrations shown in columns $B$ and $C$ in Table 6-3 are based on the assumption of congruent leaching of all contaminants with nitrate. The assumed data shown for nitrate in Table 6-3 in recharge water (column B) and interstitial liquid (column C) are based on nitrate solubility information in Serne and Wood (1990) and Boomer et al. (1993), respectively. Assumed solubilities for each of the COCs reported by Serne and Wood (1990) are also shown for comparison in Table 6-3 (column D). The column D solubilities are generally based on the highest concentrations observed in samples of drainable aqueous waste removed from Hanford Site tanks. Column E contains averages of the samples of the aqueous waste as reported in Schultz (1978), Weiss (1986) and Weiss and Schull (1988a thru 1988i).

Concentrations reported in columns $\mathrm{B}$ and $\mathrm{C}$ exceed the concentrations of nitrate, EDTA, ${ }^{14} \mathrm{C}$, and ${ }^{238} \mathrm{U}$ in columns $\mathrm{D}$ and $\mathrm{E}$. The converse is true for nitrite, ${ }^{129} \mathrm{I}$ and ${ }^{99} \mathrm{Tc}$. Thus; the concentrations shown in columns $B$ and $C$ were used as representative of the compositions of tank liquids that may drain or leak from the tanks in order to facilitate the computations required to estimate relative risk and hazard. A sensitivity analysis based on the average concentrations of COCs in drainable liquid waste (column E) was conducted and reported in Section 8. The purpose of this analysis was to test the validity of the assumption that risk can be modeled with fair accuracy assuming congruent leaching of all COCs with nitrate.

The residual inventories of only nitrate in the seven sources of potential groundwater contamination are analyzed in Section 6.1.2 through 6.1.8. The inventories and fluxes of nitrate are reported to facilitate comparison of the relative importance of each source. Section 6.2 provides a description of the use of MEPAS to compute relative risk. Section 6.3 provides a first approximation estimate of the groundwater risks associated with all eight COCs.

\subsubsection{Residue In Tank Following Waste Retrieval}

The residual waste in the tanks following waste retrieval is represented schematically in Figure 6-1. Each of the alternatives evaluated in this study included one of the following four retrieval options: 
Table 6-3. Assumed Contaminant Data for Hypothetical Tank Farm.

\begin{tabular}{|c|c|c|c|c|c|}
\hline Contaminant & Inventory & $\begin{array}{c}\text { B } \\
\text { Assumed } \\
\text { Recharge } \\
\text { Concentration } \\
\text { Exiting Tanks }\end{array}$ & $\begin{array}{c}\text { C } \\
\text { Assumed } \\
\text { Interstitial } \\
\text { Liquid } \\
\text { Concentration }\end{array}$ & $\begin{array}{l}\text { Assumed } \\
\text { Solubility }^{\mathrm{a}}\end{array}$ & $\begin{array}{c}\mathrm{E} \\
\text { Average Measured } \\
\text { Drainable Water } \\
\text { Concentration }^{\mathrm{b}}\end{array}$ \\
\hline $\mathrm{NO}_{3}{ }^{\mathrm{c}}$ & $7,800,000 \mathrm{~kg}$ & $360 \mathrm{~g} / \mathrm{L}$ & $250 \mathrm{~g} / \mathrm{L}$ & $360 \mathrm{~g} / \mathrm{L}$ & $155 \mathrm{~g} / \mathrm{L}$ \\
\hline $\mathrm{NO}_{2}^{\mathrm{d}}$ & $390,000 \mathrm{~kg}$ & $18 \mathrm{~g} / \mathrm{L}$ & $12 \mathrm{~g} / \mathrm{L}$ & $60 \mathrm{~g} / \mathrm{L}$ & $26 \mathrm{~g} / \mathrm{L}$ \\
\hline TBPe & $950 \mathrm{~kg}$ & $0.04 \mathrm{~g} / \mathrm{L}$ & $0.03 \mathrm{~g} / \mathrm{L}$ & $N / A^{s}$ & $N / A^{B}$ \\
\hline EDTA $^{f}$ & $1,400 \mathrm{~kg}$ & $0.062 \mathrm{~g} / \mathrm{L}$ & $0.04 \mathrm{~g} / \mathrm{L}$ & $0.0028 \mathrm{~g} / \mathrm{L}$ & N/A ${ }^{8}$ \\
\hline${ }^{14} \mathrm{C}$ & $240 \mathrm{Ci}$ & $1.1 \times 10^{-5} \mathrm{Ci} / \mathrm{L}$ & $8.0 \times 10^{-6} \mathrm{Ci} / \mathrm{L}$ & $3.0 \times 10^{-6} \mathrm{Ci} / \mathrm{L}$ & $1.1 \times 10^{-6} \mathrm{Ci} / \mathrm{L}$ \\
\hline${ }^{129} \mathrm{I}$ & $2 \mathrm{Ci}$ & $9.0 \times 10^{-8} \mathrm{Ci} / \mathrm{L}$ & $6.0 \times 10^{-8} \mathrm{Ci} / \mathrm{L}$ & $3.0 \times 10^{-7} \mathrm{Ci} / \mathrm{L}$ & $2.1 \times 10^{-7} \mathrm{Ci} / \mathrm{L}$ \\
\hline${ }^{99} \mathrm{Tc}$ & $1,300 \mathrm{Ci}$ & $5.8 \times 10^{-5} \mathrm{Ci} / \mathrm{L}$ & $4.0 \times 10^{-5} \mathrm{Ci} / \mathrm{L}$ & $3.0 \times 10^{-4} \mathrm{Ci} / \mathrm{L}$ & $1.4 \times 10^{-4} \mathrm{Ci} / \mathrm{L}$ \\
\hline${ }^{238} \mathrm{U}$ & $37 \mathrm{Ci}$ & $2.0 \times 10^{-6} \mathrm{Ci} / \mathrm{L}$ & $1.0 \times 10^{-6} \mathrm{Ci} / \mathrm{L}$ & $9.0 \times 10^{-7} \mathrm{Ci} / \mathrm{L}$ & $1.4 \times 10^{-7} \mathrm{Ci} / \mathrm{L}$ \\
\hline
\end{tabular}

aSerne and Wood (1990)

bSchultz (1978), Weiss (1986), and Weiss and Schull (1988a thru 1988i)

${ }^{\mathrm{C}} \mathrm{NO}_{3}$ - nitrate

${ }^{\mathrm{d}} \mathrm{NO}_{2}$ - nitrite

'TBP - tributyl phosphate

EDTA - ethylenediaminetetraacetic acid

${ }^{8} \mathrm{~N} / \mathrm{A}$ - not available 
WHC-SD-WM-ES-300 REV. 1

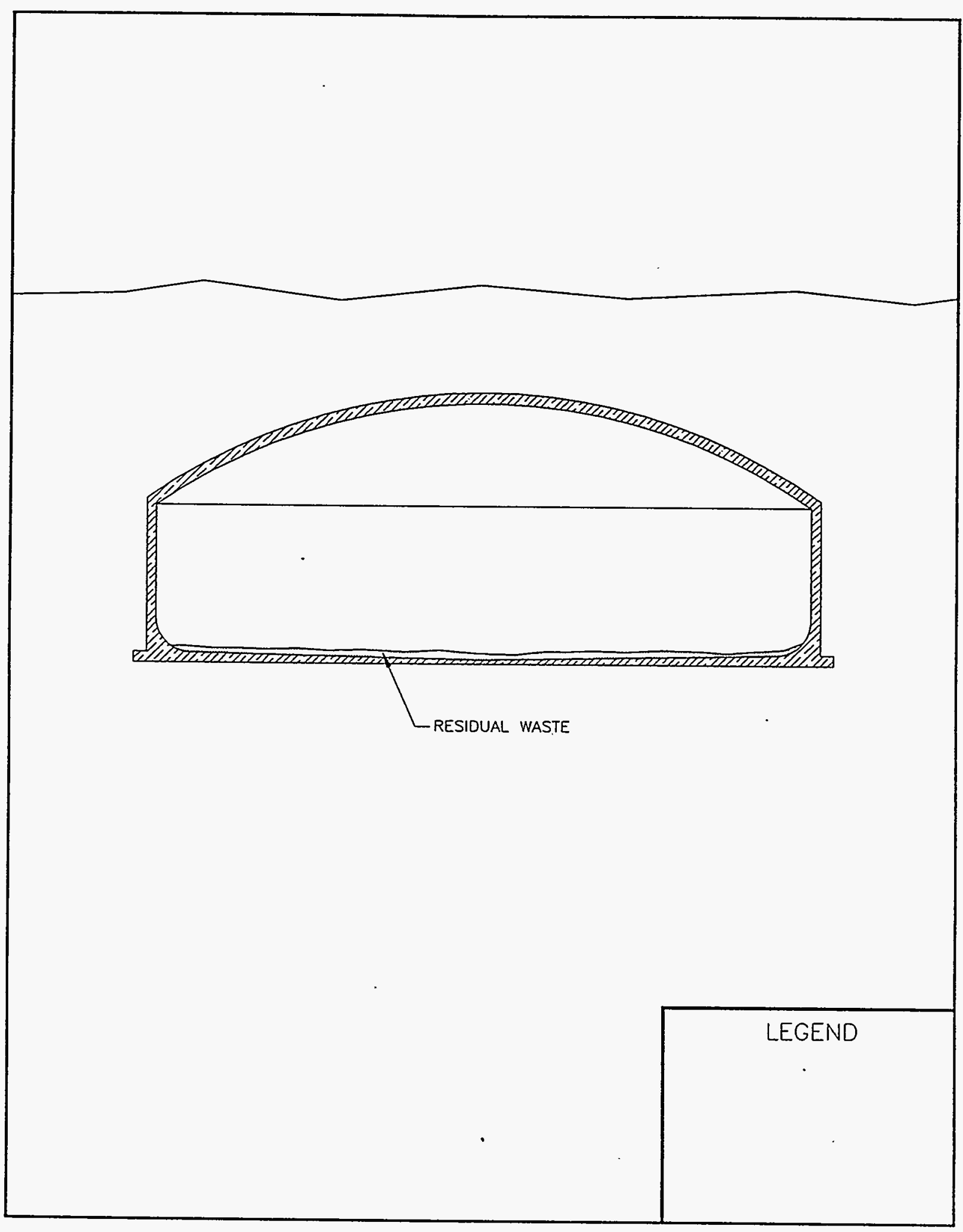

Figure 6-1. Residual Waste in Tanks Following Retrieval. 


\section{- No retrieval \\ - Retrieval using traditional sluicing \\ - Retrieval using robotic sluicing \\ - Retrieval using mechanical retrieval techniques.}

When no retrieval occurs as in the No-Action Alternative, the residual waste inventory in the tank would be equal to the current assumed inventory. When retrieval is conducted using traditional sluicing, $1 \%$ of the inventory of each of the COCs was assumed to remain. When retrieval is conducted using robotic sluicing, $0.1 \%$ of the inventory was assumed to remain. When retrieval is conducted using mechanical retrieval techniques, $5 \%$ of the inventory was assumed to remain. These removal efficiencies are based on data presented in Boomer et al. (1993). For comparison with the nitrate levels in the six other sources of potential groundwater contamination described in this section, the total residual nitrate in the 12 tanks following retrieval would be $78,000 \mathrm{~kg}(172,000 \mathrm{lb}), 7,800 \mathrm{~kg}(17,200 \mathrm{lb})$, and $390,000 \mathrm{~kg}$ $(860,000 \mathrm{lb})$ for traditional sluicing, robotic sluicing, and mechanical retrieval, respectively. This residual inventory was assumed to be mobilized by water advecting through the combined area of the tanks $\left(4,900 \mathrm{~m}^{2}\left[53,000 \mathrm{ft}^{2}\right]\right)$. At recharge rates of 5 and $0.05 \mathrm{~cm} / \mathrm{yr}$ ( 2 and $0.02 \mathrm{in} / \mathrm{yr}$ ), this was equivalent to 0.7 and $0.007 \mathrm{~m}^{3} /$ day (24 and $0.24 \mathrm{ft}^{3} /$ day) of total recharge water, respectively. Advection rates through individual tanks were assumed to be 0.06 and $0.0006 \mathrm{~m}^{3} / \mathrm{day}$ ( 2 and $0.02 \mathrm{ft}^{3} / \mathrm{day}$ ), for the respective recharge rates.

The solubility of nitrate in tank waste was assumed to be $360 \mathrm{~g} / \mathrm{L}$ or $22.4 \mathrm{lb} / \mathrm{ft}^{3}$ (Serne and Wood 1990). Thus, the assumed total dissolution rates of nitrate would be 240 and $2.4 \mathrm{~kg} /$ day (530 and $5.3 \mathrm{lb} / \mathrm{day}$ ) for the $5-$ and $0.05-\mathrm{cm} / \mathrm{yr}$ (2- and $0.02-\mathrm{in} / \mathrm{yr}$ ) recharge scenarios, respectively. The time $(t)$ required to deplete the nitrate inventory by dissolution is defined by the following equation:

Where:

$$
\mathrm{t}=\mathrm{I} / \mathrm{m}_{\mathrm{d}}
$$

$$
\begin{aligned}
& I=\quad \text { total residual nitrate inventory in the tank farm following retrieval } \\
& (\mathrm{M}=\text { mass }) \\
& \mathrm{m}_{\mathrm{d}}=\quad \text { mass of nitrate dissolved per day }(\mathrm{M} / \mathrm{T}=\text { time })
\end{aligned}
$$

The results of the nitrate inventory analysis are shown in Table 6-4.

The waste inventory in the tanks was assumed to be released from an elevation $15 \mathrm{~m}$ (50 ft) belowgrade until the entire inventory was depleted. Species with relatively low solubilities could be released over a longer time period than nitrate. It was assumed in this analysis that all COCs leach congruently with nitrate. This assumption may be conservative in certain cases (e.g., where relatively insoluble species have been formed, such as uranium phosphate). Data presented in Serne and Wood (1990) and in Table 6-3 also support the conservatism of the congruent leaching assumption. A sensitivity analysis was conducted in Section 8 to evaluate the effects of solubility-limited releases of individual COCs. 
Table 6-4. Tank Residual Nitrate Data.

\begin{tabular}{|l|c|c|c|}
\hline \multicolumn{1}{|c|}{ Retrieval Method } & $\begin{array}{c}\text { Total } \\
\text { Residual } \\
\text { Inventory }(\mathrm{kg})\end{array}$ & $\begin{array}{c}\text { Total Mass } \\
\text { Dissolved } \\
\text { Per Day (kg) }\end{array}$ & $\begin{array}{c}\text { Time to } \\
\text { Complete } \\
\text { Dissolution (yr) }\end{array}$ \\
\hline No-Action $^{\mathrm{a}}$ & $7,800,000$ & 240 & 89 \\
\hline Tradition Sluicing & 78,000 & 2.4 & 89 \\
\hline Robotic Sluicing & 7,800 & 2.4 & 9 \\
\hline Mechanical Retrieval & 390,000 & 2.4 & 445 \\
\hline
\end{tabular}

${ }^{a}$ The No-Action Alternative is based on the assumption of a $5-\mathrm{cm} / \mathrm{yr}(2-\mathrm{in} / \mathrm{yr})$ recharge rate. All other alternatives are based on the assumption of a $0.05-\mathrm{cm} / \mathrm{yr}(0.02-\mathrm{in} / \mathrm{yr})$ recharge rate through a Hanford Permanent Isolation Surface Barrier installed over the structurally stabilized tank farm.

\section{Assumptions for Sensitivity Analysis}

It may be possible to increase the effectiveness of the traditional sluicing technology if a weak acid is used during the final stages of tank cleanout. Boomer et al. (1993) reported that inhibited sulfuric acid was used in a laboratory test to dissolve hard, agglomerated sludges that resisted erosion by traditional sluicing methods. Boomer et al. (1993) also reported that the acid was believed to have been used in the cleanout of at least one tank. If the acid is successful in breaking up the sludge to increase its surface area, the sluicing water may be effective in leaching the COCs as most are soluble. Although a significant volume of insoluble waste species would remain after several in-tank leaching cycles, the insoluble species would have relatively little impact on groundwater contamination due to their low mobilities. They are relatively immobile because of low solubilities and because most would adsorb strongly to Hanford Site soil.

Consequently, for purposes of the sensitivity analysis, it was assumed that the use of weak acids would result in recovery of $99.9 \%$ of each COC. Thus, the effectiveness of traditional and robotic sluicing would be equal. In contrast, the presence of the hard, agglomerated sludges may render traditional sluicing less effective than predicted in Boomer et al. (1993). A recovery efficiency of $95 \%$ may be more appropriate if agglomerated sludges are common and weak acid is not used. Thus, the effectiveness of traditional sluicing and mechanical retrieval would be equal in this case. 


\subsubsection{Residue Between Tank Steel and Concrete Foundation}

The residual waste between the tank steel bottom and the concrete foundation is shown schematically in Figure 6-2. Any tank that has leaked waste to the soil through its base is also likely to have at least partially filled the void space between the tank steel and concrete foundation with liquid waste. The liquid waste may also entrain solid waste particles as it flows into this void space. The small void space (assumed to average $1 \mathrm{~mm}$ [0.039 in.] thick) was assumed to exist because the steel bottom of the tank was constructed upon a previously formed concrete base. In certain cases (e.g., Tank 241-C-103) the steel bottom was constructed after applying a thin asphalt coating on the concrete base. The void space was assumed to exist because of roughness in the finish of the concrete and because of warpage induced by welding the sheets of steel that form the steel bottom.

No void space was assumed to exist between the wall of the tank and the concrete shell because this concrete was poured against the steel wall, which acted as a form. This assumption may be nonconservative. Lowe (1993), for example, reported that the most likely leak mechanism during the sluicing of Tank 241-C-106 would be formation of cracks in the steel wall, with resultant migration of the leak between the steel and concrete to the construction joint between vertical and horizontal concrete members of the tank structure.

Five of the 12 tanks in the hypothetical tank farm were assumed to contain liquid waste between the steel and concrete base. The five tanks in 12 are proportional to the 67 of 149 tanks overall that were assumed to have leaked (Hanlon 1993). An additional two tanks in the hypothetical tank farm were assumed to develop leaks through the bases of the tanks during new sluicing operations. The assumption of two additional leaking tanks was based on the assumption that the total number of leaking tanks would increase proportionately with age. Thus, alternatives that include sluicing were evaluated assuming that the hypothetical tank farm had waste between the steel and concrete in seven of its 12 tanks.

The concentration of the waste in the void space was assumed to be that of interstitial liquid shown in Table 6-3. Boomer et al. (1993) reported that $1.1 \times 10^{10} \mathrm{~g}\left(2.4 \times 10^{7} \mathrm{lb}\right)$ of interstitial liquid in SSTs contains $1.8 \times 10^{9} \mathrm{~g}\left(4.0 \times 10^{6} \mathrm{lb}\right)$ of nitrate. Metz (1976) reported that the density of interstitial liquid is about $1.5 \mathrm{~g} / \mathrm{cm}^{3}\left(94 \mathrm{lb} / \mathrm{ft}^{3}\right)$. Thus, the nitrate concentration of the interstitial liquid would be $250 \mathrm{~g} / \mathrm{L}\left(15.6 \mathrm{lb} / \mathrm{ft}^{3}\right)$. All other COCs in interstitial liquid were assumed to be in concentrations proportional to the nitrate concentrations in interstitial liquid and total tank waste.

The mass of a contaminant in the void space was assumed to equal to the volume of the void times the contaminant concentration in the waste liquid. Each tank in the hypothetical tank farm was assumed to have a $23-\mathrm{m}(75-\mathrm{ft})$ diameter base. Thus, the volume of a single tank void space would be $0.4 \mathrm{~m}^{3}\left(14.5 \mathrm{ft}^{3}\right)$ and the mass of nitrate in the steel/concrete void space in a single tank would be $100 \mathrm{~kg}(230 \mathrm{lb})$. For alternatives that do not involve sluicing, the total mass of nitrate in the void space of the five affected tanks would be $510 \mathrm{~kg}(1,100 \mathrm{lb})$. For alternatives that involve sluicing, the total nitrate mass would be $720 \mathrm{~kg}(1,600 \mathrm{lb})$ in the seven affected tanks. 
WHC-SD-WM-ES-300 REV. 1

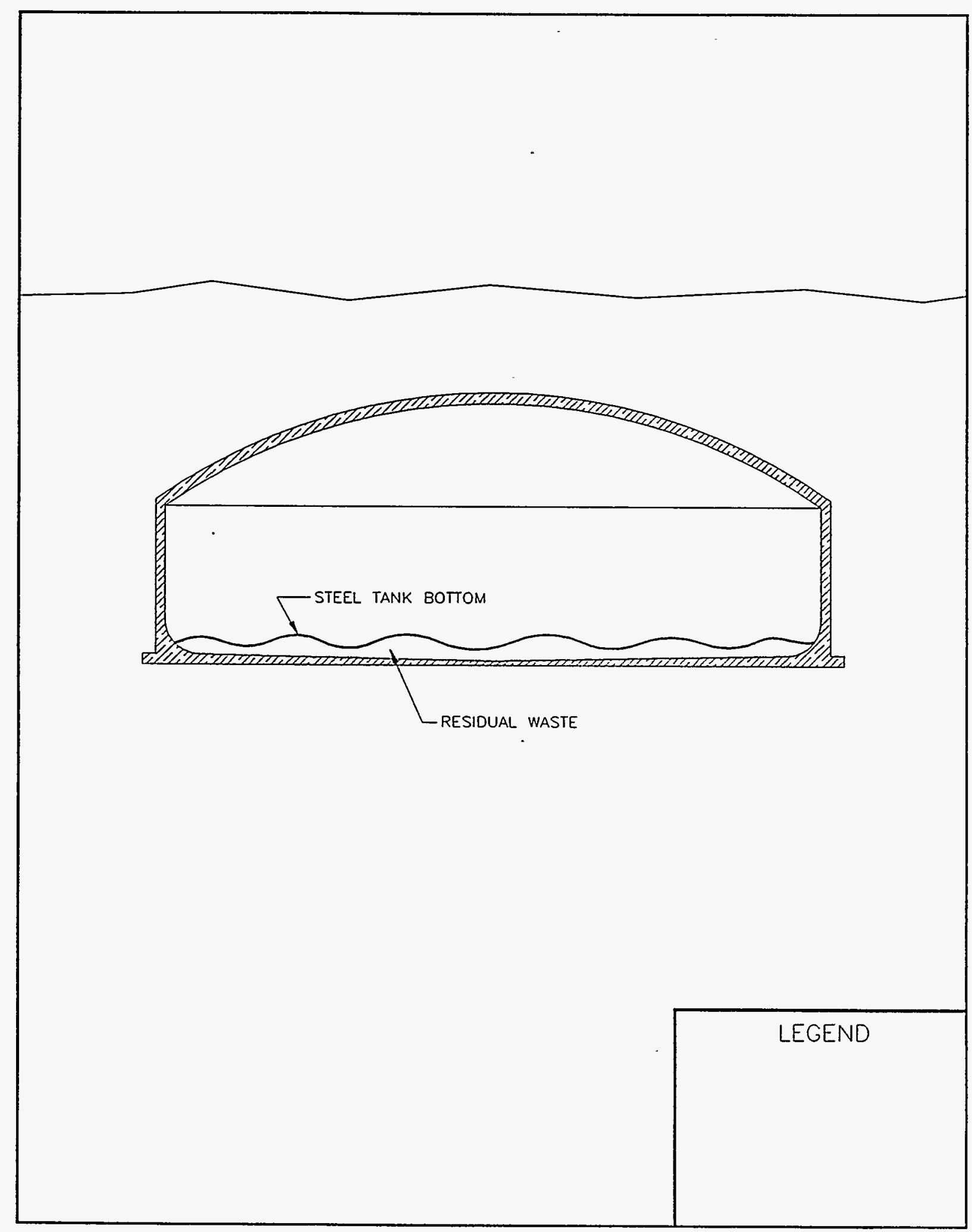

Figure 6-2. Residual Waste Trapped Between Tank Steel and Concrete Foundation. 
It was assumed that the residual inventory of contaminants between the shell and concrete would be released through displacement by advecting recharge water. The time $(t)$ required for the advecting water to displace the waste liquid in the void space is given by the following equation:

$$
\mathrm{t}=\mathrm{V}_{\mathrm{stv}} / \mathrm{R}_{\mathrm{st}}
$$

Where:

$$
\begin{array}{ll}
\mathrm{V}_{\mathrm{stv}}= & \begin{array}{l}
\text { volume of waste liquid in a single tank void }\left(0.4 \mathrm{~m}^{3}\left[14.5 \mathrm{ft}^{3}\right]\right) \\
\left(\mathrm{L}^{3}=\text { length }\right)
\end{array} \\
\mathrm{R}_{\mathrm{st}}= & \begin{array}{l}
\text { recharge rate into single tank }\left(0.06 \mathrm{~m}^{3} / \mathrm{d} \text { or } 0.0006 \mathrm{~m}^{3} / \mathrm{d}\left[2 \mathrm{ft}^{3} /\right. \text { day or }\right. \\
\left.\left.0.02 \mathrm{ft}^{3} / \text { day }\right]\right)\left(\mathrm{L}^{3} / \mathrm{T}\right)
\end{array}
\end{array}
$$

The time required to displace the liquid in the voids would be 7.3 days and 730 days for recharge rates of 5 and $0.05 \mathrm{~cm} / \mathrm{yr}(2$ and $0.02 \mathrm{in} / \mathrm{yr}$ ), respectively. The total flux of nitrate from this source in the five affected tanks in the No-Action Alternative would be $71 \mathrm{~kg} / \mathrm{day}$ $(160 \mathrm{lb} /$ day $)$. The total nitrate flux for the Mechanical Retrieval Alternative, which does not involve sluicing, would be $7.1 \mathrm{~kg} /$ day $(1.6 \mathrm{lb} /$ day). The total nitrate flux for all other alternatives would be $1 \mathrm{~kg} /$ day $(2.2 \mathrm{lb} /$ day $)$. The waste source was assumed to release its COCs to the soil at an elevation of $15 \mathrm{~m}(50 \mathrm{ft})$ belowgrade.

\section{Assumptions for Sensitivity Analysis}

It was assumed that one tank in the hypothetical tank farm is similar to Tank 241-A-105. This tank has a $300,000-\mathrm{L}\left(80,000\right.$-gal) bulge in the steel base. An estimated 57 to $110 \mathrm{~m}^{3}$ $\left(2,000\right.$ to $\left.4,000 \mathrm{ft}^{3}\right)$ of sludge were assumed to fill the void created by the bulge (Woodward-Clyde Consultants 1978). Air is assumed to fill most of the bulge space. For this study it was assumed that the tank contains $83 \mathrm{~m}^{3}\left(3,000 \mathrm{ft}^{3}\right)$ of sludge with a density of $1.8 \mathrm{~g} / \mathrm{cm}^{3}\left(110 \mathrm{lb} / \mathrm{ft}^{3}\right)$. Thus, the total mass of the sludge would be $150,000 \mathrm{~kg}(330,000 \mathrm{lb})$. The masses of the COCs in the sludge were assumed to be in proportion to their relative concentrations in the assumed tank waste inventory. Boomer et al. (1993) reported that the ratio of total nitrate to total sludge is 15 to 78 . Thus, the inventory of nitrate in the bulge space of this hypothetical tank would be $29,000 \mathrm{~kg}(64,000 \mathrm{lb})$. This quantity greatly exceeds the mass assumed to exist in the void space of seven tanks $(710 \mathrm{~kg}[1,600 \mathrm{lb}])$. For this analysis, the time for dissolution of the nitrate would be 4.0 years and 400 years for recharge rates of 5 and $0.5 \mathrm{~cm} / \mathrm{yr}(2$ and $0.02 \mathrm{in} / \mathrm{yr})$, respectively. The associated fluxes are 20 and $0.2 \mathrm{~kg} /$ day (45 and $0.45 \mathrm{lb} /$ day) from this tank, respectively. 


\subsubsection{Residue Within Tank Concrete}

Contaminants assumed to have penetrated into a tank's concrete are shown schematically in Figure 6-3. Any tank that has leaked waste to the soil was assumed to have had its concrete shell exposed to contamination by advective and/or diffusive mechanisms. For purposes of defining conditions to evaluate this waste source, it was assumed that five of the 12 tanks had leaked in the past. In each case, the leak was assumed to have filled the void space between the steel and concrete base with liquid waste, as described in Section 6.1.3. The void space was assumed to have been connected hydraulically to a head of interstitial liquid contained by the tank.

\section{$\underline{\text { Advection }}$}

The head of liquid on the concrete was assumed to have been the driving force for advection of interstitial liquid waste into the concrete in accordance to Darcy's law:

$$
Q=-K A d h / d x
$$

Where:

$$
\begin{aligned}
\mathrm{Q}= & \text { rate of flow }\left(\mathrm{L}^{3} / \mathrm{T}\right) \\
\mathrm{K}= & \text { hydraulic conductivity }(\mathrm{L} / \mathrm{T}) \\
\mathrm{A}= & \text { cross-sectional area contacted at right angle by the liquid under head } \\
& \left(\mathrm{L}^{2}\right) \\
\mathrm{h}= & \text { liquid head }(\mathrm{L}) \\
\mathrm{x}= & \text { distance along direction of transport }(\mathrm{L}) .
\end{aligned}
$$

The flux through the concrete also depends on the effective porosity of the concrete and time;

$$
\mathrm{Q}=\mathrm{nAdx} / \mathrm{dt}
$$

Where:

$$
\begin{aligned}
& \mathrm{n}=\text { effective porosity of the concrete (unitless) } \\
& \mathrm{t}=\text { time (T). }
\end{aligned}
$$

By combining these two equations and integrating,

$$
x^{2}=2(K h / n) t
$$

The mass $(M)$ of a contaminant that has advected a distance of $\mathrm{x}$ into the concrete is given by:

$$
M=C_{0} \times n A
$$


WHC-SD-WM-ES-300 REV. 1

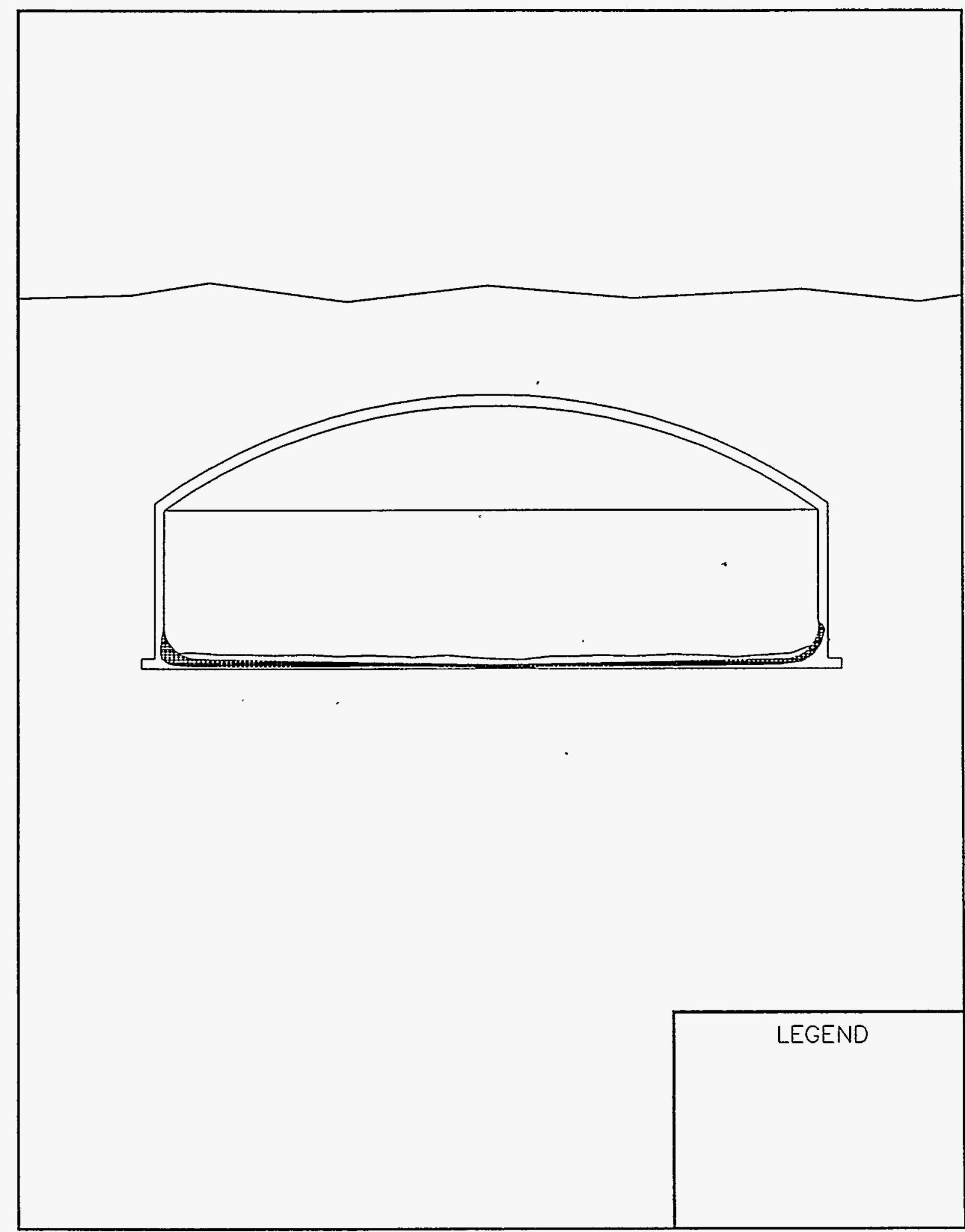

Figure 6-3. Diffusion and Advection of Waste into Concrete Foundation. 
Where:

$$
\mathrm{C}_{\mathrm{o}}=\text { initial contaminant concentration }\left(\mathrm{M} / \mathrm{L}^{3}\right)
$$

Combining Equations 5 and 6 yields:

$$
M=C_{\sigma} A \sqrt{2 K h n t}
$$

The validity of this equation is predicated on several assumptions:

- Rate of flow (Q) occurs in slug flow in one direction into the concrete, filling the entire effective porosity (n), over cross-sectional area (A) perpendicular to the flow

- The concrete provides no interference to the advancement of the slug due to the presence of air in the concrete

- The concentration $\left(C_{0}\right)$ is constant throughout the advective section

- No retardation occurs

- The variation of head (h) throughout the flow zone is linear

- The gradient $(-\mathrm{h} / \mathrm{x})$ is uniform at a given time but diminishes over time as the depth of liquid penetration $(x)$ increases

- The front of the advecting liquid $(x)$ does not break through the concrete/soil interface.

The assumed initial concentration $\left(C_{o}\right)$ of each $C O C$ is that of interstitial liquid defined in Section 6.1.1.3. It was assumed that sufficient flow of the interstitial liquid into the steel/ concrete void area would occur to prevent depletion of the concentration by diffusive losses. The area $(A)$ for the contaminant mass calculation was that defined by the $23-\mathrm{m}(75-\mathrm{ft})$ diameter of each tank base $\left(410 \mathrm{~m}^{2}\left[4,400 \mathrm{ft}^{2}\right]\right)$. The hydraulic conductivity $(\mathrm{K})$ of the concrete was assumed to be $3.75 \times 10^{-10} \mathrm{~cm} / \mathrm{s}\left(1.06 \times 10^{-6} \mathrm{ft} /\right.$ day $)$ and the porosity was assumed to be 0.22 . Both values were used to estimate the performance of concrete vaults for the disposal of Hanford Site grout (Blanchard et al. 1993).

The average height of interstitial liquid on the concrete was assumed to be $0.3 \mathrm{~m}(1 \mathrm{ft})$, or $0.5 \mathrm{~m}(1.5 \mathrm{ft})$ of water head based on the assumed density of $1.5 \mathrm{~g} / \mathrm{cm}^{3}\left(94 \mathrm{lb} / \mathrm{ft}^{3}\right)$ for interstitial liquid. It was assumed that this head had been applied for an average of 15 years. Approximately 15 years has elapsed since the typical SST leak was detected. Under these conditions, a total of $1,900 \mathrm{~kg}(4,300 \mathrm{lb})$ of nitrate were calculated to have advected into the concrete of each affected tank. 
Nitrate was assumed to advect into the concrete during sluicing operations. For traditional

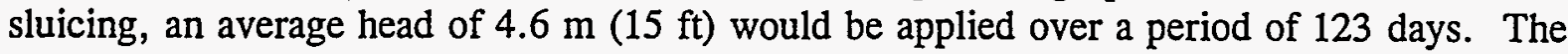
sum of the two advective terms results in $14,000 \mathrm{~kg}(31,000 \mathrm{lb})$ of nitrate advected into the concrete of the leaking tanks. Based on the assumptions associated with alternatives that employ traditional sluicing and Equation 5, the following penetrations into concrete would occur:

- $4.1 \mathrm{~cm}$ (1.6 in.) into two tanks (123 days at $4.6 \mathrm{~m} \mathrm{head)}$

- $8.6 \mathrm{~cm}(3.4$ in.) into two tanks ( 15 years at $0.46 \mathrm{~m} \mathrm{head)}$

- $12.7 \mathrm{~cm}(5.0$ in.) into three tanks (123 days of $4.6 \mathrm{~m}$ head plus 15 years at $0.46 \mathrm{~m}$ head).

Lower heads generated during robotic sluicing do not significantly change the total masses advected into the concrete.

It was assumed that $\mathrm{COCs}$ in this waste source would be leached from the concrete when the advecting recharge water passed through the associated tanks, following depletion of the entire COC inventory in the tank and void space between the tank steel and concrete. As reported in Section 6.1.2, the time to complete depletion of the tank inventory would be 89 years for the $5 \mathrm{~cm} / \mathrm{yr}(2 \mathrm{in} / \mathrm{yr}$ ) scenario and ranged from nine years for the Robotic Sluicing Alternative to 445 years for the Mechanical Retrieval Alternative for the $0.05 \mathrm{~cm} / \mathrm{yr}$ $(0.02 \mathrm{in} / \mathrm{yr})$ scenario. As reported in Section 6.1.3, the time to deplete the void space between the tank steel and concrete of COCs would be 7.3 days for the $5 \mathrm{~cm} / \mathrm{yr}(2 \mathrm{in.} / \mathrm{yr})$ recharge scenario and 730 days for the $0.05 \mathrm{~cm} / \mathrm{yr}(0.02 \mathrm{in} / \mathrm{yr})$ recharge scenario.

When these inventories were depleted, the recharge water was assumed to leach the contaminants in the concrete at a rate yielding one-half the concentration of the initial waste concentration in contact with the concrete. This lower level of recovery was assumed to be appropriate because the contaminants would be diluted by water previously contained in the concrete and because the contaminants would have to diffuse to the surface of the concrete before they could be mobilized by advecting recharge water. One-half the initial concentration of nitrate in contact with the concrete would be $125 \mathrm{~g} / \mathrm{L}\left(7.8 \mathrm{lb} / \mathrm{ft}^{3}\right)$. At recharge rates of $5 \mathrm{~cm} / \mathrm{yr}\left(2 \mathrm{ft}^{3} /\right.$ day per tank) and $0.05 \mathrm{~cm} / \mathrm{yr}\left(0.02 \mathrm{ft}^{3} /\right.$ day per tank), the time $(t)$ for complete removal of the nitrate in the concrete would be determined by:

$$
\mathrm{t}=\mathrm{M}_{\mathrm{sl}} / \mathrm{C}_{\mathrm{t}} \mathrm{R}_{\mathrm{st}}
$$

Where:

$$
\begin{aligned}
M_{s t}= & \begin{array}{l}
\text { mass of contaminant advected into concrete of a single tank } \\
(M)
\end{array} \\
C_{1}= & \begin{array}{l}
\text { resulting concentration of a contaminant in recharge water } \\
\left(M / L^{3}\right)
\end{array} \\
R_{s t}= & \text { recharge rate through a single tank }\left(L^{3} / T\right) .
\end{aligned}
$$


The time (t) required to deplete COCs from the concrete for the 5 and $0.05 \mathrm{~cm} / \mathrm{yr}(2$ and $0.02 \mathrm{in} / \mathrm{yr}$ ) scenarios would be 0.76 years and 77 years, respectively. The associated fluxes for these cases would be $35 \mathrm{~kg} /$ day and $0.50 \mathrm{~kg} /$ day $(78 \mathrm{lb} /$ day and $1.1 \mathrm{lb} /$ day). The elevation of this source of contamination was assumed to be $15.25 \mathrm{~m}(50 \mathrm{ft})$ belowgrade.

\section{Assumptions for Sensitivity Analysis Involving Adrection}

Finely grained sludge particles may have effectively plugged the joints and cracks in the shell and concrete, thereby restricting the area and flow of waste liquid into the voids. Thus, the volume estimated to have advected into the concrete could be substantially too high (e.g., by a factor of 10). This would result in a total nitrate inventory of $1,400 \mathrm{~kg}(3,100 \mathrm{lb})$ in the seven affected tanks.

Conversely, cracks are likely to exist in the concrete and its quality may be lower since it was constructed using standards applicable 40 years ago. Degradation of the concrete over time may also have occurred. Any of these factors may have increased the effective conductivity of the concrete structure. If the average conductivity is a factor of 10 above that assumed for concrete in Blanchard et al. (1993), the mass of nitrate advected into the concrete would increase by a factor of 3.2 , in accordance to Equation 7 . This would result in a total nitrate mass of $45,000 \mathrm{~kg}(99,000 \mathrm{lb})$ for alternatives involving traditional sluicing. The No Action, Surface Barrier Only, Robotic Sluicing, and Mechanical Retrieval Alternatives would have a nitrate mass of $31,000 \mathrm{~kg}(68,000 \mathrm{lb})$ in this case.

\section{Diffusion}

Contaminants may also migrate into the concrete as a consequence of diffusion. The diffusive mass flow rate $(\mathrm{J})$ can be determined by Fick's Law;

$$
J=-\theta_{\mathrm{m}} \mathrm{DAdc} / \mathrm{dx}
$$

Where:

$$
\begin{aligned}
\theta_{\mathrm{m}} & =\text { mass moisture content of concrete (unitless) } \\
\mathrm{D} & =\text { effective ionic diffusivity in concrete }\left(\mathrm{L}^{2} / \mathrm{T}\right) \\
\mathrm{A} & =\text { area across which diffusion occurs }\left(\mathrm{L}^{2}\right) \\
\mathrm{c} & =\text { waste concentration }\left(\mathrm{M} / \mathrm{L}^{3}\right) \\
\mathrm{x} & =\text { distance for diffusive transport }(\mathrm{L}) .
\end{aligned}
$$

Several assumptions must be made to simplify diffusion calculations.

- Conceptually, diffusion proceeds one-dimensionally beyond the interface of the contaminated medium (waste solution), into the uncontaminated medium (concrete). 
- The concentration gradient can be represented as approximately linear from concentration equals $C_{o}$ at the interface of the liquid and concrete to concentration $=0$ at some distance beyond the interface.

- Moisture content $\left(\theta_{\mathrm{m}}\right)$ is constant at some initial moisture value $\left(\theta_{\mathrm{mi}}\right)$ ahead of the interface. No moisture transport occurs within the diffusion zone. (Moisture transport was considered in the advection calculations earlier in this section.)

Given these assumptions Fick's law can be restated as:

$$
\mathrm{J}=\theta_{\mathrm{mi}} \mathrm{DAC} / \Delta \mathrm{x}
$$

The associated relationship for continuity is:

$$
\mathrm{J}=\theta_{\mathrm{mi}} \mathrm{AC}_{\mathrm{o}} \mathrm{d}(\Delta \mathrm{x}) / \dot{\mathrm{d} t}
$$

Where:

$$
\mathrm{t}=\text { time }(\mathrm{T})
$$

By combining and integrating these equations:

$$
\begin{aligned}
& (\Delta x)^{2}=2 D \Delta t \\
& \Delta x=\sqrt{2 D \Delta t}
\end{aligned}
$$

Using the simplifying assumption that the concentration profile is approximately linear, the mass $(M)$ diffused into the concrete can be calculated as a triangle of height $C_{o}$ and length $\Delta \mathrm{x}:$

$$
M=1 / 2 C_{o} \Delta x \theta_{m i} A=C_{o} \theta_{m i} A \sqrt{D \Delta t / 2}
$$

Assumed values for contaminant concentration $\left(C_{0}\right)$, area $(A)$ and time period $(\Delta t)$ are the same as those used earlier in this section. The moisture content of the concrete ahead of the advection front is estimated to be $70 \%$ of the total porosity, or 0.15 . This value is based on the assumption that the fine pores in concrete will be largely filled with water under the humid conditions that exist belowground. The effective diffusivity of the concrete is assumed to be $5 \times 10^{-8} \mathrm{~cm}^{2} / \mathrm{s}\left(4.7 \times 10^{-6} \mathrm{ft}^{2} /\right.$ day). The Hanford and Savannah River Sites used this value in performance assessments of grouted waste to be disposed at those sites (Blanchard et al. 1993). For these conditions, the mass of nitrate that has diffused into the concrete in an individual tank was estimated to be $750 \mathrm{~kg}(1,600 \mathrm{lb})$. 
The depth of diffusive penetration determined by this simplistic method was $6.9 \mathrm{~cm}(2.7$ in.). This penetration "depth" is approximately equal to the 4.1 to $12.7 \mathrm{~cm}$ (1.6 to $5.0 \mathrm{in}$.) penetration depth estimated for advection. Most of the driving force for diffusion would be dissipated because advection would occur in the same space in the concrete that would be affected by diffusion. Thus, diffusion cannot be expected to control the mass of contamination in the concrete. For modeling purposes, it was assumed that the impacts of diffusion are insignificant.

\section{Assumptions for Sensitivity Analysis Involving Diffusion}

The assumed effective diffusivity value of $5 \times 10^{-8} \mathrm{~cm}^{2} / \mathrm{s}\left(7.8 \times 10^{-9} \mathrm{in}^{2} / \mathrm{s}\right)$ may be somewhat low since it was based on diffusion studies involving cesium and strontium. Both of these species tend to adsorb to calcic mineral phases within the concrete, thereby lowering the effective diffusivity.

Several of the contaminants of interest to this study (e.g., nitrate, nitrite, and ${ }^{129} \mathrm{I}$ ) are unlikely to sorb within the concrete and will exhibit higher effective diffusivities. A ten-fold increase in the effective diffusivity would result in 3.2 times more mass and distance diffused. The resulting mass of nitrate diffused into the concrete of a single tank would be $1,700 \mathrm{~kg}(3,700 \mathrm{lb})$, an amount similar to the $2,800 \mathrm{~kg}(6,200 \mathrm{lb})$ assumed to advect into the concrete of a tank with the highest advection. Because the advective flux would encroach into the space in which diffusion is occurring, the concentration driving force from the concrete/waste solution interface would largely be eliminated. Thus, the overall effects of diffusion in this case would also be small and consequently are ignored in the sensitivity analysis.

\subsubsection{Residue in Soil Due to Old and New Leaks}

Soil contaminated by old and new leaks is shown schematically in Figure 6-4. It was assumed that five of the 12 tanks in the hypothetical tank farm previously leaked. Boomer et al. (1993) reported that 67 of the 149 SSTs leaked and discharged a total of about $2,850,000 \mathrm{~L}$ ( $750,000 \mathrm{gal})$. Thus, the average leakage per tank was assumed to be $42,000 \mathrm{~L}$ $(11,000 \mathrm{gal})$. It was assumed further that each of the five hypothetical tanks leaked $42,000 \mathrm{~L}$ $(11,000 \mathrm{gal})$ with a concentration equal to half that assumed for interstitial liquid. The reduced concentration was assumed because historic leaks occurred in many cases before the wastes were fully concentrated and after dilution of tank waste to facilitate sluicing operations. New leakage would be expected for alternatives that require sluicing except for those that include close-coupled barriers. In the cases of the Close-Coupled Chemical Barrier without Flushing Alternative and the Clean-Closure With Close-Coupled Chemical Barrier Alternative, it was assumed that two additional tanks leak 42,000 L (11,000 gal) each before barriers would be installed. In the case of the Modified Close-Coupled Barrier Without Flushing Alternative, it was assumed that two additional tanks would leak 150,000 L $(40,000 \mathrm{gal})$ each due to the absence of a barrier underneath the tanks. 
WHC-SD-WM-ES-300 REV. 1

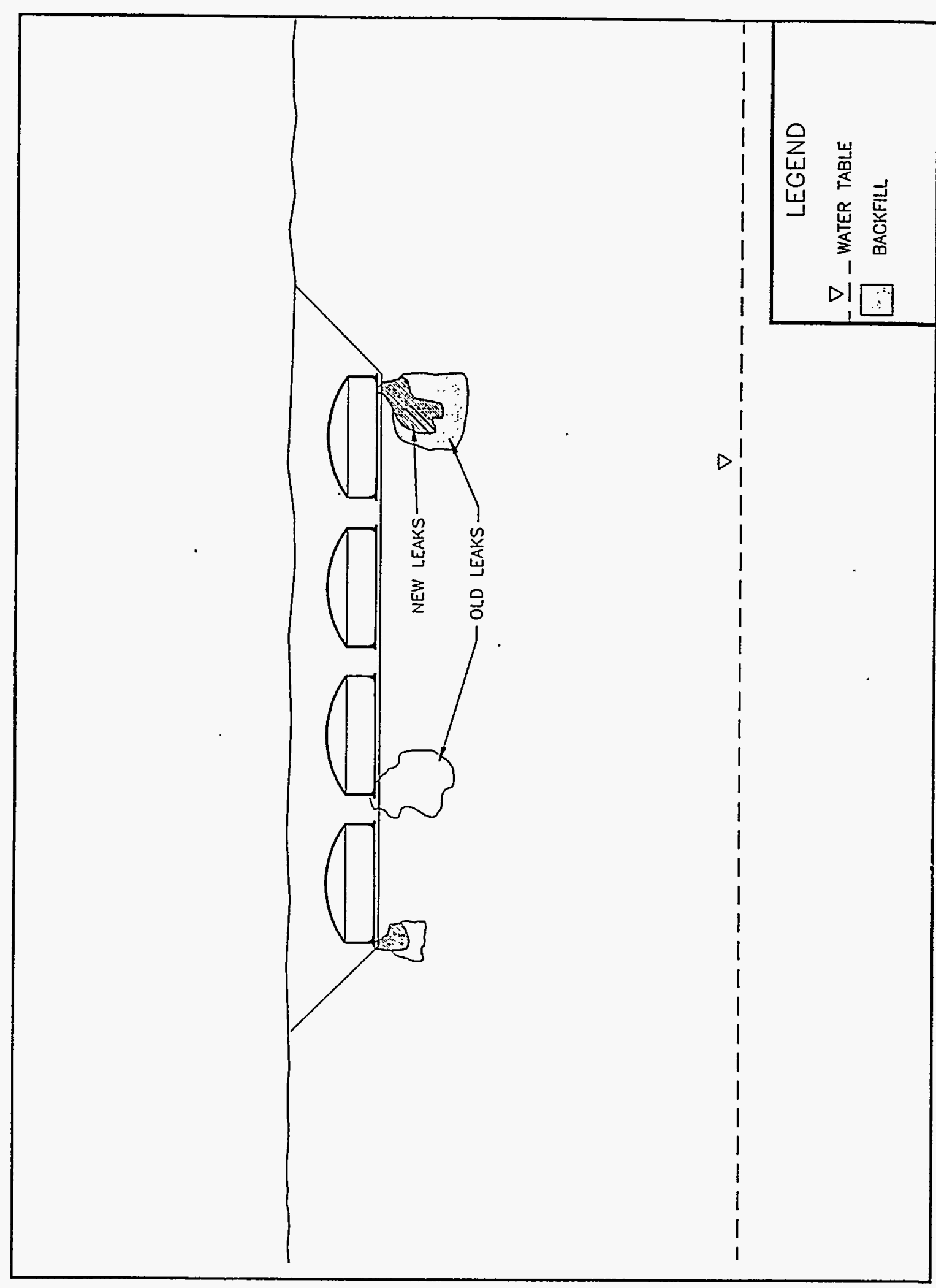

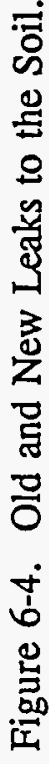


Lowe (1993) estimated that a leak of up to $150,000 \mathrm{~L}(40,000$ gal) may occur during traditional sluicing of Tank $241-\mathrm{C}-106$ by the most likely leak mechanism. For this study it was assumed that five of the 12 tanks leak $150,000 \mathrm{~L}$ (40,000 gal) each during new sluicing operations at concentrations of half that of the interstitial liquid. It was also assumed that a total of $15,000 \mathrm{~L}(4,000 \mathrm{gal})$ leak from each of five of the 12 tanks in the case of robotic sluicing. This assumption was predicated on the lower head of liquid that will exist in tanks during robotic sluicing. This head was assumed to be $1 / 10$ that required for traditional sluicing. The average head of liquid during traditional sluicing is expected to be about $4.6 \mathrm{~m}$ $(15 \mathrm{ft}$ ) and the average head of liquid during robotic sluicing is expected to be about $0.5 \mathrm{~m}$ $(1.5 \mathrm{ft})$. It is assumed that the lower head would be assured by pumping liquid as it slowly accumulates at existing and new salt wells in the tanks.

New leaks would likely occur in cracks or corroded areas of the tank wall where previous leaks occurred. Some locations of past leaks may have become sealed by particles or may exist at elevations above new sluicing liquid levels. New cracks may open during renewed sluicing operations. For ease of modeling, it was assumed that the five tanks that leak during renewed sluicing operations would discharge liquid waste through past leak locations.

Thus, alternatives without close-coupled barriers that involve traditional sluicing operations are modeled with five leaking tanks, each with assumed cumulative $193,000-\mathrm{L}$ (51,000-gal) leaks. For comparison, the total nitrate discharged to the soil, per tank for assumed 42,000and $193,000-\mathrm{L}(11,000$ - and 51,000-gal) leaks, is 5,200 and $24,000 \mathrm{~kg}(11,000$ and $53,000 \mathrm{lb})$, respectively. The total nitrate released from the five tanks was assumed to be $26,000 \mathrm{~kg}(57,000 \mathrm{lb})$ for old leaks and $120,000 \mathrm{~kg}(265,000 \mathrm{lb})$ for combined old and new leaks, respectively.

For robotic sluicing, the total old and new leakage per tank was assumed to be $57,000 \mathrm{~L}$ $(15,000 \mathrm{gal})$, or $285,000 \mathrm{~L}(75,000 \mathrm{gal})$ for the five leaking tanks. This would be equivalent to $36,000 \mathrm{~kg}(80,000 \mathrm{lb})$ of nitrate released to the ground. For the Close-Coupled Chemical Barrier without Flushing Alternative and the Clean-Closure with Close-Coupled Chemical Barrier Alternative, a total of $293,000 \mathrm{~L}(77,000 \mathrm{gal})$ and $36,000 \mathrm{~kg}(79,000 \mathrm{lb})$ of nitrate would be released for each alternative. For the Modified Close-Coupled Chemical Barrier Without Flushing Alternative, a total of $26,000 \mathrm{~kg}(57,000 \mathrm{lb})$ of nitrate was assumed to have been released from old leaks. A total of $300,000 \mathrm{~L}(80,000$ gal) would leak at the unprotected bases of two tanks during renewed sluicing operations. This would be equivalent to $39,000 \mathrm{~kg}(85,000 \mathrm{lb})$ of nitrate. Thus, the total nitrate that would leak to the soil in this alternative would be $63,000 \mathrm{~kg}(138,000 \mathrm{lb})$.

Boomer et al. (1993) reported data on the estimated depth of past SST leaks below the bottom of tanks, which are located $15 \mathrm{~m}$ (50 ft) beneath the surface. Data on the estimated depths of leaks reported by Boomer et al. (1993) are based on the assumptions that (1) plume dimensions are proportional to the well-characterized plume from Tank 241-C-106, and (2) plume volume is 57 times the leak volume. Local stratigraphy may greatly impact the size, shape, and depth of individual plumes. Using the data in Boomer et al. (1993), plume thicknesses of 8.5 and $15 \mathrm{~m}$ ( 28 and $49 \mathrm{ft}$ ) were estimated for leaks of 42,000 and 194,000 L 
$(11,000$ and 51,000 gal) respectively. Thus, the bases of these plumes would be located 24 and $30 \mathrm{~m}$ (78 and $99 \mathrm{ft}$ ) below the ground surface. Plumes of 57,000 L (15,000 gal) leaks resulting from robotic sluicing would be located $25 \mathrm{~m}(81 \mathrm{ft})$ below the ground surface.

The average flux ( $f$ ) of contaminants from the base of a plume is modeled as:

$$
\mathrm{f}=\underline{\mathrm{Md}}
$$

Where:

$$
\begin{aligned}
& M=\text { total mass of contaminant in plumes }(M) \\
& t_{\mathbf{L}}=\text { time for recharge to travel from the base of the tank to the aquifer } \\
& (T) \\
& d_{\mathbf{a}}=\text { distance from the base of tank to the aquifer }(\mathrm{L}) \\
& d_{\mathrm{p}}=\text { distance from the base of tank to the base of plume, i.e., plume } \\
& \text { thickness }(\mathrm{L}) .
\end{aligned}
$$

The time ( $\left.t_{2}\right)$ for recharge to travel from the base of the tank to the aquifer was estimated using the MEPAS code. This code accounted for hydrogeologic definition of three strata between the surface and the aquifer (See Appendix A). Travel times of 190 years and 19,000 years were projected for recharge rates of 5 and $0.05 \mathrm{~cm} / \mathrm{yr}$ ( 2 and $0.02 \mathrm{in} / \mathrm{yr}$ ), respectively. Travel times of 19,000 years were assumed for each alternative except for the No-Action Alternative which would not include the use of the Hanford Permanent Isolation Surface Barrier. It was assumed that the distance between the tank base and the water table is $79 \mathrm{~m}(259 \mathrm{ft})$. Thus, the average pore velocity of contaminant plumes would be $0.4 \mathrm{~m} / \mathrm{yr}$ $(1.3 \mathrm{ft} / \mathrm{yr})$ for the $5 \mathrm{~cm} / \mathrm{yr}(2 \mathrm{in} / \mathrm{yr})$ recharge scenario and $0.004 \mathrm{~m} / \mathrm{yr}(0.013 \mathrm{ft} / \mathrm{yr})$ for the $0.05 \mathrm{~cm} / \mathrm{yr}(0.02 \mathrm{in} / \mathrm{yr})$ scenario.

The duration (d) of the release is given by:

$$
\mathrm{d}=\mathrm{M} / \mathrm{R}
$$

Where:

$$
\begin{aligned}
M & =\text { total mass of contaminant in plumes }(M) \\
R & =\text { average contaminant release rate }(M / T) .
\end{aligned}
$$

The overall release rates of nitrate, release durations, and plume depths below ground surface are summarized in Table 6-5. This table also includes nitrate release data for the CloseCoupled Chemical Barrier and Circulating Air Barrier Alternatives that use soil flushing as described in Section 6.1.6. 
Table 6-5. Nitrate Release Data for Old and New Leaks. ${ }^{2}$

\begin{tabular}{|c|c|c|c|c|c|c|c|c|}
\hline Alternative & $\begin{array}{l}\text { Total Nitrate } \\
\text { Mass in } \\
\text { Plumes, M } \\
(\mathrm{kg})\end{array}$ & $\begin{array}{l}\text { Recharge } \\
\text { Time, } t_{2} \\
(y r)\end{array}$ & $\begin{array}{c}\text { Tank to } \\
\text { Aquifer } \\
\text { Distance, } \\
d_{a}(m)\end{array}$ & $\begin{array}{l}\text { Plume } \\
\text { Thickness, } \\
d_{p}(m)\end{array}$ & $\begin{array}{l}\text { Recharge } \\
\text { Travel } \\
\text { Rate, } r_{\mathrm{r}} \\
(\mathrm{m} / \mathrm{yr})\end{array}$ & $\begin{array}{c}\text { Overall Plume } \\
\text { Release Rate, } \\
\text { R (kg/day) }\end{array}$ & $\begin{array}{l}\text { Release } \\
\text { Rate } \\
\text { Duration, } \\
d(y r)\end{array}$ & $\begin{array}{l}\text { Depth of } \\
\text { Plume } \\
\text { Base (m) }\end{array}$ \\
\hline 1. No Action & 26,000 & 190 & 79 & 8.5 & 0.4 & 3.5 & 20 & 23.8 \\
\hline 2. Surface Barrier Only & 26,000 & 19,000 & 79 & 8.5 & 0.004 & 0.03 & 2,000 & 23.8 \\
\hline 3. Traditional Sluicing & 120,000 & 19,000 & 79 & 15 & 0.004 & 0.1 & 3,600 & 30.2 \\
\hline 4. Robotic Sluicing & 36,000 & 19,000 & 79 & 9.2 & 0.004 & 0.05 & 2,200 & 24.4 \\
\hline 5. Mechanical Retrieval & 26,000 & 19,000 & 79 & 8.5 & 0.004 & 0.03 & 2,000 & 23.8 \\
\hline $\begin{array}{l}\text { 6. Close-Coupled } \\
\text { Chemical Barrier With } \\
\text { Flushing" }\end{array}$ & 1,500 & 19,000 & 79 & 8.5 & 0.004 & 0.002 & 2,000 & 23.8 \\
\hline $\begin{array}{l}\text { 7. Close-Coupled } \\
\text { Chemical Barrier w/o } \\
\text { Flushing }\end{array}$ & 36,000 & 19,000 & 79 & 8.5 & 0.004 & 0.05 & 2,000 & 23.8 \\
\hline $\begin{array}{l}\text { 8. Modified Close- } \\
\text { Coupled Chemical Barrier } \\
\text { w/o Flushing }\end{array}$ & 63,000 & 19,000 & 79 & 15 & 0.004 & 0.05 & 3,600 & 30.3 \\
\hline 9. Circulating Air Barrier ${ }^{2}$ & 7,200 & 19,000 & 79 & $8.5^{b}$ & 0.004 & 0.01 & 2,000 & 23.8 \\
\hline $\begin{array}{l}\text { 10. Traditional Sluicing } \\
\text { (Low Sensitivity Case) }\end{array}$ & 50,000 & 19,000 & 79 & 10 & .0 .004 & 0.06 & 2,400 & 25.3 \\
\hline $\begin{array}{l}\text { 11. Traditional Sluicing } \\
\text { (High Sensitivity Case) }\end{array}$ & 168,000 & 19,000 & 79 & 16 & 0.004 & 0.12 & 3,800 & 31.3 \\
\hline
\end{tabular}

2Results presented for the Close-Coupled Barrier and Circulating Air Barrier Alternatives represent conditions following soil flushing, as evaluated in Section 6.1.6.

"Plume thickness for the Circulating Air Barrier Alternative was assumed to be limited to the thickness of the original $41,800 \mathrm{~L}$ (11,000-gal) leak (8.5 $\mathrm{m}$ or $28 \mathrm{ft}$ ). 


\section{Assumptions for Sensitivity Analysis}

New leakage may be smaller than estimated for alternatives employing traditional sluicing. For this sensitivity case, it was assumed that only 38,000 L (10,000 gal) of new leakage per tank occurs. This amount of leakage would be similar to the average of $42,000 \mathrm{~L}$ (11,000 gal) per tank that occurred in past leaks. The resulting 79,800 L (21,000 gal) plumes (past plus new leakage) from each of the five leaking tanks would penetrate to a depth of about $10 \mathrm{~m}$ (34 ft) below their associated tanks, based on interpolation of data presented in Boomer et al. (1993). The total leakage from the five tanks would be $400,000 \mathrm{~L}(105,000 \mathrm{gal})$ and $49,000 \mathrm{~kg}(110,000 \mathrm{lb})$ of nitrate.

It was also assumed that a higher amount of past leakage can occur. Tank $241-\dot{\mathrm{T}}-106$, for example, was estimated to have leaked a total of $437,000 \mathrm{~L}(115,000 \mathrm{gal})$ (Boomer et al. 1993). If the average past leak was assumed to be $114,000 \mathrm{~L}(30,000$ gal), which is representative of a tank farm containing Tank 241-T-106 and four average leaking tanks, the cumulative old plus new leak total of $266,000 \mathrm{~L}$ (70,000 gal) per leaking tank would be assumed to penetrate to an average depth of $16 \mathrm{~m}(53 \mathrm{ft})$ below the tank using data in Boomer et al. (1993). The total leakage from the five tanks in this scenario would be $1,330,000 \mathrm{~L}(350,000 \mathrm{gal})$ and $165,000 \mathrm{~kg}(364,000 \mathrm{lb})$ of nitrate.

Release data for the low and high sensitivity cases are summarized on Table 6-5. Total nitrate masses released due to old and new leakage are summarized in Table 6-6.

\subsubsection{Residue Following Soil Flushing of Old and New Leaks}

Residual contamination in the soil following soil flushing is shown schematically in

Figure 6-5. It was assumed that flushing of COCs from the vadose zone using water will be effective for SST applications. Although the technology has not been developed for these applications, the low sorptive potential for the COCs and the hydraulically conductive nature of Hanford Site soils are conditions that are conducive to the successful application of the technology. A review of the literature revealed that soil flushing has resulted in removal efficiencies ranging to $98 \%$ in laboratory tests for a nonsorbing chemical following flushing with three pore volumes (Ellis and Payne 1984). Soil flushing is generally ineffective for removing strongly sorbed species.

It was assumed that retrieval of $94 \%$ of the leaked SST waste can be achieved. This removal efficiency is predicated on the assumption that $50 \%$ of the residual COCs will be removed with each succeeding pore volume flush. At this removal efficiency, the residual nitrate in the ground following 42,000 and $194,000 \mathrm{~L}$ (11,000 and 51,000 gal) of leakage and subsequent flushing would be 320 and $1,450 \mathrm{~kg}(690$ and $3,200 \mathrm{lb})$, respectively, per affected tank. The total residual nitrate for five leaking tanks would be 1,550 and $7,220 \mathrm{~kg}(3,400$ and $16,000 \mathrm{lb}$ ). Release data for residual nitrate following flushing for the Close-Coupled Chemmical Barrier With Flushing and the Circulating Air Barrier Alternatives were provided in Table 6-5. 
Table 6-6. Summary of Pre-Flushing Leakage Into Soil.

\begin{tabular}{|c|c|c|c|}
\hline & \multicolumn{3}{|c|}{ Total Leaked Nitrate $(\mathrm{kg})^{\mathbf{a}}$} \\
\hline Alternative & Low Casè & Best Case & High Case \\
\hline 1. No Action & 26,000 & 26,000 & 70,000 \\
\hline 2. Surface Barrier Only & 26,000 & 26,000 & 70,000 \\
\hline 3. Traditional Sluicing & 49,000 & 120,000 & 165,000 \\
\hline 4. Robotic Sluicing & 36,000 & 36,000 & 79,000 \\
\hline 5. Mechanical Retrieval Barrier & 26,000 & 26,000 & 70,000 \\
\hline 6. Close-Coupled Chemical w/Flushing ${ }^{\mathrm{b}}$ & 26,000 & 26,000 & 70,000 \\
\hline 7. Close-Coupled Chemical w/o Flushing ${ }^{\mathrm{b}}$ & 36,000 & 36,000 & 80,000 \\
\hline $\begin{array}{l}\text { 8. Modified Close-Coupled Chemical } \\
\text { Barrier w/o Flushing }\end{array}$ & 35,000 & 63,000 & 107,000 \\
\hline 9. Box-Shaped Chemical Barrier & 49,000 & 120,000 & 165,000 \\
\hline 10. V-Shaped Chemical Barrier & 49,000 & 120,000 & 165,000 \\
\hline 11. V-Shaped Freeze Wall & 49,000 & 120,000 & 165,000 \\
\hline 12. Circulating Air Barrier & 49,000 & 120,000 & 165,000 \\
\hline 13. Clean-Closure w/o Barrier & 49,000 & 120,000 & 165,000 \\
\hline 14. Clean-Closure with Barrier ${ }^{b}$ & 36,000 & 36,000 & 80,000 \\
\hline
\end{tabular}

${ }^{a}$ Total nitrate mass includes nitrate in old and new leakage.

${ }^{b}$ Does not include nitrate that advects into the barrier. 
WHC-SD-WM-ES-300 REV. 1

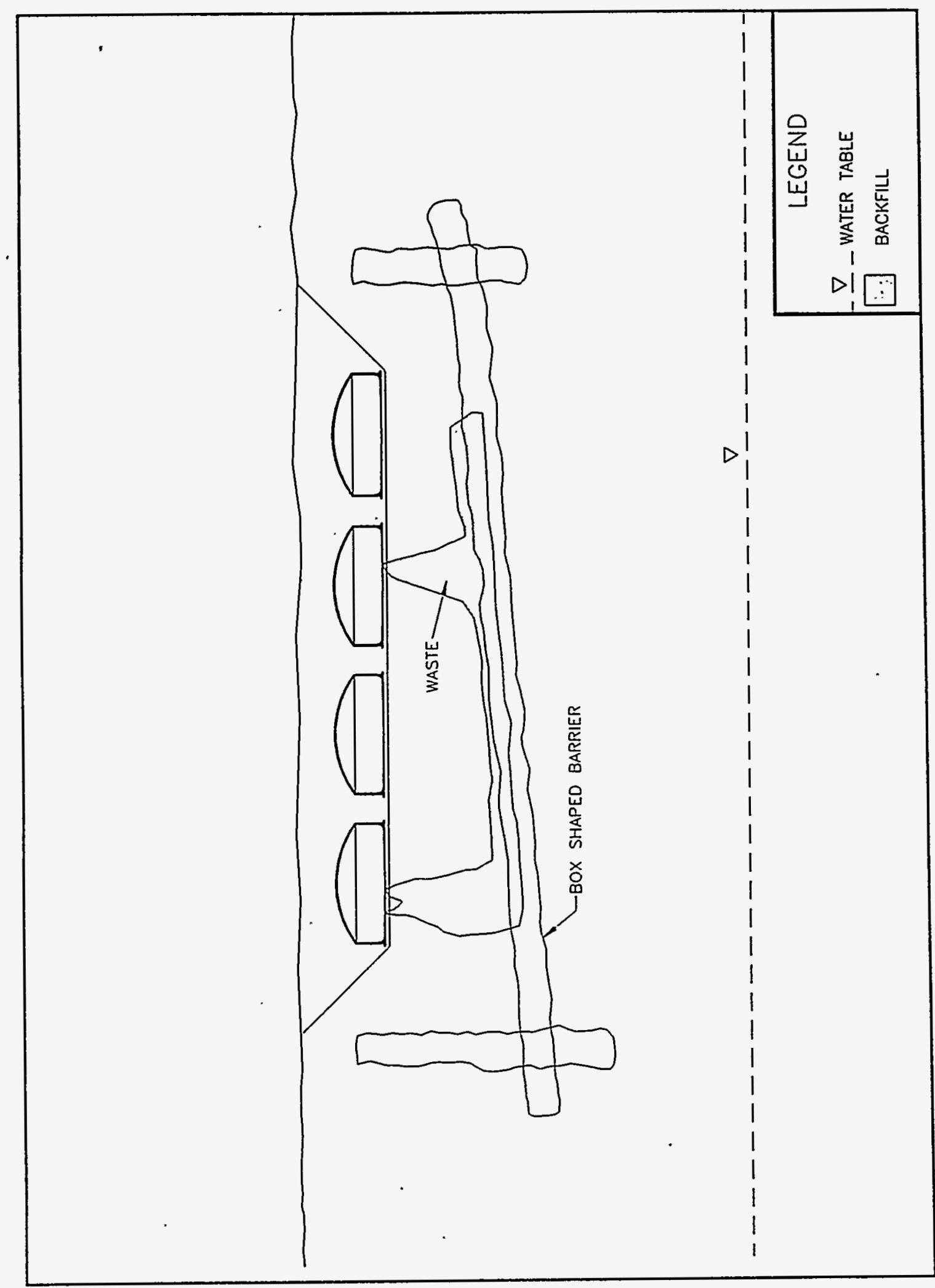

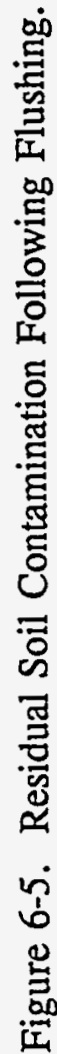


The estimated total volume of water required to flush five $42,000 \mathrm{~L}$ (11,000 gal) leaks using vacuum flushing was $5.2 \times 10^{7} \mathrm{~L}$ (14 Mgal). This estimate was based on the assumption that the volume requiring flushing under each tank that has leaked is defined by a cylindrical column of soil with a diameter of $30 \mathrm{~m}(100 \mathrm{ft})$ and a height of $9.1 \mathrm{~m}(30 \mathrm{ft})$. It was also assumed that the soil has a porosity of 0.4 and that flushing with four pore volumes is required to achieve acceptable cleanup.

\section{Assumptions for Sensitivity Analysis}

A potentially attractive flushing option is adding water to leaking SSTs to flush residual contaminants from the tanks and leak pathways. The resulting leaks would be recovered from the soil beneath the tank using vacuuming techniques. For this low case it was assumed that one-half the COCs in the residual tank waste in leaking tanks would be recovered using this approach. For options that employ traditional sluicing, the residual waste volume would be reduced to $0.5 \%$ of the inventory in the five leaking tanks. This would be equivalent to a total residual nitrate inventory of $61,700 \mathrm{~kg}(136,000 \mathrm{lb})$ in the 12 tanks.

The difficulties of emplacing flush water injection and recovery pipes under the tanks may render the technology much less-effective than expected; in this high case, a $50 \%$ recovery effectiveness was assumed. This would result in a total inventory of nitrate in the soil of 12,500 and $60,000 \mathrm{~kg}(27,500$ and $132,000 \mathrm{lb})$ following 42,000 and $194,000 \mathrm{~L}(11,000$ and 51,000 gal) leaks with subsequent soil flushing under all five leaking tanks.

\subsubsection{Residue Within Close-Coupled Barrier}

Contaminants may penetrate into the close-coupled barrier as shown schematically in Figure 6-6. It was assumed that the use of sluicing to retrieve SST wastes would impart a head and a concentration gradient on any surface of the close-coupled barrier connected hydraulically to the waste in the tank. This head and concentration gradient were assumed to result in advection and diffusion of contaminants into the barrier. The mass of contaminants assumed to be advected and diffused into the barrier is dependent on Darcy's and Fick's Laws as in the case of advection and diffusion into the tank's structural concrete. Estimation of the advected and diffused mass of contaminants is complicated by the two- or threedimensional mass transfer that would occur along a crack or at a point source. For modeling purposes, it was assumed that waste solution with half the interstitial liquid concentration would be in contact with the barrier along a line that circumscribes the tank at the intersection of the tank's vertical and horizontal concrete structural members. This location coincides with an actual construction joint between these two members. It was also assumed that the interstitial liquid would be in contact with the barrier through a crack that passes diametrically through the concrete base (Figure 6-7). Lowe (1993) also postulated leakage at the construction joint and a crack in the concrete base. Observations of plots of past SST leaks indicate that leakage occurs at discrete points rather than evenly around the joint or in other cracks. Thus, it was assumed that leakage occurs along only $10 \%$ of the assumed 
WHC-SD-WM-ES-300 REV. 1

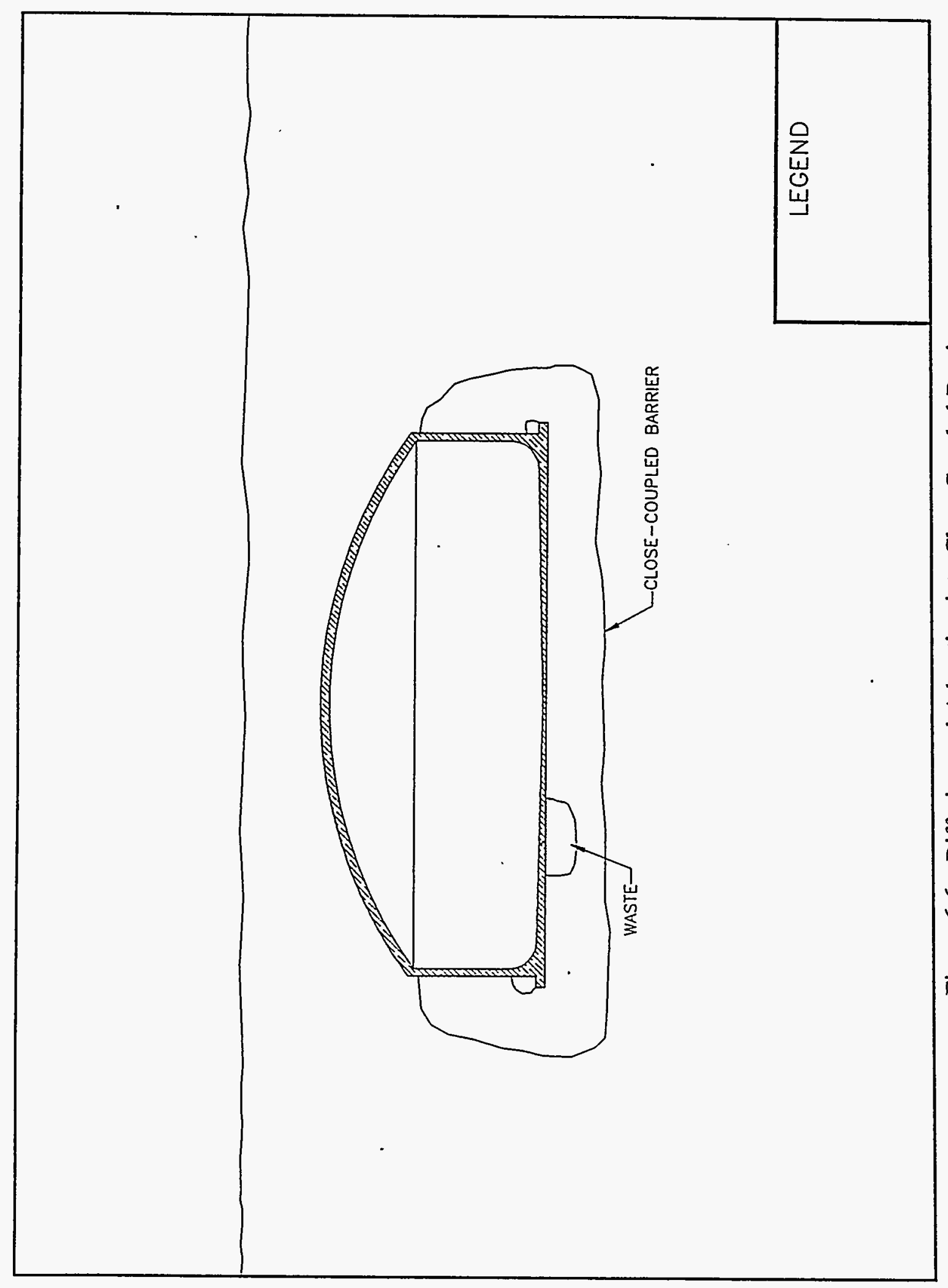




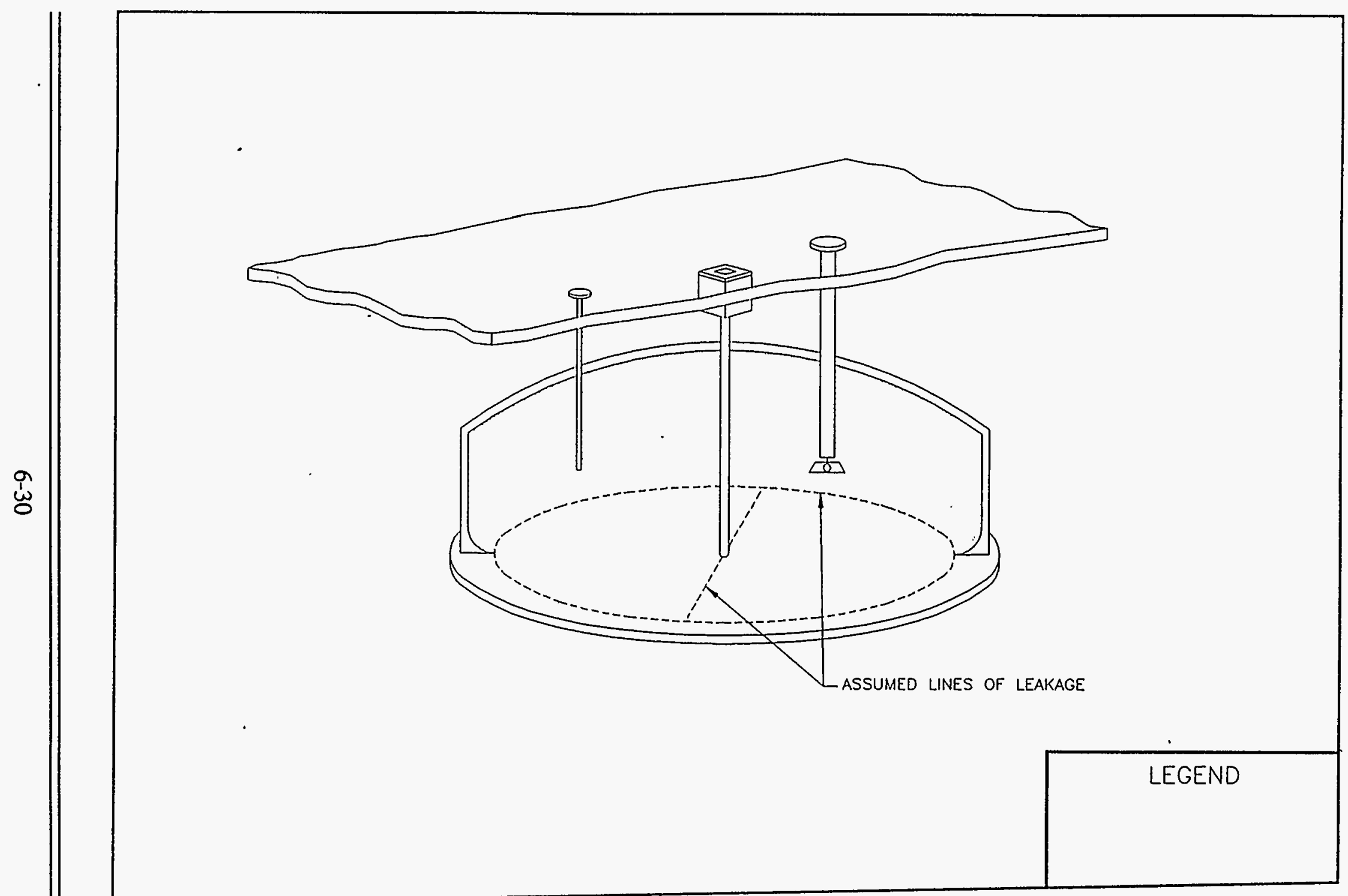

Figure 6-7. Assumed Lines of Potential Leakage from SSTs. 
crack line and that the remaining $90 \%$ of the crack line remains sealed. The overall length (L) of the line source is represented by the following equation:

$$
L=\left(\pi D_{0}+D_{0}\right) / 10
$$

For outer tank diameter, $D_{0}=24 \mathrm{~m}(79 \mathrm{ft})$, the line source length is $10 \mathrm{~m}(33 \mathrm{ft})$. This scenario was modeled by first calculating the advective distance for an advection period equal to the duration of the applied head. The advective distance was calculated using Equation 5, which can be restated as:

$$
x=\sqrt{2 K h t / n}
$$

The applied average head (h) was assumed to be $4.6 \mathrm{~m}(15 \mathrm{ft})$ for traditional sluicing. The time $(\mathrm{t})$ required to achieve cleanout of a tank is provided by the following expression:

$$
\mathrm{t}=\frac{\mathrm{V}}{\mathrm{RE}}
$$

Where:

$$
\begin{aligned}
& V=\text { total volume of waste in the tank }\left(\mathrm{L}^{3}\right) \\
& \mathrm{R}=\text { average waste retrieval rate }\left(\mathrm{L}^{3} / \mathrm{T}\right) \\
& \mathrm{E}=\text { total operating efficiency (unitless). }
\end{aligned}
$$

Boomer et al. (1993) reported expected average retrieval rates of $9.5 \mathrm{~L} / \mathrm{min}(2.5 \mathrm{gal} / \mathrm{min})$ and an estimated total operating efficiency of $56 \%$ for traditional sluicing. Boomer et al. (1993) also reported a total volume of $1.4 \times 10^{8} \mathrm{~L}$ (37 Mgal) of waste in 149 SSTs. Thus, the time predicted for cleanout of an average tank using traditional sluicing was 123 days.

The hydraulic conductivity of the injected grouts that may be emplaced around SSTs in a close-coupled configuration is unknown. However, Golder (1994) reported hydraulic conductivities as low as $10^{-6} \mathrm{~cm} / \mathrm{s}(0.0028 \mathrm{ft} /$ day $)$ for laboratory samples injected with a sodium silicate grout. The requirement that chemical grouts gel within a few hours to prevent excessive loss of the grout formers by percolation through the soil makes it unlikely that the grout formers will penetrate adequately into soils with conductivities of $10^{-5} \mathrm{~cm} / \mathrm{s}$ $\left(0.028 \mathrm{ft} /\right.$ day) or lower. The head (typically less than $\left.50 \mathrm{lb} / \mathrm{in}^{2}\right)$ and time are not sufficient to drive the barrier-forming material into the finer pores of the soil before gelation occurs. It was assumed that most of the barrier volume in an adequate barrier would exhibit conductivities lower than $10^{-6} \mathrm{~cm} / \mathrm{s}(0.0028 \mathrm{ft} /$ day $)$. Thus, a hydraulic conductivity of $10^{-6} \mathrm{~cm} / \mathrm{s}(0.0028 \mathrm{ft} /$ day) was selected as a performance goal for injected grout barriers. Emplacement methods other than injection grouting (e.g., mechanical mixing) may be necessary to produce a barrier with an overall hydraulic conductivity of lower than $10^{-6} \mathrm{~cm} / \mathrm{s}$ (0.0028 ft/day). 
The expected effective porosity of the barrier is also unknown. Injection grouting typically involves the use of aqueous solutions or emulsions with high water contents to fill the soil pores. With this information and knowledge that the overall porosity of Hanford Site soils is about 0.4 , a barrier effective porosity of 0.2 may be reasonable. The above assumptions and the linear advection equation (Equation 18) were used to estimate an advective penetration

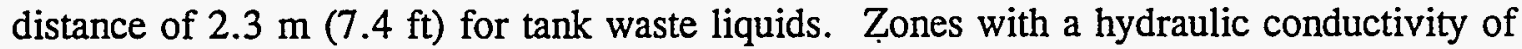
$10^{-5} \mathrm{~cm} / \mathrm{s}(0.028 \mathrm{ft} /$ day) would be penetrated $7.3 \mathrm{~m}(24 \mathrm{ft})$.

The assumed penetration distance and length of the line of projected leakage can be used to estimate the volume of the contaminated barrier matrix.

The cross-section of the conceptual advection zone was assumed to be represented by a halfcircle with a radius of $2.3 \mathrm{~m}(7.4 \mathrm{ft})$. Therefore, the volume of the penetrated barrier region would be $78 \mathrm{~m}^{3}\left(2,800 \mathrm{ft}^{3}\right)$. Twenty percent of this volume was assumed to contain interstitial liquid with half its initially assumed concentrations. Based on these assumptions, the total mass of nitrate that would have advected into the close-coupled barrier would be $2,000 \mathrm{~kg}(4,400 \mathrm{lb})$ for each tank. The total nitrate advected from the five leaking tanks into the barriers would be $10,000 \mathrm{~kg}(22,000 \mathrm{lb})$.

Contaminants released from the barrier are treated in a manner similar to contaminants released from concrete. The concentration of contaminants after entering the recharge water in the vadose zone were assumed to be one-quarter the interstitial water concentrations.

\section{Assumptions for Sensitivity Analysis Involving Advection}

For purposes of the sensitivity analysis, it was assumed that the effective hydraulic conductivity of the barrier matrix could be improved to $10^{-7} \mathrm{~cm} / \mathrm{s}\left(3.9 \times 10^{-8} \mathrm{in} / \mathrm{s}\right)$ through the use of innovative barrier forming materials and improved emplacement techniques. For this case, the total nitrate estimated to advect into the barrier would be $950 \mathrm{~kg}(2,100 \mathrm{lb})$ for

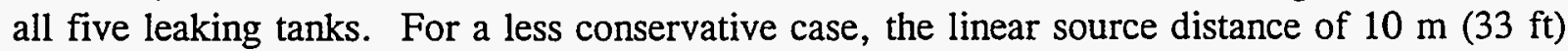
for advection and diffusion into the barrier was assumed to be understated by a factor of 10 . This condition would exist if the barrier former fails to seal effectively along the joint line, thereby allowing liquid waste to flow along this line and create a longer line source from which advection would occur. For this case, the total advected nitrate would be $95,000 \mathrm{~kg}$ $(210,000 \mathrm{lb})$. This quantity is similar to $120,000 \mathrm{~kg}(265,000 \mathrm{lb})$ estimated for leakage into the ground for the No Action Alternative, which does not include a subsurface barrier. Thus, the barrier would have no beneficial effect under this assumed condition.

\section{$\underline{\text { Diffusion }}$}

It was assumed that most of the diffusion occurs in the aqueous phase of the barrier matrix. The diffusive penetration distance $(\Delta \mathrm{x})$ was provided earlier in Equation 13:

$$
\Delta x=\sqrt{2 D \Delta t}
$$


The effective diffusivity (D) of subsurface barrier matrixes is unknown but may be estimated from the following equation used by Boomer et al. (1993) to estimate the diffusivity of soils:

$$
D=\frac{D_{m} a e^{(b \theta)}}{\theta}
$$

Where:

$$
\begin{aligned}
\mathrm{D}_{\mathrm{m}} & =\text { molecular diffusivity of solute materials in water }\left(\mathrm{L}^{2} / \mathrm{T}\right) \\
\theta & =\text { moisture content of barrier (unitless) } \\
\mathrm{a} & =0.005 \text { (empirical constant) (unitless) } \\
\mathrm{b} & =10.0 \text { (empirical constant) (unitless). }
\end{aligned}
$$

The molecular diffusivity of dissolved species in water is generally $2 \times 10^{-5} \mathrm{~cm}^{2} / \mathrm{s}$ $\left(0.0019 \mathrm{ft}^{2} /\right.$ day) or lower. The moisture content of the barrier matrix was assumed to be 0.35 , which represents a typical fine-grained Hanford Site soil with $88 \%$ of the pores filled with water. Applying these values to Equation 20 would yield an effective diffusivity of $1 \times 10^{-5} \mathrm{~cm}^{2} / \mathrm{s}\left(0.0009 \mathrm{ft}^{2} /\right.$ day).

The assumed diffusive penetration "distance," $(\Delta \mathrm{x})$, would be $0.14 \mathrm{~m}(0.47 \mathrm{ft})$ when $\Delta \mathrm{t}$ equals 123 days. The advective penetration distance was $2.2 \mathrm{~m}(7.2 \mathrm{ft})$; thus, advective flow would clearly dominate. Diffusion-induced contamination would be insignificant.

\subsubsection{Residue Following Use of Stand-off Barriers}

The assumed distribution of contaminants following use of a standoff barrier is shown schematically in Figure 6-8. Sources of potential groundwater contamination would include contaminated soil and the abandoned barrier matrix. The purpose of a standoff barrier would be to provide containment of both past and new leakage to the soil and to facilitate recovery of leaked waste from the low point of the barrier.

Leaks from SSTs would be expected to migrate slowly in Hanford Site soils. The slow rate of migration of leaked SST waste is evident from plume migration data collected to track the 437,000 L (115,000 gal) leak from Tank 241-T-106. Between 1978 and 1994, the depth of leakage from this tank may have increased from 32 to $46 \mathrm{~m}$ (105 to $151 \mathrm{ft}$ ) belowground surface, based on measurements of ${ }^{99} \mathrm{Tc}$. This migration rate, which is a function of advection and diffusion, is equivalent to about $1 \mathrm{~m} / \mathrm{yr}(3 \mathrm{ft} / \mathrm{yr}$ ). It should be noted that this migration rate may be artificially high due to factors such as cross-contamination of the soil during dry well emplacement and creation of preferential water flow paths along the well casing-soil interface. Run off of meteoric water from the roof of the tank may also have induced water channeling along and below the circumference of the tanks. This can drive contaminants deeper in selected locations. Smaller leaks from other SSTs may have migrated to depths of $30.5 \mathrm{~m}$ (100 ft), for example, due to longer migration times, higher 
WHC-SD-WM-ES-300 REV. 1

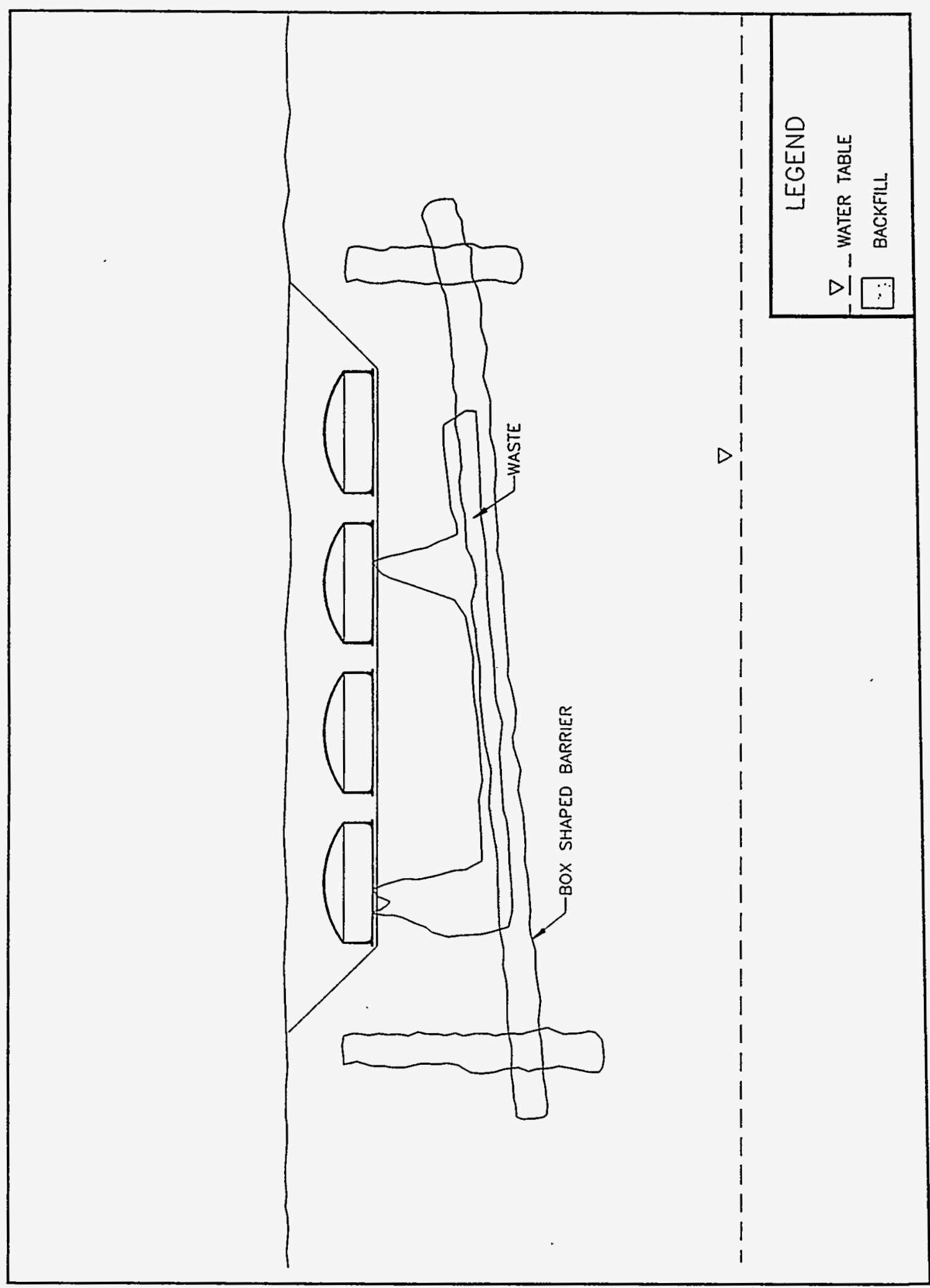


conductivities, preferential flow paths (e.g., along clastic dikes), and/or lower field capacities in soils under those tanks. Thus, it was assumed that the standoff barrier would be installed to a depth of at least $30.5 \mathrm{~m}(100 \mathrm{ft})$ below the entire boundary of the hypothetical 12-tank tank farm to ensure containment of past leaks. Deeper barriers, installed to depth of $46 \mathrm{~m}$ (150 ft) or more, would be required to confine deep leaks, such as the Tank 241-T-106 leak. Calculations based on the 46-m (150-ft) depth, the $1-\mathrm{m} / \mathrm{yr}(3-\mathrm{ft} / \mathrm{yr})$ travel time and the $15-\mathrm{m}$ (50-ft) depth of the base of the tanks indicate that more than 30 years would be required for the front of a small leak to migrate to a $46-\mathrm{m}(150-\mathrm{ft})$ deep barrier. By comparison, the $437,000 \mathrm{~L}(115,000 \mathrm{gal})$ leak from Tank $241-\mathrm{T}-106$ may have required 21 years for the plume front to apparently migrate to this depth. (The migration rate of this plume is under review; some believe the migration rate to be lower than estimated here, which would result in longer travel times to the barrier. This belief may be predicated, in part, by the past practice of disposing liquid wastes to the soil via cribs, ponds, and trenches. In designing these disposal systems, it was assumed that the wastewater would remain in the vadose zone if the volume of liquids disposed did not exceed one-third the porosity of the soil between the system and the aquifer.) After the front of the plume has reached the barrier at the 46-m (150-ft) depth, it must still travel a significant vertical and/or horizontal distance to a collection point where it would be pumped to the ground surface for treatment.

The collection point at the base of the V-shaped barrier was assumed to be $76 \mathrm{~m}(250 \mathrm{ft})$ below the ground surface. Thus, under the assumed conditions of the Tank 241-T-106 plume, an additional 30 years are projected for the front of the plume to migrate to and begin to collect in the low point of the barrier. A substantial delay would also be expected in the case of the box-shaped barrier due to long horizontal travel distances to the barrier low point. A considerably longer time would be required for the tail of the plume to collect in the barrier low point.

A projected travel time of more than 50 years for most plumes exceeds the current schedule for the cleanup of the Hanford Site. Therefore, it was assumed that soil flushing would be used to accelerate the migration rate of leaked contaminants to the barrier collection points. The addition of flush water to the soil under slug flow conditions at a hydraulic conductivity of $1.55 \times 10^{-3} \mathrm{~cm} / \mathrm{s}$ ( $4.4 \mathrm{ft} /$ day) and unit gradient was assumed. This conductivity was used for the sandy sequence of the Hanford formation in modeling the flow of contaminants for the Hanford Grout Performance Assessment (Blanchard et al. 1993).

It was further assumed that each of four pore volumes of injected water would be only $50 \%$ effective in flushing contaminants due to the effects of channeling and difficulty in removing contaminants diffused into larger particles. Channeling would be expected to be especially pronounced if unsaturated conditions are required to minimize the head on the barrier surface. At $50 \%$ effectiveness per flush, a total of four pore volume flushes would remove $94 \%$ of the leaked contaminants from the sediments. At the assumed hydraulic conductivity, the total time required for collection of the four pore volumes is 180 days for the V-shaped barrier and 120 days for the box-shaped barrier (Figure 6-9). These times are based on pore velocities at unit gradient, i.e., saturated conditions over the height of the soil column. The presence of caliche or other lenses of low hydraulic conductivity material under tank farms 


\section{WHC-SD-WM-ES-300 REV. 1}

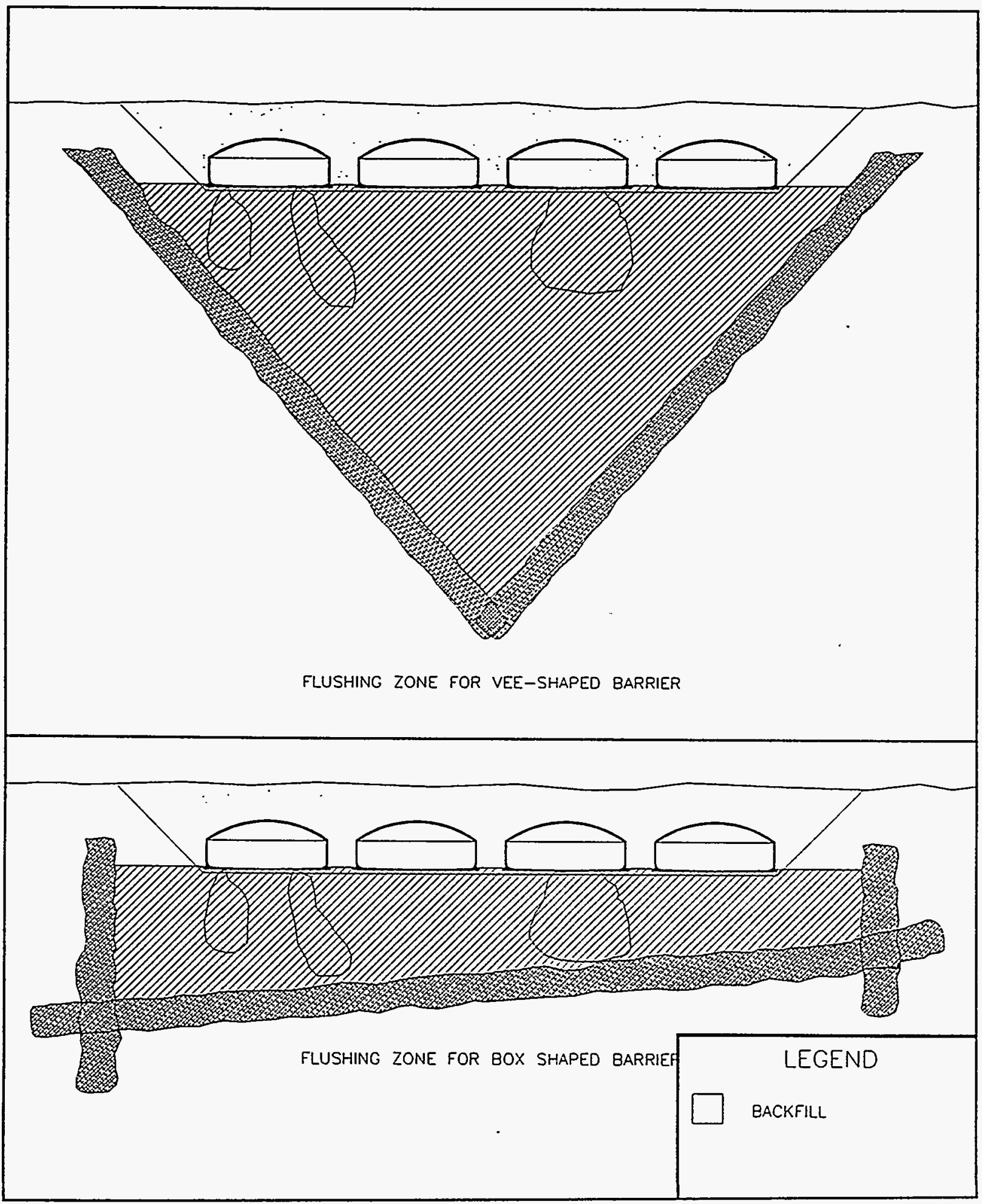

Figure 6-9. Cross-Sectional View of In Situ Flushing Zones for V-Shaped and Box-Shaped Barriers. 
would complicate soil flushing and greatly increase the time required to complete flushing. For this case, pumping of collected flush solution from the surface of low conductivity layers or drilling through such layers to promote drainage may be required to support flushing operations.

It was assumed for modeling purposes that residual contamination in the soil after leaks had occurred is evenly distributed under the tanks between a depth of 15 and $76 \mathrm{~m}$ (50 and $250 \mathrm{ft}$ ) for $\mathrm{V}$-shaped barriers and between a depth of 15 and $55 \mathrm{~m} \mathrm{(50} \mathrm{and} 180 \mathrm{ft}$ ) for boxshaped barriers (Figure 6-9). For comparison purposes, the residual nitrate in the soil following flushing would be $6 \%$ of the total mass of old and new leaks, or $7,100 \mathrm{~kg}$ $(15,700 \mathrm{lb})$ as described in Section 6.1.6. The nitrate fluxes for the $\mathrm{V}$-shaped and box-shaped barrier alternatives would be 0.001 and $0.002 \mathrm{~kg} /$ day $(0.003$ and $0.004 \mathrm{lb} /$ day $)$, respectively. The associated durations of the fluxes would be 15,000 and 10,000 years. These time periods represent the time for advecting water to move from the base of the tank to the base of the plume, thereby flushing the contaminants into clean soil at the 76 or $55 \mathrm{~m}$ (250 or $180 \mathrm{ft}$ ) depths.

\section{$\underline{\text { Advection }}$}

The head of flush water applied to the standoff barrier would likely cause contaminants to advect and diffuse into the barrier. Contaminated barrier material is another source of contamination that would eventually migrate to the groundwater, except in the case of freeze wall barriers. It was assumed that the freeze wall barrier would be constructed with heating pipes installed above and parallel to the freeze pipes to enable controlled thawing of the contaminated ice. The resulting melted ice would flow to a collection point where it would be pumped to the surface for treatment. Eventually all of the decontaminated ice would melt, leaving only soil and pore water. It was assumed that the ice decontamination strategy would be successful (i.e., the soil originally included within the ice barrier would not be contaminated to any significant degree). Thus, the soil originally within the ice barrier is not considered a source of future contamination.

Unlike freeze wall barriers, injected chemical standoff barriers likely could not be removed from the subsurface without excavating the site. Excavating the barrier would defeat one of the primary attractions of the standoff subsurface barrier (i.e., to enable use of in situ soil flushing to clean contaminants from the soil). Contaminated chemical barriers would resist cleaning using flushing because the head of liquid applied to the surface of the barrier during flushing would force contamination deeper into the barrier. The level of contamination in the injected chemical barrier would be a function of the same factors that cause contamination to be forced into the close-coupled barrier. The analysis of residual contamination in close-coupled barriers in Section 6.1.7 showed that advective transport dominated diffusive transport under the expected properties of the barrier. Thus, advective transport was modeled as the primary source of barrier contamination.

The total time the head would be applied to the barrier was assumed to be the flushing time, 180 days for the V-shaped barrier and 120 days for the box-shaped barrier. The head 
applied to the barrier was assumed to be limited through the use of unsaturated flushing and/or the use of multiple wells or drain pipes installed along the upper surface of the barrier. It was assumed that this strategy would limit the average head to $1.5 \mathrm{~m}(5 \mathrm{ft})$ of water. Otherwise, part of the flush water could advect through the barrier. Flushing time would be greatly increased under unsaturated flushing conditions because the soil's hydraulic conductivity decreases rapidly with only small decreases in water content below saturated conditions. Close spacing of well points or drain lines may be necessary to ensure that the head does not exceed $1.5 \mathrm{~m}(5 \mathrm{ft})$.

The contaminants in the solution that contacts the barrier were assumed to be diluted by the flush water. The average concentration (C) of the waste in contact with the barrier is given by:

$$
\mathrm{C}=0.94 \mathrm{M} /\left(\mathrm{V}_{\mathrm{nl}}+\mathrm{V}_{\mathrm{ol}}+\mathrm{V}_{\mathrm{fw}}\right)
$$

Where:

$M=$ total mass of contaminants in old and new leaks (M)

$\mathrm{V}_{\mathrm{nl}}=$ volume of new leaks $\left(\mathrm{L}^{3}\right)$

$\mathrm{V}_{\mathrm{ol}}=$ volume of old leaks $\left(\mathrm{L}^{3}\right)$

$\mathrm{V}_{\mathrm{fw}}=$ volume of flush water $\left(\mathrm{L}^{3}\right)$.

The volume of flush water $\left(\mathrm{V}_{\mathrm{fw}}\right)$ is given by:

$$
\mathrm{V}_{\mathrm{fw}}=\mathrm{V}_{\mathrm{s}} \theta \mathrm{N}
$$

Where:

$$
\begin{aligned}
\mathrm{V}_{\mathrm{s}} & =\text { volume of soil contacted by flush water }\left(\mathrm{L}^{3}\right) \\
\theta & =\text { total porosity of soil (unitless) } \\
\mathrm{N} & =\text { number of flushes (unitless). }
\end{aligned}
$$

The volume of soil contacted by the flush water was estimated using dimensions shown for $\mathrm{V}$-shaped and box-shaped barriers in Figure 6-9. These volumes would be 644,000 and $574,000 \mathrm{~m}^{3}\left(23,200,000\right.$ and $\left.20,500,000 \mathrm{ft}^{3}\right)$, respectively. The area of the barriers contacted by the flush liquid was also estimated using Figure 6-9. These areas would be 25,000 and $19,000 \mathrm{~m}^{2}\left(271,000\right.$ and $\left.206,000 \mathrm{ft}^{2}\right)$ for $\mathrm{V}$-shaped and box-shaped barriers, respectively. The soil porosity and number of flushes were previously given as 0.4 and 4 , respectively. The total calculated volumes of flush solution $\left(1.1 \times 10^{9}\right.$ and $9.3 \times 10^{8} \mathrm{~L}[278$ and $245 \mathrm{Mgal}$ ] for $\mathrm{V}$-shaped and box-shaped barriers, respectively) were added to the total volume of new and old leaks $(965,000 \mathrm{~L}$ [255,000 gal]). The resulting average contaminant concentrations in the flush liquid were then determined. For nitrate, these concentrations were $0.11 \mathrm{~g} / \mathrm{L}\left(0.0067 \mathrm{lb} / \mathrm{ft}^{3}\right)$ for V-shaped barriers and $0.12 \mathrm{~g} / \mathrm{L}\left(0.0076 \mathrm{lb} / \mathrm{ft}^{3}\right)$ for box-shaped barriers. 
The total mass of contaminants assumed to have advected into the barrier was determined using Equation 7. The hydraulic conductivity of the barrier $(0.09 \mathrm{~cm} /$ day $[0.0028 \mathrm{ft} /$ day] $)$ and effective porosity (0.2) used to analyze advection into close-coupled injected chemical barriers were also used in this analysis.

The estimated total nitrate advected into the V-shaped and box-shaped barriers would be 817 and $590 \mathrm{~kg}(1,800$ and 1,300 $\mathrm{lb})$, respectively. The penetrations of the advected fronts into the V-shaped and box-shaped barriers were calculated to be 1.5 and $1.3 \mathrm{~m}$ (5.0 and $4.1 \mathrm{ft}$ ), respectively. It was assumed for ease of modeling that this contamination would be distributed within the barriers uniformly with depth between depths of 46 and $76 \mathrm{~m}$ (150 and $250 \mathrm{ft})$ in the case of the V-shaped barrier and 46 and $55 \mathrm{~m} \mathrm{(150} \mathrm{and} 180 \mathrm{ft})$ in the case of the box-shaped barrier. These conditions and a recharge rate of $0.05 \mathrm{~cm} / \mathrm{yr}(0.02 \mathrm{in} / \mathrm{yr})$, would result in a nitrate flux and duration for the V-shaped barrier of $0.0003 \mathrm{~kg} / \mathrm{day}$ $(0.0006 \mathrm{lb} /$ day) and $2,800,000$ days, respectively. The flux and duration for the box-shaped barrier would be $0.0007 \mathrm{~kg} /$ day $(0.0015 \mathrm{lb} /$ day) and 840,000 days, respectively.

A small amount of contamination would also be held up in depressions in the upper surface of the barrier. Difficulties in emplacing the barrier in the highly heterogenous sediments of the Hanford formation would likely result in undulations in the barrier surface. The low points in the undulations would collect flush solution. The masses of contaminants in these low points would be relatively small because progressively cleaner flush solution would flow through these low points. This would result in low contaminant concentrations in the low points when flushing is completed. Thus, this source of contamination was not evaluated.

\section{Assumptions for Sensitivity Analysis}

The contaminants for this source would be relatively low in mass and dispersed over a

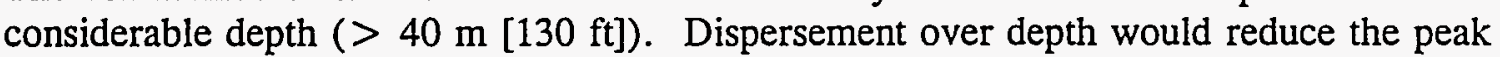
impact of the waste source in terms of groundwater contamination (i.e., it would flatten the peak concentrations). Thus, the impacts to the groundwater would be relatively low. Complete penetration of the barrier by flush water due to excessive head resulting from clogging drain pipes or pump failures would be unlikely to cause a significant fraction of the contaminant inventory to collect in the vadose zone below the barrier unless no provisions were made for monitoring and maintenance. No other uncertainties were identified that would significantly increase the contribution of this source to groundwater risk. Thus, no further sensitivity analyses were deemed necessary.

\subsection{CONTAMINANT TRANSPORT AND HUMAN HEALTH RISK}

Following definition of residual contaminant source terms, the MEPAS code (Droppo et. al 1989) was used to model contaminant transport through the vadose zone and aquifer, and estimate the relative magnitude of human exposure to those contaminants based on assumed withdrawal and use of the groundwater. The objective of these calculations was to provide a consistent evaluation of peak groundwater contaminant concentrations and relative health 
risks as points for comparison of the various retrieval alternatives. The distributions of concentrations and relative health risks as a function of time after closure of the tank farm were also evaluated to provide additional information regarding the performance of different retrieval and barrier systems.

The MEPAS code was used to consistently evaluate the relative magnitude of human health impacts from radiological and chemical contaminants released to the environment under each of the retrieval alternatives. This one-dimensional model, which is still being developed, has not yet been adopted for quantitative baseline risk analyses at the Hanford Site (DOE 1993), but is suitable for the type of screening-level analysis reported in this study. Other EPAapproved models are currently deemed appropriate for quantitative baseline risk analyses. The MEPAS was selected for this application over other models and codes because of its versatility and ability to be used cost-effectively in this type of application.

The MEPAS code employs a nontraditional approach of integrating all major exposure pathways into a single public health computational tool. It couples radiological and nonradiological contaminant release, migration, and fate for environmental media with exposure estimates for the major exposure routes. The MEPAS code uses empirical, analytical, and semi-analytical mathematical algorithms to model the following processes:

- Potential release of contaminants into the environment

- Transport of contaminants through and between multiple environmental media

- Exposure to surrounding human populations through the following exposure pathways: ingestion of water and food products, inhalation, dermal contact, and external radiation (Note: inhalation, dermal contact, and external radiation were not modeled in this analysis.)

- Human health effects associated with exposure to chemicals and radionuclides.

The MEPAS code Version 3.0g was used to evaluate contaminant transport and relative human health risks associated with each of the alternatives discussed in Section 5 . The transport modeling and calculation of potential contaminant concentrations in groundwater are discussed in Section 6.2.1. The modeling of human exposure to these contaminants and evaluation of relative health risks are discussed in Section 6.2.2.

\subsubsection{Contaminant Transport and Groundwater Concentrations}

Concentrations of contaminants in groundwater were calculated based on the contaminant sources described in Section 6.1. Contaminants released from these sources were assumed to migrate through partially saturated and saturated groundwater zones. In the partially saturated zone, flow was assumed to be in the vertical direction. The MEPAS code was used for one-dimensional modeling of contaminant transport in the vadose zone. In the 
saturated zone, the predominant movement of the contaminants was assumed to be in the direction of the groundwater flow. The MEPAS code employs a three-dimensional advective-dispersive equation to describe the migrating plume as it disperses and attenuates through the saturated aquifer. Dispersion is considered in the longitudinal, lateral, and vertical directions. The saturated aquifer modeling function of MEPAS was not used in this analysis for reasons discussed in Section 6.3.1. .

The source and geologic setting input data required for the vadose zone and groundwater transport pathway calculations are extensive and encompass the following:

- Contaminant release data

- Source characteristics

- Geologic media (partially saturated zone) characteristics

- Aquifer (saturated zone) characteristics.

The alternatives and their applicable sources are summarized in Table 6-7. Geologic media and aquifer data used in the MEPAS calculations are provided in Appendix A. Separate MEPAS calculations were performed for each source to account for source-specific characteristics, alternative-specific transport conditions, and to produce source-specific groundwater concentrations that support comparative evaluations of the alternatives. The contaminant-specific release data (timing and duration of contaminant releases) used in the MEPAS calculations are reported in Appendix A.

Figures summarizing the results of the MEPAS transport modeling and groundwater concentration calculations are presented in Appendix B. The results are also discussed and summarized in Section 6.3.

The reader is cautioned to avoid using the groundwater concentration and relative risk quantities reported in this study for other purposes unless uncertainties are properly qualified. The sensitivity analyses discussed in Section 6.1 indicated order of magnitude uncertainties for most of the sources of potential groundwater contamination that were evaluated. Large uncertainties exist in fate, transport, and toxicity determinations, regardless of the code used to assess risk. Rigorous quantitative assessments of potential risk must include a more formal definition of the uncertainties associated with the analysis. Such risk assessments will also include formal supporting analyses including toxicity assessments and risk characterizations. The uncertainties in the results of more formal and rigorous quantitative risk analyses may be little better than those associated with the use of MEPAS in this analysis, but they will be better quantified. Quantification of the myriad of uncertainties that exist in the risk analysis is beyond the scope of this study; however, it may be an important component of future analyses to support decision making on whether to implement subsurface barriers in actual SST applications. 
Table 6-7. Tank Remedial Alternatives and Applicable Sources.

\begin{tabular}{|c|c|c|c|c|c|c|c|c|c|}
\hline \multirow[b]{2}{*}{ No. } & \multirow[b]{2}{*}{ Alternative Name } & \multicolumn{8}{|c|}{ Source } \\
\hline & & $\begin{array}{l}\text { Tank } \\
\text { Residual }\end{array}$ & $\begin{array}{r}\text { Between } \\
\text { Tank and } \\
\text { Concrete }\end{array}$ & $\begin{array}{c}\text { Concrete } \\
\text { Pad }\end{array}$ & $\begin{array}{l}\text { Old Leaks } \\
\text { to Soil }\end{array}$ & $\begin{array}{l}\text { Retrieval- } \\
\text { Induced } \\
\text { New Leaks } \\
\text { to Soil }\end{array}$ & $\begin{array}{c}\text { Close- } \\
\text { Coupled } \\
\text { Barrier }\end{array}$ & $\begin{array}{l}\text { Standoff } \\
\text { Barrier }\end{array}$ & Landfill \\
\hline 1. & No Action & $\mathrm{x}$ & $\mathrm{x}$ & $\mathrm{x}$ & $\mathrm{x}$ & & & & \\
\hline 2. & Surface Barrier Only & $\mathrm{x}$ & $\mathrm{x}$ & $\mathrm{x}$ & $\mathrm{x}$ & & & & \\
\hline 3. & Baseline & $\mathrm{x}$ & $\mathrm{x}$ & $\mathrm{x}$ & $\mathrm{x}$ & $\mathrm{x}$ & & & \\
\hline 4. & Robotic Sluicing & $\mathrm{x}$ & $\mathrm{x}$ & $\mathrm{X}$ & $\mathrm{x}$ & $\mathrm{x}$ & & & \\
\hline 5. & Mechanical Retrieval & $\mathrm{x}$ & $\mathrm{x}$ & $\mathrm{X}$ & $\mathrm{x}$ & & & & \\
\hline 6. & $\begin{array}{l}\text { Close-Coupled Chemical Barrier } \\
\text { With Flushing }\end{array}$ & $\mathrm{x}$ & $\mathrm{x}$ & $\mathrm{x}$ & $\mathrm{x}$ & & $\mathrm{x}$ & & \\
\hline 7. & $\begin{array}{l}\text { Close-Coupled Chemical Barrier } \\
\text { w/o Flushing }\end{array}$ & $\mathrm{x}$ & $\mathrm{x}$ & $\mathrm{x}$ & $\mathrm{x}$ & $\mathrm{x}$ & $\mathrm{x}$ & & \\
\hline 8. & $\begin{array}{l}\text { Modified Close-Coupled Chemical } \\
\text { Barrier w/o Flushing }\end{array}$ & $\mathrm{x}$ & $\mathrm{x}$ & $\mathrm{x}$ & $\mathrm{x}$ & $\mathrm{x}$ & $\mathrm{X}^{2}$ & & \\
\hline 9. & Box-Shaped Chemical Barrier & $\mathrm{x}$ & $\mathrm{x}$ & $\mathrm{x}$ & $\mathrm{X}$ & $\mathrm{x}$ & & $\mathrm{x}$ & \\
\hline 10. & V-Shaped Chemical Barrier & $\mathrm{x}$ & $\mathrm{x}$ & $\mathrm{x}$ & $\mathrm{x}$ & $\mathrm{x}$ & & $\mathrm{x}$ & \\
\hline 11. & V-Shaped Freeze Wall Barrier & $\mathrm{x}$ & $\mathrm{x}$ & $\mathrm{x}$ & $\mathrm{x}$ & $\mathrm{x}$ & & $\mathrm{x}$ & \\
\hline 12. & Circulating Air Barrier & $\mathrm{x}$ & $\mathrm{x}$ & $\mathrm{x}$ & $\mathrm{x}$ & $\mathrm{x}$ & & & $\cdot$ \\
\hline 13. & $\begin{array}{l}\text { Clean-Closure w/o Subsurface } \\
\text { Barrier }\end{array}$ & & & & & . & & & $\mathrm{x}$ \\
\hline 14. & $\begin{array}{l}\text { Clean-Closure with Close-Coupled } \\
\text { Chemical Barrier }\end{array}$ & & & & & & & & $\mathrm{x}$ \\
\hline
\end{tabular}

apartial close-coupled barrier 


\subsubsection{Human Exposure and Health Risk}

The relative magnitude of human health risks were evaluated based on assumed exposure to : contaminated groundwater at the point of interest immediately downgradient of the hypothetical tank farm. Pathways by which contaminants were assumed to reach and expose a hypothetical individual at that location, based on the standards used at the Hanford Site, include:

- Drinking water ingestion

- Crop ingestion from farmland contaminated by irrigation from groundwater

- Animal product ingestion from animals fed contaminated forage and groundwater.

The exposure analyses were based on an assumed 70-year lifetime exposure to constant groundwater contaminant concentrations which are based on the average value over the 70-year period. Relative health risks were evaluated separately for exposure to carcinogenic and noncarcinogenic materials. Carcinogenic health risk was expressed as the incremental lifetime cancer risk, based on a $1 \times 10^{-06}$ risk level, to an individual from exposure to radioactive contaminants and nonradioactive carcinogenic chemicals. The relative impact on an individual from exposure to noncarcinogenic toxic chemicals was evaluated by calculating the HI ratio of the calculated exposure level (dose) to a toxic threshold reference dose. An HI less than 1 is taken to indicate the probable absence of detrimental toxic effects.

Relative health risks (cancer risk and $\mathrm{HI}$ ) were calculated for each source as the product of contaminant groundwater concentration and unit-concentration risk and $\mathrm{HI}$ factors derived using MEPAS. The unit risk and $\mathrm{HI}$ factors, and the basis of their calculations are presented in Appendix A. The results of the source-specific calculations are contaminant-specific risk and $\mathrm{HI}$, as a function of time, at the point of interest immediately downgradient of the tank farm. Figures detailing the results of the relative risk and $\mathrm{HI}$ calculations are presented in Appendix B. The results are also discussed and summarized in Section 6.3.

\subsection{SUMMARY OF RISK RESULTS}

As described in the preceding sections, the MEPAS was used to estimate peak groundwater contaminant concentrations and relative health risks as points for comparison of the various retrieval alternatives. The time-distributions of concentrations and health risks were also evaluated to provide additional information regarding the relative performance of different retrieval and barrier systems. Results of the groundwater contaminant concentrations and relative health risk evaluations are discussed separately in the sections that follow. 
The groundwater concentration and relative health risk values presented in these sections are screening-level results subject to ongoing review. They may be adjusted in the event that the future evaluations are performed using alternative modeling tools and input data.

\subsubsection{Groundwater Concentrations}

Contaminant concentrations in groundwater at the point of interest were estimated as a function of time up to 30,000 years following closure for each of the 14 alternatives. Tables of source-specific groundwater contaminant concentrations for each of the alternatives, and plots of contaminant groundwater concentrations, as a function of time, summed across all sources, are presented in Appendix B. Peak groundwater contaminant concentrations for each of the alternatives are presented in Table 6-8. The contaminant concentrations detailed in Appendix B were subsequently used as the bases for calculating potential human health risks, as discussed in Section 6.2.2.

For the clean-closure alternatives, it was assumed that the clean-closed tank farm does not release contamination into the groundwater, but the landfill at which residues from retrieval and decontamination operations are disposed does. These residues were assumed to contain $1 \%$ of the total contaminants in the tank farm following traditional sluicing. This was equivalent to 1,400 and $2,100 \mathrm{~kg}(3,100$ and $4,700 \mathrm{lb})$ of nitrate for the clean closure options, with and without barriers respectively. It was further assumed that containers in which the residue would be packaged prior to emplacement in the landfill would provide no resistance to leaching after several hundred years as a result of corrosion. Thus, containment of the residues was assumed to be inconsequential for the 30,000-year modeling period. The waste residues from a single tank farm were assumed to be distributed in the landfill such that the surface area of the filled landfill would be equal to that of the original tank farm, $9,580 \mathrm{~m}^{2}\left(103,000 \mathrm{ft}^{2}\right)$. A Hanford Protective Isolation Barrier was assumed to be installed over the landfill after the landfill was filled with residual waste. Properties of the geologic setting of the landfill were assumed to be the same as those of the tank farm.

The concentrations shown in Table 6-8 are based on a modification of the MEPAS code to reflect concentrations most likely to be experienced in a well located close to the tank farm. The MEPAS code without modification can be used to calculate contaminant concentrations in the dispersive layer formed initially on the surface of the aquifer as contaminated water advects from the vadose zone in the aquifer. These initially high concentrations of contaminants in this layer would gradually decrease as contaminants disperse into the aquifer while flowing downgradient.

In the event a well is located immediately downgradient from a waste site, as is assumed in this case, the well intake (screened interval) may or may not be exposed to the contaminated water layer. If the screened interval is located substantially below the surface of the aquifer, only uncontaminated water would be drawn into the well. If the screened interval is assumed to be located near the aquifer surface, as appropriate for a conservative analysis, contaminated water would be drawn into the operating well, but it would be diluted with 


\begin{tabular}{|c|c|c|c|c|c|c|c|c|c|c|c|c|c|c|c|c|}
\hline 兽 & 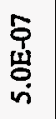 & $\begin{array}{c}0 \\
9 \\
\text { w } \\
\text { ș } \\
-\end{array}$ & 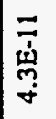 & $\underset{\text { 它 }}{\vec{\sigma}}$ & 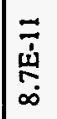 & $\underset{\overrightarrow{\vec{\omega}}}{\overrightarrow{\vec{j}}}$ & 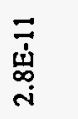 & 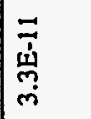 & 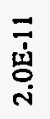 & 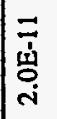 & 离 & $\overrightarrow{\overline{\dot{\omega}}}$ & 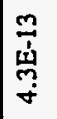 & 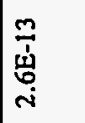 & $\overline{\underline{\alpha}}$ & \\
\hline मे & 离 & 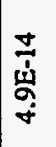 & 岂 & $\begin{array}{l}\stackrel{0}{\dot{\omega}} \\
\underset{\sim}{\omega} \\
\text { m. }\end{array}$ & 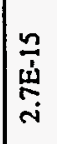 & 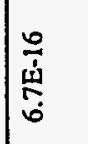 & $\frac{n}{d}$ & 吕 & 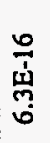 & 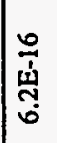 & 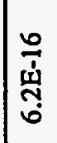 & 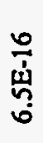 & 高 & 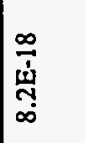 & 章 & \\
\hline 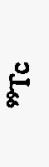 & $\begin{array}{l}\text { 号 } \\
\text { 岁 } \\
\text { ñ }\end{array}$ & 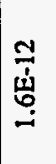 & 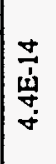 & 咅 & 离 & 立 & 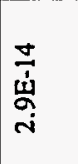 & 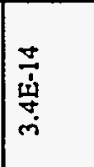 & $\frac{\vec{T}}{\stackrel{\vec{\varphi}}{\vec{i}}}$ & $\begin{array}{l} \\
\text { 离 } \\
\text { i }\end{array}$ & 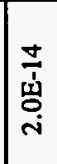 & 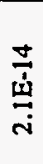 & 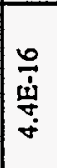 & $\frac{0}{\frac{\vec{d}}{\tilde{\omega}}}$ & 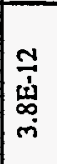 & 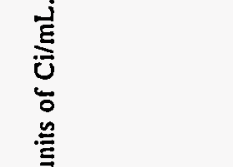 \\
\hline $\bar{\Xi}$ & 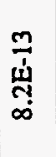 & 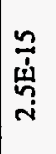 & $\begin{array}{l}\frac{a}{1} \\
\frac{1}{2}\end{array}$ & 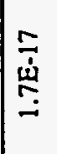 & 里 & 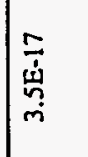 & 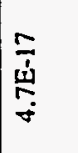 & 变 & $\underset{\substack{\dot{\omega} \\
m}}{\stackrel{n}{m}}$ & 立 & 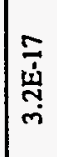 & 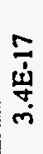 & 㻤 & 旁 & 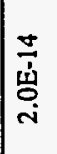 & 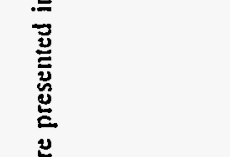 \\
\hline 巳 & 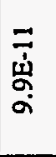 & 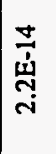 & $\frac{n}{\underline{\omega}}$ & $\begin{array}{l}0 \\
\dot{\dot{\mu}} \\
\infty \\
\sim \\
\text { r }\end{array}$ & 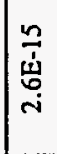 & $\begin{array}{l}\frac{0}{3} \\
\text { 岁 } \\
\dot{0}\end{array}$ & $\mid \begin{array}{l}\frac{0}{\dot{d}} \\
\frac{m}{2} \\
\infty\end{array}$ & 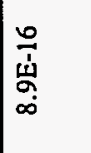 & 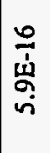 & 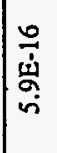 & 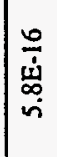 & 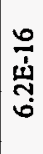 & 离 & 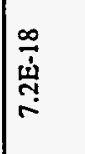 & 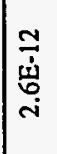 & 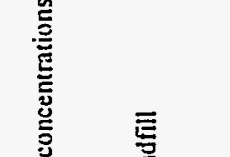 \\
\hline 苋 & 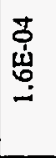 & 点 & 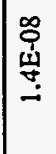 & $\begin{array}{l}\text { Oे } \\
\text { 岁 } \\
\text { ले }\end{array}$ & 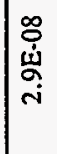 & $\begin{array}{l}\text { oे } \\
\text { 岇 } \\
\text { مे }\end{array}$ & 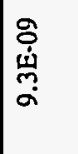 & 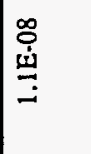 & $\begin{array}{l}0 \\
0 \\
\omega \\
\omega \\
0 \\
0\end{array}$ & 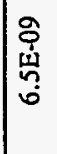 & 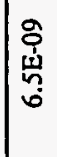 & 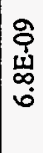 & $\frac{9}{4}$ & $\mid \begin{array}{l}\overline{7} \\
\text { 岕 } \\
\infty \\
\infty\end{array}$ & 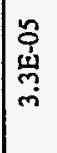 & 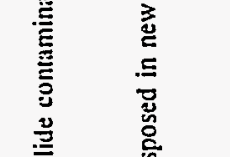 \\
\hline 总 & 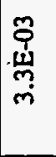 & 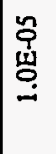 & $\mid \begin{array}{c}\hat{9} \\
\text { 䋆 } \\
\text { ণi }\end{array}$ & 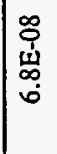 & 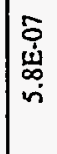 & 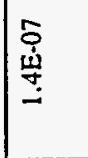 & | & 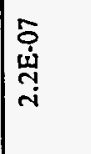 & 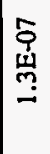 & $\mid \begin{array}{c}0 \\
\vdots \\
\omega \\
\mathfrak{m} \\
-\end{array}$ & 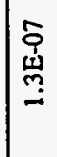 & 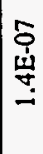 & 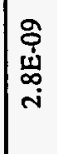 & 总 & 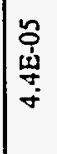 & 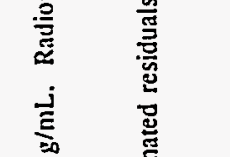 \\
\hline 画 & 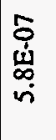 & 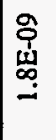 & $\begin{array}{l}\overrightarrow{\overrightarrow{\dot{d}}} \\
\text { 它 }\end{array}$ & 离 & 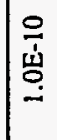 & $\underset{\text { 离 }}{\overrightarrow{\dot{u}}}$ & $\begin{array}{l}\overrightarrow{\overrightarrow{\dot{\omega}}} \\
\stackrel{m}{m}\end{array}$ & $\begin{array}{l}\overrightarrow{\overrightarrow{\dot{d}}} \\
\dot{\omega} \\
\dot{\sim}\end{array}$ & 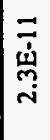 & $\begin{array}{l}\overrightarrow{\vec{j}} \\
\stackrel{\vec{\mu}}{\tilde{m}} \\
\dot{\sim}\end{array}$ & $\begin{array}{l}\overline{\vec{j}} \\
\stackrel{w}{\sim} \\
\dot{\sim}\end{array}$ & 离 & 商 & $\frac{m}{\dot{\omega}}$ & 茫 & 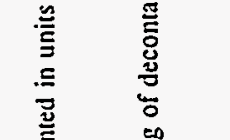 \\
\hline & 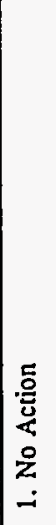 & 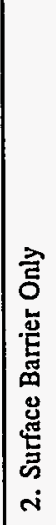 & 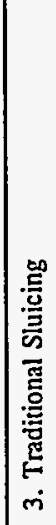 & 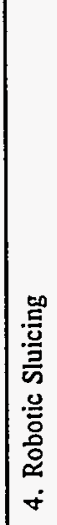 & 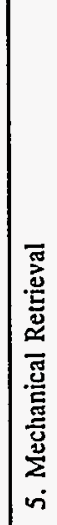 & 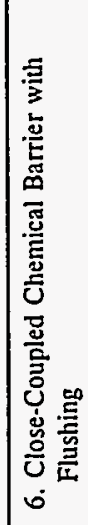 & 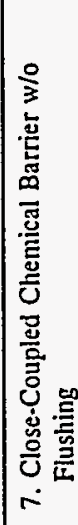 & 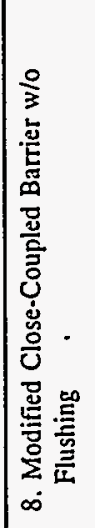 & 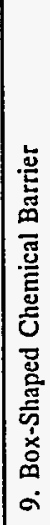 & 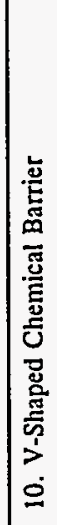 & 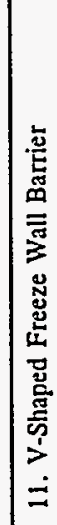 & 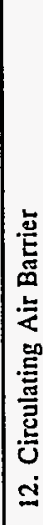 & 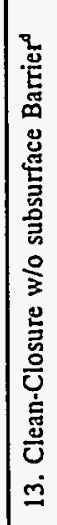 & 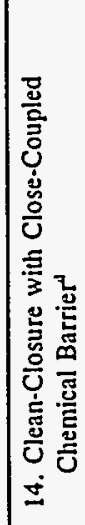 & 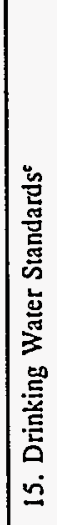 & 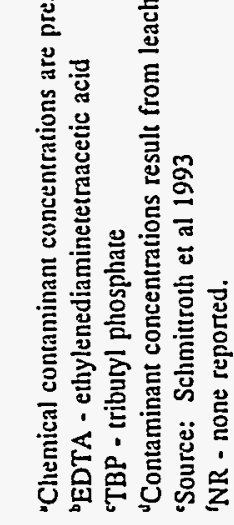 \\
\hline
\end{tabular}


uncontaminated water also drawn into the well. The unmodified MEPAS does not account for this dilution effect. Therefore, using the unmodified MEPAS to calculate groundwater contaminant concentrations immediately downgradient of the source would result in an overly conservative and unrealistically high estimate of relative risks.

A more appropriate method was used by Blanchard et al. (1993). They used the following equation to estimate well water concentrations for a scenario in which well water would be pumped at a location $100 \mathrm{~m}(328 \mathrm{ft})$ downgradient of the proposed grout disposal facility at the Hanford Site:

$$
\mathrm{W}_{\mu}=\mathrm{F}_{\mathrm{i}} \mathrm{r}_{\mathrm{v}} / \mathrm{r}_{\mathrm{p}}
$$

Where:

$$
\begin{aligned}
\mathrm{W}_{\mu}= & \text { well-intercept factor, i.e., the ratio of the concentration of a } \\
& \text { contaminant in the well water to its concentration in the vadose zone } \\
& \text { water (unitless) } \\
\mathrm{F}_{\mathrm{i}}= & \text { fraction of plume intercepted by the operating well (unitless) } \\
\mathrm{r}_{\mathrm{v}}= & \text { volumetric recharge rate through waste site }\left(\mathrm{L}^{3} / \mathrm{T}\right) \\
\mathrm{r}_{\mathrm{p}}= & \text { groundwater well pumping rate }\left(\mathrm{L}^{3} / \mathrm{T}\right) .
\end{aligned}
$$

Blanchard et al. (1993) used the groundwater model, Single Layer Analytical Element Method-Stratified (SLAEMS), to estimate the width of interception of the contaminated water plume by a well located $100 \mathrm{~m}(328 \mathrm{ft})$ downgradient of the grout disposal site. The well pump was assumed to withdraw water at a rate of $45 \mathrm{~m}^{3} /$ day $\left(1,600 \mathrm{ft}^{3} /\right.$ day $)$ via a $4.6-\mathrm{m}$ (15-ft) long screened interval positioned near the water table. This water withdrawal rate was used to simulate drinking water and irrigation needs for a 2-ha (5-acre) farm.

The SLAEMS model predicted a plume interception width of approximately $61 \mathrm{~m} \mathrm{(200} \mathrm{ft)}$ based on the assumption of a fully penetrating well and aquifer properties assumed to exist near the grout disposal facility. When a partially penetrating well was assumed, the computed intercept width increased to $83.2 \mathrm{~m}(273 \mathrm{ft}$ ) for isotropic conditions and to $113 \mathrm{~m}$ (371 ft) for anisotropic conditions.

The surface dimensions of the hypothetical tank farm that served as the basis for this analysis were 84 by $114 \mathrm{~m}$ ( 275 by $375 \mathrm{ft}$ ). If the tank farm is assumed to be oriented longitudinally with the direction of groundwater flow and a partially penetrating well is assumed, $100 \%$ of the plume width $(84 \mathrm{~m}$ [ $275 \mathrm{ft}]$ ) would be intercepted by the well. This conservative assumption was made for the hypothetical tank farm in this analysis.

Vadose zone contaminant concentration data are required to apply Equation 23 . The vadose zone flux (f) can be expressed as:

$$
f=C_{v} r_{v}
$$


Where:

$$
\begin{aligned}
C_{v}= & \text { concentration in vadose zone }\left(M / L^{3}\right) \\
r_{v}= & \text { volumetric recharge rate through waste site, as previously defined } \\
& \left(L^{3} / T\right) .
\end{aligned}
$$

The well intercept factor $\left(\mathrm{W}_{\mu}\right)$ in Equation 23 can also be expressed as shown below, in accordance to the definition of $\mathrm{W}_{\mu}$ :

$$
\mathrm{W}_{\mu}=\mathrm{C}_{\mathrm{g}} / \mathrm{C}_{\mathrm{v}}
$$

Where:

$$
\mathrm{C}_{\mathrm{g}}=\text { concentration in the groundwater }\left(\mathrm{M} / \mathrm{L}^{3}\right) \text {. }
$$

Thus, the well intercept factor can be restated as:

$$
\mathrm{W}_{\mu}=\mathrm{C}_{\mathrm{g}} \mathrm{r}_{\mathrm{v}} / \mathrm{f}=\mathrm{F}_{\mathrm{i}} \mathrm{r}_{\mathrm{v}} / \mathrm{r}_{\mathrm{p}}
$$

Because $F_{i}$ is 1.0 and $r_{p}$ is $45 \mathrm{~m}^{3} /$ day $\left(1,600 \mathrm{ft}^{3} /\right.$ day) as assumed previously, the groundwater concentration is given by the following intuitive equation:

$$
\mathrm{C}_{\mathrm{g}}=\mathrm{f} \div 45 \mathrm{~m}^{3} / \mathrm{day}
$$

\subsubsection{Health Risk}

Relative health risks (cancer risk and HI) were calculated for each source as the product of contaminant groundwater concentration and unit-concentration risk and HI factors derived using the MEPAS. The unit risk and HI factors, and the basis of their calculation are presented in Appendix A. The results of the source-specific calculations are contaminantspecific relative risk and $\mathrm{HI}$, as a function of time, at the point of interest. The relative cancer risks calculated for the alternatives are summarized and presented graphically in Figure 6-10. In order to present all alternatives in a single plot, a log-log scale that compressed the vertical range of risk results was used. As shown in Table 6-9, the peak relative cancer risks for the alternatives span a range of approximately seven orders of magnitude.

Figure 6-11 presents the relative cancer risks as a function of time after closure for 10 retrieval alternatives excluding the No-Action Surface Barrier Only Alternatives and the two clean closure alternatives. Because the relative risks calculated for the included alternatives span a narrower range, a linear plotting scale of relative risk was used allowing greater resolution among alternatives. 


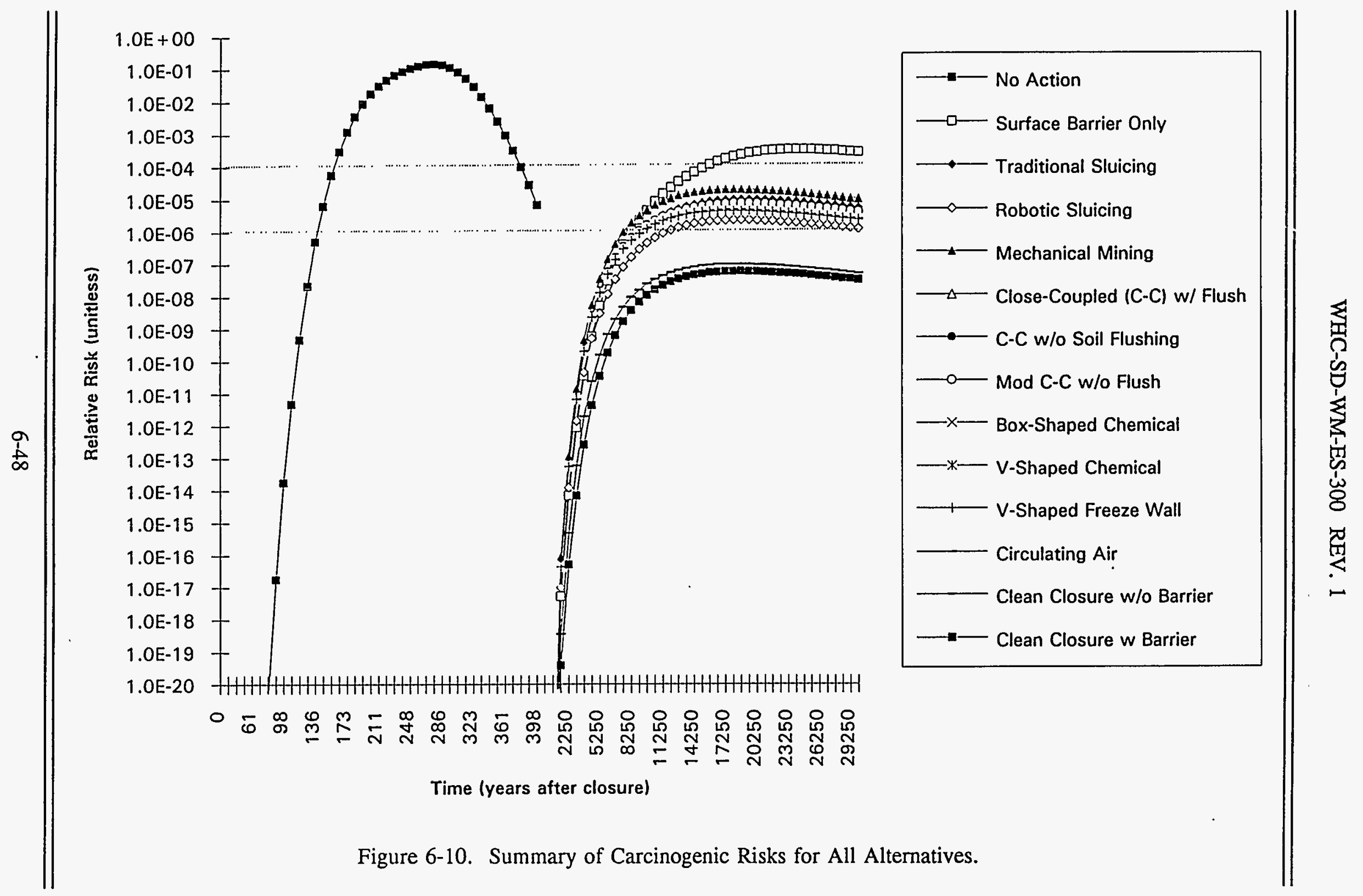


Table 6-9. Peak Relative Cancer Risks and Hazard Index - Each Alternative, All Sources.

\begin{tabular}{|c|c|c|c|c|}
\hline Alternative & $\begin{array}{l}\text { Relative } \\
\text { Cancer } \\
\text { Risk }\end{array}$ & $\begin{array}{c}\text { Year of } \\
\text { Peak Relative } \\
\text { Risk }^{2}\end{array}$ & $\begin{array}{l}\text { Relative } \\
\text { HI }\end{array}$ & $\begin{array}{c}\text { Year of } \\
\text { Peak Relative } \\
\mathrm{HI}^{\mathrm{a}}\end{array}$ \\
\hline 1. No Action & $1.5 \mathrm{E}-01$ & 276 & $2.8 \mathrm{E}+03$ & 276 \\
\hline 2. Surface Barrier Only & $3.7 \mathrm{E}-04$ & 24,750 & $8.6 \mathrm{E}+00$ & 24,750 \\
\hline 3. Traditional Sluicing & $1.1 \mathrm{E}-05$ & 19,500 & $2.4 \mathrm{E}-01$ & 19,500 \\
\hline 4. Robotic Sluicing & $2.5 \mathrm{E}-06$ & 18,750 & $5.7 \mathrm{E}-02$ & 17,750 \\
\hline 5. Mechanical Retrieval & $2.1 \mathrm{E}-05$ & 18,750 & $4.9 \mathrm{E}-01$ & 18,750 \\
\hline $\begin{array}{l}\text { 6. Close-Coupled Chemical } \\
\text { Barrier with Flushing }\end{array}$ & $5.2 \mathrm{E}-06$ & 18,000 & $1.2 \mathrm{E}-01$ & 18,000 \\
\hline $\begin{array}{l}\text { 7. Close-Coupled Chemical } \\
\text { Barrier w/o Flushing }\end{array}$ & $7.0 \mathrm{E}-06$ & 18,000 & $1.6 \mathrm{E}-01$ & 18,000 \\
\hline $\begin{array}{l}\text { 8. Modified Close-Coupled } \\
\text { Chemical Barrier w/o } \\
\text { Flushing }\end{array}$ & $8.0 \mathrm{E}-06$ & 18,750 & $1.8 \mathrm{E}-01$ & 18,750 \\
\hline $\begin{array}{l}\text { 9. Box-Shaped Chemical } \\
\text { Barrier }\end{array}$ & $4.9 \mathrm{E}-06$ & 18,000 & $1.1 \mathrm{E}-01$ & 18,750 \\
\hline $\begin{array}{l}\text { 10. V-Shaped Chemical } \\
\text { Barrier }\end{array}$ & $4.9 \mathrm{E}-06$ & 18,000 & $1.1 \mathrm{E}-01$ & 18,000 \\
\hline $\begin{array}{l}\text { 11. V-Shaped Freeze Wall } \\
\text { Barrier }\end{array}$ & $4.8 \mathrm{E}-06$ & 18,000 & $1.1 \mathrm{E}-01$ & 18,000 \\
\hline 12. Circulating Air Barrier & $5.1 \mathrm{E}-06$ & 18,000 & $1.2 \mathrm{E}-01$ & 18,000 \\
\hline $\begin{array}{l}\text { 13. Clean-Closure w/o } \\
\text { Subsurface Barrier }\end{array}$ & $1.1 \mathrm{E}-07$ & 18,750 & $2.4 \mathrm{E}-03$ & 18,750 \\
\hline $\begin{array}{l}\text { 14. Clean-Closure with Close- } \\
\text { Coupled Chemical Barrier }\end{array}$ & $6.3 \mathrm{E}-08$ & 18,750 & $1.4 \mathrm{E}-03$ & 18,750 \\
\hline
\end{tabular}

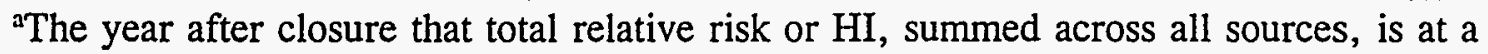
maximum. The contributions to relative risk or $\mathrm{HI}$ from individual sources will peak at differing points in time. 


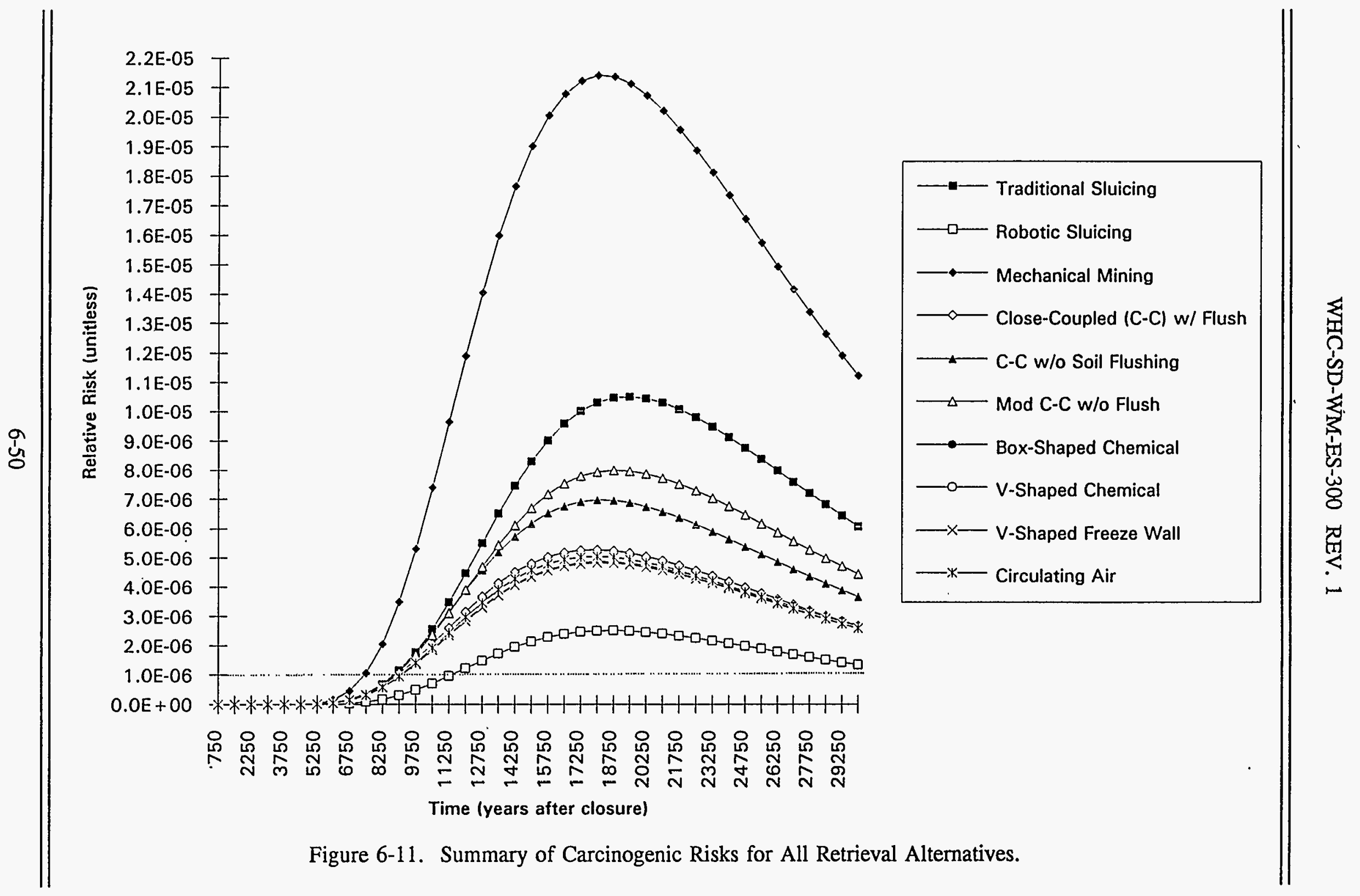


The relative HIs calculated for the alternatives are summarized and presented graphically in Figure 6-12. In order to present all cases in a single plot, a log-log scale that compressed the vertical range of $\mathrm{HI}$ results was used. As shown in Table 6-9, the peak relative HIs for the 14 alternatives also span a range of about seven orders of magnitude.

Figure 6-13 presents the relative HIs as a function of time for the 10 selected retrieval alternatives, excluding the No-Action, Surface Barrier Only, and the two clean-closure alternatives. Because the HIs calculated for these 10 alternatives span a narrower range, a linear plotting scale of $\mathrm{HI}$ was used allowing greater resolution among alternatives.

In these screening-level analyses, the dominant contributor to relative cancer contributions for all cases is ${ }^{99} \mathrm{Tc}$ and the dominant contributor to $\mathrm{HI}$ is nitrate as shown in Table 6-10. The relative risks of the COCs are approximately constant with time because all are assumed to leach congruently with nitrate, all have a $K_{d}$ of zero, and little radioactive decay occurs. The dominant contaminant source is the tank residual waste as shown in Tables 6-11 through 6-14. The nonretrieval alternatives (No Action and Surface Barrier Only) would result in significantly higher relative carcinogenic risk and HI as shown in Figures 6-10 and 6-12. The high relative health risk of these alternatives is directly related to the inventory of waste remaining in the tanks, in the absence of any retrieval action. The relative health risks for the Surface Barrier Only Alternative are significantly less than for the No-Action Alternative as a result of the reduction in recharge rate caused by the surface barrier.

For the retrieval cases, as shown in Figures 6-11 and 6-13, the Mechanical Retrieval Alternative would result in the highest relative health risks as a direct result of the larger residual inventory remaining in the tanks (5\% versus $1 \%$ for traditional sluicing). The Robotic Sluicing Alternative would result in the lowest relative health risk, aside from the clean-closure alternatives. Relative health risks for these two alternatives are the lowest of all the alternatives. Each of the alternatives involving use of barriers, excluding the CleanClosure with Close-Coupled Chemical Barrier Alternative, appear to result in a fairly narrow range of risks. The barrier alternatives would result in relative risks and HIs of less than a factor of three below the estimated risk and HI of the Traditional Sluicing Alternative.

Although flushing was assumed to be effective in removing the same quantity of contaminants in each of the standoff barrier (V-Shaped and Box-Shaped) and the Circulating Air Barrier alternatives, the residual contaminants would be more dispersed after flushing in the case of the standoff barriers. This dispersed contamination source resulted in a flatter concentration curve and in a somewhat lower peak relative health risk for the standoff barriers. 
WHC-SD-WM-ES-300 REV. 1
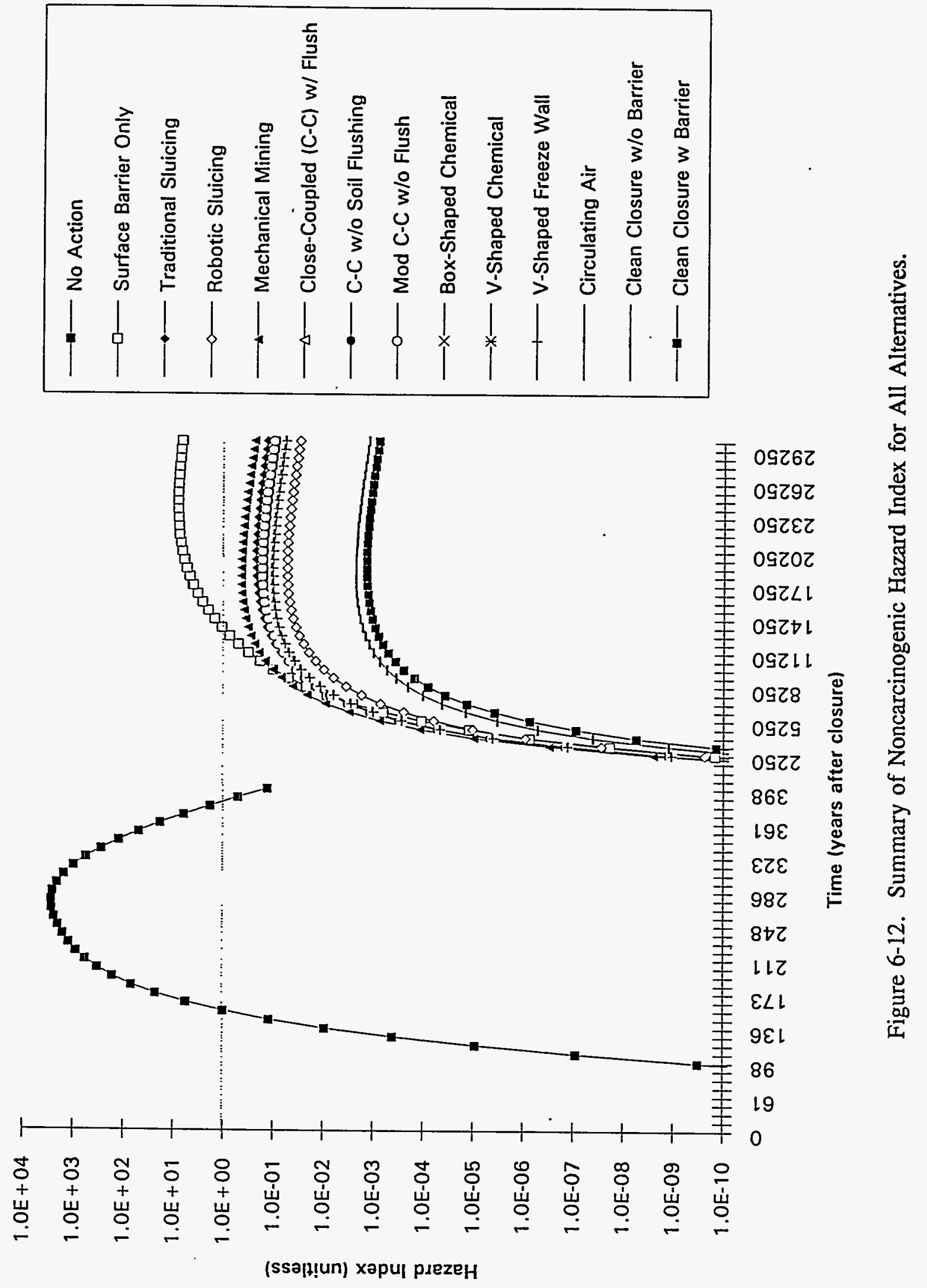

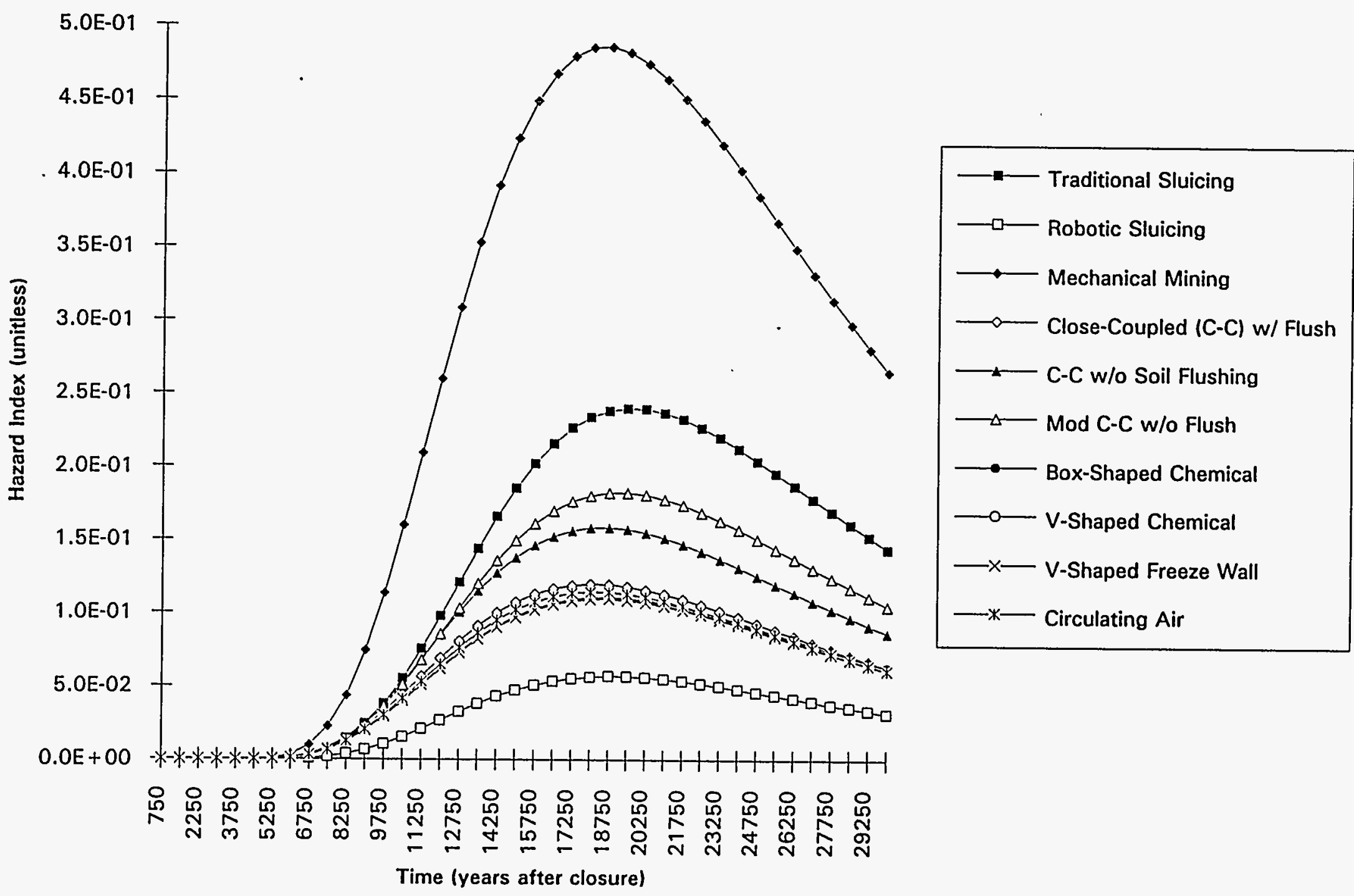

通

Figure 6-13. Summary of Noncarcinogenic Hazard Index for Selected Retrieval Alternatives. 
WHC-SD-WM-ES-30C REV. 1

Table 6-10. Relative Cancer Risks and Hazard Index for Constituents of Concern.

\begin{tabular}{|c|c|c|c|}
\hline Carcinogens & $\begin{array}{c}\text { Contribution to } \\
\text { Relative } \\
\text { Cancer Risk (\%) }\end{array}$ & Noncarcinogens & $\begin{array}{c}\text { Contribution to } \\
\text { Relative } \\
\text { HI (\%) }\end{array}$ \\
\hline${ }^{99} \mathrm{Tc}$ & 63 & nitrate & 89 \\
\hline${ }^{238} \mathrm{U}$ & 24 & EDTA $^{\mathrm{a}}$ & 7 \\
\hline${ }^{129} \mathrm{I}$ & 10 & nitrite & 4 \\
\hline${ }^{14} \mathrm{C}$ & 3 & Total & 100 \\
\hline TBP & 0 & & \\
\hline Total & 100 & & \\
\hline
\end{tabular}

EDTA - ethylenediamenetetraacetic acid 
Table 6-11. Relative Source Contribution to Carcinogenic Risk. (sheet 1 of 2)

\begin{tabular}{|c|c|c|c|}
\hline Alternative & Source & $\begin{array}{l}\text { Cancer Risk } \\
\text { Contribution } \\
\text { at Peak }\end{array}$ & $\begin{array}{c}\text { Relative } \\
\text { Contribution } \\
(\%)\end{array}$ \\
\hline 1. No Action & $\begin{array}{c}\text { Tank Residual } \\
\text { Between Tank and Concrete } \\
\text { In Concrete } \\
\text { Old Leaks }\end{array}$ & $\begin{array}{l}1.5 \mathrm{E}-01 \\
2.4 \mathrm{E}-05 \\
1.6 \mathrm{E}-04 \\
\frac{2.9 \mathrm{E}-05}{1.5 \mathrm{E}-01}\end{array}$ & $\begin{array}{c}100 \\
0 \\
0 \\
0 \\
100 \%\end{array}$ \\
\hline 2. Surface Barrier Only & $\begin{array}{l}\text { Tank Residual } \\
\text { Between Tank and Concrete } \\
\text { In Concrete } \\
\text { Old Leaks }\end{array}$ & $\begin{array}{c}3.7 \mathrm{E}-04 \\
0.0 \mathrm{E}+00 \\
4.8 \mathrm{E}-07 \\
\frac{1.1 \mathrm{E}-06}{3.7 \mathrm{E}-04}\end{array}$ & $\begin{array}{c}100 \\
0 \\
0 \\
0 \\
100 \%\end{array}$ \\
\hline $\begin{array}{l}\text { 3. Traditional Sluicing } \\
\text { (Baseline) }\end{array}$ & $\begin{array}{c}\text { Tank Residual } \\
\text { Between Tank and Concrete } \\
\text { In Concrete } \\
\text { Old and New Leaks }\end{array}$ & $\begin{array}{l}3.9 \mathrm{E}-06 \\
6.5 \mathrm{E}-09 \\
7.0 \mathrm{E}-07 \\
5.9 \mathrm{E}-06 \\
1.1 \mathrm{E}-05\end{array}$ & $\begin{array}{c}37 \\
0 \\
7 \\
56 \\
100 \%\end{array}$ \\
\hline 4. Robotic Sluicing & $\begin{array}{c}\text { Tank Residual } \\
\text { Between Tank and Concrete } \\
\text { In Concrete } \\
\text { Old and New Leaks }\end{array}$ & $\begin{array}{l}2.6 \mathrm{E}-07 \\
1.6 \mathrm{E}-08 \\
5.0 \mathrm{E}-07 \\
1.7 \mathrm{E}-06 \\
2.5 \mathrm{E}-06\end{array}$ & $\begin{array}{c}10 \\
1 \\
20 \\
69 \\
100 \%\end{array}$ \\
\hline 5. Mechanical Retrieval & $\begin{array}{l}\text { Tank Residual } \\
\text { Between Tank and Concrete } \\
\text { In Concrete } \\
\text { Old Leaks }\end{array}$ & $\begin{array}{l}2.0 \mathrm{E}-05 \\
8.8 \mathrm{E}-09 \\
4.9 \mathrm{E}-07 \\
1.3 \mathrm{E}-06 \\
2.1 \mathrm{E}-05\end{array}$ & $\begin{array}{c}92 \\
0 \\
2 \\
6 \\
100 \%\end{array}$ \\
\hline $\begin{array}{l}\text { 6. Close-Coupled } \\
\text { Chemical Barrier } \\
\text { with Flushing }\end{array}$ & $\begin{array}{l}\text { Tank Residual } \\
\text { Between Tank and Concrete } \\
\text { In Concrete } \\
\text { Flushed Old Leaks } \\
\text { In Barrier }\end{array}$ & $\begin{array}{l}4.0 \mathrm{E}-06 \\
7.5 \mathrm{E}-09 \\
7.2 \mathrm{E}-07 \\
2.5 \mathrm{E}-10 \\
5.1 \mathrm{E}-07 \\
5.2 \mathrm{E}-06\end{array}$ & $\begin{array}{c}76 \\
0 \\
14 \\
0 \\
10 \\
100 \%\end{array}$ \\
\hline $\begin{array}{l}\text { 7. Close-Coupled } \\
\text { Chemical Barrier } \\
\text { w/o Flushing }\end{array}$ & $\begin{array}{c}\text { Tank Residual } \\
\text { Between Tank and Concrete } \\
\text { In Concrete } \\
\text { Old and New Leaks. } \\
\text { In Barrier }\end{array}$ & $\begin{array}{l}4.0 \mathrm{E}-06 \\
7.5 \mathrm{E}-09 \\
7.2 \mathrm{E}-07 \\
1.8 \mathrm{E}-06 \\
5.1 \mathrm{E}-07 \\
7.0 \mathrm{E}-06\end{array}$ & $\begin{array}{c}57 \\
0 \\
10 \\
26 \\
7 \\
100 \%\end{array}$ \\
\hline
\end{tabular}


Table 6-11. Relative Source Contribution to Carcinogenic Risk. (sheet 2 of 2)

\begin{tabular}{|c|c|c|c|}
\hline Alternative & Source & $\begin{array}{l}\text { Cancer Risk } \\
\text { Contribution } \\
\text { at Peak }\end{array}$ & $\begin{array}{c}\text { Relative } \\
\text { Contribution } \\
(\%)\end{array}$ \\
\hline $\begin{array}{l}\text { 8. Modified Close- } \\
\text { Coupled Chemical } \\
\text { Barrier } \\
\text { w/o Flushing }\end{array}$ & $\begin{array}{c}\text { Tank Residual } \\
\text { Between Tank and Concrete } \\
\text { In Concrete } \\
\text { Old and New Leaks } \\
\text { In Barrier }\end{array}$ & $\begin{array}{l}4.0 \mathrm{E}-06 \\
7.0 \mathrm{E}-09 \\
7.1 \mathrm{E}-07 \\
3.1 \mathrm{E}-06 \\
3.0 \mathrm{E}-07 \\
8.0 \mathrm{E}-06\end{array}$ & $\begin{array}{c}49 \\
0 \\
9 \\
38 \\
\frac{4}{100 \%}\end{array}$ \\
\hline $\begin{array}{l}\text { 9. Box-Shaped } \\
\text { Chemical } \\
\text { Barrier }\end{array}$ & $\begin{array}{l}\text { Tank Residual } \\
\text { Between Tank and Concrete } \\
\text { In Concrete } \\
\text { Flushed Old and New Leaks } \\
\text { In Barrier }\end{array}$ & $\begin{array}{l}4.0 \mathrm{E}-06 \\
7.5 \mathrm{E}-09 \\
7.2 \mathrm{E}-07 \\
1.6 \mathrm{E}-07 \\
2.3 \mathrm{E}-08 \\
4.9 \mathrm{E}-08\end{array}$ & $\begin{array}{c}81 \\
0 \\
15 \\
3 \\
\frac{1}{100 \%}\end{array}$ \\
\hline $\begin{array}{l}\text { 10. V-Shaped } \\
\text { Chemical } \\
\text { Barrier }\end{array}$ & $\begin{array}{l}\text { Tank Residual } \\
\text { Between Tank and Concrete } \\
\text { In Concrete } \\
\text { Flushed Old and New Leaks } \\
\text { In Barrier }\end{array}$ & $\begin{array}{l}4.0 \mathrm{E}-06 \\
7.5 \mathrm{E}-09 \\
7.2 \mathrm{E}-07 \\
1.2 \mathrm{E}-07 \\
3.6 \mathrm{E}-08 \\
4.9 \mathrm{E}-06\end{array}$ & $\begin{array}{c}82 \\
0 \\
15 \\
2 \\
1 \\
100 \%\end{array}$ \\
\hline $\begin{array}{l}\text { 11. V-Shaped } \\
\text { Freeze Wall } \\
\text { Barrier }\end{array}$ & $\begin{array}{l}\text { Tank Residual } \\
\text { Between Tank and Concrete } \\
\text { In Concrete } \\
\text { Flushed Old and New Leaks }\end{array}$ & $\begin{array}{l}4.0 \mathrm{E}-06 \\
7.5 \mathrm{E}-09 \\
7.2 \mathrm{E}-07 \\
1.2 \mathrm{E}-07 \\
4.8 \mathrm{E}-06\end{array}$ & $\begin{array}{c}83 \\
0 \\
15 \\
2 \\
100 \%\end{array}$ \\
\hline $\begin{array}{l}\text { 12. Circulating Air } \\
\text { Barrier }\end{array}$ & $\begin{array}{l}\text { Tank Residual } \\
\text { Between Tank and Concrete } \\
\text { In Concrete } \\
\text { Flushed Old and New Leaks }\end{array}$ & $\begin{array}{l}4.0 \mathrm{E}-06 \\
7.5 \mathrm{E}-09 \\
7.2 \mathrm{E}-07 \\
3.5 \mathrm{E}-07 \\
5.1 \mathrm{E}-06\end{array}$ & $\begin{array}{c}79 \\
0 \\
14 \\
7 \\
100 \%\end{array}$ \\
\hline $\begin{array}{l}\text { 13. Clean-Closure } \\
\text { w/o subsurface } \\
\text { Barrier }\end{array}$ & Landfill & $1.1 \mathrm{E}-07$ & $100 \%$ \\
\hline $\begin{array}{l}\text { 14. Clean-Closure with } \\
\text { Close-Coupled } \\
\text { Chemical Barrier }\end{array}$ & Landfill & $6.3 \mathrm{E}-08$ & $100 \%$ \\
\hline
\end{tabular}


Table 6-12. Relative Source Contribution to Hazard Index Risk. (sheet 1 of 2)

\begin{tabular}{|c|c|c|c|}
\hline Alternative & Source & $\begin{array}{l}\text { HI } \\
\text { Contribution } \\
\text { at Peak }\end{array}$ & $\begin{array}{c}\text { Relative } \\
\text { Contribution } \\
\text { (\%) }\end{array}$ \\
\hline 1. No Action & $\begin{array}{l}\text { Tank Residual } \\
\text { Between Tank and Concrete } \\
\text { In Concrete } \\
\text { Old Leaks }\end{array}$ & $\begin{array}{c}2.8 \mathrm{E}+03 \\
4.0 \mathrm{E}-01 \\
3.0 \mathrm{E}+00 \\
\frac{5.3 \mathrm{E}-01}{2.8 \mathrm{E}+03}\end{array}$ & $\begin{array}{c}100 \\
0 \\
0 \\
0 \\
100 \%\end{array}$ \\
\hline 2. Surface Barrier Only & $\begin{array}{c}\text { Tank Residual } \\
\text { Between Tank and Concrete } \\
\text { In Concrete } \\
\text { Old Leaks }\end{array}$ & $\begin{array}{l}8.6 \mathrm{E}+00 \\
0.0 \mathrm{E}+00 \\
1.1 \mathrm{E}-02 \\
\frac{2.5 \mathrm{E}-02}{8.6 \mathrm{E}+00}\end{array}$ & $\begin{array}{c}100 \\
0 \\
0 \\
0 \\
100 \%\end{array}$ \\
\hline $\begin{array}{l}\text { 3. Traditional Sluicing } \\
\text { (Baseline) }\end{array}$ & $\begin{array}{l}\text { Tank Residual } \\
\text { Between Tank and Concrete } \\
\text { In Concrete } \\
\text { Old and New Leaks }\end{array}$ & $\begin{array}{l}8.9 E-02 \\
2.3 E-04 \\
1.6 E-02 \\
1.4 E-01 \\
2.4 E-01\end{array}$ & $\begin{array}{c}37 \\
0 \\
7 \\
\frac{56}{100 \%}\end{array}$ \\
\hline 4. Robotic Sluicing & $\begin{array}{c}\text { Tank Residual } \\
\text { Between Tank and Concrete } \\
\text { In Concrete } \\
\text { Old and New Leaks }\end{array}$ & $\begin{array}{l}6.0 \mathrm{E}-03 \\
3.8 \mathrm{E}-04 \\
1.1 \mathrm{E}-02 \\
3.9 \mathrm{E}-02 \\
5.7 \mathrm{E}-02\end{array}$ & $\begin{array}{c}10 \\
1 \\
20 \\
\frac{69}{100 \%}\end{array}$ \\
\hline 5. Mechanical Retrieval & $\begin{array}{l}\text { Tank Residual } \\
\text { Between Tank and Concrete } \\
\text { In Concrete } \\
\text { Old Leaks }\end{array}$ & $\begin{array}{l}4.5 E-01 \\
3.4 E-04 \\
1.1 E-02 \\
\frac{2.9 E-02}{4.9 E-01}\end{array}$ & $\begin{array}{c}92 \\
0 \\
2 \\
6 \\
100 \%\end{array}$ \\
\hline $\begin{array}{l}\text { 6. Close-Coupled } \\
\text { Chemical Barrier } \\
\text { with Flushing }\end{array}$ & $\begin{array}{c}\text { Tank Residual } \\
\text { Between Tank and Concrete } \\
\text { In Concrete } \\
\text { Flushed Old Leaks } \\
\text { In Barrier }\end{array}$ & $\begin{array}{l}9.0 \mathrm{E}-02 \\
2.6 \mathrm{E}-04 \\
1.6 \mathrm{E}-02 \\
5.0 \mathrm{E}-09 \\
\frac{1.2 \mathrm{E}-02}{1.2 \mathrm{E}-01}\end{array}$ & $\begin{array}{c}76 \\
0 \\
14 \\
0 \\
\frac{10}{100 \%}\end{array}$ \\
\hline $\begin{array}{l}\text { 7. Close-Coupled } \\
\text { Chemical Barrier } \\
\text { w/o Flushing }\end{array}$ & $\begin{array}{c}\text { Tank Residual } \\
\text { Between Tank and Concrete } \\
\text { In Concrete } \\
\text { Old and New Leaks } \\
\text { In Barrier }\end{array}$ & $\begin{array}{l}9.0 \mathrm{E}-02 \\
2.6 \mathrm{E}-04 \\
1.6 \mathrm{E}-02 \\
4.0 \mathrm{E}-02 \\
\frac{1.2 \mathrm{E}-02}{1.6 \mathrm{E}-01}\end{array}$ & $\begin{array}{c}57 \\
0 \\
10 \\
26 \\
\frac{7}{100 \%}\end{array}$ \\
\hline
\end{tabular}


Table 6-12. Relative Source Contribution to Hazard Index Risk. (sheet 2 of 2)

\begin{tabular}{|c|c|c|c|}
\hline Alternative & Source & $\begin{array}{l}\text { HI Risk } \\
\text { Contribution } \\
\text { at Peak }\end{array}$ & $\begin{array}{c}\text { Relative } \\
\text { Contribution } \\
\text { (\%) }\end{array}$ \\
\hline $\begin{array}{l}\text { 8. Modified Close-Coupled } \\
\text { Chemical Barrier } \\
\text { w/o Flushing }\end{array}$ & $\begin{array}{c}\text { Tank Residual } \\
\text { Between Tank and Concrete } \\
\text { In Concrete } \\
\text { Old and New Leaks } \\
\text { In Barrier }\end{array}$ & $\begin{array}{l}9.0 \mathrm{E}-02 \\
2.5 \mathrm{E}-04 \\
1.6 \mathrm{E}-02 \\
6.9 \mathrm{E}-02 \\
\frac{6.8 \mathrm{E}-03}{1.8 \mathrm{E}-01}\end{array}$ & $\begin{array}{c}49 \\
0 \\
9 \\
38 \\
\frac{4}{100 \%}\end{array}$ \\
\hline $\begin{array}{l}\text { 9. Box-Shaped } \\
\text { Chemical Barrier }\end{array}$ & $\begin{array}{l}\text { Tank Residual } \\
\text { Between Tank and Concrete } \\
\text { In Concrete } \\
\text { Flushed Old and New Leaks } \\
\text { In Barrier }\end{array}$ & $\begin{array}{l}9.0 E-02 \\
2.6 E-04 \\
1.6 E-02 \\
3.6 E-03 \\
5.2 E-04 \\
1.1 E-01\end{array}$ & $\begin{array}{c}81 \\
0 \\
15 \\
3 \\
0 \\
100 \%\end{array}$ \\
\hline $\begin{array}{l}\text { 10. V-Shaped Chemical } \\
\text { Barrier }\end{array}$ & $\begin{array}{l}\text { Tank Residual } \\
\text { Between Tank and Concrete } \\
\text { In Concrete } \\
\text { Flushed Old and New Leaks } \\
\text { In Barrier }\end{array}$ & $\begin{array}{l}9.0 \mathrm{E}-02 \\
2.6 \mathrm{E}-04 \\
1.6 \mathrm{E}-02 \\
2.7 \mathrm{E}-03 \\
\frac{8.1 \mathrm{E}-04}{1.1 \mathrm{E}-01}\end{array}$ & $\begin{array}{c}82 \\
0 \\
15 \\
2 \\
\frac{1}{100 \%}\end{array}$ \\
\hline $\begin{array}{l}\text { 11. V-Shaped } \\
\text { Freeze Wall } \\
\text { Barrier }\end{array}$ & $\begin{array}{l}\text { Tank Residual } \\
\text { Between Tank and Concrete } \\
\text { In Concrete } \\
\text { Flushed Old and New Leaks }\end{array}$ & $\begin{array}{l}9.0 \mathrm{E}-02 \\
2.6 \mathrm{E}-04 \\
1.6 \mathrm{E}-02 \\
2.7 \mathrm{E}-03 \\
1.1 \mathrm{E}-01\end{array}$ & $\begin{array}{c}83 \\
0 \\
15 \\
\frac{2}{100 \%}\end{array}$ \\
\hline $\begin{array}{l}\text { 12. Circulating Air } \\
\text { Barrier }\end{array}$ & $\begin{array}{l}\text { Tank Residual } \\
\text { Between Tank and Concrete } \\
\text { In Concrete } \\
\text { Flushed Old and New Leaks }\end{array}$ & $\begin{array}{l}9.0 \mathrm{E}-02 \\
2.6 \mathrm{E}-04 \\
1.6 \mathrm{E}-02 \\
7.9 \mathrm{E}-03 \\
1.2 \mathrm{E}-01\end{array}$ & $\begin{array}{c}79 \\
0 \\
14 \\
7 \\
100 \%\end{array}$ \\
\hline $\begin{array}{l}\text { 13. Clean-Closure w/o } \\
\text { subsurface Barrier }\end{array}$ & Landfill & $2.4 E-03$ & $100 \%$ \\
\hline $\begin{array}{l}\text { 14. Clean-Closure with } \\
\text { Close-Coupled Chemical } \\
\text { Barrier }\end{array}$ & Landfill & $1.4 \mathrm{E}-03$ & $100 \%$ \\
\hline
\end{tabular}




\subsection{COST ANALYSIS}

This section presents estimated rough-order-of-magnitude costs for the alternatives and their component technology options discussed in this report. The component options include three retrieval options, seven subsurface barrier options, soil flushing, flush water treatment, tank stabilization, a surface barrier, and clean-closure.

\subsection{METHODOLOGY AND GENERAL ASSUMOPTIONS}

The estimated costs were developed using available published information and best engineering judgement. The cost data were mostly derived from Boomer et al., Appendixes F, J, K, M, N, and R (1993) and (KEH 1993b). The estimated costs are provided as they apply to one hypothetical tank farm with 12 single-shell underground high-level waste (HLW) storage tanks. The costs are categorized according to the options for retrieval, subsurface barriers, soil flushing, flush water treatment, stabilization, and surface barriers addressed in this report. Estimated technology readiness costs, capital costs, operating and maintenance (O\&M) costs, and decontamination and decommissioning (D\&D) costs are provided for each option. The total cost of each alternative and costs of individual options are expressed three ways: (1) equivalent uniform annual cost (EUAC), (2) total net present worth (TNPW), and (3) total life cycle cost (TLCC).

\subsubsection{Definition of Costing Terms}

Technology

Readiness

Capital

O\&M

D\&D

EUAC
Technology development costs include costs associated with technology testing and demonstration, trade-off studies, National Environmental Policy Act and RCRA permitting, and safety analysis.

Capital costs include costs of the following items, where applicable: design, inspection, escalation, contingency, site preparation, drilling, coffercells, buildings, mechanical equipment, piping, grout, freezing solution, surface barrier, contractor additions, and other.

The O\&M costs include costs of electricity usage, labor, sampling and analysis, parts and replacement equipment, and disposal of radioactive mixed waste and HLW.

The D\&D costs include costs of those components used at the surface or that are retrievable from the subsurface and are potentially radioactive.

The EUAC reflects the annual costs for all cash flows in the alternative adjusted to a base year (Ruegg 1987). EUAC is reported in units of 1994 dollars per year. 
TNPW

The TNPW reflects the finances currently needed to meet all requirements over the life of the alternative (Ruegg 1987). TNPW is reported as total lifetime costs (not costs per year) in 1994 dollars.

TLCC

The TLCC reflects the equivalent value of the alternative's cash flow over the life span of the alternative (Ruegg 1987). TLCC is reported as total lifetime costs (not costs per year) in 1994 dollars.

\subsubsection{Simplifying Assumptions}

Several simplifying assumptions were made in costing the technologies. The data and assumptions used are outlined below. Bases for these and other assumptions are provided in Appendix C.

- All costs are based on one hypothetical tank farm

- The tank farm consists of twelve, $3.8 \times 10^{6} \mathrm{~L}$ (1-Mgal) SSTs in a three by four array on $30.5-\mathrm{m}(100-\mathrm{ft})$ centers

- The tanks are in use for storage of high-level radioactive waste

- The life of all operations up to closure of the tank farm is 15 years

- The EUAC is based on a $10 \%$ discount rate per year

- The TNPW is based on a $10 \%$ discount rate per year

- The TLCC is the sum of capital costs plus D\&D costs plus number of life cycle years times the O\&M costs, adjusted to 1994 dollars

- All technology readiness and capital costs are incurred in the first year

- $\quad$ All D\&D costs are incurred at the end of the life cycle

- Costs for design, inspection, escalation, and contingency of subsurface barriers are $80 \%$ of construction costs and equal to $44 \%$ of capital cost

- $\quad$ Costs of operating personnel are between $3 \%$ and $8.6 \%$ per year of capital costs for active subsurface barrier options and $1 \%$ to $2.7 \%$ per year for chemical barrier options (which are passive)

- Costs of operating personnel are from $3.8 \%$ to $13.2 \%$ per year of capital costs for retrieval options 
- Costs of operating personnel are $12.3 \%$ per year of capital costs for flush water treatment options

- The ratio of annual O\&M costs to capital costs is 0.02 to 0.037 for subsurface barrier options using chemicals (passive technology, little maintenance required)

- The ratio of annual O\&M costs to capital costs is 0.129 to 0.166 for the circulating air barrier option and the flushing water and vacuum option (active technologies)

- The ratio of annual O\&M costs to capital costs is 0.09 to 0.118 for the freeze wall subsurface barrier option and the soil flushing and pumping option (active technologies)

- The D\&D costs are zero for passive technologies such as subsurface chemical barriers, backfill, and surface barriers

- The D\&D costs are $10 \%$ of capital cost plus one year labor costs for active subsurface barrier technologies such as cryogenic, desiccant and soil flushing

- The D\&D costs are $20 \%$ of capital cost plus one or two years labor cost for clean closure

- The D\&D costs are $30 \%$ of capital cost plus two years labor cost for flush water treatment

- Pipe drilling and jacking costs are $\$ 500 / \mathrm{ft}$

- The injected chemical volume is $15 \mathrm{ft}^{3}$ per foot of pipe at a pipe spacing of $7 \mathrm{ft}$. The installed material cost is $\$ 30 / \mathrm{ft}^{3}$ of injected barrier-forming chemicals

- Concentrated wastes recovered from soil flushing operations and from soil and debris washing operations are treated in the high- and low-level waste pretreatment and treatment systems

- Excess waste retrieved from tanks above $99 \%$ retrieval, as in robotic sluicing, would incur proportionally added costs for high- and low-level waste pretreatment and treatment. Reduced waste retrieval, as in mechanical retrieval, would incur proportionately reduced costs. 


\subsection{COSTS OF RETRIEVAL OPTIONS}

Three retrieval options were considered in this report: (1) traditional sluicing, (2) robotic sluicing, and (3) mechanical retrieval. The robotic sluicing and mechanical retrieval options would be arm-based and require much of the same hardware and equipment for operation. Traditional sluicing does not use a robotic arm and requires much less equipment than either robotic sluicing or mechanical retrieval, resulting in much lower capital, O\&M, and D\&D costs. The estimated total costs for the retrieval options are shown in Table 7-1.

Table 7-1. Estimated Total Costs of Retrieval Options (in millions of dollars).

\begin{tabular}{|l|c|c|c|c|c|c|c|}
\hline \multicolumn{1}{|c|}{ Retrieval Option } & $\begin{array}{c}\text { Tech } \\
\text { Ready }\end{array}$ & Capital & O\&M & D\&D & EUAC & TNPW & TLCC \\
\hline Traditional sluicing & 2 & 63 & 4 & 9 & 13 & 97 & 132 \\
\hline Robotic sluicing & 18 & 183 & 25 & 61 & 54 & 410 & 646 \\
\hline Mechanical retrieval & 15 & 154 & 23 & 48 & 46 & 347 & 545 \\
\hline
\end{tabular}

${ }^{\mathrm{a}}$ Costs are presented in millions of dollars per year (not lifetime cost).

\subsection{COSTS OF SUBSURFACE BARRIER OPTIONS}

Seven subsurface barrier options are considered in this report: (1) close-coupled chemical with flushing, (2) box-shaped chemical, (3) V-shaped chemical, (4) V-shaped freeze wall, (5) circulating air, (6) close-coupled chemical without flushing, and (7) close-coupled chemical on tank sides only without flushing. The capital costs for all options using chemicals are estimated to be more than twice the capital costs for the circulating air barrier option (Table 7-2). The chemical options, however, would not incur D\&D costs because the chemical would remain in the subsurface following waste retrieval operations, while V-shaped freeze wall and circulating air barrier options would incur D\&D costs. The O\&M costs for the five chemical options are projected to be comparable. The V-shaped freeze wall and V-shaped chemical options would be the most costly. The V-shaped freeze wall option would entail a high capital cost because it is assumed that three layers of pipe in a V-shaped configuration would be used to ensure barrier integrity, monitor for leak-tightness and promote interior surface melting of the barrier interior to aid in recovering contaminants that become trapped in the ice barrier. Costs for the chemical barriers reflect use of two layers of pipe for injection of chemical grout to assure barrier integrity. Additional costs would be incurred if a third pipe layer is needed to verify and monitor chemical barrier integrity. 
Table 7-2. Estimated Costs of Subsurface Barrier Options (in millions of dollars).

\begin{tabular}{|l|c|c|c|c|c|c|c|}
\hline \multicolumn{1}{|c|}{$\begin{array}{c}\text { Subsurface Barrier } \\
\text { Option }\end{array}$} & $\begin{array}{c}\text { Tech } \\
\text { Dev. }\end{array}$ & Capital & O\&M & D\&D & EUAC $^{\mathrm{a}}$ & TNPW & TLCC \\
\hline $\begin{array}{l}\text { Close-Coupled } \\
\text { Chemical-sides \& under } \\
12 \text { tanks }\end{array}$ & 13 & 211 & 5 & 0 & 35 & 263 & 301 \\
\hline $\begin{array}{l}\text { Close-Coupled } \\
\text { Chemical w/o Flushing, } \\
7 \text { tanks }\end{array}$ & 13 & 145 & 5 & 0 & 25 & 192 & 225 \\
\hline $\begin{array}{l}\text { Modified Close-Coupled } \\
\text { Chemical - sides only }\end{array}$ & 7 & 111 & 4 & 0 & 20 & 149 & 180 \\
\hline $\begin{array}{l}\text { Box-Shaped Chemical } \\
\text { V-Shaped Chemical }\end{array}$ & 13 & 218 & 5 & 0 & 36 & 272 & 312 \\
\hline V-Shaped Freeze Wall & 12 & 208 & 19 & 27 & 48 & 369 & 527 \\
\hline Circulating Air & 4 & 71 & 12 & 16 & 23 & 171 & 273 \\
\hline
\end{tabular}

${ }^{2}$ Costs are stated in millions of dollars per year (not lifetime cost). 


\subsection{COSTS OF SOIL FLUSHING OPTIONS}

The two soil flushing options considered were: (1) traditional soil flushing, and (2) soil flushing with vacuum recovery. Both options would require subsequent recovery and treatment of flush water. The costs for the flushing with vacuum recovery option are from $16 \%$ to $37 \%$ greater than the costs of the conventional flushing option (Table 7-3). Estimated costs for flush water treatment with associated transport piping are also included in this table.

Table 7-3. Estimated Costs of Soil Flushing Options (in millions of dollars).

\begin{tabular}{|l|c|c|c|c|c|c|c|}
\hline \multicolumn{1}{|c|}{$\begin{array}{c}\text { Soil Flushing } \\
\text { Option }\end{array}$} & $\begin{array}{c}\text { Tech } \\
\text { Dev. }\end{array}$ & Capital & O\&M $^{\mathrm{a}}$ & D\&D & EUAC & TNPW & TLCC \\
\hline Traditional flushing & 6 & 92 & 11 & 15 & 24 & 185 & 276 \\
\hline $\begin{array}{l}\text { Vacuum soil flushing } \\
\text { with circulating air }\end{array}$ & 10 & 126 & 16 & 19 & 35 & 264 & 399 \\
\hline $\begin{array}{l}\text { Vacuum soil flushing } \\
\text { with close-coupled } \\
\text { chemical }\end{array}$ & 10 & 107 & 15 & 17 & 31 & 234 & 356 \\
\hline $\begin{array}{l}\text { Flush water } \\
\text { treatment for close- } \\
\text { coupled barrier }\end{array}$ & 2 & 8 & 1 & 5 & 3 & 22 & 37 \\
\hline $\begin{array}{l}\text { Flush water } \\
\text { treatment for box- } \\
\text { shaped barrier }\end{array}$ & 2 & 44 & 7 & 27 & 15 & 114 & 195 \\
\hline $\begin{array}{l}\text { Flush water } \\
\text { treatment for V- } \\
\text { shaped barrier }\end{array}$ & 2 & 47 & 8 & 28 & 17 & 122 & 208 \\
\hline $\begin{array}{l}\text { Flush water } \\
\text { treatment for } \\
\text { circulating air barrier }\end{array}$ & 2 & 14 & 2 & 10 & 5 & 41 & 72 \\
\hline
\end{tabular}

${ }^{\mathrm{a}}$ Costs are stated in millions of dollars per year (not lifetime cost).

\subsection{TANK STABILIZATION AND SURFACE BARRIER}

Following retrieval operations, the tanks would be stabilized by grout fill and a surface barrier would be placed over the top of the tanks. A surface barrier would also be placed over the landfill used in the clean-closure alternatives. The estimated costs for the tank stabilization and surface barrier are shown in Table 7-4. 
Table 7-4. Estimated Costs of Tank Stabilization and Surface Barrier (in millions of dollars).

\begin{tabular}{|l|c|c|c|c|c|c|c|}
\hline \multicolumn{1}{|c|}{ Closure Option } & $\begin{array}{c}\text { Tech } \\
\text { Dev. }\end{array}$ & Capital & O\&M & D\&D & EUAC & TNPW & TLCC \\
\hline Tank stabilization & 1 & 2 & 0.2 & 0.2 & 0.7 & 5 & 7 \\
\hline Surface barrier & 2 & 4 & 0.2 & 0 & 1 & 8 & 10 \\
\hline
\end{tabular}

"Costs are stated in millions of dollars per year (not lifetime cost).

\subsection{CLEAN CLOSURE}

Two alternatives would employ a series of linked technologies that would result in clean closure of the hypothetical tank farm. The alternatives differ only in the use or absence of use of a close-coupled chemical barrier. The use of a barrier would result in reduced leakage during sluicing and lower quantities of contaminated soil below the tanks. The technologies assumed to be used in the alternatives and their costs are provided in Table 7-5.

\subsection{SUMMARY OF ALTERNATIVES COSTS}

The purpose of estimating the costs of individual options was to facilitate their comparison and to enable summing the costs in accordance with the combinations of options that define the various alternatives. Tables 7-6, 7-7, and 7-8 show the costs of options and alternatives based on EUAC, TNPW, and TLCC, respectively. 


\begin{tabular}{|c|c|c|c|c|c|c|c|}
\hline & Tech Ready & Capital & O\&M* & D\&D & EAUC ${ }^{b}$ & TNPW & TLCC \\
\hline ALTERNATIVE 13, NO BARRIER & & & & & & & . \\
\hline Removal & 7 & 141 & 23 & 51 & 44 & 334 & 541 \\
\hline Tank farm confinement & 3 & 270 & 28 & 67 & 66 & 504 & 765 \\
\hline Hauling \& mixed waste landfill & 2 & 19 & 4 & 6 & 7 & 53 & 89 \\
\hline Soil \& debris water wash & 4 & 169 & 20 & 47 & 44 & 338 & 524 \\
\hline Wash water treatment & 2 & 50 & 7 & 11 & 14 & 109 & 172 \\
\hline Washed solids to mixed waste disposal & 1 & 0.06 & 0.02 & 0 & 0.16 & 1 & 1 \\
\hline Recycle piping & 1 & 65 & 10 & 23 & 20 & 150 & 245 \\
\hline Backfill & 0.2 & 5 & 0 & 0 & 1 & 5 & 5 \\
\hline HLW processing \& disposal & 0 & 11 & 2 & 10 & 5 & 38 & 69 \\
\hline Totals & 20 & 730 & 94 & 215 & 201 & 1,532 & 2,411 \\
\hline ALTERNATIVE 14, WITII CLOSE-C & & & & & & & \\
\hline Close-coupled chemical barrier & 13 & 145 & 5 & 0 & 25 & 192 & 225 \\
\hline Removal & 7 & 96 & 19 & 42 & 34 & 259 & 432 \\
\hline Tank farm confinement & 3 & 270 & 28 & 67 & 66 & 504 & 765 \\
\hline Hauling \& mixed waste landfill & 2 & 13 & 4 & 5 & 6 & 44 & 75 \\
\hline Soil \& debris water wash & 4 & 115 & 16 & 36 & 33 & 249 & 393 \\
\hline Wash watẹr treatment & 2 & 34 & 6 & 13 & 11 & 82 & 134 \\
\hline Solids to mixed waste disposal & 1 & 0.04 & 0.02 & 0 & 0.15 & 1 & 1 \\
\hline Recycle piping & 1 & 44 & 9 & 19 & 15 & 116 & 195 \\
\hline Backfill & 0.2 & 4 & 0 & 0 & 0.5 & 4 & 4 \\
\hline HLW processing \& disposal & 0 & 8 & 2 & 8 & 4 & 29 & 53 \\
\hline Totals & 33 & 729 & 89 & 190 & 195 & 1,480 & 2,277 \\
\hline
\end{tabular}


Table 7-6. Estimated EUAC Costs of Alternatives (in millions of dollars).

\begin{tabular}{|c|c|c|c|c|c|c|c|}
\hline Alemative & Subsurfinoc Burrict Optioa & Retricval Oplios & Flushing & Flush Wales Trealineax & Thank Subilizod & Surfeco Berrier & Totel Coste \\
\hline 1. No Action & sone & none & $\infty 000$ & $n 000$ & mo & $\infty \infty \infty$ & 0 \\
\hline 2. Surface Barrier Oaly & $\operatorname{sanc}$ & $D 000$ & $n 000$ & sone & - & $\frac{2 \text { 편 }}{1}$ & 1 \\
\hline $\begin{array}{l}\text { 3. Traditionel Sluicing } \\
\text { (Baseline) }\end{array}$ & Done & $\frac{\text { tred. pluicing }}{13}$ & saro & $n 000$ & 0.7 & $\frac{15}{1}$ & 15 \\
\hline 4. Roboxic Sluicing & Dane & $\frac{\text { roboxic aluicing }}{54}$ & noso & sance & $\frac{200}{0.7}$ & $\frac{200}{1}$ & 56 \\
\hline 5. Mcctenical Rectricval & nonos & $\frac{\text { mecth. retrieval }}{46}$ & Dono & Domo & 0.7 & $\frac{1}{1}$ & 48 \\
\hline $\begin{array}{l}\text { 6. Close-Couplod } \\
\text { Chemical Barrict with } \\
\text { Flushing }\end{array}$ & $\frac{\text { slooc-ocumped chemical }}{36}$ & $\frac{\text { Ired. aluiging }}{13}$ & $\frac{\text { Nushing \& vacoumn }}{31}$ & $\frac{14 M_{8 \text { sal }}}{3}$ & 0.7 & $\frac{200}{1}$ & 85 \\
\hline $\begin{array}{l}\text { 7. Closo-Coupled } \\
\text { Chemical Barrier w/o } \\
\text { Flushing }\end{array}$ & $\frac{\text { slooe-ooupled demiogl }}{25}$ & $\frac{\text { Ind. eluicing }}{13}$ & nane & Dano & $\frac{v e a}{0.7}$ & $\frac{200}{1}$ & $\infty$ \\
\hline $\begin{array}{l}\text { 8. Modified Clooo } \\
\text { Couplod Chemical Barrice } \\
\text { w/o Flushing }\end{array}$ & $\frac{\text { partial close-ouplod chernical }}{30}$ & $\frac{\text { Ind. aluicins }}{13}$ & Dano & naso & $\frac{200}{0.7}$ & $\frac{200}{1}$ & 35 \\
\hline $\begin{array}{l}\text { 9. Bax-Shapod Chemical } \\
\text { Barrier }\end{array}$ & $\frac{\text { box-sheped chemical }}{36}$ & $\frac{\text { Irad. Aluicing }}{13}$ & $\frac{\text { Aushing \& pumping }}{24}$ & $\frac{245 \text { Mral }}{15}$ & $\frac{y e d}{0.7}$ & $\frac{\frac{2 a t}{1}}{1}$ & 90 \\
\hline $\begin{array}{l}\text { 10. V-Shapod Chemioal } \\
\text { Busrice }\end{array}$ & $\frac{\text { V. herpod chemical }}{49}$ & $\frac{\text { irad. aluicing }}{13}$ & $\frac{\text { Nushing \& pumping }}{24}$ & $\frac{278 \text { Mral }}{16}$ & $\frac{50}{0.7}$ & $\frac{\mathrm{yea}}{1}$ & 104 \\
\hline $\begin{array}{l}\text { 11. V-Shaped Froeze Wall } \\
\text { Barrier }\end{array}$ & $\frac{\text { V.ahupped froese wall }}{48}$ & $\frac{\text { tred. Aluicing }}{13}$ & $\frac{\text { Nushing \& pumping }}{24}$ & $\frac{278 M_{821}}{16}$ & $\frac{\text { yese }}{0.7}$ & $\frac{\mathrm{yea}}{1}$ & 103 \\
\hline 12. Circulating Air Merricr & $\frac{\text { siraulutine air }}{23}$ & $\frac{\text { Ireul. sluicing }}{13}$ & $\frac{\text { Nunhine \& veenum }}{35}$ & $\frac{20 \text { Mpd }}{5}$ & $\frac{50}{0.7}$ & $\frac{200}{1}$ & 78 \\
\hline $\begin{array}{l}\text { 13. Clean-Closure w/o } \\
\text { subsurfuce Barrier }\end{array}$ & none & $\frac{\text { Ind. aluicing and minings: }}{214}$ & none & none & ned applicable & no & 214 \\
\hline 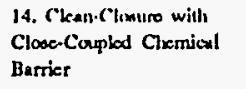 & 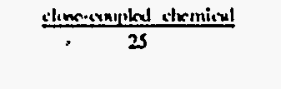 & $\frac{\text { Iful. aluivine und minims:" }}{182}$ & mero & tomo & nox opplicatitio & no & 207 \\
\hline
\end{tabular}

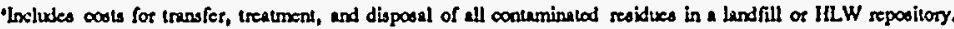


Table 7-7. Estimated TNPW Costs of Alternatives (in millions of dollars).

\begin{tabular}{|c|c|c|c|c|c|c|c|}
\hline Alemelive & Subsurficos Bearrier Optioc & Retricval Option & Flushing & Flunh Walcs Treatread & Tank Subilitiod & Surfino Barrict & Toal Costs \\
\hline 1. No Action & nono & sode & $n+\infty$ & sano & $\infty$ & noso & 0 \\
\hline 2. Surface Barricr Only & nase & $\operatorname{san}$ & naxe & naso & - & $\frac{200}{8}$ & 8 \\
\hline $\begin{array}{l}\text { 3. Treditional Sluicing } \\
\text { (Becelinc) }\end{array}$ & $\operatorname{sax}$ & $\frac{\text { trad. alusing }}{97}$ & noxece & sane & $\frac{20 a}{s}$ & $\frac{y a t}{8}$ & 110 \\
\hline 4. Robotic Slüicing & Donce & $\frac{\text { roboxic aluicing }}{410}$ & $\operatorname{nose}$ & nose & $\frac{y e s}{5}$ & $\frac{\text { vea }}{8}$ & 43 \\
\hline 5. Mechenical Recrieval & nanc & $\frac{\text { mech. retrieval }}{347}$ & none & none & $\frac{y e s}{s}$ & $\frac{y e a}{8}$ & 360 \\
\hline $\begin{array}{l}\text { 6. Cloocecoupled Chemical } \\
\text { Barrier with } \\
\text { Flushing }\end{array}$ & $\frac{\text { closecoupled dremial }}{263}$ & $\frac{\text { ind slusing }}{97}$ & $\frac{\text { nushing \& vacumm }}{234}$ & $\frac{14 M_{p 21}}{2}$ & $\frac{r a s}{5}$ & $\frac{y a t}{8}$ & 629 \\
\hline $\begin{array}{l}\text { 7. Closo-Cauplod } \\
\text { Clanical Barrict } \\
\text { w/o Flushing }\end{array}$ & $\frac{n \text { none \& cloos-oupled demial }}{192}$ & $\frac{\text { inded. oluicing }}{9}$ & nodec & nosoo & $\frac{y e d}{5}$ & $\frac{7 a}{8}$ & 302 \\
\hline $\begin{array}{l}\text { 8. Modifirod Close-Caupled } \\
\text { Chemical Barricr w/o } \\
\text { Flushing }\end{array}$ & $\frac{\text { peniil close- oopplad chemical }}{149}$ & $\frac{\text { Ind. eluving }}{9}$ & $\operatorname{man}$ & nomo & $\frac{v e d}{s}$ & $\frac{50}{8}$ & 259 \\
\hline $\begin{array}{l}\text { 9. Box.Shapod Chemical } \\
\text { Barrice }\end{array}$ & $\frac{\text { boxeshoped chemical }}{2 n}$ & $\frac{\text { trad. slusing }}{97}$ & $\frac{\text { Rushing \& panping }}{185}$ & $\frac{245 \mathrm{M} / \mathrm{gd}}{114}$ & $\frac{y e d}{5}$ & $\frac{y \in a}{8}$ & $\infty 81$ \\
\hline $\begin{array}{l}\text { 10. V.Shaped Chemical } \\
\text { Berricr }\end{array}$ & $\frac{\text { V.ahpopd chemical }}{375}$ & $\frac{\text { trod. oluciens }}{9}$ & $\frac{\text { nushing \& pamping }}{185}$ & $\frac{278 \mathrm{Mpad}}{122}$ & $\frac{y e d}{5}$ & $\frac{100}{8}$ & 292 \\
\hline $\begin{array}{l}\text { 11. V-Shapod Froceso Wall } \\
\text { Barrier }\end{array}$ & $\frac{\text { Voshepod froexc wall }}{369}$ & $\frac{\text { trad. alusing }}{97}$ & $\frac{\text { Munhing \& pumping }}{185}$ & $\frac{278 \mathrm{Mpal}}{122}$ & $\frac{y e a}{s}$ & $\frac{y e a}{8}$ & 786 \\
\hline 12. Cirrulating Air Barricer & $\frac{\text { dircultring air }}{171}$ & $\frac{\text { ind. slucings }}{97}$ & $\frac{\text { Aushing \& vaenem }}{264}$ & $\frac{20 M_{B 21}}{41}$ & $\frac{y e s}{s}$ & $\frac{y e s}{8}$ & 586 \\
\hline $\begin{array}{l}\text { 13. Cken-Closuro w/o } \\
\text { subsurface Baries }\end{array}$ & none & $\frac{\text { Irod. slucing and mining". }}{1629}$. & $\operatorname{nax}$ & $\operatorname{nax}$ & Dox applicable & mo & 1629 \\
\hline 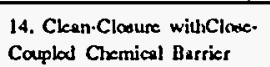 & $\frac{\text { slane- anprod clemiagl }}{192}$ & $\frac{\text { Ind. aluicing unt mining:" }}{1384}$ & nxme & nano & nox applicatb & no & 1576 \\
\hline
\end{tabular}

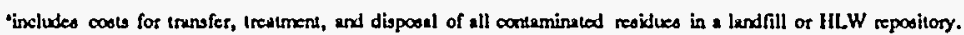


Table 7-8. Estimated TLCC Costs of Alternatives (in millions of dollars).

\begin{tabular}{|c|c|c|c|c|c|c|c|}
\hline Alemative & Subsorficos Barrier Option & Retrieval Option & Fhusting & Fhush Whater Treatment & Tank Subilitiod & Surfico Berrios & Toul Costs \\
\hline 1. No Acion & sone & nonece & $\sin$ & nomo & so & $\infty \infty \infty$ & o \\
\hline 2. Surficos Barrier Only & som & 5000 & nanc & now & mo & $\frac{\mathrm{ra}}{10}$ & 10 \\
\hline $\begin{array}{l}\text { 3. Troditional Sluicing } \\
\text { (Bascline) }\end{array}$ & Done & $\frac{\text { Lod. olucing }}{132}$ & $\operatorname{senc}$ & Done & $\frac{109}{7}$ & $\frac{200}{10}$ & 149 \\
\hline 4. Robatic Sluicing & Dono & $\frac{\frac{\text { mobaxic atucing }}{646}}{46}$ & nono & poos & $\frac{100}{7}$ & $\frac{20}{10}$ & 663 \\
\hline 5. Mecthenical Recrieval & nowe & $\frac{\text { mech. retrieval }}{545}$ & Dane & Daso & $\frac{r a d}{7}$ & $\frac{y a x}{10}$ & 562 \\
\hline $\begin{array}{l}\text { 6. Clowo-Cauplod Chemical } \\
\text { Barricer with } \\
\text { Flushing }\end{array}$ & $\frac{\text { elone-arplod themieal }}{301}$ & $\frac{\text { Ind. slueing }}{132}$ & $\frac{\text { Aluhhins \& venum }}{366}$ & $\frac{14 M_{p a l}}{37}$ & $\frac{y a x}{7}$ & $\frac{\mathrm{vec}}{10}$ & 843 \\
\hline $\begin{array}{l}\text { 7. Closo-Capplod } \\
\text { Chemical Barrict } \\
\text { w/o Flushing }\end{array}$ & $\frac{\text { clooc-anplod demical }}{25}$ & $\frac{\text { Ind. atuicing }}{132}$ & nano & noos & $\frac{7 x}{7}$ & $\frac{x a t}{10}$ & 374 \\
\hline $\begin{array}{l}\text { 8. Modifirod Closoc-Caplod } \\
\text { Chemical Burricer w/o Flusting }\end{array}$ & 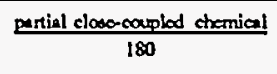 & $\frac{\frac{1 \text { red. glusings }}{132}}{132}$ & $\operatorname{pax}$ & 2000 & $\frac{r e a}{7}$ & $\frac{10}{10}$ & 329 \\
\hline $\begin{array}{l}\text { 9. Bax-Shaped Chemical } \\
\text { Barrict }\end{array}$ & 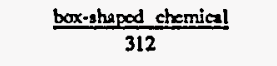 & $\frac{\text { Ind. glusings }}{132}$ & $\frac{\text { Nushing \& pumping }}{276}$ & $\frac{245 \mathrm{Mgl}}{195}$ & $\frac{y e c}{7}$ & $\frac{r e s}{10}$ & 932 \\
\hline $\begin{array}{l}\text { 10. V-Shapod Chemial } \\
\text { Barrier }\end{array}$ & $\frac{\text { V.thphod chemial }}{423}$ & $\frac{\text { trad. sluiging }}{132}$ & $\frac{\text { Dushing \& pamping }}{276}$ & $\frac{278 \mathrm{Mgl}}{208}$ & $\frac{\text { rea }}{7}$ & $\frac{\mathrm{res}}{10}$ & 1056 \\
\hline $\begin{array}{l}\text { 11. V.Shaped Frocece Wall } \\
\text { Barrier }\end{array}$ & $\frac{\text { V.ahsopd frece wall }}{527}$ & $\frac{\text { trd. Alucing }}{132}$ & $\frac{\text { Aluhhing \& pumping }}{276}$ & $\frac{278 \mathrm{Mral}}{208}$ & $\frac{\mathrm{res}}{7}$ & $\frac{\mathrm{kat}}{10}$ & 1160 \\
\hline 12. Circulatuing Air Berrier & $\frac{\text { dirculating air }}{273}$ & $\frac{\text { Ind. slusing }}{132}$ & $\frac{\text { nushing \& vanum }}{399}$ & $\frac{32 M_{\text {gel }}}{7}$ & $\frac{y-e}{7}$ & $\frac{50}{10}$ & 893 \\
\hline $\begin{array}{l}\text { 13. Ckan-Clooure w/o } \\
\text { cubburface Barrier }\end{array}$ & pare & $\frac{\text { Ind. Alucing and mining" }}{2543}$ & $\operatorname{man}$ & pare & nor applicable & no & 2443 \\
\hline $\begin{array}{l}\text { 14. Ckean-Clooure with Close. } \\
\text { compled Chrmical Barricrer }\end{array}$ & $\frac{\text { clase-counled chemiend }}{225}$ & $\frac{\text { trud, glusing and minings. }}{2185}$. & nore & none & nox appllable & no & 2410 \\
\hline
\end{tabular}

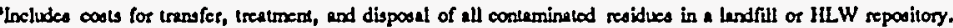


WHC-SD-WM-ES-300 REV. 1

This page intentionally left blank. 


\subsection{COST-BENEFIT AND SENSITIVITY ANALYSIS}

This section contains an analysis of the relative cost-benefit of the 14 alternatives and an evaluation of the uncertainty and variability of selected factors that may impact cost and risk.

\subsection{COST-BENEFIT ANALYSIS}

The cost-benefit of the 14 alternatives was estimated using peak relative risk and HI measures presented in Section 6 and TNPW measures presented in Section 7. The TNPW was selected as the most appropriate measure of cost for this analysis because it reflects the discounted cost of the alternative, a true measure of overall cost.

Benefit is normally calculated by the risk-difference method. This method is defined as one minus the ratio of the relative risk ( Risk $_{i}$ or $\mathrm{HI}_{\mathfrak{i}}$ ) after the selected action(s) is taken to mitigate the risk (or HI) to the relative risk ( Risk $_{\mathrm{a}}$ or $\mathrm{HI}_{\mathrm{n}}$ ) of an initial or baseline case:

Risk-Difference Method for Calculating Benefit (B).

$$
B=1-\left(\frac{\operatorname{Risk}_{n}}{\operatorname{Risk}_{i}}\right)
$$

Hence, benefit by this method reflects the fractional reduction in risk. However, for the case of a large difference between the riskiest alternative and several alternatives of similar risk, the fractional differences are relatively small and provide poor discrimination among benefits of the alternatives. Table 8-1 shows benefits calculated by this method. For Alternatives 3 through 12, which feature relative risk differences of only a maximum of about 1 order of magnitude, the benefits calculated by the risk-difference method vary by about $0.01 \%$. Thus, an alternate method of calculating benefit was used, which enhances discrimination of benefit among alternatives.

Benefit in this analysis is defined as the ratio of relative risk or HI for an initial or baseline case to relative risk or HI after an action(s) is taken to mitigate the risk, minus one. Hence, benefit reflects the proportional reduction in risk or hazard. This method for calculating benefit was deemed appropriate because it allows for discrimination among alternatives when there is a large difference between the riskiest alternative and several alternatives with similar risks:

Risk-Ratio Method for Calculating Benefit (B).

$$
B=\left(\frac{\operatorname{Risk}_{i}}{\operatorname{Risk}_{n}}\right)-1
$$


Table 8-1. Benefit of Alternatives Using Risk-Difference Method.

\begin{tabular}{|ll|c|c|}
\hline \multicolumn{1}{|c|}{ Alternative } & Relative Risk & Benefit \\
\hline 1. & No Action & $1.5 \times 10^{-1}$ & 0.0 \\
\hline 2. & Surface Barrier Only & $3.7 \times 10^{-4}$ & 0.99753 \\
\hline 3. & Traditional Sluicing & $1.1 \times 10^{-5}$ & 0.99993 \\
\hline 4. & Robotic Sluicing & $2.5 \times 10^{-6}$ & 0.99998 \\
\hline 5. & Mechanical Retrieval & $2.1 \times 10^{-5}$ & 0.99986 \\
\hline 6. & $\begin{array}{l}\text { Close-Coupled } \\
\text { Chemical Barrier }\end{array}$ & $5.2 \times 10^{-6}$ & 0.99997 \\
\hline 7. & $\begin{array}{l}\text { Close-Coupled } \\
\text { Chemical Barrier w/o }\end{array}$ & $7.0 \times 10^{-6}$ & 0.99995 \\
\hline Flushing & $\begin{array}{l}\text { Modified Close- } \\
\text { Coupled Chemical } \\
\text { Barrier w/o Flushing }\end{array}$ & $8.0 \times 10^{-6}$ & 0.99995 \\
\hline 9. & $\begin{array}{l}\text { Box-Shaped Chemical } \\
\text { Barrier }\end{array}$ & $4.9 \times 10^{-6}$ & 0.99997 \\
\hline 10. & $\begin{array}{l}\text { V-Shaped Chemical } \\
\text { Barrier }\end{array}$ & $4.9 \times 10^{-6}$ & 0.99997 \\
\hline 11. & $\begin{array}{l}\text { V-Shaped Freeze Wall } \\
\text { Barrier }\end{array}$ & $4.8 \times 10^{-6}$ & 0.99997 \\
\hline 12. & Circulating Air Barrier & $5.1 \times 10^{-6}$ & 0.99997 \\
\hline 13. & $\begin{array}{l}\text { Clean-Closure w/o } \\
\text { Subsurface Barrier }\end{array}$ & $1.1 \times 10^{-6}$ & 0.99999 \\
\hline 14. & $\begin{array}{l}\text { Clean-Closure with } \\
\text { Close-Coupled } \\
\text { Chemical Barrier }\end{array}$ & $6.3 \times 10^{-8}$ & 0.99999 \\
\hline
\end{tabular}


Compared to the calculation of benefit using the risk-difference method, the risk-ratio method provides a range of over 300\% in benefits calculated for Alternatives 3 through 12 .

Cost-benefit (C-B) in this analysis is defined as the ratio of the risk-ratio benefit (the "bang") to the TNPW (the "buck"), as show below:

$$
\begin{gathered}
C-B_{\text {risk }}=\left(\left(\text { Risk }_{i} / \text { Risk }_{n}\right)-1\right) / T N P W \\
C-B_{H I}=\left(\left(H I_{i} / H I_{n}\right)-1\right) / T N P W
\end{gathered}
$$

For example, a reduction of relative risk from a level of 20 to 2 at a cost of 3 would equate to a cost-benefit of 3 . No reduction of risk would equate to a cost-benefit of 0 , regardless of cost. The cost-benefit of each alternative relative to the No-Action Alternative is shown in Table 8-2. Several conclusions can be drawn from this table, ignoring the high uncertainties in both the cost and risk analyses and other factors important in the decision making process.

- There is relatively little difference in the cost-benefit of the various subsurface barrier alternatives.

- The Robotic Sluicing and Traditional Sluicing Alternatives would be two to six times more cost-effective than would alternatives that employ subsurface barriers to support closure of tank farms as landfills. From a risk differential standpoint (i.e., benefit equals the difference in risks as opposed to the ratio of risks), costbenefit is essentially proportional to cost. In this case, the Traditional Sluicing Alternative is two to nine times more cost-effective; the cost-effectiveness of robotic sluicing is similar to that of the other alternatives.

- Clean-closure alternatives would be similar in risk cost-effectiveness in protecting groundwater to alternatives that employ subsurface barriers. This conclusion is based on the risk-ratio method for determining benefit. For the risk-difference method, clean-closure would be two to seven times less cost-effective.

- The use of subsurface barriers to support clean-closure would improve HI costeffectiveness, based on the HI ratio method. Using the difference method, clean-closure would be two to seven times less cost-effective than alternatives that employ subsurface barriers. The incremental cost-effectiveness of selected actions taken to reduce risk is shown in Table 8-3. This table was developed to enable comparison of the cost-benefit (based on the ratio method) of individual actions included in the alternatives. Table 8-3 includes a measure of the costeffectiveness of an alternative not previously analyzed in this study. The alternative is the same as the Traditional Sluicing Alternative (Baseline Alternative), but without a surface barrier. This alternative was analyzed in 


\begin{tabular}{|c|c|c|c|c|c|}
\hline Alternative & Relative Risk & $\mathrm{HI}$ & TNPW & $\begin{array}{l}\text { Risk Cost- } \\
\text { Benefit }\end{array}$ & HI Cost-Benefit \\
\hline 1. No Action ${ }^{a}$ & $1.5 \times 10^{-1}$ & $2.8 \times 10^{3}$ & 0 & $\mathrm{~N} / \mathrm{A}^{\mathrm{b}}$ & $N / A^{b}$ \\
\hline 2. Surface Barrier Only ${ }^{a}$ & $3.7 \times 10^{-4}$ & 8.6 & 8 & 51 & 41 \\
\hline 3. Traditional Sluicing & $1.1 \times 10^{-5}$ & $2.4 \times 10^{-1}$ & 110 & 124 & 106 \\
\hline 4. Robotic Sluicing & $2.5 \times 10^{-6}$ & $5.7 \times 10^{-2}$ & 423 & 142 & 116 \\
\hline 5. Mechanical Retrieval & $2.1 \times 10^{-5}$ & $4.9 \times 10^{-1}$ & 360 & 29 & 16 \\
\hline $\begin{array}{l}\text { 6. Close-Coupled Chemical Barrier with } \\
\text { Flushing }\end{array}$ & $5.2 \times 10^{-6}$ & $1.2 \times 10^{-1}$ & 629 & 46 & 37 \\
\hline $\begin{array}{l}\text { 7. Close-Coupled Chemical Barrier w/o } \\
\text { Flushing }\end{array}$ & $7.0 \times 10^{-6}$ & $1.6 \times 10^{-1}$ & 302 & 71 & 58 \\
\hline $\begin{array}{l}\text { 8. Modified Close-Coupled Chemical } \\
\text { Barrier w/o Flushing }\end{array}$ & $8.0 \times 10^{-6}$ & $1.8 \times 10^{-1}$ & 259 & 72 & 60 \\
\hline 9. Box-Shaped Chemical Barrier ${ }^{c}$ & $4.9 \times 10^{-6}$ & $1.1 \times 10^{-1}$ & 681 & 45 & 38 \\
\hline 10. V-Shaped Chemical Barrier ${ }^{c}$ & $4.9 \times 10^{-6}$ & $1.1 \times 10^{-1}$ & 792 & 39 & 32 \\
\hline 11. V-Shaped Freeze Wall Barrier & $4.8 \times 10^{-6}$ & $1.1 \times 10^{-1}$ & 786 & 40 & 33 \\
\hline 12. Circulating Air Barrier ${ }^{c}$ & $5.1 \times 10^{-6}$ & $1.2 \times 10^{-1}$ & 586 & 50 & 40 \\
\hline 13. Clean-Closure w/o Subsurface Barrier & $1.1 \times 10^{-7} \mathrm{~d}$ & $2.4 \times 10^{-3}$ & 1,629 & 92 & 720 \\
\hline $\begin{array}{l}\text { 14. Clean-Closure with Close-Coupled } \\
\text { Chemical Barrier }\end{array}$ & $6.3 \times 10^{-8 d}$ & $1.4 \times 10^{-3}$ & 1,576 & 92 & 1,300 \\
\hline
\end{tabular}


Table 8-3. Incremental Cost-Effectiveness of Selected Actions.

\begin{tabular}{|c|c|c|c|c|c|}
\hline \multirow{3}{*}{ Actions } & \multicolumn{4}{|c|}{ Cost-Effectivencas of Action(s) (Risk-Ratio Method) } & \multirow{3}{*}{$\begin{array}{c}\text { Ineremental } \\
\text { Cont-Effoctiveness } \\
\text { Compared to: }\end{array}$} \\
\hline & \multicolumn{2}{|c|}{ Risk-Effectiveness } & \multicolumn{2}{|c|}{ HI-Effectiveness } & \\
\hline & Overalr & Incremental & Overalf & Ineremental & \\
\hline $\begin{array}{l}\text { A. Use traditional oluicing and grout tank voids-no eurface } \\
\text { barrier (new altermative) }\end{array}$ & 0.3 & 0.3 & 0.3 & 0.3 & No Action (Alternative 1) \\
\hline B. Add a surface barrier to A (Altemative 3) & 124 & 54 & 106 & 46 & $\begin{array}{l}\text { Treditional shuicing and void grouting (new altemative } \\
\text { i.e., Action A) }\end{array}$ \\
\hline $\begin{array}{l}\text { C. Add a close-coupled chemical barrier with flushing to B } \\
\text { (Altemative } 6 \text { ) }\end{array}$ & 46 & 0.0021 & 37 & 0.0019 & $\begin{array}{l}\text { Treditional shicing, void srouting, and surface barrier } \\
\text { (Alternative 3) }\end{array}$ \\
\hline $\begin{array}{l}\text { D. Add a close-coupled chemical barrier w/o flushing to B } \\
\text { (Altemative } 7 \text { ) }\end{array}$ & 71 & 0.003 & 58 & 0.0026 & $\begin{array}{l}\text { Traditional shicing, void grouting, and surface barrier } \\
\text { (Alternative 3) }\end{array}$ \\
\hline $\begin{array}{l}\text { E. Add a modified close-coupled chemical barrier w/o flushing } \\
\text { to B. (Alternative 8) }\end{array}$ & 72 & 0.0025 & 60 & 0.0024 & $\begin{array}{l}\text { Traditional aluicing, void grouting, end aurfuce barrier } \\
\text { (Alternative 3) }\end{array}$ \\
\hline $\begin{array}{l}\text { F. Add a box-shapod chemical barrier with flushing to } B \text {. } \\
\text { (Altemative 9) }\end{array}$ & 45 & 0.0022 & 38 & 0.0021 & $\begin{array}{l}\text { Traditional shicing, void grouting, and surface barrier } \\
\text { (Alternative 3) }\end{array}$ \\
\hline $\begin{array}{l}\text { G. Add a vahaped chemical barrier with flushing } \\
\text { to B. (Altemative 10) }\end{array}$ & 39 & 0.0018 & 32 & 0.0017 & $\begin{array}{l}\text { Traditional aluicinz, void zrouting, end surface barrier } \\
\text { (Alternative 3) }\end{array}$ \\
\hline $\begin{array}{l}\text { H. Add a v-shapod freeze wall barrier with flushing to B. } \\
\text { (Altemative 11) }\end{array}$ & 40 & 0.0019 & 33 & 0.0017 & $\begin{array}{l}\text { Traditional aluicing, void zroutiog, and surface barrier } \\
\text { (Alternative 3) }\end{array}$ \\
\hline $\begin{array}{l}\text { 1. Add a circulating air barrier with flushing to } B \text {. } \\
\text { (Altemntive 12) }\end{array}$ & 50 & 0.0024 & 40 & 0.0021 & $\begin{array}{l}\text { Traditional aluiciog, void srouting, and surface barricr } \\
\text { (Alicrative 3) }\end{array}$ \\
\hline $\begin{array}{l}\text { J. Add a stand-off barrier w/o flushing to } B . \\
\text { (modifiad Alternatives 9.12) }\end{array}$ & 0 & 0 & 0 & 0 & $\begin{array}{l}\text { Traditional sluicing, void grouting, and surface barricr } \\
\text { (Altemative 3) }\end{array}$ \\
\hline K. Clean-close with close-couplod barrierb (Alternative 14) & 92 & $-0.014^{b}$ & 1,300 & $-0.013^{b}$ & Clean-close w/o closo-coupled barrier (Altemntive 13) \\
\hline
\end{tabular}

Relative to No-Action Alternative

'Results are negative because risk, HI, and overall cost are roducod. Thus, uee of a barrier is cost-effective in this case basod on actual relative risk

'Relative risk determinod to be 4.8x10:' and HI determinod to be 89, per MEPAS code, Appendix A, censitivity case 1. 
order to evaluate the incremental cost-effectiveness of the surface barrier. Costs for the individual actions are based on TNPW.

Incremental cost-benefit of an action was determined by dividing the risks of two alternatives that differ only in the specific action and subtracting 1 , by the difference in the cost of the alternatives, as below:

$$
\begin{gathered}
\text { Incremental } C-B_{r i s k}=\frac{\left(\text { Risk }_{n} / \text { Risk }_{m}\right)-1}{T N P W_{m}-T N P W_{n}} \\
\text { Incremental } C-B_{H I}=\frac{\left(H I_{n} / H I_{m}\right)-1}{T N P W_{m}-T N P W_{n}}
\end{gathered}
$$

Where: $\quad$ Risk $_{\mathrm{n}}=$ baseline or initial risk

Conclusions that can be drawn from Table 8-3, ignoring uncertainties and other important factors, are listed below.

- The most cost-effective individual action is adding a close-coupled subsurface barrier to support clean-closure. This results in lowering both risk and HI and the overall cost of the alternative. This apparent anomaly arises from the substantial reduction in contaminated soil and recovered contaminants requiring treatment when a subsurface barrier is used. The resulting cost savings more than offset the cost of installing the barrier.

- $\quad$ The next most cost-effective action is adding a surface barrier following traditional sluicing and tank void stabilization. This action is more than two orders of magnitude more cost-effective than traditional sluicing and void stabilization, and more than four orders of magnitude more cost-effective than the use of any subsurface barrier for supporting the combined actions of traditional sluicing, void stabilization, and capping with a surface barrier. The differences are much greater if the risk-difference method is used to calculate benefit.

- Incremental cost-effectiveness of the various subsurface barrier options varies by about a factor of two. The most cost-effective option among these fairly equivalent options is the use of the close-coupled chemical barrier without flushing. This alternative would use barriers only on those tanks that leaked previously and to those that develop leaks during new sluicing operations.

- Adding a standoff barrier without flushing results in a cost-effectiveness of 0 because no reduction in risk would occur. 


\subsection{SENSITIVITY ANALYSIS}

Analyses were conducted in five phases to evaluate the effects of uncertainty in various parameters that impact risk and HI. The five phases consisted of the following:

Phase I Uncertainty in Source Inventories and Release Rates

Phase II Uncertainty in Tank Waste Inventory and Geology

Phase III Solubility-Limited Release

Phase IV Very High Leakage With Variability in Recharge Rate and Flushing Effectiveness

Phase V Effect of Large Leak Volume on Travel Time Through the Unsaturated Zone.

Other uncertainties should be considered in the decision making process. For example, only the two clean-closure alternatives were shown as potentially achieving a $10^{-6}$ relative risk level in Figure 6-10. Each alternative that includes traditional sluicing, with or without a subsurface barrier, was shown as achieving at least a $10^{-4}$ risk level. As noted earlier, the measures of relative risk shown in this figure should be considered only as rough approximations of incremental cancer risk. If these measures prove to be reasonably accurate after applying more rigorous risk assessment methodologies and using better modeling data, then it would be possible to conclude that projected average risk for the hypothetical tank farm through the groundwater pathway would fall within the $10^{-4}$ to $10^{-6}$ range generally accepted by the EPA and Ecology for cleanup of waste sites.

\subsubsection{Phase I - Uncertainty in Source Inventories and Release Rates}

The following sensitivity analysis is based on a comparison of the range of estimated nitrate levels in sources of potential groundwater contamination evaluated in Section 6 . Nitrate is a good indicator of both carcinogenic risk and $\mathrm{HI}$ as shown in Figure 8-1. This figure shows the best estimates of risk and HI analyzed in Section 6 as a function of total nitrate levels for all sources in each of the retrieval alternatives, including the two clean-closure alternatives. The strong correlation is due to (1) the assumption of congruent leaching of all COCs by recharge water (i.e., limited only by the solubility of nitrate), (2) the assumption that none of the COCs adsorb to Hanford Site soils, (3) the fact that only limited radioactive decay of COCs occurs, and (4) the existence of most of the contamination from different sources at approximately the same depth in the ground. Thus, all COCs are mobilized with nitrate and their concentrations remain in proportion to the nitrate concentration. 


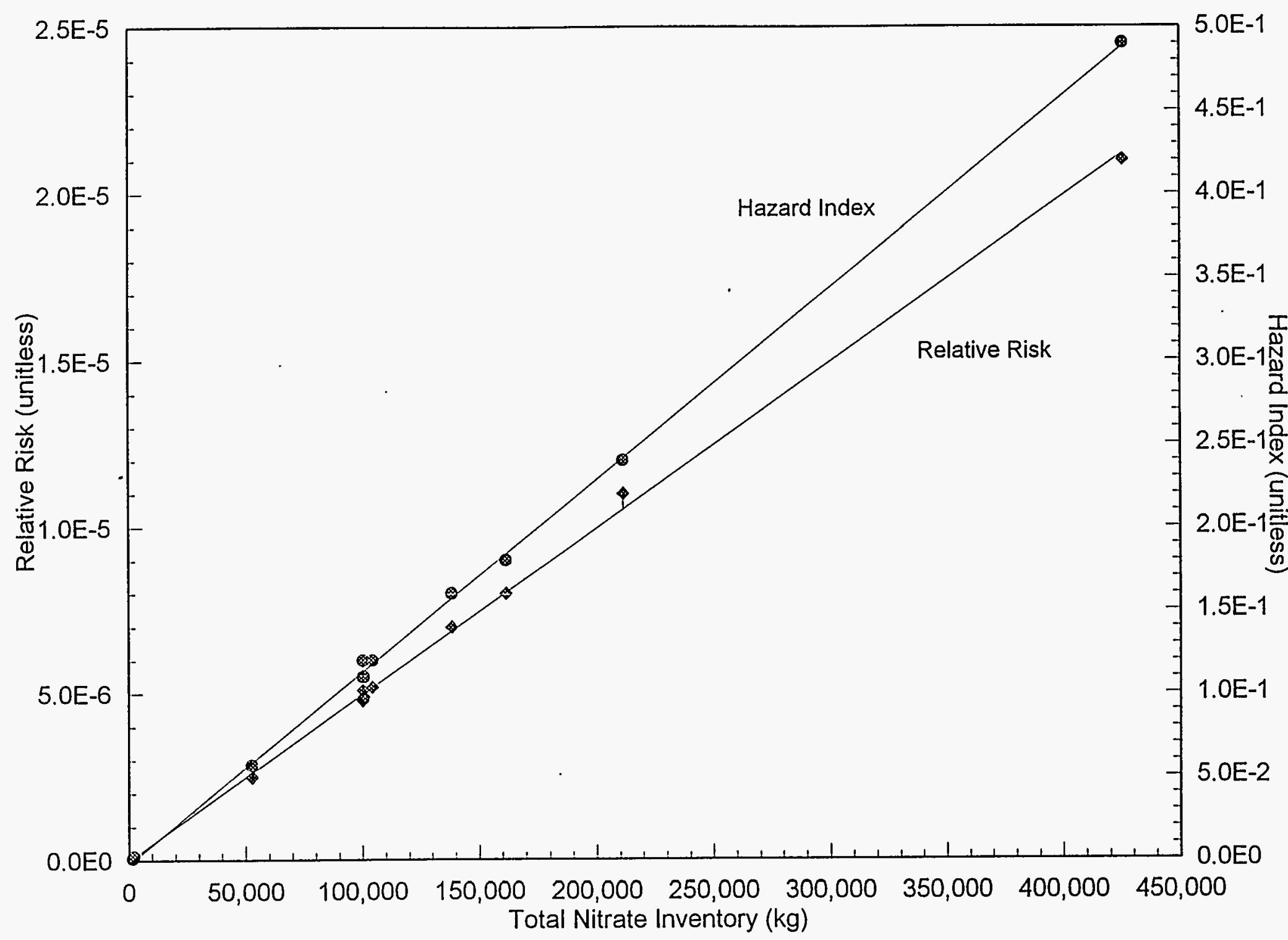

Figure 8-1. Risk and Hazard Index Versus Total Nitrate in All Sources. 
The total nitrate levels of each of the seven alternatives that include subsurface barriers, excluding the Clean-Closure with Close-Coupled Chemical Barrier Alternative, were compared to that of the Traditional Sluicing (Baseline) Alternative. Each of these alternatives includes traditional sluicing as a common basis. Table 8-4 shows a summary of the low, best, and high estimates of nitrate levels for these alternatives and their associated waste sources. These estimates were reported and their bases described in Section 6 . Table 8-4 shows that the four primary sources of nitrate (and risk) are (1) best and high cases of residual waste in the tank (all alternatives), (2) unflushed leakage to the soil (Traditional Sluicing, Close-Coupled Chemical Barrier, and Modified Close-Coupled Chemical Barrier w/o Flushing Alternatives - in soil), (3) the high cases of flushed leakage (the three standoff barrier and desiccant barrier alternatives - in soil), and (4) the high cases of advection into the close-coupled barrier (all three close-coupled barrier alternatives in barrier).

Each alternative features the same nitrate levels in the tank residuals (the first primary source of risk) because each uses traditional sluicing. Nitrate levels between the tank shell and concrete and in the concrete are also the same for each alternative. The nitrate levels in the tank residuals for the low, best, and high estimates correspond to $99.9 \%, 99 \%$, and $95 \%$ retrieval effectiveness, respectively. A level of $99.9 \%$ may be achievable if enhanced technology (e.g., use of weak acids) is used to soften and dissolve agglomerated sludge. A level of $99 \%$ retrieval represents best judgement; however, enhanced technology may also be necessary to achieve this goal. A level of approximately $95 \%$ retrieval was probably exceeded in past sluicing campaigns. The level of residual nitrate in the tanks resulting from $95 \%$ retrieval would dominate all other potential sources. In this case, the use of subsurface barriers would have relatively little impact on nitrate levels and risk.

Unflushed leakage is the second primary contributor to nitrate levels and risk. The best estimate of nitrate levels in the case of unflushed leakage is based on the following key assumptions: (1) five of the 12 tanks in the hypothetical tank farm leaked an average of $42,000 \mathrm{~L}(11,000 \mathrm{gal})$ each during past operations, (2) five of the tanks would leak an average of $152,000 \mathrm{~L}(40,000 \mathrm{gal})$ each during new sluicing operations, and (3) the average nitrate concentration would be one-half that of typical interstitial liquid. The high level of nitrate estimated in the case of unflushed leakage is based on the assumption that one tank would leak the equivalent of that leaked from Tank 241-T-106 (i.e., 115,000 gal).

The low and best estimates for alternatives that include soil flushing are based on the assumption of $94 \%$ nitrate removal by flushing and vacuuming or pumping. This would result in a level of residual nitrate in the soil that is similar to that in the tanks following 99.9\% waste retrieval (the low estimate). The assumption of relatively ineffective (50\% removal) soil flushing as in the V-Shaped Chemical Barrier, "in soil" high estimate case (the third primary source of risk) would result in a residual nitrate level in the soil that is similar to the best estimate of tank residual nitrate ( $99 \%$ retrieval). 
Table 8-4. Summary of Nitrate Levels in Subsurface Barrier Alternative Sources (thousand $\mathrm{kg}$ of nitrate).

\begin{tabular}{|c|c|c|c|c|c|c|c|}
\hline \multirow{2}{*}{\multicolumn{2}{|c|}{ Alternative }} & \multirow{2}{*}{$\begin{array}{c}\text { Estimated Nitrate } \\
\text { Case }\end{array}$} & \multicolumn{5}{|c|}{ Sources } \\
\hline & & & Residual in Tank & Between tank & In Concrete & In Soil & In Barrier \\
\hline 3. & Traditional Sluicing & $\begin{array}{l}\text { Low } \\
\text { Best } \\
\text { High }\end{array}$ & $\begin{array}{c}7.8^{\circ} \\
78^{\circ} \\
390^{\circ}\end{array}$ & $\begin{array}{l}0.7 \\
0.7 \\
30^{4}\end{array}$ & $\begin{array}{c}14 \\
14 \\
45^{\circ}\end{array}$ & $\begin{array}{c}50 \\
120 \\
166^{t}\end{array}$ & $\begin{array}{l}0 \\
0 \\
0\end{array}$ \\
\hline 6. & Close-Coupled Chemical with Flushing & $\begin{array}{l}\text { Low } \\
\text { Best } \\
\text { High }\end{array}$ & $\begin{array}{c}7.8^{\circ} \\
78^{b} \\
390^{\circ}\end{array}$ & $\begin{array}{l}0.7 \\
0.7 \\
30^{4}\end{array}$ & $\begin{array}{c}14 \\
14 \\
45^{\circ}\end{array}$ & $\begin{array}{l}1.5 \\
1.5 \\
35^{t}\end{array}$ & $\begin{array}{c}1 \\
10 \\
100\end{array}$ \\
\hline 7. & Close-Coupled Chemical w/o Flushing & $\begin{array}{l}\text { Low } \\
\text { Best } \\
\text { High }\end{array}$ & $\begin{array}{c}7.8^{\mathrm{a}} \\
78^{\mathrm{b}} \\
390^{\circ}\end{array}$ & $\begin{array}{l}0.7 \\
0.7 \\
30^{8}\end{array}$ & $\begin{array}{c}14 \\
14 \\
45^{\circ}\end{array}$ & $\begin{array}{l}36 \\
36 \\
80^{4}\end{array}$ & $\begin{array}{c}1 \\
10 \\
100\end{array}$ \\
\hline 8. & Modified Close-Coupled Chemical & $\begin{array}{l}\text { Low } \\
\text { Best } \\
\text { High }\end{array}$ & $\begin{array}{c}7.8^{\mathrm{a}} \\
78^{\mathrm{b}} \\
390^{\circ}\end{array}$ & $\begin{array}{l}0.7 \\
0.7 \\
30^{4}\end{array}$ & $\begin{array}{c}14 \\
14 \\
45^{\circ}\end{array}$ & $\begin{array}{c}35 \\
63 \\
107^{t}\end{array}$ & $\begin{array}{c}0.6 \\
6 \\
60^{*}\end{array}$ \\
\hline 9. & Box-Shaped Chemical & $\begin{array}{l}\text { Low } \\
\text { Best } \\
\text { High }\end{array}$ & $\begin{array}{c}7.8^{2} \\
78^{b} \\
390^{\circ}\end{array}$ & $\begin{array}{l}0.7 \\
0.7 \\
30^{4}\end{array}$ & $\begin{array}{c}14 \\
14 \\
45^{\circ}\end{array}$ & $\begin{array}{c}3 \\
7 \\
81^{t}\end{array}$ & $\begin{array}{c}0.06 \\
0.6 \\
6\end{array}$ \\
\hline 10. & V-Shaped Chemical & $\begin{array}{l}\text { Low } \\
\text { Best } \\
\text { High }\end{array}$ & $\begin{array}{c}7.8^{\circ} \\
78^{\circ} \\
390^{\circ}\end{array}$ & $\begin{array}{l}0.7 \\
0.7 \\
30^{4}\end{array}$ & $\begin{array}{c}14 \\
14 \\
45^{\circ}\end{array}$ & $\begin{array}{c}3 \\
7 \\
81^{\natural}\end{array}$ & $\begin{array}{c}0.08 \\
0.8 \\
88\end{array}$ \\
\hline 11. & V-Shaped Freeze Wall & $\begin{array}{l}\text { Low } \\
\text { Best } \\
\text { High }\end{array}$ & $\begin{array}{c}7.8^{a} \\
78^{b} \\
390^{c}\end{array}$ & $\begin{array}{l}0.7 \\
0.7 \\
30^{4}\end{array}$ & $\begin{array}{l}14 \\
14 \\
45^{\circ}\end{array}$ & $\begin{array}{c}3 \\
7 \\
81^{t}\end{array}$ & $\begin{array}{l}0 \\
0 \\
0\end{array}$ \\
\hline 12. & Circulating Air & $\begin{array}{l}\text { Low } \\
\text { Best } \\
\text { High }\end{array}$ & $\begin{array}{c}7.8^{a} \\
78^{b} \\
390^{a}\end{array}$ & $\begin{array}{l}0.7 \\
0.7 \\
30^{4}\end{array}$ & $\begin{array}{c}14 \\
14 \\
45^{\circ}\end{array}$ & $\begin{array}{c}3 \\
7 \\
81^{1}\end{array}$ & $\begin{array}{l}0 \\
0 \\
0\end{array}$ \\
\hline
\end{tabular}

Based on $9.9 \%$ waste retrieval

Based on $99 \%$ waste retrieval

'Based on $95 \%$ waste retrieval

dBased on assumption that one tank in the 12-tank tank farm is similar to Tank 241-A-105 which has a large bulge in steel liner containing $29,000 \mathrm{~kg}$ nitrate.

Based on a $10 x$ increase in hydraulic conductivity due to poor quality or degradation overtime.

'Based on one tank leaking $115,000 \mathrm{gal}$ as occurred in Tank 241-T-106 and only 50\% flushing effectiveness where applicable.

Based on a $10 \mathrm{x}$ increase in hydraulic conductivity to $10^{.5} \mathrm{~cm} / \mathrm{s}$. 
The high estimate of advection into the close-coupled barrier (the fourth primary source of risk) would result from the assumption of a factor of 10 increase in either the hydraulic conductivity of the barrier to $10^{-5} \mathrm{~cm} / \mathrm{s}\left(2 \times 10^{-5} \mathrm{in} / \mathrm{s}\right)$ or in the length of cracks through which leaks occur (to $101 \mathrm{~m}$ [330 ft]).

Although Table 8-4 shows that considerable uncertainty exists in the levels of nitrate that would occur in the tank residuals, between the tank shell and concrete, and within the concrete, this uncertainty is not addressed further in this analysis since the focus of the analysis is on subsurface barriers. Risks associated with the use of subsurface barriers will primarily be affected by the residual levels of nitrate and other COCs in the soil and within the barrier. Thus, cumulative low and high nitrate estimates were made for each of the seven subsurface barrier alternatives by adding the best estimate nitrate values for residual tank waste, waste between the tank shell and concrete, and within the concrete, to the low and high estimates for the sources related to the barrier and soil. These totals are shown in Table 8-5 with the projected relative risk and HI based on Figure 8-1.

Table 8-5 shows that uncertainty in the effectiveness of the various subsurface barrier systems would have little impact on the magnitude of overall risk or HI posed by the alternatives. Relative risk would range from $4.2 \times 10^{-6}$ to $1.5 \times 10^{-5}$ and HI would range from $1.0 \times 10^{-1}$ to $3.8 \times 10^{-1}$. The small overall range in uncertainty of relative risk and $\mathrm{HI}$ impacted by the subsurface barrier (about a factor of $4 \mathrm{x}$ ), when compared to the high range in risk and $\mathrm{HI}$ reduction that potentially would be achieved among the 10 viable landfillclosure alternatives (about a factor of $400 \mathrm{x}$ ), attests to the relatively small impact subsurface barriers would be expected to have in reducing overall risk.

\subsubsection{Phase II - Uncertainty in Tank Waste Inventory and Geology}

Some tank farms will exhibit higher or lower levels of risk than estimated for the hypothetical farms, which was modeled assuming average waste inventories and an assumed set of geologic conditions. The variability in the inventories of COCs in separate SST tank farm groupings was investigated by Schmittroth et al. (1993). Schmittroth et al. (1993) reported inventories of COCs that would contribute to risk and hazard, including six COCs that served as bases for this feasibility study. The inventories are summarized in Table 8-6. Table 8-7 shows the average inventories of the same COCs within individual tank farms by grouping, and the variabilities of those inventories from those of the overall average SST farm.

Table 8-7 shows that the variability in inventories of radioactive COCs by individual tank farm is relatively small. Risk due to variability in ${ }^{99} \mathrm{Tc}$, the risk-controlling COC as shown in Table $6-10$, would be only about $50 \%$ from average assuming all other conditions are equal and that risk is proportional to inventory as indicated in Figure 8-1. Thus the variability in the starting inventories of carcinogenic COCs in individual tank farms would appear to have a relatively minor impact on potential risk. However, the variability in nitrate and nitrite inventories is greater, which would lead to a greater impact on HI. It 
Table 8-5. Projected Impacts of Uncertainty in the Effectiveness of Subsurface Barrier Alternatives.

\begin{tabular}{|l|c|c|c|c|c|c|}
\hline \multirow{2}{*}{ Alternative } & \multicolumn{3}{|c|}{ Low Case } & \multicolumn{3}{c|}{ High Case } \\
\cline { 2 - 7 } & $\begin{array}{c}\text { Total Nitrate } \\
(\mathrm{kg} \div 1,000)\end{array}$ & $\begin{array}{c}\text { Projected } \\
\text { Risk }\end{array}$ & $\begin{array}{c}\text { Projected } \\
\text { HI }\end{array}$ & $\begin{array}{c}\text { Total Nitrate } \\
(\mathrm{kg} \div 1,000)\end{array}$ & $\begin{array}{c}\text { Projected } \\
\text { Risk }\end{array}$ & $\begin{array}{c}\text { Projected } \\
\text { HI }\end{array}$ \\
\hline $\begin{array}{l}\text { 6. Close-Coupled Chemical Barrier } \\
\text { w/Flushing }\end{array}$ & 95 & $4.2 \mathrm{E}-6$ & $1.0 \mathrm{E}-1$ & 228 & $1.0 \mathrm{E}-5$ & $2.5 \mathrm{E}-1$ \\
\hline $\begin{array}{l}\text { 7. Close-Coupled Chemical Barrier w/o } \\
\text { Flushing }\end{array}$ & 130 & $5.7 \mathrm{E}-6$ & $1.4 \mathrm{E}-1$ & 273 & $1.2 \mathrm{E}-5$ & $3.0 \mathrm{E}-1$ \\
\hline $\begin{array}{l}\text { 8. Modified Close-Coupled Chemical Barrier } \\
\text { w/o Flushing }\end{array}$ & 128 & $5.7 \mathrm{E}-6$ & $1.4 \mathrm{E}-1$ & 260 & $1.3 \mathrm{E}-5$ & $3.3 \mathrm{E}-1$ \\
\hline 9. Box-Shaped Chemical Barrier & 96 & $4.2 \mathrm{E}-6$ & $1.1 \mathrm{E}-1$ & 180 & $7.9 \mathrm{E}-6$ & $2.0 \mathrm{E}-1$ \\
\hline 10. V-Shaped Chemical Barrier & 96 & $4.2 \mathrm{E}-6$ & $1.1 \mathrm{E}-1$ & 182 & $8.0 \mathrm{E}-6$ & $2.0 \mathrm{E}-1$ \\
\hline 11. V-Shaped Freeze Wall Barrier & 96 & $4.2 \mathrm{E}-6$ & $1.1 \mathrm{E}-1$ & 174 & $7.6 \mathrm{E}-6$ & $1.9 \mathrm{E}-1$ \\
\hline 12. Circulating Air Barrier & 96 & $4.2 \mathrm{E}-6$ & $1.1 \mathrm{E}-1$ & 174 & $7.6 \mathrm{E}-6$ & $1.9 \mathrm{E}-1$ \\
\hline
\end{tabular}

'Totals are based on best case inventories shown in Table 8-4 for sources that would not be impacted by the use of subsurface barriers (i.e., residuals in tank, between sheil and concrete, and in concrete), added to low or high cases for sources that would be impacted by the presence of the barrier (i.e., in soil and in barrier). 
would also have an effect on the rate at which carcinogenic COCs would be released since it was assumed that all COCs would be released congruently with nitrate. Thus, a tank with a low nitrate inventory would release its carcinogenic COC inventory relatively quickly.

Table 8-6. Inventory of Selected Constituents of Concern by Tank Farm Grouping ${ }^{2}$.

\begin{tabular}{|c|c|c|c|c|c|c|c|}
\hline \multirow{2}{*}{ Radioisotope } & \multicolumn{6}{|c|}{ Tank Farm Groupings } & \multirow{2}{*}{ Sum } \\
\hline & $A+A X$ & $B+B X+B Y$ & C & $s+s X$ & $\mathrm{~T}+\mathrm{TX}+\mathrm{TY}$ & $\mathbf{U}$ & \\
\hline${ }^{14} \mathrm{C}$ & $440 \mathrm{Ci}$ & $1,000 \mathrm{Ci}$ & $200 \mathrm{Ci}$ & $1,100 \mathrm{Ci}$ & $1,200 \mathrm{Ci}$ & $400 \mathrm{Ci}$ & $4,400 \mathrm{Ci}$ \\
\hline "Tc & $2,100 \mathrm{Ci}$ & $6,700 \mathrm{Ci}$ & $1,000 \mathrm{Ci}$ & $6,800 \mathrm{Ci}$ & $8,200 \mathrm{Ci}$ & $2,000 \mathrm{Ci}$ & $27,000 \mathrm{Ci}$ \\
\hline${ }^{129} \mathrm{I}$ & $3.2 \mathrm{Ci}$ & $11 \mathrm{Ci}$ & $2.0 \mathrm{Ci}$ & $9.0 \mathrm{Ci}$ & $12 \mathrm{Ci}$ & $4.0 \mathrm{Ci}$ & $42 \mathrm{Ci}$ \\
\hline${ }^{234} \mathrm{U}$ & $21 \mathrm{Ci}$ & $68 \mathrm{Ci}$ & $80 \mathrm{Ci}$ & $40 \mathrm{Ci}$ & $220 \mathrm{Ci}$ & $30 \mathrm{Ci}$ & $460 \mathrm{Ci}$ \\
\hline NO, & $4,400 \mathrm{Mg}$ & $40,000 \mathrm{Mg}$ & $5,600 \mathrm{Mg}$ & $56,000 \mathrm{Mg}$ & $20,000 \mathrm{Mg}$ & $4,300 \mathrm{Mg}$ & $130,000 \mathrm{Mg}$ \\
\hline $\mathrm{NO}_{2}$ & $160 \mathrm{Mg}$ & $2,500 \mathrm{Mg}$ & $9.2 \mathrm{Mg}$ & $550 \mathrm{Mg}$ & $880 \mathrm{Mg}$ & $92 \mathrm{Mg}$ & $4,000 \mathrm{Mg}$ \\
\hline
\end{tabular}

source: Schmittroth et al. (1993)

$\mathrm{Mg}$ - million grams

Table 8-7. Average Tank Farm Inventory of Selected Constituents of Concern by Tank Farm Groupinga.

\begin{tabular}{|c|c|c|c|c|c|c|c|c|}
\hline \multirow{2}{*}{ Radioisotope } & \multicolumn{6}{|c|}{ Tank Farm Grouping } & \multirow{2}{*}{$\begin{array}{c}\text { Overall } \\
\text { Avg. }\end{array}$} & \multirow{2}{*}{$\begin{array}{c}\text { Variability } \\
\text { from } \\
\text { Overall } \\
\text { Average }\end{array}$} \\
\hline & $A+A X$ & $B+B X+B Y$ & C & $s+s X$ & $T+T X+T Y$ & $\mathbf{U}$ & & \\
\hline${ }^{14} \mathrm{C}$ & $220 \mathrm{Ci}$ & $333 \mathrm{Ci}$ & $200 \mathrm{Ci}$ & $550 \mathrm{Ci}$ & $400 \mathrm{Ci}$ & $400 \mathrm{Ci}$ & $367 \mathrm{Ci}$ & $-45 \%,+50 \%$ \\
\hline "rc & $1,050 \mathrm{Ci}$ & $2,230 \mathrm{Ci}$ & $1,000 \mathrm{Ci}$ & $3,400 \mathrm{Ci}$ & $2,730 \mathrm{Ci}$ & $2,000 \mathrm{Ci}$ & $2,250 \mathrm{Ci}$ & $-56 \%,+51 \%$ \\
\hline${ }^{129} I$ & $1.6 \mathrm{Ci}$ & $3.7 \mathrm{Ci}$ & $2.0 \mathrm{Ci}$ & $4.5 \mathrm{Ci}$ & $4.0 \mathrm{Ci}$ & $4.0 \mathrm{Ci}$ & $3.5 \mathrm{Ci}$ & $-54 \%,+29 \%$ \\
\hline${ }^{2 x} \mathrm{U}$ & $10.5 \mathrm{Ci}$ & $23 \mathrm{Ci}$ & $80 \mathrm{Ci}$ & $20 \mathrm{Ci}$ & $73 \mathrm{Ci}$ & $30 \mathrm{Ci}$ & $38 \mathrm{Ci}$ & $-66 \%,+111 \%$ \\
\hline $\mathrm{NO}_{3}$ & $2,200 \mathrm{Mg}$ & $13,000 \mathrm{Mg}$ & $5,600 \mathrm{Mg}$ & $28,000 \mathrm{Mg}$ & $6,700 \mathrm{Mg}$ & $4,300 \mathrm{Mg}$ & $10,800 \mathrm{Mg}$ & $-80 \%,+159 \%$ \\
\hline $\mathrm{NO}_{2}$ & $80 \mathrm{Mg}$ & $820 \mathrm{Mg}$ & $9.2 \mathrm{Mg}$ & $270 \mathrm{Mg}$ & $290 \mathrm{Mg}$ & $92 \mathrm{Mg}$ & $330 \mathrm{Mg}$ & $-97 \%,+148 \%$ \\
\hline
\end{tabular}

Adapted from Schmittroth et al. (1993)

$\mathrm{Mg}$ - million grams

A sensitivity case was analyzed to evaluate the impacts of variability and uncertainty in inventories of COCs. The effects of uncertainties in tank farm geology and solubilities of $\mathrm{COCs}$ were also analyzed, following the COC inventory analysis. 


\section{High and Low COC Inventory Cases}

For this sensitivity analysis, it was assumed that a high COC inventory case is based on the inventory shown for the S+SX Tank Farm grouping in Table 8-7. A low COC inventory case is based on the inventory shown for the A+AX Tank Farm grouping. Inventories for TBP and EDTA were assumed to be the same as used for previous analyses in this feasibility study. These organics are minor contributors to risk and HI as shown in Table 6-10. Overall inventories for these cases are summarized in Table 8-8.

Table 8-8. High and Low Constituent of Concern Inventory Cases' for Sensitivity Analysis.

\begin{tabular}{|c|c|c|}
\hline Constituent of Concern & High Case & Low Case \\
\hline${ }^{14} \mathrm{C}$ & $550 \mathrm{Ci}$ & $220 \mathrm{Ci}$ \\
\hline${ }^{99} \mathrm{Tc}$ & $3,400 \mathrm{Ci}$ & $1,050 \mathrm{Ci}$ \\
\hline${ }^{129} \mathrm{I}$ & $4.5 \mathrm{Ci}$ & $1.6 \mathrm{Ci}$ \\
\hline${ }^{238} \mathrm{U}$ & $20 \mathrm{Ci}$ & $10.5 \mathrm{Ci}$ \\
\hline $\mathrm{NO}_{3}$ & $28,000 \mathrm{Mg}$ & $2,200 \mathrm{Mg}$ \\
\hline $\mathrm{NO}_{2}$ & $270 \mathrm{Mg}$ & $80 \mathrm{Mg}$ \\
\hline $\mathrm{EDTA}$ & $1.4 \mathrm{Mg}$ & $1.4 \mathrm{Mg}$ \\
\hline $\mathrm{TBP}$ & $0.95 \mathrm{Mg}$ & $0.95 \mathrm{Mg}$ \\
\hline
\end{tabular}

$\mathrm{Mg}$ - million grams

The relative risks and $\mathrm{HI}$ for the high and low COC inventory cases were computed using all other assumptions made for the Traditional Sluicing Alternative. Results and discussion of this analysis are presented later in this section with those of other sensitivity analyses.

Uncertainty also exists in the overall inventory of COCs in all SSTs. Differences between the overall SST inventories assumed for two recent studies are shown in Table 8-9. The differences shown in Table 8-9 reflect the uses of different sources of inventory information and different levels of conservatism. Inventories used in this feasibility study were based primarily on inventories provided in Boomer et al. (1993). Except for nitrite, Boomer et al. (1993) inventories are 0 to $40 \%$ lower than used by Schmittroth et al. (1993). Thus uncertainty in initial inventory of the waste adds slightly to the overall uncertainty in projecting risk and $\mathrm{HI}$. 
Table 8-9. Variability in Single-Shell Tank Farm Waste Inventories.

\begin{tabular}{|c|c|c|c|c|}
\hline \multirow{2}{*}{$\begin{array}{c}\text { Constituent of } \\
\text { Concern }\end{array}$} & \multicolumn{2}{|c|}{ Study No. $1^{\mathbf{a}}$} & \multicolumn{2}{c|}{ Study No. $2^{\mathrm{b}}$} \\
\cline { 2 - 5 } & Overall & $\begin{array}{c}\text { Average for 12- } \\
\text { tank farm }\end{array}$ & Overall & $\begin{array}{c}\text { Average for 12- } \\
\text { tank farm }\end{array}$ \\
\hline${ }^{14} \mathrm{C}$ & $4,400 \mathrm{Ci}$ & $354 \mathrm{Ci}$ & $3,000 \mathrm{Ci}$ & $240 \mathrm{Ci}$ \\
\hline${ }^{99} \mathrm{Tc}$ & $27,000 \mathrm{Ci}$ & $2,170 \mathrm{Ci}$ & $16,000 \mathrm{Ci}$ & $1,300 \mathrm{Ci}$ \\
\hline${ }^{129} \mathrm{I}$ & $42 \mathrm{Ci}$ & $3.4 \mathrm{Ci}$ & $24 \mathrm{Ci}$ & $2 \mathrm{Ci}$ \\
\hline${ }^{238} \mathrm{U}$ & $460 \mathrm{Ci}$ & $37 \mathrm{Ci}$ & $460 \mathrm{Ci}$ & $37 \mathrm{Ci}$ \\
\hline $\mathrm{NO}_{3}$ & $130,000 \mathrm{Mg}$ & $10,500 \mathrm{Mg}$ & $96,800 \mathrm{Mg}$ & $7,800 \mathrm{Mg}$ \\
\hline $\mathrm{NO}_{2}$ & $4,000 \mathrm{Mg}$ & $322 \mathrm{Mg}$ & $4,800 \mathrm{Mg}$ & $390 \mathrm{Mg}$ \\
\hline $\mathrm{EDTA}$ & $67 \mathrm{Mg}$ & $5.4 \mathrm{Mg}$ & $\mathrm{NR}^{\mathrm{c}}$ & $\mathrm{NR}^{\mathrm{c}}$ \\
\hline $\mathrm{TBP}$ & $\mathrm{NR}^{\mathrm{c}}$ & $\mathrm{NR}^{\mathrm{c}}$ & $\mathrm{NR}^{\mathrm{c}}$ & $\mathrm{NR}^{\mathrm{c}}$ \\
\hline
\end{tabular}

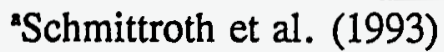

bBoomer et al. (1993)

'NR - not reported

$\mathrm{Mg}$ - million grams

EDTA - ethylenediaminetetraacetic acid

TBP - tributyl phosphate

\section{High and Low Vadose Zone Travel Rate Cases}

Two sensitivity cases involving different geologies beneath the tank farm were also evaluated. One results in a projected higher vadose zone travel rate and the other in a lower rate than would occur using prior assumptions. The rate of travel affects the level of diffusion and dispersion that would occur in the vadose zone and hence, the peak concentrations of COCs and corresponding risks. The geologies evaluated are those reported for the S Tank Farm grouping and the B Tank Farm grouping in Droppo et al. (1991).

Key geologic information for the two tank farm groupings in Droppo et al. (1991) and the geologic conditions previously assumed for the hypothetical tank farm are shown in Table 8-10. The relative risks and HIs computed in this analysis were based on the same conditions used to model the Traditional Sluicing Alternative, except for the changes in the geology. These previous conditions are shown in the "Feasibility Study" row in the table. Results are presented later in this section. 
Table 8-10. Variability in Single-Shell Tank Farm Geologies.

\begin{tabular}{|l|c|c|c|c|}
\hline \multicolumn{1}{|c|}{ Case } & $\begin{array}{c}\text { Description of } \\
\text { Descending Layers } \\
\text { Beneath Tank Farm }\end{array}$ & $\begin{array}{c}\text { Thickness } \\
(\mathrm{cm})\end{array}$ & $\begin{array}{c}\text { Field } \\
\text { Capacity } \\
(\%)\end{array}$ & $\begin{array}{c}\text { Estimated } \\
\text { Travel Time } \\
(\mathrm{yr})^{\mathbf{2}}\end{array}$ \\
\hline Feasibility & Sand & 1,000 & 19 & 3,800 \\
Study & Sand & 5,000 & 8.5 & 8,500 \\
& Sand & $\frac{1,900}{7,900}$ & 19 & $\frac{7,220}{19,520}$ \\
\hline \multirow{5}{*}{ B Tank Farm } & Sand & 5,000 & 9 & 9,000 \\
& Loamy Sand & 150 & 12 & 360 \\
& Sand & $\frac{2,680}{7,830}$ & 9 & $\frac{4,824}{14,184}$ \\
& Loamy Sand & 2,743 & 12 & 6,583 \\
& Sandy Loam & 1,524 & 17 & 5,181 \\
& Sandy Clay Loam & 762 & 24 & 3,658 \\
& Clay Loam & 305 & 34 & 2,074 \\
& Clay & 152 & 40 & 1,216 \\
& Sand & $\frac{914}{6,400}$ & 9 & 1,645 \\
& & & 20,357 \\
\hline
\end{tabular}

${ }^{2}$ Based on $0.05 \mathrm{~cm} / \mathrm{yr}(0.02 \mathrm{in} / \mathrm{yr})$ recharge rate.

Table 8-11. Summary of Relative Risks and Hazard Index for Sensitivity and Baseline Cases.

\begin{tabular}{|l|c|c|}
\hline \multicolumn{1}{|c|}{ Case } & Relative Risk & $\mathrm{HI}$ \\
\hline Traditional Sluicing (Baseline) & $1.0 \times 10^{-5}$ & $2.3 \times 10^{-1}$ \\
\hline High COC Inventory & $6.1 \times 10^{-6}$ & $2.2 \times 10^{-1}$ \\
\hline Low COC Inventory & $2.8 \times 10^{-5}$ & $2.8 \times 10^{-1}$ \\
\hline High Vadose Zone Travel Rate & $1.3 \times 10^{-5}$ & $2.9 \times 10^{-1}$ \\
\hline Low Vadose Zone Travel Rate & $2.5 \times 10^{-6}$ & $5.7 \times 10^{-2}$ \\
\hline
\end{tabular}

\section{Discussion of Results}

Maximum relative risk and $\mathrm{HI}$ for the high and low COC inventory cases, high and low vadose zone travel time cases, and the Traditional Sluicing Alternative are shown in

Table 8-11. Relative risks and $\mathrm{HI}$ for these cases are also plotted on Figure 8-2 and 8-3 with 


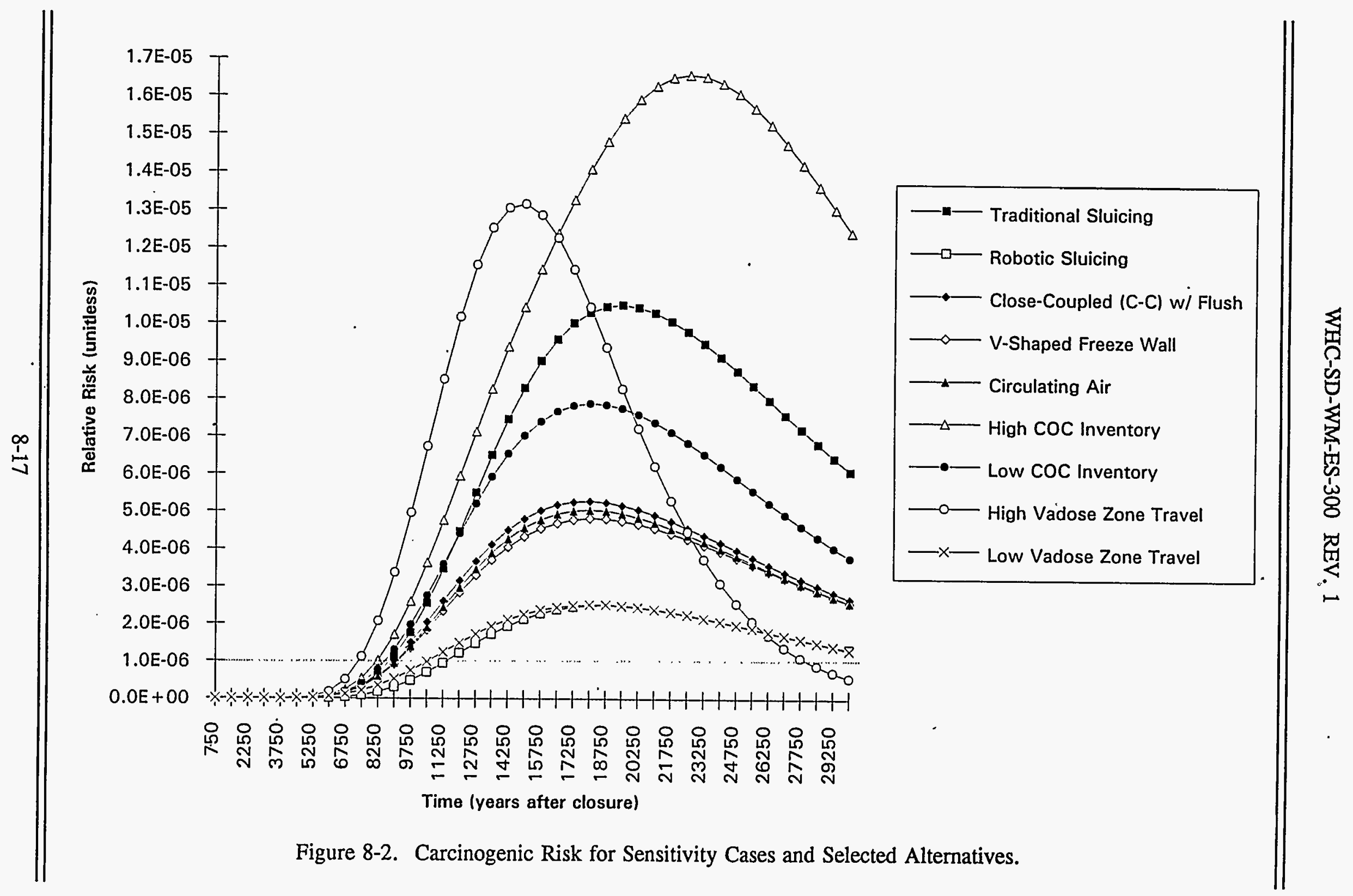




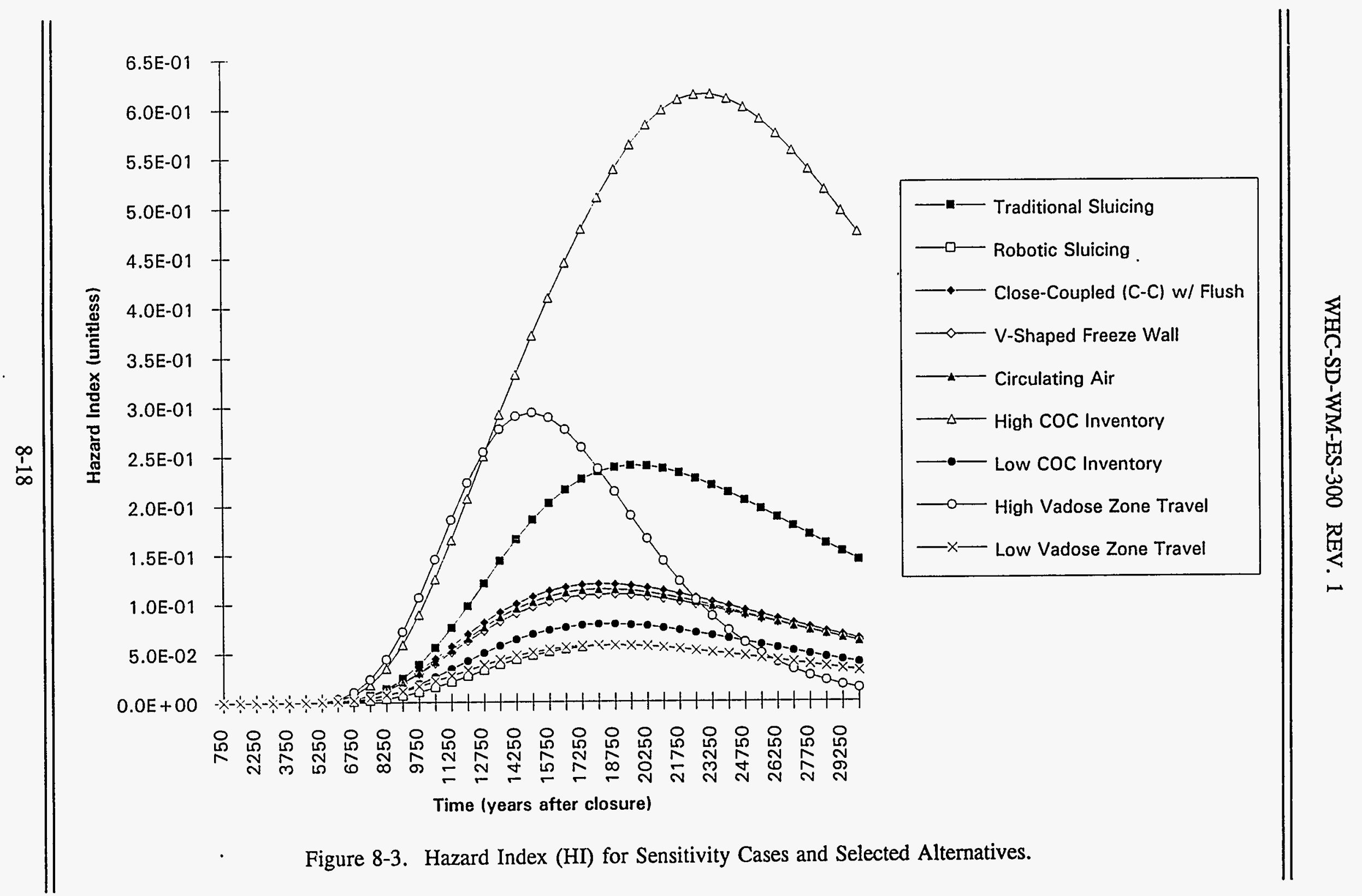


risks and HI for selected alternatives, i.e., Robotic Sluicing, Close-Coupled Chemical Barrier with Flushing, V-Shaped Freeze Wall Barrier, and Circulating Air Barrier.

The following conclusions can be drawn from Table 8-11 and Figures 8-2 and 8-3:

- The impact of high versus low inventory of COCs on $\mathrm{HI}$ is small (about $25 \%$ ); on relative risk it is higher (about $5 \mathrm{X}$ )

- A high vadose zone travel rate would yield relative risks and $\mathrm{HI}$ about $5 \mathrm{X}$ greater than risks and $\mathrm{HI}$ associated with slow vadose zone travel rates

- Excluding the low carcinogenic COC inventory case, the range in estimated risks and $\mathrm{HI}$ between the baseline case (traditional sluicing) and the highest risk tank waste retrieval case (robotic sluicing) approximates the range of uncertainty in the sensitivity parameters evaluated earlier in this section. The relatively higher risks associated with the low carcinogenic COC inventory case is anomalous due to the assumption of congruent leaching of all COCs with the relatively small amount of nitrate in this case.

\subsubsection{Phase III - Solubility-Limited Release}

Sensitivity cases involving solubility-limited release and leaching of tank waste were conducted. Chemical solubility would limit the concentration of COCs that may penetrate between tank steel and concrete, advect into the concrete and leak from the tank. It would also limit the rate of leaching of residual tank waste by advecting recharge water. Previous analyses in this feasibility study were based on the assumption that all COCs would leak and leach congruently with nitrate.

Solubility limits for the COCs were presented in column D of Table 6-3. Average concentrations of drainable tank wastes determined by laboratory analysis were provided in column E. Column E concentrations were used in this sensitivity analysis to represent the solubility limits of the average drainable liquid.

The masses of COCs in the residual tank waste following retrieval operations were assumed as before to be $1 \%$ of the initial inventory before sluicing. The time required for recharge water to dissolve the residual COCs was calculated using the following equation:

$$
t=\frac{m}{C_{d} r_{f}}
$$

Where: $\quad t=$ time to complete dissolution $(T)$ $\mathrm{m}=$ mass of individual $\mathrm{COC}$ in residual waste $(\mathrm{M})$ 
$\mathrm{C}_{\mathrm{d}}=$ drainable liquid concentration of individual $\operatorname{COC}\left(\mathrm{M} / \mathrm{L}^{3}\right)$

$\mathrm{I}_{\mathrm{f}}=$ recharge rate through all $12 \operatorname{tanks}\left(\mathrm{L}^{3} / \mathrm{T}\right)$

The masses of COCs that would exist between the tank steel and concrete, within the concrete, and in the soil due to old and new leaks are given by:

$$
\mathrm{m}=\mathrm{C}_{\mathrm{d}} \mathrm{V}
$$

Where: $\quad \mathrm{m}=$ mass of individual $\mathrm{COC}$ in specific source $(\mathrm{M})$

$\mathrm{C}_{\mathrm{d}}=$ drainable liquid concentration of individual $\operatorname{COC}\left(\mathrm{M} / \mathrm{L}^{3}\right)$

$\mathrm{V}=$ volume of liquid drained into specific source

The volumes of liquid drained into the three sources were inferred from the information provided in Section 6, and are summarized below:

- $\quad$ Between tank steel and concrete: 2,910 L

- $\quad$ Advected into concrete: $56,000 \mathrm{~L}$

- Total leaked into soil: $965,000 \mathrm{~L}$.

Liquid waste was assumed to leak into the soil at full-concentration, in contrast to half-concentration as in all previous analyses. This assumption may be conservative because the addition of sluicing water to the tank would tend to dilute the COCs to below their concentrations in drainable liquid as tank solids dissolve. Schultz (1978) conducted tests in which samples of tank solids were mixed in a ratio of $2 \mathrm{~mL}$ of water to $1 \mathrm{~g}$ solids. Sluicing operations will require a similar water-to-solids ratio to effectively dissolve the salt and to slurry the sludge to enable pumping. The resulting leachates were analyzed for chemicals and radionuclides. Technetium-99, the dominant source of carcinogenic risk, averaged $0.04 \mathrm{nCi}$ per gram of dissolved nitrate. The average ratio of ${ }^{99} \mathrm{Tc}$ to nitrate in drainable liquid samples from Table 6-3 was 0.90 , a factor of $22 \mathrm{X}$ higher. For comparison, the ratio assumed for interstitial liquid was $0.17 \mathrm{nCi}{ }^{99} \mathrm{Tc}$ per gram of nitrate. This ratio falls between the ratios for drainable liquid and leachate as would be expected because the ratio for interstitial liquid was based on total tank composition. Thus, the use of the drainable liquid concentrations for predicting impacts of leakage is probably appropriate when assuming slow and limited leakage between the tank steel and concrete and for advection into the concrete, but probably is conservative when large leaks occur during sluicing.

The times required for COCs to be purged from their sources by recharge water would be the same as estimated earlier because all the COCs would exist as solubilized species and would therefore not be affected by solubility limits.

The results of this analysis are plotted on Figures 8-4 and 8-5 with the previous results for Baseline Traditional Sluicing Alternative which was based on congruent leaching with nitrate. The results for solubility-limited carcinogenic risk are 3.7X higher due to the higher concentration of ${ }^{99} \mathrm{Tc}$, the dominant source of risk. A comparison of each COC's fractional contribution to risk for the solubility-limited and congruent leaching leak cases is shown in 


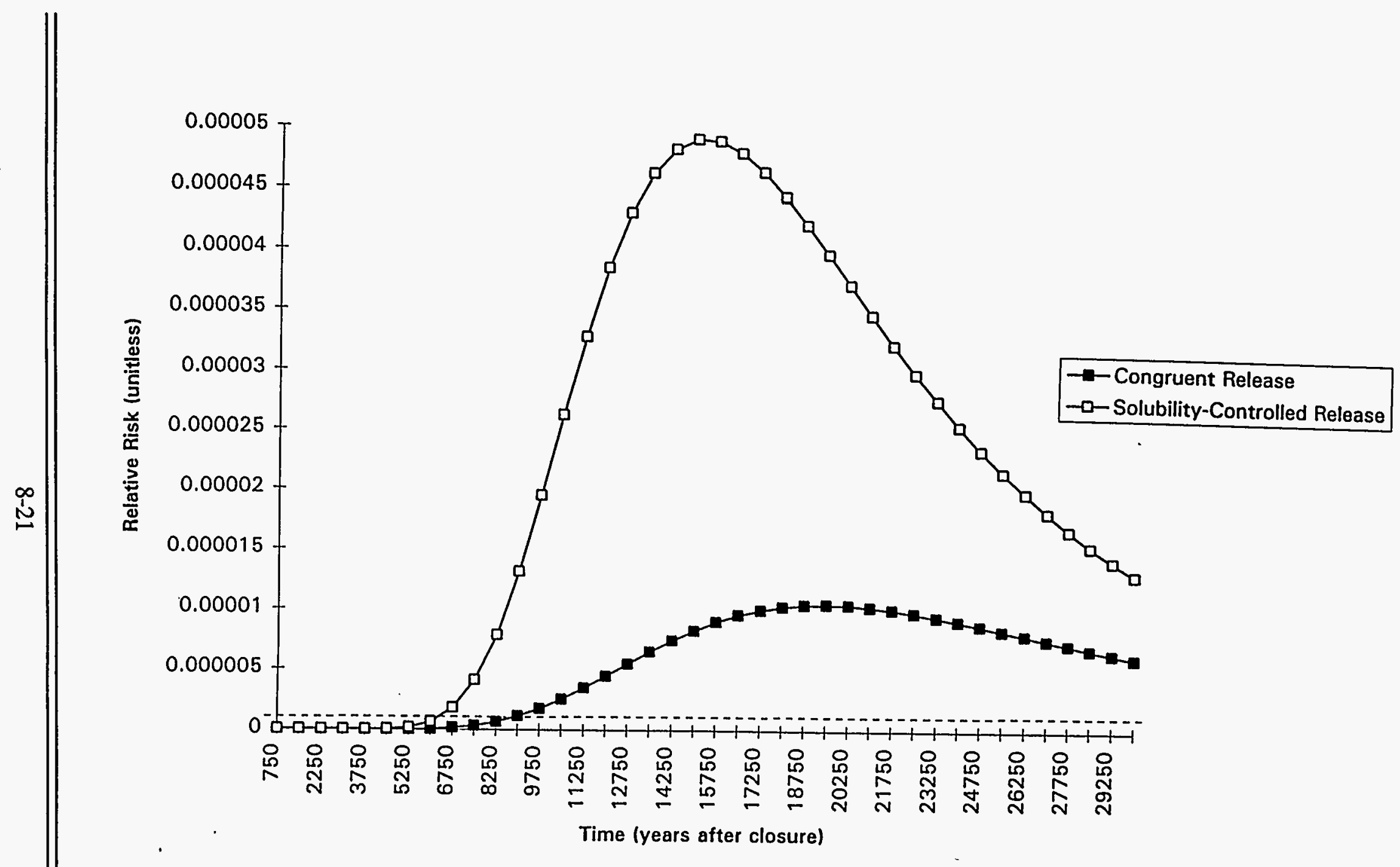

Figure 8-4. Relative Carcinogenic Risk for Baseline Alternative: Congruent Release Versus Solubility-Limited Release. 


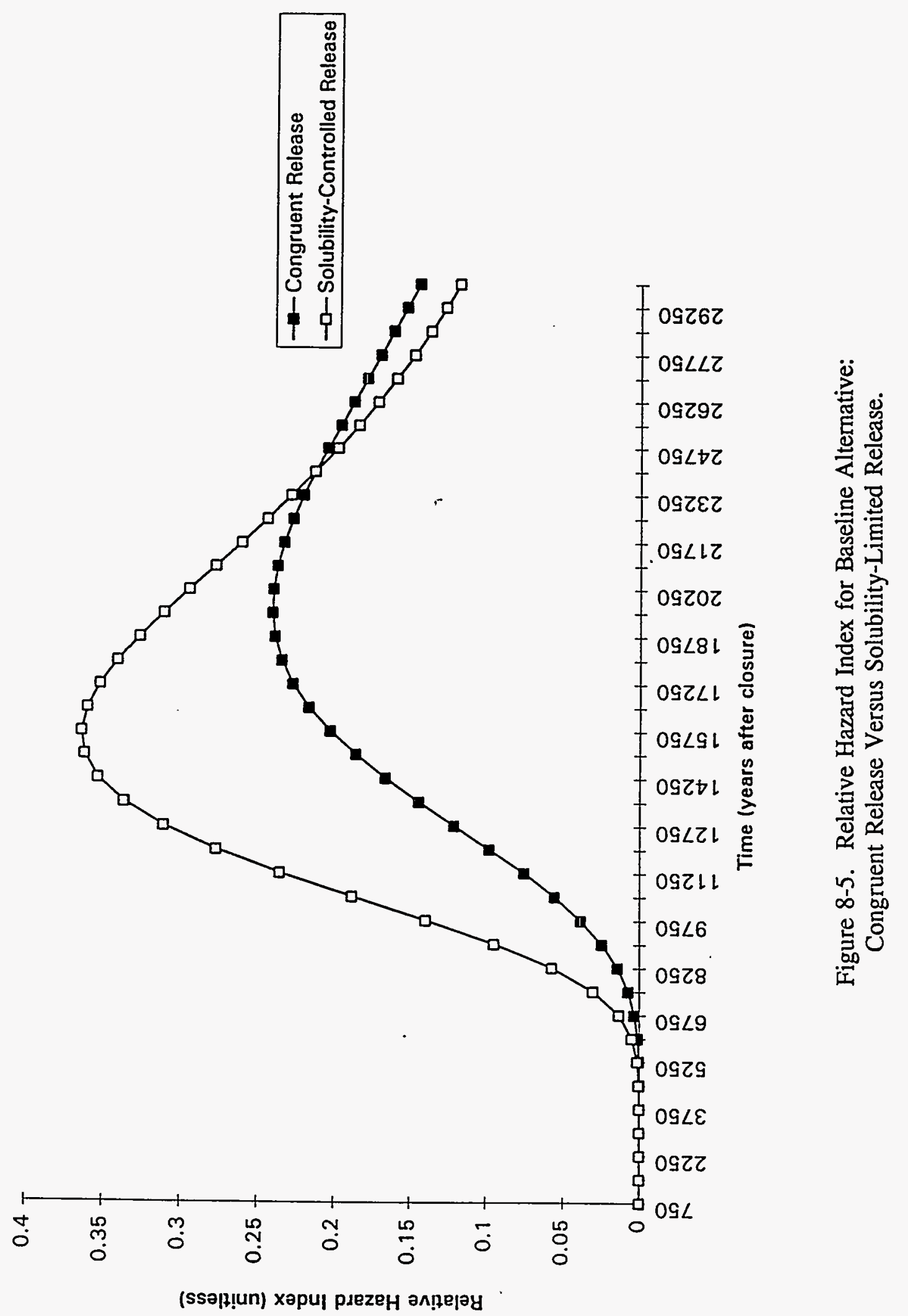


Table 8-12. This table shows that ${ }^{99} \mathrm{Tc}$ accounts for nearly all of the carcinogenic risk for solubility-limited leakage.

Table 8-12. Comparison of Contribution to Cancer Risk and Hazard Index by Constituents of Concern.

\begin{tabular}{|c|c|c|}
\hline & \multicolumn{2}{|c|}{ Contribution' to Relative Cancer Risk (\%) } \\
\hline Carcinogens & $\begin{array}{c}\text { Congruent Leakage } \\
\text { with Nitrate }\end{array}$ & $\begin{array}{c}\text { Solubility-Limited } \\
\text { Leakage }\end{array}$ \\
\hline \hline${ }^{99} \mathrm{Tc}$ & 64 & 86 \\
${ }^{238} \mathrm{U}$ & 24 & 1 \\
${ }^{129} \mathrm{I}$ & 10 & 13 \\
${ }^{14} \mathrm{C}$ & 3 & 0.2 \\
TBP & 0 & 0 \\
TOTALS & 100 & 100 \\
\hline
\end{tabular}

\begin{tabular}{|c|c|c|}
\hline & \multicolumn{2}{|c|}{ Contribution of Relative Hazard Index (\%) } \\
\hline Noncarcinogens & $\begin{array}{c}\text { Congruent Leakage } \\
\text { with Nitrate }\end{array}$ & $\begin{array}{c}\text { Solubility-Limited } \\
\text { Leakage }\end{array}$ \\
\hline \hline nitrate & 89 & 80 \\
EDTA & 7 & 7 \\
nitrite & 4 & 13 \\
TOTALS & 100 & 100 \\
\hline
\end{tabular}

A separate analysis consequently was conducted to assess the impacts of solubility-limited leakage of ${ }^{99} \mathrm{Tc}$ on risk associated with all 14 alternatives. The results of this analysis are plotted on Figures 8-6 and 8-7. Peak risk values are shown for this analysis in Table 8-13 with those for the Section 6 analyses which were based on congruent releases with nitrate.

\section{Discussion of Results}

Figures 8-6 and 8-7 show that each of the alternatives, except for the two nonviable alternatives (Alternatives 1 and 2 ) would yield risks and HIs within the normally accepted 
WHC-SD-WM-ES-300 REV. 1

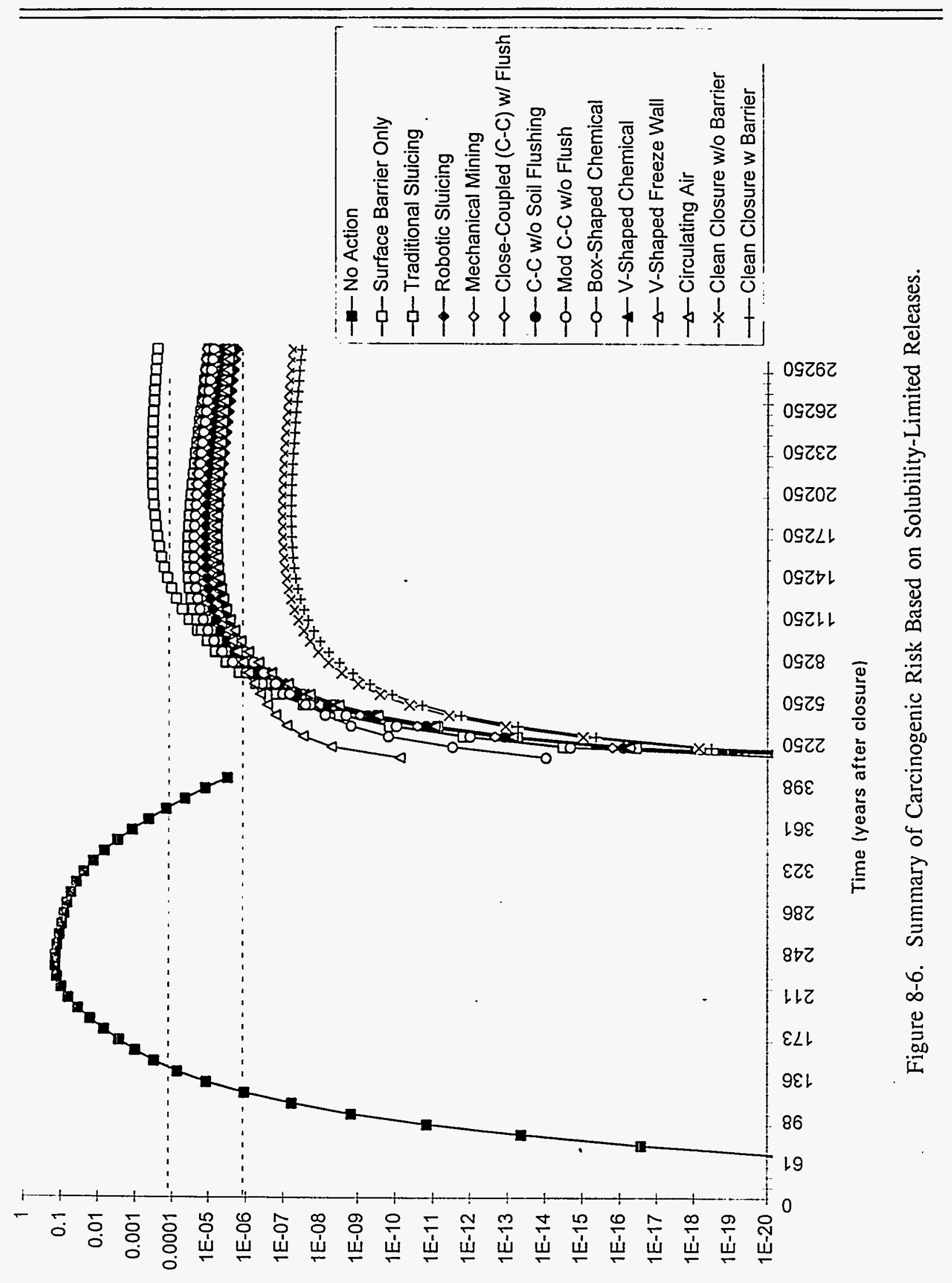

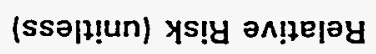


Relative Hazard Index (unitless)

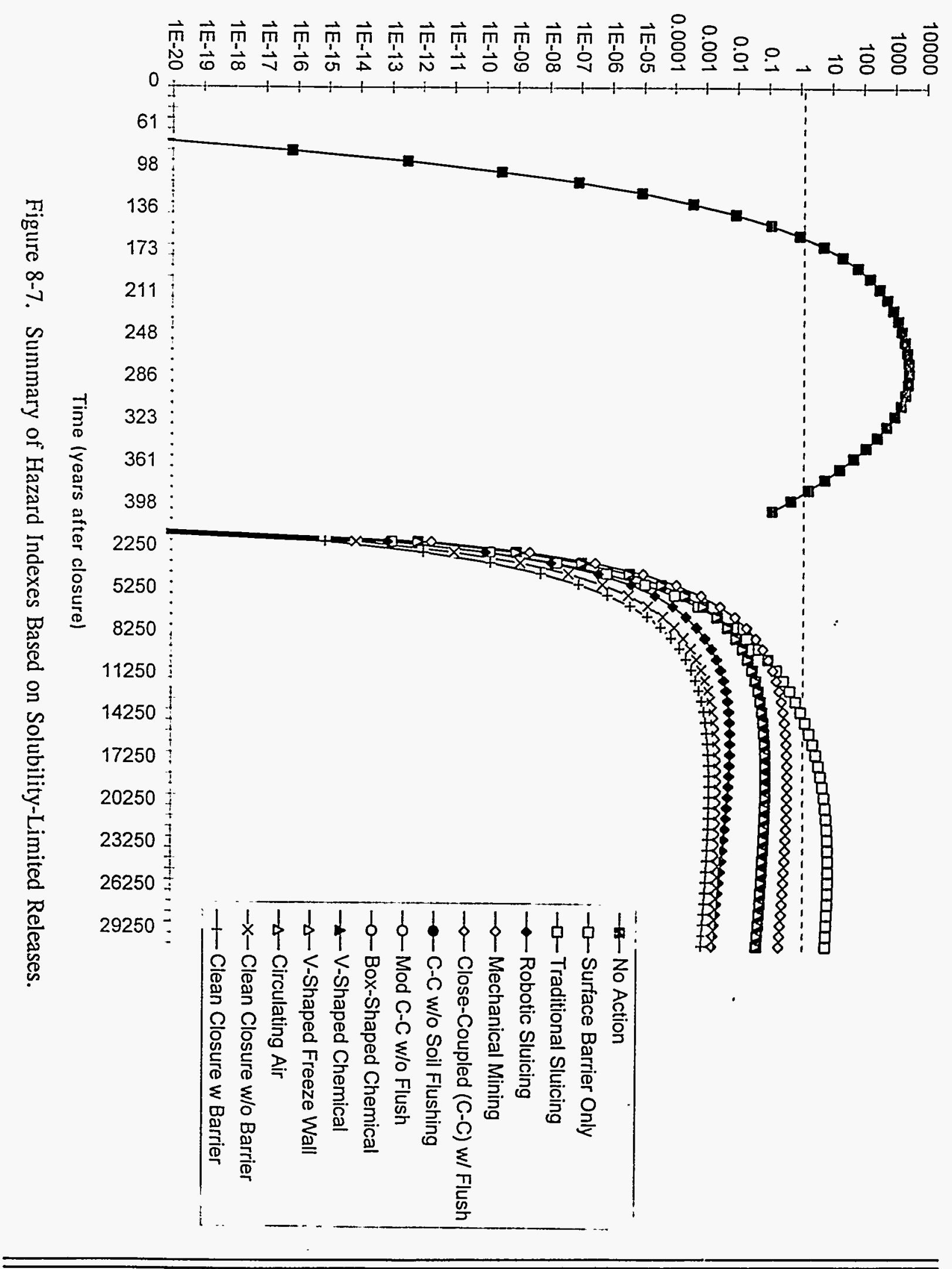


Table 8-13. Comparison of Peak Cancer Risks for Congruent Release and Solubility-Limited Release Cases.

\begin{tabular}{|l|c|c|c|}
\multicolumn{1}{|c|}{ Alternative } & \multicolumn{2}{c|}{ Relative Cancer Risk } & \multirow{2}{*}{$\begin{array}{c}\text { Difference } \\
\text { B }\end{array}$} \\
\cline { 2 - 4 } & $\begin{array}{c}\text { A. Congruent } \\
\text { Release with Nitrate }\end{array}$ & $\begin{array}{c}\text { B. Solubility- } \\
\text { Limited Release }\end{array}$ & 1.0 \\
\hline 1. No Action & $1.5 \mathrm{E}-01$ & $1.5 \mathrm{E}-01$ & 1.0 \\
\hline 2. Surface Barrier Only & $3.7 \mathrm{E}-04$ & $3.7 \mathrm{E}-04$ & 3.7 \\
\hline 3. Traditional Sluicing & $1.1 \mathrm{E}-05$ & $4.1 \mathrm{E}-05$ & 2.6 \\
\hline 4. Robotic Sluicing & $2.5 \mathrm{E}-06$ & $6.5 \mathrm{E}-06$ & 1.2 \\
\hline 5. Mechanical Retrieval & $2.1 \mathrm{E}-05$ & $2.5 \mathrm{E}-05$ & 1.4 \\
\hline 6. Close-Coupled Chemical Barrier with Flushing & $5.2 \mathrm{E}-06$ & $7.2 \mathrm{E}-06$ & 1.9 \\
\hline 7. Close-Coupled Chemical Barrier w/o Flushing & $7.0 \mathrm{E}-06$ & $1.3 \mathrm{E}-05$ & \\
\hline 8. Modified Close-Coupled Chemical Barrier w/o Flushing & $8.0 \mathrm{E}-06$ & $2.7 \mathrm{E}-05$ & 3.4 \\
\hline 9. Box-Shaped Chemical Barrier & $4.9 \mathrm{E}-06$ & $7.6 \mathrm{E}-06$ & 1.6 \\
\hline 10. V-Shaped Chemical Barrier & $4.9 \mathrm{E}-06$ & $6.6 \mathrm{E}-06$ & 1.3 \\
\hline 11. V-Shaped Freeze Wall Barrier & $4.8 \mathrm{E}-06$ & $6.6 \mathrm{E}-06$ & 1.3 \\
\hline 12. Circulating Air Barrier & $5.1 \mathrm{E}-06$ & $6.7 \mathrm{E}-06$ & 1.3 \\
\hline 13. Clean-Closure w/o Subsurface Barrier & $1.1 \mathrm{E}-07$ & $1.1 \mathrm{E}-07$ & 1.0 \\
\hline 14. Clean-Closure with Close-Coupled Chenical Barrier & $6.3 \mathrm{E}-08$ & $6.3 \mathrm{E}-08$ & 1.0 \\
\hline
\end{tabular}


thresholds of $10^{-4}$ for risk and 1 for HI. The same conclusion was drawn in Section 6 for the case of congruent releases.

Table 8-13 shows that Alternatives 3, 4, and 8 would yield cancer risk about $3 X$ higher than in the case where all COCs would be released congruently with nitrate. Higher cancer risks were estimated for these alternatives due to the relatively high ratio of leakage to residual waste in the tanks. The leakage would contain higher levels of ${ }^{99} \mathrm{Tc}$ than assumed previously, leading to higher risk.

An impact of the higher cancer risks in Alternatives 3, 4, and 8 would be about a factor of $3 X$ reduction in the cost-benefit described earlier in Section 8 . Solubility-limited leaking would narrow the range of cost-benefit values to the point that little real difference would exist among alternatives.

Actual average leakage may contain ${ }^{99} \mathrm{Tc}$ at concentrations between levels assumed for congruent release and for release of drainable liquid. The concentration would depend on the fraction of leakage of diluted waste that would occur through holes or cracks in the tank steel exposed by sluicing and the fraction that would occur through holes covered by sludge containing drainable liquid. Thus, the results of the solubility-limited release analysis may be somewhat conservative for the average leak case. Individual tanks may leak drainable liquid at levels of ${ }^{99} \mathrm{Tc}$ more than $2 \mathrm{X}$ higher than assumed for drainable liquid, however, based on analyses conducted by Schultz (1978), Weiss (1986), and Weiss and Schull (1988a, 1988b, 1988c, 1988d, 1988e, 1988f, 1988g, 1988h, 1988i). Therefore, risks could be somewhat higher for individual tanks, although these risks would probably be reduced within a tank farm due to the presence of leaks at lower ${ }^{99} \mathrm{Tc}$ concentrations.

\subsubsection{Phase IV - Very-High Leakage With Variability In Recharge Rate and Flushing Effectiveness}

Previous sensitivity analyses dealt with uncertainties associated with source inventories, release rates of contaminants from the individual sources, initial inventories of COCs among tank farms, travel rates of COCs in the vadose zone, and solubility of the COCs. Three issues raised by reviewers of the previous sections are the bases for the sensitivity analyses presented in this section:

\section{Issue 1}

Tanks may have deteriorated significantly in the 10 or more years since their use for liquid waste storage was terminated. Also, some tank farms were installed in geologic formations with high hydraulic conductivities. These conditions could lead to higher leakages than predicted. 


\section{Response to Issue 1}

All prior analyses were based on the assumption that five tanks in the hypothetical tank farm would each leak $151,000 \mathrm{~L}$ (40,000 gal) during new sluicing operations. Leakage would be much higher under highly deteriorated conditions. For example, assume that the bottom of a tank, including its concrete foundation had deteriorated to the point that it had no ability to restrict leakage. When sluicing operations begin, water would run out the base of the tank and through the soil in accordance to Darcy's Law. Equation 7, which is based on Darcy's Law, can be restated to estimate the volume leaked under these conditions:

$$
V=A \sqrt{2 K h n t}
$$

$$
\text { Where: } \quad \begin{array}{ll}
\mathrm{V}=\text { Volume }\left(\mathrm{L}^{3}\right) \\
\mathrm{A}=\text { Area }\left(\mathrm{L}^{2}\right) \\
\mathrm{K}=\text { hydraulic conductivity }(\mathrm{L} / \mathrm{T}) \\
\mathrm{n}=\text { effective porosity. (unitless) } \\
\mathrm{t}=\text { time }(\mathrm{T}) .
\end{array}
$$

The area (A) of a single tank is $410 \mathrm{~m}^{2}\left(4,400 \mathrm{ft}^{2}\right)$. Sluicing operations were assumed to be completed in 123 days $(\mathrm{t})$ with a $4.6 \mathrm{~m}(15 \mathrm{ft})$ liquid head $(\mathrm{h})$. The hydraulic conductivity $(\mathrm{K})$ and effective porosity $(\mathrm{n})$ of the soil were assumed to be $1.55 \times 10^{-3} \mathrm{~cm} / \mathrm{s}(4.4 \mathrm{ft} /$ day) and 0.4 , respectively. Under these conditions, a single tank would leak $10,100,000 \mathrm{~L}(2,670,000 \mathrm{gal})$. This level of leakage is highly unrealistic because even badly cracked concrete will provide a substantial barrier to leakage if sludge fines fill the cracks and soil pores as expected. If sludge fines are only partly successful in restricting leakage, leakage of $1,510,000 \mathrm{~L}$ (400,000 gal) per tank represents a very high but hypothetically possible estimate. This is 10 times the $151,000 \mathrm{~L}(40,000 \mathrm{gal})$ per tank assumed previously, and about $15 \%$ of the level of leakage estimated with the assumption that the tank had lost all ability to hold liquid. It was assumed for the $1,510,000 \mathrm{~L}(400,000 \mathrm{gal})$ leakage case that 10 of the 12 tanks would leak versus five tanks that would each leak $151,000 \mathrm{~L}(40,000 \mathrm{gal})$ in previous analyses. Thus, the total estimated new leakage for the tank farm would be $15,100,000 \mathrm{~L}(4,000,000 \mathrm{gal})$ in the very-high leakage cases evaluated in this section. This is a factor of $20 \mathrm{X}$ the new leakage assumed in previous analyses.

One-half of the assumed interstitial liquid concentrations shown in Table 6-3 were used to represent leak concentrations in the very-high leakage cases. It is assumed that these concentrations are more representative of expected conditions than the drainable water concentrations used in the Phase III sensitivity analysis due to expected dilution and other factors. Dilution of the sluicing water would occur as water is added to make up for the high level of leakage assumed. A leak volume of $1,510,000 \mathrm{~L}$ $(400,000 \mathrm{gal})$ is about half the total volume of a typical SST. Much of the leaked liquid must be replenished to effectively slurry the sludge which typically underlies the 
saltcake. Also, the drainable liquid phase, which contains ${ }^{99} \mathrm{Tc}$ at highly enriched concentrations, may be held largely in check by the salt and sludge layers because the layers probably exhibit low hydraulic conductivities. A low hydraulic conductivity would impede the flow of drainable liquid contained within the sludge and saltcake toward an exposed crack or hole in the tank, resulting in preferential leakage of diluted solution.

\section{Issue 2}

The effectiveness of soil flushing may be lower than the assumed level, due to channeling of the flush water.

\section{Response to Issue 2}

Previous analyses were based on the assumption that flushing would remove $94 \%$ of the COCs leaked to the soil. A sensitivity analysis reported earlier in Section 8 was based on removal of only $50 \%$ of the COCs. A removal effectiveness of $50 \%$ was also assumed in four cases involving subsurface barriers in the sensitivity analyses in this section because channeling would likely occur due to the need to accomplish flushing under partially saturated conditions. Partially saturated flushing would be necessary to avoid development of excessive liquid heads which could reșult in liquid penetration of the standoff barrier, or bypassing the flush water suction pipes when soil flushing is used in combination with close-coupled or circulating air barriers.

\section{Issue 3}

The surface barrier may lose its effectiveness if it is not maintained.

\section{Response to Issue 3}

The surface barrier was assumed to limit recharge to $0.05 \mathrm{~cm} / \mathrm{yr}(0.02 \mathrm{in} / \mathrm{yr})$ based on results of lysimeter tests being conducted at the Hanford Site (Gee et al. 1993). A recharge rate of $5 \mathrm{~cm} / \mathrm{yr}(2 \mathrm{in} / \mathrm{yr}$ ) was evaluated in the HDW-EIS (DOE 1987). The surface barrier would be constructed of materials that restrict water movement and promote plant growth to enhance evaporation and transpiration of soil water (Wing 1993). These materials and the effectiveness of the barrier are not likely to deteriorate to a significant degree unless damaged by human or animal intruders. A recharge rate of $0.5 \mathrm{~cm} / \mathrm{yr}(0.2 \mathrm{in} / \mathrm{yr})$ was selected as representative of a damaged barrier and serves as the basis for three of the cases evaluated in this section.

These issues served as the foundation for the following comparative analysis of eight cases that involve very-high leakage and variation in recharge rates and soil flushing effectiveness. These cases are summarized in Table 8-14. 
Table 8-14. Sensitivity Cases Involving Very High Leakage.

\begin{tabular}{|c|c|c|c|c|c|c|c|c|}
\hline & \multicolumn{8}{|c|}{ Case } \\
\hline Conditions & 1 & 2 & 3 & 4 & 5 & 6 & 7 & 8 \\
\hline 400,000 gal leak from each of 10 tanks & $\mathrm{x}$ & $\mathrm{x}$ & $\mathrm{X}$ & $\mathrm{x}$ & $\mathrm{X}$ & $\mathrm{X}$ & $\mathrm{X}$ & $\mathrm{x}$ \\
\hline Recharge remains at $0.05 \mathrm{~cm} / \mathrm{yr}(0.02 \mathrm{in} / \mathrm{yr})$ & $\mathrm{X}$ & & $\mathrm{X}$ & $\mathrm{X}$ & & $\mathrm{X}$ & $\mathrm{X}$ & \\
\hline Recharge increases to $0.5 \mathrm{~cm} / \mathrm{yr}(0.2 \mathrm{in} / \mathrm{yr})$ & & $\mathrm{X}$ & & & $\mathrm{X}$ & & & $\mathrm{X}$ \\
\hline Soil flushing efficiency is $50 \%$ & & & & $\mathrm{X}$ & $\mathrm{X}$ & & $\mathrm{X}$ & $\mathrm{X}$ \\
\hline Soil flushing efficiency is $94 \%$ & & & $\mathrm{x}$ & & & $\mathrm{X}$ & & \\
\hline Close-coupled barrier is applied to all tanks & & & $\mathrm{X}$ & $\mathrm{X}$ & $\mathrm{X}$ & & & \\
\hline V-shaped ice barrier is installed under tank farm & & & & & & $\mathrm{X}$ & $\mathrm{X}$ & $\mathrm{X}$ \\
\hline
\end{tabular}

\section{High Leakage Case 1}

This case is identical to the Traditional Sluicing (Baseline) Alternative except that a very-high level of leakage during sluicing was assumed. The total leakage from old and new leaks includes five tanks that would previously have leaked 42,000 L (11,000 gal) each and 10 tanks that would leak $1,510,000 \mathrm{~L}(400,000 \mathrm{gal})$ each. Thus the total leakage would be $15,300,000 \mathrm{~L}(4,050,000 \mathrm{gal})$. The concentration of nitrate in leaked waste was assumed to be half the concentration of interstitial liquid, or $125 \mathrm{~g} / \mathrm{L}$. Thus, the total nitrate in the old and new leaks would be $1,910,000 \mathrm{~kg}$. For comparison, the mass of nitrate in the leakage assumed for the Traditional Sluicing (Baseline) Alternative analyzed in Section 6 was $120,000 \mathrm{~kg}$.

The depth of the leaked plume was estimated using an algorithm developed to describe the shape of the plume resulting from the 435,000-L (115,000-gal) leak from Tank 241-T-106 (Boomer et al. 1993):

$$
57 \mathrm{~V}=4 / 3 \pi \mathrm{abc}
$$

Where: $\quad \mathrm{V}=$ volume of leaked waste $\left(\mathrm{L}^{3}\right)$

$\mathrm{a}=$ horizontal semiaxis, equal to $2.3 \mathrm{c}(\mathrm{L})$

$\mathrm{b}=$ horizontal semiaxis, equal to $3.0 \mathrm{c}(\mathrm{L})$

$c=$ vertical semiaxis $(L)$

The height of the plume is equal to $2 \mathrm{c}$. For a $1,552,000-\mathrm{L}$ (411,000-gal) leak, the height of the plume would be $29.1 \mathrm{~m}(95.3 \mathrm{ft})$. The plume would be based $29.1 \mathrm{~m}(95.3 \mathrm{ft})$ below the

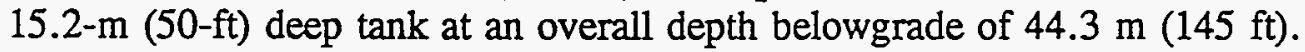


The nitrate flux resulting from the passage of recharge water through the plume at $0.05 \mathrm{~cm} / \mathrm{yr}(0.02 \mathrm{in} / \mathrm{yr})$ was calculated using Equation 15 . The resulting nitrate flux would be $0.73 \mathrm{~kg} /$ day $(1.6 \mathrm{lb} /$ day). The duration of this flux, estimated using Equation 16 , would be 7,000 years.

An increased level of nitrate would advect into the concrete because 10 tanks were assumed to leak during sluicing instead of five as in previous analyses. It was assumed as before that a 4.6-cm (15-ft) head of liquid waste would be applied to the concrete at the tank's base during 123 days of sluicing. The resulting estimated nitrate inventory in the concrete, $18,900 \mathrm{~kg}(42,000 \mathrm{lb})$, was calculated using Equation 7 and includes nitrate previously advected into the concrete of five tanks at a head of $4.6 \mathrm{~m}(15 \mathrm{ft})$ over 15 years.

A slightly elevated level of nitrate was assumed to exist between the tank steel and concrete because 10 tanks were assumed to have leaked in contrast to seven in previous analyses. The level of nitrate in the residual tank waste was assumed to remain at $1 \%$ of the inventory before sluicing, as in previous analyses.

\section{Case 2}

This case is identical to Case 1 except that the surface barrier was assumed to be damaged, resulting in increasing the recharge rate to $0.5 \mathrm{~cm} / \mathrm{yr}(0.2 \mathrm{in} / \mathrm{yr})$. The effect of this change would be a ten-fold increase in the flux rates of COCs from the various sources and a tenfold reduction in the associated durations of release. Another effect would be less damping of the COC concentration profiles in the vadose zone because less time is available for diffusion to spread out the COCs within the vadose zone.

\section{Case 3}

In this case it was assumed that close-coupled chemical barriers would be installed around all 12 tanks in the hypothetical tank farm as in the Close-Coupled Chemical Barrier Alternative. It was assumed further that in situ flushing of old leaks prior to installing the barriers would be $94 \%$ effective in removing COCs from the soil. The close-coupled barrier was assumed to be effective in preventing new leakage to the soil, although the barrier itself was assumed to be partly penetrated by the sluicing liquid in accordance to Darcy's Law. It was assumed that penetration would occur through $10 \mathrm{~m}$ (33 ft) of cracks in the concrete as in previous analyses. An estimated $160,000 \mathrm{~L}(42,000 \mathrm{gal})$ would penetrate into the 10 barriers surrounding leaking tanks. The surface barrier was assumed to function as designed, limiting recharge to $0.05 \mathrm{~cm} / \mathrm{yr}(0.02 \mathrm{in} / \mathrm{yr})$.

\section{Case 4}

This case is identical to Case 3 except that the efficiency of soil flushing was assumed to be only $50 \%$. This change would result in increasing the amount of the residual COCs in the soil by about $8 \mathrm{X}$, making contaminated soil the dominant source of risk. 


\section{Case 5}

This case is identical to Case 4 except that the surface barrier is assumed to be degraded, resulting in a recharge rate of $0.5 \mathrm{~cm} / \mathrm{yr}(0.2 \mathrm{in} / \mathrm{yr})$. The faster time for water to travel through the vadose zone would result in less diffusion and less damping of the $\mathrm{COC}$ concentration profiles as the COCs move toward the water table.

\section{Case 6}

In this case it was assumed that a V-shaped freeze wall barrier would be installed beneath the hypothetical tank farm. Traditional flushing would be used to remove $94 \%$ of the COCs leaked into the soil during sluicing.

The $15,300,000 \mathrm{~L}(4,050,000 \mathrm{gal})$ of liquid waste assumed to leak from the tanks in Case 1 would also leak in this case because the barrier would be installed well below the base of the tank. The close-coupled barrier included in Cases 3 through 5, in contrast, would limit leakage because it would be installed in contact with each tank. The surface barrier was assumed to function as designed, limiting recharge to $0.05 \mathrm{~cm} / \mathrm{yr}(0.02 \mathrm{in} / \mathrm{yr})$.

\section{Case 7.}

This case is identical to Case 6 except that soil flushing was assumed to be only $50 \%$ effective in removing COCs from the soil. Recharge was assumed to be limited to $0.05 \mathrm{~cm} / \mathrm{yr}(0.02 \mathrm{in} / \mathrm{yr})$.

\section{Case 8}

This case is identical to Case 7 except that the surface barrier was assumed to be degraded, resulting in a recharge rate of $0.5 \mathrm{~cm} / \mathrm{yr}(0.2 \mathrm{in} / \mathrm{yr})$.

\section{Discussion of Results}

The results of the high-leakage analysis are shown in Figures 8-8 through 8-11 and in Table 8-15. Several conclusions can be drawn from this analysis:

- Increasing the assumed level of new leakage during sluicing operations by a factor of 20 (to $1,510,000 \mathrm{~L}$ [400,000 gal] for each of 10 tanks) would result in computed risks just above the upper cancer risk threshold of $10^{-4}$. The computed HI, however, would be a factor of 3.2 above the HI threshold of 1 . By interpolation of results in this analysis and results of the previous lower leak analysis, the maximum leakage for each of 10 leaking tanks would be about $120,000 \mathrm{gal}$ for $\mathrm{HI}$ to remain below 1 . 


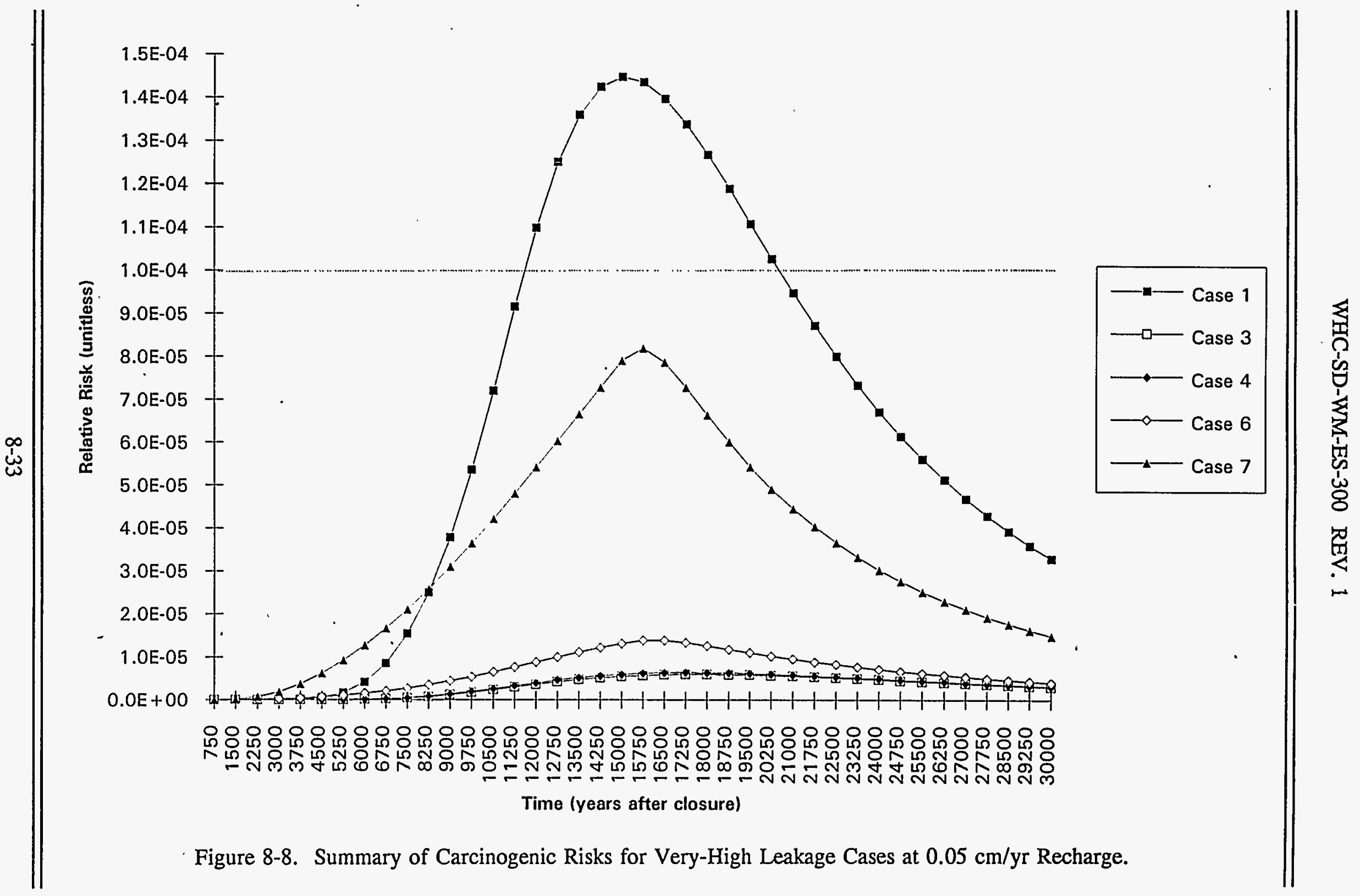




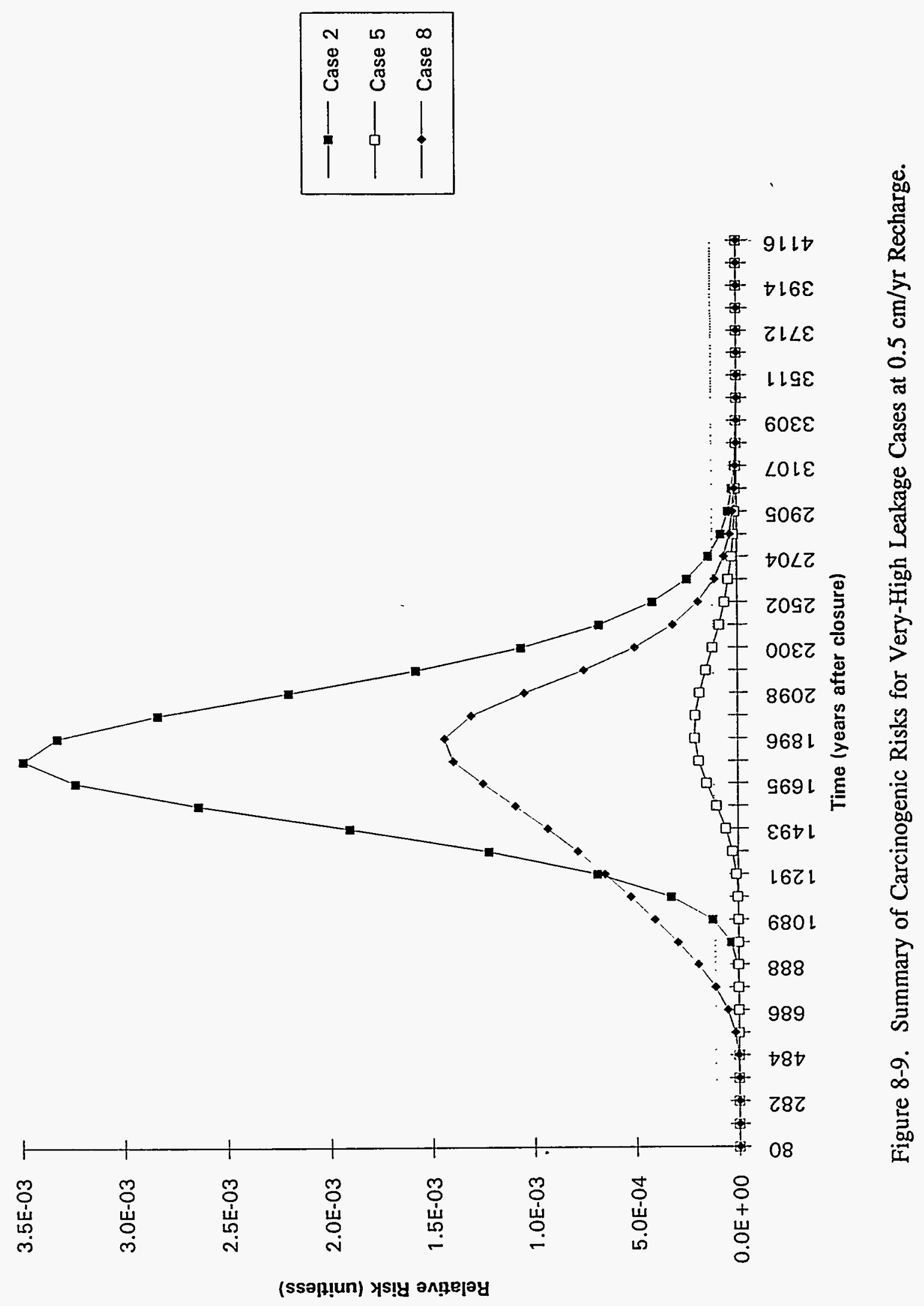



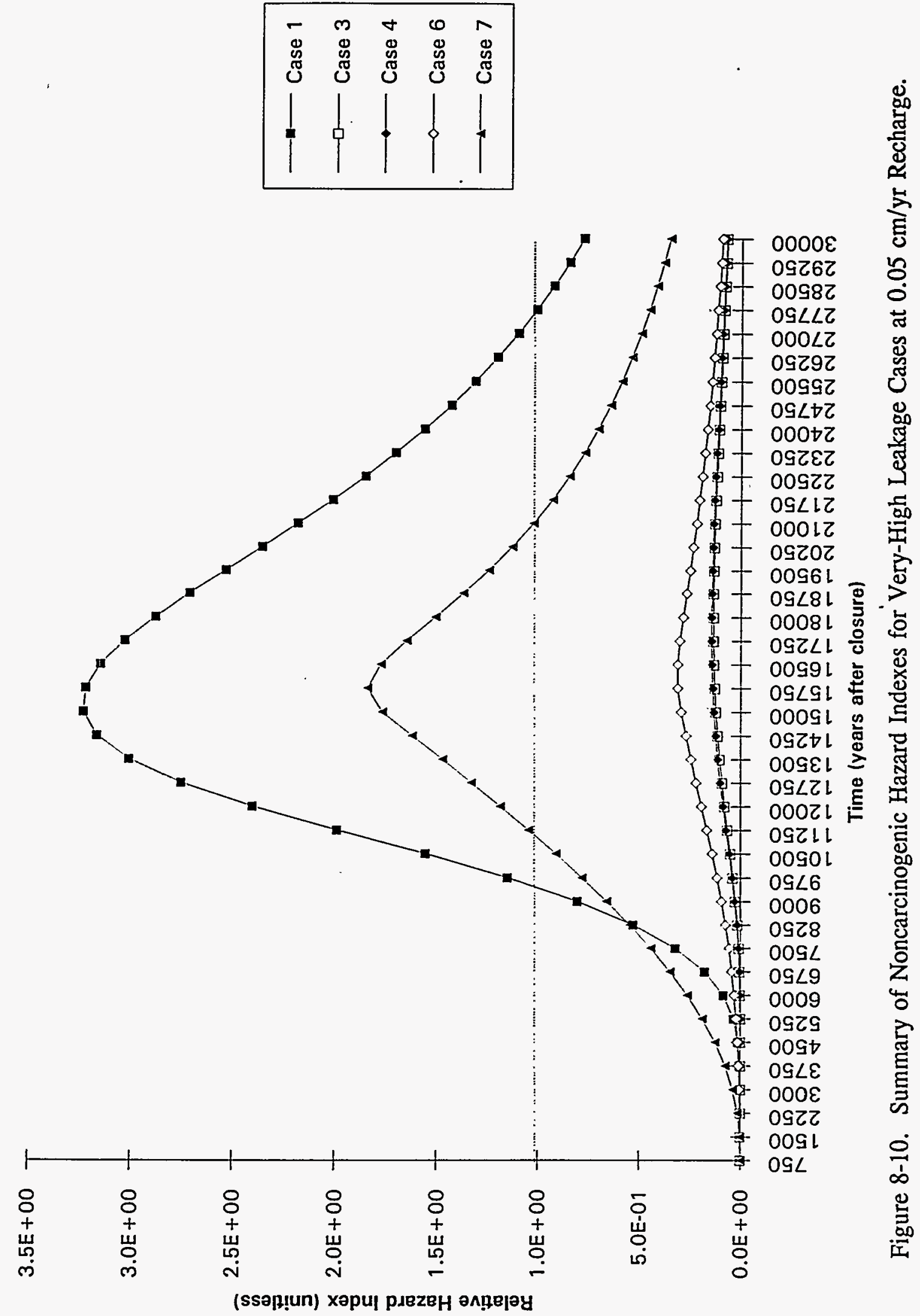


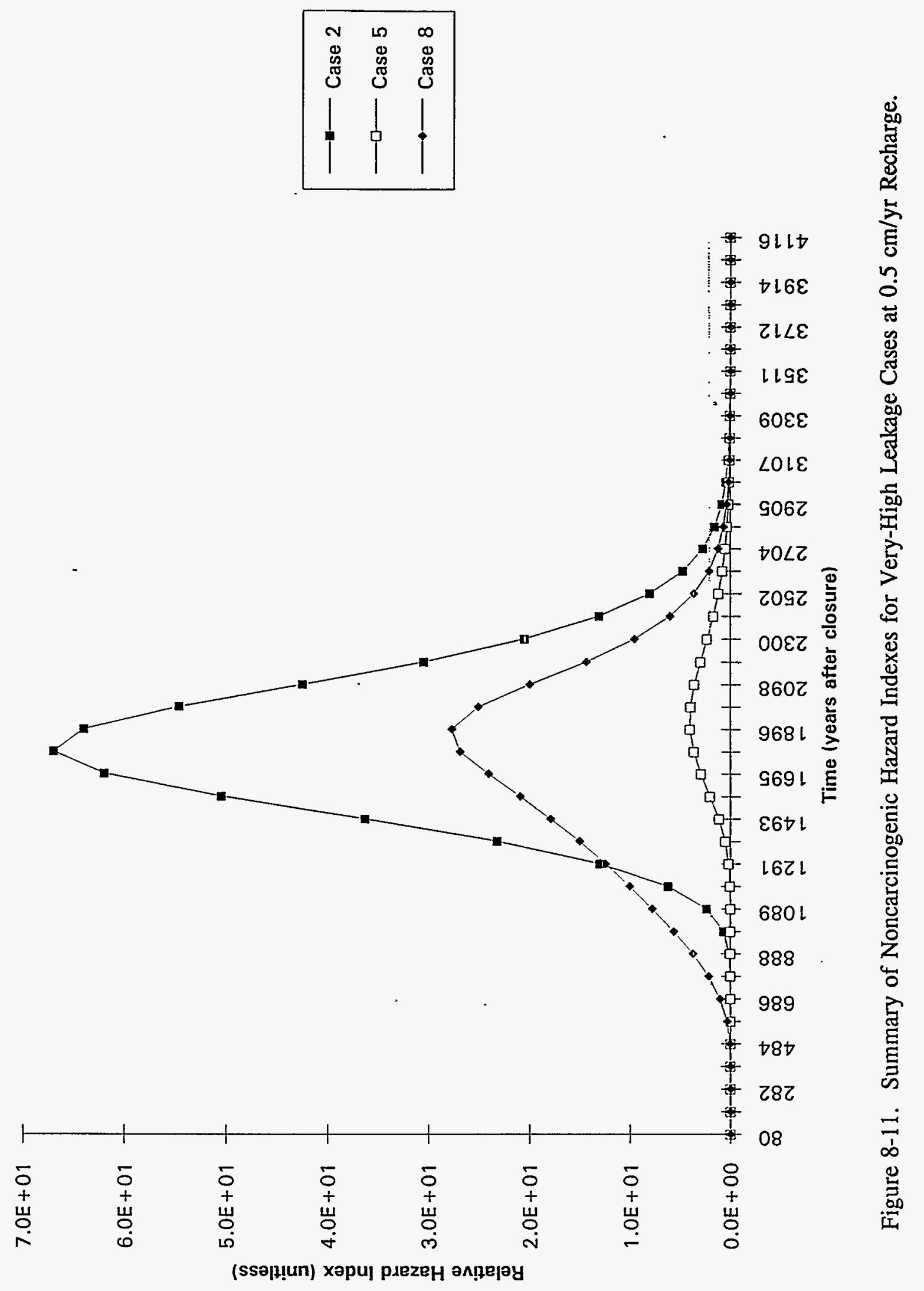


Table 8-15. Peak Cancer Risks and Hazard Indexes for Very-High Leakage Cases.

\begin{tabular}{|c|c|c|c|}
\hline & $\begin{array}{l}\text { Description of Cases } \\
(400,000 \text { gal leak from each of } \\
10 \text { tanks in all cases })\end{array}$ & $\begin{array}{c}\text { Relative } \\
\text { Cancer } \\
\text { Risk }\end{array}$ & $\begin{array}{c}\text { Relative } \\
\text { HII }\end{array}$ \\
\hline Case 1: & $\begin{array}{l}0.05 \mathrm{~cm} / \mathrm{yr}(0.02 \mathrm{in} / \mathrm{yr}) \text { surface barrier recharge } \\
\text { No subsurface barrier } \\
\text { No soil flushing }\end{array}$ & $1.5 \mathrm{E}-4$ & 3.2 \\
\hline Case 2: & $\begin{array}{l}0.5 \mathrm{~cm} / \mathrm{yr}(0.02 \mathrm{in} / \mathrm{yr}) \text { surface barrier recharge } \\
\text { No subsurface barrier } \\
\text { No soil flushing }\end{array}$ & $3.5 \mathrm{E}-3$ & 67 \\
\hline Case 3: & $\begin{array}{l}0.05 \mathrm{~cm} / \mathrm{yr}(0.02 \mathrm{in} / \mathrm{yr}) \text { surface barrier recharge } \\
\text { Close-coupled chemical barrier } \\
94 \% \text { effective soil flushing }\end{array}$ & $6.0 \mathrm{E}-6$ & 0.14 \\
\hline Case 4: & $\begin{array}{l}0.05 \mathrm{~cm} / \mathrm{yr}(0.02 \mathrm{in} / \mathrm{yr}) \text { surface barrier recharge } \\
\text { Close-coupled chemical barrier } \\
50 \% \text { effective soil flushing }\end{array}$ & $6.4 \mathrm{E}-6$ & 0.15 \\
\hline Case 5: & $\begin{array}{l}0.5 \mathrm{~cm} / \mathrm{yr}(0.02 \mathrm{in} / \mathrm{yr}) \text { surface barrier recharge } \\
\text { Close-coupled chemical barrier } \\
50 \% \text { effective soil flushing }\end{array}$ & $2.1 E-4$ & 4.1 \\
\hline Case 6: & $\begin{array}{l}0.05 \mathrm{~cm} / \mathrm{yr}(0.02 \mathrm{in} / \mathrm{yr}) \text { surface barrier recharge } \\
\text { V-shaped freeze wall barrier } \\
94 \% \text { effective soil flushing }\end{array}$ & $1.1 E-5$ & 0.23 \\
\hline Case 7: & $\begin{array}{l}0.05 \mathrm{~cm} / \mathrm{yr}(0.02 \mathrm{in} / \mathrm{yr}) \text { surface barrier recharge } \\
\text { V-shaped freeze wall barrier } \\
50 \% \text { effective soil flushing }\end{array}$ & $6.7 \mathrm{E}-5$ & 1.5 \\
\hline Case 8: & $\begin{array}{l}0.5 \mathrm{~cm} / \mathrm{yr}(0.02 \mathrm{in} / \mathrm{yr}) \text { surface barrier recharge } \\
\text { V-shaped freeze wall barrier } \\
50 \% \text { effective soil flushing }\end{array}$ & $1.5 \mathrm{E}-3$ & 28 \\
\hline
\end{tabular}


- Deterioration of the surface barrier, leading to a $10 \mathrm{X}$ increase in recharge, would cause the upper cancer risk threshold to be exceeded by a factor of about $35 \mathrm{X}$ and the HI threshold to be exceeded by about $67 \mathrm{X}$. Figure $8-12$ shows that the $1 \%$ residual waste in the tanks alone would cause the cancer risk and HI thresholds to be exceeded. This result demonstrates the critical importance of maintaining the function of the barrier to limit recharge to the lowest level achievable.

A related issue not addressed in this analysis is the potential for drawing recharge water from surrounding soils into the vadose zone column directly beneath the surface barrier. The vadose zone column beneath the barrier will exhibit a higher soil suction pressure than will the bordering vadose zone because it will drain to a lower water content. This will result in movement of water into the soil column beneath the surface barrier. The effect of this water movement would be similar to increasing the recharge rate because the water travel time to the aquifer would be reduced, thereby reducing the time for diffusion to spread and flatten the COC concentration profiles within the vadose zone. This undesired effect, which was not modeled in this study, may be minimized or avoided if the surface barrier is extended significantly beyond the boundary of the tank farm. A less-expensive option is a barrier composed of the same material used to create the top soil layers of the Hanford Surface Barrier. Both barriers would require monitoring to ensure that plant growth is sufficient to induce the required degree of evapotranspiration and that animal or human intrusion has not occurred.

- The close-coupled barrier, regardless of the effectiveness of soil flushing, would result in cancer risks and HIs substantially below the associated thresholds, if the surface barrier performs as designed. If the performance of the surface barrier is degraded to allow a recharge rate of $0.5 \mathrm{~cm} / \mathrm{yr}(0.02 \mathrm{in} / \mathrm{yr})$, both the cancer risk and $\mathrm{HI}$ would exceed associated thresholds by factors of $2.1 \mathrm{X}$ and $4.0 \mathrm{X}$, respectively. As in the previous case in which no surface barrier was assumed, the residual inventory in the tank alone would cause both thresholds to be exceeded.

- The V-shaped freeze wall barrier would satisfy threshold guidelines if soil flushing is $94 \%$ effective and if recharge is limited to $0.05 \mathrm{~cm} / \mathrm{yr}$. $(0.02 \mathrm{in} / \mathrm{yr})$. The HI threshold would be exceeded by about $50 \%$ at a $50 \%$ soil-washing effectiveness, if the integrity of the surface barrier is maintained. If the surface barrier is degraded, both cancer risk and HI would exceed associated thresholds by factors of $15 \mathrm{X}$ and $28 \mathrm{X}$, respectively. 


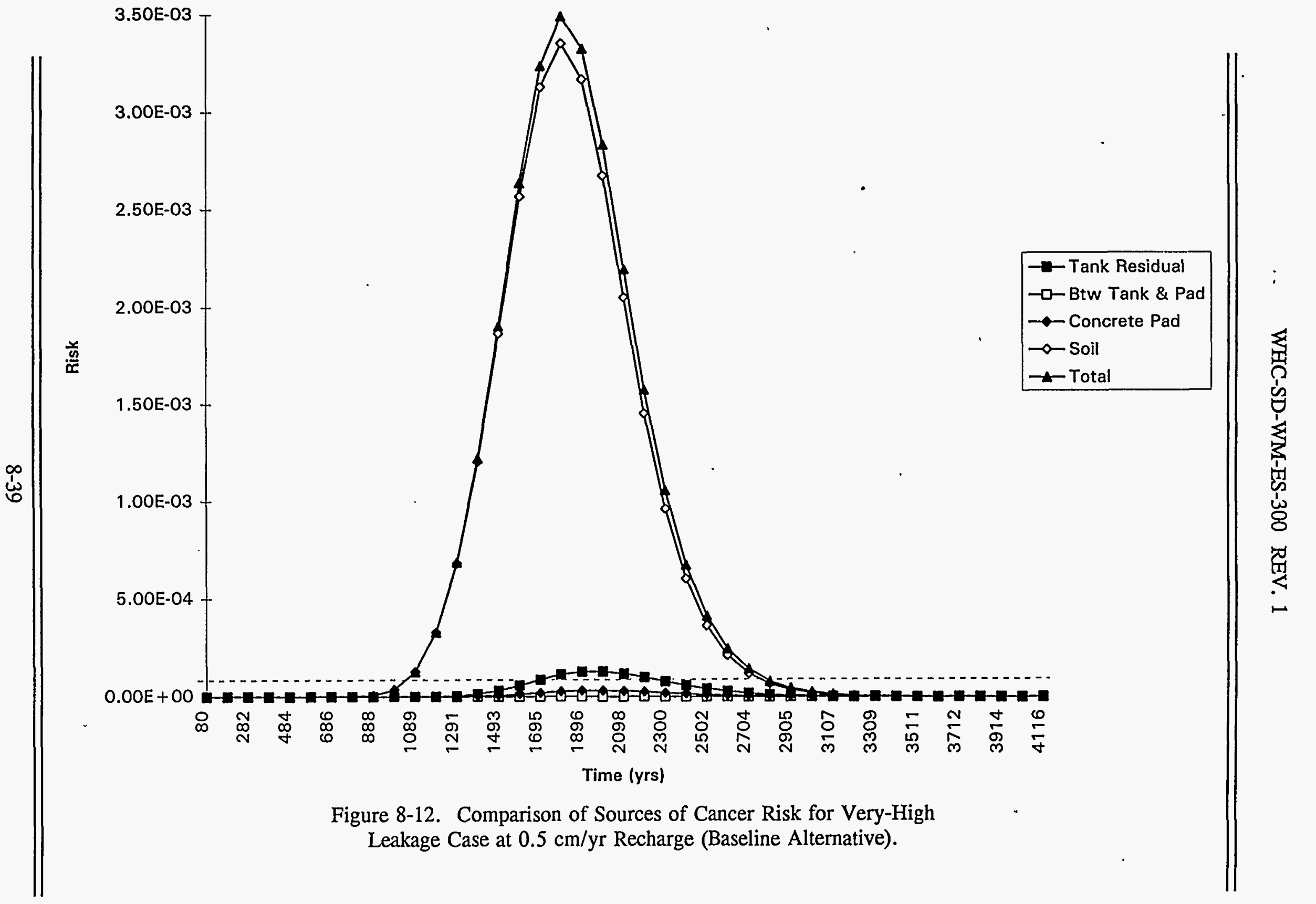




\subsubsection{Phase V - Effect of Large Leak Volume on Travel Time Through the Unsaturated Zone}

This sensitivity analysis was performed to evaluate the mobilizing effect of the additional water in the unsaturated zone following a large leak and the resulting consequences on human health risk via the groundwater pathway. The previous analysis assumed steady state conditions within the unsaturated zone where only the advective/dispersive effects of natural recharge beneath a barrier were considered. The masses of contaminants were assumed to leach from beneath the tank and were transported to the groundwater at recharge rates varying from 0.05 to $5 \mathrm{~cm} / \mathrm{yr}(0.02$ to $2 \mathrm{in} / \mathrm{yr})$. Under ponded water conditions or where the tank leak rate exceeds the natural infiltration/recharge rate the hydraulic conductivity of the soil will increase along with moisture content as the plume moves with gravity through the soil. The extent to which the travel time to the groundwater is affected by an influx of water from beneath a tank was examined using flow and transport models.

The focus of this analysis was limited to the determination of the relative variation in travel time in the unsaturated zone. A quantitative evaluation of contaminant concentrations in the saturated zone or the ultimate exposire to the maximally exposed individual was not required to address the issue and therefore not included in the analysis.

The tank leak scenario developed for this analysis employed a leakage volume equivalent to the largest documented leak at the tank farms. Approximately 435,000 L (115,000 gal) was assumed to leak from a single tank as occurred in a documented leak from Tank 241-T-106. This volume and the description of the Tank 241-T-106 leak from Boomer et al. (1993) was used to develop the plume profile. The methodology for determining the shape and characteristics of the plume are consistent with previous leak evaluations.

Two test cases were defined. Case 1: Natural Recharge Only, predicts the rate of contaminant transport to the groundwater assuming flow is associated with steady state recharge conditions of $0.05 \mathrm{~cm} / \mathrm{yr}(0.02 \mathrm{in} / \mathrm{yr})$, as expected to exist beneath a Hanford Site barrier. Case 2: Natural Recharge Plus Leakage, predicts the rate of contaminant transport to the groundwater assuming natural flow is accompanied by an influx of $435,000 \mathrm{~L}$ $(115,000 \mathrm{gal})$ of water from beneath a tank. Case 1 represents conditions assumed in the previous analysis.

\section{Model Description}

A two dimensional finite element computer model, SEEP/W, was utilized to simulate the flow of water through unsaturated soil. The SEEP/W model is capable of simulating both saturated and unsaturated flows (Geo-Slope 1994). The model is based on the following partial differential equation:

$$
\frac{\partial \theta}{\partial t}=\frac{\partial}{\partial x}\left(k_{x} \frac{\partial H}{\partial x}\right)+\frac{\partial}{\partial y}\left(k_{y} \frac{\partial H}{\partial y}\right)+Q
$$


Where:

$$
\begin{aligned}
& \mathrm{H}=\text { total head } \\
& \mathrm{k}_{\mathrm{x}}=\text { hydraulic conductivity in the } \mathrm{x} \text {-direction } \\
& \mathrm{k}_{\mathrm{y}}=\text { hydraulic conductivity in the } \mathrm{y} \text {-direction } \\
& \mathrm{Q}=\text { applied boundary flux } \\
& \theta=\text { volumetric water content } \\
& \mathrm{t}=\text { time. }
\end{aligned}
$$

Equation 36 is formulated for conditions of constant total stress and based on the assumption that pore air pressure remains constant at atmospheric pressure during transient processes.

The model requires a functional relationship between hydraulic conductivity and volumetric water content, and between volumetric water content and matric potential. These functional relationships were developed by utilizing the van Genuchten model (van Genuchten 1980). The mathematical representation of these relationships is given below.

$$
\begin{gathered}
\theta=\theta_{r}+\frac{\theta_{s}-\theta_{r}}{\left[1+\left(\alpha\left(\Psi-\Psi_{a}\right)\right)^{\theta}\right]^{\gamma}} \\
k(\theta)=k s S_{e}^{1 / 2}\left[1-\left(1-S_{e}^{\frac{1}{\gamma}}\right)^{\gamma}\right]^{2} \\
S_{e}=\frac{\theta-\theta_{r}}{\theta-\theta_{r}}
\end{gathered}
$$

Where: $\quad \theta=$ volumetric water content

$$
\begin{aligned}
\theta_{3} & =\text { volumetric water content at saturation } \\
\theta_{\mathrm{r}} & =\text { residual water content } \\
\alpha, \beta, \gamma & =\text { empirical constants } \\
\Psi & =\text { pressure head } \\
\Psi_{\mathrm{a}} & =\text { air entry pressure } \\
\mathrm{S}_{\mathrm{c}} & =\text { effective saturation } \\
\mathrm{ks} & =\text { saturated hydraulic conductivity } \\
\mathrm{k} & =\text { hydraulic conductivity. }
\end{aligned}
$$

Chemical transport through the unsaturated zone was simulated by utilizing the CTRAN/W computer code which is also a two-dimensional finite element model (Geo-Slope 1994). The CTRAN/W model utilizes flow data from SEEP/W to simulate chemical transport. The basic governing partial differential equation on which the transport model is based is given below. 


$$
\frac{\partial C}{\partial t}=-v_{x} \frac{\partial C}{\partial x}+D_{x} \frac{\partial^{2} C}{\partial x^{2}}-v_{y} \frac{\partial C}{\partial y}+D_{y} \frac{\partial^{2} C}{\partial y^{2}}
$$

Where: $\quad v_{x}=$ average linear velocity in the $x$-direction

$v_{y}=$ average linear velocity in the $y$-direction

$\mathrm{C}=$ concentration of the contaminant

$\mathrm{D}_{\mathrm{x}}=$ hydrodynamic dispersion in the $\mathrm{x}$-direction

$D_{y}=$ hydrodynamic dispersion in the y-direction.

The above equation does not include terms representing adsorption and degradation. The CTRAN/W model can account for both adsorption and degradation. Since the objective was only to simulate advective-dispersive flow, the terms are not included in Equation 40.

\section{Conceptual Model, Spatial Discretization, And Input Parameters}

The unsaturated soil profile was divided into four layers to facilitate modeling (Figure 8-13). Layers 1, 2, and 4 have the same geologic and hydrogeologic characteristics as noted below:

$$
\begin{aligned}
& \rho_{\mathrm{b}}=\text { Bulk density }=1.76 \mathrm{~g} / \mathrm{cm}^{3} \\
& \mathrm{n}=\text { Total porosity }=0.36 \\
& \theta_{\mathrm{r}}=\text { Residual water content }=19 \% \\
& \mathrm{ks}=\text { Saturated hydraulic conductivity }=1.53 \times 10^{-3} \mathrm{~cm} / \mathrm{s} .
\end{aligned}
$$

Layer 3 has somewhat different characteristics as given below:

$$
\begin{aligned}
\rho_{\mathrm{b}} & =\text { Bulk density }=1.60 \mathrm{~g} / \mathrm{cm}^{3} \\
\mathrm{n} & =\text { Total porosity }=0.4 \\
\theta_{\mathrm{r}} & =\text { Field capacity }=8.5 \% \\
\mathrm{ks} & =\text { Saturated hydraulic conductivity }=5.08 \times 10^{-3} \mathrm{~cm} / \mathrm{s} .
\end{aligned}
$$

Natural recharge was simulated by assigning a constant flux of $0.05 \mathrm{~cm} / \mathrm{yr}(0.02 \mathrm{in} / \mathrm{yr})$ at the ground surface. The water table was simulated by assigning a pressure head of zero at the bottom boundary. The plume created by the $435,000-\mathrm{L}(115,000$-gal) leak was assumed to occupy a rectangular area 57 by $20 \mathrm{~m}$ (187 by $66 \mathrm{ft}$ ) as shown in Figure 8-13. The highest concentration is assumed to exist at the horizontal center line of the rectangle. The concentration then decreases linearly to zero at the boundaries of the rectangle. This idealization of the initial distribution of the contaminants was considered solely for modeling purposes. In reality, the distribution of the contaminants may be different. 


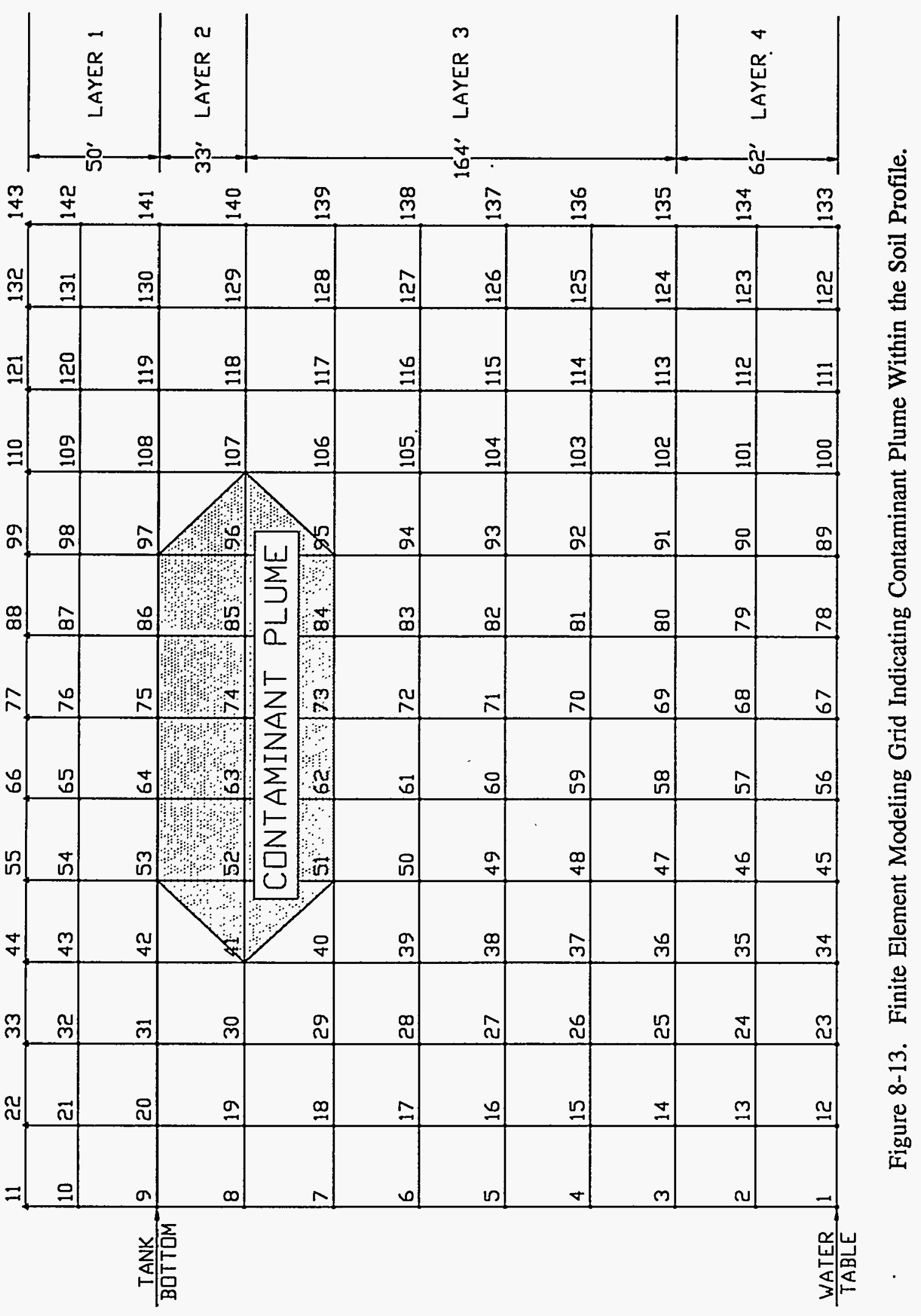


The domain of interest was discretized into four-noded rectangular finite elements as shown in Figure 8-13. The site specific relationships between hydraulic conductivity and water content, and water content and pressure head were developed by utilizing available data on saturated hydraulic conductivity, porosity, field capacity, and literature values of van Genuchten parameters representative of the site soil. These values are shown in Table 8-16. The hydraulic conductivity and water content characteristic curves for layers 1 through 4 developed using the van Genuchten model are presented in Figures 8-14 and 8-15, respectively.

Table 8-16. Parameters for Water Content and Hydraulic Conductivity Characteristic Curves.

\begin{tabular}{|c|c|c|c|c|c|}
\hline Layer & $\alpha$ & $\beta$ & $\gamma$ & $\begin{array}{c}\theta_{\mathrm{r}} \\
\text { Residual Water Content }\end{array}$ & $\begin{array}{c}\theta_{\text {Water Content }} \\
\text { at Saturation }\end{array}$ \\
\hline 1 & 0.145 & 2.68 & 0.62 & $19 \%$ & $36 \%$ \\
\hline 2 & 0.145 & 2.68 & 0.62 & $19 \%$ & $36 \%$ \\
\hline 3 & 0.145 & 2.68 & 0.62 & $8.5 \%$ & $42 \%$ \\
\hline 4 & 0.145 & 2.68 & 0.62 & $19 \%$ & $36 \%$ \\
\hline
\end{tabular}

The layers were considered homogeneous and isotropic. Therefore, the conductivity in the $\mathrm{x}$-direction was assumed to be the same as in the y-direction. All subsurface parameters were consistent with those used in the MEPAS evaluation with the exception of dispersivity. Dispersivity in the y-direction for each layer was assumed to be $3 \mathrm{~m} \mathrm{(10} \mathrm{ft)} \mathrm{with} 30.5 \mathrm{~mm}$ $(0.1 \mathrm{ft})$ in the $\mathrm{x}$-direction. A dispersivity of $3 \mathrm{~m}(10 \mathrm{ft})$ may not be considered appropriate. However, to suppress numerical oscillation in transport modeling such a high value was needed. It is not expected to impact the outcome of the comparative modeling because both cases use the same dispersivity value.

Initial head values were obtained by adding elevation heads to pressure heads of respective nodes. The pressure heads were obtained from the water content characteristic curves utilizing known nodal water contents. The initial heads for Case 1: Natural Recharge Only and Case 2: Natural Recharge Plus Leakage are presented in Appendix E. The water content for Case 2 was obtained by adding an additional $1.8 \%$ to the Case 1 water content in the $57-$ by $20-\mathrm{m}$ (187- by $66-\mathrm{ft}$ ) rectangular area as shown in Figures $8-13$. The increase of $1.8 \%$ in water content is attributable to a leak of $435,000 \mathrm{~L}(115,000 \mathrm{gal})$ of fluid from a underground tank. 
WHC-SD-WM-ES-300 REV. 1

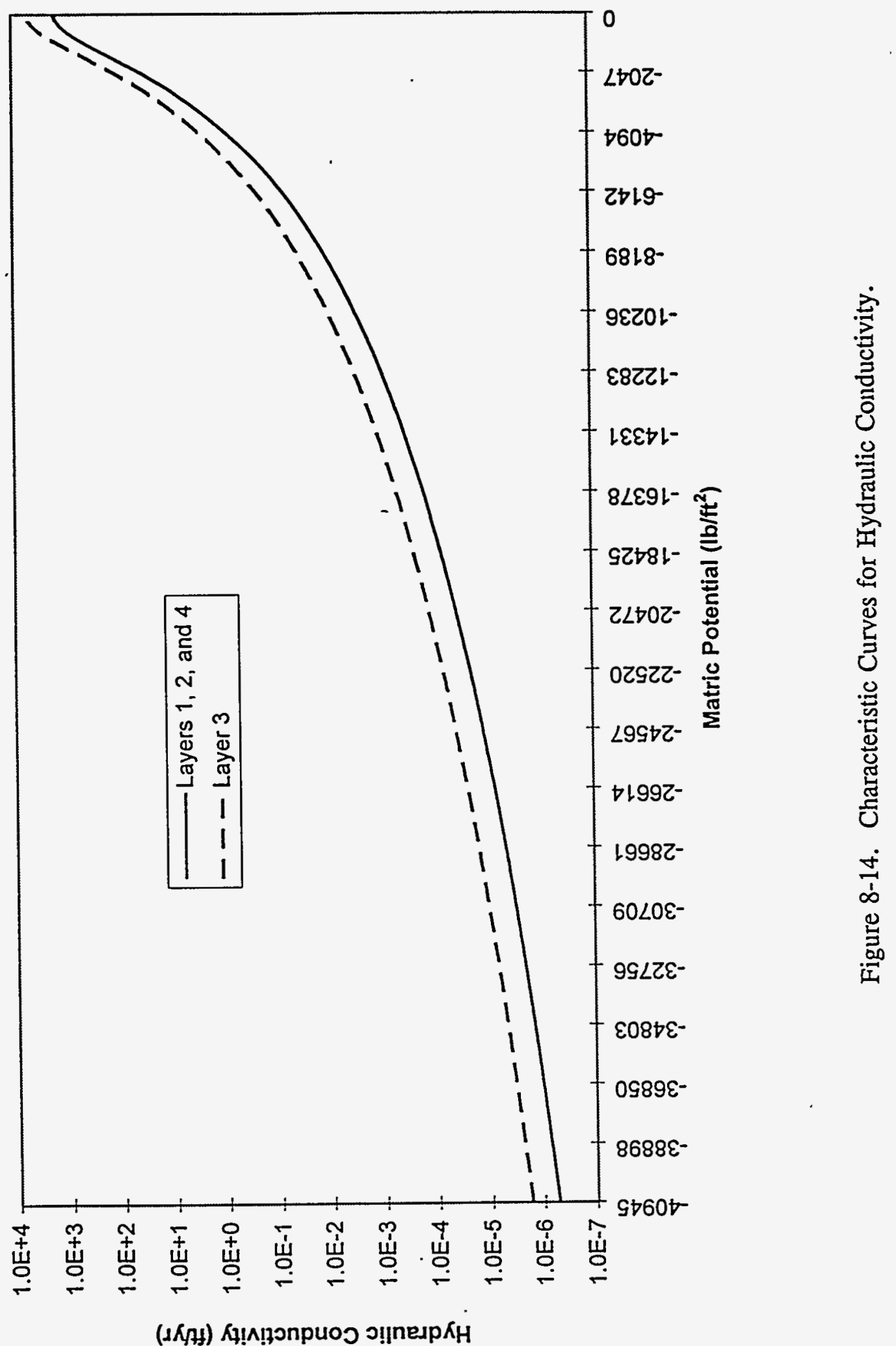




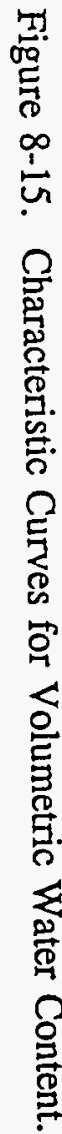

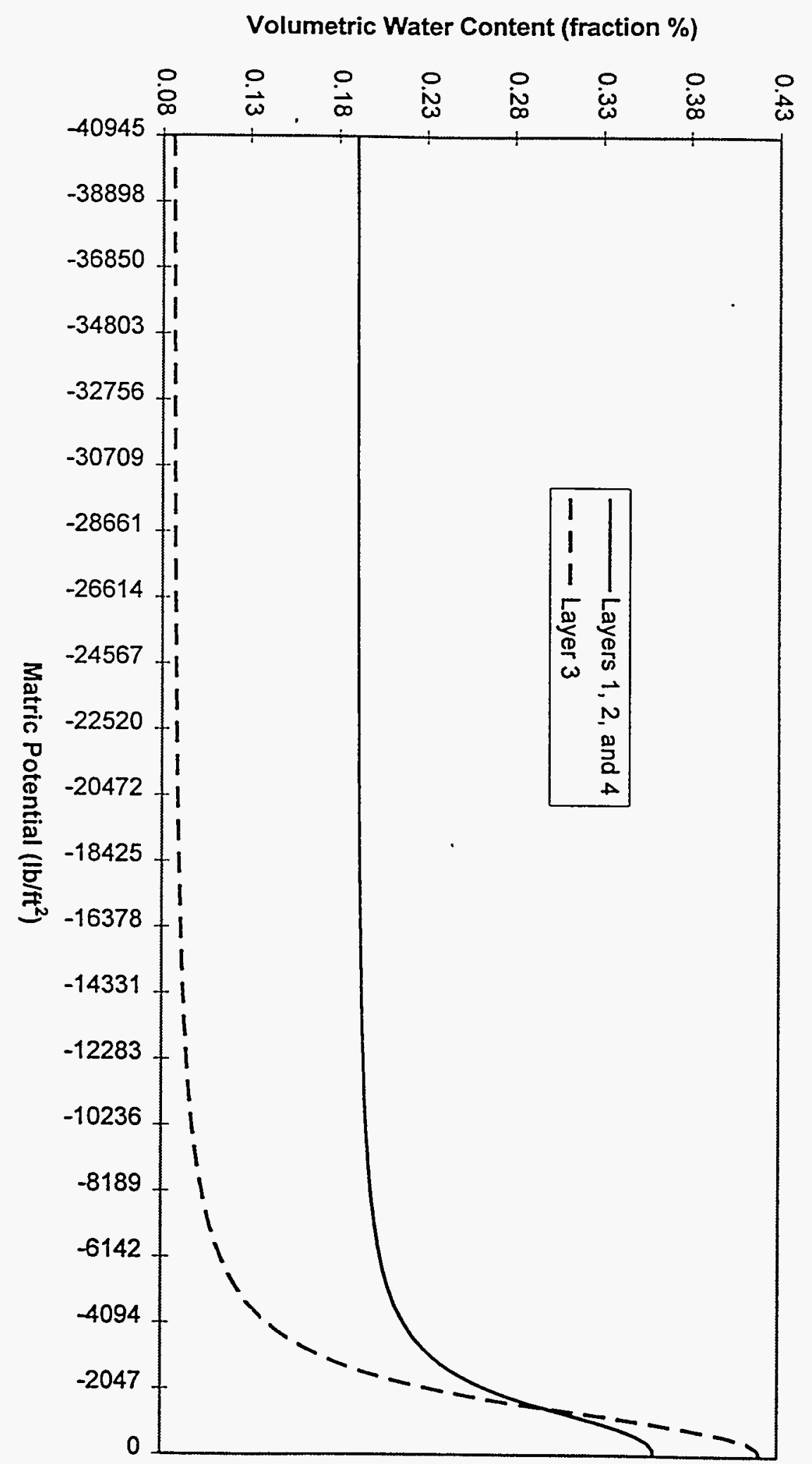




\section{Results And Discussion}

The approximate time required for the center of the contaminant plume to reach the water table was estimated by the method of particle tracking (Geo-Slope 1994). The center of the plume requires approximately 22,384 years to reach the water table under natural recharge conditions (Case 1) and 21,484 years when the leakage is considered. As expected, the additional water content, due to the leak, has accelerated the chemical transport as a result of a decrease in matric potentials. Particle tracking considers only advective transport associated with the bulk motion of flowing water. It does not consider dispersion-facilitated transport known to spread contaminants faster than the average plume velocity. Therefore, these estimates should be considered the upper bound of the time required by the center of the plume to travel to the water table.

The temporal variation of the contaminant flux at the bottom of the unsaturated zone was determined by running the models under transient conditions. The variation in the flux as a function of time for Case 1: Natural Recharge Only and Case 2: Natural Recharge Plus Leakage are shown in Figure 8-16. Data tables are presented in Appendix E. The concentrations at the center of the plume were $1 \mathrm{mg} / \mathrm{L}$ and $0.87 \mathrm{mg} / \mathrm{L}$ respectively. The horizontal center line of the existing plume is at the interface of layers 2 and 3 . It was assumed that the water content in the existing plume uniformly increased by $1.8 \%$ from its pre-leak conditions. The concentration of $0.87 \mathrm{mg} / \mathrm{L}$ was computed by conserving the chemical mass in the plume. It appears that the added water content resulted in an earlier breakthrough of the contaminant at bottom of the soil profile. The approximate time to breakthrough for Case 1 is 1,274 years with Case 2 requiring 885 years.

\section{Conclusions}

In the light of the above discussion, it can be concluded that the added water content, due to the leak, accelerates the migration of the chemical plume toward the water table. The acceleration is due to the decrease in matric potential as a result of an increase in the water content.

The change in the estimation of impacts on public health risk associated with reduced travel time to the groundwater is minimal. The very long travel times through the unsaturated and saturated zones are not significantly altered by the addition of the leak volume. 


\section{$8 t-8$}

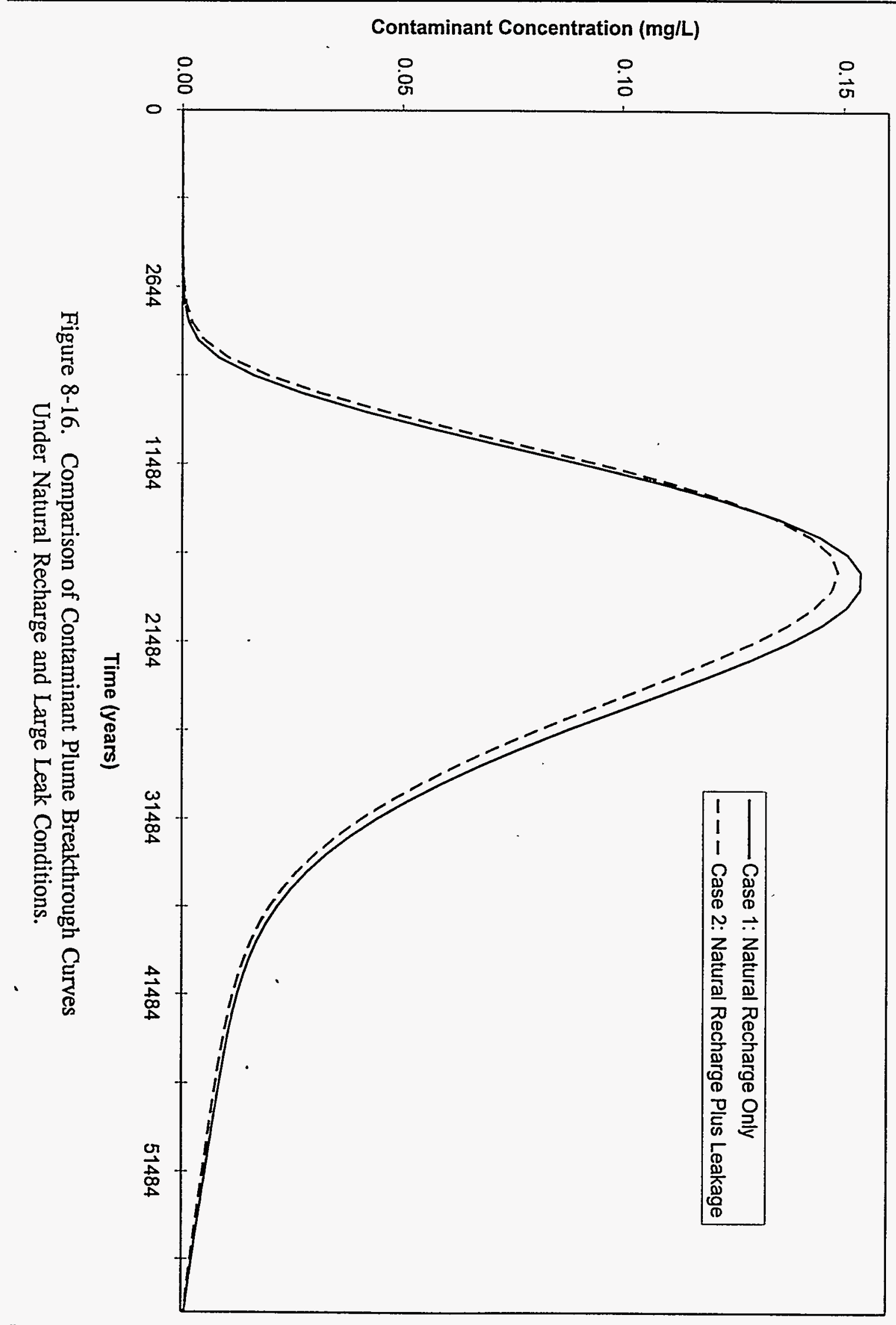




\subsection{ASSESSMENT OF RISKS TO WORKERS}

This section provides additional risk-based input to the evaluation of the feasibility of subsurface barriers. It supplements the evaluation of public health impact presented in Section 6 with an evaluation of potential health risks to workers involved in the implementation of 14 integrated alternatives described in Section 5 . The alternatives were defined based on combinations of waste retrieval, soil flushing, and barrier (surface and subsurface) technologies. A total of 21 technology options (A through $U$ ) were considered in developing the 14 alternatives. The technology options, shown in Table 9-1, also served as the bases for developing costs for the alternatives in Section 7. The 14 alternatives are listed in Table 9-2, which also identifies the technology options (A though $U$ ) included in each alternative. Because these technology options represent engineering concepts that have not yet been characterized beyond a pre-conceptual level of design detail, this assessment of potential risks to workers is strictly qualitative. Consistent with the objectives of this feasibility study, the results of this assessment are used solely for the purpose of initial comparisons between alternatives. The methods, data, and assumptions used to estimate worker risks are discussed in Section 9.1, and the results are presented in Section 9.2.

\subsection{METHODS, DATA, AND ASSUMPTIONS}

With the exception of the No Action and Surface Barrier Only Alternatives, the waste retrieval/barrier alternatives listed in Table 9-2 combine a number of technology options to form integrated alternatives. An assessment approach was developed to estimate worker risks for an integrated alternative as the sum of risks from each of the applicable technology options. Specific assessment methods selected were' consistent with the level of information presently available regarding the technology options. This assessment of potential risks to workers is necessarily qualitative, and does not attempt to address all potential risks to worker health and safety.

This section discusses the worker risks that were addressed in this assessment, and the risk factors that were used to estimate those risks. This section also discusses the characterization of technology options and worker risks at the technology option level.

\subsubsection{Risks and Risk Factors}

Potential risks to worker health and safety during implementation of the tank waste remediation alternatives can result from exposures to the following:

- Radioactive and hàzardous materials present in the tank wastes and the work environment

- Physical hazards associated with the work activities. 
WHC-SD-WM-ES-300 REV. 1

Table 9-1. Remedial Technology Options.

\begin{tabular}{|l|l|}
\hline No. & \multicolumn{1}{|c|}{ Remedial Technology Options } \\
\hline A & Traditional Sluicing \\
\hline B & Robotic Sluicing \\
\hline C & Mechanical Retrieval \\
\hline D & Close-Captured Barrier (around 12 tanks) \\
\hline E & Close-Captured Barrier (12 sides only) \\
\hline F & Close-Captured Barrier (around 7 tanks only) \\
\hline G & Box-Shaped Chemical Barrier \\
\hline H & V-Shaped Chemical Barrier \\
\hline I & V-Shaped Freeze Wall Barrier \\
\hline J & Circulating Air Barrier \\
\hline K & Vacuum Soil Flushing (for circulating Air Barrier) \\
\hline L & Vacuum Soil Flushing (for Close-Coupled Barrier) \\
\hline M & Traditional Flushing \\
\hline N & Flush Water Treatment (for Close-Coupled Barrier) \\
\hline O & Flush Water Treatment (for Box Barrier) \\
\hline P & Flush Water Treatment (for V-Shaped Barrier) \\
\hline Q & Flush Water Treatment (for Circulating Air Barrier) \\
\hline R & Tank Stabilization \\
\hline S & Surface Barrier \\
\hline T & Clean Closure (no barrier) \\
\hline U & Clean Closure (with Close-Coupled Barrier) \\
\hline & \\
\hline
\end{tabular}


WHC-SD-WM-ES-300 REV. 1

Table 9-2. Alternative Descriptions.

\begin{tabular}{|c|l|l|}
\hline $\begin{array}{c}\text { Alternative } \\
\text { Number }\end{array}$ & \multicolumn{1}{|c|}{ Alternative Descriptions } & \multicolumn{1}{|c|}{$\begin{array}{c}\text { Technology Options* } \\
\text { Included }\end{array}$} \\
\hline \hline 1 & No Action & None \\
\hline 2 & Surface Barrier Only & $\mathrm{S}$ \\
\hline 3 & Traditional Sluicing (Baseline) & $\mathrm{A}+\mathrm{R}+\mathrm{S}$ \\
\hline 4 & Robotic Sluicing & $\mathrm{B}+\mathrm{R}+\mathrm{S}$ \\
\hline 5 & Mechanical Retrieval & $\mathrm{C}+\mathrm{R}+\mathrm{S}$ \\
\hline 6 & $\begin{array}{l}\text { Close-Coupled Chemical Barrier with } \\
\text { Flushing }\end{array}$ & $\mathrm{A}+\mathrm{D}+\mathrm{L}+\mathrm{R}+\mathrm{S}$ \\
\hline 7 & $\begin{array}{l}\text { Close-Coupled Chemical Barrier w/o } \\
\text { Flushing }\end{array}$ & $\mathrm{A}+\mathrm{F}+\mathrm{R}+\mathrm{S}$ \\
\hline 8 & $\begin{array}{l}\text { Modified Close-Coupled Chemical } \\
\text { Barrier w/o Flushing }\end{array}$ & $\mathrm{A}+\mathrm{E}+\mathrm{R}+\mathrm{S}$ \\
\hline 9 & Box-Shaped Chemical Barrier & $\mathrm{A}+\mathrm{G}+\mathrm{O}+\mathrm{R}+\mathrm{S}$ \\
\hline 10 & V-Shaped Chemical Barrier & $\mathrm{A}+\mathrm{H}+\mathrm{P}+\mathrm{R}+\mathrm{S}$ \\
\hline 11 & V-Shaped Freeze Wall Barrier & $\mathrm{A}+\mathrm{I}+\mathrm{P}+\mathrm{R}+\mathrm{S}$ \\
\hline 12 & Circulating Air Barrier & $\mathrm{A}+\mathrm{J}+\mathrm{K}+\mathrm{R}+\mathrm{S}$ \\
\hline 13 & Clean-Closure w/o Subsurface Barrier & $\mathrm{A}+\mathrm{T}$ \\
\hline 14 & $\begin{array}{l}\text { Clean-Closure with Close-Coupled } \\
\text { Chemical Barrier }\end{array}$ & $\mathrm{A}+\mathrm{F}+\mathrm{U}$ \\
\hline & & \\
\hline
\end{tabular}

* Technology Options listed in Table 9-1. 
Exposures to radioactive and carcinogenic hazardous materials can result in an increased risk of illness and death from cancer, while exposure to noncarcinogenic hazardous materials can result in the occurrence of illness and death from toxic effects. The nature and potential magnitude of worker exposures to radioactive and hazardous materials in the work environment will be highly dependent on the specific design and operational characteristics of each option. Because the technology options are not fully characterized, a number of simplifying assumptions were made for the purpose of this initial evaluation of worker risks.

With regard to internal exposures to radioactive and hazardous materials (i.e., via ingestion, inhalation, or dermal absorption), it was assumed that engineering and procedural controls would be effective in preventing such exposures. This assumption is considered reasonable based on the general effectiveness of worker protection programs at the Hanford Site in preventing internal exposures during routine operations. Internal exposures to radioactive and hazardous materials can also occur as a result of equipment failures, operator errors, or other upset/accident conditions. However, while accident safety analyses are appropriate during the later stages of technology development, and may result in significant distinctions between technology options, they are beyond the scope of this initial evaluation. An interim quantitative risk analysis incorporating the results of pilot-scale testing could provide useful risk mitigation information before a full safety analysis report is available.

External exposures to radiation in the work environment are generally controlled through facility and process design features that reduce exposure rates, and operating procedures that reduce exposure frequencies and durations. While these factors are effective in maintaining worker external exposures within operating guidelines, it is generally not practical nor cost effective to reduce external exposures associated with these types of operations to background levels. For the purpose of this initial evaluation, it was assumed that standard design practices and radiation protection programs would be applied during the implementation of the technology options, and that external radiation doses would be similar to the historical averages for Hanford Site workers involved in comparable activities. Benchmarks used for estimating external radiation doses included $400 \mathrm{mrem} / \mathrm{yr}$ to operators and maintenance workers in highly radioactive facilities and $40 \mathrm{mrem} / \mathrm{yr}$ to management and engineering staffs in the same facilities (Boomer et al. 1993).

The range of physical hazards potentially present in the work environment includes heavy equipment operations, kinetic energy associated with power tools, high voltage, working at heights, and confined space entry. In addition to hazards in the work environment, hazards are also associated with vehicular travel to and from the work site. Exposure to work site and transportation hazards can result in a range of injuries, and in extreme instances, fatalities. Although DOE safety programs have been effective in maintaining occupational injury and fatality rates well below the national average, it is not possible to eliminate these hazards. For the purpose of this initial evaluation of alternatives, it was assumed that the incidence of injuries and fatalities during the implementation of the technology options is consistent with the historical averages for DOE workers involved in comparable activities. 
The specific methods and data used to estimate worker risks associated with transportation to and from the work site, physical hazards during work site operations, and external exposure to ionizing radiation are discussed in the following sections.

9.1.1.1 Transportation Risks. Transportation risks are defined as physical injuries and fatalities associated with the incidence of vehicular accidents during travel to and from the work site. Risks associated with vehicular transportation within the work site are addressed in Section 9.1.1.2. The risks of injury and fatality associated with vehicular transportation were calculated using risk factors based on statistics compiled by the U.S. Department of Transportation. These risk factors, in units of injuries per mile traveled and fatalities per mile traveled are shown in Table 9-3. The risks of injury and fatality were estimated by multiplying these factors by the total distance traveled. For the purposes of this analysis, it was assumed that the average Hanford Site worker would travel through two population zones (suburban and rural) enroute to the work site. It was further assumed that one-third of the route would be a suburban population zone, and the remaining two-thirds of the route would be a rural population zone. The resultant effective risk factors for this route are shown in the final column of Table 9-3. The transportation requirements of the technology options are described in Section 9.1.2. The application of the risk factors in estimating transportation risks associated with the technology options is discussed in Section 9.1.3.

Tạble 9-3. Unit-Risk Factors for Vehicular Transportation.

\begin{tabular}{|l|c|c|c|}
\hline \multirow{2}{*}{\multicolumn{1}{|c|}{ Risk }} & \multicolumn{3}{|c|}{ Population Zone } \\
\cline { 2 - 4 } & Suburban & Rural & Weighted Average $^{\mathbf{2}}$ \\
\hline \hline Fatalities per mile & $2.0 \times 10^{-9}$ & $8.1 \times 19^{-9}$ & $6.06 \times 10^{-9}$ \\
\hline Injuries per mile & $7.02 \times 10^{-9}$ & $1.51 . \times 10^{-8}$ & $1.24 \times 10^{-8}$ \\
\hline
\end{tabular}

${ }^{2}$ Weighted average $=33 \%$ suburban plus $67 \%$ rural risk factors.

9.1.1.2 Operational Risks. Operational risks are defined in terms of the injuries and fatalities associated with exposure to physical hazards in the work environment. For the purpose of this evaluation, injuries are defined as any reportable nonfatal injury or illness, with or without associated lost work time. The risks of injuries and fatalities associated with physical hazards in the work environment were estimated using factors based on statistics compiled by the DOE for its operations (DOE 1987), and by the National Safety Council (NSC) for commercial industries in the United States (NSC 1987, 1988, 1989, 1990, 1991). These factors, in units of injuries/person-year worked and fatalities/person-year worked, are strongly influenced by the nature and location of work activities.

For the purpose of this evaluation, workers and work activities associated with implementation of the technology options are categorized as follows. 
- Management and Engineering. These workers provide supervision, design, and engineering support. The work environment is assumed to be typical of an indoor office setting, with periodic visits to the field site/facility.

- Construction/Decommissioning Crafts and Laborers. These workers provide the construction, excavation equipment installation, and heavy equipment operations. The work environment is assumed to be typical of outdoor construction/earth moving and large facility construction projects. In the case of certain subsurface barrier technology options, the work environment may be similar to that of surface mining sites.

- Maintenance Crafts. These workers provide equipment and system repair and preventive maintenance. Typical craft-labor categories are millwright, pipefitter, and electrician. The work environment is assumed to be typical of that of operating radiological process facilities on the Hanford Site.

- $\quad$ Operators. These workers conduct routine facility operations and monitoring. Typical craft-labor categories include power-operator, nuclear-operator, and technician. Other onsite staff include test engineers and health physics technicians. The work environment is assumed to typical of that of operating radiological process facilities on the Hanford Site.

- Infrastructure Staff. These workers provide indirect infrastructure support to the operating facilities. Infrastructure staff typically work in offices in Richland; therefore, their exposure to risks common in operating facilities is limited. Typical worker categories include accountants, purchasers, and human resource specialists.

A summary of the injury and fatality risk factors for each of these worker categories, -in units of injuries/person-year worked and fatalities/person-year worked, is presented in Table 9-4. A summary of risk factors for each worker category and each technology option is included in Appendix D.1. Single factors are presented for management and engineering workers, based on statistics compiled by the NSC for the "services" industry. Two sets of factors are presented for construction/decommissioning crafts and laborers based on statistics compiled by the NSC for (1) "construction" industries and (2) "mining" industries. The NSC statistics were compiled for the period 1985 to 1989 for injuries, and 1985 to 1990 for fatalities. A single set of factors are presented for the maintenance crafts and operators categories, based on statistics compiled by the DOE for its operating sites during the period 1976 through 1981 (DOE 1982). 
Table 9-4. Physical Hazard Risk Factors.

\begin{tabular}{|l|c|c|}
\hline \multicolumn{1}{|c|}{ Workers } & Injuries/Person-Year & Fatalities/Person-Year \\
\hline \hline $\begin{array}{l}\text { Management and } \\
\text { Engineering }\end{array}$ & 0.028 & 0.00005 \\
\hline $\begin{array}{l}\text { Construction/ } \\
\text { Decommissioning Crafts } \\
\text {-Construction } \\
\text {-Mining }\end{array}$ & 0.080 & \\
\hline Maintenance Crafts & 0.035 & 0.00035 \\
\hline Operators & 0.011 & 0.00040 \\
\hline
\end{tabular}

The collective work force risks of injury and fatality were estimated by multiplying these factors by the person-years in each worker category. The work force requirements of the technology options are described in Section 9.1.2, while the application of the risk factors in estimating operational risks associated with the technologies is discussed in Section 9.1.3.

9.1.1.3 External Radiation Risks. Radiation risk is defined in terms of the incremental increase in lifetime risk of fatality from cancer (cancer risk) as a result of external exposure to ionizing radiation. Individual cancer risk is calculated as the product of annual external radiation dose (rem), multiplied by a cancer risk conversion factor (risk/rem per year). Collective cancer risk is calculated as the product of individual cancer risk multiplied by the number of exposed individuals.

The cancer risk conversion factor used in this evaluation is $2.5 \times 10^{-4} \mathrm{rem}^{-1}$ (NRC 1990). The annual external radiation doses to technology option workers are discussed in Section 9.1.2, and the application of the risk factor in estimating the cancer risks associated with the technologies is discussed in Section 9.1.3.

\subsubsection{Characterization of Technology Options.}

As described in Section 9.1.1, worker risks were evaluated in terms of (1) injuries and fatalities associated with vehicular transportation to and from the work site, (2) injuries and fatalities associated with exposure to physical hazards within the work environment, and (3) cancer risk associated with external exposure to ionizing radiation. The estimation of these risks necessitates the characterization of the technology options relative to the following:

- Vehicular mileage to and from the work site for the calculation of injuries and fatalities associated with vehicle accidents 
- Work force requirements (person-years) associated with the technology options for the calculation of injuries and fatalities associated with exposure to physical hazards in the work environment

- Annual external radiation doses (rem/year) associated with the technology options for the calculation of cancer risks.

9.1.2.1 Vehicular Mileage. Vehicular mileage associated with travel to and from the work site was estimated based on an average one-way distance of 30 miles. Based on 50 workweeks per year, and 5 work days per week, the annual mileage per work-year is calculated to be 15,000 miles. A second mileage allowance was made for the vehicular transport associated with infrastructure workers indirectly associated with the technology options. The annual mileage for infrastructure staff was estimated to be 4,000 miles per work-year based on 16 miles round trip per work day.

9.1.2.2 Work Force Requirements. Work force requirements were estimated for each of the technology options and for each of the five worker categories described earlier. To facilitate the development of those estimates, each technology option was evaluated relative to the following life-cycle phases.

- Technology Readiness. This phase includes technology development and demonstration, and preparation of pre-construction documents including engineering studies, safety analysis reports, and National Environmental Policy Act documents. Management and engineering workers dominate this phase.

- Capital. This phase provides the capital design and construction efforts associated with implementation of the technology option. This phase includes Title I and II design, site preparation, excavation, construction, equipment installation, and operational testing. Construction crafts and laborers dominate this phase.

- Operations and Maintenance. This phase provides the efforts associated with operation, maintenance, and monitoring of the processing facilities. Operators and maintenance crafts dominate this phase.

- Decontamination and Decommissioning. This phase provides the facility D\&D efforts following completion of operations. Construction crafts and laborers dominate this phase. 
Work force requirements, and life-cycle phase durations, were estimated for each of the technology options based on engineering studies and data developed for the Tank Waste Technical Options Report (Boomer et al. 1993). Work force estimates (person-years) and phase durations (years) are tabulated in Appendix D.2 for each of the 21 technology options. Infrastructure work force requirements were estimated as $50 \%$ of the direct work force. Work force requirements for each technology option are summarized in Tables 9-5 and 9-6. Table 9-5 divides the work force among the four life-cycle phases and Table 9-6 divides the work force among the four primary worker categories. Total work force for each, alternative is summarized in Table 9-7.

9.1.2.3 External Radiation Dose. Annual external radiation doses were estimated for each worker category and life-cycle phase of the 21 technology options. These estimates were developed based on characteristics of the technology options, and actual radiation doses observed during past Hanford Site operations with similar characteristics. The estimates of annual dose (mrem) for each worker category and life-cycle phase are tabulated in Appendix D. 2 for each of the 21 technology options.

\subsubsection{Risk Characterization}

Worker risks were estimated for each of the technology options listed in Table 9-1. As indicated in Section 9.1.1, these risks were evaluated in terms of (1) the number of work force injuries and fatalities associated with vehicular transportation and physical hazards in the work environment, and (2) the collective cancer fatality risk associated with external exposure to penetrating radiation. The estimates were calculated using risk factors based on statistics compiled by the DOE for its operations, and by the NSC for commercial industries in the United States, and characteristics of the technology options relative to vehicular transportation mileage, work force person-years, and annual radiation dose.

For the purpose of this evaluation, injuries are defined as reportable injuries, whether or not they involve lost work time. The incremental lifetime risk of cancer fatality was estimated for individuals within the work force, and the collective cancer risk was calculated by multiplying the individual risk by the size of the work force. The calculational process used is depicted in Table 9-8, and the results of the calculations for technology options are summarized in Table 9-9. Full details of these technology option risk calculations are tabulated in Appendix D.3.

The options that ranked first and second (highest and second highest risk) across all technologies in terms of highest risk were the two clean closure options, $T$ and $U$. These rankings reflect the significantly greater work force requirements associated with these options in all four life-cycle phases and all four worker categories. For both options, approximately $50 \%$ of the fatalities are attributable to vehicular transportation, with the remainder attributable to the capital phase (30\%), operating phase (12\%), and D\&D phase (10\%). For both options, approximately $45 \%$ of the injuries are attributable to the capital phase, and approximately $40 \%$ to the operating phase. Approximately $68 \%$ of the cancer 
Table 9-5. Life-Cycle Work Force Requirements for Technology Options (person-years).

\begin{tabular}{|c|c|c|c|c|c|}
\hline \multirow[b]{2}{*}{ Technology Option } & \multicolumn{4}{|c|}{ Life Cycle Phases (1) } & \multirow[b]{2}{*}{ TOTAL } \\
\hline & $\begin{array}{l}\text { Technology } \\
\text { Readiness }\end{array}$ & Capital & $\begin{array}{l}\text { Operations \& } \\
\text { Maintenance }\end{array}$ & $\begin{array}{c}\text { Decontamination \& } \\
\text { Decommissioning }\end{array}$ & \\
\hline A. Traditional Sluicing & 16 & 319 & 368 & 24 & 727 \\
\hline B. Robotic Sluicing & 147 & 933 & 3,112 & 414 & 4,606 \\
\hline C. Mechanical Retrieval & 123 & 785 & 3,112 & 414 & 4,434 \\
\hline D. Close-Coupled Chemical Barrier (around 12 tanks) & 107 & 1,076 & 465 & 0 & 1,648 \\
\hline E. Close-Coupled Chemical Barrier (12 sides only) & 57 & 565 & 465 & 0 & 1,087 \\
\hline F. Close-Coupled Chemical Barrier (around 7 tanks only) & 107 & 738 & 465 & 0 & 1,310 \\
\hline G. Box-Shaped Chemical Barrier & 107 & 1,111 & 465 & 0 & 1,683 \\
\hline H. V-Shaped Chemical Barrier & 107 & 1,596 & 465 & 0 & 2,168 \\
\hline I. V-Shaped Freeze Wall Barrier & 97 & 1,060 & 945 & 63 & 2,165 \\
\hline J. Circulating Air Barrier & 32 & 361 & 945 & 63 & 1,401 \\
\hline K. Vacuum Soil Flushing (for Circulating Air Barrier) & 81 & 642 & 945 & 63 & 1,731 \\
\hline L. Vacuum Soil Flushing (for Close-Coupled Barrier) & 81 & 545 & 945 & 63 & 1,634 \\
\hline M. Traditional Flushing & 49 & 468 & 820 & 54 & 1,391 \\
\hline N. Flush Water Treatment (for Close-Coupled Barrier) & 16 & 40 & 153 & 20 & 229 \\
\hline O. Flush Water Treatment (for Box Barrier) & 16 & 223 & 810 & 110 & 1,159 \\
\hline P. Flush Water Treatment (for V-Shaped Barrier) & 16 & 238 & 887 & 118 & 1,259 \\
\hline Q. Flush Water Treatment (for Circulating Air Barrier) & 16 & 70 & 265 & 36 & 387 \\
\hline R. Tank Stabilization & 8 & 10 & 30 & 0 & 48 \\
\hline S. Surface Barrier & 16 & 20 & 30 & 0 & 66 \\
\hline T. Clean Closure (no barrier) & 165 & 3,723 & 5,615 & 760 & 10,263 \\
\hline U. Clean Closure (with Close-Coupled Chemical Barrier) & 165 & 2,978 & 5,577 & 746 & 9,466 \\
\hline
\end{tabular}

(1) Does no include infrastructure Supporh estimaed at $50 \%$ of faclity work force. 
Table 9-6. Worker Category Requirements for Technology Options (person-years).

\begin{tabular}{|c|c|c|c|c|c|}
\hline \multirow[b]{2}{*}{ Technology Option } & \multicolumn{4}{|c|}{ Worker Category (1) } & \multirow[b]{2}{*}{ TOTAL } \\
\hline & $\begin{array}{c}\text { Management and } \\
\text { Engineering }\end{array}$ & $\begin{array}{c}\text { Construction } \\
\text { Decommissioning } \\
\text { Crafts and Laborers } \\
\end{array}$ & $\begin{array}{c}\text { Maintenance } \\
\text { Crafts } \\
\end{array}$ & Operators & \\
\hline A. Traditional Sluicing & 359 & 145 & 74 & 149 & 727 \\
\hline B. Robotic Sluicing & 2,039 & 659 & 622 & 1,286 & 4,606 \\
\hline C. Mechanical Retrieval & 1,932 & 594 & 622 & 1,286 & 4,434 \\
\hline D. Close-Coupled Chemical Barrier (around 12 tanks) & 912 & 457 & 93 & 186 & 1,648 \\
\hline E. Close-Coupled Chemical Barrier (12 sides only) & 568 & 240 & 93 & 186 & 1,087 \\
\hline F. Close-Coupled Chemical Barrier (around 7 tanks only) & 709 & 322 & 93 & 186 & 1,310 \\
\hline G. Box-Shaped Chemical Barrier & 933 & 471 & 93 & $186^{\circ}$ & 1,683 \\
\hline II. V-Shaped Chemical Barrier & 1,224 & 665 & $\cdot 93$ & 186 & 2.168 \\
\hline I. V-Shaped Freeze Wall Barrier & 1,106 & 486 & 189 & 384 & 2,165 \\
\hline J. Circulating Air Barrier & 638 & 190 & 189 & 384 & 1,401 \\
\hline K. Vncuum Soil Flushing (for Circulating Air Barrier) & 843 & 315 & 189 & 38.4 & 1,731 \\
\hline L. Vacuum Soil Flushing (for Close-Coupled Barrier) & 785 & 276 & 189 & 384 & 1,634 \\
\hline M. Traditional Flushing & 662 & 232 & 164 & 333 & 1,391 \\
\hline N. Flush Water Treatment (for Close-Coupled Barrier) & 103 & 32 & 31 & 63 & 229 \\
\hline O. Flush Water Treatment (for Box Barrier) & 501 & 159 & 166 & 333 & 1,159 \\
\hline P. Flush Water Treatment (for V-Sllaped Barrier) & 545 & 170 & 177 & 367 & 1,259 \\
\hline Q. Flush Water Treatment (for Circulating Air Barricr) & 171 & 53 & 53 & 110 & 387 \\
\hline R. Tank Stabilization & 24 & 6 & 6 & 12 & 48 \\
\hline S. Surface Barrier & 36 & 12 & 6 & 12 & 66 \\
\hline T. Clean Closure (no bartier) & 4,833 & 1,988 & 1.123 & 2,319 & 10,263 \\
\hline U. Clean Closure (with Close-Coupled Chemical Barrier) & 4,367 & 1,681 & 1,115 & 2,303 & 9,466 \\
\hline
\end{tabular}

(1) Does not include Infmstructure Support, estumated at $50 \%$ of facilty work force. 
WHC-SD-WM-ES-300 REV. 1

Table 9-7. Worker Category Requirements for Alternatives (person-years).

\begin{tabular}{|c|c|c|c|c|c|}
\hline \multirow[b]{2}{*}{ Alternative } & \multicolumn{4}{|c|}{ Worker Category (1) } & \multirow[b]{2}{*}{ TOTAL } \\
\hline & $\begin{array}{c}\text { Management and } \\
\text { Engineering } \\
\end{array}$ & $\begin{array}{c}\text { Construction/ } \\
\text { Decommissioning } \\
\text { Crafts and Workers } \\
\end{array}$ & $\begin{array}{c}\text { Maintenance } \\
\text { Crafts } \\
\end{array}$ & Operators & \\
\hline 1. No-Action & 0 & 0 & 0 & 0 & 0 \\
\hline 2. Suface Barrier Only & 36 & 12 & 6 & 12 & 66 \\
\hline 3. Traditional Sluicing & 419 & 163 & 86 & 173 & 841 \\
\hline 4. Robotic Sluicing & 2,099 & 677 & 634 & 1,310 & 4,720 \\
\hline 5. Mechanical Retrieval & 1,992 & 612 & 634 & 1,310 & 4,548 \\
\hline $\begin{array}{l}\text { 6. Close-Coupled Chemical Barrier with } \\
\text { Flushing }\end{array}$ & 2,116 & 896 & 368 & 743 & 4,123 \\
\hline $\begin{array}{l}\text { 7. Close-Coupled Chemical Barrier } \\
\text { without Flushing }\end{array}$ & 1,128 & 485 & 179 & 359 & 2,151 \\
\hline $\begin{array}{l}\text { 8. Modified Close-Coupled Chemical } \\
\text { Barrier without Flushing }\end{array}$ & 987 & 403 & 179 & 359 & 1,928 \\
\hline 9. Box-Shaped Chemical Barrier & 1,853 & 793 & 345 & 692 & 3,683 \\
\hline 10. V-Shaped Chemical Barrier & 2,188 & 998 & 356 & 726 & 4,268 \\
\hline 11. V-Shaped Freeze Wall Barrier & 2,070 & 819 & 452 & 924 & 4,265 \\
\hline 12. Circulating Air Barrier & 1,900 & 668 & 464 & 941 & 3,973 \\
\hline 13. Clean-Closure without Barrier & 5,192 & 2,133 & 1,197 & 2,468 & 10,990 \\
\hline $\begin{array}{l}\text { 14. Clean-Closure with Close-Coupled } \\
\text { Chemical Barrier }\end{array}$ & 5,435 & 2,148 & 1,282 & 2,638 & 11,503 \\
\hline
\end{tabular}

(1) Does not include infrastructure Support, estumated as 50\% of faclity work force. 
Table 9-8. Risk Calculation Approach.

\begin{tabular}{|c|c|c|c|c|c|c|c|c|c|c|}
\hline \multirow{4}{*}{ Activity } & \multicolumn{10}{|c|}{ Workers (Typical) } \\
\hline & \multicolumn{5}{|c|}{ Annual } & \multicolumn{5}{|c|}{ Total } \\
\hline & \multicolumn{2}{|c|}{ Transportation } & \multicolumn{3}{|c|}{ Operation } & \multicolumn{2}{|c|}{ Transportation } & \multicolumn{3}{|c|}{ Operation } \\
\hline & Death & Injury & Death & Injury & Dose & Death & Injury & Death & Injury & Dose \\
\hline Technology Readiness & A & B & $\mathrm{C}$ & D & $\mathrm{E}$ & $\mathrm{F}$ & G & $\mathrm{H}$ & I & $\mathrm{J}$ \\
\hline Capital & A & B & $\mathrm{C}$ & D & E & $\mathrm{F}$ & G & $\mathrm{H}$ & I & $\mathrm{J}$ \\
\hline $\begin{array}{l}\text { Operations \& } \\
\text { Maintenance }\end{array}$ & A & B & $C^{\prime}$ & D & $\mathrm{E}$ & F & G & $\mathrm{H}$ & I & $\mathrm{J}$ \\
\hline $\begin{array}{l}\text { Decontamination } \\
\text { \& Decommissioning }\end{array}$ & A & B & C & D & $\mathrm{E}$ & $\mathrm{F}$ & G & $\mathrm{H}$ & I & $\mathrm{J}$ \\
\hline TOTAL & & मै। & : & : & (1) & $\Sigma F$ & $\Sigma \mathrm{G}$ & $\Sigma \mathrm{H}$ & $\Sigma \mathrm{I}$ & $\Sigma \mathrm{J}$ \\
\hline
\end{tabular}

$\mathrm{A}=[$ (person-years/duration $) *($ miles/person-years $)] *(\mathrm{RF}$ death risk/milc)

$\mathrm{B}=[$ (person-years/duration) $*$ (miles/person-ycars $)] *(\mathrm{RF}$ injury risk/mile $)$

$\mathrm{C}=$ (person-years/duration $) *(\mathrm{RF}$ death risk/person-years $)$

$\mathrm{D}=$ (person-years/duration $) *(\mathrm{RF}$ injury risk/person-years $)$

$\mathrm{E}=($ person-years/duration $) *($ annual dose/worker $) *(\mathrm{RF}$ cancer risk/REM $) * 0.001$

$\mathrm{F}=\mathrm{A} *$ activity duration

$\mathrm{G}=\mathrm{B} *$ activity duration

$\mathrm{H}=\mathrm{C} *$ activity duration

$\mathrm{I}=\mathrm{D} *$ activity duration

$\mathrm{J}=\mathrm{E} *$ activity duration

$\mathrm{RF}=$ Risk Factor

Assumptions:

- Transportation is to and from the site only

- Operational risks encompass industrial/physical hazards associated with equipment operation and onsite operations

- Infrastructure staff support the staff above. They receive no annual Cancer risk, average 4,000 travel miles, and average $50 \%$ of the facility totals above

- Collective risks have been calculated as the product of individual risk, multiplied by the number of exposed individuals. Individual risks provide estimates of the probability of health detriment for the individual, and the collective risks provide a measure of overall detriment to the work force. 


\section{WHC-SD-WM-ES-300 REV. 1}

Table 9-9. Total Worker Risks Associated with Technology Options (1).

\begin{tabular}{|c|c|c|c|}
\hline Option & $\begin{array}{c}\text { Number of } \\
\text { Fatalities }\end{array}$ & $\begin{array}{l}\text { Number of } \\
\text { Injuries }\end{array}$ & $\begin{array}{c}\text { Collective } \\
\text { Cancer Risk }\end{array}$ \\
\hline A. Traditional Sluicing & 0.15 & 24 & $3.5 \mathrm{E}-02$ \\
\hline B. Robotic Sluicing & 0.89 & 130 & $2.6 \mathrm{E}-01$ \\
\hline C. Mechanical Retrieval & 0.85 & 120 & $2.6 \mathrm{E}-01$ \\
\hline D. Close-Coupled Chemical Barrier (around 12 tanks) & 0.41 & 45 & $5.6 \mathrm{E}-02$ \\
\hline E. Close-Coupled Chemical Barrier (12 sides only) & 0.25 & 28 & $3.1 \mathrm{E}-02$ \\
\hline F. Close-Coupled Chemical Barrier (around 7 tanks only) & 0.31 & 34 & $4.3 \mathrm{E}-02$ \\
\hline G. Box-Shaped Chemical Barrier & 0.40 & 67 & $4.0 \mathrm{E}-() 2$ \\
\hline H. V-Shaped Chemical Barrier & 0.53 & 91 & $5.1 \mathrm{E}-02$ \\
\hline I. V-Shaped Freeze Wall Barrier & 0.47 & 77 & $5.8 \mathrm{E}-02$ \\
\hline J. Circulating Air Barrier & 0.27 & 40 & $+.2 \mathrm{E}-(02$ \\
\hline K. Vacuum Soil Flushing (for Circulating Air Barrier) & 0.36 & 55 & $9.2 \mathrm{E}-(\mathbf{2} 2$ \\
\hline L. Vacuum Soil Flushing (for Close-Coupled Chemical Barri & 0.33 & 51 & $8.8 \mathrm{E}-() 2$ \\
\hline M. Traditional Flushing & 0.29 & 32 & $+.7 \mathrm{E}-() 2$ \\
\hline N. Flush Water Treatment (for Close-Coupled Chemical Barr & 0.044 & 6.5 & $1.1 \mathrm{E}-() 2$ \\
\hline O. Flush Water Treatment (for Box-Shaped Barrier) & 0.22 & 32 & 4.7E-(1)2 \\
\hline P. Flush Water Treatment (for V-Shaped Barrier) & 0.24 & 35 & $5.1 \mathrm{E}-(1) 2$ \\
\hline Q. Flush Water Treatment (for Circulating Air Barrier) & 0.074 & 11 & $2.0 \mathrm{E}-02$ \\
\hline R. Tank Stabilization & 0.0091 & 1.4 & $1.2 \mathrm{E}-0) 3$ \\
\hline S. Surface Barrier & 0.014 & 2.2 & $8.0 \mathrm{E}-04$ \\
\hline T. Clean Closure (no barrier) & 2.2 & 240 & $5.3 \mathrm{E}-01$ \\
\hline U. Clean Closure (with Close-Coupled Chemical Barrier) & 2.0 & 220 & $5.0 \mathrm{E}-01$ \\
\hline
\end{tabular}

(1) Basis: One SST tank farm with 12 tanks 
phase, and approximately $40 \%$ to the operating phase. Approximately $68 \%$ of the cancer risk is attributable to the operating phase while $22 \%$ is attributable to the capital phase.

Of the three waste retrieval technologies (options A, B, and C), Robotic Sluicing (option B) ranked first in risk in all three risk categories. Approximately half the fatalities for this option are attributable to vehicular transportation, with the capital and operational phases contributing equally to the remainder. Approximately $42 \%$ of the injuries are attributed to the operating phase with approximately $35 \%$ and $18 \%$ attributed to the capital and D\&D phases, respectively. Approximately $75 \%$ of the cancer risk is attributable to the operating phase. Robotic sluicing presented the highest risk compared to traditional sluicing and mechanical retrieval because it has the highest work force requirement performing high risk activities.

Of the seven subsurface barrier technologies (options D through J), the V-Shaped Chemical Barrier and V-Shaped Freeze Wall Barrier (options H and I) ranked first and second respectively in the fatality and injury risk categories. For both options, approximately $40 \%$ of the fatalities are attributable to vehicular transportation, with the capital phase contributing the remainder. For the V-Shaped Chemical Barrier, approximately $85 \%$ of the injuries are attributable to the capital phase. In the case of the V-Shaped Freeze Wall Barrier, approximately $67 \%$ of the injuries are attributable to the capital phase while $22 \%$ are attributable to the operating phase, reflecting the increased operational requirements associated with that option. The V-Shaped Freeze Wall Barrier option ranked first in the cancer risk category, with approximately $55 \%$ attributable to the operating phase, again reflecting the increased operational requirements associated with that option. The CloseCoupled Chemical Barrier (option D) ranked second in the cancer risk category, with approximately $70 \%$ attributable to the capital phase, reflecting the increased external dose rates associated with installation of the barrier in proximity to the tank.

Of the seven soil flushing technologies (options $\mathrm{K}$ through $\mathrm{Q}$ ), the two Vacuum Soil Flushing Options (options $\mathrm{K}$ and $\mathrm{L}$ ) ranked first and second respectively in all three risk categories. For both options, approximately $50 \%$ of the fatalities are attributable to vehicular transportation, with the capital phase contributing the majority of the remainder. For both options, approximately $56 \%$ of the injuries are attributable to the capital phase, and $30 \%$ to the operating phase. For both options approximately $65 \%$ of the cancer risk is attributable to the operating phase, with approximately $30 \%$ to the capital phase.

\subsection{RESULTS}

The integrated alternatives combine various technology options associated with (1) waste retrieval, (2) subsurface barrier, (3) soil flushing, and (4) surface barrier to form 14 complete remediation alternatives listed in Table 9-2. The risks associated with these complete alternatives were derived by summing the risks associated with individual technology options. 
The worker risks estimated for the 14 alternatives, in terms of fatalities, injuries, and cancer risk, are summarized in Tables 9-10 through 9-12. Risks shown in these tables are based on retrieval of wastes from one tank farm. Overall risks would be about $12 \mathrm{X}$ higher due to the presence of 12 SST tank farms at the Hanford Site. Full details of the alternative risks are tabulated in Appendix D.4. As discussed below, these results reflect differences between the alternatives in two key areas: (1) work force requirements (person-years), and (2) proximity/duration of exposure to the tank wastes.

The alternatives that ranked first and second across all alternatives in terms of worker risk were the clean closure alternatives (13 and 14). For both alternatives, approximately $48 \%$ of the fatalities are attributable to vehicular transport, while $30 \%$ are attributable to the capital phase. The capital and operational phases combine to produce approximately $90 \%$ of the estimated injuries. Greater than $60 \%$ of the cancer risk associated with these two alternatives is attributable to the operations phase. These alternatives, and their technology options $\mathrm{T}$ and $\mathrm{U}$, feature the maximum work force requirements, proximity to the tank wastes, and duration of near-tank operations.

Of the seven waste retrieval/barrier alternatives (Alternatives 6 through 12), the V-Shaped Chemical Barrier with Flush Water Treatment (Alternative 10) ranked first in the fatality and injury risk categories, and third across all alternatives in those risk categories. This alternative uses technology option $\mathrm{H}$ (V-Shaped Chemical Barrier) which ranked highest among the barrier options in fatalities and injuries, based on work force requirements. Approximately $46 \%$ of the fatalities are attributable to vehicular transportation, with the capital phase accounting for approximately $39 \%$. Approximately $70 \%$ of the injuries are attributable to the capital phase, with $20 \%$ attributable to operations. The Close-Coupled Chemical Barrier with Flushing (Alternative 6) ranked first in the cancer risk category, and third across all alternatives in that risk category. This alternative uses technology option D (Close-Coupled Chemical Barrier) which ranked second highest among the barrier options in cancer risk, based on proximity to the tank wastes. Approximately 55\% of the cancer risk is attributable to the operations phase, with the capital phase contributing approximately $41 \%$.

Of the three retrieval alternatives that do not use subsurface barriers (Alternatives 3 , 4 , and 5), the Robotic Sluicing Alternative (Alternative 4) ranked highest in all risk categories, and fourth across all alternatives in the fatality and injury risk categories, based on work force requirements. This alternative also ranked third across all alternatives in the cancer risk category, using the robotic sluicing technology (option B), which ranked third across all options, for all three risk categories, based on work force requirements and proximity to the tank wastes. Approximately $53 \%$ of the fatalities are attributable to vehicular transportation, with the remainder attributable to the capital phase (17\%), operating phase (16\%), and D\&D phase $(10 \%)$. Approximately $40 \%$ of the injuries are attributable to the operating phase, with $35 \%$ attributable to capital, and $18 \%$ to D\&D. Approximately $77 \%$ of the cancer risk is attributable to the operating phase for this alternative with the remainder approximately equally divided between capital and D\&D phases. Fatalities, injuries, and collective cancer risks for the alternatives are summarized relative to risks for the Traditional (Baseline) Alternative in Table 9-13. 
Table 9-10. Fatality Risks Associated with Alternatives (number of fatalities) (1).

Vehicular

Transpor- Technology

Alternative

tation

Readiness

Capital

Operations

D\&D

TOTAL

1. No-Action

0

0

0

0

0

0

2. Suface Barrier Only

$6: 8 \mathrm{E}-03 \quad 2.0 \mathrm{E}-03$

$3.4 \mathrm{E}-03$

$1.4 \mathrm{E}-03$

0

1.4E-02

3. Traditional Sluicing

8.7E-02 $\quad 5.0 \mathrm{E}-03$

$5.9 \mathrm{E}-02$

$2.0 \mathrm{E}-02$

$5.7 \mathrm{E}-03$

$1.8 \mathrm{E}-01$

4. Robotic Sluicing

4.9E- 01

2.1E-02

1.6E-01

1.5E-01

9.5E-02

9.2E-01

5. Mechanical Retrieval

$4.7 \mathrm{E}-01 \quad 1.8 \mathrm{E}-02$

$1.4 \mathrm{E}-01$

1.5E-01

9.5E-02

8.7E-01

6. Close-Coupled Chemical

4.2E-01

3.0E-02

$3.6 \mathrm{E}-01$

$8.6 \mathrm{E}-02$

2.0E-02

$9.2 \mathrm{E}-01$

Barrier with Flushing

7. Close-Coupled Chemical

2.2E-0

2.0E-02

2.0E-01

4.2E-02

5.7E-03

$4.9 \mathrm{E}-01$

Barrier without Flushing

8. Modified Close-Coupled

2.0E-01

1.3E-02

1.7E-01

4.2E-02

$5.7 \mathrm{E}-03$

4.3E-01

Chemical Barrier without Flushing

9. Box-Shaped Chemical

$3.8 \mathrm{E}-01$

2.0E-02

$2.9 \mathrm{E}-01$

8.0E-02

$3.1 \mathrm{E}-02$

$8.0 \mathrm{E}-01$

Barrier

10. V-Shaped Chemical

4.4E-01 . 2.0E-02

3.7E-01

8.4E-02

3.3E-02

$9.5 \mathrm{E}-01$

Barrier

11. V-Shaped Freeze Wall Barrier

$\begin{array}{llllll}4.4 \mathrm{E}-01 \quad 1.9 \mathrm{E}-02 & 2.8 \mathrm{E}-01 \quad 1.1 \mathrm{E}-01 \quad 4.7 \mathrm{E}-02 & 8.9 \mathrm{E}-01\end{array}$

12. Circulating Air Barrier

4.1E-01

1.9E-02

2.3E-01

$1.1 \mathrm{E}-01$

3.5E-02

$8.0 \mathrm{E}-01$

13. Clean-Closure without Barrier

$1.1 \mathrm{E}+00$

2.5E-02

$7.6 \mathrm{E}-01$

$2.8 \mathrm{E}-01$

2.0E-01

$2.4 \mathrm{E}+00$

14. Clean-Closure with Close

$1.2 \mathrm{E}+00$

3.9E-02

$7.6 \mathrm{E}-01$

3.0E-01

2.0E-01

$2.5 \mathrm{E}+00$ Coupled Chemical Barrier

(l) Basis: One SST unk farm with 12 tanks 
Table 9-11, Injury Risks Associated with Alternatives (number of reportable injuries) (1).

\begin{tabular}{|c|c|c|c|c|c|c|}
\hline Alternative & $\begin{array}{c}\text { Vehicular } \\
\text { Transportation }\end{array}$ & $\begin{array}{c}\text { Technology } \\
\text { Readiness } \\
\end{array}$ & Capital & Operations & D\&D & TOTAL \\
\hline 1. No-Action & 0 & 0 & 0 & 0 & 0 & 0 \\
\hline 2. Suface Barrier Only & 0.014 & 0.66 & 0.98 & 0.53 & 0 & 2.2 \\
\hline 3. Traditional Sluicing & 0.18 & 1.6 & 17 & 7.6 & 1.4 & 28 \\
\hline 4. Robotic Sluicing & 1.0 & 7.0 & 47 & 56 & 24 & 140 \\
\hline 5. Mechanical Retrieval & 0.96 & 6.0 & 40 & 56 & 24 & 130 \\
\hline $\begin{array}{l}\text { 6. Close-Coupled Chemical } \\
\text { Barrier with Flushing }\end{array}$ & 0.87 & 8.1 & 77 & 33 & 5.1 & 120 \\
\hline $\begin{array}{l}\text { 7. Close-Coupled Chemical } \\
\text { Barrier without Flushing }\end{array}$ & 0.45 & 4.8 & 40 & 16 & 1.4 & 62 \\
\hline $\begin{array}{l}\text { 8. Modified Close-Coupled } \\
\text { Chemical Barrier without } \\
\text { Flushing }\end{array}$ & 0.41 & 3.3 & 34 & 16 & 1.4 & 55 \\
\hline $\begin{array}{l}\text { 9. Box-Shaped Chemical } \\
\text { Barrier }\end{array}$ & 0.78 & 6.7 & 82 & 30 & 7.7 & 130 \\
\hline $\begin{array}{l}\text { 10. V-Shaped Chemical } \\
\text { Barrier }\end{array}$ & 0.90 & 6.7 & 110 & 32 & 8.2 & 150 \\
\hline $\begin{array}{l}\text { 11. V-Shaped Freeze Wall } \\
\text { Barrier }\end{array}$ & 0.90 & 6.3 & 80 & 40 & 12 & 140 \\
\hline 12. Circulating Air Barrier & 0.84 & 6.3 & 66 & 41 & 8.7 & 120 \\
\hline $\begin{array}{l}\text { 13. Clean-Closure without } \\
\text { Barrier }\end{array}$ & 2.3 & 5.6 & 130 & 110 & 25 & 270 \\
\hline $\begin{array}{l}\text { 14. Clean-Closure with Close } \\
\text { Coupled Chemical } \\
\text { Barrier }\end{array}$ & 2.4 & 8.7 & 130 & 110 & 24 & 280 \\
\hline
\end{tabular}


Table 9-12. Collective Cancer Risks Associated with Alternatives (1).

\begin{tabular}{|c|c|c|c|c|c|c|}
\hline Alternative & $\begin{array}{l}\text { Vehicular } \\
\text { Transpor- } \\
\text { tation } \\
\end{array}$ & $\begin{array}{c}\text { Technology } \\
\text { Readiness } \\
\end{array}$ & Capital & Operations & D\&D & TOTAL \\
\hline 1. No-Action & 0 & 0 & 0 & 0 & 0 & 0 \\
\hline 2. Suface Barrier Only & 0 & 0 & 2.5E-04 & $5.6 \mathrm{E}-04$ & NA & $8.0 \mathrm{E}-04$ \\
\hline 3. Traditional Sluicing & 0 & 0 & $1.1 \mathrm{E}-02$ & $2.5 \mathrm{E}-02$ & $1.8 \mathrm{E}-03$ & 3.7E-02 \\
\hline 4. Robotic Sluicing & 0 & 0 & 3.1E-02 & $2.0 \mathrm{E}-01$ & $3.0 \mathrm{E}-02$ & 2.6E-01 \\
\hline 5. Mechanical Retrieval & 0 & 0 & $3.0 \mathrm{E}-02$ & $2.0 \mathrm{E}-0 \mathrm{l}$ & $3.0 \mathrm{E}-02$ & $2.6 \mathrm{E}-01$ \\
\hline $\begin{array}{l}\text { 6. Close-Coupled Chemical } \\
\text { Barrier with Flushing }\end{array}$ & 0 & 0 & $7.4 \mathrm{E}-02$ & $1.0 \mathrm{E}-01$ & $6.3 \mathrm{E}-03$ & $1.8 \mathrm{E}-01$ \\
\hline $\begin{array}{l}\text { 7. Close-Coupled Chemical } \\
\text { Barrier without Flushing }\end{array}$ & 0 & 0 & $3.8 \mathrm{E}-02$ & $4.1 \mathrm{E}-02$ & $1.8 \mathrm{E}-03$ & $8.0 \mathrm{E}-02$ \\
\hline $\begin{array}{l}\text { 8. Modified Close-Coupled } \\
\text { Chemical Barrier without } \\
\text { Flushing }\end{array}$ & 0 & 0 & $2.6 \mathrm{E}-02$ & 4.1E-02 & $1.8 \mathrm{E}-03$ & $6.8 \mathrm{E}-02$ \\
\hline $\begin{array}{l}\text { 9. Box-Shaped Chemical } \\
\text { Barrier }\end{array}$ & 0 & 0 & 3.7E-02 & $8.0 \mathrm{E}-02$ & $7.8 \mathrm{E}-03$ & $1.2 \mathrm{E}-01$ \\
\hline $\begin{array}{l}\text { 10. V-Shaped Chemical } \\
\text { Barrier }\end{array}$ & 0 & 0 & 4.8E-02 & $8.4 \mathrm{E}-02$ & $8.3 \mathrm{E}-03$ & $1.4 \mathrm{E}-01$ \\
\hline $\begin{array}{l}\text { 11. V-Shaped Freeze Wall } \\
\text { Barrier }\end{array}$ & 0 & 0 & $3.6 \mathrm{E}-02$ & $1.0 \mathrm{E}-01$ & $1.1 \mathrm{E}-02$ & $1.5 \mathrm{E}-01$ \\
\hline 12. Circulating Air Barrier & 0 & 0 & 4.6E-02 & $1.2 \mathrm{E}-01$ & $8.7 \mathrm{E}-03$ & $1.7 \mathrm{E}-01$ \\
\hline $\begin{array}{l}\text { 13. Clean-Closure without } \\
\text { Barrier }\end{array}$ & 0 & 0 & $1.3 \mathrm{E}-0 \mathrm{I}$ & $3.8 \mathrm{E}-01$ & $5.7 \mathrm{E}-02$ & $5.7 \mathrm{E}-01$ \\
\hline $\begin{array}{l}\text { 14. Clean-Closure with Close } \\
\text { Coupled Chemical } \\
\text { Barrier }\end{array}$ & 0 & 0 & $1.3 \mathrm{E}-01$ & $3.9 \mathrm{E}-01$ & $5.6 \mathrm{E}-02$ & $5.8 \mathrm{E}-0 \mathrm{l}$ \\
\hline
\end{tabular}


Table 9-13. Worker Risks Relative to Baseline Alternative Risks.

\begin{tabular}{|c|c|c|c|}
\hline Alternative & $\begin{array}{c}\text { Relative Number of } \\
\text { Fatalities (unitless) } \\
\end{array}$ & $\begin{array}{c}\text { Relative Number of } \\
\text { Injuries (unitless) }\end{array}$ & $\begin{array}{c}\text { Relative Collective } \\
\text { Cancer Risk (unitless) }\end{array}$ \\
\hline 1. No-Action & 0.0 & 0.0 & 0.0 \\
\hline 2. Suface Barrier Only & 0.08 & 0.08 & 0.02 \\
\hline 3. Traditional Sluicing & 1.0 & 1.0 & 1.0 \\
\hline 4. Robotic Sluicing & $\cdot 5.1$ & 5.0 & 7.0 \\
\hline 5. Mechanical Retrieval & 4.8 & 4.6 & 7.0 \\
\hline $\begin{array}{l}\text { 6. Close-Coupled Chemical } \\
\text { Barrier with Flushing }\end{array}$ & 5.1 & 4.3 & 4.9 \\
\hline $\begin{array}{l}\text { 7. Close-Coupled Chemical } \\
\text { Barrier without Flushing }\end{array}$ & 2.7 & 2.2 & 2.2 \\
\hline $\begin{array}{l}\text { 8. Modified Close-Coupled } \\
\text { Chemical Barrier without } \\
\text { Flushing }\end{array}$ & 2.4 & 2.0 & 1.8 \\
\hline $\begin{array}{l}\text { 9. Box-Shaped Chemical } \\
\text { Barrier }\end{array}$ & 4.4 & 4.6 & 3.2 \\
\hline $\begin{array}{l}\text { 10. V-Shaped Chemical } \\
\text { Barrier }\end{array}$ & 5.3 & 5.4 & 3.8 \\
\hline $\begin{array}{l}\text { 11. V-Shaped Freeze Wall } \\
\text { Barrier }\end{array}$ & 4.9 & 5.0 & 4.1 \\
\hline 12. Circulating Air Barrier & 4.4 & 4.3 & 4.6 \\
\hline $\begin{array}{l}\text { 13. Clean-Closure without } \\
\text { Barrier }\end{array}$ & 13.3 & 9.6 & 15.4 \\
\hline $\begin{array}{l}\text { 14. Clean-Closure with Close- } \\
\text { Coupled Chemical Barrier }\end{array}$ & 13.9 & 10.0 & 15.7 \\
\hline
\end{tabular}




\subsection{COMPLIANCE WITH FUNCTIONS AND REQUIREMENTS}

The eight alternatives that include subsurface barriers were evaluated against their potential ability to satisfy functions and requirements identified in Functions and Requirements for Single-Shell Tank Leakage Mitigation (Cruse 1994b). The evaluation was made based on the following observations and assumptions.

- Little technical data exist on the performance of subsurface barriers for the intended application to support a detailed evaluation of functional requirements.

- Few requirements have been quantified at the current stage of development of Functions and Requirements for Single-Shell Tank Leakage Mitigation (Cruse 1994b). Quantitative requirements can be developed as understanding of functional needs matures based on (1) testing of the technologies, (2) completion of in-depth technical analyses, and (3) as a consequence of regulator negotiations to establish permit conditions.

The evaluation was based on the potential of an alternative to satisfy functional requirements, as currently defined, using engineering judgement. The results of the evaluation are summarized in Tables 10-1 through 10-4. Each table is based on one of four primary Level 7 functions identified in Cruse (1994b):

- Prevent new leakage

- Confine past leakage

- Monitor performance/verify compliance

- Remove soil contamination.

The requirements for each function as defined in Cruse (1994b) are summarized in Tables 10-1 through 10-4.

No requirement was identified that cannot be met, given sufficient time and resources. However, the ability of subsurface barriers to prevent further migration of contaminants is questionable, since there is no material known that will prevent molecular diffusion. It is assumed that the regulatory interpretation of this requirement will allow some migration. Further quantification of requirements and improved data are needed before an in-depth evaluation of ability to satisfy requirements can be made. 


\section{WHC-SD-WM-ES-300 REV. 1}

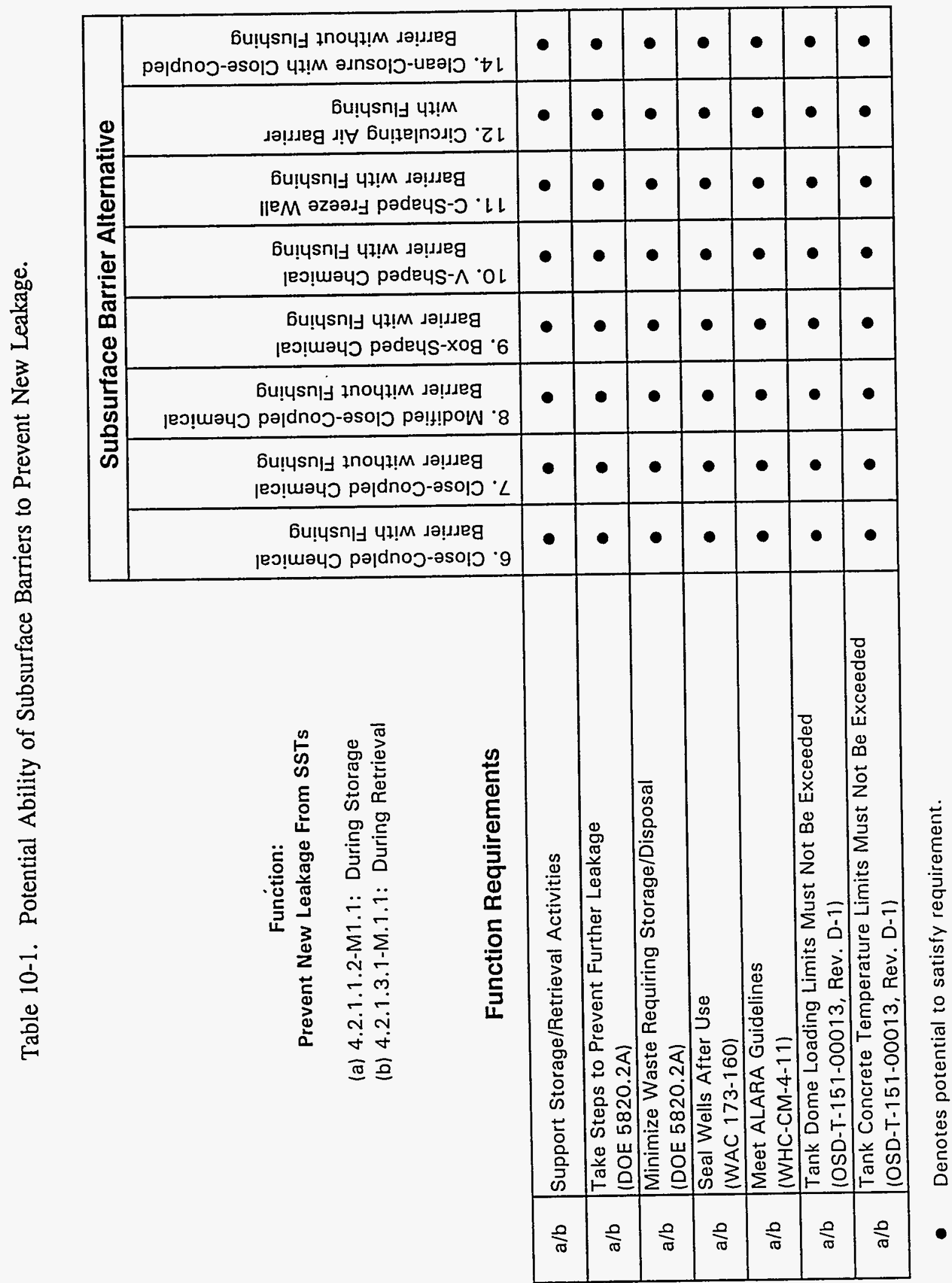




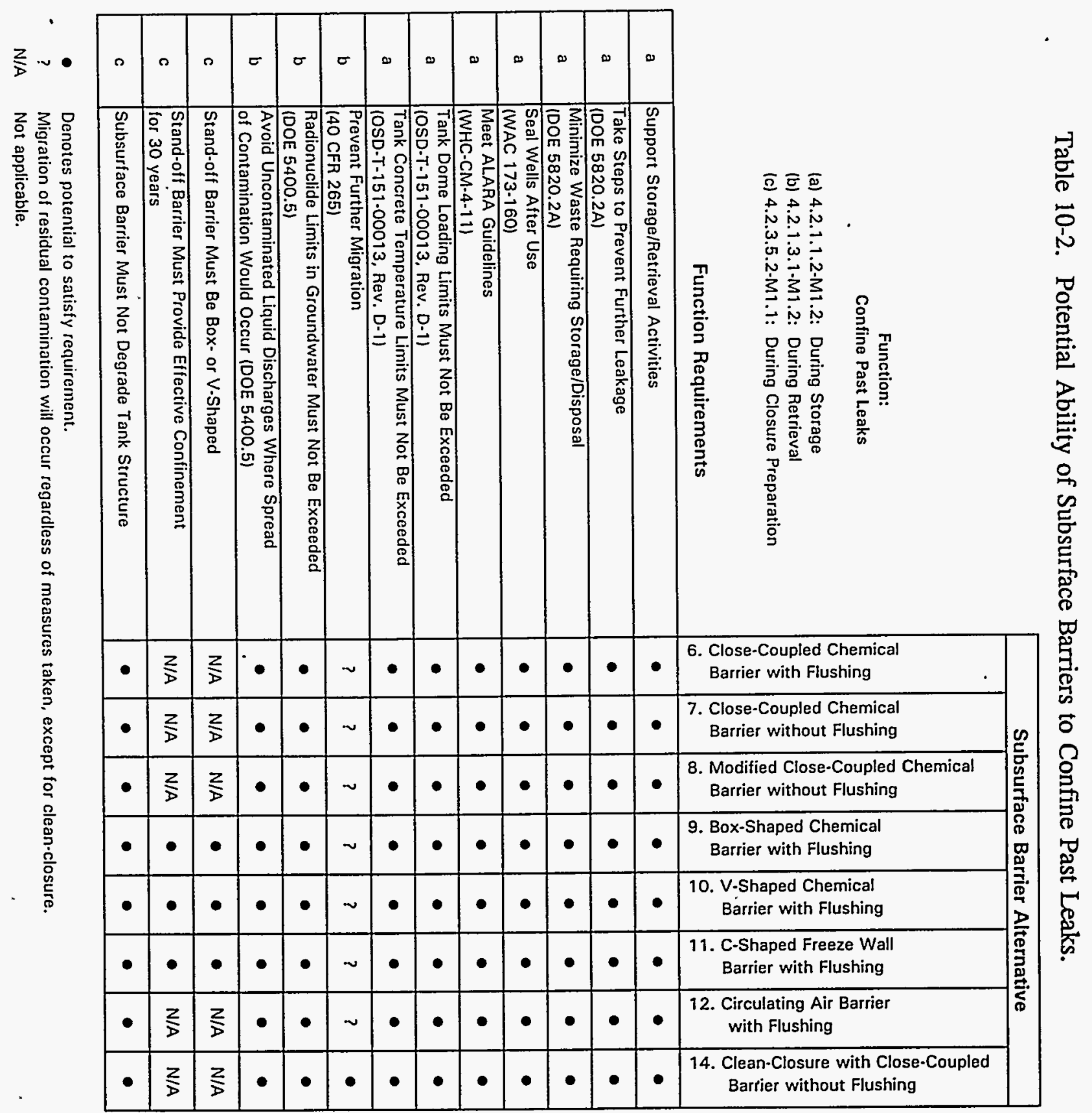


WHC-SD-WM-ES-300 REV. 1

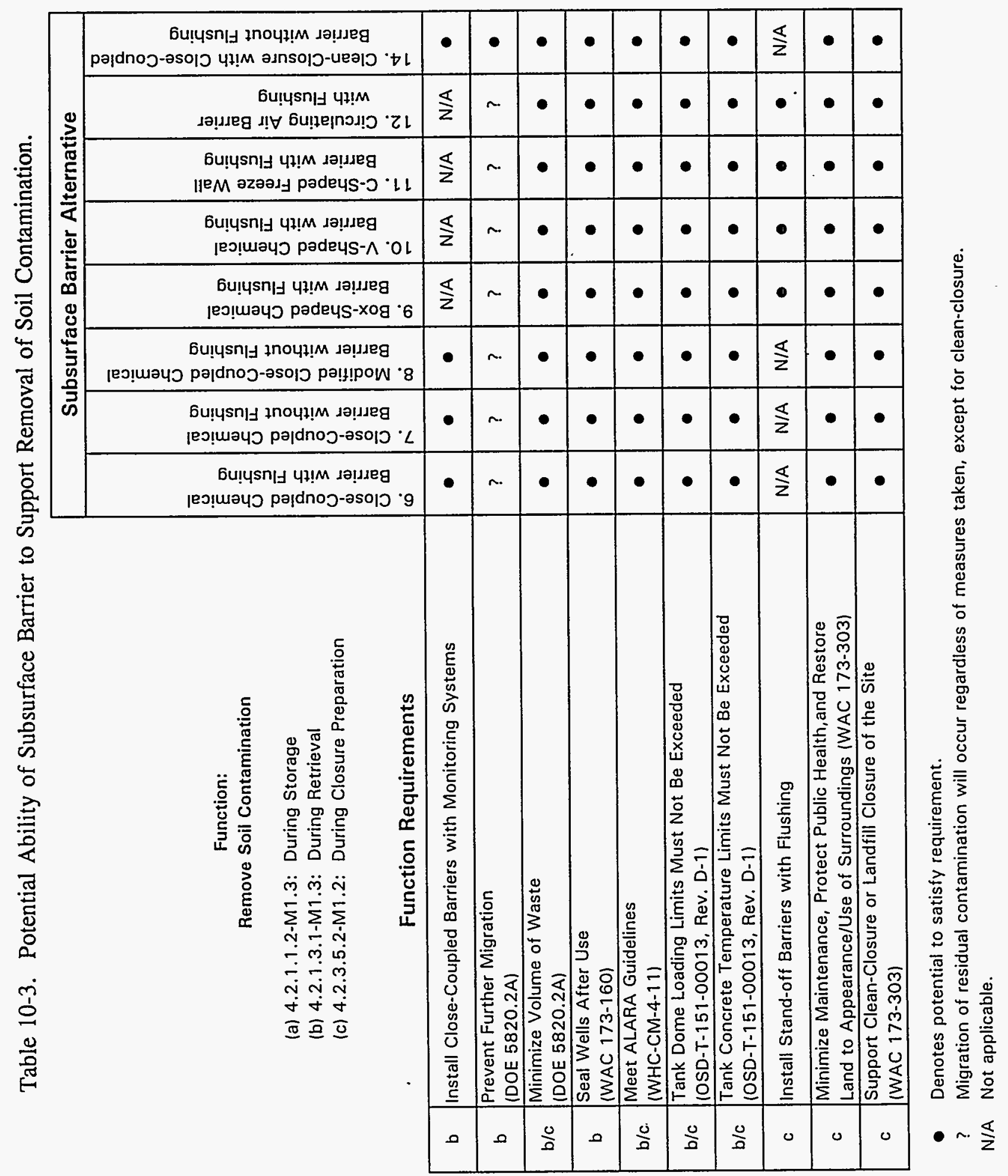




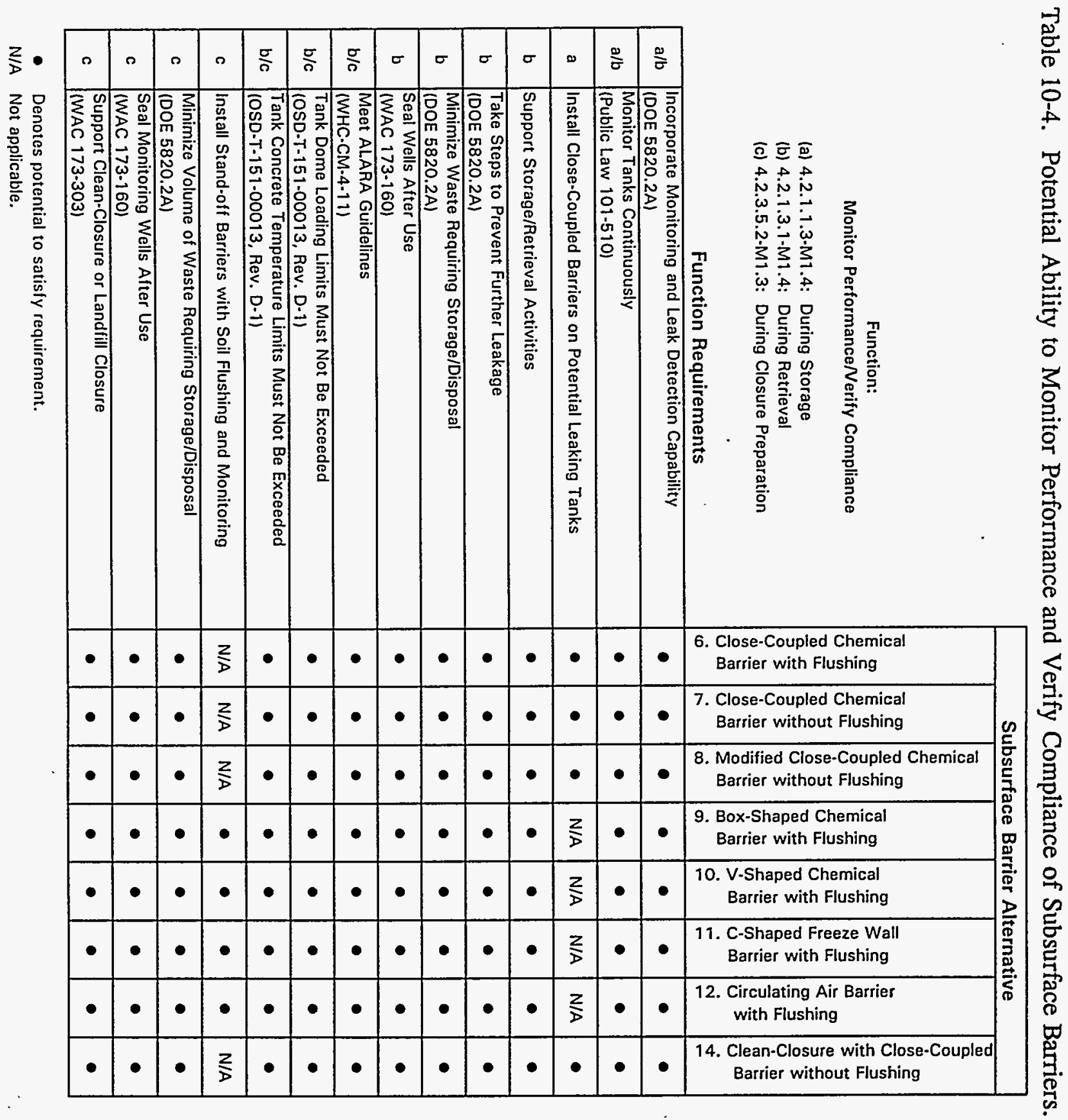


WHC-SD-WM-ES-300 REV. 1

This page intentionally left blank. 


\subsection{REFERENCES}

Blanchard, K. A., M. D. Freshley, C. T. Kincaid, B. G. Lauzon, M. G. Piepho, K. Rhoads, J. W. Shade, J. A. Voogd, J. H. Westsik, Jr., and G. A. Whyatt, 1993, Performance Assessment of Grouted Double-Shell Tank Waste Disposal at Hanford, WHC-SD-WM-EE-004, Rev. 0, Westinghouse Hanford Company, Richland, Washington.

Boomer, K. D., S. K. Baker, A. L. Boldt, J. D. Galbraith, J. S. Garfield, C. E. Golberg, B. A. Higley, L. J. Johnson, M. J. Kupfer, R. M. Marusich, R. J. Parazin, A. N. Praga, G. W. Reddick, J. A. Reddick, E. J. Slaathaug, L. M. Swanson, T. L. Waldo, and C. E. Worcester, 1993, Tank Waste Technical Options, WHC-EP-0616, Rev. 0, Westinghouse Hanford Company, Richland, Washington.

Bovay Northwest, Inc., 1992, Interim Subsurface Barrier Technologies Workshop Report, prepared for WHC under Contract No. MDR-SVV-274303, Bovay Project No. 1842-001, Richland, Washington.

Bruce, D. A., 1990, Monitoring and Quality Control of a 100-Meter Deep Diaphragm Wall, International Conference on Piling and Deep Foundations, London, England.

Cantrell, K. J., P. F. Martin, and J. Szecsody, 1994, Clinoptilolite as an In Situ Permeable Barrier to Sr Migration in Ground Water, Battelle-Pacific Northwest Laboratory, Richland, Washington.

Cantrell, K. J., et al., 1993, FY 1993 Laboratory Results for the Chemically Enhanced Barriers Project (draft), Battelle-Pacific Northwest Laboratory, Richland, Washington.

Cruse, J. M., 1994a, Mission Analysis for Single-Shell Tank Leak Mitigation, WHC-SD-WM-MAR-001, Rev. 0, Westinghouse Hanford Company, Richland, Washington.

Cruse, J. M., 1994b, Functions and Requirements for Single-Shell Tank Leakage Mitigation, WHC-SD-WM-FRD-019, Rev. 0, Westinghouse Hanford Company, Richland, Washington.

DOE, 1993, Hanford Site Baseline Risk Assessment Methodology, DOE/RL-91-45, Rev. 2, U.S. Department of Energy, Richland, Washington.

DOE, 1987, Final Environmental Impact Statement of Disposal of Hanford Defense HighLevel, Transuranic and Tank Wastes, DOE/EIS-0113, Vol. II, U.S. Department of Energy, Richland, Washington. 
Droppo, J. G., D. L. Strenge, J. W. Buck, B. L. Hoopes, R. D. Brockhaus, M. B. Walter, and G. Whelan, 1989, Multimedia Environmental Pollutant Assessment System (MEPAS) Application Guidance, PNL-7216, Battelle-Pacific Northwest Laboratory, Richland, Washington.

Droppo, J.G., J.W. Buck, J.S. Wilbur, D.L. Strenge, M.D. Freshley, 1991, Single-Shell Tank Constituent Rankins for Use in Preparing Waste Characterization Plans, PNL7572, Pacific Northwest Laboratory, Richland, Washington.

Ecology, EPA, and DOE, 1990, Hanford Federal Facility Agreement and Consent Order, Washington State Department of Ecology, U.S. Environmental Protection Agency, and the U.S. Department of Energy, Olympia, Washington.

Ellis, W. D. and J. R. Payne, 1984, The Development of Chemical Countermeasures for Hazardous Waste Contaminated Soil, Proceedings of the 1984 Hazardous Material Spills Conference, April 9-12, 1984, Nashville, Tennessee.

EPA, 1982, RCRA (Resource Conservation and Recovery Act) Guidance Document: Landfill Design, Liner Systems and Final Cover, PB87-157657, National Technical Information Service, Springfield, Virginia.

EPA, 1990, Seminars--Design and Construction of RCRA/CERCLA Final Covers, Center for Environmental Research Information 90-55, U.S. Environmental Protection Agency, Office of Research and Development, Washington, D.C.

Fowler, D. W., 1990, "State of the Art of Polymer Concrete," Proceedings: Sixth International Congress of Polymers in Concrete, Shanghai, China.

Garnich, M. R., 1990, Thermal Stress Modeling of In Situ Vitrified Barriers for Hazardous Waste Containment, PNL-SA-1934575, Battelle-Pacific Northwest Laboratory, Richland, Washington.

Gee, G., et al., 1993, Field Lysimeter Status Report - FY 93, PNL-8911, Battelle-Pacific Northwest Laboratory, Richland, Washington.

Geo-Slope, 1994, Geo-Slope International Ltd., Calgary, Alberta, Canada.

Golder Associates, 1994a, Preliminary Results of Permeation Tests using Montan Wax and Sodium Silicate Barrier Materials in Unconsolidated Soils at the Mixed Waste Landfill Integrated Demonstration Site.

Golder Associates, 1994b, Draft Test Plan, Version 1.0, Multiple-Borehole Permeation Tests using Montan Wax and Sodium Silicate Barrier Materials in Unconsolidated Soils at the Mixed Waste Landfill Integrated Demonstration Site. 
Hampsten, K. L., 1994, Qualitative Risk Assessment of Subsurface Barriers in applications Supporting Retrieval of SST Waste, WHC-SD-WM-RA-010, Rev. 0, Westinghouse Hanford Company, Richland, Washington.

Hanlon, B. M., 1993, Tank Farm Surveillance and Waste Status Summary Report for August 1993, WHC-EP-0182-65, Westinghouse Hanford Company, Richland, Washington.

Heiser, J. H., and L. W. Milian, 1994, Laboratory Evaluation of Performance and Durability of Polymer Grouts for Subsurface Hydraulic/Diffusion Barriers, Environmental \& Waste Technology Center, Department of Advanced Technology, Brookhaven National Laboratory, Upton, New York.

HFSUWG , 1992, The Future for Hanford: Uses and Cleanup, Hanford Future Site Uses Working Group, Richland, Washington.

Jensen, E. J., S. P. Airhart, C. L. Edison, and G. W. McLellan, 1992, Horizontal Drilling Workshop Summary Report for the Arid Site Integrated Demonstration Program, Bovay Northwest Incorporated, Richland, Washington.

KEH, 1993a, Evaluation of Alternative Drilling Technologies and Subsurface Confinement Barriers for Single-Shell Tanks At Hanford, prepared for Kaiser Engineers Hanford Company by $\mathrm{K} \& \mathrm{M}$ Engineering and Consulting Corp. and BDM International, Inc. Contract No. DE-AC21-90MC27346.

KEH, 1993b, Subsurface Barrier Engineering Study, WHC-SD-WM-ES-256, Rev. 0, Kaiser Engineers Hanford Company, Richland, Washington.

LATA, 1992, Single-Shell Tank Barrier Technology Assessment, prepared for Westinghouse Hanford Company under Contract No. MGM-SVV-032915, Task 19, Los Alamos Technical Associates, Kennewick, Washington.

Lowe, S. S., 1993, Engineering Study of Tank Leaks Related to Hydraulic Retrieval of Sludge from Tank 241-C-106, WHC-SD-WM-ES-218, Rev. 0, Westinghouse Hanford Company, Richland, Washington.

Metz, W. P., 1976, A Topical Report on Interstitial Liquid Removal from Hanford Salt Cakes, ARH-CD-545, Atlantic Richfield Hanford Company, Richland, Washington.

Moridis, G. J., P. Persoff, H.-Y. Holman, S. J. Muller, K. Pruess, and C. J. Radke, 1993, New Barrier Fluids for Subsurface Containment of Contaminants, Lawrence Berkeley Laboratory, Berkeley, California.

Naudts, A., 1989, Brief Overview of the Various Families of Grouts and Their Applications, Trow Geotechnical Limited. 
Persoff, P., G. J. Moridis, J. Apps, and K. Pruess, 1994, Designing Injectable Colloidal Silica Barriers for Waste Isolation at the Hanford Site, LBL-35447, Lawrence Berkeley Laboratory, Berkeley, California.

Raymond, J. R. and E. G. Shdo, 1966, Characterization of Subsurface Contamination in the SX Tank Farm, BNWL-CC-701, Pacific Northwest Laboratory, Richland, Washington.

Resource Conservation and Recovery Act of 1976, 42 USC 6901, et seq.

Riggsbee, W. H., R. L. Treat, H. J. Stansfield, R. M. Schwarz, K. J. Cantrell, and S. J. Phillips, 1994, Review of Potential Subsurface Permeable Barrier Emplacement and Monitoring Technologies, Battelle Pacific Northwest Laboratory, Richland, Washington.

Rodenhizer, D. G., 1987, Hanford Tank Sluicing History, WHC-SD-WM-TI-302, Westinghouse Hanford Company, Richland, Washington.

Ruegg, R. T., 1987, Life-Cycle Costing Manual for the Federal Management Program, National Bureau of Standards, U.S. Department of Commerce, NBS Handbook 135, Washington, D.C.

Schmittroth, F., F. M. Mann, T. H. DeLorenzo, and P. A. Rittman, 1993, Risk-Based Preliminary Assessment Supporting Closure of the Hanford Site Single-Shell Tanks as Landfills, WHC-EP-0692, Not Approved for Public Release, Westinghouse Hanford Company, Richland, Washington.

Schramke, J. A., C. S. Glantz, and G. R. Holdren, 1994, Hanford Site Environmental Setting Data Developed for the Unit Risk Factor Methodology in Support of the Programmatic Environmental Impact Statement (PEIS), PNL-9801, Battelle-Pacific Northwest Laboratory, Richland, Washington.

Schultz, W.W., 1978, Removal of Radionuclides from Hanford Defense Waste Solutions, RHO-SA-51, Rockwell Hanford Operations, Richland, Washington.

SEG, 1992, SEG Proposal No. WS-9108-418, Demonstration of CRYOCELL Technology for Application on the Hanford Tanks, $100 \mathrm{~N}$-Springs Area, and Emergency Response, Scientific Ecology Group, Inc. and RKK, Ltd., Richland, Washington.

Serne, R. J. and M. I. Wood, 1990, Hanford Waste Form Releases and Sediment Interactions, PNL 7297, Battelle Pacific Northwest Laboratory, Richland, Washington.

Smith, E., 1994, Regulatory Assessment for the Use of Underground Barriers at the Hanford Site Tank Farms, WHC-SD-EN-RD-010, Rev. 0, Westinghouse Hanford Company, Richland, Washington. 
Sresty, G. C., English, J. J., 1993, RF In-situ Formation of Active Desiccating Subsurface Barriers, Proposal to Westinghouse Hanford Company, IIT Research Institute, Chicago, Illinois.

Van Genuchten, M. Th., 1993, "A Closed-Form Equation for Predicting the Hydraulic Conductivity of Unsaturated Soil," Soil Science Society of American Journal, Vol. 44, No. 5, pp. 892-898.

WAC 173-303, 1993, Dangerous Waste Regulation, Washington Administrative Code, as amended.

Waterloo, 1994, Waterloo Barrier - A Low Permeability Containment Wall for Groundwater Pollution Control, Waterloo Groundwater Control Technologies, Waterloo, Ontario, Canada.

Weiss, R.L., 1986, TY Tank Farm Waste Characterization Data, RHO-WM-TI-IP, Rockwell Hanford Operations, Richland, Washington.

- Weiss, R.L., and K.E. Schull, 1988a, Data Transmittal Package for 241-A-103 Waste Tank Characterization, SD-RE-TI-198, Westinghouse Hanford Company, Richland, Washington.

Weiss, R.L., and K.E. Schull, 1988b, Data Transmittal Package for 241-C-104 Waste Tank Characterization, SD-RE-TI-199, Westinghouse Hanford Company, Richland, Washington.

Weiss, R.L., and K.E. Schull, 1988c, Data Transmittal Package for 241-A-106 Waste Tank Characterization, SD-RE-TI-200, Westinghouse Hanford Company, Richland, Washington.

Weiss, R.L., and K.E. Schull, 1988d, Data Transmittal Package for 241-A-102 Waste Tank Characterization, SD-RE-TI-201, Westinghouse Hanford Company, Richland, Washington.

Weiss, R.L., and K.E. Schull, 1988e, Data Transmittal Package for 241-BX-105 Waste Tank Characterization, SD-RE-TI-202, Westinghouse Hanford Company, Richland, Washington.

Weiss, R.L., and K.E. Schull, 1988f, Data Transmittal Package for 241-C-103 Waste Tank Characterization, SD-RE-TI-203, Westinghouse Hanford Company, Richland, Washington. 
Weiss, R.L., and K.E. Schull, 1988g, Data Transmittal Package for 241-C-105 Waste Tank Characterization, SD-RE-TI-204, Westinghouse Hanford Company, Richland, Washington.

Weiss, R.L., and K.E. Schull, 1988h, Data Transmittal Package for 241-C-106 Waste Tank Characterization, SD-RE-TI-205, Westinghouse Hanford Company, Richland, Washington.

Weiss, R.L., and K.E. Schull, 1988i, Data Transmittal Package for 241-BX-104 Waste Tank Characterization, SD-RE-TI-206, Westinghouse Hanford Company, Richland, Washington.

Wing, N. R., 1993, Permanent Isolation Surface Barrier: Functional Performance, WHC-EP-0650, Westinghouse Hanford Company, Richland, Washington.

Woodward-Clyde Consultants, 1978, An Estimate of Bottom Topography, Volume and Other Conditions in Tank 105A, Hanford, Washington, WCC Project 13974A -0300, San Francisco, California. 
WHC-SD-WM-ES-300 REV. 1

APPENDIX A

MEPAS CODE INPUT AND OUTPUT

A-1 
WHC-SD-WM-ES-300 REV. 1

This page intentionally left blank. 


\section{A.0 MEPAS CODE INPUT AND OUTPUT}

The Multimedia Environmental Pollutant Assessment System (MEPAS) is a computer-based system used to quantify relative human health impact from radiological and chemical contaminants released to the environment (Droppo et. al 1989). The MEPAS code uses empirical, analytical, and semi-analytical mathematical algorithms and a pathway analysis to estimate the following processes:

- Potential release of contaminants into the environment

- - Transport of contaminants through and between multiple environmental media, including subsurface or groundwater, surface water, overland, and atmospheric

- Exposure to surrounding human populations through the following exposure pathways: inhalation, ingestion of water and food products, dermal contact, and external radiation

- Human health effects associated with exposure to chemicals and radionuclides.

For the barriers technology assessment, the MEPAS code was used to evaluate the discharge of liquid effluents to the subsurface during tank remediation, resulting in transport to groundwater and through groundwater offsite, where this water is used by the public for drinking, showering, irrigation of crops, and animal water.

MEPAS Version 3.0g was used for the public human health risk evaluation. The input parameters required by the MEPAS code are described in the following sections for the groundwater pathway.

\section{A.1 INPUT DATA}

MEPAS requires a great deal of input data to execute the transport and exposure models. The groundwater pathway requires the following types of data for execution.

- Contaminant release data

- Source characteristics

- Geologic media (partially saturated zone) characteristics

- Groundwater (saturated zone) characteristics

- Human exposure pathway selection 
- Receptor location and exposure characteristics.

Table A-1 lists the input parameters required by the MEPAS code for the groundwater pathway. The values used in this evaluation for each of the input parameters are also listed in this table. In addition, Table A-2 lists the MEPAS input parameters used for the geologic media characteristics. These values were obtained directly from the data used for the Hanford Programmatic Environmental Impact Statement (Schramke 1994), based on the 200 East Area. It is assumed for the purposes of this relative risk evaluation that this data is representative of the physical characteristics associated with Hanford Site geologic stratigraphy. In addition, certain MEPAS default parameter values are used for all cases evaluated, including receptor inhalation and ingestion rates and contaminant-specific reference doses and cancer slope factors, based on a risk level of $1 \mathrm{E}-06$.

For the tank waste remediation evaluation, it is assumed that liquid releases to the ground occur in the subsurface partially saturated zone, located beneath the underground storage tanks. The source of release is assumed to be represented by an area configuration equal to the average area of a tank farm. Values for the depth of release are dependent upon the source and case being evaluated. These values are listed in Table A-3. Flux values and release durations are also dependent upon the source and case under investigation and are listed in Tables A-4 through A-17 for each of the 14 alternatives and in Tables A-18 through A-23 for the five sensitivity cases. These values are computed based on the flux rates that were determined for nitrate. The fluxes of the other constituents of concern are computed as follows.

$$
\text { Flux }_{i}=\text { Flux }_{\text {nitrate }} \times \frac{\text { Inventory }_{i}}{\text { Inventory }_{\text {nitrate }}}
$$

Where:

$$
\begin{aligned}
\text { Flux }_{\mathbf{i}} & =\text { flux rate of constituent } \mathrm{i}(\mathrm{g} / \mathrm{yr}) \\
\text { Flux }_{\text {nitrate }} & =\text { flux rate of nitrate }(\mathrm{g} / \mathrm{yr}) \\
\text { Inventory }_{\mathrm{i}} & =\text { inventory of constituent } \mathrm{i} \text { in all } 149 \text { tanks }(\mathrm{g}) \\
\text { Inventory }_{\text {nitrate }} & =\text { inventory of nitrate in all } 149 \operatorname{tanks}(\mathrm{g})
\end{aligned}
$$

The inventory of each of the constituents of concern in the Hanford Site 149 tanks is listed in Table A-24. These values were obtained from Boomer (1993), except for the values presented for EDTA and TBP. For these constituents, only the inventory for total organic carbon (TOC) was available from Boomer (1993). However, the Hanford Defense Waste Environmental Impact Statement (HDW-EIS; DOE 1987) provided analyses of organics in different types of tank wastes. The highest measured quantities of EDTA and TBP were used as a basis for evaluating the potential quantities by determining the percentage of EDTA and TBP comprising the TOC in the tanks to be $8.4 \%$ and $7.3 \%$. In addition, the MEPAS toxicity values for each COC is listed in Table A-24. 


\section{A.2 OUTPUT DATA}

The MEPAS code provides output data in the form of risk values for radionuclides and chemical carcinogens and RfD ratios for noncarcinogenic chemicals. These values are computed only for the 70 year lifetime period during which the maximum groundwater concentration is calculated and assumed to remain constant. Groundwater concentrations and geological strata flux rates are computed for a certain number of user-specified time intervals. For this evaluation, forty time steps were selected, resulting in a determination of time periods in increments of 13 years for cases that assumed a recharge rate of $5 \mathrm{~cm} / \mathrm{yr}$ and 750 years for cases that assume a recharge rate of $0.5 \mathrm{~cm} / \mathrm{yr}$. Intermediate output, contained in *.POL files, present the computed groundwater concentrations and geological strata flux rates for all time intervals evaluated. These output values are used in combination with risk conversion factors and saturated zone dilution factors for each contaminant to compute risk or HI values for each time interval evaluated. Risk conversion factors are computed from the MEPAS output and intermediate data files as shown below.

Where:

$$
\begin{aligned}
& \mathrm{RCF}_{\mathrm{i}}=\frac{\mathrm{Risk}_{\mathrm{i}}}{\mathrm{C}_{\mathrm{gw}, \mathrm{i}}} \\
& \mathrm{RCF}_{\mathrm{i}}=\frac{\mathrm{HI}_{\mathrm{i}}}{\mathrm{C}_{\mathrm{gw}, \mathrm{i}}}
\end{aligned}
$$

$$
\begin{aligned}
& \mathrm{RCF}_{\mathrm{i}}=\text { risk conversion factor for constituent } \mathrm{i}\left[(\mathrm{g} / \mathrm{ml})^{-1} \text { or }(\mathrm{Ci} / \mathrm{ml})^{-1}\right] \\
& \text { Risk }_{i}=\text { risk value computed by MEPAS for constituent' } i \text { for the maximum } \\
& \text { groundwater concentration } \\
& \mathrm{HI}_{\mathrm{i}} \quad=\quad \text { hazard index (or RfD ratio) computed by MEPAS for constituent } \mathrm{i} \\
& \text { for the maximum groundwater concentration } \\
& \mathrm{C}_{\mathrm{gw}, \mathrm{i}}=\text { maximum groundwater concentration computed by MEPAS for } \\
& \text { constituent i }[(\mathrm{g} / \mathrm{ml}) \text { or }(\mathrm{Ci} / \mathrm{ml})]
\end{aligned}
$$

Table A-24 includes the risk conversion factors for each constituent of concern for the groundwater pathway. 
Table A-1. MEPAS Code Input Parameters for the Groundwater Pathway (Sheet 1 of 4).

\begin{tabular}{|c|c|c|c|}
\hline Parameter Type & Parameter Description & Value & $\begin{array}{l}\text { Data Source or } \\
\text { Justification }\end{array}$ \\
\hline \multirow[t]{5}{*}{$\begin{array}{l}\text { Contaminant } \\
\text { Release Data }\end{array}$} & Contaminant-specific flux & see Schramke 1994 & $\begin{array}{l}\text { Dependent upon the } \\
\text { alternative and source }\end{array}$ \\
\hline & Discharge duration & see Table A-3 & $\begin{array}{l}\text { Dependent upon the } \\
\text { alternative and source }\end{array}$ \\
\hline & Starting date of release & $04 / 94$ & Arbitrary assignment \\
\hline & Starting date for risk calculations & $04 / 94$ & Arbitrary assignment \\
\hline & Waste liquid infiltration rate & $\begin{array}{l}0.00045 \mathrm{ft} / \text { day for } \\
\text { alternative } 1 \\
0.0000045 \mathrm{ft} / \text { day for } \\
\text { all other alternatives }\end{array}$ & $\begin{array}{l}\text { Based on assumed } \\
\text { recharge rates of } 5 \\
\mathrm{~cm} / \mathrm{yr} \text { and } 0.05 \mathrm{~cm} / \mathrm{yr}\end{array}$ \\
\hline \multirow[t]{2}{*}{$\begin{array}{l}\text { Source } \\
\text { Characteristics }\end{array}$} & Area source dimensions (length and width) & $\begin{array}{l}375 \mathrm{ft} \text { long } \times 275 \mathrm{ft} \\
\text { wide }\end{array}$ & $\begin{array}{l}\text { Average dimensions of } \\
\text { a tank farm containing } \\
12 \text { tanks }\end{array}$ \\
\hline & Depth of release & see Tables A-3 & $\begin{array}{l}\text { Dependent upon the } \\
\text { alternative and source }\end{array}$ \\
\hline \multirow[t]{2}{*}{$\begin{array}{l}\text { Geologic Media } \\
\text { Data }\end{array}$} & $\begin{array}{l}\text { Medium types encountered moving from source } \\
\text { to receptor (e.g., partially saturated zone to } \\
\text { saturated zone to surface water or well) }\end{array}$ & 4 , see Table A-2 & Schramke 1994 \\
\hline & $\begin{array}{l}\text { Soil classification associated with the media } \\
\text { encountered from source to receptor (e.g., sand, } \\
\text { clay, silt, etc.) }\end{array}$ & see Table A-2 & Schramke 1994 \\
\hline
\end{tabular}


Table A-1. MEPAS Code Input Parameters for the Groundwater Pathway (Sheet 2 of 4).

\begin{tabular}{|c|c|c|c|}
\hline Parameter Type & Parameter Description & Value & $\begin{array}{l}\text { Data Source or } \\
\text { Justification }\end{array}$ \\
\hline \multirow[t]{7}{*}{$\begin{array}{l}\text { Geologic Media } \\
\text { Data (continued) }\end{array}$} & $\begin{array}{l}\text { Percent sand, silt, and clay associated with each } \\
\text { media classification encountered }\end{array}$ & see Table A-2 & Schramke 1994 \\
\hline & $\begin{array}{l}\text { Percent organic matter content in each media } \\
\text { classification encountered }\end{array}$ & see Table A-2 & Schramke 1994 \\
\hline & $\begin{array}{l}\mathrm{pH} \text { of pore water in each media classification } \\
\text { encountered }\end{array}$ & see Table A-2 & Schramke 1994 \\
\hline & Thickness of media zone & see Table A-2 & Schramke 1994 \\
\hline & Bulk density of media zone & see Table A-2 & Schramke 1994 \\
\hline & Longitudinal dispersivity of media zone & see Table A-2 & Schramke 1994 \\
\hline & Saturated hydraulic conductivity & see Table A-2 & Schramke 1994 \\
\hline \multirow[t]{3}{*}{ Groundwater Data } & Effective porosity of the saturated zone & $10 \%$ & Schramke 1994 \\
\hline & Pore water velocity of the saturated zone & $10.8 \mathrm{ft} /$ day & Schramke 1994 \\
\hline & Groundwater travel distance & $164 \mathrm{ft}$ & $\begin{array}{l}\text { Based on an assumed } \\
\text { distance of } 50 \mathrm{~m} \text {. }\end{array}$ \\
\hline
\end{tabular}


Table A-1. MEPAS Code Input Parameters for the Groundwater Pathway (Sheet 3 of 4).

\begin{tabular}{|c|c|c|c|}
\hline Parameter Type & Parameter Description & Value & $\begin{array}{l}\text { Data Source or } \\
\text { Justification }\end{array}$ \\
\hline \multirow{6}{*}{$\begin{array}{l}\text { Groundwater Data } \\
\text { (continued) }\end{array}$} & Longitudinal dispersivity of the saturated zone & $16.4 \mathrm{ft}$ & Droppo et. al 1989 \\
\hline & Transverse dispersivity of the saturated zone & $3.28 \mathrm{ft}$ & Droppo et. al 1989 \\
\hline & Vertical dispersivity of the saturated zone & $0.019 \mathrm{ft}$ & Droppo et. al 1989 \\
\hline & Percent of contaminant flux to saturated zone & $100 \%$ & $\begin{array}{l}\text { Conservative } \\
\text { assumption. }\end{array}$ \\
\hline & Perpendicular distance to plume centerline & $0 \mathrm{ft}$ & $\begin{array}{l}\text { Conservative } \\
\text { assumption. }\end{array}$ \\
\hline & $\begin{array}{l}\text { Contaminant-specific subsurface adsorption } \\
\text { coefficients }(\mathrm{Kd}) \text { for each media zone }\end{array}$ & 0 & Conservative assumption \\
\hline $\begin{array}{l}\text { Exposure Pathway } \\
\text { Selection }\end{array}$ & $\begin{array}{cl}\text { Exposure pathways considered } \\
-\quad \text { ingestion of groundwater } \\
-\quad \text { ingestion of vegetation } \\
-\quad \text { ingestion of meat and milk products } \\
-\quad \text { inhalation during showering } \\
\text { - } & \text { dermal contact during showering }\end{array}$ & None & Assumption \\
\hline
\end{tabular}


Table A-1. MEPAS Code Input Parameters for the Groundwater Pathway (Sheet 4 of 4).

\begin{tabular}{|l|l|l|l|}
\hline \multicolumn{1}{|c|}{ Parameter Type } & \multicolumn{1}{|c|}{ Parameter Description } & \multicolumn{1}{|c|}{ Value } & \multicolumn{1}{c|}{$\begin{array}{c}\text { Data Source or } \\
\text { Justification }\end{array}$} \\
\hline $\begin{array}{l}\text { Receptor Exposure } \\
\text { Characteristics }\end{array}$ & Location of public receptor & $\begin{array}{l}50 \mathrm{~m} \text { downgradient of } \\
\text { the tank farm }\end{array}$ & Conservative assumption \\
\hline & Drinking population served & 1 & $\begin{array}{l}\text { Assumption used for the } \\
\text { computation of risks to } \\
\text { maximally exposed } \\
\text { individual. }\end{array}$ \\
\hline & Selection of water treatment (Y or $\mathrm{N})$ & $\begin{array}{l}\text { Conservative } \\
\text { assumption. }\end{array}$ \\
\hline & Water distribution time & $\mathrm{N}$ & Droppo et. al 1989 \\
\hline & Type of irrigation usage selection & $0.5 \mathrm{days}$ & Assumption \\
& Irrigation rate & $100 \mathrm{~L} / \mathrm{m}^{2}$-month & Droppo et. al 1989 \\
\hline & Human body weight & $70 \mathrm{~kg}$ & USEPA 1989 \\
\hline & Exposure duration & $70 \mathrm{yrs}$ & USEPA 1989 \\
\hline
\end{tabular}


WHC-SD-WM-ES-300 REV. 1

Table A-2. MEPAS Input Parameters for Geologic Media Characteristics'.

\begin{tabular}{|l|c|c|c|c|}
\hline \multirow{2}{*}{ Parameter } & \multicolumn{3}{c|}{ Partially Saturated Zone } & \multirow{2}{*}{$\begin{array}{c}\text { Saturated } \\
\text { Zone }\end{array}$} \\
\cline { 2 - 4 } & Layer 1 & Layer 2 & Layer 3 & Loamy sand \\
\hline Soil classification & Sand & Sand & Sand & 83 \\
\hline Percent sand (\%) & 90 & 95 & 90 & 11 \\
\hline Percent silt (\%) & 9 & 3 & 9 & 6 \\
\hline Percent clay (\%) & 1 & 2 & 1 & 0 \\
\hline $\begin{array}{l}\text { Percent organic matter } \\
\text { content (\%) }\end{array}$ & 0 & 0 & 0 & 0 \\
\hline $\begin{array}{l}\text { Percent iron and } \\
\text { aluminum (\%) }\end{array}$ & 2 & 2 & 2 & 7.7 \\
\hline pH of pore water & 8.5 & 8.5 & 8.5 & 18 \\
\hline Thickness (ft) & 33 & 164 & 62 & 1.64 \\
\hline Bulk density (g/cm $\left.{ }^{3}\right)$ & 1.76 & 1.6 & 1.76 & 18 \\
\hline Total porosity (\%) & 36 & 42 & 36 & NA \\
\hline Field capacity (\%) & 19 & 8.5 & 19 & 16.4 \\
\hline $\begin{array}{l}\text { Longitudinal dispersivity } \\
\text { (ft) }\end{array}$ & 0.33 & 1.64 & 0.62 & NA \\
\hline $\begin{array}{l}\text { Saturated hydraulic } \\
\text { conductivity (cm/s) }\end{array}$ & 4.34 & 14.2 & 4.34 & \\
\hline
\end{tabular}

${ }^{1}$ All values are taken directly from Schramke 1994. 
Table A-3. Depth, Duration, and Timing of Releases from Alternative Sources. (Sheet 1 of 3)

\begin{tabular}{|c|c|c|c|c|c|}
\hline No. & $\begin{array}{c}\text { Alternative } \\
\text { Name }\end{array}$ & Source & $\begin{array}{l}\text { Depth of } \\
\text { Release } \\
\text { (ft) }\end{array}$ & $\begin{array}{c}\text { Duration } \\
\text { of } \\
\text { Release } \\
\text { (yrs) }\end{array}$ & $\begin{array}{c}\text { Time Period } \\
\text { Released }\end{array}$ \\
\hline \multirow[t]{4}{*}{1} & \multirow[t]{4}{*}{ No Action } & Tank Residual & 50 & 89 & $0-89$ \\
\hline & & Between Tank and Concrete & 50 & 0.02 & $89-89.1^{2}$ \\
\hline & & Concrete Pad & 50 & 0.8 & $89.1-89.9$ \\
\hline & & Old Leaks to Soil & 78 & 20 & $0-20$ \\
\hline \multirow[t]{4}{*}{2} & \multirow{4}{*}{$\begin{array}{l}\text { Surface Barrier } \\
\text { Only }\end{array}$} & Tank Residual & 50 & 8890 & $0-8890$ \\
\hline & & Between Tank and Concrete & 50 & 2 & $8890-8892$ \\
\hline & & Concrete Pad & 50 & 77 & $8892-8969$ \\
\hline & & Old Leaks to Soil & 78 & 2030 & $0-2030$ \\
\hline \multirow[t]{4}{*}{3} & \multirow{4}{*}{$\begin{array}{l}\text { Traditional } \\
\text { Sluicing }\end{array}$} & Tank Residual & 50 & 89 & $0-89$ \\
\hline & & Between Tank and Concrete & 50 & 2 & $89-91$ \\
\hline & & Concrete Pad & 50 & 112 & $91-203$ \\
\hline & & Old \& New Leaks to Soil & 99 & 3630 & $0-3630$ \\
\hline \multirow[t]{4}{*}{4} & \multirow{4}{*}{$\begin{array}{l}\text { Robotic } \\
\text { Sluicing }\end{array}$} & Tank Residual & 50 & 9 & $0-9$ \\
\hline & & Between Tank and Concrete & 50 & 2 & $9-11$ \\
\hline & & Concrete Pad & 50 & 77 & $11-88$ \\
\hline & & Old \& New Leaks to Soil & 81 & 2340 & $0-2340$ \\
\hline \multirow[t]{4}{*}{5} & \multirow{4}{*}{$\begin{array}{l}\text { Mechanical } \\
\text { Retrieval }\end{array}$} & Tank Residual & 50 & 445 & $0-445$ \\
\hline & & Between Tank and Concrete & 50 & 2 & $445-447$ \\
\hline & & Concrete Pad & 50 & 77 & $447-524$ \\
\hline & & Old Leaks to Soil & 78 & 2030 & $0-2030$ \\
\hline
\end{tabular}


WFIC-SD-WM-ES-300 REV. 1

Table A-3. Depth, Duration, and Timing of Releases from Alternative Sources. (Sheet 2 of 3)

\begin{tabular}{|c|c|c|c|c|c|}
\hline No. & $\begin{array}{l}\text { Alternative } \\
\text { Name }\end{array}$ & Source & $\begin{array}{l}\text { Depth of } \\
\text { Release } \\
\text { (ft) }\end{array}$ & $\begin{array}{l}\text { Duration } \\
\text { of } \\
\text { Release } \\
\text { (yrs) }\end{array}$ & $\begin{array}{l}\text { Time Period } \\
\text { Released }\end{array}$ \\
\hline \multirow[t]{5}{*}{6} & \multirow{5}{*}{$\begin{array}{l}\text { Close-Coupled } \\
\text { with Soil } \\
\text { Flushing }\end{array}$} & Tank Residual & 50 & 89 & $0-89$ \\
\hline & & Between Tank and Concrete & 50 & 2 & $89-91$ \\
\hline & & Concrete Pad & 50 & 112 & $91-203$ \\
\hline & & Old Leaks to Soil & 78 & 1980 & $0-1980$ \\
\hline & & Close-Coupled Barrier & 50 & 159 & $0-159$ \\
\hline \multirow[t]{5}{*}{7} & \multirow{5}{*}{$\begin{array}{l}\text { Close-Coupled } \\
\text { without Soil } \\
\text { Flushing }\end{array}$} & Tank Residual & 50 & 89 & $0-89$ \\
\hline & & Between Tank and Concrete & 50 & 2 & $89-91$ \\
\hline & & Concrete Pad & 50 & 112 & $91-203$ \\
\hline & & Old Leaks to Soil & 78 & 1970 & $0-1970$ \\
\hline & & Close-Coupled Barrier & 50 & 159 & $0-159$ \\
\hline \multirow[t]{5}{*}{8} & \multirow{5}{*}{$\begin{array}{l}\text { Modified } \\
\text { Close-Coupled } \\
\text { without Soil } \\
\text { Flushing }\end{array}$} & Tank Residual & 50 & 89 & $0-89$ \\
\hline & & Between Tank and Concrete & 50 & 2 & $89-91$ \\
\hline & & Concrete Pad & 50 & 112 & $91-203$ \\
\hline & & Old Leaks to Soil & 99 & 3440 & $0-3440$ \\
\hline & & Close-Coupled Barrier & 50 & 155 & $0-155$ \\
\hline \multirow[t]{5}{*}{9} & \multirow{5}{*}{$\begin{array}{l}\text { Box-Shaped } \\
\text { Chemical }\end{array}$} & Tank Residual & 50 & 89 & $0-89$ \\
\hline & & Between Tank and Concrete & 50 & 2 & $89-91$ \\
\hline & & Concrete Pad & 50 & 112 & $91-203$ \\
\hline & & $\begin{array}{l}\text { Flushed Old \& New Leaks to } \\
\text { Soil }\end{array}$ & 180 & 10800 & $0-9999^{b}$ \\
\hline & & Stand-Off Barrier & 180 & 9 & $0-9$ \\
\hline
\end{tabular}


Table A-3. Depth, Duration, and Timing of Releases . from Alternative Sources. (Sheet 3 of 3)

\begin{tabular}{|c|c|c|c|c|c|}
\hline No. & $\begin{array}{l}\text { Alternative } \\
\text { Name }\end{array}$ & Source & $\begin{array}{l}\text { Depth of } \\
\text { Release } \\
\text { (ft) }\end{array}$ & $\begin{array}{c}\text { Duration } \\
\text { of } \\
\text { Release } \\
\text { (yrs) }\end{array}$ & $\begin{array}{l}\text { Time Period } \\
\text { Released }\end{array}$ \\
\hline \multirow[t]{5}{*}{10} & \multirow{5}{*}{$\begin{array}{l}\text { V-Shaped } \\
\text { Chemical }\end{array}$} & Tank Residual & 50 & 89 & $0-89$ \\
\hline & & Between Tank and Concrete & 50 & 2 & $89-91$ \\
\hline & & Concrete Pad & 50 & 112 & $91-203$ \\
\hline & & $\begin{array}{l}\text { Flushed Old \& New Leaks to } \\
\text { Soil }\end{array}$ & 250 & 14300 & $0-9999^{b}$ \\
\hline & & Stand-Off Barrier & 250 & 13 & $0-13$ \\
\hline \multirow[t]{4}{*}{11} & \multirow{4}{*}{$\begin{array}{l}\text { V-Shaped } \\
\text { Freeze Wall }\end{array}$} & Tank Residual & 50 & 89 & $0-89$ \\
\hline & & Between Tank and Concrete & 50 & 2 & $89-91$ \\
\hline & & Concrete Pad & 50 & 112 & $91-203$ \\
\hline & & $\begin{array}{l}\text { Flushed Old \& New Leaks to } \\
\text { Soil }\end{array}$ & 250 & 14300 & $0-9999^{b}$ \\
\hline \multirow[t]{4}{*}{12} & \multirow[t]{4}{*}{ Circulating Air } & Tank Residual & 50 & 89 & $0-89$ \\
\hline & & Between Tank and Concrete & 50 & 2 & $89-91$ \\
\hline & & Concrete Pad & 50 & 112 & $91-203$ \\
\hline & & $\begin{array}{l}\text { Flushed Old \& New Leaks to } \\
\text { Soil }\end{array}$ & 78 & 2050 & $0-2050$ \\
\hline 13 & $\begin{array}{l}\text { Clean Closure } \\
\text { without Barrier }\end{array}$ & Landfill & 50 & 1280 & $0-1280$ \\
\hline 14 & $\begin{array}{l}\text { Clean Closure } \\
\text { with Barrier }\end{array}$ & Landfill & 50 & 531 & $0-531$ \\
\hline
\end{tabular}

"Although the release duration is less than 0.1 years, it has been set to 0.1 , because this is the minimum requirement for the MEPAS code.

${ }^{b}$ Although the release duration is greater than 9999 years, it has been set to 9999 years, because this is the maximum value required by the MEPAS code. 
Table A-4. Inventories, Flux Rates, and Release Durations for the No Action Alternative.

\begin{tabular}{|c|c|c|c|c|c|c|c|c|}
\hline \multirow[b]{2}{*}{ Contaminant } & \multicolumn{4}{|c|}{ Tank Residual } & \multicolumn{4}{|c|}{ Btw Tank \& Pad } \\
\hline & $\begin{array}{c}\text { Inventory } \\
\text { (g) }\end{array}$ & $\begin{array}{c}\text { Flux Rate } \\
(g / y r)\end{array}$ & $\begin{array}{c}\text { Flux Rate } \\
(\mathrm{Ci} / \mathrm{yr})\end{array}$ & $\begin{array}{c}\text { Release } \\
\text { Duration } \\
(y r)\end{array}$ & $\begin{array}{c}\text { Inventory } \\
\text { (g) }\end{array}$ & $\begin{array}{c}\text { Flux Rate } \\
(\mathrm{g} / \mathrm{yr})\end{array}$ & $\begin{array}{c}\text { Flux Rate } \\
(\mathrm{Ci} / \mathrm{yr})\end{array}$ & $\begin{array}{c}\text { Release } \\
\text { Duration } \\
(y r)\end{array}$ \\
\hline EDTA & $1.4 E+06$ & $1.5 E+04$ & NA & $8.9 E+01$ & $8.6 E+01$ & $4.3 E+03$ & NA & 2.0E-02 \\
\hline Nitrate & $7.8 E+09$ & $8.8 E+07$ & NA & $8.9 E+01$ & $5.0 E+05$ & $2.5 E+07$ & NA & 2.0E-02 \\
\hline Nitrite & $3.9 E+08$ & $4.3 E+06$ & NA & $8.9 E+01$ & $2.5 E+04$ & $1.2 E+06$ & NA & 2.0E-02 \\
\hline TBP & $1.2 E+06$ & $1.3 E+04$ & NA & $8.9 E+01$ & $7.5 E+01$ & $3.7 E+03$ & NA & 2.0E-02 \\
\hline C-14 & $5.4 E+01$ & $6.1 \mathrm{E}-01$ & $2.7 E+00$ & $8.9 E+01$ & $3.5 \mathrm{E}-03$ & 1.7E-01 & 7.7E-01 & $2.0 \mathrm{E}-02$ \\
\hline $\mid-129$ & $1.2 E+04$ & $1.3 E+02$ & $2.2 \mathrm{E}-02$ & $8.9 E+01$ & $7.6 \mathrm{E}-01$ & $3.8 E+01$ & $6.1 \mathrm{E}-03$ & $2.0 \mathrm{E}-02$ \\
\hline Tc-99 & $7.6 E+04$ & $8.5 E+02$ & $1.4 E+01$ & $8.9 E+01$ & $4.8 E+00$ & $2.4 E+02$ & $4.1 E+00$ & $2.0 \mathrm{E}-02$ \\
\hline U-238 & $1.1 E+08$ & $1.2 E+06$ & $4.2 \mathrm{E}-01$ & $8.9 \mathrm{E}+01$ & $7.1 E+03$ & $3.5 E+05$ & $1.2 \mathrm{E}-01$ & 2.0E-02 \\
\hline & \multicolumn{4}{|c|}{ Concrete Pad } & \multicolumn{4}{|c|}{ Old Leaks } \\
\hline Contaminant & $\begin{array}{c}\text { Inventory } \\
\text { (g) }\end{array}$ & $\begin{array}{c}\text { Flux Rate } \\
(\mathrm{g} / \mathrm{yr})\end{array}$ & $\begin{array}{c}\text { Flux Rate } \\
\text { (Ci/yr) }\end{array}$ & $\begin{array}{c}\text { Release } \\
\text { Duration } \\
\text { (yr) }\end{array}$ & $\begin{array}{c}\text { Inventory } \\
\text { (g) }\end{array}$ & $\begin{array}{c}\text { Flux Rate } \\
(g / y r)\end{array}$ & $\begin{array}{c}\text { Flux Rate } \\
(\mathrm{Ci} / \mathrm{yr})\end{array}$ & $\begin{array}{c}\text { Release } \\
\text { Duration } \\
(y r)\end{array}$ \\
\hline EDTA & $1.7 E+03$ & $2.2 E+03$ & NA & 7.7E-01 & $4.5 E+03$ & $2.2 E+02$ & NA & $2.0 E+01$ \\
\hline Nitrate & $1.0 E+07$ & $1.3 E+07$ & NA & 7.7E-01 & $2.6 E+07$ & $1.3 E+06$ & NA & $2.0 E+01$ \\
\hline Nitrite & $4.9 E+05$ & $6.4 E+05$ & NA & 7.7E-01 & $1.3 E+06$ & $6.3 E+04$ & NA & $2.0 E+01$ \\
\hline TBP & $1.5 E+03$ & $1.9 E+03$ & NA & 7.7E-01 & $3.9 E+03$ & $1.9 E+02$ & NA & $2.0 E+01$ \\
\hline$C-14$ & $6.9 \mathrm{E}-02$ & $9.0 \mathrm{E}-02$ & 4.0E-01 & 7.7E-01 & $1.8 \mathrm{E}-01$ & $8.8 \mathrm{E}-03$ & $3.9 \mathrm{E}-02$ & $2.0 E+01$ \\
\hline $1-129$ & $1.5 E+01$ & $2.0 E+01$ & $3.2 \mathrm{E}-03$ & 7.7E-01 & $3.9 E+01$ & $1.9 E+00$ & $3.2 E-04$ & $2.0 E+01$ \\
\hline Tc-99 & $9.7 E+01$ & $1.3 E+02$ & $2.1 E+00$ & 7.7E-01 & $2.5 E+02$ & $1.2 E+01$ & 2.1E-01 & $2.0 E+01$ \\
\hline $\mathrm{U}-238$ & $1.4 E+05$ & $1.8 E+05$ & $6.1 \mathrm{E}-02$ & 7.7E-01 & $3.7 E+05$ & $1.8 E+04$ & $6.0 E-03$ & $2.0 E+01$ \\
\hline
\end{tabular}


Table A-5. Inventories, Flux Rates, and Release Durations for the Surface Barrier Only Alternative.

\begin{tabular}{|c|c|c|c|c|c|c|c|c|}
\hline \multirow[b]{2}{*}{ Contaminant } & \multicolumn{4}{|c|}{ Tank Residual } & \multicolumn{4}{|c|}{ Btw Tank \& Pad } \\
\hline & $\begin{array}{c}\text { Inventory } \\
(g)\end{array}$ & $\begin{array}{c}\text { Flux Rate } \\
(\mathrm{g} / \mathrm{yr})\end{array}$ & $\begin{array}{c}\text { Flux Rate } \\
\text { (Ci/yr) }\end{array}$ & $\begin{array}{c}\text { Release } \\
\text { Duration } \\
\text { (yr) }\end{array}$ & $\begin{array}{c}\text { Inventory } \\
\text { (g) }\end{array}$ & $\begin{array}{c}\text { Flux Rate } \\
(\mathrm{g} / \mathrm{yr})\end{array}$ & $\begin{array}{c}\text { Flux Rate } \\
(\mathrm{Ci} / \mathrm{yr})\end{array}$ & $\begin{array}{c}\text { Release } \\
\text { Duration } \\
(y r)\end{array}$ \\
\hline EDंTA & $1.4 E+06$ & $1.5 E+02$ & NA & $8.9 E+03$ & $8.6 \mathrm{E}+01$ & $4.3 E+01$ & NA & $2.0 E+00$ \\
\hline Nitrate & $7.8 E+09$ & $8.8 E+05$ & NA & $8.9 E+03$ & $5.0 E+05$ & $2.5 E+05$ & NA & $2.0 E+00$ \\
\hline Nitrite & $3.9 E+08$ & $4.3 E+04$ & NA & $8.9 E+03$ & $2.5 E+04$ & $1.2 E+04$ & NA & $2.0 E+00$ \\
\hline TBP & $1.2 E+06$ & $1.3 E+02$ & NA & $8.9 E+03$ & $7.5 E+01$ & $3.7 E+01$ & NA & $2.0 E+00$ \\
\hline$C-14$ & $5.4 E+01$ & $6.1 \mathrm{E}-03$ & 2.7E-02 & $8.9 E+03$ & $3.5 E-03$ & 1.7E-03 & 7.7E-03 & $2.0 E+00$ \\
\hline $1-129$ & $1.2 E+04$ & $1.3 E+00$ & $2.2 E-04$ & $8.9 E+03$ & $7.6 \mathrm{E}-01$ & $3.8 \mathrm{E}-01$ & $6.1 E-05$ & $2.0 E+00$ \\
\hline Tc-99 & $7.6 E+04$ & $8.5 E+00$ & $1.4 \mathrm{E}-01$ & $8.9 E+03$ & $4.8 E+00$ & $2.4 E+00$ & $4.1 \mathrm{E}-02$ & $2.0 E+00$ \\
\hline U-238 & $1.1 E+08$ & $1.2 \mathrm{E}+04$ & $4.2 \mathrm{E}-03$ & $8.9 E+03$ & $7.1 E+03$ & $3.5 E+03$ & $1.2 E-03$ & $2.0 E+00$ \\
\hline & \multicolumn{4}{|c|}{ Concrete Pad } & \multicolumn{4}{|c|}{ Old Leaks } \\
\hline Contaminant & $\begin{array}{c}\text { Inventory } \\
\text { (g) }\end{array}$ & $\begin{array}{c}\text { Flux Rate } \\
(\mathrm{g} / \mathrm{yr})\end{array}$ & $\begin{array}{c}\text { Flux Rate } \\
(\mathrm{Ci} / \mathrm{yr})\end{array}$ & $\begin{array}{c}\text { Release } \\
\text { Duration } \\
(y r)\end{array}$ & $\begin{array}{c}\text { Inventory } \\
\text { (g) }\end{array}$ & $\begin{array}{c}\text { Flux Rate } \\
(\mathrm{g} / \mathrm{yr})\end{array}$ & $\begin{array}{c}\text { Flux Rate } \\
\text { (Ci/yr) }\end{array}$ & $\begin{array}{c}\text { Release } \\
\text { Duration } \\
(y r)\end{array}$ \\
\hline EDTA & $1.7 E+03$ & $2.2 E+01$ & NA & $7.7 E+01$ & $4.5 E+03$ & $2.2 \mathrm{E}+00$ & NA & $2.0 E+03$ \\
\hline Nitrate & $1.0 E+07$ & $1.3 E+05$ & NA & $7.7 E+01$ & $2.6 E+07$ & $1.3 E+04$ & NA & $2.0 E+03$ \\
\hline Nitrite & $4.9 E+05$ & $6.4 E+03$ & NA & $7.7 E+01$ & $1.3 E+06$ & $6.3 E+02$ & NA & $2.0 E+03$ \\
\hline TBP & $1.5 E+03$ & $1.9 E+01$ & NA & $7.7 E+01$ & $3.9 E+03$ & $1.9 E+00^{\circ}$ & NA & $2.0 E+03$ \\
\hline$C-14$ & $6.9 E-02$ & $9.0 \mathrm{E}-04$ & 4.0E-03 & $7.7 E+01$ & $1.8 \mathrm{E}-01$ & 8.8E-05 & $3.9 E-04$ & $2.0 E+03$ \\
\hline $1-129$ & $1.5 E+01$ & 2.OE-01 & $3.2 E-05$ & $7.7 E+01$ & $3.9 E+01$ & $1.9 \mathrm{E}-02$ & $3.2 E-06$ & $2.0 E+03$ \\
\hline Tc-99 & $9.7 E+01$ & $1.3 E+00$ & $2.1 E-02$ & $7.7 E+01$ & $2.5 E+02$ & $1.2 \mathrm{E}-01$ & 2.1E-03 & $2.0 E+03$ \\
\hline$U-238$ & $1.4 E+05$ & $1.8 E+03$ & 6.1E-04 & $7.7 E+01$ & $3.7 E+05$ & $1.8 E+02$ & $6.0 \mathrm{E}-05$ & $2.0 E+03$ \\
\hline
\end{tabular}


Table A-6. Inventories, Flux Rates, and Release Durations for the Traditional Sluicing Alternative.

\begin{tabular}{|c|c|c|c|c|c|c|c|c|}
\hline \multirow[b]{2}{*}{ Contaminant } & \multicolumn{4}{|c|}{ Tank Residual } & \multicolumn{4}{|c|}{ Btw Tank \& Pad } \\
\hline & $\begin{array}{c}\text { Inventory } \\
\text { (g) }\end{array}$ & $\begin{array}{c}\text { Flux Rate } \\
(\mathrm{g} / \mathrm{yr})\end{array}$ & $\begin{array}{c}\text { Flux Rate } \\
(\mathrm{Ci} / \mathrm{yr})\end{array}$ & $\begin{array}{c}\text { Release } \\
\text { Duration } \\
\text { (yr) }\end{array}$ & $\begin{array}{c}\text { Inventory } \\
\text { (g) }\end{array}$ & $\begin{array}{c}\text { Flux Rate } \\
(\mathrm{g} / \mathrm{yr})\end{array}$ & $\begin{array}{c}\text { Flux Rate } \\
(\mathrm{Ci} / \mathrm{yr})\end{array}$ & $\begin{array}{c}\text { Release } \\
\text { Duration } \\
(y r) \\
\end{array}$ \\
\hline EDTA & $1.4 E+04$ & $1.5 E+02$ & NA & $8.9 E+01$ & $1.3 E+02$ & $6.3 E+01$ & NA & $2.0 E+00$ \\
\hline Nitrate & $7.8 E+07$ & $8.8 E+05$ & NA & $8.9 E+01$ & $7.3 E+05$ & $3.6 \mathrm{E}+05$ & NA & $2.0 \dot{\mathrm{E}}+00$ \\
\hline Nitrite & $3.9 E+06$ & $4.3 E+04$ & NA & $8.9 E+01$ & $3.6 E+04$ & $1.8 E+04$ & NA & $2.0 E+00$ \\
\hline TBP & $1.2 E+04$ & $1.3 E+02$ & NA & $8.9 E+01$ & $1.1 E+02$ & $5.5 E+01$ & NA & $2.0 E+00$ \\
\hline C-14 & $5.4 \mathrm{E}-01$ & $6.1 \mathrm{E}-03$ & 2.7E-02 & $8.9 E+01$ & $5.0 \mathrm{E}-03$ & $2.5 E-03$ & 1.1E-02 & $2.0 E+00$ \\
\hline $1-129$ & $1.2 E+02$ & $1.3 E+00$ & $2.2 E-04$ & $8.9 E+01$ & $1.1 E+00$ & $5.5 \mathrm{E}-01$ & 9.0E-05 & $2.0 E+00$ \\
\hline Tc-99 & $7.6 E+02$ & $8.5 E+00$ & $1.4 \mathrm{E}-01$ & $8.9 E+01$ & $7.0 E+00$ & $3.5 \mathrm{E}+00$ & $6.0 \mathrm{E}-02$ & $2.0 E+00$ \\
\hline U-238 & $1.1 E+06$ & $1.2 E+04$ & $4.2 \mathrm{E}-03$ & $8.9 E+01$ & $1.0 E+04$ & $5.2 E+03$ & 1.7E-03 & $2.0 \mathrm{E}+00$ \\
\hline & \multicolumn{4}{|c|}{ Concrete Pad } & \multicolumn{4}{|c|}{ Old \& New Leaks } \\
\hline Contaminant & $\begin{array}{c}\text { Inventory } \\
\text { (g) }\end{array}$ & $\begin{array}{c}\text { Flux Rate } \\
(\mathrm{g} / \mathrm{yr})\end{array}$ & $\begin{array}{c}\text { Flux Rate } \\
(\mathrm{Ci} / \mathrm{yr})\end{array}$ & $\begin{array}{c}\text { Release } \\
\text { Duration } \\
(y r)\end{array}$ & $\begin{array}{c}\text { Inventory } \\
\text { (g) }\end{array}$ & $\begin{array}{c}\text { Flux Rate } \\
(\mathrm{g} / \mathrm{yr})\end{array}$ & $\begin{array}{c}\text { Flux Rate } \\
\text { (Ci/yr) }\end{array}$ & $\begin{array}{c}\text { Release } \\
\text { Duration } \\
(y r)\end{array}$ \\
\hline EDTA & $2.4 E+03$ & $2.2 \mathrm{E}+01$ & NA & $1.1 E+02$ & $2.1 E+04$ & $5.7 E+00$ & NA & $3.6 \mathrm{E}+03$ \\
\hline Nitrate & $1.4 E+07$ & $1.3 E+05$ & NA & $1.1 E+02$ & $1.2 E+08$ & $3.3 E+04$ & NA & $3.6 E+03$ \\
\hline Nitrite & $7.0 E+05$ & $6.2 E+03$ & NA & $1.1 E+02$ & $5.9 E+06$ & $1.6 \mathrm{E}+03$ & NA & $3.6 \mathrm{E}+03$ \\
\hline TBP & $2.1 E+03$ & $1.9 E+01$ & NA & $1.1 E+02$ & $1.8 E+04$ & $5.0 \mathrm{E}+00$ & NA & $3.6 E+03$ \\
\hline C-14 & $9.8 \mathrm{E}-02$ & 8.7E-04 & 3.9E-03 & $1.1 \mathrm{E}+02$ & 8.3E-01 & 2.3E-04 & 1.0E-03 & $3.6 \mathrm{E}+03$ \\
\hline 1.129 & $2.1 E+01$ & $1.9 E-01$ & $3.1 \mathrm{E}-05$ & $1.1 \mathrm{E}+02$ & $1.8 \mathrm{E}+02$ & $5.0 \mathrm{E}-02$ & 8.2E-06 & $3.6 \mathrm{E}+03$ \\
\hline Tc-99 & $1.4 E+02$ & $1.2 E+00$ & 2.1E-02 & $1.1 E+02$ & $1.2 E+03$ & $3.2 \mathrm{E}-01$ & $5.5 E-03$ & $3.6 \mathrm{E}+03$ \\
\hline U-238 & $2.0 E+05$ & $1.8 \mathrm{E}+03$ & $6.0 \mathrm{E}-04$ & $1.1 E+02$ & $1.7 E+06$ & 4.7E + 02 & $1.6 \mathrm{E}-04$ & $3.6 E+03$ \\
\hline
\end{tabular}


Table A-7. Inventories, Flux Rates, and Release Durations for the Robotic Sluicing Alternative.

\begin{tabular}{|c|c|c|c|c|c|c|c|c|}
\hline \multirow[b]{2}{*}{ Contaminant } & \multicolumn{4}{|c|}{ Tank Residual } & \multicolumn{4}{|c|}{ Btw Tank \& Pad } \\
\hline & $\begin{array}{c}\text { Inventory } \\
\text { (g) }\end{array}$ & $\begin{array}{c}\text { Flux Rate } \\
(g / y r)\end{array}$ & $\begin{array}{c}\text { Flux Rate } \\
\text { (Ci/yr) }\end{array}$ & $\begin{array}{c}\text { Release } \\
\text { Duration } \\
\text { (yr) }\end{array}$ & $\begin{array}{c}\text { Inventory } \\
\text { (g) }\end{array}$ & $\begin{array}{c}\text { Flux Rate } \\
(g / y r)\end{array}$ & $\begin{array}{c}\text { Flux Rate } \\
\text { (Ci/yr) }\end{array}$ & $\begin{array}{c}\text { Release } \\
\text { Duration } \\
(y r)\end{array}$ \\
\hline EDTA & $1.4 E+03$ & $1.5 E+02$ & NA & $8.9 E+00$ & $1.3 E+02$ & $6.3 E+01$ & NA & $2.0 E+00$ \\
\hline Nitrate & $7.8 E+06$ & $8.8 E+05$ & NA & $8.9 E+00$ & $7.3 E+05$ & $3.6 E+05$ & NA & $2.0 E+00$ \\
\hline Nitrite & $3.9 E+05$ & $4.3 E+04$ & NA & $8.9 E+00$ & $3.6 \mathrm{E}+04$ & $1.8 E+04$ & NA & $2.0 E+00$ \\
\hline TBP & $1.2 E+03$ & $1.3 E+02$ & NA & $8.9 E+00$ & $1.1 E+02$ & $5.5 E+01$ & NA & $2.0 E+00$ \\
\hline C-14 & $5.4 \mathrm{E}-02$ & $6.1 \mathrm{E}-03$ & 2.7E-02 & $8.9 E+00$ & $5.0 \mathrm{E}-03$ & $2.5 \mathrm{E}-03$ & $1.1 \mathrm{E}-02$ & $2.0 E+00$ \\
\hline $1-129$ & $1.2 E+01$ & $1.3 E+00$ & 2.2E-04 & $8.9 E+00$ & $1.1 E+00$ & $5.5 \mathrm{E}-01$ & $9.0 \mathrm{E}-05$ & $2.0 E+00$ \\
\hline Tc-99 & $7.6 E+01$ & $8.5 E+00$ & $1.4 \mathrm{E}-01$ & $8.9 E+00$ & $7.0 E+00$ & $3.5 E+00$ & $6.0 E-02$ & $2.0 E+00$ \\
\hline $\mathrm{U}-238$ & $1.1 E+05$ & $1.2 E+04$ & $4.2 \mathrm{E}-03$ & $8.9 E+00$ & $1.0 E+04$ & $5.2 E+03$ & $1.7 \mathrm{E}-03$ & $2.0 E+00$ \\
\hline & \multicolumn{4}{|c|}{ Concrete Pad } & \multicolumn{4}{|c|}{ Old \& New Leaks } \\
\hline Contaminant & $\begin{array}{c}\text { Inventory } \\
\text { (g) }\end{array}$ & $\begin{array}{c}\text { Flux Rate } \\
(\mathrm{g} / \mathrm{yr})\end{array}$ & $\begin{array}{c}\text { Flux Rate } \\
\text { (Ci/yr) }\end{array}$ & $\begin{array}{c}\text { Release } \\
\text { Duration } \\
(y r)\end{array}$ & $\begin{array}{l}\text { Inventory } \\
\text { (g) }\end{array}$ & $\begin{array}{c}\text { Flux Rate } \\
(\mathrm{g} / \mathrm{yr})\end{array}$ & $\begin{array}{c}\text { Flux Rate } \\
(\mathrm{Ci} / \mathrm{yr})\end{array}$ & $\begin{array}{c}\text { Release } \\
\text { Duration } \\
(y r)\end{array}$ \\
\hline EDTA & $1.7 E+03$ & $2.2 E+01$ & NA & $7.7 E+01$ & $6.0 E+03$ & $2.6 E+00$ & NA & $2.3 E+03$ \\
\hline Nitrate & $1.0 E+07$ & $1.3 E+05$ & NA & $7.7 E+01$ & $3.5 E+07$ & $1.5 E+04$ & NA & $2.3 E+03$ \\
\hline Nitrite & $4.9 E+05$ & $6.4 E+03$ & NA & $7.7 E+01$ & $1.7 E+06$ & $7.4 E+02$ & NA & $2.3 E+03$ \\
\hline TBP & $1.5 E+03$ & $1.9 E+01$ & NA & $7.7 E+01$ & $5.3 E+03$ & $2.2 E+00$ & NA & $2.3 E+03$ \\
\hline C-14 & $6.9 \mathrm{E}-02$ & $9.0 \mathrm{E}-04$ & 4.0E-03 & $7.7 E+01$ & $2.4 \mathrm{E}-01$ & $1.0 \mathrm{E}-04$ & $4.6 \mathrm{E}-04$ & $2.3 E+03$ \\
\hline $1-129$ & $1.5 E+01$ & 2.0E-01 & $3.2 \mathrm{E}-05$ & $7.7 E+01$ & $5.3 E+01$ & $2.3 E-02$ & 3.7E-06 & $2.3 E+03$ \\
\hline Tc-99 & $9.7 E+01$ & $1.3 E+00$ & $2.1 \mathrm{E}-02$ & $7.7 E+01$ & $3.4 E+02$ & 1.4E-01 & $2.5 \mathrm{E}-03$ & $2.3 E+03$ \\
\hline$U-238$ & $1.4 E+05$ & $1.8 E+03$ & $6.1 \mathrm{E}-04$ & $7.7 E+01$ & $5.0 E+05$ & $2.1 E+02$ & 7.1E-05 & $2.3 E+03$ \\
\hline
\end{tabular}


Table A-8. Inventories, Flux Rates, and Release Durations for the Mechanical Mining Alternatives.

\begin{tabular}{|c|c|c|c|c|c|c|c|c|}
\hline \multirow[b]{2}{*}{ Contaminant } & \multicolumn{4}{|c|}{ Tank Residual } & \multicolumn{4}{|c|}{ Btw Tank \& Pad } \\
\hline & $\begin{array}{c}\text { Inventory } \\
\text { (g) }\end{array}$ & $\begin{array}{c}\text { Flux Rate } \\
(g / y r)\end{array}$ & $\begin{array}{c}\text { Flux Rate } \\
(\mathrm{Ci} / \mathrm{yr})\end{array}$ & $\begin{array}{c}\text { Release } \\
\text { Duration } \\
(y r) \\
\end{array}$ & $\begin{array}{c}\text { Inventory } \\
\text { (g) }\end{array}$ & $\begin{array}{c}\text { Flux Rate } \\
(g / y r)\end{array}$ & $\begin{array}{c}\text { Flux Rate } \\
\text { (Ci/yr) }\end{array}$ & $\begin{array}{c}\text { Release } \\
\text { Duration } \\
(y r)\end{array}$ \\
\hline EDTA & $6.8 E+04$ & $1.5 E+02$ & NA & $4.4 E+02$ & $8.6 E+01$ & $4.3 E+01$ & NA & $2.0 E+00$ \\
\hline Nitrate & $3.9 E+08$ & $8.8 E+05$ & NA & $4.4 E+02$ & $5.0 E+05$ & $2.5 E+05$ & NA & $2.0 E+00$ \\
\hline Nitrite & $1.9 E+07$ & $4.3 E+04$ & NA & $4.4 E+02$ & $2.5 E+04$ & $1.2 E+04$ & NA & $2.0 E+00$ \\
\hline TBP & $5.9 E+04$ & $1.3 E+02$ & NA & $4.4 E+02$ & $7.5 E+01$ & $3.7 E+01$ & NA & $2.0 E+00$ \\
\hline$C-14$ & $2.7 E+00$ & $6.1 \mathrm{E}-03$ & 2.7E-02 & $4.4 E+02$ & $3.5 \mathrm{E}-03$ & 1.7E-03 & 7.7E-03 & $2.0 \mathrm{E}+00$ \\
\hline $1-129$ & $5.9 E+02$ & $1.3 E+00$ & $2.2 E-04$ & $4.4 E+02$ & 7.6E-01 & $3.8 \mathrm{E}-01$ & 6.1E-05 & $2.0 \mathrm{E}+00$ \\
\hline Tc-99 & $3.8 E+03$ & $8.5 E+00$ & $1.4 \mathrm{E}-01$ & $4.4 E+02$ & $4.8 E+00$ & $2.4 E+00$ & 4.1E-02 & $2.0 \mathrm{E}+00$ \\
\hline U-238 & $5.6 E+06$ & $1.2 E+04$ & 4.2E-03 & $4.4 E+02$ & $7.1 E+03$ & $3.5 E+03$ & 1.2E-03 & $2.0 E+00$ \\
\hline & \multicolumn{4}{|c|}{ Concrete Pad } & \multicolumn{4}{|c|}{ Old Leaks } \\
\hline Contaminant & $\begin{array}{c}\text { Inventory } \\
\text { (g) }\end{array}$ & $\begin{array}{c}\text { Flux Rate } \\
(g / y r)\end{array}$ & $\begin{array}{c}\text { Flux Rate } \\
(\mathrm{Ci} / \mathrm{yr})\end{array}$ & $\begin{array}{c}\text { Release } \\
\text { Duration } \\
(y r) \\
\end{array}$ & $\begin{array}{c}\text { Inventory } \\
\text { (g) }\end{array}$ & $\begin{array}{c}\text { Flux Rate } \\
(g / y r)\end{array}$ & $\begin{array}{c}\text { Flux Rate } \\
\text { (Ci/yr) }\end{array}$ & $\begin{array}{c}\text { Release } \\
\text { Duration } \\
\text { (yr) }\end{array}$ \\
\hline EDTA & $1.7 E+03$ & $2.2 E+01$ & NA & $7.7 E+01$ & $4.5 E+03$ & $2.2 E+00$ & NA & $2.0 E+03$ \\
\hline Nitrate & $1.0 E+07$ & $1.3 E+05$ & NA & $7.7 E+01$ & $2.6 E+07$ & $1.3 E+04$ & NA & $2.0 E+03$ \\
\hline Nitrite & $4.9 E+05$ & $6.4 E+03$ & NA & $7.7 E+01$ & $1.3 E+06$ & $6.3 E+02$ & NA & $2.0 E+03$ \\
\hline TBP & $1.5 E+03$ & $1.9 E+01$ & NA & $7.7 E+01$ & $3.9 E+03$ & $1.9 E+00$ & NA & $2.0 E+03$ \\
\hline$C-14$ & $6.9 \mathrm{E}-02$ & $9.0 \mathrm{E}-04$ & 4.0E-03 & $7.7 E+01$ & $1.8 \mathrm{E}-01$ & $8.8 \mathrm{E}-05$ & $3.9 E-04$ & $2.0 E+03$ \\
\hline $1-129$ & $1.5 E+01$ & 2.0E-01 & 3.2E-05 & $7.7 E+01$ & $3.9 E+01$ & $1.9 \mathrm{E}-02$ & $3.2 \mathrm{E}-06$ & $2.0 E+03$ \\
\hline Tc-99 & $9.7 E+01$ & $1.3 E+00$ & 2.1E-02 & $7.7 E+01$ & $2.5 E+02$ & $1.2 \mathrm{E}-01$ & 2.1E-03 & $2.0 E+03$ \\
\hline U.238 & $1.4 E+05$ & $1.8 \mathrm{E}+03$ & $6.1 \mathrm{E}-04$ & $7.7 E+01$ & $3.7 E+05$ & $1.8 E+02$ & $6.0 \mathrm{E}-05$ & $2.0 \mathrm{E}+03$ \\
\hline
\end{tabular}


Table A-9. Inventories, Flux Rates, and Release Durations for the Close-Coupled w/Soil Flushing Alternative. (Sheet 1 of 2)

\begin{tabular}{|c|c|c|c|c|c|c|c|c|}
\hline \multirow[b]{2}{*}{ Contaminant } & \multicolumn{4}{|c|}{ Tank Residual } & \multicolumn{4}{|c|}{ Btw Tank \& Pad } \\
\hline & $\begin{array}{c}\text { Inventory } \\
(\mathrm{g})\end{array}$ & $\begin{array}{c}\text { Flux Rate } \\
(\mathrm{g} / \mathrm{yr})\end{array}$ & $\begin{array}{c}\text { Flux Rate } \\
(\mathrm{Ci} / \mathrm{yr})\end{array}$ & $\begin{array}{c}\text { Release } \\
\text { Duration } \\
\text { (yr) }\end{array}$ & $\begin{array}{l}\text { Inventory } \\
\text { (g) }\end{array}$ & $\begin{array}{c}\text { Flux Rate } \\
(\mathrm{g} / \mathrm{yr})\end{array}$ & $\begin{array}{c}\text { Flux Rate } \\
(\mathrm{Ci} / \mathrm{yr})\end{array}$ & $\begin{array}{c}\text { Release } \\
\text { Duration } \\
(y r)\end{array}$ \\
\hline EDTA & $1.4 E+04$ & $1.5 E+02$ & NA & $8.9 E+01$ & $1.3 E+02$ & $6.3 E+01$ & NA & $2.0 E+00$ \\
\hline Nitrate & $7.8 E+07$ & $8.8 E+05$ & NA & $8.9 E+01$ & $7.3 E+05$ & $3.6 E+05$ & NA & $2.0 E+00$ \\
\hline Nitrite & $3.9 E+06$ & $4.3 E+04$ & NA & $8.9 E+0 i$ & $3.6 \mathrm{E}+04$ & $1.8 E+04$ & NA & $2.0 E+00$ \\
\hline TBP & $1.2 E+04$ & $1.3 E+02$ & NA & $8.9 E+01$ & $1.1 E+02$ & $5.5 E+01$ & NA & $2.0 E+00$ \\
\hline$C-14$ & $5.4 \mathrm{E}-01$ & $6.1 \mathrm{E}-03$ & 2.7E-02 & $8.9 E+01$ & $5.0 \mathrm{E}-03$ & $2.5 \mathrm{E}-03$ & 1.1E-02 & $2.0 E+00$ \\
\hline $1-129$ & $1.2 E+02$ & $1.3 E+00$ & $2.2 E-04$ & $8.9 E+01$ & $1.1 E+00$ & $5.5 \mathrm{E}-01$ & $9.0 \mathrm{E}-05$ & $2.0 E+00$ \\
\hline Tc-99 & $7.6 \mathrm{E}+02$ & $8.5 E+00$ & $1.4 \mathrm{E}-01$ & $8.9 E+01$ & $7.0 E+00$ & $3.5 E+00$ & $6.0 \mathrm{E}-02$ & $2.0 E+00$ \\
\hline U-238 & $1.1 E+06$ & $1.2 E+04$ & 4.2E-03 & $8.9 \mathrm{E}+01$ & $1.0 E+04$ & $5.2 E+03$ & 1.7E-03 & $2.0 E+00$ \\
\hline & \multicolumn{4}{|c|}{ Concrete Pad } & \multicolumn{4}{|c|}{ Flushed Old Leaks } \\
\hline Contaminant & $\begin{array}{c}\text { Inventory } \\
\text { (g) }\end{array}$ & $\begin{array}{c}\text { Flux Rate } \\
(\mathrm{g} / \mathrm{yr})\end{array}$ & $\begin{array}{c}\text { Flux Rate } \\
(\mathrm{Ci} / \mathrm{yr})\end{array}$ & $\begin{array}{c}\text { Release } \\
\text { Duration } \\
\text { (yr) }\end{array}$ & $\begin{array}{c}\text { Inventory } \\
\text { (g) }\end{array}$ & $\begin{array}{c}\text { Flux Rate } \\
(\mathrm{g} / \mathrm{yr})\end{array}$ & $\begin{array}{c}\text { Flux Rate } \\
(\mathrm{Ci} / \mathrm{yr})\end{array}$ & $\begin{array}{c}\text { Release } \\
\text { Duration } \\
\text { (yr) }\end{array}$ \\
\hline EDTA & $2.4 E+03$ & $2.2 E+01$ & NA & $1.1 E+02$ & $2.7 E+02$ & 1.3E-01 & NA & $2.0 E+03$ \\
\hline Nitrate & $1.4 E+07$ & $1.3 E+05$ & NA & $1.1 E+02$ & $1.5 E+06$ & $7.8 E+02$ & NA & $2.0 E+03$ \\
\hline Nitrite & $7.0 E+05$ & $6.2 E+03$ & NA & $1.1 E+02$ & $7.6 E+04$ & $3.9 E+01$ & NA & $2.0 E+03$ \\
\hline TBP & $2.1 E+03$ & $1.9 E+01$ & NA & $1.1 E+02$ & $2.3 E+02$ & $1.2 \mathrm{E}-01$ & NA & $2.0 E+03$ \\
\hline$C-14$ & $9.8 \mathrm{E}-02$ & 8.7E-04 & $3.9 E-03$ & $1.1 E+02$ & 1.1E-02 & 5.4E-06 & 2.4E-05 & $2.0 E+03$ \\
\hline $1-129$ & $2.1 E+01$ & $1.9 \mathrm{E}-01$ & $3.1 E-05$ & $1.1 E+02$ & $2.3 E+00$ & $1.2 E-03$ & 1.9E-07 & $2.0 E+03$ \\
\hline Tc-99 & $1.4 E+02$ & $1.2 E+00$ & 2.1E-02 & $1.1 E+02$ & $1.5 E+01$ & 7.6E-03 & $1.3 E-04$ & $2.0 E+03$ \\
\hline U-238 & $2.0 E+05$ & $1.8 E+03$ & $6.0 E-04$ & $1.1 E+02$ & $2.2 E+04$ & $1.1 E+01$ & $3.7 E-06$ & $2.0 E+03$ \\
\hline
\end{tabular}


Table A-9. Inventories, Flux Rates, and Release Durations for the Close-Coupled w/Soil Flushing Alternative. (Sheet 2 of 2)

\begin{tabular}{lcccc}
\hline & \multicolumn{4}{c}{ Barrier } \\
\cline { 2 - 5 } Contaminant & $\begin{array}{c}\text { Inventory } \\
(\mathrm{g})\end{array}$ & $\begin{array}{c}\text { Flux Rate } \\
(\mathrm{g} / \mathrm{yr})\end{array}$ & $\begin{array}{c}\text { Flux Rate } \\
(\mathrm{Ci} / \mathrm{yr})\end{array}$ & $\begin{array}{c}\text { Release } \\
\text { Duration } \\
(\mathrm{yr})\end{array}$ \\
\hline EDTA & $1.7 \mathrm{E}+03$ & $1.1 \mathrm{E}+01$ & $\mathrm{NA}$ & $1.6 \mathrm{E}+02$ \\
Nitrate & $1.0 \mathrm{E}+07$ & $6.3 \mathrm{E}+04$ & $\mathrm{NA}$ & $1.6 \mathrm{E}+02$ \\
Nitrite & $4.9 \mathrm{E}+05$ & $3.1 \mathrm{E}+03$ & $\mathrm{NA}$ & $1.6 \mathrm{E}+02$ \\
TBP & $1.5 \mathrm{E}+03$ & $9.5 \mathrm{E}+00$ & $\mathrm{NA}$ & $1.6 \mathrm{E}+02$ \\
$\mathrm{C}-14$ & $6.9 \mathrm{E}-02$ & $4.4 \mathrm{E}-04$ & $1.9 \mathrm{E}-03$ & $1.6 \mathrm{E}+02$ \\
$\mathrm{I}-129$ & $1.5 \mathrm{E}+01$ & $9.5 \mathrm{E}-02$ & $1.6 \mathrm{E}-05$ & $1.6 \mathrm{E}+02$ \\
TC-99 & $9.7 \mathrm{E}+01$ & $6.1 \mathrm{E}-01$ & $1.0 \mathrm{E}-02$ & $1.6 \mathrm{E}+02$ \\
$\mathrm{U}-238$ & $1.4 \mathrm{E}+05$ & $9.0 \mathrm{E}+02$ & $3.0 \mathrm{E}-04$ & $1.6 \mathrm{E}+02$ \\
\hline
\end{tabular}


Table A-10. Inventories, Flux Rates, and Release Durations for the

Close-Coupled Alternative w/o Soil Flushing. (Sheet 1 of 2)

\begin{tabular}{|c|c|c|c|c|c|c|c|c|}
\hline \multirow[b]{2}{*}{ Contaminant } & \multicolumn{4}{|c|}{ Tank Residual } & \multicolumn{4}{|c|}{ Btw Tank \& Pad } \\
\hline & $\begin{array}{l}\text { Inventory } \\
\text { (g) }\end{array}$ & $\begin{array}{c}\text { Flux Rate } \\
(\mathrm{g} / \mathrm{yr})\end{array}$ & $\begin{array}{c}\text { Flux Rate } \\
\text { (Ci/yr) }\end{array}$ & $\begin{array}{c}\text { Release } \\
\text { Duration } \\
(y r) \\
\end{array}$ & $\begin{array}{c}\text { Inventory } \\
\text { (g) }\end{array}$ & $\begin{array}{c}\text { Flux Rate } \\
(\mathrm{g} / \mathrm{yr})\end{array}$ & $\begin{array}{c}\text { Flux Rate } \\
(\mathrm{Ci} / \mathrm{yr})\end{array}$ & $\begin{array}{c}\text { Release } \\
\text { Duration } \\
(y r)\end{array}$ \\
\hline EDTA & $1.4 E+04$ & $1.5 E+02$ & NA & $8.9 E+01$ & $1.3 E+02$ & $6.3 E+01$ & NA & $2.0 E+00$ \\
\hline Nitrate & $7.8 E+07$ & $8.8 E+05$ & NA & $8.9 E+01$ & $7.3 E+05$ & $3.6 \mathrm{E}+05$ & NA & $2.0 E+00$ \\
\hline Nitrite & $3.9 E+06$ & $4.3 E+04$ & NA & $8.9 E+01$ & $3.6 \mathrm{E}+04$ & $1.8 E+04$ & NA & $2.0 E+00$ \\
\hline TBP & $1.2 E+04$ & $1.3 E+02$ & NA & $8.9 E+01$ & $1.1 E+02$ & $5.5 E+01$ & NA & $2.0 E+00$ \\
\hline$C-14$ & $5.4 \mathrm{E}-01$ & $6.1 \mathrm{E}-03$ & 2.7E-02 & $8.9 E+01$ & $5.0 \mathrm{E}-03$ & $2.5 \mathrm{E}-03$ & 1.1E-02 & $2.0 E+00$ \\
\hline 1.129 & $1.2 E+02$ & $1.3 E+00$ & $2.2 \mathrm{E}-04$ & $8.9 E+01$ & $1.1 E+00$ & $5.5 \mathrm{E}-01$ & $9.0 E-05$ & $2.0 E+00$ \\
\hline Tc-99 & $7.6 E+02$ & $8.5 E+00$ & $1.4 \mathrm{E}-01$ & $8.9 E+01$ & $7.0 \mathrm{E}+00$ & $3.5 E+00$ & $6.0 \mathrm{E}-02$ & $2.0 E+00$ \\
\hline \multirow[t]{3}{*}{$\mathrm{U}-238$} & $1.1 E+06$ & $1.2 E+04$ & $4.2 \mathrm{E}-03$ & $8.9 E+01$ & $1.0 E+04$ & $5.2 E+03$ & 1.7E-03 & $2.0 E+00$ \\
\hline & \multicolumn{4}{|c|}{ Concrete Pad } & \multicolumn{4}{|c|}{ Old Leaks } \\
\hline & $\begin{array}{c}\text { Inventory } \\
\text { (g) }\end{array}$ & $\begin{array}{c}\text { Flux Rate } \\
(\mathrm{g} / \mathrm{yr})\end{array}$ & $\begin{array}{c}\text { Flux Rate } \\
(\mathrm{Ci} / \mathrm{yr})\end{array}$ & $\begin{array}{c}\text { Release } \\
\text { Duration } \\
(y r) \\
\end{array}$ & $\begin{array}{c}\text { Inventory } \\
\text { (g) }\end{array}$ & $\begin{array}{c}\text { Flux Rate } \\
(\mathrm{g} / \mathrm{yr})\end{array}$ & $\begin{array}{c}\text { Flux Rate } \\
(\mathrm{Ci} / \mathrm{yr})\end{array}$ & $\begin{array}{c}\text { Release } \\
\text { Duration } \\
(y r)\end{array}$ \\
\hline EDTA & $2.4 E+03$ & $2.2 E+01$ & NA & $1.1 E+02$ & $6.2 E+03$ & $3.2 E+00$ & NA & $2.0 E+03$ \\
\hline Nitrate & $1.4 E+07$ & $1.3 E+05$ & NA & $1.1 E+02$ & $3.6 E+07$ & $1.8 \mathrm{E}+04$ & NA & $2.0 E+03$ \\
\hline Nitrite & $7.0 E+05$ & $6.2 E+03$ & NA & $1.1 E+02$ & $1.8 E+06$ & $9.0 E+02$ & NA & $2.0 E+03$ \\
\hline TBP & 2.1E+03 & $1.9 E+01$ & NA & $1.1 E+02$ & $5.4 E+03$ & $2.7 E+00$ & NA & $2.0 E+03$ \\
\hline C-14 & $9.8 E-02$ & 8.7E-04 & $3.9 \mathrm{E}-03$ & $1.1 E+02$ & $2.5 \mathrm{E}-01$ & 1.3E-04 & $5.6 E-04$ & $2.0 E+03$ \\
\hline $1-129$ & $2.1 E+01$ & $1.9 E-01$ & $3.1 E-05$ & $1.1 E+02$ & $5.4 E+01$ & $2.8 \mathrm{E}-02$ & $4.5 E-06$ & $2.0 E+03$ \\
\hline Tc-99 & $1.4 E+02$ & $1.2 E+00$ & 2.1E-02 & $1.1 E+02$ & $3.5 E+02$ & $1.8 \mathrm{E}-01$ & $3.0 E-03$ & $2.0 E+03$ \\
\hline$U-238$ & $2.0 E+05$ & $1.8 E+03$ & $6.0 \mathrm{E}-04$ & $1.1 E+02$ & $5.1 E+05$ & $2.6 E+02$ & 8.6E-05 & $2.0 E+03$ \\
\hline
\end{tabular}


Table A-10. Inventories, Flux Rates, and Release Durations for the Close-Coupled Alternative w/o Soil Flushing. (Sheet 2 of 2)

\begin{tabular}{lcccc}
\hline & \multicolumn{4}{c}{ Barrier } \\
\cline { 2 - 5 } Contaminant & $\begin{array}{c}\text { Inventory } \\
(\mathrm{g})\end{array}$ & $\begin{array}{c}\text { Flux Rate } \\
(\mathrm{g} / \mathrm{yr})\end{array}$ & $\begin{array}{c}\text { Flux Rate } \\
(\mathrm{Ci} / \mathrm{yr})\end{array}$ & $\begin{array}{c}\text { Release } \\
\text { Duration } \\
(\mathrm{yr})\end{array}$ \\
\hline EDTA & $1.7 \mathrm{E}+03$ & $1.1 \mathrm{E}+01$ & $\mathrm{NA}$ & $1.6 \mathrm{E}+02$ \\
Nitrate & $1.0 \mathrm{E}+07$ & $6.3 \mathrm{E}+04$ & $\mathrm{NA}$ & $1.6 \mathrm{E}+02$ \\
Nitrite & $4.9 \mathrm{E}+05$ & $3.1 \mathrm{E}+03$ & $\mathrm{NA}$ & $1.6 \mathrm{E}+02$ \\
TBP & $1.5 \mathrm{E}+03$ & $9.5 \mathrm{E}+00$ & $\mathrm{NA}$ & $1.6 \mathrm{E}+02$ \\
C-14 & $6.9 \mathrm{E}-02$ & $4.4 \mathrm{E}-04$ & $1.9 \mathrm{E}-03$ & $1.6 \mathrm{E}+02$ \\
l-129 & $1.5 \mathrm{E}+01$ & $9.5 \mathrm{E}-02$ & $1.6 \mathrm{E}-05$ & $1.6 \mathrm{E}+02$ \\
TC-99 & $9.7 \mathrm{E}+01$ & $6.1 \mathrm{E}-01$ & $1.0 \mathrm{E}-02$ & $1.6 \mathrm{E}+02$ \\
U-238 & $1.4 \mathrm{E}+05$ & $9.0 \mathrm{E}+02$ & $3.0 \mathrm{E}-04$ & $1.6 \mathrm{E}+02$ \\
\hline
\end{tabular}


Table A-11. Inventories, Flux Rates, and Release Durations for the Modified Close-Coupled Alternative w/o Soil Flushing. (Sheet 1 of 2)

\begin{tabular}{|c|c|c|c|c|c|c|c|c|}
\hline \multirow[b]{2}{*}{ Contaminant } & \multicolumn{4}{|c|}{ Tank Residual } & \multicolumn{4}{|c|}{ Btw Tank \& Pad } \\
\hline & $\begin{array}{c}\text { Inventory } \\
\text { (g) }\end{array}$ & $\begin{array}{c}\text { Flux Rate } \\
(\mathrm{g} / \mathrm{yr})\end{array}$ & $\begin{array}{c}\text { Flux Rate } \\
\text { (Ci/yr) }\end{array}$ & $\begin{array}{c}\text { Release } \\
\text { Duration } \\
(y r)\end{array}$ & $\begin{array}{c}\text { Inventory } \\
\text { (g) }\end{array}$ & $\begin{array}{c}\text { Flux Rate } \\
(\mathrm{g} / \mathrm{yr})\end{array}$ & $\begin{array}{c}\text { Flux Rate } \\
\text { (Ci/yr) }\end{array}$ & $\begin{array}{c}\text { Release } \\
\text { Duration } \\
(y r)\end{array}$ \\
\hline EDTA & $1.4 E+04$ & $1.5 E+02$ & NA & $8.9 E+01$ & $1.3 E+02$ & $6.3 E+01$ & NA & $2.0 E+00$ \\
\hline Nitrate & $7.8 E+07$ & $8.8 E+05$ & NA & $8.9 E+01$ & $7.3 E+05$ & $3.6 E+05$ & NA & $2.0 E+00$ \\
\hline Nitrite & $3.9 E+06$ & $4.3 E+04$ & NA & $8.9 E+01$ & $3.6 \mathrm{E}+04$ & $1.8 E+04$ & NA & $2.0 E+00$ \\
\hline TBP & $1.2 E+04$ & $1.3 E+02$ & NA & $8.9 E+01$ & $1.1 E+02$ & $5.5 E+01$ & NA & $2.0 E+00$ \\
\hline C-14 & $5.4 E-01$ & $6.1 E-03$ & 2.7E-02 & $8.9 E+01$ & $5.0 E-03$ & $2.5 \mathrm{E}-03$ & 1.1E-02 & $2.0 E+00$ \\
\hline $1-129$ & $1.2 E+02$ & $1.3 E+00$ & $2.2 E-04$ & $8.9 E+01$ & $1.1 E+00$ & 5.5E-01 & 9.0E-05 & $2.0 E+00$ \\
\hline Tc-99 & $7.6 E+02$ & $8.5 E+00$ & $1.4 \mathrm{E}-01$ & $8.9 E+01$ & $7.0 E+00$ & $3.5 E+00$ & $6.0 E-02$ & $2.0 E+00$ \\
\hline $\mathrm{U}-238$ & $1.1 E+06$ & $1.2 E+04$ & $4.2 E-03$ & $8.9 E+01$ & $1.0 E+04$ & $5.2 \mathrm{E}+03$ & 1.7E-03 & $2.0 E+00$ \\
\hline & \multicolumn{4}{|c|}{ Concrete Pad } & \multicolumn{4}{|c|}{ Old Leaks } \\
\hline Contaminant & $\begin{array}{c}\text { Inventory } \\
\text { (g) }\end{array}$ & $\begin{array}{c}\text { Flux Rate } \\
(\mathrm{g} / \mathrm{yr})\end{array}$ & $\begin{array}{c}\text { Flux Rate } \\
(\mathrm{Ci} / \mathrm{yr})\end{array}$ & $\begin{array}{c}\text { Release } \\
\text { Duration } \\
(y r) \\
\end{array}$ & $\begin{array}{c}\text { Inventory } \\
\text { (g) }\end{array}$ & $\begin{array}{c}\text { Flux Rate } \\
(g / y r)\end{array}$ & $\begin{array}{c}\text { Flux Rate } \\
\text { (Ci/yr) }\end{array}$ & $\begin{array}{c}\text { Release } \\
\text { Duration } \\
(y r)\end{array}$ \\
\hline EDTA & $2.4 E+03$ & $2.2 \mathrm{E}+01$ & NA & $1.1 \mathrm{E}+02$ & $1.1 E+04$ & $3.2 E+00$ & NA & $3.4 E+03$ \\
\hline Nitrate & $1.4 E+07$ & $1.3 E+05$ & NA & $1.1 E+02$ & $6.3 E+07$ & $1.8 E+04$ & NA & $3.4 \mathrm{E}+03$ \\
\hline Nitrite & $7.0 E+05$ & $6.2 E+03$ & NA & $1.1 E+02$ & $3.1 E+06$ & $9.0 E+02$ & NA & $3.4 E+03$ \\
\hline TBP & $2.1 E+03$ & $1.9 E+01$ & NA & $1.1 E+02$ & $9.4 E+03$ & $2.7 E+00$ & NA & $3.4 E+03$ \\
\hline$C-14$ & $9.8 E-02$ & 8.7E-04 & $3.9 E-03$ & $1.1 E+02$ & 4.3E-01 & $1.3 \mathrm{E}-04$ & $5.6 \mathrm{E}-04$ & $3.4 E+03$ \\
\hline $1-129$ & $2.1 E+01$ & 1.9E-01 & $3.1 \mathrm{E}-05$ & $1.1 \mathrm{E}+02$ & $9.5 \mathrm{E}+01$ & $2.8 E-02$ & $4.5 E-06$ & $3.4 E+03$ \\
\hline Тc-99 & $1.4 E+02$ & $1.2 E+00$ & 2.1E-02 & $1.1 E+02$ & $6.1 E+02$ & $1.8 \mathrm{E}-01$ & 3.0E-03 & $3.4 E+03$ \\
\hline U-238 & $2.0 E+05$ & $1.8 \mathrm{E}+03$ & $6.0 \mathrm{E}-04$ & $1.1 E+02$ & $8.9 \mathrm{E}+05$ & $2.6 \mathrm{E}+02$ & 8.6E-05 & $3.4 \mathrm{E}+03$ \\
\hline
\end{tabular}


Table A-11. Inventories, Flux Rates, and Release Durations for the Modified Close-Coupled Alternative w/o Soil Flushing. (Sheet 2 of 2)

\begin{tabular}{lcccc}
\hline & \multicolumn{4}{c}{ Barrier } \\
\cline { 2 - 5 } Contaminant & $\begin{array}{c}\text { Inventory } \\
(\mathrm{g})\end{array}$ & $\begin{array}{c}\text { Flux Rate } \\
(\mathrm{g} / \mathrm{yr})\end{array}$ & $\begin{array}{c}\text { Flux Rate } \\
(\mathrm{Ci} / \mathrm{yr})\end{array}$ & $\begin{array}{c}\text { Release } \\
\text { Duration } \\
(\mathrm{yr})\end{array}$ \\
\hline EDTA & $1.0 \mathrm{E}+03$ & $6.6 \mathrm{E}+00$ & $\mathrm{NA}$ & $1.5 \mathrm{E}+02$ \\
Nitrate & $5.9 \mathrm{E}+06$ & $3.8 \mathrm{E}+04$ & $\mathrm{NA}$ & $1.5 \mathrm{E}+02$ \\
Nitrite & $2.9 \mathrm{E}+05$ & $1.9 \mathrm{E}+03$ & $\mathrm{NA}$ & $1.5 \mathrm{E}+02$ \\
TBP & $8.9 \mathrm{E}+02$ & $5.7 \mathrm{E}+00$ & $\mathrm{NA}$ & $1.5 \mathrm{E}+02$ \\
$\mathrm{C}-14$ & $4.1 \mathrm{E}-02$ & $2.6 \mathrm{E}-04$ & $1.2 \mathrm{E}-03$ & $1.5 \mathrm{E}+02$ \\
l-129 & $9.0 \mathrm{E}+00$ & $5.8 \mathrm{E}-02$ & $9.4 \mathrm{E}-06$ & $1.5 \mathrm{E}+02$ \\
TC-99 & $5.7 \mathrm{E}+01$ & $3.7 \mathrm{E}-01$ & $6.3 \mathrm{E}-03$ & $1.5 \mathrm{E}+02$ \\
U-238 & $8.4 \mathrm{E}+04$ & $5.4 \mathrm{E}+02$ & $1.8 \mathrm{E}-04$ & $1.5 \mathrm{E}+02$ \\
\hline
\end{tabular}


Table A-12. Inventories, Flux Rates, and Release Durations for the Box-Shaped Chemical Standoff Alternative. (Sheet 1 of 2)

\begin{tabular}{|c|c|c|c|c|c|c|c|c|}
\hline \multirow[b]{2}{*}{ Contaminant } & \multicolumn{4}{|c|}{ Tank Residual } & \multicolumn{4}{|c|}{ Btw Tank \& Pad } \\
\hline & $\begin{array}{c}\text { Inventory } \\
\text { (g) }\end{array}$ & $\begin{array}{c}\text { Flux Rate } \\
(g / y r)\end{array}$ & $\begin{array}{c}\text { Flux Rate } \\
\text { (Ci/yr) }\end{array}$ & $\begin{array}{c}\text { Release } \\
\text { Duration } \\
\text { (yr) }\end{array}$ & $\begin{array}{c}\text { Inventory } \\
\text { (g) }\end{array}$ & $\begin{array}{c}\text { Flux Rate } \\
(\mathrm{g} / \mathrm{yr})\end{array}$ & $\begin{array}{c}\text { Flux Rate } \\
(\mathrm{Ci} / \mathrm{yr})\end{array}$ & $\begin{array}{c}\text { Release } \\
\text { Duration } \\
(y r) \\
\end{array}$ \\
\hline EDTA & $1.4 E+04$ & $1.5 E+02$ & NA & $8.9 E+01$ & $1.3 E+02$ & $6.3 E+01$ & NA & $2.0 E+00$ \\
\hline Nitrate & $7.8 E+07$ & $8.8 E+05$ & NA & $8.9 E+01$ & $7.3 E+05$ & $3.6 E+05$ & NA & $2.0 E+0 O$ \\
\hline Nitrite & $3.9 E+06$ & $4.3 E+04$ & NA & $8.9 E+01$ & $3.6 \mathrm{E}+04$ & $1.8 E+04$ & NA & $2.0 E+00$ \\
\hline TBP • & $1.2 E+04$ & $1.3 E+02$ & NA & $8.9 E+01$ & $1.1 E+02$ & $5.5 E+01$ & NA & $2.0 E+00$ \\
\hline$C-14$ & $5.4 \mathrm{E}-01$ & $6.1 \mathrm{E}-03$ & $2.7 \mathrm{E}-02$ & $8.9 E+01$ & 5.0E-03 & $2.5 \mathrm{E}-03$ & $1.1 \mathrm{E}-02$ & $2.0 E+00$ \\
\hline $1-129$ & $1.2 E+02$ & $1.3 E+00$ & $2.2 E-04$ & $8.9 E+01$ & $1.1 E+00$ & $5.5 \mathrm{E}-01$ & $9.0 \mathrm{E}-05$ & $2.0 E+00$ \\
\hline Tc-99 & $7.6 E+02$ & $8.5 E+00$ & $1.4 \mathrm{E}-01$ & $8.9 E+01$ & $7.0 E+00$ & $3.5 E+00$ & $6.0 \mathrm{E}-02$ & $2.0 E+00$ \\
\hline \multirow[t]{3}{*}{$\underline{U}-238$} & 1.1E+06 & $1.2 E+04$ & $4.2 \mathrm{E}-03$ & $8.9 E+01$ & $1.0 E+04$ & $5.2 E+03$ & 1.7E-03 & $2.0 E+00$ \\
\hline & \multicolumn{4}{|c|}{ Concrete Pad } & \multicolumn{4}{|c|}{ Flushed Old \& New Leaks } \\
\hline & $\begin{array}{c}\text { Inventory } \\
\text { (g) }\end{array}$ & $\begin{array}{c}\text { Flux Rate } \\
(\mathrm{g} / \mathrm{yr})\end{array}$ & $\begin{array}{c}\text { Flux Rate } \\
(\mathrm{Ci} / \mathrm{yr})\end{array}$ & $\begin{array}{c}\text { Release } \\
\text { Duration } \\
(y r)\end{array}$ & $\begin{array}{c}\text { Inventory } \\
\text { (g) }\end{array}$ & $\begin{array}{c}\text { Flux Rate } \\
(\mathrm{g} / \mathrm{yr})\end{array}$ & $\begin{array}{c}\text { Flux Rate } \\
\text { (Ci/yr) }\end{array}$ & $\begin{array}{c}\text { Release } \\
\text { Duration } \\
(y r)\end{array}$ \\
\hline EDTA & $2.4 E+03$ & $2.2 E+01$ & NA & $1.1 E+02$ & $1.2 E+03$ & $1.1 \mathrm{E}-01$ & NA & $1.1 E+04$ \\
\hline Nitrate & $1.4 E+07$ & $1.3 E+05$ & NA & $1.1 E+02$ & $7.1 E+06$ & $6.6 E+02$ & NA & $1.1 E+04$ \\
\hline Nitrite & $7.0 \mathrm{E}+05$ & $6.2 E+03$ & NA & $1.1 \mathrm{E}+02$ & $3.5 E+05$ & $3.3 E+01$ & NA & $1.1 E+04$ \\
\hline TBP & $2.1 E+03$ & $1.9 \mathrm{E}+01$ & NA & $1.1 E+02$ & $1.1 E+03$ & $1.0 E-01$ & NA & $1.1 E+04$ \\
\hline C-14 & $9.8 \mathrm{E}-02$ & 8.7E-04 & $3.9 E-03$ & $1.1 E+02$ & $4.9 E-02$ & 4.6E-06 & 2.0E-05 & $1.1 E+04$ \\
\hline $1-129$ & $2.1 E+01$ & $1.9 E-01$ & $3.1 E-05$ & $1.1 E+02$ & $1.1 E+01$ & 1.0E-03 & $1.6 \mathrm{E}-07$ & $1.1 E+04$ \\
\hline Tc-99 & $1.4 E+02$ & $1.2 E+00$ & $2.1 \mathrm{E}-02$ & $1.1 E+02$ & $6.9 E+01$ & $6.4 E-03$ & $1.1 \mathrm{E}-04$ & $1.1 E+04$ \\
\hline U-238 & $2.0 \mathrm{E}+05$ & $1.8 E+03$ & $6.0 \mathrm{E}-04$ & $1.1 \mathrm{E}+02$ & $1.0 E+05$ & $9.4 E+00$ & $3.1 E-06$ & $1.1 E+04$ \\
\hline
\end{tabular}


Table A-12. Inventories, Flux Rates, and Release Durations for the Box-Shaped Chemical Standoff Alternative. (Sheet 2 of 2)

\begin{tabular}{lcccc}
\hline & \multicolumn{4}{c}{ Barrier } \\
\cline { 2 - 5 } Contaminant & $\begin{array}{c}\text { Inventory } \\
(g)\end{array}$ & $\begin{array}{c}\text { Flux Rate } \\
(g / y r)\end{array}$ & $\begin{array}{c}\text { Flux Rate } \\
(\mathrm{C} / \mathrm{yr})\end{array}$ & $\begin{array}{c}\text { Release } \\
\text { Duration } \\
(y r)\end{array}$ \\
\hline EDTA & $1.0 \mathrm{E}+02$ & $1.1 \mathrm{E}+01$ & $\mathrm{NA}$ & $9.4 \mathrm{E}+00$ \\
Nitrate & $5.9 \mathrm{E}+05$ & $6.3 \mathrm{E}+04$ & $\mathrm{NA}$ & $9.4 \mathrm{E}+00$ \\
Nitrite & $2.9 \mathrm{E}+04$ & $3.1 \mathrm{E}+03$ & $\mathrm{NA}$ & $9.4 \mathrm{E}+00$ \\
TBP & $8.9 \mathrm{E}+01$ & $9.5 \mathrm{E}+00$ & $\mathrm{NA}$ & $9.4 \mathrm{E}+00$ \\
C-14 & $4.1 \mathrm{E}-03$ & $4.4 \mathrm{E}-04$ & $1.9 \mathrm{E}-03$ & $9.4 \mathrm{E}+00$ \\
I-129 & $9.0 \mathrm{E}-01$ & $9.5 \mathrm{E}-02$ & $1.6 \mathrm{E}-05$ & $9.4 \mathrm{E}+00$ \\
TC-99 & $5.7 \mathrm{E}+00$ & $6.1 \mathrm{E}-01$ & $1.0 \mathrm{E}-02$ & $9.4 \mathrm{E}+00$ \\
U-238 & $8.4 \mathrm{E}+03$ & $9.0 \mathrm{E}+02$ & $3.0 \mathrm{E}-04$ & $9.4 \mathrm{E}+00$ \\
\hline
\end{tabular}


Table A-13. Inventories, Flux Rates, and Release Durations for the V-Shaped Chemical Standoff Alternative. (Sheet 1 of 2)

\begin{tabular}{|c|c|c|c|c|c|c|c|c|}
\hline \multirow[b]{2}{*}{ Contaminant } & \multicolumn{4}{|c|}{ Tank Residual } & \multicolumn{4}{|c|}{ Btw Tank \& Pad } \\
\hline & $\begin{array}{c}\text { Inventory } \\
\text { (g) }\end{array}$ & $\begin{array}{c}\text { Flux Rate } \\
(\mathrm{g} / \mathrm{yr})\end{array}$ & $\begin{array}{c}\text { Flux Rate } \\
(\mathrm{Ci} / \mathrm{yr})\end{array}$ & $\begin{array}{c}\text { Release } \\
\text { Duration } \\
(y r) \\
\end{array}$ & $\begin{array}{c}\text { Inventory } \\
\text { (g) }\end{array}$ & $\begin{array}{c}\text { Flux Rate } \\
(\mathrm{g} / \mathrm{yr})\end{array}$ & $\begin{array}{c}\text { Flux Rate } \\
(\mathrm{Ci} / \mathrm{yr})\end{array}$ & $\begin{array}{c}\text { Release } \\
\text { Duration } \\
(y r)\end{array}$ \\
\hline EDTA & $1.4 E+04$ & $1.5 E+02$ & NA & $8.9 E+01$ & $1.3 E+02$ & $6.3 E+01$ & NA & $2.0 E+00$ \\
\hline Nitrate & $7.8 E+07$ & $8.8 E+05$ & NA & $8.9 E+01$ & $7.3 E+05$ & $3.6 E+05$ & NA & $2.0 E+00$ \\
\hline Nitrite & $3.9 E+06$ & $4.3 E+04$ & NA & $8.9 E+01$ & $3.6 E+04$ & $1.8 E+04$ & NA & $2.0 E+00$ \\
\hline TBP & $1.2 E+04$ & $1.3 E+02$ & NA & $8.9 E+01$ & $1.1 E+02$ & $5.5 E+01$ & NA & $2.0 E+00$ \\
\hline C-14 & $5.4 \mathrm{E}-01$ & $6.1 \mathrm{E}-03$ & 2.7E-02 & $8.9 E+01$ & $5.0 E-03$ & $2.5 \mathrm{E}-03$ & 1.1E-02 & $2.0 E+00$ \\
\hline $1-129$ & $1.2 E+02$ & $1.3 E+00$ & $2.2 \mathrm{E}-04$ & $8.9 E+01$ & $1.1 E+00$ & $5.5 E-01$ & $9.0 E-05$ & $2.0 E+00$ \\
\hline Tc-99 & $7.6 E+02$ & $8.5 E+00$ & $1.4 \mathrm{E}-01$ & $8.9 E+01$ & $7.0 E+00$ & $3.5 E+00$ & $6.0 E-02$ & $2.0 E+00$ \\
\hline U-238 & $1.1 E+06$ & $1.2 E+04$ & $4.2 \mathrm{E}-03$ & $8.9 E+01$ & $1.0 E+04$ & $5.2 \mathrm{E}+03$ & $1.7 \mathrm{E}-03$ & $2.0 E+00$ \\
\hline & \multicolumn{4}{|c|}{ Concrete Pad } & \multicolumn{4}{|c|}{ Flushed Old \& New Leaks } \\
\hline Contaminant & $\begin{array}{c}\text { Inventory } \\
\text { (g) }\end{array}$ & $\begin{array}{c}\text { Flux Rate } \\
(g / y r)\end{array}$ & $\begin{array}{c}\text { Flux Rate } \\
(\mathrm{Ci} / \mathrm{yr})\end{array}$ & $\begin{array}{c}\text { Release } \\
\text { Duration } \\
(y r)\end{array}$ & $\begin{array}{c}\text { Inventory } \\
\text { (g) }\end{array}$ & $\begin{array}{c}\text { Flux Rate } \\
(g / y r)\end{array}$ & $\begin{array}{c}\text { Flux Rate } \\
(\mathrm{Ci} / \mathrm{yr})\end{array}$ & $\begin{array}{c}\text { Release } \\
\text { Duration } \\
\text { (yr) }\end{array}$ \\
\hline EDTA & $2.4 E+03$ & $2.2 E+01$ & NA & $1.1 E+02$ & $1.2 E+03$ & $8.6 \mathrm{E}-02$ & NA & $1.4 \mathrm{E}+04$ \\
\hline Nitrate & $1.4 E+07$ & $1.3 E+05$ & NA & $1.1 E+02$ & $7.1 E+06$ & $5.0 E+02$ & NA & $1.4 E+04$ \\
\hline Nitrite & $7.0 E+05$ & $6.2 E+03$ & NA & $1.1 \mathrm{E}+02$ & $3.5 E+05$ & $2.5 E+01$ & NA & $1.4 \mathrm{E}+04$ \\
\hline TBP & $2.1 E+03$ & $1.9 E+01$ & NA & $1.1 E+02$ & $1.1 E+03$ & 7.5E-02 & NA & $1.4 E+04$ \\
\hline C-14 & $9.8 \mathrm{E}-02$ & $8.7 E-04$ & $3.9 \mathrm{E}-03$ & $1.1 E+02$ & $4.9 \mathrm{E}-02$ & $3.4 \mathrm{E}-06$ & $1.5 \mathrm{E}-05$ & $1.4 E+04$ \\
\hline $\mid-129$ & $2.1 E+01$ & $1.9 \mathrm{E}-01$ & $3.1 \mathrm{E}-05$ & $1.1 E+02$ & $1.1 E+01$ & $7.5 \mathrm{E}-04$ & $1.2 \mathrm{E}-07$ & $1.4 E+04$ \\
\hline Tc-99 & $1.4 E+02$ & $1.2 E+00$ & $2.1 \mathrm{E}-02$ & $1.1 E+02$ & $6.9 E+01$ & $4.8 \mathrm{E}-03$ & $8.2 E-05$ & $1.4 E+04$ \\
\hline $\mathrm{U}-238$ & $2.0 E+05$ & $1.8 E+03$ & $6.0 E-04$ & $1.1 E+02$ & $1.0 E+05$ & $7.1 \mathrm{E}+00$ & 2.4E-06 & $1.4 E+04$ \\
\hline
\end{tabular}


Table A-13. Inventories, Flux Rates, and Release Durations for the V-Shaped Chemical Standoff Alternative. (Sheet 2 of 2)

\begin{tabular}{lcccc}
\hline & \multicolumn{4}{c}{ Barrier } \\
\cline { 2 - 5 } Contaminant & $\begin{array}{c}\text { Inventory } \\
(\mathrm{g})\end{array}$ & $\begin{array}{c}\text { Flux Rate } \\
(\mathrm{g} / \mathrm{yr})\end{array}$ & $\begin{array}{c}\text { Flux Rate } \\
(\mathrm{Ci} / \mathrm{yr})\end{array}$ & $\begin{array}{c}\text { Release } \\
\text { Duration } \\
(\mathrm{yr})\end{array}$ \\
\hline EDTA & $1.4 \mathrm{E}+02$ & $1.1 \mathrm{E}+01$ & $\mathrm{NA}$ & $1.3 \mathrm{E}+01$ \\
Nitrate & $8.2 \mathrm{E}+05$ & $6.3 \mathrm{E}+04$ & $\mathrm{NA}$ & $1.3 \mathrm{E}+01$ \\
Nitrite & $4.0 \mathrm{E}+04$ & $3.1 \mathrm{E}+03$ & $\mathrm{NA}$ & $1.3 \mathrm{E}+01$ \\
TBP & $1.2 \mathrm{E}+02$ & $9.5 \mathrm{E}+00$ & $\mathrm{NA}$ & $1.3 \mathrm{E}+01$ \\
C-14 & $5.7 \mathrm{E}-03$ & $4.4 \mathrm{E}-04$ & $1.9 \mathrm{E}-03$ & $1.3 \mathrm{E}+01$ \\
I-129 & $1.2 \mathrm{E}+00$ & $9.5 \mathrm{E}-02$ & $1.6 \mathrm{E}-05$ & $1.3 \mathrm{E}+01$ \\
TC-99 & $7.9 \mathrm{E}+00$ & $6.1 \mathrm{E}-01$ & $1.0 \mathrm{E}-02$ & $1.3 \mathrm{E}+01$ \\
U-238 & $1.2 \mathrm{E}+04$ & $9.0 \mathrm{E}+02$ & $3.0 \mathrm{E}-04$ & $1.3 \mathrm{E}+01$ \\
\hline
\end{tabular}


Table A-14. Inventories, Flux Rates, and Release Durations for the V-Shaped Freeze Wall Alternative.

\begin{tabular}{|c|c|c|c|c|c|c|c|c|}
\hline \multirow[b]{2}{*}{ Contaminant } & \multicolumn{4}{|c|}{ Tank Residual } & \multicolumn{4}{|c|}{ Btw Tank \& Pad } \\
\hline & $\begin{array}{c}\text { Inventory } \\
\text { (g) }\end{array}$ & $\begin{array}{c}\text { Flux Rate } \\
(\mathrm{g} / \mathrm{yr})\end{array}$ & $\begin{array}{c}\text { Flux Rate } \\
(\mathrm{Ci} / \mathrm{yr})\end{array}$ & $\begin{array}{c}\text { Release } \\
\text { Duration } \\
(y r)\end{array}$ & $\begin{array}{c}\text { Inventory } \\
\text { (g) }\end{array}$ & $\begin{array}{c}\text { Flux Rate } \\
(g / y r)\end{array}$ & $\begin{array}{c}\text { Flux Rate } \\
(\mathrm{Ci} / \mathrm{yr})\end{array}$ & $\begin{array}{c}\text { Release } \\
\text { Duration } \\
\text { (yr) }\end{array}$ \\
\hline EDTA & $1.4 E+04$ & $1.5 E+02$ & NA & $8.9 E+01$ & $1.3 E+02$ & $6.3 E+01$ & NA & $2.0 E+00$ \\
\hline Nitrate & $7.8 E+07$ & $8.8 E+05$ & NA & $8.9 E+01$ & $7.3 E+05$ & $3.6 E+05$ & NA & $2.0 E+00$ \\
\hline Nitrite & $3.9 E+06$ & $4.3 E+04$ & NA & $8.9 E+01$ & $3.6 \mathrm{E}+04$ & $1.8 E+04$ & NA & $2.0 E+00$ \\
\hline TBP & $1.2 E+04$ & $1.3 E+02$ & NA & $8.9 E+01$ & $1.1 E+02$ & $5.5 E+01$ & NA & $2.0 E+00$ \\
\hline$C-14$ & $5.4 \mathrm{E}-01$ & $6.1 \mathrm{E}-03$ & 2.7E-02 & $8.9 E+01$ & $5.0 \mathrm{E}-03$ & $2.5 \mathrm{E}-03$ & $1.1 \mathrm{E}-02$ & $2.0 E+00$ \\
\hline $1-129$ & $1.2 E+02$ & $1.3 E+00$ & $2.2 E-04$ & $8.9 E+01$ & $1.1 E+00$ & 5.5E-01 & $9.0 E-05$ & $2.0 E+00$ \\
\hline Tc-99 & $7.6 E+02$ & $8.5 E+00$ & $1.4 \mathrm{E}-01$ & $8.9 E+01$ & $7.0 E+00$ & $3.5 E+00$ & $6.0 \mathrm{E}-02$ & $2.0 E+00$ \\
\hline \multirow[t]{3}{*}{ U-238 } & $1.1 E+06$ & $1.2 E+04$ & $4.2 \mathrm{E}-03$ & $8.9 E+01$ & $1.0 E+04$ & $5.2 E+03$ & 1.7E-03 & $2.0 E+00$ \\
\hline & \multicolumn{4}{|c|}{ Concrete Pad } & \multicolumn{4}{|c|}{ Flushed Old \& New Leaks } \\
\hline & $\begin{array}{c}\text { Inventory } \\
\text { (g) }\end{array}$ & $\begin{array}{c}\text { Flux Rate } \\
(\mathrm{g} / \mathrm{yr})\end{array}$ & $\begin{array}{c}\text { Flux Rate } \\
(\mathrm{Ci} / \mathrm{yr})\end{array}$ & $\begin{array}{c}\text { Release } \\
\text { Duration } \\
(y r) \\
\end{array}$ & $\begin{array}{c}\text { Inventory } \\
\text { (g) }\end{array}$ & $\begin{array}{c}\text { Flux Rate } \\
(\mathrm{g} / \mathrm{yr})\end{array}$ & $\begin{array}{c}\text { Flux Rate } \\
(\mathrm{Ci} / \mathrm{yr})\end{array}$ & $\begin{array}{c}\text { Release } \\
\text { Duration } \\
(y r) \\
\end{array}$ \\
\hline EDTA & $2.4 E+03$ & $2.2 E+01$ & NA & $1.1 E+02$ & $1.2 E+03$ & 8.6E-02 & NA & $1.4 E+04$ \\
\hline Nitrate & $1.4 E+07$ & $1.3 E+05$ & NA & 1.1E+02 & $7.1 E+06$ & $5.0 \mathrm{E}+02$ & NA & $1.4 E+04$ \\
\hline Nitrite & $7.0 E+05$ & $6.2 E+03$ & NA & $1.1 E+02$ & $3.5 E+05$ & $2.5 E+01$ & NA & $1.4 E+04$ \\
\hline TBP & $2.1 E+03$ & $1.9 E+01$ & NA & $1.1 E+02$ & $1.1 E+03$ & $7.5 \mathrm{E}-02$ & NA & $1.4 E+04$ \\
\hline$C-14$ & $9.8 \mathrm{E}-02$ & 8.7E-04 & $3.9 \mathrm{E}-03$ & $1.1 E+02$ & $4.9 \mathrm{E}-02$ & $3.4 \mathrm{E}-06$ & $1.5 \mathrm{E}-05$ & $1.4 \mathrm{E}+04$ \\
\hline 1.129 & 2.1E+01 & $1.9 \mathrm{E}-01$ & $3.1 E-05$ & $1.1 E+02$ & $1.1 E+01$ & $7.5 \mathrm{E}-04$ & $1.2 E-07$ & $1.4 E+04$ \\
\hline Tc-99 & $1.4 E+02$ & $1.2 E+00$ & $2.1 E-02$ & $1.1 E+02$ & $6.9 E+01$ & $4.8 \mathrm{E}-03$ & $8.2 \mathrm{E}-05$ & $1.4 E+04$ \\
\hline $\mathrm{U}-238$ & $2.0 E+05$ & $1.8 E+03$ & $6.0 E-04$ & $1.1 E+02$ & $1.0 E+05$ & $7.1 E+00$ & $2.4 \mathrm{E}-06$ & $1.4 E+04$ \\
\hline
\end{tabular}


Table A-15. Inventories, Flux Rates, and Release Durations for the Circulating Air Barrier Alternative.

\begin{tabular}{|c|c|c|c|c|c|c|c|c|}
\hline \multirow[b]{2}{*}{ Contaminant } & \multicolumn{4}{|c|}{ Tank Residual } & \multicolumn{4}{|c|}{ Btw Tank \& Pad } \\
\hline & $\begin{array}{c}\text { Inventory } \\
\text { (g) }\end{array}$ & $\begin{array}{c}\text { Flux Rate } \\
(\mathrm{g} / \mathrm{yr})\end{array}$ & $\begin{array}{c}\text { Flux Rate } \\
(\mathrm{Ci} / \mathrm{yr})\end{array}$ & $\begin{array}{c}\text { Release } \\
\text { Duration } \\
(y r)\end{array}$ & $\begin{array}{c}\text { Inventory } \\
\text { (g) }\end{array}$ & $\begin{array}{c}\text { Flux Rate } \\
(\mathrm{g} / \mathrm{yr})\end{array}$ & $\begin{array}{c}\text { Flux Rate } \\
(\mathrm{Ci} / \mathrm{yr})\end{array}$ & $\begin{array}{c}\text { Release } \\
\text { Duration } \\
(y r)\end{array}$ \\
\hline EDTA & $1.4 E+04$ & $1.5 E+02$ & NA & $8.9 E+01$ & $1.3 E+02$ & $6.3 E+01$ & NA & $2.0 E+00$ \\
\hline Nitrate & $7.8 E+07$ & $8.8 E+05$ & NA & $8.9 E+01$ & $7.3 E+05$ & $3.6 \mathrm{E}+05$ & NA & $2.0 E+00$ \\
\hline Nitrite & $3.9 E+06$ & $4.3 E+04$ & NA & $8.9 E+01$ & $3.6 E+04$ & $1.8 E+04$ & NA & $2.0 E+00$ \\
\hline TBP & $1.2 E+04$ & $1.3 E+02$ & NA & $8.9 E+01$ & $1.1 E+02$ & $5.5 E+01$ & NA & $2.0 E+00$ \\
\hline C-14 & $5.4 E-01$ & $6.1 \mathrm{E}-03$ & 2.7E-02 & $8.9 E+01$ & 5.0E-03 & $2.5 \mathrm{E}-03$ & $1.1 \mathrm{E}-02$ & $2.0 E+00$ \\
\hline $1-129$ & $1.2 \mathrm{E}+02$ & $1.3 E+00$ & $2.2 \mathrm{E}-04$ & $8.9 E+01$ & $1.1 E+00$ & $5.5 \mathrm{E}-01$ & $9.0 \mathrm{E}-05$ & $2.0 E+00$ \\
\hline Tc-99 & $7.6 \mathrm{E}+02$ & $8.5 E+00$ & $1.4 \mathrm{E}-01$ & $8.9 E+01$ & $7.0 E+00$ & $3.5 E+00$ & $6.0 \mathrm{E}-02$ & $2.0 E+00$ \\
\hline U-238 & $1.1 E+06$ & $1.2 E+04$ & $4.2 E-03$ & $8.9 E+01$ & $1.0 E+04$ & $5.2 E+03$ & 1.7E-03 & $2.0 E+00$ \\
\hline & \multicolumn{4}{|c|}{ Concrete Pad } & \multicolumn{4}{|c|}{ Flushed Old \& New Leaks } \\
\hline Contaminant & $\begin{array}{c}\text { Inventory } \\
\text { (g) }\end{array}$ & $\begin{array}{c}\text { Flux Rate } \\
(g / y r)\end{array}$ & $\begin{array}{c}\text { Flux Rate } \\
(\mathrm{Ci} / \mathrm{yr})\end{array}$ & $\begin{array}{c}\text { Release } \\
\text { Duration } \\
(y r)\end{array}$ & $\begin{array}{c}\text { Inventory } \\
\text { (g) }\end{array}$ & $\begin{array}{c}\text { Flux Rate } \\
(g / y r)\end{array}$ & $\begin{array}{c}\text { Flux Rate } \\
(\mathrm{Ci} / \mathrm{yr})\end{array}$ & $\begin{array}{c}\text { Release } \\
\text { Duration } \\
(y r)\end{array}$ \\
\hline EDTA & $2.4 E+03$ & $2.2 E+01$ & NA & $1.1 E+02$ & $1.2 E+03$ & $6.0 \mathrm{E}-01$ & NA & $2.0 E+03$ \\
\hline Nitrate & $1.4 E+07$ & $1.3 E+05$ & NA & $1.1 E+02$ & $7.1 E+06$ & $3.5 E+03$ & NA & $2.0 E+03$ \\
\hline Nitrite & $7.0 E+05$ & $6.2 E+03$ & NA & 1.1E+02 & $3.5 E+05$ & $1.7 E+02$ & NA & $2.0 E+03$ \\
\hline TBP & $2.1 E+03$ & $1.9 E+01$ & NA & $1.1 E+02$ & $1.1 E+03$ & $5.2 \mathrm{E}-01$ & NA & $2.0 \mathrm{E}+03$ \\
\hline$C-14$ & $9.8 \mathrm{E}-02$ & 8.7E-04 & $3.9 \mathrm{E}-03$ & $1.1 E+02$ & $4.9 \mathrm{E}-02$ & $2.4 \mathrm{E}-05$ & 1.1E-04 & $2.0 E+03$ \\
\hline $1-129$ & $2.1 E+01$ & $1.9 E-01$ & $3.1 \mathrm{E}-05$ & $1.1 E+02$ & $1.1 E+01$ & 5.3E-03 & $8.6 \mathrm{E}-07$ & $2.0 E+03$ \\
\hline Tc-99 & $1.4 E+02$ & $1.2 E+00$ & 2.1E-02 & $1.1 E+02$ & $6.9 E+01$ & $3.4 \mathrm{E}-02$ & $5.7 E-04$ & $2.0 E+03$ \\
\hline U-238 & $2.0 E+05$ & $1.8 E+03$ & $6.0 \mathrm{E}-04$ & $1.1 E+02$ & $1.0 E+05$ & $5.0 E+01$ & 1.6E-05 & $2.0 \mathrm{E}+03$ \\
\hline
\end{tabular}


Table A-16. Inventories, Flux Rates, and Release Durations for the Clean Closure w/o Barrier Alternative.

\begin{tabular}{lcccc}
\hline & \multicolumn{5}{c}{ Disposal } \\
\cline { 2 - 5 } Contaminant & $\begin{array}{c}\text { Inventory } \\
(\mathrm{g})\end{array}$ & $\begin{array}{c}\text { Flux Rate } \\
(\mathrm{g} / \mathrm{yr})\end{array}$ & $\begin{array}{c}\text { Flux Rate } \\
(\mathrm{Ci} / \mathrm{yr})\end{array}$ & $\begin{array}{c}\text { Release } \\
\text { Duration } \\
(\mathrm{yr})\end{array}$ \\
\hline EDTA & $3.7 \mathrm{E}+02$ & $6.9 \mathrm{E}-01$ & $\mathrm{NA}$ & $5.3 \mathrm{E}+02$ \\
Nitrate & $2.1 \mathrm{E}+06$ & $4.0 \mathrm{E}+03$ & $\mathrm{NA}$ & $5.3 \mathrm{E}+02$ \\
Nitrite & $1.0 \mathrm{E}+05$ & $2.0 \mathrm{E}+02$ & $\mathrm{NA}$ & $5.3 \mathrm{E}+02$ \\
TBP & $3.2 \mathrm{E}+02$ & $6.0 \mathrm{E}-01$ & $\mathrm{NA}$ & $5.3 \mathrm{E}+02$ \\
C-14 & $1.5 \mathrm{E}-02$ & $2.8 \mathrm{E}-05$ & $1.2 \mathrm{E}-04$ & $5.3 \mathrm{E}+02$ \\
1-129 & $3.2 \mathrm{E}+00$ & $6.0 \mathrm{E}-03$ & $9.8 \mathrm{E}-07$ & $5.3 \mathrm{E}+02$ \\
Tc-99 & $2.0 \mathrm{E}+01$ & $3.9 \mathrm{E}-02$ & $6.6 \mathrm{E}-04$ & $5.3 \mathrm{E}+02$ \\
U-238 & $3.0 \mathrm{E}+04$ & $5.7 \mathrm{E}+01$ & $1.9 \mathrm{E}-05$ & $5.3 \mathrm{E}+02$ \\
\hline
\end{tabular}


Table A-17. Inventories, Flux Rates, and Release Durations for the Clean Closure w/Barrier Alternative.

\begin{tabular}{lcccc}
\hline & \multicolumn{5}{c}{ Disposal } \\
\cline { 2 - 5 } Contaminant & $\begin{array}{c}\text { Inventory } \\
(\mathrm{g})\end{array}$ & $\begin{array}{c}\text { Flux Rate } \\
(\mathrm{g} / \mathrm{yr})\end{array}$ & $\begin{array}{c}\text { Flux Rate } \\
(\mathrm{Ci} / \mathrm{yr})\end{array}$ & $\begin{array}{c}\text { Release } \\
\text { Duration } \\
(\mathrm{yr})\end{array}$ \\
\hline EDTA & $2.2 \mathrm{E}+02$ & $1.7 \mathrm{E}-01$ & $\mathrm{NA}$ & $1.3 \mathrm{E}+03$ \\
Nitrate & $1.3 \mathrm{E}+06$ & $9.9 \mathrm{E}+02$ & $\mathrm{NA}$ & $1.3 \mathrm{E}+03$ \\
Nitrite & $6.3 \mathrm{E}+04$ & $4.9 \mathrm{E}+01$ & $\mathrm{NA}$ & $1.3 \mathrm{E}+03$ \\
TBP & $1.9 \mathrm{E}+02$ & $1.5 \mathrm{E}-01$ & $\mathrm{NA}$ & $1.3 \mathrm{E}+03$ \\
$\mathrm{C}-14$ & $8.8 \mathrm{E}-03$ & $6.9 \mathrm{E}-06$ & $3.1 \mathrm{E}-05$ & $1.3 \mathrm{E}+03$ \\
I-129 & $1.9 \mathrm{E}+00$ & $1.5 \mathrm{E}-03$ & $2.5 \mathrm{E}-07$ & $1.3 \mathrm{E}+03$ \\
TC-99 & $1.2 \mathrm{E}+01$ & $9.6 \mathrm{E}-03$ & $1.6 \mathrm{E}-04$ & $1.3 \mathrm{E}+03$ \\
$\mathrm{U}-238$ & $1.8 \mathrm{E}+04$ & $1.4 \mathrm{E}+01$ & $4.7 \mathrm{E}-06$ & $1.3 \mathrm{E}+03$ \\
\hline
\end{tabular}


Table A-18. Inventories, Flux Rates, and Release Durations for Sensitivity Case \#1 Traditional Sluicing w/o Surface Barrier Alternative.

\begin{tabular}{|c|c|c|c|c|c|c|c|c|}
\hline \multirow[b]{2}{*}{ Contaminant } & \multicolumn{4}{|c|}{ Tank Residual } & \multicolumn{4}{|c|}{ Btw Tank \& Pad } \\
\hline & $\begin{array}{c}\text { Inventory } \\
\text { (g) }\end{array}$ & $\begin{array}{c}\text { Flux Rate } \\
(\mathrm{g} / \mathrm{y})\end{array}$ & $\begin{array}{c}\text { Flux Rate } \\
(\mathrm{Ci} / \mathrm{yr})\end{array}$ & $\begin{array}{c}\text { Release } \\
\text { Duration } \\
\text { (yr) }\end{array}$ & $\begin{array}{c}\text { Inventory } \\
\text { (g) }\end{array}$ & $\begin{array}{c}\text { Flux Rate } \\
(\mathrm{g} / \mathrm{yr})\end{array}$ & $\begin{array}{c}\text { Flux Rate } \\
\text { (Ci/yr) }\end{array}$ & $\begin{array}{c}\text { Release } \\
\text { Duration } \\
\text { (yr) }\end{array}$ \\
\hline EDTA & $1.4 E+04$ & $1.5 E+04$ & NA & $8.9 E-01$ & $1.3 E+02$ & $6.3 E+03$ & NA & 2.0E-02 \\
\hline Nitrate & $7.8 E+07$ & $8.8 E+07$ & NA & $8.9 E-01$ & $7.3 E+05$ & $3.6 E+07$ & NA & 2.0E-02 \\
\hline Nitrite & $3.9 E+06$ & $4.3 E+06$ & NA & $8.9 \mathrm{E}-01$ & $3.6 \mathrm{E}+04$ & $1.8 E+06$ & NA & $2.0 \mathrm{E}-02$ \\
\hline TBP & $1.2 E+04$ & $1.3 E+04$ & NA & $8.9 \mathrm{E}-01$ & $1.1 E+02$ & $5.5 E+03$ & NA & 2.0E-02 \\
\hline$C-14$ & $5.4 E-01$ & $6.1 \mathrm{E}-01$ & $2.7 E+00$ & $8.9 \mathrm{E}-01$ & $5.0 \mathrm{E}-03$ & $2.5 \mathrm{E}-01$ & $1.1 E+00$ & 2.0E-02 \\
\hline $1-129$ & $1.2 E+02$ & $1.3 E+02$ & $2.2 \mathrm{E}-02$ & 8.9E-01 & $1.1 E+00$ & $5.5 E+01$ & $9.0 \mathrm{E}-03$ & 2.0E-02 \\
\hline Tc-99 & $7.6 E+02$ & $8.5 E+02$ & $1.4 E+01$ & $8.9 \mathrm{E}-01$ & $7.0 E+00$ & $3.5 E+02$ & $6.0 E+00$ & 2.0E-02 \\
\hline \multirow[t]{3}{*}{ U-238 } & $1.1 E+06$ & $1.2 E+06$ & 4.2E-01 & $8.9 \mathrm{E}-01$ & $1.0 E+04$ & $5.2 E+05$ & $1.7 \mathrm{E}-01$ & $2.0 \mathrm{E}-02$ \\
\hline & \multicolumn{4}{|c|}{ Concrete Pad } & \multicolumn{4}{|c|}{ Old \& New Leaks } \\
\hline & $\begin{array}{c}\text { Inventory } \\
\text { (g) }\end{array}$ & $\begin{array}{c}\text { Flux Rate } \\
(\mathrm{g} / \mathrm{yr})\end{array}$ & $\begin{array}{c}\text { Flux Rate } \\
\text { (Ci/yr) }\end{array}$ & $\begin{array}{c}\text { Release } \\
\text { Duration } \\
(y r)\end{array}$ & $\begin{array}{c}\text { Inventory } \\
\text { (g) }\end{array}$ & $\begin{array}{c}\text { Flux Rate } \\
(\mathrm{g} / \mathrm{yr})\end{array}$ & $\begin{array}{c}\text { Flux Rate } \\
(\mathrm{Ci} / \mathrm{yr})\end{array}$ & $\begin{array}{c}\text { Release } \\
\text { Duration } \\
\text { (yr) }\end{array}$ \\
\hline EDTA - & $2.4 E+03$ & $2.2 E+03$ & NA & $1.1 E+00$ & $2.1 E+04$ & $5.7 E+02$ & NA & $3.6 E+01$ \\
\hline Nitrate & $1.4 E+07$ & $1.3 E+07$ & NA & $1.1 E+00$ & $1.2 E+08$ & $3.3 E+06$ & NA & $3.6 \mathrm{E}+01$ \\
\hline Nitrite & $7.0 E+05$ & $6.2 E+05$ & NA & $1.1 \mathrm{E}+00$ & $5.9 E+06$ & $1.6 E+05$ & NA & $3.6 \mathrm{E}+01$ \\
\hline TBP & $2.1 E+03$ & $1.9 E+03$ & NA & $1.1 E+00$ & $1.8 E+04$ & $5.0 E+02$ & NA & $3.6 E+01$ \\
\hline C-14 & $9.8 \mathrm{E}-02$ & 8.7E-02 & $3.9 E-01$ & $1.1 \mathrm{E}+00$ & 8.3E-01 & 2.3E-02 & 1.0E-01 & $3.6 E+01$ \\
\hline $1-129$ & $2.1 E+01$ & $1.9 E+01$ & $3.1 \mathrm{E}-03$ & $1.1 E+00$ & $1.8 E+02$ & $5.0 \mathrm{E}+00$ & $8.2 E-04$ & $3.6 E+01$ \\
\hline Tc-99 & $1.4 E+02$ & $1.2 E+02$ & $2.1 E+00$ & $1.1 E+00$ & $1.2 E+03$ & $3.2 \mathrm{E}+01$ & $5.5 E-01$ & $3.6 E+01$ \\
\hline U-238 & $2.0 E+05$ & $1.8 E+05$ & $6.0 \mathrm{E}-02$ & $1.1 E+00$ & $1.7 E+06$ & $4.7 E+04$ & $1.6 \mathrm{E}-02$ & $3.6 E+01$ \\
\hline
\end{tabular}


Table A-19. Inventories, Flux Rates, and Release Durations for Sensitivity Case \#2A Traditional Sluicing with Low Nitrate Inventory Alternative.

\begin{tabular}{|c|c|c|c|c|c|c|c|c|}
\hline \multirow[b]{2}{*}{ Contaminant } & \multicolumn{4}{|c|}{ Tank Residual } & \multicolumn{4}{|c|}{ Btw Tank \& Pad } \\
\hline & $\begin{array}{c}\text { Inventory } \\
\text { (g) }\end{array}$ & $\begin{array}{c}\text { Flux Rate } \\
(g / y r)\end{array}$ & $\begin{array}{c}\text { Flux Rate } \\
(\mathrm{Ci} / \mathrm{yr})\end{array}$ & $\begin{array}{c}\text { Release } \\
\text { Duration } \\
(y r)\end{array}$ & $\begin{array}{c}\text { Inventory } \\
\text { (g) }\end{array}$ & $\begin{array}{c}\text { Flux Rate } \\
(\mathrm{g} / \mathrm{yr})\end{array}$ & $\begin{array}{c}\text { Flux Rate } \\
\text { (Ci/yr) }\end{array}$ & $\begin{array}{c}\text { Release } \\
\text { Duration } \\
\text { (yr) }\end{array}$ \\
\hline EDTA & $5.0 E+04$ & $5.7 E+02$ & NA & $8.9 E+01$ & $4.7 E+02$ & $2.4 \mathrm{E}+02$ & NA & $2.0 E+00$ \\
\hline Nitrate & $7.8 E+07$ & $8.8 E+05$ & NA & $8.9 E+01$ & $7.3 E+05$ & $3.6 E+05$ & NA & $2.0 E+00$ \\
\hline Nitrite & $2.9 E+06$ & $3.3 E+04$ & NA & $8.9 E+01$ & $2.7 E+04$ & $1.4 E+04$ & NA & $2.0 E+00$ \\
\hline TBP & $3.4 E+04$ & $3.8 E+02$ & NA & $8.9 E+01$ & $3.2 E+02$ & $1.6 E+02$ & NA & $2.0 E+00$ \\
\hline C-14 & $1.8 E+00$ & $2.0 \mathrm{E}-02$ & 8.9E-02 & $8.9 E+01$ & $1.6 \mathrm{E}-02$ & $8.2 E-03$ & $3.7 E-02$ & $2.0 E+00$ \\
\hline $1-129$ & $3.5 E+02$ & $4.0 E+00$ & $6.4 E-04$ & $8.9 E+01$ & $3.3 E+00$ & $1.6 \mathrm{E}+00$ & 2.7E-04 & 2.0E +00 \\
\hline Tc-99 & $2.2 E+03$ & $2.5 E+01$ & $4.2 \mathrm{E}-01$ & $8.9 E+01$ & $2.1 E+01$ & $1.0 E+01$ & $1.8 \mathrm{E}-01$ & $2.0 E+00$ \\
\hline \multirow[t]{2}{*}{ U-238 } & 1.1E+06 & $1.3 E+04$ & $4.2 \mathrm{E}-03$ & $8.9 E+01$ & $1.1 E+04$ & $5.3 E+03$ & $1.8 \mathrm{E}-03$ & $2.0 E+00$ \\
\hline & \multicolumn{4}{|c|}{ Concrete Pad } & \multicolumn{4}{|c|}{ Old \& New Leaks } \\
\hline Contaminant & $\begin{array}{c}\text { Inventory } \\
\text { (g) }\end{array}$ & $\begin{array}{c}\text { Flux Rate } \\
(g / y r)\end{array}$ & $\begin{array}{c}\text { Flux Rate } \\
(\mathrm{Ci} / \mathrm{yr})\end{array}$ & $\begin{array}{c}\text { Release } \\
\text { Duration } \\
\text { (yr) }\end{array}$ & $\begin{array}{c}\text { Inventory } \\
\text { (g) }\end{array}$ & $\begin{array}{c}\text { Flux Rate } \\
(\mathrm{g} / \mathrm{yr})\end{array}$ & $\begin{array}{c}\text { Flux Rate } \\
(\mathrm{Ci} / \mathrm{yr})\end{array}$ & $\begin{array}{c}\text { Release } \\
\text { Duration } \\
(y r)\end{array}$ \\
\hline EDTA & $9.1 E+03$ & $8.1 E+01$ & NA & $1.1 E+02$ & $7.8 E+04$ & $2.1 E+01$ & NA & $3.6 E+03$ \\
\hline Nitrate & $1.4 E+07$ & $1.3 E+05$ & NA & $1.1 E+02$ & $1.2 E+08$ & $3.3 E+04$ & NA & $3.6 E+03$ \\
\hline Nitrite & $5.3 E+05$ & $4.7 E+03$ & NA & $1.1 E+02$ & $4.5 E+06$ & $1.2 E+03$ & $N A$ & $3.6 E+03$ \\
\hline TBP & $6.2 E+03$ & $5.5 E+01$ & NA & $1.1 E+02$ & $5.3 E+04$ & $1.4 \mathrm{E}+01$ & NA & $3.6 E+03$ \\
\hline C-14 & $3.2 \mathrm{E}-01$ & $2.8 E-03$ & $1.3 E-02$ & $1.1 E+02$ & $2.7 E+00$ & $7.5 \mathrm{E}-04$ & 3.3E-03 & $3.6 E+03$ \\
\hline $1-129$ & $6.3 E+01$ & $5.7 E-01$ & $9.2 E-05$ & $1.1 E+02$ & $5.4 \mathrm{E}+02$ & $1.5 \mathrm{E}-01$ & 2.4E-05 & $3.6 \mathrm{E}+03$ \\
\hline Tc-99 & $4.0 E+02$ & $3.6 \mathrm{E}+00$ & $6.1 E-02$ & $1.1 E+02$ & $3.4 E+03$ & $9.4 \mathrm{E}-01$ & 1.6E-02 & $3.6 E+03$ \\
\hline U-238 & $2.0 E+05$ & $1.8 E+03$ & $6.1 E-04$ & $1.1 E+02$ & $1.7 E+06$ & $4.8 E+02$ & 1.6E-04 & $3.6 E+03$ \\
\hline
\end{tabular}


Table A-20. Inventories, Flux Rates, and Release Durations for Sensitivity Case \#2B Traditional Sluicing with High Nitrate Inventory Alternative.

\begin{tabular}{|c|c|c|c|c|c|c|c|c|}
\hline \multirow[b]{2}{*}{ Contaminant } & \multicolumn{4}{|c|}{ Tank Residual } & \multicolumn{4}{|c|}{ Btw Tank \& Pad } \\
\hline & $\begin{array}{c}\text { Inventory } \\
\text { (g) }\end{array}$ & $\begin{array}{c}\text { Flux Rate } \\
(g / y r)\end{array}$ & $\begin{array}{c}\text { Flux Rate } \\
(\mathrm{Ci} / \mathrm{yr})\end{array}$ & $\begin{array}{c}\text { Release } \\
\text { Duration } \\
\text { (yr) }\end{array}$ & $\begin{array}{c}\text { Inventory } \\
\text { (g) }\end{array}$ & $\begin{array}{c}\text { Flux Rate } \\
(g / y r)\end{array}$ & $\begin{array}{c}\text { Flux Rate } \\
(\mathrm{Ci} / \mathrm{yr})\end{array}$ & $\begin{array}{c}\text { Release } \\
\text { Duration } \\
(y r)\end{array}$ \\
\hline EDTA & $4.0 \mathrm{E}+03$ & $4.5 \mathrm{E}+01$ & NA & $8.9 E+01$ & $3.7 E+01$ & $1.9 E+01$ & NA & $2.0 E+00$ \\
\hline Nitrate & $7.8 E+07$ & $8.8 E+05$ & NA & $8.9 E+01$ & $7.3 E+05$ & $3.6 \mathrm{E}+05$ & NA & $2.0 E+00$ \\
\hline Nitrite & $7.5 E+0.5$ & $8.5 E+03$ & NA & $8.9 E+01$ & $7.0 E+03$ & $3.5 E+03$ & NA & $2.0 E+00$ \\
\hline TBP & $2.7 E+03$ & $3.0 E+01$ & NA & $8.9 E+01$ & $2.5 E+01$ & $1.3 E+01$ & NA & $2.0 E+00$ \\
\hline$C-14$ & $3.5 \mathrm{E}-01$ & $3.9 \mathrm{E}-03$ & 1.7E-02 & $8.9 E+01$ & $3.2 \mathrm{E}-03$ & $1.6 \mathrm{E}-03$ & 7.2E-03 & $2.0 E+00$ \\
\hline $1-129$ & $7.8 E+01$ & 8.7E-01 & $1.4 \mathrm{E}-04$ & $8.9 E+01$ & $7.2 \mathrm{E}-01$ & 3.6E-01 & 5.9E-05 & $2.0 E+00$ \\
\hline Tc-99 & $5.6 \mathrm{E}+02$ & $6.3 E+00$ & $1.1 \mathrm{E}-01$ & $8.9 E+01$ & $5.2 E+00$ & $2.6 \mathrm{E}+00$ & $4.5 \mathrm{E}-02$ & $2.0 E+00$ \\
\hline \multirow[t]{2}{*}{$\mathrm{U}-238$} & $1.1 \mathrm{E}+05$ & $1.2 \mathrm{E}+03$ & 4.1E-04 & $8.9 E+01$ & $1.0 \mathrm{E}+03$ & $5.1 E+02$ & 1.7E-04 & $2.0 \mathrm{E}+00$ \\
\hline & \multicolumn{4}{|c|}{ Concrete Pad } & \multicolumn{4}{|c|}{ Old \& New Leaks } \\
\hline Contaminant & $\begin{array}{c}\text { Inventory } \\
\text { (g) }\end{array}$ & $\begin{array}{c}\text { Flux Rate } \\
(g / y r)\end{array}$ & $\begin{array}{c}\text { Flux Rate } \\
(\mathrm{Ci} / \mathrm{yr})\end{array}$ & $\begin{array}{c}\text { Release } \\
\text { Duration } \\
(y r) \\
\end{array}$ & $\begin{array}{c}\text { Inventory } \\
\text { (g) }\end{array}$ & $\begin{array}{c}\text { Flux Rate } \\
(\mathrm{g} / \mathrm{yr})\end{array}$ & $\begin{array}{c}\text { Flux Rate } \\
\text { (Ci/yr) }\end{array}$ & $\begin{array}{c}\text { Release } \\
\text { Duration } \\
\text { (yr) }\end{array}$ \\
\hline EDTA & $7.1 E+02$ & $6.4 E+00$ & NA & $1.1 \mathrm{E}+02$ & $6.1 E+03$ & $1.7 E+00$ & NA & $3.6 E+03$ \\
\hline Nitrate & $1.4 E+07$ & $1.3 E+05$ & NA & $1.1 E+02$ & $1.2 E+08$ & $3.3 E+04$ & NA & $3.6 E+03$ \\
\hline Nitrite & $1.4 E+05$ & $1.2 E+03$ & NA & $1.1 E+02$ & $1.2 E+06$ & $3.2 E+02$ & NA & $3.6 E+03$ \\
\hline TBP & $4.8 E+02$ & $4.3 E+00$ & NA & $1.1 E+02$ & $4.1 E+03$ & $1.1 E+00$ & NA & $3.6 E+03$ \\
\hline C-14 & $6.3 \mathrm{E}-02$ & $5.6 \mathrm{E}-04$ & $2.5 \mathrm{E}-03$ & $1.1 E+02$ & $5.4 \mathrm{E}-01$ & $1.5 \mathrm{E}-04$ & $6.6 \mathrm{E}-04$ & $3.6 E+03$ \\
\hline $1-129$ & $1.4 E+01$ & 1.3E-01 & 2.0E-05 & $1.1 \mathrm{E}+02$ & $1.2 E+02$ & 3.3E-02 & 5.4E-06 & $3.6 E+03$ \\
\hline Tc-99 & $1.0 E+02$ & $9.1 \mathrm{E}-01$ & $1.5 \mathrm{E}-02$ & $1.1 E+02$ & $8.7 E+02$ & 2.4E-01 & 4.1E-03 & $3.6 E+03$ \\
\hline $\mathrm{U}-238$ & $2.0 E+04$ & $1.8 \mathrm{E}+02$ & $5.9 \mathrm{E}-05$ & $1.1 E+02$ & $1.7 E+05$ & $4.7 E+01$ & 1.6E-05 & $3.6 E+03$ \\
\hline
\end{tabular}


Table A-21. Inventories, Flux Rates, and Release Durations for Sensitivity Case \#3 Traditional Sluicing with Faster Vadose Zone Travel.

\begin{tabular}{|c|c|c|c|c|c|c|c|c|}
\hline \multirow[b]{2}{*}{ Contaminant } & \multicolumn{4}{|c|}{ Tank Residual } & \multicolumn{4}{|c|}{ Btw Tank \& Pad } \\
\hline & $\begin{array}{c}\text { Inventory } \\
\text { (g) }\end{array}$ & $\begin{array}{c}\text { Flux Rate } \\
(\mathrm{g} / \mathrm{yr})\end{array}$ & $\begin{array}{c}\text { Flux Rate } \\
(\mathrm{Ci} / \mathrm{yr})\end{array}$ & $\begin{array}{c}\text { Release } \\
\text { Duration } \\
(y r)\end{array}$ & $\begin{array}{c}\text { Inventory } \\
\text { (g) }\end{array}$ & $\begin{array}{c}\text { Flux Rate } \\
(g / y r)\end{array}$ & $\begin{array}{c}\text { Flux Rate } \\
\text { (Cilyr) }\end{array}$ & $\begin{array}{c}\text { Release } \\
\text { Duration } \\
\text { (yr) }\end{array}$ \\
\hline EDTA & $1.4 E+04$ & $1.5 E+02$ & NA & $8.9 E+01$ & $1.3 E+02$ & $6.3 E+01$ & NA & $2.0 \mathrm{E}+00$ \\
\hline Nitrate & $7.8 E+07$ & $8.8 E+05$ & NA & $8.9 E+01$ & $7.3 E+05$ & $3.6 E+05$ & NA & $2.0 E+00$ \\
\hline Nitrite & $3.9 E+06$ & $4.3 E+04$ & NA & $8.9 E+01$ & $3.6 E+04$ & $1.8 E+04$ & NA & $2.0 E+00$ \\
\hline TBP & $1.2 E+04$ & $1.3 E+02$ & NA & $8.9 E+01$ & $1.1 E+02$ & $5.5 E+01$ & NA & $2.0 E+00$ \\
\hline$C-14$ & $5.4 \mathrm{E}-01$ & $6.1 \mathrm{E}-03$ & $2.7 \mathrm{E}-02$ & $8.9 E+01$ & 5.0E-03 & $2.5 \mathrm{E}-03$ & $1.1 \mathrm{E}-02$ & $2.0 E+00$ \\
\hline $1-129$ & $1.2 E+02$ & $1.3 E+00$ & $2.2 E-04$ & $8.9 E+01$ & $1.1 E+00$ & $5.5 \mathrm{E}-01$ & $9.0 \mathrm{E}-05$ & $2.0 E+00$ \\
\hline Tc-99 & $7.6 E+02$ & $8.5 E+00$ & $1.4 \mathrm{E}-01$ & $8.9 E+01$ & $7.0 E+00$ & $3.5 E+00$ & $6.0 E-02$ & $2.0 E+00$ \\
\hline U-238 & $1.1 E+06$ & $1.2 E+04$ & $4.2 \mathrm{E}-03$ & $8.9 E+01$ & $1.0 E+04$ & $5.2 E+03$ & 1.7E-03 & $2.0 E+00$ \\
\hline & \multicolumn{4}{|c|}{ Concrete Pad } & \multicolumn{4}{|c|}{ Old \& New Leaks } \\
\hline Contaminant & $\begin{array}{c}\text { Inventory } \\
\text { (g) }\end{array}$ & $\begin{array}{c}\text { Flux Rate } \\
(g / y r)\end{array}$ & $\begin{array}{c}\text { Flux Rate } \\
(\mathrm{Ci} / \mathrm{yr})\end{array}$ & $\begin{array}{c}\text { Release } \\
\text { Duration } \\
(y r)\end{array}$ & $\begin{array}{c}\text { Inventory } \\
\text { (g) }\end{array}$ & $\begin{array}{c}\text { Flux Rate } \\
(g / y r)\end{array}$ & $\begin{array}{c}\text { Flux Rate } \\
\text { (Ci/yr) }\end{array}$ & $\begin{array}{c}\text { Release } \\
\text { Duration } \\
(y r)\end{array}$ \\
\hline EDTA & $2.4 E+03$ & $2.2 E+01$ & NA & $1.1 E+02$ & $2.1 E+04$ & $5.7 E+00$ & NA & $3.6 \mathrm{E}+03$ \\
\hline Nitrate & $1.4 E+07$ & $1.3 E+05$ & NA & $1.1 E+02$ & $1.2 E+08$ & $3.3 E+04$ & NA & $3.6 E+03$ \\
\hline Nitrite & $7.0 \mathrm{E}+05$ & $6.2 E+03$ & NA & $1.1 E+02$ & $5.9 E+06$ & $1.6 E+03$ & NA & $3.6 E+03$ \\
\hline TBP & $2.1 E+03$ & $1.9 E+01$ & NA & $1.1 E+02$ & $1.8 \mathrm{E}+04$ & $5.0 E+00$ & NA & $3.6 E+03$ \\
\hline$C-14$ & $9.8 E-02$ & 8.7E-04 & $3.9 E-03$ & $1.1 E+02$ & 8.3E-01 & $2.3 \mathrm{E}-04$ & 1.0E-03 & $3.6 E+03$ \\
\hline $1-129$ & $2.1 E+01$ & $1.9 \mathrm{E}-01$ & $3.1 \mathrm{E}-05$ & $1.1 E+02$ & $1.8 \mathrm{E}+02$ & $5.0 E-02$ & 8.2E-06 & $3.6 E+03$ \\
\hline Tc-99 & $1.4 \mathrm{E}+02$ & $1.2 E+00$ & $2.1 E-02$ & $1.1 E+02$ & $1.2 E+03$ & $3.2 \mathrm{E}-01$ & 5.5E-03 & $3.6 E+03$ \\
\hline$U-238$ & $2.0 E+05$ & $1.8 E+03$ & $6.0 \mathrm{E}-04$ & $1.1 E+02$ & $1.7 E+06$ & $4.7 E+02$ & 1.6E-04 & $3.6 E+03$ \\
\hline
\end{tabular}


Table A-22. Inventories, Flux Rates, and Release Durations for Sensitivity Case \#3 Traditional Sluicing with Slower Vadose Zone Travel.

\begin{tabular}{|c|c|c|c|c|c|c|c|c|}
\hline \multirow[b]{2}{*}{ Contaminant } & \multicolumn{4}{|c|}{ Tank Residual } & \multicolumn{4}{|c|}{ Btw Tank \& Pad } \\
\hline & $\begin{array}{c}\text { Inventory } \\
\text { (g) }\end{array}$ & $\begin{array}{c}\text { Flux Rate } \\
(g / y r)\end{array}$ & $\begin{array}{c}\text { Flux Rate } \\
\text { (Ci/yr) }\end{array}$ & $\begin{array}{c}\text { Release } \\
\text { Duration } \\
\text { (yr) }\end{array}$ & $\begin{array}{c}\text { Inventory } \\
\text { (g) }\end{array}$ & $\begin{array}{c}\text { Flux Rate } \\
(\mathrm{g} / \mathrm{y} r)\end{array}$ & $\begin{array}{c}\text { Flux Rate } \\
\text { (Ci/yr) }\end{array}$ & $\begin{array}{c}\text { Release } \\
\text { Duration } \\
(y r)\end{array}$ \\
\hline EDTA & $1.4 E+04$ & $1.5 E+02$ & NA & $8.9 E+01$ & $1.3 E+02$ & $6.3 E+01$ & NA & $2.0 E+00$ \\
\hline Nitrate & $7.8 E+07$ & $8.8 E+05$ & NA & $8.9 E+01$ & $7.3 E+05$ & $3.6 E+05$ & NA & $2.0 E+00$ \\
\hline Nitrite & $3.9 E+06$ & $4.3 E+04$ & NA & $8.9 E+01$ & $3.6 E+04$ & $1.8 E+04$ & NA & $2.0 E+00$ \\
\hline TBP & $1.2 E+04$ & $1.3 E+02$ & NA & $8.9 E+01$ & $1.1 E+02$ & $5.5 E+01$ & NA & $2.0 E+00$ \\
\hline C-14 & $5.4 \mathrm{E}-01$ & $6.1 \mathrm{E}-03$ & 2.7E-02 & $8.9 E+01$ & 5.0E-03 & $2.5 \mathrm{E}-03$ & $1.1 \mathrm{E}-02$ & $2.0 E+00$ \\
\hline $1-129$ & $1.2 E+02$ & $1.3 E+00$ & $2.2 E-04$ & $8.9 E+01$ & $1.1 E+00$ & 5.5E-01 & $9.0 \mathrm{E}-05$ & $2.0 E+00$ \\
\hline Tc-99 & $7.6 E+02$ & $8.5 E+00$ & $1.4 \mathrm{E}-01$ & $8.9 E+01$ & $7.0 E+00$ & $3.5 E+00$ & $6.0 \mathrm{E}-02$ & $2.0 E+00$ \\
\hline \multirow[t]{3}{*}{ U-238 } & $1.1 E+06$ & $1.2 E+04$ & $4.2 E-03$ & $8.9 E+01$ & $1.0 E+04$ & $5.2 E+03$ & $1.7 \mathrm{E}-03$ & $2.0 E+00$ \\
\hline & \multicolumn{4}{|c|}{ Concrete Pad } & \multicolumn{4}{|c|}{ Old \& New Leaks } \\
\hline & $\begin{array}{c}\text { Inventory } \\
\text { (g) }\end{array}$ & $\begin{array}{c}\text { Flux Rate } \\
(\mathrm{g} / \mathrm{yr})\end{array}$ & $\begin{array}{c}\text { Flux Rate } \\
(\mathrm{Ci} / \mathrm{yr})\end{array}$ & $\begin{array}{c}\text { Release } \\
\text { Duration } \\
(y r)\end{array}$ & $\begin{array}{c}\text { Inventory } \\
\text { (g) }\end{array}$ & $\begin{array}{c}\text { Flux Rate } \\
(\mathrm{g} / \mathrm{yr})\end{array}$ & $\begin{array}{c}\text { Flux Rate } \\
\text { (Ci/yr) }\end{array}$ & $\begin{array}{c}\text { Release } \\
\text { Duration } \\
(y r)\end{array}$ \\
\hline EDTA & $2.4 E+03$ & $2.2 E+01$ & NA & $1.1 \mathrm{E}+02$ & $2.1 E+04$ & $5.7 E+00$ & NA & $3.6 E+03$ \\
\hline Nitrate & $1.4 \mathrm{E}+07$ & $1.3 E+05$ & NA & $1.1 E+02$ & $1.2 E+08$ & $3.3 E+04$ & NA & $3.6 E+03$ \\
\hline Nitrite & $7.0 E+05$ & $6.2 E+03$ & NA & i. $1 E+02$ & $5.9 E+06$ & $1.6 \mathrm{E}+03$ & NA & $3.6 \mathrm{E}+03$ \\
\hline TBP & $2.1 E+03$ & $1.9 E+01$ & NA & $1.1 E+02$ & $1.8 \mathrm{E}+04$ & $5.0 E+00$ & NA & $3.6 \mathrm{E}+03$ \\
\hline$C-14$ & $9.8 \mathrm{E}-02$ & 8.7E-04 & $3.9 \mathrm{E}-03$ & $1.1 E+02$ & 8.3E-01 & 2.3E-04 & 1.0E-03 & $3.6 E+03$ \\
\hline $1-129$ & $2.1 E+01$ & $1.9 \mathrm{E}-01$ & 3.1E-05 & $1.1 E+02$ & $1.8 \mathrm{E}+02$ & $5.0 \mathrm{E}-02$ & 8.2E-06 & $3.6 \mathrm{E}+03$ \\
\hline Tc-99 & $1.4 E+02$ & $1.2 E+00$ & 2.1E-02 & $1.1 E+02$ & $1.2 E+03$ & $3.2 \mathrm{E}-01$ & 5.5E-03 & $3.6 E+03$ \\
\hline U-238 & $2.0 E+05$ & $1.8 E+03$ & 6.0E-04 & $1.1 E+02$ & $1.7 E+06$ & $4.7 E+02$ & $1.6 \mathrm{E}-04$ & $3.6 E+03$ \\
\hline
\end{tabular}


Table A-23. Inventories, Flux Rates, and Release Durations for Sensitivity Case \#5 Traditional Sluicing with Solubility Limited Release Alternative.

\begin{tabular}{|c|c|c|c|c|c|c|}
\hline \multirow[b]{2}{*}{ Contaminant } & \multicolumn{3}{|c|}{ Tank Residual } & \multicolumn{3}{|c|}{ Btw Tank \& Pad } \\
\hline & $\begin{array}{l}\text { Inventory } \\
\text { (Ci or } \mathrm{g} \text { ) }\end{array}$ & $\begin{array}{c}\text { Flux Rate } \\
\text { (Ci/yr or } \\
g / y r)\end{array}$ & $\begin{array}{c}\text { Release } \\
\text { Duration } \\
\text { (yr) }\end{array}$ & $\begin{array}{c}\text { Inventory } \\
\text { (g) }\end{array}$ & $\begin{array}{c}\text { Flux Rate } \\
(g / y r)\end{array}$ & $\begin{array}{c}\text { Release } \\
\text { Duration } \\
(y r)\end{array}$ \\
\hline TBP & $1.2 E+04$ & $1.3 E+02$ & $8.9 E+01$ & $1.1 E+02$ & $5.5 E+01$ & $2.0 E+00$ \\
\hline$C-14$ & $2.4 E+00$ & 7.3E-06 & $3.3 E+05$ & $9.4 E-06$ & 4.7E-06 & $2.0 E+00$ \\
\hline $1-129$ & $2.0 \mathrm{E}-02$ & 7.7E-07 & $2.6 E+04$ & $9.3 E-07$ & $4.4 E-07$ & $2.1 E+00$ \\
\hline Tc-99 & $1.3 E+01$ & 7.7E-04 & $1.7 E+04$ & $9.1 \mathrm{E}-04$ & $4.4 \mathrm{E}-04$ & $2.1 E+00$ \\
\hline \multirow[t]{3}{*}{$\mathrm{U}-238$} & 3.7E-01 & $1.9 \mathrm{E}-06$ & $2.0 E+05$ & 3.1E-06 & $1.5 \mathrm{E}-06$ & $2.1 E+00$ \\
\hline & \multicolumn{3}{|c|}{ Concrete Pad } & \multicolumn{3}{|c|}{ Old \& New Leaks } \\
\hline & $\begin{array}{c}\text { Inventory } \\
\text { (g) }\end{array}$ & $\begin{array}{c}\text { Flux Rate } \\
(\mathrm{g} / \mathrm{yr})\end{array}$ & $\begin{array}{c}\text { Release } \\
\text { Duration } \\
(y r)\end{array}$ & $\begin{array}{c}\text { Inventory } \\
\text { (g) }\end{array}$ & $\begin{array}{c}\text { Flux Rate } \\
(\mathrm{g} / \mathrm{yr})\end{array}$ & $\begin{array}{c}\text { Release } \\
\text { Duration } \\
(y r)\end{array}$ \\
\hline TBP & $2.1 E+03$ & $1.9 E+01$ & $1.1 E+02$ & $1.8 E+04$ & $5.0 E+00$ & $3.6 \mathrm{E}+03$ \\
\hline$C-14$ & $1.8 \mathrm{E}-04$ & $1.6 \mathrm{E}-06$ & $1.1 E+02$ & $3.2 \mathrm{E}-03$ & $8.8 \mathrm{E}-07$ & $3.7 E+03$ \\
\hline $1-129$ & $1.8 E-05$ & $1.6 \mathrm{E}-07$ & $1.1 \mathrm{E}+02$ & $3.1 \mathrm{E}-04$ & 8.8E-08 & $3.5 E+03$ \\
\hline Tc-99 & $1.7 E-02$ & $1.6 \mathrm{E}-04$ & $1.1 E+02$ & $3.0 E-01$ & $8.4 \mathrm{E}-05$ & $3.6 \mathrm{E}+03$ \\
\hline$U-238$ & $6.0 E-05$ & 5.5E-07 & $1.1 E+02$ & 1.0E-03 & $2.9 E-07$ & $3.5 E+03$ \\
\hline
\end{tabular}


Table A-24. Inventory Distribution and Risk Conversion Factors of COCs in Tank Waste.

\begin{tabular}{|c|c|c|c|c|}
\hline $\begin{array}{l}\text { Constituent } \\
\text { of Concern }\end{array}$ & $\begin{array}{l}\text { Distribution of } \\
\text { Inventory in } 149 \\
\text { Tanks (kg or Ci) }\end{array}$ & $\begin{array}{l}\text { MEPAS Slope } \\
\text { Factor } \\
\text { (mg/kg-day) }^{-1}\end{array}$ & $\begin{array}{l}\text { MEPAS RfD } \\
\text { (mg/kg-day) }^{c}\end{array}$ & $\begin{array}{l}\text { Risk Conversion } \\
\text { Factor }\left[(\mathrm{g} / \mathrm{ml})^{-1} \text { or }\right. \\
\left.(\mathrm{Ci} / \mathrm{ml})^{-1}\right]\end{array}$ \\
\hline Nitrate & $9.7 \mathrm{E}+07$ & & $1.6 \mathrm{E}+00$ & $7.5 E+05$ \\
\hline Nitrite & $4.8 \mathrm{E}+06$ & & $3.4 \mathrm{E}-02$ & $6.7 E+05$ \\
\hline EDTA & $1.7 \mathrm{E}+04$ & & 1.3E-03 & $3.2 E+08$ \\
\hline $\mathrm{TBP}^{\mathrm{b}}$ & $1.5 E+04$ & $\begin{array}{c}0.0 \mathrm{E}+00 \text { (inh) } \\
7.9 \mathrm{E}-03 \text { (ing) }\end{array}$ & & $4.1 E+02$ \\
\hline $\mathrm{C}^{14}$ & $3 E+03$ & $\begin{array}{l}6.4 \mathrm{E}-15 \text { (inh) } \\
9.0 \mathrm{E}-13 \text { (ing) }\end{array}$ & & $2.5 E+08$ \\
\hline $\mathrm{I}^{129}$ & $2.4 \mathrm{E}+01$ & $\begin{array}{l}1.2 \mathrm{E}-10 \text { (inh) } \\
1.9 \mathrm{E}-10 \text { (ing) }\end{array}$ & & $1.5 E+10$ \\
\hline $\mathrm{Tc}^{99}$ & $1.6 \mathrm{E}+04$ & $\begin{array}{l}8.3 \mathrm{E}-12 \text { (inh) } \\
1.3 \mathrm{E}-12 \text { (ing) }\end{array}$ & $\cdot$ & $1.5 \mathrm{E}+08$ \\
\hline$U^{238}$ & $4.6 \mathrm{E}+02$ & $\begin{array}{l}5.2 \mathrm{E}-08 \text { (inh) } \\
2.8 \mathrm{E}-11 \text { (ing) }\end{array}$ & & $1.9 E+09$ \\
\hline
\end{tabular}

${ }^{a}$ EDTA - ethylenediaminetetraacetic acid

'TBP - tributyl phosphate

${ }^{c} \mathrm{RfD}$ values for COCs are the same for both ingestion and inhalation exposure pathways. 
WHC-SD-WM-ES-300 REV. 1

This page intentionally left blank. 
WHC-SD-WM-ES-300 REV. 1

APPENDIX B

GROUNDWATER CONCENTRATION AND

HUMAN HEALTH RISK RESULTS

B-1 
WHC-SD-WM-ES-300 REV. 1

This page intentionally left blank. 


\section{B.0 GROUNDWATER CONCENTRATION AND HUMAN HEALTH RISK RESULTS}

This appendix presents the results of groundwater contaminant concentration and human health risk calculations performed using the MEPAS computer program. For each of the 14 alternative cases and the six sensitivity cases evaluated, plots have been generated depicting groundwater concentration, relative risk, and $\mathrm{HI}$ as a function of time.

Appendix B.1 presents the groundwater contaminant concentrations computed for each alternative or sensitivity case. These plots are presented to provide perspective to the relative contaminant concentrations for each alternative. Appendix B.2 presents the cancer risk and toxic HI results for each source within each alternative or sensitivity case.

\section{B.1 GROUNDWATER CONTAMINANT CONCENTRATIONS}

Separate MEPAS calculations were performed for each source to account for source-specific characteristics, case-specific transport conditions, and to produce source-specific groundwater concentrations that support detailed evaluations of the alternative cases. The contaminant release data used in the MEPAS calculations are detailed in Appendix A. The timing and duration of contaminant releases are summarized in Table A-3 for each source and alternative case.

The results of these source-specific calculations are contaminant concentrations in groundwater, as a function of time, at the point of exposure located near the tank farm. A 30,000 year time period was specified for the MEPAS modelling runs in order to ensure that concentration peaks for all alternatives were encompassed in the MEPAS output.

\section{B.2 HUMAN HEALTH RISKS}

Health risks (cancer risk and HI) have been calculated for each source as the product of contaminant flux rate out of the last geological strata, the dilution factor as described in Section 6.0, and unit-concentration risk and HI factors derived using the MEPAS. The unit risk and $\mathrm{HI}$ factors, and the basis of their calculation are presented in Appendix A. The results of the source-specific calculations are contaminant-specific risk and HI, as a function of time, at the point of interest ( $50 \mathrm{~m}$ down gradient). For each of the 14 alternative cases and six sensitivity cases evaluated, figures present the cancer risk and $\mathrm{HI}$ as a function of time for each applicable source. 
WHC-SD-WM-ES-300 REV. 1

This page intentionally left blank. 


\section{APPENDIX B.1}

\section{GROUNDWATER CONCENTRATION RESULTS}


WHC-SD-WM-ES-300 REV. 1

This page intentionally left blank. 


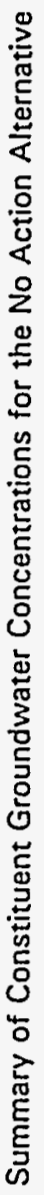

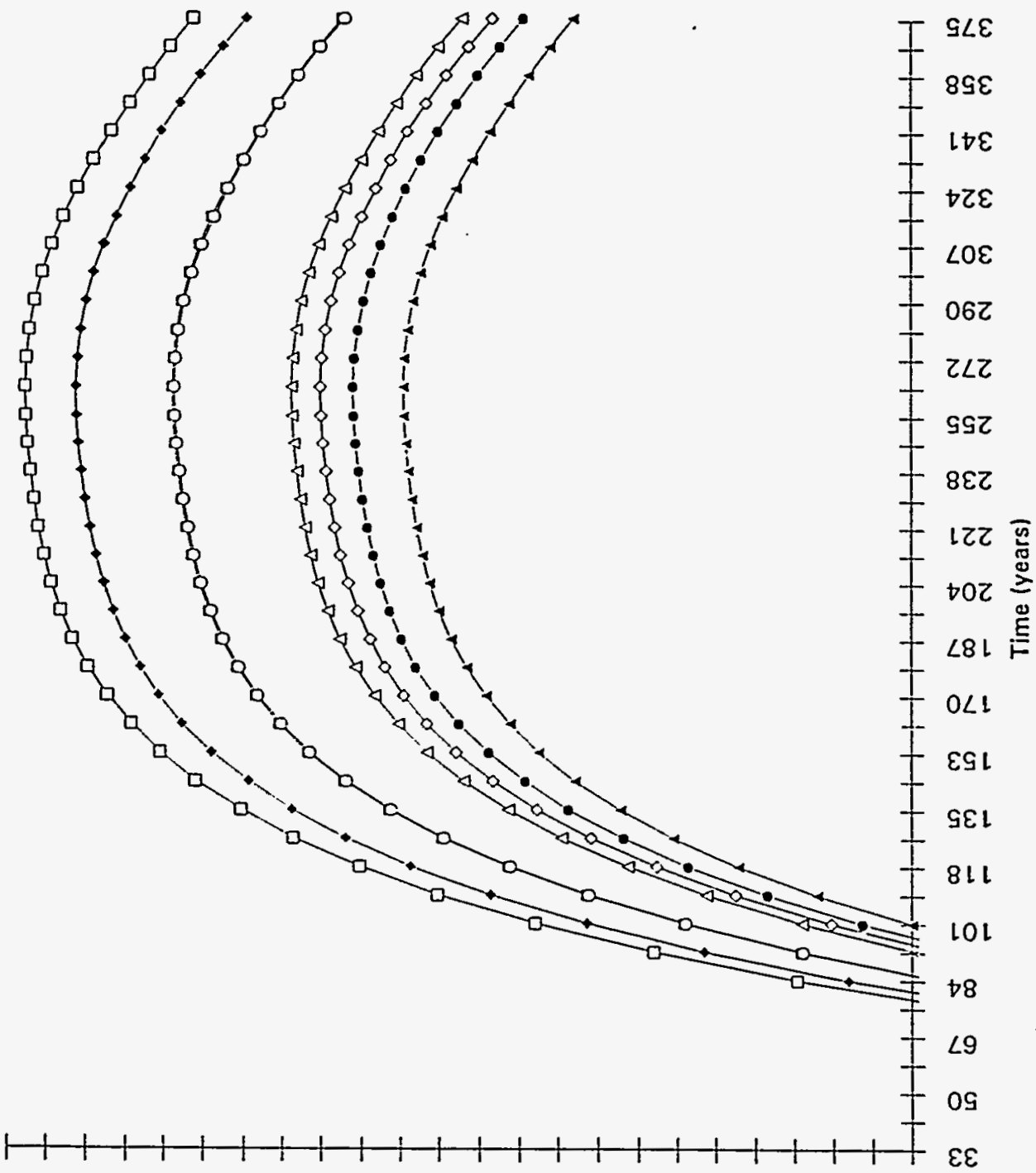

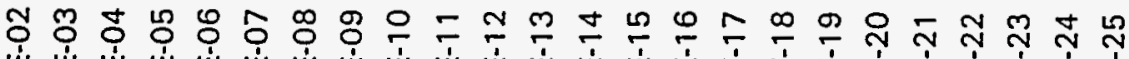
岁 岁 岁 岁

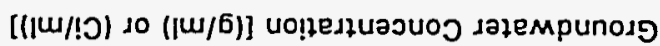




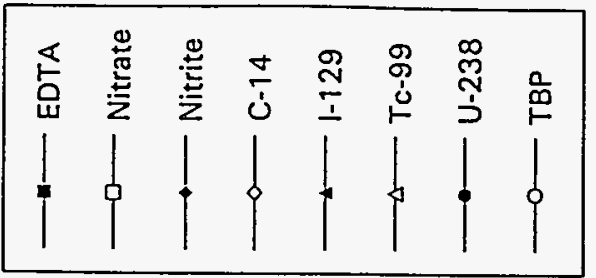

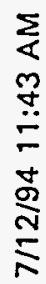

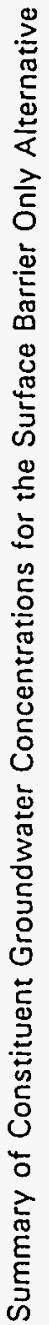

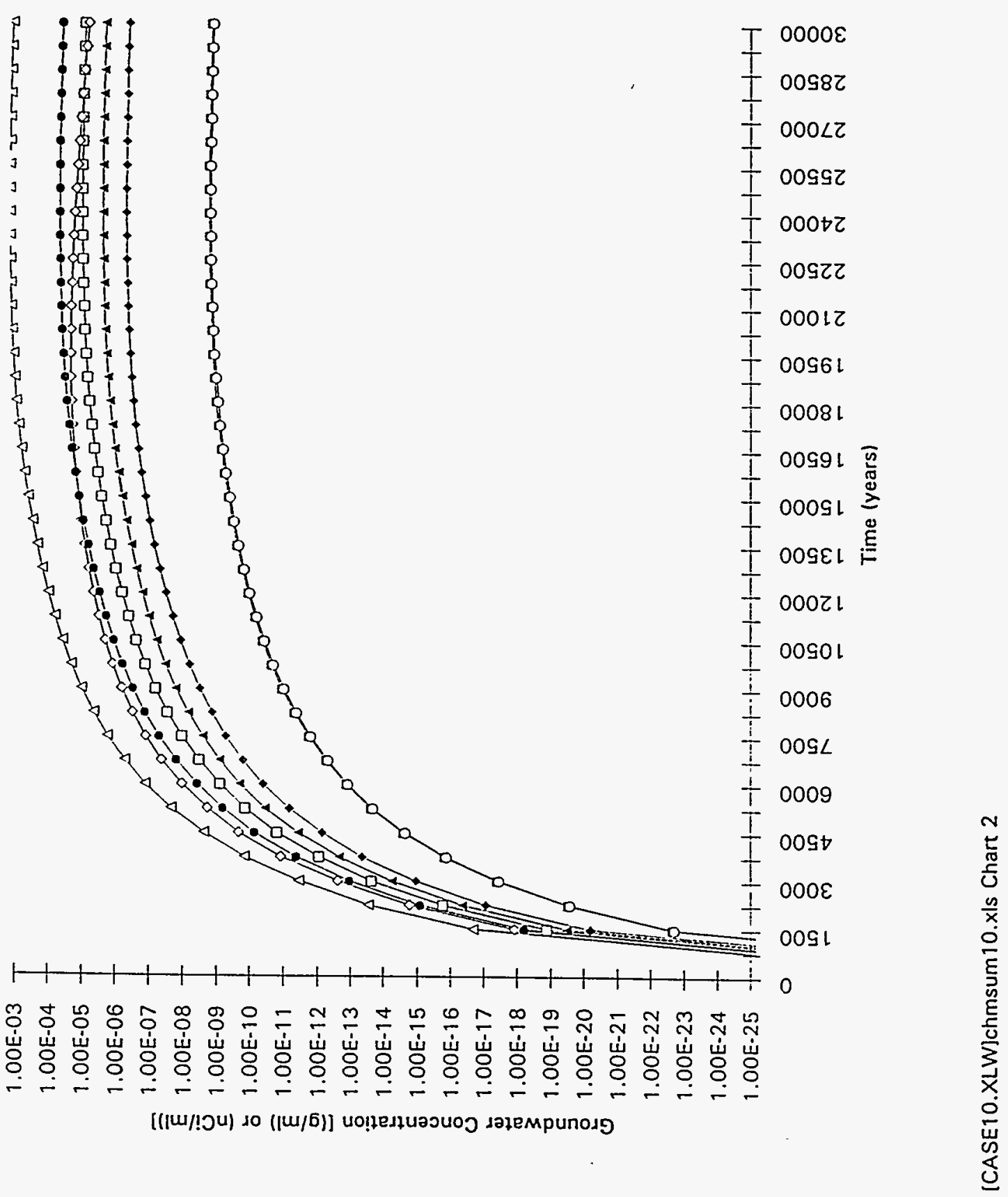


WHC-SD-WM-ES-300 REV. 1

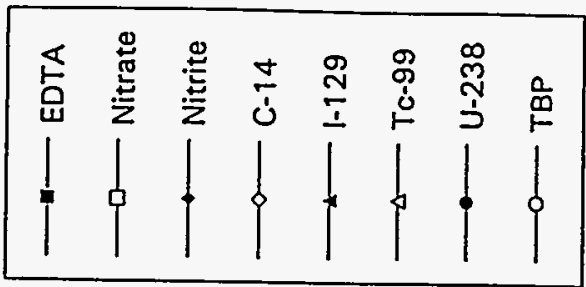

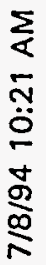

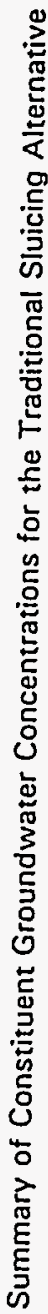

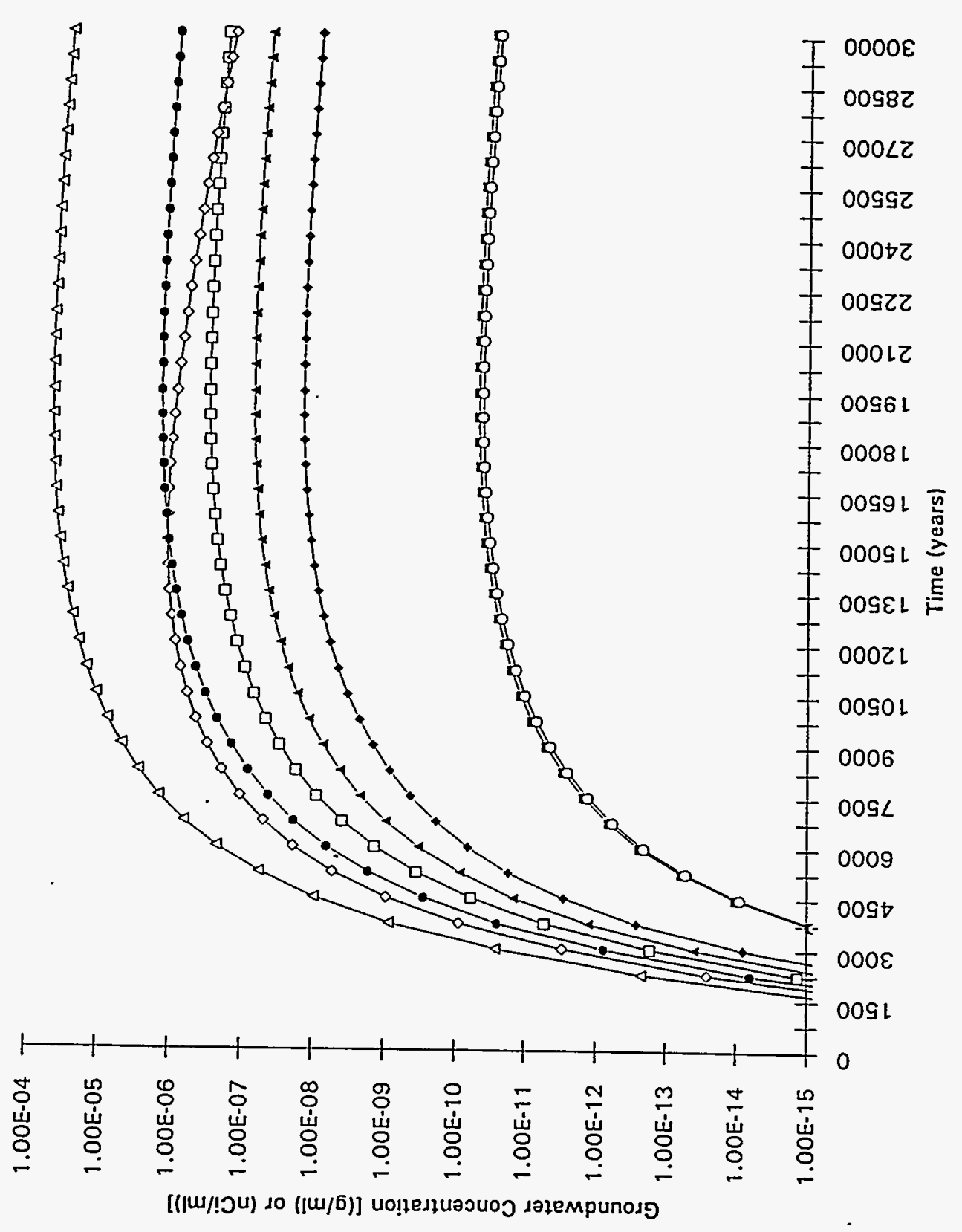

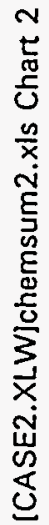




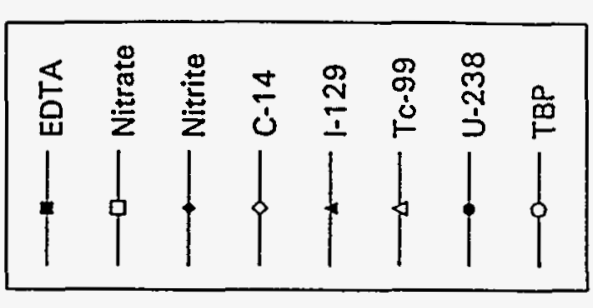

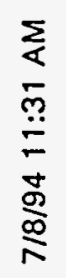

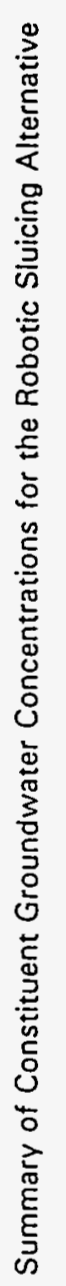

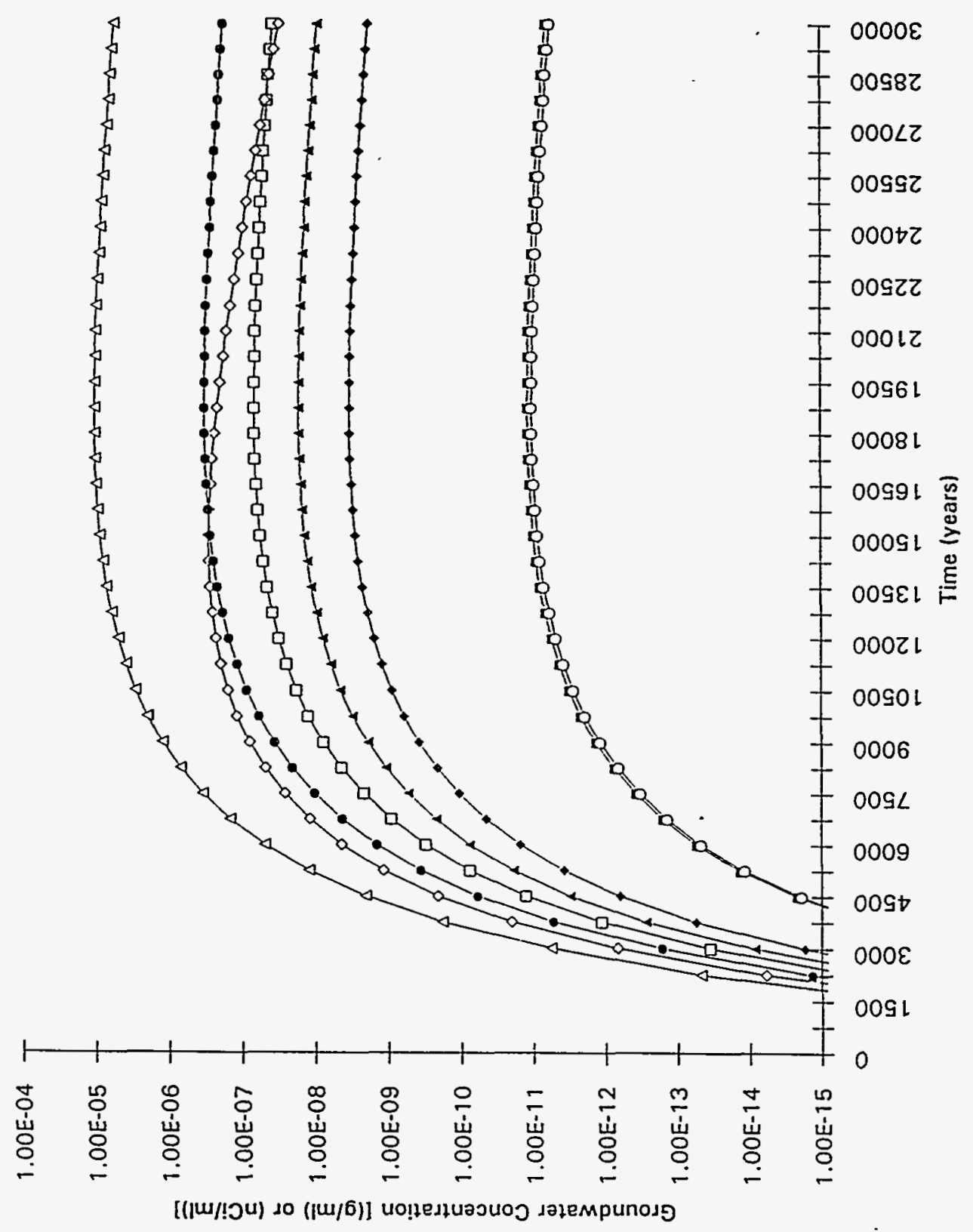

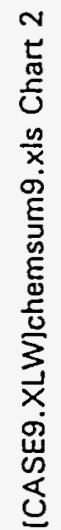




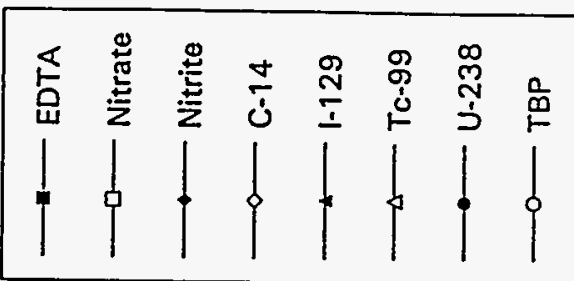

空

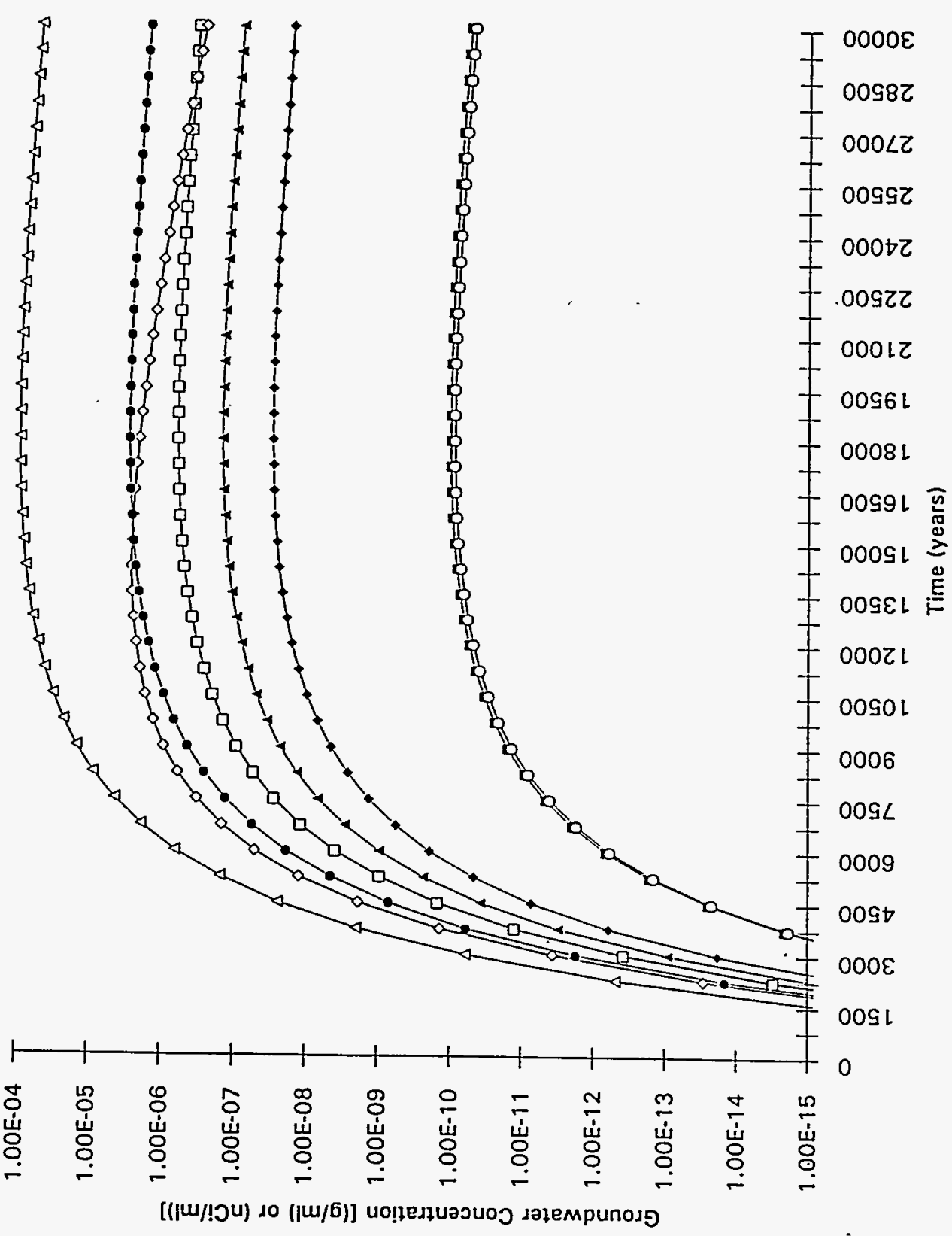

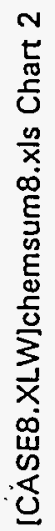



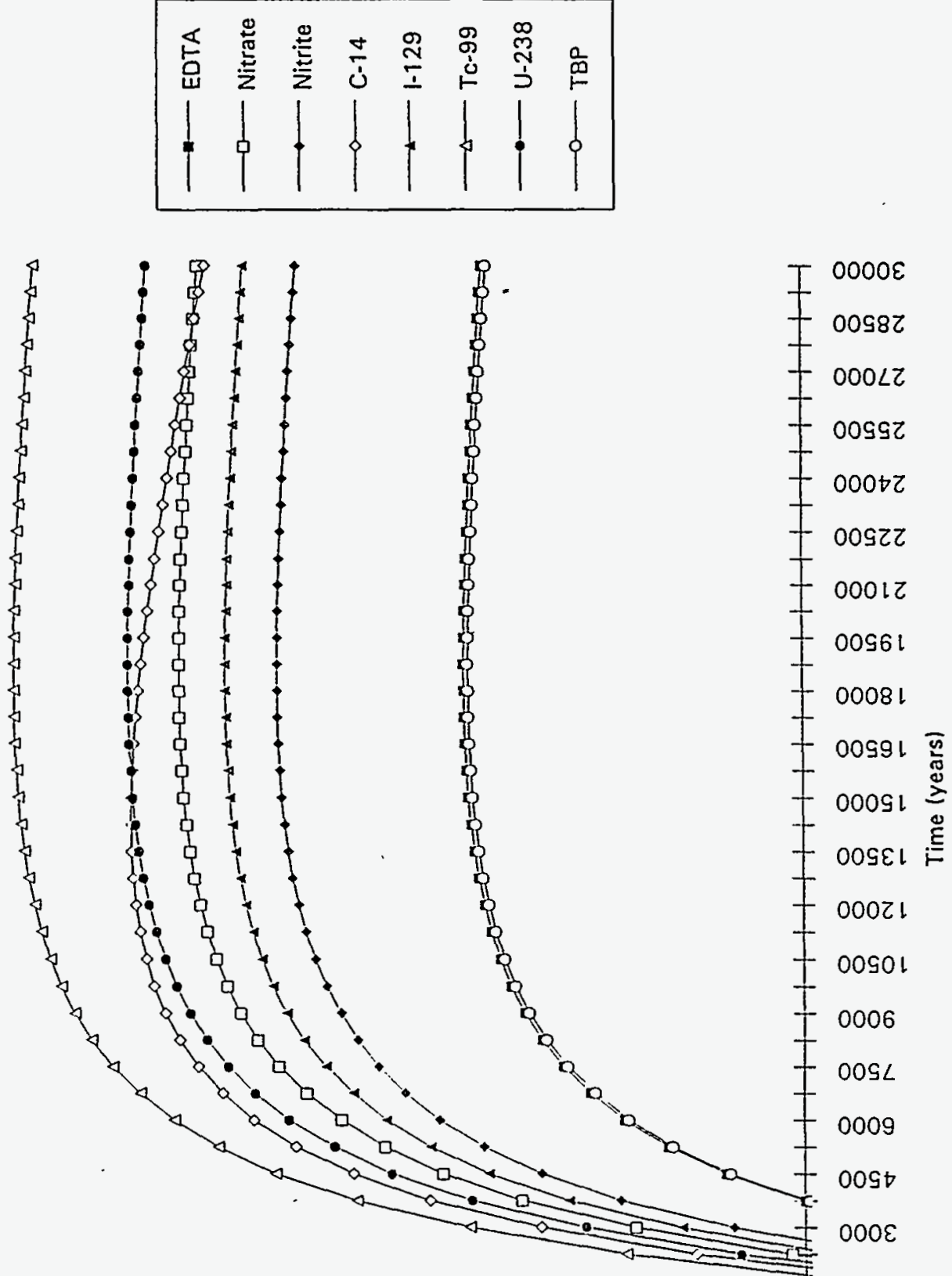


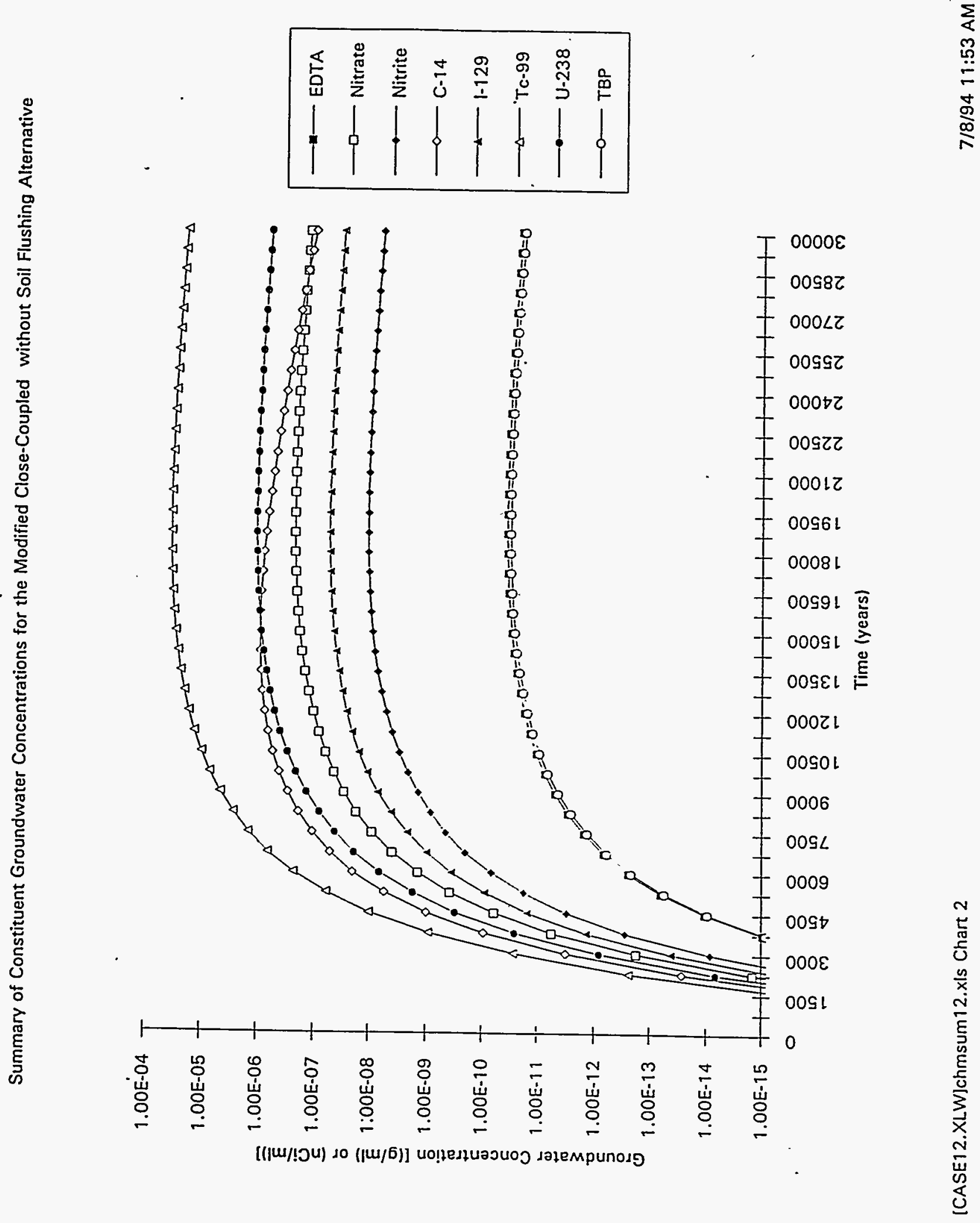




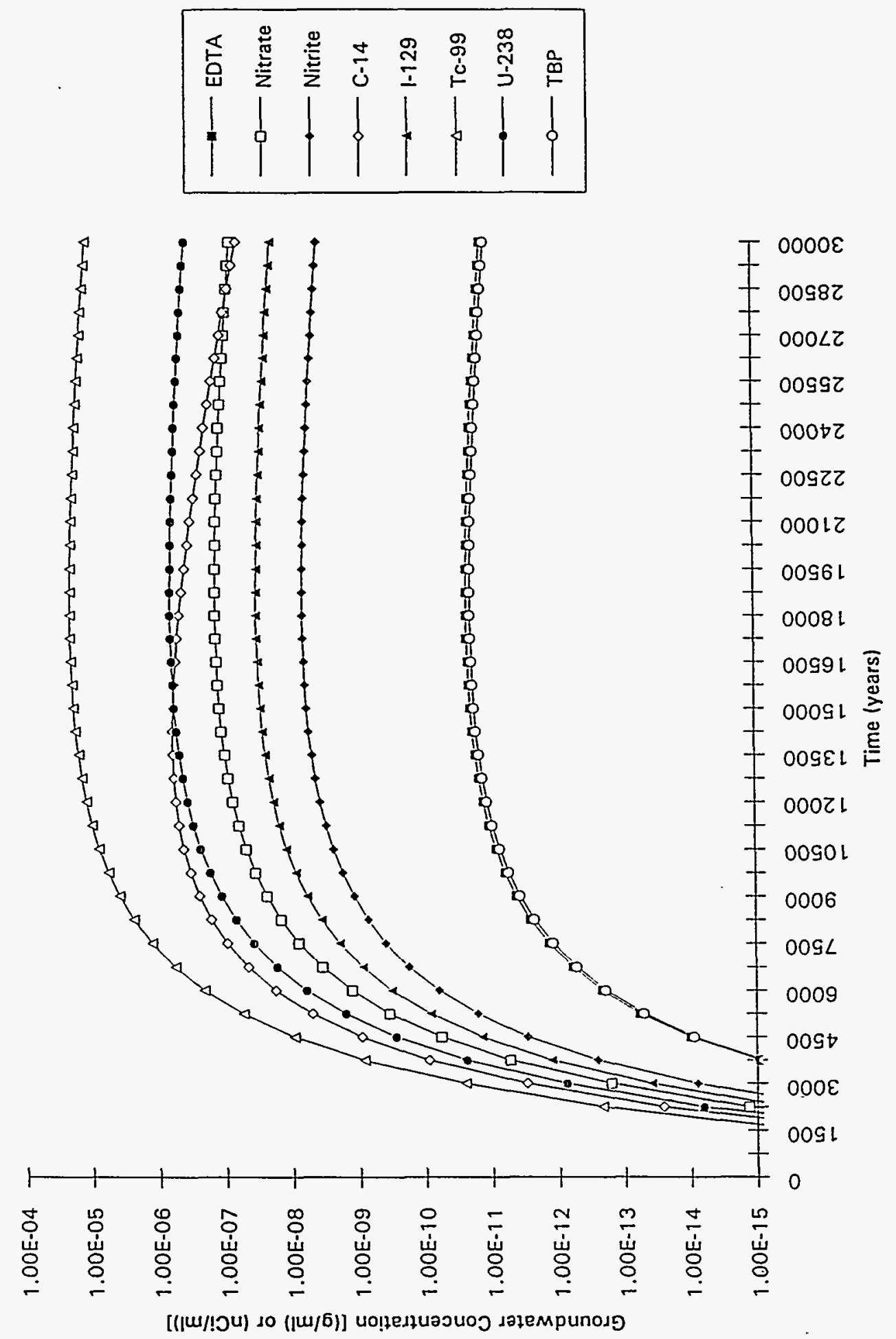

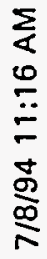



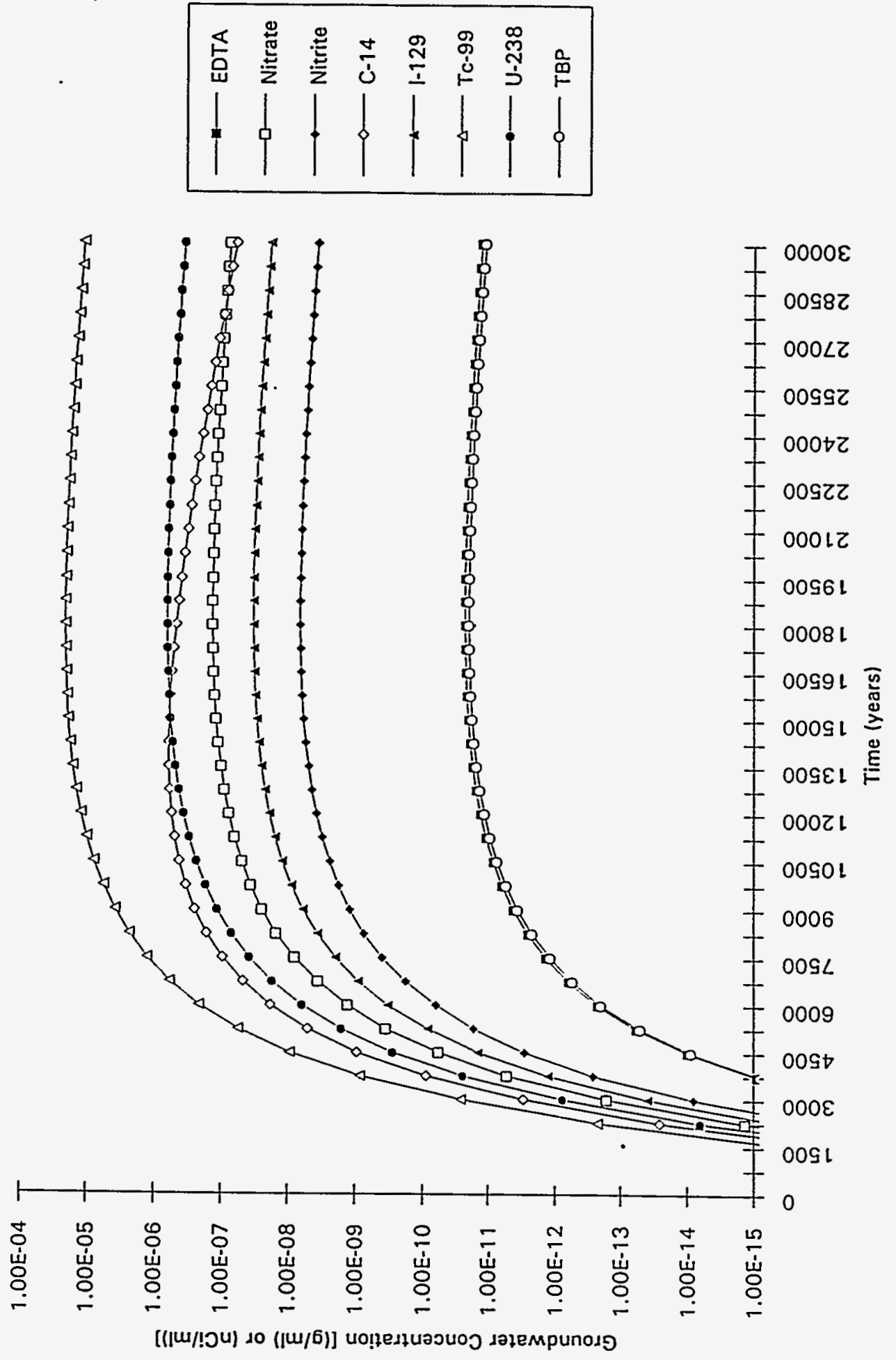

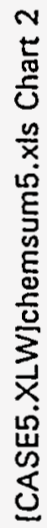




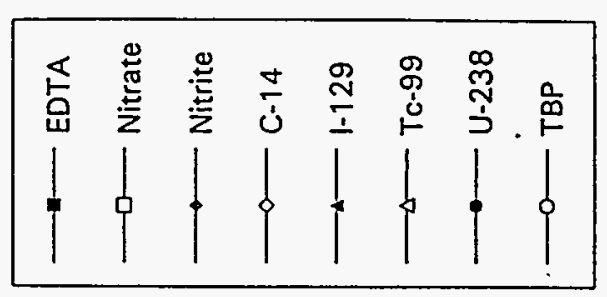

$\sum$
0
0
0
$\frac{0}{0}$
$\frac{5}{0}$
$\frac{1}{\pi}$

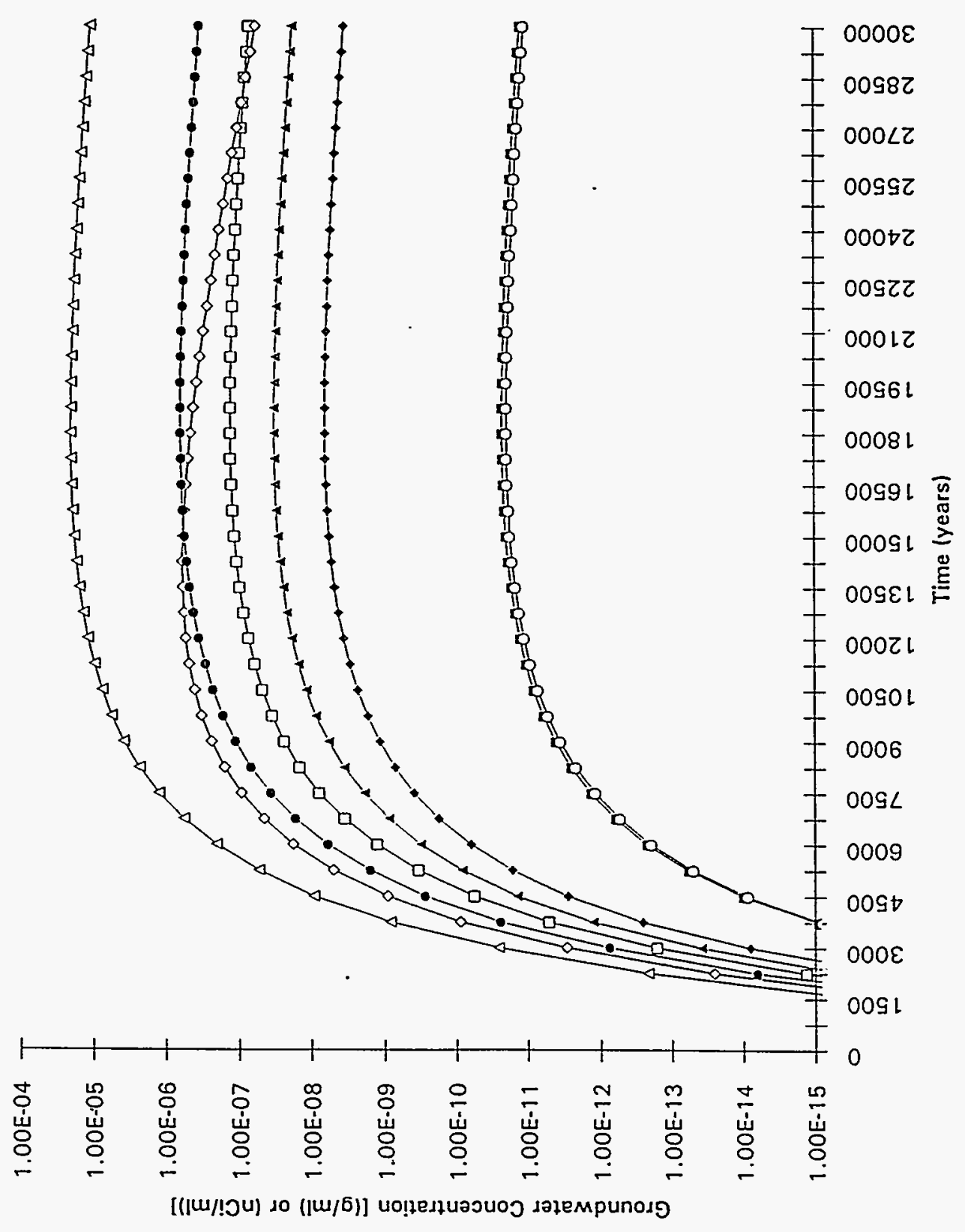

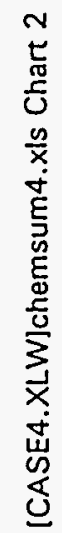



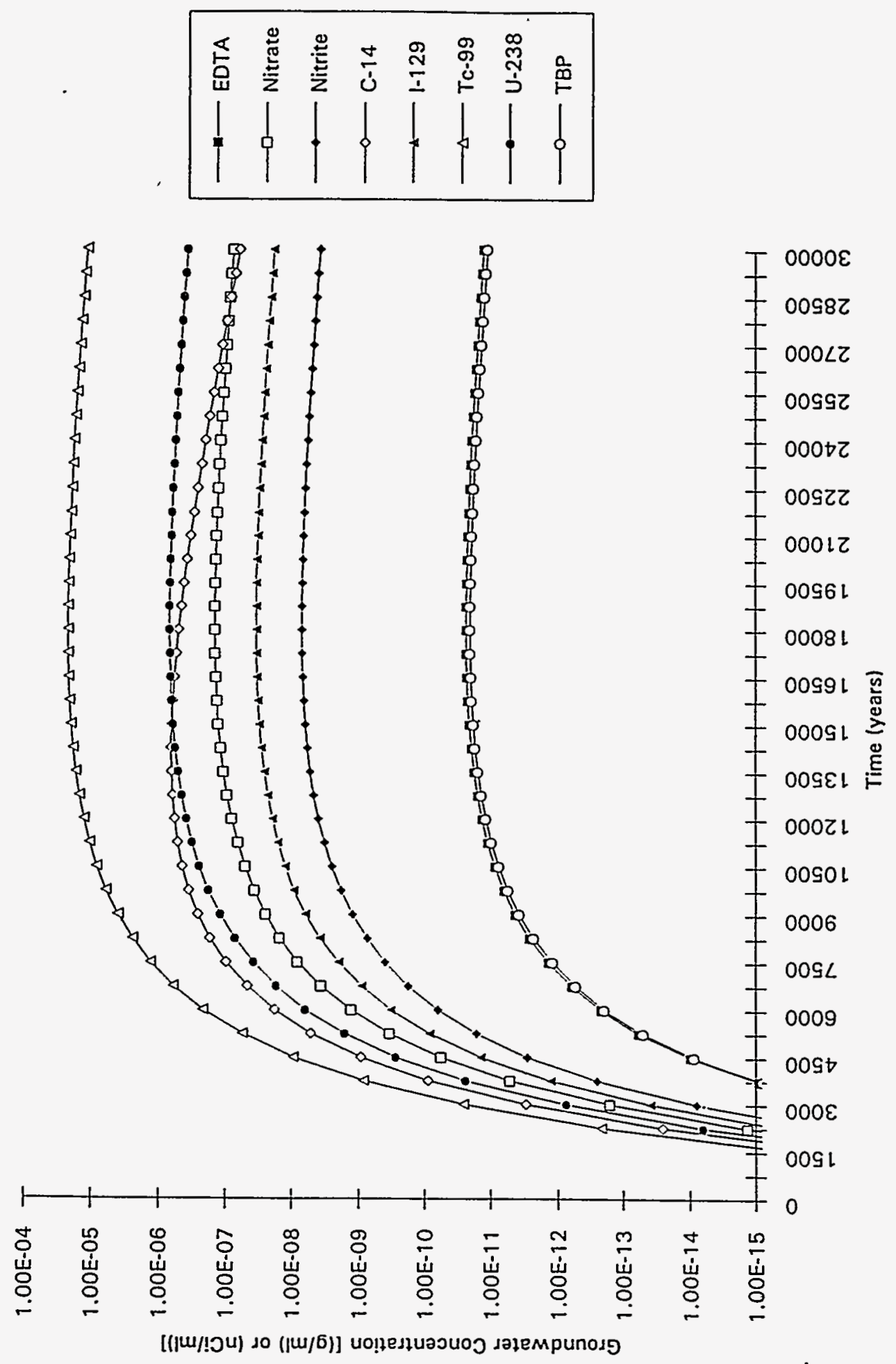

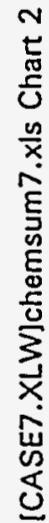




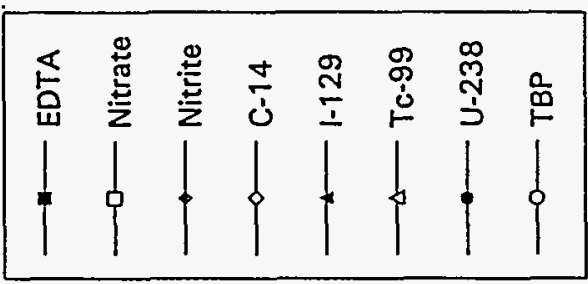

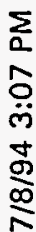

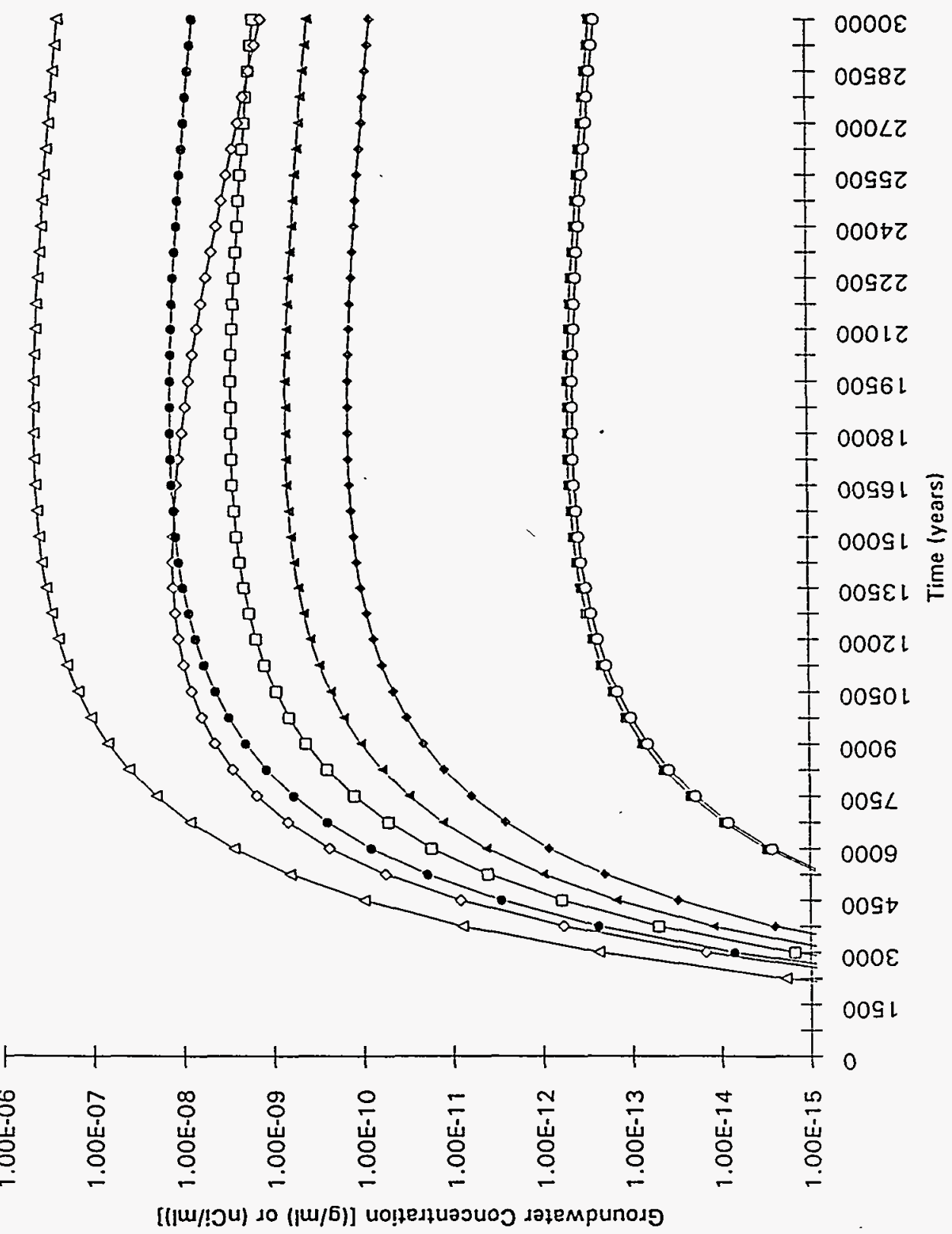

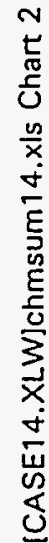




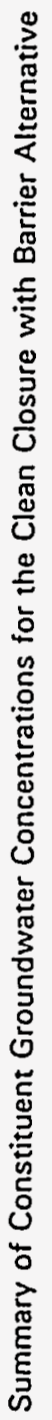

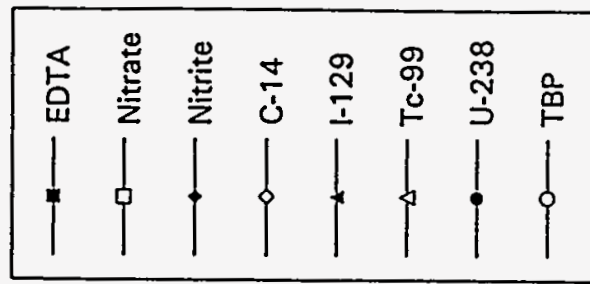

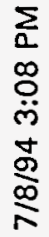

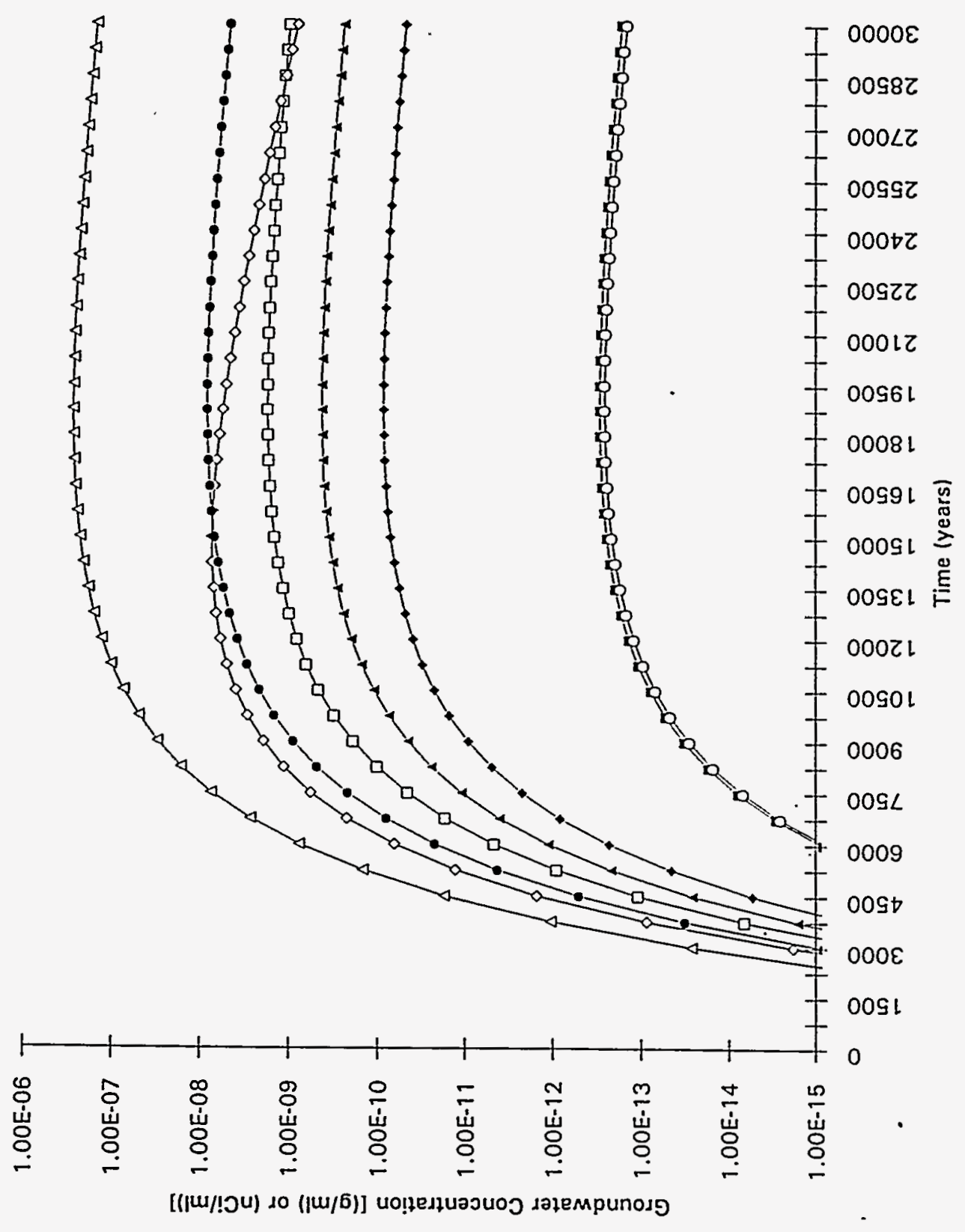

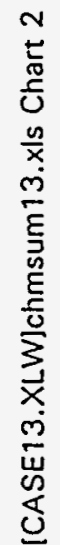




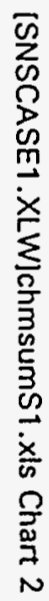

Groundwater Concentration $[(\mathrm{g} / \mathrm{ml})$ or $(\mathrm{Ci} / \mathrm{ml})]$

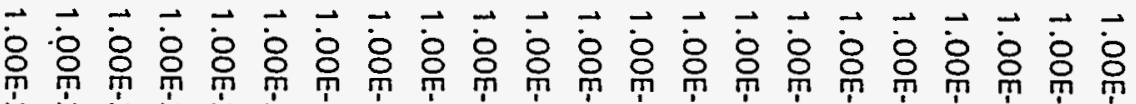
芯芯 芯

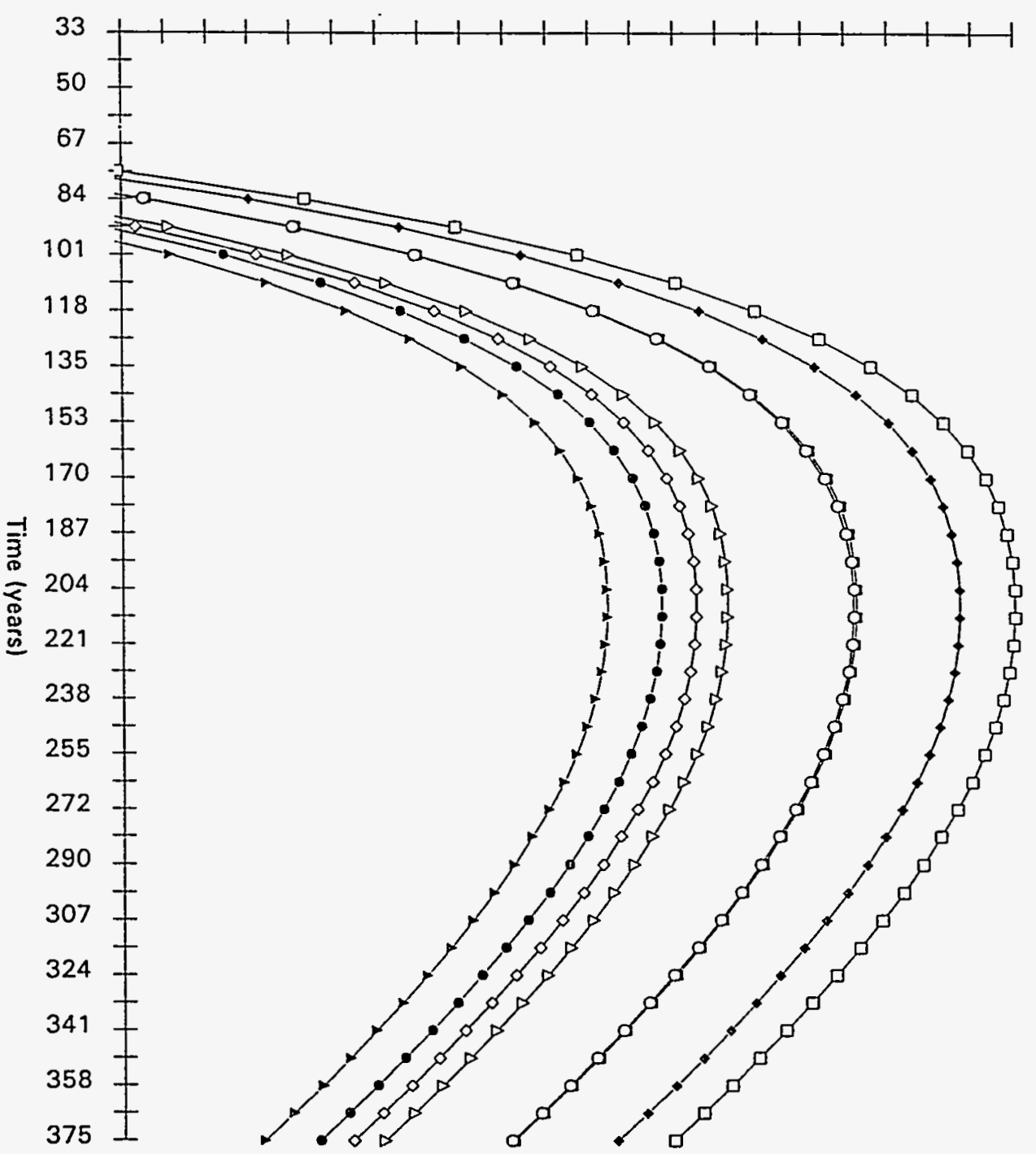

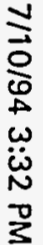

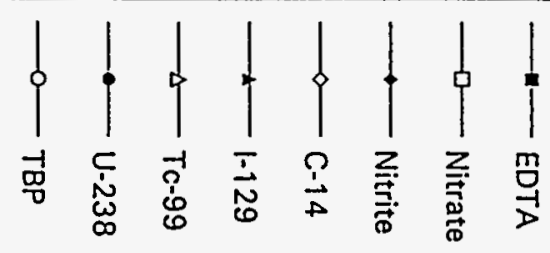




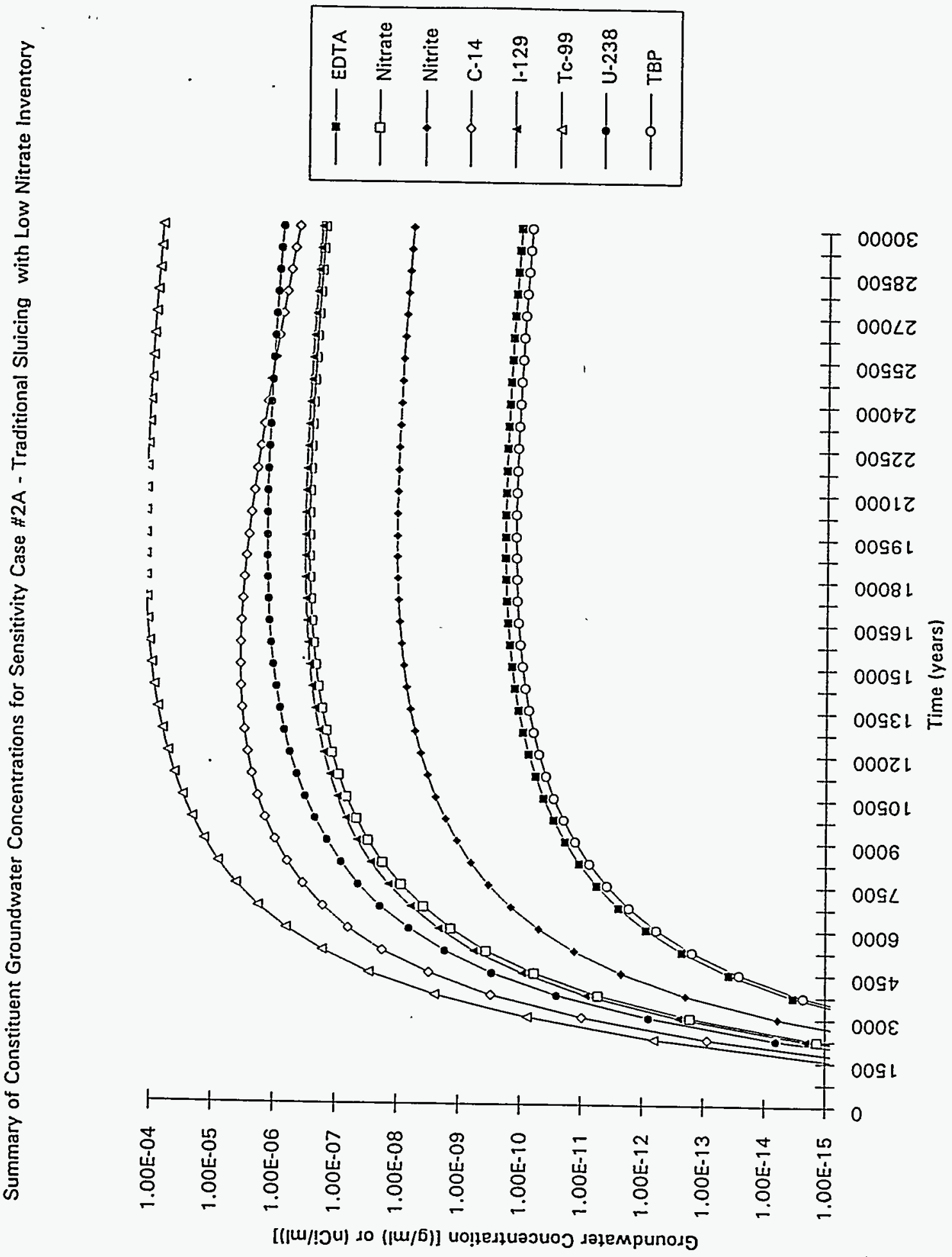

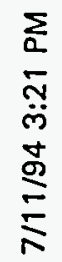



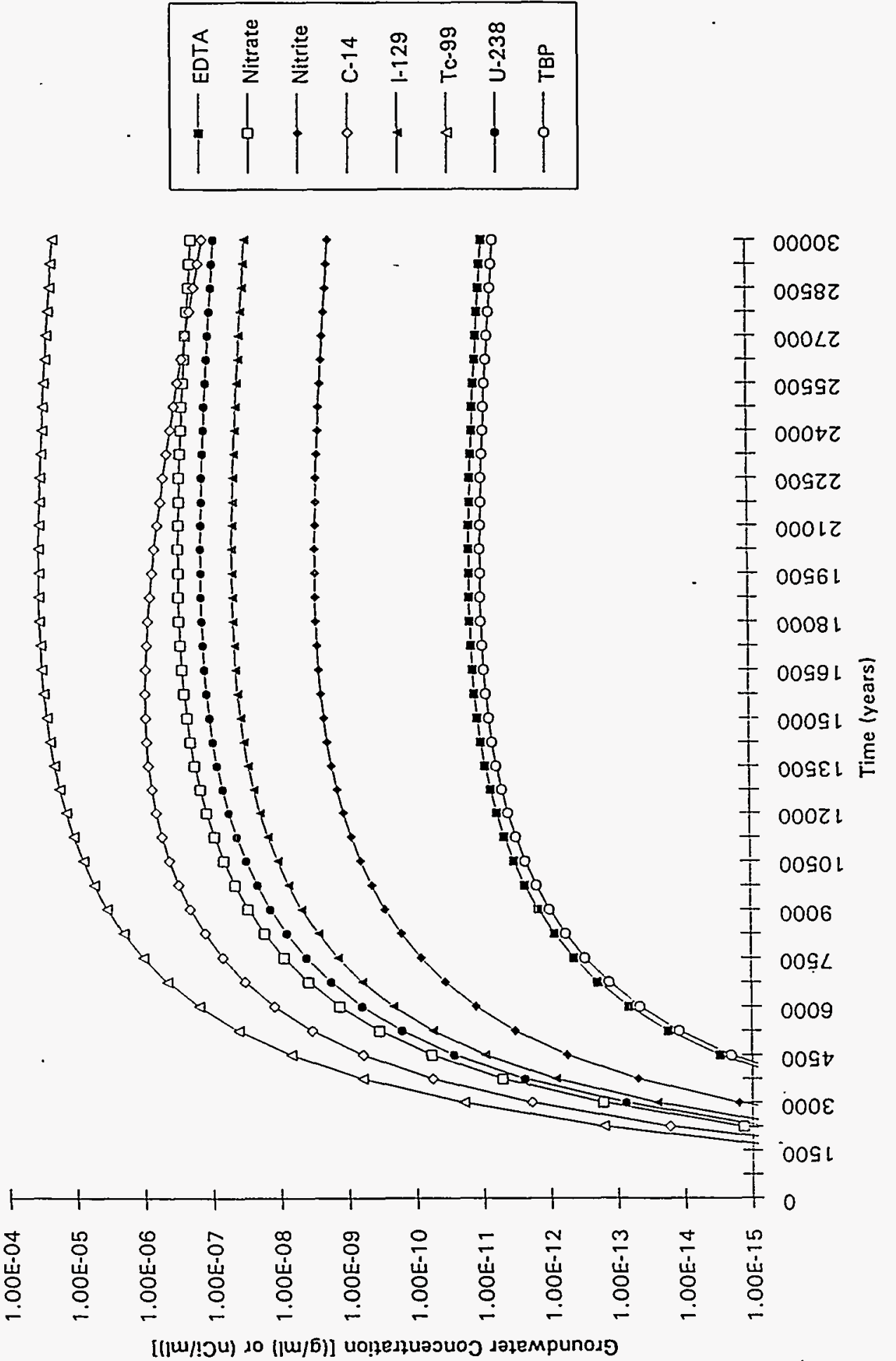

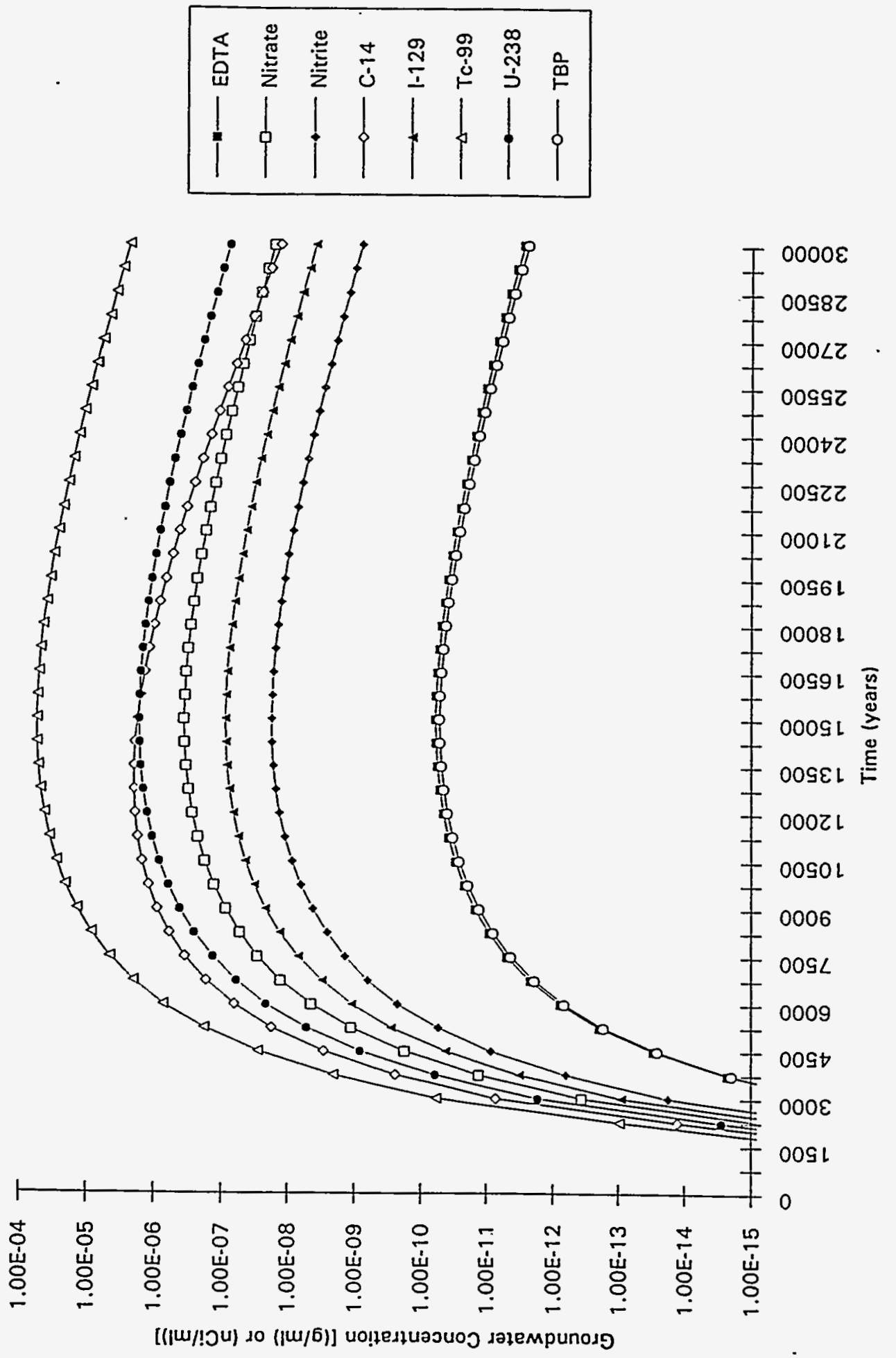

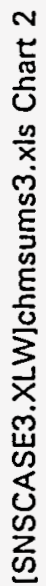



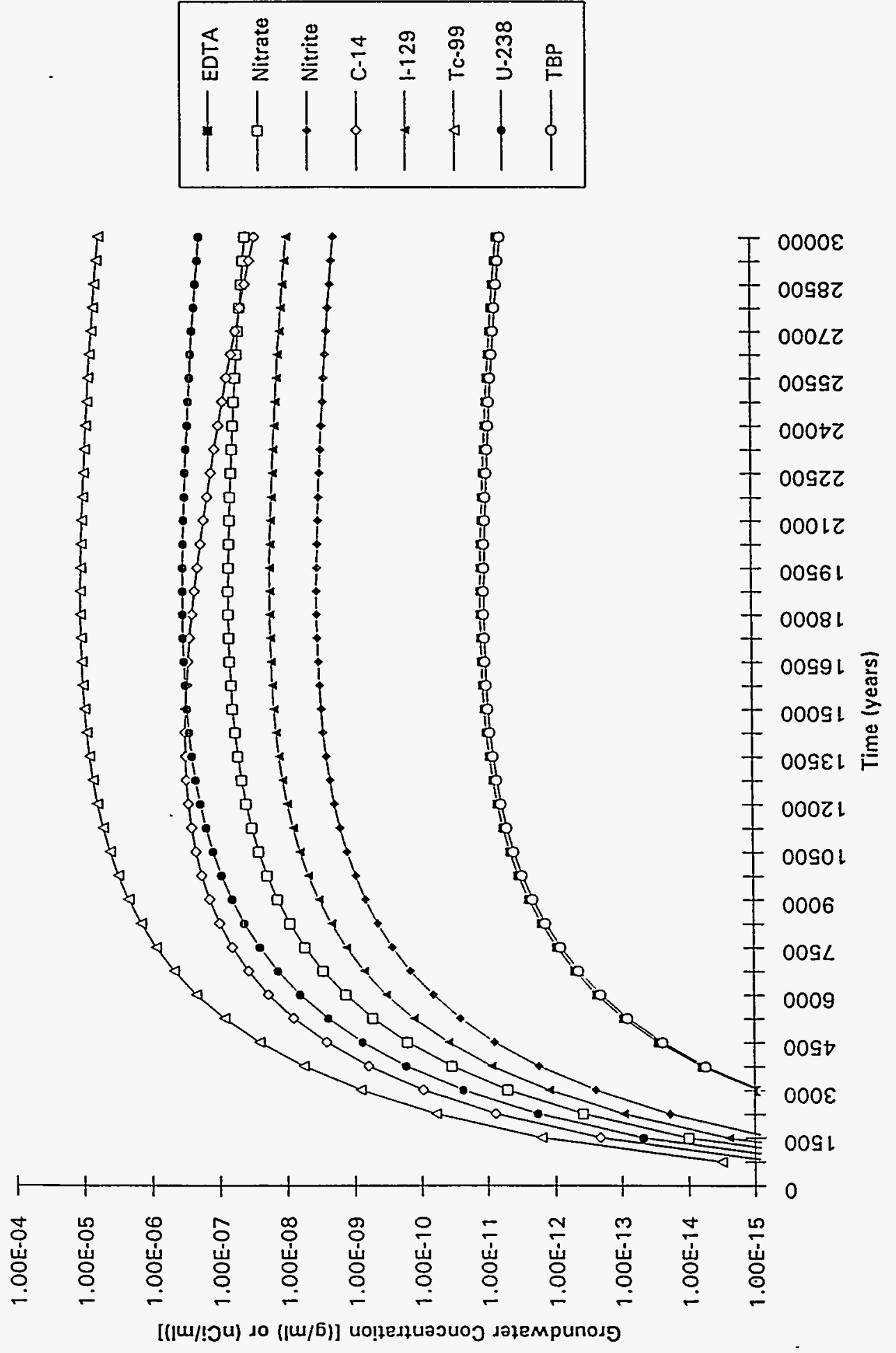

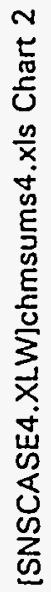




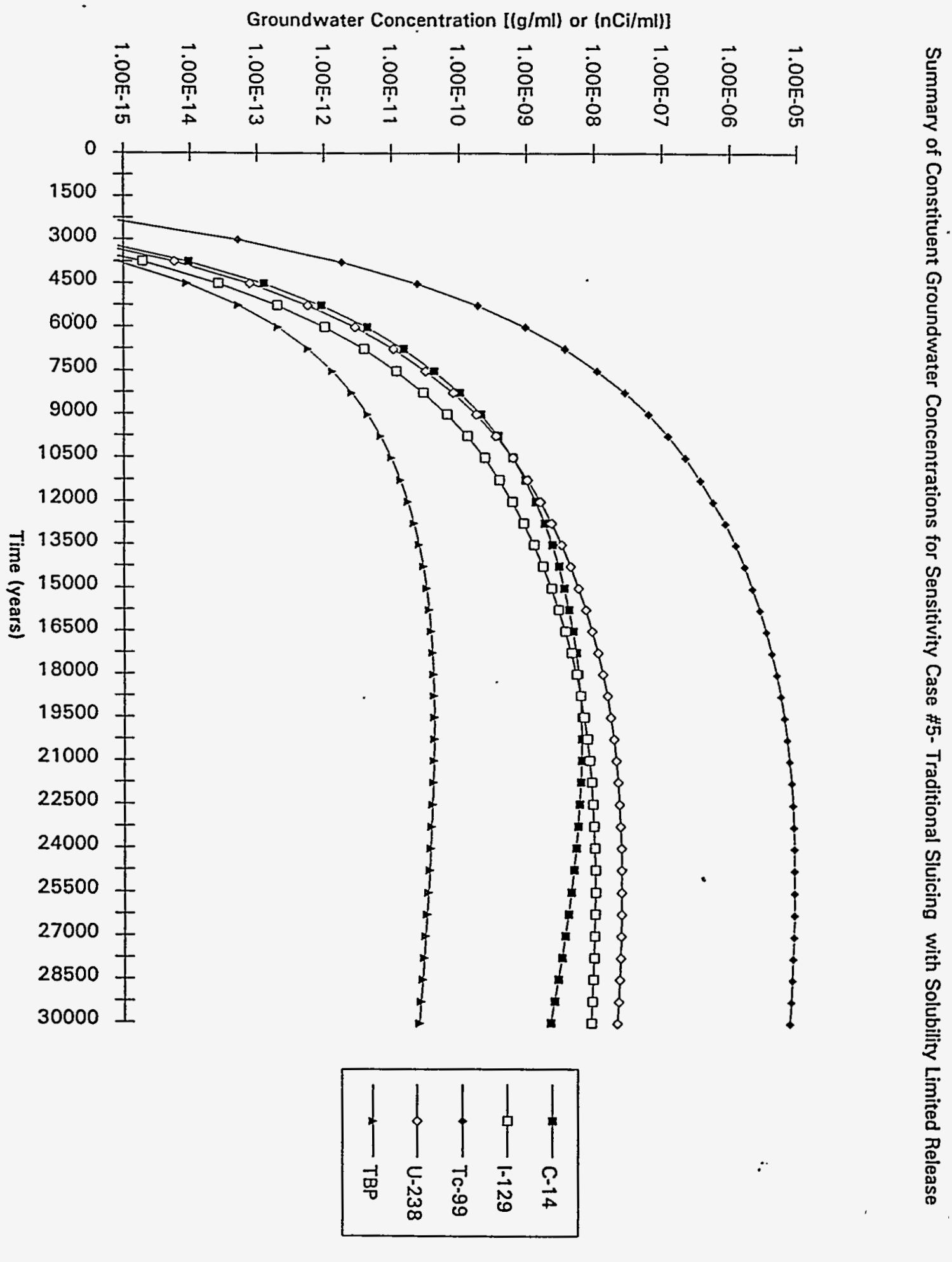


WHC-SD-WM-ES-300 REV. 1

This page intentionally left blank. 
WHC-SD-WM-ES-300 REV. 1

\section{APPENDIX B.2}

HUMAN HEALTH RISK RESULTS 
WHC-SD-WM-ES-300 REV. 1

This page intentionally left blank. 


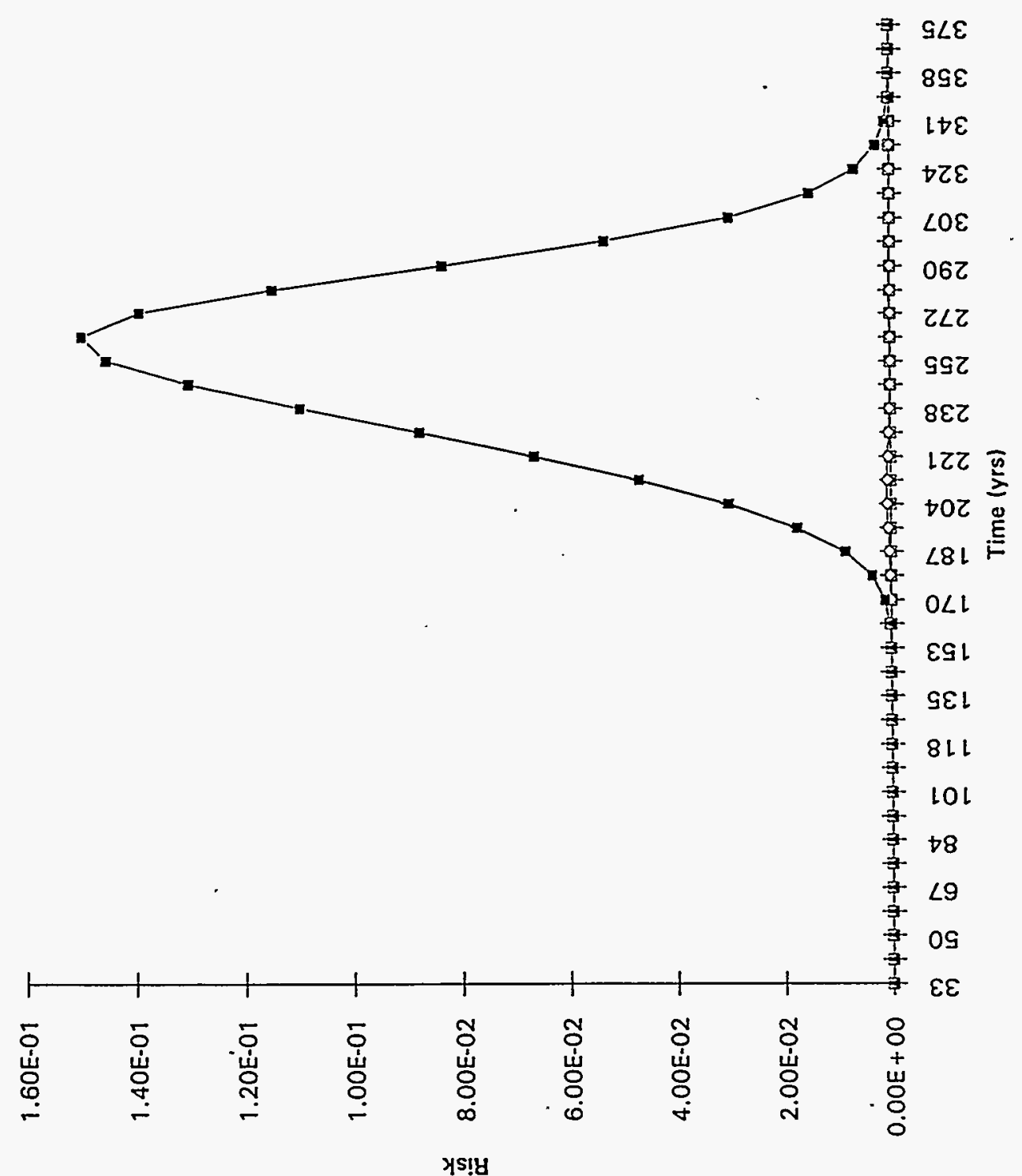




\section{WHC-SD-WM-ES-300 REV. 1}

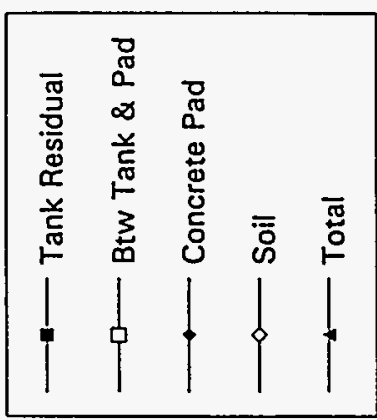

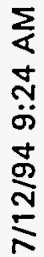

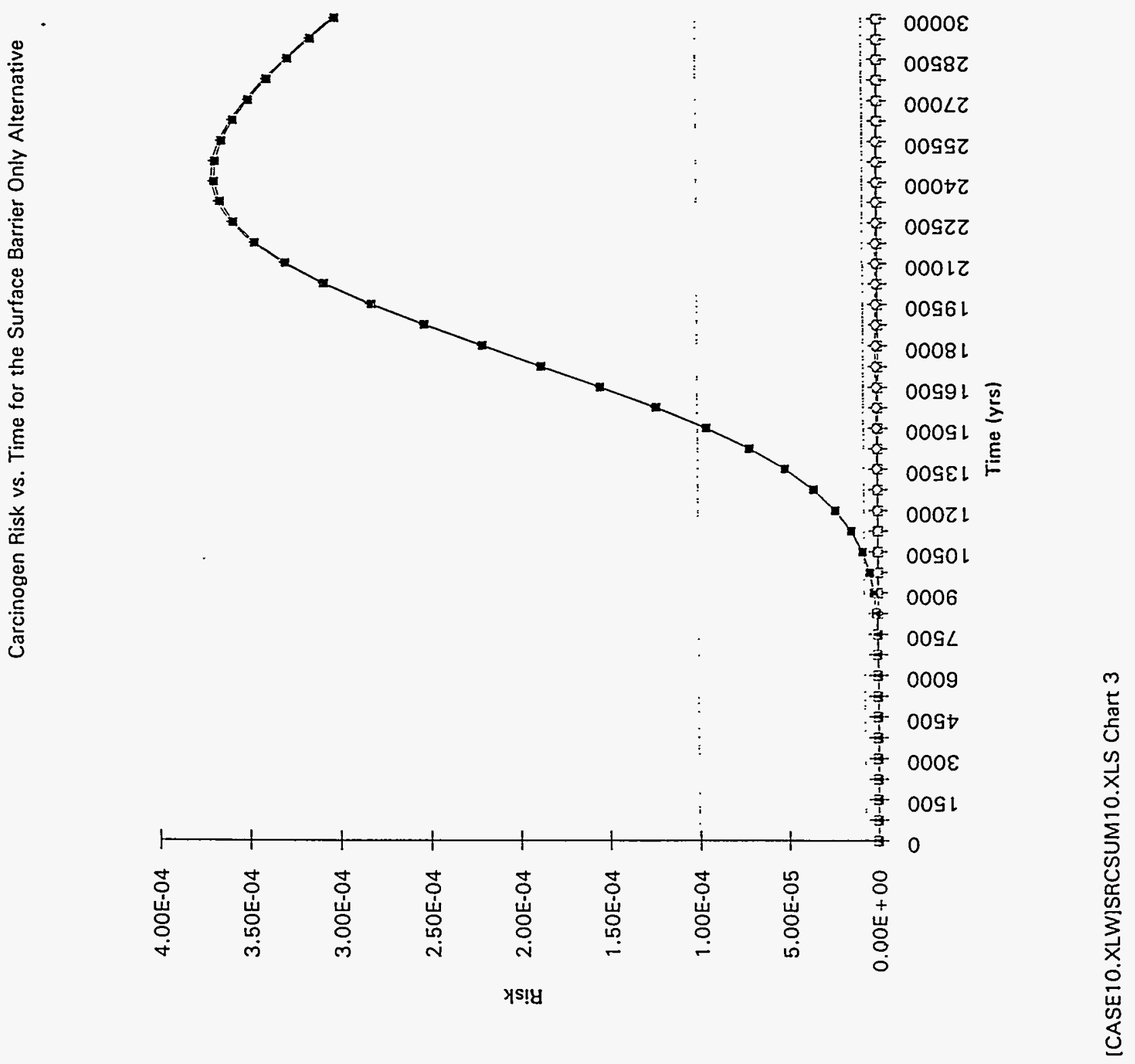




\section{WHC-SD-WM-ES-300 REV. 1}



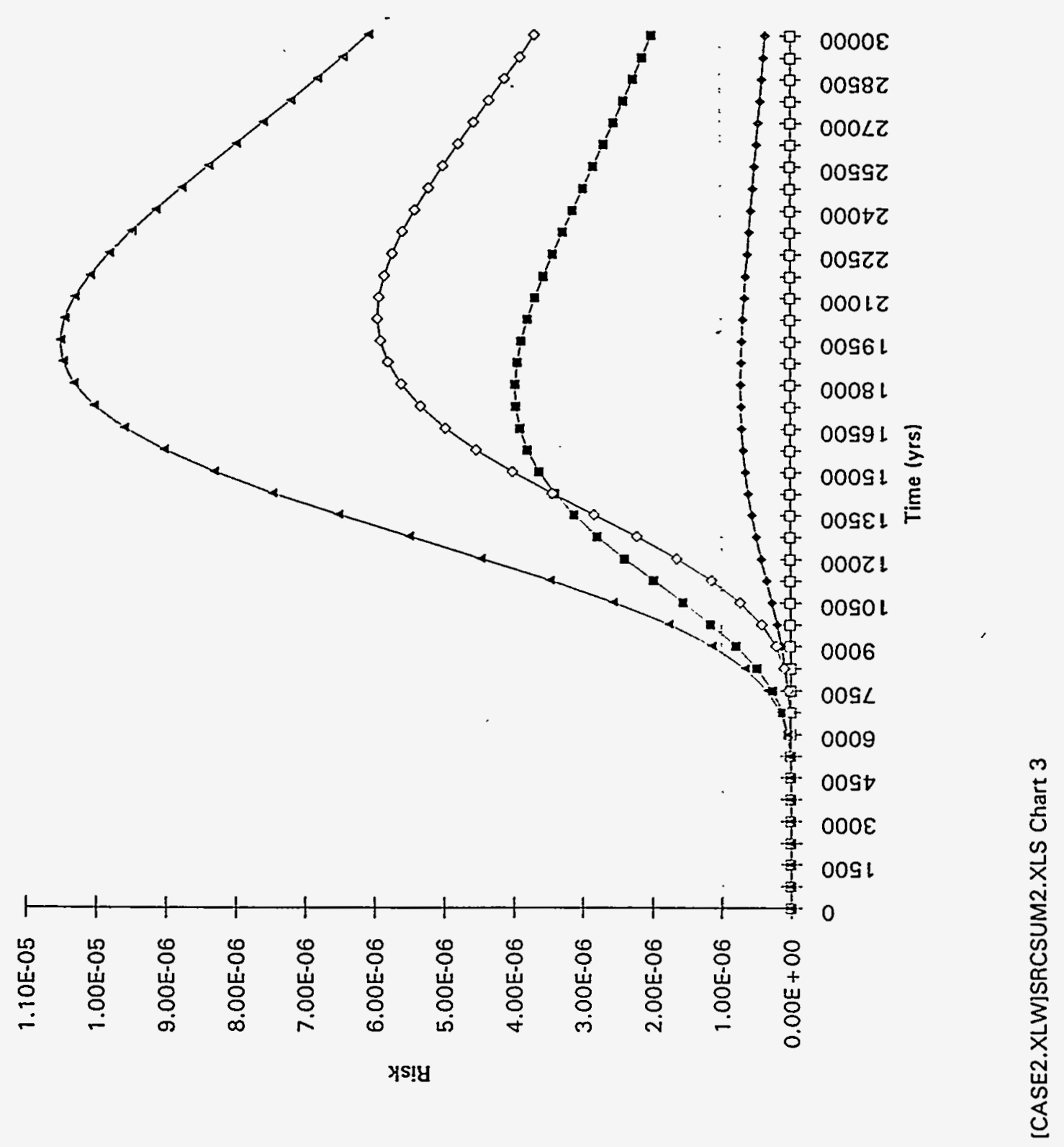




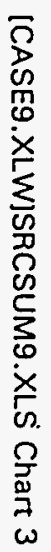

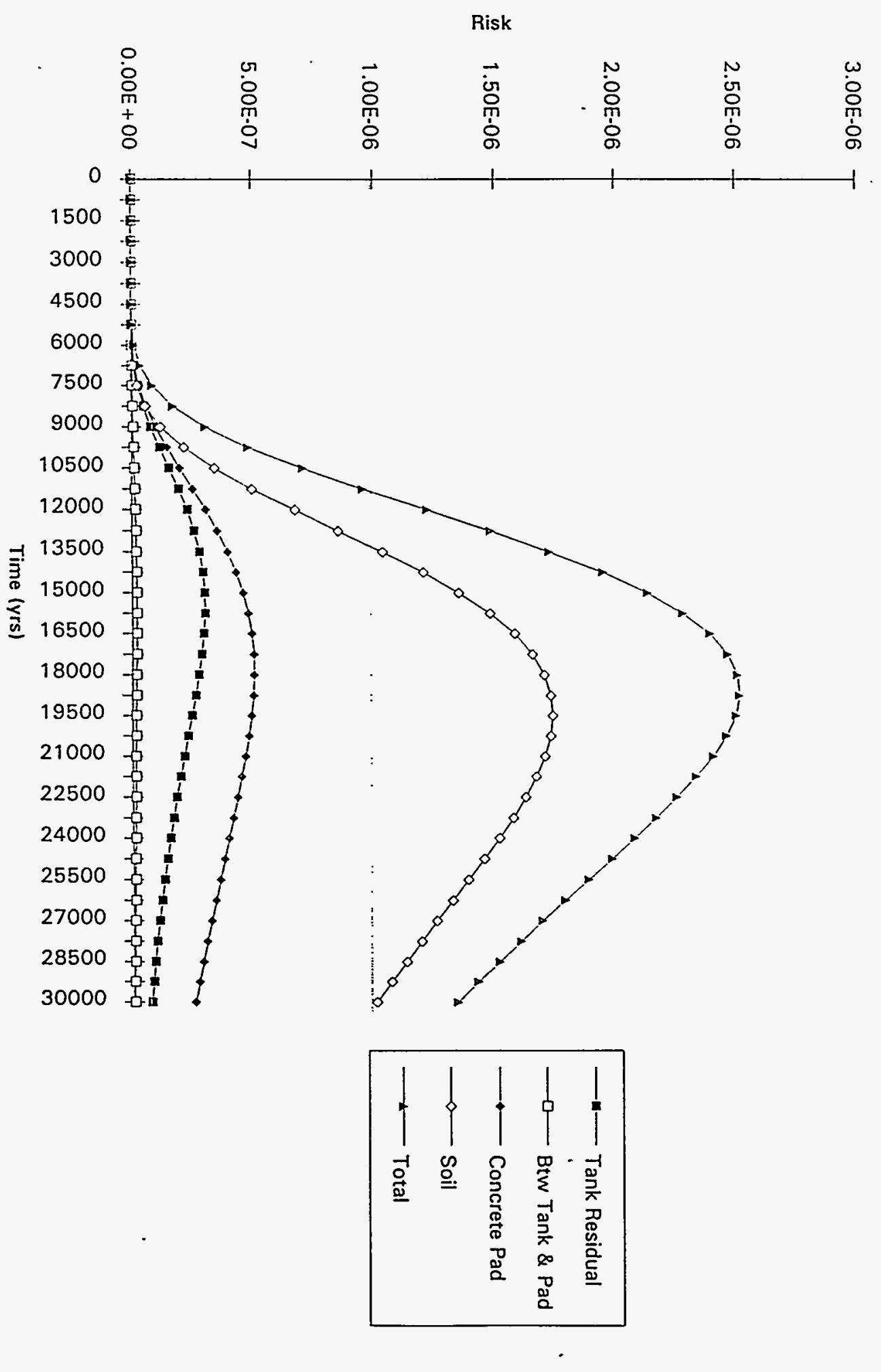




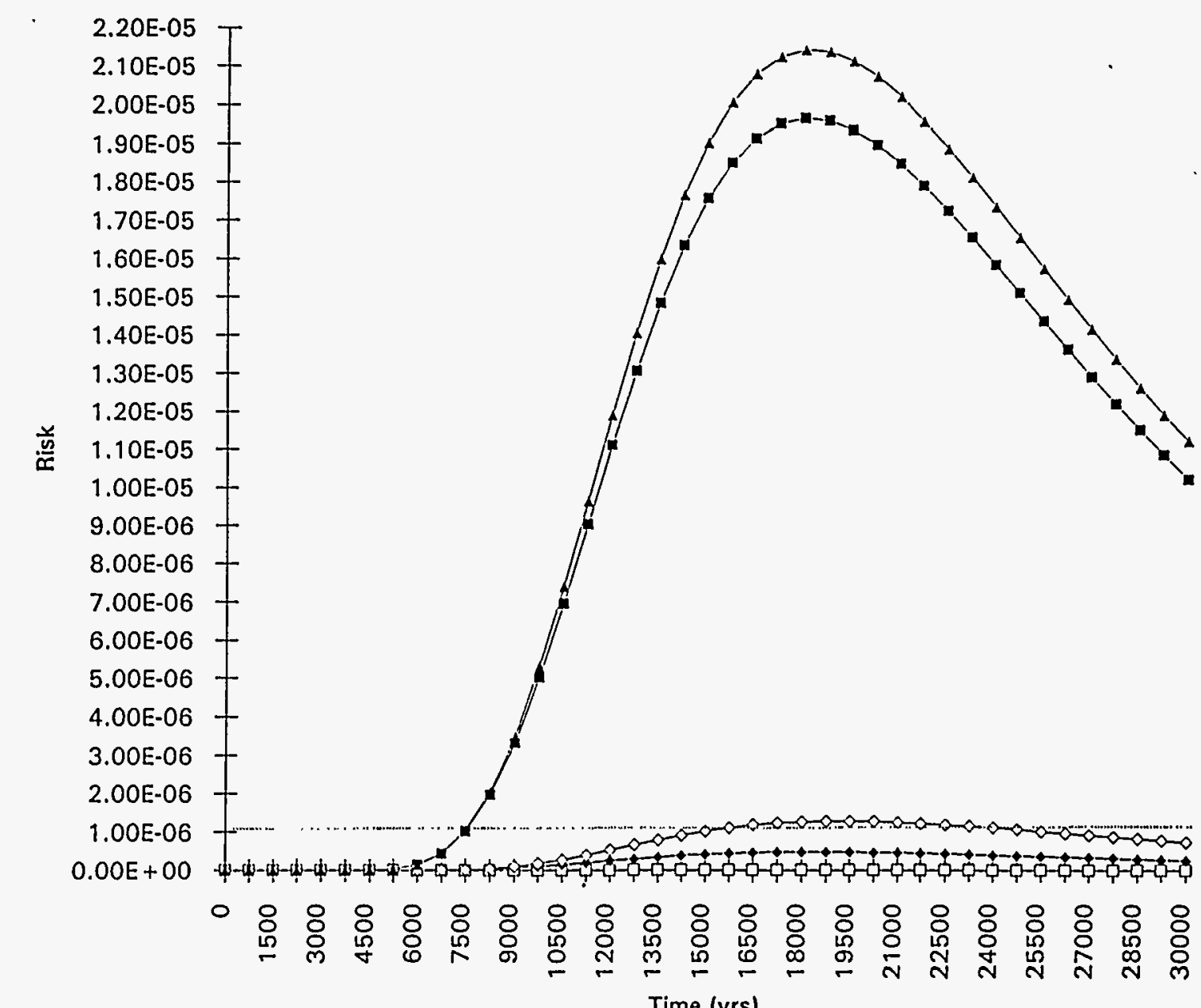




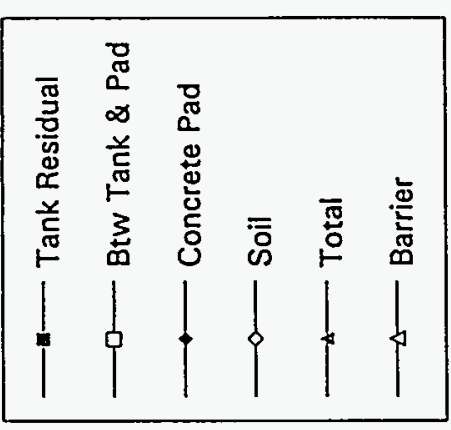

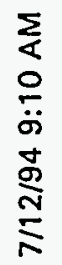

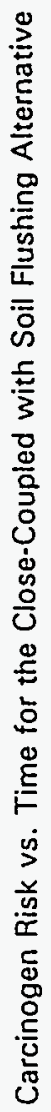

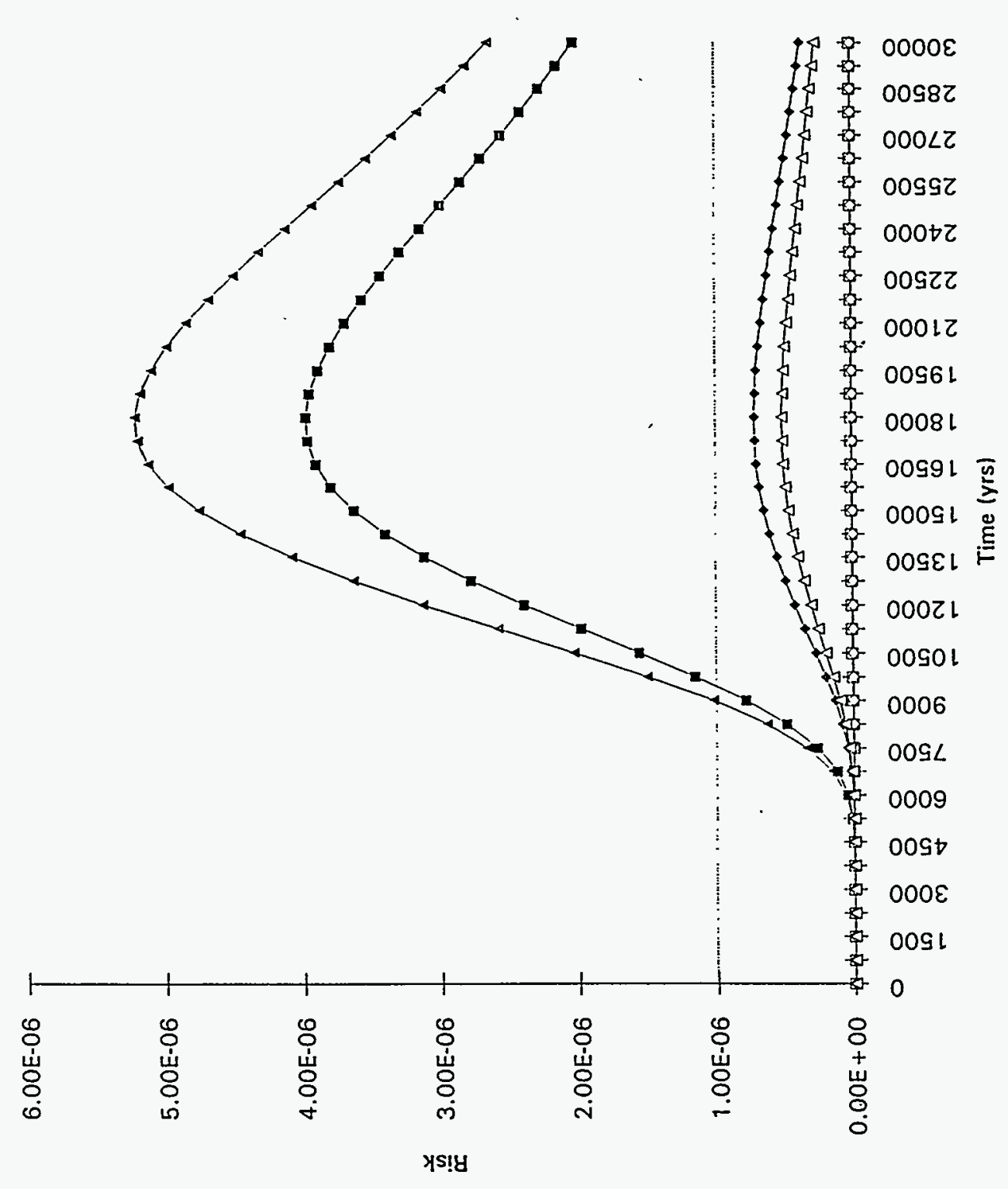

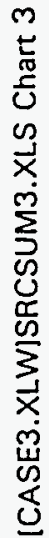




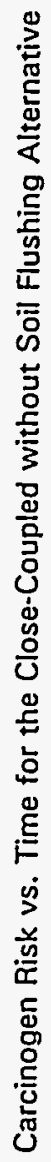

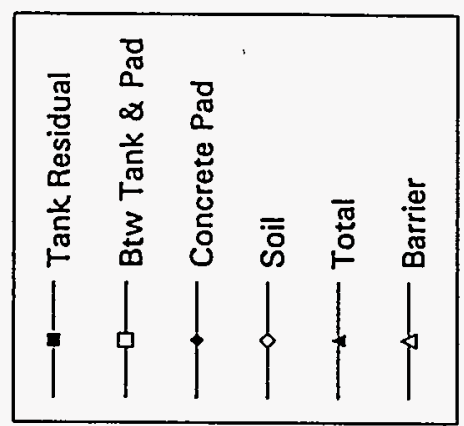

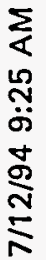

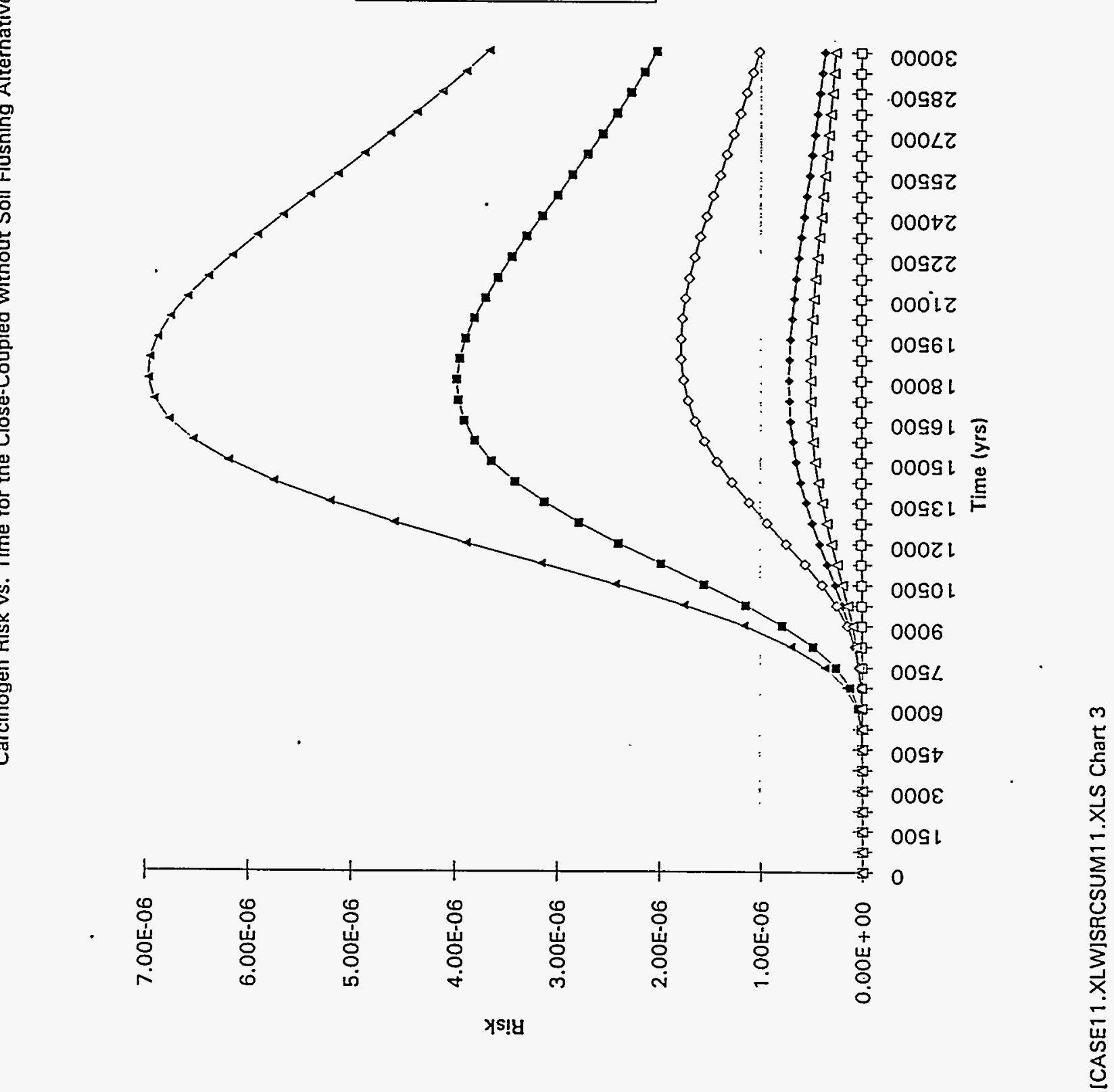




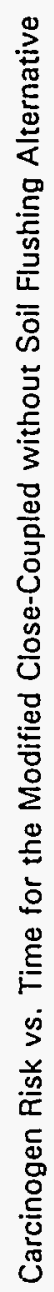

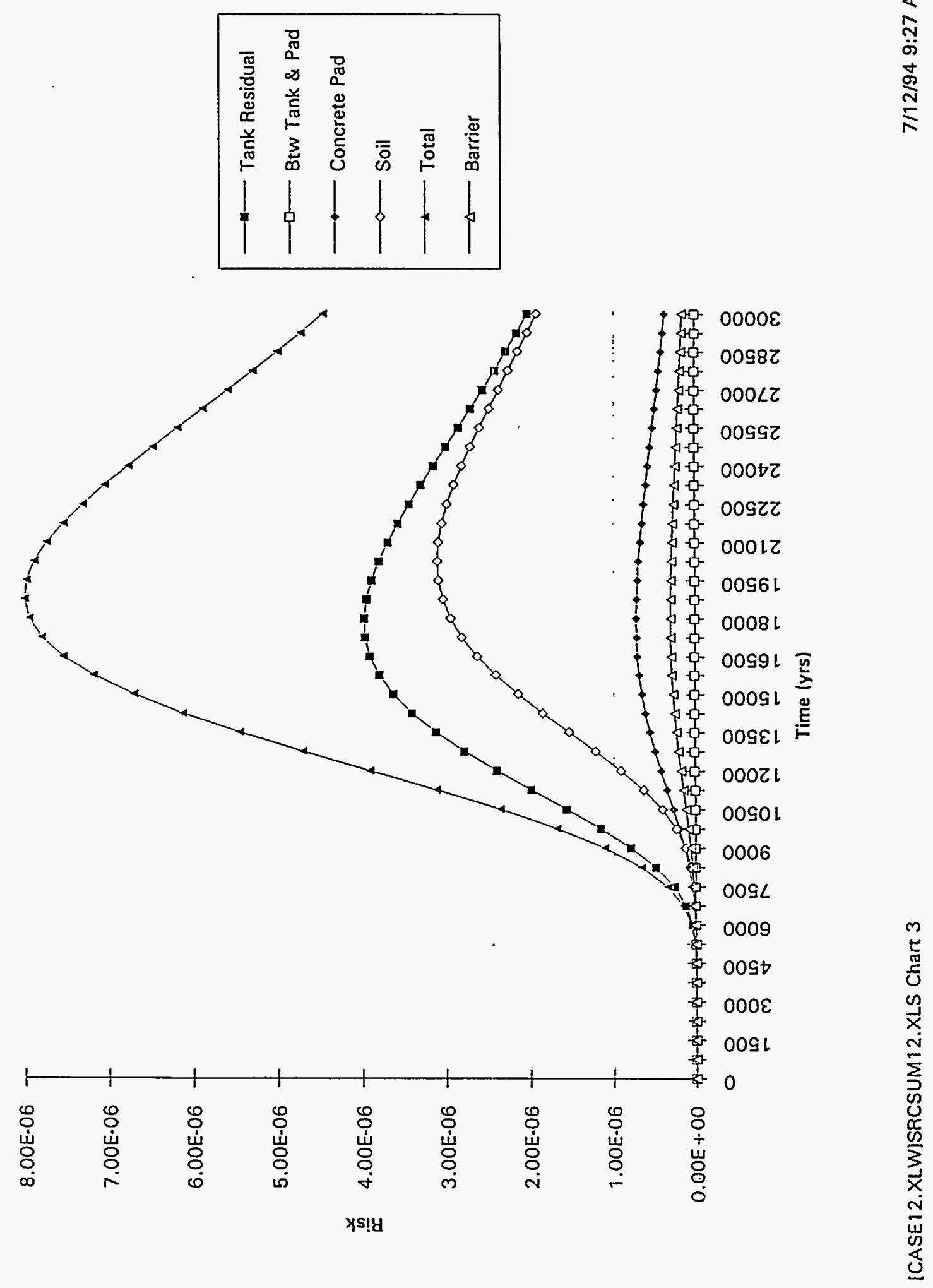




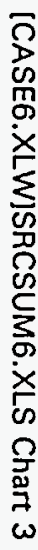

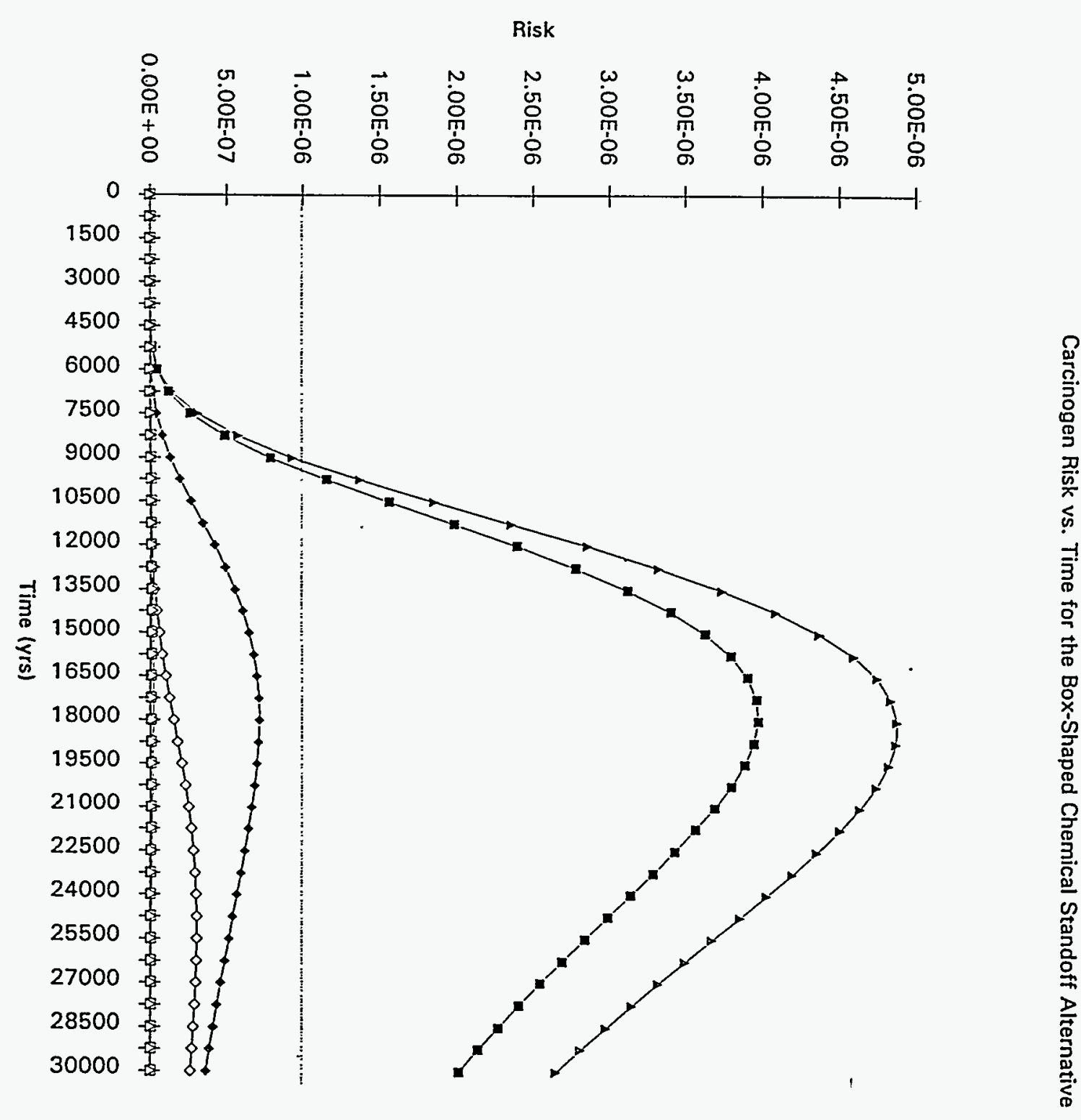

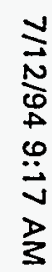

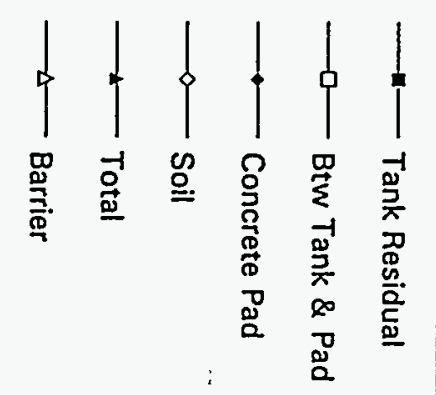




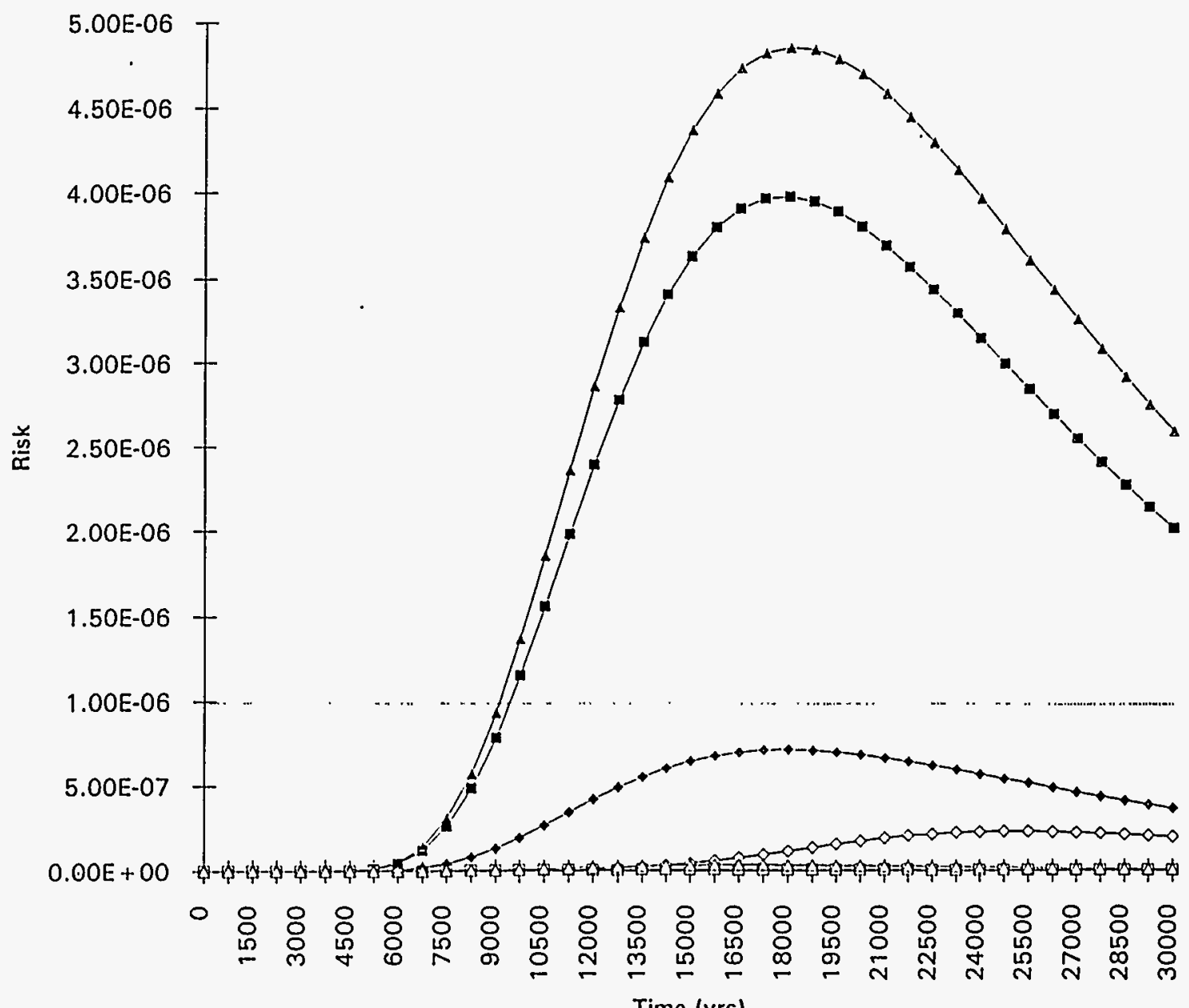

Time (yrs) 


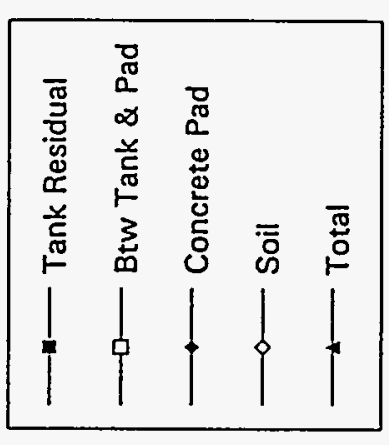

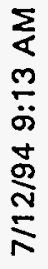

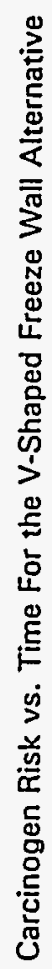

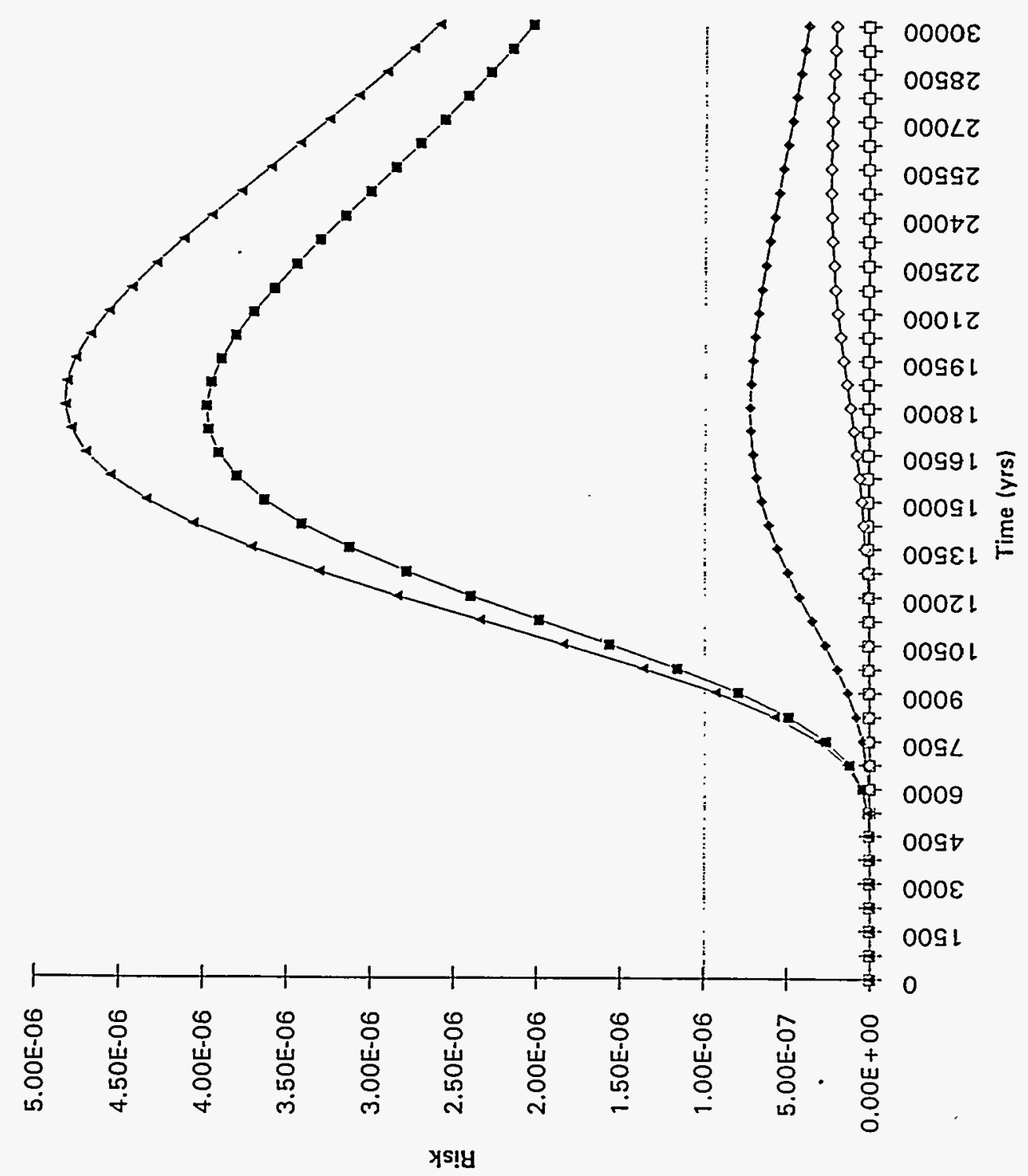

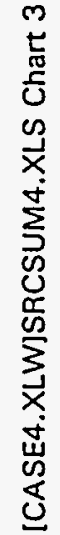




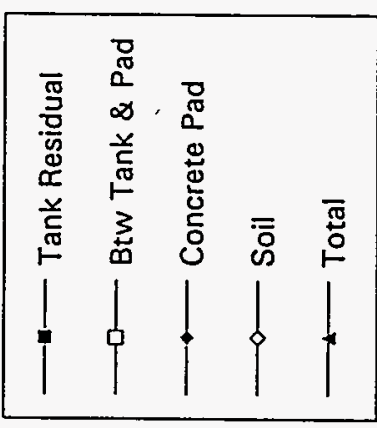

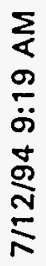

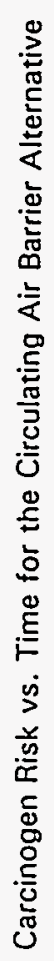

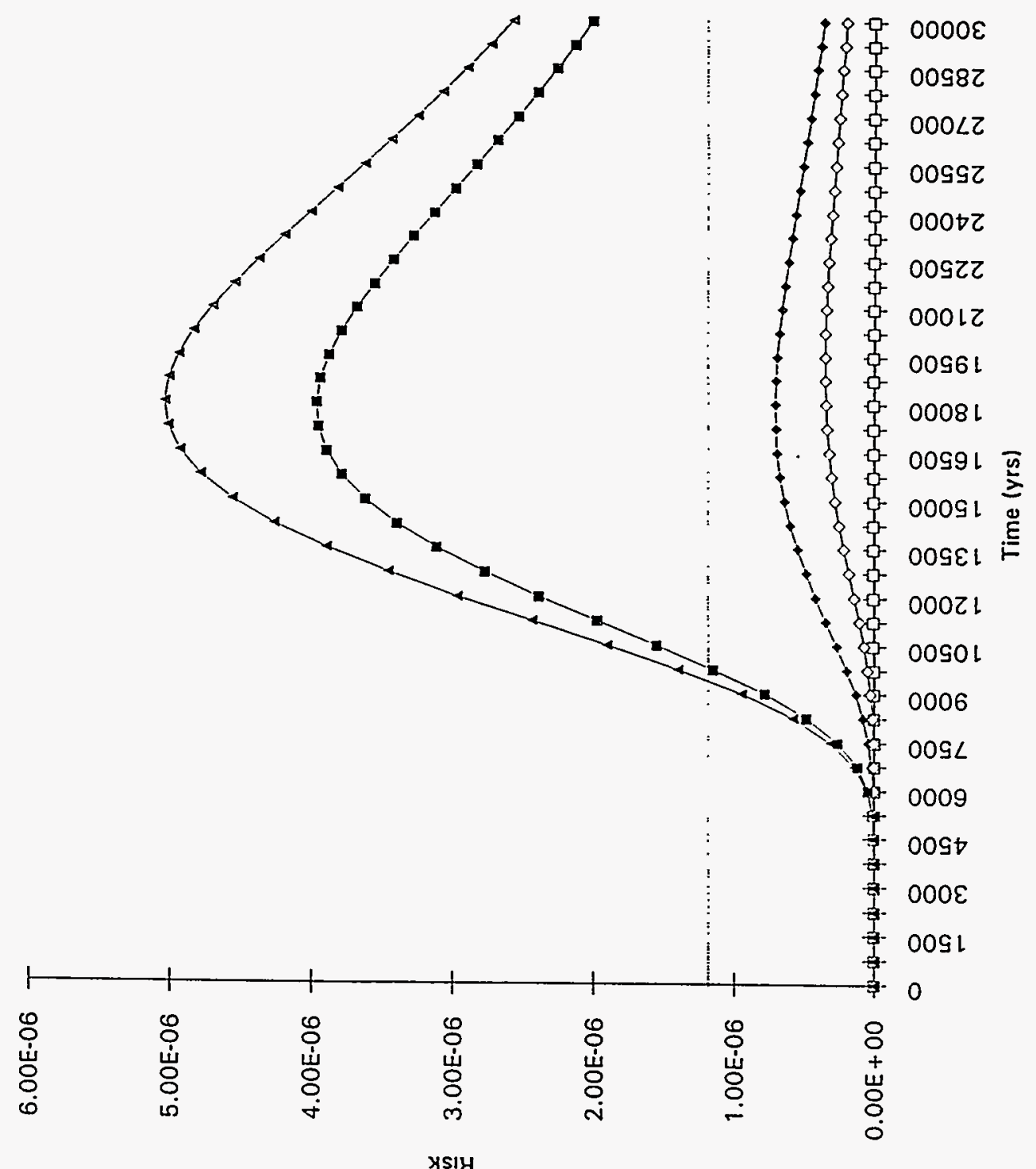

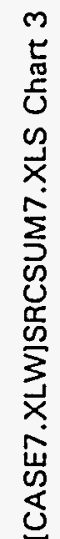




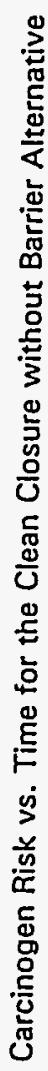

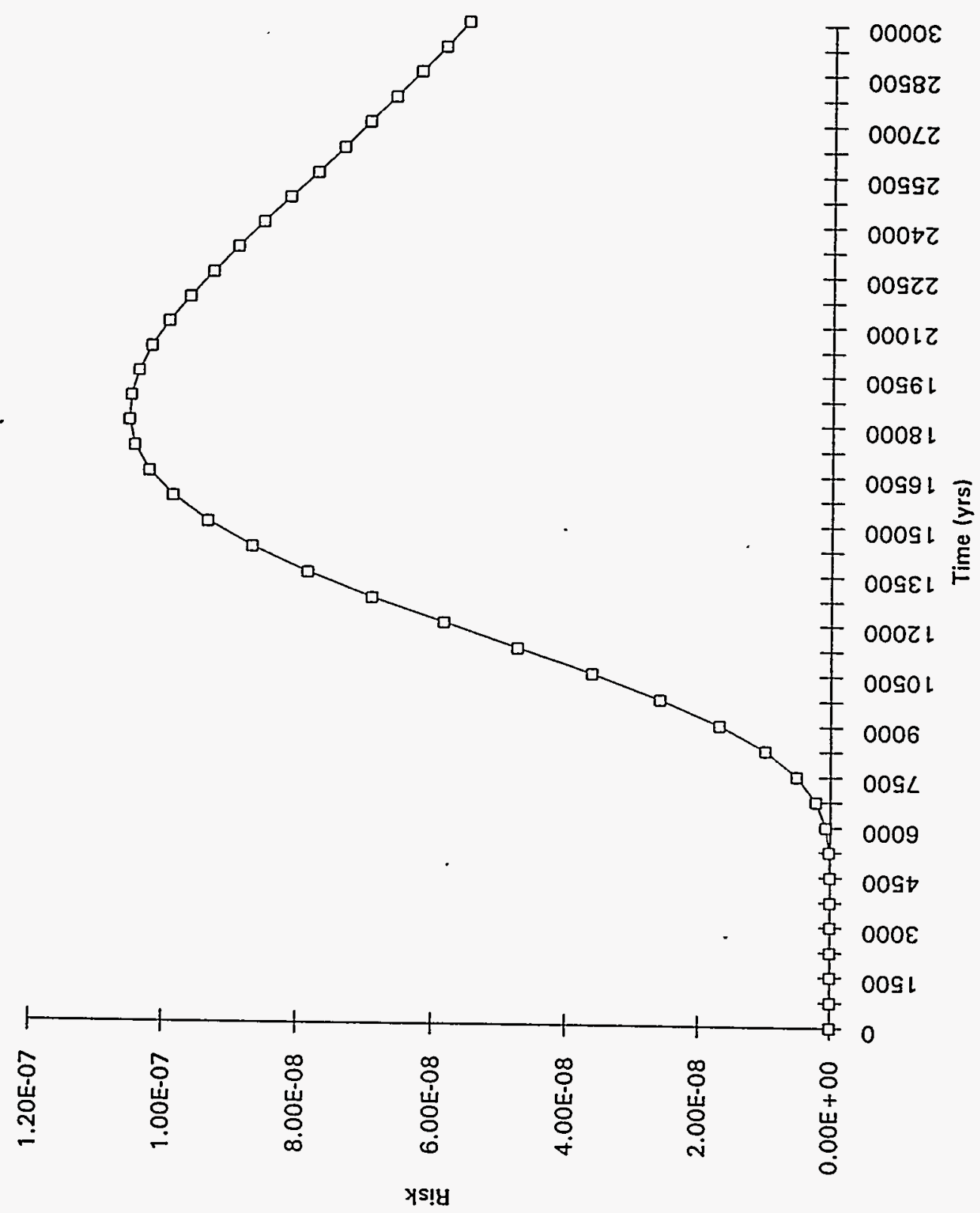




\section{WHC-SD-WM-ES-300 REV. 1}

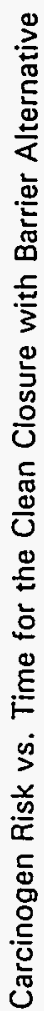

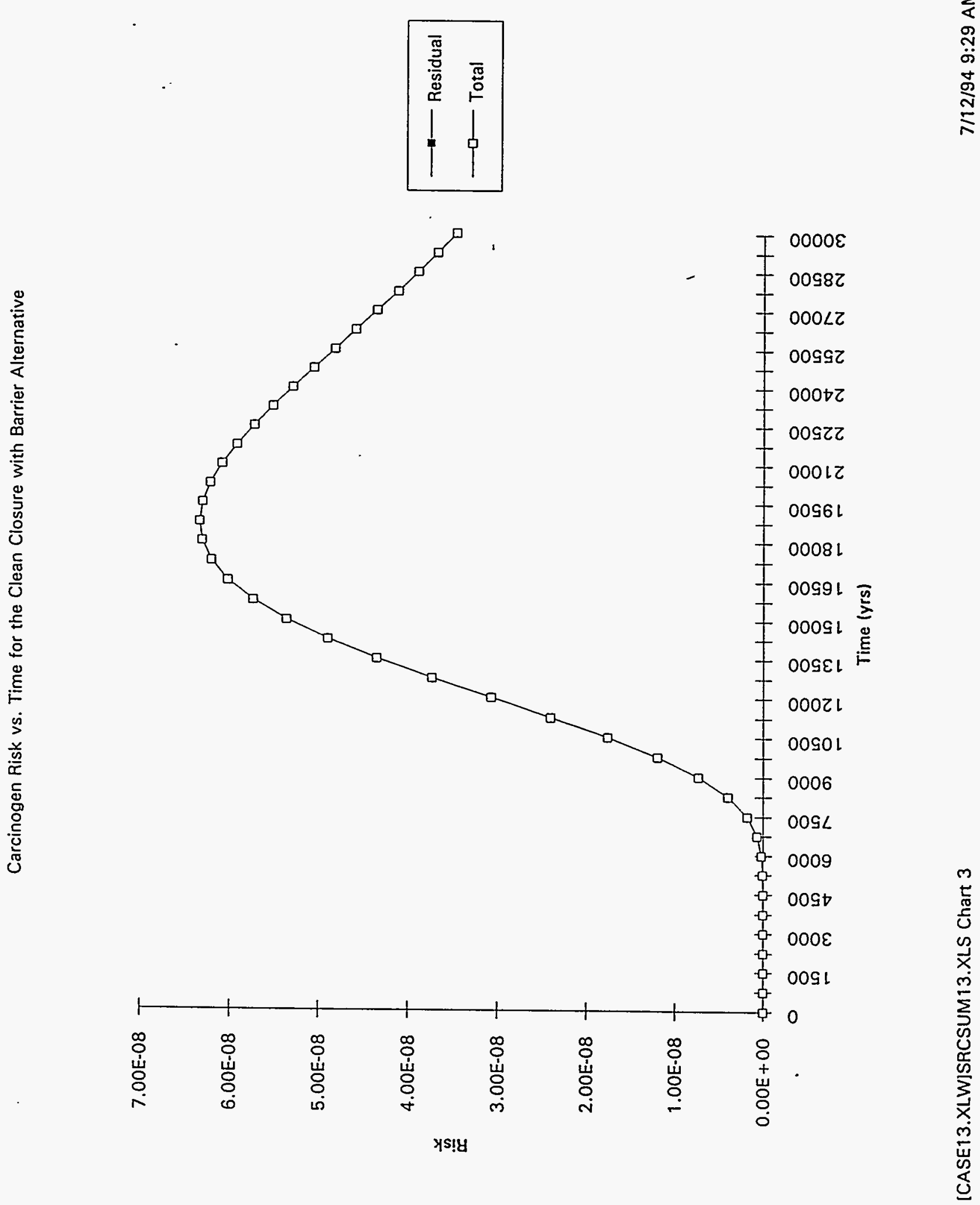

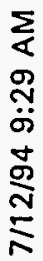



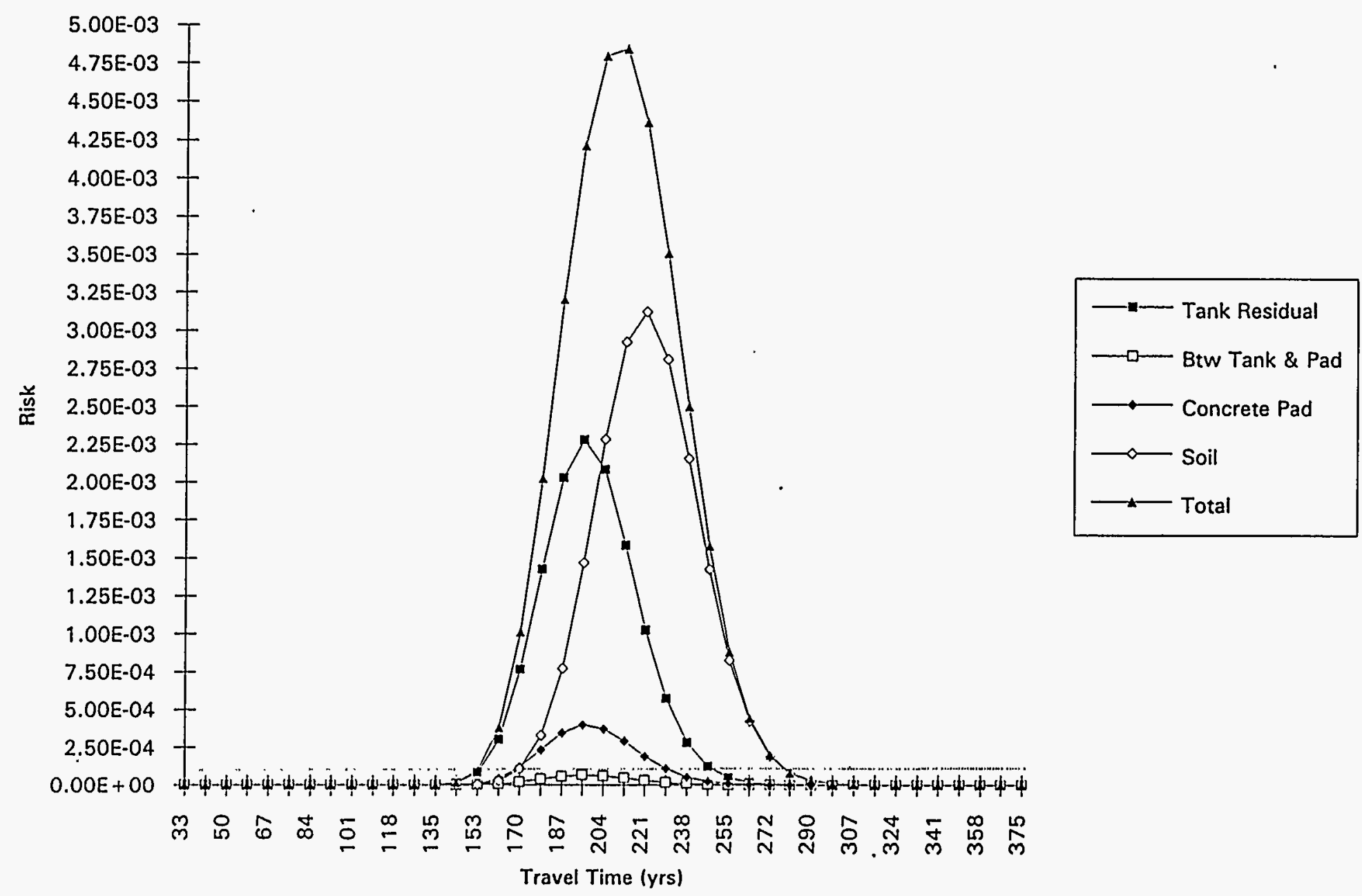

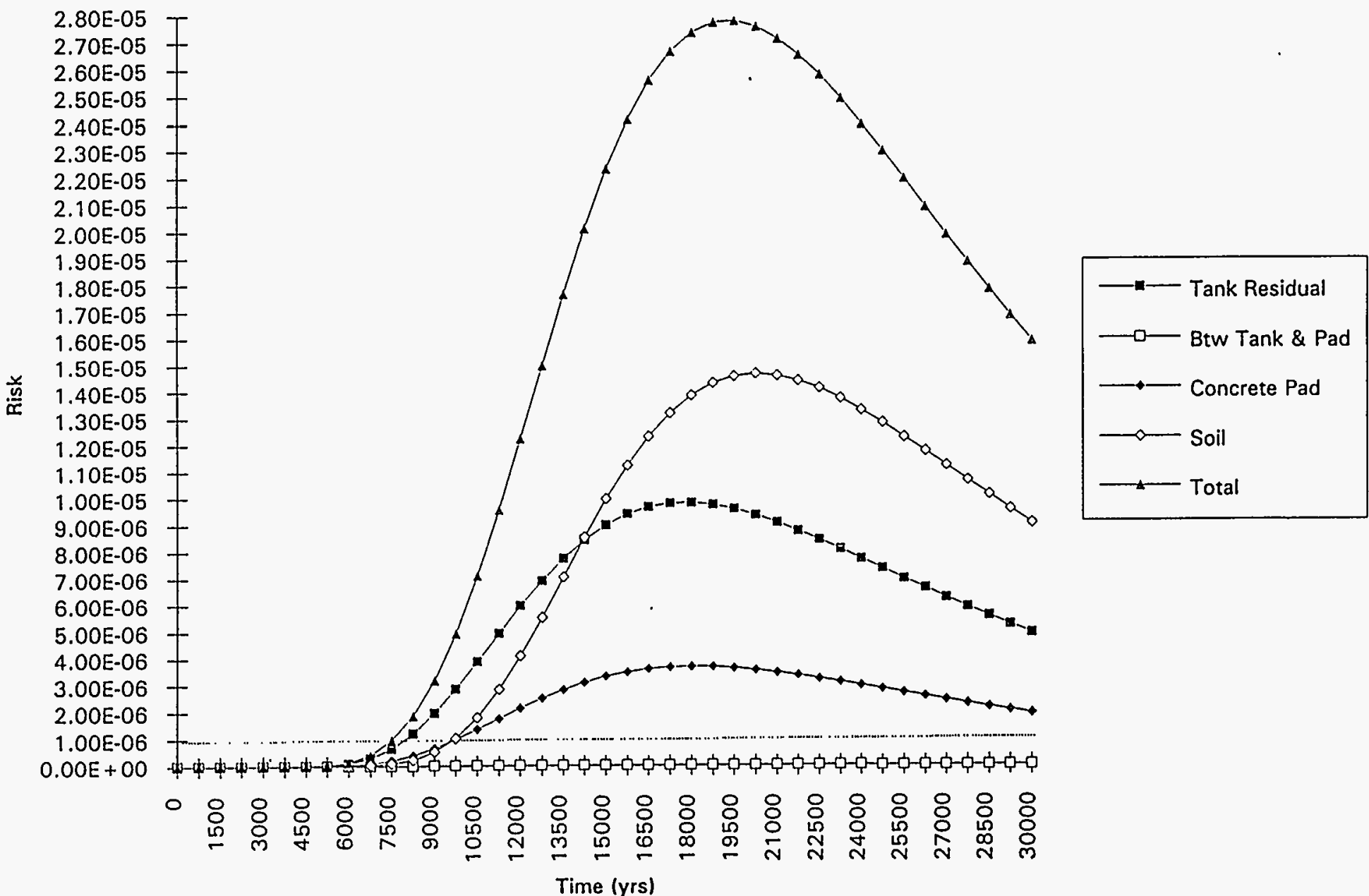
空

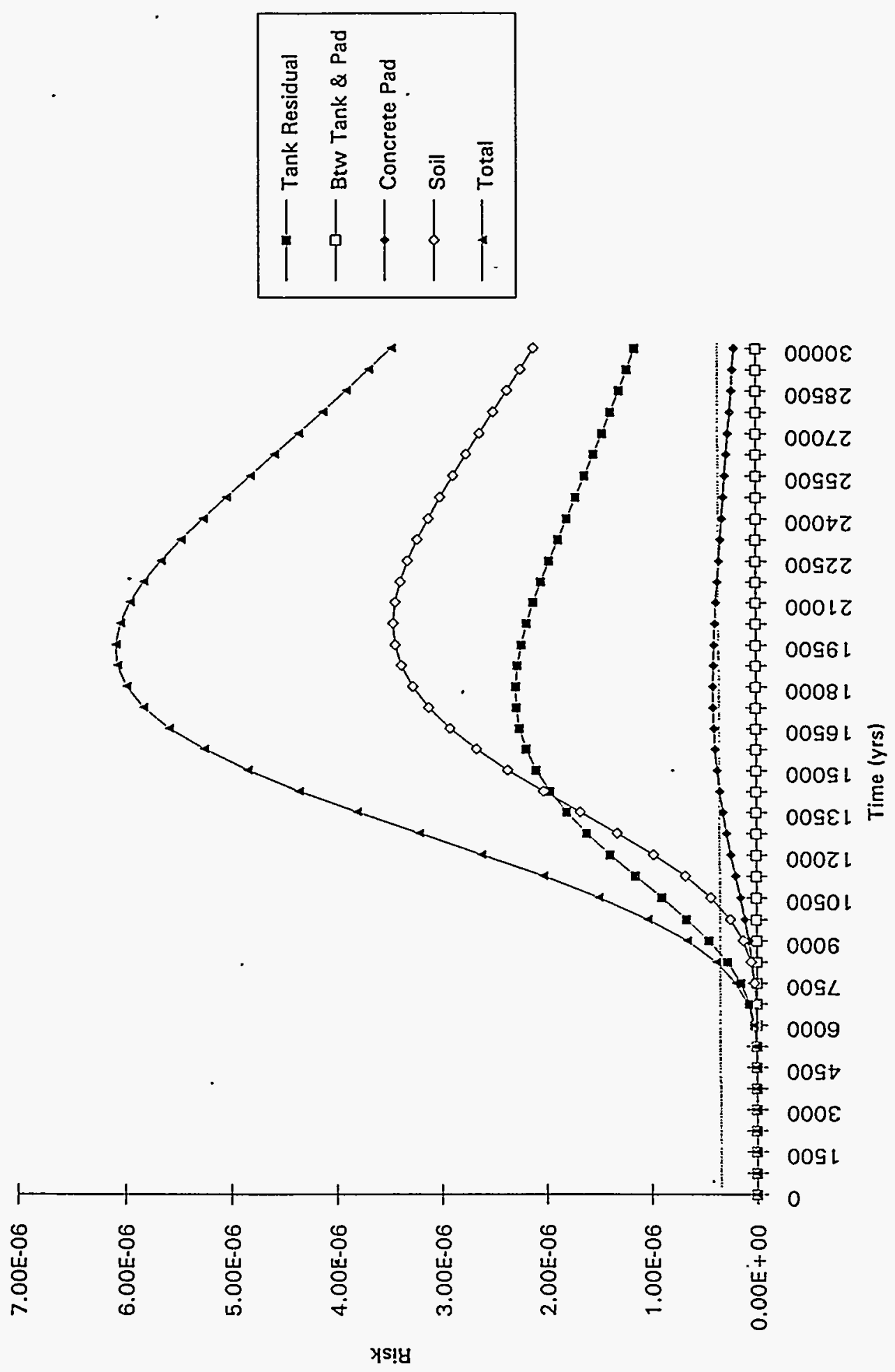

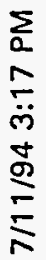

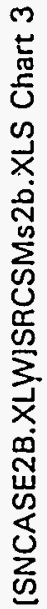


WHC-SD-WM-ES-300 REV. 1

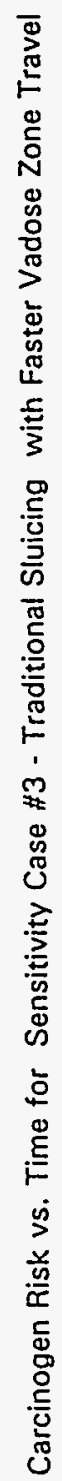

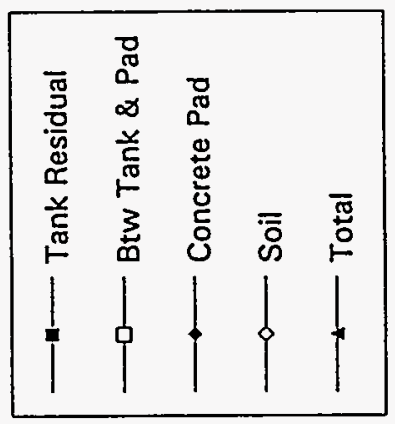

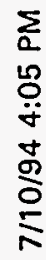

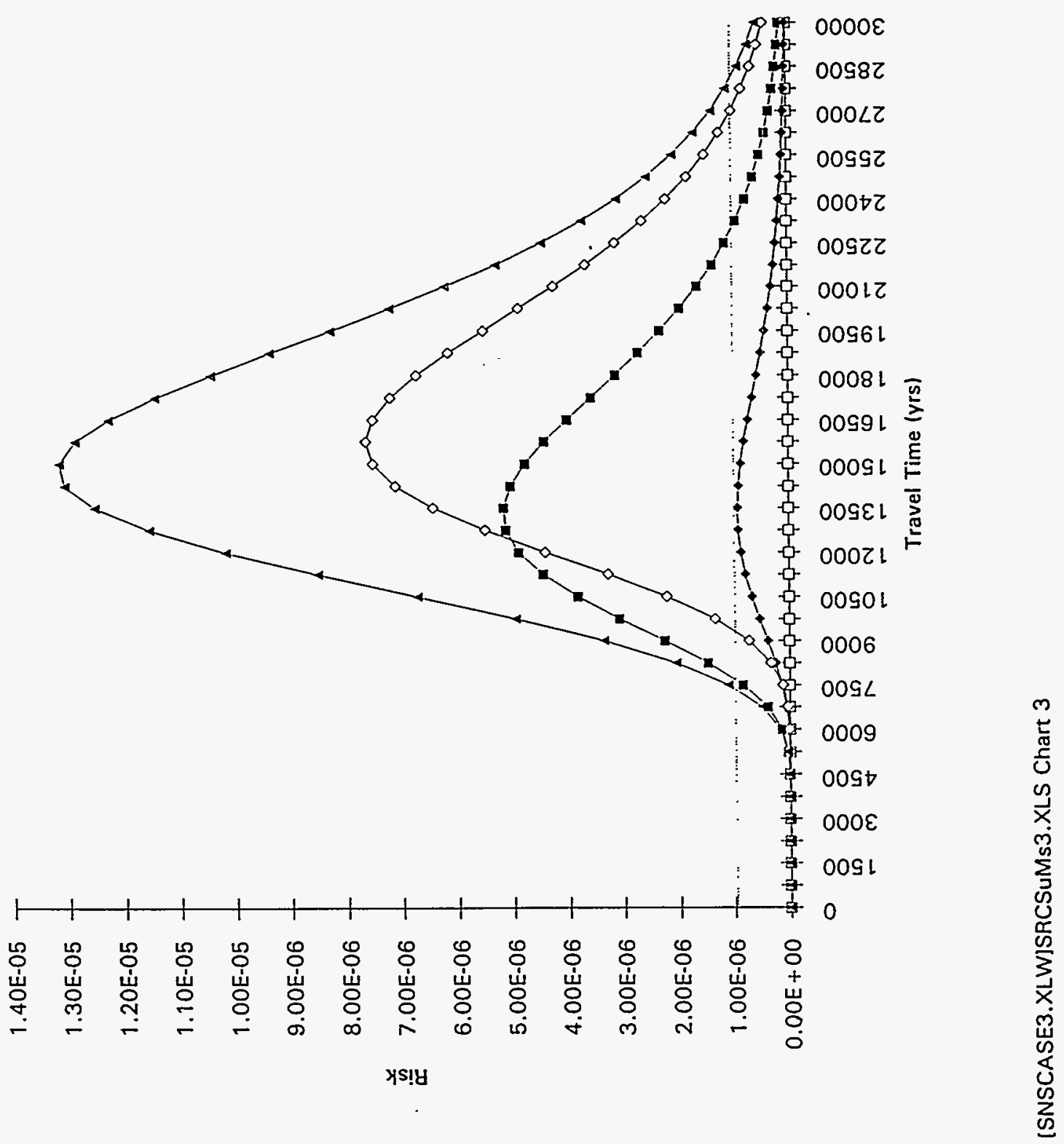


O)

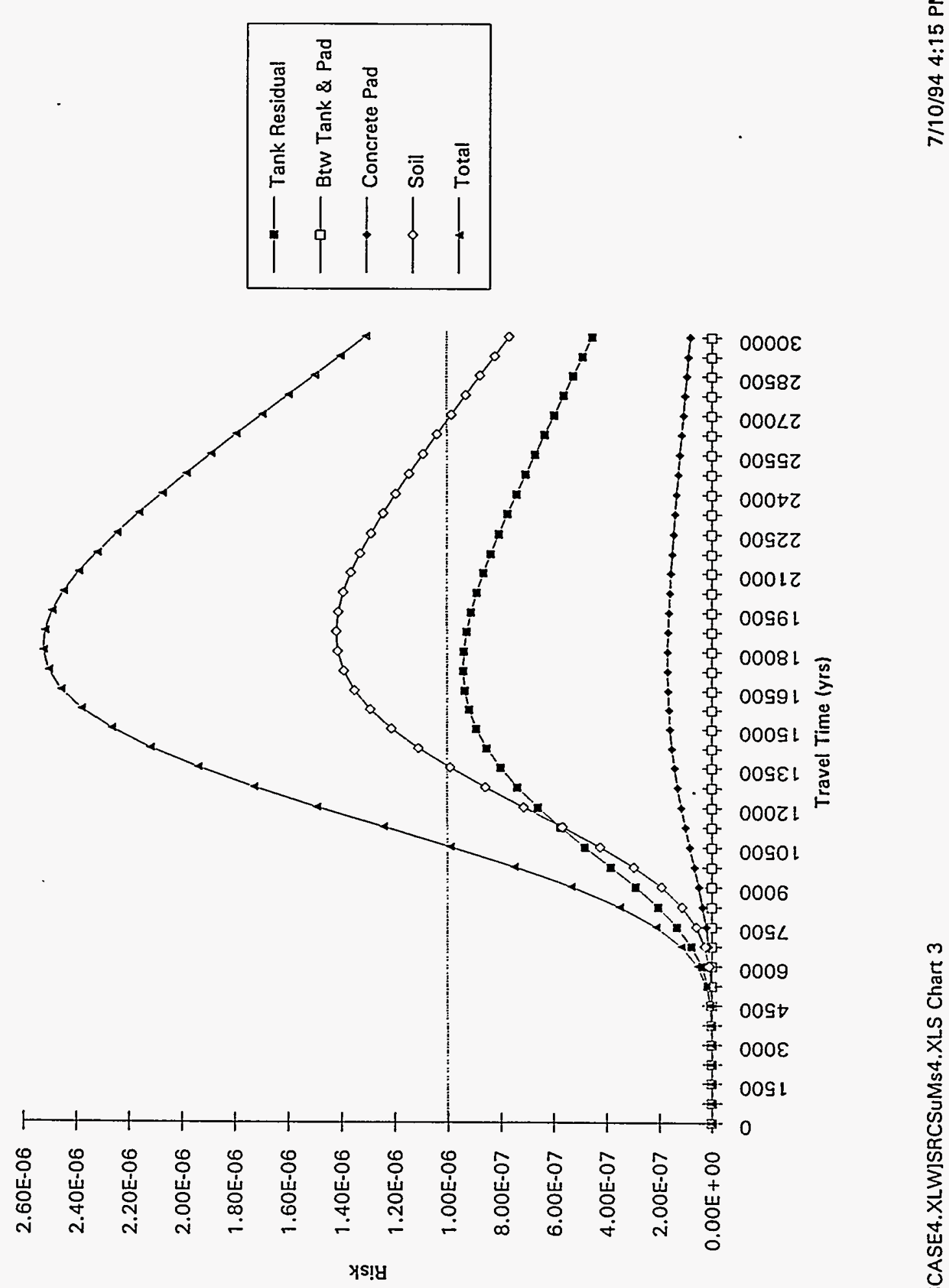

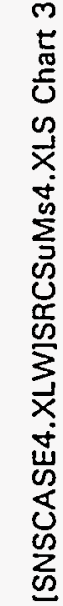



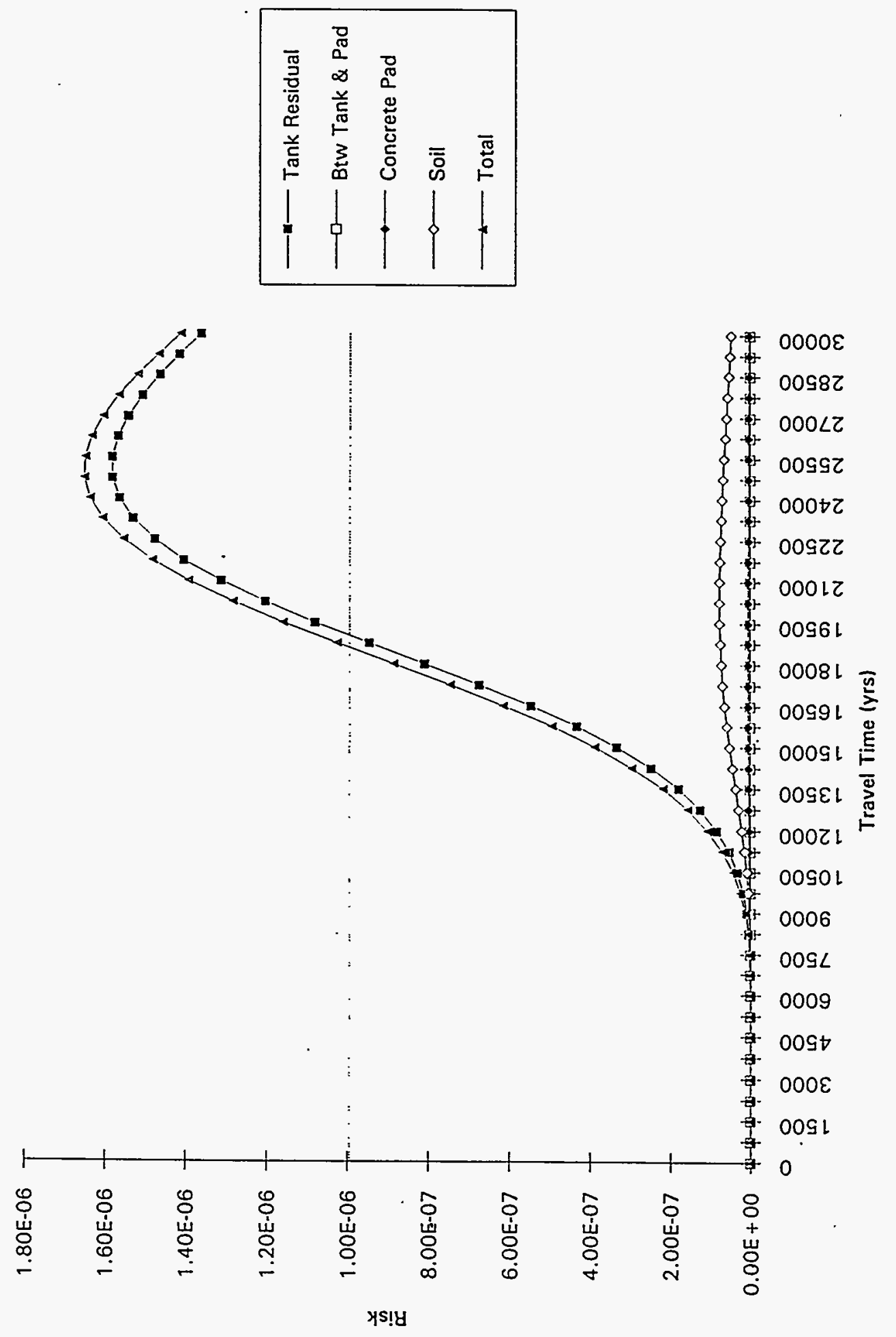


\section{WHC-SD-WM-ES-300 REV. 1}

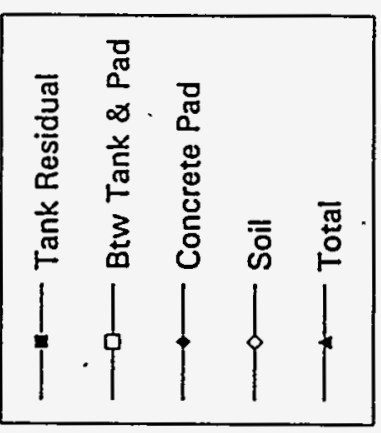

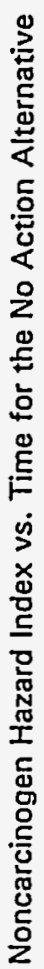

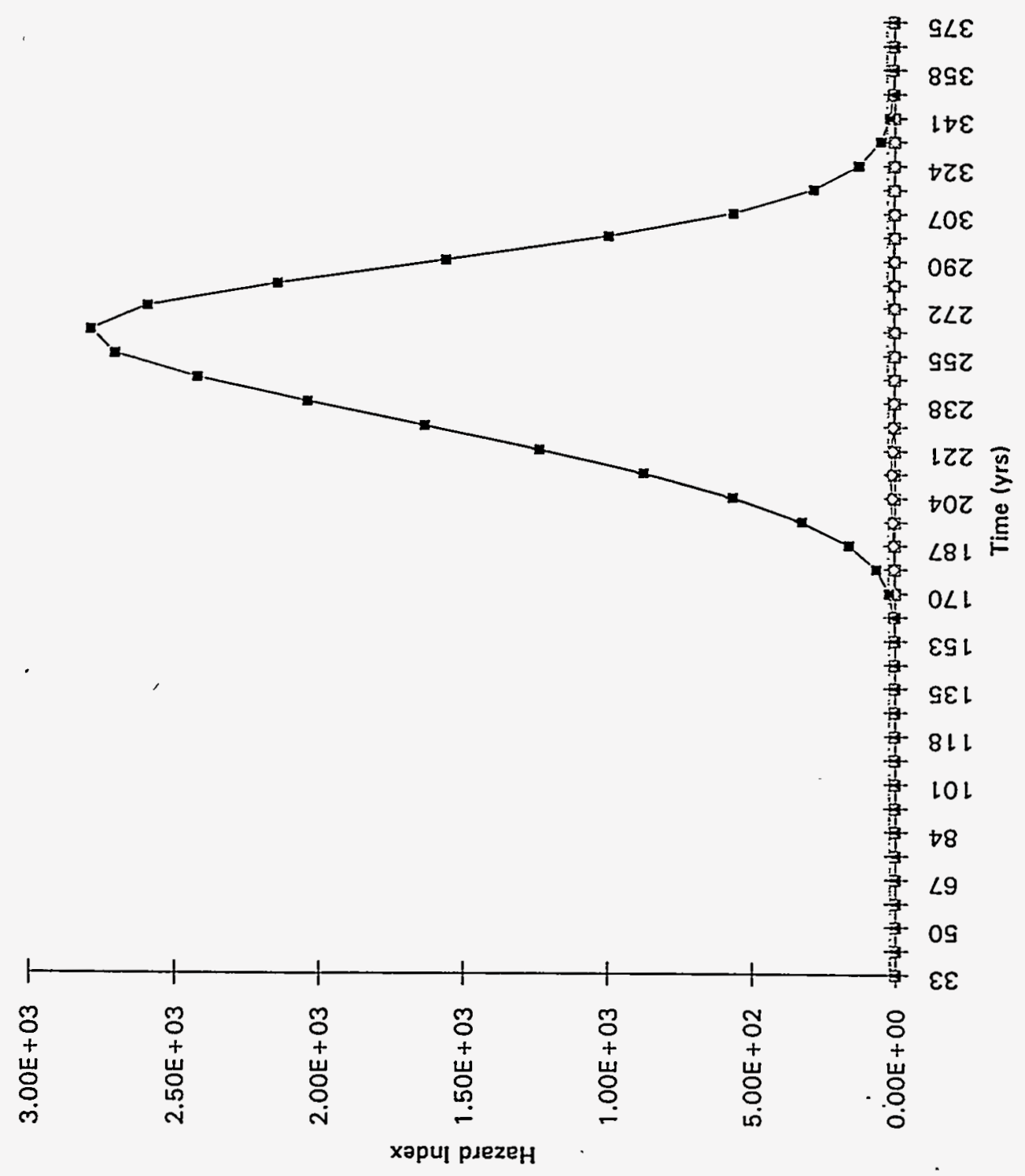



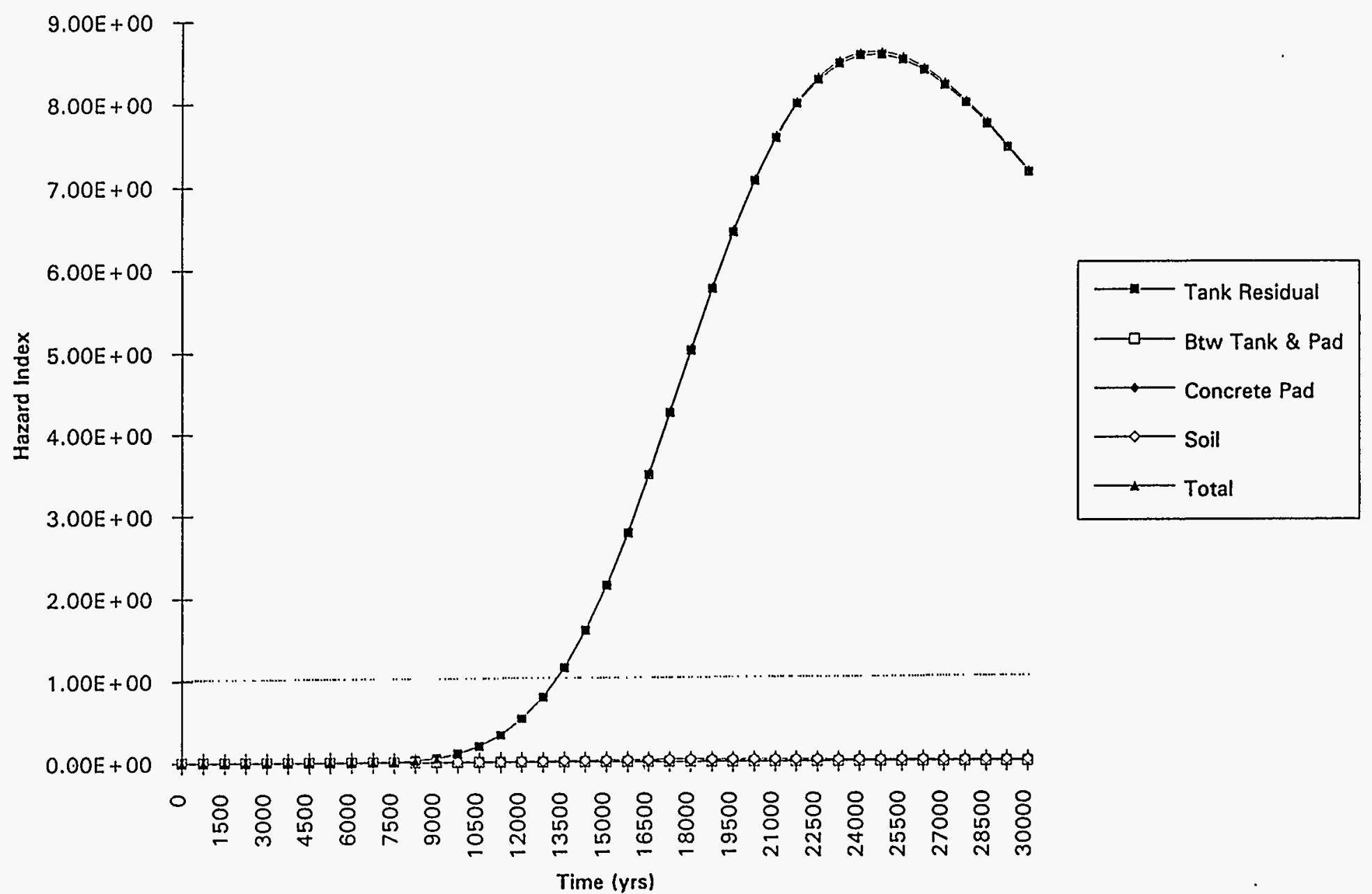
WHC-SD-WM-ES-300 REV. 1

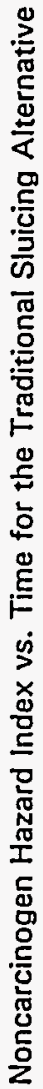

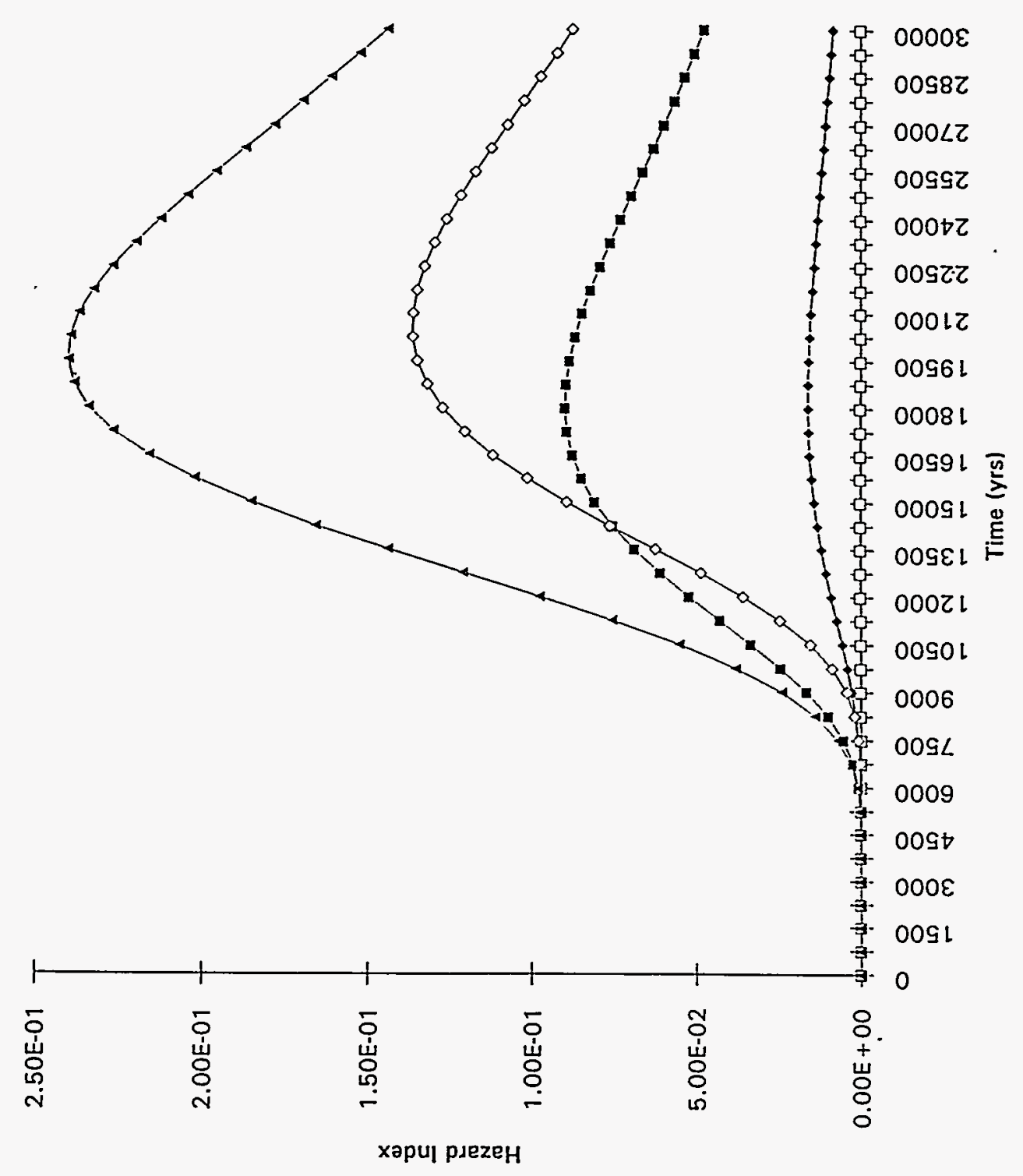

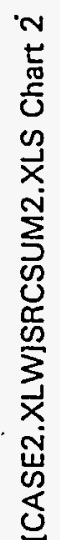




\section{WHC-SD-WM-ES-300 REV. 1}

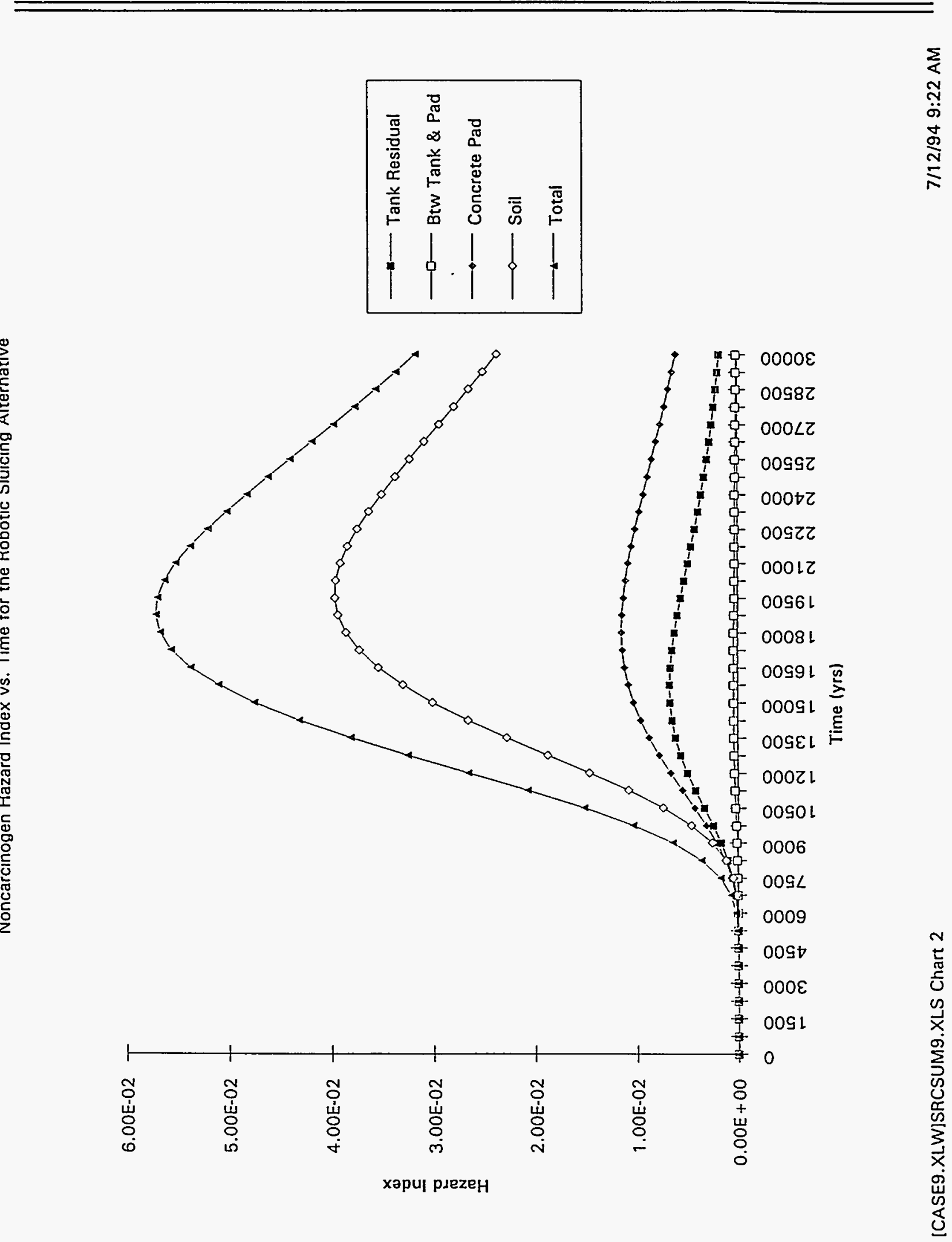




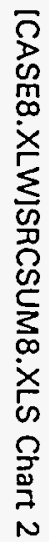

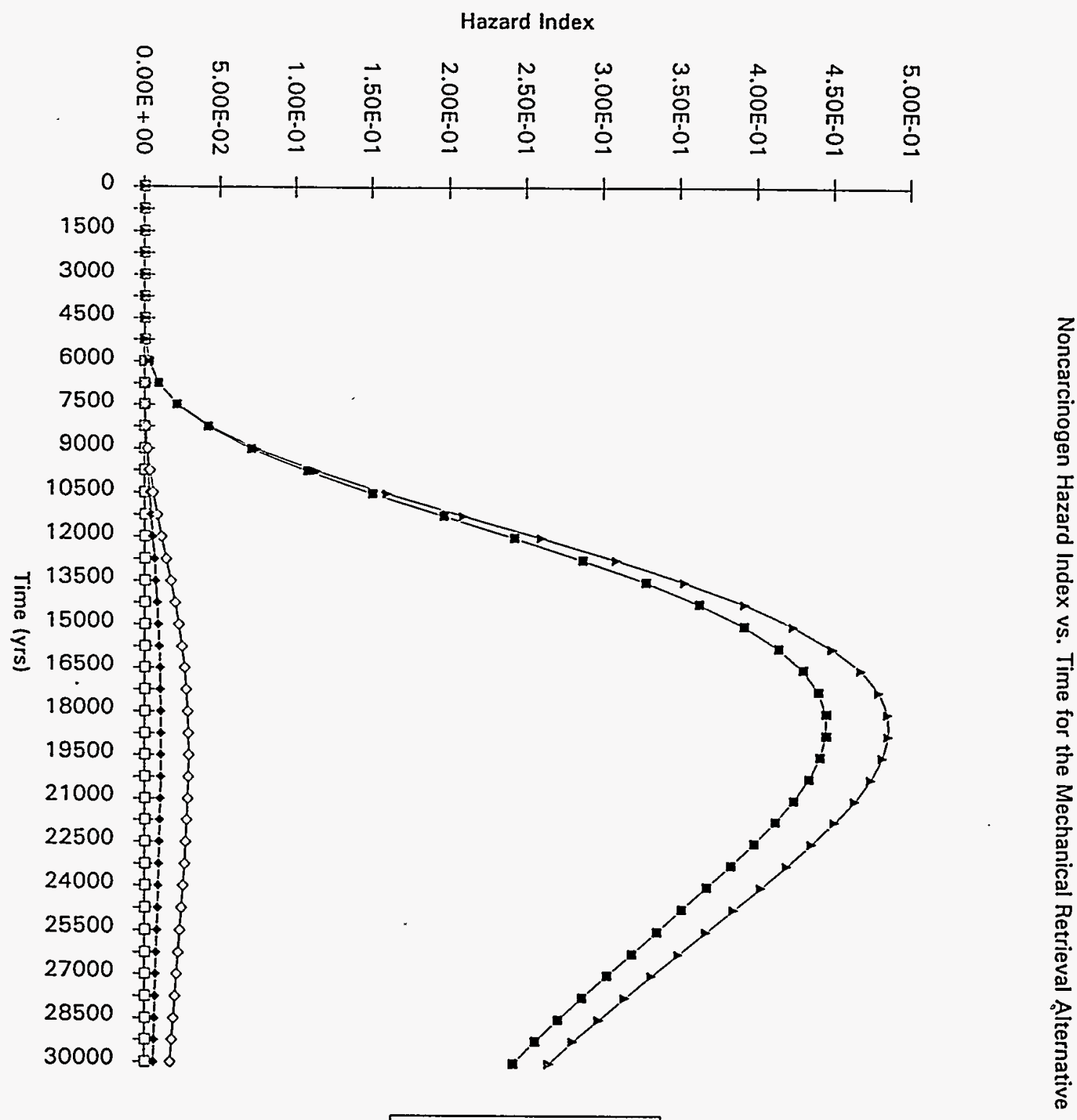

$N$
$N$
0
0
0
$\dot{N}$
0
3
3

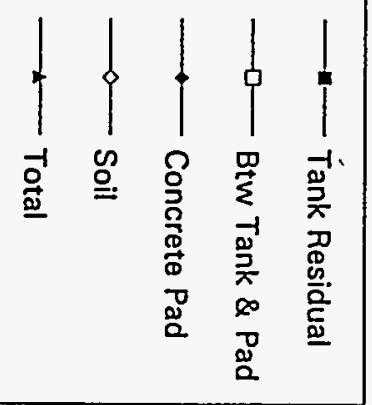


WHC-SD-WM-ES-300 REV. 1

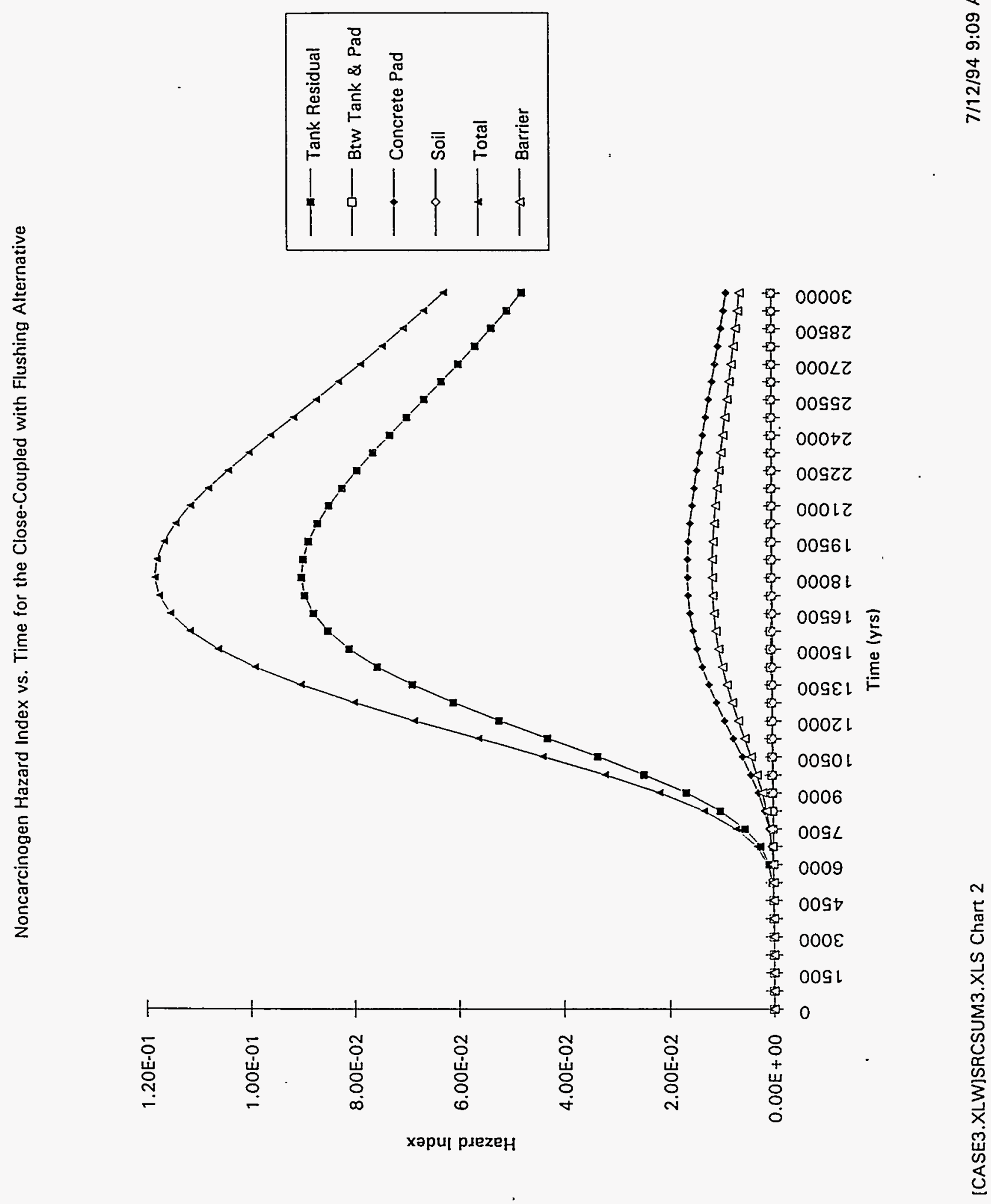




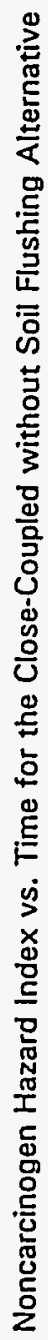

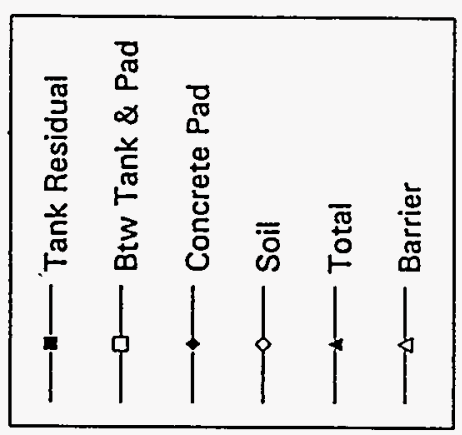

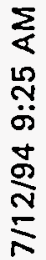

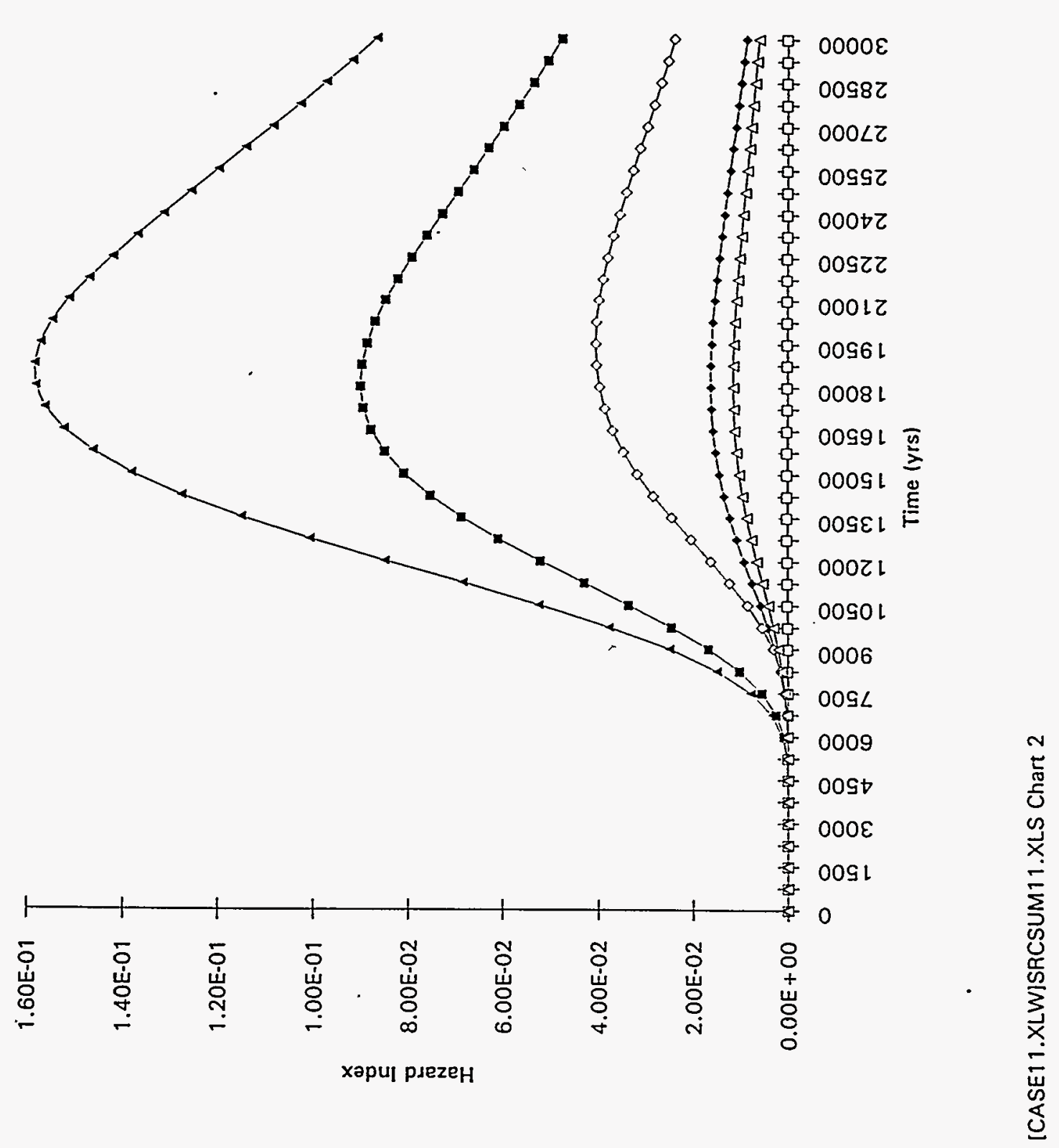




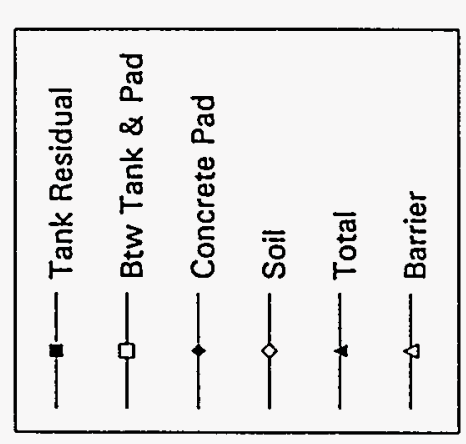

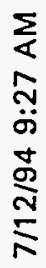

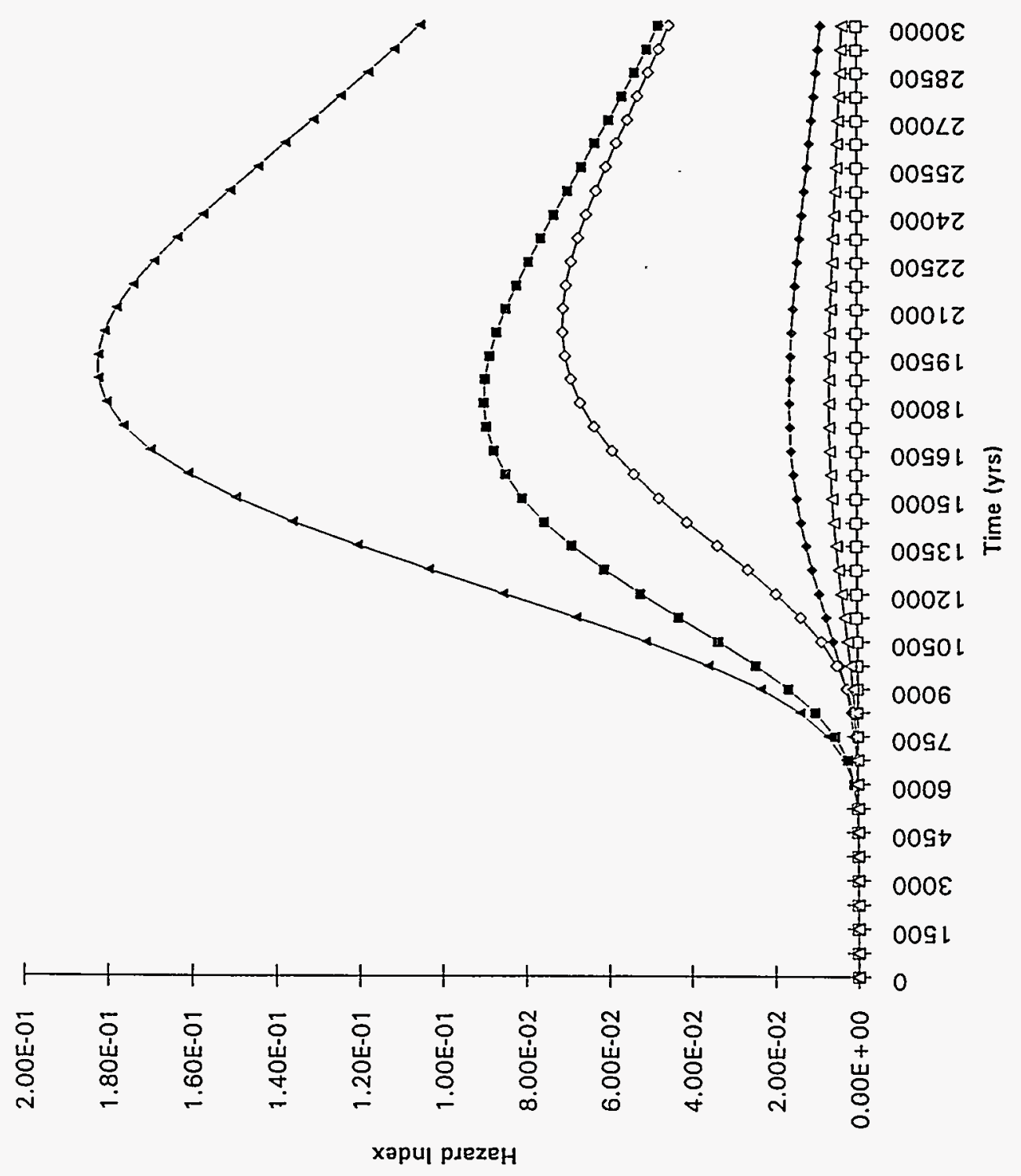


WHC-SD-WM-ES-300 REV. 1

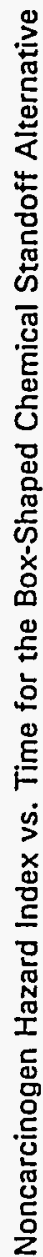

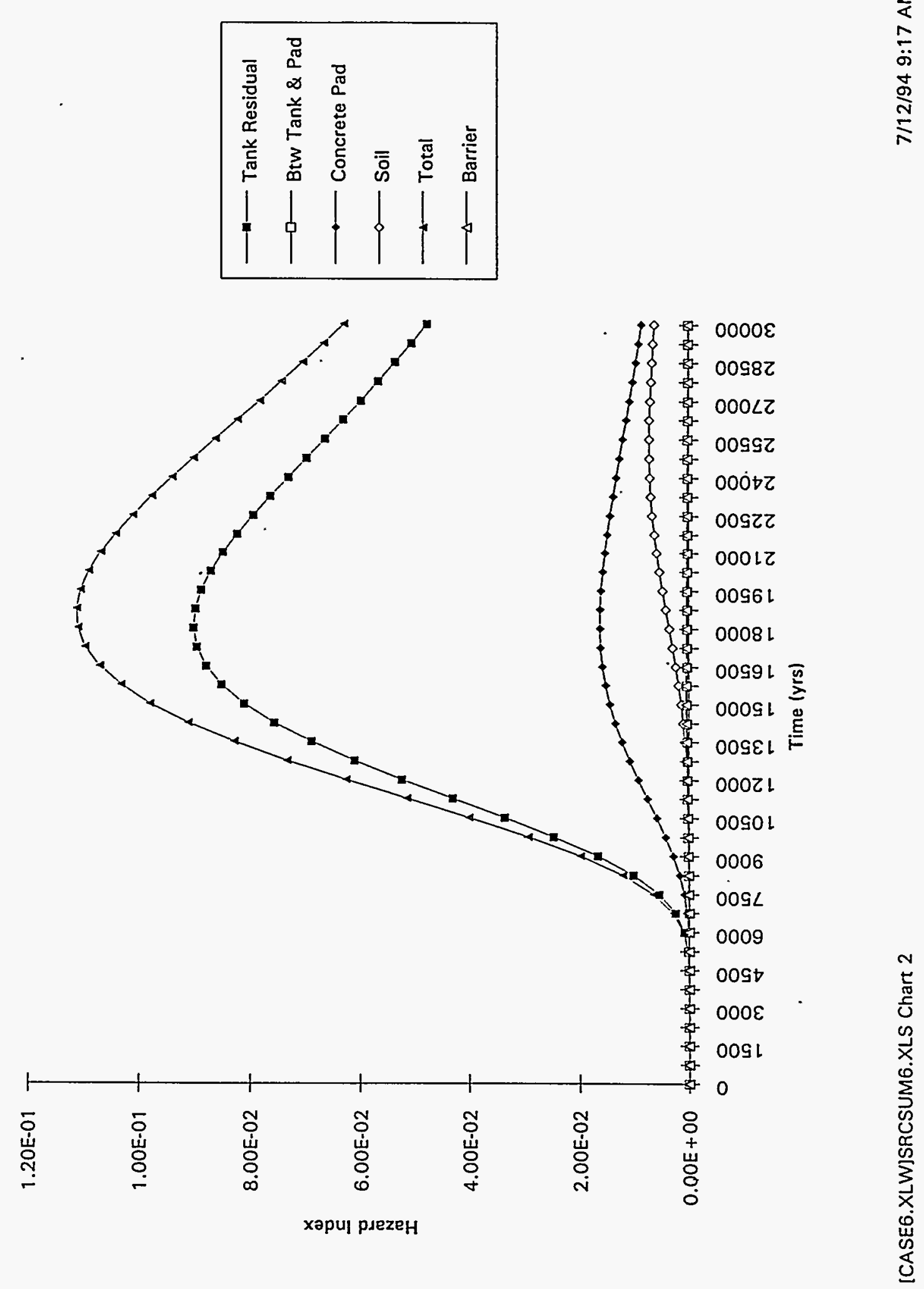


WHC-SD-WM-ES-300 REV. 1

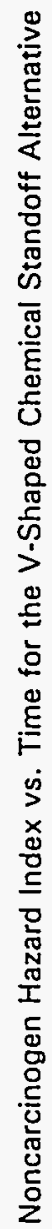

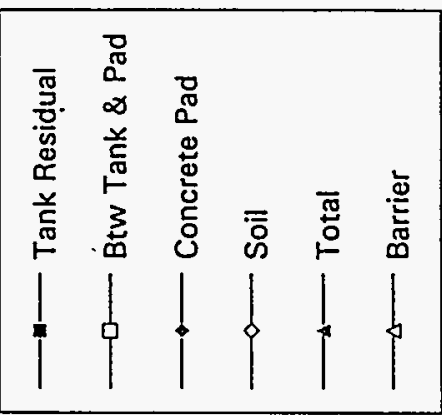

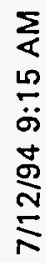

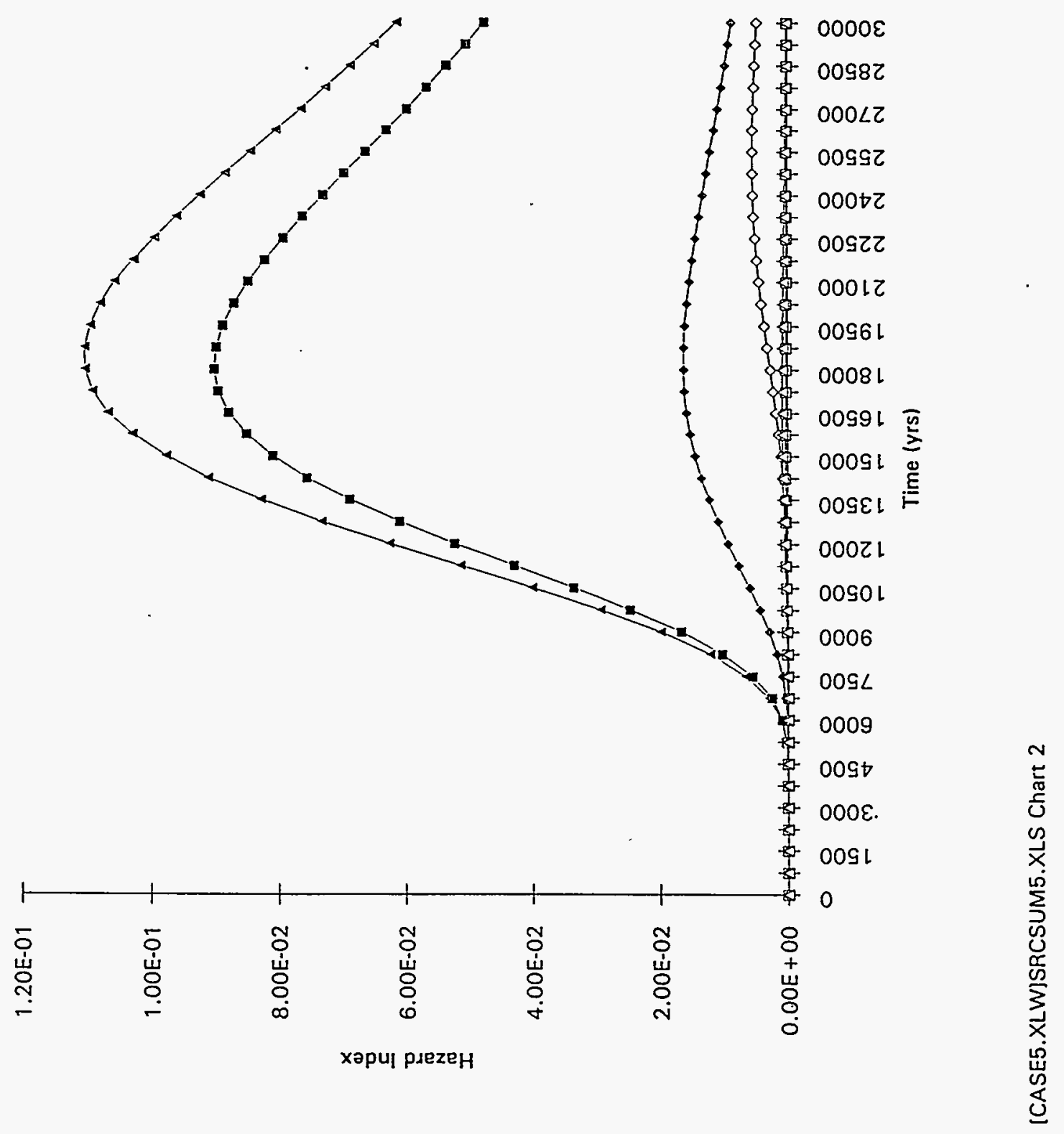


空
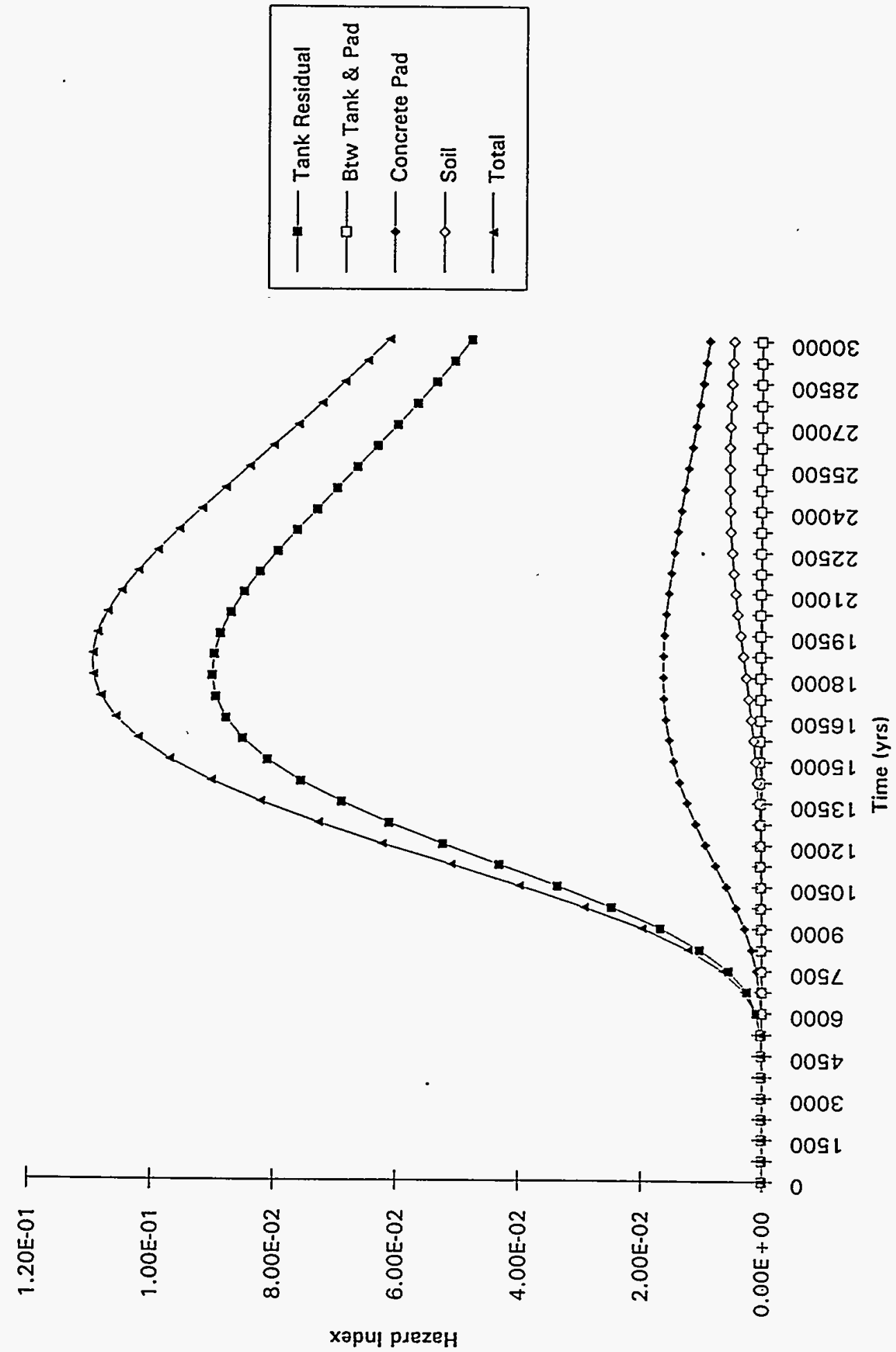

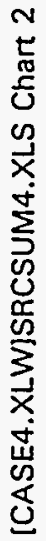




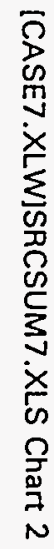

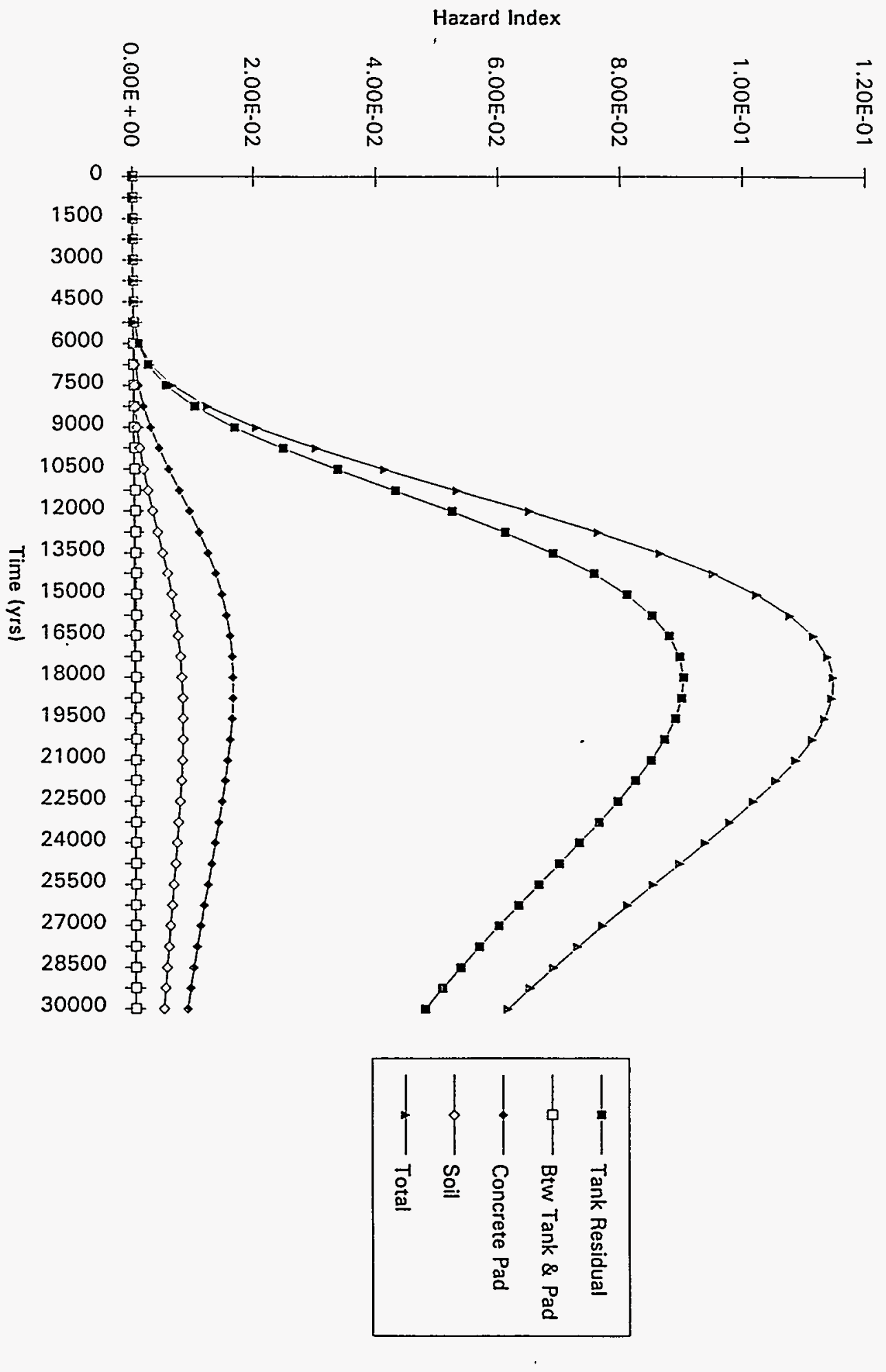


疋

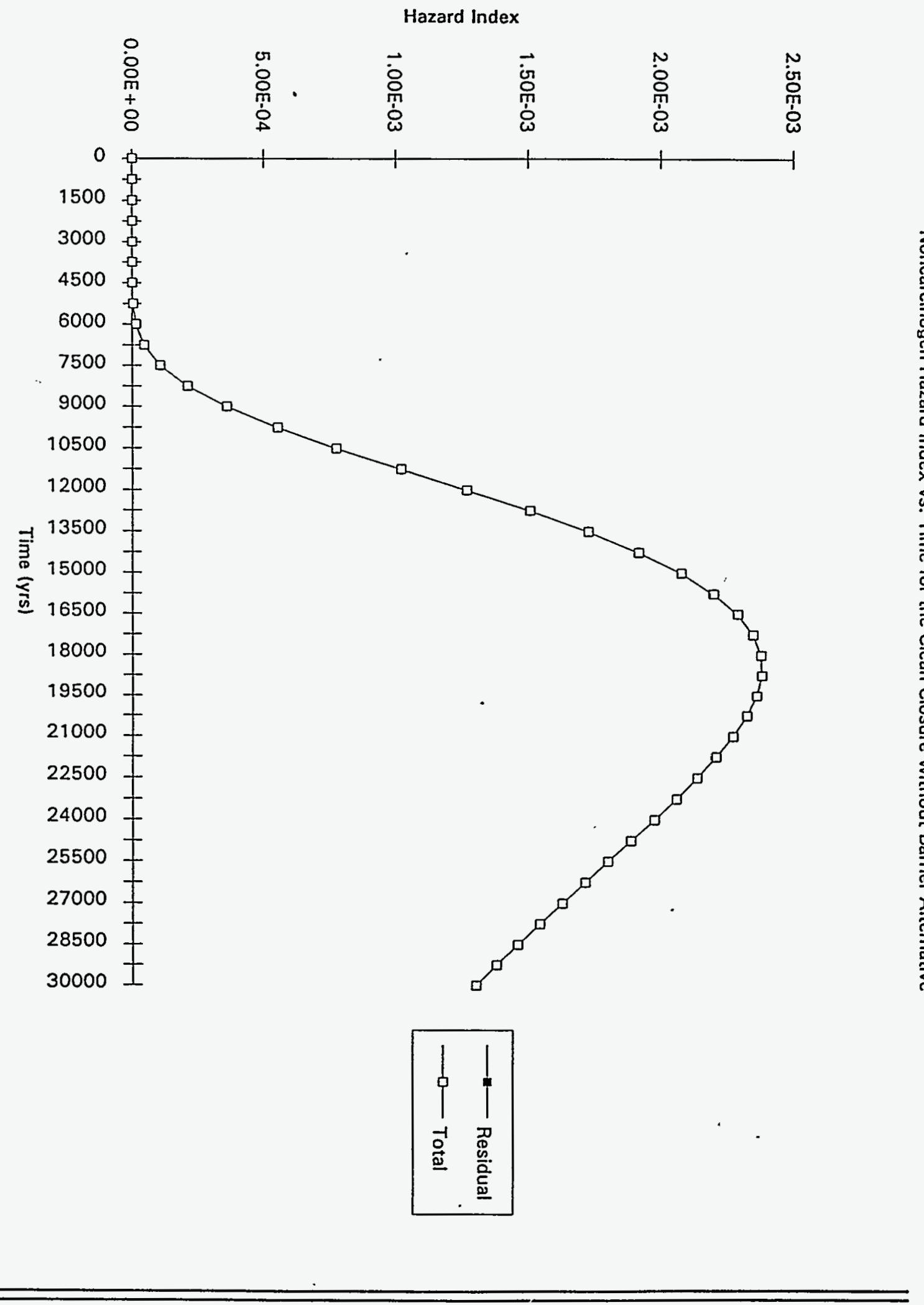


WHC-SD-WM-ES-300 REV. 1

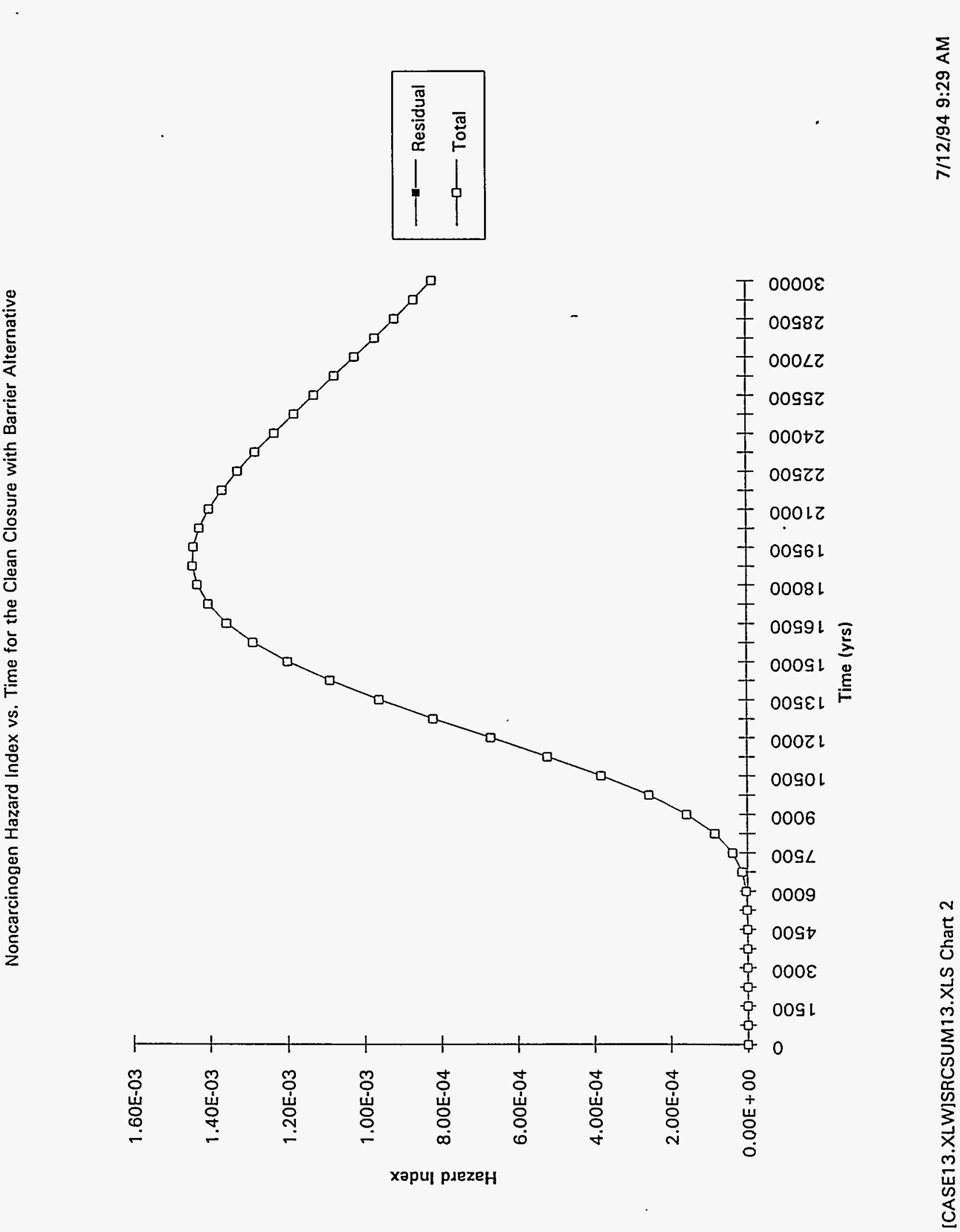




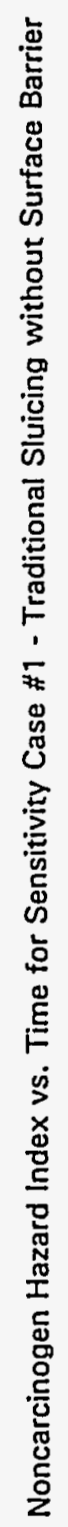

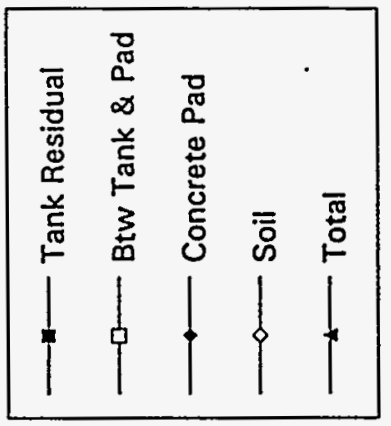

$\sum_{0}$

$\stackrel{2}{~}$

ले

응

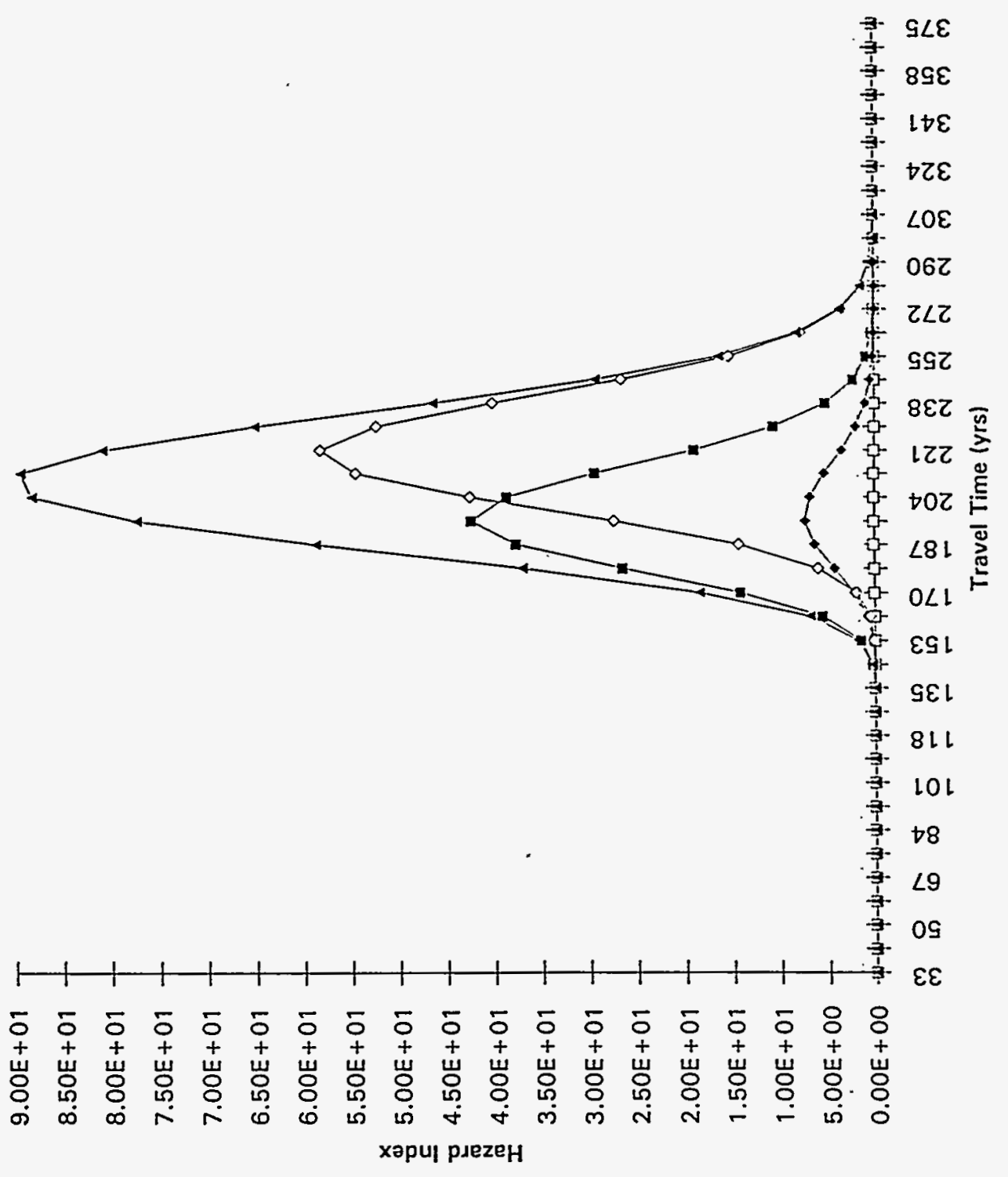




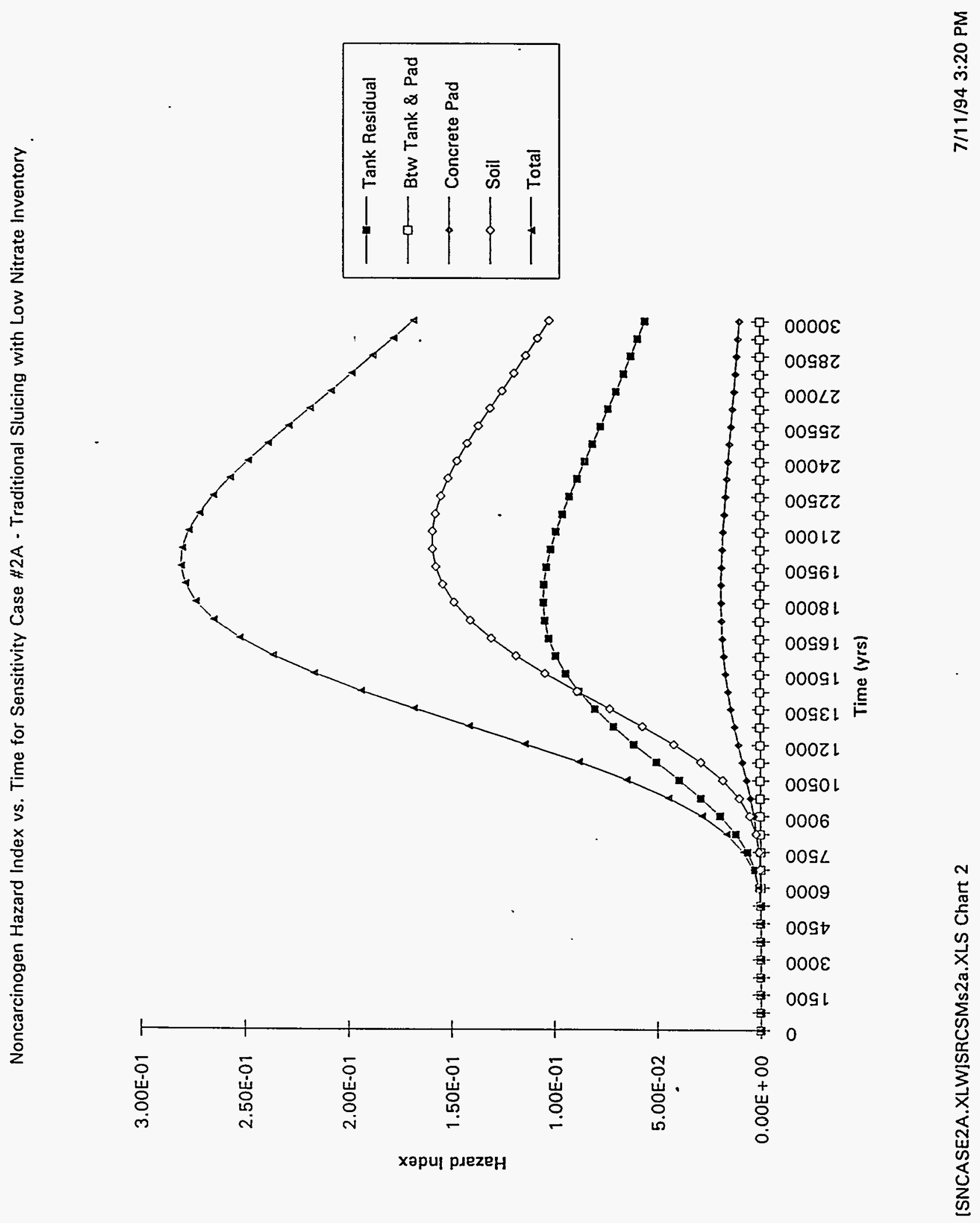


弚

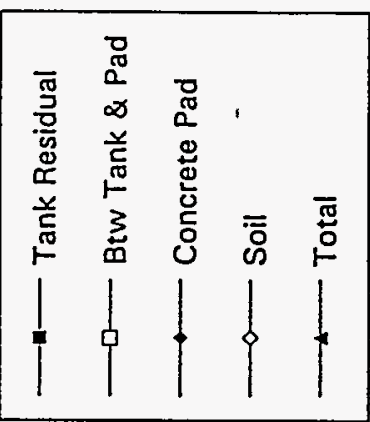

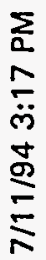

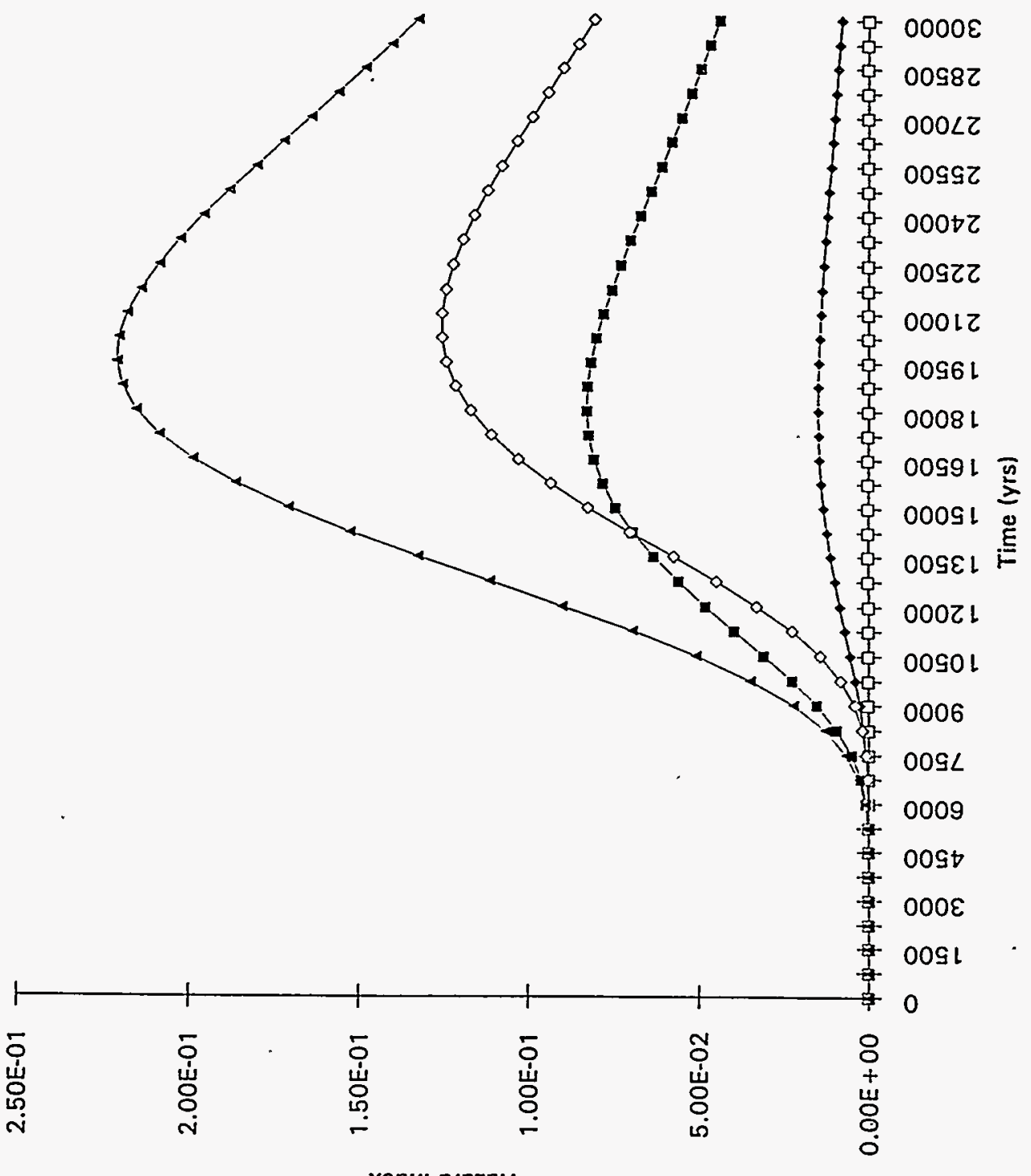

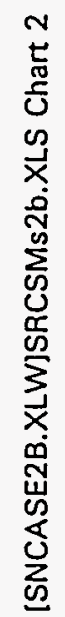



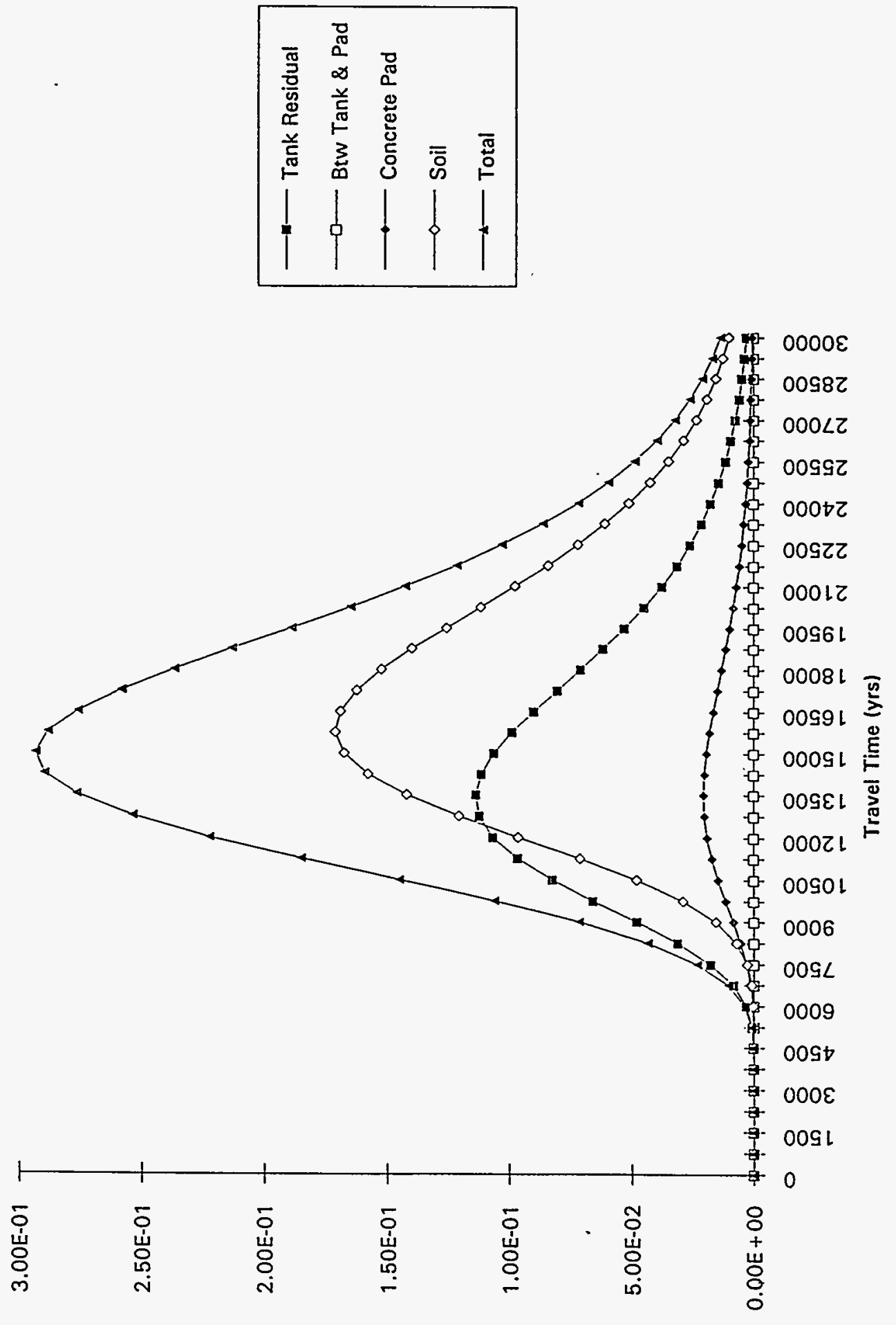

хәриј рлеzен 


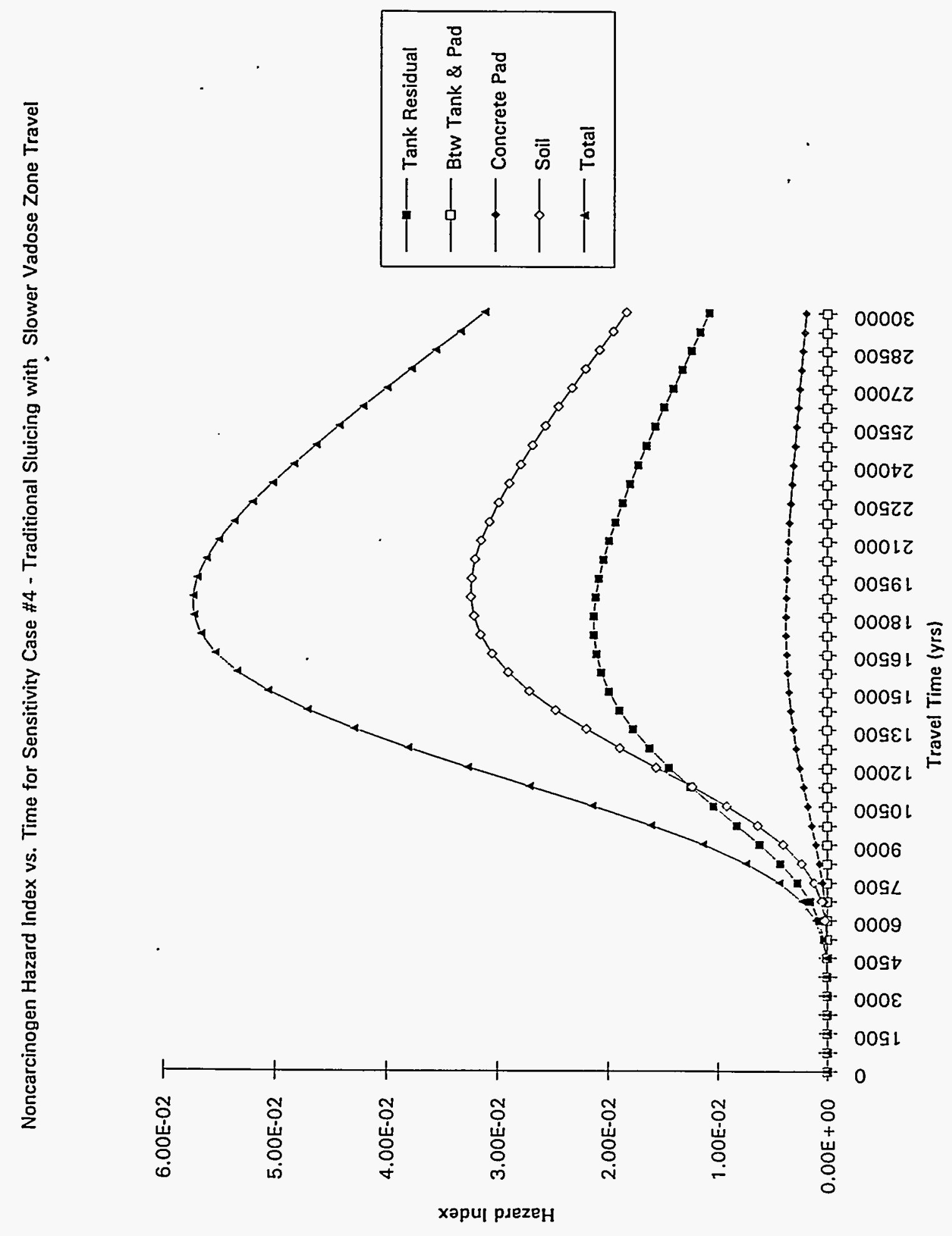

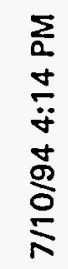

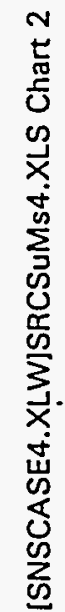


WHC-SD-WM-ES-300 REV. 1

This page intentionally left blank. 
WHC-SD-WM-ES-300 REV. 1

\author{
APPENDIX C
}

COST ESTIMATION

C-1 
WHC-SD-WM-ES-300 REV. 1

This page intentionally left blank. 


\section{COST ESTIMATION}

This appendix provides detail regarding assumptions, sources, and analysis methods for rough order of magnitude cost estimates. Table $C-1$ provides estimated cost components and detail for subsurface barriers and soil flushing. Table C-2 provides detail cost factors for the nine elements of the two clean closure alternatives. Table C-3 provides estimated cost components for all 21 options including subsurface barriers and soil flushing. Table C-4 summarizes overall cost for the 21 options combined in 14 alternatives. Annual cost is. estimated as equivalent uniform annual cost (EUAC). Overall cost during the life cycle is estimated as total net present worth (TNPW) and total life cycle cost (TLCC). Cost for subsurface barriers and soil flushing options are presented as footnotes designated by letters [a] through [v] with related numbered sub-footnotes as required. These notes are so extensive that they are provided as text following Tables C-1, C-2, C-3, and C-4.

Nine alternatives have high-level waste (HLW) processing and disposal requirements that differ from the common baseline of $99 \%$ retrieval. The change in HLW processing and disposal costs associated with these differences are listed below.

\begin{tabular}{|l|c|}
\hline \multicolumn{1}{|c|}{ Option } & Cost Change \\
\hline Robotic sluicing & +0.009 \\
\hline Mechanical retrieval & -0.04 \\
\hline Close-coupled chemical with flushing & +0.003 \\
\hline Box-shaped chemical & +0.014 \\
\hline V-shaped chemical & +0.014 \\
\hline Circulating air barrier & +0.014 \\
\hline Clean closure with close-coupled chemical barrier & +0.021 \\
\hline Clean closure w/o subsurface barrier & +0.027 \\
\hline
\end{tabular}

The baseline costs as adjusted from Boomer et al. (1993) for 149 SSTs before adjustment for $84 \%$ of the nitrate feed to the vitrification process and disposal and before adding $5 \%$ for inflation from early 1993 to mid-1994 are: capital at $\$ 5.54$ billion, annual operating and maintenance (O\&M) at $\$ 188$ million, annual disposal to HLW repository (assumed to be on the Hanford Site since transportation cost is zero) at $\$ 499$ million, and decontamination and decommissioning (D\&D) at $\$ 2.71$ billion. Robotic sluicing and mechanical retrieval have different retrieval fractions from baseline and thus have more or less slurry feed. Flush water treatments pass through the Liquid Effluent Purification and Recycle or Discharge 
(LEPRD) and produces HLW streams. Clean closure soil and debris wash water is treated in LEPRD and resulting HLW waste streams must be processed.

Note [a] applies to all options listed in Tables C-1, C-2, C-3, and C-4. Notes [b] through [v] apply to specific options as listed on Tables $\mathrm{C}-1$ and $\mathrm{C}-3$. Notes [aa] through [qq] apply to clean closure options on Table C-2.

[a] General notes:

a1. A tank farm consists of 12 SSTs $75 \mathrm{ft}$ in diameter. The tanks are arranged in a 3 by 4 array on $100 \mathrm{ft}$ centers. Each tank has a capacity of 1,000,000 gal. Overall tank farm dimensions tangent to the tanks would be 275 by $375 \mathrm{ft}$ with the bottom of the concrete tank bases at $50 \mathrm{ft}$ belowgrade and the tank tops at $7 \mathrm{ft}$ belowgrade.

22. Costs are given in millions of dollars except for O\&M and EUAC, where they are given in millions of dollars per year.

a3. Life cycle is 15 years per the Tri-Party Agreement of January 1994. Operating duration is planned as 10 years per Boomer et al. (1993).

a4. Capital costs for the following items are included where applicable: design, inspection, inflation, contingency, site preparation, process equipment, controls, drilling, coffercells, buildings, mechanical equipment, utilities, piping, grout, freezing solution, surface barrier, contractor additions, and other. Capital costs that are common to all systems with retrieval are excluded. These excluded costs are slurry transport, processing, and waste disposal.

a5. All technology readiness and capital costs are incurred in the first year and have been increased for inflation by $5 \%$ from early 1993 to mid 1994.

a6. $\quad$ O\&M = operating and maintenance includes labor, chemicals, utilities, sampling and analysis, and replacement parts and equipment.

a7. $\mathrm{D} \& \mathrm{D}=$ decontamination and decommissioning cost are incurred at the end of the life cycle and include a fraction of capital cost plus labor.

a8. $\quad$ EUAC $=$ equivalent uniform annualized cost is based on $10 \% / \mathrm{yr}$ and is $(0.13147 *$ (technology readiness + capital $))+($ O\&M $)+$ disposal + (0.03147* D\&D) per Ruegg (1987).

a9. TNPW $=$ total net present worth is based on a discount factor of $10 \% / y r$ and is (technology readiness + capital) $+(7.606 *($ O\&M + disposal $)+$ (0.2394* D\&D) per Ruegg (1987). 
Table C-1. Cost Estimates for Subsurface Barriers and Soil Flushing [a]. (sheet 1 of 2)

\begin{tabular}{|c|c|c|c|c|c|c|c|c|c|c|c|}
\hline & Notes: & $\begin{array}{c}\text { [g] } \\
\text { V-Shaped } \\
\text { Chemical }\end{array}$ & $\begin{array}{c}\text { [f] } \\
\text { Box- } \\
\text { Shaped } \\
\text { Chemical }\end{array}$ & $\begin{array}{c}\text { [h] } \\
\text { V-Shaped } \\
\text { Freeze } \\
\text { Wall }\end{array}$ & $\begin{array}{c}\text { [c] } \\
\text { Close-Coupled } \\
\text { Chemical Sides } \\
\text { \& Under } 12 \\
\text { Taniss }\end{array}$ & $\begin{array}{c}\text { [i] } \\
\text { Circulating } \\
\text { Air Barrier }\end{array}$ & $\begin{array}{c}\text { [i] } \\
\text { Vacuum Soil } \\
\text { Flushing } \\
\text { w/Circulating } \\
\text { Air [i] }\end{array}$ & $\begin{array}{l}\text { [k] } \\
\text { Traditional } \\
\text { Flushing }\end{array}$ & $\begin{array}{c}\text { [r] } \\
\text { Modified } \\
\text { Chemical } \\
\text { Close- } \\
\text { Coupled } \\
\text { Sides Only }\end{array}$ & $\begin{array}{c}\text { [u] } \\
\text { Vacuum Soil } \\
\text { Flushing } \\
\text { w/Close-Coupled } \\
\text { Chemical [e] }\end{array}$ & $\begin{array}{c}\text { [v] \& [s] } \\
\text { Close-Coupled } \\
\text { Chemical Sides } \\
\text { and Under } 7 \\
\text { Tanks }\end{array}$ \\
\hline 1 & Pipe layers & 2 & 2 & 3 & 2 & 1 & $1 / 3$ & $1 / 1$ & 2 & 1/3 & 2 \\
\hline 2 & Grout cost, $\left.\$ / f^{\prime}\right\}$ chem] & 30 & 30 & & 30 & & & & 30 & & 30 \\
\hline 3 & Grout volume, $f^{3} /$ linear $f t[c h e m]$ & 15 & 15 & . & 15 & & & & 15 & & 14 \\
\hline 4 & Pipe space belowgrade, ft & 7 & 7 & 10 & 7 & 100 & 10 & $10 / 20$ & 7 & 10 & 7 \\
\hline 5 & Drill or jack, ft & 148,327 & 103,200 & 155,743 & 81,768 & 3,000 & 53,473 & 43,393 & 44,054 & 53,473 & 47,698 \\
\hline 6 & drill or jack cost, S/R & 500 & 500 & 500 & 500 & 500 & 500 & 500 & 500 & 500 & 500 \\
\hline 7 & Grout vol., kft' $[\mathrm{chem}]$ & 2,282 & 1,588 & 0 & 1,258 & $\mathbf{0}$ & $\overline{0}$ & $\mathbf{0}$ & 678 & 0 & 668 \\
\hline 8 & Coffercell lincar $\AA$, 15 ft dia. & . 0 & 0 & 0 & 1,200 & 0 & 1,200 & $\overline{0}$ & 1,200 & & 1,120 \\
\hline 9 & Coffercell cost, $\$ / \mathrm{ft}$ & $\mathbf{0}$ & 0 & 0 & 5,000 & 0 & 5,000 & 0 & 5,000 & & 5,000 \\
\hline 10 & Air, scfm & $\mathbf{0}$ & $\mathbf{0}$ & 0 & 0 & 100,000 & 100,000 & 0 & 0 & & $\mathbf{0}$ \\
\hline 11 & Comp. hp & 0 & $\overline{0}$ & 0 & 0 & 12,000 & 12,000 & 0 & 0 & & $\overline{0}$ \\
\hline 12 & Site preparation, $k \$$ & 940 & 670 & 1,100 & 1,120 & 380 & 790 & 350 & 650 & 790 & 1,120 \\
\hline 13 & Drilljack \& pipe, kS & 74,200 & 51,600 & 77,900 & 40,900 & 1,500 & 26,700 & 21,700 & 22,000 & 26,700 & 23,800 \\
\hline 14 & Coffereell, ks & 0 & 0 & 0 & 6,000 & 0 & 6,000 & $\mathbf{0}$ & 6,000 & 0 & 5,600 \\
\hline 15 & Buildings, $\mathbf{k S}$ & 0 & 0 & 255 & 0 & 1,031 & 1,031 & 1,031 & 0 & 1,031 & $\overline{0}$ \\
\hline 16 & Mech. equipment, kS & 2,512 & 2,512 & 1,380 & 2,512 & 12,951 & 12,951 & 5,000 & 2,512 & 12,951 & 2,512 \\
\hline 17 & Surface piping, $\mathrm{kS}$ & 0 & 0 & 600 & 0 & 1,600 & 2,400 & 1,360 & 0 & 2,400 & 0 \\
\hline 18 & Chermical grout, $\mathrm{kS}$ & 68,500 & 47,600 & 0 & 37,700 & 0 & 0 & 0 & 20,300 & $\overline{0}$ & 20,000 \\
\hline 19 & Dry or flush/vacuum, $\mathrm{kS}$ & 0 & $\mathbf{0}$ & 0 & 0 & 12,336 & 12,336 & 12,336 & 0 & 12,336 & 0 \\
\hline 20 & lireeze, ks & 0 & 0 & 5,388 & 0 & 0 & 0 & 0 & 0 & $\mathbf{0}$ & 0 \\
\hline 21 & Other, ks & 6,580 & 4,690 & 7,700 & 7,840 & 2,660 & 5,530 & 2,500 & 4,550 & 5,530 & 7,840 \\
\hline 22 & KEH adds, $\mathrm{KS}$ & 11,280 & 8,040 & 13,200 & 13,440 & 4,560 & 9,480 & 4,200 & 7,800 & 9,480 & 13,440 \\
\hline 23 & Surface cover, kS & 1,880 & 1,340 & 2,200 & 2240 & .760 & 1,580 & 700 & 1300 & 1,580 & 2,240 \\
\hline 24 & Subtotal $1, \mathrm{kS}$ & 166,000 & 116,000 & 110,000 & 112,000 & 38,000 & 79,000 & 49,000 & 65,000 & 73,000 & 77,000 \\
\hline
\end{tabular}


Table C-1. Cost Estimates for Subsurface Barriers and Soil Flushing [a]. (sheet 2 of 2)

a

\begin{tabular}{|c|c|c|c|c|c|c|c|c|c|c|c|}
\hline & Notes: & $\begin{array}{c}\text { [g] } \\
\text { V-Shaped } \\
\text { Chemical }\end{array}$ & $\begin{array}{c}\text { [f] } \\
\text { Box-Shaped } \\
\text { Chemical }\end{array}$ & $\begin{array}{c}\text { [h] } \\
\text { V-Shaped } \\
\text { Freeze Wall }\end{array}$ & $\begin{array}{c}\text { [c] } \\
\text { Close-Coupled } \\
\text { Chemical Sides } \\
\text { \& Under } \\
12 \text { Tanks }\end{array}$ & $\begin{array}{c}\text { [i] } \\
\text { Circulating } \\
\text { Air Barrier }\end{array}$ & $\begin{array}{c}\text { [j] } \\
\text { Vacuum Soil } \\
\text { Flushing } \\
\text { w/Circulating } \\
\text { Air [i] }\end{array}$ & $\begin{array}{c}\text { [k] } \\
\begin{array}{c}\text { Traditional } \\
\text { Flushing }\end{array}\end{array}$ & $\begin{array}{c}\text { [r] } \\
\text { Modified } \\
\text { Close-Coupled } \\
\text { Chemical Sides } \\
\text { Only }\end{array}$ & $\begin{array}{c}\text { [u] } \\
\text { Vacuum Soil } \\
\text { Flushing w/ } \\
\text { Close-Coupled } \\
\text { Chemical [e] }\end{array}$ & $\begin{array}{c}\text { [v] \& [s] } \\
\text { Close-coupled } \\
\text { Chemical Sides } \\
\text { \& Under } 7 \\
\text { Tanks }\end{array}$ \\
\hline 25 & Design, $\mathbf{k S}$ & & & & & 385 & & & & & \\
\hline 26 & Inspection, $\mathbf{k S}$ & & & & & 4,110 & & & & & \\
\hline 27 & Escalation, kS & & & & & 10,596 & & & & & \\
\hline 28 & Contingency, kS & & & & & 15,200 & & & & & \\
\hline 29) & Subtotal 2, kS & 132,324 & 92,467 & 87,684 & 89,279 & 30,291 & 62,973 & 39,059 & 51,814 & 58,191 & 61,379 \\
\hline 30| & Subtota12/subtotal1 & 0.80 & 0.80 & 0.80 & 0.80 & 0.80 & 0.80 & 0.80 & 0.80 & 0.80 & 0.80 \\
\hline 31 & Capital total $=1+2, \mathrm{kS}$ & 312,900 & 218,400 & 207,900 & 211,050 & 71,400 & 126,100 & 92,400 & 111,000 & 107,000 & 144,900 \\
\hline 32 & Dlectricity, $\mathbf{k} \$ \mathbf{S y r}$ & & & 415 & & 1,806 & 1,806 & & & 1,806 & \\
\hline 33 & Labor, $\mathbf{k} \mathbf{S / y r}$ & 6,260 & 4,370 & 20,790 & 4,220 & 7,140 & 14,910 & 9,240 & 2,460 & 13,760 & 2,900 \\
\hline 34 & Labor/capital & 0.020 & 0.020 & 0.100 & 0.020 & 0.100 & 0.100 & 0.100 & 0.020 & 0.100 & 0.020 \\
\hline 35 & Sample \& analysis, $\mathbf{k S} / \mathrm{yr}$ & 300 & 300 & 300 & 300 & 300 & 300 & 300 & 300 & 300 & 300 \\
\hline 36 & Parts \& equipment, kS/yr & & & & & 3,654 & 9,784 & & & 8,934 & \\
\hline 37 & O\&M total cost, $\mathrm{k} \$ / \mathrm{yr}$ & 6,000 & 5,000 & 19,000 & 5,000 & 12,000 & 16,000 & 11,000 & 3,700 & 15,000 & 5,000 \\
\hline 38 & O\&M/capital & 0.03 & 0.03 & 0.16 & 0.03 & 0.18 & 0.18 & 0.16 & 0.03 & 0.18 & 0.03 \\
\hline 39 & Parts \& equipment/capital & & & & & 0.051 & 0.066 & & & 0.065 & \\
\hline 40 & D\&D, kS & 0 & 0 & 27,000 & $\mathbf{0}$ & 16,000 & 19,000 & 15,000 & $\mathbf{0}$ & 17,000 & 0 \\
\hline
\end{tabular}


Table C-2. Estimated Costs of Clean Closure.

\begin{tabular}{|c|c|c|c|c|c|c|c|c|c|}
\hline Note & & \multicolumn{4}{|c|}{$\begin{array}{c}\text { Option } 13{ }^{\prime} \\
\text { Clean-Closure w/o Subsurface Barrier }\end{array}$} & \multicolumn{4}{|c|}{$\begin{array}{c}\text { Option } 14 \\
\text { Clean-Closure with Close-Coupled } \\
\text { Chemical Barrier }\end{array}$} \\
\hline [aa] & CLEAN CLOSURE & & & & & & & & \\
\hline [bb] & Leak volume, gal & \multicolumn{4}{|c|}{255,000} & \multicolumn{4}{|c|}{77,000} \\
\hline [cc] & Soil below tanks, $y d^{3}$ & \multicolumn{4}{|c|}{72,000} & \multicolumn{4}{|c|}{22,000} \\
\hline [dd] & Leak depth, ft & \multicolumn{4}{|c|}{$28,45,49$} & \multicolumn{4}{|c|}{28} \\
\hline [ee] & Soil below tanks, ktons & \multicolumn{4}{|c|}{97} & \multicolumn{4}{|c|}{30} \\
\hline [ff] & Tank soil and debris, ktons & \multicolumn{4}{|c|}{45} & \multicolumn{4}{|c|}{45} \\
\hline [gg] & Total soil and debris, ktons & \multicolumn{4}{|c|}{142} & \multicolumn{4}{|c|}{75} \\
\hline \multirow[t]{3}{*}{ [qq] } & $\begin{array}{l}\text { Cost fraction for HLW processing } \\
\text { \& disposal }\end{array}$ & \multicolumn{4}{|c|}{0.027} & \multicolumn{4}{|c|}{0.021} \\
\hline & & $\begin{array}{l}\text { Tech } \\
\text { Ready }\end{array}$ & $\begin{array}{c}\text { Capital } \\
\text { [hh] }\end{array}$ & O\&M & Disposal & $D \& D$ & EUAC & TNPW & TLCC \\
\hline & $\begin{array}{l}\text { Option } 13 \text {, Clean-closure w/o } \\
\text { subsurface bartier }\end{array}$ & MS & MS & $M S / y r$ & $\mathrm{MS} / \mathrm{yr}$ & MS & $\mathrm{MS} / \mathrm{yr}$ & MS & MS \\
\hline [ii] & Removal & 7 & 141 & 23 & & 51 & 44 & 334 & 541 \\
\hline [ii] & Tank farm confinement & 3 & 270 & 28 & & 67 & 66 & 504 & 765 \\
\hline [kk] & Hauling \& $M W$ land fill & 2 & 19 & 4 & & 6 & 7 & 53 & 89 \\
\hline [III] & Soil \& debris water wash & 4 & 169 & 20 & & 47 & 44 & 338 & 524 \\
\hline$[\mathrm{mm}]$ & LEPRD wash water treat & 2 & 50 & 7 & & 11 & 14 & 109 & 172 \\
\hline [nn] & LEPRD solids to MW disposal & 1 & 0.06 & 0.02 & & $\overline{0}$ & 0.16 & 1 & 1 \\
\hline [oo] & Recycle piping, no SALDS & 1 & 65 & 10 & & 23 & 20 & 150 & 245 \\
\hline [pp] & Backfill & 0.2 & 5 & 0 & & 0 & 1 & 5 & 5 \\
\hline \multirow[t]{4}{*}{ [qq] } & HLW processing \& disposal & 0 & 11 & 2 & 1 & 10 & 5 & 38 & 69 \\
\hline & Totals & 20 & 730 & 94 & 1 & 215 & 201 & 1,532 & 2,411 \\
\hline & $\begin{array}{l}\text { Option 14, Clean-closure with } \\
\text { close-coupled chemical barrier }\end{array}$ & MS & MS & $\mathrm{MS} / \mathrm{yr}$ & $\mathbf{M S / y r}$ & MS & MS/yr & MS & MS \\
\hline & Close-coupled chemical barrier & 13 & 145 & 5 & & $\mathbf{0}$ & 25 & 192 & 225 \\
\hline [ii] & Removal & 7 & 96 & 19 & & 42 & 34 & 259 & 432 \\
\hline [ij] & Tank farm confinement & 3 & 270 & 28 & & 67 & 66 & 504 & 765 \\
\hline [kk] & Hauling \& MW land fill & 2 & 13 & 4 & $\cdot$ & 5 & 6 & 44 & 75 \\
\hline [II] & Soil \& debris water wash & 4 & 115 & 16 & & 36 & 33 & 249 & 393 \\
\hline [mm] & LEPRD wash water treat & 2 & 34 & 6 & & 13 & 11 & 82 & 134 \\
\hline$[\mathrm{nn}]$ & LEPRD solids to MW disposal & 1 & 0.04 & 0.02 & & 0 & 0.15 & 1 & 1 \\
\hline [oo] & Recycle piping, no SALDS & 1 & 44 & 9 & & 19 & 15 & 116 & 195 \\
\hline [pp] & Backfill & 0.2 & 4 & 0 & & 0 & 0.5 & 4 & 4 \\
\hline \multirow[t]{2}{*}{ [qq] } & HLW processing \& disposal & $\overline{0}$ & 8 & 2 & 1 & 8 & 4 & 29 & 53 \\
\hline & Totals & 33 & 729 & 89 & 1 & 190 & 195 & 1,480 & 2,277 \\
\hline
\end{tabular}

O\&M and EUAC are stated in millions of dollars per year (not lifetime cost) 


\begin{tabular}{|c|c|c|c|c|c|c|c|c|c|c|}
\hline$\angle 20^{\circ} 0$ & IIt? & $z \varepsilon s^{\prime} I$ & I0Z & siz & I & \pm 6 & $\tau S L$ & $0 \varepsilon L$ & $0 z$ & 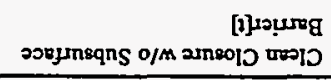 \\
\hline $120^{\circ} 0$ & $\angle L Z^{\prime} Z$ & $08 b^{\circ} I$ & S6I & $06 \mathrm{I}$ & I & 68 & OSL & $62 L$ & $\varepsilon \varepsilon$ & 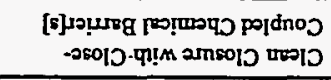 \\
\hline & oI & 8 & I & $\tau \cdot 0$ & 0 & 200 & $s$ & $\triangleright$ & 2 & 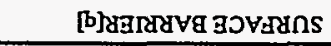 \\
\hline & $L$ & $s$ & $\angle 0$ & $\tau^{*} 0$ & 0 & 20 & $\varepsilon$ & $\tau$ & $\mathbf{I}$ & [d]NOLLVZMIGVIS XNVL \\
\hline$\$ 10.0$ & $2 L$ & It & $s$ & ol & I & 2 & SI & \pm 1 & $\tau$ & 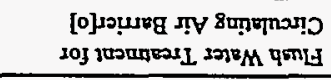 \\
\hline$\$ 10^{\circ} 0$ & 802 & ZZI & 91 & 82 & I & 8 & $6 t$ & $\angle b$ & 2 & 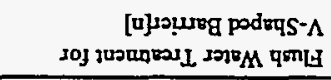 \\
\hline$\$ 10^{\circ} 0$ & S6I & $\$ I t$ & SI & $\angle 2$ & I & $L$ & $9 t$ & t & $\tau$ & 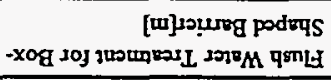 \\
\hline \multirow[t]{4}{*}{$\varepsilon 00^{\circ} 0$} & $\measuredangle \varepsilon$ & $z z$ & $\varepsilon$ & $s$ & I0 & I & 8 & 8 & 2 & 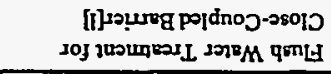 \\
\hline & $9 L 2$ & $\$ 8 \mathrm{I}$ & $\Delta z$ & SI & 0 & II & 86 & 26 & 9 & 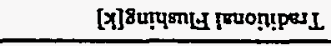 \\
\hline & $95 \varepsilon$ & $\triangleright \varepsilon 己$ & 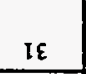 & $\angle I$ & 0 & SI & $98 \mathrm{I}$ & LOI & or & 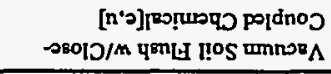 \\
\hline & $66 \varepsilon$ & 592 & $S \varepsilon$ & 61 & 0 & 91 & +91 & $92 \mathrm{I}$ & oI & 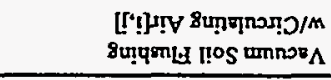 \\
\hline \multicolumn{11}{|r|}{ DNIHSRTX TIOS } \\
\hline & $\varepsilon L \tau$ & ILI & $\varepsilon 己$ & 91 & 0 & $2 !$ & $9 L$ & $\mathrm{I} L$ & 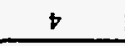 & כ!] \\
\hline & $\angle 25$ & $69 \varepsilon$ & 87 & $\iota \tau$ & 0 & 61 & $0 z z$ & 802 & $z \mathrm{I}$ & [4] \\
\hline & $\varepsilon Z$ & $S L \varepsilon$ & $6 b$ & 0 & 0 & 9 & 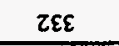 & $\varepsilon I \varepsilon$ & EI & 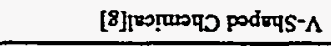 \\
\hline & $2 I \varepsilon$ & $\tau \iota \tau$ & $9 \varepsilon$ & 0 & 0 & 5 & Z£Z & 812 & $\varepsilon I$ & 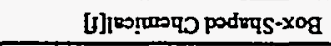 \\
\hline & $52 z$ & $26 \mathrm{I}$ & $\Omega$ & 0 & 0 & $s$ & $\forall S I$ & StI & $\varepsilon \mathbf{I}$ & 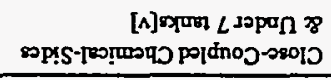 \\
\hline & $08 \mathfrak{I}$ & $6 t r$ & $0 z$ & 0 & 0 & $t$ & o\&I & III & $L$ & 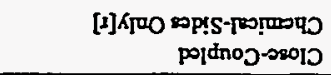 \\
\hline & $s 22$ & $26 \mathrm{I}$ & $\Omega$ & 0 & 0 & s & $p z z$ & $\mathrm{II \tau}$ & $\varepsilon \mathbf{I}$ & 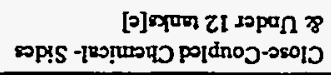 \\
\hline \multicolumn{11}{|r|}{ 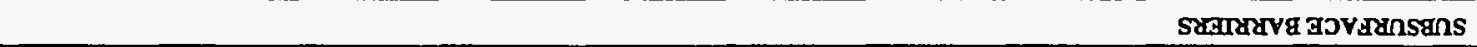 } \\
\hline$\left(0 \pm 0^{\circ} 0\right)$ & sts & $\angle P E$ & 90 & 80 & (z) & $\varepsilon \tau$ & $0 L I$ & $\forall S I$ & SI & 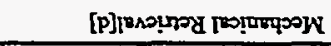 \\
\hline $600^{\circ} 0$ & $9+9$ & ort & $\forall s$ & 19 & $\$ 0$ & $s \tau$ & $20 z$ & $\varepsilon 8 \mathrm{I}$ & 81 & 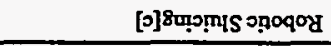 \\
\hline & ZEI & $\angle 6$ & EI & 6 & 0 & $b$ & 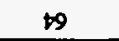 & $\varepsilon 9$ & $\tau$ & 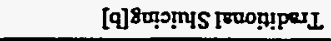 \\
\hline \multicolumn{11}{|r|}{ TV ATIDUF⿱ } \\
\hline 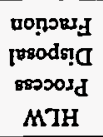 & $\underset{\text { STII }}{\text { SW }}$ & $\begin{array}{l}\text { SW } \\
\text { MdNL }\end{array}$ & $\begin{array}{l}I K / \text { SW } \\
\text { SYתI }\end{array}$ & $\begin{array}{l}\text { SW } \\
\text { aجם }\end{array}$ & $\begin{array}{l}\text { sK/SW } \\
\text { [rodma }\end{array}$ & $\begin{array}{l}1 K / \text { SW } \\
\text { WPO }\end{array}$ & $\begin{array}{c}\text { SW } \\
\text { YII+dx }\end{array}$ & $\underset{\text { [mițej }}{\text { Sw }}$ & 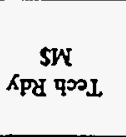 & NOLIdO \\
\hline
\end{tabular}

'[e] suoṇdo ure 


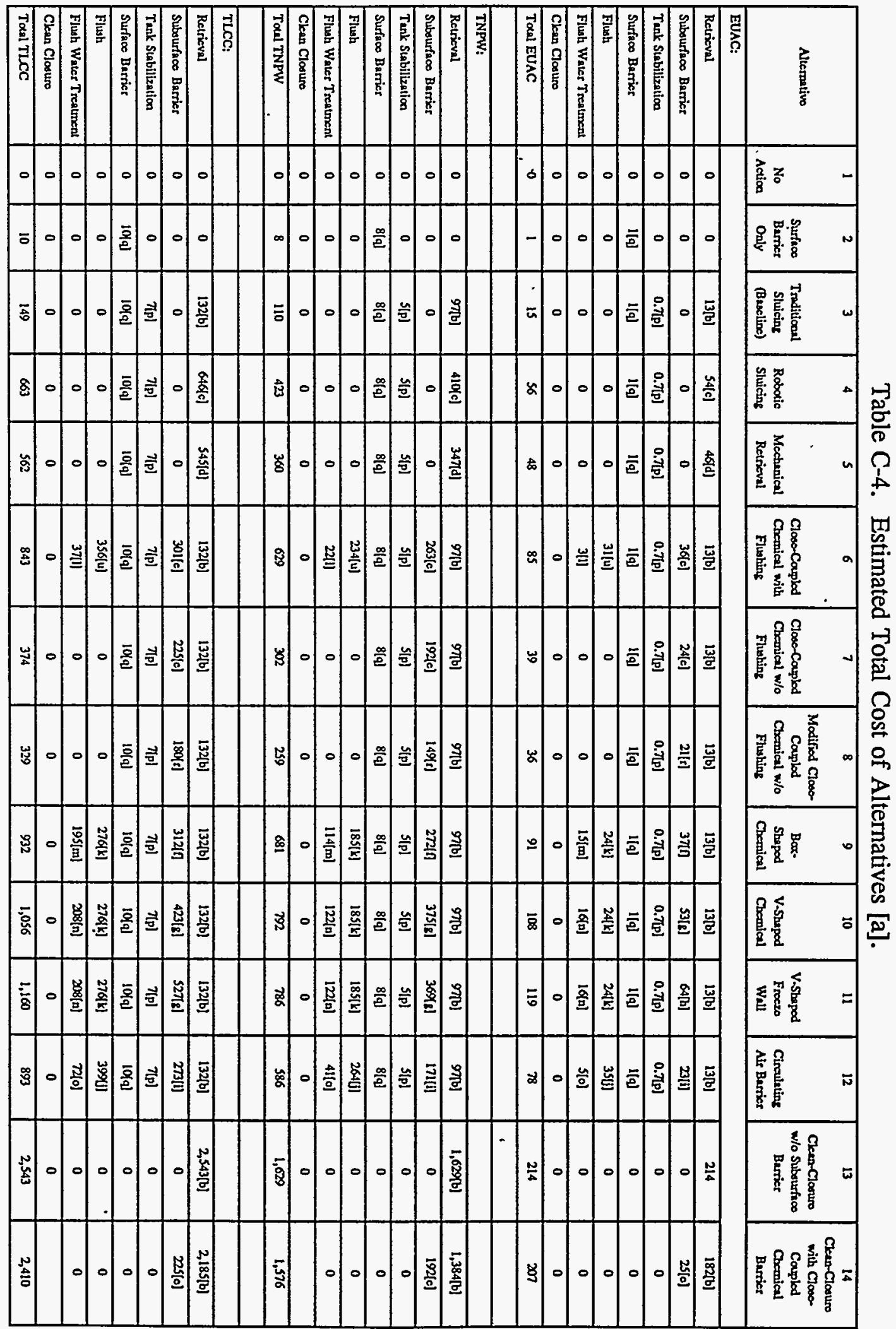


a10. TLCC $=$ total life cycle cost and is the sum of technology readiness plus capital plus 15 times (O\&M and disposal) plus D\&D per Ruegg (1987).

a11. Values were adjusted from Boomer et al. (1993, Appendixes F, J, K, M, and N) and from KEH (1993).

a12. Technology readiness includes safety analysis, permitting engineering studies, and testing and demonstration, for a range of 1 to $46 \%$ of capital.

[b] Traditional Sluicing. Assumptions used to develop cost estimates for traditional sluicing are based on information from Boomer et al. (1993, Appendix F). All costs are ratioed to 12 tanks from the total 149 SSTs and 12 sluicing systems as briefly described in Section 4.2.1 of this report. The processing adjacent to tank farms, pipeline transport, and central processing into storable waste forms of the slurried waste are excluded from these cost estimates since they are estimated to be the same for all retrieval systems.

b1. Capital costs of $\$ 740$ million for 149 SSTs from Boomer et al. (1993, pp. F4-99) were ratioed to 12 tanks. These costs include engineering, project management, equipment, and support facilities. A 50\% contingency is included in the capital costs. No confinement facilities are required outside the tank.

b2. O\&M annual cost is estimated at $6.3 \%$ of capital cost as adjusted from Boomer et al. (1993, pp. F4-19 and F4-99). O\&M is the sum of personnel, electricity, and CENRTC \& GPP costs. No steam or chemicals are planned for use. No disposal costs are included.

b3. O\&M Personnel annual cost is $3.8 \%$ of capital cost as adjusted from the basis of 305 total employees for a 149 SST tank farm, per Boomer et al. (1993, p. F499).

b4. Electricity annual cost is estimated at $\$ 0.023 / \mathrm{kWh}$ for $5,200,000 \mathrm{kWh} / \mathrm{yr}$ from Boomer et al. (1993, pp. N-84 and F4-99).

b5. CENRTC and GPP total annual cost is $2.25 \%$ of capital cost per Boomer et al. (1993, p. F4-99). The $2.25 \%$ factor is based on Hanford Site experience where equipment cost is typically $15 \%$ of total capital cost for chemical processes in canyon buildings and CENRTC \& GPP are annually $15 \%$ of equipment cost.

b6. D\&D cost is estimated at $10 \%$ of capital cost plus one year of personnel cost. This is less than the $30 \%$ of capital cost plus three years of personnel cost from Boomer et al. (1993, p. F4-99). For traditional sluicing there are no canyon buildings or other aboveground structures. The contaminated components could 
be left in the tanks where they would be covered by grout during tank stabilization and closure.

[c] Robotic Sluicing. Assumptions used to develop cost estimates for robotic sluicing are based on information from Boomer et al. (1993, Appendix F). All costs are ratioed to 12 tanks from the total 149 SSTs, 29 robotic systems, and 29 bridge confinements as described in Section 4.2.2 of this report. Robotic sluicing would use high pressure, low volume water to prepare the sludge for pneumatic conveying from the tank to a separation system. A bridge confinement would provide structural support for each robotic system. The processing adjacent to tank farms, transport, and central processing into storable waste forms of the slurried waste are excluded from these cost estimates since they are estimated to be the same for all retrieval systems.

c1. Capital cost for robotic sluicing is the sum of costs for in-tank robotic arms and end effectors plus the surface support structure and contamination confinement plus processing and disposal of a HLW increment. Capital costs for robotic arms and end effectors were adjusted from Boomer et al. (1993, p. F4-11) for 149 SSTs by multiplying the cost of $\$ 23.5$ million for one system from Boomer et al. (1993, p. F4-85) by 29. More systems are required than for traditional sluicing since the retrieval rate is slower. A total of 29 systems are tabulated in Boomer et al. (1993, pp. F4-73 to F4-78), although a total of 36 systems is indicated in Boomer et al. (1993, p. F4-78), and 43 systems are implied by the $\$ 1.01$ billion capital cost in Boomer et al. (1993, p. 4-86). Capital costs for bridge confinement were adjusted from Boomer et al. (1993, p. F7-14) by adding the $\$ 74.2$ million cost of one system including nonrecurring Title I and II and project management costs to $28^{\circ}$ times the $\$ 49$ million system cost without project management. Also included in capital cost is the incremental factor (from Table C-3) times the baseline capital cost $\$ 4,654$ million for 149 tanks, adjusted to 12 tanks. Total capital cost includes engineering, project management, equipment, structural single tank bridge confinement, and support facilities. A $50 \%$ contingency is included in the capital costs.

c2. O\&M annual cost, as for traditional sluicing, is estimated at $13.7 \%$ of capital cost as adjusted from Boomer et al. (1993, pp. F4-11, F4-84, F4-86, F7-14, and F7-44) for 149 SSTs. O\&M is the sum of personnel, electricity, and CENRTC \& GPP costs. No steam or chemicals are planned for use. No disposal costs are included.

c3. O\&M Personnel annual cost, as for traditional sluicing, is estimated at $11.1 \%$ of capital cost as adjusted from the basis 1,452 employees listed in Boomer et al. (1993, p. F4-86) plus 1,124 employees listed in Boomer et al. (1993, p. F7-44).

c4. Electricity annual cost is estimated at $\$ 0.023 / \mathrm{kWh}$ from Boomer et al. (1993, p. N-84) for 4,700,000 kWh/yr from Boomer et al. (1993, p. F7-44) plus $22,000,000 \mathrm{kWh} / \mathrm{yr}$ adjusted from Boomer et al. (1993, p. F4-84). The 
adjustment was made by assuming 182 operating years per Boomer et al. (1993, p. F4-78) divided among 29 systems for an average 6.3 systems operating at any time for $8,760 \mathrm{~h} / \mathrm{yr}$ at a $400 \mathrm{~kW}$ power level. The power to drive a $20,000 \mathrm{lb} / \mathrm{in}^{2}, 8 \mathrm{gal} / \mathrm{min}$ pump is estimated to be $99 \mathrm{~kW}$ and was added to the power for the vacuum pump, air heater, and other equipment in the pneumatic system estimated at $301 \mathrm{~kW}$ as adjusted from Boomer et al. (1993, p. F4-84).

c5. CENRTC and GPP total annual cost is estimated at $2.25 \%$ of capital cost per Boomer et al. (1993, p. F4-86). The 2.25\% factor is based on Hanford Site experience as in note $[\mathrm{b} 5]$.

c6. D\&D cost is estimated at $10 \%$ of capital cost plus two years of personnel cost, plus the incremental fraction shown in Table C-3) of HLW processing and disposal, times the waste processing baseline cost of $\$ 193$ million. This is less than the $30 \%$ of capital cost plus three years of personnel cost from Boomer et al. (1993, pp. F4-86 and F7-44). For robotic sluicing there are no canyon buildings or other aboveground structures. The contaminated components could be left in the tanks where they would be covered by grout during tank stabilization and closure.

[d] Mechanical Retrieval. Assumptions used to develop cost estimates for mechanical retrieval are based on information from Boomer et al. (1993, Appendix F). All costs are ratioed to 12 tanks from the total 149 SSTs, 29 robotic systems, and 29 bridge confinements as briefly described in Section 4.2.3 of this report. Mechanical retrieval would use digging devices on a robotic arm to prepare the sludge for pneumatic conveying from the tank to a separation system. The processing adjacent to tank . farms, transport, and central processing into storable waste forms of the slurried waste are excluded from these cost estimates since they are estimated to be the same for all retrieval systems.

Capital cost for mechanical retrieval is the sum of costs for in-tank robotic arms and end effectors plus the surface support structure and contamination confinement minus processing and disposal of a HLW increment.

d1. Capital costs for robotic equipment were adjusted from Boomer et al. (1993, p. F4-4) by multiplying the $\$ 19,500,000$ cost for one system from Boomer et al. (1993, p. F4-80) by 29 as in note [c1]. Capital costs for bridge confinement were adjusted from Boomer et al. (1993, p. F7-14) by adding the $\$ 74.2$ million cost of one system including nonrecurring Title I and II and project management costs to 28 times the $\$ 49$ million system cost without project management. Also included in capital cost is the incremental factor (from Table C-3) times the capital cost baseline of $\$ 4,654$ million for 149 tanks, adjusted to 12 tanks. Total capital cost includes engineering, project management, equipment, structural single tank bridge confinement, and support facilities. A $50 \%$ contingency is included in the capital costs escalated to January 1993 dollars. 
d2. O\&M annual cost, as for traditional sluicing, is estimated at $15.2 \%$ of capital cost as adjusted from Boomer et al. (1993, pp. F4-11, F4-84, F4-86, F7-14, and F7-44). O\&M is the sum of personnel, electricity, and CENRTC \& GPP costs. No steam or chemicals are planned for use. No sampling analysis or disposal costs are included.

d3. O\&M personnel annual cost is $13.2 \%$ of capital cost as adjusted from the basis 1,452 total employees listed in Boomer et al. (1993, p. F4-81) plus 1,124 employees listed in Boomer et al. (1993, p. F7-44).

d4. Electricity annual cost is estimated at $\$ 0.023 / \mathrm{kWh}$ from Boomer et al. (1993, p. $\mathrm{N}-84$ ) for $4,700,000 \mathrm{kWh} / \mathrm{yr}$ from Boomer et al. (1993, p. F7-44) plus $10,600,000 \mathrm{kWh} / \mathrm{yr}$ adjusted from Boomer et al. (1993, p. F4-81).

d5. CENRTC and GPP total annual cost is $2.25 \%$ of capital cost per Boomer et al. (1993, p. F4-86). The $2.25 \%$ factor is based on Hanford Site experience as in note $[\mathrm{b} 5]$.

d6. D\&D cost is estimated at $10 \%$ of capital cost plus two years of personnel cost, plus the incremental fraction (shown in Table C-3) of HLW processing and disposal, times the waste processing baseline cost of $\$ 193$ million. This is less than the $30 \%$ of capital cost plus three years of personnel cost from Boomer et al. (1993, pp. F4-86 and F7-44). For robotic sluicing there are no canyon buildings or other aboveground structures. The contaminated components could be left in the tanks where they would be covered by grout during tank stabilization and closure.

[e] Close-Coupled Chemical Sides and Under 12 Tanks. Assumptions used to develop cost estimates for close-coupled chemical are based on information from KEH (1993b). All costs are ratioed to 12 tanks as in note [a1] and as briefly described in Section 4.3 .1 of this report. On each tank there would be a ring of vertical pipes at $80 \mathrm{ft}$ diameter to a depth of $46 \mathrm{ft}$ and at $90 \mathrm{ft}$ diameter to a depth of $50 \mathrm{ft}$. Two horizontal crossed layers of pipes under each tank at $55 \mathrm{ft}$ and $63 \mathrm{ft}$ belowgrade would radiate from 15 coffercells of $15 \mathrm{ft}$ diameter and $100 \mathrm{ft}$ depth. Three coffercells would be located within the 12 tank array and 12 would be located at the perimeter of the array.

e1. Capital costs based on KEH (1993b, p. 20) include those for engineering, project management, equipment, and support facilities. A $40 \%$ contingency is included in the capital costs. No confinement facilities are required outside the tanks. The assumed installed grout cost of $\$ 30 / \mathrm{ft}^{3}$ for $15 \mathrm{ft}^{3} /$ lineal $\mathrm{ft}$ of pipe was applied to $81,768 \mathrm{ft}$ of pipe. A maximum pipe spacing of $7 \mathrm{ft}$ resulted in minimum overall cost for a pipe drilling and jacking cost of $\$ 500 / \mathrm{ft}$. A coffercell cost of $\$ 5,000 / \mathrm{ft}$ was applied to a $1,200 \mathrm{ft}$ length. 
e2. O\&M annual cost is estimated at $2.4 \%$ of capital cost as adjusted from $\mathrm{KEH}$ (1993b, p. A-4-2) for a static underground barrier. O\&M is the sum of personnel including sampling and analysis, electricity, and CENRTC \& GPP costs. No steam or chemicals are planned for use. No disposal costs are included as the chemical grout is planned to stay permanently underground.

e3. O\&M personnel annual cost, primarily for sampling and analysis, is assumed at $1.4 \%$ of capital cost at an average annual cost of $\$ 98,000$ for each employee.

e4. Electricity annual cost was included in the O\&M cost in note [e2].

e5. CENRTC and GPP annual cost was included in the O\&M cost of note [e2].

e6. No $D \& D$ cost is estimated for this subsurface barrier, which will be abandoned in place.

[f] Box-Shaped Chemical. Assumptions used to develop cost estimates for box-shaped chemical are based on information from KEH (1993b). All costs are ratioed to 12 tanks as in note [a1] and as briefly described in Section 4.3 .2 of this report. There would be a series of pipes at a 25 degree angle to grade and transitioning to horizontal at $130 \mathrm{ft}$ belowgrade. The box would enclose 430 by $490 \mathrm{ft}$ at the surface. It would have two vertical walls of $460 \mathrm{ft}$ and one vertical wall of $430 \mathrm{ft}$. Pipes would be at a maximum spacing of $7 \mathrm{ft}$.

f1. Capital costs based on KEH (1993b, p. 20) include those for engineering, project management, equipment, and support facilities. A $40 \%$ contingency is included in the capital costs. No confinement facilities are required outside the tanks. The assumed installed grout cost of $\$ 30 / \mathrm{ft}^{3}$ for $15 \mathrm{ft}^{3} /$ lineal $\mathrm{ft}$ of pipe was applied to $103,200 \mathrm{ft}$ of pipe. A maximum pipe spacing of $7 \mathrm{ft}$ resulted in minimum overall cost for a pipe drilling and jacking cost of $\$ 500 / \mathrm{ft}$.

f2. O\&M annual cost is estimated at $2.4 \%$ of capital cost as adjusted from KEH (1993b, p. A-4-2) for a static underground barrier. O\&M is the sum of personnel including sampling and analysis, electricity, and CENRTC \& GPP costs. No steam or chemicals are planned for use. No disposal costs are included as the chemical grout is planned to stay permanently underground.

f3. O\&M Personnel annual cost, primarily for sampling and analysis, is assumed at $1.4 \%$ of capital cost at an average annual cost of $\$ 98,000$ for each employee.

f4. Electricity annual cost was included in the O\&M cost in note [f2].

f5. CENRTC and GPP annual cost was included in the O\&M cost of note [f2]. 
f6. No D\&D cost is estimated for this subsurface barrier, which will be abandoned in place.

[g] V-Shaped Chemical. Assumptions used to develop cost estimates for V-shaped chemical are based on information from KEH (1993b). Specific adjustments to the values from KEH are listed below. All costs are ratioed to 12 tanks as in note [a1] and as briefly described in Section 4.3 .3 of this report. Two staggered layers of pipes would be angled at 37 degrees to grade to a depth of $250 \mathrm{ft}$ for a $96 \mathrm{ft}$ minimum clearance below the tanks and from a surface width of $660 \mathrm{ft}$. The vertical end walls would have a length of $540 \mathrm{ft}$.

g1. Capital costs based on KEH (1993b, p. 20) include those for engineering, project management, equipment, and support facilities. A $40 \%$ contingency is included in the capital costs. No confinement facilities are required outside the tanks. The assumed installed grout cost of $\$ 30 / \mathrm{ft}^{3}$ for $15 \mathrm{ft}^{3} /$ lineal $\mathrm{ft}$ of pipe was applied to $148,327 \mathrm{ft}$ of pipe. A maximum pipe spacing of $7 \mathrm{ft}$ resulted in minimum overall cost for a pipe drilling and jacking cost of $\$ 500 / \mathrm{ft}$.

g2. O\&M annual cost is estimated at $2.0 \%$ of capital cost as adjusted from $\mathrm{KEH}$ (1993b, p. A-4-2) for a static underground barrier. O\&M is the sum of personnel including sampling and analysis, electricity, and CENRTC \& GPP costs. No steam or chemicals are planned for use. No disposal costs are included as the chemical grout is planned to stay permanently underground.

g3. O\&M personnel annual cost, primarily for sampling and analysis, is assumed at $1.0 \%$ of capital cost at an average annual cost of $\$ 98,000$ for each employee.

g4. Electricity annual cost was included in the O\&M cost in note [g2].

g5. CENRTC and GPP annual cost was included in the O\&M cost of note [g2].

g6. No D\&D cost is estimated for this subsurface barrier, which will be abandoned in place.

[h] V-Shaped Freeze Wall. Assumptions used to develop cost estimates for V-shaped freeze wall are based on information from $\mathrm{KEH}$ (1993b). All costs are ratioed to 12 tanks as in note [a1] and as briefly described in Section 4.3.4 of this report. Three staggered layers of pipes at a $10 \mathrm{ft}$ spacing will allow two layers for ice and one layer for water supply, heating, and monitoring. Pipes would be angled at 37 degrees to grade to a depth of $250 \mathrm{ft}$ for a $96 \mathrm{ft}$ minimum clearance below the tanks and from a surface width of $660 \mathrm{ft}$. The vertical end walls would have a length of $540 \mathrm{ft}$.

h1. Capital costs based on $\mathrm{KEH}$ (1993b, p. 20) include those for engineering, project management, equipment, and support facilities. A $40 \%$ contingency is included in the capital costs. No confinement facilities are required outside the tanks. 
The assumed installed double wall pipe cost of $\$ 500 / \mathrm{ft}$ was applied to $155,743 \mathrm{ft}$ of pipe.

h2. O\&M annual cost is estimated at $9.0 \%$ of capital cost as adjusted from $\mathrm{KEH}$ (1993b, p. A-4-2) for an active underground barrier. O\&M is the sum of personnel including sampling and analysis, electricity, and CENRTC \& GPP costs. No steam or chemicals are planned for use. No disposal costs are included as the ice is planned to stay permanently underground.

h3. O\&M personnel annual cost, primarily for sampling and analysis, is assumed at $3.0 \%$ of capital cost at an average annual cost of $\$ 98,000$ for each employee.

h4. Electricity for refrigeration compressors totaling $2,700 \mathrm{hp}$ was included in the O\&M cost.

h5. CENRTC and GPP annual cost of $2.25 \%$ of capital cost was included in the O\&M cost of note [h2].

h6. D\&D cost is estimated at $10 \%$ of capital cost plus one year of personnel cost. This is less than the $30 \%$ of capital cost plus three years of personnel cost used in Boomer et al. (1993) for canyon buildings or other major aboveground structures.

[i] Circulating Air Barrier. Assumptions used to develop cost estimates for circulating air are based on information from KEH (1993b). All costs are ratioed to 12 tanks as in note [a1] and as briefly described in Section 4.3 .5 of this report. Ten supply and 10 vacuum pipes will be placed vertically to a depth of $150 \mathrm{ft}$.

i1. Capital costs based on KEH (1993b, p. 20) include those for engineering, project management, equipment, and support facilities. A $40 \%$ contingency is included in the capital costs. No confinement facilities are required outside the tanks. The assumed installed cost of $\$ 500 / \mathrm{ft}$ was applied to $3,000 \mathrm{ft}$ of pipe.

i2. O\&M annual cost is estimated at $16.6 \%$ of capital cost as adjusted from $\mathrm{KEH}$ (1993b, p. A-4-2) for an active underground barrier. O\&M is the sum of personnel including sampling and analysis, electricity, and CENRTC \& GPP costs. No steam or chemicals are planned for use. No disposal costs are expected.

i3. O\&M personnel annual cost, primarily for compressor and system operation plus sampling and analysis, is assumed at $8.6 \%$ of capital cost at an average annual cost of $\$ 98,000$ for each employee.

i4. Electricity for air compressors totaling $12,000 \mathrm{hp}$ was included in the O\&M cost. 
i5. CENRTC and GPP annual cost of $2.25 \%$ of capital cost was included in the O\&M cost of note [i2].

i6. D\&D cost is estimated at $10 \%$ of capital cost plus one year of personnel cost. This is less than the $30 \%$ of capital cost plus three years of personnel cost used in Boomer et al. (1993) for canyon buildings or other major aboveground structures.

[j] Vacuum Soil Flushing with Circulating Air. Assumptions used to develop cost estimates for vacuum soil flushing are based on information from KEH (1993b). All costs are ratioed to 12 tanks as in note [a1] and as briefly described in Section 4.4 .2 of this report. Around each tank there would be a ring of vertical pipes at $80 \mathrm{ft}$ diameter to a depth of $46 \mathrm{ft}$. Three horizontal crossed layers of pipes under each tank at $70 \mathrm{ft}$ and $75 \mathrm{ft}$ belowgrade would radiate from 15 coffercells of $15 \mathrm{ft}$ diameter and $100 \mathrm{ft}$ depth. Three coffercells would be located within the 12 tank array and 12 would be located at the perimeter of the array.

j1. Capital costs based on $\mathrm{KEH}$ (1993b, p. 20) include those for engineering, project management, equipment, and support facilities. A $40 \%$ contingency is included in the capital costs. No confinement facilities are required outside the tanks. The assumed installed cost of $\$ 500 / \mathrm{ft}$ was applied to $31,193 \mathrm{ft}$ of pipe. A coffercell cost of $\$ 5,000 / \mathrm{ft}$ was applied to a $1,120 \mathrm{ft}$ length.

j2. O\&M annual cost is estimated at $12.9 \%$ of capital cost as adjusted from KEH (1993b, p. A-4-2) for an active underground barrier. O\&M is the sum of personnel including sampling and analysis, electricity, and CENRTC \& GPP costs. No steam or chemicals are planned for use. No disposal costs are expected.

j3. O\&M personnel annual cost, primarily for air compressor and system operation plus sampling and analysis, is assumed at $4.9 \%$ of capital cost at an average annual cost of $\$ 98,000$ for each employee.

j4. Electricity for air compressors totaling $12,000 \mathrm{hp}$ was included in the O\&M cost.

j5. CENRTC and GPP annual cost of $2.25 \%$ of capital cost was included in the O\&M cost of note [j2].

j6. D\&D cost is estimated at $10 \%$ of capital cost plus one year of personnel cost. This is less than the $30 \%$ of capital cost plus three years of personnel cost used in Boomer et al. (1993) for canyon buildings or other major aboveground structures.

[k] Traditional Flushing. Assumptions used to develop cost estimates for traditional flushing are based on information from $\mathrm{KEH}$ (1993b). All costs are ratioed to 12 tanks 
as in note [a1] and as briefly described in Section 4.4.1 of this report. Around each tank there would be a ring of vertical pipes at $80 \mathrm{ft}$ diameter to a depth of $46 \mathrm{ft}$. An array of vertical pipes on $20 \mathrm{ft}$ centers would be installed between tanks to the barrier below.

k1. Capital costs based on KEH (1993b, p. 20) include those for engineering, project management, equipment, and support facilities. A $40 \%$ contingency is included in the capital costs. No confinement facilities are required outside the tanks. The assumed installed cost of $\$ 500 / \mathrm{ft}$ was applied to $43,393 \mathrm{ft}$ of pipe.

k2. O\&M annual cost is estimated at $11.8 \%$ of capital cost as adjusted from $\mathrm{KEH}$ (1993b, p. A-4-2) for an active system of pumps. O\&M is the sum of personnel including sampling and analysis, electricity, and CENRTC \& GPP costs. No steam or chemicals are planned for use. No disposal costs are expected.

k3. O\&M personnel annual cost, primarily for pump and flush system operation plus sampling and analysis, is assumed at $5.8 \%$ of capital cost at an average annual cost of $\$ 98,000$ for each of the 678 employees for 149 tanks, Boomer et al (1993).

k4. Electricity annual cost was included in the O\&M cost in note [k2].

k5. CENRTC and GPP annual cost of $2.25 \%$ of capital cost was included in the O\&M cost of note $[\mathrm{k} 2]$.

k6. D\&D cost is estimated at $10 \%$ of capital cost plus one year of personnel cost. This is less than the $30 \%$ of capital cost plus three years of personnel cost used in Boomer et al. (1993) for canyon buildings or other major aboveground structures.

[1] Flush Water Treatment for Close-Coupled Chemical Barrier. Assumptions used to develop cost estimates for flush water treatment for close-coupled chemical are based on information from Boomer et al. (1993, Appendixes K, N, and R). All costs for 12 tanks as described in Section 4.4.3 of this report were ratioed from the total 149 SSTs and include facilities for flush water treatment as well as disposal of resulting radioactive mixed waste (MW) and HLW at the Hanford site. The cost of wastewater pipeline transport from the tank farms to the treatment facility is assumed to be in the retrieval system pipeline transport cost. The cost of a State Approved Land Disposal System (SALDS) is not included.

11. Capital cost for flush water treatment is estimated as the sum of costs for water treatment and disposal of MW and HLW. Capital cost is based on a flow rate of $3 \mathrm{gal} / \mathrm{min}$ as calculated from $14 \mathrm{Mgal}$ of wastewater treated during 15 years and 365 days/yr with a total operating efficiency of 0.6 . The equivalent flow rate for 149 tanks would be $36.7 \mathrm{gal} / \mathrm{min}$ compared to the total design flow to the 
LEPRD of $316 \mathrm{gal} / \mathrm{min}$ as stated in Boomer et al. (1993, p. N-44). Cost for 149 tanks is based on the ratio of these flow rates to the 0.6 power multiplied by the sum of the $\$ 297$ million cost for LEPRD from Boomer et al. (1993, pp. N-55 and R-397) plus the $\$ 110$ million cost for $\mathrm{MW}$ transport and disposal from Boomer et al. (1993, p. H-178) multiplied by the 0.6 power of the mixed waste flow ratio, minus 1, plus the incremental cost factor (from Table C-3) times the baseline capital cost of $\$ 4,654$ million for 149 tanks, adjusted to 12 tanks. Total mixed waste flow is the sum of 2,860 lb/day from Boomer et al. (1993, p. N-46) and the baseline flow of 511,000 lb/day from Boomer et al. (1993, p. K-8). The MW solids disposal cost for 149 tanks includes trucks, 50 $\mathrm{yd}^{3}$ containers, and disposal trenches with surface barrier. Total capital cost includes engineering, project management, equipment, and support facilities. A $50 \%$ contingency is included in the capital costs.

12. O\&M annual cost is estimated at $15.9 \%$ of capital cost as adjusted from (1993, p. $\mathrm{N}-55$ ) for an active and complex flush water treatment system. O\&M is the sum of personnel including sampling and analysis, electricity, and CENRTC \& GPP costs. No steam or chemicals are planned for use. Disposal costs are included.

13. O\&M personnel annual cost, primarily for system operation plus sampling and analysis, is assumed at $12.3 \%$ of capital cost at an average annual cost of $\$ 98,000$ for each of the 373 employees for 149 tanks, per Boomer et al (1993).

14. Electricity annual cost was included in the O\&M cost in note [12].

15. CENRTC and GPP annual cost of $2.25 \%$ of capital cost was included in the O\&M cost of note [12].

16. D\&D cost is estimated at $30 \%$ of capital cost plus two years of personnel cost where three years was used in Boomer et al. (1993) for canyon buildings or other major aboveground structures, plus the incremental factor (shown in Table C-3) of HLW processing and disposal, times the waste processing baseline cost of $\$ 193$ million.

[m] Flush Water Treatment for Box-Shaped Barrier. Assumptions usèd to develop cost estimates for flush water treatment for the box-shaped barrier are based on information from Boomer et al. (1993, Appendixes $\mathrm{K}, \mathrm{N}$, and R). All costs for 12 tanks as described in Section 4.4 .3 of this report were ratioed from the total 149 SSTs and include facilities for flush water treatment as well as disposal of resulting $\mathrm{MW}$ and HLW at the Hanford Site. The cost of wastewater pipeline transport from the tank farms to the treatment facility is assumed to be in the retrieval system pipeline transport cost. The cost of a SALDS is not included. 
m1. Capital cost for flush water treatment is estimated as the sum of costs for water treatment and disposal of MW and HLW. Capital cost is based on a flow rate of $51.8 \mathrm{gal} / \mathrm{min}$ as calculated from $245 \mathrm{Mgal}$ of wastewater treated during 15 years and 365 days/yr with a total operating efficiency of 0.6 . The equivalent flow rate for 149 tanks would be $643 \mathrm{gal} / \mathrm{min}$ compared to the total design flow to the LEPRD of $316 \mathrm{gal} / \mathrm{min}$ as stated in Boomer et al. (1993, p. N-44). Cost for 149 tanks is based on the ratio of these flow rates to the 0.6 power multiplied by the sum of the $\$ 297$ million cost for LEPRD from Boomer et al. (1993, pp. N-55 and R-397) plus the $\$ 110$ million cost for MW transport and disposal from Boomer et al. (1993, p. K-178) multiplied by the 0.6 power of the mixed waste flow ratio minus 1 , plus the incremental cost factor (from Table C-3) times the baseline capital cost of $\$ 4,654$ million for 149 tanks, adjusted for 12 tanks. Total mixed waste flow is the sum of $2,860 \mathrm{lb} /$ day from Boomer et al. (1993, p. $\mathrm{N}-46$ ) and the baseline flow of $511,000 \mathrm{lb} /$ day from Boomer et al. (1993, p. K-8). The MW solids disposal cost for 149 tanks includes trucks, $50 \mathrm{yd}^{3}$ containers, and disposal trenches with surface barrier. Total capital cost includes engineering, project management, equipment, and support facilities. A 50\% contingency is included in the capital costs.

m2. O\&M annual cost is estimated at $15.9 \%$ of capital cost as adjusted from $\mathrm{KEH}$ (1993, p. A-4-2) for an active and complex flush water treatment system. O\&M is the sum of personnel including sampling and analysis, electricity, and CENRTC \& GPP costs. No steam or chemicals are planned for use. Disposal costs are included.

m3. O\&M personnel annual cost, primarily for system operation plus sampling and analysis, is assumed at $12.3 \%$ of capital cost at an average annual cost of $\$ 98,000$ for each of the 373 employees for 149 tanks per Boomer et al (1993).

m4. Electricity annual cost was included in the O\&M cost in note [m2].

m5. CENRTC and GPP annual cost of $2.25 \%$ of capital cost was included in the O\&M cost of note [m2].

m6. D\&D cost is estimated at $30 \%$ of capital cost plus two years of personnel cost as used in Boomer et al. (1993) for canyon buildings or other major aboveground structures, plus the incremental factor (shown in Table C-3) of HLW processing and disposal, times the waste processing baseline cost of $\$ 193$ million.

[n] Flush Water Treatment for V-Shaped Barrier. Assumptions used to develop cost estimates for flush water treatment for $\mathrm{V}$-shaped barriers are based on information from Boomer et al. (1993, Appendixes K, N, and R). All costs for 12 tanks as described in Section 4.4.3 of this report were ratioed from the total 149 SSTs and include facilities for flush water treatment as well as disposal of resulting MW and HLW at the Hanford Site. The cost of wastewater pipeline transport from the tank 
farms to the treatment facility is assumed to be in the retrieval system pipeline transport cost. The cost of a SALDS is not included.

n1. Capital cost for flush water treatment is estimated as the sum of costs for water treatment and disposal of MW and HLW. Capital cost is based on a flow rate of $58.8 \mathrm{gal} / \mathrm{min}$ as calculated from $278 \mathrm{Mgal}$ of wastewater treated during 15 years and 365 days/yr with a total operating efficiency of 0.6 . The equivalent flow rate for 149 tanks would be $730 \mathrm{gal} / \mathrm{min}$ compared to the total design flow to the LEPRD of $316 \mathrm{gal} / \mathrm{min}$ as stated in Boomer et al. (1993, p. N-44). Cost for 149 tanks is based on the ratio of these flow rates to the 0.6 power multiplied by the sum of the $\$ 297$ million cost for LEPRD from Boomer et al. (1993, p. N-55 and $\mathrm{R}-397)$ plus the $\$ 110$ million cost for $\mathrm{MW}$ transport and disposal from Boomer et al. (1993, p. K-178) multiplied by the 0.6 power of the mixed waste flow ratio minus 1 , plus the incremental factor (from Table C-3) times the baseline capital cost of $\$ 4,654$ million for 149 tanks, adjusted to 12 tanks. Total mixed waste flow is the sum of $2,860 \mathrm{lb} /$ day from Boomer et al. (1993, p. N-46) and the baseline flow of $511,000 \mathrm{lb}$ /day from Boomer et al. (1993, p. K-8). The MW solids disposal cost for 149 tanks includes trucks, $50 \mathrm{yd}^{3}$ containers, and disposal trenches with surface barrier. Total capital cost includes engineering, project management, equipment, and support facilities. A $50 \%$ contingency is included in the capital costs.

n2. O\&M annual cost is estimated at $15.9 \%$ of capital cost as adjusted from KEH (1993, p. A-4-2) for an active and complex flush water treatment system. O\&M is the sum of personnel including sampling and analysis, electricity, and CENRTC \& GPP costs. No steam or chemicals are planned for use. Disposal costs are included.

n3. O\&M personnel annual cost, primarily for system operation plus sampling and analysis, is assumed at $12.3 \%$ of capital cost at an average annual cost of $\$ 98,000$ for each of the 373 employees for 149 tanks, per Boomer et al (1993).

n4. Electricity annual cost was included in the O\&M cost in note [ $\mathrm{n} 2]$.

n5. CENRTC and GPP annual cost of $2.25 \%$ of capital cost was included in the O\&M cost of note [n2].

n6. D\&D cost is estimated at $30 \%$ of capital cost plus two years of personnel cost where three years was used in Boomer et al. (1993) for canyon buildings or other major aboveground structures, plus the incremental factor (shown in Table C-3) of HLW processing and disposal, times the waste processing baseline cost of $\$ 193$ million.

[o] Flush Water Treatment for Circulating Air Barrier. Assumptions used to develop cost estimates for flush water treatment for a circulating air barrier are based on 
information from Boomer et al. (1993, Appendixes K, N, and R). All costs for 12 tanks as described in Section 4.4 .3 of this report were ratioed from the total 149 SSTs and include facilities for flush water treatment as well as disposal of resulting MW and HLW at the Hanford Site. The cost of wastewater pipeline transport from the tank farms to the treatment facility is assumed to be in the retrieval system pipeline transport cost. The cost of a SALDS is not included.

o1. Capital costs for flush water treatment are the sum of costs for water treatment and disposal of MW and HLW. Capital cost is based on a flow rate of $4.2 \mathrm{gal} / \mathrm{min}$ as calculated from $20 \mathrm{Mgal}$ of wastewater treated during 15 years and 365 days/yr with a total operating efficiency of 0.6 . The equivalent flow rate for 149 tanks would be $52.5 \mathrm{gal} / \mathrm{min}$ compared to the total design flow to the LEPRD of $316 \mathrm{gal} / \mathrm{min}$ as stated in Boomer et al. (1993, p. N-44). Cost for 149 tanks is based on the ratio of these flow rates to the 0.6 power multiplied by the sum of the $\$ 297$ million cost for LEPRD from Boomer et al. (1993, pp. $\mathrm{N}-55$ and $\mathrm{R}-397$ ) plus the $\$ 110$ million cost for $\mathrm{MW}$ transport and disposal from Boomer et al. (1993, p. K-178) multiplied by the 0.6 power of the mixed waste flow ratio minus 1 , plus the incremental factor (from Table C-3) times the baseline capital cost of $\$ 4,654$ million for 149 tanks, adjusted for 12 tanks. Total mixed waste flow is the sum of $2,860 \mathrm{lb} /$ day from Boomer et al. (1993, p. N-46) and the baseline flow of $511,000 \mathrm{lb} /$ day from Boomer et al. (1993, p. K-8). The MW solids disposal cost for 149 tanks includes trucks, $50 \mathrm{yd}^{3}$ containers, and disposal trenches with surface barrier. Total capital cost includes engineering, project management, equipment, and support facilities. A 50\% contingency is included in the capital costs.

02. O\&M annual cost is estimated at $15.9 \%$ of capital cost as adjusted from $\mathrm{KEH}$ (1993, p. A-4-2) for an active and complex flush water treatment system. O\&M is the sum of personnel including sampling and analysis, electricity, and CENRTC \& GPP costs. No steam or chemicals are planned for use. Disposal costs are included.

o3. Personnel annual cost, primarily for system operation plus sampling and analysis, is assumed at $12.4 \%$ of capital cost at an average annual cost of $\$ 98,000$ for each of the 373 employees for 149 tanks per Boomer et al (1993).

04. Electricity annual cost was included in the O\&M cost in note [02].

05. CENRTC and GPP annual cost of $2.25 \%$ of capital cost was included in the O\&M cost of note [02].

o6. D\&D cost is estimated at $30 \%$ of capital cost plus two years of personnel cost where three years was used in Boomer et al. (1993) for canyon buildings or other major aboveground structures, plus the incremental factor (shown in Table C-3) 
of HLW processing and disposal, times the waste processing baseline cost of $\$ 193$ million.

[p] Tank Stabilization. Assumptions used to develop cost estimates for tank stabilization are based on information from Boomer et al. (1993, Appendix M). All costs are ratioed to 12 tanks from the total 149 SSTs. The process is briefly described in Section 4.5 .1 of this report.

p1. Capital cost for stabilization by grout of 149 SSTs is estimated from the $\$ 28.6$ million basis from Boomer et al. (1993, p. M135) and includes costs for engineering, project management, equipment, and support facilities. A 50\% contingency is included in the capital costs. No confinement facilities are required outside the tanks.

p2. O\&M annual cost is estimated at $9.1 \%$ of capital cost as adjusted from Boomer et al. (1993, p. M135) for a static underground barrier. O\&M is the sum of personnel including sampling and analysis, electricity, and CENRTC \& GPP costs. No steam or chemicals are planned for maintenance use. No disposal costs are included as the chemical grout is planned to stay permanently in the tanks.

p3. O\&M personnel annual cost, primarily for sampling and analysis, is assumed at $8.1 \%$ of capital cost at an average annual cost of $\$ 98,000$ for each employee far fewer than the 121 estimated for 149 tanks by Boomer et al (1993).

p4. Electricity annual cost was included in the O\&M cost in note [p2].

p5. CENRTC and GPP annual cost was included in the O\&M cost of note [p2].

p6. D\&D cost is estimated at $10 \%$ of capital cost plus one year of personnel cost. This is less than the $30 \%$ of capital cost plus three years of personnel cost used in Boomer et al. (1993) for canyon buildings or other major aboveground structures.

[q] Surface Barrier. Assumptions used to develop cost estimates for surface barriers are based on information from Boomer et al. (1993, Appendix M). All costs are ratioed to 12 tanks from the total 149 SSTs. The process is briefly described in Section 4.5 .2 of this report.

q1. Capital costs of $\$ 51$ million for 149 SSTs from Boomer et al. (1993, p. M138) include those for engineering, project management, equipment, and support facilities. A $50 \%$ contingency is included in the capital costs. No confinement facilities are required outside the tanks. The capital cost is based on 41.13 acres of an engineered barrier that is a nominal $15 \mathrm{ft}$ thick. 
q2. O\&M annual cost is estimated at $5.5 \%$ of capital cost as adjusted from Boomer et al. (1993, p. M138) for a static barrier. O\&M is the sum of personnel including sampling and analysis, electricity, and CENRTC \& GPP costs. No steam or chemicals are planned for use. No disposal costs are included as the barrier is planned to stay permanently in place.

q3. O\&M personnel annual cost, primarily for sampling and analysis, is assumed at $4.5 \%$ of capital cost at an average annual cost of $\$ 98,000$ for each employee, far fewer than proportional to the 295 estimated for 149 tanks per Boomer et al (1993).

q4. Electricity annual cost was included in the O\&M cost in note [q2].

q5. CENRTC and GPP annual cost was included in the O\&M cost of note [q2].

q6. No D\&D cost is estimated for this subsurface barrier, which will be abandoned in place.

[r] Modified Close-Coupled Chemical, Sides Only. Assumptions used to develop cost estimates for modified close-coupled chemical sides only are based on information from KEH (1993b). All costs are ratioed to 12 tanks as in note [a1] and as briefly described in Section 2.2.1 of this report. On each tank there would be two rings of vertical pipes, one at $80 \mathrm{ft}$ diameter to a depth of $46 \mathrm{ft}$, and one at $90 \mathrm{ft}$ diameter to a depth of $50 \mathrm{ft}$.

r1. Capital costs based on $\mathrm{KEH}$ (1993b, p. 20) include those for engineering, project management, equipment, and support facilities. A $40 \%$ contingency is included in the capital costs. No confinement facilities are required outside the tanks. The assumed installed grout cost of $\$ 30 / \mathrm{ft}^{3}$ for $15 \mathrm{ft}^{3} /$ lineal $\mathrm{ft}$ of pipe was applied to $44,054 \mathrm{ft}$ of pipe. A maximum pipe spacing of $7 \mathrm{ft}$ resulted in minimum cost for a pipe drilling and jacking cost of $\$ 500 / \mathrm{ft}$.

r2. O\&M annual cost is estimated at $3.7 \%$ of capital cost as adjusted from $\mathrm{KEH}$ (1993b, p. A-4-2) for a static underground barrier. O\&M is the sum of personnel including sampling and analysis, electricity, and CENRTC \& GPP costs. No steam or chemicals are planned for use. No disposal costs are included as the chemical grout is planned to stay permanently underground.

r3. Personnel annual cost, primarily for sampling and analysis, is assumed at $2.7 \%$ of capital cost at an average annual cost of $\$ 98,000$ for each employee.

r4. Electricity annual cost was included in the $O \& M$ cost in note [ $\mathrm{r} 2]$.

r5. CENRTC and GPP annual cost was included in the O\&M cost of note [r2]. 
r6. No D\&D cost is estimated for this subsurface barrier, which will be abandoned in place.

[s] \& [t] Clean Closure with Close-Coupled Chemical Barrier and w/o Subsurface Barriers. Assumptions used to develop cost estimates for clean closure are based . on information from Boomer et al. (1993). All costs for 12 tanks were ratioed from the total 149 SSTs and include facilities for flush water treatment as well as disposal of resulting MW and HLW at the Hanford Site. The cost of wastewater pipeline transport from the tank farms to the treatment facility is assumed to be in the retrieval system pipeline transport cost. The cost of a SALDS is not included.

s\&t1. Capital costs for each of the process elements is listed below in notes [ii] through [qq]. The MW solids disposal cost for 149 tanks includes trucks, $50 \mathrm{yd}^{3}$ containers, and disposal trenches with surface barrier. Total capital cost includes engineering, project management, equipment, and support facilities as briefly described in Section 4.5 .3 of this report. A $50 \%$ contingency is included in the capital costs.

s\&t2. O\&M annual cost is estimated at $13 \%$ to $14.2 \%$ of capital cost as typical for an active and complex Hanford Site systems. O\&M is the sum of personnel cost including sampling and analysis, electricity, and CENRTC \& GPP costs. No steam or chemicals are planned for use. Disposal costs are included.

s\&t3. O\&M personnel annual cost, primarily for system operation plus sampling and analysis, is assumed at $5.0 \%$ to $6.2 \%$ of capital cost at an average annual cost of $\$ 98,000$ for each employee as proportional from the 5,140 estimated Boomer et al (1993) for all clean closure related subsystems.

s\&t4. Electricity annual cost was included in the O\&M cost in note [12].

s\&t5. CENRTC and GPP annual cost of $2.25 \%$ of capital cost was included in the O\&M cost of note [12].

s\&t6. D\&D cost is estimated as $20 \%$ of capital cost plus two years of personnel costs. These are less than $30 \%$ of capital cost plus three years of personnel cost.as used in Boomer et al. (1993) for canyon buildings or other major aboveground structures.

[u] Vacuum Soil Flushing with Close-Coupled Chemical. Assumptions used to develop cost estimates for vacuum soil flushing for close-coupled chemical are based on information from KEH (1993b). All costs are ratioed to 12 tanks as in note [a1] and as briefly described in Section 4.4.2 of this report. Around each tank there would be a ring of vertical pipes at $80 \mathrm{ft}$ diameter to a depth of $46 \mathrm{ft}$. Three horizontal crossed 
layers of pipes under each tank at $70 \mathrm{ft}$ and $75 \mathrm{ft}$ belowgrade would radiate from 15 coffercells of $15 \mathrm{ft}$ diameter and $100 \mathrm{ft}$ depth placed for construction of the closecoupled chemical barrier. Three coffercells would be located within the 12 tank array and 12 would be located at the perimeter of the array.

u1. Capital costs based on $\mathrm{KEH}$ (1993b, p. 20) include those for engineering, project management, equipment, and support facilities. A $40 \%$ contingency is included in the capital costs. No confinement facilities are required outside the tanks. The assumed installed cost of $\$ 500 / \mathrm{ft}$ was applied to $53,473 \mathrm{ft}$ of pipe.

u2. O\&M annual cost is estimated at $14 \%$ of capital cost as adjusted from $\mathrm{KEH}$ (1993b, p. A-4-2) for an active underground barrier. O\&M is the sum of personnel including sampling and analysis, electricity, and CENRTC \& GPP costs. No steam or chemicals are planned for use. No disposal costs are expected.

u3. Personnel annual cost, primarily for air compressor and system operation plus sampling and analysis, is assumed at $5.8 \%$ of capital cost at an average annual cost of $\$ 98,000$ for each employee.

44. Electricity for air compressors totaling $12,000 \mathrm{hp}$ was included in the O\&M cost.

u5. CENRTC and GPP annual cost of $2.25 \%$ of capital cost was included in the O\&M cost of note [u2].

u6. D\&D cost is estimated at $10 \%$ of capital cost plus one year of personnel cost. This is less than the $30 \%$ of capital cost plus three years of personnel cost used in Boomer et al. (1993) for canyon buildings or other major aboveground structures.

[v] Close-Coupled Chemical Sides and Under 7 Tanks. Assumptions used to develop cost estimates for close-coupled chemical are based on information from KEH (1993b). All costs are ratioed to 7 tanks as briefly described in Section 4.3 .1 of this report. On each tank there would be a ring of vertical pipes at $80 \mathrm{ft}$ diameter to a depth of $46 \mathrm{ft}$ and at $90 \mathrm{ft}$ diameter to a depth of $50 \mathrm{ft}$. Two horizontal crossed layers of pipes under each tank at $55 \mathrm{ft}$ and $63 \mathrm{ft}$ belowgrade would radiate from 15 coffercells of $15 \mathrm{ft}$ diameter and $100 \mathrm{ft}$ depth. Three coffercells would be located within the tank array and 12 would be located at the perimeter of the array.

v1. Capital costs based on KEH (1993b, p. 20) include those for engineering, project management, equipment, and support facilities. A $40 \%$ contingency is included in the capital costs. No confinement facilities are required outside the tanks. The assumed installed grout cost of $\$ 30 / \mathrm{ft}^{3}$ for $15 \mathrm{ft}^{3} /$ lineal $\mathrm{ft}$ of pipe was applied to $81,768 \mathrm{ft}$ of pipe. A maximum pipe spacing of $7 \mathrm{ft}$ resulted in minimum 
overall cost for a pipe drilling and jacking cost of $\$ 500 / \mathrm{ft}$. A coffercell cost of $\$ 5,000 / \mathrm{ft}$ was applied to a $1,200 \mathrm{ft}$ length.

v2. O\&M annual cost is estimated at $3.1 \%$ of capital cost as adjusted from KEH (1993b, p. A-4-2) for a static underground barrier. O\&M is the sum of personnel including sampling and analysis, electricity, and CENRTC \& GPP costs. No steam or chemicals are planned for use. No disposal costs are included as the chemical grout is planned to stay permanently underground.

v3. Personnel annual cost, primarily for sampling and analysis, is assumed at $2.1 \%$ of capital cost at an average annual cost of $\$ 98,000$ for each employee.

v4. Electricity annual cost was included in the O\&M cost in note [v2].

v5. CENRTC and GPP annual cost was included in the O\&M cost of note [v2].

v6. No $D \& D$ cost is estimated for this subsurface barrier, which will be abandoned in place.

Notes [aa] through [qq] also apply to clean closure notes [s] and [t].

[aa] For 12 of 149 SSTs with all systems scaled for a 3 by 4 tank array. Size and cost of systems was increased to stay within a 10 year operating time with the soil and debris increased by the soil from below the tanks.

[bb] Option 14 has five old leaks of 11,000 gal each. Option 13 has two old leaks of 11,000 gal each, three combined leaks of 51,000 gal each composed of three sluicing produced leaks of 40,000 gal each combined with three old leaks of 11,000 gal each, and two sluicing produced leaks of 40,000 gal each.

[cc] Per Boomer et al. (1993, p. J-8), the ratio volume contaminated soil/volume spill $=57=7.6 \mathrm{ft}^{3} / \mathrm{gal}$.

[dd] Leak depth in addition to tank base bottom elevation of $50 \mathrm{ft}$ belowgrade.

[ee] Per Boomer et al. (1993, p. K-8), soil density $=100 \mathrm{lb} / \mathrm{ft}^{3}=2,700 \mathrm{lb} / \mathrm{yd}^{3}=$ 1.35 tons $/ \mathrm{yd}^{3}$.

[ff] Soil and debris includes soil from above and around tanks, concrete, rebar, steel tank liner plate, and for option 14, chemically grouted soil. Soil and debris were multiplied by the ratio $12 / 149$. Per Boomer et al. (1993, p. K-8), total for 149 SSTs $=561,000$ ton $=362,000$ ton of concrete $+177,000$ ton of soil + 22,000 ton of steel. Per Boomer et al. (1993, p. K-8), this will fill 
9,900 containers of $50 \mathrm{yd}^{3}=5,300$ containers of concrete $+2,800$ containers of soil $+1,800$ containers of steel.

[gg] Sum of soil from below tanks plus soil, remaining tank contents, concrete and steel debris down to and including reinforced concrete tank base.

[hh] Capital costs include 50\% contingency and 5\% inflation from early 1993 to mid 1994.

[ii] Capital cost of removal is estimated from the basis $\$ 839$ million per Boomer et al. (1993, p. J-50) proportional to the 0.6 power of the ratio of total soil to soil and debris. Cost per Boomer et al. (1993, p. J-40) $=\$ 780$ million not used. Removal $=$ demolition and excavation similar to mechanical retrieval.

[ji] Capital cost of confinement is adjusted up 5\% for inflation from the basis $\$ 257$ million per Boomer et al. (1993, pp. J-98 and F7-38). Confinement would be a $500 \mathrm{ft}$ clear span by 150 high arch truss by $600 \mathrm{ft}$ building composed of eight sections of $75 \mathrm{ft}$ width moved onto pre-placed foundations. It would have an operating, crane support, and shield floor suspended $20 \mathrm{ft}$ abovegrade.

[kk] Capital cost of hauling and mixed waste disposal is estimated from the basis $\$ 110$ million per Boomer et al. (1993, p. K-178) proportional to the 0.6 power of the ratio of total soil to soil and debris. Hauling and mixed waste disposal includes trucks, containers, haul roads, burial boxes, onsite MW trenches, and surface barrier.

[11] Capital cost of soil and debris water wash is estimated from the basis $\$ 1,006$ million per Boomer et al. (1993, p. R-386) proportional to the 0.6 power of the ratio of total soil and debris to tank soil and debris. Soil and debris water wash would include the process facilities to reduce size, classify, and separate mixed waste from waste for backfill.

[mm] Capital cost of LEPRD wash water treatment is estimated from the basis $\$ 297$ million per Boomer et al. (1993, p. R-397) proportional to the 0.6 power of the ratio of total soil to soil and debris. LEPRD wash water treatment is as described in Section 2.3.3 of this report.

[nn] Capital cost of disposing LEPRD solids as radioactive mixed waste is estimated as the incremental cost from the basis $\$ 110$ million per Boomer et al. (1993, p. $\mathrm{K}-178$ ) proportional to the 0.6 power of the solids flow ratio. Total flow is the sum of 1.43 ton/day from Boomer et al. (1993, p. N46) and the baseline flow of 256 tons/day per Boomer et al. (1993, p. K-8). This result is raised to the 0.6 power of the ratio of total soil and debris to tank soil and debris. 
[0o] Capital cost of recycle piping without a SALDS is estimated from the basis $\$ 385$ million per Boomer et al. (1993, p. R-348) proportional to the 0.6 power of the ratio of total soil and debris to tank soil and debris.

[pp] Capital cost of backfill is estimated from the basis $\$ 51$ million for surface barriers per Boomer et al. (1993, p. R-396) proportional to the 0.6 power of the ratio of total soil and debris plus $12 \mathrm{Mgal}$ to the basis surface barrier volume of $1.04 \mathrm{Myd}^{3}$. Surface barrier volume is estimated from 41.13 acres per Boomer et al. (1993, p. M44) by $15 \mathrm{ft}$ thick per Boomer et al. (1993, p. M-125).

[qq] Capital cost of processing and disposal of HLW effluent from LEPRD is estimated as the SST nitrate fraction of 0.84 multiplied by the $\$ 5.54$ billion cost for the entire 11 module system excluding retrieval. The 11 module names adapted from Boomer et al. (1993) are double-shell tank sludge wash, cesium ion exchange system, LLW glass in sulphur, LLW glass in sulfur vaults, HLW glass cullet feed lag storage, HLW glass cullet, HLW glass cullet cask storage, cullet rework and melter offgas processing, liquid effluent treatment, chemical make-up unit, and air/vapor filtration. The 0.84 factor is the ratio of $9.23 \times 10^{7} \mathrm{~kg}$ nitrate from the SSTs to $10.98 \times 10^{7} \mathrm{~kg}$ total nitrate. 
WHC-SD-WM-ES-300 REV. 1

This page intentionally left blank. 
WHC-SD-WM-ES-300 REV. 1

APPENDIX D

SUPPORTING DATA FOR ASSESSMENT OF RISKS TO WORKERS 
WHC-SD-WM-ES-300 REV. 1

This page intentionally left blank. 
WHC-SD-WM-ES-300 REV. 1

\section{TABLE OF CONTENTS}

APPENDIX D.1 RISK FACTORS $\ldots \ldots \ldots \ldots \ldots \ldots \ldots \ldots \ldots$ D.1-1

APPENDIX D.2 TECHNOLOGY OPTIONS CHARACTERISTICS $\ldots \ldots \ldots$ D.2-1

APPENDIX D.3 OPTIONS WORKER RISKS $\ldots \ldots \ldots \ldots \ldots \ldots$ D.3-1

APPENDIX D.4 ALTERNATIVES WORKERS RISK $\ldots \ldots \ldots \ldots$ D.4-1 
WHC-SD-WM-ES-300 REV. 1

This page intentionally left blank. 
WHC-SD-WM-ES-300 REV. 1

\section{SUPPORTING DATA FOR ASSESSMENT OF RISKS TO WORKERS}

This data was generated using assumptions and calculations described in Section 9 to assess the risk to workers. 
WHC-SD-WM-ES-300 REV. 1

This page intentionally left blank. 
WHC-SD-WM-ES-300 REV. 1

APPENDIX D.1

RISK FACTORS

D.1-1 
WHC-SD-WM-ES-300 REV. 1

This page intentionally left blank.

D.1-2 
WHC-SD-WM-ES-300 REV. 1

\section{RISK FACTORS}

This section lists the injury and fatality risk factors for each worker category and each technology option.

D.1-3 
WHC-SD-WM-ES-300 REV. 1

This page intentionally left blank.

D. $1-4$ 


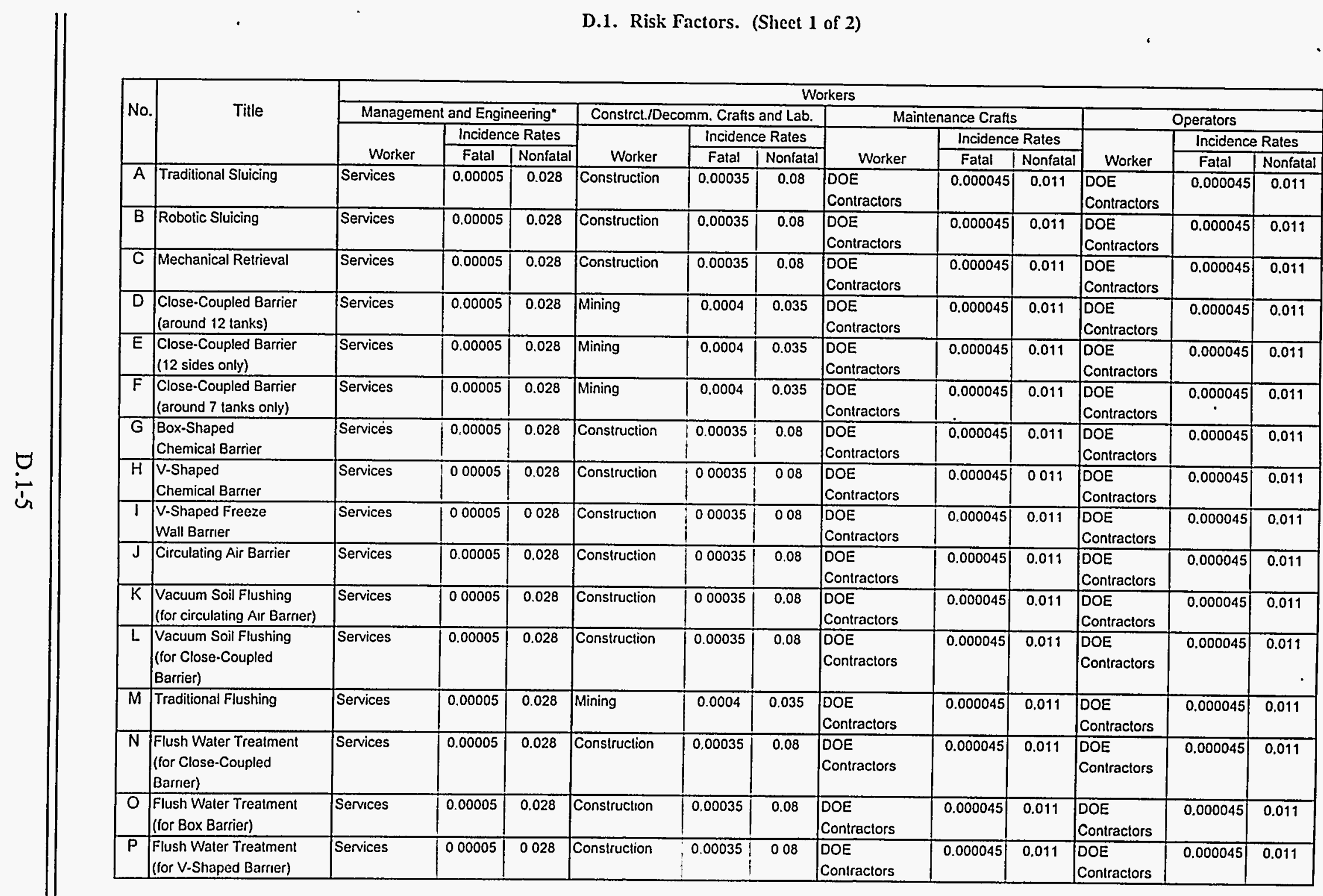

RF.XLS

1/4/94 (3:04 PM) 


\begin{tabular}{|c|c|c|c|c|c|c|c|c|c|c|c|c|c|}
\hline \multirow{4}{*}{ No. } & \multirow{4}{*}{ Title } & \multicolumn{12}{|c|}{ Workers } \\
\hline & & \multicolumn{3}{|c|}{ Management and Engıneering* } & \multicolumn{3}{|c|}{ Constrct /Decomm Crafts and Lab } & \multicolumn{3}{|c|}{ Maintenance Crafts } & \multicolumn{3}{|c|}{ Operators } \\
\hline & & \multirow[b]{2}{*}{ Worker } & \multicolumn{2}{|c|}{ Incidence Rates } & \multirow[b]{2}{*}{ Worker } & \multicolumn{2}{|c|}{ Incidence Rates } & \multirow[b]{2}{*}{ Worker } & \multicolumn{2}{|c|}{ Incidence Rales } & \multirow[b]{2}{*}{ Worker } & \multicolumn{2}{|c|}{ Incidence Rales } \\
\hline & & & Fatal & Nonfatal & & Fatal & Nonfatal & & Fatal & Nonfatal & & Fatal & Nonfatal \\
\hline$Q$ & $\begin{array}{l}\text { Flush Water Treatment } \\
\text { (for Circulating } \\
\text { Air Barrier) }\end{array}$ & Services & 0.00005 & 0.028 & Construction & 0.00035 & 0.08 & $\begin{array}{l}\mathrm{DOE} \\
\text { Contractors }\end{array}$ & 0.000045 & 0.011 & $\begin{array}{l}\mathrm{DOE} \\
\text { Contractors }\end{array}$ & 0.000045 & 0.011 \\
\hline $\bar{R}$ & Tank Stabilization & Services & 0.00005 & 0.028 & Construction & 000035 & 0.08 & $\begin{array}{l}\text { DOE } \\
\text { Contractors }\end{array}$ & 0,000045 & 0.011 & $\begin{array}{l}\text { DOE } \\
\text { Contractors }\end{array}$ & 0.000045 & 0.011 \\
\hline$S$ & Surface Barrier & Services & 0.00005 & 0.028 & Construction & 0.00035 & 0.08 & \begin{tabular}{|l|}
$\mathrm{DOE}$ \\
Contractors \\
\end{tabular} & 0.000045 & 0.011 & \begin{tabular}{|l|} 
DOE \\
Contractors \\
\end{tabular} & 0.000045 & 0.011 \\
\hline$T$ & $\begin{array}{l}\text { Clean Closure } \\
\text { (no barrier) }\end{array}$ & Services & 0.00005 & 0.028 & Mining & 0.0004 & 0.035 & $\begin{array}{l}\text { DOE } \\
\text { Contraclors }\end{array}$ & 0.000045 & 0.011 & \begin{tabular}{|l|} 
DOE \\
Contractors
\end{tabular} & 0.000045 & 0.011 \\
\hline$U$ & $\begin{array}{l}\text { Clean Closure } \\
\text { (with Close- } \\
\text { Coupled Barrier) }\end{array}$ & Senvices & 0.00005 & 0.028 & Mining & 00004 & 0.035 & \begin{tabular}{|l} 
DOE \\
Contractors
\end{tabular} & 0.000045 & 0.011 & $\begin{array}{l}\text { DOE } \\
\text { Contractors }\end{array}$ & 0.000045 & 0.011 \\
\hline
\end{tabular}

- All 'Services'. 'Construction', and 'Mining' incidence rates from the National Satety Councll Accident Facts. are averaged from $1985 \cdot 1989$ (injury) and $1985 \cdot 1990$ (death)

*- All 'DOE Contractor' incidence rates are from Department of Energy (DOE) 1982. Environment Safely. Health at DOE facilties. Annual Report, Calendar Year 1981. DOE/ep-0024/1. Washington. D.C 
APPENDIX D.2

TECHNOLOGY OPTIONS CHARACTERISTICS 
WHC-SD-WM-ES-300 REV. 1

This page intentionally left blank. 


\section{TECHNOLOGY OPTIONS CHARACTERISTICS}

This section lists the annual dose (mrem) for each worker category and life-cycle phase for each technology option. 
WHC-SD-WM-ES-300 REV. 1

This page intentionally left blank. 
Option: A. Traditional Sluicing

Capital Cost: $\$ 63$ million Annual Worker Mileage: 15000 miles

\begin{tabular}{|c|c|c|c|c|c|c|c|c|c|}
\hline \multirow[t]{2}{*}{ Activity } & \multirow{2}{*}{$\begin{array}{l}\text { Activity } \\
\text { Duration } \\
\text { (years) }\end{array}$} & \multicolumn{2}{|c|}{$\begin{array}{l}\text { Management and } \\
\text { Engineering }\end{array}$} & \multicolumn{2}{|c|}{$\begin{array}{c}\text { Construction/Decommissioning } \\
\text { Crafts and Laborers }\end{array}$} & \multicolumn{2}{|c|}{ Malntenance Crafts } & \multicolumn{2}{|c|}{ Operators } \\
\hline & & $\begin{array}{l}\text { Total Person- } \\
\text { Years } \\
\end{array}$ & Annual Dose & $\begin{array}{c}\text { Total Person- } \\
\text { Years } \\
\end{array}$ & Annual Dose & $\begin{array}{c}\text { Total Person: } \\
\text { Years }\end{array}$ & Annual Dose & $\begin{array}{c}\text { Total Person- } \\
\text { Years } \\
\end{array}$ & Annual Dose \\
\hline $\begin{array}{l}\text { Technology } \\
\text { Readiness }\end{array}$ & 5 & 12 & 0 & 4 & 0 & 0 & 0 & 0 & 0 \\
\hline Capital & 5 & 193 & 15 & 126 & 300 & 0 & 0 & 0 & 0 \\
\hline $\begin{array}{l}\text { Operations \& } \\
\text { Maintenance }\end{array}$ & 15 & 147 & 35 & 0 & 0 & 74 & 400 & 147 & 400 \\
\hline $\begin{array}{l}\text { Decontamination } \\
\text { \& Decommissioning }\end{array}$ & 1 & 7 & 35 & 15 & 400 & 0 & 0 & 2 & 400 \\
\hline TOTAL & & 359 & $\therefore$ & 145 & & 74 & 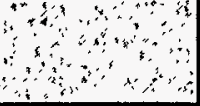 & 149 & 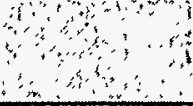 \\
\hline
\end{tabular}

NOTE: Inirastructure staff support the staff above. They receive no annual dose, average 4,000 travel miles, and average $50 \%$ of the facility totals above. 
Option: B. Robotic Sluicing

Capital Cost: $\$ 183$ million

Annual Worker Mileage: 15000 miles

Activity $\quad$ Management and

\begin{tabular}{|c|c|c|c|c|c|c|c|c|c|}
\hline \multirow[t]{2}{*}{ Activity } & \multirow{2}{*}{$\begin{array}{c}\text { Activity } \\
\text { Duration } \\
\text { (years) }\end{array}$} & \multicolumn{2}{|c|}{$\begin{array}{c}\text { Management and } \\
\text { Engineering } \\
\end{array}$} & \multicolumn{2}{|c|}{$\begin{array}{c}\text { Construction/Decommissioning } \\
\text { Crafts and Laborers }\end{array}$} & \multicolumn{2}{|c|}{ Maintenance Crafts } & \multicolumn{2}{|c|}{ Operators } \\
\hline & & $\begin{array}{c}\text { Total Person. } \\
\text { Years }\end{array}$ & Annual Dose & \begin{tabular}{|c|}
$\begin{array}{c}\text { Total Person- } \\
\text { Years }\end{array}$ \\
\end{tabular} & Annual Dose & $\begin{array}{c}\text { Total Person- } \\
\text { Years }\end{array}$ & Annual Dose & $\begin{array}{c}\text { Total Porson- } \\
\text { Years }\end{array}$ & Annual Dose \\
\hline $\begin{array}{c}\text { Technology } \\
\text { Readiness } \\
\end{array}$ & 5 & 110 & 0 & 37 & 0 & 0 & 0 & 0 & 0 \\
\hline Capital & 5 & 560 & 15 & 373 & 300 & 0 & 0 & 0 & 0 \\
\hline $\begin{array}{l}\text { Operations \& } \\
\text { Maintenance }\end{array}$ & 15 & 1245 & 35 & 0 & 0 & 622 & 400 & 1245 & 400 \\
\hline $\begin{array}{l}\text { Decontamination } \\
\text { \& Decommissioning }\end{array}$ & 2 & 124 & 35 & 249 & 400 & 0 & 0 & 41 & 400 \\
\hline TOTAL & & 2039 & & 659 & & 622 & 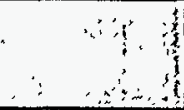 & 1286 & 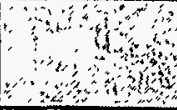 \\
\hline
\end{tabular}

NOTE: Infrastructure staft support the staff above They receive no annual dose, average 4.000 travel miles, and average $50 \%$ of the facility totals above. 
WHC-SD-WM-ES-300 REV. 1

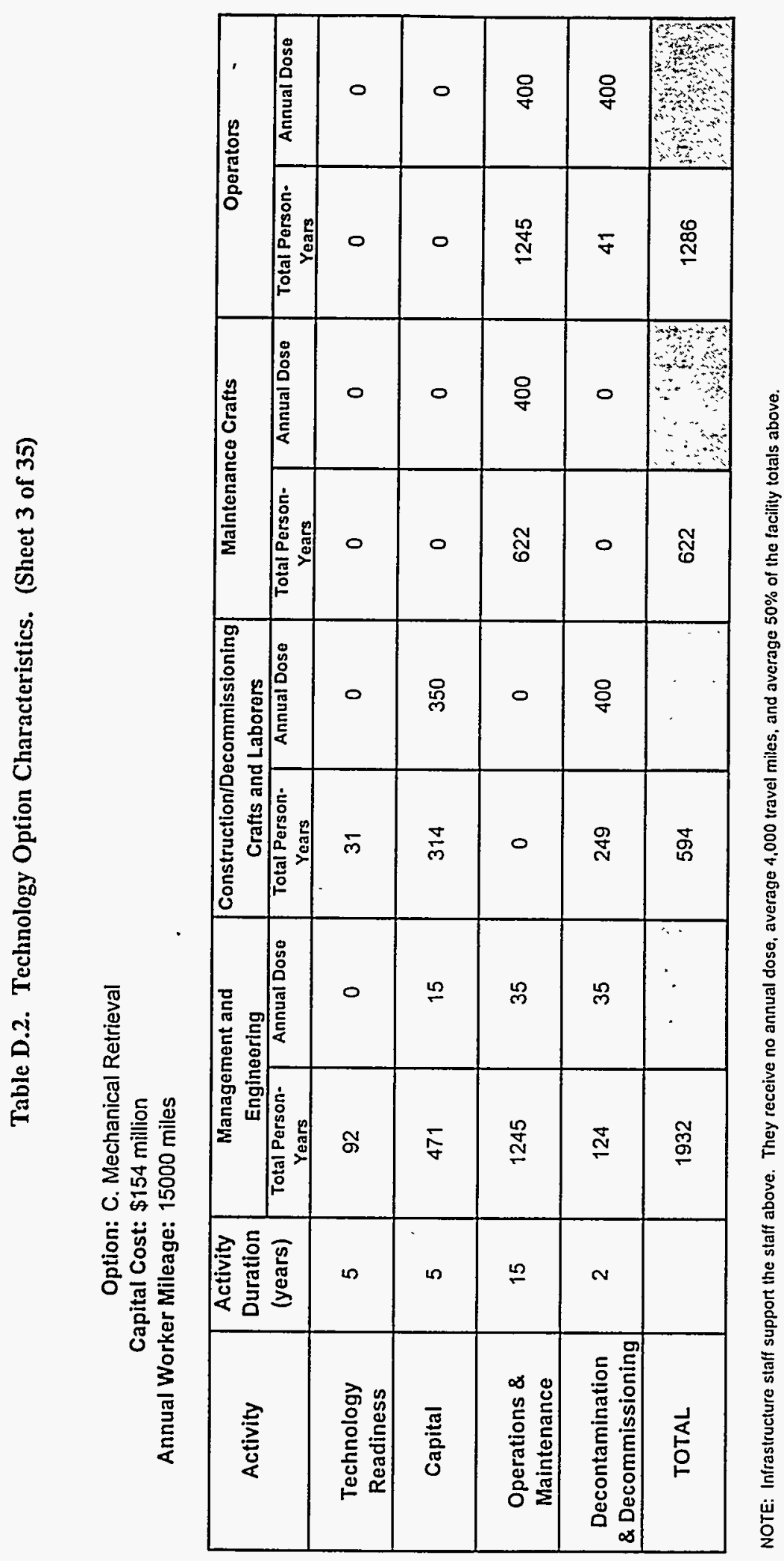

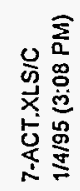

\section{D.2-7}


Table D.2. Technology Option Characteristics. (Sheet 4 of 35)

Option: D. Close-Couple Barrier (around 12 tanks)

Capital Cost: $\$ 211$ million

Annual Worker Mileage: 15000 miles

\begin{tabular}{|c|c|c|c|c|c|c|c|c|c|}
\hline \multirow[t]{2}{*}{ Activity } & \multirow{2}{*}{$\begin{array}{c}\text { Activity } \\
\text { Duration } \\
\text { (years) }\end{array}$} & \multicolumn{2}{|c|}{$\begin{array}{l}\text { Management and } \\
\text { Engineering }\end{array}$} & \multicolumn{2}{|c|}{$\begin{array}{c}\text { Construction/Decommissioning } \\
\text { Crafts and Laborers }\end{array}$} & \multicolumn{2}{|c|}{ Maintenance Crafts } & \multicolumn{2}{|c|}{ Operators } \\
\hline & & $\begin{array}{l}\text { Total Person- } \\
\text { Years }\end{array}$ & Annual Doso & $\begin{array}{c}\text { Tota! Person- } \\
\text { Years }\end{array}$ & Annual Dose & $\begin{array}{c}\text { Total Person- } \\
\text { Years } \\
\end{array}$ & Annual Dose & $\begin{array}{c}\text { Total Person- } \\
\text { Years }\end{array}$ & Annual Dose \\
\hline $\begin{array}{l}\text { Technology } \\
\text { Readiness }\end{array}$ & 5 & 80 & 0 & 27 & 0 & 0 & 0 & 0 & 0 \\
\hline Capital & 5 & 646 & 15 & 430 & 350 & 0 & 0 & 0 & 0 \\
\hline $\begin{array}{l}\text { Operations \& } \\
\text { Maintenance }\end{array}$ & 15 & 186 & 35 & 0 & 0 & 93 & 200 & 186 & 200 \\
\hline $\begin{array}{l}\text { Decontamination } \\
\text { \& Decommissioning }\end{array}$ & 0 & 0 & 0 & 0 & 0 & 0 & 0 & 0 & 0 \\
\hline TOTAL & & 912 & & 457 & & 93 & 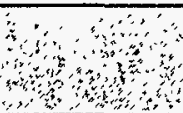 & 186 & 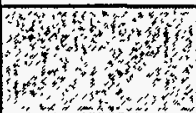 \\
\hline
\end{tabular}

NOTE: Infrastructure staff support the staff above. They receive no annual dose, average 4,000 travel miles, and average $50 \%$ of the faclity totals above. 
Table D.2. Technology Option Characteristics. (Sheet 5 of 35)

Option: E. Close-Coupled Barrier (12 sides only)

Capital Cost: $\$ 111$ million

Annual Worker Mileage: 15000 miles

\begin{tabular}{|c|c|c|c|c|c|c|c|c|c|}
\hline \multirow[t]{2}{*}{ Activity } & \multirow{2}{*}{$\begin{array}{c}\text { Activity } \\
\text { Duration } \\
\text { (years) }\end{array}$} & \multicolumn{2}{|c|}{$\begin{array}{c}\text { Management and } \\
\text { Engineering }\end{array}$} & \multicolumn{2}{|c|}{$\begin{array}{c}\text { Construction/Decommissioning } \\
\text { Crafts and Laborers }\end{array}$} & \multicolumn{2}{|c|}{ Maintenance Crafts } & \multicolumn{2}{|c|}{ Operators } \\
\hline & & $\begin{array}{c}\text { Total Person- } \\
\text { Years }\end{array}$ & Annual Dose & $\begin{array}{c}\text { Total Person- } \\
\text { Years } \\
\end{array}$ & Annual Dose & $\begin{array}{c}\text { Total Person- } \\
\text { Years } \\
\end{array}$ & Annual Dose & $\begin{array}{c}\text { Total Person- } \\
\text { Years }\end{array}$ & Annual Dose \\
\hline $\begin{array}{l}\text { Technology } \\
\text { Readiness }\end{array}$ & 5 & 43 & 0 & 14 & 0 & 0 & 0 & 0 & 0 \\
\hline Capital & 5 & 339 & 15 & 226 & 250 & 0 & 0 & 0 & 0 \\
\hline $\begin{array}{l}\text { Operations \& } \\
\text { Maintenance }\end{array}$ & 15 & 186 & 35 & 0 & 0 & 93 & 200 & 186 & 200 \\
\hline $\begin{array}{c}\text { Decontamination } \\
\text { \& Decommissioning } \\
\end{array}$ & 0 & 0 & 0 & 0 & 0 & 0 & 0 & 0 & 0 \\
\hline TOTAL & & 568 & 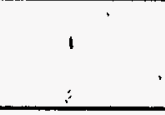 & 240 & $\therefore$ & 93 & 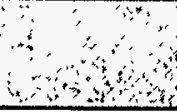 & 186 & 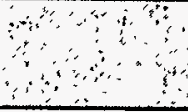 \\
\hline
\end{tabular}

NOTE: Infrastructure staff support the staff above. They receive no annual dose, average 4,000 travel miles, and average $50 \%$ of the facility totals above. 
Option: F. Close-Coupled Barrier (around 7 tanks only)

Capital Cost: $\$ 145$ million Annual Worker Mileage: 15000 miles

\begin{tabular}{|c|c|c|c|c|c|c|c|c|c|}
\hline \multirow[t]{2}{*}{ Activity } & \multirow{2}{*}{$\begin{array}{c}\text { Activity } \\
\text { Duration } \\
\text { (years) }\end{array}$} & \multicolumn{2}{|c|}{$\begin{array}{l}\text { Management and } \\
\text { Engineering }\end{array}$} & \multicolumn{2}{|c|}{$\begin{array}{c}\text { Construction/Decommissioning } \\
\text { Crafts and Laborers }\end{array}$} & \multicolumn{2}{|c|}{ Maintenance Crafts } & \multicolumn{2}{|c|}{ Operators } \\
\hline & & $\begin{array}{c}\text { Total Person- } \\
\text { Years }\end{array}$ & Annual Dose & $\begin{array}{c}\begin{array}{c}\text { Total Person- } \\
\text { Years }\end{array} \\
\end{array}$ & Annual Dose & $\begin{array}{c}\text { Total Person- } \\
\text { Years } \\
\end{array}$ & Annual Doso & $\begin{array}{c}\text { Total Person- } \\
\text { Years } \\
\end{array}$ & Annual Dose \\
\hline $\begin{array}{l}\text { Technology } \\
\text { Readiness }\end{array}$ & 5 & 80 & 0 & 27 & 0 & 0 & 0 & 0 & 0 \\
\hline Capital & 5 & 443 & 15 & 295 & 350 & 0 & 0 & 0 & 0 \\
\hline $\begin{array}{l}\text { Operations \& } \\
\text { Maintenance }\end{array}$ & 15 & 186 & 35 & 0 & 0 & 93 & 200 & 186 & 200 \\
\hline $\begin{array}{l}\text { Decontamination } \\
\text { \& Decommissioning }\end{array}$ & 0 & 0 & 0 & 0 & 0 & 0 & 0 & 0 & 0 \\
\hline TOTAL & & 709 & & 322 & & 93 & 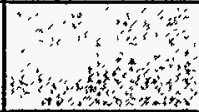 & 186 & 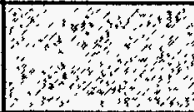 \\
\hline
\end{tabular}

NOTE: Infrastructure staff support the staff above. They receive no annual dose, average 4,000 travel miles, and average $50 \%$ of the facility totals above. 
Option: G. Box-Shaped Chemical Barrier

Capital Cost: $\$ 218$ million

Annual Worker Mileage: 15000 miles

\begin{tabular}{|c|c|c|c|c|c|c|c|c|c|}
\hline \multirow[t]{2}{*}{ Activity } & \multirow{2}{*}{$\begin{array}{c}\text { Activity } \\
\text { Duration } \\
\text { (years) }\end{array}$} & \multicolumn{2}{|c|}{$\begin{array}{c}\text { Management and } \\
\text { Engineering } \\
\end{array}$} & \multicolumn{2}{|c|}{$\begin{array}{c}\text { Construction/Decommissioning } \\
\text { Crafts and Laborers }\end{array}$} & \multicolumn{2}{|c|}{ Maintenance Crafts } & \multicolumn{2}{|c|}{ Operators } \\
\hline & & $\begin{array}{c}\text { Total Person* } \\
\text { Years } \\
\end{array}$ & Annual Dose & $\begin{array}{c}\begin{array}{c}\text { Total Person- } \\
\text { Years }\end{array} \\
\end{array}$ & Annual Dose & $\begin{array}{l}\text { Total Person- } \\
\text { Years } \\
\end{array}$ & Annual Dose & $\begin{array}{l}\text { Total Person- } \\
\text { Years } \\
\end{array}$ & Annual Dose \\
\hline $\begin{array}{l}\text { Technology } \\
\text { Readiness }\end{array}$ & 5 & 80 & 0 & 27 & 0 & 0 & 0 & 0 & 0 \\
\hline Capital & 5 & 667 & 15 & 444 & 200 & 0 & 0 & 0 & 0 \\
\hline $\begin{array}{l}\text { Operations \& } \\
\text { Maintenance }\end{array}$ & 15 & 186 & 35 & 0 & 0 & 93 & 200 & 186 & 200 \\
\hline $\begin{array}{c}\text { Decontamination } \\
\text { \& Decommissioning }\end{array}$ & 0 & 0 & 0 & 0 & 0 & 0 & 0 & 0 & 0 \\
\hline TOTAL & & 933 & & 471 & & 93 & 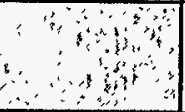 & 186 & \\
\hline
\end{tabular}

NOTE: Infrastructure staff support the staff above. They receive no annual dose, average 4,000 travel miles, and average $50 \%$ of the facility totals above. 
Option: H. V-Shaped Chemical Barrier

Capital Cost: $\$ 313$ million Annual Worker Mileage: 15000 miles

\begin{tabular}{|c|c|c|c|c|c|c|c|c|c|}
\hline \multirow[t]{2}{*}{ Activity } & \multirow{2}{*}{$\begin{array}{l}\text { Activity } \\
\text { Duration } \\
\text { (years) }\end{array}$} & \multicolumn{2}{|c|}{$\begin{array}{l}\text { Management and } \\
\text { Engineering }\end{array}$} & \multicolumn{2}{|c|}{$\begin{array}{c}\text { Construction/Decommissioning } \\
\text { Crafts and Laborers }\end{array}$} & \multicolumn{2}{|c|}{ Maintenance Crafts } & \multicolumn{2}{|c|}{ Operators } \\
\hline & & $\begin{array}{l}\text { Total Person- } \\
\text { Years } \\
\end{array}$ & Annual Doso & \begin{tabular}{|c|}
$\begin{array}{c}\text { Total Person- } \\
\text { Years }\end{array}$ \\
\end{tabular} & Annual Dose & $\begin{array}{c}\text { Total Porson- } \\
\text { Years }\end{array}$ & Annual Dose & $\begin{array}{c}\text { Total Person- } \\
\text { Years } \\
\end{array}$ & Annual Dose \\
\hline $\begin{array}{c}\text { Technology } \\
\text { Readiness }\end{array}$ & 5 & 80 & 0 & 27 & 0 & 0 & 0 & 0 & 0 \\
\hline Capital & 5 & 958 & 15 & 638 & 200 & 0 & 0 & 0 & 0 \\
\hline $\begin{array}{l}\text { Operations \& } \\
\text { Maintenance }\end{array}$ & 15 & 186 & 35 & 0 & 0 & 93 & 200 & 186 & 200 \\
\hline $\begin{array}{l}\text { Decontamination } \\
\text { \& Decommissioning } \\
\end{array}$ & 0 & 0 & 0 & 0 & 0 & 0 & 0 & 0 & 0 \\
\hline TOTAL & & 1224 & , & 665 & $\cdot$ & 93 & $\therefore$ & 186 & \\
\hline
\end{tabular}

NOTE: Infrastructure staff support the staff above. They receive no annual dose, average 4,000 travel miles, and average $50 \%$ of the facility totals above. 
Option: I. V-Shaped Freeze Wall Barrier

Capital Cost: \$208 million

Annual Worker Mileage: 15000 miles

\begin{tabular}{|c|c|c|c|c|c|c|c|c|c|}
\hline \multirow[t]{2}{*}{ Activity } & \multirow{2}{*}{$\begin{array}{l}\text { Activity } \\
\text { Duration } \\
\text { (years) }\end{array}$} & \multicolumn{2}{|c|}{$\begin{array}{c}\text { Management and } \\
\text { Engineering } \\
\end{array}$} & \multicolumn{2}{|c|}{$\begin{array}{c}\text { Construction/Decommissioning } \\
\text { Crafts and Laborers }\end{array}$} & \multicolumn{2}{|c|}{ Maintenance Crafts } & \multicolumn{2}{|c|}{ Operators } \\
\hline & & $\begin{array}{l}\text { Total Person- } \\
\text { Years }\end{array}$ & Annual Dose & $\begin{array}{l}\text { Total Person- } \\
\text { Years } \\
\end{array}$ & Annual Dose & $\begin{array}{l}\text { Total Person- } \\
\text { Years } \\
\end{array}$ & Annual Dose & $\begin{array}{c}\text { Total Porson- } \\
\text { Years } \\
\end{array}$ & Annual Dose \\
\hline $\begin{array}{l}\text { Technology } \\
\text { Readiness }\end{array}$ & 5 & 73 & 0 & 24 & 0 & 0 & 0 & 0 & 0 \\
\hline Capital & 5 & 636 & 15 & 424 & 200 & 0 & 0 & 0 & 0 \\
\hline $\begin{array}{l}\text { Operations \& } \\
\text { Maintenance }\end{array}$ & 15 & 378 & 35 & 0 & 0 & 189 & 200 & 378 & 200 \\
\hline $\begin{array}{c}\text { Decontamination } \\
\text { \& Decommissioning } \\
\end{array}$ & 1 & 19 & 35 & 38 & 200 & 0 & 0 & 6 & 200 \\
\hline TOTAL & & 1106 & & 486 & & 189 & 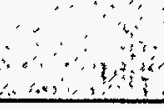 & 384 & 准 \\
\hline
\end{tabular}

NOTE: Infrastructure staff support the staff above. They receive no annual dose, average 4,000 travel miles, and average $50 \%$ of the facility totals above. 


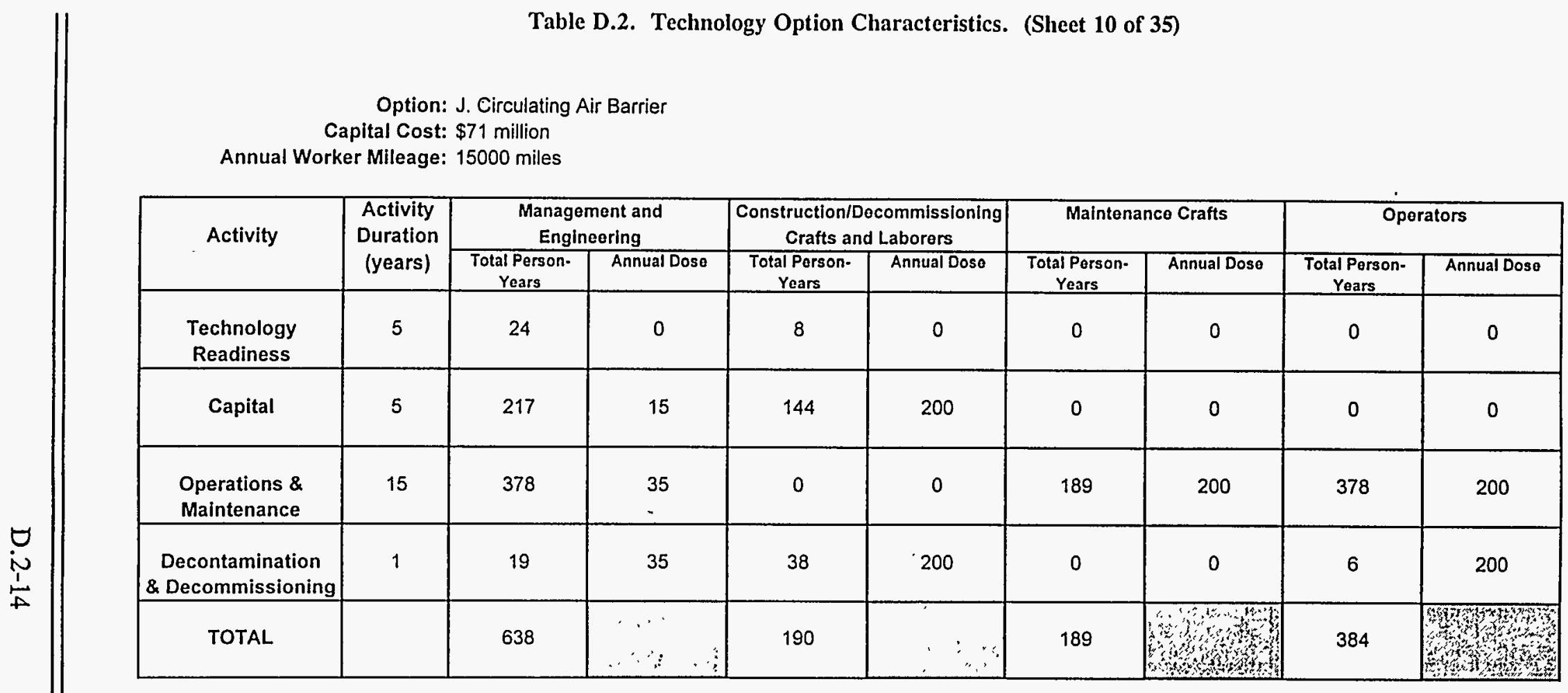

NOTE: Infrastructure stafl support the staff above They receive no annual dose, average 4,000 travel miles, and average $50 \%$ of the facility totals above. 


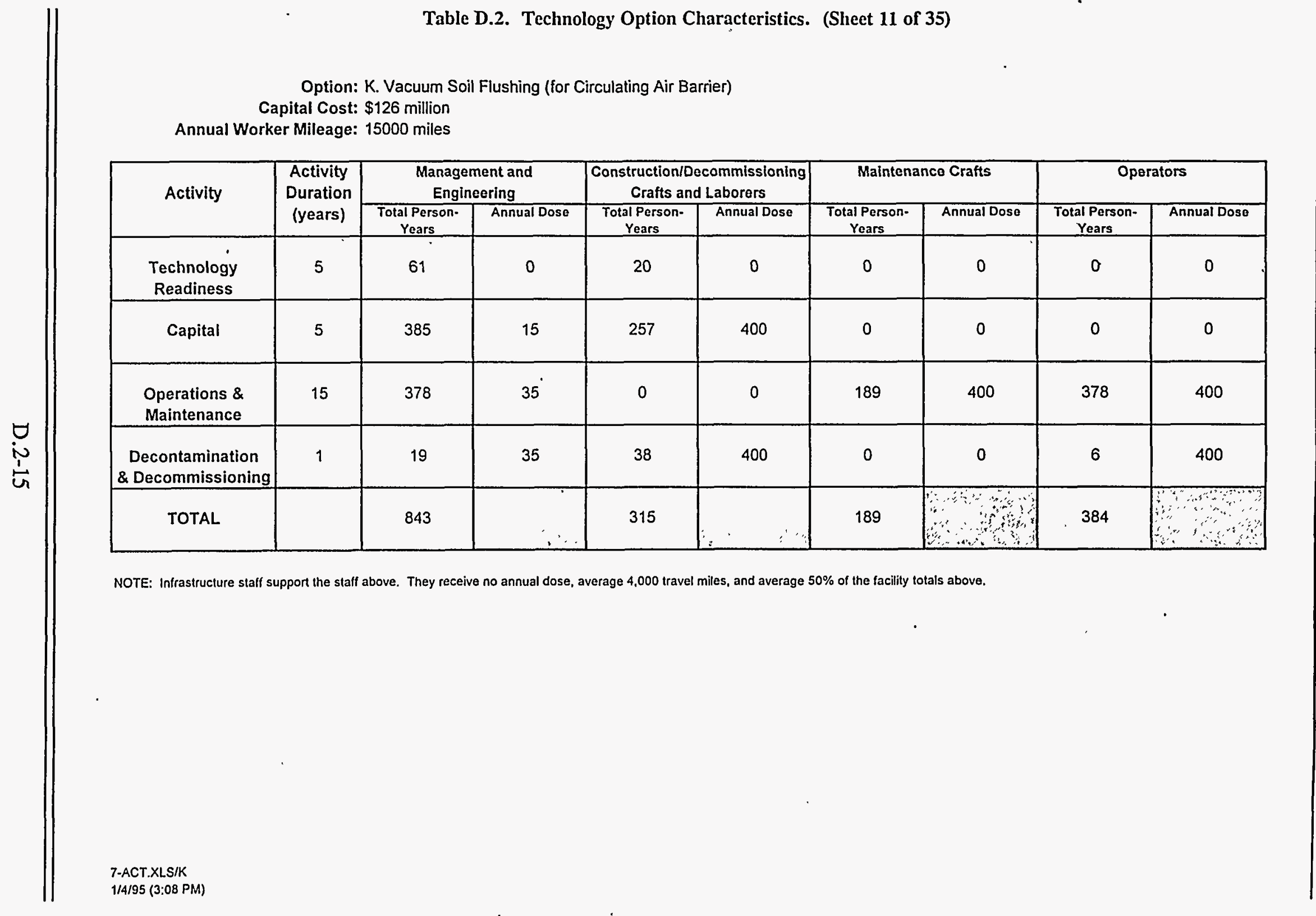


Option: L. Vacuum Soil Flushing (for Close-Coupled Barrier)

Capital Cost: $\$ 107$ million Annual Worker Mileage: 15000 miles

\begin{tabular}{|c|c|c|c|c|c|c|c|c|c|}
\hline \multirow[t]{2}{*}{ Activity } & \multirow{2}{*}{$\begin{array}{l}\text { Activity } \\
\text { Duration } \\
\text { (years) }\end{array}$} & \multicolumn{2}{|c|}{$\begin{array}{c}\text { Management and } \\
\text { Engineoring } \\
\end{array}$} & \multicolumn{2}{|c|}{$\begin{array}{c}\text { Construction/Docommissioning } \\
\text { Crafts and Laborors }\end{array}$} & \multicolumn{2}{|c|}{ Maintenance Crafts } & \multicolumn{2}{|c|}{ Operators } \\
\hline & & $\begin{array}{c}\text { Total Person- } \\
\text { Years } \\
\end{array}$ & Annual Doso & $\begin{array}{l}\text { Total Person- } \\
\text { Years }\end{array}$ & Annual Doso & $\begin{array}{c}\text { Total Person- } \\
\text { Years }\end{array}$ & Annual Dose & $\begin{array}{c}\text { Total Person- } \\
\text { Years }\end{array}$ & Annual Doso \\
\hline $\begin{array}{l}\text { Technology } \\
\text { Readiness }\end{array}$ & 5 & 61 & 0 & 20 & 0 & 0 & 0 & 0 & 0 \\
\hline Capital & 5 & 327 & 15 & 218 & 400 & 0 & 0 & 0 & 0 \\
\hline $\begin{array}{l}\text { Operations \& } \\
\text { Maintenance } \\
\end{array}$ & 15 & 378 & 35 & 0 & 0 & 189 & 400 & 378 & 400 \\
\hline $\begin{array}{c}\text { Decontamination } \\
\& \text { Decommissioning } \\
\end{array}$ & 1 & 19 & 35 & 38 & 400 & 0 & 0 & 6 & 400 \\
\hline TOTAL & & 785 & $\therefore \quad 18$ & 276 & 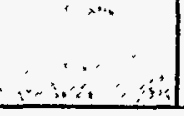 & 189 & 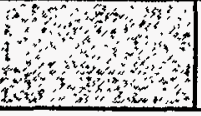 & 384 & 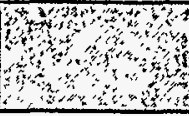 \\
\hline
\end{tabular}

NOTE: Infrastructure staff support the staff above. They receive no annual dose, average 4.000 travel miles, and average $50 \%$ of the facility totals above. 
Table D.2. Technology Option Characteristics. (Sheet 13 of 35)

Option: M. Traditional Flushing

Capital Cost: $\$ 92$ million

Annual Worker Mileage: 15000 miles

\begin{tabular}{|c|c|c|c|c|c|c|c|c|c|}
\hline \multirow[t]{2}{*}{ Activity } & \multirow{2}{*}{$\begin{array}{c}\text { Activity } \\
\text { Duration } \\
\text { (years) }\end{array}$} & \multicolumn{2}{|c|}{$\begin{array}{c}\text { Management and } \\
\text { Engineering } \\
\end{array}$} & \multicolumn{2}{|c|}{$\begin{array}{c}\text { Construction/Decommissioning } \\
\text { Crafts and Laborers }\end{array}$} & \multicolumn{2}{|c|}{ Maintenance Crafts } & \multicolumn{2}{|c|}{ Operators } \\
\hline & & $\begin{array}{l}\text { Total Person- } \\
\text { Years } \\
\end{array}$ & Annual Dose & $\begin{array}{c}\text { Total Person- } \\
\text { Years } \\
\end{array}$ & Annual Dose & $\begin{array}{l}\text { Total Person- } \\
\text { Years } \\
\end{array}$ & Annual Dose & $\begin{array}{l}\text { Total Person- } \\
\text { Years } \\
\end{array}$ & Annual Dose \\
\hline $\begin{array}{l}\text { Technology } \\
\text { Readiness }\end{array}$ & 5 & 37 & 0 & 12 & 0 & 0 & 0 & 0 & 0 \\
\hline Capital & 5 & 281 & 15 & 187 & 200 & 0 & 0 & 0 & 0 \\
\hline $\begin{array}{l}\text { Operations \& } \\
\text { Maintenance } \\
\end{array}$ & 15 & 328 & 35 & 0 & 0 & 164 & 250 & 328 & 250 \\
\hline $\begin{array}{c}\text { Decontamination } \\
\text { \& Decommissioning }\end{array}$ & 1 & 16 & 35 & 33 & 250 & 0 & 0 & 5 & 250 . \\
\hline TOTAL & & 662 & - & 232 & & 164 & 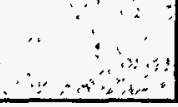 & 333 & 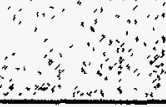 \\
\hline
\end{tabular}

NOTE: Infrastructure staff support the staff above They receive no annual dose, average 4,000 travel miles, and average $50 \%$ of the facility totals above. 
Option: N. Flush Water Treatment (for Close-Coupled Barrier)

Capital Cost: $\$ 8$ million Annual Worker Mileage: 15000 miles

\begin{tabular}{|c|c|c|c|c|c|c|c|c|c|}
\hline \multirow[t]{2}{*}{ Activity } & \multirow{2}{*}{$\begin{array}{l}\text { Activity } \\
\text { Duration } \\
\text { (years) }\end{array}$} & \multicolumn{2}{|c|}{$\begin{array}{c}\text { Management and } \\
\text { Engineering } \\
\end{array}$} & \multicolumn{2}{|c|}{$\begin{array}{c}\text { Construction/Decommissioning } \\
\text { Crafts and Laborers }\end{array}$} & \multicolumn{2}{|c|}{ Maintenance Crafts } & \multicolumn{2}{|c|}{ Operators } \\
\hline & & $\begin{array}{l}\text { Total Person- } \\
\text { Years } \\
\end{array}$ & Annual Dose & $\begin{array}{c}\text { Total Person- } \\
\text { Years } \\
\end{array}$ & Annual Dose & $\begin{array}{c}\text { Total Person- } \\
\text { Years }\end{array}$ & Annual Dose & $\begin{array}{c}\text { Total Person- } \\
\text { Years }\end{array}$ & Annual Dose \\
\hline $\begin{array}{l}\text { Technology } \\
\text { Readiness }\end{array}$ & 5 & 12 & 0 & 4 & 0 & 0 & 0 & 0 & 0 \\
\hline Capital & 5 & 24 & 15 & 16 & 50 & 0 & 0 & 0 & 0 \\
\hline $\begin{array}{l}\text { Operations \& } \\
\text { Maintenance } \\
\end{array}$ & 15 & 61 & 35 & 0 & 0 & 31 & 400 & 61 & 400 \\
\hline $\begin{array}{c}\text { Decontamination } \\
\& \text { Decommissioning } \\
\end{array}$ & 2 & 6 & 35 & 12 & 400 & 0 & 0 & 2 & 400 \\
\hline TOTAL & & 103 & $\because$ & 32 & & 31 & 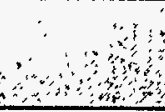 & 63 & 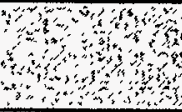 \\
\hline
\end{tabular}

NOTE: Infrastructure staff support the staff above. They receive no annual dose, average 4,000 travel miles, and average $50 \%$ of the facility totals above. 


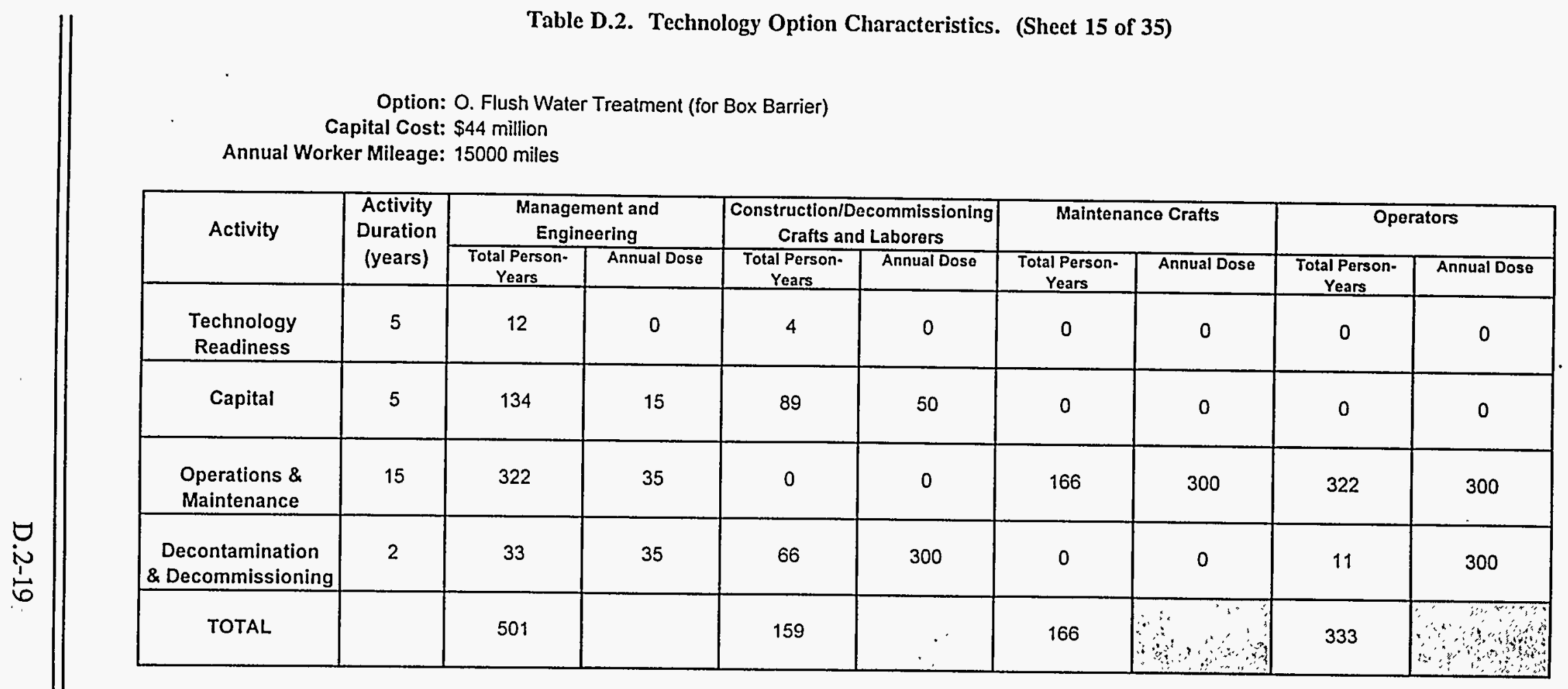

NOTE: Infrastructure staft support the staff above. They receive no annual dose, average 4,000 travel miles, and average $50 \%$ of the facility totals above. 
Table D.2. Technology Option Characteristics. (Sheet 16 of 35)

Option: P. Flush Water Treatment (for V-Shaped Barrier)

Capital Cost: $\$ 47$ million Annual Worker Mileage: 15000 miles

\begin{tabular}{|c|c|c|c|c|c|c|c|c|c|}
\hline \multirow[t]{2}{*}{ Activity } & \multirow{2}{*}{$\begin{array}{l}\text { Activity } \\
\text { Duration } \\
\text { (years) }\end{array}$} & \multicolumn{2}{|c|}{$\begin{array}{c}\text { Management and } \\
\text { Engineoring } \\
\end{array}$} & \multicolumn{2}{|c|}{$\begin{array}{c}\text { Construction/Decommissioning } \\
\text { Crafts and Laborers }\end{array}$} & \multicolumn{2}{|c|}{ Maintenance Crafts } & \multicolumn{2}{|c|}{ Operators } \\
\hline & & $\begin{array}{l}\text { Total Porson- } \\
\text { Years } \\
\end{array}$ & Annual Dose & $\begin{array}{c}\text { Total Person- } \\
\text { Years } \\
\end{array}$ & Annual Dose & $\begin{array}{l}\text { Total Person- } \\
\text { Years } \\
\end{array}$ & Annual Dose & $\begin{array}{l}\text { Total Porson- } \\
\text { Years } \\
\end{array}$ & Annual Dose \\
\hline $\begin{array}{c}\text { Technology } \\
\text { Readiness }\end{array}$ & 5 & 12 & 0 & 4 & 0 & 0 & 0 & 0 & 0 \\
\hline Capital & 5 & 143 & 15 & 95 & 50 & 0 & 0 & 0 & 0 \\
\hline $\begin{array}{l}\text { Operations \& } \\
\text { Maintenance }\end{array}$ & 15 & 355 & 35 & 0 & 0 & 177 & 300 & 355 & 300 \\
\hline $\begin{array}{c}\text { Decontamination } \\
\text { \& Decommissioning } \\
\end{array}$ & 2 & 35 & 35 & 71 & 300 & 0 & 0 & 12 & 300 \\
\hline TOTAL & & 545 & & 170 & & 177 & 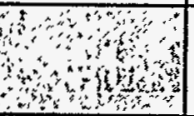 & 367 & and \\
\hline
\end{tabular}

NOTE. Infrastructure staff support the staff above. They receive no annual dose, average 4.000 travel miles, and average $50 \%$ of the facility totals above. 
Table D.2. Technology Option Characteristics. (Sheet 17 of 35)

Option: Q. Flush Water Treatment (for Circulating Air Barrier)

Capital Cost: \$14 million

Annual Worker Mileage: 15000 miles

\begin{tabular}{|c|c|c|c|c|c|c|c|c|c|}
\hline \multirow[t]{2}{*}{ Activity } & \multirow{2}{*}{$\begin{array}{l}\text { Activity } \\
\text { Duration } \\
\text { (years) }\end{array}$} & \multicolumn{2}{|c|}{$\begin{array}{l}\text { Management and } \\
\text { Engineering }\end{array}$} & \multicolumn{2}{|c|}{$\begin{array}{c}\text { Construction/Decommissioning } \\
\text { Crafts and Laborers }\end{array}$} & \multicolumn{2}{|c|}{ Maintenance Crafts } & \multicolumn{2}{|c|}{ Operators } \\
\hline & & $\begin{array}{c}\text { Total Porson- } \\
\text { Years } \\
\end{array}$ & Annual Doso & $\begin{array}{c}\text { Total Person- } \\
\text { Years } \\
\end{array}$ & \begin{tabular}{l|} 
Annual Dose \\
\end{tabular} & $\begin{array}{l}\text { Total Person- } \\
\text { Years } \\
\end{array}$ & Annual Dose & $\begin{array}{c}\text { Total Person- } \\
\text { Years }\end{array}$ & Annual Dose \\
\hline $\begin{array}{l}\text { Technology } \\
\text { Readiness }\end{array}$ & 5 & 12 & 0 & 4 & 0 & 0 & 0 & 0 & 0 \\
\hline Capital & 5 & 42 & 15 & 28 & 50 & 0 & 0 & 0 & 0 \\
\hline $\begin{array}{l}\text { Operations \& } \\
\text { Maintenance }\end{array}$ & 15 & 106 & 35 & 0 & 0 & 53 & 400 & 106 & 400 \\
\hline $\begin{array}{l}\text { Decontamination } \\
\text { \& Decommissioning }\end{array}$ & 2 & 11 & 35 & 21 & 400 & 0 & 0 & 4 & 400 \\
\hline TOTAL & & 171 & & 53 & & 53 & 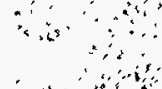 & 110 & \\
\hline
\end{tabular}

NOTE: infrastructure staff support the staff above. They receive no annual dose, average 4,000 travel miles, and average $50 \%$ of the facility totals above. 
Option: R. Tank Stabilization

Capital Cost: $\$ 2$ million

Annual Worker Mileage: 15000 miles

\begin{tabular}{|c|c|c|c|c|c|c|c|c|c|}
\hline \multirow[t]{2}{*}{ Activity } & \multirow{2}{*}{$\begin{array}{l}\text { Activity } \\
\text { Duration } \\
\text { (years) }\end{array}$} & \multicolumn{2}{|c|}{$\begin{array}{l}\text { Management and } \\
\text { Engineering }\end{array}$} & \multicolumn{2}{|c|}{$\begin{array}{c}\text { Construction/Decommissioning } \\
\text { Grafts and Laborers }\end{array}$} & \multicolumn{2}{|c|}{ Maintenance Crafts } & \multicolumn{2}{|c|}{ Operators } \\
\hline & & $\begin{array}{l}\text { Total Person- } \\
\text { Years }\end{array}$ & Annual Dose & $\begin{array}{c}\begin{array}{c}\text { Total Person- } \\
\text { Years }\end{array} \\
\end{array}$ & Annual Dose & $\begin{array}{l}\text { Total Person- } \\
\text { Years } \\
\end{array}$ & Annual Dose & $\begin{array}{c}\begin{array}{c}\text { Total Person- } \\
\text { Years }\end{array} \\
\end{array}$ & Annual Dose \\
\hline $\begin{array}{l}\text { Technology } \\
\text { Readiness }\end{array}$ & 5 & 6 & 0 & 2 & 0 & 0 & 0 & 0 & 0 \\
\hline Capital & 5 & 6 & 15 & 4 & 200 & 0 & 0 & 0 & 0 \\
\hline $\begin{array}{l}\text { Operations \& } \\
\text { Maintenance } \\
\end{array}$ & 15 & 12 & 35 & 0 & 0 & 6 & 200 & 12 & 200 \\
\hline $\begin{array}{l}\text { Decontamination } \\
\text { \& Decommissioning } \\
\end{array}$ & 0 & 0 & 35 & 0 & 200 & 0 & 0 & 0 & 200 \\
\hline TOTAL & & 24 & : & 6 & . & 6 & 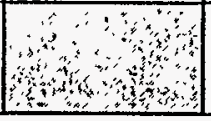 & 12 & 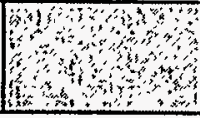 \\
\hline
\end{tabular}

NOTE: Infrastructure staff support the staff above. They receive no annual dose, average 4,000 travel miles, and average $50 \%$ of the faclity totals above. 
Option: S. Surface Barrier

Capital Cost: $\$ 4$ million

Annual Worker Mileage: 15000 miles

\begin{tabular}{|c|c|c|c|c|c|c|c|c|c|}
\hline \multirow[t]{2}{*}{ Activity } & \multirow{2}{*}{$\begin{array}{l}\text { Activity } \\
\text { Duration } \\
\text { (years) }\end{array}$} & \multicolumn{2}{|c|}{$\begin{array}{c}\text { Management and } \\
\text { Engineering }\end{array}$} & \multicolumn{2}{|c|}{$\begin{array}{c}\text { Construction/Decommissioning } \\
\text { Crafts and Laborers } \\
\end{array}$} & \multicolumn{2}{|c|}{ Maintenance Crafts } & \multicolumn{2}{|c|}{ Operators } \\
\hline & & $\begin{array}{c}\text { Total Person- } \\
\text { Years } \\
\end{array}$ & Annual Dose & $\begin{array}{c}\text { Total Person- } \\
\text { Years } \\
\end{array}$ & Annual Dose & $\begin{array}{l}\text { Total Person- } \\
\text { Years } \\
\end{array}$ & Annual Dose & $\begin{array}{l}\text { Total Porson- } \\
\text { Years } \\
\end{array}$ & Annual Dose \\
\hline $\begin{array}{l}\text { Technology } \\
\text { Readiness }\end{array}$ & 5 & 12 & 0 & 4 & 0 & 0 & 0 & 0 & 0 \\
\hline Capital & 5 & 12 & 15 & 8 & 100 & 0 & 0 & 0 & 0 \\
\hline $\begin{array}{l}\text { Operations \& } \\
\text { Maintenance }\end{array}$ & 15 & 12 & 35 & 0 & 0 & 6 & 100 & 12 & 100 \\
\hline $\begin{array}{c}\text { Decontamination } \\
\& \text { Decommissioning }\end{array}$ & 0 & 0 & 0 & 0 & 0 & 0 & 0 & 0 & 0 \\
\hline TOTAL & & 36 & & 12 & & 6 & 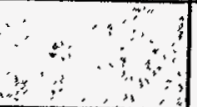 & 12 & 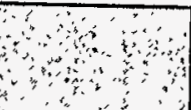 \\
\hline
\end{tabular}

NOTE: Infrastructure staff support the staff above. They receive no annual dose, average 4,000 travel miles, and average $50 \%$ or the facility totals above. 
Option: T. Clean Closure (no barrier)

Capital Cost: $\$ 730$ million

Annual Worker Mileage: 15000 miles

\begin{tabular}{|c|c|c|c|c|c|c|c|c|c|}
\hline \multirow[t]{2}{*}{ Activity } & \multirow{2}{*}{$\begin{array}{c}\text { Activity } \\
\text { Duration } \\
\text { (years) }\end{array}$} & \multicolumn{2}{|c|}{$\begin{array}{c}\text { Managoment and } \\
\text { Englnooring }\end{array}$} & \multicolumn{2}{|c|}{$\begin{array}{c}\text { Construction/Decommissioning } \\
\text { Crafts and Laborers }\end{array}$} & \multicolumn{2}{|c|}{ Maintenanco Crafts } & \multicolumn{2}{|c|}{ Operators } \\
\hline & & $\begin{array}{l}\text { Total Porson- } \\
\text { Years } \\
\end{array}$ & Annual Doso & $\begin{array}{c}\begin{array}{c}\text { Total Person- } \\
\text { Years }\end{array} \\
\end{array}$ & Annual Dose & $\begin{array}{l}\text { Total Person- } \\
\text { Years } \\
\end{array}$ & Annual Dose & $\begin{array}{c}\text { Total Porson- } \\
\text { Years }\end{array}$ & Annual Doso \\
\hline $\begin{array}{l}\text { Technology } \\
\text { Readiness }\end{array}$ & 5 & 124 & 0 & 41 & 0 & 0 & 0 & 0 & 0 \\
\hline Capital & 5 & 2234 & 15 & 1489 & 300 & 0 & 0 & 0 & 0 \\
\hline $\begin{array}{l}\text { Operations \& } \\
\text { Maintenance }\end{array}$ & 20 & 2246 & 35 & 0 & 0 & 1123 & 400 & 2246 & 400 \\
\hline $\begin{array}{l}\text { Decontamination } \\
\text { \& Decommissioning }\end{array}$ & 3 & 229 & 35 & 458 & 400 & 0 & 0 & 73 & 400 \\
\hline TOTAL & & 4833 & $x \quad \therefore \quad \therefore \quad \therefore$ & 1988 & $\therefore,^{i}:$ & 1123 & 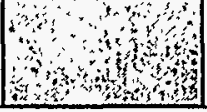 & 2319 & 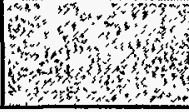 \\
\hline
\end{tabular}

NOTE: Infrastructure staff support the staff above. They receive no annual dose, average 4,000 travel miles, and average $50 \%$ of the facility totals above. 
Table D.2. Technology Option Characteristics. (Sheet 21 of 35)

Option: U. Clean Closure (with Close-Coupled Barrier)

Capital Cost: $\$ 584$ million Annual Worker Mileage: 15000 miles

\begin{tabular}{|c|c|c|c|c|c|c|c|c|c|}
\hline \multirow[t]{2}{*}{ Activity. } & \multirow{2}{*}{$\begin{array}{l}\text { Activity } \\
\text { Duration } \\
\text { (years) }\end{array}$} & \multicolumn{2}{|c|}{$\begin{array}{l}\text { Management and } \\
\text { Engineering }\end{array}$} & \multicolumn{2}{|c|}{$\begin{array}{c}\text { Construction/Decommissioning } \\
\text { Crafts and Laborers }\end{array}$} & \multicolumn{2}{|c|}{ Maintenance Crafts } & \multicolumn{2}{|c|}{ Operators } \\
\hline & & $\begin{array}{c}\text { Total Person- } \\
\text { Years }\end{array}$ & Annual Dose & \begin{tabular}{|c|}
$\begin{array}{c}\text { Total Person- } \\
\text { Years }\end{array}$ \\
\end{tabular} & Annual Dose & $\begin{array}{l}\text { Total Person- } \\
\text { Years } \\
\end{array}$ & Annual Doso & $\begin{array}{c}\text { Total Person- } \\
\text { Years } \\
\end{array}$ & Annual Dose \\
\hline $\begin{array}{l}\text { Technology } \\
\text { Readiness }\end{array}$ & 5 & 124 & 0 & 41 & 0 & 0 & 0 & 0 & 0 \\
\hline Capital & 5 & 1787 & 15 & 1191 & 300 & 0 & 0 & 0 & 0 \\
\hline $\begin{array}{l}\text { Operations \& } \\
\text { Maintenance }\end{array}$ & 20 & 2231 & 35 & 0 & 0 & 1115 & 400 & 2231 & 400 \\
\hline $\begin{array}{c}\text { Decontamination } \\
\text { \& Decommissioning } \\
\end{array}$ & 3 & 225 & 35 & 449 & 400 & 0 & 0 & 72 & 400 \\
\hline TOTAL & & 4367 & & 1681 & & 1115 & 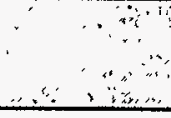 & 2303 & 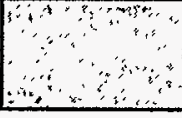 \\
\hline
\end{tabular}

NOTE: Infrastructure staff support the staff above, They recelve no annual dose, average 4,000 travel miles, and average $50 \%$ of the facility totals above. 
Alternative: 1 No Action

Capital Cost: $\$ 0$ million Annual Worker Mileage: 0 miles

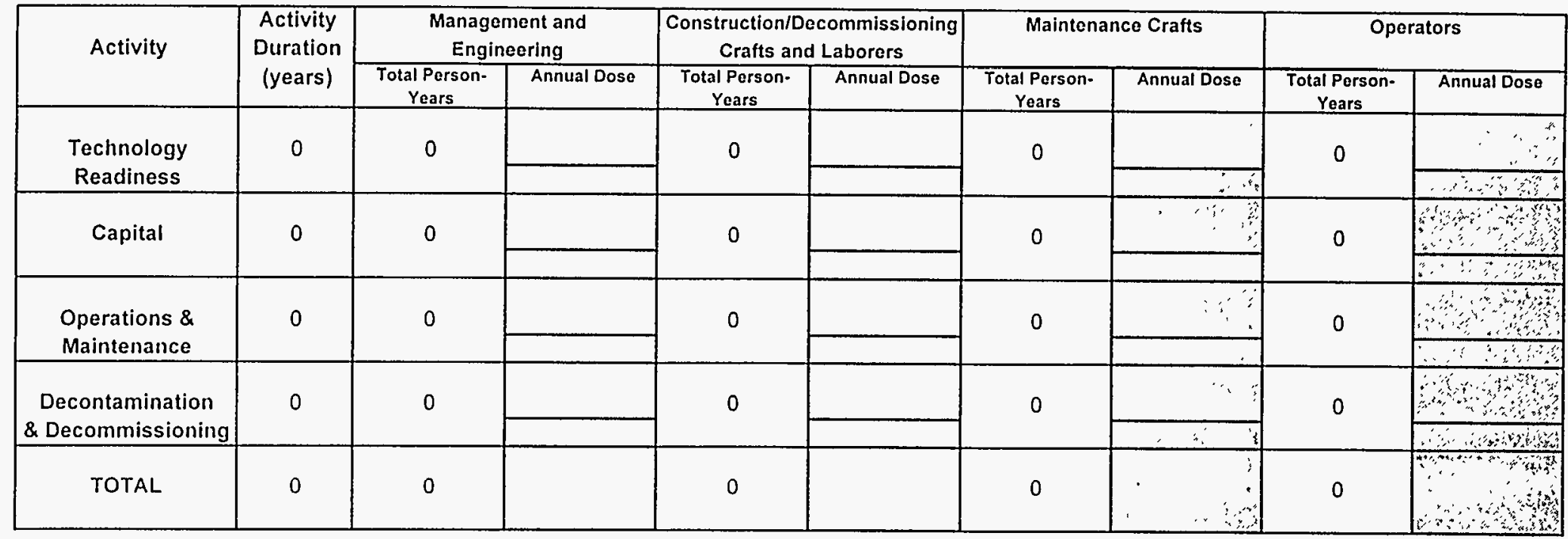

NOTE Infrastructure staff support the staff above They receive no annual dose, average 4,000 travel miles, and average $50 \%$ of the facility totals above 


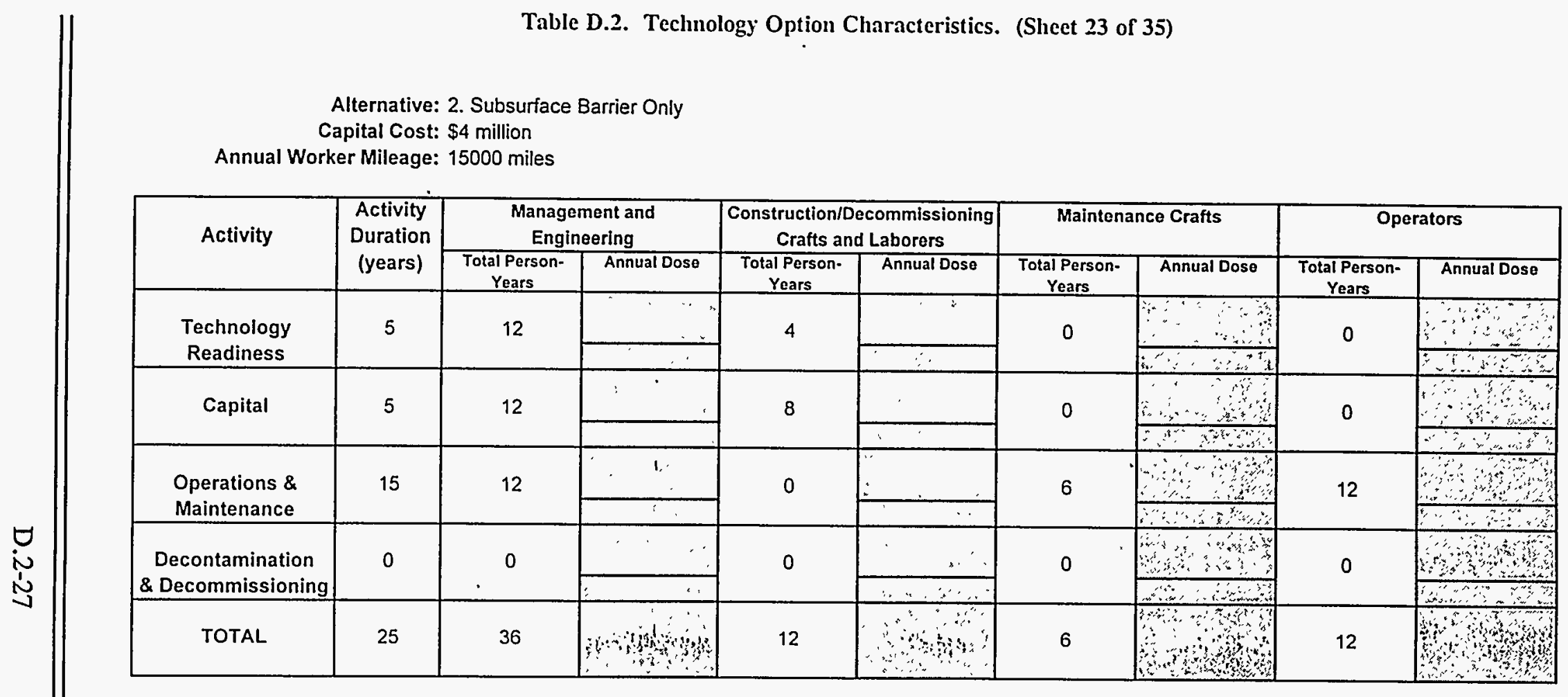

NOTE. Infrastructure stafl support the staff above They receive no annual dose, average 4,000 travel miles, and average $50 \%$ of the facility totals above. 
Option: 3. Traditional Sluicing

Capital Cost: $\$ 69$ million

Annual Worker Mileage: 15000 miles

\begin{tabular}{|c|c|c|c|c|c|c|c|c|c|}
\hline \multirow[t]{2}{*}{ Activity } & \multirow{2}{*}{$\begin{array}{l}\text { Activity } \\
\text { Duration } \\
\text { (years) }\end{array}$} & \multicolumn{2}{|c|}{$\begin{array}{c}\text { Management and } \\
\text { Engineering }\end{array}$} & \multicolumn{2}{|c|}{$\begin{array}{l}\text { Construction/Decommissioning } \\
\text { Crafts and Laborers }\end{array}$} & \multicolumn{2}{|c|}{ Maintenance Crafts } & \multicolumn{2}{|c|}{ Operators } \\
\hline & & $\begin{array}{c}\text { Total Person- } \\
\text { Years }\end{array}$ & Annual Dose & $\begin{array}{c}\text { Total Person- } \\
\text { Years }\end{array}$ & Annual Dose & $\begin{array}{l}\text { Total Person- } \\
\text { Years }\end{array}$ & Annual Dose & $\begin{array}{l}\text { Total Person- } \\
\text { Years }\end{array}$ & Annual Doso \\
\hline \multirow{2}{*}{$\begin{array}{l}\text { Technology } \\
\text { Readiness }\end{array}$} & \multirow[t]{2}{*}{15} & \multirow[t]{2}{*}{30} & 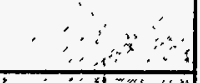 & \multirow[t]{2}{*}{10} & 17 & \multirow{2}{*}{ 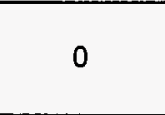 } & \multirow{2}{*}{ 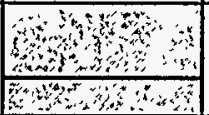 } & \multirow{2}{*}{ (2) } & atos \\
\hline & & & 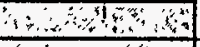 & & $\because+\cdots$ & & & & is \\
\hline \multirow[t]{2}{*}{ Capital } & \multirow[t]{2}{*}{15} & \multirow[t]{2}{*}{211} & $\therefore 4$ & \multirow[t]{2}{*}{138} & $\because \cdots, \because \because \cdots$ & \multirow[t]{2}{*}{0} & and & \multirow[t]{2}{*}{0} & and \\
\hline & & & 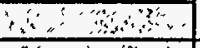 & & $0,1, \div, \% 3$ & & 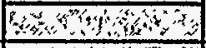 & & 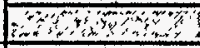 \\
\hline \multirow{2}{*}{$\begin{array}{l}\text { Operations \& } \\
\text { Maintenance }\end{array}$} & \multirow[t]{2}{*}{45} & \multirow[t]{2}{*}{171} & $\because \because \cdots$ & \multirow[t]{2}{*}{0} & 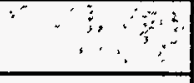 & \multirow[t]{2}{*}{86} & 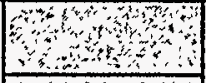 & \multirow[t]{2}{*}{171} & 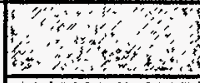 \\
\hline & & & $w$ & & $\cdots \quad \therefore$ & & $y$ a d & & a \\
\hline \multirow{2}{*}{$\begin{array}{l}\text { Decontamination } \\
\text { \& Decommissioning }\end{array}$} & \multirow{2}{*}{1} & \multirow{2}{*}{7} & $\because \because \because \because \because \cdots$ & \multirow{2}{*}{15} & $x^{2}$ & \multirow{2}{*}{0} & 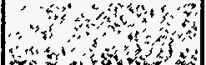 & \multirow{2}{*}{2} & (1) \\
\hline & & & $\ldots$ & & & & and & & 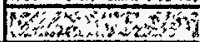 \\
\hline TOTAL & 76 & 419 & & 163 & $\therefore \quad \because \hat{\imath} \cdot \cdots$ & 86 & 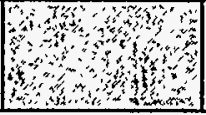 & 173 & 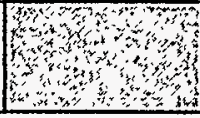 \\
\hline
\end{tabular}

NOTE: Infrastructure staff support the staff above They receive no annual dose, average 4.000 travel miles, and average $50 \%$ of the facilty totals above. 
Table D.2. Technology Option Characteristics. (Sheet 25 of 35)

Alternative: 4. Robotic Sluicing

Capital Cost: $\$ 189$ million

Annual Worker Mileage: 15000 miles

\begin{tabular}{|c|c|c|c|c|c|c|c|c|c|}
\hline \multirow[t]{2}{*}{ Activity } & \multirow{2}{*}{$\begin{array}{l}\text { Activity } \\
\text { Duration } \\
\text { (years) }\end{array}$} & \multicolumn{2}{|c|}{$\begin{array}{c}\text { Management and } \\
\text { Engineering }\end{array}$} & \multicolumn{2}{|c|}{$\begin{array}{c}\text { Construction/Decommissioning } \\
\text { Crafts and Laborers }\end{array}$} & \multicolumn{2}{|c|}{ Maintenance Crafts } & \multicolumn{2}{|c|}{ Operators } \\
\hline & & $\begin{array}{l}\text { Total Person- } \\
\text { Years } \\
\end{array}$ & Annual Dose & $\begin{array}{c}\text { Total Person- } \\
\text { Years } \\
\end{array}$ & \begin{tabular}{|l|} 
Annual Dose \\
\end{tabular} & $\begin{array}{l}\text { Total Person- } \\
\text { Years } \\
\end{array}$ & Annual Dose & $\begin{array}{c}\text { Total Person- } \\
\text { Years }\end{array}$ & Annual Dose \\
\hline $\begin{array}{c}\text { Technology } \\
\text { Readiness }\end{array}$ & 15 & 128 & $\frac{1}{0}$ & 43 & 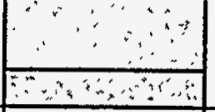 & 0 & 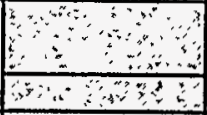 & 0 & \\
\hline Capital & 15 & 578 & 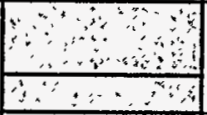 & 385 & 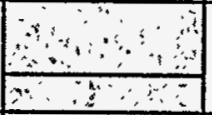 & 0 & 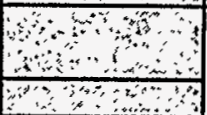 & 0 & \\
\hline $\begin{array}{l}\text { Operations \& } \\
\text { Maintenance }\end{array}$ & 45 & 1269 & 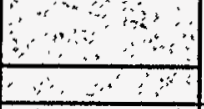 & 0 & 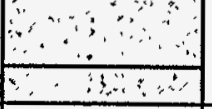 & 634 & $\frac{1}{4}$ & 1269 & \\
\hline $\begin{array}{c}\text { Decontamination } \\
\text { \& Decommissioning } \\
\end{array}$ & 2 & 124 & $\frac{1}{\therefore}$ & 249 & 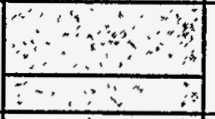 & 0 & 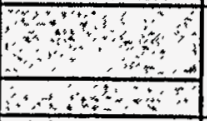 & 41 & \begin{tabular}{|c|c|} 
\\
3
\end{tabular} \\
\hline TOTAL & 77 & 2099 & 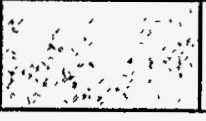 & 677 & 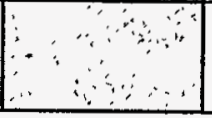 & 634 & 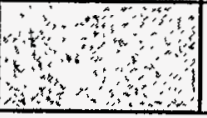 & 1310 & 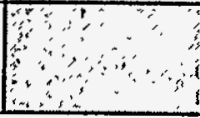 \\
\hline
\end{tabular}

NOTE: Infrastructure staff support the staff above. They receive no annual dose, average 4,000 travel miles, and average $50 \%$ of the facility totals above. 


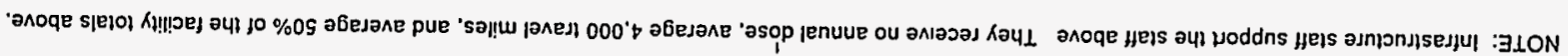

\begin{tabular}{|c|c|c|c|c|c|c|c|c|c|}
\hline 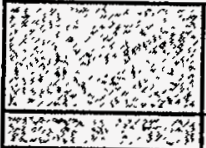 & OLEL & 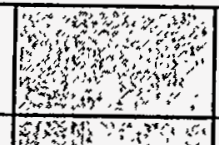 & $\triangleright \varepsilon 9$ & 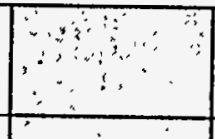 & Zl9 & 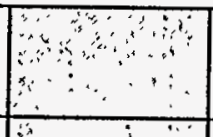 & 2661 & $\angle L$ & 7V1OL \\
\hline 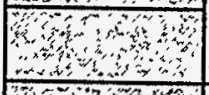 & It & 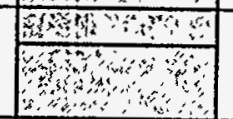 & 0 & $\therefore w, \therefore$ & $6 \hookleftarrow 2$ & 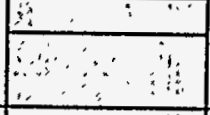 & $\nabla Z L$ & $z$ & 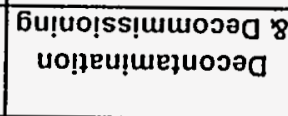 \\
\hline 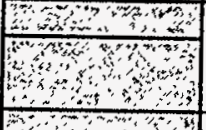 & $69 z$ & 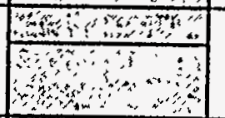 & $\downarrow \varepsilon 9$ & $\therefore \quad: \quad: \cdots$ & 0 & 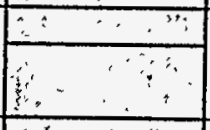 & $692 \mathrm{~L}$ & Sb & $\begin{array}{l}\text { әJueuaju!ew } \\
8 \text { suo!jesado }\end{array}$ \\
\hline 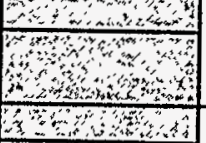 & 0 & 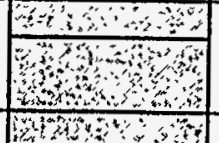 & 0 & 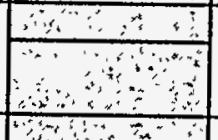 & $92 \varepsilon$ & 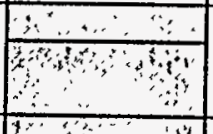 & $68 b$ & Sl & ןej!des \\
\hline $\begin{array}{r}4 \\
4\end{array}$ & 0 & and & ( & $\frac{1}{3}$ & $\angle \mathcal{E}$ & \begin{tabular}{ccc}
$*$ \\
\hdashline \\
\hdashline
\end{tabular} & Oll & Gl & $\begin{array}{l}\text { Ssau!peay } \\
\text { KБо|оuчग्ग }\end{array}$ \\
\hline osog jenuay & $\begin{array}{c}\text { SDeoर } \\
\text { - पossod } \\
\end{array}$ & osog jenuuy & 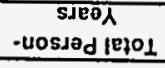 & \begin{tabular}{|l|} 
osoo jenuuy \\
\end{tabular} & $\begin{array}{c}\text { Sseod } \\
\text { - Uosiod } 18101 \\
\end{array}$ & esogjenuev & 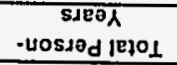 & (s.seəK) & \multirow[b]{2}{*}{ 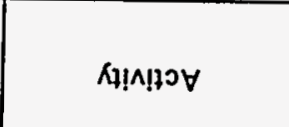 } \\
\hline \multicolumn{2}{|c|}{ suǫ̧esodo } & \multicolumn{2}{|c|}{ 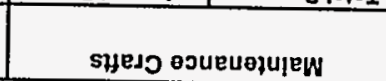 } & \multicolumn{2}{|c|}{ 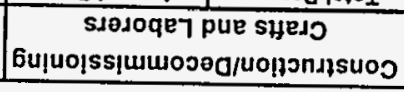 } & \multicolumn{2}{|c|}{$\begin{array}{c}\text { 6u!doou!bug } \\
\text { pur juour6euew }\end{array}$} & 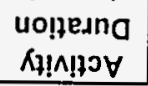 & \\
\hline
\end{tabular}

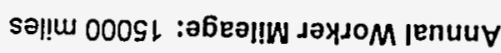
Uo!n!w 09l\$ : isoo ley!des.

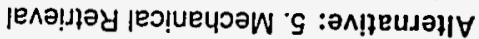

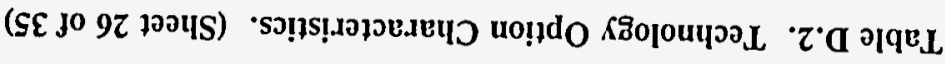




\begin{tabular}{|c|c|c|c|c|c|c|c|c|c|}
\hline Annual Worl & $\begin{array}{l}\text { Iternative: } \\
\text { pital Cost: } \\
\text { er Mileage: }\end{array}$ & $\begin{array}{l}\text { Close-Coup } \\
387 \text { million } \\
5000 \text { miles }\end{array}$ & d Chemical B & & & & & & \\
\hline \multirow[t]{2}{*}{ Activity } & \multirow{2}{*}{$\begin{array}{l}\text { Activity } \\
\text { Duration } \\
\text { (years) }\end{array}$} & \multicolumn{2}{|c|}{$\begin{array}{l}\text { Management and } \\
\text { Engineering }\end{array}$} & \multicolumn{2}{|c|}{$\begin{array}{l}\text { Construction/Decommissioning } \\
\text { Crafts and Laborers }\end{array}$} & \multicolumn{2}{|c|}{ Maintenance Crafts } & \multicolumn{2}{|c|}{ Operators } \\
\hline & & $\begin{array}{c}\begin{array}{c}\text { Total Person- } \\
\text { Years }\end{array} \\
\end{array}$ & Annual Dose & $\begin{array}{c}\text { Total Person- } \\
\text { Years } \\
\end{array}$ & Annual Dose & $\begin{array}{c}\text { Total Person- } \\
\text { Years }\end{array}$ & Annual Dose & $\begin{array}{l}\text { Total Person- } \\
\text { Years } \\
\end{array}$ & Annual Dose \\
\hline $\begin{array}{l}\text { Technology } \\
\text { Readiness }\end{array}$ & 25 & 171 & & 57 & & 0 & & 0 & 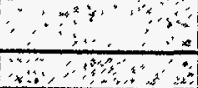 \\
\hline Capital & 25 & .1184 & $\therefore \quad \cdots$ & 786 & & 0 & (2) & 0 & $\therefore$ \\
\hline $\begin{array}{l}\text { Operations \& } \\
\text { Maintenance }\end{array}$ & 75 & 735 & $\because$ & 0 & $\because$ & 368 & $\frac{1}{4}$ & 735 & 4 \\
\hline $\begin{array}{l}\text { Decontamination } \\
\text { \& Decommissioning } \\
\end{array}$ & 2 & 26 & $\frac{1}{1}$ & 53 & ' & 0 & $\frac{1}{4}$ & $8^{\prime}$ & ( \\
\hline TOTAL & 127 & 2116 & & 896 & $:$ & 368 & $\begin{array}{l}\because \\
\because \\
\therefore\end{array}$ & 743 & 40 \\
\hline
\end{tabular}

NOTE: Infrastructure slaff support the staff above. They receive no annual dose, average 4.000 travel miles, and average $50 \%$ of the facility totals above 
Alternative: 7. Close-Coupled Chemical Barrier without Flushing

Capital Cost: $\$ 214$ million

Annual Worker Mileage: 15000 miles

\begin{tabular}{|c|c|c|c|c|c|c|c|c|c|}
\hline \multirow[t]{2}{*}{ Activity } & \multirow{2}{*}{$\begin{array}{l}\text { Activity } \\
\text { Duration } \\
\text { (years) }\end{array}$} & \multicolumn{2}{|c|}{$\begin{array}{c}\text { Management and } \\
\text { Engineering }\end{array}$} & \multicolumn{2}{|c|}{$\begin{array}{c}\text { Construction/Decommissioning } \\
\text { Crafts and Laborers }\end{array}$} & \multicolumn{2}{|c|}{ Maintenance Crafts } & \multicolumn{2}{|c|}{ Operators } \\
\hline & & $\begin{array}{l}\text { Total Person- } \\
\text { Years }\end{array}$ & Annual Dose & $\begin{array}{c}\text { Total Person. } \\
\text { Years } \\
\end{array}$ & Annual Dose & $\begin{array}{l}\text { Total Person- } \\
\text { Years }\end{array}$ & Annual Dose & $\begin{array}{l}\text { Total Person- } \\
\text { Years }\end{array}$ & Annual Dose \\
\hline $\begin{array}{l}\text { Technology } \\
\text { Readiness }\end{array}$ & 20 & 110 & $\frac{\because !}{\cdots !}$ & 37 & & $\cdot$ & 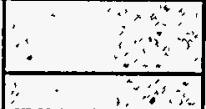 & 0 & 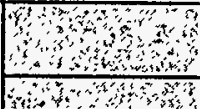 \\
\hline Capital & 20 & 654 & $\frac{1}{2 !}$ & 433 & & 0 & 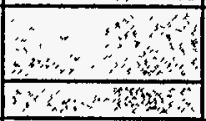 & 0 & 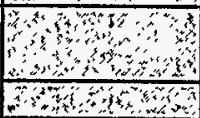 \\
\hline $\begin{array}{l}\text { Operations \& } \\
\text { Maintenance }\end{array}$ & 60 & 357 & & 0 & $\therefore$ & 179 & 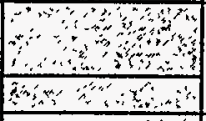 & 357 & 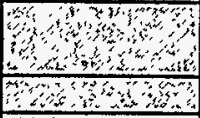 \\
\hline $\begin{array}{c}\text { Decontamination } \\
\text { \& Decommissioning } \\
\end{array}$ & 1 & 7 & \begin{tabular}{r}
3 \\
$\vdots$ \\
\hdashline \\
\end{tabular} & 15 & $\therefore$ & 0 & 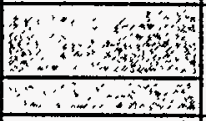 & 2 & 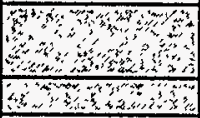 \\
\hline TOTAL & 101 & 1128 & & 485 & & 179 & 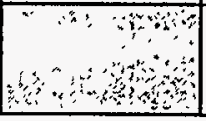 & 359 & 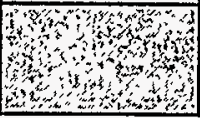 \\
\hline
\end{tabular}

NOTE: Infrastructure staff support the staff above They receive no annual dose, average 4.000 travel miles, and average $50 \%$ of the facility totals above. 
Alternative: 8 . Modified Close-Coupled Barrier without Flushing

Capital Cost: $\$ 180$ million

Annual Worker Mileage: 15000 miles

\begin{tabular}{|c|c|c|c|c|c|c|c|c|c|}
\hline \multirow[t]{2}{*}{ Activity } & \multirow{2}{*}{$\begin{array}{l}\text { Activity } \\
\text { Duration } \\
\text { (years) }\end{array}$} & \multicolumn{2}{|c|}{$\begin{array}{c}\text { Management and } \\
\text { Engineering }\end{array}$} & \multicolumn{2}{|c|}{$\begin{array}{c}\text { Construction/Decommissioning } \\
\text { Crafts and Laborers }\end{array}$} & \multicolumn{2}{|c|}{ Maintenance Crafts } & \multicolumn{2}{|c|}{ Operators } \\
\hline & & $\begin{array}{l}\text { Total Person- } \\
\text { Years }\end{array}$ & Annual Dose & $\begin{array}{c}\begin{array}{c}\text { Total Person- } \\
\text { Years }\end{array} \\
\end{array}$ & Annual Dose & $\begin{array}{l}\text { Total Person- } \\
\text { Years } \\
\end{array}$ & Annual Dose & $\begin{array}{c}\text { Total Person- } \\
\text { Years } \\
\end{array}$ & Annual Dose \\
\hline \multirow{2}{*}{$\begin{array}{l}\text { Technology } \\
\text { Readiness }\end{array}$} & \multirow[t]{2}{*}{20} & \multirow[t]{2}{*}{73} & & \multirow[t]{2}{*}{24} & & \multirow[t]{2}{*}{0} & 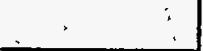 & \multirow[t]{2}{*}{0} & \\
\hline & & & & & & & $1 \quad \therefore \quad \cdots$ & & $\because y$ \\
\hline \multirow[t]{2}{*}{ Capital } & \multirow[t]{2}{*}{20} & \multirow[t]{2}{*}{550} & . & \multirow[t]{2}{*}{364} & & \multirow[t]{2}{*}{0} & 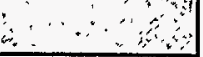 & \multirow[t]{2}{*}{0} & $\because \therefore a^{2}=$ \\
\hline & & & & & & & $\therefore$ & & $7, x^{\prime \prime 2}$ \\
\hline \multirow{2}{*}{$\begin{array}{l}\text { Operations \& } \\
\text { Maintenance }\end{array}$} & \multirow[t]{2}{*}{60} & \multirow[t]{2}{*}{357} & & \multirow[t]{2}{*}{0} & 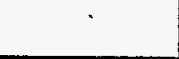 & \multirow[t]{2}{*}{179} & & \multirow[t]{2}{*}{357} & \\
\hline & & & & & & & 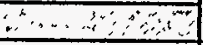 & & $27 \div, x^{\prime \prime}=3$ \\
\hline \multirow{2}{*}{$\begin{array}{c}\text { Decontamination } \\
\& \text { Decommissioning }\end{array}$} & \multirow[t]{2}{*}{1} & \multirow[t]{2}{*}{7} & & \multirow[t]{2}{*}{15} & & \multirow[t]{2}{*}{0} & 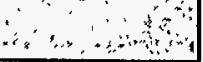 & \multirow[t]{2}{*}{2} & 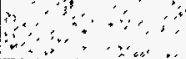 \\
\hline & & & & & & & $\therefore, \quad \cdots$ & & 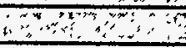 \\
\hline TOTAL & 101 & 987 & - & 403 & & 179 & $\because \because \cdots$ & 359 & \\
\hline & & & & & & & $x^{2}, \ldots, 0$ & & 策 \\
\hline
\end{tabular}

NOTE. Infrastructure staff support the staff above They receive no annual dose, average 4.000 travel miles, and average $50 \%$ of the faclity totals above. 
Alternative: 9 . Box-Shaped Stand-Off Chemical Barrier

Capital Cost: $\$ 331$ million Annual Worker Mileage: 15000 miles

\begin{tabular}{|c|c|c|c|c|c|c|c|c|c|}
\hline \multirow[t]{2}{*}{ Activity } & \multirow{2}{*}{$\begin{array}{c}\text { Activity } \\
\text { Duration } \\
\text { (years) }\end{array}$} & \multicolumn{2}{|c|}{$\begin{array}{c}\text { Management and } \\
\text { Engineering }\end{array}$} & \multicolumn{2}{|c|}{$\begin{array}{c}\text { Construction/Decommissioning } \\
\text { Crafts and Laborers }\end{array}$} & \multicolumn{2}{|c|}{ Maintenance Crafts } & \multicolumn{2}{|c|}{ Operators } \\
\hline & & $\begin{array}{l}\text { Total Person- } \\
\text { Years }\end{array}$ & Annual Dose & $\begin{array}{c}\begin{array}{c}\text { Total Porson- } \\
\text { Yoars }\end{array} \\
\end{array}$ & Annual Dose & $\begin{array}{c}\text { Total Porson- } \\
\text { Years } \\
\end{array}$ & Annual Dose & $\begin{array}{l}\text { Total Person- } \\
\text { Years }\end{array}$ & Annual Dose \\
\hline Technology & 25 & 122 & & 41 & & 0 & and & 0 & and \\
\hline Readiness & & & 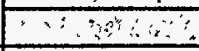 & & $\therefore \quad .3 \%$ & & 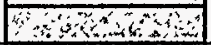 & & 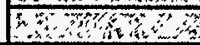 \\
\hline Capital & 25 & 1012 & $\therefore y$ & 671 & 政, & 0 & 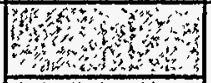 & 0 & and \\
\hline & & & $0,36 y_{2}=0$ & & 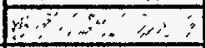 & & Sory & & 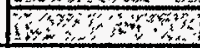 \\
\hline $\begin{array}{l}\text { Operations \& } \\
\text { Maintenance }\end{array}$ & 75 & 679 & 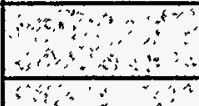 & 0 & 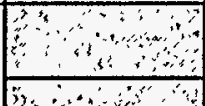 & 345 & 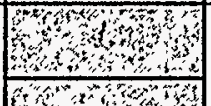 & 679 & 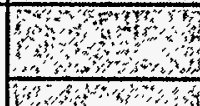 \\
\hline $\begin{array}{l}\text { Decontamination } \\
\text { \& Decommissioning }\end{array}$ & 3 & 40 & $\frac{1}{1}$ & 81 & $\frac{1}{20}$ & 0 & 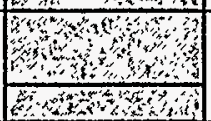 & 13 & 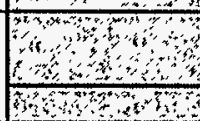 \\
\hline TOTAL & 128 & 1853 & 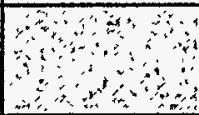 & 793 & 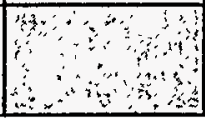 & 345 & 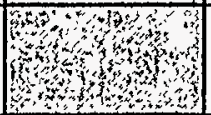 & 692 & 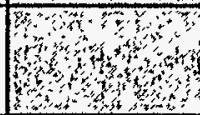 \\
\hline
\end{tabular}

NOTE: Infrastructure staff support the staff above. They receive no annual dose, average 4.000 travel miles, and average $50 \%$ of the facility totals above. 
Table D.2. Technology Option Characteristics. (Sheet 31 of 35)

\begin{tabular}{|c|c|c|c|c|c|c|c|c|c|}
\hline Annual Work & $\begin{array}{l}\text { Iternative: } \\
\text { pital Cost: } \\
\text { er Mileage: }\end{array}$ & $\begin{array}{l}\text { 0. V-Shaped } \\
429 \text { million } \\
5000 \text { miles }\end{array}$ & hemical Barrier & & & & & & \\
\hline \multirow[t]{2}{*}{ Activity } & \multirow{2}{*}{$\begin{array}{c}\text { Activity } \\
\text { Duration } \\
\text { (years) }\end{array}$} & \multicolumn{2}{|c|}{$\begin{array}{c}\text { Management and } \\
\text { Engineering } \\
\end{array}$} & \multicolumn{2}{|c|}{$\begin{array}{c}\text { Construction/Decommissioning } \\
\text { Crafts and Laborers }\end{array}$} & \multicolumn{2}{|c|}{ Maintenance Crafts } & \multicolumn{2}{|c|}{ Operators } \\
\hline & & $\begin{array}{l}\text { Total Person- } \\
\text { Years } \\
\end{array}$ & Annual Dose & $\begin{array}{c}\text { Total Person- } \\
\text { Years } \\
\end{array}$ & Annual Dose & $\begin{array}{c}\text { Total Person- } \\
\text { Years } \\
\end{array}$ & Annual Dose & $\begin{array}{l}\text { Total Person- } \\
\text { Years } \\
\end{array}$ & Annual Dose \\
\hline $\begin{array}{l}\text { Technology } \\
\text { Readiness }\end{array}$ & 25 & 122 & $\therefore$ & 41 & & 0 & \begin{tabular}{|r}
$\therefore$ \\
$\therefore$ \\
\end{tabular} & 0 & $\begin{array}{lll}4 & \\
4 & \\
4\end{array}$ \\
\hline Capital & 25 & 1312 & 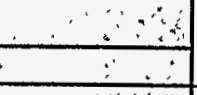 & 871 & $\begin{array}{l}1 \\
\cdots \quad \cdots \\
\end{array}$ & 0 & 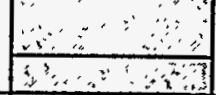 & 0 & $\frac{1}{3}$ \\
\hline $\begin{array}{l}\text { Operations \& } \\
\text { Maintenance }\end{array}$ & 75 & 712 & 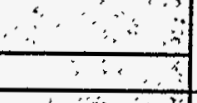 & 0 & $\begin{array}{r}\because \\
\\
\end{array}$ & 356 & $\frac{3}{4 a t}$ & 712 & $\frac{1}{x+8}$ \\
\hline $\begin{array}{c}\text { Decontamination } \\
\text { \& Decommissioning } \\
\end{array}$ & 3 & 42 & 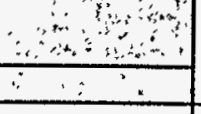 & 86 & $\begin{array}{r}r \\
\times 1 \\
\quad \times 19 \\
\end{array}$ & 0 & 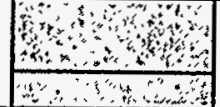 & 14 & 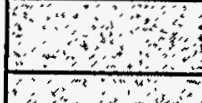 \\
\hline TOTAL & 128 & 2188 & $\begin{array}{lll} & \vdots \\
\because \quad & \ddots & \ddots \\
\end{array}$ & 998 & 的 & 356 & (4) & 726 & 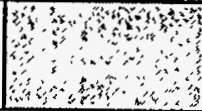 \\
\hline
\end{tabular}

NOTE- Infrastructure slafl support the staft above They receive no annual dose, average 4,000 travel miles, and average $50 \%$ of the facility totals above 
Alternative: 11. V-Shaped Freeze Wall Barrier

Capital Cost: $\$ 324$ million

Annual Worker Mileage: 15000 miles

\begin{tabular}{|c|c|c|c|c|c|c|c|c|c|}
\hline \multirow[t]{2}{*}{ Activity } & \multirow{2}{*}{$\begin{array}{c}\text { Activity } \\
\text { Duration } \\
\text { (years) }\end{array}$} & \multicolumn{2}{|c|}{$\begin{array}{l}\text { Management and } \\
\text { Engineering }\end{array}$} & \multicolumn{2}{|c|}{$\begin{array}{c}\text { Construction/Decommissioning } \\
\text { Crafts and Laborers }\end{array}$} & \multicolumn{2}{|c|}{ Maintenance Crafts } & \multicolumn{2}{|c|}{ Operators } \\
\hline & & $\begin{array}{l}\text { Total Person- } \\
\text { Years }\end{array}$ & Annual Dose & $\begin{array}{c}\begin{array}{c}\text { Total Person- } \\
\text { Years }\end{array} \\
\end{array}$ & Annual Dose & $\begin{array}{c}\text { Total Person- } \\
\text { Years } \\
\end{array}$ & Annual Dose & $\begin{array}{c}\text { Total Person- } \\
\text { Years } \\
\end{array}$ & Annual Dose \\
\hline $\begin{array}{c}\text { Technology } \\
\text { Readiness }\end{array}$ & 25 & 115 & 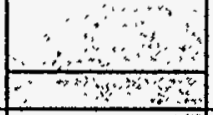 & 38 & 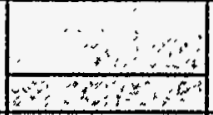 & 0 & 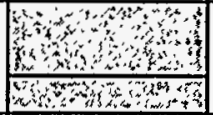 & 0 & $\frac{1}{r_{1}}$ \\
\hline Capital & 25 & 990 & 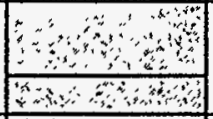 & 657 & \begin{tabular}{|c|} 
\\
4 \\
0 \\
0 \\
0
\end{tabular} & 0 & 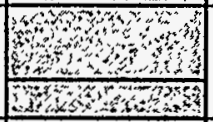 & 0 & 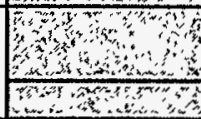 \\
\hline $\begin{array}{l}\text { Operations \& } \\
\text { Maintenance }\end{array}$ & 75 & 904 & 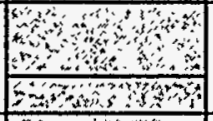 & 0 & 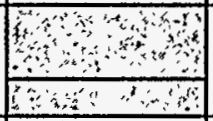 & 452 & 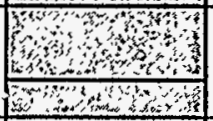 & 904 & 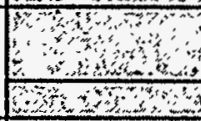 \\
\hline $\begin{array}{l}\text { Decontamination } \\
\text { \& Decommissioning }\end{array}$ & 4 & 61 & 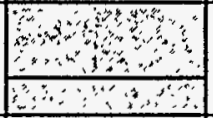 & 124 & 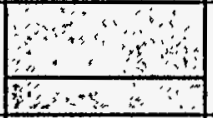 & 0 & 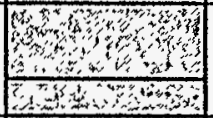 & 20 & 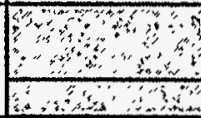 \\
\hline TOTAL & 129 & 2070 & 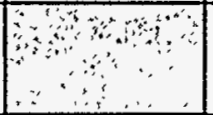 & 819 & & 452 & 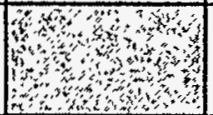 & 924 & 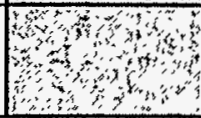 \\
\hline
\end{tabular}

NOTE: Infrastructure staff support the staff above They receive no annual dose, average 4.000 travel miles, and average $50 \%$ of the facility totals above. 
Alternative: 12. Circulating Air Barrier

Capital Cost: $\$ 266$ million

Annual Worker Mileage: 15000 miles

\begin{tabular}{|c|c|c|c|c|c|c|c|c|c|}
\hline \multirow[t]{2}{*}{ Activity } & \multirow{2}{*}{$\begin{array}{l}\text { Activity } \\
\text { Duration } \\
\text { (years) }\end{array}$} & \multicolumn{2}{|c|}{$\begin{array}{c}\text { Management and } \\
\text { Engineering }\end{array}$} & \multicolumn{2}{|c|}{$\begin{array}{c}\text { Construction/Decommissioning } \\
\text { Crafts and Laborers } \\
\end{array}$} & \multicolumn{2}{|c|}{ Maintenance Crafts } & \multicolumn{2}{|c|}{ Operators } \\
\hline & & $\begin{array}{l}\text { Total Person- } \\
\text { Years } \\
\end{array}$ & Annual Dose & $\begin{array}{c}\begin{array}{c}\text { Total Person- } \\
\text { Years }\end{array} \\
\end{array}$ & Annual Dose & $\begin{array}{c}\text { Total Person- } \\
\text { Years } \\
\end{array}$ & Annual Dose & $\begin{array}{c}\text { Total Person- } \\
\text { Years } \\
\end{array}$ & Annual Dose \\
\hline $\begin{array}{l}\text { Technology } \\
\text { Readiness } \\
\end{array}$ & 25 & 115 & & 38 & & 0 & $\because$ & 0 & 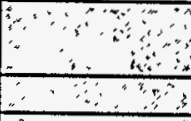 \\
\hline Capital & 25 & 813 & & 539 & $\cdot$ & 0 & & 0 & $\begin{array}{l}\therefore \\
\vdots \quad 13 \\
\end{array}$ \\
\hline $\begin{array}{l}\text { Operations \& } \\
\text { Maintenance }\end{array}$ & 75 & 927 & & 0 & & 464 & ; & 927 & 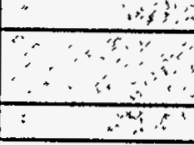 \\
\hline $\begin{array}{c}\text { Decontamination } \\
\& \text { Decommissioning } \\
\end{array}$ & 3 & 45 & & 91 & & 0 & $\begin{array}{r}\cdot+x: \\
\\
\end{array}$ & 14 & 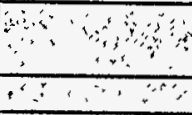 \\
\hline TOTAL & 128 & 1900 & & 668 & & 464 & $\because$ & 941 & 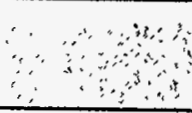 \\
\hline
\end{tabular}

NOTE* Infrastructure stalf support the staff above They receive no annual dose, average 4,000 travel miles, and average $50 \%$ of the facility totals above 
Table D.2. Technology Option Characteristics. (Sheet 34 of 35)

Alternative: 13. Clean-Closure without a Barrier

Capital Cost: $\$ 793$ million

Annual Worker Mileage: 15000 miles

\begin{tabular}{|c|c|c|c|c|c|c|c|c|c|}
\hline \multirow[t]{2}{*}{ Activity } & \multirow{2}{*}{$\begin{array}{c}\text { Activity } \\
\text { Duration } \\
\text { (years) }\end{array}$} & \multicolumn{2}{|c|}{$\begin{array}{c}\text { Management and } \\
\text { Engineering } \\
\end{array}$} & \multicolumn{2}{|c|}{$\begin{array}{c}\text { Construction/Decommissioning } \\
\text { Crafts and Laborers }\end{array}$} & \multicolumn{2}{|c|}{ Maintenance Crafts } & \multicolumn{2}{|c|}{ Operators } \\
\hline & & $\begin{array}{l}\text { Total Person- } \\
\text { Years }\end{array}$ & Annual Dose & \begin{tabular}{|c|}
$\begin{array}{c}\text { Total Person- } \\
\text { Years }\end{array}$ \\
\end{tabular} & Annual Dose & $\begin{array}{c}\text { Total Person- } \\
\text { Years } \\
\end{array}$ & Annual Dose & $\begin{array}{c}\text { Total Person- } \\
\text { Years }\end{array}$ & Annual Doso \\
\hline $\begin{array}{l}\text { Technology } \\
\text { Readiness }\end{array}$ & 10 & 136 & $\frac{6}{4}$ & 45 & 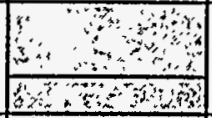 & 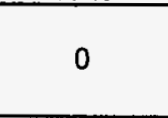 & 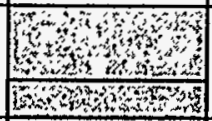 & 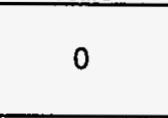 & 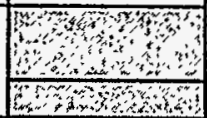 \\
\hline Capital & 10 & 2427 & 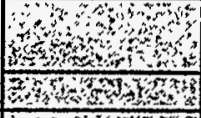 & 1615 & 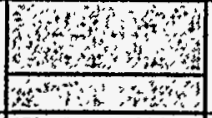 & 0 & 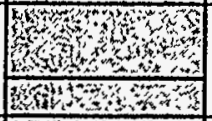 & 0 & 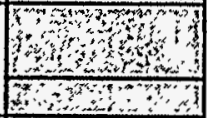 \\
\hline $\begin{array}{l}\text { Operations \& } \\
\text { Maintenance }\end{array}$ & 35 & 2393 & 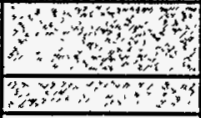 & 0 & 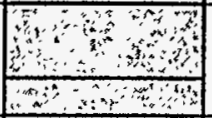 & 1197 & 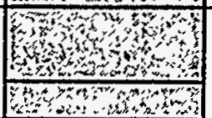 & 2393 & 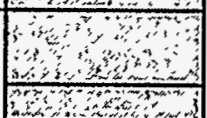 \\
\hline $\begin{array}{l}\text { Decontamination } \\
\text { \& Decommissioning }\end{array}$ & 4 & 236 & 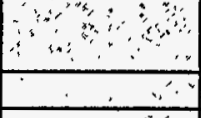 & 473 & 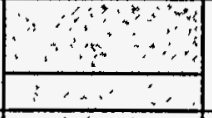 & 0 & 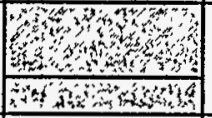 & 75 & 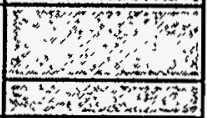 \\
\hline TOTAL & 59 & 5192 & 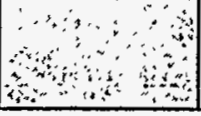 & 2133 & & 1197 & 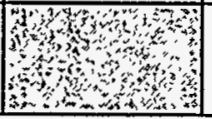 & 2468 & 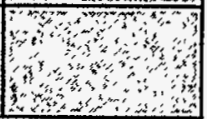 \\
\hline
\end{tabular}

NOTE. Infrastructure staff support the staff above They receive no annual dose, average 4,000 travel miles, and average $50 \%$ of the facility totals above. 


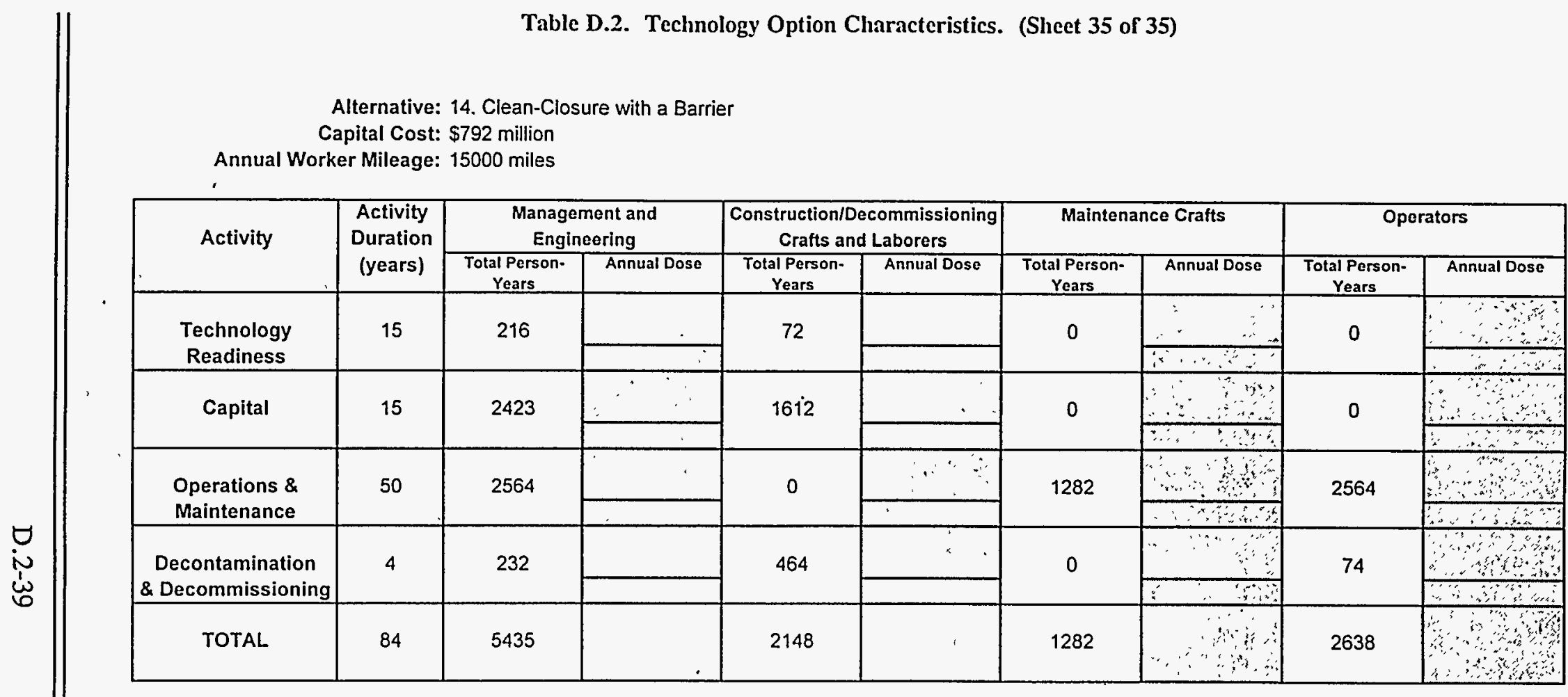

NOTE: Infrastructure staff support the staff above They receive no annual dose, average 4.000 travel miles, and average $50 \%$ of the facilty totals above 
WHC-SD-WM-ES-300 REV. 1

This page left intentionally blank. 
WHC-SD-WM-ES-300 REV. 1

APPENDIX D.3

OPTIONS WORKER RISKS

D.3-1 


\section{WHC-SD-WM-ES-300 REV. 1}

This page intentionally left blank.

D. 3-2 
WHC-SD-WM-ES-300 REV. 1

\section{OPTIONS WORKER RISKS}

This section lists the annual and total risks to workers for each technology option. 
WHC-SD-WM-ES-300 REV. 1

This page intentionally left blank.

D. 3-4 
Option: A. Traditional Sluicing Capital Cost: $\$ 63$ million

Annual Worker Milcage: 15,000

\begin{tabular}{|c|c|c|c|c|c|c|c|c|c|c|}
\hline \multirow{4}{*}{ Activity } & \multicolumn{10}{|c|}{$\begin{array}{c}\text { Management and } \\
\text { Engineering }\end{array}$} \\
\hline & \multicolumn{5}{|c|}{ Annual } & \multicolumn{5}{|c|}{ Total } \\
\hline & \multicolumn{2}{|c|}{ Transportation } & \multicolumn{3}{|c|}{ Operational } & \multicolumn{2}{|c|}{ Transportation } & \multicolumn{3}{|c|}{ Operational } \\
\hline & Death & Injury & Death & Injury & Cancer & Death & Injury & Death & Injury & Cancer \\
\hline $\begin{array}{c}\text { Technology Readiness } \\
\text { (Duration - } 5 \text { years) }\end{array}$ & $2.5 \mathrm{E}-04$ & $5.1 \mathrm{E}-04$ & $1.2 \mathrm{E}-04$ & 6.7E-02 & $0.0 \mathrm{E}+00$ & $1.2 \mathrm{E}-03$ & $2.5 \mathrm{E}-03$ & $6.0 \mathrm{E}-04$ & $3.4 \mathrm{E}-01$ & $0.0 \mathrm{E}+00$ \\
\hline $\begin{array}{c}\text { Capital } \\
\text { (Duration - } 5 \text { years) } \\
\end{array}$ & $4.0 \mathrm{E}-03$ & 8.1E-03 & $1.9 \mathrm{E}-03$ & $1.1 E+00$ & $1.4 \mathrm{E}-04$ & $2.0 \mathrm{E}-02$ & 4.1E-02 & $9.7 \mathrm{E}-03$ & $5.4 \mathrm{E}+00$ & $7.2 \mathrm{E}-04$ \\
\hline $\begin{array}{c}\text { Operators \& } \\
\text { Maintenance } \\
\text { (Duration - 15 y'cars) } \\
\end{array}$ & $1.0 \mathrm{E}-03$ & $2.1 \mathrm{E}-03$ & $4.9 \mathrm{E}-04$ & 2.7E-01 & $8.6 E-05$ & $1.5 \mathrm{E}-02$ & $3.1 \mathrm{E}-02$ & $7.4 \mathrm{E}-03$ & $4.1 \mathrm{E}+00$ & $1.3 \mathrm{E}-03$ \\
\hline $\begin{array}{l}\text { Decontamination \& } \\
\text { Decommissioning } \\
\text { (Duration - 1 year) }\end{array}$ & $7.2 \mathrm{E}-04$ & $1.5 \mathrm{E}-03$ & $3.5 \mathrm{E}-04$ & $2.0 \mathrm{E}-01$ & $6.1 \mathrm{E}-05$ & 7.2E-04 & $1.5 \mathrm{E}-03$ & $3.5 \mathrm{E}-04$ & $2.0 \mathrm{E}-01$ & $6.1 \mathrm{E}-05$ \\
\hline TO'TAL & ४ै। & $\because \quad \therefore$ & (4) & $\begin{array}{l}0 \\
\because \\
\cdots \\
3\end{array}$ & $\begin{array}{l}4 \% \\
4 \\
4\end{array}$ & $3.7 \mathrm{E}-02$ & $7.6 \mathrm{E}-02$ & $1.8 \mathrm{E}-02$ & $1.0 \mathrm{E}+01$ & $2.1 E-03$ \\
\hline
\end{tabular}

Assumptions:

- Transportation is to and from the site only

- Operational risks encompass industrial/physical hazards associated with equipment operation and onsite operations

- Infrastructure staff support the staff above. They receive no annual Cancer, average 4,000 travel miles, and average $50 \%$ of the facility totals above.

- Collective risks have been calculated as the product of individual risk, multiplied by the number of exposed individuals.

Individual risks provide estimates of the probability of health detriment for the individual, and the collective risks provide a measure of overall detriment

to the work force. 
Option: A. Traditional Sluicing

Capital Cost: $\$ 63$ million

Annual Worker Mileage: 15,000

\begin{tabular}{|c|c|c|c|c|c|c|c|c|c|c|}
\hline \multirow{4}{*}{ Activity } & \multicolumn{10}{|c|}{$\begin{array}{l}\text { Construction/Decommissioning } \\
\text { Crafts and Laborers }\end{array}$} \\
\hline & \multicolumn{5}{|c|}{ Annual } & \multicolumn{5}{|c|}{ Total } \\
\hline & \multicolumn{2}{|c|}{ Transportation } & \multicolumn{3}{|c|}{ Operational } & \multicolumn{2}{|c|}{ Transportation } & \multicolumn{3}{|c|}{ Operational } \\
\hline & Death & Injury & Death & Injury & Cancer & Death & Injury & Death & Injury & Cancer \\
\hline $\begin{array}{l}\text { Technology Readiness } \\
\text { (Duration - } 5 \text { years) }\end{array}$ & $8.2 \mathrm{E}-05$ & $1.7 \mathrm{E}-04$ & $2.8 \mathrm{E}-04$ & $6.4 \mathrm{E}-02$ & $0.0 \mathrm{E}+00$ & $4.1 E-04$ & $8.4 \mathrm{E}-04$ & $1.4 \mathrm{E}-03$ & $3.2 \mathrm{E}-01$ & $0.0 \mathrm{E}+00$ \\
\hline $\begin{array}{c}\text { Capital } \\
\text { (Duration }-5 \text { years) }\end{array}$ & $2.6 \mathrm{E}-03$ & $5.3 \mathrm{E}-03$ & $8.8 \mathrm{E}-03$ & $2.0 \mathrm{E}+00$ & $1.9 \mathrm{E}-03$ & $1.3 \mathrm{E}-02$ & 2.7E-02 & $4.4 \mathrm{E}-02$ & $1.0 \mathrm{E}+01$ & $9.5 \mathrm{E}-03$ \\
\hline $\begin{array}{c}\text { Operators \& } \\
\text { Maintenance } \\
\text { (Duration - 15 years) }\end{array}$ & $0.0 \mathrm{E}+00$ & $0.0 \mathrm{E}+00$ & $0.0 \mathrm{E}+00$ & $0.0 \mathrm{E}+00$ & $0.0 \mathrm{E}+00$ & $0.0 \mathrm{E}+00$ & $0.0 \mathrm{E}+00$ & $0.0 \mathrm{E}+00$ & $0.0 \mathrm{E}+00$ & $0.0 \mathrm{E}+00$ \\
\hline $\begin{array}{l}\text { Decontamination \& } \\
\text { Decommissioning } \\
\text { (Duration - } 1 \text { year) }\end{array}$ & $1.5 \mathrm{E}-03$ & $3.2 \mathrm{E}-03$ & $5.3 \mathrm{E}-03$ & $1.2 E+00$ & $1.5 \mathrm{E}-03$ & $1.5 \mathrm{E}-03$ & $3.2 \mathrm{E}-03$ & $5.3 E-03$ & $1.2 \mathrm{E}+00$ & $1.5 \mathrm{E}-03$ \\
\hline TOTAL & के & a & के। & ১২। & \begin{tabular}{lll}
4 \\
\hdashline \\
\hdashline
\end{tabular} & $1.5 \mathrm{E}-02$ & 3.1E-02 & $5.1 \mathrm{E}-02$ & $1.2 \mathrm{E}+01$ & $1.1 \mathrm{E}-02$ \\
\hline
\end{tabular}

Assumptions:

- Transportation is to and from the site only

- Operational risks encompass industrial/physical hazards associated with equipment operation and onsite operations

- Infrastructure staff support the staff above. They receive no annual Cancer, average 4.000 travel miles, and average $50 \%$ of the facility totals above.

- Collective risks have been calculated as the product of individual risk, multiplied by the number of exposed individuals.

Individual risks provide estimates of the probability of health detriment for the individual, and the collective risks provide a measure of overall detriment

to the work force. 
Option: A. Traditional Sluicing

Capital Cost: $\$ 63$ million

Annual Worker Mlilcage: 15,000

\begin{tabular}{|c|c|c|c|c|c|c|c|c|c|c|}
\hline \multirow{4}{*}{ Activity } & \multicolumn{10}{|c|}{ Maintenance Crafts } \\
\hline & \multicolumn{5}{|c|}{ Annual } & \multicolumn{5}{|c|}{ Total } \\
\hline & \multicolumn{2}{|c|}{ Transportation } & \multicolumn{3}{|c|}{ Opcrational } & \multicolumn{2}{|c|}{ Transportation } & \multicolumn{3}{|c|}{ Operational } \\
\hline & Death & Injury & Death & Injury & Cancer & Death & Injury & Death & Injury & Cancer \\
\hline $\begin{array}{l}\text { Technology Readiness } \\
\text { (Duration - } 5 \text { years) }\end{array}$ & $0.0 \mathrm{E}+00$ & $0.0 \mathrm{E}+00$ & $0.0 \mathrm{E}+00$ & $0.0 \mathrm{E}+00$ & $0.0 \mathrm{E}+00$ & $0.0 E+00$ & $0.0 \mathrm{E}+00$ & $0.0 \mathrm{E}+00$ & $0.0 \mathrm{E}+00$ & $0.0 \mathrm{E}+00$ \\
\hline $\begin{array}{c}\text { Capital } \\
\text { (Duration - } 5 \text { ycars) }\end{array}$ & $0.0 \mathrm{E}+00$ & $0.0 \Gamma+00$ & $0.0 E+00$ & $0.0 \mathrm{E}+00$ & $0.0 \mathrm{E}+00$ & $0.01 E+00$ & $0.0 \mathrm{E}+00$ & $0.0 E+00$ & $0.0 \mathrm{E}+00$ & $0.0 \mathrm{E}+00$ \\
\hline $\begin{array}{c}\text { Operators \& } \\
\text { Maintenance } \\
\text { (1)uration - } 15 \text { years) }\end{array}$ & $5.1 \mathrm{E}-04$ & $1.0 \mathrm{E}-03$ & 2.2E-04 & $5.4 \mathrm{E}-02$ & $4.9 \mathrm{E}-04$ & $7.6 \mathrm{E}-03$ & $1.6 \mathrm{E}-02$ & $3.3 \mathrm{E}-03$ & $8.1 \mathrm{E}-01$ & $7.4 \mathrm{E}-03$ \\
\hline $\begin{array}{l}\text { Decontamination \& } \\
\text { Decommissioning } \\
\text { (Duration - } 1 \text { year) }\end{array}$ & $0.0[E+00$ & $0.0 \mathrm{E}+00$ & $0.0 \mathrm{E}+00$ & $0.0 \mathrm{E}+00$ & $0.0 \mathrm{E}+00$ & $0.0 E+00$ & $0.0 \mathrm{E}+00$ & $0.0 \mathrm{E}+00$ & $0.0 \mathrm{E}+00$ & $0.0 \mathrm{E}+00$ \\
\hline TOTAL & $\begin{array}{lll}\because & \end{array}$ & 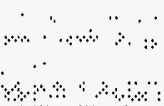 & $\begin{array}{c}a \\
\therefore \\
\cdots\end{array}$ & 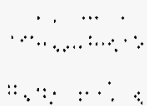 & $\because \quad$ & $7.6 \mathrm{E}-03$ & $1.6 \mathrm{E}-02$ & 3.3E-03 & $8.1 E-01$ & $7.4 \mathrm{E}-03$ \\
\hline
\end{tabular}

Assumptions:

- Transportation is to and from the site only

- Operational risks encompass industrial/physical hazards associated with equipment operation and onsite operations

- Infrastructure staff support the staff above. They receive no annual Cancer, average 4,000 travel miles, and average $50 \%$ of the facility totals above.

- Collective risks have been calculated as the product of individual risk, multiplied by the number of exposed individuals.

Individual risks provide estimates of the probability of health detriment for the individual, and the collective risks provide a measure of overall detriment

to the work force. 
Option: A. Traditional Sluicing Capital Cost: $\$ 63$ million

Annual Worker Mileage: 15,000

\begin{tabular}{|c|c|c|c|c|c|c|c|c|c|c|}
\hline \multirow{4}{*}{ Activity } & \multicolumn{10}{|c|}{ Operators } \\
\hline & \multicolumn{5}{|c|}{ Annual } & \multicolumn{5}{|c|}{ Total } \\
\hline & \multicolumn{2}{|c|}{ Transportation } & \multicolumn{3}{|c|}{ Operational } & \multicolumn{2}{|c|}{ Transportation } & \multicolumn{3}{|c|}{ Operational } \\
\hline & Death & Injury & Death & Injury & Cancer & Death & Injury & Death & Injury & Cancer \\
\hline $\begin{array}{l}\text { Technology Readincss } \\
\text { (Duration - } 5 \text { years) }\end{array}$ & $0.0 \mathrm{E}+00$ & $0.0 \mathrm{E}+00$ & $0.0 \mathrm{E}+00$ & $0.0 \mathrm{E}+00$ & $0.0 \mathrm{E}+00$ & $0.0 \mathrm{E}+00$ & $0.0 \mathrm{E}+00$ & $0.0 \mathrm{E}+00$ & $0.0 \mathrm{E}+00$ & $0.0 \mathrm{E}+00$ \\
\hline $\begin{array}{c}\text { Capital } \\
\text { (Duration - } 5 \text { ycars) }\end{array}$ & $0.0 \mathrm{E}+00$ & $0.0 \mathrm{E}+00$ & $0.0 \mathrm{E}+00$ & $0.0 \mathrm{E}+00$ & $0.0 \mathrm{E}+00$ & $0.0 \mathrm{E}+00$ & $0.0 \mathrm{E}+00$ & $0.0 \mathrm{E}+00$ & $0.0 \mathrm{E}+00$ & $0.0 \mathrm{E}+00$ \\
\hline $\begin{array}{c}\text { Operators \& } \\
\text { Maintenance } \\
\text { (Duration - 15 years) } \\
\end{array}$ & $1.0 \mathrm{E}-03$ & $2.1 \mathrm{E}-03$ & $4.4 \mathrm{E}-04$ & $1.1 \mathrm{E}-01$ & $9.8 \mathrm{E}-04$ & $1.5 \mathrm{E}-02$ & $3.1 \mathrm{E}-02$ & $6.6 \mathrm{E}-03$ & $1.6 \mathrm{E}+00$ & $1.5 \mathrm{E}-02$ \\
\hline $\begin{array}{l}\text { Decontamination \& } \\
\text { Decommissioning } \\
\text { (Duration - } 1 \text { year) }\end{array}$ & 2.1E-04 & $4.2 \mathrm{E}-04$ & $9.0 \mathrm{E}-05$ & $2.2 \mathrm{E}-02$ & $2.0 \mathrm{E}-04$ & 2.1E-04 & $4.2 \mathrm{E}-04$ & $9.0 \mathrm{E}-05$ & $2.2 \mathrm{E}-02$ & $2.0 \mathrm{E}-04$ \\
\hline TOTAL & कि & किखे & कै। & कै। & किसे & $1.5 \mathrm{E}-02$ & $3.1 \mathrm{E}-02$ & $6.7 \mathrm{E}-03$ & $1.6 \mathrm{E}+00$ & $1.5 \mathrm{E}-02$ \\
\hline
\end{tabular}

\section{Assumptions:}

- Transportation is to and from the site only

- Operational risks encompass industrial/physical hazards associated with equipment operation and onsite operations

- Infrastructure staff support the staff above. They receive no annual Cancer, average 4,000 travel miles, and average $50 \%$ of the facility totals above.

- Collective risks have been calculated as the product of individual risk, multiplied by the number of exposed individuals.

Individual risks provide estimates of the probability of health detriment for the individual, and the collective risks provide a measure of overall detriment to the work force. 
Option: A. Traditional Sluicing

Capital Cost: $\$ 63$ million

Annual Worker Mileage: 15,000

\begin{tabular}{|c|c|c|c|c|c|c|c|c|c|c|c|c|c|c|c|c|}
\hline \multirow{4}{*}{ Activity } & \multicolumn{10}{|c|}{ All Workers } & \multicolumn{6}{|c|}{ All Workers } \\
\hline & \multicolumn{5}{|c|}{ Annual } & \multicolumn{5}{|c|}{ Total } & \multirow{2}{*}{\multicolumn{3}{|c|}{ Annuals }} & \multirow{2}{*}{\multicolumn{3}{|c|}{ Totals }} \\
\hline & \multicolumn{2}{|c|}{ Transportation } & \multicolumn{3}{|c|}{ Operational } & \multicolumn{2}{|c|}{\begin{tabular}{|l|} 
Transportation \\
\end{tabular}} & \multicolumn{3}{|c|}{ Operational } & & & & & & \\
\hline & Death & Injury & Death & \begin{tabular}{|l|} 
Injury \\
\end{tabular} & Cancer & Death & \begin{tabular}{|l|} 
Injury \\
\end{tabular} & Death & \begin{tabular}{|l|} 
Injury \\
\end{tabular} & Cancer & Death & Injury & Cancer & Death & Injury & Cancer \\
\hline $\begin{array}{l}\text { Technology Readiness } \\
\text { (Duration - } 5 \text { ycars) }\end{array}$ & 3.3E-04 & $6.7 \mathrm{E}-04$ & $4.0 \mathrm{E}-04$ & 1.3E-01 & $00 \mathrm{E}+00$ & $1.6 \mathrm{E}-03$ & $3.4 \mathrm{E}-03$ & $2.0 \mathrm{E}-03$ & $6.6 \mathrm{E}-01$ & $0.0 \mathrm{E}+00$ & $7.3 \mathrm{E}-04$ & $\mid 1.3 \mathrm{E}-01$ & $0.0 E+00$ & $3.6 \mathrm{E}-03$ & $6.6 \mathrm{E}-01$ & $0.0 \mathrm{E}+00$ \\
\hline $\begin{array}{c}\text { Capital } \\
\text { (Duration -5 y'cars) }\end{array}$ & $6.6 \mathrm{E}-03$ & $1.3 \mathrm{E}-02$ & $1.1 \mathrm{E}-02$ & $3.1 E+00$ & $2.0 \mathrm{E}-03$ & $3.3 \mathrm{E}-02$ & 6.7E-02 & $5.4 \mathrm{E}-02$ & $1.5 E+01$ & $1.0 \mathrm{E}-02$ & $1.7 \mathrm{E}-02$ & $|3.1 E+00|$ & $2.0 \mathrm{E}-03$ & $8.7 \mathrm{E}-02$ & $1.6 \mathrm{E}+01$ & $1.0 \mathrm{E}-02$ \\
\hline $\begin{array}{c}\text { Operators \& } \\
\text { Maintenance } \\
\text { (Duration - } 15 \text { years) }\end{array}$ & $2.5 \mathrm{E}-03$ & $5.2 \mathrm{E}-03$ & $1.2 \mathrm{E}-03$ & $4.4 \mathrm{E}-01$ & $1.6 \mathrm{E}-03$ & $3.8 \mathrm{E}-02$ & $7.8 \mathrm{E}-02$ & $1.7 \mathrm{E}-02$ & $6.5 E+00$ & $2.3 \mathrm{E}-02$ & $3.7 \mathrm{E}-03$ & $4.4 \mathrm{E}-01$ & $1.6 \mathrm{E}-03$ & $5.5 \mathrm{E}-02$ & $6.6 \mathrm{E}+00$ & $2.3 \mathrm{E}-02$ \\
\hline $\begin{array}{c}\text { Decontamination \& } \\
\text { Decommissioning } \\
\text { (Duration - } 1 \text { year) }\end{array}$ & $2.5 \mathrm{E}-03$ & $5.1 \mathrm{E}-03$ & $57 \mathrm{E}-03$ & $1.4 \mathrm{E}+00$ & $1.8 \mathrm{E}-03$ & $2.5 \mathrm{E}-03$ & $5.1 \mathrm{E}-03$ & $5.7 \mathrm{E}-03$ & $1.4 \mathrm{E}+00$ & $1.8 \mathrm{E}-03$ & $8.2 \mathrm{E}-03$ & $1.4 E+00 \mid$ & $1.8 \mathrm{E}-03$ & $8.2 \mathrm{E}-03$ & $1.4 \mathrm{E}+00$ & $1.8 \mathrm{E}-03$ \\
\hline TOTAL. & & & & का & & $75 L-012$ & $1.5 \mathrm{E}-01$ & $7.98-02$ & $241:+01$ & $351:-02$ & \% & $\left|\begin{array}{rr|}\ddots & \vdots \\
\cdots & \vdots \\
3 & \vdots\end{array}\right|$ & $\begin{array}{ll}\cdots \\
\cdots \\
\cdots \\
\cdots\end{array}$ & $1.51:-01$ & $241 \leqslant+01$ & $3.5 \mathrm{~L}-02$ \\
\hline
\end{tabular}

\section{Assumptions:}

- Transportation is to and from the site only

- Operational risks encompass industrial/physical hazards associated with equipment operation and onsite operations

- Infrastructure staff support the staff above. They receive no annual Cancer, average 4,000 travel miles, and average $50 \%$ of the facility totals above.

- Collective risks have been calculated as the product of individual risk, multiplied by the number of exposed individuals.

Individual risks provide estimates of the probability of health detriment for the individual, and the collective risks provide a measure of overall detriment to the work force. 
Option: B. Robotic Sluicing

Capital Cost: $\$ 183$ million

Annual Worker Milcage: 15,000

\begin{tabular}{|c|c|c|c|c|c|c|c|c|c|c|}
\hline \multirow{4}{*}{ Activity } & \multicolumn{10}{|c|}{$\begin{array}{l}\text { Management and } \\
\text { Engincering }\end{array}$} \\
\hline & \multicolumn{5}{|c|}{ Annual } & \multicolumn{5}{|c|}{ Total } \\
\hline & \multicolumn{2}{|c|}{ Transportation } & \multicolumn{3}{|c|}{ Operational } & \multicolumn{2}{|c|}{ Transportation } & \multicolumn{3}{|c|}{ Operational } \\
\hline & Death & Injury & Death & Injury & Cancer & Death & Injury & Death & Injury & Cancer \\
\hline $\begin{array}{l}\text { Technology Readiness } \\
\text { (Duration - } 5 \text { years) }\end{array}$ & $2.3 \mathrm{E}-03$ & $4.6 \mathrm{E}-03$ & $1.1 \mathrm{E}-03$ & $6.2 \mathrm{E}-0 \mathrm{I}$ & $0.0 \mathrm{E}+00$ & $1.1 \mathrm{E}-02$ & 2.3E-02 & $5.5 \mathrm{E}-03$ & $3.1 \mathrm{E}+00$ & $0.0 \mathrm{E}+00$ \\
\hline $\begin{array}{c}\text { Capital } \\
\text { (Duration }-5 \text { ycars) }\end{array}$ & $1.2 \mathrm{E}-02$ & $2.4 \mathrm{E}-02$ & $5.6 \mathrm{E}-03$ & $3.1 \mathrm{E}+00$ & $4.2 E-04$ & $5.8 \mathrm{E}-02$ & $1.2 \mathrm{E}-01$ & $2.8 \mathrm{E}-02$ & $1.6 \mathrm{E}+01$ & 2.1E-03 \\
\hline $\begin{array}{c}\text { Operators \& } \\
\text { Maintenahce } \\
\text { (Duration - } 15 \text { years) }\end{array}$ & $8.5 \mathrm{E}-03$ & $1.8 \mathrm{E}-02$ & $4.2 \mathrm{E}-03$ & $2.3 \mathrm{E}+00$ & 7.3E-04 & $1.3 \mathrm{E}-01$ & $2.6 \mathrm{E}-01$ & $6.2 \mathrm{E}-02$ & $3.5 \mathrm{E}+01$ & $1.1 \mathrm{E}-02$ \\
\hline $\begin{array}{l}\text { Decontamination \& } \\
\text { Decommissioning } \\
\text { (Duration - 1 year) }\end{array}$ & $6.4 \mathrm{E}-03$ & $1.3 \mathrm{E}-02$ & $3.1 \mathrm{E}-03$ & $1.7 E+00$ & $5.4 \mathrm{E}-04$ & $1.3 \mathrm{E}-02$ & $2.6 \mathrm{E}-02$ & $6.2 \mathrm{E}-03$ & $3.5 \mathrm{E}+00$ & $1.1 \mathrm{E}-03$ \\
\hline TO'TAL & $\therefore$ & $\because \cdots$ & $\because 3$ & अ० & . & $2.1 \mathrm{E}-01$ & $4.3 \mathrm{E}-01$ & $1.0 \mathrm{E}-01$ & $5.7 \mathrm{E}+01$ & $1.4 \mathrm{E}-02$ \\
\hline
\end{tabular}

Assumptions:

- Transportation is to and lrom the site only

- Operational risks encompass industrial/physical hazards associated with equipment operation and onsite operations

- Infrastructure staff support the staff above. They receive no annual Cancer, average 4,000 travel miles, and average $50 \%$ of the facility totals above.

- Collective rists have been calculated as the product of individual risk, multiplied by the number of exposed inidividuals.

Individual risks provide estimates of the probability of health detriment for the individual, and the collective risks provide a measure of overall detriment

to the work force. 
Option: B. Robotic Sluicing

Capital Cost: $\$ 183$ million

Annual Worker Mileage: 15,000

\begin{tabular}{|c|c|c|c|c|c|c|c|c|c|c|}
\hline \multirow{4}{*}{ Activity } & \multicolumn{10}{|c|}{$\begin{array}{c}\text { Construction/Decommissioning } \\
\text { Crafts and Laborers } \\
\end{array}$} \\
\hline & \multicolumn{5}{|c|}{ Annual } & \multicolumn{5}{|c|}{ Total } \\
\hline & \multicolumn{2}{|c|}{ Transportation } & \multicolumn{3}{|c|}{ Operational } & \multicolumn{2}{|c|}{ Transportation } & \multicolumn{3}{|c|}{ Operational } \\
\hline & Death & Injury & Death & Injury & Cancer & Death & Injury & Death & Injury & Cancer \\
\hline $\begin{array}{l}\text { Technology Readiness } \\
\text { (Duration - } 5 \text { years) }\end{array}$ & $7.6 \mathrm{E}-04$ & $1.6 \mathrm{E}-03$ & 2.6E- 03 & $5.9 \mathrm{E}-01$ & $0.0 \mathrm{E}+00$ & $3.8 \mathrm{E}-03$ & $7.8 \mathrm{E}-03$ & $1.3 \mathrm{E}-02$ & $3.0 \mathrm{E}+00$ & $\begin{array}{c}0.0 \mathrm{E}+00 \\
\cdots\end{array}$ \\
\hline $\begin{array}{c}\text { Capital } \\
\text { (Duration }-5 \text { years) }\end{array}$ & 7.7E-03 & $1.6 \mathrm{E}-02$ & $2.6 \mathrm{E}-02$ & $6.0 \mathrm{E}+00$ & $5.6 \mathrm{E}-03$ & $3.8 \mathrm{E}-02$ & $7.9 \mathrm{E}-02$ & $1.3 \mathrm{E}-01$ & $3.0 \mathrm{E}+01$ & $2.8 \mathrm{E}-02$ \\
\hline $\begin{array}{c}\text { Operators \& } \\
\text { Maintenance } \\
\text { (Duration - 15 y'cars) }\end{array}$ & $0.0 \mathrm{E}+00$ & $0.0 \mathrm{E}+00$ & $0.0 \mathrm{E}+00$ & $0.0 \mathrm{E}+00$ & $0.0 \mathrm{E}+00$ & $0.0 \mathrm{E}+00$ & $0.0 \mathrm{E}+00$ & $0.0 \mathrm{E}+00$ & $0.0 \mathrm{E}+00$ & $0.0 \mathrm{E}+00$ \\
\hline $\begin{array}{l}\text { Decontamination \& } \\
\text { Decommissioning } \\
\text { (Duration - } 1 \text { year) }\end{array}$ & $1.3 \mathrm{E}-02$ & $2.6 \mathrm{E}-02$ & $4.4 \mathrm{E}-02$ & $1.0 \mathrm{E}+01$ & $1.2 \mathrm{E}-02$ & 2.6E-02 & $5.3 \mathrm{E}-02$ & 8.7E-02 & $2.0 \mathrm{E}+01$ & $2.5 \mathrm{E}-02$ \\
\hline TOTAL & $\begin{array}{l}\cdots \\
\therefore \quad \therefore \quad \cdots \\
\therefore\end{array}$ & 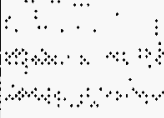 & 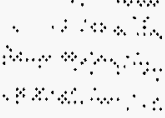 & 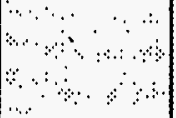 & a & $6.8 \mathrm{E}-02$ & $1.4 \mathrm{E}-01$ & $2.3 \mathrm{E}-01$ & $5.3 \mathrm{E}+01$ & $5.3 \mathrm{E}-02$ \\
\hline
\end{tabular}

Assumptions:

- Transportation is to and from the site only

- Operational risks encompass industrial/physical hazards associated with equipment operation and onsite operations

- Infrastructure staff support the stiuf above. They receive no annual Cancer. average 4.000 travel miles, and average $50 \%$ of the facility totals above.

- Collective risks have been calculated as the product of individual risk, multiplied by the number of exposed inidividuals.

Individual risks provide estimates of the probability of health detriment for the individual, and the collective risks provide a measure of overall detriment

to the work force. 


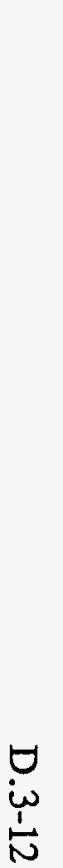

Table D.3. Options Worker Risks. (Sheet 8 of 105)

Option: B. Robotic Sluicing

Capital Cost: $\$ 183$ million

Annual Worker Mileage: 15,000

\begin{tabular}{|c|c|c|c|c|c|c|c|c|c|c|}
\hline \multirow{4}{*}{ Activity } & \multicolumn{10}{|c|}{ Maintenance Crafts } \\
\hline & \multicolumn{5}{|c|}{ Annual } & \multicolumn{5}{|c|}{ Total } \\
\hline & \multicolumn{2}{|c|}{ Transportation } & \multicolumn{3}{|c|}{ Operational } & \multicolumn{2}{|c|}{ Transportation } & \multicolumn{3}{|c|}{ Operational } \\
\hline & Death & Injury & Death & \begin{tabular}{|l|} 
Injury \\
\end{tabular} & Cancer & Death & Injury & Death & Injury & Cancer \\
\hline $\begin{array}{c}\text { Technology Readiness } \\
\text { (Duration - } 5 \text { years) }\end{array}$ & $0.0 \mathrm{E}+00$ & $0.0 \mathrm{E}+00$ & $0.0 \mathrm{E}+00$ & $0.0 \mathrm{E}+00$ & $0.0 \mathrm{E}+00$ & $0.0 \mathrm{E}+00$ & $0.0 \mathrm{E}+00$ & $0.0 \mathrm{E}+00$ & $0.0 \mathrm{E}+00$ & $0.0 \mathrm{E}+00$ \\
\hline $\begin{array}{c}\text { Capital } \\
\text { (Duration - } 5 \text { years) } \\
\end{array}$ & $\begin{array}{c}0.0 \mathrm{E}+00 \\
. \\
\end{array}$ & $0.0 \mathrm{E}+00$ & $0.0 \mathrm{E}+00$ & $0.0 \mathrm{E}+00$ & $0.0 \mathrm{E}+00$ & $0.0 \mathrm{E}+00$ & $0.0 \mathrm{E}+00$ & $0.0 \mathrm{E}+00$ & $0.0 \mathrm{E}+00$ & $0.0 \mathrm{E}+00$ \\
\hline $\begin{array}{c}\text { Operators \& } \\
\text { Maintenance } \\
\text { (Duration - 15 years) } \\
\end{array}$ & $4.3 E-03$ & $8.7 \mathrm{E}-03$ & $1.9 E-03$ & $4.6 \mathrm{E}-01$ & $4.1 \mathrm{E}-03$ & $6.4 E-02$ & $1.3 \mathrm{E}-01$ & $2.8 \mathrm{E}-02$ & $6.8 E+00$ & $6.2 \mathrm{E}-02$ \\
\hline $\begin{array}{c}\text { Decontamination \& } \\
\text { Decommissioning } \\
\text { (Duration - } 1 \text { year) }\end{array}$ & $0.0 \mathrm{E}+00$ & $0.0 \mathrm{E}+00$ & $0.0 \mathrm{E}+00$ & $0.0 \mathrm{E}+00$ & $0.0 \mathrm{E}+00$ & $0.0 E+00$ & $0.0 \mathrm{E}+00$ & $0.0 \mathrm{E}+00$ & $0.0 \mathrm{E}+00$ & $0.0 \mathrm{E}+00$ \\
\hline TOTAL & अ. & ४ै। & औ. & के। & अओ & $6.4 \mathrm{E}-02$ & $1.3 \mathrm{E}-01$ & $2.8 \mathrm{E}-02$ & $6.8 \mathrm{E}+00$ & $6.2 \mathrm{E}-02$ \\
\hline
\end{tabular}

Assumptions:

- Transportation is to and from the site only

- Operational risks encompass industrial/physical hazards associated with equipment operation and onsite operations

- Infrastructure staff support the staff above. They receive no atnual Cancer, average 4,000 travel miles, and average $50 \%$ of the facility totals above.

- Collective risks have been calculated as the product of individual rish, multiplied by the number of exposed inidividuals.

Individual risks provide estimates of the probability of health detriment for the individual, and the collective risks provide a measure of overall detriment

to the work force. 


\begin{tabular}{|c|c|c|c|c|c|c|c|c|c|c|}
\hline $\begin{array}{r}\text { Option } \\
\text { Capital Cost } \\
\text { Annual Worker Mileage }\end{array}$ & $\begin{array}{l}\text { Robotic SI } \\
183 \text { million } \\
5,000\end{array}$ & icing & & & & & & & & \\
\hline \multirow{4}{*}{ Activity } & \multicolumn{10}{|c|}{ Operators } \\
\hline & \multicolumn{5}{|c|}{ Annual } & \multicolumn{5}{|c|}{ Total } \\
\hline & \multicolumn{2}{|c|}{ Transportation } & \multicolumn{3}{|c|}{ Operational } & \multicolumn{2}{|c|}{ Transportation } & \multicolumn{3}{|c|}{ Operational } \\
\hline & Death & Injury & Death & Injury & Cancer & Death & Injury & Death & Injury & Cancer \\
\hline $\begin{array}{l}\text { Technology Readiness } \\
\text { (Duration - } 5 \text { years) }\end{array}$ & $0.0 \mathrm{E}+00$ & $0.0 \mathrm{E}+00$ & $0.0 \mathrm{E}+00$ & $0.0 \mathrm{E}+00$ & $0.0 \mathrm{E}+00$ & $0.0 \mathrm{E}+00$ & $0.0 \mathrm{E}+00$ & $0.0 \mathrm{E}+00$ & $0.0 \mathrm{E}+00$ & $0.0 \mathrm{E}+00$ \\
\hline $\begin{array}{c}\text { Capital } \\
\text { (Duration - } 5 \text { years) }\end{array}$ & $0.0 \mathrm{E}+00$ & $0.0 \mathrm{E}+00$ & $0.0 \mathrm{E}+00$ & $0.0 \mathrm{E}+00$ & $0.0 \mathrm{E}+00$ & $0.0 E+00$ & $0.0 \mathrm{E}+00$ & $0.0 \mathrm{E}+00$ & $0.0 \mathrm{E}+00$ & $0.0 \mathrm{E}+00$ \\
\hline $\begin{array}{c}\text { Operators \& } \\
\text { Mlaintenance } \\
\text { (Duration-15years) }\end{array}$ & $8.5 E-03$ & $1.8 \mathrm{E}-02$ & $3.7 \mathrm{E}-03$ & $9.1 E-01$ & $8.3 \mathrm{E}-03$ & $1.3 \mathrm{E}-01$ & $2.6 \mathrm{E}-01$ & $5.6 \mathrm{E}-02$ & $1.4 \mathrm{E}+01$ & $1.2 \mathrm{E}-01$ \\
\hline $\begin{array}{c}\text { Decontamination \& } \\
\text { Decommissioning } \\
\text { (Duration - } 1 \text { year) }\end{array}$ & $2.1 \mathrm{E}-03$ & $4.3 E-03$ & $9.2 \mathrm{E}-04$ & $2.3 \mathrm{E}-01$ & $2.1 E-03$ & $4.2 \mathrm{E}-03$ & $8.6 \mathrm{E}-03$ & $1.8 \mathrm{E}-03$ & 4.5E-01 & $4.1 \mathrm{E}-03$ \\
\hline TOTAL & \%ই। & \% & ঝ & ब। & $\therefore$ & $1.3 \mathrm{E}-01$ & $2.7 \mathrm{E}-01$ & $5.8 \mathrm{E}-02$ & $1.4 \mathrm{E}+01$ & $1.3 \mathrm{E}-01$ \\
\hline
\end{tabular}

Assumptions:

- Transportation is to and from the site only

- Operational risks encompass industrial/physical hazards associated with equipment operation and onsite operations

- Infrastructure staff support the staff above. They receive no annual Cancer, average 4,000 travel miles, and average $50 \%$ of the facility totals above.

- Collective risks have been calculated as the product of individual risk, multiplied by the number of exposed inidividuals.

Individual risks provide estimates of the probability of health detriment for the individual, and the collective risks provide a measure of overall detriment to the work force. 
Option: B. Robotic Sluicing

Capital Cost: \$183 million

Annual Worker Mileage: 15,000

\begin{tabular}{|c|c|c|c|c|c|c|c|c|c|c|c|c|c|c|c|c|}
\hline \multirow{4}{*}{ Activity } & \multicolumn{10}{|c|}{ All Workers } & \multicolumn{6}{|c|}{ All Workers } \\
\hline & \multicolumn{5}{|c|}{$\begin{array}{c}\text { Annual } \\
\end{array}$} & \multicolumn{5}{|c|}{ Total } & \multirow{2}{*}{\multicolumn{3}{|c|}{ Annuals }} & \multirow{2}{*}{\multicolumn{3}{|c|}{ Totals }} \\
\hline & \multicolumn{2}{|c|}{ Transportation } & \multicolumn{3}{|c|}{ Operational } & \multicolumn{2}{|c|}{ Transportation } & \multicolumn{3}{|c|}{ Operational } & & & & & & \\
\hline & Death & Injury & Death & Injury & Cancer & Death & \begin{tabular}{|l|} 
Injury \\
\end{tabular} & Death & \begin{tabular}{|l|} 
Injury \\
\end{tabular} & Cancer & Death & Injury & Cancer & Death & Injury & Cancer \\
\hline $\begin{array}{c}\text { Technology Readiness } \\
\text { (Duration - } 5 \text { years) }\end{array}$ & $3.0 \mathrm{E}-03$ & $6.2 \mathrm{E}-03$ & $3.7 \mathrm{E}-03$ & $12 \mathrm{E}+00$ & $0.0 E+00 \mid$ & $1.5 \mathrm{E}-02$ & 3 IE-02 & $1.8 \mathrm{E}-02$ & $60 \mathrm{E}+00$ & $00 \mathrm{E}+00$ & $6.7 \mathrm{E}-03$ & $1.2 \mathrm{E}+00$ & $0.0 \mathrm{E}+00$ & $3.4 \mathrm{E}-02$ & $6.1 E+00$ & $0.0 \mathrm{E}+00$ \\
\hline $\begin{array}{c}\text { Capital } \\
\text { (Duration - } 5 \text { years) }\end{array}$ & $19 E-02$ & $39 E-02$ & 32 2E-02 & 9 IE +00 & 60 EE- 03 & $96 \mathrm{E}-02$ & 2 OE-01 & $16 E-01$ & $46 E+01$ & $30 \mathrm{E}-02$ & $5 \mid E-02$ & $91 \mathrm{E}+00$ & $60 \mathrm{E}-03$ & $2.5 \mathrm{E}-01$ & $4.6 \mathrm{E}+01$ & $3.0 \mathrm{E}-02$ \\
\hline $\begin{array}{c}\text { Operators \& } \\
\text { Maintenance } \\
\text { (Duration - 15 years) } \\
\end{array}$ & $21 \mathrm{E}-02$ & $44 \mathrm{E}-02$ & $98 \mathrm{E}-03$ & $37 E+00$ & $13 \mathrm{E}-02$ & $32 \mathrm{E}-01$ & $66 \mathrm{E}-01$ & $\mid 5 E-01$ & $55 \mathrm{E}+01$ & 2 OE-01 & $3.1 \mathrm{E}-02$ & $37 E+00$ & $1.3 \mathrm{E}-02$ & $4.7 \mathrm{E}-01$ & $5.6 \mathrm{E}+01$ & $2.0 \mathrm{E}-01$ \\
\hline $\begin{array}{l}\text { Decontamination \& } \\
\text { Decommissioning } \\
\text { (Duration - 1 year) }\end{array}$ & $21 E-02$ & $44 E-02$ & $48 E-02$ & $1.2 \mathrm{E}+01$ & $15 \mathrm{E}-02$ & $43 \mathrm{E}-02$ & $87 \mathrm{E}-02$ & $95 \mathrm{E}-02$ & $24 E+01$ & 3 OE- 02 & $69 \mathrm{E}-02$ & $12 E+01$ & $1.5 \mathrm{E}-02$ & $1.4 \mathrm{E}-01$ & $2.4 \mathrm{E}+01$ & $3.0 \mathrm{E}-02$ \\
\hline TOTAL & औ & \% & $\begin{array}{cc}\because & \ddots \\
\ddots & \ddots \\
3\end{array}$ & $\mid \begin{array}{cc}\vdots & \vdots \\
\ddots & \\
\vdots\end{array}$ & 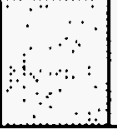 & $4.7 \mathrm{E}-01$ & $97 \mathrm{E}-01$ & $+2 \mathrm{E}-01$ & $1.3 E+02$ & $2.6 \mathrm{E}-01$ & के & के & के & $8.9 \mathrm{E}-01$ & $1.3 \mathrm{E}+02$ & $2.6 \mathrm{E}-01$ \\
\hline
\end{tabular}

Assumptions:

- Transportation is to and from the site only

- Operational risks encompass industrial/physical hazards associated with equipment operation and onsite operations

- Infrastructure staff support the staff above. They receive no annual Cancer, average 4,000 travel miles, and average $50 \%$ of the facility totals above.

- Collective risks have been calculated as the product of individual risk, multiplied by the number of exposed inidividuals.

Individual risks provide estimates of the probability of health detriment for the individual, and the collective risks provide a measure of overall detriment

to the work force. 
Option: C. Mechanical Retrieval

Capital Cost: $\$ 154$ million

Annual Worker Mileage: 15,000

\begin{tabular}{|c|c|c|c|c|c|c|c|c|c|c|}
\hline \multirow{4}{*}{ Activity } & \multicolumn{10}{|c|}{$\begin{array}{l}\text { Management and } \\
\text { Engineering }\end{array}$} \\
\hline & \multicolumn{5}{|c|}{ Annual } & \multicolumn{5}{|c|}{ Total } \\
\hline & \multicolumn{2}{|c|}{ Transportation } & \multicolumn{3}{|c|}{ Operational } & \multicolumn{2}{|c|}{ Transportation } & \multicolumn{3}{|c|}{ Operational } \\
\hline & Death & Injury & Death & Injury & Cancer & Death & Injury & Death & Injury & Cancer \\
\hline $\begin{array}{l}\text { Technology Readincss } \\
\text { (Duration - } 5 \text { years) }\end{array}$ & 1.9E-03 & $3.9 \mathrm{E}-03$ & $9.2 \mathrm{E}-04$ & $5.2 \mathrm{E}-01$ & $0.0 \mathrm{E}+00$ & $9.5 \mathrm{E}-03$ & $1.9 \mathrm{E}-02$ & $4.6 \mathrm{E}-03$ & $2.6 \mathrm{E}+00$ & $0.0 \mathrm{E}+00$ \\
\hline $\begin{array}{c}\text { Capital } \\
\text { (Duration - } 5 \text { years) }\end{array}$ & 9.7E-03 & 2.0E-02 & 4.7E-03 & $2.6 \mathrm{E}+00$ & $3.5 E-04$ & $4.9 \mathrm{E}-02$ & 9.9E-02 & $2.4 \mathrm{E}-02$ & $1.3 \mathrm{E}+01$ & $1.8 \mathrm{E}-03$ \\
\hline $\begin{array}{c}\text { Operators \& } \\
\text { Maintenance } \\
\text { (Duration - } 15 \text { ycars) }\end{array}$ & $8.5 \mathrm{E}-03$ & $1.8 \mathrm{E}-02$ & $4.2 \mathrm{E}-03$ & $2.3 \mathrm{E}+00$ & $7.3 \mathrm{E}-0.4$ & $1.3 \mathrm{E}-01$ & $2.6 \mathrm{E}-01$ & $6.2 \mathrm{E}-02$ & $3.5 \mathrm{E}+01$ & 1.1E-02 \\
\hline $\begin{array}{l}\text { Decontamination \& } \\
\text { Decommissioning } \\
\text { (Duration - } 1 \text { year) }\end{array}$ & $6.4 \mathrm{E}-03$ & $1.3 \mathrm{E}-02$ & 3.1E-03 & $1.7 \mathrm{E}+00^{\circ}$ & 5.4E-04 & 1.3E-02 & $2.6 \mathrm{E}-02$ & $6.2 \mathrm{E}-03$ & $3.5 \mathrm{E}+00$ & $1.1 \mathrm{E}-03$ \\
\hline TOTAL & ক্য & & & $\cdots \cdot$ & $\therefore$ & 2.0E-01 & 4.1E-01 & 9.7E-02 & $5.4 \mathrm{E}+01$ & $1.4 \mathrm{E}-02$ \\
\hline
\end{tabular}

Assumptions:

- Transportation is to and from the site only

- Operational risks encompass industrial/physical hazards associated with equipment operation and onsite operations

- Infrastructure staff support the staff above. They receive no annual Cancer, average 4,000 travel miles, and average $50 \%$ of the facility totals above.

- Collective rists have been calculated as the product of individual risk, multiplied by the number of exposed inidividuals.

Individual risks provide estimates of the probability of health detriment for the individual, and the collective risks provide a measure of overall detriment

to the work force. 
Option: C. Mechanical Retrieval.

Capital Cost: $\$ 154$ million

Annual Worker Mileage: 15,000

\begin{tabular}{|c|c|c|c|c|c|c|c|c|c|c|}
\hline \multirow{4}{*}{ Activity } & \multicolumn{10}{|c|}{$\begin{array}{c}\text { Construction/Decommissioning } \\
\text { Crafts and Laborers }\end{array}$} \\
\hline & \multicolumn{5}{|c|}{ Annual } & \multicolumn{5}{|c|}{ Total } \\
\hline & \multicolumn{2}{|c|}{ Transportation } & \multicolumn{3}{|c|}{ Operational } & \multicolumn{2}{|c|}{ Transportation } & \multicolumn{3}{|c|}{ Operational } \\
\hline & Death & Injury & Death & Injury & Cancer & Death & Injury & Death & Injury & Cancer \\
\hline $\begin{array}{l}\text { Technology Readiness } \\
\text { (Duration - } 5 \text { years) }\end{array}$ & $6.4 \mathrm{E}-04$ & $1.3 \mathrm{E}-03$ & $2.2 \mathrm{E}-03$ & $5.0 \mathrm{E}-01$ & $0.0 \mathrm{E}+00$ & $3.2 \mathrm{E}-03$ & $6.5 \mathrm{E}-03$ & $1.1 \mathrm{E}-02$ & $2.5 \mathrm{E}+00$ & $0.0 \mathrm{E}+00$ \\
\hline $\begin{array}{c}\text { Capital } \\
\text { (Duration - } 5 \text { years) }\end{array}$ & $6.5 \mathrm{E}-03$ & $1.3 \mathrm{E}-02$ & $2.2 \mathrm{E}-02$ & $5.0 \mathrm{E}+00$ & $5.5 \mathrm{E}-03$ & $3.2 \mathrm{E}-02$ & $6.6 \mathrm{E}-02$ & $1.1 \mathrm{E}-01$ & $2.5 \mathrm{E}+01$ & $2.7 \mathrm{E}-02$ \\
\hline $\begin{array}{c}\text { Operators } \& \\
\text { Maintenance } \\
\text { (Duration - } 15 \text { years) }\end{array}$ & $0.0 \mathrm{E}+00$ & $0.0 \mathrm{E}+00$ & $0.0 \mathrm{E}+00$ & $0.0 \mathrm{E}+00$ & $0.0 \mathrm{E}+00$ & $0.0 \mathrm{E}+00$ & $0.0 \mathrm{E}+00$ & $0.0 \mathrm{E}+00$ & $0.0 \mathrm{E}+00$ & $0.0 \mathrm{E}+00$ \\
\hline $\begin{array}{c}\text { Decontamination \& } \\
\text { Decommissioning } \\
\text { (Duration - } 1 \text { year) }\end{array}$ & $1.3 \mathrm{E}-02$ & $2.6 \mathrm{E}-02$ & $4.4 \mathrm{E}-02$ & $1.0 \mathrm{E}+01$ & $1.2 \mathrm{E}-02$ & $2.6 \mathrm{E}-02$ & 5.3E-02 & 8.7E-02 & $2.0 \mathrm{E}+01$ & $2.5 \mathrm{E}-02$ \\
\hline TOTAL & अু। & अे। & +\%। & ४ै। & ४ফ। & $6.1 \mathrm{E}-02$ & $1.3 \mathrm{E}-01$ & 2.1E-01 & $4.8 \mathrm{E}+01$ & $5.2 \mathrm{E}-02$ \\
\hline
\end{tabular}

Assumptions:

- Transportation is to and from the site only

- Operational risks encompass industrial/physical hazards associated with equipment operation and onsite operations

- Infrastructure stalf support the staff above. They receive no annual Cancer, average 4,000 travel miles, and average $50 \%$ of the ficeility totals above.

- Collective risks have been calculated as the product of individual risk, multiplied by the number of exposed inidividuals.

Individual risks provide estimates of the probability of health detriment for the individual, and the collective risks provide a measure of overali detriment

to the work force. 
Option: C. Mechanical Retrieval

Capital Cost: $\$ 154$ million

Annual Worker Mfileage: 15,000

\begin{tabular}{|c|c|c|c|c|c|c|c|c|c|c|}
\hline \multirow{4}{*}{ Activity } & \multicolumn{10}{|c|}{ Maintenance Crafts } \\
\hline & \multicolumn{5}{|c|}{ Annual } & \multicolumn{5}{|c|}{ Total } \\
\hline & \multicolumn{2}{|c|}{ Transportation } & \multicolumn{3}{|c|}{ Opcrational } & \multicolumn{2}{|c|}{ Transportation } & \multicolumn{3}{|c|}{ Operational } \\
\hline & Death & Injury & Death & Injury & Cancer & Death & Injury & Death & Injury & Cancer \\
\hline $\begin{array}{l}\text { Tcchnology Readiness } \\
\text { (Duration - } 5 \text { years) }\end{array}$ & $0.0 \mathrm{E}+00$ & $0.0 \mathrm{E}+00$ & $0.0 \mathrm{E}+00$ & $0.0 \mathrm{E}+00$ & $0.0 \mathrm{E}+00$ & $0.0 \mathrm{E}+00$ & $0.0 E+00$ & $0.0 \mathrm{E}+00$ & $0.0 \mathrm{E}+00$ & $0.0 \mathrm{E}+00$ \\
\hline $\begin{array}{c}\text { Capital } \\
\text { (Duration }-5 \text { years) }\end{array}$ & $0.0 \mathrm{E}+00$ & $0.0 \mathrm{E}+00$ & $\cdot 0.0 \mathrm{E}+00$ & $0.0 \mathrm{E}+00$ & $0.0 \mathrm{E}+00$ & $0.0 \mathrm{E}+00$ & $0.0 \mathrm{E}+00$ & $0.0 \mathrm{E}+00$ & $0.0 \mathrm{E}+00$ & $0.0 \mathrm{E}+00$ \\
\hline $\begin{array}{c}\text { Operators \& } \\
\text { Maintenance } \\
\text { (Duration - } 15 \text { years) }\end{array}$ & $4.3 \mathrm{E}-03$ & $8.7 \mathrm{E}-03$ & $1.9 \mathrm{E}-03$ & $4.6 \mathrm{E}-01$ & $4.1 \mathrm{E}-03$ & $6.4 \mathrm{E}-02$ & $1.3 \mathrm{E}-01$ & $2.8 \mathrm{E}-02$ & $6.8 \mathrm{E}+00$ & $6.2 \mathrm{E}-02$ \\
\hline $\begin{array}{l}\text { Decontamination \& } \\
\text { Decommissioning } \\
\text { (Duration - } 1 \text { year) }\end{array}$ & $0.0 \mathrm{E}+00$ & $0.0 \mathrm{E}+00$ & $0.0 \mathrm{E}+00$ & $0.0 \mathrm{E}+00$ & $0.0 \mathrm{E}+00$ & $0.0 \mathrm{E}+00$ & $0.0 \mathrm{E}+00$ & $0.0 \mathrm{E}+00$ & $0.0 \mathrm{E}+00$ & $0.0 \mathrm{E}+00$ \\
\hline TOTAL & किक & क्ष & \% & $\begin{array}{l}\text { किक } \\
\text { के }\end{array}$ & कि & $6.4 \mathrm{E}-02$ & $1.3 \mathrm{E}-01$ & $2.8 \mathrm{E}-02$ & $6.8 \mathrm{E}+00$ & $6.2 \mathrm{E}-02$ \\
\hline
\end{tabular}

Assumptions:

- Transportation is to and from the site only

- Operational risks encompass industrial/physical hazards associated with equipment operation and onsite operations

- Infrastructure staff support the staff above. They receive no annual Cancer, average 4,000 travel miles, and average $50 \%$ of the facility totals above.

- Collective risks have been calculated as the product of individual risk, multiplied by the number of exposed inidividuals.

Individual risks provide estimates of the probability of health detriment for the individual, and the collective risks provide a measure of overall detriment

to the work force. 
Option: C. Mechanical Retrieval

Capital Cost: $\$ 154$ million

Annual Worker Mileage: 15,000

\begin{tabular}{|c|c|c|c|c|c|c|c|c|c|c|}
\hline \multirow{4}{*}{ Activity } & \multicolumn{10}{|c|}{ Operators } \\
\hline & \multicolumn{5}{|c|}{ Annual } & \multicolumn{5}{|c|}{ Total } \\
\hline & \multicolumn{2}{|c|}{ Transportation } & \multicolumn{3}{|c|}{ Operational } & \multicolumn{2}{|c|}{ Transportation } & \multicolumn{3}{|c|}{ Operational } \\
\hline & Death & Injury & Death & Injury & Cancer & Death & Injury & Death & Injury & Cancer \\
\hline $\begin{array}{l}\text { Technology Readiness } \\
\text { (Duration - } 5 \text { years) }\end{array}$ & $0.0 \mathrm{E}+00$ & $0.0 \mathrm{E}+00$ & $0.0 \mathrm{E}+00$ & $0.0 \mathrm{E}+00$ & $0.0 \mathrm{E}+00$ & $0.0 \mathrm{E}+00$ & $0.0 \mathrm{E}+00$ & $0.0 \mathrm{E}+00$ & $0.0 \mathrm{E}+00$ & $0.0 \mathrm{E}+00$ \\
\hline $\begin{array}{c}\text { Capital } \\
\text { (Duration - } 5 \text { years) }\end{array}$ & $0.0 \mathrm{E}+00$ & $0.0 \mathrm{E}+00$ & $0.0 \mathrm{E}+00$ & $0.0 \mathrm{E}+00$ & $0.0 \mathrm{E}+00$ & $0.0 \mathrm{E}+00$ & $0.0 \mathrm{E}+00$ & $0.0 \mathrm{E}+00$ & $0.0 \mathrm{E}+00$ & $0.0 \mathrm{E}+00$ \\
\hline $\begin{array}{c}\text { Operators \& } \\
\text { Maintenance } \\
\text { (Duration - } 15 \text { years) }\end{array}$ & $8.5 \mathrm{E}-03$ & $1.8 \mathrm{E}-02$ & $3.7 \mathrm{E}-03$ & $9.1 \mathrm{E}-01$ & $8.3 \mathrm{E}-03$ & $1.3 \mathrm{E}-01$ & $2.6 \mathrm{E}-01$ & $5.6 \mathrm{E}-02$ & $1.4 E+01$ & $1.2 \mathrm{E}-01$ \\
\hline $\begin{array}{c}\text { Decontamination \& } \\
\text { Decommissioning } \\
\text { (Duration - } 1 \text { year) }\end{array}$ & $2.1 \mathrm{E}-03$ & $4.3 \mathrm{E}-03$ & $9.2 \mathrm{E}-04$ & $2.3 \mathrm{E}-01$ & $2.1 \mathrm{E}-03$ & $4.2 \mathrm{E}-03$ & $8.6 \mathrm{E}-03$ & $1.8 \mathrm{E}-03$ & 4.5E-0! & $4.1 \mathrm{E}-03$ \\
\hline TOTAL & a & 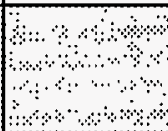 & 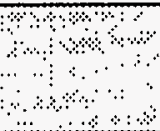 & 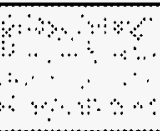 & $\begin{array}{r}0 \\
\vdots \\
\vdots \\
y\end{array}$ & $1.3 \mathrm{E}-01$ & $2.7 \mathrm{E}-01$ & $5.8 \mathrm{E}-02$ & $1.4 \mathrm{E}+01$ & $1.3 \mathrm{E}-01$ \\
\hline
\end{tabular}

Assumptions:

- Transportation is to and from the site only

- Operational risks encompass industrial/physical hazards associaled with equipment operation and onsite operations

- Infrastructure staff support the staff above. They receive no annual Cancer, average 4,000 travel miles, and average $50 \%$ of the facility totals above.

- Collective risks have been calculated as the product of individual risk, multiplied by the number of exposed inidividuals.

Individual risks provide estimates of the probability of health detriment for the individual, and the collective risks provide a measure of overall detriment

to the work force. 


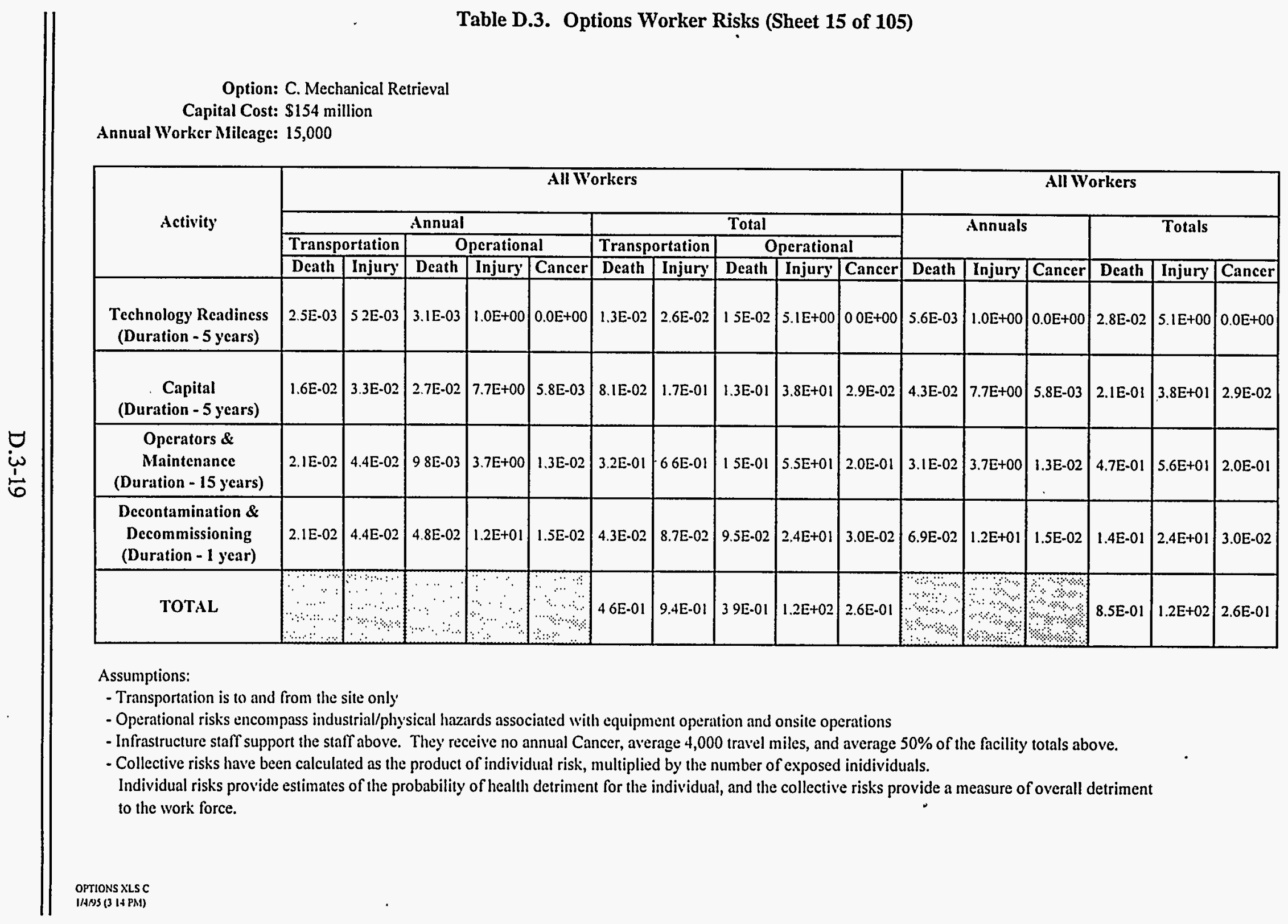




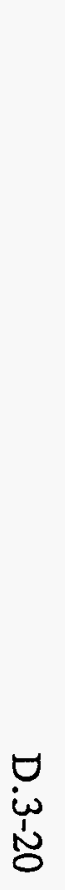

Table D.3. Options Worker Risks (Sheet 16 of 105)

Option: D. Close-Couple Barrier (around 12 tanks)

Capital Cost: $\$ 211$ million

Annual Worker Mileage: 15,000

\begin{tabular}{|c|c|c|c|c|c|c|c|c|c|c|}
\hline \multirow{4}{*}{ Activity } & \multicolumn{10}{|c|}{$\begin{array}{l}\text { Management and } \\
\text { Engineering }\end{array}$} \\
\hline & \multicolumn{5}{|c|}{ Annual } & \multicolumn{5}{|c|}{ Total } \\
\hline & \multicolumn{2}{|c|}{ Transportation } & \multicolumn{3}{|c|}{ Opcrational } & \multicolumn{2}{|c|}{ Transportation } & \multicolumn{3}{|c|}{ Operational } \\
\hline & Death & Injury & Death & \begin{tabular}{|l|} 
Injury \\
\end{tabular} & Cancer & Death & Injury & Death & Injury & Cancer \\
\hline $\begin{array}{l}\text { Technology Readiness } \\
\text { (Duration - } 5 \text { years) }\end{array}$ & $1.6 \mathrm{E}-03$ & $3.4 E-0.3$ & 8.0E-04 & $4.5 \mathrm{E}-01$ & $0.0 \mathrm{E}+00$ & 8.2E-03 & $1.7 \mathrm{E}-02$ & $4.0 \mathrm{E}-03$ & $2.2 \mathrm{E}+00$ & $0.0 \mathrm{E}+00$ \\
\hline $\begin{array}{c}\text { Capital } \\
\text { (Duration }-5 \text { ycars) }\end{array}$ & $1.3 \mathrm{E}-02$ & $2.7 \mathrm{E}-02$ & $6.5 \mathrm{E}-03$ & $3.6 \mathrm{E}+00$ & $4.8 \mathrm{E}-04$ & $6.7 \mathrm{E}-02$ & $1.4 \mathrm{E}-01$ & $3.2 \mathrm{E}-02$ & $1.8 \mathrm{E}+01$ & $2.4 \mathrm{E}-03$ \\
\hline $\begin{array}{c}\text { Operators \& } \\
\text { Maintenance } \\
\text { (Duration - 15 years) }\end{array}$ & 1.3E-03 & $2.6 \mathrm{E}-03$ & $6.2 \mathrm{E}-04$ & $3.5 \mathrm{E}-01$ & $1.1 \mathrm{E}-04$ & $1.9 \mathrm{E}-02$ & $3.9 \mathrm{E}-02$ & $9.3 \mathrm{E}-03$ & $5.2 \mathrm{E}+00$ & $1.6 \mathrm{E}-03$ \\
\hline $\begin{array}{l}\text { Decontamination \& } \\
\text { Decommissioning } \\
\text { (Duration - } 1 \text { year) }\end{array}$ & NA & NA & NA & NA & NA & NA & NA & - NA & NA & NA \\
\hline TOTAL & 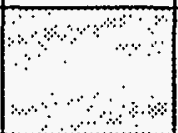 & 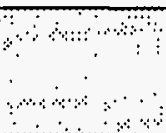 & 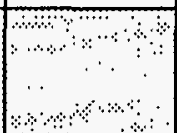 & 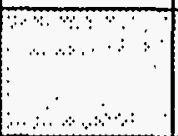 & 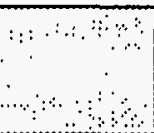 & $9.4 \mathrm{E}-02$ & $1.9 \mathrm{E}-01$ & $4.6 \mathrm{E}-02$ & $2.6 \mathrm{E}+01$ & 4.1E-03 \\
\hline
\end{tabular}

\section{Assumptions:}

- Transportation is to and from the site only

- Operational risks encompass industrial/physical hazards associated with equipment operation and onsite operations

- Infrastructure staff support the staff above. They receive no annual Cancer, average 4.000 travel miles, and average $50 \%$ of the facility totals above.

- Collective risks have been calculated as the product of individual risk, multiplied by the number of exposed inidividuals.

Individual risks provide estimates of the probability of health detriment for the individual, and the collective risks provide a mensure of overall detriment

to the work force. 


\begin{tabular}{|c|c|c|c|c|c|c|c|c|c|c|}
\hline $\begin{array}{l}\text { Option: } \\
\text { Capital Cost: } \\
\text { Annual Worker Mileage: }\end{array}$ & $\begin{array}{l}\text { Close-Co } \\
211 \text { million } \\
5,000\end{array}$ & e Barrier (a & ind 12 tanks & & & & & & & \\
\hline \multirow{4}{*}{ Activity } & \multicolumn{10}{|c|}{$\begin{array}{l}\text { Construction/Decommissioning } \\
\text { Crafts and Laborers }\end{array}$} \\
\hline & \multicolumn{5}{|c|}{ Annual } & \multicolumn{5}{|c|}{ Total } \\
\hline & \multicolumn{2}{|c|}{ Transportation } & \multicolumn{3}{|c|}{ Operational } & \multicolumn{2}{|c|}{ Transportation } & \multicolumn{3}{|c|}{ Operational } \\
\hline & Death & Injury & Death & Injury & Cancer & Death & Injury & Death & Injury & Cancer \\
\hline $\begin{array}{l}\text { Technology Readiness } \\
\text { (Duration - } 5 \text { years) }\end{array}$ & $5.6 \mathrm{E}-04$ & 1.1E-03 & 2.2E-03 & $1.9 \mathrm{E}-01$ & $0.0 \mathrm{E}+00$ & $2.8 \mathrm{E}-03$ & $5.7 \mathrm{E}-03$ & $1.1 \mathrm{E}-02$ & $9.5 \mathrm{E}-01$ & $0.0 \mathrm{E}+00$ \\
\hline $\begin{array}{c}\text { Capital } \\
\text { (Duration - } 5 \text { years) }\end{array}$ & $8.9 \mathrm{E}-03$ & $1.8 \mathrm{E}-02$ & 3.4E-02 & $3.0 \mathrm{E}+00$ & $7.5 \mathrm{E}-03$ & $4.4 \mathrm{E}-02$ & 9.1E-02 & $1.7 \mathrm{E}-01$ & $1.5 \mathrm{E}+01$ & $3.8 \mathrm{E}-02$ \\
\hline $\begin{array}{c}\text { Operators \& } \\
\text { Maintenance } \\
\text { (Duration - } 15 \text { years) } \\
\end{array}$ & $0.0 \mathrm{E}+00$ & $0.0 \mathrm{E}+00$ & $0.0 \mathrm{E}+00$ & $0.0 \mathrm{E}+00$ & $0.0 \mathrm{E}+00$ & $0.0 \mathrm{E}+00$ & $0.0 \mathrm{E}+00$ & $0.0 \mathrm{E}+00$ & $0.0 \mathrm{E}+00$ & $0.0 \mathrm{E}+00$ \\
\hline $\begin{array}{c}\text { Decontamination \& } \\
\text { Decommissioning } \\
\text { (Duration - } 1 \text { year) }\end{array}$ & NA & $\mathrm{NA}$ & NA & NA & $N A$ & $N A$ & NA & NA & NA & NA \\
\hline Total. & & & & & $\begin{array}{cc}\ddots & \ddots \\
\ddots \cdots & \ddots\end{array}$ & $4.7 \mathrm{E}-02$ & $9.6 \mathrm{E}-02$ & $1.8 \mathrm{E}-01$ & $1.6 \mathrm{E}+01$ & $3.8 \mathrm{E}-02$ \\
\hline $\begin{array}{l}\text { Assumptions: } \\
\text { - Transpornation is to and } \\
\text { - Operational risks encon } \\
\text { - Infrastructure staff supp } \\
\text { - Collective risks have be } \\
\text { Individual risks provide } \\
\text { to the work force. }\end{array}$ & $\begin{array}{l}\text { om the site } \\
\text { ass industria } \\
t \text { the staff at } \\
\text { calculated } \\
\text { stimates of }\end{array}$ & $\begin{array}{l}\text { Iy } \\
\text { hysical haz } \\
\text { e. They re } \\
\text { the product } \\
\text { probability }\end{array}$ & $\begin{array}{l}\text { Sassociated } \\
\text { eno annual } \\
\text { individual } r \\
\text { health detri }\end{array}$ & $\begin{array}{l}\text { th equipme } \\
\text { ancer, aver } \\
\text { multiplied } \\
\text { nt for the ir }\end{array}$ & $\begin{array}{l}\text { peration an } \\
4,000 \text { trave } \\
\text { the number } \\
\text { idual, and } 1\end{array}$ & $\begin{array}{l}\text { nsite opera } \\
\text { iles, and av } \\
\text { exposed in } \\
\text { collective } r\end{array}$ & $\begin{array}{l}\text { s } \\
\text { ge } 50 \% \text { of } t \\
\text { iduals. } \\
\text { provide a }\end{array}$ & $\begin{array}{l}\text { acility total } \\
\text { sure of ove }\end{array}$ & $\begin{array}{l}\text { bove. } \\
\text { I detriment }\end{array}$ & \\
\hline
\end{tabular}


Option: D. Close-Couple Barrier (around 12 tanks)

Capital Cost: $\$ 211$ million

Annual Worker Mileage: 15,000

\begin{tabular}{|c|c|c|c|c|c|c|c|c|c|c|}
\hline \multirow{4}{*}{ Activity } & \multicolumn{10}{|c|}{ Maintenance Crafts } \\
\hline & \multicolumn{5}{|c|}{ Annual } & \multicolumn{5}{|c|}{ Total } \\
\hline & \multicolumn{2}{|c|}{ Transportation } & \multicolumn{3}{|c|}{ Operational } & \multicolumn{2}{|c|}{ Transportation } & \multicolumn{3}{|c|}{ Operational } \\
\hline & Death & Injury & Death & Injury & Cancer & Death & Injury & Death & Injury & Cancer \\
\hline $\begin{array}{l}\text { Technology Readiness } \\
\text { (Duration - } 5 \text { years) }\end{array}$ & $0.0 \mathrm{E}+00$ & $0.0 \mathrm{E}+00$ & $0.0 \mathrm{E}+00$ & $0.0 \mathrm{E}+00$ & $0.0 \mathrm{E}+00$ & $0.0 \mathrm{E}+00$ & $0.0 \mathrm{E}+00$ & $0.0 \mathrm{E}+00$ & $0.0 E+00$ & $0.0 \mathrm{E}+00$ \\
\hline $\begin{array}{c}\text { Capital } \\
\text { (Duration - } 5 \text { years) } \\
\end{array}$ & $0.0 \mathrm{E}+00$ & $0.0 \mathrm{E}+00$ & $0.0 \mathrm{E}+00$ & $0.0 \mathrm{E}+00$ & $0.0 \mathrm{E}+00$ & $0.0 \mathrm{E}+00$ & $0.0 \mathrm{E}+00$ & $0.0 \mathrm{E}+00$ & $0.0 \mathrm{E}+00$ & $0.0 \mathrm{E}+00$ \\
\hline $\begin{array}{c}\text { Operators \& } \\
\text { Maintenance } \\
\text { (Duration - } 15 \text { years) }\end{array}$ & $6.4 \mathrm{E}-04$ & $1.3 \mathrm{E}-03$ & $2.8 \mathrm{E}-04$ & $6.8 \mathrm{E}-02$ & $3.1 \mathrm{E}-04$ & $9.6 \mathrm{E}-03$ & $2.0 \mathrm{E}-02$ & $4.2 \mathrm{E}-03$ & $1.0 \mathrm{E}+00$ & 4.7E-03 \\
\hline $\begin{array}{c}\text { Decontamination \& } \\
\text { Decommissioning } \\
\text { (Duration - } 1 \text { year) }\end{array}$ & NA & NA & NA & NA & NA & NA & NA & NA & NA & NA \\
\hline TOTAL & 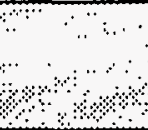 & : & 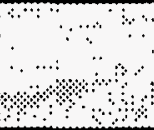 & अन & আ & $9.6 \mathrm{E}-03$ & 2.0E-02 & 4.2E-03 & $1.0 \mathrm{E}+00$ & 4.7E-03 \\
\hline
\end{tabular}

Assumptions:

- Transportation is to and from the sitc only

- Operational risks encompass industrial/physical hazards associated with equipment operation and onsite operations

- Infrastructure staff support the staff above. They receive no annual Cancer, average 4,000 travel niles, and average $50 \%$ of the facility totals above

- Collective risks have been calculated as the product of individual risk, multiplied by the number of exposed inidividuals.

Individual risks provide estimates of the probability of health detriment for the individual, and the collective risks provide a measure of overall detriment

to the work force. 
Option: D. Close-Couple Barrier (around 12 tanks) Capital Cost: $\$ 211$ million

Annual Worker Mileage: 15,000

\begin{tabular}{|c|c|c|c|c|c|c|c|c|c|c|}
\hline \multirow{4}{*}{ Activity } & \multicolumn{10}{|c|}{ Operators } \\
\hline & \multicolumn{5}{|c|}{ Annual } & \multicolumn{5}{|c|}{ Total } \\
\hline & \multicolumn{2}{|c|}{ Transportation } & \multicolumn{3}{|c|}{ Operational } & \multicolumn{2}{|c|}{ Transportation } & \multicolumn{3}{|c|}{ Operational } \\
\hline & Death & Injury & Death & Injury & Cancer & Death & Injury & Death & Injury & Cancer \\
\hline $\begin{array}{l}\text { Technology' Readiness } \\
\text { (Duration - 5years) }\end{array}$ & $0.0 \mathrm{E}+00$ & $0.0 \mathrm{E}+00$ & $0.0 \mathrm{E}+00$ & $0.0 \mathrm{E}+00$ & $0.0 \mathrm{E}+00$ & $0.0 \mathrm{E}+00$ & $0.0 \mathrm{E}+00$ & $0.0 \mathrm{E}+00$ & $0.0 \mathrm{E}+00$ & $0.0 \mathrm{E}+00$ \\
\hline $\begin{array}{c}\text { Capital } \\
\text { (Duration - } 5 \text { years) } \\
\end{array}$ & $0.0 \mathrm{E}+00$ & $0.0 \mathrm{E}+00$ & $0.0 \mathrm{E}+00$ & $0.0 \mathrm{E}+00$ & $0.0 \mathrm{E}+00$ & $0.0 E+00$ & $0.0 \mathrm{E}+00$ & $0.0 \mathrm{E}+00$ & $0.0 \mathrm{E}+00$ & $0.0 \mathrm{E}+00$ \\
\hline $\begin{array}{c}\text { Operators } \& \\
\text { Maintenance } \\
\text { (Duration - } 15 \text { years) }\end{array}$ & $1.3 \mathrm{E}-03$ & $2.6 \mathrm{E}-03$ & $5.6 \mathrm{E}-04$ & $1.4 \mathrm{E}-01$ & $6.2 \mathrm{E}-04$ & $1.9 \mathrm{E}-02$ & $3.9 \mathrm{E}-02$ & $8.4 \mathrm{E}-03$ & $2.0 \mathrm{E}+00$ & $9.3 \mathrm{E}-03$ \\
\hline $\begin{array}{l}\text { Decontamination \& } \\
\text { Decommissioning } \\
\text { (Duration - } 1 \text { year) }\end{array}$ & NA & NA & NA & NA & NA & NA & NA & NA & NA & NA \\
\hline TO'TAL & $\begin{array}{c}\cdots \\
\cdots \\
\cdots\end{array}$ & $\therefore$ & \begin{tabular}{c}
$\ddots$ \\
\hdashline \\
\hdashline
\end{tabular} & \% & 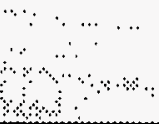 & $1.9 \mathrm{E}-02$ & $3.9 \mathrm{E}-02$ & $8.4 \mathrm{E}-03$ & $2.0 \mathrm{E}+00$ & $9.3 \mathrm{E}-03$ \\
\hline
\end{tabular}

Assumptions:

- Transportation is to and from the site only

- Operational risks encompass industrial/physical hazards associated with equipment operation and onsite operations

- Infrastructure staff support the staff above. They receive no annual Cancer, average 4,000 travel miles, and average $50 \%$ of the facility totals above.

- Collective risks have been calculated as the product of individual risk, multiplied by the number of exposed inidividuals.

Individual risks provide estimates of the probability of health detriment for the individual, and the collective risks provide a measure of overall detriment

to the work force. 


\begin{tabular}{|c|c|c|c|c|c|c|c|c|c|c|c|c|c|c|c|c|}
\hline $\begin{array}{r}\text { Option } \\
\text { Capital Cost } \\
\text { Annual Worker Milcage }\end{array}$ & $\begin{array}{l}\text { D. Close } \\
\$ 211 \mathrm{mil} \\
15,000\end{array}$ & $\begin{array}{l}\text { Couple } \\
\text { lion }\end{array}$ & Barrier (ar & round 12 & tanks) & & & & & & & & & & & \\
\hline \multirow{4}{*}{ Activity } & \multicolumn{10}{|c|}{ All Workers } & \multicolumn{6}{|c|}{ All Workers } \\
\hline & \multicolumn{5}{|c|}{ Annual } & \multicolumn{5}{|c|}{ Total } & \multirow{2}{*}{\multicolumn{3}{|c|}{ Annuals }} & \multirow{2}{*}{\multicolumn{3}{|c|}{ Totals }} \\
\hline & \multicolumn{2}{|c|}{ Transportation } & \multicolumn{3}{|c|}{ Operational } & \multicolumn{2}{|c|}{ Transportation } & \multicolumn{3}{|c|}{ Operational } & & & & & & \\
\hline & \begin{tabular}{l|l} 
Death \\
\end{tabular} & Injury & \begin{tabular}{|l|} 
Death \\
\end{tabular} & Injury & \begin{tabular}{|l|} 
Cancer \\
\end{tabular} & \begin{tabular}{|l|} 
Death \\
\end{tabular} & Injury & \begin{tabular}{|l|} 
Death \\
\end{tabular} & \begin{tabular}{|l|} 
Injury \\
\end{tabular} & \begin{tabular}{|l|} 
Cancer \\
\end{tabular} & \begin{tabular}{|l|} 
Death \\
\end{tabular} & \begin{tabular}{|l|} 
Injury \\
\end{tabular} & \begin{tabular}{|l|} 
Cancer \\
\end{tabular} & \begin{tabular}{|l|} 
Death \\
\end{tabular} & \begin{tabular}{|l|} 
Injury \\
\end{tabular} & Cancer \\
\hline $\begin{array}{l}\text { Technology Readiness } \\
\text { (Duration - } 5 \text { years) }\end{array}$ & $22 \mathrm{E}-03$ & $45 \mathrm{E}-03$ & $30 \mathrm{OE}-03$ & $64 \mathrm{E}-01$ & $|00 E+00|$ & $11 \mathrm{E}-02$ & $23 \mathrm{E}-02$ & $15 \mathrm{E}-02$ & $32 E+00 \mid$ & $|00 \mathrm{E}+00|$ & $52 \mathrm{E}-03$ & $64 \mathrm{E}-01$ & $00 E+00 \mid$ & $2.6 \mathrm{E}-02$ & $3.2 \mathrm{E}+00$ & $0.0 \mathrm{E}+00$ \\
\hline $\begin{array}{c}\text { Capital } \\
\text { (Duration }-5 \text { years) }\end{array}$ & $2.2 \mathrm{E}-02$ & $45 \mathrm{E}-02$ & $+1 \mathrm{IE}-02$ & $66 \mathrm{E}+00$ & $80 \mathrm{E}-03$ & $11 \mathrm{E}-01$ & $23 \mathrm{E}-01$ & $20 \mathrm{E}-01$ & $33 E+01 \mid$ & $40 \mathrm{OE}-02$ & $63 \mathrm{E}-02$ & $|6.7 E+00|$ & $8.0 \mathrm{E}-03$ & $3.2 \mathrm{E}-01$ & $3.3 \mathrm{E}+01$ & $4.0 \mathrm{E}-02$ \\
\hline $\begin{array}{c}\text { Operators \& } \\
\text { Maintenance } \\
\text { (Duration-15 years) } \\
\end{array}$ & $32 \mathrm{E}-03$ & $6.5 \mathrm{E}-03$ & $15 E-03$ & $55 \mathrm{E}-01$ & $10 \mathrm{E}-03$ & $48 \mathrm{E}-02$ & $98 \mathrm{E}-02$ & $22 \mathrm{E}-02$ & $83 \mathrm{E}+00 \mid$ & $16 \mathrm{E}-02$ & $4.7 \mathrm{E}-03$ & $56 \mathrm{E}-01$ & $1.0 \mathrm{E}-03$ & $7.0 \mathrm{E}-02$ & $84 E+00 \mid$ & $16 \mathrm{E}-02$ \\
\hline $\begin{array}{c}\text { Decontamination \& } \\
\text { Decommissioning } \\
\text { (Duration - } 1 \text { year) }\end{array}$ & NA & NA & NA & $\mathrm{NA}$ & NA & NA & $\mathrm{NA}$ & $\mathrm{NA}$ & $\mathrm{NA}$ & $\mathrm{NA}$ & $\mathrm{NA}$ & NA & $\mathrm{NA}$ & NA & $\mathrm{NA}$ & NA \\
\hline TOTAL & अ. & अ: & \%थ & अ & $\mid \begin{array}{r}\because \\
3 \\
\square\end{array}$ & $17 \mathrm{E}-01$ & $35 \mathrm{E}-01$ & $2.4 \mathrm{E}-01$ & $|4.5 E+01|$ & $5.6 \mathrm{E}-02$ & ?. & +. & ?. & $4.1 \mathrm{E}-01$ & $4.5 E+01$ & $5.6 \mathrm{E}-02$ \\
\hline
\end{tabular}

\section{Assumptions:}

- Transportation is to and from the site only

- Operational risks encompass industrial/physical hazards associated with equipment operation and onsite operations

- Infrastructure staff support the staff above. They' receive no annual Cancer, average 4,000 travel miles, and average $50 \%$ of the facility totals above.

- Collective risks have been calculated as the product of individual risk, multiplied by the number of exposed inidividuals.

Individual risks provide estimates of the probability of health detriment for the individual, and the collective risks provide a measure of overall detriment

to the work force. 
Option: E. Close-Coupled Barrier (12 sides only)

Capital Cost: $\$ 111$ million

Annual Worker Milcage: 15,000

\begin{tabular}{|c|c|c|c|c|c|c|c|c|c|c|}
\hline \multirow{4}{*}{ Activity } & \multicolumn{10}{|c|}{$\begin{array}{l}\text { Management and } \\
\text { Engineering }\end{array}$} \\
\hline & \multicolumn{5}{|c|}{ Annual } & \multicolumn{5}{|c|}{ Total } \\
\hline & \multicolumn{2}{|c|}{ Transportation } & \multicolumn{3}{|c|}{ Operational } & \multicolumn{2}{|c|}{ Transportation } & \multicolumn{3}{|c|}{ Operational } \\
\hline & Death & Injury & Death & Injury & Cancer & Death & Injury & Death & Injury & Cancer \\
\hline $\begin{array}{l}\text { Technology Readincss } \\
\text { (Duration - } 5 \text { years) }\end{array}$ & 8.9E-04 & $1.8 \mathrm{E}-03$ & $4.3 E-04$ & $2.4 \mathrm{E}-0 \mathrm{I}$ & $0.0 \mathrm{E}+00$ & 4.4E-03 & 9.1E-03 & 2.2E-03 & $1.2 \mathrm{E}+00$ & $0.0 \mathrm{E}+00$ \\
\hline $\begin{array}{c}\text { Capital } \\
\text { (Duration - } 5 \text { ycars) }\end{array}$ & $7.0 \mathrm{E}-03$ & $1.4 \mathrm{E}-02$ & $3.4 \mathrm{E}-03$ & $1.9 \mathrm{E}+00$ & $2.5 \mathrm{E}-04$ & $3.5 \mathrm{E}-02$ & $7.1 \mathrm{E}-02$ & $1.7 \mathrm{E}-02$ & $9.5 \mathrm{E}+00$ & $1.3 \mathrm{E}-03$ \\
\hline $\begin{array}{c}\text { Operators \& } \\
\text { Maintenance } \\
\text { (Duration - } 15 \text { ycars) }\end{array}$ & $1.3 \mathrm{E}-03$ & $2.6 \mathrm{E}-03$ & $6.2 \mathrm{E}-04$ & $3.5 \mathrm{E}-01$ & 1.1E-04 & $1.9 \mathrm{E}-02$ & $3.9 \mathrm{E}-02$ & $9.3 \mathrm{E}-03$ & $5.2 \mathrm{E}+00$ & $1.6 \mathrm{E}-03$ \\
\hline $\begin{array}{l}\text { Decontamination \& } \\
\text { Decommissioning } \\
\text { (Duration - } 1 \text { year) }\end{array}$ & NA & NA & NA & NA & NA & NA & NA & NA & NA & $\mathrm{NA}$ \\
\hline TOTAL & के & कि & and &  & 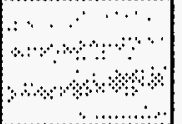 & $5.9 \mathrm{E}-02$ & $1.2 \mathrm{E}-01$ & $2.8 \mathrm{E}-02$ & $1.6 \mathrm{E}+01$ & $2.9 \mathrm{E}-03$ \\
\hline
\end{tabular}

Assumptions:

- Transportation is to and from the site only

- Operational risks encompass industrial/physical hazards associated with equipment operation and onsite operations

- Infrastrueture staff support the stafr above. They receive no annual Cancer, average $\mathbf{4 . 0 0 0}$ travel miles, and average $\mathbf{5 0 \%}$ of the facility totals above.

- Collective risks have been calculated as the product of individual risk, multiplied by the number of exposed inidividuals.

Individual risks provide estimates of the probability of health detriment for the individual, and the collective risks provide a measure of overall detriment

to the work force. 
Option: E. Close-Coupled Barrier (12 sides only)

Capital Cost: \$111 million

Annual Worker Mileage: 15,000

\begin{tabular}{|c|c|c|c|c|c|c|c|c|c|c|}
\hline \multirow{4}{*}{ Activity } & \multicolumn{10}{|c|}{$\begin{array}{l}\text { Construction/Decommissioning } \\
\text { Crafts and Laborers }\end{array}$} \\
\hline & \multicolumn{5}{|c|}{ Annual } & \multicolumn{5}{|c|}{ Total } \\
\hline & \multicolumn{2}{|c|}{ Transportation } & \multicolumn{3}{|c|}{ Operational } & \multicolumn{2}{|c|}{ Transportation } & \multicolumn{3}{|c|}{ Operational } \\
\hline & Death & Injury' & Death & Injury & Cancer & Death & Injury & Death & Injury & Cancer \\
\hline $\begin{array}{l}\text { Technology Readiness } \\
\text { (Duration - } 5 \text { years) }\end{array}$ & $2.9 \mathrm{E}-04$ & $5.9 E-04$ & I.1E-03 & $9.8 \mathrm{E}-02$ & $0.0 \mathrm{E}+00$ & $1.4 \mathrm{E}-03$ & $3.0 \mathrm{E}-03$ & $5.6 \mathrm{E}-03$ & $4.9 \mathrm{E}-01$ & $0.0 \mathrm{E}+00$ \\
\hline $\begin{array}{c}\text { Capital } \\
\text { (Duration - } 5 \text { years) }\end{array}$ & $4.7 F:-0.3$ & $9.5 \Gamma:-0.3$ & $1.85:-02$ & $1.6 \mathrm{~F}+00$ & $2.8[\mathrm{E}-03$ & $2.3 \mathrm{E}-02$ & $4.8 \mathrm{r}:-02$ & $9.0 \mathrm{E}-02$ & $7.9 \Gamma+00$ & $1.4 \mathrm{E}-02$ \\
\hline $\begin{array}{c}\text { Operators \& } \\
\text { Maintenance } \\
\text { (Duration - } 15 \text { years) }\end{array}$ & $0.0 \mathrm{E}+00$ & $0.0 \mathrm{E}+00$ & $0.0 \mathrm{E}+00$ & $0.0 \mathrm{E}:+00$ & $0.0 F+00$ & $0.0 \mathrm{E}+00$ & $0.0 \mathrm{E}+00$ & $0.0 \mathrm{E}+00$ & $0.0 \mathrm{E}+00$ & $0.0 \Gamma+00$ \\
\hline $\begin{array}{c}\text { Decontamination \& } \\
\text { Decommissioning } \\
\text { (Duration - } 1 \text { year) }\end{array}$ & NA & NA & NA & NA & NA & NA & NA & NA & NA & NA \\
\hline TOTAL & : & औ। & का & 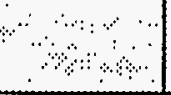 & $\begin{array}{cccc}\because & \cdots & \ddots & \vdots \\
\ddots & \cdots & \cdots & \cdots \\
\end{array}$ & $2.5 \mathrm{E}-02$ & $5.1 \mathrm{E}-02$ & $9.6 \mathrm{E}-02$ & $8.4 \mathrm{E}+00$ & $1.4 \mathrm{E}-02$ \\
\hline
\end{tabular}

Assumptions: •

- Transportation is to and from the site only

- Operational risks encompass industrial/physical hazards associated with equipment operation and onsite operations

- Infrastrueture statf support the staff above. They receive no annual Cancer. alerage 4.000 travel miles, and average $50 \%$ of the facility totals above.

- Collective risks han been calculated as the product of indis idual rish. mulliplied by the number ol exposed indedividuals.

Individual risks provide estimates of the probability of health detriment for the individual, and the collective risks provide a measure of overall detriment

to the work force. 
Table D.3. Options Worker Risks (Sheet 23 of 105)

Option: E. Close-Coupled Barrier (12 sides only)

Capital Cost: \$111 million

Annual Worker Mileage: 15,000

\begin{tabular}{|c|c|c|c|c|c|c|c|c|c|c|}
\hline \multirow{4}{*}{ Activity } & \multicolumn{10}{|c|}{ Maintenance Crafts } \\
\hline & \multicolumn{5}{|c|}{ Annual } & \multicolumn{5}{|c|}{ Total } \\
\hline & \multicolumn{2}{|c|}{ Transportation } & \multicolumn{3}{|c|}{ Operational } & \multicolumn{2}{|c|}{ Transportation } & \multicolumn{3}{|c|}{ Operational } \\
\hline & Death & Injury & Death & Injury & Cancer & Death & Injury & Death & Injury & Cancer \\
\hline $\begin{array}{l}\text { Technology Readincss } \\
\text { (Duration - } 5 \text { years) }\end{array}$ & $0.0 \mathrm{E}+00$ & $0.0 \mathrm{E}+00$ & $0.0 \mathrm{E}+00$ & $0.0 \mathrm{E}+00$ & $0.0 \mathrm{E}+00$ & $0.0 \mathrm{E}+00$ & $0.0 \mathrm{E}+00$ & $0.0 \mathrm{E}+00$ & $0.0 \mathrm{E}+00$ & $0.0 \mathrm{E}+00$ \\
\hline $\begin{array}{c}\text { Capital } \\
\text { (Duration - } 5 \text { years) } \\
\end{array}$ & $0.0 \mathrm{E}+00$ & $0.0 \mathrm{E}+00$ & $0.0 \mathrm{E}+00$ & $0.0 \mathrm{E}+00$ & $0.0 \mathrm{E}+00$ & $0.0 \mathrm{E}+00$ & $0.0 \mathrm{E}+00$ & $0.0 \mathrm{E}+00$ & $0.0 \mathrm{E}+00$ & $0.0 \mathrm{E}+00$ \\
\hline $\begin{array}{c}\text { Operators \& } \\
\text { Maintenance } \\
\text { (Duration - } 15 \text { years) }\end{array}$ & $6.4 \mathrm{E}-04$ & $1.3 \mathrm{E}-03$ & $2.8 \mathrm{E}-04$ & $6.8 \mathrm{E}-02$ & 3.1E-04 & $9.6 \mathrm{E}-03$ & $2.0 \mathrm{E}-02$ & $4.2 \mathrm{E}-03$ & $1.0 \mathrm{E}+00$ & 4.7E-03 \\
\hline $\begin{array}{c}\text { Decontamination \& } \\
\text { Decommissioning } \\
\text { (Duration - } 1 \text { year) }\end{array}$ & $\mathrm{NA}$ & NA & $\mathrm{NA}$ & NA & NA & NA & NA & NA & NA & NA \\
\hline TOTAL & a & $\left(\begin{array}{cc}3 \\
\hdashline\end{array}\right.$ & a & 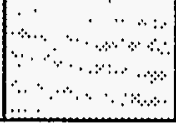 & 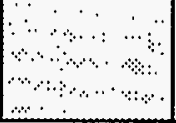 & $9.6 \mathrm{E}-03$ & $2.0 \mathrm{E}-02$ & $4.2 \mathrm{E}-03$ & $1.0 \mathrm{E}+00$ & 4.7E-03 \\
\hline
\end{tabular}

Assumptions:

- Transportation is to and from the site only

- Operational risks encompass industrial/physical hazards associated with equipment operation and onsite operations

- Infrastructure stalf support the staff above. They receive no annual Cincer, average 4,000 travel miles, and average $50 \%$ of the facility totals above.

- Collective risks have been calculated as the product of individual risk, multiplied by the number of exposed inidividuals.

Individual risks provide estimates of the probability of health detriment for the individual, and the collective risks provide a measure of overall detriment

to the work force. 
Option: E. Close-Coupled Barrier (12 sides only)

Capital Cost: $\$ 111$ million

Annual Worker Mileage: 15,000

\begin{tabular}{|c|c|c|c|c|c|c|c|c|c|c|}
\hline \multirow{4}{*}{ Activity } & \multicolumn{10}{|c|}{ Operators } \\
\hline & \multicolumn{5}{|c|}{ Annual } & \multicolumn{5}{|c|}{ Total } \\
\hline & \multicolumn{2}{|c|}{ Transportation } & \multicolumn{3}{|c|}{ Operational } & \multicolumn{2}{|c|}{ Transportation } & \multicolumn{3}{|c|}{ Operational } \\
\hline & Death & Injury & Death & Injury & Cancer & Death & Injury & Death & Injury & Cancer \\
\hline $\begin{array}{l}\text { Technology Readiness } \\
\text { (Duration - } 5 \text { years) }\end{array}$ & $0.0 \mathrm{E}+00$ & $0.0 \mathrm{E}+00$ & $0.0 \mathrm{E}+00$ & $0.0 \mathrm{E}+00$ & $0.0 \mathrm{E}+00$ & $0.0 \mathrm{E}+00$ & $0.0 \mathrm{E}+00$ & $0.0 \mathrm{E}+00$ & $0.0 \mathrm{E}+00$ & $0.0 \mathrm{E}+00$ \\
\hline $\begin{array}{c}\text { Capital } \\
\text { (Duration }-5 \text { years) }\end{array}$ & $0.0 \mathrm{E}+00$ & $0.0 \mathrm{E}+00$ & $0.0 \mathrm{E}+00$ & $0.0 \mathrm{E}+00$ & $0.0 \mathrm{E}+00$ & $0.0 \mathrm{E}+00$ & $0.0 \mathrm{E}+00$ & $0.0 \mathrm{E}+00$ & $0.0 \mathrm{E}+00$ & $0.0 \mathrm{E}+00$ \\
\hline $\begin{array}{c}\text { Operators \& } \\
\text { Maintenance } \\
\text { (Duration - 15 years) }\end{array}$ & $1.3 \mathrm{E}-03$ & $2.6 \mathrm{E}-03$ & $5.6 \mathrm{E}-04$ & $1.4 \mathrm{E}-01$ & $6.2 \mathrm{E}-04$ & $1.9 \mathrm{E}-02$ & $3.9 \mathrm{E}-02$ & $8.4 \mathrm{E}-03$ & $2.0 \mathrm{E}+00$ & $9.3 \mathrm{E}-03$ \\
\hline $\begin{array}{l}\text { Decontamination \& } \\
\text { Decommissioning } \\
\text { (Duration - } 1 \text { year) }\end{array}$ & NA & NA & NA & NA & NA & NA & NA & NA & NA & NA \\
\hline TOTAL & अे। & ४ै। & 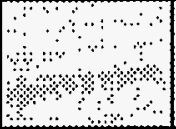 & 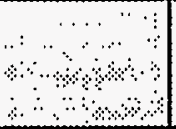 & ওে & $1.9 \mathrm{E}-02$ & $3.9 \mathrm{E}-02$ & $8.4 \mathrm{E}-03$ & $2.0 \mathrm{E}+00$ & $9.3 \mathrm{E}-03$ \\
\hline
\end{tabular}

Assumptions:

- Transportation is to and from the site only

- Operational risks encompass industrial/physical hazards associated with equipment operation and onsite operations

- Infrastructure staff support the staff above. They receive no annual Cancer. average 4.000 travel miles, and average $50 \%$ of the facility totals above.

- Collective risks have been calculated as the product of individual risk, multiplied by the number of exposed inidividuals.

Individual risks provide estimates of the probability of health detriment for the individual, and the collective risks provide a measure of overall detriment

to the work force. 


\begin{tabular}{|c|c|c|c|c|c|c|c|c|c|c|c|c|c|c|c|c|}
\hline $\begin{array}{r}\text { Option } \\
\text { Capital Cost } \\
\text { Annual Worker Mileage }\end{array}$ & $\begin{array}{l}\text { E. Close } \\
\$ 111 \mathrm{mi} \\
15,000\end{array}$ & $\begin{array}{l}\text { Coupled } \\
\text { lion }\end{array}$ & Barrier & 12 sides & only) & & & & & & & . & & & & \\
\hline \multirow{4}{*}{ Activity } & \multicolumn{10}{|c|}{ All Workers } & \multicolumn{6}{|c|}{ All Workers } \\
\hline & \multicolumn{5}{|c|}{ Annual } & \multicolumn{5}{|c|}{ Total } & \multirow{2}{*}{\multicolumn{3}{|c|}{ Annuals }} & \multirow{2}{*}{\multicolumn{3}{|c|}{ Totals }} \\
\hline & \multicolumn{2}{|c|}{\begin{tabular}{|l|} 
Transportation \\
\end{tabular}} & \multicolumn{3}{|c|}{ Operational } & \multicolumn{2}{|c|}{ Transportation } & \multicolumn{3}{|c|}{ Operational } & & & & & & \\
\hline & Death & Injury & Death & \begin{tabular}{|l|} 
Injury \\
\end{tabular} & Cancer & Death & Injury & Death & \begin{tabular}{|l|} 
Injury \\
\end{tabular} & Cancer & Death & \begin{tabular}{|l|} 
Injury \\
\end{tabular} & Cancer & Death & Injury & Cancer \\
\hline $\begin{array}{l}\text { Technology Readiness } \\
\text { (Duration - } 5 \text { years) }\end{array}$ & $1,2 \mathrm{E}-03$ & $2.4 \mathrm{E}-03$ & $1.6 \mathrm{E}-03$ & $3.4 \mathrm{E}-01$ & $00 E+00$ & $5.9 \mathrm{E}-03$ & $1.2 \mathrm{E}-02$ & $7.8 \mathrm{E}-03$ & $1.7 E+00$ & $00 E+00$ & $2.7 \mathrm{E}-03$ & $3.4 \mathrm{E}-01$ & $|0.0 E+00|$ & $1.4 \mathrm{E}-02$ & $1.7 \mathrm{E}+00$ & $0.0 E+00$ \\
\hline $\begin{array}{c}\text { Capital } \\
\text { (Duration - } 5 \text { years) }\end{array}$ & $1.2 \mathrm{E}-02$ & $24 \mathrm{E}-02$ & $2.1 \mathrm{E}-02$ & $3.5 \mathrm{E}+00$ & $3.1 \mathrm{E}-03$ & $5.8 \mathrm{E}-02$ & $1.2 \mathrm{E}-01$ & $1.1 \mathrm{E}-01$ & $1.7 \mathrm{E}+01$ & $1.5 \mathrm{E}-02$ & 3.3E-02 & $3.5 \mathrm{E}+00$ & $3.1 \mathrm{E}-03$ & $1.7 \mathrm{E}-01$ & $|1.8 \mathrm{E}+01|$ & $1.5 \mathrm{E}-02$ \\
\hline $\begin{array}{c}\text { Operators \& } \\
\text { Maintenance } \\
\text { (Duration - 15 years) }\end{array}$ & $3.2 \mathrm{E}-03$ & $6.5 \mathrm{E}-03$ & $1.5 \mathrm{E}-03$ & $5.5 \mathrm{E}-01$ & $1.0 \mathrm{E}-03$ & $4.8 \mathrm{E}-02$ & $9.8 \mathrm{E}-02$ & $2.2 \mathrm{E}-02$ & $8.3 E+00$ & $1.6 \mathrm{E}-02$ & $4.7 \mathrm{E}-03$ & $5.6 \mathrm{E}-01$ & $1.0 \mathrm{E}-03$ & $7.0 \mathrm{E}-02$ & $8.4 E+00 \mid$ & 1.6E-02 \\
\hline $\begin{array}{c}\text { Decontamination \& } \\
\text { Decommissioning } \\
\text { (Duration - } 1 \text { year) }\end{array}$ & NA & NA & NA & $\mathrm{NA}$ & $\mathrm{NA}$ & $\mathrm{NA}$ & $\mathrm{NA}$ & NA & $\mathrm{NA}$ & $\mathrm{NA}$ & $\mathrm{NA}$ & NA & NA & $\mathrm{NA}$ & NA & NA \\
\hline TOTAL & $\cdots$ & अ & खे & अ & & $1.1 \mathrm{E}-01$ & $2.3 \mathrm{E}-01$ & $1.4 \mathrm{E}-01$ & $2.7 \mathrm{E}+01$ & $3.1 \mathrm{E}-02$ & अे: & ?.। & अै। & $2.5 \mathrm{E}-01$ & $2.8 \mathrm{E}+01$ & 3.1E-02 \\
\hline
\end{tabular}

Assumptions:

- Transportation is to and from the site only

- Operational risks encompass industrial/physical hazards associated with equipment operation and onsite operations

- Infrastructure staff support the staff above. They receive no annual Cancer, average 4,000 travel miles, and average $50 \%$ of the facility totals above.

- Collective risks have been calculated as the product of individual risk, multiplied by the number of exposed inidividuals.

Individual risks provide estimates of the probability of health detriment for the individual, and the collective risks provide a measure of overall detriment to the work force. 
Option: F. Close-Coupled Barrier (around 7 tanks only) Capital Cost: $\$ 145$ million Annual Worker Mileage: 15,000

\begin{tabular}{|c|c|c|c|c|c|c|c|c|c|c|}
\hline \multirow{4}{*}{ Activity } & \multicolumn{10}{|c|}{$\begin{array}{l}\text { Management and } \\
\text { Engineering }\end{array}$} \\
\hline & \multicolumn{5}{|c|}{ Annual } & \multicolumn{5}{|c|}{ Total } \\
\hline & \multicolumn{2}{|c|}{ Transportation } & \multicolumn{3}{|c|}{ Operational } & \multicolumn{2}{|c|}{ Transportation } & \multicolumn{3}{|c|}{ Operational } \\
\hline & Death & Injury & Death & Injury & Cancer & Death & Injury & Death & Injury & Cancer \\
\hline $\begin{array}{l}\text { Technology Readiness } \\
\text { (Duration - } 5 \text { years) }\end{array}$ & $1.6 \mathrm{E}-03$ & $3.4 E-03$ & $8.0 \mathrm{E}-04$ & $4.5 \mathrm{E}-01$ & $0.0 \mathrm{E}+00$ & 8.2E-03 & $1.7 \mathrm{E}-02$ & $4.0 \mathrm{E}-03$ & $2.2 \mathrm{E}+00$ & $0.0 \mathrm{E}+00$ \\
\hline $\begin{array}{c}\text { Capital } \\
\text { (Duration - } 5 \text { ycars) }\end{array}$ & $9.1 \mathrm{E}-03$ & $1.9 \mathrm{E}-02$ & $4.4 E-03$ & $2.5 \mathrm{E}+00$ & 3.3E-04 & $4.6 \mathrm{E}-02$ & $9.3 \mathrm{E}-02$ & $2.2 \mathrm{E}-02$ & $1.2 \mathrm{E}+01$ & $1.7 \mathrm{E}-03$ \\
\hline $\begin{array}{c}\text { Operators \& } \\
\text { Maintenance } \\
\text { (Duration - } 15 \text { years) } \\
\end{array}$ & $1.3 \mathrm{E}-03$ & $2.6 \mathrm{E}-03$ & $6.2 \mathrm{E}-04$ & $3.5 \mathrm{E}-01$ & $1.1 E-04$ & $1.9 \mathrm{E}-02$ & $3.9 E-02$ & $9.3 E-03$ & $5.2 \mathrm{E}+00$ & $1.6 \mathrm{E}-03$ \\
\hline $\begin{array}{c}\text { Decontamination \& } \\
\text { Decommissioning } \\
\text { (Duration - } 1 \text { year) }\end{array}$ & NA & NA & $N A^{\prime}$ & $\mathrm{NA}$ & NA & NA & NA & NA & NA & NA \\
\hline TOTAL & $\begin{array}{l} \\
4 \quad \\
\therefore \quad\end{array}$ & 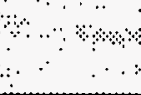 & & $\because$ & \begin{tabular}{c} 
\\
\hdashline \\
\hdashline
\end{tabular} & $7.3 \mathrm{E}-02$ & $1.5 \mathrm{E}-01$ & $3.5 \mathrm{E}-02$ & $2.0 \mathrm{E}+01$ & $3.3 \mathrm{E}-03$ \\
\hline
\end{tabular}

Assumptions:

- Transportation is to and from the site only

- Operational risks encompass industrial/phy'sical hazards associated with equipment operation and onsite operations

- Infrastructure staff support the staff above. They receive no annual Cancer, average 4,000 travel miles, and average $50 \%$ of the facility totals above.

- Collective risks have been calctlated as the product of individual risk, multiplied by the number of exposed inidividuals.

Individual risks provide estimates of the probability of health detriment for the individual, and the collective risks provide a measure of overall detriment

to the work force. 
Option: F. Close-Coupled Barrier (around 7 tanks only)

Capital Cost: $\$ 145$ million

Annual Worker Milcage: 15,000

\begin{tabular}{|c|c|c|c|c|c|c|c|c|c|c|}
\hline \multirow{4}{*}{ Activity } & \multicolumn{10}{|c|}{$\begin{array}{c}\text { Construction/Decommissioning } \\
\text { Crafts and Laborers }\end{array}$} \\
\hline & \multicolumn{5}{|c|}{ Annual } & \multicolumn{5}{|c|}{ Total } \\
\hline & \multicolumn{2}{|c|}{ Transportation } & \multicolumn{3}{|c|}{ Operational } & \multicolumn{2}{|c|}{ Transportation } & \multicolumn{3}{|c|}{ Operational } \\
\hline & Death & Injury & Death & Injury & Cancer & Death & Injury & Death & Injury & Cancer \\
\hline $\begin{array}{l}\text { Technology Readiness } \\
\text { (Duration - } 5 \text { y'ears) }\end{array}$ & $5.6 \mathrm{E}-04$ & 1.1E-03 & 2.2E-03 & $1.9 \mathrm{E}-01$ & $0.0 \mathrm{E}+00$ & $2.8 \mathrm{E}-03$ & 5.7E-03 & $1.1 \mathrm{E}-02$ & $9.5 \mathrm{E}-01$ & $0.0 \mathrm{E}+00$ \\
\hline $\begin{array}{c}\text { Capital } \\
\text { (Duration - } 5 \text { ycars) }\end{array}$ & $6.1 E-03$ & $1.2 \mathrm{E}-02$ & 2.4E-02 & 2.1E+00 & 5.2E-03 & $3.0 \mathrm{E}-02$ & $6.2 \mathrm{E}-02$ & $1.2 \mathrm{E}-01$ & $1.0 \mathrm{E}+01$ & $2.6 \mathrm{E}-02$ \\
\hline $\begin{array}{c}\text { Operators \& } \\
\text { Maintenance } \\
\text { (Duration - } 15 \text { years) }\end{array}$ & $0.0 \mathrm{E}+00$ & $0.0 \mathrm{E}+00$ & $0.0 \mathrm{E}+00$ & $0.0 \mathrm{E}+00$ & $0.0 \mathrm{E}+00$ & $0.0 \mathrm{E}+00$ & $0.0 \mathrm{E}+00$ & $0.0 \mathrm{E}+00$ & $0.0 \mathrm{E}+00$ & $0.0 \mathrm{E}+00$ \\
\hline $\begin{array}{c}\text { Decontamination \& } \\
\text { Decommissioning } \\
\text { (Duration - } 1 \text { year) }\end{array}$ & NA & NA & NA & NA & NA & NA & NA & NA & NA & NA \\
\hline TOTAL & 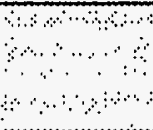 & 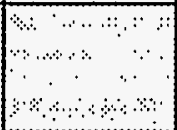 & 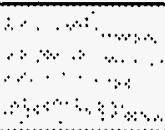 & 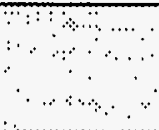 & 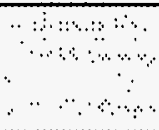 & 3.3E-02 & $6.8 \mathrm{E}-02$ & $1.3 \mathrm{E}-01$ & $1.1 \mathrm{E}+01$ & $2.6 \mathrm{E}-02$ \\
\hline
\end{tabular}

Assumptions:

- Transportation is to and from the site only

- Operational risks encompass industrial/physical hazards associated with equipment operation and onsite operations

- Infrastructure staff support the staff above. They receive no annual Cancer, average 4,000 travel miles, and average $50 \%$ of the facility totals above.

- Collective risks have been calculated as the product of individual risk, multiplied by the number of exposed inidividuals.

Individual risks provide estimates of the probability of health detriment for the individual, and the collective risks provide a measure of overall detriment

to the work force. 
Option: F. Close-Coupled Barrier (around 7 tanks only) Capital Cost: $\$ 145$ million

Annual Worker Mileage: 15,000

\begin{tabular}{|c|c|c|c|c|c|c|c|c|c|c|}
\hline \multirow{4}{*}{ Activity } & \multicolumn{10}{|c|}{ Maintenance Crafts } \\
\hline & \multicolumn{5}{|c|}{ Annual } & \multicolumn{5}{|c|}{ Total } \\
\hline & \multicolumn{2}{|c|}{ Transportation } & \multicolumn{3}{|c|}{ Operational } & \multicolumn{2}{|c|}{ Transportation } & \multicolumn{3}{|c|}{ Operational } \\
\hline & Death & Injury & Death & Injury & Cancer & Death & Injury & Death & Injury & Cancer \\
\hline $\begin{array}{c}\text { Technology Readiness } \\
\text { (Duration }-5 \text { years) }\end{array}$ & $0.0 \mathrm{E}+00$ & $0.0 \mathrm{E}+00$ & $0.0 \mathrm{E}+00$ & $0.0 \mathrm{E}+00$ & $0.0 \mathrm{E}+00$ & $0.0 \mathrm{E}+00$ & $0.0 \mathrm{E}+00$ & $0.0 \mathrm{E}+00$ & $0.0 \mathrm{E}+00$ & $0.0 \mathrm{E}+00$ \\
\hline $\begin{array}{c}\text { Capital } \\
\text { (Duration - } 5 \text { years) }\end{array}$ & $0.0 \mathrm{E}+00$ & $0.0 \mathrm{E}+00$ & $0.0 \mathrm{E}+00$ & $0.0 \mathrm{E}+00$ & $0.0 \mathrm{E}+00$ & $0.0 \mathrm{E}+00$ & $0.0 \mathrm{E}+00$ & $0.0 \mathrm{E}+00$ & $0.0 \mathrm{E}+00$ & $0.0 \mathrm{E}+00$ \\
\hline $\begin{array}{c}\text { Operators \& } \\
\text { Maintenance } \\
\text { (Duration - 15 years) }\end{array}$ & $6.4 \mathrm{E}-04$ & $1.3 \mathrm{E}-03$ & $2.8 \mathrm{E}-04$ & $6.8 \mathrm{E}-02$ & 3.1E-04 & $9.6 \mathrm{E}-03$ & $2.0 \mathrm{E}-02$ & 4.2E-03 & $1.0 \mathrm{E}+00$ & 4.7E-03 \\
\hline $\begin{array}{c}\text { Decontamination \& } \\
\text { Decommissioning } \\
\text { (Duration - } 1 \text { year) }\end{array}$ & NA & NA & NA & NA & NA & NA & NA & NA & NA & NA \\
\hline TOTAL & 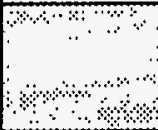 & 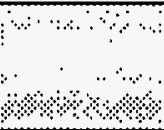 & ক্ষি & 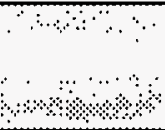 & 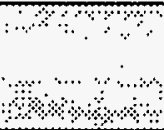 & $9.6 \mathrm{~L}=03$ & $2.0 \mathrm{E}-02$ & 4.2L-03 & $1.0 \mathrm{E}+00$ & $4.7 \mathrm{E}-03$ \\
\hline
\end{tabular}

Assumptions:

- Transportation is to and from the site only

- Operational risks encompass industrial/phy'sical hazards associated with equipment operation and onsite operations

- Infrastructure staff support the staff above. They receive no annual Cancer, average 4,000 travel miles, and average $50 \%$ of the facility totals above.

- Collective risks have been calculated as the product of individual risk. multiplied by the number of exposed inidividuals.

Individual risks provide estimates of the probability of health detriment for the individual, and the collective risks provide a measure of overall detriment

to the work force. 


\begin{tabular}{|c|c|c|c|c|c|c|c|c|c|c|}
\hline \multirow[t]{5}{*}{$\begin{array}{r}\text { Option: } \\
\text { Capital Cost: } \\
\text { Annual Worker Mileage: }\end{array}$} & $\begin{array}{l}\text { F. Close-Coup } \\
\$ 145 \text { million } \\
15,000\end{array}$ & led Barrier (arc & ound 7 tanks & & & & & & & \\
\hline & \multicolumn{10}{|c|}{ Operators } \\
\hline & \multicolumn{5}{|c|}{ Annual } & \multicolumn{5}{|c|}{ Total } \\
\hline & \multicolumn{2}{|c|}{ Transportation } & \multicolumn{3}{|c|}{ Operational } & \multicolumn{2}{|c|}{ Transportation } & \multicolumn{3}{|c|}{ Operational } \\
\hline & Death & Injury & Death & Injury & Cancer & Death & Injury & Death & Injury & Cancer \\
\hline $\begin{array}{l}\text { Technology Readiness } \\
\text { (Duration - } 5 \text { years) }\end{array}$ & $0.0 \mathrm{E}+00$ & $0.0 \mathrm{E}+00$ & $0.0 \mathrm{E}+00$ & $0.0 \mathrm{E}+00$ & $0.0 \mathrm{E}+00$ & $0.0 \mathrm{E}+00$ & $0.0 \mathrm{E}+00$ & $0.0 \mathrm{E}+00$ & $0.0 \mathrm{E}+00$ & $0.0 \mathrm{E}+00$ \\
\hline $\begin{array}{c}\text { Capital } \\
\text { (Duration - } 5 \text { years) }\end{array}$ & $0.0 \mathrm{E}+00$ & $0.0 \mathrm{E}+00$ & $0.0 \mathrm{E}+00$ & $0.0 E+00$ & $0.0 \mathrm{E}+00$ & $0.0 \mathrm{E}+00$ & $0.0 \mathrm{E}+00$ & $0.0 \mathrm{E}+00$ & $0.0 \mathrm{E}+00$ & $0.0 \mathrm{E}+00$ \\
\hline $\begin{array}{c}\text { Operators \& } \\
\text { Maintenance } \\
\text { (Duration - } 15 \text { y'ars) }\end{array}$ & $1.3 \mathrm{E}-03$ & $2.6 \mathrm{E}-03$ & $5.6 \mathrm{E}-04$ & $1.4 \mathrm{E}-01$ & $6.2 \mathrm{E}-04$ & $1.9 \mathrm{E}-02$ & $3.9 \mathrm{E}-02$ & $8.4 \mathrm{E}-03$ & $2.0 \mathrm{E}+00$ & $9.3 \mathrm{E}-03$ \\
\hline $\begin{array}{c}\text { Decontamination \& } \\
\text { Decommissioning } \\
\text { (Duration - 1 year) }\end{array}$ & $\mathrm{NA}$ & $\mathrm{NA}$ & NA & $\mathrm{NA}$ & NA & NA & $\mathrm{NA}$ & $\mathrm{NA}$ & $\mathrm{NA}$ & $\mathrm{NA}$ \\
\hline TOTAL & $\begin{array}{r}8 \\
\cdots \\
3\end{array}$ & \begin{tabular}{lll}
$\cdots$ & & $\cdots$ \\
\hdashline & & 9
\end{tabular} & " & \begin{tabular}{l}
$\cdots$ \\
$\cdots$ \\
\hdashline
\end{tabular} & ब. & $1.9 \mathrm{E}-02$ & $3.9 \mathrm{E}-02$ & $8.4 \mathrm{E}-03$ & $2.0 \mathrm{E}+00$ & $9.3 \mathrm{E}-03$ \\
\hline $\begin{array}{l}\text { Assumptions: } \\
\text { - Transportation is to and } \\
\text { - Operational risks encon } \\
\text { - Infrastructure staff supp } \\
\text { - Collective risks have be } \\
\text { Individual risks provide } \\
\text { to the work force. }\end{array}$ & $\begin{array}{l}\text { rom the site o } \\
\text { ass industrial } \\
\text { th the staff abo } \\
\text { n calculated as } \\
\text { estimates of th }\end{array}$ & $\begin{array}{l}\text { ly. } \\
\text { hysical hazarc } \\
\text { e. They recei } \\
\text { the product of } \\
\text { probability of }\end{array}$ & $\begin{array}{l}\text { ds associated } \\
\text { we no annual } \\
\text { individual ris } \\
\text { f health detrin }\end{array}$ & $\begin{array}{l}\text { th equipme } \\
\text { ancer. aver: } \\
\text { multiplied } \\
\text { nt for the ir }\end{array}$ & $\begin{array}{l}\text { operation an } \\
4,000 \text { trave } \\
\text { the number } \\
\text { vidual, and } 1\end{array}$ & $\begin{array}{l}\text { Insite opera } \\
\text { iles, and as } \\
\text { exposed in } \\
\text { collective } r\end{array}$ & $\begin{array}{l}\text { gs } \\
\text { ge } 50 \% \text { of } \\
\text { iduals. } \\
\text { provide a }\end{array}$ & facility tota & above. & \\
\hline
\end{tabular}




\begin{tabular}{|c|c|c|c|c|c|c|c|c|c|c|c|c|c|c|c|c|}
\hline $\begin{array}{r}\text { Option } \\
\text { Capital Cost } \\
\text { Annual Worker Mileage }\end{array}$ & $\begin{array}{l}\text { F. Close- } \\
\$ 145 \text { mil } \\
15,000\end{array}$ & $\begin{array}{l}\text { - Coupled } \\
\text { llion }\end{array}$ & Barrier (a & around 7 & tanks onl & & & & & & & & & & & \\
\hline \multirow{3}{*}{ Activity } & \multicolumn{10}{|c|}{ All Workers } & \multicolumn{6}{|c|}{ All Workers } \\
\hline & \multicolumn{5}{|c|}{ Annual } & \multicolumn{5}{|c|}{ Total } & \multicolumn{3}{|c|}{ Annuals } & \multicolumn{3}{|c|}{ Totals } \\
\hline & Death & \begin{tabular}{|l|l|} 
Injury \\
\end{tabular} & \begin{tabular}{|l|} 
Death \\
\end{tabular} & \begin{tabular}{|l|} 
Injury \\
\end{tabular} & \begin{tabular}{|l|} 
Cançer \\
\end{tabular} & \begin{tabular}{|l|} 
Death \\
\end{tabular} & \begin{tabular}{|l|} 
Injury \\
\end{tabular} & \begin{tabular}{|l|} 
Death \\
\end{tabular} & \begin{tabular}{|l|} 
Injury \\
\end{tabular} & \begin{tabular}{|l|} 
Cancer \\
\end{tabular} & \begin{tabular}{|l|} 
Death \\
\end{tabular} & \begin{tabular}{|l|} 
Injury \\
\end{tabular} & Cancer & \begin{tabular}{|l|} 
Death \\
\end{tabular} & \begin{tabular}{|l|} 
Injury \\
\end{tabular} & Cancer \\
\hline $\begin{array}{l}\text { Technology Readiness } \\
\text { (Duration - } 5 \text { years) }\end{array}$ & $2.2 \mathrm{E}-03$ & $45 \mathrm{E}-03$ & $\mid 30 \mathrm{E}-03$ & $64 \mathrm{E}-01$ & $|00 E+00|$ & $\mid 11 \mathrm{E}-02$ & $2.3 \mathrm{E}-02$ & $\mid 1.5 \mathrm{E}-02$ & $3.2 E+00 \mid$ & $|0.0 \mathrm{E}+00|$ & $5.2 \mathrm{E}-03$ & $6.4 \mathrm{E}-01$ & $|0.0 \mathrm{E}+00|$ & $2.6 \mathrm{E}-02$ & $3.2 E+00$ & $0.0 \mathrm{E}+00$ \\
\hline $\begin{array}{c}\text { Capital } \\
\text { (Duration - } 5 \text { years) }\end{array}$ & $15 \mathrm{E}-02$ & $3.1 \mathrm{E}-02$ & $28 \mathrm{E} \cdot 02$ & $45 \mathrm{E}+00$ & $5.5 \mathrm{E}-03$ & $76 \mathrm{E}-02$ & $16 \mathrm{E}-01$ & $14 \mathrm{E}-01$ & $23 E+01 \mid$ & $2.7 \mathrm{E}-02$ & $4.3 \mathrm{E}-02$ & $|4.6 \mathrm{E}+00|$ & $5.5 \mathrm{E}-03$ & $2.2 \mathrm{E}-01$ & $|2.3 E+01|$ & $2.7 \mathrm{E}-02$ \\
\hline $\begin{array}{c}\text { Operators \& } \\
\text { Maintenance } \\
\text { (Duration - 15 ycars) }\end{array}$ & $3.2 \mathrm{E}-03$ & $65 \mathrm{E}-03$ & $15 \mathrm{E}-03$ & $5.5 \mathrm{E}-01$ & $10 \mathrm{E}-03$ & $48 \mathrm{E}-02$ & $98 \mathrm{E}-02$ & $22 \mathrm{E}-02$ & $|8.3 E+00|$ & $1.6 \mathrm{E}-02$ & $4.7 \mathrm{E}-03$ & $5.6 \mathrm{E}-01$ & $1.0 \mathrm{E}-03$ & $7.0 \mathrm{E}-02$ & $|8.4 E+\infty 0|$ & $1.6 \mathrm{E}-02$ \\
\hline TOTAL & ?ै: & +ै। & अे। & \%. & \%४। & $1.3 \mathrm{E}-01$ & $2.8 \mathrm{E}-01$ & $1.8 \mathrm{E}-01$ & $3.4 E+01$ & $4.3 \mathrm{E}-02$ & 13 & $1 \%$ & (2) & $3.1 \mathrm{E}-01$ & $3.4 E+01$ & $4.3 \mathrm{E}-02$ \\
\hline $\begin{array}{l}\text { Assumptions: } \\
\text { - Transportation is to and } \\
\text { - Operational risks encon } \\
\text { - Infrastructure stilf supt } \\
\text { - Collective risks have bo } \\
\text { Individual risks provid } \\
\text { to the work force. }\end{array}$ & $\begin{array}{l}\text { from the } \\
\text { pass indus } \\
\text { ort the stal } \\
\text { en calculat } \\
\text { estimates }\end{array}$ & $\begin{array}{l}\text { site only } \\
\text { strial/phys } \\
\text { If illove. } \\
\text { ted as the } \\
\text { s of the pr }\end{array}$ & $\begin{array}{l}\text { Sical haze } \\
\text { They rec } \\
\text { a product } \\
\text { robability }\end{array}$ & $\begin{array}{l}\text { ards assoc } \\
\text { cuive no at } \\
\text { of indivic } \\
\text { of health }\end{array}$ & $\begin{array}{l}\text { ciated wit } \\
\text { innual Cat } \\
\text { dual risk. } \\
\text { idetrimen }\end{array}$ & $\begin{array}{l}\text { hequipm } \\
\text { mucur. ine } \\
\text { multiplic } \\
\text { it for the }\end{array}$ & $\begin{array}{l}\text { ent oper } \\
\text { rage } 4.00 \\
\text { individur }\end{array}$ & $\begin{array}{l}\text { ation and } \\
\text { no trivel } n \\
\text { number o } \\
\text { al, and the }\end{array}$ & $\begin{array}{l}\text { onsite op } \\
\text { miles, and } \\
\text { exposed } \\
\text { e collectiv }\end{array}$ & $\begin{array}{l}\text { erations } \\
\text { average } \\
\text { inidivid } \\
\text { e risks pr }\end{array}$ & $\begin{array}{l}50 \% \text { of } 11 \\
\text { luals. } \\
\text { rovide a n }\end{array}$ & $\begin{array}{l}\text { he facility } \\
\text { measure o }\end{array}$ & foverall & detriment & & \\
\hline
\end{tabular}


Option: G. Box-Shaped Chemical Barrier Capital Cost: $\$ 218$ million

Annual Worker Mileage: 15,000

\begin{tabular}{|c|c|c|c|c|c|c|c|c|c|c|}
\hline \multirow{4}{*}{ Activity } & \multicolumn{10}{|c|}{$\begin{array}{l}\text { Management and } \\
\text { Engineering }\end{array}$} \\
\hline & \multicolumn{5}{|c|}{ Annual } & \multicolumn{5}{|c|}{ Total } \\
\hline & \multicolumn{2}{|c|}{ Transportation } & \multicolumn{3}{|c|}{ Operational } & \multicolumn{2}{|c|}{ Transportation } & \multicolumn{3}{|c|}{ Operational } \\
\hline & Death & Injury' & Death & Injury & Cancer & Death & Injury & Death & Injury & Cancer \\
\hline $\begin{array}{l}\text { Technology Readiness } \\
\text { (Duration }-5 \text { years) }\end{array}$ & $1.6 \mathrm{E}-03$ & . $3.4 \mathrm{E}-03$ & 8.0E-0. & $4.5 \mathrm{E}-01$ & $0.0 E+00$ & 8.2E-03 & $1.7 \mathrm{E}-02$ & $4.0 \mathrm{E}-03$ & $2.2 \mathrm{E}+00$ & $0.0 \mathrm{E}+00$ \\
\hline $\begin{array}{c}\text { Capital } \\
\text { (Duration - } 5 \text { y'cars) }\end{array}$ & $1.4 \mathrm{E}-02$ & $2.8 \mathrm{E}-02$ & $6.7 \mathrm{E}-03$ & $3.7 \mathrm{E}+00$ & $5.0 \mathrm{E}-04$ & $6.9 \mathrm{E}-02$ & $1.4 E-01$ & 3.3E-02 & $1.9 \mathrm{E}+01$ & $2.5 \mathrm{E}-03$ \\
\hline $\begin{array}{c}\text { Operators \& } \\
\text { Maintenance } \\
\text { (Duration - } 15 \text { years) }\end{array}$ & 1.3E-03 & $2.6 \mathrm{E}-03$ & $6.2 \mathrm{E}-04$ & $3.5 \mathrm{E}-01$ & $1.1 \mathrm{E}-04$ & $1.9 E-02$ & $3.9 \mathrm{E}-02$ & 9.3E-03 & $5.2 \mathrm{E}+00$ & $1.6 \mathrm{E}-03$ \\
\hline $\begin{array}{l}\text { Decontamination \& } \\
\text { Decommissioning } \\
\text { (Duration - } 1 \text { ycar) }\end{array}$ & NA & NA & NA & $\mathrm{NA}$ & NA & NA & NA & NA & NA & NA \\
\hline TOTAL & की & \& & an & 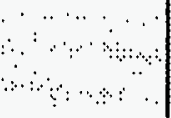 & \begin{tabular}{lll}
$\ddots$ & $\vdots$ \\
\hdashline & $\vdots$
\end{tabular} & $9.6 \mathrm{E}-02$ & $2.0 \mathrm{E}-01$ & 4.7E-02 & $2.6 \mathrm{E}+01$ & 4.1E-03 \\
\hline
\end{tabular}

Assumptions:

- Transportation is to and from the site only

- Operational risks encompass industrial/pliysical hazards associated with equipment operation and onsite operations

- Infrastructure stall support the stafl above. They receive no ammual Comeer. alverage 4.000 trivel miles, and average $50 \%$ of the facility totals above.

- Collective risks have been calculated as the product of individual risk, multiplied by the number of exposed inidividuals.

Individual risks provide estimates of the probability of health detriment for the individual, and the collective risks provide a measure of overall detriment

to the work force. 
Option: G. Box-Shaped Chemical Barrier Capital Cost: $\$ 218$ million

Annual Worker Mileage: 15,000

\begin{tabular}{|c|c|c|c|c|c|c|c|c|c|c|}
\hline \multirow{4}{*}{ Activity } & \multicolumn{10}{|c|}{$\begin{array}{c}\text { Construction/Decommissioning } \\
\text { Crafts and Laborers } \\
\end{array}$} \\
\hline & \multicolumn{5}{|c|}{ Annual } & \multicolumn{5}{|c|}{ Total } \\
\hline & \multicolumn{2}{|c|}{ Transportation } & \multicolumn{3}{|c|}{ Operational } & \multicolumn{2}{|c|}{ Transportation } & \multicolumn{3}{|c|}{ Operational } \\
\hline & Death & Injury & Death & Injury & Cancer & Death & Injury & Death & Injury & Cancer \\
\hline $\begin{array}{l}\text { Technology Readiness } \\
\text { (Duration - } 5 \text { years) }\end{array}$ & $5.6 \mathrm{E}-04$ & 1.1E-03 & $1.9 \mathrm{E}-03$ & $4.3 \mathrm{E}-01$ & $0.0 \mathrm{E}+00$ & $2.8 \mathrm{E}-03$ & $5.7 \mathrm{E}-03$ & $9.5 \mathrm{E}-03$ & $2.2 \mathrm{E}+00$ & $0.0 \mathrm{E}+00$ \\
\hline $\begin{array}{c}\text { Capital } \\
\text { (Duration - } 5 \text { ycars) }\end{array}$ & $9.1 E:-03$ & $1.95:-02$ & $3.1 \mathrm{E}-02$ & $7.11:+00$ & $4.415-0.3$ & $4.6[:-02$ & $9.4 \mathrm{E}:-02$ & $1.6 \mathrm{E}-01$ & $3.6 \mathrm{E}+01$ & $2.2 \mathrm{E}-02$ \\
\hline $\begin{array}{c}\text { Operators \& } \\
\text { Maintenance } \\
\text { (Duration - } 15 \text { years) } \\
\end{array}$ & $0.0 \mathrm{E}+00$ & $0.0 \mathrm{E}+00$ & $0.0 \mathrm{E}+00$ & $0.0 \mathrm{E}+00$ & $0.0 \mathrm{E}+00$ & $0.0 \mathrm{E}+00$ & $0.0 \mathrm{E}+00$ & $0.0 \mathrm{E}+00$ & $0.0 \mathrm{E}+00$ & $0.0 \mathrm{E}+00$ \\
\hline $\begin{array}{c}\text { Decontamination \& } \\
\text { Decommissioning } \\
\text { (Duration - } 1 \text { year) }\end{array}$ & NA & NA & NA & NA & NA & NA & NA & NA & NA & NA' \\
\hline TOTAL & 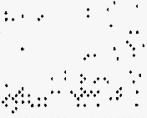 & $\begin{array}{lll}\cdots & \because \\
\because & \vdots\end{array}$ & $\begin{array}{ll}\because \\
\ddots\end{array}$ & $\begin{array}{l}\ddots \because \cdots \\
\therefore \quad:\end{array}$ & 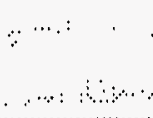 & $4.9 \mathrm{E}-02$ & $9.9 \mathrm{E}-02$ & $1.6 \mathrm{E}-01$ & $3.8 \mathrm{E}+01$ & $2.2 \mathrm{E}-02$ \\
\hline
\end{tabular}

Assumptions:

- Transportation is to and from the site only

- Operational risks encompass industrial/physical hazards associated with equipment operation and onsite operations

- Infrastructure staff support the staff above. They receive no annual Cancer, average 4,000 travel miles. and average $50 \%$ of the facility totals above.

- Collective risks have been calculated as the product of individual risk. multiplied by the number of exposed inidividuals.

Individual risks provide estimates of the probability of health detriment for the individual, and the collective risks provide a measure of overall detriment

to the work force. 
Option: G. Box-Shaped Chemical Barrier

Capital Cost: $\$ 218$ million

Annual Worker Milcage: 15,000

\begin{tabular}{|c|c|c|c|c|c|c|c|c|c|c|}
\hline \multirow{4}{*}{ Activity } & \multicolumn{10}{|c|}{ Maintenance Crafts } \\
\hline & \multicolumn{5}{|c|}{ Annual } & \multicolumn{5}{|c|}{ Total } \\
\hline & \multicolumn{2}{|c|}{ Transportation } & \multicolumn{3}{|c|}{ Operational } & \multicolumn{2}{|c|}{ Transportation } & \multicolumn{3}{|c|}{ Operational } \\
\hline & Death & Injury & Death & Injury & Cancer & Death & Injury & Death & Injury & Cancer \\
\hline $\begin{array}{c}\text { Technology Readiness } \\
\text { (Duration - } 5 \text { years) }\end{array}$ & $0.0 \mathrm{E}+00$ & $0.0 \mathrm{E}+00$ & $0.0 \mathrm{E}+00$ & $0.0 \mathrm{E}+00$ & $0.0 \mathrm{E}+00$ & $0.0 \mathrm{E}+00$ & $0.0 \mathrm{E}+00$ & $0.0 \mathrm{E}+00$ & $0.0 \mathrm{E}+00$ & $0.0 \mathrm{E}+00$ \\
\hline $\begin{array}{c}\text { Capital } \\
\text { (Duration - } 5 \text { y'ars) }\end{array}$ & $0.0 E+00$ & $0.0 \mathrm{E}+00$ & $0.0[+00$ & $0.0 \mathrm{E}+00$ & $0.0 \mathrm{E}+00$ & $0.0 E+00$ & $0.0 \mathrm{E}+00$ & $0.0 \mathrm{E}+00$ & $0.0 \mathrm{E}+00$ & $0.0 \mathrm{E}+00$ \\
\hline $\begin{array}{c}\text { Operators \& } \\
\text { Maintenance } \\
\text { (Duration - } 15 \text { ycars) }\end{array}$ & $6.4 \mathrm{E}-04$ & $1.3 \mathrm{E}-03$ & $2.8 \mathrm{E}-04$ & $6.8 \mathrm{E}-02$ & $3.1 \mathrm{E}-04$ & $9.6 \mathrm{E}-03$ & $2.0 \mathrm{E}-02$ & 4.2E-03 & $1.0 \mathrm{E}+00$ & 4.7E-03 \\
\hline $\begin{array}{c}\text { Decontamination \& } \\
\text { Decommissioning } \\
\text { (Duration - } 1 \text { year) }\end{array}$ & NA & NA & NA & NA & NA & NA & NA & NA & NA & NA \\
\hline TOTAL & a & {$\left[\begin{array}{lll}\cdots & \cdots \\
3 & \cdots\end{array}\right.$} & 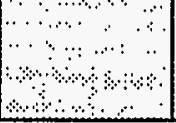 & 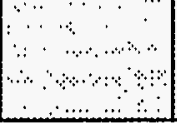 & 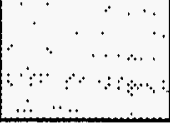 & $9.6 \mathrm{E}-03$ & $2.0 \mathrm{E}-02$ & $4.2 \mathrm{E}-03$ & $1.0 \mathrm{E}+00$ & 4.7E-03 \\
\hline
\end{tabular}

Assumptions:

- Transportation is to and from the site only

- Operational risks encompass industrial/phy'sical hazards associated with equipment operation and onsite operations

- Infrastructure staff support the staff above. They receive no annual Cancer, average 4,000 travel miles, and average $50 \%$ of the facility totals above.

- Collective risks have been calculated as the product of individual risk, multiplied by the number of exposed inidividuals.

Individual risks provide estimates of the probability of health detriment for the individual, and the collective risks provide a measure of overall detriment

to the work force. 


\begin{tabular}{|c|c|c|c|c|c|c|c|c|c|c|}
\hline $\begin{array}{r}\text { Option: } \\
\text { Capital Cost: } \\
\text { Annual Worker Mileage: }\end{array}$ & $\begin{array}{l}\text { G. Box-Shap } \\
\$ 218 \text { million } \\
15,000\end{array}$ & d Chemical Ba & & & & & & & & \\
\hline \multirow{4}{*}{ Activity } & \multicolumn{10}{|c|}{ Operators } \\
\hline & \multicolumn{5}{|c|}{ Annual } & \multicolumn{5}{|c|}{ Total } \\
\hline & \multicolumn{2}{|c|}{ Transportation } & \multicolumn{3}{|c|}{ Operational } & \multicolumn{2}{|c|}{ Transportation } & \multicolumn{3}{|c|}{ Operational } \\
\hline & Death & Injury & Death & Injury & Cancer & Death & Injury & Death & Injury & Cancer \\
\hline $\begin{array}{l}\text { Technology Readiness } \\
\text { (Duration - } 5 \text { ycars) }\end{array}$ & $0.0 E+00$ & $0.0 \mathrm{E}+00$ & $0.0 \mathrm{E}+00$ & $0.0 \mathrm{E}+00$ & $0.0 \mathrm{E}+00$ & $0.0 \mathrm{E}+00$ & $0.0 \mathrm{E}+00$ & $0.0 \mathrm{E}+00$ & $0.0 \mathrm{E}+00$ & $0.0 \mathrm{E}+00$ \\
\hline $\begin{array}{c}\text { Capital } \\
\text { (Duration - } 5 \text { years) }\end{array}$ & $0.0 \mathrm{E}+00$ & $0.0 \mathrm{E}+00$ & $0.0 \mathrm{E}+00$ & $0.0 \mathrm{E}+00$ & $0.0 \mathrm{E}+00$ & $0.0 \mathrm{E}+00$ & $0.0 \mathrm{E}+00$ & $0.0 \mathrm{E}+00$ & $0.0 E+00$ & $0.0 E+00$ \\
\hline $\begin{array}{c}\text { Operators \& } \\
\text { Maintenance } \\
\text { (Duration - } 15 \text { years) }\end{array}$ & $1.3 \mathrm{E}-03$ & $2.6 \mathrm{E}-03$ & $5.6 \mathrm{E}-04$ & $1.4 \mathrm{E}-01$ & $6.2 \mathrm{E}-04$ & $1.9 \mathrm{E}-02$ & $3.9 \mathrm{E}-02$ & $8.4 \mathrm{E}-03$ & $2.0 \mathrm{E}+00$ & $9.3 \mathrm{E}-03$ \\
\hline $\begin{array}{l}\text { Decontamination \& } \\
\text { Decommissioning } \\
\text { (Duration - } 1 \text { year) }\end{array}$ & $\mathrm{NA}$ & $\mathrm{NA}$ & $\mathrm{NA}$ & $\mathrm{NA}$ & $\mathrm{NA}$ & $\mathrm{NA}$ & $\mathrm{NA}$ & NA & NA & $\mathrm{NA}$ \\
\hline TOTAL & अै? & \%ै। & अै। & मै। & कि & $1.9 \mathrm{E}-02$ & $3.9 \mathrm{E}-02$ & $8.4 \mathrm{E}-03$ & $2.0 \mathrm{E}+00$ & $9.3 \mathrm{E}-03$ \\
\hline
\end{tabular}

Assumptions:

- Transportation is to and from the site only

- Operational risks encompass industrial/physical hazards associated with equipment operation and onsite operations

- Infrastructure staff support the staff above. They receive no annual Cancer, average 4,000 travel miles, and average $50 \%$ of the facility totals above.

- Collective risks have been calculated as the product of individual risk, multiplied by the number of exposed inidividuals.

Individual risks provide estimates of the probability of health detriment for the individual, and the collective risks provide a measure of overall detriment to the work force. 
Option: G. Box-Shaped Chemical Barrier

Capital Cost: $\$ 218$ million

Annual Worker Mileage: 15,000

\begin{tabular}{|c|c|c|c|c|c|c|c|c|c|c|c|c|c|c|c|c|}
\hline & \multicolumn{10}{|c|}{ All Workers } & \multicolumn{6}{|c|}{ All Workers } \\
\hline \multirow[t]{3}{*}{ Activity } & \multicolumn{5}{|c|}{ Annual } & \multicolumn{5}{|c|}{ Total. } & \multirow{2}{*}{\multicolumn{3}{|c|}{ Annuals }} & \multirow{2}{*}{\multicolumn{3}{|c|}{ Totals }} \\
\hline & \multicolumn{2}{|c|}{ Transportation } & \multicolumn{3}{|c|}{\begin{tabular}{|c|} 
Operational \\
\end{tabular}} & \multicolumn{2}{|c|}{ Transportation } & \multicolumn{3}{|c|}{ Operational } & & & & & & \\
\hline & Death & Injury & Death & Injury & Cancer & Death & Injury & Death & Injury & Cancer & Death & Injury & Cancer & Death & Injury & Cancer \\
\hline $\begin{array}{l}\text { Technology Readiness } \\
\text { (Duration - } 5 \text { years) }\end{array}$ & $2.2 \mathrm{E}-03$ & $4.5 \mathrm{E}-03$ & $2.7 \mathrm{E}-03$ & $8.8 \mathrm{E}-01$ & $0.0 E+00$ & $1.1 \mathrm{E}-02$ & $2.3 \mathrm{E}-02$ & $1.3 \mathrm{E}-02$ & $4.4 E+00$ & $0.0 \mathrm{E}+00$ & $4.9 \mathrm{E}-03$ & $8.8 \mathrm{E}-01$ & $0.0 \mathrm{E}+00$ & $2.4 \mathrm{E}-02$ & $4.4 \mathrm{E}+00$ & $0.0 \mathrm{E}+00$ \\
\hline $\begin{array}{c}\text { Capital } \\
\text { (Duration - } 5 \text { years) }\end{array}$ & $2.3 \mathrm{E}-02$ & 4.7E-02 & $3.8 \mathrm{E}-02$ & $1.1 E+01$ & $4.9 \mathrm{E}-03$ & $1.1 \mathrm{E}-01$ & $2.3 \mathrm{E}-01$ & $1.9 \mathrm{E}-01$ & $5.4 \mathrm{E}+01$ & $2.5 \mathrm{E}-02$ & $6.1 \mathrm{E}-02$ & $1.1 \mathrm{E}+01$ & $4.9 \mathrm{E}-03$ & $3.0 \mathrm{E}-01$ & $5.4 \mathrm{E}+0 \mathrm{l}$ & $2.5 \mathrm{E}-02$ \\
\hline $\begin{array}{c}\text { Operators \& } \\
\text { Maintenance } \\
\text { (Duration - } 15 \text { years) }\end{array}$ & $3.2 \mathrm{E}-03$ & $6.5 \mathrm{E}-03$ & $1.5 \mathrm{E}-03$ & $5.5 \mathrm{E}-01$ & $1.0 \mathrm{E}-03$ & $4.8 \mathrm{E}-02$ & $9.8 \mathrm{E}-02$ & $2.2 \mathrm{E}-02$ & $8.3 \mathrm{E}+00$ & $1.6 \mathrm{E}-02$ & 4.7E-03 & $5.6 \mathrm{E}-01$ & $1.0 \mathrm{E}-03$ & 7.0E-02 & $8.4 \mathrm{E}+00$ & $1.6 \mathrm{E}-02$ \\
\hline $\begin{array}{c}\text { Decontamination } \& \\
\text { Decommissioning } \\
\text { (Duration - } 1 \text { year) }\end{array}$ & NA & NA & NA & NA & NA & NA & NA & NA & NA & NA & NA & NA & NA & NA & NA & NA \\
\hline TOTAL & \% & 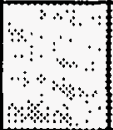 & 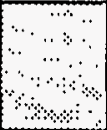 & $\begin{array}{cc}\cdots & \cdots \\
\cdots & \cdots \\
3 & \cdots\end{array}$ & । & $1.7 \mathrm{E}-01$ & $3.5 \mathrm{E}-01$ & $2.2 \mathrm{E}-01$ & $6.7 E+01$ & $4.0 \mathrm{E}-02$ & के & की & कि & $4.0 \mathrm{E}-01$ & $6.7 \mathrm{E}+01$ & $4.0 \mathrm{E}-02$ \\
\hline
\end{tabular}

\section{Assumptions:}

- Transportation is to and from the site only

- Operational risks encompass industrial/physical hazards associated with equipment operation and onsite operations

- Infrastructure staff support the staff above. They receive no annual Cancer, average 4,000 travel miles, and average $50 \%$ of the facility totals above.

- Collective risks have been calculated as the product of individual risk, multiplied by the number of exposed inidividuals.

Individual risks provide estimates of the probability of health detriment for the individual, and the collective risks provide a measure of overall detriment

to the work force. 
Option: H. V-Shaped Chemical Barrier Capital Cost: $\$ 313$ million

Annual Worker Mileage: 15,000

\begin{tabular}{|c|c|c|c|c|c|c|c|c|c|c|}
\hline \multirow{4}{*}{ Activity } & \multicolumn{10}{|c|}{$\begin{array}{c}\text { Management and } \\
\text { Engineering }\end{array}$} \\
\hline & \multicolumn{5}{|c|}{ Annual } & \multicolumn{5}{|c|}{ Total } \\
\hline & \multicolumn{2}{|c|}{ Transportation } & \multicolumn{3}{|c|}{ Operational } & \multicolumn{2}{|c|}{ Transportation } & \multicolumn{3}{|c|}{ Operational } \\
\hline & Death & Injury & Death & Injury & Cancer & Death & Injury & Death & Injury & Cancer \\
\hline $\begin{array}{c}\text { Technology Readincss } \\
\text { (Duration - } 5 \text { years) }\end{array}$ & $1.6 \mathrm{E}-03$ & $3.4 \mathrm{E}-03$ & $8.0 \mathrm{E}-04$ & $4.5 \mathrm{E}-01$ & $0.0 \mathrm{E}+00$ & $8.2 E-03$ & $1.7 \mathrm{E}-02$ & $4.0 \mathrm{E}-03$ & $2.2 \mathrm{E}+00$ & $0.0 \mathrm{E}+00$ \\
\hline $\begin{array}{c}\text { Capital } \\
\text { (Duration - } 5 \text { years) } \\
\end{array}$ & $2.0 \mathrm{E}-02$ & $4.0 \mathrm{E}-02$ & $9.6 \mathrm{E}-03$ & $5.4 E+00$ & $7.2 E-04$ & $9.9 \mathrm{E}-02$ & $2.0 \mathrm{E}-01$ & $4.8 \mathrm{E}-02$ & $2.7 \mathrm{E}+01$ & $3.6 \mathrm{E}-03$ \\
\hline $\begin{array}{c}\text { Operators \& } \\
\text { Maintenance } \\
\text { (Duration - 15 y'ears) } \\
\end{array}$ & $1.3 \mathrm{E}-03$ & $2.6 \mathrm{E}-03$ & $6.2 \mathrm{E}-04$ & $3.5 E-01$ & $1.1 E \cdot 04$ & 1.9E-02 & $3.9 \mathrm{E}-02$ & $9.3 \mathrm{E}-03$ & $5.2 \mathrm{E}+00$ & $1.6 \mathrm{E}-03$ \\
\hline $\begin{array}{c}\text { Decontamination \& } \\
\text { Decommissioning } \\
\text { (Duration - 1 year) }\end{array}$ & $\mathrm{NA}$ & NA & NA & NA & $\mathrm{NA}$ & $\mathrm{NA}$ & NA & NA & $\mathrm{NA}$ & $\mathrm{NA}$ \\
\hline TO'TAL & $\begin{array}{r}\text { के } \\
4 \\
4 \\
\end{array}$ & 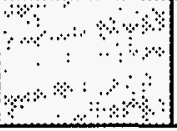 & $\begin{array}{r}\because \\
3 \\
3\end{array}$ & $\begin{array}{c}3 \\
3 \\
4\end{array}$ & 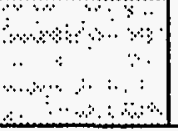 & $1.3 \mathrm{E}-01$ & $2.6 \mathrm{E}-01$ & $6.1 \mathrm{E}-02$ & $3.4 E+01$ & $5.2 \mathrm{E}-03$ \\
\hline
\end{tabular}

Assumptions:

- Transportation is to and from the site only

- Operational risks encompass industrial/physical hazards associated with equipment operation and onsite operations

- Infrastructure staff support the staff above. They receive no annual Cancer, average 4,000 travel miles, and average $50 \%$ of the facility totals above.

- Collective risks have been calculated as the product of individual risk, multiplied by the number of exposed inidividuals.

Individual risks provide estimates of the probability of health detriment for the individual, and the collective risks provide a measure of overall detriment

to the work force. 
Option: H. V-Shaped Chemical Barrier

Capital Cost: $\$ 313$ million

Annual Worker Mileage: 15,000

\begin{tabular}{|c|c|c|c|c|c|c|c|c|c|c|}
\hline \multirow{4}{*}{ Activity } & \multicolumn{10}{|c|}{$\begin{array}{l}\text { Construction/Decommissioning } \\
\text { Crafts and Laborers }\end{array}$} \\
\hline & \multicolumn{5}{|c|}{ Annual } & \multicolumn{5}{|c|}{ Total } \\
\hline & \multicolumn{2}{|c|}{ Transportation } & \multicolumn{3}{|c|}{ Operational } & \multicolumn{2}{|c|}{ Transportation } & \multicolumn{3}{|c|}{ Operational } \\
\hline & Death & Injury & Death & Injury & Cancer & Death & Injury & Death & Injury & Cancer \\
\hline $\begin{array}{l}\text { Technology Readiness } \\
\text { (Duration - } 5 \text { years) }\end{array}$ & $5.6 \mathrm{E}-04$ & $1.1 \mathrm{E}-03$ & $1.9 \mathrm{E}-03$ & $4.3 \mathrm{E}-01$ & $0.0 \mathrm{E}+00$ & $2.8 \mathrm{E}-03$ & 5.7E-03 & $9.5 \mathrm{E}-03$ & $2.2 \mathrm{E}+00$ & $0.0 \mathrm{E}+00$ \\
\hline $\begin{array}{c}\text { Capital } \\
\text { (Duration - } 5 \text { years) }\end{array}$ & $1.3 \mathrm{E}-02$ & 2.7E-02 & $4.5 \mathrm{E}-02$ & $1.0 \mathrm{E}+01$ & $6.4 \mathrm{E}-03$ & $6.6 \mathrm{E}-02$ & $1.3 \mathrm{E}-01$ & $2.2 \mathrm{E}-01$ & $5.1 E+01$ & $3.2 \mathrm{E}-02$ \\
\hline $\begin{array}{c}\text { Operators \& } \\
\text { Maintenance } \\
\text { (Duration - } 15 \text { years) }\end{array}$ & $0.0 \mathrm{E}+00$ & $0.0 \mathrm{E}+00$ & $0.0 \mathrm{E}+00$ & $0.0 \mathrm{E}+00$ & $0.0 \mathrm{E}+00$ & $0.0 \mathrm{E}+00$ & $0.0 \mathrm{E}+00$ & $0.0 \mathrm{E}+00$ & $0.0 \mathrm{E}+00$ & $0.0 \mathrm{E}+00$ \\
\hline $\begin{array}{c}\text { Decontamination \& } \\
\text { Decommissioning } \\
\text { (Duration - } 1 \text { year) }\end{array}$ & NA & NA & NA & NA & NA & NA & NA & NA & NA & NA \\
\hline TOTAL & and & 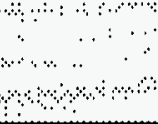 & $\begin{array}{lll}\cdots & \cdots \\
\cdots & \cdots\end{array}$ & 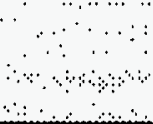 & $\begin{array}{l}\therefore \\
\cdots \\
\cdots\end{array}$ & $6.9 \mathrm{E}-02$ & $1.4 \mathrm{E}-01$ & $2.3 \mathrm{E}-01$ & $5.3 \mathrm{E}+01$ & $3.2 \mathrm{E}-02$ \\
\hline
\end{tabular}

Assumptions:

- Transportation is to and from the site only

- Operational risks encompass industrial/physical hazards associated with equipment operation and onsite operations

- Infrastructure staff support the staff above. They receive no annual Cancer, average 4,000 travel miles, and average $50 \%$ of the facility totals above.

- Collective ristis have been calculated as the product of individual risk, multiplied by the number of exposed inidividuals.

Individual risks provide estimates of the probability of health detriment for the individual, and the collective risks provide a measure of overall detriment

to the work force. 
Option: H. V-Shaped Chemical Barrier

Capital Cost: $\$ 313$ million

Annual Worker Mileage: 15,000

\begin{tabular}{|c|c|c|c|c|c|c|c|c|c|c|}
\hline \multirow{4}{*}{ Activity } & \multicolumn{10}{|c|}{ Maintenance Crafts } \\
\hline & \multicolumn{5}{|c|}{ Annual } & \multicolumn{5}{|c|}{ Total } \\
\hline & \multicolumn{2}{|c|}{ Transportation } & \multicolumn{3}{|c|}{ Operational } & \multicolumn{2}{|c|}{ Transportation } & \multicolumn{3}{|c|}{ Operational } \\
\hline & Death & Injury & Death & Injury & Cancer & Death & Injury & Death & Injury & Cancer \\
\hline $\begin{array}{c}\text { Technology Readiness } \\
\text { (Duration - } 5 \text { years) }\end{array}$ & $0.0 \mathrm{E}+00$ & $0.0 \mathrm{E}+00$ & $0.0 \mathrm{E}+00$ & $0.0 \mathrm{E}+00$ & $0.0 \mathrm{E}+00$ & $0.0 \mathrm{E}+00$ & $0.0 \mathrm{E}+00$ & $0.0 \mathrm{E}+00$ & $0.0 \mathrm{E}+00$ & $0.0 \mathrm{E}+00$ \\
\hline $\begin{array}{c}\text { Capital } \\
\text { (Duration - 5'years) }\end{array}$ & $0.0 \mathrm{E}+00$ & $0.0 \mathrm{E}+00$ & $0.0 \mathrm{E}+00$ & $0.0 \mathrm{E}+00$ & $0.0 \mathrm{E}+00$ & $0.0 \mathrm{E}+00$ & $0.0 \mathrm{E}+00$ & $0.0 \mathrm{E}+00$ & $0.0 \mathrm{E}+00$ & $0.0 \mathrm{E}+00$ \\
\hline $\begin{array}{c}\text { Operators \& } \\
\text { Maintenance } \\
\text { (Duration - } 15 \text { years) }\end{array}$ & $6.4 \mathrm{E}-04$ & $1.3 \mathrm{E}-03$ & $2.8 \mathrm{E}-04$ & $6.8 \mathrm{E}-02$ & 3.1E-04 & $9.6 \mathrm{E}-03$ & $2.0 \mathrm{E}-02$ & $4.2 \mathrm{E}-03$ & $1.0 \mathrm{E}+00$ & 4.7E-03 \\
\hline $\begin{array}{c}\text { Decontamination \& } \\
\text { Decommissioning } \\
\text { (Duration - } 1 \text { year) }\end{array}$ & NA & NA & NA & NA & NA & NA & NA & NA & NA & NA \\
\hline Total. & 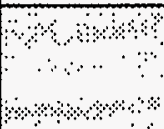 & $\begin{array}{r}6 \% \\
\cdots \\
\cdots\end{array}$ & 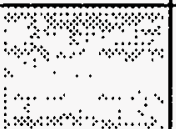 & $\begin{array}{r}0 \\
3 \\
3 \\
\vdots \\
3\end{array}$ & 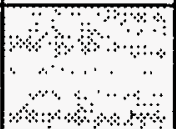 & $9.6 \mathrm{E}-03$ & $2.0 \mathrm{E}-02$ & $4.2 \mathrm{E}-03$ & $1.0 \mathrm{E}+00$ & 4.7E-03 \\
\hline
\end{tabular}

Assumptions:

- Transportation is to and from the site only

- Operational risks encompass industrial/phy'sical hazards associated with equipment operation and onsite operations

- Infrastructure staff support the staff above. They receive no annual Cancer, average 4,000 travel miles, and average $50 \%$ of the facility totals above.

- Collective risks have been calculated as the product of individual risk, multiplied by the number of exposed inidividuals.

Individual risks provide estimates of the probability of health detriment for the individual, and the collective risks provide a measure of overall detriment

to the work force. 
$\forall$
$\vdots$
$\vdots$
$\vdots$
$\vdots$

Table D.3. Options Worker Risks (Sheet 39 of 105)

Option: H. V-Shaped Chemical Barrier

Capital Cost: $\$ 313$ million

Annual Worker Mileage: 15,000

\begin{tabular}{|c|c|c|c|c|c|c|c|c|c|c|}
\hline \multirow{4}{*}{ Activity } & \multicolumn{10}{|c|}{ Operators } \\
\hline & \multicolumn{5}{|c|}{ Annual } & \multicolumn{5}{|c|}{ Total } \\
\hline & \multicolumn{2}{|c|}{ Transportation } & \multicolumn{3}{|c|}{ Operational } & \multicolumn{2}{|c|}{ Transportation } & \multicolumn{3}{|c|}{ Operational } \\
\hline & Death & Injury & Death & Injury & Cancer & Death & Injury & Death & Injury & Cancer \\
\hline $\begin{array}{l}\text { Technology Readiness } \\
\text { (Duration - } 5 \text { years) }\end{array}$ & $0.0 \mathrm{E}+00$ & $0.0 \mathrm{E}+00$ & $0.0 \mathrm{E}+00$ & $0.0 \mathrm{E}+00$ & $0.0 \mathrm{E}+00$ & $0.0 \mathrm{E}+00$ & $0.0 \mathrm{E}+00$ & $0.0 \mathrm{E}+00$ & $0.0 \mathrm{E}+00$ & $0.0 \mathrm{E}+00$ \\
\hline $\begin{array}{c}\text { Capital } \\
\text { (Duration - } 5 \text { ycars) }\end{array}$ & $0.0 \mathrm{E}+00$ & $0.0 \mathrm{E}+00$ & $0.0 \mathrm{E}+00$ & $0.0 \mathrm{E}+00$ & $0.0 E+00$ & $0.0 \mathrm{E}+00$ & $0.0 \mathrm{E}+00$ & $0.0 \mathrm{E}+00$ & $0.0 \mathrm{E}+00$ & $0.0 \mathrm{E}+00$ \\
\hline $\begin{array}{c}\text { Operators \& } \\
\text { Maintenance } \\
\text { (Duration - } 15 \text { years) }\end{array}$ & $1.3 E-03$ & $2.6 \mathrm{E}-03$ & $5.6 \mathrm{E}-04$ & $1.4 \mathrm{E}-01$ & $6.2 \mathrm{E}-04$ & $1.9 E-02$ & $3.9 \mathrm{E}-02$ & $8.4 E-03$ & $2.0 \mathrm{E}+00$ & $9.3 \mathrm{E}-03$ \\
\hline $\begin{array}{l}\text { Decontamination \& } \\
\text { Decommissioning } \\
\text { (Duration - } 1 \text { year) }\end{array}$ & NA & NA & NA & $\mathrm{NA}$ & NA & NA & NA & NA & NA & NA \\
\hline TOTAL. & $\therefore$ & $\begin{array}{c}a \\
\cdots \\
\cdots \\
\cdots\end{array}$ & $\begin{array}{c}\cdot \ldots \\
\cdots \\
\vdots \\
\vdots \\
\vdots\end{array}$ & $\therefore \quad \therefore \quad \cdots$ & 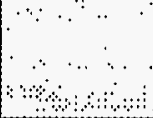 & $1.91:-02$ & 3.9L:-02 & $8.4 \mathrm{E}-03$ & $2.0 \mathrm{E}+00$ & $9.3 \mathrm{~L}-03$ \\
\hline
\end{tabular}

Assumptions:

- Transportation is to and from the site only

- Operational risks encompass industrial/physical hazards associated with equipment operation and onsite operations

- Infrastructure staff support the staff above. They receive no annual Cancer, average 4,000 travel miles, and average $50 \%$ of the facility totals above.

- Collective risks have been calculated as the product of individual risk, multiplied by the number of exposed inidividuals.

Individual risks provide estimates of the probability of health detriment for the individual, and the collective risks provide a measure of overall detriment

to the work force. 
Option: H. V-Shaped Chemical Barrier

Capital Cost: $\$ 313$ million

Annual Worker Mileage: 15,000

\begin{tabular}{|c|c|c|c|c|c|c|c|c|c|c|c|c|c|c|c|c|}
\hline \multirow{4}{*}{ Activity } & \multicolumn{10}{|c|}{ All Workers } & \multicolumn{6}{|c|}{ All Workers } \\
\hline & \multicolumn{5}{|c|}{ Annual } & \multicolumn{5}{|c|}{ Total } & \multirow{2}{*}{\multicolumn{3}{|c|}{ Annuals }} & \multirow{2}{*}{\multicolumn{3}{|c|}{ Totals }} \\
\hline & \multicolumn{2}{|c|}{ Transportation } & \multicolumn{3}{|c|}{ Operational } & \multicolumn{2}{|c|}{ Transportation } & \multicolumn{3}{|c|}{ Operational } & & & & & & \\
\hline & Death & Injury & Death & Injury & Cancer & Death & Injury & Death & Injury & Cancer & Death & Injury & Cancer & Death & Injury & Cancer \\
\hline $\begin{array}{l}\text { Technology Readiness } \\
\text { (Duration - } 5 \text { years) }\end{array}$ & $22 \mathrm{E}-03$ & $45 \mathrm{E}-03$ & 2.7E-03 & $88 \mathrm{E}-01$ & $00 \mathrm{E}+00$ & $1.1 \mathrm{E}-02$ & $23 \mathrm{E}-02$ & $13 \mathrm{E}-02$ & $4.4 E+00$ & $0.0 E+00$ & $49 \mathrm{E}-03$ & $88 \mathrm{E}-01$ & $0.0 \mathrm{E}+00$ & $2.4 \mathrm{E}-02$ & $4.4 \mathrm{E}+00$ & $00 \mathrm{E}+00$ \\
\hline $\begin{array}{c}\text { Capital } \\
\text { (Duration - } 5 \text { years) }\end{array}$ & $33 \mathrm{E}-02$ & 6.7E-02 & $54 \mathrm{E}-02$ & $16 E+01$ & $71 \mathrm{E}-03$ & $1.6 \mathrm{E}-01$ & $34 \mathrm{E}-01$ & $27 \mathrm{E}-01$ & $78 \mathrm{E}+01$ & $35 E-02$ & $87 \mathrm{E}-02$ & $16 \mathrm{E}+01$ & 7.1E-03 & $4.4 \mathrm{E}-01$ & $7.8 \mathrm{E}+01$ & $35 \mathrm{E}-02$ \\
\hline $\begin{array}{c}\text { Operators \& } \\
\text { Maintenance } \\
\text { (Duration - 15 years) }\end{array}$ & $3.2 E-03$ & $6.5 \mathrm{E}-03$ & $1.5 \mathrm{E}-03$ & $55 \mathrm{E}-01$ & $10 \mathrm{E}-03$ & 4.8E-02 & $98 \mathrm{E}-02$ & $22 \mathrm{E}-02$ & $8.3 \mathrm{E}+00$ & $16 E-02$ & 4.7E-03 & $56 \mathrm{E}-01$ & $1.0 \mathrm{E}-03$ & $7.0 \mathrm{E}-02$ & $8.4 \mathrm{E}+00$ & $1.6 \mathrm{E}-02$ \\
\hline $\begin{array}{c}\text { Decontamination \& } \\
\text { Decommissioning } \\
\text { (Duration - } 1 \text { year) }\end{array}$ & NA & NA & $\mathrm{NA}$ & NA & NA & NA & NA & NA & $\mathrm{NA}$ & NA & $\mathrm{NA}$ & NA & NA & NA & NA & $\mathrm{NA}$ \\
\hline TOTAL & कि: & कि & \% & कि & की & $22 \mathrm{E}-01$ & $4.6 \mathrm{E}-01$ & $3.1 \mathrm{E}-01$ & $91 \mathrm{E}+01$ & $5.1 \mathrm{E}-02$ & अै. & कै। & \%ै/ & $5.3 \mathrm{E}-01$ & $9.1 \mathrm{E}+01$ & $5.1 \mathrm{E}-02$ \\
\hline
\end{tabular}

Assumptions:

- Transportation is to and from the site only

- Operational risks encompass industrial/phy'sical hazards associated with equipment operation and onsite operations

- Infrastructure staff support the staff above. They receive no annual Cancer, average 4.000 travel miles, and average $50 \%$ of the facility totals above.

- Collective risks have been calculated as the product of individual risk, multiplied by the number of exposed inidividuals.

Individual risks provide estimates of the probability of health detriment for the individual, and the collective risks provide a measure of overall detriment

to the work force. 
Table D.3. Options Worker Risks (Sheet 41 of 105)

Option: I. V-Shaped Freeze Wall Barrier

Capital Cost: $\$ 208$ million

Annual Worker Milcage: 15,000

\begin{tabular}{|c|c|c|c|c|c|c|c|c|c|c|}
\hline \multirow{4}{*}{ Activity } & \multicolumn{10}{|c|}{$\begin{array}{l}\text { Management and } \\
\text { Engineering }\end{array}$} \\
\hline & \multicolumn{5}{|c|}{ Annual } & \multicolumn{5}{|c|}{ Total } \\
\hline & \multicolumn{2}{|c|}{ Transportation } & \multicolumn{3}{|c|}{ Operational } & \multicolumn{2}{|c|}{ Transportation } & \multicolumn{3}{|c|}{ Operational } \\
\hline & Death & Injury' & Death & Injury & Cancer & Death & Injury & Death & Injury & Cancer \\
\hline $\begin{array}{l}\text { Technology Readiness } \\
\text { (Duration - } 5 \text { years) }\end{array}$ & $1.5 \mathrm{E}-03$ & $3.1 E-03$ & $7.3 \mathrm{E}-04$ & 4.1E-01 & $0.0 \mathrm{E}+00$ & $7.5 E-03$ & $1.5 \mathrm{E}-02$ & $3.7 \mathrm{E}-03$ & $2.0 \mathrm{E}+00$ & $0.0 \mathrm{E}+00$ \\
\hline $\begin{array}{c}\text { Capital } \\
\text { (Duration - } 5 \text { years) }\end{array}$ & $1.3 \mathrm{E}-02$ & 2.7E-02 & $6.4 \mathrm{E}-03$ & $3.6 \mathrm{E}+00$ & 4.8E-04 & $6.6 \mathrm{E}-02$ & $1.3 \mathrm{E}-01$ & $3.2 \mathrm{E}-02$ & $1.8 \mathrm{E}+01$ & $2.4 \mathrm{E}-03$ \\
\hline $\begin{array}{c}\text { Operators \& } \\
\text { Maintenance } \\
\text { (Duration - 15 ycars) }\end{array}$ & $2.6 \mathrm{E}-03$ & 5.3E-03 & $1.3 \mathrm{E}-03$ & 7.1E-01 & $2.2 \mathrm{E}-04$ & $3.9 E-02$ & $\begin{array}{c}8.0 \mathrm{E}-02 \\
.\end{array}$ & $1.9 \mathrm{E}-02$ & $1.1 \mathrm{E}+01$ & $3.3 E-03$ \\
\hline $\begin{array}{c}\text { Decontamination \& } \\
\text { Decommissioning } \\
\text { (Duration - } 1 \text { year) }\end{array}$ & $2.0 \mathrm{E}-03$ & $4.0 \mathrm{E}-03$ & $9.5 \mathrm{E}-04$ & 5.3E-0I & $1.7 \mathrm{E}-0.4$ & $2.0 \mathrm{E}-03$ & $4.0 \mathrm{E}-03$ & $9.5 E-04$ & $5.3 \mathrm{E}-0 \mathrm{I}$ & $1.7 \mathrm{E}-04$ \\
\hline TOTAL & $\begin{array}{r} \\
\cdots \\
\cdots\end{array}$ & 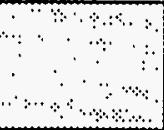 & 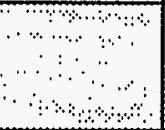 &  & 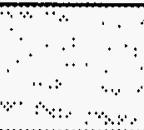 & $1.1 \mathrm{E}-01$ & $2.3 \mathrm{E}-01$ & $5.5 \mathrm{E}-02$ & $3.1 E+01$ & $5.9 \mathrm{E}-03$ \\
\hline
\end{tabular}

Assumptions:

- Transportation is to and from the site only

- Operational risks encompass industrial/physical hazards associated with equipment operation and onsite operations

- Infrastructure staff support the staff above. They receive no annual Cancer, average 4,000 travel miles, and average $50 \%$ of the facility totals above.

- Collective risks have been calculated as the product of individtal risk. multiplied by the number of exposed inidividuals.

Individual risks provide estimates of the probability of health detriment lor the individual, and the collective risks provide a measure of overall detriment

to the work force. 
Option: I. V-Shaped Freeze Wall Barrier

Capital Cost: $\$ 208$ million

Annual Worker Mileage: 15,000

\begin{tabular}{|c|c|c|c|c|c|c|c|c|c|c|}
\hline \multirow{4}{*}{ Activity } & \multicolumn{10}{|c|}{$\begin{array}{c}\text { Construction/Decommissioning } \\
\text { Crafts and Laborers }\end{array}$} \\
\hline & \multicolumn{5}{|c|}{ Annual } & \multicolumn{5}{|c|}{ Total } \\
\hline & \multicolumn{2}{|c|}{ Transportation } & \multicolumn{3}{|c|}{ Operational } & \multicolumn{2}{|c|}{ Transportation } & \multicolumn{3}{|c|}{ Operational } \\
\hline & Death & Injury & Death & Injury & Cancer & Death & Injury & Death & Injury & Cancer \\
\hline $\begin{array}{l}\text { Technology Readiness } \\
\text { (Duration - } 5 \text { years) }\end{array}$ & $4.9 \mathrm{E}-04$ & $1.0 \mathrm{E}-03$ & $1.7 \mathrm{E}-03$ & $3.8 \mathrm{E}-01$ & $0.0 \mathrm{E}+00$ & $2.5 \mathrm{E}-03$ & $5.1 E-03$ & $8.4 \mathrm{E}-03$ & $1.9 \mathrm{E}+00$ & $0.0 \mathrm{E}+00$ \\
\hline $\begin{array}{c}\text { Capital } \\
\text { (Duration }-5 \text { ycars) }\end{array}$ & 8.7E-03 & $1.8 \mathrm{E}-02$ & $3.0 \mathrm{E}-02$ & $6.8 \mathrm{E}+00$ & $4.2 \mathrm{E}-03$ & $4.4 \mathrm{E}-02$ & $8.9 E-02$ & $1.5 \mathrm{E}-01$ & $3.4 \mathrm{E}+01$ & 2.1E-02 \\
\hline $\begin{array}{c}\text { Operators \& } \\
\text { Maintenance } \\
\text { (Duration - } 15 \text { years) }\end{array}$ & $0.0 \mathrm{E}+00$ & $0.0 \mathrm{E}+00$ & $0.0 \mathrm{E}+00$ & $0.0 \mathrm{E}+00$ & $0.0 \mathrm{E}+00$ & $0.0 \mathrm{E}+00$ & $0.0 \mathrm{E}+00$ & $0.0 \mathrm{E}+00$ & $0.0 \mathrm{E}+00$ & $0.0 \mathrm{E}+00$ \\
\hline $\begin{array}{l}\text { Decontamination \& } \\
\text { Decommissioning } \\
\text { (Duration - } 1 \text { year) }\end{array}$ & $3.9 \mathrm{E}-03$ & 8.0E-03 & $1.3 \mathrm{E} \div 02$ & $3.0 \mathrm{E}+00$ & $1.9 \mathrm{E}-03$ & $3.9 \mathrm{E}-03$ & $8.0 \mathrm{E}-03$ & $1.3 \mathrm{E}-02$ & $3.0 \mathrm{E}+00$ & $1.9 \mathrm{E}-03$ \\
\hline TOTAL & a & ४⿻ & क्ष & \begin{tabular}{lll}
$\because$ & $\ddots$ \\
\hdashline & $\ddots$
\end{tabular} & $\begin{array}{r}\quad \\
\vdots \\
\vdots\end{array}$ & $5.0 \mathrm{E}-02$ & $1.0 \mathrm{E}-01$ & $1.7 \mathrm{E}-01$ & $3.9 \mathrm{E}+01$ & 2.3E-02 \\
\hline
\end{tabular}

\section{Assumptions:}

- Transportation is to and from the site only

- Operational risks encompass industrial/physical hazards associated with equipment operation and onsite operations

- Infrastructure staff support the staff above. They receive no annual Cancer, average 4,000 travel miles, and average $50 \%$ of the facility totals above

- Collective risks have been calculated as the product of individual risk, multiplied by the number of exposed inidividuals.

Individual risks provide estimates of the probability of health detriment for the individual, and the collective risks provide a measure of overall detriment

to the work force. 
Option: I. V-Shaped Freeze Wall Barrier

Capital Cost: $\$ 208$ million

Annual Worker Mileage: 15,000

\begin{tabular}{|c|c|c|c|c|c|c|c|c|c|c|}
\hline \multirow{4}{*}{ Activity } & \multicolumn{10}{|c|}{ Maintenance Crafts } \\
\hline & \multicolumn{5}{|c|}{ Annual } & \multicolumn{5}{|c|}{ Total } \\
\hline & \multicolumn{2}{|c|}{ Transportation } & \multicolumn{3}{|c|}{ Operational } & \multicolumn{2}{|c|}{ Transportation } & \multicolumn{3}{|c|}{ Operational } \\
\hline & Death & Injury & Death & \begin{tabular}{|l|} 
Injury \\
\end{tabular} & Cancer & Death & Injury & Death & Injury & Cancer \\
\hline $\begin{array}{l}\text { Technology Readiness } \\
\text { (Duration - } 5 \text { years) }\end{array}$ & $0.0 \mathrm{E}+00$ & $0.0 \mathrm{E}+00$ & $0.0 \mathrm{E}+00$ & $0.0 \mathrm{E}+00$ & $0.0 \mathrm{E}+00$ & $0.0 \mathrm{E}+00$ & $0.0 \mathrm{E}+00$ & $0.0 \mathrm{E}+00$ & $0.0 \mathrm{E}+00$ & $0.0 \mathrm{E}+00$ \\
\hline $\begin{array}{c}\text { Capital } \\
\text { (Duration - } 5 \text { years) }\end{array}$ & $0.0 \mathrm{E}+00$ & $0.0 \mathrm{E}+00$ & $0.0 \mathrm{E}+00$ & $0.0 \mathrm{E}+00$ & $0.0 \mathrm{E}+00$ & $0.0 \mathrm{E}+00$ & $0.0 \mathrm{E}+00$ & $0.0 \mathrm{E}+00$ & $0.0 \mathrm{E}+00$ & $0.0 \mathrm{E}+00$ \\
\hline $\begin{array}{c}\text { Opcrators \& } \\
\text { Maintenance } \\
\text { (Duration - 15 years) }\end{array}$ & $1.3 \mathrm{E}-03$ & $2.7 \mathrm{E}-03$ & $5.7 \mathrm{E}-04$ & $1.4 \mathrm{E}-01$ & $6.3 \mathrm{E}-04$ & $1.9 \mathrm{E}-02$ & $4.0 \mathrm{E}-02$ & $8.5 \mathrm{E}-03$ & 2.1E+00 & $9.5 \mathrm{E}-03$ \\
\hline $\begin{array}{l}\text { Decontamination \& } \\
\text { Decommissioning } \\
\text { (Duration - } 1 \text { year) }\end{array}$ & $0.0 \mathrm{E}+00$ & $0.0 \mathrm{E}+00$ & $0.0 \mathrm{E}+00$ & $0.0 \mathrm{E}+00$ & $0.0 \mathrm{E}+00$ & $0.0 \mathrm{E}+00$ & $0.0 \mathrm{E}+00$ & $0.0 \mathrm{E}+00$ & $0.0 \mathrm{E}+00$ & $0.0 \mathrm{E}+00$ \\
\hline TOTAL & and & and & क्ष & r. & \% & $1.9 \mathrm{E}-02$ & $4.0 \mathrm{E}-02$ & $8.5 \mathrm{E}-03$ & $2.1 \mathrm{E}+00$ & $9.5 \mathrm{E}-03$ \\
\hline
\end{tabular}

Assumptions:

- Transportation is to and from the site only

- Operational risks encompass industrial/physical hazards associated with equipment operation and onsite operations

- Infrastructure staff support the staff above. They receive no annual Cancer, average 4,000 travel miles, and average $50 \%$ of the facility totals above.

- Collective risks have been calculated as the product of individual risk, multiplied by the number of exposed inidividuals.

-

Individual risks provide estimates of the probability of health detriment for the individual, and the collective risks provide a measure of overall detriment

to the work force. 
Option: I. V-Shaped Freeze Wall Barrier

Capital Cost: $\$ 208$ million

Annual Worker Mileage: 15,000

\begin{tabular}{|c|c|c|c|c|c|c|c|c|c|c|}
\hline \multirow{4}{*}{ Activity } & \multicolumn{10}{|c|}{ Operators } \\
\hline & \multicolumn{5}{|c|}{ Annual } & \multicolumn{5}{|c|}{ Total } \\
\hline & \multicolumn{2}{|c|}{ Transportation } & \multicolumn{3}{|c|}{ Operational } & \multicolumn{2}{|c|}{ Transportation } & \multicolumn{3}{|c|}{ Operational } \\
\hline & Death & Injury & Death & Injury & Cancer & Death & Injury & Death & Injury & Cancer \\
\hline $\begin{array}{l}\text { Technology Readiness } \\
\text { (Duration - } 5 \text { years) }\end{array}$ & $0.0 \mathrm{E}+00$ & $0.0 \mathrm{E}+00$ & $0.0 \mathrm{E}+00$ & $0.0 \mathrm{E}+00$ & $0.0 \mathrm{E}+00$ & $0.0 \mathrm{E}+00$ & $0.0 \mathrm{E}+00$ & $0.0 \mathrm{E}+00$ & $0.0 \mathrm{E}+00$ & $0.0 \mathrm{E}+00$ \\
\hline $\begin{array}{c}\text { Capital } \\
\text { (Duration - } 5 \text { years) }\end{array}$ & $0.0 \mathrm{E}+00$ & $0.0 \mathrm{E}+00$ & $0.0 \mathrm{E}+00$ & $0.0 \mathrm{E}+00$ & $0.0 \mathrm{E}+00$ & $0.0 \mathrm{E}+00$ & $0.0 \mathrm{E}+00$ & $0.0 \mathrm{E}+00$ & $0.0 \mathrm{E}+00$ & $0.0 \mathrm{E}+00$ \\
\hline $\begin{array}{c}\text { Operators \& } \\
\text { Maintenance } \\
\text { (Duration - 15 years) }\end{array}$ & $2.6 \mathrm{E}-03$ & $5.3 \mathrm{E}-03$ & 1.1E-03 & $2.8 \mathrm{E}-01$ & $1.3 \mathrm{E}-03$ & $3.9 \mathrm{E}-02$ & $8.0 \mathrm{E}-02$ & $1.7 \mathrm{E}-02$ & $\begin{array}{c}4.2 \mathrm{E}+00 \\
.\end{array}$ & $1.9 \mathrm{E}-02$ \\
\hline $\begin{array}{c}\text { Decontamination \& } \\
\text { Decommissioning } \\
\text { (Duration - } 1 \text { year) }\end{array}$ & 6.2E-04 & $1.3 \mathrm{E}-03$ & 2.7E-04 & $6.6 \mathrm{E}-02$ & 3.0E-04 & $6.2 \mathrm{E}-04$ & $1.3 \mathrm{E}-03$ & 2.7E-04 & $6.6 \mathrm{E}-02$ & $3.0 \mathrm{E}-04$ \\
\hline TOTAL & कै। & ४। & ४ै। & अ०० & ४ै। & $4.0 \mathrm{E}-02$ & $8.1 E-02$ & $1.7 \mathrm{E}-02$ & $4.2 \mathrm{E}+00$ & $1.9 \mathrm{E}-02$ \\
\hline
\end{tabular}

Assumptions:

- Transportation is to and from the site only

- Operational risks encompass industrial/physical hazards associated with equipment operation and onsite operations

- Infrastructure staff support the staff above. They receive no annual Cancer, average 4,000 travel miles, and average $50 \%$ of the facility totals above.

- Collective risks have been calculated as the product of individual risk, multiplied by the number of exposed inidividuals.

Individual risks provide estimates of the probability of health detriment for the individual, and the collective risks provide a measure of overall detriment

to the work force. 
Option: I. V-Shaped Freeze Wall Barrier

Capital Cost: $\$ 208$ million

Annual Worker Milcage: 15,000

\begin{tabular}{|c|c|c|c|c|c|c|c|c|c|c|c|c|c|c|c|c|}
\hline \multirow{4}{*}{ Activity } & \multicolumn{10}{|c|}{ All Workers } & \multicolumn{6}{|c|}{ All Workers } \\
\hline & \multicolumn{5}{|c|}{ Annual } & \multicolumn{5}{|c|}{ Total } & \multirow{2}{*}{\multicolumn{3}{|c|}{ Annuals }} & \multirow{2}{*}{\multicolumn{3}{|c|}{ Totals }} \\
\hline & \multicolumn{2}{|c|}{ Transportation } & \multicolumn{3}{|c|}{ Opcrational } & \multicolumn{2}{|c|}{ Transportation } & \multicolumn{3}{|c|}{ Operational } & & & & & & \\
\hline & Death & Injury & Death & Injury & Cancer & Death & Injury & Death & Injury & Cancer & Death & Injury & Cancer & Death & Injury & Cancer \\
\hline $\begin{array}{l}\text { Technology Readiness } \\
\text { (Duration - } 5 \text { years) }\end{array}$ & 2.0E-03 & $4.1 \mathrm{E}-03$ & $2.4 \mathrm{E}-03$ & $7.9 \mathrm{E}-01$ & $0.0 \mathrm{E}+00$ & $1.0 \mathrm{E}-02$ & $2.0 \mathrm{E}-02$ & $1.2 \mathrm{E}-02$ & $4.0 \mathrm{E}+00$ & $0.0 \mathrm{E}+00$ & $4.4 \mathrm{E}-03$ & $8.0 \mathrm{E}-01$ & $0.0 \mathrm{E}+00$ & $2.2 \mathrm{E}-02$ & $4.0 \mathrm{E}+00$ & $0.0 \mathrm{E}+00$ \\
\hline $\begin{array}{c}\text { Capital } \\
\text { (Duration - } 5 \text { years) }\end{array}$ & $2.2 \mathrm{E}-02$ & $4.5 \mathrm{E}-02$ & $3.6 \mathrm{E}-02$ & $10 E+01$ & $4.7 \mathrm{E}-03$ & I.1E-0! & $2.2 \mathrm{E}-01$ & $1.8 \mathrm{E}-01$ & $5.2 E+01$ & $2.4 \mathrm{E}-02$ & $5.8 \mathrm{E}-02$ & $1.0 \mathrm{E}+01$ & 4.7E-03 & $2.9 \mathrm{E}-01$ & $5.2 \mathrm{E}+01$ & $2.4 \mathrm{E}-02$ \\
\hline $\begin{array}{c}\text { Operators \& } \\
\text { Maintenance } \\
\text { (Duration - } 15 \text { years) }\end{array}$ & $6.5 \mathrm{E}-03$ & $1.3 \mathrm{E}-02$ & $3.0 \mathrm{E}-03$ & $1.1 \mathrm{E}+00$ & $2.1 \mathrm{E}-03$ & 9.7E-02 & $2.0 \mathrm{E}-01$ & $4.4 \mathrm{E}-02$ & $1.7 \mathrm{E}+01$ & $3.2 \mathrm{E}-02$ & $9.5 \mathrm{E}-03$ & $1.1 \mathrm{E}+00$ & 2.1E-03 & $1.4 \mathrm{E}-01$ & $1.7 \mathrm{E}+01$ & 3.2E-02 \\
\hline $\begin{array}{l}\text { Decontamination \& } \\
\text { Decommissioning } \\
\text { (Duration - } 1 \text { year) }\end{array}$ & $65 \mathrm{E}-03$ & $1.3 \mathrm{E}-02$ & $1.5 \mathrm{E}-02$ & $36 E+00$ & $24 \mathrm{E}=03$ & $6.5 \mathrm{E}-03$ & $1.3 \mathrm{E}-02$ & $1.5 \mathrm{E}-02$ & $3.6 E+00$ & $24 \mathrm{E}-03$ & 2.1E-02 & $3.7 \mathrm{E}+00$ & $2.4 \mathrm{E}-03$ & $2.1 \mathrm{E}-02$ & $3.7 \mathrm{E}+00$ & 2.4E-03 \\
\hline TOTAL & $\begin{array}{c}4 \cdots \\
\cdots \cdots \cdots \\
\cdots \cdots \cdots\end{array}$ & 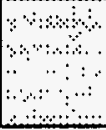 & 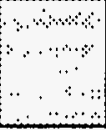 & \begin{tabular}{rr} 
\\
\hdashline & \\
\hdashline & \\
\end{tabular} & {$\left[\begin{array}{c}6 \\
\cdots \\
\hdashline \\
\cdots \\
\cdots\end{array}\right]$} & $22 \mathrm{E}-01$ & $46 E-01$ & $25 E-01$ & $7.6 \mathrm{E}+01$ & $58 \mathrm{E}-02$ & $\begin{array}{r}\text { के } \\
\cdots \\
\cdots\end{array}$ & 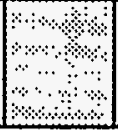 & का & $4.7 \mathrm{E}-01$ & $7.7 E+01$ & $5,8 \mathrm{E}-02$ \\
\hline
\end{tabular}

Assumptions:

- Transportation is to and from the site only

- Operational risks encompass industrial/physical hazards associated with equipment operation and onsite operations

- Infrastructure staff support the staff above. They receive no annual Cancer, average 4,000 travel miles, and average $50 \%$ of the facility totals above.

- Collective risks have been calculated as the product of individual risk, multiplied by the number of exposed inidividuals.

Individual risks provide estimates of the probability of health detriment for the individual, and the collective risks provide a measure of overall detriment

to the work force. 
Option: J. Circulating Air Barrier

Capital Cost: $\$ 71$ million

Annual Worker Mileage: 15,000

\begin{tabular}{|c|c|c|c|c|c|c|c|c|c|c|}
\hline \multirow{4}{*}{ Activity } & \multicolumn{10}{|c|}{$\begin{array}{l}\text { Management and } \\
\text { Enginecring }\end{array}$} \\
\hline & \multicolumn{5}{|c|}{ Annual } & \multicolumn{5}{|c|}{ Total } \\
\hline & \multicolumn{2}{|c|}{ Transportation } & \multicolumn{3}{|c|}{ Operational } & \multicolumn{2}{|c|}{ Transportation } & \multicolumn{3}{|c|}{ Operational } \\
\hline & Death & Injury & Death & Injury & Cancer & Death & Injury & Death & Injury & Cancer \\
\hline $\begin{array}{l}\text { Technology Readiness } \\
\text { (Duration - } 5 \text { years) }\end{array}$ & $4.9 \mathrm{E}-04$ & $1.0 \mathrm{E}-03$ & $2.4 \mathrm{E}-04$ & $1.3 \mathrm{E}-01$ & $0.0 \mathrm{E}+00$ & $2.5 \mathrm{E}-03$ & $5.1 \mathrm{E}-03$ & $1.2 \mathrm{E}-03$ & $6.7 \mathrm{E}-01$ & $0.0 \mathrm{E}+00$ \\
\hline $\begin{array}{c}\text { Capital } \\
\text { (Duration - } 5 \text { years) }\end{array}$ & $4.5 \mathrm{E}-03$ & $9.2 \mathrm{E}-03$ & $2.2 \mathrm{E}-03$ & $1.2 \mathrm{E}+00$ & $1.6 \mathrm{E}-04$ & $2.2 \mathrm{E}-02$ & $4.6 \mathrm{E}-02$ & $1.1 \mathrm{E}-02$ & $6.1 E+00$ & $8.1 \mathrm{E}-04$ \\
\hline $\begin{array}{c}\text { Operators \& } \\
\text { Maintenance } \\
\text { (Duration - 15 years) } \\
\end{array}$ & $2.6 \mathrm{E}-03$ & $5.3 \mathrm{E}-03$ & $1.3 \mathrm{E}-03$ & $7.1 \mathrm{E}-01$ & $2.2 \mathrm{E}-04$ & $3.9 E-02$ & $8.0 \mathrm{E}-02$ & $1.9 \mathrm{E}-02$ & $1.1 \mathrm{E}+01$ & $3.3 \mathrm{E}-03$ \\
\hline $\begin{array}{c}\text { Decontamination \& } \\
\text { Decommissioning } \\
\text { (Duration - } 1 \text { year) }\end{array}$ & $2.0 \mathrm{E}-03$ & $4.0 \mathrm{E}-03$ & $9.5 \mathrm{E}-04$ & $5.3 \mathrm{E}-01$ & $1.7 \mathrm{E}-04$ & $2.0 \mathrm{E}-03$ & $4.0 \mathrm{E}-03$ & $9.5 \mathrm{E}-04$ & $5.3 E-01$ & $1.7 \mathrm{E}-04$ \\
\hline TOTAL & $\begin{array}{r}4 \% \\
4 \% \\
4 \%\end{array}$ & 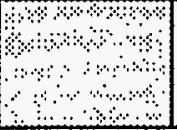 & 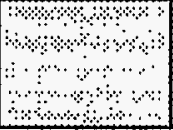 & 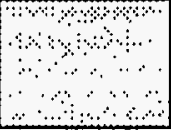 & 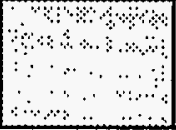 & $6.6 \mathrm{E}-02$ & $1.3 \mathrm{E}-01$ & $3.2 \mathrm{E}-02$ & $1.8 \mathrm{E}+01$ & 4.3E-03 \\
\hline
\end{tabular}

Assumptions:

- Transportation is to and from the site only

- Operational risks encompass industrial/phy'sical hazards associated with equipment operation and onsite operations

- Infrastructure staff support the staff above. They receive no annual Cancer, average 4,000 travel miles, and average $50 \%$ of the facility totals above.

- Collective risks have been calculated as the product of individual risk, multiplied by the number of exposed inidividuals.

Individual risks provide estimates of the probability of health detriment for the individual, and the collective risks provide a measure of overall detriment

to the work force. 
Option: J. Circulating Air Barrier

Capital Cost: $\$ 71$ million

Annual Worker Mileage: 15,000

\begin{tabular}{|c|c|c|c|c|c|c|c|c|c|c|}
\hline \multirow{4}{*}{ Activity } & \multicolumn{10}{|c|}{$\begin{array}{l}\text { Construction/Decommissioning } \\
\text { Crafts and Laborers }\end{array}$} \\
\hline & \multicolumn{5}{|c|}{ Annual } & \multicolumn{5}{|c|}{ Total } \\
\hline & \multicolumn{2}{|c|}{ Transportation } & \multicolumn{3}{|c|}{ Operational } & \multicolumn{2}{|c|}{ Transportation } & \multicolumn{3}{|c|}{ Operational } \\
\hline & Death & Injury & Death & Injury & Cancer & Death & Injury & Death & Injury & Cancer \\
\hline $\begin{array}{l}\text { Technology Readiness } \\
\text { (Duration - } 5 \text { yeàrs) }\end{array}$ & $1.6 \mathrm{E}-04$ & $3.4 \mathrm{E}-04$ & $5.6 \mathrm{E}-04$ & $1.3 \mathrm{E}-01$ & $0.0 \mathrm{E}+00$ & 8.2E-04 & $1.7 \mathrm{E}-03$ & $2.8 \mathrm{E}-03$ & $6.4 \mathrm{E}-01$ & $0.0 \mathrm{E}+00$ \\
\hline $\begin{array}{c}\text { Capital } \\
\text { (Duration - } 5 \text { years) }\end{array}$ & $3.0 \mathrm{E}-03$ & 6.1E-03 & $1.0 \mathrm{E}-02$ & $2.3 \mathrm{E}+00$ & $1.4 \mathrm{E}-03$ & $1.5 \mathrm{E}-02$ & $3.0 \mathrm{E}-02$ & $5.0 \mathrm{E}-02$ & $1.2 \mathrm{E}+01$ & $7.2 \mathrm{E}-03$ \\
\hline $\begin{array}{c}\text { Opcrators \& } \\
\text { Maintenance } \\
\text { (Duration - 15 years) }\end{array}$ & $0.0 \mathrm{E}+00$ & $0.0 \mathrm{E}+00$ & $0.0 \mathrm{E}+00$ & $0.0 \mathrm{E}+00$ & $0.0 \mathrm{E}+00$ & $0.0 \mathrm{E}+00$ & $0.0 \mathrm{E}+00$ & $0.0 \mathrm{E}+00$ & $0.0 \mathrm{E}+00$ & $0.0 \mathrm{E}+00$ \\
\hline $\begin{array}{l}\text { Decontamination \& } \\
\text { Decommissioning } \\
\text { (Duration - } 1 \text { year) }\end{array}$ & $3.9 \mathrm{E}-03$ & $8.0 \mathrm{E}-03$ & $1.3 \mathrm{E}-02$ & $3.0 \mathrm{E}+00$ & 1.9E-03 & $3.9 \mathrm{E}-03$ & $8.0 \mathrm{E}-03$ & $1.3 \mathrm{E}-02$ & $3.0 \mathrm{E}+00$ & $1.9 \mathrm{E}-03$ \\
\hline TOTAL. & 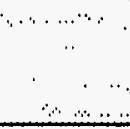 & 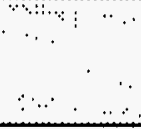 & $\begin{array}{c}\cdots+\cdots \\
\cdots \\
\cdots\end{array}$ & $\begin{array}{l}\cdots \cdots \cdots \cdots \\
\cdots, \ldots, \cdots\end{array}$ & $\begin{array}{lll}\ddots \cdots & \cdots \\
\ddots \cdots & \cdots\end{array}$ & $2.01:-02$ & 4.0I:-02 & $6.7 \mathrm{E}-02$ & $1.5 \mathrm{E}+01$ & $9.1 \mathrm{E}-03$ \\
\hline
\end{tabular}

\section{Assumptions:}

- Transportation is to and from the site only

- Operational risks encompass industrial/phy'sical hazards associated with equipnent operation and onsite operations

- Infrastructure staff support the staff above. They receive no annual Cancer, average 4,000 travel miles, and average $50 \%$ of the facility totals above.

- Collective risks have been calculated as the product of individual risk, multiplied by the number of exposed inidividuals.

Individual risks provide estimates of the probability of health detriment for the individual, and the collective risks provide a measure of overall detriment

to the work force. 
Option: J. Circulating Air Barrier

Capital Cost: $\$ 71$ million

Annual Worker Mileage: 15,000

\begin{tabular}{|c|c|c|c|c|c|c|c|c|c|c|}
\hline \multirow{4}{*}{ Activity } & \multicolumn{10}{|c|}{ Maintenance Crafts } \\
\hline & \multicolumn{5}{|c|}{ Annual } & \multicolumn{5}{|c|}{ Total } \\
\hline & \multicolumn{2}{|c|}{ Transportation } & \multicolumn{3}{|c|}{ Opcrational } & \multicolumn{2}{|c|}{ Transportation } & \multicolumn{3}{|c|}{ Operational } \\
\hline & Death & Injury & Death & \begin{tabular}{|l|} 
Injury \\
\end{tabular} & Cancer & Death & Injury & Death & Injury & Cancer \\
\hline $\begin{array}{l}\text { Technology Readiness } \\
\text { (Duration - } 5 \text { years) }\end{array}$ & $0.0 \mathrm{E}+00$ & $0.0 \mathrm{E}+00$ & $0.0 \mathrm{E}+00$ & $0.0 \mathrm{E}+00$ & $0.0 \mathrm{E}+00$ & $0.0 \mathrm{E}+00$ & $0.0 \mathrm{E}+00$ & $0.0 \mathrm{E}+00$ & $0.0 \mathrm{E}+00$ & $0.0 \mathrm{E}+00$ \\
\hline $\begin{array}{c}\text { Capital } \\
\text { (Duration - } 5 \text { years) }\end{array}$ & $0.0 \mathrm{E}+00$ & $0.0 \mathrm{E}+00$ & $0.0 \mathrm{E}+00$ & $0.0 \mathrm{E}+00$ & $0.0 \mathrm{E}+00$ & $0.0 \mathrm{E}+00$ & $0.0 \mathrm{E}+00$ & $0.0 \mathrm{E}+00$ & $0.0 \mathrm{E}+00$ & $0.0 \mathrm{E}+00$ \\
\hline $\begin{array}{c}\text { Operators \& } \\
\text { Maintenance } \\
\text { (Duration - } 15 \text { years) }\end{array}$ & $1.3 \mathrm{E}-03$ & 2.7E-03 & $5.7 \mathrm{E}-04$ & $1.4 \mathrm{E}-01$ & 6.3E-04 & $1.9 \mathrm{E}-02$ & $4.0 \mathrm{E}-02$ & 8.5E-03 & $2.1 \mathrm{E}+00$ & $9.5 \mathrm{E}-03$ \\
\hline $\begin{array}{c}\text { Decontamination \& } \\
\text { Decommissioning } \\
\text { (Duration - } 1 \text { year) }\end{array}$ & $0.0 \mathrm{E}+00$ & $0.0 \mathrm{E}+00$ & $0.0 \mathrm{E}+00$ & $0.0 \mathrm{E}+00$ & $0.0 \mathrm{E}+00$ & $0.0 \mathrm{E}+00$ & $0.0 \mathrm{E}+00$ & $0.0 \mathrm{E}+00$ & $0.0 \mathrm{E}+00$ & $0.0 \mathrm{E}+00$ \\
\hline TOTAL & +. & के & अै। & के & Ho & $1.9 \mathrm{E}-02$ & $4.0 \mathrm{E}-02$ & 8.5E-03 & $2.1 E+00$ & $9.5 \mathrm{E}-03$ \\
\hline
\end{tabular}

Assumptions:

- Transportation is to and from the site only

- Operational risks encompass industrial/physical hazards associated with equipment operation and onsite operations

- Infrastructure staff support the stafr above. They receive no annual Cancer, average 4.000 travel miles, and average $50 \%$ of the facility totals above.

- Collective risks have been calculated as the product of individual risk, multiplied by the number of exposed inidividuats.

Individual risks provide estimates of the probability of health detriment for the individual, and the collective risks provide a measure of overall detriment

to the work force. 
Option: J. Circulating Air Barrier

Capital Cost: $\$ 71$ million

Annual Worker Milcage: 15,000

\begin{tabular}{|c|c|c|c|c|c|c|c|c|c|c|}
\hline \multirow{4}{*}{ Activity } & \multicolumn{10}{|c|}{ Operators } \\
\hline & \multicolumn{5}{|c|}{ Annual } & \multicolumn{5}{|c|}{ Total } \\
\hline & \multicolumn{2}{|c|}{ Transportation } & \multicolumn{3}{|c|}{ Operational } & \multicolumn{2}{|c|}{ Transportation } & \multicolumn{3}{|c|}{ Operational } \\
\hline & Death & Injury & Death & Injury & Cancer & Death & Injury & Death & Injury & Cancer \\
\hline $\begin{array}{c}\text { Technology Readiness } \\
\text { (Duration - } 5 \text { years) }\end{array}$ & $0.0 \mathrm{E}+00$ & $0.0 \mathrm{E}+00$ & $0.0 \mathrm{E}+00$ & $0.0 \mathrm{E}+00$ & $0.0 \mathrm{E}+00$ & $0.0 \mathrm{E}+00$ & $0.0 \mathrm{E}+00$ & $0.0 \mathrm{E}+00$ & $0.0 \mathrm{E}+00$ & $0.0 \mathrm{E}+00$ \\
\hline $\begin{array}{c}\text { Capital } \\
\text { (Duration }-5 \text { ycars) }\end{array}$ & $0.0 \mathrm{E}+00$ & $0.0 \mathrm{E}+00$ & $0.0 \mathrm{E}+00$ & $0.0 \mathrm{E}+00$ & $0.0 \mathrm{E}+00$ & $0.0 \mathrm{E}+00$ & $0.0 \mathrm{E}+00$ & $0.0 \mathrm{E}+00$ & $0.0 \mathrm{E}+00$ & $0.0 \mathrm{E}+00$ \\
\hline $\begin{array}{c}\text { Operators \& } \\
\text { Maintenance } \\
\text { (Duration - } 15 \text { years) }\end{array}$ & $2.6 \mathrm{E}-03$ & 5.3E-03 & $1.1 \mathrm{E}-03$ & $2.8 \mathrm{E}-01$ & $1.3 \mathrm{E}-03$ & $3.9 \mathrm{E}-02$ & $8.0 \mathrm{E}-02$ & $1.7 \mathrm{E}-02$ & $4.2 \mathrm{E}+00$ & $1.9 \mathrm{E}-02$ \\
\hline $\begin{array}{c}\text { Decontamination \& } \\
\text { Decommissioning } \\
\text { (Duration - } 1 \text { year) }\end{array}$ & $6.2 \mathrm{E}-04$ & $1.3 \mathrm{E}-03$ & 2.7E-04 & $6.6 \mathrm{E}-02$ & $3.0 \mathrm{E}-04$ & $6.2 \mathrm{E}-04$ & $1.3 \mathrm{E}-03$ & 2.7E-04 & $6.6 \mathrm{E}-02$ & $3.0 \mathrm{E}-04$ \\
\hline To'sAL & 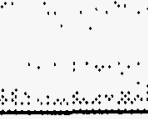 & . & 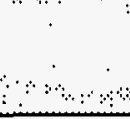 & שח & 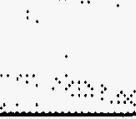 & $4.01 \mathrm{E}-02$ & $8.1 E-02$ & $1.7 \mathrm{E}-02$ & $4.2 \mathrm{E}+00$ & $1.9 \mathrm{E}-02$ \\
\hline
\end{tabular}

\section{Assumptions:}

- Transportation is to and from the site only

- Operational risks encompass industrial/physical hazards associated with equipment operation and onsite operations

- Infrastructure staff support the staff above. They receive no annual Cancer, average 4,000 travel miles, and average $50 \%$ of the facility totals above.

- Collective risks have been calculated as the product of individual risk, multiplied by the number of exposed inidividuals.

Individual risks provide estimates of the probability of health detriment for the individual, and the collective risks provide a measure of overall detriment

to the work force. 
Option: J. Circulating Air Barrier

Capital Cost: \$7I million

Annual Worker Mileage: 15,000

\begin{tabular}{|c|c|c|c|c|c|c|c|c|c|c|c|c|c|c|c|c|}
\hline \multirow{4}{*}{ Activity } & \multicolumn{10}{|c|}{ All Workers } & \multicolumn{6}{|c|}{ All Workers } \\
\hline & \multicolumn{5}{|c|}{ Annual } & \multicolumn{5}{|c|}{ Total } & \multirow{2}{*}{\multicolumn{3}{|c|}{ Annuals }} & \multirow{2}{*}{\multicolumn{3}{|c|}{ Totals }} \\
\hline & \multicolumn{2}{|c|}{ Transportation } & \multicolumn{3}{|c|}{ Operational } & \multicolumn{2}{|c|}{ Transportation } & \multicolumn{3}{|c|}{ Operational } & & & & & & \\
\hline & Death & Injury' & Death & Injury & Cancer & Death & Injury & Death & Injury & Cancer & Death & Injury & Cancer & Death & Injury & Cancer \\
\hline $\begin{array}{l}\text { Technology Readiness } \\
\text { (Duration - } 5 \text { ycars) }\end{array}$ & $66 \mathrm{E}-04$ & 1.3E-03 & $80 \mathrm{E}-04$ & $26 \mathrm{E} \cdot 01$ & $00 \mathrm{E}+00$ & $33 \mathrm{E}-03$ & $67 \mathrm{E}-03$ & $40 \mathrm{OE}-03$ & $1.3 E+\infty$ & $00 \mathrm{E}+00$ & $15 E-03$ & $26 \mathrm{E}-01$ & $0.0 \mathrm{E}+00$ & 7.3E-03 & $1.3 \mathrm{E}+00$ & $0.0 E+00$ \\
\hline $\begin{array}{c}\text { Capital } \\
\text { (Duration - } 5 \text { years) }\end{array}$ & $74 \mathrm{E}-03$ & $15 \mathrm{E}-02$ & $1.2 \mathrm{E}-02$ & $35 E+00$ & $1.6 \mathrm{E}-03$ & 3.7E-02 & $76 \mathrm{E}-02$ & $6 \mathrm{IE}-02$ & $1.8 \mathrm{E}+01$ & $80 \mathrm{E}-03$ & $2.0 \mathrm{E}-02$ & $3.5 \mathrm{E}+00$ & $1.6 \mathrm{E}-03$ & $9.8 \mathrm{E}-02$ & $1.8 \mathrm{E}+01$ & $8.0 \mathrm{E}-03$ \\
\hline $\begin{array}{c}\text { Operators \& } \\
\text { Maintenance } \\
\text { (Duration - 15 ycars) }\end{array}$ & $6.5 \mathrm{E}-03$ & $13 \mathrm{E}-02$ & $30 \mathrm{E}-03$ & $1.1 \mathrm{E}+00$ & $2.1 \mathrm{E}-03$ & $97 \mathrm{E}-02$ & $20 \mathrm{E}-01$ & 4 4E-02 & $1.7 \mathrm{E}+01$ & $3.2 \mathrm{E}-02$ & $9.5 \mathrm{E}-03$ & $1.1 E+00$ & 2.1E-03 & $1.4 \mathrm{E}-01$ & $1.7 \mathrm{E}+01$ & $3.2 \mathrm{E}-02$ \\
\hline $\begin{array}{l}\text { Decontamination \& } \\
\text { Decommissioning } \\
\text { (Duration - } 1 \text { year) }\end{array}$ & 6 SE- 03 & $13 \mathrm{E}-02$ & $1.5 \mathrm{E}-02$ & $3.6 \mathrm{E}+00$ & $24 \mathrm{E}-03$ & $6.5 \mathrm{E}-03$ & $1.3 \mathrm{E}-02$ & $15 \mathrm{E}-02$ & $3.6 \mathrm{E}+00$ & 2.4E-03 & $2.1 \mathrm{E}-02$ & $3.7 \mathrm{E}+00$ & $2.4 \mathrm{E}-03$ & $2.1 \mathrm{E}-02$ & $3.7 E+00$ & $2.4 \mathrm{E}-03$ \\
\hline TOTAL & $\begin{array}{c}0 . \\
\cdots, \\
\cdots \\
\cdots\end{array}$ & 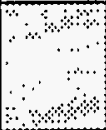 & $\begin{array}{r}\vdots \\
\ddots \vdots \\
\vdots\end{array}$ & $\begin{array}{r}0 \\
\vdots \\
\vdots \\
\vdots\end{array}$ & \begin{tabular}{|cc|} 
& 0 \\
\hdashline & $\vdots$ \\
\hdashline & $\vdots$ \\
\hdashline
\end{tabular} & $|4 E-0|$ & $30 \mathrm{E}-01$ & | $2 \mathrm{E}-01$ & $39 \mathrm{E}+01$ & $4.2 \mathrm{E}-02$ & में & ڤै। & के & $2.7 \mathrm{E}-01$ & $4.0 \mathrm{E}+01$ & 4.2E-02 \\
\hline
\end{tabular}

\section{Assumptions:}

- Transportation is to and from the site only

- Operational risks encompass industrial/physical hazards associated with equipment operation and onsite operations

- Infrastructure staff support the staff above. They receive no annual Cancer, average 4,000 travel miles, and average $50 \%$ of the facility totals above.

- Collective rists have been calculated as the product of individual risk, multiplied by the number of exposed inidividuals.

Individual risks provide estimates of the probability of health detriment for the individual, and the collective risks provide a measure of overall detriment

to the work force. 
Option: K. Vacuum Soil Flushing (for Circulating Air Barrier) Capital Cost: $\$ 126$ million

Annual Workcr Milcagc: 15,000

\begin{tabular}{|c|c|c|c|c|c|c|c|c|c|c|}
\hline \multirow{4}{*}{ Activity } & \multicolumn{10}{|c|}{$\begin{array}{l}\text { Management and } \\
\text { Engineering }\end{array}$} \\
\hline & \multicolumn{5}{|c|}{ Annual } & \multicolumn{5}{|c|}{ Total } \\
\hline & \multicolumn{2}{|c|}{ Transportation } & \multicolumn{3}{|c|}{ Operational } & \multicolumn{2}{|c|}{ Transportation } & \multicolumn{3}{|c|}{ Opcrational } \\
\hline & Death & Injury & Death & Injury & Cancer & Death & Injury & Death & Injury & Cancer \\
\hline $\begin{array}{l}\text { Technology Readiness } \\
\text { (Duration - } 5 \text { ycars) }\end{array}$ & 1.3E-03 & $2.6 \mathrm{E}-03$ & $6.1 E-04$ & $3.4 \mathrm{E}-01$ & $0.0 \mathrm{E}+00$ & $6.3 \mathrm{E}-03$ & 1.3E-02 & $3.1 \mathrm{E}-03$ & $1.7 \mathrm{E}+00$ & $0.0 \mathrm{E}+00$ \\
\hline $\begin{array}{c}\text { Capita! } \\
\text { (Duration -5 years) }\end{array}$ & $7.9 \mathrm{E}-03$ & $1.6 \mathrm{E}-02$ & $3.9 \mathrm{E}-03$ & $2.2 \mathrm{E}+00$ & 2.9E-04 & 4.0E-02 & 8.1E-02 & $1.9 \mathrm{E}-02$ & $1.1 \mathrm{E}+01$ & $1.4 \mathrm{E}-03$ \\
\hline $\begin{array}{c}\text { Operators \& } \\
\text { Maintenance } \\
\text { (Duration - } 15 \text { ycars) }\end{array}$ & $2.6 \mathrm{E}-03$ & $5.3 \mathrm{E}-03$ & $1.3 \mathrm{E}-03$ & $7.1 \mathrm{E}-01$ & $2.2 \mathrm{E}-04$ & $3.9 \mathrm{E}-02$ & $8.0 \mathrm{E}-02$ & $1.9 \mathrm{E}-02$ & $1.1 \mathrm{E}+01$ & $3.3 \mathrm{E}-03$ \\
\hline $\begin{array}{l}\text { Decontamination \& } \\
\text { Decommissioning } \\
\text { (Duration - } 1 \text { ycar) }\end{array}$ & $2.0 \mathrm{E}-03$ & 4.0E-03 & $9.5 \mathrm{E}-04$ & $5.3 \mathrm{E}-01$ & 1.7E-04 & $2.0 \mathrm{E}-03$ & $4.0 \mathrm{E}-03$ & $9.5 \mathrm{E}-04$ & $5.3 \mathrm{E}-01$ & $1.7 \mathrm{E}-04$ \\
\hline TOTAL & 3......... & $\therefore \quad: \quad: \quad \cdots$ & $\therefore \begin{array}{llll}\therefore & \therefore & \ddots \\
& & \ddots & \ddots\end{array}$ & & $\therefore$ & 8.7E-02 & $1.8 \mathrm{E}-01$ & $4.2 \mathrm{E}-02$ & $2.4 \mathrm{E}+01$ & $4.9 \mathrm{E}-03$ \\
\hline
\end{tabular}

Assumptions:

- Transportation is to and from the site only

- Operational risks encompass industrial/physical hazards associated with equipment operation and onsite operations

- Infrastructure staff support the staff above. They receive no annual Cancer. average 4,000 travel miles. and average $50 \%$ of the facility totals above.

- Collective risks have been calculated as the product of individual risk, multiplied by the number of exposed inidividuals.

Individual risks provide estimates of the probability of health detriment for the individual, and the collective risks provide a measure of overall detriment to the work force. 


\begin{tabular}{|c|c|c|c|c|c|c|c|c|c|c|}
\hline $\begin{array}{r}\text { Option } \\
\text { Capital Cost } \\
\text { Annual Worker Mileage }\end{array}$ & $\begin{array}{l}\text { K. Vacuum } \\
\$ 126 \text { million } \\
15,000\end{array}$ & I Flushing & Circulatin & ir Barrier) & & & & & & \\
\hline \multirow{4}{*}{ Activity } & \multicolumn{10}{|c|}{$\begin{array}{l}\text { Construction/Decommissioning } \\
\text { Crafts and Laborers }\end{array}$} \\
\hline & \multicolumn{5}{|c|}{ Annual } & \multicolumn{5}{|c|}{ Total } \\
\hline & \multicolumn{2}{|c|}{ Transportation } & \multicolumn{3}{|c|}{ Operational } & \multicolumn{2}{|c|}{ Transportation } & \multicolumn{3}{|c|}{ Operational } \\
\hline & Death & Injury & Death & Injury & Cancer & Death & Injury & Death & Injury & Cancer \\
\hline $\begin{array}{l}\text { Technology Readiness } \\
\text { (Duration - } 5 \text { y'ears) }\end{array}$ & $4.1 E-04$ & $8.4 \mathrm{E}-04$ & $1.4 \mathrm{E}-03$ & $3.2 \mathrm{E}-01$ & $0.0 \mathrm{E}+00$ & $2.1 \mathrm{E}-03$ & $4.2 \mathrm{E}-03$ & $7.0 \mathrm{E}-03$ & $1.6 \mathrm{E}+00$ & $0.0 \mathrm{E}+00$ \\
\hline $\begin{array}{c}\text { Capital } \\
\text { (Duration }-5 \text { years) } \\
\end{array}$ & $5.3 \mathrm{E}-03$ & $1.1 \mathrm{E}-02$ & $1.8 \mathrm{E}-02$ & $4.1 E+00$ & $5.1 \mathrm{E}-03$ & $2.6 \mathrm{E}-02$ & $5.4 \mathrm{E}-02$ & $9.0 \mathrm{E}-02$ & $2.1 E+01$ & $2.6 \mathrm{E}-02$ \\
\hline $\begin{array}{c}\text { Operators \& } \\
\text { Maintenance } \\
\text { (Duration - 15 years) }\end{array}$ & $0.0 \mathrm{E}+00$ & $0.0 \mathrm{E}+00$ & $0.0 \mathrm{E}+00$ & $0.0 \mathrm{E}+00$ & $0.0 \mathrm{E}+00$ & $0.0 \mathrm{E}+00$ & $0.0 \mathrm{E}+00$ & $0.0 \mathrm{E}+00$ & $0.0 \mathrm{E}+00$ & $0.0 \mathrm{E}+00$ \\
\hline $\begin{array}{c}\text { Decontamination \& } \\
\text { Decommissioning } \\
\text { (Duration - 1 year) }\end{array}$ & $3.9 \mathrm{E}-03$ & $8.0 \mathrm{E}-03$ & $1.3 \mathrm{E}-02$ & $3.0 E+00$ & $3.8 \mathrm{E}-03$ & $3.9 \mathrm{E}-03$ & $8.0 \mathrm{E}-03$ & $1.3 \mathrm{E}-02$ & $3.0 \mathrm{E}+00$ & $3.8 \mathrm{E}-03$ \\
\hline TOTAL & \% & & & ৷ & \% & $3.2 \mathrm{E}-02$ & $6.6 \mathrm{E}-02$ & $1.1 \mathrm{E}-01$ & $2.5 \mathrm{E}+01$ & $3.0 \mathrm{E}-02$ \\
\hline
\end{tabular}

Assumptions:

- Transportation is to and from the site only

- Operational risks encompass industrial/physical hazards associated with equipment operation and onsite operations

- Infrastructure staff support the staff above. They receive no annual Cancer, average 4,000 travel miles, and average $50 \%$ of the facility totals above.

- Collective risks have been calculated as the product of individual risk, multiplied by the number of exposed inidividuals.

Individual risks provide estimates of the probability of health detriment for the individual, and the collective risks provide a measure of overall detriment

to the work force. 
Table D.3. Options Worker Risks (Sheet 53 of 105)

Option: K. Vacuum Soil Flushing (for Circulating Air Barrier) Capital Cost: $\$ 126$ million

Annual Worker Mileage: 15,000

\begin{tabular}{|c|c|c|c|c|c|c|c|c|c|c|}
\hline \multirow{4}{*}{ Activity } & \multicolumn{10}{|c|}{ Maintenance Crafts } \\
\hline & \multicolumn{5}{|c|}{ Annual } & \multicolumn{5}{|c|}{ Total } \\
\hline & \multicolumn{2}{|c|}{ Transportation } & \multicolumn{3}{|c|}{ Operational } & \multicolumn{2}{|c|}{ Transportation } & \multicolumn{3}{|c|}{ Operational } \\
\hline & Death & Injury & Death & Injury & Cancer & Death & Injury & Death & Injury & Cancer \\
\hline $\begin{array}{l}\text { Technology Readiness } \\
\text { (Duration - } 5 \text { years) }\end{array}$ & $0.0 \mathrm{E}+00$ & $0.0 \mathrm{E}+00$ & $0.0 \mathrm{E}+00$ & $0.0 \mathrm{E}+00$ & $0.0 \mathrm{E}+00$ & $0.0 \mathrm{E}+00$ & $0.0 \mathrm{E}+00$ & $0.0 \mathrm{E}+00$ & $0.0 \mathrm{E}+00$ & $0.0 \mathrm{E}+00$ \\
\hline $\begin{array}{c}\text { Capital } \\
\text { (Duration - } 5 \text { years) }\end{array}$ & $0.0 \mathrm{E}+00$ & $0.0 \mathrm{E}+00$ & $0.0 \mathrm{E}+00$ & $0.0 \mathrm{E}+00$ & $0.0 \mathrm{E}+00$ & $0.0 \mathrm{E}+00$ & $0.0 \mathrm{E}+00$ & $0.0 \mathrm{E}+00$ & $0.0 \mathrm{E}+00$ & $0.0 \mathrm{E}+00$ \\
\hline $\begin{array}{c}\text { Operators \& } \\
\text { Maintenance } \\
\text { (Duration - } 15 \text { years) }\end{array}$ & $1.3 \mathrm{E}-03$ & 2.7E-03 & $5.7 \mathrm{E}-04$ & $1.4 \mathrm{E}-01$ & $1.3 \mathrm{E}-03$ & $1.9 \mathrm{E}-02$ & $4.0 \mathrm{E}-02$ & $8.5 \mathrm{E}-03$ & $2.1 \mathrm{E}+00$ & $1.9 \mathrm{E}-02$ \\
\hline $\begin{array}{c}\text { Decontamination \& } \\
\text { Decommissioning } \\
\text { (Duration - } 1 \text { ycar) }\end{array}$ & $0.0 \mathrm{E}+00$ & $0.0 \mathrm{E}+00$ & $0.0 \mathrm{E}+00$ & $0.0 \mathrm{E}+00$ & $0.0 \mathrm{E}+00$ & $0.0 \mathrm{E}+00$ & $0.0 \mathrm{E}+00$ & $0.0 \mathrm{E}+00$ & $0.0 \mathrm{E}+00$ & $0.0 \mathrm{E}+00$ \\
\hline TOTAL & \%ి & कि & किमें & किक। & कि। & $1.9 \mathrm{E}-02$ & $4.0 \mathrm{E}-02$ & $8.5 \mathrm{E}-03$ & $2.1 E+00$ & $1.9 \mathrm{E}-02$ \\
\hline
\end{tabular}

\section{Assumptions:}

- Transportation is to and from the site only

- Operational risks encompass industrial/physical hazards associated with equipment operation and onsite operations

- Infrastructure staff support the staff above. They receive no annual Cancer, average 4,000 travel miles, and average $50 \%$ of the facility totals above.

- Collective risks have been calculated as the product of individual risk, multiplied by the number of exposed inidividuals.

Individual risks provide estimates of the probability of health detriment for the individual, and the collective risks provide a measure of overall detriment

to the work force. 


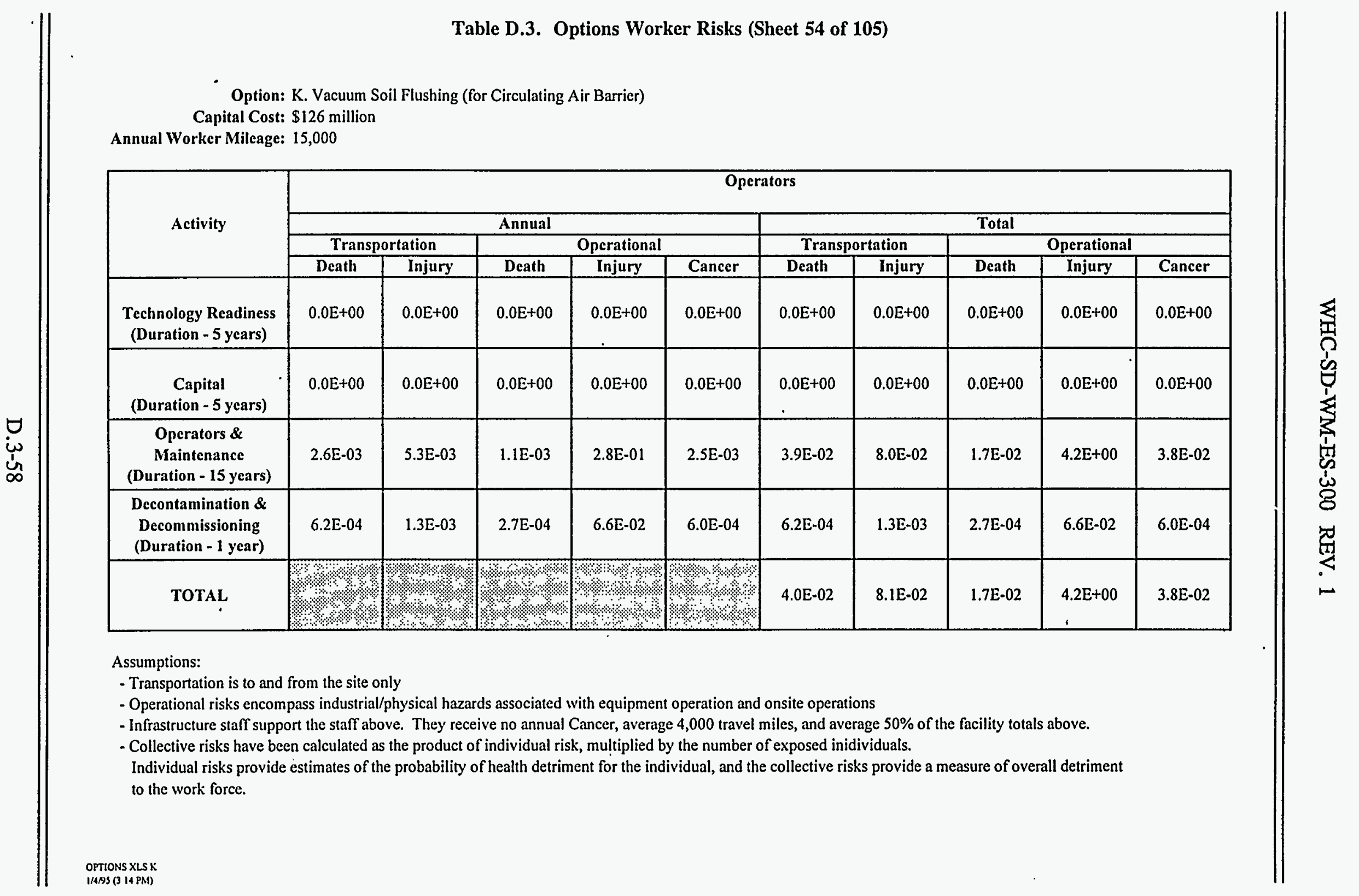


Option: K. Vacuum Soil Flushing (for Circulating Air Barrier) Capital Cost: $\$ 126$ million Annual Worker Mileage: 15,000

\begin{tabular}{|c|c|c|c|c|c|c|c|c|c|c|c|c|c|c|c|c|}
\hline \multirow{4}{*}{ Activity } & \multicolumn{10}{|c|}{ All Workers } & \multicolumn{6}{|c|}{ All Workers } \\
\hline & \multicolumn{5}{|c|}{$\begin{array}{r}\text { Annual } \\
\end{array}$} & \multicolumn{5}{|c|}{ Total } & \multirow{2}{*}{\multicolumn{3}{|c|}{ Annuals }} & \multirow{2}{*}{\multicolumn{3}{|c|}{ Totals }} \\
\hline & \multicolumn{2}{|c|}{\begin{tabular}{|l|} 
Transportation \\
\end{tabular}} & \multicolumn{3}{|c|}{ Operational } & \multicolumn{2}{|c|}{ Transportation } & \multicolumn{3}{|c|}{ Operational } & & & & & & \\
\hline & Death & Injury & Death & Injury & Cancer & Death & Injury & Dcath & Injury & Cancer & Death & Injury & Cancer & Death & Injury & Cancer \\
\hline $\begin{array}{c}\text { Technology Readiness } \\
\text { (Duration - } 5 \text { years) }\end{array}$ & $1.7 \mathrm{E}-03$ & $3.4 \mathrm{E}-03$ & $2.0 \mathrm{E}-03$ & $6.6 \mathrm{E}-01$ & $0.0 \mathrm{E}+00$ & $8.3 \mathrm{E}-03$ & $1.7 \mathrm{E}-02$ & $1.0 \mathrm{E}-02$ & $3.3 E+00$ & $0.0 E+00$ & $3.7 \mathrm{E}-03$ & $6.7 \mathrm{E}-01$ & $0.0 E+00$ & $1.8 \mathrm{E}-02$ & $3.3 \mathrm{E}+00$ & $0.0 \mathrm{E}+00$ \\
\hline $\begin{array}{c}\text { Capital } \\
\text { (Duration - } 5 \text { years) } \\
\end{array}$ & $1.3 \mathrm{E}-02$ & $2.7 \mathrm{E}-02$ & $2.2 \mathrm{E}-02$ & $6.3 E+00$ & $5.4 \mathrm{E}-03$ & $6.6 \mathrm{E}-02$ & $1.4 \mathrm{E}-01$ & $1.1 \mathrm{E}-01$ & $3.1 \mathrm{E}+01$ & $2.7 \mathrm{E}-02$ & $3.5 \mathrm{E}-02$ & $6.3 \mathrm{E}+00$ & $5.4 \mathrm{E}-03$ & $1.8 \mathrm{E}-0 !$ & $3.1 E+01$ & $\begin{array}{c}2.7 \mathrm{E}-02 \\
.\end{array}$ \\
\hline $\begin{array}{c}\text { Operators \& } \\
\text { Maintenance } \\
\text { (Duration - } 15 \text { years) } \\
\end{array}$ & $6.5 \mathrm{E}-03$ & $1.3 \mathrm{E}-02$ & $3.0 \mathrm{E}-03$ & $1.1 E+00$ & $4.0 \mathrm{E}-03$ & $9.7 \mathrm{E}-02$ & $2.0 \mathrm{E}-01$ & $4.4 \mathrm{E}-02$ & $1.7 \mathrm{E}+01$ & $6.0 \mathrm{E}-02$ & $9.5 \mathrm{E}-03$ & $1.1 \mathrm{E}+00$ & $4.0 \mathrm{E}-03$ & $1.4 \mathrm{E}-01$ & $1.7 \mathrm{E}+01$ & $6.0 \mathrm{E}-02$ \\
\hline $\begin{array}{c}\text { Decontamination \& } \\
\text { Decommissioning } \\
\text { (Duration - } 1 \text { ycar) }\end{array}$ & $6.5 \mathrm{E}-03$ & $1.3 \mathrm{E}-02$ & $1.5 \mathrm{E}-02$ & $3.6 \mathrm{E}+00$ & $4.6 \mathrm{E}-03$ & $6.5 \mathrm{E}-03$ & $1.3 \mathrm{E}-02$ & $1.5 \mathrm{E}-02$ & $3.6 \mathrm{E}+00$ & $4.6 \mathrm{E}-03$ & $2.1 \mathrm{E}-02$ & $3.7 \mathrm{E}+00$ & $4.6 \mathrm{E}-03$ & $2.1 \mathrm{E}-02$ & $3.7 \mathrm{E}+00$ & $4.6 \mathrm{E}-03$ \\
\hline TO'TAL & $\begin{array}{r}3 \\
\cdots\end{array}$ & के & 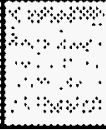 & 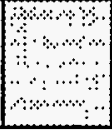 & 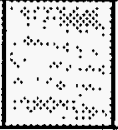 & $1,8 \mathrm{E}-01$ & $37 \mathrm{E}-01$ & $1.8 \mathrm{E}-01$ & $5.5 E+01$ & $9.2 \mathrm{E}-02$ & कि & के। & के & $3.6 \mathrm{E}-01$ & $5.5 \mathrm{E}+01$ & $9.2 \mathrm{E}-02$ \\
\hline
\end{tabular}

\section{Assumptions:}

- Transportation is to and from the site only

- Operational risks encompass industrial/physical hazards associated with equipment operation and onsite operations

- Infrastructure staff support the staff above. They receive no annual Cancer, average 4,000 travel miles, and average $50 \%$ of the facility totals above.

- Collective risks have been calculated as the product of individual risk, multiplied by the number of exposed inidividuals.

Individual risks provide estimates of the probability of health detriment for the individual, and the collective risks provide a measure of overall detriment to the work force. 
Option: L. Vacuum Soil Flushing (for Close-Coupled Barrier) Capital Cost: $\$ 107$ million

Annual Worker Mileage: 15,000

\begin{tabular}{|c|c|c|c|c|c|c|c|c|c|c|}
\hline \multirow{4}{*}{ Activity } & \multicolumn{10}{|c|}{$\begin{array}{l}\text { Management and } \\
\text { Engineering }\end{array}$} \\
\hline & \multicolumn{5}{|c|}{ Annual } & \multicolumn{5}{|c|}{ Total } \\
\hline & \multicolumn{2}{|c|}{ Transportation } & \multicolumn{3}{|c|}{ Operational } & \multicolumn{2}{|c|}{ Transportation } & \multicolumn{3}{|c|}{ Operational } \\
\hline & Death & \begin{tabular}{|l|} 
Injury \\
\end{tabular} & Death & Injury & Cancer & Death & Injury & Death & Injury & Cancer \\
\hline $\begin{array}{l}\text { Technology Readiness } \\
\text { (Duration - } 5 \text { years) }\end{array}$ & $1.3 \mathrm{E}-03$ & $2.6 \mathrm{E}-03$ & $6.1 \mathrm{E}-04$ & $3.4 \mathrm{E}-01$ & $0.0 \mathrm{E}+00$ & $6.3 \mathrm{E}-03$ & $1.3 \mathrm{E}-02$ & $3.1 E-03$ & $1.7 \mathrm{E}+00$ & $0.0 \mathrm{E}+00$ \\
\hline $\begin{array}{c}\text { Capital } \\
\text { (Duration - } 5 \text { years) }\end{array}$ & $6.7 \mathrm{E}-03$ & $1.4 \mathrm{E}-02$ & 3.3E-03 & $1.8 \mathrm{E}+00$ & 2.5E-04 & $3.4 \mathrm{E}-02$ & $6.9 \mathrm{E}-02$ & $1.6 \mathrm{E}-02$ & $9.2 \mathrm{E}+00$ & $1.2 \mathrm{E}-03$ \\
\hline $\begin{array}{c}\text { Operators \& } \\
\text { Maintenance } \\
\text { (Duration - } 15 \text { years) }\end{array}$ & $2.6 \mathrm{E}-03$ & $5.3 \mathrm{E}-03$ & $1.3 \mathrm{E}-03$ & $7.1 \mathrm{E}-01$ & $2.2 \mathrm{E}-04$ & $3.9 \mathrm{E}-02$ & $8.0 \mathrm{E}-02$ & $1.9 \mathrm{E}-02$ & $1.1 \mathrm{E}+01$ & $3.3 \mathrm{E}-03$ \\
\hline $\begin{array}{c}\text { Decontamination \& } \\
\text { Decommissioning } \\
\text { (Duration - } 1 \text { ycar) }\end{array}$ & $2.0 \mathrm{E}-03$ & $4.0 \mathrm{E}-03$ & $9.5 \mathrm{E}-04$ & $5.3 \mathrm{E}-01$ & $1.7 \mathrm{E}-04$ & $2.0 \mathrm{E}-03$ & $4.0 \mathrm{E}-03$ & 9.5E-04 & $5.3 \mathrm{E}-01$ & $1.7 \mathrm{E}-04$ \\
\hline TOTAL & के & में & 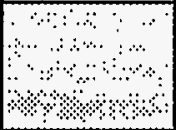 & 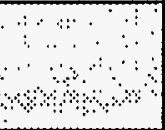 & : & 8.1E-02 & $1.7 \mathrm{E}-01$ & $3.9 \mathrm{E}-02$ & $2.2 \mathrm{E}+01$ & $4.7 \mathrm{E}-03$ \\
\hline
\end{tabular}

\section{Assumptions:}

- Transportation is to and from the site only

- Operational risks encompass industrial/physical hazards associated with equipment operation and onsite operations

- Infrastructure staff support the staff above. They receive no annual Cancer, average 4,000 travel miles, and average $50 \%$ of the facility totals above.

- Collective risks have been calculated as the product of individual risk. multiplied by the number of exposed inidividuals.

Individual risks provide estimates of the probability of health detriment for the individual, and the collective risks provide a measure of overall detriment

to the work force. 
Option: L. Vacuum Soil Flushing (for Close-Coupled Barrier) Capital Cost: $\$ 107$ million

Annual Worker Milcage: 15,000

\begin{tabular}{|c|c|c|c|c|c|c|c|c|c|c|}
\hline \multirow{4}{*}{ Activity } & \multicolumn{10}{|c|}{$\begin{array}{c}\text { Construction/Decommissioning } \\
\text { Crafts and Laborers } \\
\end{array}$} \\
\hline & \multicolumn{5}{|c|}{ Annual } & \multicolumn{5}{|c|}{ Total } \\
\hline & \multicolumn{2}{|c|}{ Transportation } & \multicolumn{3}{|c|}{ Operational } & \multicolumn{2}{|c|}{ Transportation } & \multicolumn{3}{|c|}{ Operational } \\
\hline & Death & Injury & Death & Injury & Cancer & Death & Injury & Death & Injury & Cancer \\
\hline $\begin{array}{l}\text { Technology Readiness } \\
\text { (Duration - } 5 \text { years) }\end{array}$ & $4.1 E-04$ & $8.4 \mathrm{E}-04$ & $1.4 \mathrm{E}-03$ & $3.2 \mathrm{E}-01$ & $0.0 \mathrm{E}+00$ & 2. $1 \mathrm{E}-03$ & 4.2E-03 & $7.0 \mathrm{E}-03$ & $1.6 \mathrm{E}+00$ & $\begin{array}{c}0.0 \mathrm{E}+00 \\
.\end{array}$ \\
\hline $\begin{array}{c}\text { Capital } \\
\text { (1)uration }-5 \text { years) }\end{array}$ & $4.5 E-03$ & $9.2 \mathrm{E}-03$ & $1.5 E-02$ & $3.5 \mathrm{E}+00$ & $4.4 \mathrm{E}-03$ & 2.2E-02 & $4.6 \mathrm{E}-02$ & $7.6 \mathrm{E}-02$ & $1.7 \mathrm{E}+01$ & 2.2E-02 \\
\hline $\begin{array}{c}\text { Operators } \& \\
\text { Maintenance } \\
\text { (Duration - } 15 \text { years) }\end{array}$ & $0.0 \mathrm{E}+00$ & $0.0 \mathrm{E}+00$ & $0.0 \mathrm{E}+00$ & $0.0 \mathrm{E}+00$ & $0.0 \mathrm{E}+00$ & $0.0 \mathrm{E}+00$ & $0.0 \mathrm{E}+00$ & $0.0 \mathrm{E}+00$ & $0.0 \mathrm{E}+00$ & $0.0 \mathrm{E}+00$ \\
\hline $\begin{array}{l}\text { Decontamination \& } \\
\text { Decommissioning } \\
\text { (Duration - } 1 \text { year) }\end{array}$ & 3.9E-03 & 8.0E-03 & 1.3E-02 & $3.0 \mathrm{E}+00$ & $3.8 \mathrm{E}-03$ & $3.9 \mathrm{E}-03$ & $8.0 E-03$ & $1.3 \mathrm{E}-02$ & $3.0 \mathrm{E}+00$ & $3.8 \mathrm{E}-03$ \\
\hline TOTAL & $\begin{array}{c}\ddots \\
\cdots\end{array}$ & \begin{tabular}{cc} 
& $\vdots$ \\
\hdashline \\
\hdashline \\
\end{tabular} & , & : & $3 \cdots$ & $2.8 \mathrm{E}-02$ & $5.8 \mathrm{E}-02$ & $9.7 \mathrm{E}-02$ & $2.2 \mathrm{E}+01$ & $2.6 \mathrm{E}-02$ \\
\hline
\end{tabular}

Assumptions:

- Transportation is to and from the site only

- Operational risks encompass industrial/physical hazards associated with equipment operation and onsite operations .

- Infrastructure staff support the staff above. They receive no annual Cancer, average 4,000 travel miles, and average $50 \%$ of the facility totals above.

- Collective risks have been calculated as the product of individual risk. multiplied by the number of exposed inidividuals.

Individual risks provide estimates of the probability of health detriment for the individual, and the collective ristis provide a measure of overall detriment

to the work force. 


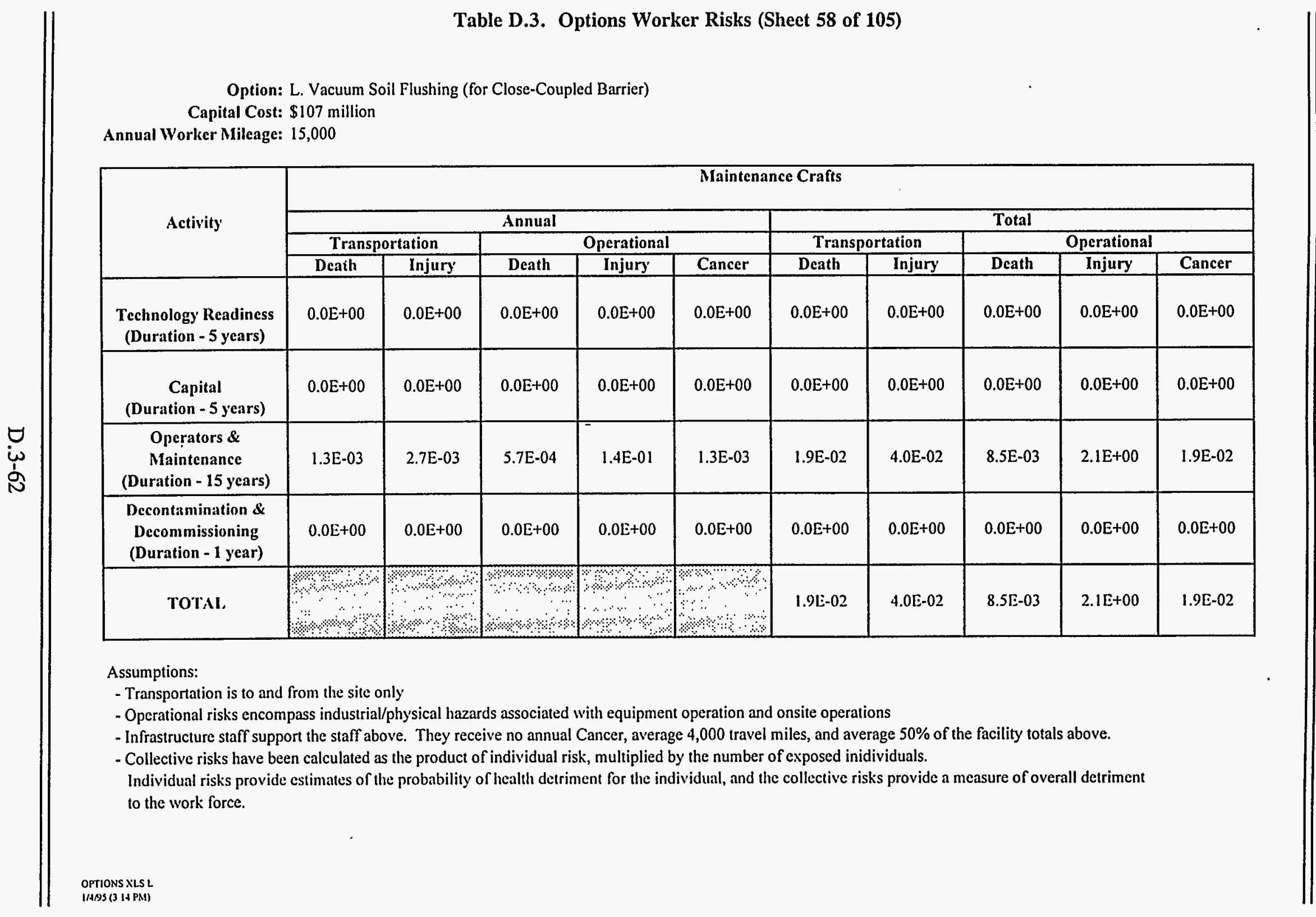


Option: L. Vacuum Soil Flushing (for Close-Coupled Barrier) Capital Cost: \$107 million

Annual Worker Mileage: 15,000 .

\begin{tabular}{|c|c|c|c|c|c|c|c|c|c|c|}
\hline \multirow{4}{*}{ Activity } & \multicolumn{10}{|c|}{ Operators } \\
\hline & \multicolumn{5}{|c|}{ Annual } & \multicolumn{5}{|c|}{ Total } \\
\hline & \multicolumn{2}{|c|}{ Transportation } & \multicolumn{3}{|c|}{ Operational } & \multicolumn{2}{|c|}{ Transportation } & \multicolumn{3}{|c|}{ Opcrational } \\
\hline & Death & Injury & Death & Injury & Cancer & Death & Injury & Death & Injury & Cancer \\
\hline $\begin{array}{l}\text { Teclinology Readiness } \\
\text { (Duration - } 5 \text { ycars) }\end{array}$ & $0.0 \mathrm{E}+00$ & $0.0 \mathrm{E}+00$ & $0.0 E+00$ & $0.0 \mathrm{E}+00$ & $0.0 \mathrm{E}+00$ & $0.0 \mathrm{E}+00$ & $0.0 \mathrm{E}+00$ & $0.0 \mathrm{E}+00$ & $0.0 \mathrm{E}+00$ & $0.0 \mathrm{E}+00$ \\
\hline $\begin{array}{c}\text { Capital } \\
\text { (Duration - } 5 \text { y'cars) } \\
\end{array}$ & $0.0 €+00$ & $0.0 \mathrm{E}+00$ & $0.0 \mathrm{E}+00$ & $0.0 \mathrm{E}+00$ & $0.0 \mathrm{E}+00$ & $0.0 \mathrm{E}+00$ & $0.0 \mathrm{E}+00$ & $0.0 \mathrm{E}+00$ & $0.0 \mathrm{E}+00$ & $0.0 \mathrm{E}+00$ \\
\hline $\begin{array}{c}\text { Operators \& } \\
\text { Maintenance } \\
\text { (Duration - } 15 \text { years) } \\
\end{array}$ & $2.6 \mathrm{E}-03$ & $5.3 \mathrm{E}-03$ & $1.1 \mathrm{E}-03$ & $2.8 \mathrm{E}-01$ & $2.5 \mathrm{E}-03$ & $3.9 \mathrm{E}-02$ & $8.0 \mathrm{E}-02$ & $1.7 \mathrm{E}-02$ & $4.2 \mathrm{E}+00$ & $3.8 \mathrm{E}-02$ \\
\hline $\begin{array}{c}\text { Decontamination \& } \\
\text { Decommissioning } \\
\text { (Duration - } 1 \text { year) }\end{array}$ & $6.2 \mathrm{E}-04$ & $1.3 \mathrm{E}-03$ & 2.7E-04 & $6.6 \mathrm{E}-02$ & $6.0 \mathrm{E}-04$ & $6.2 \mathrm{E}-04$ & $1.3 \mathrm{E}-03$ & 2.7E-04 & $6.6 \mathrm{E}-02$ & $6.0 \mathrm{E}-04$ \\
\hline TOTAL & 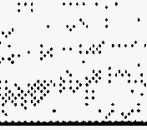 & (4) & \% & 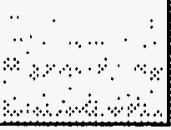 & 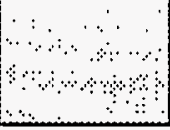 & $4.0 \mathrm{E}-02$ & $8.1 E-02$ & $1.7 \mathrm{E}-02$ & $4.2 \mathrm{E}+00$ & $3.8 \mathrm{E}-02$ \\
\hline
\end{tabular}

Assumptions:

- Transportation is to and from the site only

- Operational risks encompass industrial/physical hazards associated with equipment operation and onsite operations

- Infrastructure staff support the staff above. They receive no annual Cancer, average 4,000 travel miles, and average $50 \%$ of the facility totals above.

- Collective risks have been calculated as the product of individual risk, multiplied by the number of exposed inidividuals.

Individual risks provide estimates of the probability of health detriment for the individual, and the collective risks provide a measure of overall detriment to the work force. 


\begin{tabular}{|c|c|c|c|c|c|c|c|c|c|c|c|c|c|c|c|c|}
\hline $\begin{array}{r}\text { Option: } \\
\text { Capital Cost: } \\
\text { Annual Worker Mlileage: }\end{array}$ & $\begin{array}{l}\text { L. Vacu } \\
\$ 107 \mathrm{mi} \\
15,000\end{array}$ & $\begin{array}{l}\text { um Soil F } \\
\text { illion }\end{array}$ & Fushing ( & for Close- & -Coupled & Barrier) & & & & & & & & & & \\
\hline \multirow{4}{*}{ Activity } & \multicolumn{10}{|c|}{ All Workers } & \multicolumn{6}{|c|}{ All Workers } \\
\hline & \multicolumn{5}{|c|}{ Annual } & \multicolumn{5}{|c|}{ Total } & \multirow{2}{*}{\multicolumn{3}{|c|}{ Annuals }} & \multirow{2}{*}{\multicolumn{3}{|c|}{ Totals }} \\
\hline & \multicolumn{2}{|c|}{ Transportation } & \multicolumn{3}{|c|}{ Operational } & \multicolumn{2}{|c|}{ Transportation } & \multicolumn{3}{|c|}{ Operational } & & & & & & \\
\hline & Death & Injury & Death & \begin{tabular}{|l|} 
Injury \\
\end{tabular} & Cancer & Death & \begin{tabular}{|l|} 
Injury \\
\end{tabular} & Death & Injury & Cancer & Death & \begin{tabular}{|l|} 
Injury \\
\end{tabular} & \begin{tabular}{|l|} 
Cancer \\
\end{tabular} & \begin{tabular}{|l|} 
Death \\
\end{tabular} & \begin{tabular}{|l|} 
Injury \\
\end{tabular} & Cancer \\
\hline $\begin{array}{l}\text { Technology Readiness } \\
\text { (Duration - } 5 \text { years) }\end{array}$ & $1.7 \mathrm{E}-03$ & $34 \mathrm{E}-03$ & $20 \mathrm{E}-03$ & $66 E-01$ & $00 E+00$ & $83 \mathrm{E}-03$ & $|17 \mathrm{E}-02|$ & $\mid 10 \mathrm{E}-02$ & $33 E+00 \mid$ & $|00 E+00|$ & $37 \mathrm{E}-03$ & $67 E-01 \mid$ & $|0.0 E+00|$ & $\mid 1.8 \mathrm{E}-02$ & $33 E+00 \mid$ & $00 \mathrm{E}+00$ \\
\hline $\begin{array}{c}\text { Capital } \\
\text { (Duration - } 5 \text { years) }\end{array}$ & 1 IE- 02 & $23 \mathrm{E}-02$ & $19 \mathrm{E}-02$ & $53 \mathrm{E}+00 \mid$ & $46 \mathrm{E}-03$ & $5.6 \mathrm{E}-02$ & $\mid 1.1 \mathrm{E}-01$ & $93 \mathrm{E}-02$ & $2.7 E+01 \mid$ & $23 \mathrm{E}-02$ & $\mid 3.0 \mathrm{E}-02$ & $5.3 \mathrm{E}+00$ & $4.6 \mathrm{E}-03$ & $\mid 1.5 \mathrm{E}-01$ & $|2.7 \mathrm{E}+01|$ & $2.3 \mathrm{E}-02$ \\
\hline $\begin{array}{c}\text { Operators \& } \\
\text { Maintenance } \\
\text { (Duration - 15 years) }\end{array}$ & $65 \mathrm{E}-03$ & $\mid$ I 3E-02 & $30 \mathrm{E}-03$ & $|11 E+00|$ & $40 \mathrm{E}-03$ & $|97 \mathrm{E}-02|$ & $20 \mathrm{E}-01$ & $\mid 4+\mathrm{E}-02$ & $|1.7 E+01|$ & $6.0 \mathrm{E}-02$ & $95 \mathrm{E}-03$ & $|1.1 E+00|$ & $4.0 \mathrm{E}-03$ & $1.4 \mathrm{E}-01$ & $|1.7 E+01|$ & $6.0 \mathrm{E}-02$ \\
\hline $\begin{array}{c}\text { Decontamination \& } \\
\text { Decommissioning } \\
\text { (Duration-1 year) }\end{array}$ & $6.5 \mathrm{E}-03$ & 1.3E-02 & $15 \mathrm{E}-02$ & $36 E+00 \mid$ & $46 \mathrm{E}-03$ & $65 \mathrm{E}-03$ & $\mid 13 E-02$ & $1.5 \mathrm{E}-02$ & $36 \mathrm{E}+00$ & $46 \mathrm{E}-03$ & $2.1 \mathrm{E}-02$ & $3.7 E+00 \mid$ & $4.6 \mathrm{E}-03$ & $2.1 \mathrm{E}-02$ & $3.7 \mathrm{E}+00$ & $4.6 \mathrm{E}-03$ \\
\hline TOTAL & ४ & \% & 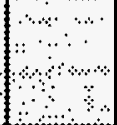 & अ & ४ & $1.7 \mathrm{E}-01$ & $3.4 \mathrm{E}-01$ & $1.6 \mathrm{E}-01$ & $5.0 \mathrm{E}+01$ & $8.8 \mathrm{E}-02$ & अे & अ.: & 1\%: & $3.3 \mathrm{E}-01$ & $5.1 \mathrm{E}+01$ & $8.8 \mathrm{E}-02$ \\
\hline
\end{tabular}

Assumptions:

- Transportation is to and from the site only

- Operational risks encompass industrial/physical hazards associated with equipment operation and onsite operations

- Infrastructure stalf support the staff above. They receive no annual Cancer, average 4.000 travel miles, and average $50 \%$ of the facility totals above.

- Collective risks have been calculated as the product of individual risk, multiplied by the number of exposed inidividuals.

Individual risks provide estimates of the probability of health detriment for the individual, and the collective risks provide a measure of overall detriment

to the work force. 
Option: M. Traditional Flushing Capital Cost: $\$ 92$ million Annual Worker Mileage: 15,000

\begin{tabular}{|c|c|c|c|c|c|c|c|c|c|c|}
\hline \multirow{4}{*}{$\begin{array}{c}\text { Activity } \\
.\end{array}$} & \multicolumn{10}{|c|}{$\begin{array}{l}\text { Management and } \\
\text { Enginecring }\end{array}$} \\
\hline & \multicolumn{5}{|c|}{ Annual } & \multicolumn{5}{|c|}{ Total } \\
\hline & \multicolumn{2}{|c|}{ Transportation } & \multicolumn{3}{|c|}{ Operational } & \multicolumn{2}{|c|}{ Transportation } & \multicolumn{3}{|c|}{ Opcrational } \\
\hline & Death & Injury & Death & Injury & Cancer & Death & Injury & Death & Injury & Cancer \\
\hline $\begin{array}{l}\text { Technology Readiness } \\
\text { (Duration - } 5 \text { years) }\end{array}$ & $7.6 \mathrm{E}-04$ & $1.6 \mathrm{E}-03$ & 3.7E-04 & 2.1E-01 & $0.0 \mathrm{E}+00$ & $3.8 \mathrm{E}-03$ & $7.8 \mathrm{E}-03$ & $1.9 \mathrm{E}-03$ & $1.0 \mathrm{E}+00$ & $0.0 \mathrm{E}+00$ \\
\hline $\begin{array}{c}\text { Capital } \\
\text { (Duration - } 5 \text { years) }\end{array}$ & $5.8 \mathrm{E}-03$ & 1.2E-02 & $2.8 \mathrm{E}-03$ & $1.6 \mathrm{E}+00$ & 2.1E-04 & 2.9E-02 & $5.9 \mathrm{E}-02$ & $1.4 \mathrm{E}-02$ & $7.9 \mathrm{E}+00$ & $1.1 \mathrm{E}-03$ \\
\hline $\begin{array}{c}\text { Operators \& } \\
\text { Maintenance } \\
\text { (Duration - } 15 \text { years) }\end{array}$ & $2.3 \mathrm{E}-03$ & $4.6 \mathrm{E}-03$ & 1.1E-03 & $6.1 \mathrm{E}-01$ & $1.9 \mathrm{E}-04$ & $3.4 \mathrm{E}-02$ & $6.9 \mathrm{E}-02$ & $1.6 \mathrm{E}-02$ & $9.2 \mathrm{E}+00$ & $2.9 \mathrm{E}-03$ \\
\hline $\begin{array}{c}\text { Decontamination } \& \\
\text { Decommissioning } \\
\text { (Duration - } 1 \text { year) }\end{array}$ & $1.6 \mathrm{E}-03$ & $3.4 \mathrm{E}-03$ & $8.0 \mathrm{E}-04$ & $4.5 \mathrm{E}-01$ & $1.4 \mathrm{E}-04$ & $1.6 \mathrm{E}-03$ & $3.4 \mathrm{E}-03$ & $8.0 \mathrm{E}-04$ & $4.5 \mathrm{E}-01$ & $1.4 \mathrm{E}-04$ \\
\hline TOTAL & "... & $\therefore$ & $\because \because$ & 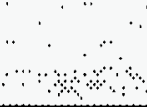 & \begin{tabular}{l}
$\cdots$ \\
\hdashline$\quad{ }^{\prime}$
\end{tabular} & $6.8 \mathrm{E}-02$ & $1.4 \mathrm{E}-01$ & $3.3 \mathrm{E}-02$ & $1.9 \mathrm{E}+01$ & $4.1 \mathrm{E}-03$ \\
\hline
\end{tabular}

Assumptions:

- Transportation is to and from the site only

- Operational risks encompass industrial/physical hazards associated with equipment operation and onsite operations

- Infrastructure staff support the staff above. They receive no annual Cancer, average 4,000 travel miles, and average $50 \%$ of the facility totals above.

- Collective risks have been calculated as the product of individual risk, multiplied by the number of cxposed inidividuals.

Individual risks provide estimates of the probability of health detriment lor the individual, and the collective risks provide a measure of overall detriment

to the work force. 
Option: M. Traditional Flushing

Capital Cost: $\$ 92$ million

Annual Worker Mileage: 15,000

\begin{tabular}{|c|c|c|c|c|c|c|c|c|c|c|}
\hline \multirow{4}{*}{ Activity } & \multicolumn{10}{|c|}{$\begin{array}{c}\text { Construction/Decommissioning } \\
\text { Crafts and Laborers }\end{array}$} \\
\hline & \multicolumn{5}{|c|}{ Annual } & \multicolumn{5}{|c|}{ Total } \\
\hline & \multicolumn{2}{|c|}{ Transportation } & \multicolumn{3}{|c|}{ Operational } & \multicolumn{2}{|c|}{ Transportation } & \multicolumn{3}{|c|}{ Operational } \\
\hline & Death & Injury & Death & Injury & Cancer & Death & Injury & Death & Injury & Cancer \\
\hline $\begin{array}{c}\text { Technology Readiness } \\
\text { (Duration - } 5 \text { years) }\end{array}$ & $2.5 \mathrm{E}-04$ & 5.IE-04 & $9.6 \mathrm{E}-04$ & $8.4 \mathrm{E}-02$ & $0.0 E+00$ & $1.2 \mathrm{E}-03$ & $2.5 \mathrm{E}-03$ & $4.8 \mathrm{E}-03$ & $4.2 \mathrm{E}-01$ & $0.0 \mathrm{E}+00$ \\
\hline $\begin{array}{c}\text { Capital } \\
\text { (Duration }-5 \text { years) }\end{array}$ & $3.9 \mathrm{E}-03$ & $7.9 \mathrm{E}-03$ & $1.5 \mathrm{E}-02$ & $1.3 \mathrm{E}+00$ & $1.9 \mathrm{E}-03$ & $1.9 \mathrm{E}-02$ & $3.9 \mathrm{E}-02$ & $7.5 \mathrm{E}-02$ & $6.5 \mathrm{E}+00$ & $9.4 \mathrm{E}-03$ \\
\hline $\begin{array}{c}\text { Operators \& } \\
\text { Maintenance } \\
\text { (Duration - } 15 \text { years) }\end{array}$ & $0.0 \mathrm{E}+00$ & $0.0 \mathrm{E}+00$ & $0.0 \mathrm{E}+00$ & $0.0 \mathrm{E}+00$ & $0.0 \mathrm{E}+00$ & $0.0 \mathrm{E}+00$ & $0.0 \mathrm{E}+00$ & $0.0 \mathrm{E}+00$ & $0.0 \mathrm{E}+00$ & $0.0 \mathrm{E}+00$ \\
\hline $\begin{array}{l}\text { Decontamination } \mathcal{E} \\
\text { Decommissioning } \\
\text { (Duration - } 1 \text { ycar) }\end{array}$ & $3.4 \mathrm{E}-03$ & $7.0 \mathrm{E}-03$ & $1.3 \mathrm{E}-02$ & $1.2 \mathrm{E}+00$ & $2.1 \mathrm{E}-03$ & $3.4 \mathrm{E}-03$ & $7.0 \mathrm{E}-03$ & $1.3 \mathrm{E}-02$ & $1.2 \mathrm{E}+00$ & $2.1 \mathrm{E}-03$ \\
\hline TOTAL & \begin{tabular}{lll}
$\cdots$ & $\vdots$ \\
\hdashline & $\vdots$ & $\vdots$ \\
\hdashline & $\vdots$
\end{tabular} & 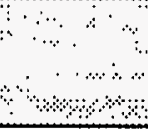 & \begin{tabular}{l}
$\cdots$ \\
$\because \cdots$ \\
\hdashline
\end{tabular} & 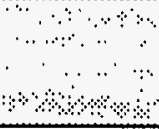 & 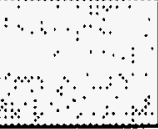 & 2.4E-02 & $4.9 \mathrm{E}-02$ & $9.3 \mathrm{E}-02$ & $8.1 E+00$ & $1.1 \mathrm{E}-02$ \\
\hline
\end{tabular}

Assumptions:

- Transportation is to and from the site only

- Operational risks encompass industrial/physical hazards associated with equipment operation and onsite operations

- Infrastructure staff support the staff above. They receive no annual Cancer, average 4,000 travel miles, and average $50 \%$ of the facility totals above.

- Collective risks have been calculated as the product of individual risk, multiplied by the number of exposed inidividuals.

Individual risks provide estimates of the probability of health detriment for the individual, and the collective risks provide a measure of overall detriment

to the work force. 
Option: M. Traditional Flushing

Capital Cost: $\$ 92$ million

Annual Worker Milcagc: 15,000

\begin{tabular}{|c|c|c|c|c|c|c|c|c|c|c|}
\hline \multirow{4}{*}{ Activity } & \multicolumn{10}{|c|}{ Maintenance Crafts } \\
\hline & \multicolumn{5}{|c|}{ Annual } & \multicolumn{5}{|c|}{ Total } \\
\hline & \multicolumn{2}{|c|}{ Transportation } & \multicolumn{3}{|c|}{ Operational } & \multicolumn{2}{|c|}{ Transportation } & \multicolumn{3}{|c|}{ Operational } \\
\hline & Death & \begin{tabular}{|l|} 
Injury \\
\end{tabular} & Death & \begin{tabular}{|l|} 
Injury \\
\end{tabular} & Cancer & Death & Injury & Death & Injury & Cancer \\
\hline $\begin{array}{l}\text { Technology Readiness } \\
\text { (Duration }-5 \text { years) }\end{array}$ & $0.0 \mathrm{E}+00$ & $0.0 \mathrm{E}+00$ & $0.0 \mathrm{E}+00$ & $0.0 \mathrm{E}+00$ & $0.0 \mathrm{E}+00$ & $0.0 \mathrm{E}+00$ & $0.0 \mathrm{E}+00$ & $0.0 \mathrm{E}+00$ & $0.0 \mathrm{E}+00$ & $0.0 \mathrm{E}+00$ \\
\hline $\begin{array}{c}\text { Capital } \\
\text { (Duration - } 5 \text { ycars) }\end{array}$ & $0.0 \mathrm{E}+00$ & $0.0 \mathrm{E}+00$ & $0.0 \mathrm{E}+00$ & $0.0 \mathrm{E}+00$ & $0.0 \mathrm{E}+00$ & $0.0 \mathrm{E}+00$ & $0.0 \mathrm{E}+00$ & $0.0 \mathrm{E}+00$ & $0.0 \mathrm{E}+00$ & $0.0 \mathrm{E}+00$ \\
\hline $\begin{array}{c}\text { Operators } \& \\
\text { Maintenance } \\
\text { (Duration - } 15 \text { years) } \\
\end{array}$ & $1.1 \mathrm{E}-03$ & 2.3E-03 & $4.9 \mathrm{E}-04$ & $1.2 \mathrm{E}-01$ & $6.8 \mathrm{E}-04$ & $1.7 \mathrm{E}-02$ & $3.5 \mathrm{E}-02$ & $7.4 \mathrm{E}-03$ & $1.8 \mathrm{E}+00$ & $1.0 \mathrm{E}-02$ \\
\hline $\begin{array}{l}\text { Decontamination \& } \\
\text { Decommissioning } \\
\text { (Duration - } 1 \text { year) }\end{array}$ & $0.0 \mathrm{E}+00$ & $0.0 \mathrm{E}+00$ & $0.0 \mathrm{E}+00$ & $0.0 \mathrm{E}+00$ & $0.0 \mathrm{E}+00$ & $0.0 \mathrm{E}+00$ & $0.0 \mathrm{E}+00$ & $0.0 \mathrm{E}+00$ & $0.0 \mathrm{E}+00$ & $0.0 \mathrm{E}+00$ \\
\hline TOTAL & $\begin{array}{rr}\because & \ldots \ldots \\
\because & \vdots\end{array}$ & 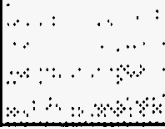 & $\begin{array}{c} \\
\cdots \\
\cdots \\
3\end{array}$ & 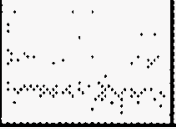 & $\begin{array}{l}\because \\
\therefore \cdots \\
\cdots\end{array}$ & $1.7 \mathrm{E}-02$ & $3.5 \mathrm{E}-02$ & $7.4 \mathrm{E}-03$ & $\begin{array}{c}1.8 \mathrm{E}+00 \\
.\end{array}$ & $1.0 \mathrm{E}-02$ \\
\hline
\end{tabular}

Assumptions:

- Transportation is to and from the site only

- Operational risks encompass industrial/physical hazards associated with equipment operation and onsite operations

- Infrastructure staff support the staff above. They receive no annual Cancer, average 4,000 travel miles, and average $50 \%$ of the facility totals above.

- Collective risks have been calculated as the product of individual risk, multiplied by the number of exposed inidividuals.

Individual risks provide estimates of the probability of health detriment for the individual, and the collective risks provide a measure of overall detriment

to the work force. 
Option: M. Traditional Flushing

Capital Cost: $\$ 92$ million

Annual Worker Mileage: 15,000

\begin{tabular}{|c|c|c|c|c|c|c|c|c|c|c|}
\hline \multirow{4}{*}{ Activity } & \multicolumn{10}{|c|}{ Operators } \\
\hline & \multicolumn{5}{|c|}{ Annual } & \multicolumn{5}{|c|}{ Total } \\
\hline & \multicolumn{2}{|c|}{ Transportation } & \multicolumn{3}{|c|}{ Operational } & \multicolumn{2}{|c|}{ Transportation } & \multicolumn{3}{|c|}{ Operational } \\
\hline & Death & Injury & Death & Injury & Cancer & Death & Injury & Death & Injury & Cancer \\
\hline $\begin{array}{l}\text { Technology Readiness } \\
\text { (Duration - } 5 \text { years) }\end{array}$ & $0.0 \mathrm{E}+00$ & $0.0 \mathrm{E}+00$ & $0.0 \mathrm{E}+00$ & $0.0 \mathrm{E}+00$ & $0.0 \mathrm{E}+00$ & $0.0 \mathrm{E}+00$ & $0.0 \mathrm{E}+00$ & $0.0 \mathrm{E}+00$ & $0.0 \mathrm{E}+00$ & $0.0 \mathrm{E}+00$ \\
\hline $\begin{array}{c}\text { Capital } \\
\text { (Duration }-5 \text { years) }\end{array}$ & $0.0 \mathrm{E}+00$ & $0.0 \mathrm{E}+00$ & $0.0 \mathrm{E}+00$ & $0.0 \mathrm{E}+00$ & $0.0 \mathrm{E}+00$ & $0.0 \mathrm{E}+00$ & $0.0 \mathrm{E}+00$ & $0.0 \mathrm{E}+00$ & $0.0 \mathrm{E}+00$ & $0.0 \mathrm{E}+00$ \\
\hline $\begin{array}{c}\text { Operators \& } \\
\text { Maintenance } \\
\text { (Duration - 15 years) }\end{array}$ & $2.3 \mathrm{E}-03$ & 4.6E-03 & $9.8 \mathrm{E}-04$ & $2.4 \mathrm{E}-01$ & $1.4 \mathrm{E}-03$ & $3.4 \mathrm{E}-02$ & $6.9 \mathrm{E}-02$ & $1.5 \mathrm{E}-02$ & $3.6 \mathrm{E}+00$ & 2.1E-02 \\
\hline $\begin{array}{c}\text { Decontamination \& } \\
\text { Decommissioning } \\
\text { (Duration - } 1 \text { year) }\end{array}$ & $5.2 \mathrm{E}-04$ & $1.1 \mathrm{E}-03$ & $2.3 \mathrm{E}-04$ & $5.5 \mathrm{E}-02$ & $3.1 E-04$ & $5.2 \mathrm{E}-04$ & 1.1E-03 & $2.3 \mathrm{E}-04$ & $5.5 \mathrm{E}-02$ & $3.1 \mathrm{E}-04$ \\
\hline TOTAL & मै। & 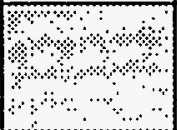 & 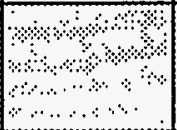 & \begin{tabular}{cc} 
\\
\hdashline
\end{tabular} & and & $3.4 \mathrm{E}-02$ & 7.0E-02 & $1.5 \mathrm{E}-02$ & $3.7 \mathrm{E}+00$ & 2.1E-02 \\
\hline
\end{tabular}

Assumptions:

- Transportation is to and from the site only

- Operational risks encompass industrial/ply'sical hazards associated with equipment operation and onsite operations

- Infrastructure staff support the staff above. They receive no annual Cancer, average 4,000 travel miles, and average $50 \%$ of the facility totals above.

- Collective risks have been calculated as the product of individual risk, multiplied by the number of exposed inidividuals.

Individual risks provide estimates of the probability of health detriment for the individual, and the collective risks provide a measure of overall detriment

to the work force. 
Option: M. Traditional Flushing

Capital Cost: $\$ 92$ million

Annual Worker Milcage: 15,000

\begin{tabular}{|c|c|c|c|c|c|c|c|c|c|c|c|c|c|c|c|c|}
\hline \multirow{4}{*}{ Activity } & \multicolumn{10}{|c|}{ All Workers } & \multicolumn{6}{|c|}{ All Workers } \\
\hline & \multicolumn{5}{|c|}{$\begin{array}{c}\text { Annual } \\
\end{array}$} & \multicolumn{5}{|c|}{ Total } & \multirow{2}{*}{\multicolumn{3}{|c|}{ Annuals }} & \multirow{2}{*}{\multicolumn{3}{|c|}{ Totals }} \\
\hline & \multicolumn{2}{|c|}{ Transportation } & \multicolumn{3}{|c|}{ Operational } & \multicolumn{2}{|c|}{ Transportation } & \multicolumn{3}{|c|}{ Opcrational } & & & & & & \\
\hline & Death & Injury & Death & Injury & Cancer & Death & Injury & Death & Injury & Cancer & Death & Injury & Cancer & Death & Injury & Cancer \\
\hline $\begin{array}{l}\text { Technology Readiness } \\
\text { (Duration - } 5 \text { years) }\end{array}$ & $1.0 \mathrm{E}-03$ & $2.1 \mathrm{E}-03$ & $1.3 \mathrm{E}-03$ & $29 \mathrm{E}-01$ & $0.0 \mathrm{E}+00$ & $5.0 \mathrm{E}-03$ & 1.0E-02 & $6.7 \mathrm{E}-03$ & $|5 E+00|$ & $0.0 \mathrm{E}+00$ & 2.3E-03 & $2.9 \mathrm{E}-01$ & $0.0 \mathrm{E}+00$ & $1.2 \mathrm{E}-02$ & $1.5 \mathrm{E}+00$ & $\begin{array}{c}0.0 \mathrm{E}+00 \\
-\end{array}$ \\
\hline $\begin{array}{c}\text { Capital } \\
\text { (Duration - } 5 \text { ycars) } \\
\end{array}$ & $9.6 \mathrm{E}-03$ & $2.0 \mathrm{E}-02$ & $1.8 \mathrm{E}-02$ & $2.9 \mathrm{E}+00$ & 2.1E-03 & $4.8 \mathrm{E}-02$ & $9.9 \mathrm{E}-02$ & $8.9 \mathrm{E}-02$ & $1.4 E+01$ & $1.0 \mathrm{E}-02$ & $2.7 \mathrm{E}-02$ & $2.9 E+00$ & $2.1 \mathrm{E}-03$ & $1.4 \mathrm{E}-01$ & $1.5 \mathrm{E}+01$ & $1.0 \mathrm{E}-02$ \\
\hline $\begin{array}{c}\text { Operators \& } \\
\text { Maintenance } \\
\text { (Duration - 15 years) }\end{array}$ & $5.6 \mathrm{E}-03$ & $1,2 \mathrm{E}-02$ & $2.6 \mathrm{E}-03$ & $9.7 \mathrm{E}-01$ & $2.2 \mathrm{E}-03$ & $8.4 \mathrm{E}-02$ & $1.7 \mathrm{E}-01$ & $3.9 \mathrm{E}-02$ & $1.5 E+01$ & 3.4E-02 & $8.2 \mathrm{E}-03$ & $9.8 \mathrm{E}-0 \mathrm{I}$ & 2.2E-03 & $1.2 \mathrm{E}-01$ & $1.5 \mathrm{E}+01$ & $3.4 \mathrm{E}-02$ \\
\hline $\begin{array}{c}\text { Decontamination \& } \\
\text { Decommissioning } \\
\text { (Duration - } 1 \text { year) }\end{array}$ & $5.6 \mathrm{E}-03$ & $1.1 E-02$ & $14 \mathrm{E}-02$ & $1.7 \mathrm{E}+00$ & $25 \mathrm{E}-03$ & $5.6 \mathrm{E}-03$ & 1.1E-02 & $14 \mathrm{E}-02$ & $1.7 E+00$ & 2 5E-03 & $2.0 \mathrm{E}-02$ & $1.7 E+00$ & 2.5E-03 & $2.0 \mathrm{E}-02$ & $1.7 \mathrm{E}+00$ & $2.5 \mathrm{E}-03$ \\
\hline TOTAL & $\begin{array}{l}\cdots \\
\therefore \therefore \\
\therefore \cdots \cdots\end{array}$ & 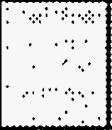 & & & 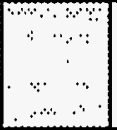 & $14 E-01$ & $29 \mathrm{E}-01$ & $1.5 \mathrm{E}-01$ & $32 \mathrm{E}+01$ & $47 \mathrm{E}-02$ & an & 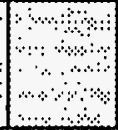 & की & $2.9 \mathrm{E}-01$ & $3.2 \mathrm{E}+01$ & $4.7 \mathrm{E}-02$ \\
\hline
\end{tabular}

\section{Assumptions:}

- Transportation is to and from the site only

- Operational risks encompass industrial/physical hazards associated with equipment operation and onsite operations

- Infrastructure staff support the staff above. They receive no annual Cancer, average 4,000 travel miles, and average $50 \%$ of the facility totals above.

- Collective risks have been calculated as the product of individual risk, multiplied by the number of exposed inidividuals.

Individual risks provide estimates of the probability of health detriment for the individual, and the collective risks provide a measure of overall detriment

to the work force. 
Option: N. Flush Water Treatment (for Close-Coupled Barrier)

Capital Cost: $\$ 8$ million

Annual Worker Mileage: 15,000

\begin{tabular}{|c|c|c|c|c|c|c|c|c|c|c|}
\hline \multirow{4}{*}{ Activity } & \multicolumn{10}{|c|}{$\begin{array}{l}\text { Management and } \\
\text { Enginecring }\end{array}$} \\
\hline & \multicolumn{5}{|c|}{ Annual } & \multicolumn{5}{|c|}{ Total } \\
\hline & \multicolumn{2}{|c|}{ Transportation } & \multicolumn{3}{|c|}{ Operational } & \multicolumn{2}{|c|}{ Transportation } & \multicolumn{3}{|c|}{ Operational } \\
\hline & Dcath & Injury & Death & \begin{tabular}{|l|} 
Injury \\
\end{tabular} & Cancer & Death & Injury & Death & Injury & Cancer \\
\hline $\begin{array}{l}\text { Technology Readiness } \\
\text { (Duration - } 5 \text { years) }\end{array}$ & 2.5E-04 & 5.1E-04 & $1.2 \mathrm{E}-04$ & $6.7 \mathrm{E}-02$ & $0.0 \mathrm{E}+00$ & $1.2 \mathrm{E}-03$ & $2.5 \mathrm{E}-03$ & $6.0 \mathrm{E}-04$ & $3.4 \mathrm{E}-01$ & $0.0 \mathrm{E}+00$ \\
\hline $\begin{array}{c}\text { Capital } \\
\text { (Duration - } 5 \text { years) }\end{array}$ & $4.9 \mathrm{E}-04$ & $1.0 \mathrm{E}-03$ & $2.4 \mathrm{E}-04$ & $1.3 \mathrm{E}-01$ & $1.8 \mathrm{E}-05$ & $2.5 \mathrm{E}-03$ & 5.1E-03 & $1.2 \mathrm{E}-03$ & $6.7 \mathrm{E}-01$ & $9.0 \mathrm{E}-05$ \\
\hline $\begin{array}{c}\text { Operators \& } \\
\text { Maintenance } \\
\text { (Duration - 15 years) }\end{array}$ & $4.2 E-04$ & $8.6 \mathrm{E}-04$ & $2.0 \mathrm{E}-04$ & $1.1 \mathrm{E}-01$ & $3.6 \mathrm{E}-05$ & $6.3 \mathrm{E}-03$ & $1.3 \mathrm{E}-02$ & $3.1 \mathrm{E}-03$ & $1.7 \mathrm{E}+00$ & $5.3 \mathrm{E}-04$ \\
\hline $\begin{array}{l}\text { Decontamination \& } \\
\text { Decommissioning } \\
\text { (Duration - } 1 \text { year) }\end{array}$ & 3.1E-04 & $6.3 \mathrm{E}-04$ & $1.5 \mathrm{E}-04$ & $8.4 \mathrm{E}-02$ & $2.6 \mathrm{E}-05$ & $6.2 \mathrm{E}-04$ & $1.3 \mathrm{E}-03$ & $3.0 \mathrm{E}-04$ & $1.7 \mathrm{E}-01$ & $5.3 \mathrm{E}-05$ \\
\hline TOTAL & 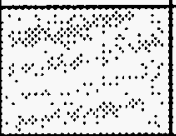 & 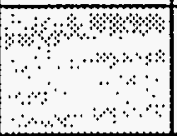 & 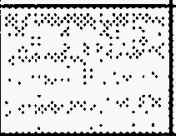 & 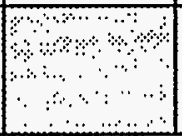 & 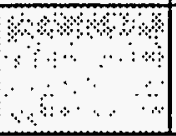 & $1.1 \mathrm{E}-02$ & $2.2 \mathrm{E}-02$ & $5.2 \mathrm{E}-03$ & $2.9 \mathrm{E}+00$ & $6.8 \mathrm{E}-04$ \\
\hline
\end{tabular}

Assumptions:

- Transportation is to and from the site only

- Operational risks encompass industrial/phy'sical hazards associaled with equipment operation and onsite operations

- Infrastructure staff support the staff above. They receive no annual Cancer, average 4,000 travel miles, and average $50 \%$ of the facility totals above.

- Collective risks have been calculated as the product of individual risk, multiplied by the number of exposed inidividuals.

Individual risks provide estimates of the probability of health detriment for the individual, and the collective risks provide a measure of overall detriment

to the work force. 
Option: N. Flush Water Treatment (for Close-Coupled Barrier) Capital Cost: $\$ 8$ million Annual Worker Mileage: 15,000

\begin{tabular}{|c|c|c|c|c|c|c|c|c|c|c|}
\hline \multirow{4}{*}{ Activity } & \multicolumn{10}{|c|}{$\begin{array}{l}\text { Construction/Decommissioning } \\
\text { Crafts and Laborers }\end{array}$} \\
\hline & \multicolumn{5}{|c|}{ Annual } & \multicolumn{5}{|c|}{ Total } \\
\hline & \multicolumn{2}{|c|}{ Transportation } & \multicolumn{3}{|c|}{ Operational } & \multicolumn{2}{|c|}{ Transportation } & \multicolumn{3}{|c|}{ Opcrational } \\
\hline & Death & Injury & Death & Injury & Cancer & Death & Injury & Death & Injury & Cancer \\
\hline $\begin{array}{l}\text { Technology Readiness } \\
\text { (Duration - } 5 \text { years) }\end{array}$ & 8.2E-05 & $1.7 \mathrm{E}-04$ & $2.8 \mathrm{E}-0.4$ & $6.4 E-02$ & $0.0 \mathrm{E}+00$ & 4.1E-04 & $8.4 \mathrm{E}-04$ & $1.4 \mathrm{E}-03$ & $3.2 \mathrm{E}-01$ & $0.0 \mathrm{E}+00$ \\
\hline $\begin{array}{c}\text { Capital } \\
\text { (Duration - } 5 \text { years) }\end{array}$ & $3.3 \mathrm{E}-04$ & $6.7 E-04$ & 1.1E-03 & $2.6 \mathrm{E}-01$ & $4.0 \mathrm{E}-05$ & $1.6 \mathrm{E}-03$ & $3.4 \mathrm{E}-03$ & $5.6 \mathrm{E}-03$ & $-1.3 \mathrm{E}+00$ & $2.0 \mathrm{E}-04$ \\
\hline $\begin{array}{c}\text { Operators \& } \\
\text { Maintenance } \\
\text { (Duration - } 15 \text { years) }\end{array}$ & $0.0 \mathrm{E}+00$ & $0.0 \mathrm{E}+00$ & $0.0 \mathrm{E}+00$ & $0.0 \mathrm{E}+00$ & $0.0 \mathrm{E}+00$ & $0.0 \mathrm{E}+00$ & $0.0 \mathrm{E}+00$ & $0.0 \mathrm{E}+00$ & $0.0 \mathrm{E}+00$ & $0.0 \mathrm{E}+00$ \\
\hline $\begin{array}{c}\text { Decontamination \& } \\
\text { Decommissioning } \\
\text { (Duration - } 1 \text { year) }\end{array}$ & $6.2 E-04$ & 1.3E-03 & 2.1E-03 & $4.8 \mathrm{E}-01$ & $6.0 \mathrm{E}-04$ & $1.2 \mathrm{E}-03$ & $2.5 \mathrm{E}-03$ & $4.2 \mathrm{E}-03$ & $9.6 \mathrm{E}-01$ & $1.2 \mathrm{E}-03$ \\
\hline roril. & $\cdot: ; \cdots: \cdot$ & $\cdots \quad \therefore \quad \therefore$ & & : & .. & $3.31:-0.3$ & $6.71 \vdots-03$ & 1.11:-02 & $2.6 \mathrm{E}+00$ & $1.41:-03$ \\
\hline
\end{tabular}

Assumptions:

- Transportation is to and from the site only

- Operational risks encompass industrial/physical hazards associated with equipment operation and onsite operations

- Infrastructure staff support the staff above. They receive no annual Cancer, average 4,000 travel miles, and average $50 \%$ of the facility totals above.

- Collective risks have been calculated as the product of individual risk. multiplied by the number of exposed inidividuals.

Individual risks provide estimates of the probability of health detriment for the individual, and the collective ristis provide a measure of overall detriment to the work force. 
Table D.3. Options Worker Risks (Sheet 68 of 105)

Option: N. Flush Water Treatment (for Close-Coupled Barrier)

Capital Cost: $\$ 8$ million

Annual Worker Mileage: 15,000

\begin{tabular}{|c|c|c|c|c|c|c|c|c|c|c|}
\hline \multirow{4}{*}{ Activity } & \multicolumn{10}{|c|}{ Maintenance Crafts } \\
\hline & \multicolumn{5}{|c|}{ Annual } & \multicolumn{5}{|c|}{ Total } \\
\hline & \multicolumn{2}{|c|}{ Transportation } & \multicolumn{3}{|c|}{ Operational } & \multicolumn{2}{|c|}{ Transportation } & \multicolumn{3}{|c|}{ Operational } \\
\hline & Death & Injury & Death & \begin{tabular}{|l|} 
Injury \\
\end{tabular} & Cancer & Death & Injury & Death & Injury & Cancer \\
\hline $\begin{array}{l}\text { Technology Readiness } \\
\text { (Duration - } 5 \text { years) }\end{array}$ & $0.0 \mathrm{E}+00$ & $0.0 \mathrm{E}+00$ & $0.0 \mathrm{E}+00$ & $0.0 \mathrm{E}+00$ & $0.0 \mathrm{E}+00$ & $0.0 \mathrm{E}+00$ & $0.0 \mathrm{E}+00$ & $0.0 \mathrm{E}+00$ & $0.0 \mathrm{E}+00$ & $0.0 \mathrm{E}+00$ \\
\hline $\begin{array}{c}\text { Capital } \\
\text { (Duration - } 5 \text { years) }\end{array}$ & $0.0 \mathrm{E}+00$ & $0.0 \mathrm{E}+00$ & $0.0 \mathrm{E}+00$ & $0.0 \mathrm{E}+00$ & $0.0 \mathrm{E}+00$ & $0.0 \mathrm{E}+00$ & $0.0 \mathrm{E}+00$ & $0.0 \mathrm{E}+00$ & $0.0 \mathrm{E}+00$ & $0.0 \mathrm{E}+00$ \\
\hline $\begin{array}{c}\text { Operators \& } \\
\text { Maintenance } \\
\text { (Duration - } 15 \text { years) }\end{array}$ & 2.1E-04 & $4.4 \mathrm{E}-04$ & $9.3 \mathrm{E}-05$ & $2.3 \mathrm{E}-02$ & 2.1E-04 & $3.2 \mathrm{E}-03$ & $6.5 \mathrm{E}-03$ & $1.4 \mathrm{E}-03$ & $3.4 \mathrm{E}-01$ & $3.1 \mathrm{E}-03$ \\
\hline $\begin{array}{c}\text { Decontamination \& } \\
\text { Decommissioning } \\
\text { (Duration - } 1 \text { year) }\end{array}$ & $0.0 \mathrm{E}+00$ & $0.0 \mathrm{E}+00$ & $0.0 \mathrm{E}+00$ & $0.0 \mathrm{E}+00$ & $0.0 \mathrm{E}+00$ & $0.0 \mathrm{E}+00$ & $0.0 \mathrm{E}+00$ & $0.0 \mathrm{E}+00$ & $0.0 \mathrm{E}+00$ & $0.0 \mathrm{E}+00$ \\
\hline TOTAL & मैফ & मै। & की & an & कि & $3.2 \mathrm{E}-03$ & $6.5 \mathrm{E}-03$ & $1.4 \mathrm{E}-03$ & $3.4 \mathrm{E}-01$ & 3.1E-03 \\
\hline
\end{tabular}

Assumptions:

- Transportation is to and from the site only

- Operational risks encompass industrial/physical hazards associated with equipment operation and onsite operations

- Infrastructure staff support the staff above. They receive no annual Cancer, average 4.000 travel miles, and average $50 \%$ of the facility totals above.

- Collective risks have been calculated as the product of individual risk, multiplied by the number of exposed inidividuals.

Individual risks provide estimates of the probability of health detriment for the individual, and the collective risks provide a measure of overall detriment

to the work force. 
Option: N. Flush Water Treatment (for Close-Coupled Barrier)

Capital Cost: $\$ 8$ million

Annual Worker Milcage: 15,000

\begin{tabular}{|c|c|c|c|c|c|c|c|c|c|c|}
\hline \multirow{4}{*}{ Activity } & \multicolumn{10}{|c|}{ Operators } \\
\hline & \multicolumn{5}{|c|}{ Annual } & \multicolumn{5}{|c|}{ Total } \\
\hline & \multicolumn{2}{|c|}{ Transportation } & \multicolumn{3}{|c|}{ Operational } & \multicolumn{2}{|c|}{ Transportation } & \multicolumn{3}{|c|}{ Operational } \\
\hline & Death & Injury & Death & Injury & Cancer & Death & Injury & Death & Injury & Cancer \\
\hline $\begin{array}{l}\text { Technology Readiness } \\
\text { (Duration - } 5 \text { years) }\end{array}$ & $0.0 \mathrm{E}+00$ & $0.0 \mathrm{E}+00$ & $0.0 \mathrm{E}+00$ & $0.0 \mathrm{E}+00$ & $0.0 \mathrm{E}+00$ & $0.0 \mathrm{E}+00$ & $0.0 \mathrm{E}+00$ & $0.0 \mathrm{E}+00$ & $0.0 \mathrm{E}+00$ & $0.0 \mathrm{E}+00$ \\
\hline $\begin{array}{c}\text { Capital } \\
\text { (Duration }-5 \text { years) }\end{array}$ & $0.0 \mathrm{E}+00$ & $0.0 \mathrm{E}+00$ & $0.0 \mathrm{E}+00$ & $0.0 \mathrm{E}+00$ & $0.0 \mathrm{E}+00$ & $0.0 \mathrm{E}+00$ & $0.0 \mathrm{E}+00$ & $0.0 \mathrm{E}+00$ & $0.0 \mathrm{E}+00$ & $0.0 \mathrm{E}+00$ \\
\hline $\begin{array}{c}\text { Operators \& } \\
\text { Maintenance } \\
\text { (Duration - } 15 \text { years) }\end{array}$ & $4.2 \mathrm{E}-04$ & 8.6E-04 & $1.8 \mathrm{E}-04$ & 4.5E-02 & 4.1E-04 & $6.3 \mathrm{E}-03$ & $1.3 \mathrm{E}-02$ & 2.7E-03 & $6.7 \mathrm{E}-01$ & 6.1E-03 \\
\hline $\begin{array}{l}\text { Decontamination \& } \\
\text { Decommissioning } \\
\text { (Duration - } 1 \text { year) }\end{array}$ & $1.0 \mathrm{E}-04$ & 2.1E-04 & $4.5 \mathrm{E}-05$ & 1.1E-02 & $1.0 \mathrm{E}-04$ & 2.1E-04 & $4.2 \mathrm{E}-04$ & $9.0 \mathrm{E}-05$ & $2.2 \mathrm{E}-02$ & $2.0 \mathrm{E}-04$ \\
\hline TOTAL & अिक्ष & a & मिब & 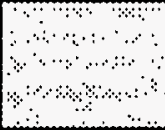 & as & $6.5 \mathrm{E}-03$ & $1.3 \mathrm{E}-02$ & $2.8 \mathrm{E}-03$ & $6.9 \mathrm{E}-01$ & $6.3 \mathrm{E}-03$ \\
\hline
\end{tabular}

\section{Assumptions:}

- Transportation is to and from the site only

- Operational risks encompass industrial/physical hazards associated with equipment operation and onsite operations

- Infrastructure staff support the staff above. They receive no annual Cancer, average 4,000 travel miles, and average $50 \%$ of the facility totals above.

- Collective risks have been calculated as the product of individual risk, multiplied by the number of exposed inidividuals.

Individual risks provide estimates of the probability of health detriment for the individual, and the collective risks provide a measure of overall detriment to the work force. 


\begin{tabular}{|c|c|c|c|c|c|c|c|c|c|c|c|c|c|c|c|c|}
\hline $\begin{array}{r}\text { Option: } \\
\text { Capital Cost: } \\
\text { Annual Worker Mileage: }\end{array}$ & $\begin{array}{l}\text { N. Flush } \\
\$ 8 \text { millio } \\
15,000\end{array}$ & $\begin{array}{l}\text { Water } \mathrm{T}, \\
\text { on }\end{array}$ & reatment ( & (for Close & e-Coupled & d Barrier) & & & & & & & & & & \\
\hline \multirow{4}{*}{ Activity } & \multicolumn{10}{|c|}{ All Workers } & \multicolumn{6}{|c|}{ All Workers } \\
\hline & \multicolumn{5}{|c|}{ Annual } & \multicolumn{5}{|c|}{ Total } & \multirow{2}{*}{\multicolumn{3}{|c|}{ Annuals }} & \multirow{2}{*}{\multicolumn{3}{|c|}{ Totals }} \\
\hline & \multicolumn{2}{|c|}{ Transportation } & \multicolumn{3}{|c|}{ Operational } & \multicolumn{2}{|c|}{ Transportation } & \multicolumn{3}{|c|}{ Operational } & & & & & & \\
\hline & Death & Injury & \begin{tabular}{|l|l|} 
Death \\
\end{tabular} & Injury & Cancer & \begin{tabular}{|l|} 
Death \\
\end{tabular} & \begin{tabular}{|l|} 
Injury \\
\end{tabular} & \begin{tabular}{|l|} 
Death \\
\end{tabular} & \begin{tabular}{|l|} 
Injury \\
\end{tabular} & Cancer & Death & Injury & \begin{tabular}{|l|} 
Cancer \\
\end{tabular} & \begin{tabular}{|l|} 
Death \\
\end{tabular} & \begin{tabular}{|l|l|} 
Injury \\
\end{tabular} & Cancer \\
\hline $\begin{array}{l}\text { Technology Readiness } \\
\text { (Duration - } 5 \text { years) }\end{array}$ & 3.3E-04 & $6.7 \mathrm{E}-04$ & $4.0 \mathrm{E}-04$ & $13 \mathrm{E}-01$ & $00 \mathrm{E}+00 \mid$ & $16 \mathrm{E}-03$ & $3.4 E-03$ & $20 \mathrm{E}-03$ & $6.6 \mathrm{E}-01$ & $00 E+00$ & 7.3E-04 & $1.3 \mathrm{E}-01$ & $0.0 \mathrm{E}+00$ & $3.6 \mathrm{E}-03$ & $6.6 \mathrm{E}-01$ & $0.0 \mathrm{E}+00$ \\
\hline $\begin{array}{c}\text { Capital } \\
\text { (Duration - } 5 \text { years) }\end{array}$ & $82 \mathrm{E}-0.4$ & $17 E-03$ & $14 \mathrm{E}-03$ & $39 \mathrm{E}-01$ & $58 \mathrm{E}-05$ & $41 \mathrm{E}-03$ & $84 E-03$ & $68 \mathrm{E}-03$ & $|20 E+00|$ & $2.9 \mathrm{E}-04$ & $2.2 \mathrm{E}-03$ & $39 \mathrm{E}-01$ & | $5.8 \mathrm{E}-05$ & $1.1 \mathrm{E}-02$ & $2.0 \mathrm{E}+00$ & $2.9 \mathrm{E}-04$ \\
\hline $\begin{array}{c}\text { Operators \& } \\
\text { Mlaintenance } \\
\text { (Duration - } 15 \text { years) }\end{array}$ & $|1| E-03$ & $22 \mathrm{E}-03$ & $48 E-04$ & $1.8 \mathrm{E}-01$ & $65 \mathrm{E}-04$ & $16 \mathrm{E}-02$ & $32 \mathrm{E}-02$ & $72 \mathrm{E}-03$ & $27 E+00 \mid$ & $97 \mathrm{E}-03$ & $1.5 \mathrm{E}-03$ & $18 \mathrm{E}-01$ & $6.5 \mathrm{E}-04$ & $2.3 \mathrm{E}-02$ & $2.8 \mathrm{E}+00$ & $9.7 \mathrm{E}-03$ \\
\hline $\begin{array}{c}\text { Decontamination \& } \\
\text { Decommissioning } \\
\text { (Duration - } 1 \text { year) }\end{array}$ & $1.0 E-03$ & $2.1 \mathrm{E}-03$ & $2.3 \mathrm{E}-03$ & $5.8 \mathrm{E}-01$ & $7.3 \mathrm{E}-04$ & $21 \mathrm{E}-03$ & $4.2 \mathrm{E}-03$ & $46 \mathrm{E}-03$ & $\mid 1.2 \mathrm{E}+00$ & $1.5 \mathrm{E}-03$ & $3.3 \mathrm{E}-03$ & $5.8 \mathrm{E}-01$ & $\mid 7.3 \mathrm{E}-04$ & $6.7 \mathrm{E}-03$ & $1.2 \mathrm{E}+00$ & $1.5 \mathrm{E}-03$ \\
\hline TOTAL & अ? & अे। & 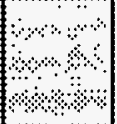 & मे. & अे & $2.4 \mathrm{E}-02$ & $4.8 \mathrm{E}-02$ & $21 E-02$ & $6.5 \mathrm{E}+00 \mid$ & $1.1 \mathrm{E} \cdot 02$ & $1 \%$ & \%ै? & भै०े: & $4.4 \mathrm{E}-02$ & $6.5 \mathrm{E}+00$ & $1.1 \mathrm{E}-02$ \\
\hline
\end{tabular}

Assumptions:

- Transportation is to and from the site only

- Operational risks encompass industrial/physical hazards associated with equipment operation and onsite operations

- Infrastructure stafl support the stalf above. They receive no ammual Cancer, average 4.000 travel miles, and average $50 \%$ of the facility totals above.

- Collective risks have been calculated as the product of individual risk, multiplied by the number of exposed inidividuals.

Individual risks provide estimates of the probability of health detriment for the individual, and the collective risks provide a measure of overall detriment

to the work force. 
Option: O. Flush Water Treatment (for Box Barrier) Capital Cost: $\$ 44$ million

Annual Worker Mileage: 15,000

\begin{tabular}{|c|c|c|c|c|c|c|c|c|c|c|}
\hline \multirow{4}{*}{ Activity } & \multicolumn{10}{|c|}{$\begin{array}{l}\text { Management and } \\
\text { Engincering }\end{array}$} \\
\hline & \multicolumn{5}{|c|}{ Annual } & \multicolumn{5}{|c|}{ Total } \\
\hline & \multicolumn{2}{|c|}{ Transportation } & \multicolumn{3}{|c|}{ Opcrational } & \multicolumn{2}{|c|}{ Transportation } & \multicolumn{3}{|c|}{ Operational } \\
\hline & Dcath & Injury & Death & Injury & Cancer & Death & Injury & Death & Injury & Cancer \\
\hline $\begin{array}{l}\text { Technology Readiness } \\
\text { (Duration - } 5 \text { years) }\end{array}$ & $2.5 \mathrm{E}-04$ & $5.1 E-04$ & $1.2 \mathrm{E}-04$ & $6.7 \mathrm{E}-02$ & $0.0 \mathrm{E}+00$ & $1.2 \mathrm{E}-03$ & $2.5 \mathrm{E}-03$ & $6.0 \mathrm{E}-04$ & $3.4 \mathrm{E}-01$ & $0.0 \mathrm{E}+00$ \\
\hline $\begin{array}{c}\text { Capital } \\
\text { (Duration - } 5 \text { years) }\end{array}$ & 2.8E-03 & $5.7 \mathrm{E}-03$ & $1.3 \mathrm{E}-03$ & $7.5 E-01$ & $1.0 \mathrm{E}-04$ & $1.4 \mathrm{E}-02$ & $2.8 \mathrm{E}-02$ & $6.7 \mathrm{E}-03$ & $3.8 \mathrm{E}+00$ & $5.0 \mathrm{E}-04$ \\
\hline $\begin{array}{c}\text { Operators \& } \\
\text { Maintenance } \\
\text { (Duration - } 15 \text { years) }\end{array}$ & 2.2E-03 & $4.5 \mathrm{E}-03$ & 1.1E-03 & $6.0 \mathrm{E}-01$ & $1.9 \mathrm{E}-04$ & $3.3 \mathrm{E}-02$ & $6.8 \mathrm{E}-02$ & $1.6 \mathrm{E}-02$ & $9.0 \mathrm{E}+00$ & $2.8 \mathrm{E}-03$ \\
\hline $\begin{array}{c}\text { Decontamination \& } \\
\text { Decommissioning } \\
\text { (Duration - } 1 \text { ycar) }\end{array}$ & $1.7 \mathrm{E}-03$ & $3.5 \mathrm{E}-03$ & 8.3E-04 & $4.6 \mathrm{E}-01$ & $1.4 \mathrm{E}-04$ & $3.4 \mathrm{E}-03$ & $7.0 \mathrm{E}-03$ & $1.7 \mathrm{E}-03$ & $9.2 \mathrm{E}-01$ & $2.9 \mathrm{E}-04$ \\
\hline TOTAL & $\begin{array}{l}\cdots \\
\cdots \\
\cdots\end{array}$ & $\begin{array}{c}\because \ldots+\cdots \\
\therefore \cdots \cdots \\
\cdots \quad \therefore\end{array}$ & . & $\because \because \cdots$ & $\because \because \therefore \quad \therefore \quad:$ & $5.2 \mathrm{E}-02$ & $1.1 \mathrm{E}-01$ & $2.5 \mathrm{E}-02$ & $1.4 \mathrm{E}+01$ & $3.6 \mathrm{E}-03$ \\
\hline
\end{tabular}

\section{Assumptions:}

- Transportation is to and from the site only

- Operational risks encompass industrial/phỵsical hazards associated with equipment operation and onsite operations

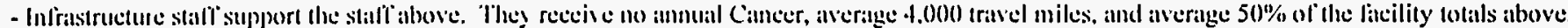

- Collective risks have been calculated as the product of individual risk, multiplied by the number of exposed inidividuals.

Individual risks provide estimates of the probability of health detriment for the individual, and the collective risks provide a measure of overall detriment to the work force. 
Table D.3. Options Worker Risks (Sheet 72 of 105)

Option: O. Flush Water Treatment (for Box Barrier)

Capital Cost: $\$ 44$ million

Annual Worker Mileage: 15,000

\begin{tabular}{|c|c|c|c|c|c|c|c|c|c|}
\hline \multirow{2}{*}{ Activity } & \multicolumn{9}{|c|}{ Annual } \\
& \multicolumn{2}{|c|}{ Construction/Decommissioning } \\
Crafts and Laborers
\end{tabular}

Assumptions:

- Transportation is to and from the site only

- Operational risks encompiss industrial/physical hazards associated with equipment operation and onsite operations

- Infrastructure staff support the stafl above. They receive no annual Cancer, average 4,000 travel miles, and average $50 \%$ of the facility totals above.

- Collective risks have been calculated as the product of individual risk, multiplied by the number of exposed inidividuals.

Individual risks provide estimates of the probability of health detriment for the individual, and the collective risks provide a measure of overall detriment

to the work force. 
Option: O. Flush Water Treatment (for Box Barrier)

Capital Cost: $\$ 44$ million

Annual Worker Mileage: 15,000

\begin{tabular}{|c|c|c|c|c|c|c|c|c|c|c|}
\hline \multirow{4}{*}{ Activity } & \multicolumn{10}{|c|}{ Maintenance Crafts } \\
\hline & \multicolumn{5}{|c|}{ Annual } & \multicolumn{5}{|c|}{ Total } \\
\hline & \multicolumn{2}{|c|}{ Transportation } & \multicolumn{3}{|c|}{ Operational } & \multicolumn{2}{|c|}{ Transportation } & \multicolumn{3}{|c|}{ Operational } \\
\hline & Death & Injury & Death & Injury & Cancer & Death & Injury & Death & Injury & Cancer \\
\hline $\begin{array}{l}\text { Technology' Readiness } \\
\text { (Duration - } 5 \text { years) }\end{array}$ & $0.0 \mathrm{E}+00$ & $0.0 \mathrm{E}+00$ & $0.0 \mathrm{E}+00$ & $0.0 \mathrm{E}+00$ & $0.0 \mathrm{E}+00$ & $0.0 \mathrm{E}+00$ & $0.0 \mathrm{E}+00$ & $0.0 \mathrm{E}+00$ & $0.0 \mathrm{E}+00$ & $0.0 \mathrm{E}+00$ \\
\hline $\begin{array}{c}\text { Capital } \\
\text { (Duration - } 5 \text { years) }\end{array}$ & $0.0 \mathrm{E}+00$ & $0.0 \mathrm{E}+00$ & $0.0 \mathrm{E}+00$ & $0.0 \mathrm{E}+00$ & $0.0 \mathrm{E}+00$ & $0.0 \mathrm{E}+00$ & $0.0 \mathrm{E}+00$ & $0.0 \mathrm{E}+00$ & $0.0 \mathrm{E}+00$ & $0.0 \mathrm{E}+00$ \\
\hline $\begin{array}{c}\text { Operators \& } \\
\text { Maintenance } \\
\text { (Duration - } 15 \text { years) }\end{array}$ & 1.1E-03 & 2.3E-03 & $5.0 \mathrm{E}-04$ & $1.2 \mathrm{E}-01$ & 8.3E-04 & 1.7E-02 & $3.5 \mathrm{E}-02$ & $7.5 \mathrm{E}-03$ & $1.8 \mathrm{E}+00$ & $1.2 \mathrm{E}-02$ \\
\hline $\begin{array}{l}\text { Decontamination \& } \\
\text { Decommissioning } \\
\text { (Duration - } 1 \text { year) }\end{array}$ & $0.0 \mathrm{E}+00$ & $0.0 \mathrm{E}+00$ & $0.0 \mathrm{E}+00$ & $0.0 \mathrm{E}+00$ & $0.0 \mathrm{E}+00$ & $0.0 \mathrm{E}+00$ & $0.0 \mathrm{E}+00$ & $0.0 \mathrm{E}+00$ & $0.0 \mathrm{E}+00$ & $0.0 \mathrm{E}+00$ \\
\hline TOTAL & में & म. & मैं & 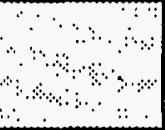 & 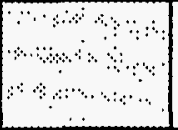 & $1.7 \mathrm{E}-02$ & $3.5 \mathrm{E}-02$ & $7.5 \mathrm{E}-03$ & $1.8 \mathrm{E}+00$ & $1.2 \mathrm{E}-02$ \\
\hline
\end{tabular}

Assumptions:

- Transportation is to and from the site only

- Operational risks encompass industrial/physical hazards associated with equipment operation and onsite operations

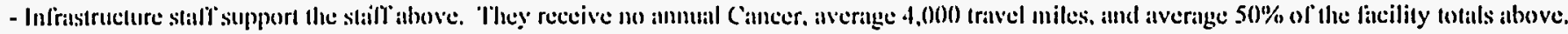

- Collective risks have been calculated as the product of individual risk, multiplied by the number of exposed inidividuals.

Individual risks provide estimates of the probability of health detriment for the individual, and the collective risks provide a measure of overall detriment

to the work force. 
Option: O. Flush Water Treatment (for Box Barrier)

Capital Cost: $\$ 44$ million

Annual Worker Mileage: 15,000

\begin{tabular}{|c|c|c|c|c|c|c|c|c|c|c|}
\hline \multirow{4}{*}{ Activity } & \multicolumn{10}{|c|}{ Operators } \\
\hline & \multicolumn{5}{|c|}{ Annual } & \multicolumn{5}{|c|}{ Total } \\
\hline & \multicolumn{2}{|c|}{ Transportation } & \multicolumn{3}{|c|}{ Operational } & \multicolumn{2}{|c|}{ Transportation } & \multicolumn{3}{|c|}{ Operational } \\
\hline & Death & Injury & Death & Injury & Cancer & Death & Injury & Death & Injury & Cancer \\
\hline $\begin{array}{l}\text { Technology Readiness } \\
\text { (Duration - } 5 \text { years) }\end{array}$ & $0.0 \mathrm{E}+00$ & $0.0 \mathrm{E}+00$ & $0.0 \mathrm{E}+00$ & $0.0 \mathrm{E}+00$ & $0.0 \mathrm{E}+00$ & $0.0 \mathrm{E}+00$ & $0.0 \mathrm{E}+00$ & $0.0 \mathrm{E}+00$ & $0.0 \mathrm{E}+00$ & $0.0 \mathrm{E}+00$ \\
\hline $\begin{array}{c}\text { Capital } \\
\text { (Duration - } 5 \text { years) }\end{array}$ & $0.0 \mathrm{E}+00$ & $0.0 E+00$ & $0.0 \mathrm{E}+00$ & $0.0 \mathrm{E}+00$ & $0.0 \mathrm{E}+00$ & $0.0 \mathrm{E}+00$ & $0.0 \mathrm{E}+00$ & $0.0 \mathrm{E}+00$ & $0.0 \mathrm{E}+00$ & $0.0 \mathrm{E}+00$ \\
\hline $\begin{array}{c}\text { Operators \& } \\
\text { Maintenance } \\
\text { (Duration - } 15 \text { years) }\end{array}$ & $2.2 \mathrm{E}-03$ & $4.5 \mathrm{E}-03$ & $9.7 \mathrm{E}-04$ & $2.4 \mathrm{E}-01$ & $1.6 \mathrm{E}-03$ & $3.3 \mathrm{E}-02$ & $6.8 \mathrm{E}-02$ & $1.4 \mathrm{E}-02$ & $3.5 \mathrm{E}+00$ & $2.4 \mathrm{E}-02$ \\
\hline $\begin{array}{l}\text { Decontamination \& } \\
\text { Decommissioning } \\
\text { (Duration - } 1 \text { year) }\end{array}$ & $5.7 \mathrm{E}-04$ & $1.2 \mathrm{E}-03$ & $2.5 E-04$ & $6.1 E-02$ & $4.1 E-04$ & $1.1 \mathrm{E}-03$ & $2.3 \mathrm{E}-03$ & $5.0 \mathrm{E}-04$ & $1.2 \mathrm{E}-01$ & 8.3E-04 \\
\hline TOTAL & ২০ & ঋै। & ২৷ & $\begin{array}{l}\cdots \\
\because \quad \cdots\end{array}$ & अ. & $3.4 \mathrm{E}-02$ & $7.0 \mathrm{E}-02$ & $1.5 \mathrm{E}-02$ & $3.7 E+00$ & $2.5 \mathrm{E}-02$ \\
\hline
\end{tabular}

Assumptions:

- Transportation is to and from the site only

- Operational risks encompass industrial/physical hazards associated with equipment operation and onsite operations

- Infrastructure staff support the staff above. They receive no annual Cancer, average 4,000 travel miles, and average $50 \%$ of the facility totals above.

- Collective risks have been calculated as the product of individual risk, multiplied by' the number of exposed inidividuals.

Individual risks provide estimates of the probability of health detriment for the individual, and the collective risks provide a measure of overall detriment

to the work force. 


\begin{tabular}{|c|c|c|c|c|c|c|c|c|c|c|c|c|c|c|c|c|}
\hline $\begin{array}{r}\text { Option } \\
\text { Capital Cost } \\
\text { Annual Worker Mileage }\end{array}$ & $\begin{array}{l}\text { O. Flush } \\
\$ 44 \text { mill } \\
15,000\end{array}$ & $\begin{array}{l}\text { Water Tr } \\
\text { ion }\end{array}$ & reatment & (for Box 1 & Barrier) & & & & & & & & & & & \\
\hline \multirow{4}{*}{ Activity } & \multicolumn{10}{|c|}{ All Workers } & \multicolumn{6}{|c|}{ All Workers } \\
\hline & \multicolumn{5}{|c|}{ Annual } & \multicolumn{5}{|c|}{ Total } & \multirow{2}{*}{\multicolumn{3}{|c|}{ Annuals }} & \multirow{2}{*}{\multicolumn{3}{|c|}{ Totals }} \\
\hline & \multicolumn{2}{|c|}{ Transportation } & \multicolumn{3}{|c|}{ Operational } & \multirow{2}{*}{\multicolumn{2}{|c|}{\begin{tabular}{|l|} 
Transportation \\
\end{tabular}}} & \multicolumn{3}{|c|}{ Operational } & & & & & & \\
\hline & Death & Injury & Death & Injury & Cancer & Death & & Death & Injury & Cancer & \begin{tabular}{|l} 
Death \\
\end{tabular} & Injury & Cancer & \begin{tabular}{|l|} 
Death \\
\end{tabular} & Injury & Cancer \\
\hline $\begin{array}{l}\text { Technology Readiness } \\
\text { (Duration - } 5 \text { years) }\end{array}$ & $3.3 \mathrm{E} \cdot 04$ & $6.7 \mathrm{E}-04$ & $4.0 \mathrm{E}-04$ & $1.3 \mathrm{E}-01$ & $0.0 \mathrm{E}+00$ & $1.6 \mathrm{E}-03$ & $3.4 \mathrm{E}-03$ & $20 \mathrm{E}-03$ & $6.6 \mathrm{E}-01$ & $0.0 \mathrm{E}+00$ & $7.3 \mathrm{E}-04$ & $1.3 \mathrm{E}-01$ & $0.0 E+00$ & $3.6 \mathrm{E}-03$ & $6.6 \mathrm{E}-01$ & $0.0 \mathrm{E}+00$ \\
\hline $\begin{array}{c}\text { Capital } \\
\text { (Duration - } 5 \text { years) }\end{array}$ & $46 \mathrm{E}-03$ & $9.4 \mathrm{E}-03$ & $7.6 \mathrm{E}-03$ & $|2.2 \mathrm{E}+00|$ & $3.2 \mathrm{E}-04$ & 2.3E-02 & $4.7 \mathrm{E}-02$ & $38 \mathrm{E}-02$ & $1.1 E+01$ & 1.6E-03 & $1.2 \mathrm{E}-02$ & $22 E+00$ & $3.2 \mathrm{E}-04$ & 6.IE-02 & $1.1 \mathrm{E}+01$ & $1.6 \mathrm{E}-03$ \\
\hline $\begin{array}{c}\text { Opcrators \& } \\
\text { Maintenance } \\
\text { (Duration - 15 years) } \\
\end{array}$ & $5.6 \mathrm{E}-03$ & $1.1 \mathrm{E}-02$ & $2.5 \mathrm{E}-03$ & $9.6 \mathrm{E}-01$ & $26 \mathrm{E}-03$ & $8.3 \mathrm{E}-02$ & $1.7 \mathrm{E}-01$ & $3.8 \mathrm{E}-02$ & $14 E+01$ & $3.9 \mathrm{E}-02$ & $8.1 \mathrm{E}-03$ & $9.7 \mathrm{E}-01$ & $2.6 \mathrm{E}-03$ & $1.2 \mathrm{E}-01$ & $1.5 \mathrm{E}+01$ & $3.9 \mathrm{E}-02$ \\
\hline $\begin{array}{c}\text { Decontamination \& } \\
\text { Decommissioning } \\
\text { (Duration - } 1 \text { year) } \\
\end{array}$ & $5.7 \mathrm{E}-03$ & $1.2 \mathrm{E}-02$ & $1.3 \mathrm{E}-02$ & $|3.2 E+00|$ & $3.0 \mathrm{E}-03$ & |.1.E-02 & $2.3 \mathrm{E}-02$ & $2.5 \mathrm{E}-02$ & $6.3 \mathrm{E}+00$ & $6.1 \mathrm{E}-03$ & $1.8 \mathrm{E}-02$ & $|3.2 \mathrm{E}+00|$ & $3.0 \mathrm{E}-03$ & $3.7 \mathrm{E}-02$ & $|6.3 E+00|$ & $6.1 \mathrm{E}-03$ \\
\hline TOTAL & कि & \% & बे। & \% & कि & $1.2 \mathrm{E}-01$ & $2.4 \mathrm{E}-01$ & $1.0 \mathrm{E}-01$ & $3.2 \mathrm{E}+01$ & $4.7 \mathrm{E}-02$ & \%.: & ?.? & \%ै? & $2.2 \mathrm{E}-01$ & $3.2 \mathrm{E}+01$ & $4.7 \mathrm{E}-02$ \\
\hline
\end{tabular}

\section{Assumptions:}

- Transportation is to and from the site only

- Operational risks encompass industrial/physical hazards associated with equipment operation and onsite operations

- Infrastructure staff' support the staff above. They receive no annual Cancer, average 4,000 travel miles, and average $50 \%$ of the facility totals above.

- Collective risks have been calculated as the product of individual risk, multiplied by the number of exposed inidividuals.

Individual risks provide estimates of the probability of health detriment for the individual, and the collective risks provide a measure of overall detriment to the work force. 
Option: P. Flush Water Treatment (for V-Shaped Barrier)

Capital Cost: $\$ 47$ million

Annual Worker Mileage: 15,000

\begin{tabular}{|c|c|c|c|c|c|c|c|c|c|c|}
\hline \multirow{4}{*}{ Activity } & \multicolumn{10}{|c|}{$\begin{array}{l}\text { Management and } \\
\text { Engineering }\end{array}$} \\
\hline & \multicolumn{5}{|c|}{ Annual } & \multicolumn{5}{|c|}{ Total } \\
\hline & \multicolumn{2}{|c|}{ Transportation } & \multicolumn{3}{|c|}{ Operational } & \multicolumn{2}{|c|}{ Transportation } & \multicolumn{3}{|c|}{ Operational } \\
\hline & Death & Injury & Death & Injury & Cancer & Death & Injury & Death & Injury & Cancer \\
\hline $\begin{array}{l}\text { Technology Readiness } \\
\text { (Duration - } 5 \text { years) }\end{array}$ & $2.5 \mathrm{E}-04$ & $5.1 E-04$ & $1.2 \mathrm{E}-04$ & $6.7 \mathrm{E}-02$ & $0.0 \mathrm{E}+00$ & $1.2 \mathrm{E}-03$ & $2.5 E-03$ & $6.0 \mathrm{E}-04$ & $3.4 \mathrm{E}-01$ & $0.0 \mathrm{E}+00$ \\
\hline $\begin{array}{c}\text { Capital } \\
\text { (Duration - 5 years) } \\
\end{array}$ & $2.9 \mathrm{E}-03$ & $6.0 \mathrm{E}-03$ & $1.4 \mathrm{E}-03$ & $8.0 \mathrm{E}-01$ & $1.1 \mathrm{E}-04$ & $1.5 \mathrm{E}-02$ & $3.0 \mathrm{E}-02$ & $7.2 \mathrm{E}-03$ & $4.0 \mathrm{E}+00$ & $5.4 \mathrm{E}-04$ \\
\hline $\begin{array}{c}\text { Operators \& } \\
\text { Maintenance } \\
\text { (Duration - } 15 \text { years) } \\
\end{array}$ & $2.4 \mathrm{E}-03$ & $5.0 \mathrm{E}-03$ & $1.2 \mathrm{E}-03$ & $6.6 \mathrm{E}-01$ & 2.1E-04 & $3.7 \mathrm{E}-02$ & 7.5E-02 & $1.8 \mathrm{E}-02$ & $9.9 \mathrm{E}+00$ & $3.1 \mathrm{E}-03$ \\
\hline $\begin{array}{c}\text { Decontamination \& } \\
\text { Decommissioning } \\
\text { (Duration - } 1 \text { year) }\end{array}$ & $1.8 \mathrm{E}-0.3$ & $\begin{array}{c}3.7 \mathrm{E}-03 \\
. \\
\end{array}$ & $8.8 \mathrm{E}-04$ & $4.9 \mathrm{E}-01$ & $1.5 \mathrm{E}-04$ & $3.6 \mathrm{E}-03$ & $7.4 \mathrm{E}-03$ & $1.8 \mathrm{E}-03$ & $9.8 \mathrm{E}-01$ & $3.1 \mathrm{E}-04$ \\
\hline TOTAL & 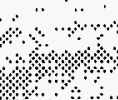 & अे & अ ४ & का & ४। & $5.6 \mathrm{E}-02$ & $1.1 \mathrm{E}-01$ & 2.7E-02 & $1.5 \mathrm{E}+01$ & $3.9 \mathrm{E}-03$ \\
\hline
\end{tabular}

\section{Assumptions:}

- Transportation is to and from the site only

- Operational risks encompass industrial/physical hazards associated with equipment operation and onsite operations

- Infrastructure staff support the staff above. They receive no annual Cancer. average 4.000 travel miles, and average $50 \%$ of the facility totals above.

- Collective ristis have been calculated as the product of individual risk, multiplied by the number of exposed inidividuals.

Individual risks provide estimates of the probability of health detriment for the individual, and the collective risks provide a measure of overall detriment

to the work force. 


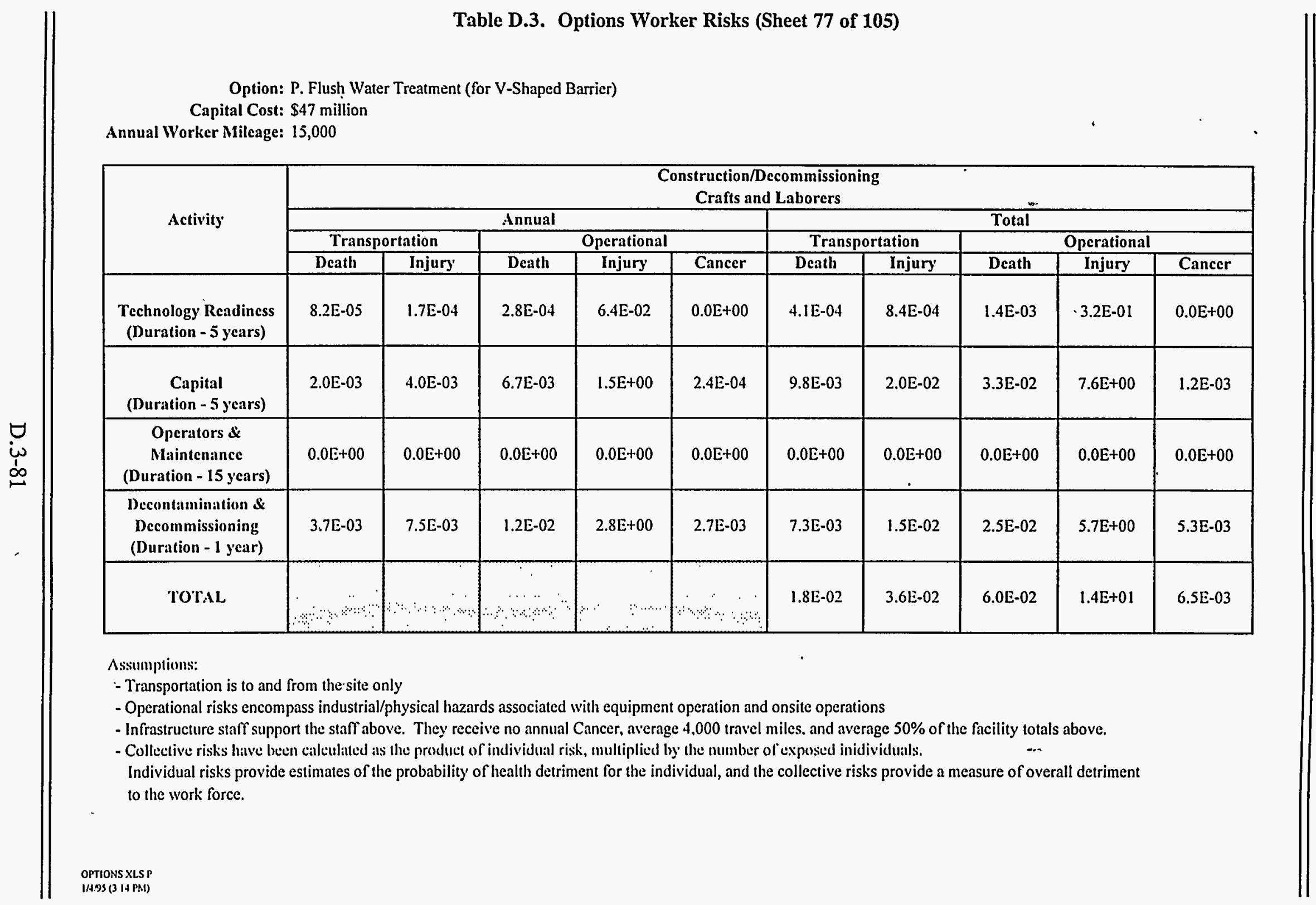




\begin{tabular}{|c|c|c|c|c|c|c|c|c|c|c|}
\hline $\begin{array}{r}\text { Option: } \\
\text { Capital Cost: } \\
\text { Annual Worker Milcage: }\end{array}$ & $\begin{array}{l}\text { P. Flush Wate } \\
\$ 47 \text { million } \\
15,000\end{array}$ & r Treatment (f & V-Shaped E & rrier) & & & & & & \\
\hline \multirow{4}{*}{ Activity } & \multicolumn{10}{|c|}{ Maintenance Crafts } \\
\hline & \multicolumn{5}{|c|}{ Annual } & \multicolumn{5}{|c|}{ Total } \\
\hline & \multicolumn{2}{|c|}{ Transportation } & \multicolumn{3}{|c|}{ Operational } & \multicolumn{2}{|c|}{ Transportation } & \multicolumn{3}{|c|}{ Operational } \\
\hline & Death & Injury & Death & Injury & Cancer & Death & Injury & Death & Injury & Cancer \\
\hline $\begin{array}{l}\text { Technology Readiness } \\
\text { (Duration - } 5 \text { years) } \\
\end{array}$ & $0.0 \mathrm{E}+00$ & $0.0 \mathrm{E}+00$ & $0.0 \mathrm{E}+00$ & $0.0 \mathrm{E}+00$ & $0.0 \mathrm{E}+00$ & $0.0 \mathrm{E}+00$ & $0.0 \mathrm{E}+00$ & $0.0 \mathrm{E}+00$ & $0.0 \mathrm{E}+00$ & $0.0 \mathrm{E}+00$ \\
\hline $\begin{array}{c}\text { Capital } \\
\text { (Duration - } 5 \text { ycars) }\end{array}$ & $0.0 \mathrm{E}+00$ & $0.0 \mathrm{E}+00$ & $0.0 \mathrm{E}+00$ & $0.0 \mathrm{E}+00$ & $0.0 \mathrm{E}+00$ & $0.0 \mathrm{E}+00$ & $0.0 \mathrm{E}+00$ & $0.0 \mathrm{E}+00$ & $0.0 \mathrm{E}+00$ & $0.0 \mathrm{E}+00$ \\
\hline $\begin{array}{c}\text { Operators \& } \\
\text { Maintenance } \\
\text { (Duration - } 15 \text { ycars) }\end{array}$ & $1.2 \mathrm{E}-03$ & $2.5 \mathrm{E}-03$ & $5.3 \mathrm{E}-04$ & $1.3 \mathrm{E}-01$ & $8.9 \mathrm{E}-0.4$ & $1.8 \mathrm{E}-02$ & $3.7 \mathrm{E}-02$ & $8.0 \mathrm{E}-03$ & $1.9 \mathrm{E}+00$ & $1.3 \mathrm{E}-02$ \\
\hline $\begin{array}{c}\text { Decontamination \& } \\
\text { Decommissioning } \\
\text { (Duration - } 1 \text { year) } \\
\end{array}$ & $0.0 \mathrm{E}+00$ & $0.0 \mathrm{E}+00$ & $0.0 \mathrm{E}+00$ & $0.0 \mathrm{E}+00$ & $0.0 \mathrm{E}+00$ & $0.0 \mathrm{E}+00$ & $0.0 \mathrm{E}+00$ & $0.0 \mathrm{E}+00$ & $0.0 \mathrm{E}+00$ & $0.0 \mathrm{E}+00$ \\
\hline TOTAL & अ। & ৪ি। & क्ष & $\begin{array}{l}\ddots \\
\ddots \\
\ddots \cdots\end{array}$ & {$\left[\begin{array}{cc}\ddots \\
\hdashline\end{array}\right]$} & $1.8 \mathrm{E}-02$ & $3.7 \mathrm{E}-02$ & $8.0 \mathrm{E}-03$ & $1.9 \mathrm{E}+00$ & $1.3 \mathrm{E}-02$ \\
\hline
\end{tabular}

Assumptions:

- Transportation is to and from the site only

- Operational risks encompass industrial/physical hazards associated with equipment operation and onsite operations

- Infrastructure staff support the staff ahove. They receive no annual Cancer, at erage 4.000 travel miles. and arerage $50 \%$ of the facility totals above.

- Collective risks have been calculated as the product of individual risk, multiplied by the number of exposed inidividuals.

Individual risks provide estimates of the probability of health detriment for the individual, and the collective risks provide a measure of overall detriment

to the work force. 
Option: P. Flush Water Treatment (for V-Shaped Barrier)

Capital Cost: $\$ 47$ million

Annual Worker Mileage: 15,000

\begin{tabular}{|c|c|c|c|c|c|c|c|c|c|c|}
\hline \multirow{4}{*}{ Activity } & \multicolumn{10}{|c|}{ Operators } \\
\hline & \multicolumn{5}{|c|}{ Annual } & \multicolumn{5}{|c|}{ Total } \\
\hline & \multicolumn{2}{|c|}{ Transportation } & \multicolumn{3}{|c|}{ Operational } & \multicolumn{2}{|c|}{ Transportation } & \multicolumn{3}{|c|}{ Operational } \\
\hline & Death & Injury & Death & Injury & Cancer & Death & Injury & Death & Injury & Cancer \\
\hline $\begin{array}{l}\text { Technology Readiness } \\
\text { (Duration - } 5 \text { years) }\end{array}$ & $0.0 \mathrm{E}+00$ & $0.0 \mathrm{E}+00$ & $0.0 \mathrm{E}+00$ & $0.0 \mathrm{E}+00$ & $0.0 \mathrm{E}+00$ & $0.0 \mathrm{E}+00$ & $0.0 \mathrm{E}+00$ & $0.0 \mathrm{E}+00$ & $0.0 \mathrm{E}+00$ & $0.0 \mathrm{E}+00$ \\
\hline $\begin{array}{c}\text { Capital } \\
\text { (Duration - } 5 \text { years) }\end{array}$ & $0.0 \mathrm{E}+00$ & $0.0 \mathrm{E}+00$ & $0.0 \mathrm{E}+00$ & $0.0 \mathrm{E}+00$ & $0.0 \mathrm{E}+00$ & $0.0 \mathrm{E}+00$ & $0.0 \mathrm{E}+00$ & $0.0 \mathrm{E}+00$ & $0.0 \mathrm{E}+00$ & $0.0 \mathrm{E}+00$ \\
\hline $\begin{array}{c}\text { Operators \& } \\
\text { Maintenance } \\
\text { (Duration - } 15 \text { years) }\end{array}$ & $2.4 \mathrm{E}-03$ & $5.0 \mathrm{E}-03$ & 1.1E-03 & $2.6 \mathrm{E}-01$ & $1.8 \mathrm{E}-03$ & 3.7E-02 & 7.5E-02 & $1.6 \mathrm{E}-02$ & $3.9 \mathrm{E}+00$ & $2.7 \mathrm{E}-02$ \\
\hline $\begin{array}{l}\text { Decontamination \& } \\
\text { Dccommissioning } \\
\text { (Duration - } 1 \text { year) }\end{array}$ & $6.2 \mathrm{E}-04$ & $1.3 \mathrm{E}-03$ & $2.7 \mathrm{E}-04$ & $6.6 \mathrm{E}-02$ & $4.5 \mathrm{E}-04$ & $1.2 \mathrm{E}-03$ & $2.5 \mathrm{E}-03$ & $5.4 \mathrm{E}-04$ & $1.3 \mathrm{E}-01$ & $9.0 \mathrm{E}-04$ \\
\hline TOTAL & 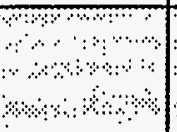 & 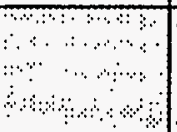 & 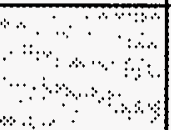 & 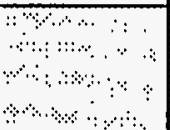 & 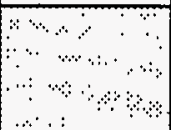 & $3.8 \mathrm{E}-02$ & 7.7E-02 & $1.7 \mathrm{E}-02$ & $4.0 \mathrm{E}+00$ & $2.8 \mathrm{E}-02$ \\
\hline
\end{tabular}

\section{Assumptions:}

- Transportation is to and from the site only

- Operational risks encompass industrial/physical hazards associated with equipnent operation and onsite operations

- Infrastructure staff support the staff above. They receive no annual Cancer, average 4,000 travel niles, and average $50 \%$ of the facility totals above.

- Collective risks have been calculated as the prodact ol individual rist, multiplied by the number of exposed inidividuals.

Individual risks provide estimates of the probability of health detriment for the individual, and the collective risks provide a measure of overall detriment

to the work force. 
Option: P. Flush Water Treatment (for V-Shaped Barrier)

Capital Cost: $\$ 47$ million

Annual Worker Mileage: 15,000

\begin{tabular}{|c|c|c|c|c|c|c|c|c|c|c|c|c|c|c|c|c|}
\hline \multirow{4}{*}{ Activity } & \multicolumn{10}{|c|}{ All Workers } & \multicolumn{6}{|c|}{ All Workers } \\
\hline & \multicolumn{5}{|c|}{ Annual } & \multicolumn{5}{|c|}{ Total } & \multirow{2}{*}{\multicolumn{3}{|c|}{ Annuals }} & \multirow{2}{*}{\multicolumn{3}{|c|}{ Totals }} \\
\hline & \multicolumn{2}{|c|}{ Transportation } & \multicolumn{3}{|c|}{ Operational } & \multicolumn{2}{|c|}{ Transportation } & \multicolumn{3}{|c|}{ Operational } & & & & & & \\
\hline & Death & Injury & Death & \begin{tabular}{|l|} 
Injury \\
\end{tabular} & Cancer & Death & Injury & Death & Injury & Cancer & Death & Injury & Cancer & Death & Injury & Cancer \\
\hline $\begin{array}{l}\text { Technology Readiness } \\
\text { (Duration - } 5 \text { years) }\end{array}$ & $33 \mathrm{E} \cdot 0.4$ & $67 \mathrm{E}-0.4$ & $40 \mathrm{E}-04$ & $13 \mathrm{E}-01$ & $00 \mathrm{E}+00 \mid$ & $16 \mathrm{E}-03$ & $34 \mathrm{E}-03$ & $20 \mathrm{E}-03$ & $66 \mathrm{E}-01$ & $00 \mathrm{E}+00$ & $73 \mathrm{E}-04$ & $1.3 \mathrm{E}-01$ & $0.0 \mathrm{E}+00$ & $3.6 \mathrm{E}-03$ & $66 \mathrm{E}-01$ & $0.0 \mathrm{E}+00$ \\
\hline $\begin{array}{c}\text { Capital } \\
\text { (Duration - } 5 \text { years) }\end{array}$ & $49 E-03$ & $1.0 \mathrm{E}-02$ & $81 \mathrm{E}-03$ & $2.3 \mathrm{E}+00$ & $34 \mathrm{E}-04$ & $25 \mathrm{E}-02$ & $50 \mathrm{E}-02$ & 4 OE-02 & $12 E+01$ & $17 E-03$ & I 3E-02 & $23 E+00$ & $3.4 \mathrm{E}-04$ & $6.5 \mathrm{E}-02$ & $1.2 \mathrm{E}+01$ & $1.7 \mathrm{E}-03$ \\
\hline $\begin{array}{c}\text { Operators \& } \\
\text { Maintenance } \\
\text { (Duration - 15 years) }\end{array}$ & $61 \mathrm{E}-03$ & $1.2 \mathrm{E}-02$ & $2.8 \mathrm{E}-03$ & $1.1 E+00$ & $2.9 \mathrm{E}-03$ & $9.1 \mathrm{E}-02$ & $1.9 \mathrm{E}-01$ & $42 \mathrm{E}-02$ & $1.6 \mathrm{E}+01$ & $4.3 \mathrm{E}-02$ & $8.9 \mathrm{E}-03$ & $1.1 \mathrm{E}+00$ & $2.9 \mathrm{E}-03$ & $1.3 \mathrm{E}-01$ & $1.6 \mathrm{E}+01$ & 4.3E-02 \\
\hline $\begin{array}{l}\text { Decontamination \& } \\
\text { Decommissioning } \\
\text { (Duration - 1 year) }\end{array}$ & $6 \mathrm{IE}-03$ & $12 \mathrm{E}-02$ & $1.4 \mathrm{E}-02$ & $3.4 \mathrm{E}+00$ & $3.3 \mathrm{E}-03$ & $1.2 \mathrm{E}-02$ & $2.5 \mathrm{E}-02$ & $2.7 \mathrm{E}-02$ & $6.8 \mathrm{E}+00$ & $6.5 \mathrm{E}-03$ & $20 \mathrm{E}-02$ & $3.4 \mathrm{E}+00$ & 3.3E-03 & $3.9 \mathrm{E}-02$ & $6.8 \mathrm{E}+00$ & $6.5 \mathrm{E}-03$ \\
\hline TOTAL & ২े & अे & के & $\begin{array}{r}0 \\
\cdots \\
3 \\
3 \\
3\end{array}$ & +। & $1.3 \mathrm{E}-01$ & $2.7 \mathrm{E}-01$ & $1.1 \mathrm{E}-01$ & $3.5 E+01$ & $5.1 \mathrm{E}-02$ & +ै। & के & की & $2.4 \mathrm{E}-01$ & $3.5 \mathrm{E}+01$ & 5.1E-02 \\
\hline
\end{tabular}

\section{Assumptións:}

- Transportation is to and from the site only

- Operational risks encompass industrial/physical hazards associated with equipment operation and onsite operations

- Infrastructure staff support the staff above. They receive no annual Cancer, average 4,000 travel miles, and average $50 \%$ of the facility totals above.

- Collective risks have been calculated as the product of individual risk, multiplied by the number of exposed inidividuals.

Individual risks provide estimates of the probability of health detriment for the individual, and the collective risks provide a measure of overall detriment

to the work force. 
Option: Q. Flush Water Treatment (for Circulating Air Barrier) Capital Cost: $\$ 14$ million

Annual Worker Mileage: 15,000

\begin{tabular}{|c|c|c|c|c|c|c|c|c|c|c|}
\hline \multirow{4}{*}{ Activity } & \multicolumn{10}{|c|}{$\begin{array}{l}\text { Management and } \\
\text { Engineering }\end{array}$} \\
\hline & \multicolumn{5}{|c|}{ Annual } & \multicolumn{5}{|c|}{ Total } \\
\hline & \multicolumn{2}{|c|}{ Transportation } & \multicolumn{3}{|c|}{ Operational } & \multicolumn{2}{|c|}{ Transportation } & \multicolumn{3}{|c|}{ Operational } \\
\hline & Death & Injury & Death & Injury' & Cancer & Death & Injury & Death & Injury & Cancer \\
\hline $\begin{array}{l}\text { Teclinology Readiness } \\
\text { (Duration - } 5 \text { years) }\end{array}$ & $2.5 \mathrm{E}-04$ & 5.1E-04 & $1.2 \mathrm{E}-04$ & $6.7 \mathrm{E}-02$ & $0.0 \mathrm{E}+00$ & $1.2 \mathrm{E}-03$ & 2.5E-03 & $6.0 \mathrm{E}-04$ & $3.4 \mathrm{E}-01$ & $0.0 \mathrm{E}+00$ \\
\hline $\begin{array}{c}\text { Capital } \\
\text { (Duration - } 5 \text { ycars) }\end{array}$ & 8.7E-04 & $1.8 \mathrm{E}-03$ & $4.2 \mathrm{E}-04$ & $2.4 \mathrm{E}-01$ & 3.2E-05 & $4.3 \mathrm{E}-03$ & 8.9E-03 & $2.1 E-03$ & $1.2 \mathrm{E}+00$ & $1.6 \mathrm{E}-04$ \\
\hline $\begin{array}{c}\text { Operators \& } \\
\text { Maintenance } \\
\text { (Duration - } 15 \text { years) } \\
\end{array}$ & $7.3 \mathrm{E}-04$ & $1.5 \mathrm{E}-03$ & $3.5 \mathrm{E}-04$ & $2.0 \mathrm{E}-01$ & $6.2 \mathrm{E}-05$ & $1.1 \mathrm{E}-02$ & 2.2E-02 & $5.3 \mathrm{E}-03$ & $3.0 \mathrm{E}+00$ & $9.3 \mathrm{E}-04$ \\
\hline $\begin{array}{l}\text { Decontamination \& } \\
\text { Decommissioning } \\
\text { (Duration - } 1 \text { year) }\end{array}$ & $5.7 \mathrm{E}-04$ & $1.2 \mathrm{E}-03$ & $2.8 \mathrm{E}-04$ & $1.5 \mathrm{E}-01$ & $4.8 \mathrm{E}-05$ & $1.1 \mathrm{E}-03$ & $2.3 \mathrm{E}-03$ & $5.5 \mathrm{E}-04$ & $3.1 \mathrm{E}-01$ & $9.6 \mathrm{E}-05$ \\
\hline TOTAL & . & a & $\therefore \quad: \quad:$ & & $\because \cdots$ & $1.8 \mathrm{E}-02$ & $3.6 \mathrm{E}-02$ & $8.6 \mathrm{E}-03$ & $4.8 \mathrm{E}+00$ & $1.2 \mathrm{E}-03$ \\
\hline
\end{tabular}

\section{Assumptions:}

- Transportation is to and from the site only

- Operational risks encompass industrial/physical hazards associated with equipment operation and onsite operations

- Infrastructure staff support the staff above. They receive no annual Cancer, average 4,000 travel miles, and average $50 \%$ of the facility totals above.

- Collective risks have been calculated as the product of individual risk, multiplied by the number of exposed inidividuals.

Individual risks provide estimates of the probability of health detriment for the individual, and the collective risks provide a measure of overall detriment

to the work force. 
Option: Q. Flush Water Treatment (for Circulating Air Barrier) Capital Cost: $\$ 14$ million

Annual Worker Mileage: 15,000

\begin{tabular}{|c|c|c|c|c|c|c|c|c|c|c|}
\hline \multirow{4}{*}{ Activity } & \multicolumn{10}{|c|}{$\begin{array}{l}\text { Construction/Decommissioning } \\
\text { Crafts and Laborers }\end{array}$} \\
\hline & \multicolumn{5}{|c|}{ Annual } & \multicolumn{5}{|c|}{ Total } \\
\hline & \multicolumn{2}{|c|}{ Transportation } & \multicolumn{3}{|c|}{ Operational } & \multicolumn{2}{|c|}{ Transportation } & \multicolumn{3}{|c|}{ Operational } \\
\hline & Death & Injury & Death & Injury & Cancer & Death & Injury & Death & Injury & Cancer \\
\hline $\begin{array}{l}\text { Technology Readiness } \\
\text { (Duration - } 5 \text { years) }\end{array}$ & 8.2E-05 & $1.7 \mathrm{E}-04$ & $2.8 \mathrm{E}-04$ & $6.4 \mathrm{E}-02$ & $0.0 \mathrm{E}+00$ & $4.1 \mathrm{E}-04$ & 8.4E-04 & $1.4 \mathrm{E}-03$ & $3.2 \mathrm{E}-01$ & $0.0 \mathrm{E}+00$ \\
\hline $\begin{array}{c}\text { Capital } \\
\text { (Duration - } 5 \text { years) }\end{array}$ & $5.8 \mathrm{E}-04$ & $1.2 \mathrm{E}-03$ & $2.0 \mathrm{E}-03$ & $4.5 E-01$ & $7.0 \mathrm{E}-05$ & $2.9 \mathrm{E}-03$ & $5.9 \mathrm{E}-03$ & $9.8 \mathrm{E}-03$ & $2.2 \mathrm{E}+00$ & $3.5 E-04$ \\
\hline $\begin{array}{c}\text { Operators \& } \\
\text { Maintenance } \\
\text { (Duration - 15 years) }\end{array}$ & $0.0 \mathrm{E}+00$ & $0.0 \mathrm{E}+00$ & $0.0 \mathrm{E}+00$ & $0.0 \mathrm{E}+00$ & $0.0 \mathrm{E}+00$ & $0.0 \mathrm{E}+00$ & $0.0 \mathrm{E}+00$ & $0.0 \mathrm{E}+00$ & $0.0 \mathrm{E}+00$ & $0.0 \mathrm{E}+00$ \\
\hline $\begin{array}{c}\text { Decontamination \& } \\
\text { Decommissioning } \\
\text { (Duration - } 1 \text { year) }\end{array}$ & $1.1 \mathrm{E}-03$ & $2.2 \mathrm{E}-03$ & 3.7E-03 & $8.4 \mathrm{E}-01$ & 1.1E-03 & $2.2 E-03$ & $4.4 \mathrm{E}-03$ & $7.4 \mathrm{E}-03$ & $1.7 \mathrm{E}+00$ & 2.1E-03 \\
\hline TOTAL & ও২। & अి & अ & ४ফ। & म্ষ। & $5.5 \mathrm{E}-03$ & $1.1 \mathrm{E}-02$ & $1.9 \mathrm{E}-02$ & $4.2 \mathrm{E}+00$ & $2.5 \mathrm{E}-03$ \\
\hline
\end{tabular}

- Assumptions:

- Transportation is to and from the site only

- Operational risks encompass industrial/physical hazards associated with equipment operation and onsite operations

- Infrastructure staff support the staff above. They receive no annual Cancer, average 4.000 travel miles, and average $50 \%$ of the facility totals above.

- Collective risks have been calculated as the product of individual risk, multiplied by the number of exposed inidividuals.

Individual risks provide estimates of the probability of health detriment for the individual, and the collective risks provide a measure of overall detriment

to the work force. 
Option: Q. Flush Water Treatment (for Circulating Air Barrier) Capital Cost: $\$ 14$ million

Annual Worker Milcage: 15,000

\begin{tabular}{|c|c|c|c|c|c|c|c|c|c|c|}
\hline \multirow{4}{*}{ Activity } & \multicolumn{10}{|c|}{ Mraintenance Crafts } \\
\hline & \multicolumn{5}{|c|}{ Annual } & \multicolumn{5}{|c|}{ Total } \\
\hline & \multicolumn{2}{|c|}{ Transportation } & \multicolumn{3}{|c|}{ Operational } & \multicolumn{2}{|c|}{ Transportation } & \multicolumn{3}{|c|}{ Operational } \\
\hline & Death & Injury & Death & \begin{tabular}{|l|} 
Injury' \\
\end{tabular} & Cancer & Death & Injury & $\overline{\text { Death }}$ & Injury & Cancer \\
\hline $\begin{array}{l}\text { Technology Readiness } \\
\text { (Duration-5 years) }\end{array}$ & $0.0 E+00$ & $0.0 \mathrm{E}+00$ & $0.0 E+00$ & $0.0 \mathrm{E}+00$ & $0.0 \mathrm{E}+00$ & $0.0 E+00$ & $0.0 \mathrm{E}+00$ & $0.0 \mathrm{E}+00$ & $0.0 \mathrm{E}+00$ & $0.0 \mathrm{E}+00$ \\
\hline $\begin{array}{c}\text { Capital } \\
\text { (Duration - } 5 \text { ycurs) }\end{array}$ & $0.0 \mathrm{E}+00$ & $0.0 \mathrm{E}+00$ & $0.0 \mathrm{E}+00$ & $0.0 \mathrm{E}+00$ & $0.0 \mathrm{E}+00$ & $0.0 \mathrm{E}+00$ & $0.0 \mathrm{E}+00$ & $0.0 \mathrm{E}+00$ & $0.0 \mathrm{E}+00$ & $0.0 \mathrm{E}+00$ \\
\hline $\begin{array}{c}\text { Operators \& } \\
\text { Maintenance } \\
\text { (Duration - } 15 \text { years) } \\
\end{array}$ & $3.6 \mathrm{E}-04$ & $7.5 \mathrm{E}-04$ & $1.6 \mathrm{E}-04$ & $3.9 \mathrm{E}-02$ & $3.5 \mathrm{E}-04$ & $5.5 \mathrm{E}-03$ & $1.1 \mathrm{E}-02$ & $2.4 \mathrm{E}-03$ & $5.8 \mathrm{E}-01$ & $5.3 \mathrm{E}-03$ \\
\hline $\begin{array}{c}\text { Decontamination \& } \\
\text { Decommissioning } \\
\text { (Duration - } 1 \text { year) }\end{array}$ & $0.0 \mathrm{E}+00$ & $0.0 \mathrm{E}+00$ & $0.0 \mathrm{E}+00$ & $0.0 \mathrm{E}+00$ & $0.0 \mathrm{E}+00$ & $0.0 \mathrm{E}+00$ & $0.0 \mathrm{E}+00$ & $0.0 \mathrm{E}+00$ & $0.0 \mathrm{E}+00$ & $0.0 \mathrm{E}+00$ \\
\hline TOTAL & क्ष। & किष & ঝ & 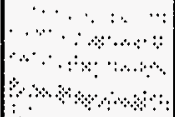 & na & $5.5 \mathrm{E}-03$ & $1.1 \mathrm{E}-02$ & $2.4 \mathrm{E}-03$ & $5.8 \mathrm{E}-01$ & $5.3 \mathrm{E}-03$ \\
\hline
\end{tabular}

Assumptions:

- Transportation is to and from the site only

- Operational risks encompass industrial/physical hazards associated with equipment operation and onsite operations

- Infrastructure staff support the staff above. They receive no annual Cancer, average 4,000 travel miles, and average $50 \%$ of the facility totals above.

- Collective risks have been calculated as the product of individual risk, multiplied by the number of exposed inidividuals. -

-

Individual risks provide estimates of the probability of health detriment for the individual, and the collective risks provide a measure of overall detriment

to the work force. 
Option: Q. Flush Water Treatment (for Circulating Air Barrier)

Capital Cost: $\$ 14$ million

Annual Worker Mileage: 15,000

\begin{tabular}{|c|c|c|c|c|c|c|c|c|c|c|}
\hline • & \multicolumn{10}{|c|}{ Operators } \\
\hline \multirow{3}{*}{ Activity } & \multicolumn{5}{|c|}{ Annual } & \multicolumn{5}{|c|}{ Total } \\
\hline & \multicolumn{2}{|c|}{ Transportation } & \multicolumn{3}{|c|}{ Operational } & \multicolumn{2}{|c|}{ Transportation } & \multicolumn{3}{|c|}{ Operational } \\
\hline & Death & Injury & Death & Injury & Cancer & Death & Injury & Death & Injury & Cancer \\
\hline $\begin{array}{l}\text { Teclnnology Readiness } \\
\text { (Duration - } 5 \text { years) }\end{array}$ & $0.0 \mathrm{E}+00$ & $0.0 \mathrm{E}+00$ & $0.0 \mathrm{E}+00$ & $0.0 \mathrm{E}+00$ & $0.0 \mathrm{E}+00$ & $0.0 \mathrm{E}+00$ & $0.0 \mathrm{E}+00$ & $0.0 \mathrm{E}+00$ & $0.0 \mathrm{E}+00$ & $0.0 \mathrm{E}+00$ \\
\hline $\begin{array}{c}\text { Capital } \\
\text { (Duration }-5 \text { ycars) }\end{array}$ & $0.0 \mathrm{E}+00$ & $0.0 \mathrm{E}+00$ & $0.0 \mathrm{E}+00$ & $0.0 \mathrm{E}+00$ & $0.0 \mathrm{E}+00$ & $0.0 \mathrm{E}+00$ & $0.0 \mathrm{E}+00$ & $0.0 \mathrm{E}+00$ & $0.0 \mathrm{E}+00$ & $0.0 \mathrm{E}+00$ \\
\hline $\begin{array}{c}\text { Operators \& } \\
\text { Maintenance } \\
\text { (Duration - } 15 \text { years) }\end{array}$ & 7.3E-04 & 1.5E-03 & $3.2 \mathrm{E}-04$ & $7.8 \mathrm{E}-02$ & $7.1 \mathrm{E}-04$ & $1.1 \mathrm{E}-02$ & $2.2 \mathrm{E}-02$ & $4.8 \mathrm{E}-03$ & $1.2 \mathrm{E}+00$ & $1.1 \mathrm{E}-02$ \\
\hline $\begin{array}{c}\text { Decontamination \& } \\
\text { Decommissioning } \\
\text { (Duration - } 1 \text { year) }\end{array}$ & $2.1 \mathrm{E}-04$ & $4.2 \mathrm{E}-04$ & $9.0 \mathrm{E}-05$ & $2.2 \mathrm{E}-02$ & 2.0E-04 & 4.1E-04 & $8.4 \mathrm{E}-04$ & $1.8 \mathrm{E}-\dot{0}$ & $4.4 \mathrm{E}-02$ & $4.0 \mathrm{E}-04$ \\
\hline TOTAL & \% & + & ४४ & ४ै। & अ? & $1.1 \mathrm{E}-02$ & $2.3 \mathrm{E}-02$ & $5.0 \mathrm{E}-03$ & $1.2 \mathrm{E}+00$ & $1.1 \mathrm{E}-02$ \\
\hline
\end{tabular}

Assumptions:

- Transportation is to and from the site only

- Operational risks encompass industrial/physical hazards associated with equipment operation and onsite operations

- Infrastructure staff support the staff above. They receive no annual Cancer, average 4,000 travel miles, and average $50 \%$ of the facility totals above.

- Collective risks have been calculated as the product of individual risk, multiplied by the number of exposed inidividuals.

Individual risks provide estimates of the probability of health detriment for the individual, and the collective risks provide a measure of overall detriment

to the work force. 


\begin{tabular}{|c|c|c|c|c|c|c|c|c|c|c|c|c|c|c|c|c|}
\hline $\begin{array}{r}\text { Option } \\
\text { Capital Cost } \\
\text { Annual Worker Milcage }\end{array}$ & $\begin{array}{l}\text { Q. Flush } \\
\$ 14 \text { mill } \\
15,000\end{array}$ & $\begin{array}{l}\text { Water T } \\
\text { ion }\end{array}$ & reatment & (for Circu & ulating $A i$ & (Barrier) & & & & & & & & & & \\
\hline \multirow{4}{*}{ Activity } & \multicolumn{10}{|c|}{ All Workers } & \multicolumn{6}{|c|}{ All Workers } \\
\hline & \multicolumn{5}{|c|}{ Annual } & \multicolumn{5}{|c|}{$\begin{array}{c}\text { Total } \\
\end{array}$} & \multirow{2}{*}{\multicolumn{3}{|c|}{ Annuals }} & \multirow{2}{*}{\multicolumn{3}{|c|}{ Totals }} \\
\hline & \multicolumn{2}{|c|}{\begin{tabular}{|l|} 
Transportation \\
\end{tabular}} & \multicolumn{3}{|c|}{ Operational } & \multicolumn{2}{|c|}{ Transportation } & \multicolumn{3}{|c|}{ Operational } & & & & & & \\
\hline & Death & Injury & Death & Injury & Cancer & Death & \begin{tabular}{|l|} 
Injury \\
\end{tabular} & Death & \begin{tabular}{|l|} 
Injury \\
\end{tabular} & Cancer & \begin{tabular}{|l|} 
Death \\
\end{tabular} & Injury & Cancer & Death & Injury & Cancer \\
\hline $\begin{array}{l}\text { Technology Readiness } \\
\text { (Duration - } 5 \text { years) }\end{array}$ & $3.3 \mathrm{E}-04$ & $6.7 \mathrm{E}-04$ & 4.0E-04 & $1.3 \mathrm{E}-01$ & $|00 E+00|$ & $1.6 \mathrm{E}-03$ & $3.4 \mathrm{E}-03$ & $2.0 \mathrm{E}-03$ & $6.6 \mathrm{E}-01$ & $0.0 \mathrm{E}+00$ & 7.3E-04 & $\mid 1.3 \mathrm{E}-01$ & $0.0 \mathrm{E}+00$ & $3.6 \mathrm{E}-03$ & $6.6 \mathrm{E}-01$ & $0.0 \mathrm{E}+00$ \\
\hline $\begin{array}{c}\text { Capital } \\
\text { (Duration - 5 years) }\end{array}$ & $1.4 \mathrm{E}-03$ & $3.0 \mathrm{E}-03$ & $2.4 \mathrm{E}-03$ & $6.8 \mathrm{E}-01$ & $1.0 \mathrm{E}-04$ & $7.2 \mathrm{E}-03$ & $1.5 \mathrm{E}-02$ & $1,2 \mathrm{E}-02$ & $3.4 \mathrm{E}+00$ & $5.1 \mathrm{E}-04$ & $\mid 3.8 \mathrm{E}-03$ & $6.9 \mathrm{E}-01$ & $1.0 \mathrm{E}-04$ & $1.9 \mathrm{E}-02$ & $3.4 \mathrm{E}+00$ & $5.1 \mathrm{E}-04$ \\
\hline $\begin{array}{c}\text { Operators \& } \\
\text { Maintenance } \\
\text { (Duration - } 15 \text { years) }\end{array}$ & $1.8 \mathrm{E}-03$ & 3.7E-03 & 8.3E-04 & $3.1 \mathrm{E}-01$ & $\mid 1.1 \mathrm{E}-03$ & $2.7 \mathrm{E}-02$ & $5.6 \mathrm{E}-02$ & $1.2 \mathrm{E}-02$ & $4.7 E+00$ & $1.7 \mathrm{E}-02$ & $2.7 \mathrm{E}-03$ & $3.2 \mathrm{E}-01$ & $1.1 \mathrm{E}-03$ & $4.0 \mathrm{E}-02$ & $4.8 \mathrm{E}+00$ & $1.7 \mathrm{E}-02$ \\
\hline $\begin{array}{c}\text { Decontamination \& } \\
\text { Decommissioning } \\
\text { (Duration - 1 year) } \\
\end{array}$ & $1.9 E-03$ & $3.8 \mathrm{E}-03$ & $4.0 \mathrm{E}-03$ & $1.0 E+00$ & $1.3 E-03$ & 3.7E-03 & $7.6 \mathrm{E}-03$ & $8.1 \mathrm{E}-03$ & $2.0 \mathrm{E}+00$ & $2.6 \mathrm{E}-03$ & $5.9 \mathrm{E}-03$ & $1.0 \mathrm{E}+00$ & $1.3 \mathrm{E}-03$ & $1.2 \mathrm{E}-02$ & $2.0 \mathrm{E}+00$ & $2.6 \mathrm{E}-03$ \\
\hline TOTAL & अ० & अ & \%? & कि & कि: & 4.0E-02 & $8.2 \mathrm{E}-02$ & $3.4 \mathrm{E}-02$ & $1.1 \mathrm{E}+01$ & $2.0 \mathrm{E}-02$ & & ४ै। & & $7.4 \mathrm{E}-02$ & $1.1 \mathrm{E}+01$ & $2.0 \mathrm{E}-02$ \\
\hline
\end{tabular}

Assumptions:

- Transportation is to and from the site only

- Operational risks encompass industrial/physical hazards associated with equipment operation and onsite operations

- Infrastructure staff support the staff above. They receive no annual Cancer, avernge 4,000 travel miles, and average $50 \%$ of the facility totals above.

- Collective risks have been calculated as the product of individual risk, multiplied by the number of exposed inidividuals. -..

Individual risks provide estimates of the probability of health detriment for the individual, and the collective risks provide a measure of overall detriment to the work force. 
Option: R. Tank Stabilization

Capital Cost: $\$ 2$ million

Annual Worker Mileage: 15,000

\begin{tabular}{|c|c|c|c|c|c|c|c|c|c|c|}
\hline \multirow{4}{*}{ Activity } & \multicolumn{10}{|c|}{$\begin{array}{c}\text { Management and } \\
\text { Engineering } \\
\end{array}$} \\
\hline & \multicolumn{5}{|c|}{ Annual } & \multicolumn{5}{|c|}{ Total } \\
\hline & \multicolumn{2}{|c|}{ Transportation } & \multicolumn{3}{|c|}{ Operational } & \multicolumn{2}{|c|}{ Transportation } & \multicolumn{3}{|c|}{ Operational } \\
\hline & Death & Injury & Death & Injury' & Cancer & Death & Injury & Death & Injury & Cancer \\
\hline $\begin{array}{l}\text { Technology Readiness } \\
\text { (Duration - } 5 \text { years) }\end{array}$ & 1.2E-04 & $2.5 \mathrm{E}-04$ & $6.0 \mathrm{E}-05$ & $3.4 \mathrm{E}-02$ & $0.0 \mathrm{E}+00$ & $6.2 \mathrm{E}-04$ & $1.3 \mathrm{E}-03$ & $3.0 \mathrm{E}-04$ & $1.7 \mathrm{E}-01$ & $0.0 \mathrm{E}+00$ \\
\hline $\begin{array}{c}\text { Capital } \\
\text { (Duration - } 5 \text { ycars) }\end{array}$ & $1.2 \mathrm{E}-04$ & 2.5E-04 & $6.0 \mathrm{E}-05$ & $3.4 \mathrm{E}-02$ & $4.5 \mathrm{E}-06$ & $6.2 \mathrm{E}-04$ & $1.3 \mathrm{E}-03$ & $3.0 \mathrm{E}-04$ & $1.7 \mathrm{E}-01$ & $2.3 \mathrm{E}-05$ \\
\hline $\begin{array}{c}\text { Operators \& } \\
\text { Maintenance } \\
\text { (Duration - 15 years) }\end{array}$ & $8.2 \mathrm{E}-05$ & $1.7 E-04$ & $4.0 \mathrm{E}-05$ & $2.2 \mathrm{E}-02$ & $7.0 \mathrm{E}-06$ & $1.2 \mathrm{E}-03$ & $2.5 \mathrm{E}-03$ & $6.0 \mathrm{E}-04$ & $3.4 \mathrm{E}-01$ & $1.1 \mathrm{E}-04$ \\
\hline $\begin{array}{l}\text { Decontamination \& } \\
\text { Decommissioning } \\
\text { (Duration - } 1 \text { ycar) }\end{array}$ & NA & NA & NA & NA & NA & NA & NA & NA & NA & NA \\
\hline TO'TAL & $\begin{array}{l}\ldots . \\
\cdots \\
\cdots \\
3\end{array}$ & 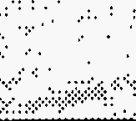 & $\begin{array}{ll}\ddots & \ddots \\
\cdots & \ddots \\
\cdots & \ddots\end{array}$ & 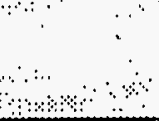 & अ & $2.5 \mathrm{E}-03$ & 5.1E-03 & $1.2 \mathrm{E}-03$ & $6.7 \mathrm{E}-01$ & $1.3 \mathrm{E}-04$ \\
\hline
\end{tabular}

Assumptions:

- Transportation is to and from the site only

- Operational risks encompass industrial/physical hazards associated with equipment operation and onsite operations

- Infrastructure staff support the staff above. They receive no annual Cancer, average 4,000 travel miles, and average $50 \%$ of the facility totals above.

- Collective risks have been calculated as the product of individual risk, multiplied by the number of exposed inidividuals.

Individual risks provide estimates of the probability of health detriment for the individual, and the collective risks provide a measure of overall detriment

to the work force. 
Option: R. Tank Stabilization

Capital Cost: $\$ 2$ million

Annual Worker Mileage: 15,000

\begin{tabular}{|c|c|c|c|c|c|c|c|c|}
\hline \multirow{3}{*}{ Activity } & \multicolumn{9}{|c|}{ Annual } & \multicolumn{3}{c|}{ Construction/Decommissioning } \\
Crafts and Laborers
\end{tabular}

\section{Assumptions:}

- Transportation is to and from the site only

- Operational risks encompass industrial/physical hazards associated with equipment operation and onsite operations

- Infrastructure staff support the staff above. They receive no annual Cancer, average 4,000 travel miles, and average $50 \%$ of the facility totals above.

- Collective risks have been calculated as the product of individual risk, multiplied by the number of exposed inidividuals.

Individual risks provide estimates of the probability of health detriment for the individual, and the collective risks provide a measure of overall detriment

to the work force. 
Option: R. Tank Stabilization

Capital Cost: $\$ 2$ million

Annual Worker Mileage: 15,000

\begin{tabular}{|c|c|c|c|c|c|c|c|c|c|c|}
\hline \multirow{4}{*}{ Activity } & \multicolumn{10}{|c|}{ Maintenance Crafts } \\
\hline & \multicolumn{5}{|c|}{ Annual } & \multicolumn{5}{|c|}{ Total } \\
\hline & \multicolumn{2}{|c|}{ Transportation } & \multicolumn{3}{|c|}{ Operational } & \multicolumn{2}{|c|}{ Transportation } & \multicolumn{3}{|c|}{ Operational } \\
\hline & Death & Injury & Death & Injury & Cancer & Death & Injury & Death & Injury & Cancer \\
\hline $\begin{array}{l}\text { Technology Readiness } \\
\text { (Duration - } 5 \text { years) }\end{array}$ & $0.0 \mathrm{E}+00$ & $0.0 \mathrm{E}+00$ & $0.0 \mathrm{E}+00$ & $0.0 \mathrm{E}+00$ & $0.0 \mathrm{E}+00$ & $0.0 \mathrm{E}+00$ & $0.0 \mathrm{E}+00$ & $0.0 \mathrm{E}+00$ & $0.0 \mathrm{E}+00$ & $0.0 \mathrm{E}+00$ \\
\hline $\begin{array}{c}\text { Capital } \\
\text { (Duration - } 5 \text { years) }\end{array}$ & $0.0 \mathrm{E}+00$ & $0.0 \mathrm{E}+00$ & $0.0 \mathrm{E}+00$ & $0.0 \mathrm{E}+00$ & $0.0 \mathrm{E}+00$ & $0.0 \mathrm{E}+00$ & $0.0 \mathrm{E}+00$ & $0.0 \mathrm{E}+00$ & $0.0 \mathrm{E}+00$ & $0.0 \mathrm{E}+00$ \\
\hline $\begin{array}{c}\text { Operators \& } \\
\text { Maintenance } \\
\text { (Duration - } 15 \text { years) }\end{array}$ & 4.1E-05 & $8.4 \mathrm{E}-\dot{0} 5$ & $1.8 \mathrm{E}-05$ & $4.4 \mathrm{E}-03$ & $2.0 \mathrm{E}-05$ & $6.2 \mathrm{E}-04$ & $1.3 \mathrm{E}-03$ & 2.7E-04 & $6.6 \mathrm{E}-02$ & $3.0 \mathrm{E}-04$ \\
\hline $\begin{array}{c}\text { Decontamination \& } \\
\text { Decommissioning } \\
\text { (Duration - } 1 \text { year) }\end{array}$ & NA & NA & NA & $\mathrm{NA}$ & $\mathrm{NA}$ & NA & NA & NA & NA & NA \\
\hline TOTAL & का & मिख्य & 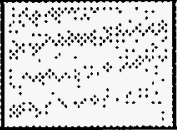 & $\mid$\begin{tabular}{c}
40 \\
\hdashline \\
\hdashline \\
\hdashline
\end{tabular} & a & $6.2 \mathrm{E}-04$ & $1.3 \mathrm{E}-03$ & $2.7 \mathrm{E}-04$ & $6.6 \mathrm{E}-02$ & $3.0 \mathrm{E}-04$ \\
\hline
\end{tabular}

Assumptions:

- Transportation is to and from the site only

- Operational risks encompass industrial/physical hazards associated with equipment operation and onsite operations

- Infrastructure staff support the staff above. They receive no annual Cancer, average 4,000 travel miles, and average $50 \%$ of the facility totals above.

- Collective risks have been calculated as the product of individual risk, multiplied by the number of exposed inidividuals.

Individual risks provide estimates of the probability of health detriment for the individual, and the collective risks provide a measure of overall detriment

to the work force. 
Option: R. Tank Stabilization

Capital Cost: $\$ 2$ million

Annual Worker Mileage: 15,000

\begin{tabular}{|c|c|c|c|c|c|c|c|c|c|c|}
\hline \multirow{4}{*}{ Activity } & \multicolumn{10}{|c|}{ Operators } \\
\hline & \multicolumn{5}{|c|}{ Annual } & \multicolumn{5}{|c|}{ Total } \\
\hline & \multicolumn{2}{|c|}{ Transportation } & \multicolumn{3}{|c|}{ Operational } & \multicolumn{2}{|c|}{ Transportation } & \multicolumn{3}{|c|}{ Operational } \\
\hline & Death & \begin{tabular}{|l} 
Injury \\
\end{tabular} & Death & \begin{tabular}{|l|} 
Injury \\
\end{tabular} & Cancer & Death & Injury & Death & Injury & Cancer \\
\hline $\begin{array}{l}\text { Technology Readiness } \\
\text { (Duration - } 5 \text { years) }\end{array}$ & $0.0 \mathrm{E}+00$ & $0.0 \mathrm{E}+00$ & $0 . \dot{0 E}+00$ & $0.0 \mathrm{E}+00$ & $0.0 \mathrm{E}+00$ & $0.0 \mathrm{E}+00$ & $0.0 \mathrm{E}+00$ & $0.0 \mathrm{E}+00$ & $0.0 \mathrm{E}+00$ & $0.0 \mathrm{E}+00$ \\
\hline $\begin{array}{c}\text { Capital } \\
\text { (Duration - } 5 \text { years) } \\
\end{array}$ & $0.0 \mathrm{E}+00$ & $0.0 \mathrm{E}+00$ & $0.0 \mathrm{E}+00$ & $0.0 \mathrm{E}+00$ & $0.0 \mathrm{E}+00$ & $0.0 \mathrm{E}+00$ & $0.0 \mathrm{E}+00$ & $0.0 \mathrm{E}+00$ & $0.0 \mathrm{E}+00$ & $0.0 \mathrm{E}+00$ \\
\hline $\begin{array}{c}\text { Operators \& } \\
\text { Maintenance } \\
\text { (Duration - } 15 \text { years) }\end{array}$ & $8.2 \mathrm{E}-05$ & $1.7 \mathrm{E}-04$ & $3.6 \mathrm{E}-05$ & $8.8 \mathrm{E}-03$ & $4.0 \mathrm{E}-05$ & $1.2 \mathrm{E}-03$ & $2.5 \mathrm{E}-03$ & $5.4 \mathrm{E}-04$ & $1.3 \mathrm{E}-01$ & $6.0 \mathrm{E}-04$ \\
\hline $\begin{array}{l}\text { Decontamination \& } \\
\text { Decommissioning } \\
\text { (Duration - } 1 \text { year) }\end{array}$ & NA & NA & $\mathrm{NA}$ & $\mathrm{NA}$ & $\mathrm{NA}$ & $\mathrm{NA}$ & $\mathrm{NA}$ & NA & NA & NA \\
\hline TOTAL & कि & औ & का & \% & क्ष & $1.2 \mathrm{E}-03$ & $2.5 \mathrm{E}-03$ & $5.4 \mathrm{E}-04$ & $1.3 \mathrm{E}-01$ & $6.0 \mathrm{E}-04$ \\
\hline
\end{tabular}

Assumptions:

- Transportation is to and from the site only

- Operational risks encompass industrial/physical hazards associated with equipment operation and onsite operations

- Infrastructure staff support the staff above. They receive no annual Cancer, average 4,000 travel miles, and average $50 \%$ of the facility totals above.

- Collective risks have been calculated as the product of individual risk, multiplied by the number of exposed inidividuals. .

Individual risks provide estimates of the probability of health detriment for the individual, and the collective risks provide a measure of overall detriment to the work force. 
Option: R. Tank Stabilization

Capital Cost: $\$ 2$ million

Annual Worker Mileage: 15,000

\begin{tabular}{|c|c|c|c|c|c|c|c|c|c|c|c|c|c|c|c|c|}
\hline \multirow{4}{*}{ Activity } & \multicolumn{10}{|c|}{ All Workers } & \multicolumn{6}{|c|}{ All Workers } \\
\hline & \multicolumn{5}{|c|}{\begin{tabular}{|c|} 
Annual \\
\end{tabular}} & \multicolumn{5}{|c|}{ Total } & \multirow{2}{*}{\multicolumn{3}{|c|}{ Annuals }} & \multirow{2}{*}{\multicolumn{3}{|c|}{ Totals }} \\
\hline & \multicolumn{2}{|c|}{ Transportation } & \multicolumn{3}{|c|}{ Operational } & \multicolumn{2}{|c|}{ Transportation } & \multicolumn{3}{|c|}{ Operational } & & & & & & \\
\hline & Death & Injury & Death & Injury & Cancer & Death & Injury & Death & Injury & Cancer & Death & Injury & Cancer & Death & Injury & Cancer \\
\hline $\begin{array}{c}\text { Technology Readiness } \\
\text { (Duration - } 5 \text { years) }\end{array}$ & $1.6 \mathrm{E}-04$ & $3.4 \mathrm{E}-04$ & 2 OE-04 & $6.6 \mathrm{E}-02$ & $0.0 \mathrm{E}+00$ & $8.2 \mathrm{E}-04$ & $1.7 \mathrm{E}-03$ & $1.0 \mathrm{E}-03$ & $3.3 \mathrm{E}-01$ & $0.0 \mathrm{E}+00$ & $3.6 \mathrm{E}-04$ & $66 \mathrm{E}-02$ & $0.0 \mathrm{E}+00$ & $1.8 \mathrm{E}-03$ & $3.3 \mathrm{E}-01$ & $0.0 \mathrm{E}+00$ \\
\hline $\begin{array}{c}\text { Capital } \\
\text { (Duration - } 5 \text { years) } \\
\end{array}$ & 2.1E-04 & $42 \mathrm{E}-04$ & $3.4 \mathrm{E}-04$ & $9.8 \mathrm{E}-02$ & $4.5 \mathrm{E}-05$ & $1.0 \mathrm{E}-03$ & 2.1E-03 & $1.7 \mathrm{E}-03$ & $4.9 \mathrm{E}-01$ & $2,2 \mathrm{E}-04$ & $5.5 \mathrm{E}-04$ & 9.8E-02 & 4.5E-05 & $2.7 \mathrm{E}-03$ & $4.9 \mathrm{E}-01$ & 2.2E-04 \\
\hline $\begin{array}{c}\text { Operators \& } \\
\text { Maintenance } \\
\text { (Duration - 15 ycars) }\end{array}$ & 2.1E-04 & 4.2E-04 & 9.4E-05 & $3.6 \mathrm{E}-02$ & $6.7 \mathrm{E}-05$ & 3.1E-03 & $6.3 \mathrm{E}-03$ & $1.4 \mathrm{E}-03$ & $53 \mathrm{E}-01$ & $1.0 \mathrm{E}-03$ & $3.0 \mathrm{E}-04$ & $3.6 \mathrm{E}-02$ & 6.7E-05 & $4.5 \mathrm{E}-03$ & $5.4 \mathrm{E}-01$ & $1.0 \mathrm{E}-03$ \\
\hline $\begin{array}{c}\text { Decontamination \& } \\
\text { Decommissioning } \\
\text { (Duration - } 1 \text { year) }\end{array}$ & NA & NA & NA & NA & $\mathrm{NA}$ & $\mathrm{NA}$ & NA & NA & $\mathrm{NA}$ & NA & NA & NA & NA & NA & NA & NA \\
\hline TOTAL & $1 \%$ & \%का & $\begin{array}{c}6 \% \\
\% \\
\%\end{array}$ & (ै.) & के & $4.9 \mathrm{E}-03$ & $1.0 \mathrm{E}-02$ & $4.1 \mathrm{E}-03$ & $1.4 \mathrm{E}+00$ & $1.2 \mathrm{E}-03$ & $1 \%$ & \%ै। & & $9.1 \mathrm{E}-03$ & $1.4 \mathrm{E}+00$ & $1.2 \mathrm{E}-03$ \\
\hline
\end{tabular}

Assumptions:

- Transportation is to and from the site only

- Operational risks encompass industrial/physical hazards associated with equipment operation and onsite operations

- Infrastructure staff support the staff above. They receive no annual Cancer, average 4,000 travel miles, and average $50 \%$ of the facility totals above.

- Collective risks have been calcuiated as the product of individual risk, multiplied by the number of exposed inidividuals.

Individual risks provide estimates of the probability of health detriment for the individual, and the collective risks provide a measure of overall detriment

to the work force. 
Option: S. Surface Barrier

Capital Cost: $\$ 4$ million

Annual Worker Mileage: 15,000

\begin{tabular}{|c|c|c|c|c|c|c|c|c|c|c|}
\hline \multirow{4}{*}{ Activity } & \multicolumn{10}{|c|}{$\begin{array}{c}\text { Management and } \\
\text { Engineering }\end{array}$} \\
\hline & \multicolumn{5}{|c|}{ Annual } & \multicolumn{5}{|c|}{ Total } \\
\hline & \multicolumn{2}{|c|}{ Transportation } & \multicolumn{3}{|c|}{ Operational } & \multicolumn{2}{|c|}{ Transportation } & \multicolumn{3}{|c|}{ Operational } \\
\hline & Death & Injury & Death & Injury & Cancer & Death & Injury & Death & Injury & Cancer \\
\hline $\begin{array}{l}\text { Technology Readiness } \\
\text { (Duration - } 5 \text { years) }\end{array}$ & $2.5 \mathrm{E}-04$ & $5.1 \mathrm{E}-04$ & $1.2 \mathrm{E}-04$ & $6.7 \mathrm{E}-02$ & $0.0 \mathrm{E}+00$ & $1.2 \mathrm{E}-03$ & $2.5 \mathrm{E}-03$ & $6.0 \mathrm{E}-04$ & $3.4 \mathrm{E}-01$ & $0.0 \mathrm{E}+00$ \\
\hline $\begin{array}{c}\text { Capital } \\
\text { (Duration - } 5 \text { years) } \\
\end{array}$ & $2.5 \mathrm{E}-04$ & $5.1 \mathrm{E}-04$ & $1.2 \mathrm{E}-04$ & $6.7 \mathrm{E}-02$ & $9.0 \mathrm{E}-06$ & $1.2 \mathrm{E}-03$ & $2.5 \mathrm{E}-03$ & $6.0 \mathrm{E}-04$ & $3.4 \mathrm{E}-01$ & $4.5 \mathrm{E}-05$ \\
\hline $\begin{array}{c}\text { Operators \& } \\
\text { Maintenance } \\
\text { (Duration - } 15 \text { years) } \\
\end{array}$ & $8.2 \mathrm{E}-05$ & $1.7 \mathrm{E}-04$ & $4.0 \mathrm{E}-05$ & $2.2 \mathrm{E}-02$ & 7.0E-06 & $1.2 \mathrm{E}-03$ & $2.5 \mathrm{E}-03$ & $6.0 \mathrm{E}-04$ & $3.4 \mathrm{E}-01$ & 1.1E-04 \\
\hline $\begin{array}{l}\text { Decontamination \& } \\
\text { Decommissioning } \\
\text { (Duration - 1 year) } \\
\end{array}$ & $\mathrm{NA}$ & $\mathrm{NA}$ & $\mathrm{NA}$ & $\mathrm{NA}$ & $\mathrm{NA}$ & $\mathrm{NA}$ & $\mathrm{NA}$ & NA & NA & NA \\
\hline TOTAL & $\begin{array}{l}\text { मे. } \\
\text { मू }\end{array}$ & अे। & r. & u & an & $3.7 \mathrm{E}-03$ & $7.6 \mathrm{E}-03$ & $1.8 \mathrm{E}-03$ & $1.0 \mathrm{E}+00$ & $1.5 \mathrm{E}-04$ \\
\hline
\end{tabular}

Assumptions:

- Transportation is to and from the site only

- Operational risks encompass industrial/physical hazards associated with equipment operation and onsite operations

- Infrastructure staff support the staff above. They receive no annual Cancer, average 4,000 travel miles, and average $50 \%$ of the facility totals above.

- Collective risks have been calculated as the product of individual risk, multiplied by the number of exposed inidividuals.

Individual risks provide estimates of the probability of health detriment for the individual, and the collective risks provide a measure of overall detriment to the work force. 
0
$\vdots$
$\vdots$
$\vdots$

Option: S. Surface Barrier

Capital Cost: $\$ 4$ million

Annual Worker Mileage: 15,000

\begin{tabular}{|c|c|c|c|c|c|c|c|c|c|c|}
\hline \multirow{4}{*}{ Activity } & \multicolumn{10}{|c|}{$\begin{array}{c}\text { Construction/Decommissioning } \\
\text { Crafts and Laborers } \\
\end{array}$} \\
\hline & \multicolumn{5}{|c|}{ Annual } & \multicolumn{5}{|c|}{ Total } \\
\hline & \multicolumn{2}{|c|}{ Transportation } & \multicolumn{3}{|c|}{ Operational } & \multicolumn{2}{|c|}{ Transportation } & \multicolumn{3}{|c|}{ Operational } \\
\hline & Death & Injury & Death & Injury & Cancer & Death & Injury & Death & Injury & Cancer \\
\hline $\begin{array}{l}\text { Technology Readiness } \\
\text { (Duration - } 5 \text { years) }\end{array}$ & $8.2 \mathrm{E}-05$ & $1.7 \mathrm{E}-04$ & $2.8 \mathrm{E}-04$ & $6.4 \mathrm{E}-02$ & $0.0 \mathrm{E}+00$ & $4.1 E-04$ & $8.4 \mathrm{E}-04$ & $1.4 \mathrm{E}-03$ & $3.2 \mathrm{E}-01$ & $0.0 \mathrm{E}+00$ \\
\hline $\begin{array}{c}\text { Capital } \\
\text { (Duration - } 5 \text { years) }\end{array}$ & $1.6 \mathrm{E}-04$ & $3.4 \mathrm{E}-04$ & $5.6 \mathrm{E}-04$ & $1.3 \mathrm{E}-01$ & 4.0E-05 & $8.2 \mathrm{E}-04$ & $1.7 \mathrm{E}-03$ & $2.8 \mathrm{E}-03$ & $6.4 \mathrm{E}-01$ & $2.0 \mathrm{E}-04$ \\
\hline $\begin{array}{c}\text { Operators \& } \\
\text { Maintenance } \\
\text { (Duration - 15 years) }\end{array}$ & $0.0 \mathrm{E}+00$ & $0.0 \mathrm{E}+00$ & $0.0 \mathrm{E}+00$ & $0.0 \mathrm{E}+00$ & $0.0 \mathrm{E}+00$ & $0.0 \mathrm{E}+00$ & $0.0 \mathrm{E}+00$ & $0.0 \mathrm{E}+00$ & $0.0 \mathrm{E}+00$ & $0.0 \mathrm{E}+00$ \\
\hline $\begin{array}{l}\text { Decontamination \& } \\
\text { Decommissioning } \\
\text { (Duration - } 1 \text { year) }\end{array}$ & $\mathrm{NA}$ & $\mathrm{NA}$ & $\mathrm{NA}$ & $\mathrm{NA}$ & $\mathrm{NA}$ & $\mathrm{NA}$ & $\mathrm{NA}$ & $\mathrm{NA}$ & NA & NA \\
\hline TOTAL & \%? & rop & \%ै। & अ\% & औ? & $1.2 \mathrm{E}-03$ & $2.5 \mathrm{E}-03$ & 4.2E-03 & $9.6 \mathrm{E}-01$ & $2.0 \mathrm{E}-04$ \\
\hline
\end{tabular}

\section{Assumptions:}

- Transportation is to and from the site only

- Operational risks encompass industrial/physical hazards associated with equipment operation and onsite operations

- Infrastructure staff support the staff above. They receive no annual Cancer, average 4,000 travel miles, and average $50 \%$ of the facility totals above.

- Collective risks have been calculated as the product of individual risk, multiplied by the number of exposed inidividuals.

Individual risks provide estimates of the probability of health detriment for the individual, and the collective risks provide a measure of overall detriment

to the work force. 
Option: S. Surface Barrier

Capital Cost: $\$ 4$ million

Annual Worker Milcage: 15,000

\begin{tabular}{|c|c|c|c|c|c|c|c|c|c|c|}
\hline \multirow{4}{*}{ Activity } & \multicolumn{10}{|c|}{ Maintenance Crafts } \\
\hline & \multicolumn{5}{|c|}{ Annual } & \multicolumn{5}{|c|}{ Total } \\
\hline & \multicolumn{2}{|c|}{ Transportation } & \multicolumn{3}{|c|}{ Operational } & \multicolumn{2}{|c|}{ Transportation } & \multicolumn{3}{|c|}{ Operational } \\
\hline & Death & Injury & Death & Injury & Cancer & Death & Injury & Death & Injury & Cancer \\
\hline $\begin{array}{l}\text { Technology Readiness } \\
\text { (Duration - } 5 \text { years) }\end{array}$ & $0.0 \mathrm{E}+00$ & $0.0 \mathrm{E}+00$ & $0.0 \mathrm{E}+00$ & $0.0 \mathrm{E}+00$ & $0.0 \mathrm{E}+00$ & $0.0 \mathrm{E}+00$ & $0.0 \mathrm{E}+00$ & $0.0 \mathrm{E}+00$ & $0.0 \mathrm{E}+00$ & $0.0 \mathrm{E}+00$ \\
\hline $\begin{array}{c}\text { Capital } \\
\text { (Duration - } 5 \text { years) }\end{array}$ & $0.0 \mathrm{E}+00$ & $0.0 \mathrm{E}+00$ & $0.0 \mathrm{E}+00$ & $0.0 \mathrm{E}+00$ & $0.0 \mathrm{E}+00$ & $0.0 \mathrm{E}+00$ & $0.0 \mathrm{E}+00$ & $0.0 \mathrm{E}+00$ & $0.0 \mathrm{E}+00$ & $0.0 \mathrm{E}+00$ \\
\hline $\begin{array}{c}\text { Operators \& } \\
\text { Maintenance } \\
\text { (Duration - } 15 \text { years) }\end{array}$ & $4.1 E-05$ & $8.4 \mathrm{E}-05$ & $1.8 \mathrm{E}-05$ & $4,4 \mathrm{E}-03$ & $1.0 \mathrm{E}-05$ & $6.2 \mathrm{E}-04$ & $1.3 \mathrm{E}-03$ & $2.7 \mathrm{E}-04$ & $6.6 \mathrm{E}-02$ & $1.5 \mathrm{E}-04$ \\
\hline $\begin{array}{c}\text { Decontamination \& } \\
\text { Decommissioning } \\
\text { (Duration - } 1 \text { year) }\end{array}$ & NA & NA & NA & NA & NA & NA & NA & NA & NA & NA \\
\hline TOTAL & अి & के। & अ४० & \&ै। & \&ै। & $6.2 \mathrm{E}-04$ & 1.3E-03 & $2.7 \mathrm{E}-04$ & $6.6 \mathrm{E}-02$ & $1.5 \mathrm{E}-04$ \\
\hline
\end{tabular}

Assumptions:

- Transportation is to and from the site only

- Operational risks encompass industrial/physical hazards associated with equipment operation and onsite operations

- Infrastructure staff support the staff above. They receive no annual Cancer, average 4,000 travel miles, and average $50 \%$ of the facility totals above.

- Collective risks have been calculated as the product of individual risk, multiplied by the number of exposed inidividuals.

Individual risks provide estimates of the probability of health detriment for the individual, and the collective risks provide a measure of overall detrimen

to the work force. 
Option: S. Surface Barrier

Capital Cost: $\$ 4$ million

Annual Worker Mileage: 15,000

\begin{tabular}{|c|c|c|c|c|c|c|c|c|c|c|}
\hline \multirow{4}{*}{ Activity } & \multicolumn{10}{|c|}{ Operators } \\
\hline & \multicolumn{5}{|c|}{ Annual } & \multicolumn{5}{|c|}{ Total } \\
\hline & \multicolumn{2}{|c|}{ Transportation } & \multicolumn{3}{|c|}{ Operational } & \multicolumn{2}{|c|}{ Transportation } & \multicolumn{3}{|c|}{ Operational } \\
\hline & Death & Injury & Death & \begin{tabular}{|l|} 
Injury \\
\end{tabular} & Cancer & Death & Injury & Death & Injury & Cancer \\
\hline $\begin{array}{l}\text { Technology Readiness } \\
\text { (Duration - } 5 \text { years) }\end{array}$ & $0.0 \mathrm{E}+00$ & $0.0 \mathrm{E}+00$ & $0.0 \mathrm{E}+00$ & $0.0 \mathrm{E}+00$ & $0.0 \mathrm{E}+00$ & $0.0 \mathrm{E}+00$ & $0.0 \mathrm{E}+00$ & $0.0 \mathrm{E}+00$ & $0.0 \mathrm{E}+00$ & $0.0 \mathrm{E}+00$ \\
\hline $\begin{array}{c}\text { Capital } \\
\text { (Duration }-5 \text { years) }\end{array}$ & $0.0 \mathrm{E}+00$ & $0.0 \mathrm{E}+00$ & $0.0 \mathrm{E}+00$ & $0.0 \mathrm{E}+00$ & $0.0 \mathrm{E}+00$ & $0.0 \mathrm{E}+00$ & $0.0 \mathrm{E}+00$ & $0.0 \mathrm{E}+00$ & $0.0 \mathrm{E}+00$ & $0.0 \mathrm{E}+00$ \\
\hline $\begin{array}{c}\text { Operators \& } \\
\text { Maintenance } \\
\text { (Duration - 15 years) }\end{array}$ & $8.2 \mathrm{E}-05$ & $1.7 \mathrm{E}-04$ & $3.6 \mathrm{E}-05$ & $8.8 \mathrm{E}-03$ & $2.0 \mathrm{E}-05$ & $1.2 \mathrm{E}-03$ & $2.5 \mathrm{E}-03$ & $5.4 \mathrm{E}-04$ & $1.3 \mathrm{E}-01$ & $3.0 \mathrm{E}-04$ \\
\hline $\begin{array}{l}\text { Decontamination \& } \\
\text { Decommissioning } \\
\text { (Duration - } 1 \text { year) }\end{array}$ & NA & NA & NA & NA & NA & NA & NA & NA & NA & NA- \\
\hline TOTAL & +ै। & ?ै+? & के & कि & की & $1.2 \mathrm{E}-03$ & $2.5 \mathrm{E}-03$ & $5.4 \mathrm{E}-04$ & $1.3 \mathrm{E}-01$ & $3.0 \mathrm{E}-04$ \\
\hline
\end{tabular}

Assumptions:

- Transportation is to and from the site only

- Operational risks encompass industrial/physical hazards associated with equipment operation and onsite operations

- Infrastructure staff support the staff above. They receive no annual Cancer, average 4,000 travel miles, and average $50 \%$ of the facility totals above.

- Collective risks have been calculated as the product of individual risk, multiplied by the number of exposed inidividuals.

Individual risks provide estimates of the probability of health detriment for the individual, and the collective risks provide a measure of overall detriment

to the work force. 
Table D.3. Options Worker Risks (Sheet 95 of 105)

Option: S. Surface Barrier

Capital Cost: $\$ 4$ million

Annual Worker Mileage: 15,000

\begin{tabular}{|c|c|c|c|c|c|c|c|c|c|c|c|c|c|c|c|c|}
\hline \multirow{4}{*}{ Activity } & \multicolumn{10}{|c|}{ All Workers } & \multicolumn{6}{|c|}{ All Workers } \\
\hline & \multicolumn{5}{|c|}{ Annual } & \multicolumn{5}{|c|}{ Total } & \multirow{2}{*}{\multicolumn{3}{|c|}{ Annuals }} & \multirow{2}{*}{\multicolumn{3}{|c|}{ Totals }} \\
\hline & \multicolumn{2}{|c|}{ Transportation } & \multicolumn{3}{|c|}{ Operational } & \multicolumn{2}{|c|}{ Transportation } & \multicolumn{3}{|c|}{ Operational } & & & & & & \\
\hline & Death & Injury & Death & Injury & Cancer & Death & Injury & Death & \begin{tabular}{|l|} 
Injury \\
\end{tabular} & Cancer & Death & Injury & Cancer & Death & Injury & Cancer \\
\hline $\begin{array}{l}\text { Technology Readiness } \\
\text { (Duration - } 5 \text { years) }\end{array}$ & 3.3E-04 & $6.7 \mathrm{E}-04$ & $4.0 \mathrm{E}-04$ & $1.3 \mathrm{E}-01$ & $0.0 \mathrm{E}+00$ & $1.6 \mathrm{E}-03$ & $3.4 \mathrm{E}-03$ & $2.0 \mathrm{E}-03$ & $6.6 \mathrm{E}-01$ & $0.0 \mathrm{E}+00$ & $7.3 \mathrm{E}-04$ & $1.3 \mathrm{E}-01$ & $0.0 E+\infty 0$ & $3.6 \mathrm{E}-03$ & $\begin{array}{l}6.6 \mathrm{E}-01 \\
\cdot\end{array}$ & $0.0 \mathrm{E}+00$ \\
\hline $\begin{array}{c}\text { Capital } \\
\text { (Duration }-5 \text { years) }\end{array}$ & 4.IE-04 & 8.4E-04 & $6.8 \mathrm{E}-04$ & 2.0E-01 & $4.9 \mathrm{E}-05$ & $2.1 \mathrm{E}-03$ & $4.2 \mathrm{E}-03$ & $3.4 \mathrm{E}-03$ & $9.8 \mathrm{E}-01$ & $2.5 \mathrm{E}-04$ & $1.1 \mathrm{E}-03$ & $2.0 \mathrm{E}-01$ & $4.9 \mathrm{E}-05$ & $5.5 \mathrm{E}-03$ & $9.8 \mathrm{E}-01$ & 2.5E-04 \\
\hline $\begin{array}{c}\text { Operators \& } \\
\text { Maintenance } \\
\text { (Duration - 15 years) }\end{array}$ & 2.1E-04 & $4.2 \mathrm{E}-04$ & $9.4 \mathrm{E}-05$ & $3.6 \mathrm{E}-02$ & 3.7E-05 & 3.1E-03 & $6.3 \mathrm{E}-03$ & $1.4 \mathrm{E}-03$ & $5.3 \mathrm{E}-01$ & $5.6 \mathrm{E}-04$ & $3.0 \mathrm{E}-04$ & $3.6 \mathrm{E}-02$ & $3.7 \mathrm{E}-05$ & $4.5 \mathrm{E}-03$ & $5.4 \mathrm{E}-01$ & $5.6 \mathrm{E}-04$ \\
\hline $\begin{array}{c}\text { Decontamination \& } \\
\text { Decommissioning } \\
\text { (Duration - } 1 \text { year) }\end{array}$ & NA & NA & NA & NA & $\mathrm{NA}$ & NA & NA & $\mathrm{NA}$ & NA & NA & NA & NA & NA & NA & NA & NA \\
\hline TOTAL & के & +ै। & के & अै: & का & $6.8 \mathrm{E}-03$ & $1.4 \mathrm{E}-02$ & $6.8 \mathrm{E}-03$ & $2.2 \mathrm{E}+00$ & $8.0 \mathrm{E}-04$ & \%... & $1 \%$ & \%ै. & $1.4 \mathrm{E}-02$ & $2.2 \mathrm{E}+00$ & $8.0 \mathrm{E}-04$ \\
\hline
\end{tabular}

Assumptions:

- Transportation is to and from the site only

- Operational risks encompass industrial/physical hazards associated with equipment operation and onsite operations

- Infrastructure staff support the staff above. They receive no annual Cancer, average 4,000 travel miles, and average $50 \%$ of the facility totals above.

- Collective risks have been calculated as the product of individual risk, multiplied by the number of exposed inidividuals.

Individual risks provide estimates of the probability of health detriment for the individual, and the collective risks provide a measure of overall detriment

to the work force. 
붕

Table D.3. Options Worker Risks (Sheet 96 of 105)

Option: T. Clean Closure (no barrier)

Capital Cost: $\$ 730$ million

Annual Worker Mileage: 15,000

\begin{tabular}{|c|c|c|c|c|c|c|c|c|c|c|}
\hline \multirow{4}{*}{ Activity } & \multicolumn{10}{|c|}{$\begin{array}{l}\text { Management and } \\
\text { Engineering }\end{array}$} \\
\hline & \multicolumn{5}{|c|}{ Annual } & \multicolumn{5}{|c|}{ Total } \\
\hline & \multicolumn{2}{|c|}{ Transportation } & \multicolumn{3}{|c|}{ Operational } & \multicolumn{2}{|c|}{ Transportation } & \multicolumn{3}{|c|}{ Operational } \\
\hline & Death & Injury & Death & Injury & Cancer & Death & Injury & Death & Injury & Cancer \\
\hline $\begin{array}{l}\text { Technology Readiness } \\
\text { (Duration - } 5 \text { years) }\end{array}$ & $2.6 \mathrm{E}-03$ & $5.2 \mathrm{E}-03$ & $1.2 \mathrm{E}-03$ & $6.9 \mathrm{E}-01$ & $0.0 \mathrm{E}+00$ & $1.3 \mathrm{E}-02$ & $2.6 \mathrm{E}-02$ & $6.2 \mathrm{E}-03$ & $3.5 \mathrm{E}+00$ & $0.0 \mathrm{E}+00$ \\
\hline $\begin{array}{c}\text { Capital } \\
\text { (Duration }-5 \text { ycars) }\end{array}$ & $4.6 \mathrm{E}-02$ & $9.4 \mathrm{E}-02$ & $2.2 \mathrm{E}-02$ & $1.3 \mathrm{E}+01$ & $1.7 E-03$ & $2.3 \mathrm{E}-01$ & 4.7E-01 & 1.|E-0| & $6.3 \mathrm{E}+01$ & $8.4 \mathrm{E}-03$ \\
\hline $\begin{array}{c}\text { Operators \& } \\
\text { Maintenance } \\
\text { (Duration - 15 years) } \\
\end{array}$ & $1.2 \mathrm{E}-02$ & $2.4 \mathrm{E}-02$ & $5.6 \mathrm{E}-03$ & $3.1 E+00$ & $9.8 \mathrm{E}-04$ & $2.3 \mathrm{E}-01$ & $4.7 \mathrm{E}-01$ & $1.1 \mathrm{E}-01$ & $6.3 E+01$ & $2.0 \mathrm{E}-02$ \\
\hline $\begin{array}{c}\text { Decontamination \& } \\
\text { Decommissioning } \\
\text { (Duration - } 1 \text { year) }\end{array}$ & $7.9 \mathrm{E}-03$ & $1.6 \mathrm{E}-02$ & $3.8 \mathrm{E}-03$ & $2.1 \mathrm{E}+00$ & $6.7 \mathrm{E}-04$ & $2.4 \mathrm{E}-02$ & $4.8 \mathrm{E}-02$ & $1.1 \mathrm{E}-02$ & $6.4 \mathrm{E}+00$ & $2.0 \mathrm{E}-03$ \\
\hline TOTAL & ४ै। & ঝै। & ४ै। & ২ै। & किका & $5.0 \mathrm{E}-01$ & $1.0 \mathrm{E}+00$ & $2.4 \mathrm{E}-01$ & $1.4 \mathrm{E}+02$ & $3.0 \mathrm{E}-02$ \\
\hline
\end{tabular}

Assumptions:

- Transportation is to and from the site only

- Operational risks encompass industrial/physical hazards associated with equipment operation and onsite operations

- Infrastructure staff support the stalf above. They receive no annual Cancer, average 4,000 travel miles, and average $50 \%$ of the facility totals above.

- Collective risks have been calculated as the product of individual risk, multiplied by the number of exposed inidividuals.

Individual risks provide estimates of the probability of health detriment for the individual, and the collective risks provide a measure of overall detriment

to the work force. 
Option: T. Clean Closure (no barrier)

Capital Cost: $\$ 730$ million

Annual Worker Mileage: 15,000

\begin{tabular}{|c|c|c|c|c|c|c|c|c|c|c|}
\hline \multirow{4}{*}{ Activity } & \multicolumn{10}{|c|}{$\begin{array}{l}\text { Construction/Decommissioning } \\
\text { Crafts and Laborers }\end{array}$} \\
\hline & \multicolumn{5}{|c|}{ Annual } & \multicolumn{5}{|c|}{ Total } \\
\hline & \multicolumn{2}{|c|}{ Transportation } & \multicolumn{3}{|c|}{ Opcrational } & \multicolumn{2}{|c|}{ Transportation } & \multicolumn{3}{|c|}{ Operational } \\
\hline & Death & Injury & Death & Injury & Cancer & Death & Injury & Death & Injury & Cancer \\
\hline $\begin{array}{l}\text { Technology Readiness } \\
\text { (Duration }-5 \text { years) }\end{array}$ & $8.4 \mathrm{E}-04$ & 1.7E-03 & $3.3 \mathrm{E}-03$ & $2.9 \mathrm{E}-01$ & $0.0 \mathrm{E}+00$ & $4.2 E-03$ & $8.6 \mathrm{E}-03$ & $1.6 \mathrm{E}-02$ & $1.4 \mathrm{E}+00$ & $0.0 \mathrm{E}+00$ \\
\hline $\begin{array}{c}\text { Capital } \\
\text { (Duration - } 5 \text { years) }\end{array}$ & $3.1 \mathrm{E}-02$ & $6.3 \mathrm{E}-02$ & $1.2 \mathrm{E}-01$ & $1.0 \mathrm{E}+01$ & $2.2 \mathrm{E}-02$ & $1.5 \mathrm{E}-01$ & $3.1 E-01$ & $6.0 \mathrm{E}-01$ & $5.2 \mathrm{E}+01$ & $1.1 \mathrm{E}-01$ \\
\hline $\begin{array}{c}\text { Operators \& } \\
\text { Maintenance } \\
\text { (Duration - 15 years) }\end{array}$ & $0.0 \mathrm{E}+00$ & $0.0 \mathrm{E}+00$ & $0.0 \mathrm{E}+00$ & $0.0 \mathrm{E}+00$ & $0.0 \mathrm{E}+00$ & $0.0 \mathrm{E}+00$ & $0.0 \mathrm{E}+00$ & $0.0 \mathrm{E}+00$ & $0.0 \mathrm{E}+00$ & $0.0 \mathrm{E}+00$ \\
\hline $\begin{array}{c}\text { Decontamination \& } \\
\text { Decommissioning } \\
\text { (Duration - } 1 \text { year) }\end{array}$ & $1.6 \mathrm{E}-02$ & $3.2 \mathrm{E}-02$ & $6.1 \mathrm{E}-02$ & $5.3 E+00$ & $1.5 \mathrm{E}-02$ & $4.7 \mathrm{E}-02$ & $9.7 \mathrm{E}-02$ & $1.8 \mathrm{E}-01$ & $1.6 \mathrm{E}+01$ & $\begin{array}{c}4.6 \mathrm{E}-02 \\
-\end{array}$ \\
\hline TOTAL & r. & $\left|\begin{array}{c}4 \\
4 \\
4\end{array}\right|$ & a & 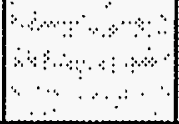 & 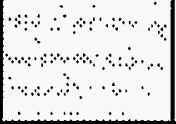 & $2.0 \mathrm{E}-01$ & $4.2 \mathrm{E}-01$ & $8.0 \mathrm{E}-01$ & $7.0 \mathrm{E}+01$ & $1.6 \mathrm{E}-01$ \\
\hline
\end{tabular}

\section{Assumptions:}

- Transportation is to and from the site only

- Operational risks cncompass industrial/plyysical halzards associated with equipment operation and onsite operations

- Infrastructure stalt support the staff above. They receive no annual Cancer, average 4,000 travel miles, and average $50 \%$ of the lacility totals above.

- Collective risks have been calculated as the product of individual risk, multiplied by the number of exposed inidividuals.

Individual risks provide estimates of the probability of health detriment for the individual, and the collective risks provide a measure of overall detriment

to the work force. 
Option: T. Clean Closure (no barrier)

Capital Cost: $\$ 730$ million

Annual Worker Mileage: 15,000

\begin{tabular}{|c|c|c|c|c|c|c|c|c|c|c|}
\hline \multirow{4}{*}{ Activity } & \multicolumn{10}{|c|}{ Maintenance Crafts } \\
\hline & \multicolumn{5}{|c|}{ Annual } & \multicolumn{5}{|c|}{ Total } \\
\hline & \multicolumn{2}{|c|}{ Transportation } & \multicolumn{3}{|c|}{ Operational } & \multicolumn{2}{|c|}{ Transportation } & \multicolumn{3}{|c|}{ Operational } \\
\hline & Death & Injury & Death & Injury & Cancer & Death & Injury & Death & Injury & Cancer \\
\hline $\begin{array}{l}\text { Technology Readiness } \\
\text { (Duration - } 5 \text { years) }\end{array}$ & $0.0 \mathrm{E}+00$ & $0.0 \mathrm{E}+00$ & $0.0 \mathrm{E}+00$ & $0.0 \mathrm{E}+00$ & $0.0 \mathrm{E}+00$ & $0.0 \mathrm{E}+00$ & $0.0 \mathrm{E}+00$ & $0.0 \mathrm{E}+00$ & $0.0 \mathrm{E}+00$ & $0.0 \mathrm{E}+00$ \\
\hline $\begin{array}{c}\text { Capital } \\
\text { (Duration }-5 \text { years) }\end{array}$ & $0.0 \mathrm{E}+00$ & $0.0 \mathrm{E}+00$ & $0.0 \mathrm{E}+00$ & $0.0 \mathrm{E}+00$ & $0.0 \mathrm{E}+00$ & $0.0 \mathrm{E}+00$ & $0.0 \mathrm{E}+00$ & $0.0 \mathrm{E}+00$ & $0.0 \mathrm{E}+00$ & $0.0 \mathrm{E}+00$ \\
\hline $\begin{array}{c}\text { Operators \& } \\
\text { Maintenance } \\
\text { (Duration - } 15 \text { ycurs) }\end{array}$ & $5.8 \mathrm{E}-03$ & $1.2 \mathrm{E}-02$ & $2.5 \mathrm{E}-03$ & $6.2 E-01$ & $5.6 \mathrm{E}-03$ & $1.2 \mathrm{E}-01$ & $2.4 \mathrm{E}-01$ & $5.1 \mathrm{E}-02$ & $1.2 \mathrm{E}+01$ & $1.1 \mathrm{E}-01$ \\
\hline $\begin{array}{l}\text { Decontamination \& } \\
\text { Decommissioning } \\
\text { (Duration - } 1 \text { year) }\end{array}$ & $0.0 \mathrm{E}+00$ & $0.0 \mathrm{E}+00$ & $0.0 \mathrm{E}+00$ & $0.0 \mathrm{E}+00$ & $0.0 \mathrm{E}+00$ & $0.0 \mathrm{E}+00$ & $0.0 \mathrm{E}+00$ & $0.0 \mathrm{E}+00$ & $0.0 \mathrm{E}+00$ & $0.0 \mathrm{E}+00$ \\
\hline TOTAL & ४ै। & ২ै। & के। & अे। & के & $1.2 \mathrm{E}-01$ & $2.4 \mathrm{E}-01$ & $5.1 \mathrm{E}-02$ & $1.2 \mathrm{E}+01$ & $1.1 \mathrm{E}-01$ \\
\hline
\end{tabular}

\section{Assumptions:}

- Transportation is to and from the site only

- Operational risks encompass industrial/physical hazards associated with equipment operation and onsite operations

- Infrastructure staff support the staff above. They receive no annual Cancer, average 4,000 travel miles. and average $50 \%$ of the facility totals above.

- Collective risks have been calculated as the product of individual risk, multiplied by the number of exposed inidividuals.

Individual risks provide estimates of the probability of health detriment for the individual, and the collective risks provide a measure of overall detriment to the work force. 
Option: T. Clean Closure (no barrier)

Capital Cost: $\$ 730$ million

Annual Worker Mileage: 15,000

\begin{tabular}{|c|c|c|c|c|c|c|c|c|c|c|}
\hline \multirow{4}{*}{ Activity } & \multicolumn{10}{|c|}{ Operators } \\
\hline & \multicolumn{5}{|c|}{ Annual } & \multicolumn{5}{|c|}{ Total } \\
\hline & \multicolumn{2}{|c|}{ Transportation } & \multicolumn{3}{|c|}{ Operational } & \multicolumn{2}{|c|}{ Transportation } & \multicolumn{3}{|c|}{ Operational } \\
\hline & Death & Injury & Death & Injury & Cancer & Death & Injury & Death & Injury & Cancer \\
\hline $\begin{array}{l}\text { Technology Readiness } \\
\text { (Duration - } 5 \text { years) }\end{array}$ & $0.0 \mathrm{E}+00$ & $0.0 \mathrm{E}+00$ & $0.0 \mathrm{E}+00$ & $0.0 \mathrm{E}+00$ & $0.0 \mathrm{E}+00$ & $0.0 \mathrm{E}+00$ & $0.0 \mathrm{E}+00$ & $0.0 \mathrm{E}+00$ & $0.0 \mathrm{E}+00$ & $0.0 \mathrm{E}+00$ \\
\hline $\begin{array}{c}\text { Capital } \\
\text { (Duration - } 5 \text { years) }\end{array}$ & $0.0 \mathrm{E}+00$ & $0.0 \mathrm{E}+00$ & $0.0 \mathrm{E}+00$ & $0.0 \mathrm{E}+00$ & $0.0 \mathrm{E}+00$ & $0.0 \mathrm{E}+00$ & $0.0 \mathrm{E}+00$ & $0.0 \mathrm{E}+00$ & $0.0 \mathrm{E}+00$ & $0.0 \mathrm{E}+00$ \\
\hline $\begin{array}{c}\text { Operators \& } \\
\text { Maintenance } \\
\text { (Duration - } 15 \text { years) }\end{array}$ & $1.2 \mathrm{E}-02$ & $2.4 \mathrm{E}-02$ & $5.1 \mathrm{E}-03$ & $1.2 \mathrm{E}+00$ & $1.1 \mathrm{E}-02$ & $2.3 E-01$ & $4.7 \mathrm{E}-01$ & $1.0 \mathrm{E}-01$ & $2.5 \mathrm{E}+01$ & $2.2 \mathrm{E}-01$ \\
\hline $\begin{array}{l}\text { Decontamination \& } \\
\text { Decommissioning } \\
\text { (Duration - 1 ycar) }\end{array}$ & $2.5 \mathrm{E}-03$ & $5.1 \mathrm{E}-03$ & 1.1E-03 & $2.7 \mathrm{E}-01$ & $2.4 \mathrm{E}-03$ & $7.5 \mathrm{E}-03$ & $1.5 \mathrm{E}-02$ & $3.3 \mathrm{E}-03$ & $8.0 \mathrm{E}-01$ & $7.3 \mathrm{E}-03$ \\
\hline TOTAL & \begin{tabular}{c}
$\cdots$ \\
$\ddots \cdots$ \\
\hdashline \\
\hdashline
\end{tabular} & $\therefore$ & $\begin{array}{c}\cdots \\
\therefore \\
\cdots \\
\cdots\end{array}$ & $\begin{array}{ccc}\therefore & \vdots \\
\cdots & \vdots\end{array}$ & $\begin{array}{l}\cdots \\
\cdots \\
\cdots\end{array}$ & $2.4 \mathrm{E}-01$ & $4.9 \mathrm{E}-01$ & $1.0 \mathrm{E}-01$ & $2.6 \mathrm{E}+01$ & $2.3 \mathrm{E}-01$ \\
\hline
\end{tabular}

\section{Assumptions:}

- Transportation is to and from the site only

- Operational risks encompass industrial/physical hazards associated with equipment operation and onsite operations

- Infrastructure staff support the staff above. They reccive no annual Cancer, average 4,000 travel miles, and average $50 \%$ of the facility totals above.

- Collective risks have been calculated as the product of individual risk, multiplied by the number of exposed inidividuals.

Individual risks provide estimates of the probability of health detriment for the individual, and the collective risks provide a measure of overall detriment

to the work force. 


\begin{tabular}{|c|c|c|c|c|c|c|c|c|c|c|c|c|c|c|c|c|}
\hline $\begin{array}{r}\text { Option } \\
\text { Capital Cost } \\
\text { Annual Worker Mileagc }\end{array}$ & $\begin{array}{l}\text { T. Clean } \\
\$ 730 \mathrm{mil} \\
15,000\end{array}$ & $\begin{array}{l}\text { Closure } \\
\text { llion }\end{array}$ & (no barri & & & & & & & & & & & & & \\
\hline \multirow{4}{*}{ Activity } & \multicolumn{10}{|c|}{ All Workers } & \multicolumn{6}{|c|}{ All Workers } \\
\hline & \multicolumn{5}{|c|}{\begin{tabular}{|c|} 
\\
\end{tabular}} & \multicolumn{5}{|c|}{ Total } & \multirow{2}{*}{\multicolumn{3}{|c|}{ Annuals }} & \multirow{2}{*}{\multicolumn{3}{|c|}{ Totals }} \\
\hline & \multicolumn{2}{|c|}{\begin{tabular}{|l|} 
Transportation \\
\end{tabular}} & \multicolumn{3}{|c|}{ Opcrational } & \multicolumn{2}{|c|}{ Transportation } & \multicolumn{3}{|c|}{ Operational } & & & & & & \\
\hline & \begin{tabular}{|l|} 
Death \\
\end{tabular} & Injury & Death & \begin{tabular}{|l|} 
Injury \\
\end{tabular} & Cancer & Death & Injury & Death & Injury & Cancer & \begin{tabular}{|l|} 
Death \\
\end{tabular} & Injury & Cancer & Death & Injury & Cancer \\
\hline $\begin{array}{c}\text { Technology Readiness } \\
\text { (Duration - } 5 \text { years) }\end{array}$ & $34 \mathrm{E}-03$ & $70 \mathrm{E}-03$ & $45 \mathrm{E}-03$ & $9.8 \mathrm{E}-01$ & $0.0 \mathrm{E}+00$ & $17 \mathrm{E}-02$ & $3.5 \mathrm{E}-02$ & $23 \mathrm{E}-02$ & $4.9 \mathrm{E}+00$ & $|0.0 E+00|$ & $7.9 \mathrm{E}-03$ & $9.9 \mathrm{E}-01$ & $0.0 \mathrm{E}+00$ & $4.0 \mathrm{E}-02$ & $4.9 \mathrm{E}+00$ & $0.0 \mathrm{E}+00$ \\
\hline $\begin{array}{c}\text { Capital } \\
\text { (Duration - } 5 \text { years) }\end{array}$ & $7.7 \mathrm{E}-02$ & $1.6 \mathrm{E}-01$ & $1.4 \mathrm{E}-01$ & $2.3 E+01 \mid$ & $2.4 \mathrm{E}-02$ & $3.8 \mathrm{E}-0$ & $7.9 \mathrm{E}-0$ & $7.1 \mathrm{E}-01$ & $1.1 \mathrm{E}+02$ & $1.2 E-01$ & $2.2 \mathrm{E}-01$ & $2.3 E+01$ & $2.4 \mathrm{E} \cdot 02$ & $1.1 \mathrm{E}+00$ & $1.2 E+02$ & $1.2 \mathrm{E}-01$ \\
\hline $\begin{array}{c}\text { Operators \& } \\
\text { Maintenance } \\
\text { (Duration - 15 years) } \\
\end{array}$ & $2.9 \mathrm{E}-02$ & $5.9 \mathrm{E}-02$ & $1.3 \mathrm{E}-02$ & $|50 \mathrm{E}+00|$ & $1.8 \mathrm{E}-02$ & $58 \mathrm{E}-01$ & $12 E+00$ & $26 \mathrm{E}-01$ & $1.0 \mathrm{E}+02$ & $3.6 \mathrm{E}-01$ & $4.2 \mathrm{E}-02$ & $5.1 \mathrm{E}+00$ & $1.8 \mathrm{E}-02$ & $8.4 \mathrm{E}-01$ & $1.0 \mathrm{E}+02$ & $3.6 \mathrm{E}-01$ \\
\hline $\begin{array}{c}\text { Decontamination \& } \\
\text { Decommissioning } \\
\text { (Duration - 1 year) }\end{array}$ & $2.6 \mathrm{E}-02$ & $5.3 \mathrm{E}-02$ & $6.6 \mathrm{E}-02$ & $|7.7 \mathrm{E}+00|$ & $1.8 \mathrm{E}-02$ & $7.8 \mathrm{E}-02$ & $1.6 \mathrm{E}-01$ & $2.0 \mathrm{E}-01$ & $2.3 \mathrm{E}+01$ & $5.5 \mathrm{E}-02$ & $9.2 \mathrm{E}-02$ & $7.8 \mathrm{E}+00$ & $1.8 \mathrm{E}-02$ & $2.8 \mathrm{E}-01$ & $2.3 E+01$ & $5.5 \mathrm{E}-02$ \\
\hline TOTAL & अे. & ?. & & $(2)$. & के। & $1.1 \mathrm{E}+00$ & $2.2 \mathrm{E}+00$ & $1.2 \mathrm{E}+00$ & $2.4 \mathrm{E}+02$ & $5.3 \mathrm{E}-01$ & (2.?. & $1 \%$ & 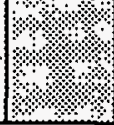 & $2.2 \mathrm{E}+00$ & $2.4 E+02$ & $5.3 \mathrm{E}-01$ \\
\hline
\end{tabular}

Assumptions:

- Transportation is to and from the site only

- Operational risks encompass industrial/physical hazards associated with equipment operation and onsite operations

- Infrastructure staff support the staff above. They receive no annual Cancer. average 4.000 travel miles, and average $50 \%$ of the facility totals above.

- Collective risks have been calculated as the product of individual risk, multiplied by the number of exposed inidividuals.

Individual risks provide estimates of the probability of health detriment for the individual, and the collective risks provide a measure of overall detriment

to the work force. 
Option: U. Clean Closure (with Close-Coupled Barrier)

Capital Cost: $\$ 584$ million

Annual Worker Milcage: 15,000

\begin{tabular}{|c|c|c|c|c|c|c|c|c|c|c|}
\hline \multirow{4}{*}{ Activity } & \multicolumn{10}{|c|}{$\begin{array}{c}\text { Management and } \\
\text { Enginecring }\end{array}$} \\
\hline & \multicolumn{5}{|c|}{ Annual } & \multicolumn{5}{|c|}{ Total } \\
\hline & \multicolumn{2}{|c|}{ Transportation } & \multicolumn{3}{|c|}{ Operational } & \multicolumn{2}{|c|}{ Transportation } & \multicolumn{3}{|c|}{ Operational } \\
\hline & Death & \begin{tabular}{|l|} 
Injury \\
\end{tabular} & Death & Injury & Cancer & Death & Injury & Death & Injury & Cancer \\
\hline $\begin{array}{c}\text { Tecinnology Readiness } \\
\text { (Duration - } 5 \text { years) }\end{array}$ & $2.6 \mathrm{E}-03$ & $5.2 E-03$ & 1.2E-03 & $6.9 \mathrm{E}-01$ & $0.0 \mathrm{E}+00$ & $1.3 \mathrm{E}-02$ & $2.6 \mathrm{E}-02$ & $6.2 \mathrm{E}-03$ & $3.5 E+00$ & $0.0 \mathrm{E}+00$ \\
\hline $\begin{array}{c}\text { Capital } \\
\text { (Duration - } 5 \text { ycars) } \\
\end{array}$ & $3.7 \mathrm{E}-02$ & $7.5 \mathrm{E}-02$ & $1.8 \mathrm{E}-02$ & $1.0 \mathrm{E}+01$ & $1.3 \mathrm{E}-03$ & $1.8 \mathrm{E}-01$ & $3.8 \mathrm{E}-01$ & $8.9 \mathrm{E}-02$ & $5.0 \mathrm{E}+01$ & $6.7 \mathrm{E}-03$ \\
\hline $\begin{array}{c}\text { Operators \& } \\
\text { Maintenance } \\
\text { (Duration - } 15 \text { years) }\end{array}$ & $1.1 \mathrm{E}-02$ & $2.4 \mathrm{E}-02$ & $5.6 \mathrm{E}-03$ & $3.1 E+00$ & $9.8 \mathrm{E}-04$ & $2.3 \mathrm{E}-01$ & $4.7 \mathrm{E}-0 \mathrm{I}$ & $1.1 \mathrm{E}-01$ & $6.2 \mathrm{E}+01$ & $2.0 \mathrm{E}-02$ \\
\hline $\begin{array}{l}\text { Decontamination \& } \\
\text { Decommissioning } \\
\text { (Duration - } 1 \text { ycar) }\end{array}$ & 7.7E-03 & $1.6 \mathrm{E}-02$ & $3.8 \mathrm{E}-03$ & 2.IE +00 & $6.6 \mathrm{E}-04$ & $2.3 \mathrm{E}-02$ & 4.7E-02 & $1.1 \mathrm{E}-02$ & $6.3 E+00$ & $2.0 \mathrm{E}-03$ \\
\hline TOTAL & a & 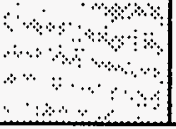 & $\mid \begin{array}{c}0 \\
0\end{array}$ & 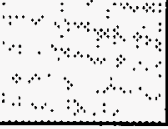 & 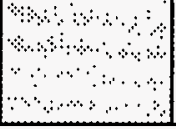 & $4.5 \mathrm{E}-01$ & $9.2 \mathrm{E}-01$ & $2.2 \mathrm{E}-01$ & $1.2 \mathrm{E}+02$ & $2.8 \mathrm{E}-02$ \\
\hline
\end{tabular}

Assumptions:

- Transportation is to and from the site only

- Operational risks encompass industrial/physical hazards associated with equipment operation and onsite operations

- Infrastructure staff support the staff above. They receive no annual Cancer, average 4,000 travel miles, and average $50 \%$ of the facility totals above.

- Collective risks have been calculated as the product of individual risk, multiplied by the number of cxposed inidividuals.

Individual risks provide estimates of the probability of health detriment for the individual, and the collective risks provide a measure of overall detriment

to the work force. 
Option: U. Clean Closure (with Close-Coupled Barrier)

Capital Cost: $\$ 584$ million

Annual Worker Mileage: 15,000

\begin{tabular}{|c|c|c|c|c|c|c|c|c|c|c|}
\hline \multirow{4}{*}{ Activity } & \multicolumn{10}{|c|}{$\begin{array}{l}\text { Construction/Decommissioning } \\
\text { Crafts and Laborers }\end{array}$} \\
\hline & \multicolumn{5}{|c|}{ Annual } & \multicolumn{5}{|c|}{ Total } \\
\hline & \multicolumn{2}{|c|}{ Transportation } & \multicolumn{3}{|c|}{ Operational } & \multicolumn{2}{|c|}{ Transportation } & \multicolumn{3}{|c|}{ Operational } \\
\hline & Death & Injury & Death & Injury & Cancer & Dcath & Injury & Death & Injury & Cancer \\
\hline $\begin{array}{l}\text { Teclinology Readiness } \\
\text { (Duration - } 5 \text { years) }\end{array}$ & $8.4 E-04$ & $1.7 \mathrm{E}-03$ & $3.3 \mathrm{E}-03$ & $2.9 \mathrm{E}-01$ & $0.0 \mathrm{E}+00$ & 4.2E-03 & $8.6 \mathrm{E}-03$ & $1.6 \mathrm{E}-02$ & $1.4 \mathrm{E}+00$ & $0.0 \mathrm{E}+00$ \\
\hline $\begin{array}{c}\text { Capital } \\
\text { (Duration - } 5 \text { y'ears) }\end{array}$ & $2.5 \mathrm{E}-02$ & $5.0 \mathrm{E}-02$ & $9.5 \mathrm{E}-02$ & $8.3 E+00$ & $1.8 \mathrm{E}-02$ & $1.2 \mathrm{E}-01$ & $2.5 \mathrm{E}-01$ & $4.8 \mathrm{E}-01$ & $4.2 \mathrm{E}+01$ & $8.9 \mathrm{E}-02$ \\
\hline $\begin{array}{c}\text { Operators \& } \\
\text { Maintenance } \\
\text { (Duration - } 15 \text { years) }\end{array}$ & $0.0 \mathrm{E}+00$ & $0.0 \mathrm{E}+00$ & $0.0 \mathrm{E}+00$ & $0.0 \mathrm{E}+00$ & $0.0 \mathrm{E}+00$ & $0.0 \mathrm{E}+00$ & $0.0 \mathrm{E}+00$ & $0.0 \mathrm{E}+00$ & $0.0 \mathrm{E}+00$ & $0.0 \mathrm{E}+00$ \\
\hline $\begin{array}{l}\text { Decontamination \& } \\
\text { Decommissioning } \\
\text { (Duration - } 1 \text { year) }\end{array}$ & $1.5 \mathrm{E}-02$ & $3.2 \mathrm{E}-02$ & $6.0 \mathrm{E}-02$ & $5.2 \mathrm{E}+00$ & $1.5 \mathrm{E}-02$ & 4.6E-02 & $9.5 \mathrm{E}-02$ & $1.8 \mathrm{E}-01$ & $1.6 \mathrm{E}+01$ & $4.5 \mathrm{E}-02$ \\
\hline TOTAL & कि & मे। & किका & किक & के। & $1.7 \mathrm{E}-01$ & $3.5 \mathrm{E}-01$ & $6.7 \mathrm{E}-01$ & $5.9 \mathrm{E}+01$ & $1.3 \mathrm{E}-01$ \\
\hline
\end{tabular}

Assumptions:

- Transportation is to and from the site only

- Operational risks encompass industrial/physical hazards associated with equipment operation and onsite operations

- Infrastructure staff support the staff above. They receive no annual Cancer, average 4,000 travel miles, and average $50 \%$ of the facility totals above.

- Collective risks have been calculated as the product of individual risk, multiplied by the number of exposed inidividuals.

Individual risks provide estimates of the probability of health detriment for the individual, and the collective risks provide a measure of overall detriment

to the work force. 
Option: U. Clean Closure (with Close-Coupled Barrier) Capital Cost: $\$ 584$ million

Annual Worker Milcage: 15,000

\begin{tabular}{|c|c|c|c|c|c|c|c|c|c|c|}
\hline \multirow{4}{*}{ Activity } & \multicolumn{10}{|c|}{ Maintenance Crafts } \\
\hline & \multicolumn{5}{|c|}{ Annual } & \multicolumn{5}{|c|}{ Total } \\
\hline & \multicolumn{2}{|c|}{ Transportation } & \multicolumn{3}{|c|}{ Operational } & \multicolumn{2}{|c|}{ Transportation } & \multicolumn{3}{|c|}{ Operational } \\
\hline & Death & \begin{tabular}{|l|} 
Injury \\
\end{tabular} & Death & Injury & Cancer & Death & Injury & Death & Injury & Cancer \\
\hline $\begin{array}{l}\text { Technology Readiness } \\
\text { (Duration - } 5 \text { years) }\end{array}$ & $0.0 \mathrm{E}+00$ & $0.0 \mathrm{E}+00$ & $0.0 \mathrm{E}+00$ & $0.0 E+00$ & $0.0 E+00$ & $0.0 \mathrm{E}+00$ & $0.0 \mathrm{E}+00$ & $0.0 \mathrm{E}+00$ & $0.0 \mathrm{E}+00$ & $0.0 \mathrm{E}+00$ \\
\hline $\begin{array}{c}\text { Capital } \\
\text { (Duration - } 5 \text { years) }\end{array}$ & $0.0 \mathrm{E}+00$ & $0.0 \mathrm{E}+00$ & $0.0 \mathrm{E}+00$ & $0.0 \mathrm{E}+00$ & $0.0 \mathrm{E}+00$ & $0.0 \mathrm{E}+00$ & $0.0 \mathrm{E}+00$ & $0.0 \mathrm{E}+00$ & $0.0 \mathrm{E}+00$ & $0.0 \mathrm{E}+00$ \\
\hline $\begin{array}{c}\text { Operators \& } \\
\text { Maintenance } \\
\text { (Duration - } 15 \text { years) } \\
\end{array}$ & $5.7 \mathrm{E}-03$ & $1.2 \mathrm{E}-02$ & $2.5 \mathrm{E}-03$ & $6.1 \mathrm{E}-01$ & $5.6 \mathrm{E}-03$ & $1.1 \mathrm{E}-01$ & $2.4 \mathrm{E}-01$ & $5.0 \mathrm{E}-02$ & $1.2 \mathrm{E}+01$ & $1.1 \mathrm{E}-01$ \\
\hline $\begin{array}{c}\text { Decontamination \& } \\
\text { Decommissioning } \\
\text { (Duration - } 1 \text { year) }\end{array}$ & $0.0 \mathrm{E}+00$ & $0.0 \mathrm{E}+00$ & $0.0 \mathrm{E}+00$ & $0.0 \mathrm{E}+00$ & $0.0 \mathrm{E}+00$ & $0.0 \mathrm{E}+00$ & $0.0 \mathrm{E}+00$ & $0.0 \mathrm{E}+00$ & $0.0 \mathrm{E}+00$ & $0.0 \mathrm{E}+00$ \\
\hline TOTAL & 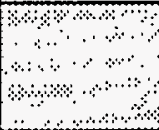 & a & 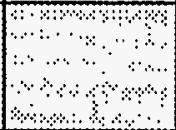 & 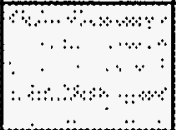 & 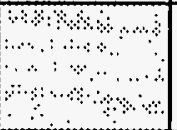 & $1.1 \mathrm{E}-01$ & $2.4 \mathrm{E}-01$ & $5.0 \mathrm{E}-02$ & $1.2 \mathrm{E}+01$ & $1.1 \mathrm{E}-01$ \\
\hline
\end{tabular}

\section{Assumptions:}

- Transportation is to and from the site only

- Operational risks encompass industrial/physical hazards associated with equipment operation and onsite operations

- Infrastructure staff support the staff above. They receive no annual Cancer, average 4,000 travel miles, and average $50 \%$ of the facility totals above.

- Collective risks have been calculated as the product of individual risk, multiplied by the number of exposed inidividuals.

Individual risks provide estimates of the probability of health detriment for the individual, and the collective risks provide a measure of overall detriment to the work force. 
Table D.3. Options Worker Risks (Sheet 104 of 105)

Option: U. Clean Closure (with Close-Coupled Barrier)

Capital Cost: $\$ 584$ million

Annual Worker Milcage: 15,000

\begin{tabular}{|c|c|c|c|c|c|c|c|c|c|c|}
\hline \multirow{4}{*}{ Activity } & \multicolumn{10}{|c|}{ Operators } \\
\hline & \multicolumn{5}{|c|}{ Annual } & \multicolumn{5}{|c|}{ Total } \\
\hline & \multicolumn{2}{|c|}{ Transportation } & \multicolumn{3}{|c|}{ Operational } & \multicolumn{2}{|c|}{ Transportation } & \multicolumn{3}{|c|}{ Operational } \\
\hline & Death & Injury & Death & Injury & Cancer & Death & Injury & Death & Injury & Cancer \\
\hline $\begin{array}{l}\text { Technology Readiness } \\
\text { (Duration - } 5 \text { years) }\end{array}$ & $0.0 \mathrm{E}+00$ & $0.0 \mathrm{E}+00$ & $0.0 \mathrm{E}+00$ & $0.0 \mathrm{E}+00$ & $0.0 \mathrm{E}+00$ & $0.0 \mathrm{E}+00$ & $0.0 \mathrm{E}+00$ & $0.0 \mathrm{E}+00$ & $0.0 \mathrm{E}+00$ & $0.0 \mathrm{E}+00$ \\
\hline $\begin{array}{c}\text { Capital } \\
\text { (Duration - } 5 \text { ycars) }\end{array}$ & $0.0 \mathrm{E}+00$ & $0.0 \mathrm{E}+00$ & $0.0 \mathrm{E}+00$ & $0.0 \mathrm{E}+00$ & $0.0 \mathrm{E}+00$ & $0.0 \mathrm{E}+00$ & $0.0 \mathrm{E}+00$ & $0.0 \mathrm{E}+00$ & $0.0 \bar{E}+00$ & $0.0 \mathrm{E}+00$ \\
\hline $\begin{array}{c}\text { Operators \& } \\
\text { Maintenance } \\
\text { (Duration - 15 years) }\end{array}$ & 1.1E-02 & $2.4 \mathrm{E}-02$ & $5.0 \mathrm{E}-03$ & $1.2 \mathrm{E}+00$ & $1.1 \mathrm{E}-02$ & $2.3 \mathrm{E}-01$ & 4.7E-01 & $1.0 \mathrm{E}-01$ & $2.5 \mathrm{E}+01$ & $2.2 \mathrm{E}-0 \mathrm{I}$ \\
\hline $\begin{array}{c}\text { Decontamination \& } \\
\text { Decommissioning } \\
\text { (Duration - } 1 \text { year) }\end{array}$ & $2.5 \mathrm{E}-03$ & $5.1 E-03$ & $1.1 \mathrm{E}-03$ & $2.6 \mathrm{E}-01$ & $2.4 \mathrm{E}-03$ & $7.4 E-03$ & $1.5 \mathrm{E}-02$ & $3.2 \mathrm{E}-03$ & $7.9 \mathrm{E}-01$ & 7.2E-03 \\
\hline TOTAL & के, & \%ै. & किमें & में? & कि? & $2.4 \mathrm{E}-01$ & $4.9 \mathrm{E}-01$ & $1.0 \mathrm{E}-01$ & $2.5 \mathrm{E}+01$ & 2.3E-01 \\
\hline
\end{tabular}

Assumptions:

- Transportation is to and from the site only

- Operational risks encompass industrial/physical hazards associated with equipment operation and onsite operations

- Infrastructure staff support the staff above. They receive no annual Cancer, average 4,000 travel miles, and average $50 \%$ of the facility totals above.

- Collective risks have been calculated as the product of individual risk, multiplied by the number of exposed inidividuals.

Individual risks provide estimates of the probability of health detriment for the individual, and the collective risks provide a measure of overall detriment

to the work force. 
Option: U. Clean Closure (with Close-Coupled Barrier) Capital Cost: $\$ 584$ million

Annual Worker Mileage: 15,000

\begin{tabular}{|c|c|c|c|c|c|c|c|c|c|c|c|c|c|c|c|c|}
\hline \multirow{4}{*}{ Activity } & \multicolumn{10}{|c|}{ All Workers } & \multicolumn{6}{|c|}{ All Workers } \\
\hline & \multicolumn{5}{|c|}{ Annual } & \multicolumn{5}{|c|}{ Total } & \multirow{2}{*}{\multicolumn{3}{|c|}{ Annuals }} & \multirow{2}{*}{\multicolumn{3}{|c|}{ Totals }} \\
\hline & \multicolumn{2}{|c|}{ Transportation } & \multicolumn{3}{|c|}{\begin{tabular}{|l|} 
Operational \\
\end{tabular}} & \multicolumn{2}{|c|}{ Transportation } & \multicolumn{3}{|c|}{ Operational } & & & & & & \\
\hline & Death & Injury & \begin{tabular}{|l|} 
Death \\
\end{tabular} & Injury & Cancer & Death & \begin{tabular}{|l|} 
Injury \\
\end{tabular} & Death & Injury & Cancer & Death & Injury & Cancer & Death & Injury & Cancer \\
\hline $\begin{array}{l}\text { Technology Readiness } \\
\text { (Duration - } 5 \text { years) }\end{array}$ & $3.4 \mathrm{E}-03$ & $7.0 \mathrm{E}-03$ & $4.5 \mathrm{E}-03$ & $9.8 \mathrm{E}-01$ & $0.0 \mathrm{E}+00$ & $1.7 \mathrm{E}-02$ & $3.5 \mathrm{E}-02$ & $2.3 \mathrm{E}-02$ & $4.9 \mathrm{E}+00$ & $0.0 \mathrm{E}+00$ & $7.9 \mathrm{E}-03$ & $9.9 \mathrm{E}-01$ & $0.0 \mathrm{E}+00$ & $4.0 \mathrm{E}-02$ & $4.9 \mathrm{E}+00$ & $0.0 \mathrm{E}+00$ \\
\hline $\begin{array}{c}\text { Capital } \\
\text { (Duration - } 5 \text { years) } \\
\end{array}$ & $6.1 \mathrm{E}-02$ & $1.3 \mathrm{E}-01$ & $1.1 \mathrm{E}-01$ & $1.8 \mathrm{E}+01$ & $1.9 \mathrm{E}-02$ & $3.1 \mathrm{E}-01$ & $6.3 \mathrm{E}-01$ & $5.7 \mathrm{E}-01$ & $9.2 \mathrm{E}+01$ & $9.6 \mathrm{E}-02$ & $1.7 \mathrm{E}-01$ & $1.8 \mathrm{E}+01$ & $1.9 \mathrm{E}-02$ & 8.7E-01 & $9.2 \mathrm{E}+01$ & $9.6 \mathrm{E}-02$ \\
\hline $\begin{array}{c}\text { Operators } \& \\
\text { Maintenance } \\
\text { (Duration - } 15 \text { years) } \\
\end{array}$ & $2.9 \mathrm{E}-02$ & $5.9 \mathrm{E}-02$ & $1.3 \mathrm{E}-02$ & $5.0 \mathrm{E}+00$ & $1.8 \mathrm{E}-02$ & $5.7 \mathrm{E}-01$ & $1.2 \mathrm{E}+00$ & $2.6 \mathrm{E}-01$ & $9.9 \mathrm{E}+01$ & $3.5 \mathrm{E}-01$ & $4.2 \mathrm{E}-02$ & $5.0 \mathrm{E}+00$ & $1.8 \mathrm{E}-02$ & $8.4 \mathrm{E}-01$ & $1.0 \mathrm{E}+02$ & $3.5 \mathrm{E}-01$ \\
\hline $\begin{array}{l}\text { Decontamination \& } \\
\text { Decommissioning } \\
\text { (Duration - } 1 \text { year) }\end{array}$ & $2.6 \mathrm{E}-02$ & $5.2 \mathrm{E}-02$ & $6.5 \mathrm{E}-02$ & $7.6 \mathrm{E}+00$ & $1.8 \mathrm{E}-02$ & 7.7E-02 & $1.6 \mathrm{E}-01$ & $1.9 \mathrm{E}-01$ & $2.3 \mathrm{E}+01$ & $5.4 \mathrm{E}-02$ & $9.0 \mathrm{E}-02$ & $7.7 \mathrm{E}+00$ & $1.8 \mathrm{E}-02$ & 2.7E-01 & $2.3 E+01$ & $5.4 \mathrm{E}-02$ \\
\hline TOTAL & के & के & \%क & के & के & $9.8 \mathrm{E}-01$ & $2.0 \mathrm{E}+00$ & $1.0 \mathrm{E}+00$ & $2.2 \mathrm{E}+02$ & $5.0 \mathrm{E}-01$ & २ैै। & के & +. & $2.0 \mathrm{E}+00$ & $2.2 \mathrm{E}+02$ & $5.0 \mathrm{E}-01$ \\
\hline
\end{tabular}

\section{Assumptions:}

- Transportation is to and from the site only

- Operational risks encompass industrial/physical hazards associated with equipment operation and onsite operations

- Infrastructure staff support the staff above. They receive no annual Cancer, average 4,000 travel miles, and average $50 \%$ of the facility totals above.

- Collective risks have been calculated as the product of individual risk, multiplied by the number of exposed inidividuals.

Individual risks provide estimates of the probability of health detriment for the individual, and the collective risks provide a measure of overall detriment

to the work force. 
WHC-SD-WM-ES-300 REV. 1

This page left intentionally blank. 
WHC-SD-WM-ES-300 REV. 1

APPENDIX D.4

ALTERNATIVES WORKERS RISKS

D.4-1 
WHC-SD-WM-ES-300 REV. 1

This page intentionally left blank. 
WHC-SD-WM-ES-300 REV. 1

\section{ALTERNATIVES WORKERS RISKS}

This section lists the annual and total risks to workers for each integrated alternative.

\section{D.4-3}


WHC-SD-WM-ES-300 REV. 1

This page intentionally left blank. 
Alternative: 1 . No Action

Capital Cost: $\$ 0$

Annual Worker Mileage: 0

\begin{tabular}{|c|c|c|c|c|c|c|c|c|c|c|c|c|c|c|c|c|}
\hline \multirow{4}{*}{ Activity } & \multicolumn{10}{|c|}{ All Workers } & \multicolumn{6}{|c|}{ All Workers } \\
\hline & \multicolumn{5}{|c|}{ Annual } & \multicolumn{5}{|c|}{ Total } & \multirow{2}{*}{\multicolumn{3}{|c|}{ Annuals }} & \multirow{2}{*}{\multicolumn{3}{|c|}{ Totals }} \\
\hline & \multicolumn{2}{|c|}{ Transportation } & \multicolumn{3}{|c|}{ Operational } & \multicolumn{2}{|c|}{ Transportation } & \multicolumn{3}{|c|}{ Operational } & & & & & & \\
\hline & Death & Injury & Death & Injury & Cancer & Death & Injury & Death & Injury & Cancer & Death & Injury & Cancer & Death & Injury & Cancer \\
\hline $\begin{array}{l}\text { Technology Readiness } \\
\text { (Duration - } 5 \text { years) }\end{array}$ & NA & NA & NA & NA & $\mathrm{NA}$ & $\mathrm{NA}$ & NA & NA & NA & NA & NA & NA & NA & NA & NA & NA \\
\hline $\begin{array}{c}\text { Capital } \\
\text { (Duration }-5 \text { years) }\end{array}$ & NA & NA & NA & NA & NA & NA & $\mathrm{NA}$ & NA & $\mathrm{NA}$ & NA & $\mathrm{NA}$ & NA & $\mathrm{NA}$ & NA & NA & NA \\
\hline $\begin{array}{c}\text { Operators \& Maintenance } \\
\text { (Duration - } 15 \text { years) }\end{array}$ & NA & NA & NA & NA & NA & $\mathrm{NA}$ & NA & NA & NA & NA & NA & $\mathrm{NA}$ & NA & $\mathrm{NA}$ & NA & NA \\
\hline $\begin{array}{c}\text { Decontamination \& } \\
\text { Decommissioning } \\
\text { (Duration - } 1 \text { year) }\end{array}$ & NA & NA & NA & NA & NA & NA & NA & NA & NA & NA & NA & $\mathrm{NA}$ & NA & $\mathrm{NA}$ & NA & NA \\
\hline TOTAL & और & $\begin{array}{c}3 \\
3 \\
\cdots \\
\cdots\end{array}$ & 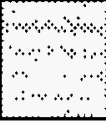 & $\begin{array}{r}0 \% \\
0 \\
\end{array}$ & $\begin{array}{r}8 \\
\cdots \\
\cdots \cdots\end{array}$ & NA & NA & NA & NA & $\mathrm{NA}$ & कै। & (1) & के & NA & NA & NA \\
\hline
\end{tabular}

Assumptions:

- Transportation is to and from the site only

- Operational risks encompass industrial/physical hazards associated with equipment operation and onsite operations

- Infrastructure staff support the staff above. They receive no annual Cancer, average 4,000 travel miles, and average $50 \%$ of the facility totals above.

- Collective risks have been calculated as the product of individual risk, multiplied by the number of exposed individuals.

Individual risks provide estimates of the probability of health detriment for the individual, and the collective risks provide a measure of overall detriment

to the work force. 


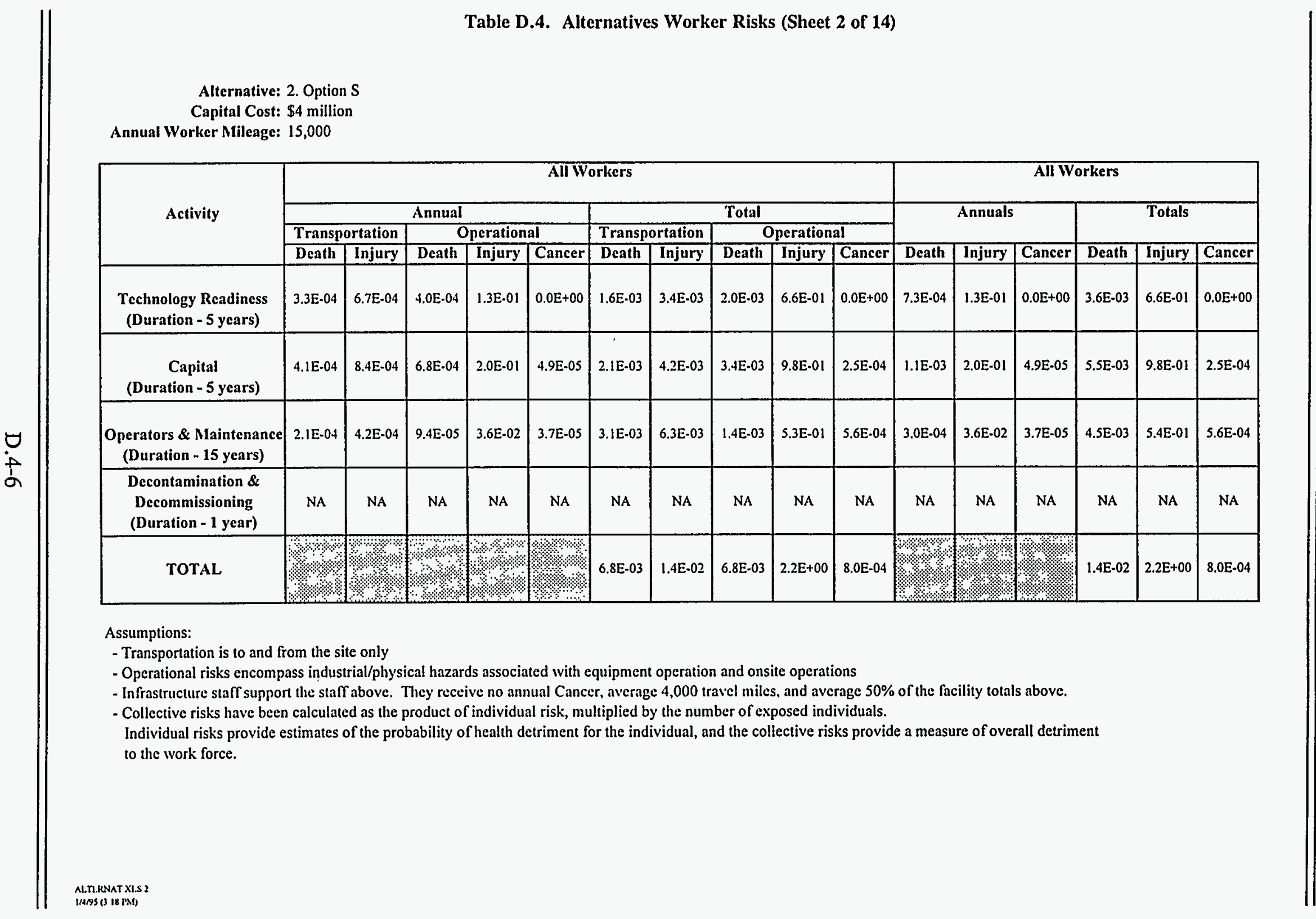


Alternative: 3. Options $A+R+S$

Capital Cost: $\$ 69$ million

Annual Worker Mileage: 15,000

\begin{tabular}{|c|c|c|c|c|c|c|c|c|c|c|c|c|c|c|c|c|}
\hline \multirow{4}{*}{ Activity } & \multicolumn{10}{|c|}{ All Workers } & \multicolumn{6}{|c|}{ All Workers } \\
\hline & \multicolumn{5}{|c|}{ Annual } & \multicolumn{5}{|c|}{ Total } & \multirow{2}{*}{\multicolumn{3}{|c|}{ Annuals }} & \multirow{2}{*}{\multicolumn{3}{|c|}{ Totals }} \\
\hline & \multicolumn{2}{|c|}{ Transportation } & \multicolumn{3}{|c|}{ Operational } & \multicolumn{2}{|c|}{ Transportation } & \multicolumn{3}{|c|}{ Operational } & & & & & & \\
\hline & Death & Injury & Death & Injury & Cancer & Death & Injury & Death & Injury & Cancer & Death & \begin{tabular}{|l|} 
Injury \\
\end{tabular} & Cancer & Death & Injury & Cancer \\
\hline $\begin{array}{l}\text { Technology Readiness } \\
\text { (Duration - } 5 \text { years) }\end{array}$ & $8.2 \mathrm{E}-04$ & $1.7 \mathrm{E}-03$ & $1.0 \mathrm{E}-03$ & $3.3 \mathrm{E}-01$ & $0.0 \mathrm{E}+00$ & $4.1 E-03$ & 8.4E- -03 & $5.0 \mathrm{E}-03$ & $1.6 \mathrm{E}+00$ & $0.0 E+00$ & $1.8 \mathrm{E}-03$ & $3.3 \mathrm{E}-01$ & $\mid 0.0 \mathrm{E}+00$ & $9.1 \mathrm{E}-03$ & $1.6 \mathrm{E}+00$ & $0.0 \mathrm{E}+00$ \\
\hline $\begin{array}{c}\text { Capital } \\
\text { (Duration - } 5 \text { ycars) }\end{array}$ & $7.2 \mathrm{E} \cdot 03$ & $1.5 \mathrm{E}-02$ & $1.2 \mathrm{E}-02$ & $3.4 E+00$ & $2.1 \mathrm{E}-03$ & $3.6 \mathrm{E}-02$ & 7.4E-02 & $5.9 \mathrm{E}-02$ & $1.7 E+01$ & 1.1E -02 & $1.9 \mathrm{E}-02$ & $3.4 E+00$ & $2.1 \mathrm{E}-03$ & $9.5 \mathrm{E}-02$ & $1.7 \mathrm{E}+01$ & $1.1 \mathrm{E}-02$ \\
\hline $\begin{array}{l}\text { Operators \& Maintenance } \\
\text { (Duration - } 15 \text { years) }\end{array}$ & $2.9 \mathrm{E}-03$ & $6.0 \mathrm{E}-03$ & $1.3 \mathrm{E}-03$ & $5.1 E-01$ & $1.7 \mathrm{E} .03$ & $4,4 E-02$ & $9.0 \mathrm{E}-02$ & $2.0 \mathrm{E}-02$ & $7.6 \mathrm{E}+00$ & $2.5 \mathrm{E}-02$ & $4.3 \mathrm{E} \cdot 03$ & 5.1E-01 & $1.7 \mathrm{E}-03$ & $6.4 \mathrm{E}-02$ & $7.7 \mathrm{E}+00$ & $2,5 \mathrm{E}-02$ \\
\hline $\begin{array}{c}\text { Decontamination \& } \\
\text { Decommissioning } \\
\text { (Duration - I year) }\end{array}$ & $2.5 \mathrm{E}-03$ & $5.1 \mathrm{E}-03$ & $5.7 \mathrm{E}-03$ & $1.4 E+00$ & $\mid \begin{array}{l}1.8 \mathrm{E}-03 \\
\end{array}$ & $2.5 \mathrm{E}-03$ & $5.1 E-03$ & $5.7 \mathrm{E}-03$ & $1.4 \mathrm{E}+00$ & $1.8 \mathrm{E} \cdot 03$ & $8.2 \mathrm{E}-03$ & $1.4 \mathrm{E}+00$ & 1.8E-03 & $8.2 \mathrm{E}-03$ & $1.4 E+00$ & $1.8 \mathrm{E}-03$ \\
\hline TOTAL & $\%$ & \% & & +. & in & $8.7 \mathrm{E}-02$ & $1.8 \mathrm{E}-01$ & $9.0 \mathrm{E}-02$ & $2.8 \mathrm{E}+01$ & $3.7 \mathrm{E}-02$ & & & ڤै. & 1.8E-01 & $2.8 \mathrm{E}+01$ & $3.7 \mathrm{E}-02$ \\
\hline
\end{tabular}

\section{Assumptions:}

- Transportation is to and from the site only

- Operational risks encompass industrial/physical hazards associated with equipment operation and onsite operations

- Infrastructure staff support the staff above. They receive no annual Cancer, average 4,000 travel miles, and average $50 \%$ of the facility totals above.

- Collective risks have been calculated as the product of individual risk, multiplied by the number of exposed individuals.

Individual risks provide estimates of the probability of health detriment for the individual, and the collective risks provide a measure of overall detriment to the work force. 
Alternative: 4 . Options $B+R+S$

Capital Cost: $\$ 189$ mitlion

Annual Worker Mileage: 15,000

\begin{tabular}{|c|c|c|c|c|c|c|c|c|c|c|c|c|c|c|c|c|}
\hline \multirow{4}{*}{ Activity } & \multicolumn{10}{|c|}{ All Workers } & \multicolumn{6}{|c|}{ All Workers } \\
\hline & \multicolumn{5}{|c|}{ Annual } & \multicolumn{5}{|c|}{ Total } & \multirow{2}{*}{\multicolumn{3}{|c|}{ Annuals }} & \multirow{2}{*}{\multicolumn{3}{|c|}{ Totals }} \\
\hline & \multicolumn{2}{|c|}{ Transportation } & \multicolumn{3}{|c|}{ Opcrational } & \multicolumn{2}{|c|}{ Transportation } & \multicolumn{3}{|c|}{ Operational } & & & & & & \\
\hline & Death & Injury & Death & Injury & Cancer & Death & Injury & Death & Injury & Cancer & Death & Injury & Cancer & Death & Injury & Cancer \\
\hline $\begin{array}{l}\text { Technology Readincss } \\
\text { (Duration - } 5 \text { years) }\end{array}$ & 3.5E-03 & $7.2 \mathrm{E}-03$ & 4.3E-03 & $1.4 \mathrm{E}+00$ & $0.0 \mathrm{E}+00$ & $1.8 \mathrm{E}-02$ & $3.6 \mathrm{E}-02$ & 2.1E-02 & $7.0 \mathrm{E}+00$ & $0.0 \mathrm{E}+00$ & $7.8 \mathrm{E}-03$ & $1.4 \mathrm{E}+00$ & $0.0 \mathrm{E}+00$ & $3: 9 \mathrm{E}-02$ & $7.1 \mathrm{E}+00$ & $0.0 \mathrm{E}+00$ \\
\hline $\begin{array}{c}\text { Capital } \\
\text { (Duration - } 5 \text { years) }\end{array}$ & $2.0 \mathrm{E}-02$ & $4.1 \mathrm{E}-02$ & $3.3 \mathrm{E}-02$ & $9.4 \mathrm{E}+00$ & $6.1 \mathrm{E}-03$ & $9.9 \mathrm{E}-02$ & $2.0 \mathrm{E}-01$ & $1.6 \mathrm{E}-01$ & $4.7 \mathrm{E}+01$ & 3.1E-02 & $5.3 \mathrm{E}-02$ & $9.4 \mathrm{E}+00$ & $6.1 \mathrm{E}-03$ & $2.6 \mathrm{E}-0 \mathrm{I}$ & $4.7 \mathrm{E}+01$ & 3.1E-02 \\
\hline $\begin{array}{c}\text { Operators \& Maintenance } \\
\text { (Duration - 15 years) }\end{array}$ & $2.2 \mathrm{E}-02$ & $4.5 \mathrm{E}-02$ & $9.9 \mathrm{E}-03$ & $3.8 \mathrm{E}+00$ & $1.3 \mathrm{E}-02$ & $3.3 \mathrm{E}-01$ & $6.7 \mathrm{E}-01$ & $1.5 \mathrm{E}-01$ & $5.6 \mathrm{E}+01$ & $2.0 \mathrm{E}-01$ & $3.2 \mathrm{E}-02$ & $3.8 \mathrm{E}+00$ & $1.3 \mathrm{E}-02$ & $4.8 \mathrm{E}-01$ & $5.7 \mathrm{E}+01$ & $2.0 \mathrm{E}-01$ \\
\hline $\begin{array}{l}\text { Decontamination \& } \\
\text { Decommissioning } \\
\text { (Duration - } 1 \text { year) }\end{array}$ & $2.1 E-02$ & $4.4 \mathrm{E}-02$ & $4.8 \mathrm{E}-02$ & $1.2 \mathrm{E}+01$ & $1.5 \mathrm{E}-02$ & 4.3E-02 & $8.7 \mathrm{E}-02$ & 9.5E-02 & $2.4 \mathrm{E}+01$ & $3.0 \mathrm{E}-02$ & $6.9 \mathrm{E}-02$ & $1.2 \mathrm{E}+01$ & $1.5 \mathrm{E}-02$ & $1.4 \mathrm{E}-01$ & $2.4 \mathrm{E}+01$ & $3.0 \mathrm{E}-02$ \\
\hline TOTAL & ?. & \%ै। & मै। & अै? & कि & $4.9 \mathrm{E}-01$ & $1.0 \mathrm{E}+00$ & $4.3 \mathrm{E}-01$ & $1.3 \mathrm{E}+02$ & $2.6 \mathrm{E}-01$ & \%. & \%ै. & \%ి & $9.2 \mathrm{E}-01$ & $1.4 \mathrm{E}+02$ & $2.6 \mathrm{E}-0 \mathrm{I}$ \\
\hline
\end{tabular}

Assumptions:

- Transportation is to and from the site only

- Operational risks encompass industrial/physical hazards associated with equipment operation and onsite operations

- Infrastructure staff support the staff above. They receive no annual Cancer, average 4,000 travel miles, and average $50 \%$ of the facility totals above.

- Collective risks have been calculated as the product of individual risk, multiplied by the number of exposed individuals.

Individual risks provide estimates of the probability of health detriment for the individual, and the collective risks provide a measure of overall detriment

to the work force. 
Alternative: 5 . Options $\mathrm{C}+\mathrm{R}+\mathrm{S}$

Capital Cost: $\$ 160$ million

Annual Worker Mileage: 15,000

\begin{tabular}{|c|c|c|c|c|c|c|c|c|c|c|c|c|c|c|c|c|}
\hline \multirow{4}{*}{ Activity } & \multicolumn{10}{|c|}{ All Workers } & \multicolumn{6}{|c|}{ All Workers } \\
\hline & \multicolumn{5}{|c|}{ Annual } & \multicolumn{5}{|c|}{ Total } & \multirow{2}{*}{\multicolumn{3}{|c|}{ Annuals }} & \multirow{2}{*}{\multicolumn{3}{|c|}{ Totals }} \\
\hline & \multicolumn{2}{|c|}{ Transportation } & \multicolumn{3}{|c|}{ Operational } & \multicolumn{2}{|c|}{ Transportation } & \multicolumn{3}{|c|}{ Operational } & & & & & & \\
\hline & Death & Injury & Death & Injury & Cancer & Death & Injury & Death & Injury & Cancer & Death & Injury & Cancer & Death & Injury & Cancer \\
\hline $\begin{array}{l}\text { Technology Readiness } \\
\text { (Duration - } 5 \text { ycars) }\end{array}$ & $3.0 \mathrm{E}-03$ & $6.2 E-03$ & $3.7 \mathrm{E}-03$ & $1.2 \mathrm{E}+00$ & $0.0 \mathrm{E}+00$ & $1.5 \mathrm{E}-02$ & $3.1 E-02$ & $1.8 \mathrm{E}-02$ & $6.0 \mathrm{E}+00$ & $0.0 \mathrm{E}+00$ & $6.7 \mathrm{E}-03$ & $1.2 E+00$ & $0.0 \mathrm{E}+00$ & $3.4 \mathrm{E}-02$ & $6.1 \mathrm{E}+00$ & $0.0 \mathrm{E}+00$ \\
\hline $\begin{array}{c}\text { Capital } \\
\text { (Duration - } 5 \text { years) }\end{array}$ & $1.7 \mathrm{E}-02$ & $3.4 E-02$ & $2.8 \mathrm{E}-02$ & $8.0 \mathrm{E}+00$ & $5.9 \mathrm{E}-03$ & $8.4 \mathrm{E}-02$ & $1.7 \mathrm{E}-01$ & $1.4 \mathrm{E}-01$ & $4.0 \mathrm{E}+01$ & $3.0 \mathrm{E}-02$ & 4.SE-02 & $8.0 \mathrm{E}+00$ & $5.9 \mathrm{E}-03$ & $2.2 \mathrm{E}-01$ & $4.0 \mathrm{E}+01$ & $3.0 \mathrm{E}-02$ \\
\hline $\begin{array}{c}\text { Operators \& Maintenance } \\
\text { (Duration - } 15 \text { years) }\end{array}$ & 2.2E-02 & + SE-02 & $9.9 E-03$ & $3.8 \mathrm{E}+00$ & $1.3 E-02$ & $3.3 E-01$ & $6.7 \mathrm{E}-01$ & $1.5 \mathrm{E}-01$ & $5.6 \mathrm{E}+01$ & $2.0 \mathrm{E}-01$ & $3.2 \mathrm{E}-02$ & $3.8 \mathrm{E}+00$ & $1.3 \mathrm{E}-02$ & 4.8E-01 & $5.7 \mathrm{E}+01$ & $2.0 \mathrm{E}-01$ \\
\hline $\begin{array}{l}\text { Decontamination \& } \\
\text { Decommissioning } \\
\text { (Duratiou - I year) }\end{array}$ & 2.1E-02 & $4,4 \mathrm{E} \cdot 02$ & $4.8 \mathrm{E}-02$ & $1.2 \mathrm{E}+01$ & $1.5 \mathrm{E}-02$ & 4.3E-02 & 8.7E-02 & 9.5E-02 & $2.4 E+01$ & $3.0 \mathrm{E}-02$ & $6.9 \mathrm{E}-02$ & $1.2 \mathrm{E}+01$ & $1.5 \mathrm{E}-02$ & $1.4 \mathrm{E}-01$ & $2.4 \mathrm{E}+01$ & 3.0E-02 \\
\hline TOTAL & 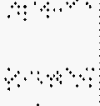 & & & अ & a. & $4.7 \mathrm{E}-01$ & $9.6 \mathrm{E}-01$ & $4.0 \mathrm{E}-01$ & $1.3 \mathrm{E}+02$ & $2.6 \mathrm{E}-01$ & & १ै? & ßै. & 8.7E-01 & $1.3 \mathrm{E}+02$ & $2.6 \mathrm{E}-01$ \\
\hline
\end{tabular}

Assumptions:

- Transportation is to and from tlie site only

- Operational risks encompass industrial/physical hazards associated with equipment operation and onsite operations

- Infrastructure staff support the staff ahove. They' receive no annual Cancer, average 4,000 travel miles, and average $50 \%$ of the facility totals above.

- Collective risks have been calculated as the product of individual risk, multiplied by the number of exposed individuals.

Individual risks provide estimates of the probability of health detriment for the individual, and the collective risks provide a measure of overall detriment

to the work force. 
Alternative: 6. Options $\mathrm{A}+\mathrm{D}+\mathrm{L}+\mathrm{R}+\mathrm{S}$

Capital Cost: $\$ 387$ million

Annual Worker Mileage: 15,000

\begin{tabular}{|c|c|c|c|c|c|c|c|c|c|c|c|c|c|c|c|c|}
\hline \multirow{4}{*}{ Activity } & \multicolumn{10}{|c|}{ All Workers } & \multicolumn{6}{|c|}{ All Workers } \\
\hline & \multicolumn{5}{|c|}{ Annual } & \multicolumn{5}{|c|}{ Total } & \multirow{2}{*}{\multicolumn{3}{|c|}{ Annuals }} & \multirow{2}{*}{\multicolumn{3}{|c|}{ Totals }} \\
\hline & \multicolumn{2}{|c|}{ Transportation } & \multicolumn{3}{|c|}{ Operational } & \multicolumn{2}{|c|}{ Transportation } & \multicolumn{3}{|c|}{ Operational } & & & & & & \\
\hline & Death & Injury & Death & Injury & \begin{tabular}{|l|} 
Cancer \\
\end{tabular} & Death & Injury & Death & Injury & Cancer & Death & Injury & Cancer & Death & Injury & Cancer \\
\hline $\begin{array}{l}\text { Tcchnology Readiness } \\
\text { (Duration - } 5 \text { years) }\end{array}$ & 4.7Е-03 & $9.6 \mathrm{E}-03$ & $6.0 \mathrm{E}-03$ & $1.6 \mathrm{E}+00$ & $0.0 \mathrm{E}+00$ & 2.3E-02 & $4.8 \mathrm{E}-02$ & $3.0 \mathrm{E}-02$ & 8.1E+00 & $0.0 \mathrm{E}+00$ & 1.1E-02 & $1.6 \mathrm{E}+00$ & $0.0 \mathrm{E}+00$ & 5.3E-02 & $8.2 \mathrm{E}+00$ & $0.0 \mathrm{E}+00$ \\
\hline $\begin{array}{c}\text { Capital } \\
\text { (Duration }-5 \text { ycars) }\end{array}$ & 4.1E-02 & 8.3E-02 & 7.1E-02 & $1.5 \mathrm{E}+01$ & $1.5 \mathrm{E}-02$ & $2.0 \mathrm{E}-01$ & 4.2E-01 & $3.6 \mathrm{E}-01$ & $7.7 E+01$ & $7.4 \mathrm{E}-02$ & $1.1 \mathrm{E}-01$ & $1.5 \mathrm{E}+01$ & $1.5 \mathrm{E}-02$ & $5.6 \mathrm{E}-01$ & $7.7 \mathrm{E}+01$ & $7.4 \mathrm{E}-02$ \\
\hline $\begin{array}{c}\text { Operators \& Maintenance } \\
\text { (Duration - } 15 \text { years) }\end{array}$ & $1.3 \mathrm{E}-02$ & $2.6 \mathrm{E}-02$ & $5.8 \mathrm{E}-03$ & $2.2 \mathrm{E}+00$ & $6.7 \mathrm{E}-03$ & $|9 E-0|$ & $3.9 \mathrm{E}-0 !$ & $8.6 \mathrm{E}-02$ & $3.3 \mathrm{E}+01$ & $1.0 \mathrm{E}-01$ & $1.8 \mathrm{E}-02$ & $2.2 \mathrm{E}+00$ & $6.7 \mathrm{E}-03$ & $2.8 \mathrm{E}-01$ & $3.3 \mathrm{E}+01$ & $1.0 \mathrm{E}-01$ \\
\hline $\begin{array}{l}\text { Decontamination \& } \\
\text { Decommissioning } \\
\text { (Duration - 1 year) }\end{array}$ & $9.0[-03$ & $1.8 \mathrm{E}-02$ & 2.0E-02 & $5.1 \mathrm{E}+00$ & $6.3 \mathrm{E}-03$ & $9.0 \mathrm{E}-03$ & $1.8 \mathrm{E}-02$ & $2.0 \mathrm{E}-02$ & $5.1 E+00$ & $6.3 \mathrm{E}-03$ & $2.9 \mathrm{E}-02$ & $5.1 \mathrm{E}+00$ & $6.3 \mathrm{E}-03$ & $2.9 \mathrm{E} \cdot 02$ & $5.1 \mathrm{E}+00$ & $6.3 \mathrm{E}-03$ \\
\hline TOTAL & \%ి & \%, & ২ै। & ২. & \%ै। & $4.2 \mathrm{E} \cdot 01$ & 8.7E-01 & $4.9 \mathrm{E}-01$ & $1.2 \mathrm{E}+02$ & $1.8 \mathrm{E}-01$ & & & & $9.2 \mathrm{E}-01$ & $1.2 \mathrm{E}+02$ & $1.8 \mathrm{E}-01$ \\
\hline
\end{tabular}

Assumptions:

- Transportation is to and from the site only

- Operational risks encompass industrial/physical hazards associated with equipment operation and onsite operations

- Infrastructure staff support the staff above. They receive no annual Cancer, average 4,000 travel miles, and average $50 \%$ of the facility totals above.

- Collective risks have been calculated as the product of individual risk, multiplied by the number of exposed individuals.

Individual risks provide estimates of the probability of heaith detriment for the individual, and the collective risks provide a measure of overall detriment

to the work force. 


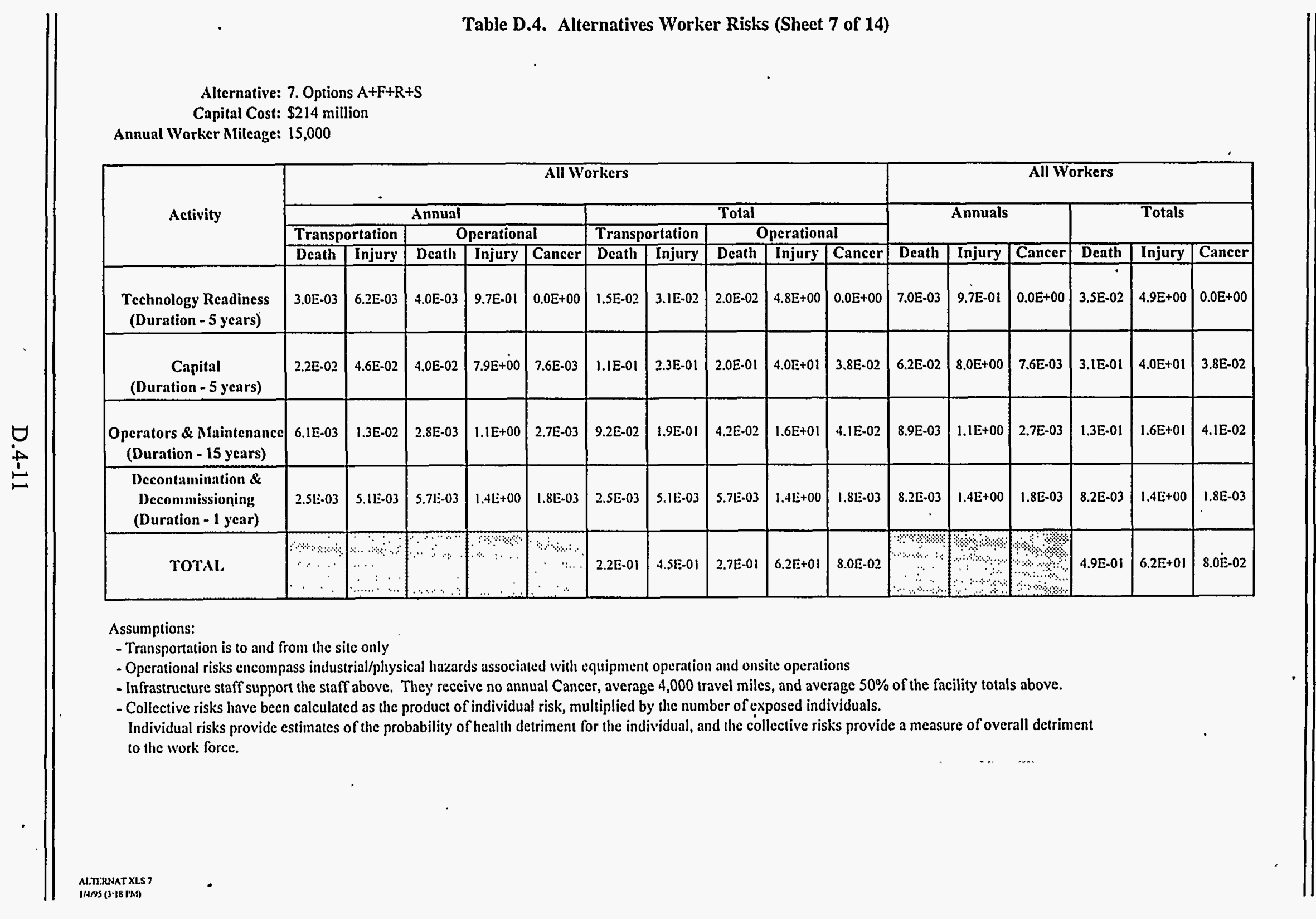


Alternative: 8 . Options $\mathrm{A}+\mathrm{E}+\mathrm{R}+\mathrm{S}$

Capital Cost: $\$ 180$ million

Annual Worker Mileage: 15,000

\begin{tabular}{|c|c|c|c|c|c|c|c|c|c|c|c|c|c|c|c|c|}
\hline \multirow{4}{*}{ Activity } & \multicolumn{10}{|c|}{ All Workers } & \multicolumn{6}{|c|}{ All Workers } \\
\hline & \multicolumn{5}{|c|}{ Annual } & \multicolumn{5}{|c|}{ Total } & \multirow{2}{*}{\multicolumn{3}{|c|}{ Annuals }} & \multirow{2}{*}{\multicolumn{3}{|c|}{ Totals }} \\
\hline & \multicolumn{2}{|c|}{ Transportation } & \multicolumn{3}{|c|}{ Operational } & \multicolumn{2}{|c|}{ Transportation } & \multicolumn{3}{|c|}{ Opcrational } & & & & & & \\
\hline & Death & \begin{tabular}{|l|} 
Injury \\
\end{tabular} & Death & Injury & Cancer & Death & Injury & Death & Injury & Cancer & Death & Injury & Cancer & Death & Injury & Cancer \\
\hline $\begin{array}{l}\text { Technology Readiness } \\
\text { (Duration - } 5 \text { years) }\end{array}$ & $2.0 \mathrm{E}-03$ & 4.1E.03 & $2.6 \mathrm{E} \cdot 03$ & 6.7E-01 & $0.0 \mathrm{E}+00$ & $1.0 \mathrm{E}-02$ & $2.0 \mathrm{E}-02$ & $1.3 \mathrm{E}-02$ & $3.3 \mathrm{E}+00$ & $0.0 \mathrm{E}+00$ & 4.5E-03 & $6.7 \mathrm{E}-01$ & $0.0 \mathrm{E}+00$ & $2.3 \mathrm{E}-02$ & $3.4 \mathrm{E}+00$ & $0.0 E+00$ \\
\hline $\begin{array}{c}\text { Capital } \\
\text { (Duration - } 5 \text { years) } \\
\end{array}$ & $1.9 \mathrm{E}-02$ & $3.9 \mathrm{E}-02$ & 3.3E-02 & $6.9 \mathrm{E}+00$ & $5.2 \mathrm{E}-03$ & $9.4 E-02$ & $1.9 E-01$ & $1.7 \mathrm{E}-01$ & $3.4 \mathrm{E}+01$ & $2.6 \mathrm{E}-02$ & $5.2 \mathrm{E}-02$ & $6.9 \mathrm{E}+00$ & $5.2 \mathrm{E}-03$ & $2.6 \mathrm{E}-01$ & $3.5 \mathrm{E}+01$ & $2.6 \mathrm{E}-02$ \\
\hline $\begin{array}{c}\text { Operators \& Maintenance } \\
\text { (Duration - } 15 \text { ycars) }\end{array}$ & $6.1 \mathrm{E}-03$ & $1.3 \mathrm{E}-02$ & $2.8 \mathrm{E}-03$ & $1.1 \mathrm{E}+00$ & 2.7E-03 & $9.2 \mathrm{E}-02$ & $1.9 \mathrm{E}-01$ & $4.2 \mathrm{E}-02$ & $1.6 \mathrm{E}+01$ & 4.1E-02 & 8.9E-03 & $1.1 \mathrm{E}+00$ & 2.7E-03 & $1.3 \mathrm{E}-01$ & $1.6 \mathrm{E}+01$ & $4.1 \mathrm{E}-02$ \\
\hline $\begin{array}{l}\text { Decontamination } \& \\
\text { Decommissioning } \\
\text { (Duration - } 1 \text { year) }\end{array}$ & $2.51:-03$ & $5.1 \mathrm{E}-03$ & $5.7 \mathrm{~L}-03$ & $1.41 E+00$ & $1.8 \mathrm{E}-03$ & $2.5 \mathrm{t}-03$ & $5.11:-03$ & $5.7 E-03$ & $1.4 E+00$ & 1.8E-03 & 8.2E- 03 & $1.4 \mathrm{E}+00$ & $1.8 \mathrm{E}-03$ & 8.2E-03 & $1.4 \mathrm{E}+00$ & $1.8 \mathrm{E}-03$ \\
\hline TOTAI. & $\therefore \quad$ & $\left(\begin{array}{c}a \\
\vdots \\
\vdots\end{array}\right.$ & । & \% & $\therefore \quad \therefore$ & 2.0F:-01 & $4.15-01$ & 2.3E-01 & $5.5 E+01$ & $6.8 \mathrm{E}-02$ & +. & +. & (4) & $4.3 \mathrm{E}-01$ & $5.5 E+01$ & $6.8 \mathrm{E}-02$ \\
\hline
\end{tabular}

\section{Assumptions:}

- Transportation is to and from the site only

- Operational risks encompass industrial/physical hazards associated with equipment operation and onsite operations

- Infrastructure staff support the staff above. They receive no annual Cancer, average 4,000 travel miles, and average $50 \%$ of the facility totals above.

- Collective risks have been calculated as the product of individual risk, multiplied by the number of exposed individuals.

Individual risks provide estimates of the probability of health detriment for the individual, and the collective risks provide a measure of overall detriment to the work force. 
Alternative: 9. Options $A+G+O+R+S$

Capital Cost: \$331 million

Annual Worker Milcage: 15,000

\begin{tabular}{|c|c|c|c|c|c|c|c|c|c|c|c|c|c|c|c|c|}
\hline \multirow{4}{*}{ Activity } & \multicolumn{10}{|c|}{ All Workers } & \multicolumn{6}{|c|}{ All Workers } \\
\hline & \multicolumn{5}{|c|}{ Annual } & \multicolumn{5}{|c|}{ Total } & \multirow{2}{*}{\multicolumn{3}{|c|}{ Annuals }} & \multirow{2}{*}{\multicolumn{3}{|c|}{ Totals }} \\
\hline & \multicolumn{2}{|c|}{ Transportation } & \multicolumn{3}{|c|}{ Operational } & \multicolumn{2}{|c|}{ Transportation } & \multicolumn{3}{|c|}{ Opcrational } & & & & & & \\
\hline & Death & Injury & Death & Injury & Cancer & Death & Injury & Death & Injury & Cancer & Death & Injury & Cancer & Death & Injury & Cancer \\
\hline $\begin{array}{l}\text { Technology Readiness } \\
\text { (Duration - } 5 \text { years) }\end{array}$ & $3.4 \mathrm{E}-03$ & $6.9 \mathrm{E}-03$ & 4.1E-03 & $1.3 E+00$ & $0.0 \mathrm{E}+00$ & 1.7E-02 & $3.4 \mathrm{E}-02$ & $2.0 E-02$ & $6.7 E+00$ & $0.0 \mathrm{E}+00$ & $7.4 \mathrm{E}-03$ & $1.3 E+00$ & $0.0 \mathrm{E}+00$ & $3.7 \mathrm{E}-02$ & $6.7 \varepsilon+00$ & $0.0 \mathrm{E}+00$ \\
\hline $\begin{array}{c}\text { Capital } \\
\text { (Duration }-5 \text { years) }\end{array}$ & $3.5 \mathrm{E}-02$ & 7.IE-02 & $5.7 \mathrm{E}-02$ & $1.6 \mathrm{E}+01$ & 7.4E-03 & $1.7 \mathrm{E}-01$ & $3.5 \mathrm{E} \cdot 01$ & $2.9 \mathrm{E}-01$ & $8.2 \mathrm{E}+01$ & $3.7 \mathrm{E}-02$ & $9.2 \mathrm{E}-02$ & $1.6 \mathrm{E}+01$ & $7.4 \mathrm{E}-03$ & $4.6 \mathrm{E}-01$ & $8.2 \mathrm{E}+01$ & 3.7E-02 \\
\hline $\begin{array}{l}\text { Operators \& Maintenance } \\
\text { (Duration - } 15 \text { years) }\end{array}$ & $1.2 \mathrm{E}-02$ & $2.4 \mathrm{E}-02$ & $5.3 \mathrm{E}-03$ & $2.0 \mathrm{E}+00$ & $5,3 E-03$ & $1.8 \mathrm{E}-01$ & $3.6 \mathrm{E}-01$ & $8.0 \mathrm{E}-02$ & $3.0 \mathrm{E}+01$ & 8.0E-02 & $1.7 \mathrm{E}-02$ & $2.0 \mathrm{E}+00$ & $5.3 \mathrm{E}-03$ & $2.6 \mathrm{E}-01$ & $3.1 \mathrm{E}+01$ & $8.0 \mathrm{E}-02$ \\
\hline $\begin{array}{l}\text { Decontamination \& } \\
\text { Decommissioning } \\
\text { (Duration - } 1 \text { year) }\end{array}$ & 8.1E.03 & $1.7 \mathrm{E}-02$ & $1.8 \mathrm{E}-02$ & $4.6 \mathrm{E}+00$ & $4.8 \mathrm{E}-03$ & $1.4 \mathrm{E}-02$ & $2.8 \mathrm{E}-02$ & $3.1 \mathrm{E}-02$ & $7.7 \mathrm{E}+00$ & $7.8 \mathrm{E}-03$ & $2.6 \mathrm{E}-02$ & $4.6 \mathrm{E}+00$ & $4.8 \mathrm{E}-03$ & 4.5E-02 & $7.8 \mathrm{E}+00$ & $7.8 \mathrm{E}-03$ \\
\hline TOTAL & 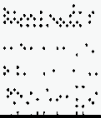 & $\begin{array}{c}0 . \\
\cdots \\
\cdots \\
\cdots\end{array}$ & $\begin{array}{c}\cdots \\
\because \cdots \\
\cdots\end{array}$ & $\begin{array}{l} \\
4 \\
\vdots\end{array}$ & $\begin{array}{l}\cdots \\
\cdots\end{array}$ & $3.8 \mathrm{E}-01$ & $7.8 \mathrm{E}-01$ & $4,2 \mathrm{E}-01$ & $1.3 E+02$ & $1.2 \mathrm{E}-01$ & की & ४ै & ২ै\% & $8.0 \mathrm{E}-01$ & $1.3 E+02$ & $1.2 \mathrm{E}-01$ \\
\hline
\end{tabular}

\section{Assumptions:}

- Transportation is to and from the site only

- Operational risks encompass industrial/physical hazards associated with equipment operation and onsite operations

- Infrastructure staff support the staff above. They recejve no annual Cancer, average 4,000 travel miles, and average $50 \%$ of the facility totals above.

- Collective risks have been calculated as the product of individual risk, multiplied by the number of exposed individuals.

Individual risks provide estimates of the probability of health detriment for the individual. and the collective risks provide a measure of overall detriment

to the work toree. 
Alternative: 10 . Options $\mathrm{A}+\mathrm{H}+\mathrm{P}+\mathrm{R}+\mathrm{S}$

Capital Cost: $\$ 429$ million

Annual Worker Mlileage: 15,000

\begin{tabular}{|c|c|c|c|c|c|c|c|c|c|c|c|c|c|c|c|c|}
\hline \multirow{4}{*}{ Activity } & \multicolumn{10}{|c|}{ All Workers } & \multicolumn{6}{|c|}{ All Workers } \\
\hline & \multicolumn{5}{|c|}{ Annual } & \multicolumn{5}{|c|}{ Total } & \multirow{2}{*}{\multicolumn{3}{|c|}{ Annuals }} & \multirow{2}{*}{\multicolumn{3}{|c|}{ Totals }} \\
\hline & \multicolumn{2}{|c|}{ Transportation } & \multicolumn{3}{|c|}{ Operational } & \multicolumn{2}{|c|}{ Transportation } & \multicolumn{3}{|c|}{ Operational } & & & & & & \\
\hline & Death & Injury & Death & Injury & Cancer & Death & Injury & Death & Injury & Cancer & Death & Injury & Cancer & Death & Injury & Cancer \\
\hline $\begin{array}{l}\text { Technology Readiness } \\
\text { (Duration - } 5 \text { years) }\end{array}$ & $3.4 E-03$ & $6.9 \mathrm{E}-03$ & $4.1 E-03$ & $1.3 E+00$ & $0.0 E+00$ & $1.7 \mathrm{E}-02$ & $3+E-02$ & $2.0 \mathrm{E}-02$ & $6.7 \mathrm{E}+00$ & $00 E+00$ & $74 \mathrm{E}-03$ & $1.3 E+00$ & $0.0 \mathrm{E}+00$ & $3.7 \mathrm{E}-02$ & $67 E+00$ & $0.0 E+00$ \\
\hline $\begin{array}{c}\text { Capital } \\
\text { (Duration - } 5 \text { ycars) }\end{array}$ & $4.5 \mathrm{E}-02$ & $9.2 \mathrm{E}-02$ & $7.4 \mathrm{E}-02$ & $2.1 \mathrm{E}+01$ & $9.6 \mathrm{E}-03$ & $2.2 \mathrm{E}-01$ & $4.6 \mathrm{E}-01$ & 3.7E-01 & $1.1 E+02$ & $4.8 \mathrm{E}-02$ & $1.2 \mathrm{E}-01$ & $2.1 E+01$ & $9.6 \mathrm{E}-03$ & $6.0 \mathrm{E}-01^{\circ}$ & $1.1 \mathrm{E}+02$ & $4.8 \mathrm{E}-02$ \\
\hline $\begin{array}{l}\text { Operators \& Maintenance } \\
\text { (Duration - } 15 \text { years) }\end{array}$ & $1.2 \mathrm{E}-02$ & $2.5 \mathrm{E}-02$ & $5.6 \mathrm{E} \cdot 03$ & $2.1 \mathrm{E}+00$ & $5.6 \mathrm{E}-03$ & $1.8 \mathrm{E}-01$ & $3.8 \mathrm{E}-01$ & $8.4 \mathrm{E}-02$ & $3.2 \mathrm{E}+01$ & $8.4 \mathrm{E}-02$ & $1.8 \mathrm{E}-02$ & $2.1 \mathrm{E}+00$ & $5.6 \mathrm{E}-03$ & $2.7 \mathrm{E}-01$ & $3.2 \mathrm{E}+01$ & $8.4 \mathrm{E}-02$ \\
\hline $\begin{array}{l}\text { Decontamination \& } \\
\text { Decommissioning } \\
\text { (Duration - } 1 \text { year) }\end{array}$ & $8.5 \mathrm{E}-03$ & $1.8 \mathrm{E}-02$ & $1.9 \mathrm{E}-02$ & $4.8 \mathrm{E}+00$ & $5.0 \mathrm{E}-03$ & $1.5 \mathrm{E}-02$ & $3.0 \mathrm{E}-02$ & 3.3E-02 & $8.2 \mathrm{E}+00$ & $8.3 \mathrm{E}-03$ & $2.8 \mathrm{E}-02$ & $4.8 \mathrm{E}+00$ & $5.0 \mathrm{E}-03$ & $4.7 \mathrm{E}-02$ & $8.2 E+00$ & $8.3 \mathrm{E}-03$ \\
\hline TOTAL & \%ै। & \%ి & \%ै। & ঋै। & मै। & $4.4 \mathrm{E}-01$ & $9.0 \mathrm{E}-01$ & $5.1 \mathrm{E}-01$ & $1.5 \mathrm{E}+02$ & $1.4 \mathrm{E}-01$ & \% & \%) & 1\%? & 9.5E-01 & $1.5 \mathrm{E}+02$ & $1.4 \mathrm{E}-01$ \\
\hline
\end{tabular}

Assumptions:

- Transportation is to and from the site only

- Operational risks encompass industrial/physical hazards associated with equipment operation and onsite operations

- Infrastructure staff support the staff above. They receive no annual Cancer, average 4,000 travel miles, and average $50 \%$ of the facility totals above.

- Collective risks have been calculated as the product of individual risk, multiplied by the number of exposed individuals.

Individual risks provide estimates of the probability of health detriment for the individual, and the collective risks provide a measure of overall detriment

to the work force. 


\begin{tabular}{|c|c|c|c|c|c|c|c|c|c|c|c|c|c|c|c|c|}
\hline \multicolumn{17}{|c|}{$\begin{array}{l}\text { Alternative: } 11 \text {. Options A+I+P+R+S } \\
\text { Capital Cost: } \$ 324 \text { million } \\
\text { Annual Worker Mileage: } 15,000\end{array}$} \\
\hline & \multicolumn{10}{|c|}{ All Workers } & \multicolumn{6}{|c|}{ All Workers } \\
\hline \multirow[t]{3}{*}{ Activity } & \multicolumn{5}{|c|}{ Annual } & \multicolumn{5}{|c|}{ Total } & \multirow{2}{*}{\multicolumn{3}{|c|}{ Annuals }} & \multirow{2}{*}{\multicolumn{3}{|c|}{ Totals }} \\
\hline & \multicolumn{2}{|c|}{ Transportation } & \multicolumn{3}{|c|}{ Operational } & \multicolumn{2}{|c|}{ Transportation } & \multicolumn{3}{|c|}{ Operational } & & & & & & \\
\hline & Death & Injury & Death & \begin{tabular}{|l|} 
Injury \\
\end{tabular} & Cancer & Death & Injury & Death & Injury & Cancer & Death & Injury & Cancer & Death & Injury & Cancer \\
\hline $\begin{array}{l}\text { Technology Readiness } \\
\text { (Duration - } 5 \text { years) }\end{array}$ & $3.2 \mathrm{E}-03$ & $6.5 \mathrm{E}-03$ & $3.8 \mathrm{E}-03$ & $1.3 E+00$ & $0.0 \mathrm{E}+00$ & $1.6 \mathrm{E}-02$ & $3.2 \mathrm{E}-02$ & $1.9 \mathrm{E}-02$ & $6.3 \mathrm{E}+00$ & $0.0 E+00$ & $7.0 \mathrm{E}-03$ & $1.3 \mathrm{E}+00$ & $0.0 \mathrm{E}+00$ & $3.5 \mathrm{E}-02$ & $6.3 \mathrm{E}+00$ & $0.0 \mathrm{E}+00$ \\
\hline $\begin{array}{c}\text { Capital } \\
\text { (Duration - } 5 \text { years) }\end{array}$ & $3.4 \mathrm{E}-02$ & $6.9 \mathrm{E}-02$ & $5.6 \mathrm{E}-02$ & $1.6 \mathrm{E}+01$ & $7.2 \mathrm{E}-03$ & $1.7 \mathrm{E}-01$ & $3.5 \mathrm{E}-01$ & $2.8 \mathrm{E}-01$ & $8.0 E+01$ & $3.6 \mathrm{E}-02$ & $9.0 \mathrm{E}-02$ & $1.6 \mathrm{E}+01$ & $7.2 \mathrm{E}-03$ & 4.5E-01 & $8.1 E+01$ & $3.6 \mathrm{E}-02$ \\
\hline $\begin{array}{l}\text { Operators \& Miaintenance } \\
\text { (Duration - } 15 \text { years) }\end{array}$ & $1.6 \mathrm{E}-02$ & $3.2 \mathrm{E}-02$ & $7.1 \mathrm{E}-03$ & $2.7 E+00$ & $6.6 \mathrm{E}-03$ & $2.3 \mathrm{E}-01$ & $4.8 \mathrm{E}-01$ & $1.1 \mathrm{E}-01$ & $4.0 \mathrm{E}+01$ & $\mid 1.0 \mathrm{E}-01$ & $2.3 \mathrm{E}-02$ & $2.7 \mathrm{E}+00$ & 6.6E-03 & $3.4 \mathrm{E}-01$ & $4.1 E+01$ & $1.0 \mathrm{E}-0 \mathrm{l}$ \\
\hline $\begin{array}{l}\text { Decontamination \& } \\
\text { Decommissioning } \\
\text { (Duration - } 1 \text { year) }\end{array}$ & $1.5 \mathrm{E}-02$ & $3.1 E-02$ & $3.4 \mathrm{E}-02$ & $8.5 \mathrm{E}+00$ & $7,4 E-03$ & $2.1 E-02$ & $4.3 \mathrm{E}-02$ & $4.7 \mathrm{E}-02$ & $1.2 \mathrm{E}+01$ & $1.1 \mathrm{E}-02$ & $4.9 \mathrm{E}-02$ & $8.5 \mathrm{E}+00$ & $7.4 \mathrm{E}-03$ & $6.8 \mathrm{E}-02$ & $1.2 \mathrm{E}+01$ & 1.1E- 02 \\
\hline TOTAL & \% & $\begin{array}{c}\infty \\
\cdots \\
\cdots\end{array}$ & $\begin{array}{c}\cdots \\
\cdots \cdots \\
\cdots \cdots \\
\cdots \cdots\end{array}$ & 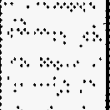 & & 4..AE-01 & $9.0 E-01$ & $4.5 \mathrm{E}-01$ & $1.4 E+02$ & $1.5 \mathrm{E}-01$ & \% & \%। & +ै.। & $8.9 \mathrm{E}-01$ & $1.4 \mathrm{E}+02$ & $1.5 \mathrm{E}-01$ \\
\hline
\end{tabular}

Assumptions:

- Transportation is to and from the site only

- Operational risks encompass industrial/physical hazards associated with equipment operation and onsite operations

- Infrastructure staff support the staff above. They receive no annual Cancer, average 4,000 travel miles, and average $50 \%$ of the facility totals above.

- Collective risks have been calculated as the product of individual risk, multiplied by the number of exposed individuals.

Individual risks provide estimates of the probability of health detriment for the individual, and the collective risks provide a measure of overall detriment to the work foree. 
Alternative: 12. Options $A+J+K+R+S$

Capital Cost: $\$ 266$ million

Annual Worker Mileage: 15,000

\begin{tabular}{|c|c|c|c|c|c|c|c|c|c|c|c|c|c|c|c|c|}
\hline \multirow{4}{*}{ Activity } & \multicolumn{10}{|c|}{ All Workers } & \multicolumn{6}{|c|}{ All Workers } \\
\hline & \multicolumn{5}{|c|}{ Annual } & \multicolumn{5}{|c|}{ Total } & \multirow{2}{*}{\multicolumn{3}{|c|}{ Annuals }} & \multirow{2}{*}{\multicolumn{3}{|c|}{ Totals }} \\
\hline & \multicolumn{2}{|c|}{ Transportation } & \multicolumn{3}{|c|}{ Operational } & \multicolumn{2}{|c|}{ Transportation } & \multicolumn{3}{|c|}{ Operational } & & & & & & \\
\hline & Death & Injury, & Death & Injury & Cancer & Death & Injury & Death & Injury & Cancer & Death & Injury & Cancer & Death & Injury & Cancer \\
\hline $\begin{array}{l}\text { Technology Readiness } \\
\text { (Duration - } 5 \text { years) }\end{array}$ & $3.2 \mathrm{E}-03$ & $6.5 \mathrm{E}-03$ & $3.8 \mathrm{E}-03$ & $1.3 \mathrm{E}+00$ & $0.0 \mathrm{E}+00$ & $1.6 \mathrm{E}-02$ & $3.2 \mathrm{E}-02$ & $1.9 \mathrm{E}-02$ & $6.3 \mathrm{E}+00$ & $0.0 \mathrm{E}+00$ & $7.0 \mathrm{E}-03$ & $1.3 \mathrm{E}+00$ & $0.0 \mathrm{E}+00$ & $3.5 \mathrm{E}-02$ & $6.3 \mathrm{E}+00$ & $0.0 \mathrm{E}+00$ \\
\hline $\begin{array}{c}\text { Capital } \\
\text { (Duration }-5 \text { years) }\end{array}$ & $2.8 \mathrm{E}-02$ & 5.7E-02 & $4.6 \mathrm{E} \cdot 02$ & $1.3 \mathrm{E}+01$ & $9.2 \mathrm{E}-03$ & $1.4 \mathrm{E}-01$ & $2.9 \mathrm{E}-01$ & $2.3 \mathrm{E}-01$ & $6.6 \mathrm{E}+01$ & $4.6 \mathrm{E}-02$ & $7.4 \mathrm{E}-02$ & $1.3 \mathrm{E}+01$ & $9.2 \mathrm{E}-03$ & $3.7 \mathrm{E} \cdot 01$ & $6.6 E+01$ & $4.6 \mathrm{E}-02$ \\
\hline $\begin{array}{l}\text { Operators \& Mlaintenance } \\
\text { (Duration - } 15 \text { years) }\end{array}$ & $1.6 \mathrm{E}-02$ & $3.3 E-02$ & 7.3E-03 & $2.8 \mathrm{E}+00$ & $7.8 \mathrm{E} \cdot 03$ & $2.4 \mathrm{E}-01$ & $4.9 \mathrm{E}-01$ & $1.1 \mathrm{E} \cdot 01$ & $4.1 E+01$ & $1.2 \mathrm{E}-01$ & $2.3 \mathrm{E}-02$ & $2.8 \mathrm{E}+00$ & $7.8 \mathrm{E}-03$ & 3.5E-01 & $4.2 \mathrm{E}+01$ & $1.2 \mathrm{E}-01$ \\
\hline $\begin{array}{l}\text { Decontamination \& } \\
\text { Decommissioning } \\
\text { (Duration - } 1 \text { year) }\end{array}$ & $1.5 E-02$ & $3.2 \mathrm{E}-02$ & $3.5 \mathrm{E}-02$ & $8.7 \mathrm{E}+00$ & $8.7 \mathrm{E}-03$ & $1.5 \mathrm{E}-02$ & $3.2 \mathrm{E}-02$ & $3.5 \mathrm{E}-02$ & $8.7 E+00$ & $8.7 \mathrm{E}-03$ & $5.0 \mathrm{E}-02$ & $8.7 \mathrm{E}+00$ & $8.7 \mathrm{E}-03$ & $5.0 \mathrm{E}-02$ & $8.7 E+00$ & $8,7 \mathrm{E}-03$ \\
\hline TOTAL & \%ి. & \%ै। & ঋै। & ४ै। & औै। & $4.1 E-01$ & $8.4 \mathrm{E}-01$ & $3.9 \mathrm{E}-01$ & $1.2 \mathrm{E}+02$ & $1.7 \mathrm{E}-01$ & +\% & \%.\% & $1+\%$ & 8.0E-01 & $1.2 \mathrm{E}+02$ & $1.7 \mathrm{E}-01$ \\
\hline
\end{tabular}

Assumptions:

- Transportation is to and from the site only

- Operational risks encompass industrial/physical hazards associated with equipment operation and onsite operations

- Infrastructure staff support the staff above. They receive no annual Cancer, average 4,000 travel miles, and average $50 \%$ of the facility totals above.

- Collective risks have been calculated as the product of individual risk, multiplied by the number of exposed individuals.

Individual risks provide estimates of the probability of health detriment for the individual, and the collective risks provide a measure of overall detriment

to the work force. 
Assumptions:

- Transportation is to and from the site only

- Operational risks encompass industrial/physical hazards associated with equipment operation and onsite operations

- Infrastructure staff support the staff above. They receive no annual Cancer, average 4,000 travel miles, and average $50 \%$ of the facility totals above.

- Collective risks have been calculated as the product of individual risk, multiplied by the number of exposed individuals.

Individual risks provide estimates of the probability of health detriment for the individual, and the collective risks provide a measure of overall detriment to the work force. 
Alternative: 14. Options $\mathrm{A}+\mathrm{F}+\mathrm{U}$

Capital Cost: $\$ 792$ million

Annual Worker Mileage: 15,000

\begin{tabular}{|c|c|c|c|c|c|c|c|c|c|c|c|c|c|c|c|c|}
\hline \multirow{4}{*}{ Activity } & \multicolumn{10}{|c|}{ All Workers } & \multicolumn{6}{|c|}{ All Workers } \\
\hline & \multicolumn{5}{|c|}{ Annual } & \multicolumn{5}{|c|}{ Total } & \multirow{2}{*}{\multicolumn{3}{|c|}{ Annuals }} & \multirow{2}{*}{\multicolumn{3}{|c|}{ Totals }} \\
\hline & \multicolumn{2}{|c|}{ Transportation } & \multicolumn{3}{|c|}{ Operational } & \multicolumn{2}{|c|}{ Transportation } & \multicolumn{3}{|c|}{ Operational } & & & & & & \\
\hline & Death & Injury & Death & \begin{tabular}{|l|} 
Injury \\
\end{tabular} & Cancer & Death & Injury & Death & Injury & Cancer & Death & Injury & Cancer & Death & Injury & Cancer \\
\hline $\begin{array}{l}\text { Technology Readiness } \\
\text { (Duration - } 5 \text { years) }\end{array}$ & $5.9 \mathrm{E}-03$ & $1.2 \mathrm{E}-02$ & $7.9 \mathrm{E}-03$ & $1.7 \mathrm{E}+00$ & $0.0 \mathrm{E}+00$ & $3.0 \mathrm{E}-02$ & $6.1 \mathrm{E}-02$ & $3.9 \mathrm{E} \cdot 02$ & $8.7 E+00$ & $0.0 \mathrm{E}+00$ & $1.4 \mathrm{E}-02$ & $1.8 \mathrm{E}+00$ & $0.0 \mathrm{E}+00$ & $6.9 \mathrm{E}-02$ & $8.8 \mathrm{E}+00$ & $0.0 \mathrm{E}+00$ \\
\hline $\begin{array}{c}\text { Capital } \\
\text { (Duration - } 5 \text { years) }\end{array}$ & $8.3 \mathrm{E}-02$ & $1.7 \mathrm{E}-01$ & $1.5 \mathrm{E}-01$ & $2.6 \mathrm{E}+01$ & 2.7E-02 & $4.2 \mathrm{E}-01$ & $8.5 \mathrm{E}-01$ & $7.6 \mathrm{E} \cdot 01$ & $1.3 E+02$ & $1.3 \mathrm{E}-01$ & $2.4 \mathrm{E}-01$ & $2.6 \mathrm{E}+01$ & $2.7 \mathrm{E}-02$ & $1.2 \mathrm{E}+00$ & $1.3 \mathrm{E}+02$ & $1.3 \mathrm{E}-01$ \\
\hline $\begin{array}{c}\text { Operators \& Maintenance } \\
\text { (Duration - } 15 \text { years) }\end{array}$ & $3.4 \mathrm{E} \cdot 02$ & $7.1 E-02$ & $1.6 \mathrm{E}-02$ & $6.0 \mathrm{E}+00$ & $2.0 \mathrm{E}-02$ & $66 \mathrm{E}-01$ & $1.4 \mathrm{E}+00$ & $3.0 \mathrm{E}-01$ & $1.1 E+02$ & $3.9 \mathrm{E}-01$ & S.0E-02 & $6.0 E+00$ & $2.0 \mathrm{E}-02$ & $9.6 \mathrm{E}-01$ & $1.2 \mathrm{E}+02$ & $3.9 \mathrm{E}-01$ \\
\hline $\begin{array}{c}\text { Decontamination \& } \\
\text { Decommissioning } \\
\text { (Duration - } 1 \text { year) }\end{array}$ & $2,815-02$ & $5.8 \mathrm{E}-02$ & $7,0 E-02$ & $9.0 \mathrm{E}+00$ & $2.0 E-02$ & $7.9 \mathrm{E}-02$ & $1.6 E-01$ & $2.0 \mathrm{E}-01$ & $2.4 E+01$ & $5.6 \mathrm{E}-02$ & $9.8 \mathrm{E}-02$ & $9.1 E+00$ & $2.0 \mathrm{E} \cdot 02$ & $2.8 \mathrm{E}-01$ & $2.4 \mathrm{E}+01$ & $5.6 \mathrm{E}-02$ \\
\hline TOTAL & मै। & ४ै। & अे & ২ै। & ফি & $1.2 \mathrm{E}+00$ & $2.4 \mathrm{E}+00$ & $1.3 \mathrm{E}+00$ & $2.8 \mathrm{E}+02$ & $5.8 \mathrm{E}-01$ & & \% & $18 \%$ & $2.5 E+00$ & $2.8 \mathrm{E}+02$ & $5.8 \mathrm{E}-01$ \\
\hline
\end{tabular}

Assumptions:

- Transportation is to and from the site only

- Operational risks encompass industrial/physical hazards associated with equipment operation and onsite operations

- Infrastructure staff support the staff above. They receive no annual Cancer, average 4,000 travel miles, and average $50 \%$ of the facility totals above.

- Collective risks have been calculated as the product of individual risk, multiplied by the number of exposed individuals.

Individual risks provide estimates of the probability of health detriment for the individual, and the collective risks provide a measure of overall detriment

to the work force. 
WHC-SD-WM-ES-300 REV. 1

APPENDIX E

CTRAN/W COMPUTER CODE OUTPUT

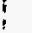

E-1 


\section{WHC-SD-WM-ES-300 REV. 1}

This page intentionally left blank. 


\section{CTRAN/W COMPUTER CODE OUTPUT}

Initial head valves and the variation in contaminant flux as a function of time for Case 1: Natural Recharge Only and Case 2: Natural Recharge Plus Leakage are shown in the following tables. 
WHC-SD-WM-ES-300 REV. 1

This page intentionally left blank. 
Table E.1. Initial Head and Contaminant Flux for Case I: Natural Recharge Only (page 1 of 4).

\begin{tabular}{|c|c|c|}
\hline Node\# & Head (ft) & Flux(Q) (ft/yr) \\
\hline 1 & $0.00 \mathrm{E}+00$ & $0.00 \mathrm{E}+00$ \\
\hline 2 & $-5.95 \mathrm{E}+02$ & $0.00 E+00$ \\
\hline 3 & $-5.64 E+02$ & $0.00 E+00$ \\
\hline 4 & $-5.33 E+02$ & $0.00 E+00$ \\
\hline 5 & $-4.99 E+02$ & $0.00 \mathrm{E}+00$ \\
\hline 6 & $-4.68 E+02$ & $0.00 E+00$ \\
\hline 7 & $-4.34 E+02$ & $0.00 \mathrm{E}+00$ \\
\hline 8 & $-4.00 E+02$ & $0.00 E+00$ \\
\hline 9 & $-3.67 E+02$ & $0.00 E+00$ \\
\hline 10 & $-3.37 E+02$ & $0.00 E+00$ \\
\hline 11 & $3.39 E+02$ & $2.55 \mathrm{E}-02$ \\
\hline 12 & $0.00 E+00$ & $0.00 E+00$ \\
\hline 13 & $-5.95 E+02$ & $0.00 E+00$ \\
\hline 14 & $-5.64 E+02$ & $0.00 \mathrm{E}+00$ \\
\hline 15 & $-5.33 E+02$ & $0.00 \mathrm{E}+00$ \\
\hline 16 & $-4.99 E+02$ & $0.00 \mathrm{E}+00$ \\
\hline 17 & $-4.68 E+02$ & $0.00 E+00$ \\
\hline 18 & $-4.34 E+02$ & $0.00 E+00$ \\
\hline 19 & $-4.00 E+02$ & $0.00 \mathrm{E}+00$ \\
\hline 20 & $-3.67 E+02$ & $0.00 \mathrm{E}+00$ \\
\hline 21 & $-3.37 E+02$ & $0.00 \mathrm{E}+00$ \\
\hline 22 & $3.39 E+02$ & $5.50 \mathrm{E}-02$ \\
\hline 23 & $0.00 E+00$ & $0.00 \mathrm{E}+00$ \\
\hline 24 & $-5.95 E+02$ & $0.00 E+00$ \\
\hline 25 & $-5.64 E+02$ & $0.00 E+00$ \\
\hline 26 & $-5.33 E+02$ & $0.00 \mathrm{E}+00$ \\
\hline 27 & $-4.99 E+02$ & $0.00 E+00$ \\
\hline 28 & $-4.68 E+02$ & $0.00 \mathrm{E}+00$ \\
\hline 29 & $-4.34 E+02$ & $0.00 E+00$ \\
\hline 30 & $-4.00 E+02$ & $0.00 \mathrm{E}+00$ \\
\hline 31 & $-3.67 E+02$ & $0.00 \mathrm{E}+00$ \\
\hline 32 & $-3.37 E+02$ & $0.00 E+00$ \\
\hline 33 & $3.39 E+02$ & $5.50 \mathrm{E}-02$ \\
\hline 34 & $0.00 E+00$ & $0.00 E+00$ \\
\hline 35 & $-5.95 E+02$ & $0.00 E+00$ \\
\hline 36 & $-5.64 E+02$ & $0.00 \mathrm{E}+00$ \\
\hline 37 & $-5.33 E+02$ & $0.00 \mathrm{E}+00$ \\
\hline 38 & $-4.99 E+02$ & $0.00 \mathrm{E}+00$ \\
\hline 39 & $-4.68 E+02$ & $0.00 \mathrm{E}+00$ \\
\hline 40 & $-4.34 E+02$ & $0.00 \mathrm{E}+00$ \\
\hline 41 & $-4.00 E+02$ & $0.00 \mathrm{E}+00$ \\
\hline 42 & $-3.67 E+02$ & $0.00 E+00$ \\
\hline
\end{tabular}

AH-TAB2.XLS 
Table E.1. Initial Head and Contaminant Flux for Case I: Natural Recharge Only (page 2 of 4).

\begin{tabular}{|c|c|c|}
\hline Node\# & Head (ft) & Flux(Q) (ft/yr) \\
\hline 43 & $-3.37 E+02$ & $0.00 \mathrm{E}+00$ \\
\hline 44 & $3.39 E+02$ & $5.50 \mathrm{E}-02$ \\
\hline 45 & $0.00 E+00$ & $0.00 E+00$ \\
\hline 46 & $-5.95 E+02$ & $0.00 \mathrm{E}+00$ \\
\hline 47 & $-5.64 E+02$ & $0.00 \mathrm{E}+00$ \\
\hline 48 & $-5.33 E+02$ & $0.00 \mathrm{E}+00$ \\
\hline 49 & $-4.99 E+02$ & $0.00 E+00$ \\
\hline 50 & $-4.68 E+02$ & $0.00 \mathrm{E}+00$ \\
\hline 51 & $-4.34 \mathrm{E}+02$ & $0.00 \mathrm{E}+00$ \\
\hline 52 & $-4.00 E+02$ & $0.00 \mathrm{E}+00$ \\
\hline 53 & $-3.67 E+02$ & $0.00 E+00$ \\
\hline 54 & $-3.37 E+02$ & $0.00 \mathrm{E}+00$ \\
\hline 55 & $3.39 E+02$ & $5.50 \mathrm{E}-02$ \\
\hline 56 & $0.00 \mathrm{E}+00$ & $0.00 \mathrm{E}+00$ \\
\hline 57 & $-5.95 E+02$ & $0.00 \mathrm{E}+00$ \\
\hline 58 & $-5.64 E+02$ & $0.00 \mathrm{E}+00$ \\
\hline 59 & $-5.33 E+02$ & $0.00 \mathrm{E}+00$ \\
\hline 60 & $-4.99 E+02$ & $0.00 \mathrm{E}+00$ \\
\hline 61 & $-4.68 E+02$ & $0.00 E+00$ \\
\hline 62 & $-4.34 E+02$ & $0.00 \mathrm{E}+00$ \\
\hline 63 & $-4.00 E+02$ & $0.00 \mathrm{E}+00$ \\
\hline 64 & $-3.67 E+02$ & $0.00 E+00$ \\
\hline 65 & $-3.37 E+02$ & $0.00 E+00$ \\
\hline 66 & $3.39 E+02$ & $5.50 \mathrm{E}-02$ \\
\hline 67 & $0.00 E+00$ & $0.00 \mathrm{E}+00$ \\
\hline 68 & $-5.95 \mathrm{E}+02$ & $0.00 E+00$ \\
\hline 69 & $-5.64 E+02$ & $0.00 \mathrm{E}+00$ \\
\hline 70 & $-5.33 E+02$ & $0.00 \mathrm{E}+00$ \\
\hline 71 & $-4.99 \mathrm{E}+02$ & $0.00 E+00$ \\
\hline 72 & $-4.68 E+02$ & $0.00 E+00$ \\
\hline 73 & $-4.34 E+02$ & $0.00 E+00$ \\
\hline 74 & $-4.00 E+02$ & $0.00 \mathrm{E}+00$ \\
\hline 75 & $-3.67 E+02$ & $0.00 E+00$ \\
\hline 76 & $-3.37 E+02$ & $0.00 \mathrm{E}+00$ \\
\hline 77 & $3.39 E+02$ & $5.50 \mathrm{E}-02$ \\
\hline 78 & $0.00 \mathrm{E}+00$ & $0.00 \mathrm{E}+00$ \\
\hline 79 & $-5.95 E+02$ & $2.00 \mathrm{E}+00$ \\
\hline 80 & $-5.64 E+02$ & $0.00 \mathrm{E}+00$ \\
\hline 81 & $-5.33 E+02$ & $0.00 \mathrm{E}+00$ \\
\hline 82 & $-4.99 E+02$ & $0.00 \mathrm{E}+00$ \\
\hline 83 & $-4.68 E+02$ & $0.00 \mathrm{E}+00$ \\
\hline 84 & $-4.34 E+02$ & $0.00 E+00$ \\
\hline
\end{tabular}

AH-TAB2.XLS 
WHC-SD-WM-ES-300 REV. 1

Table E.1. Initial Head and Contaminant Flux for Case I: Natural Recharge Only (page 3 of 4).

\begin{tabular}{|c|c|c|}
\hline Node\# & Head $(\mathrm{ft})$ & Flux(Q) (ft/yr) \\
\hline 85 & $-4.00 E+02$ & $0.00 \mathrm{E}+00$ \\
\hline 86 & $-3.67 E+02$ & $0.00 E+00$ \\
\hline 87 & $-3.37 E+02$ & $0.00 E+00$ \\
\hline 88 & $3.39 E+02$ & $5.50 \mathrm{E}-02$ \\
\hline 89 & $0.00 E+00$ & $.0 .00 E+00$ \\
\hline 90 & $-5.95 E+02$ & $0.00 E+00$ \\
\hline 91 & $-5.64 E+02$ & $0.00 \mathrm{E}+00$ \\
\hline 92 & $-5.33 E+02$ & $0.00 E+00$ \\
\hline 93 & $-4.99 E+02$ & $0.00 E+00$ \\
\hline 94 & $-4.68 E+02$ & $0.00 \mathrm{E}+00$ \\
\hline 95 & $-4.34 E+02$ & $0.00 E+00$ \\
\hline 96 & $-4.00 E+02$ & $0.00 \mathrm{E}+00$ \\
\hline 97 & $-3.67 E+02$ & $0.00 E+00$ \\
\hline 98 & $-3.37 E+02$ & $0.00 E+00$ \\
\hline 99 & $3.39 E+02$ & $5.50 \mathrm{E}-02$ \\
\hline 100 & $0.00 \mathrm{E}+00$ & $0.00 E+00$ \\
\hline 101 & $-5.95 E+02$ & $0.00 E+00$ \\
\hline 102 & $-5.64 E+02$ & $0.00 E+00$ \\
\hline 103 & $-5.33 E+02$ & $0.00 \mathrm{E}+00$ \\
\hline 104 & $-4.99 E+02$ & $0.00 E+00$ \\
\hline 105 & $-4.68 \mathrm{E}+02$ & $0.00 E+00$ \\
\hline 106 & $-4.34 E+02$ & $0.00 E+00$ \\
\hline 107 & $-4.00 E+02$ & $0.00 E+00$ \\
\hline 108 & $-3.67 E+02$ & $0.00 E+00$ \\
\hline 109 & $-3.37 E+02$ & $0.00 E+00$ \\
\hline 110 & $3.39 \mathrm{E}+02$ & $5.50 \mathrm{E}-02$ \\
\hline 111 & $0.00 E+00$ & $0.00 E+00$ \\
\hline 112 & $-5.95 E+02$ & $0.00 E+00$ \\
\hline 113 & $-5.64 \mathrm{E}+02$ & $0.00 E+00$ \\
\hline 114 & $-5.33 E+02$ & $0.00 E+00$ \\
\hline 115 & $-4.99 E+02$ & $0.00 E+00$ \\
\hline 116 & $-4.68 E+02$ & $0.00 E+00$ \\
\hline 117 & $-4.34 E+02$ & $0.00 E+00$ \\
\hline 118 & $-4.00 E+02$ & $0.00 E+00$ \\
\hline 119 & $-3.67 E+02$ & $0.00 E+00$ \\
\hline 120 & $-3.37 E+02$ & $0.00 E+00$ \\
\hline 121 & $3.39 \mathrm{E}+02$ & $5.50 \mathrm{E}-02$ \\
\hline 122 & $0.00 \mathrm{E}+00$ & $0.00 E+00$ \\
\hline 123 & $-5.95 E+02$ & $0.00 E+00$ \\
\hline 124 & $-5.64 E+02$ & $0.00 E+00$ \\
\hline 125 & $-5.33 E+02$ & $0.00 \mathrm{E}+00$ \\
\hline 126 & $-4.99 E+02$ & $0.00 E+00$ \\
\hline
\end{tabular}

AH-TAB2.XLS 
Table E.1. Initial Head and Contaminant Flux for Case I: Natural Recharge Only (page 4 of 4).

\begin{tabular}{|r|r|r|}
\hline \multicolumn{1}{|c|}{ Node\# } & \multicolumn{1}{|c|}{ Head (ft) } & Flux(Q) (ft/yr) \\
\hline 1.27 & $-4.68 \mathrm{E}+02$ & $0.00 \mathrm{E}+00$ \\
\hline 128 & $-4.34 \mathrm{E}+02$ & $0.00 \mathrm{E}+00$ \\
\hline 129 & $-4.00 \mathrm{E}+02$ & $0.00 \mathrm{E}+00$ \\
\hline 130 & $-3.67 \mathrm{E}+02$ & $0.00 \mathrm{E}+00$ \\
\hline 131 & $-3.37 \mathrm{E}+02$ & $0.00 \mathrm{E}+00$ \\
\hline 132 & $3.39 \mathrm{E}+02$ & $5.50 \mathrm{E}-02$ \\
\hline 133 & $0.00 \mathrm{E}+00$ & $0.00 \mathrm{E}+00$ \\
\hline 134 & $-5.95 \mathrm{E}+02$ & $0.00 \mathrm{E}+00$ \\
\hline 135 & $-5.64 \mathrm{E}+02$ & $0.00 \mathrm{E}+00$ \\
\hline 136 & $-5.33 \mathrm{E}+02$ & $0.00 \mathrm{E}+00$ \\
\hline 137 & $-4.99 \mathrm{E}+02$ & $0.00 \mathrm{E}+00$ \\
\hline 138 & $-4.68 \mathrm{E}+02$ & $0.00 \mathrm{E}+00$ \\
\hline 139 & $-4.34 \mathrm{E}+02$ & $0.00 \mathrm{E}+00$ \\
\hline 140 & $-4.00 \mathrm{E}+02$ & $0.00 \mathrm{E}+00$ \\
\hline 141 & $-3.67 \mathrm{E}+02$ & $0.00 \mathrm{E}+00$ \\
\hline 142 & $-3.37 \mathrm{E}+02$ & $0.00 \mathrm{E}+00$ \\
\hline 143 & $3.39 \mathrm{E}+02$ & $2.55 \mathrm{E}-02$ \\
\hline
\end{tabular}

AH-TAB2.XLS 
WHC-SD-WM-ES-300 REV. 1

Table E.2. Initial Head and Contaminant Flux for

Case II: Natural Recharge Plus Leakage (page 1 of 4).

\begin{tabular}{|c|c|c|}
\hline Node\# & Head $(\mathrm{ft})$ & Flux(Q) (ft/yr) \\
\hline 1 & $0.00 \mathrm{E}+00$ & $0.00 \mathrm{E}+00$ \\
\hline 2 & $-5.95 E+02$ & $0.00 E+00$ \\
\hline 3 & $-5.64 E+02$ & $0.00 \mathrm{E}+00$ \\
\hline 4 & $-5.33 E+02$ & $0.00 E+00$ \\
\hline 5 & $-4.99 E+02$ & $0.00 E+00$ \\
\hline 6) & $-4.68 E+02$ & $0.00 E+00$ \\
\hline 7 & $7.90 \mathrm{E}+01$ & $0.00 E+00$ \\
\hline 8 & $1.36 \mathrm{E}+02$ & $0.00 E+00$ \\
\hline 9 & $1.93 \mathrm{E}+02$ & $0.00 E+00$ \\
\hline 10 & $-3.37 E+02$ & $0.00 \mathrm{E}+00$ \\
\hline 11 & $3.39 E+02$ & $2.55 E-02$ \\
\hline 12 & $0.00 \mathrm{E}+00$ & $0.00 \mathrm{E}+00$ \\
\hline 13 & $-5.95 \mathrm{E}+02$ & $0.00 \mathrm{E}+00$ \\
\hline 14 & $-5.64 E+02$ & $0.00 \mathrm{E}+00$ \\
\hline 15 & $-5.33 E+02$ & $0.00 \mathrm{E}+00$ \\
\hline 16 & $-4.99 E+02$ & $0.00 E+00$ \\
\hline 17 & $-4.68 E+02$ & $0.00 E+00$ \\
\hline 18 & $7.90 \mathrm{E} \div 01$ & $0.00 E+00$ \\
\hline 19 & $1.36 E+02$ & $0.00 E+00$ \\
\hline 20 & $1.93 E+02$ & $0.00 E+00$ \\
\hline 21 & $-3.37 E+02$ & $0.00 E+00$ \\
\hline 22 & $3.39 E+02$ & $5.50 \mathrm{E}-02$ \\
\hline 23 & $0.00 \mathrm{E}+00$ & $0.00 E+00$ \\
\hline 24 & $-5.95 E+02$ & $0.00 E+00$ \\
\hline 25 & $-5.64 E+02$ & $0.00 E+00$ \\
\hline 26 & $-5.33 E+02$ & $0.00 E+00$ \\
\hline 27 & $-4.99 E+02$ & $0.00 \mathrm{E}+00$ \\
\hline 28 & $-4.68 E+02$ & $0.00 \mathrm{E}+00$ \\
\hline 29 & $7.90 \mathrm{E}+01$ & $0.00 E+00$ \\
\hline 30 & $1.36 E+02$ & $0.00 E+00$ \\
\hline 31 & $1.93 E+02$ & $0.00 E+00$ \\
\hline 32 & $-3.37 E+02$ & $0.00 E+00$ \\
\hline 33 & $3.39 E+02$ & $5.50 \mathrm{E}-02$ \\
\hline 34 & $0.00 \mathrm{E}+00$ & $0.00 \mathrm{E}+00$ \\
\hline 35 & $-5.95 E+02$ & $0.00 \mathrm{E}+00$ \\
\hline 36 & $-5.64 E+02$ & $0.00 \mathrm{E}+00$ \\
\hline 37 & $-5.33 E+02$ & $0.00 \mathrm{E}+00$ \\
\hline 38 & $-4.99 E+02$ & $0.00 \mathrm{E}+00$ \\
\hline 39 & $-4.68 E+02$ & $0.00 E+00$ \\
\hline 40 & $9.30 E+01$ & $0.00 \mathrm{E}+00$ \\
\hline 41 & $1.36 E+02$ & $0.00 E+00$ \\
\hline 42 & $1.93 E+02$ & $0.00 E+00$ \\
\hline 43 & $-3.37 E+02$ & $0.00 \mathrm{E}+00$ \\
\hline 44 & $3.39 \mathrm{E}+02$ & $5.50 \mathrm{E}-02$ \\
\hline
\end{tabular}

AH-TAB3.XLS 
WHC-SD-WM-ES-300 REV. 1

Table E.2. Initial Head and Contaminant Flux for

Case II: Natural Recharge Plus Leakage (page 2 of 4).

\begin{tabular}{|c|c|c|}
\hline Node\# & Head (ft) & Flux(Q) (ft/yr) \\
\hline 45 & $0.00 E+00$ & $0.00 \mathrm{E}+00$ \\
\hline 46 & $-5.95 E+02$ & $0.00 E+00$ \\
\hline 47 & $-5.64 E+02$ & $0.00 E+00$ \\
\hline 48 & $-5.33 E+02$ & $0.00 E+00$ \\
\hline 49 & $-4.99 E+02$ & $0.00 E+00$ \\
\hline 50 & $-4.68 E+02$ & $0.00 E+00$ \\
\hline 51 & $7.90 E+01$ & $0.00 E+00$ \\
\hline 52 & $1.36 E+02$ & $0.00 \mathrm{E}+00$ \\
\hline 53 & $1.93 E+02$ & $0.00 E+00$ \\
\hline 54 & $-3.37 E+02$ & $0.00 E+00$ \\
\hline 55 & $3.39 E+02$ & 5.50E-02 \\
\hline 56 & $0.00 \mathrm{E}+00$ & $0.00 E+00$ \\
\hline 57 & $-5.95 E+02$ & $0.00 E+00$ \\
\hline 58 & $-5.64 E+02$ & $0.00 E+00$ \\
\hline 59 & $-5.33 E+02$ & $0.00 E+00$ \\
\hline 60 & $-4.99 E+02$ & $0.00 E+00$ \\
\hline 61 & $-4.68 E+02$ & $0.00 \mathrm{E}+00$ \\
\hline 62 & $7.90 E+01$ & $0.00 E+00$ \\
\hline 63 & $1.36 E+02$ & $0.00 E+00$ \\
\hline 64 & $1.93 E+02$ & $0.00 E+00$ \\
\hline 65 & $-3.37 E+02$ & $0.00 E+00$ \\
\hline 66 & $3.39 E+02$ & $5.50 \mathrm{E}-02$ \\
\hline 67 & $0.00 E+00$ & $0.00 E+00$ \\
\hline 68 & $-5.95 E+02$ & $0.00 E+00$ \\
\hline 69 & $-5.64 E+02$ & $0.00 E+00$ \\
\hline 70 & $-5.33 E+02$ & $0.00 E+00$ \\
\hline 71 & $-4.99 E+02$ & $0.00 E+00$ \\
\hline 72 & $-4.68 E+02$ & $0.00 E+00$ \\
\hline 73 & $7.90 \mathrm{E}+01$ & $0.00 E+00$ \\
\hline 74 & $1.36 E+02$ & $0.00 E+00$ \\
\hline 75 & $1.93 E+02$ & $0.00 E+00$ \\
\hline 76 & $-3.37 E+02$ & $0.00 E+00$ \\
\hline 77 & $3.39 E+02$ & $5.50 \mathrm{E}-02$ \\
\hline 78 & $0.00 \mathrm{E}+00$ & $0.00 E+00$ \\
\hline 79 & $-5.95 E+02$ & $2.00 E+00$ \\
\hline 80 & $-5.64 E+02$ & $0.00 E+00$ \\
\hline 81 & $-5.33 E+02$ & $0.00 E+00$ \\
\hline 82 & $-4.99 E+02$ & $0.00 E+00$ \\
\hline 83 & $-4.68 E+02$ & $0.00 E+00$ \\
\hline 84 & $7.90 E+01$ & $0.00 E+00$ \\
\hline 85 & $1.36 E+02$ & $0.00 E+00$ \\
\hline 86 & $1.93 E+02$ & $0.00 E+00$ \\
\hline 87 & $-3.37 E+02$ & $0.00 E+00$ \\
\hline 88 & $3.39 E+02$ & $5.50 \mathrm{E}-02$ \\
\hline
\end{tabular}

AH-TAB3.XLS 
WHC-SD-WM-ES-300 REV. 1

Table E.2. Initial Head and Contaminant Flux for

Case II: Natural Recharge Plus Leakage (page 3 of 4).

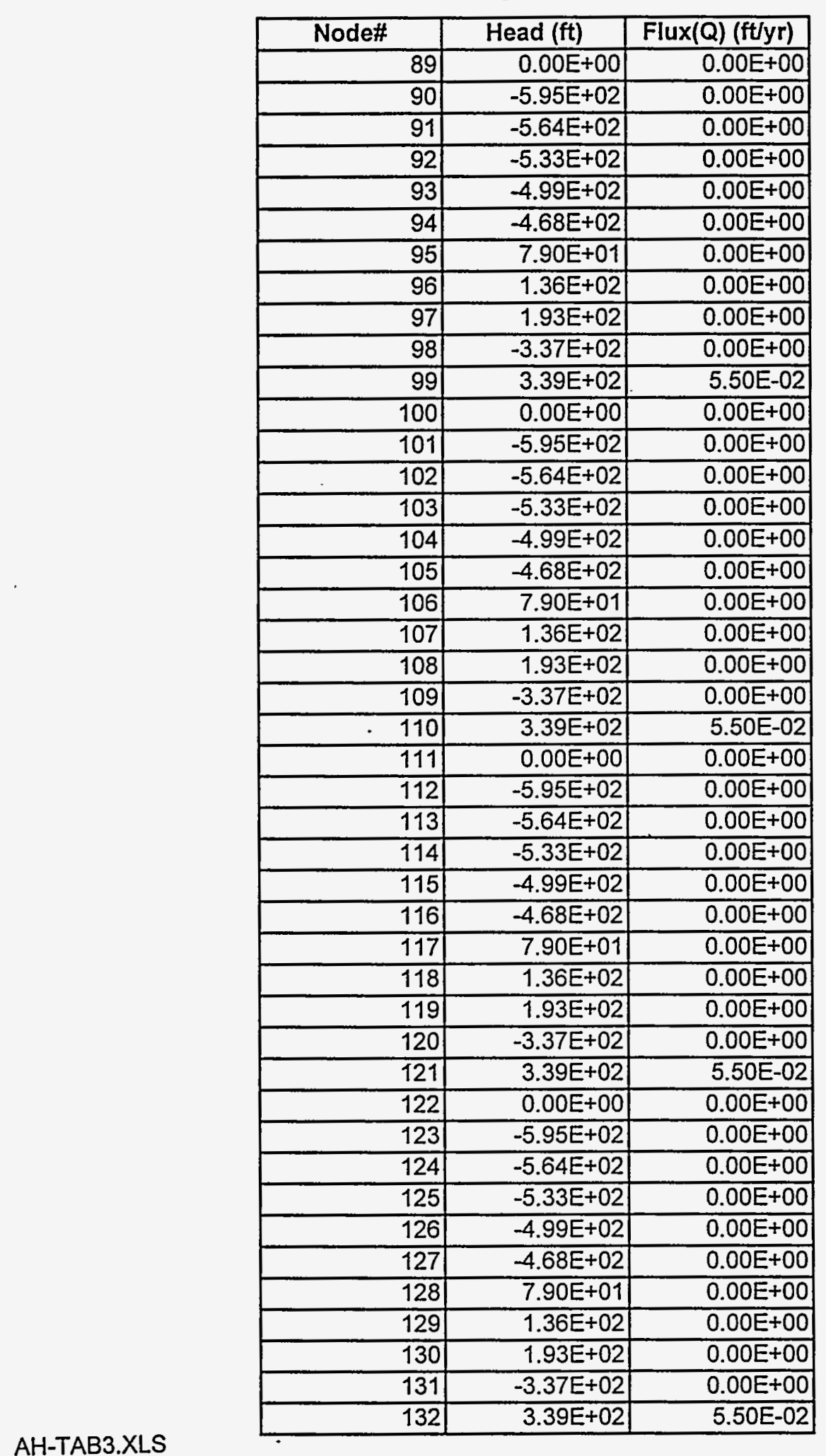


WHC-SD-WM-ES-300 REV. 1

Table E.2. Initial Head and Contaminant Flux for Case II: Natural Recharge Plus Leakage (page 4 of 4).

\begin{tabular}{|r|r|r|}
\hline \multicolumn{1}{|c|}{ Node\# } & Head (ft) & Flux(Q) (ft/yr) \\
\hline 133 & $0.00 \mathrm{E}+00$ & $0.00 \mathrm{E}+00$ \\
\hline 134 & $-5.95 \mathrm{E}+02$ & $0.00 \mathrm{E}+00$ \\
\hline 135 & $-5.64 \mathrm{E}+02$ & $0.00 \mathrm{E}+00$ \\
\hline 136 & $-5.33 \mathrm{E}+02$ & $0.00 \mathrm{E}+00$ \\
\hline 137 & $-4.99 \mathrm{E}+02$ & $0.00 \mathrm{E}+00$ \\
\hline 138 & $-4.68 \mathrm{E}+02$ & $0.00 \mathrm{E}+00$ \\
\hline 139 & $7.90 \mathrm{E}+01$ & $0.00 \mathrm{E}+00$ \\
\hline 140 & $1.36 \mathrm{E}+02$ & $0.00 \mathrm{E}+00$ \\
\hline 141 & $1.93 \mathrm{E}+02$ & $0.00 \mathrm{E}+00$ \\
\hline 142 & $-3.37 \mathrm{E}+02$ & $0.00 \mathrm{E}+00$ \\
\hline 143 & $3.39 \mathrm{E}+02$ & $2.55 \mathrm{E}-02$ \\
\hline
\end{tabular}

